\title{
Artes de canto (1492-1626) y mujeres en la cultura musical del mundo ibérico renacentista
}

\author{
Ascensión Mazuela-Anguita
}

\begin{abstract}
ADVERTIMENT. La consulta d'aquesta tesi queda condicionada a l'acceptació de les següents condicions d'ús: La difusió d'aquesta tesi per mitjà del servei TDX (www.tdx.cat) ha estat autoritzada pels titulars dels drets de propietat intel-lectual únicament per a usos privats emmarcats en activitats d'investigació i docència. No s'autoritza la seva reproducció amb finalitats de lucre ni la seva difusió i posada a disposició des d'un lloc aliè al servei TDX. No s'autoritza la presentació del seu contingut en una finestra o marc aliè a TDX (framing). Aquesta reserva de drets afecta tant al resum de presentació de la tesi com als seus continguts. En la utilització o cita de parts de la tesi és obligat indicar el nom de la persona autora.
\end{abstract}

ADVERTENCIA. La consulta de esta tesis queda condicionada a la aceptación de las siguientes condiciones de uso: La difusión de esta tesis por medio del servicio TDR (www.tdx.cat) ha sido autorizada por los titulares de los derechos de propiedad intelectual únicamente para usos privados enmarcados en actividades de investigación y docencia. No se autoriza su reproducción con finalidades de lucro ni su difusión y puesta a disposición desde un sitio ajeno al servicio TDR. No se autoriza la presentación de su contenido en una ventana o marco ajeno a TDR (framing). Esta reserva de derechos afecta tanto al resumen de presentación de la tesis como a sus contenidos. En la utilización o cita de partes de la tesis es obligado indicar el nombre de la persona autora.

WARNING. On having consulted this thesis you're accepting the following use conditions: Spreading this thesis by the TDX (www.tdx.cat) service has been authorized by the titular of the intellectual property rights only for private uses placed in investigation and teaching activities. Reproduction with lucrative aims is not authorized neither its spreading and availability from a site foreign to the TDX service. Introducing its content in a window or frame foreign to the TDX service is not authorized (framing). This rights affect to the presentation summary of the thesis as well as to its contents. In the using or citation of parts of the thesis it's obliged to indicate the name of the author. 


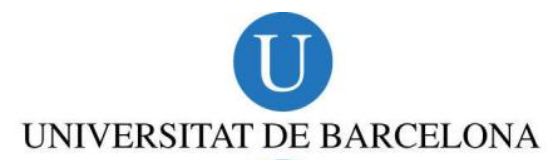

\section{ARTES DE CANTO (1492-1626) Y MUJERES \\ EN LA CULTURA MUSICAL DEL MUNDO IBÉRICO RENACENTISTA}

Tesis Doctoral presentada para la obtención del Título de Doctor Mención 'Doctorado Internacional'

\section{ASCENSIÓN MAZUELA-ANGUITA}

Realizada bajo la dirección del

Dr. EMILIO ROS-FÁBREGAS

VOLUMEN I: ESTUDIO

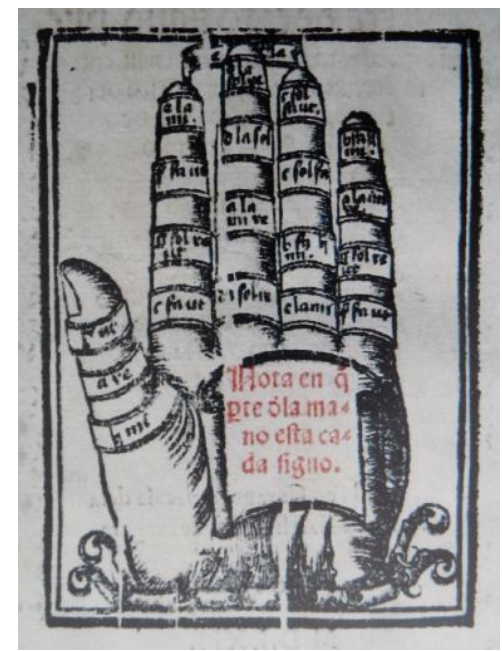

BARCELONA, 2012 



\title{
ARTES DE CANTO (1492-1626) Y MUJERES \\ EN LA CULTURA MUSICAL DEL MUNDO IBÉRICO RENACENTISTA
}

\author{
Tesis Doctoral presentada para la obtención del Título de Doctor \\ Mención 'Doctorado Internacional'
}

\section{ASCENSIÓN MAZUELA-ANGUITA}

\author{
Realizada bajo la dirección del \\ Dr. EMILIO ROS-FÁBREGAS \\ Investigador Científico, Institució Milà i Fontanals, CSIC \\ Tutor: Dr. Jaume Carbonell i Guberna \\ Departament d'Història de l'Art, Universitat de Barcelona
}

VOLUMEN I: ESTUDIO

\author{
UNIVERSITAT DE BARCELONA \\ FACULTAT DE GEOGRAFIA I HISTÒRIA \\ DEPARTAMENT D'HISTÒRIA DE L'ART \\ PROGRAMA DE DOCTORADO: MÚSICA EN LA ESPAÑA CONTEMPORÁNEA \\ BIENIO 2009-2011 \\ BARCELONA, 2012
}


ILUSTRACIÓN DE LA PORTADA:

Juan Martínez, Arte de canto llano puesta y reduzida nueuamente en su entera perfecion segun la pratica del canto. Va en cada una de las reglas su exemplo puntado. Con las intonaciones puntadas. Ordenada por Juan Martinez clerigo: maestro de los moços del coro de la sancta yglesia de Seuilla (Zaragoza: viuda de Bartholome de Nagera, 1562 [1530]) f. 1v, mano guidoniana.

Valencia, Biblioteca Històrica de la Universitat de València, BH Q/224 (3).

Este ejemplar del arte de canto más difundido del mundo hispánico del siglo XVI, que he localizado en Valencia, es de una edición desconocida hasta el momento y que resulta ser la más antigua en español, dado que la edición príncipe de 1530 se perdió y la edición incompleta de 1550 es una traducción portuguesa. 
A mi familia de músicos 



\section{Resumen / Abstract}

Esta Tesis Doctoral explora la cultura musical del mundo ibérico renacentista a través del estudio de artes de canto en lengua vernácula impresas entre 1492 y 1626 y de su relación con las mujeres de la época. La Tesis consta de siete capítulos, estructurados en dos partes (Vol. I), y de veinte apéndices (Vol. II). La primera parte (Capítulos I al IV) muestra que las características por las que estos libros que contenían los rudimentos de la música han sido infravalorados hasta ahora por la historiografía musical son precisamente las mismas que demuestran que respondían a una necesidad pedagógica y a la demanda de manuales asequibles, breves y prácticos por parte de un amplio mercado. Las artes de canto se imprimieron en tiradas de miles de ejemplares y eran vendidas a bajo precio, tuvieron una enorme circulación en la Península Ibérica y el Nuevo Mundo, y contribuyeron al incremento y la difusión de la educación musical en contextos educativos diferenciados (la iglesia, la universidad y el ámbito privado), así como entre grupos sociales hasta entonces excluidos del aprendizaje de los fundamentos de la música. El Arte de canto llano (Sevilla, 1530) de Juan Martínez emerge como el tratado de música del mundo hispánico más difundido geográfica y cronológicamente en el siglo XVI e inicios del XVII, pero del que casi nada se sabía. En la segunda parte (Capítulos V al VII), las conexiones entre estos libros de música y mujeres muestran que las áreas de superposición entre lo privado y lo público y entre lo oral y lo escrito permiten desafiar la invisibilidad de las mujeres en documentos históricos y vislumbrar trazas no sólo de la cultura musical de las mujeres de la época, sino también de la importancia de la música en la vida cotidiana. Se utiliza una diversidad de fuentes (artes de canto, libros de conducta, documentos inquisitoriales, literatura, correspondencia e inventarios de bienes, entre otras), a través de las cuales se ha podido documentar la relación con la música de, entre otras, Catalina de Zúñiga, VI Condesa de Lemos, Isabel de Plazaola, e Isabel de Aragón, IV Duquesa del Infantado. Empleando metodologías de la musicología tradicional junto a otras tomadas de los historiadores del libro y de la cultura popular, esta Tesis Doctoral presenta una panorámica de la vida musical de la época a través del prisma de doble alteridad que supone el estudio de las artes de canto, generalmente consideradas carentes de interés, y de su relación con las mujeres, insuficientemente representadas en la historiografía musical. 



\section{VOLUMEN I: ESTUDIO}

Agradecimientos $\quad$ xiii

Lista de ilustraciones $\quad$ XV

Lista de tablas $\quad$ xxi

$\begin{array}{ll}\text { Nota sobre el CD-ROM } & \text { xxv }\end{array}$

INTRODUCCIÓN

1. Objetivos y metodología 3

2. Estado de la cuestión 8

3. Fuentes 23

4. Estructura del Trabajo 33

Parte I. Las artes de canto como producto de consumo en el mundo ibérico renacentista: los otros libros de música

CAPÍTULO I. LAS ARTES DE CANTO IMPRESAS EN EL MUNDO IBÉRICO DEL SIGLO XVI: DESCRIPCIÓN E HISTORIOGRAFÍA

1. Las artes de canto como tipología libresca: una historia contada por "octavos"

1.1. Definición y origen de las artes de canto. Delimitación del objeto de estudio

1.2. Características de las artes de canto

1.2.1. Pequeño formato

1.2.2. Brevedad: porque el tiempo es "cosa muy preciosa" 54

1.2.3. Enseñanza de lo suficiente y optimización del tiempo de aprendizaje

1.2.4. Uso de recursos didácticos $\quad 58$

a) Simplificación $\quad 58$

b) Síntesis $\quad 60$

c) Referencias a experiencias pedagógicas propias 61

d) Uso de tablas "para mayor declaracion del canto llano" y ejemplos musicales

e) Otros recursos didácticos 66

1.2.5. Prioridad a la práctica 66

1.2.6. Elementos locales 68

1.2.7. Búsqueda de preceptos objetivos para no guiarse por el oído

1.2.8. Vigencia del contenido $\quad 72$

1.2.9. Limitada presencia de autoridades $\quad 78$

1.2.10. Los autores y su conexión con la enseñanza de la música $\quad 81$ 
2. Posición historiográfica de las artes de canto impresas en el mundo ibérico: los otros libros de música

3. Resumen del Capítulo I

\section{CAPÍTULO II. ARTES DE CANTO:}

1. La producción

1.1. El proceso de publicación

1.1.1. Búsqueda de financiación, autoridad y difusión: mecenas y dedicatarios

1.1.2. Aprobaciones, licencias y privilegios

1.2. La imprenta de artes de canto

116

1.2.1. Las artes de canto en el ámbito de la cultura de la imprenta

1.2.2. Cuestiones técnicas: la configuración del producto

1.2.3. La interacción producción-demanda: el tamaño de las tiradas y las reediciones

2. La distribución

2.1. La venta

2.2. Medios de difusión

2.3. Redes de distribución en la Península Ibérica y el Nuevo Mundo 140

3. Valuación y mercado potencial

3.1. Formas de consumo, valuación y accesibilidad

3.2. El mercado potencial: artes de canto, nuevas categorías de lectores y difusión del alfabetismo musical

4. Resumen del Capítulo II

CAPÍTULO III: LA RECUPERACIÓN DEL ARTE DE CANTO LLANO (SEVILLA, 1530) DE JUAN MARTÍNEZ

1. Cuestiones de historiografía nacionalista en la historia de un libro

2. La edición príncipe del libro de Juan Martínez

3. Juan Martínez en la Catedral de Sevilla (antes de 1525 - después de 1545): los tratados de canto llano R/14670 de la Biblioteca Nacional de España

4. El Arte de canto llano: un siglo de reediciones

La impresión del Arte de canto llano de Juan Martínez y la movilidad de materiales tipográficos

5. Difusión del libro de Juan Martínez en Portugal y el Nuevo Mundo

6. Reconstrucción del texto del Arte de canto llano de Juan Martínez

7. Aportaciones de la investigación sobre el libro de Martínez

8. Resumen del Capítulo III 


\section{CAPÍTULO IV. USOS DE LAS ARTES DE CANTO:} "MAESTROS MUDOS"

1. Los usos de las artes de canto

1.1. Artes de canto: usos y costumbres

1.2. Indicios de uso en los ejemplares consultados

1.2.1. Anotaciones que indican uso por parte de maestros o posteriores estudiosos de la música: correcciones, ampliaciones y referencias bibliográficas y/o musicales

1.2.2. Anotaciones que indican uso práctico por parte de principiantes

1.2.3. Uso como fuente de repertorio musical

1.2.4. Pistas sobre el poseedor/a del ejemplar

1.2.5. Apuntes, resúmenes y traducciones: los casos del Tractat de música (Barcelona, Biblioteca de Reserva de la Universitat de Barcelona, MS2044) y la Micel·lània de tractats musicals (Barcelona, Biblioteca de Catalunya, Ms. $1325 / 2)$

1.3. El contenido gráfico de las artes de canto. La cuestión de la mano guidoniana y la escala

1.4. Las artes de canto llano como base del aprendizaje de la música: el Arte de canto llano (Valladolid, 1594) de Francisco de Montanos

2. Las artes de canto como vestigio de lecciones de música en ámbitos docentes diferenciados

2.1. Vinculación de las artes de canto con las lecciones públicas de música en las capillas eclesiásticas

2.1.1. La enseñanza de la música en las catedrales de Évora, Sevilla y Coimbra

2.1.2. La publicación de manuales de canto en el contexto monástico

2.2. ¿Artes de canto en las escuelas de latín?

2.3.1. La Universidad de Alcalá de Henares

2.3.2. La Universidad de Salamanca

2.4. La enseñanza musical de carácter privado en el ámbito doméstico

2.4.1. Tutorías

2.4.2. Academias y tertulias

2.4.3. Artes de canto y formación autodidacta: ¿"no ha menester maestro el cantor"? 
Introducción

1. Punto de partida: contextualización de El arte Tripharia (Osuna, 1550) de Juan Bermudo en el debate historiográfico

1.1. Controversias generales transferidas a los libros de música

1.2. El caso de El arte Tripharia

2. Catalina de Zúñiga y el Arte de canto llano (Valladolid, 1594) de Francisco de Montanos

2.1. Francisco de Montanos y los VI Condes de Lemos

2.2. "Una señora muy varón": el mecenazgo de Catalina de Zúñiga

2.2.1. Análisis del material preliminar del Arte de canto llano de Francisco de Montanos

2.2.2. Análisis del material preliminar de otros libros dedicados a Catalina de Zúñiga

2.2.3. El Arte de canto llano de Francisco de Montanos en el contexto de Monforte de Lemos

2.3. ¿Un libro para mujeres?

3. La actividad musical de las mujeres en la esfera pública 378

4. Resumen del Capítulo V

\section{CAPÍTULO VI. VISIBILIZAR AL OTRO: ÁREAS DE SUPERPOSICIÓN COMO PUNTOS DE VISUALIZACIÓN}

1. La superposición de los ámbitos privado y público: compositoras e impresoras

1.1. ¿Mujeres autoras de libros de música? El caso de Gracia Baptista

1.1.1. El marco conceptual en torno al Libro de cifra nueua (Alcalá de Henares, 1557) de Luis Venegas de Henestrosa

1.1.2. "Gracia Baptista, monja"

1.1.3. Gracia Baptista, compositora: las técnicas de cantus firmus en los himnos Conditor alme de Gonzalo de Baena (1540), Juan Bermudo (1555) y Gracia Baptista (1557)

1.1.4. Lo privado y lo público, lo religioso y lo secular en los conventos de clausura: el Monasterio de la Piedad de Guadalajara

1.1.5. Compositoras y maestras en otras esferas femeninas

2. La superposición de tradición oral y cultura escrita: artes de canto y cancioneros

2.2. Cancioneros poéticos como libros de música 448

3. Resumen del Capítulo VI 


\section{CAPÍTULO VII. TRATADOS DE CONDUCTA FEMENINA VERSUS} REALIDAD MUSICAL

1. Tratados de conducta femenina, lectura y música

460

1.1. Música y convites

464

1.2. Una aproximación indirecta: mujeres y lectura

466

1.3. Discrepancias entre el plano teórico y la realidad

468

2. Vestigios de la música (de mujeres) en la vida cotidiana: juegos cortesanos, teatro, literatura y musicoterapias

3. Mujeres músicas y documentos de la Inquisición

3.1. Introducción y base metodológica

3.2. Mujeres músicas en el mundo ibérico renacentista: Isabel de Plazaola

3.2.1. La música Isabel de Plazaola en los documentos inquisitoriales de su madre Isabel Ortiz (1564-1565)

3.2.2. El litigio de Isabel de Plazaola en 1575

3.2.3. Actividad musical en torno a Isabel de Aragón, IV Duquesa del Infantado

a) La música en la casa del Infantado: estudio preliminar

\section{VOLUMEN II: APÉNDICES Y BIBLIOGRAFÍA}

ÍNDICE

\section{APÉNDICES}

Apéndice 1. Artes de canto impresas en la Península Ibérica: listado cronológico abreviado (siglos XV-XVIII) y listado detallado por orden alfabético de autor (1492-1626)

Apéndice 2. Portadas e índices de contenido de las artes de canto estudiadas (1492-1626)

Apéndice 3. El uso de los "Cantos diuersos en que se exercite el que aprende" del Arte de canto llano (Valladolid, 1594) de Francisco de Montanos en la Institucion harmonica (Madrid, 1748) de Antonio Ventura Roel del Río

Apéndice 4. Actividad profesional de los autores de artes de canto

Apéndice 5. Libros de características similares a las artes de canto impresos en Alemania, Francia, Italia y Reino Unido

Apéndice 6. Artes de canto impresas en la Península Ibérica (siglos XVXVIII): listado por ciudad de impresión 
Apéndice 7. Impresores de artes de canto

Apéndice 8. Las artes de canto en los inventarios de impresores, libreros y otros distribuidores

Apéndice 9. Las artes de canto en los inventarios particulares e institucionales

Apéndice 11. Juan Martínez en los estudios bibliográficos y en la historiografía

Apéndice 12. Cotejo de las artes de canto R/14670(1) y (2) de la Biblioteca Nacional de España con el Arte de canto llano (Zaragoza, 1562) de Juan Martínez

Apéndice 13. Reconstrucción del texto del Arte de canto llano (1530) de Juan Martínez

Apéndice 14. La mano musical y la escala en las artes de canto

Apéndice 15. La presencia de la música en las academias

Apéndice 16. Dedicatarios de las artes de tañer impresas en la Península Ibérica entre 1538 y 1626

Apéndice 17. Libros de música en inventarios de bienes de mujeres

Apéndice 18. Referencias a Isabel de Plazaola en los documentos inquisitoriales del "Proceso de fe de Isabel Ortiz" (1564-1565), Madrid, Archivo Histórico Nacional, Sección Inquisición, legajo 104, expediente 5

Apéndice 19. Transcripción del pleito litigado en 1575 por Isabel Ortiz contra la Duquesa de Alburquerque por anular el contrato de su hija, la música Isabel de Plazaola. Valladolid, Real Audiencia y Chancillería de Valladolid, Registro de ejecutorías, caja 1314, 80

Apéndice 20. Listado de 91 mujeres vinculadas con la música entre aproximadamente 1492 y 1626 mencionadas en esta Tesis Doctoral 


\section{Agradecimientos}

Son muchas las personas que me han ayudado en el transcurso de esta investigación. En primer lugar, agradezco a Emilio Ros-Fábregas, director de esta Tesis Doctoral, por su valioso apoyo y asesoramiento desde mi primer año en la Licenciatura en Historia y Ciencias de la Música de la Universidad de Granada, y por transmitirme el entusiasmo y rigor que exige la investigación musicológica. Tess Knighton me acogió en Cambridge como "visiting student", me orientó en la elección de un tema de investigación y me ayudó de forma desinteresada en todos los estadios de la misma. Stephen Rose, que supervisó mi trabajo de Master en el Royal Holloway de la Universidad de Londres, me aportó una apertura de miras desde el punto de vista metodológico que ha sido de gran utilidad para el desarrollo de mi investigación.

Esta Tesis Doctoral ha sido posible por el apoyo económico del Ministerio de Educación, Cultura y Deporte, que me concedió una Beca de Formación del Profesorado Universitario (FPU), de la que actualmente disfruto en la Institució Milà y Fontanals, Consejo Superior de Investigaciones Científicas (CSIC), en Barcelona. Agradezco a Xosé Aviñoa su diligencia en la tramitación de los asuntos administrativos que han surgido desde que trasladé mi expediente académico a la Universitat de Barcelona y su invitación a colaborar en la docencia del Departamento de Historia del Arte como parte de mi Contrato de Formación del Profesorado Universitario, y a Jaume Carbonell, tutor de esta Tesis Doctoral, su disponibilidad absoluta. Esta investigación se enmarca en los objetivos de 'El 'Otro' en fuentes musicales hispanas (siglos XVI-XVIII): extranjeros, mujeres y amerindios" (HAR2009-07706), Proyecto I+D financiado por el Ministerio de Ciencia e Innovación, y del Grupo de Investigación "Música, patrimoni i societat", reconocido en 2009 por la Agència de Gestió d'Ajuts Universitaris i de Recerca (AGAUR) de la Generalitat de Catalunya, ambos adscritos a la Institución Milá y Fontanals (CSIC) de Barcelona y dirigidos por María Gembero Ustárroz, a quien agradezco su asesoramiento continuo y su acogida en Barcelona. 
En el transcurso de la investigación he trabajado en varios centros: el Departamento de Historia del Arte y Música de la Universidad de Granada, el Departamento de Música del Royal Holloway de la Universidad de Londres, la Institució Milà y Fontanals (CSIC) de Barcelona y el Departamento de Historia del Arte de la Universitat de Barcelona. Quisiera dar las gracias a los compañeros y profesores de estas instituciones por su interés en mi investigación, en particular a Giuseppe Fiorentino, Concepción Fernández Vivas, Agustín Martorell, Helen Deeming, J. P. E. Harper-Scott, Julie Brown, Geoffrey Baker, Henry Stobart, Arnold Whittall, Matthew Laube, Manuel Sánchez, Joan Maria Jaime, Joana Boix, Isidre Solé y Magda Polo.

José Chitas (Biblioteca Pública de Évora), José María Soto (Biblioteca Nacional de España), José Manuel Calderón (Archivo de los Duques de Alba), Isabel de Colmenares (Biblioteca Pública Episcopal del Seminari de Barcelona) y Joan Miquel Oliver (Biblioteca de Reserva de la Universitat de Barcelona) son algunas de las personas que han facilitado mis pesquisas en las bibliotecas y archivos que he visitado. Robert Kendrick, Pilar Ramos, Bernadette Nelson y Manuel Pedro Ferreira, entre otros, me hicieron valiosos comentarios y sugerencias bibliográficas. En el ámbito personal, agradezco el apoyo incondicional que me ha proporcionado Juan, la confianza de mis hermanos y los sacrificios de mis padres en beneficio de mi formación. 


\section{Lista de ilustraciones}

\section{Volumen I}

I.1 Juan Martínez, Arte de canto llano (Sevilla: Juan Gutiérrez, 1560? [1530]), ff. A7v-A8r. Barcelona, Biblioteca de Comunicació de la Universidat Autònoma de Barcelona, Res. XVI/56.

I.2 Juan Martínez (Ioão Martinz) es citado por Pedro Thalesio en su Arte de canto chão (Coimbra: Diogo Gomez de Loureyro, 1618), p. 39. Lisboa, Biblioteca Nacional de Portugal, M. 428 P.

II.1 Francisco de Montanos, Arte de canto llano (Madrid: Imprenta Real, 1643 [1594]). Las Palmas de Gran Canaria, Biblioteca de la Universidad de Las Palmas de Gran Canaria, BIG XVII MON art.

II.2 Cotejo de las portadas de un arte de canto de principios del siglo XVI y otro de principios del XVII.

II.3 Ars cantus plani, MS (siglo XVI), f. 80r. Barcelona, Biblioteca de Catalunya, M 1327 G. Fol, ff. 72v-89r.

II.4 Música manuscrita sobre pentagrama impreso en Guillermo del Podio, Ars musicorum (Valencia: Peter Hagenbach \& Leonhard Hutz, 1495), f. 54r. Barcelona, Biblioteca de Catalunya, 11-VII-15.

II.5 "Nueva Demonstracion de los Puntos de la Guitarra" al final del ejemplar de Valencia, Biblioteca Històrica de la Universitat de València, Z-13/32 del libro de Juan Francisco Cervera, Arte y suma de canto llano (Valencia, 1595).

III.1 Juan Martínez, Arte de canto llano (Zaragoza: viuda de Bartholome de Nagera, 1562 [1530]), portada. Valencia, Biblioteca Histórica de la Universidad de Valencia, BH Q/224(3).

III.2 Juan Martínez / Afonso Perea, Arte de Canto chão (Coimbra: Antonio Barreira, 1597), portada. Évora, Biblioteca Pública, Res. 294.

III.3 Juan Martínez, Arte de canto llano (Madrid: Tomas Iunti Impresor del Rey nuestro señor, 1621 [1530]), portada. Évora, Biblioteca Pública de Évora, Nuevo Res. Maniz. № 821.

III.4a Manos guidonianas contenidas en la edición de 1562 del Arte de canto llano de Juan Martínez, en la Breue instrucion de Canto llano (1565) de Luis de Villafranca y en la edición de 1543 del Arte de canto llano et contrapunto et canto de organo de Gonzalo Martínez de Bizcargui.

III.4b Manos guidonianas contenidas en la edición de 1597 del Arte de canto llano de Juan Martínez y en el Arte de canto chão (1618) de Pedro Thalesio. 
IV.1 Anotaciones que amplían y actualizan el contenido en Andrés de Monserrate, Arte breve y compendiosa de las dificultades que se ofrecen en la musica practica del canto llano (Valencia: Pedro Patricio Mey, 1614), p. 59. Zaragoza, Biblioteca de la Universidad de Zaragoza, An-7-5-13(1).

IV.2a Andrés de Monserrate, Arte breve y compendiosa (1614), p. 85. Una anotación en el margen derecho ("Cerone trae esto mismo f. 448 y 438”) refiere al tratado de Pietro Cerone, El Melopeo y Maestro (1613).

IV.2b Andrés de Monserrate, Arte breve y compendiosa (1614), p. 102. Una anotación en el margen superior ("vide fragmentos musicos $\mathrm{f}$. 27”) refiere a la obra de Pablo Nassarre, Fragmentos musicos (1683 y 1700).

IV.3 Indicios de uso en Francisco de Montanos, Arte de canto llano (Madrid: Imprenta Real, 1648 [1594]), f. 2v. Madrid, Biblioteca Nacional de España, R/14492.

IV.4a Anotaciones de estudiantes en Dámaso Artufel, Arte de canto llano, en Modo de rezar las horas canonicas (Valladolid: Iuan Godinez de Millis, 1614), f. 17v. Madrid, Biblioteca Nacional de España, $\mathrm{R} / 13944$.

IV.4b Evidencia de uso por parte de principiantes en Melchor de Torres, Arte ingeniosa de musica (Alcalá de Henares: Pedro de Robles y Juan de Villanueva, 1566 [1544]), f. 6r. Zaragoza, Biblioteca de la Universidad de Zaragoza, An-7-5-13(2).

IV.5 Ejemplar que perteneció a la biblioteca del Convento de San Diego de Sevilla. Francisco de Montanos, Arte de canto llano (Madrid: Iuan Garcia Infanzon, 1686 [1594]), portada y tasa. Sevilla, Biblioteca de la Universidad de Sevilla, A 133/045.

IV.6 Tractat de música, MS (siglo XVI), ff. 32v-33r. Barcelona, Biblioteca de Reserva de la Universitat de Barcelona, MS2044.

IV.7 Micel·lània de tractats musicals, MS (1475-1525), última página del Arte de melodia sobre canto lano y canto dorgano y recto de la página en italiano (ff. 24v-25r). Barcelona, Biblioteca de Catalunya, Ms. 1325/2.

IV.8 La presencia de la música en las escuelas de latín. Paulus Naivis, Latinum idioma pro parvulis editum (Nuremberg: Friedrich Creussner, 1494), portada.

IV.9 Edición que hasta ahora se consideraba "fantasma" de Melchor de Torres, Arte ingeniosa de musica (Alcalá de Henares: en casa de Salzedo Librero, 1554 [1544]), portada y colofón (f. 36v). Las Palmas de Gran Canaria, Biblioteca de la Universidad, BIG XVI TOR art.

IV.10 Francisco de Montanos, Arte de canto llano (Madrid: Imprenta Real, 1648 [1594]), portada. Salamanca, Biblioteca de la Universidad de Salamanca, BG/29166. Las anotaciones en la portada de este ejemplar indican que perteneció a "Rossa Maria de $\mathrm{Sam}^{\circ} \mathrm{y}$ Serna”, que lo utilizó para recibir lecciones de canto en su casa. 
V.1 Juan Bermudo, Comiença el arte Tripharia (S.1.: s.n., c. 1892

[Facsímile de la ed. de Osuna, Juan de León, 1550]), f. 6r, Madrid, Biblioteca Nacional de España, M/1366; y Declaración de instrumentos (Osuna: Juan de León, 1555), f. 20v, Madrid, Biblioteca Nacional de España, R/5256.

V.2 Comienzo de "O domine Jesu Christe", motete a 4 de Francisco de Montanos conservado en el Códice de la Parroquia de Santiago de Valladolid (folios 2v-3r). Transcripción de Juan Bautista de Elústiza y Gonzalo Castrillo Hernández, Antología musical. Siglo de Oro de la música litúrgica de España. Polifonía vocal, siglos $X V$ y XVI (Barcelona: Rafael Casulleras, 1933), p. 100.

V.3 Alabanza de George de Santa María a Francisco de Montanos en Francisco de Montanos, Arte de musica theorica y pratica (Valladolid: Diego Fernández de Córdoba y Oviedo, 1592), s.f. Madrid, Universidad Complutense, BH FLL 27938.

V.4 "Confesión y abjuración de Juan Sherwin, inglés, natural de Auxmesta, tierra de Londres, y estante en la villa de Madrid, músico de violones y flautas, por anglicano" (1583). En este documento, Juan Sherwin, "violón de sus altezas", afirma haber trabajado para el Conde de Lemos en Galicia [MINISTERIO DE CULTURA, Archivo Histórico Nacional, ES.28079.AHN/1.1.49.3//INQUISICIÓN,108,EXP.11, f. 3r].

V.5a Francisco de Montanos, Arte de musica theorica y pratica (Valladolid: Diego Fernández de Córdoba y Oviedo, 1592), portada. Madrid, Biblioteca Nacional de España, R/9503.

V.5b Retrato de Fernando Ruiz de Castro, VI Conde de Lemos, en Domencio-Antonio Parrino, Teatro Eroico, e Politico de' Governi de' Vicere del Regno de Napoli Dal tempo del Re Ferdinando il Cattolico Fino al Presente (Nápoles: Nella nuova Stampa Del Parrino, e del Mutii, 1692), vol. 2, s.f.

V.6 Francisco Salinas, De Musica libri Septem (Salamanca: Mathias Gastius, 1557), portada y dedicatoria (página 1 de 2). Madrid, Biblioteca Nacional de España, R/9298.

V.7 Cuento sobre Catalina de Zúñiga recogido en Cuentos muy mal escritos que notó don Juan de Arguijo, MS (siglo XVII), f. 6r, cuento $n^{\circ} 33$. Madrid, Biblioteca Nacional de España, $\mathrm{MSS} / 19380$.

V.8 Francisco de Montanos, Arte de canto llano (Valladolid: Andrés de Merchan, 1594), portada. Coimbra, Universidade de Coimbra, Biblioteca Geral, R-11-36.

V.9 Francisco de Montanos, Arte de canto llano (Valladolid: Andrés de Merchan 1594), Soneto escrito por un amigo anónimo y dedicatoria. Coimbra, Biblioteca Geral de la Universidade de Coimbra, R-11-36.

V.10 Carta de Diego García al Padre Gaspar Moro, datada a 15 de mayo de 1595 , en la que se propone la fundación de una cátedra de canto en el Colegio de Monforte. Madrid, Archivo de los Duques de Alba, C. 152-47, ff. 1v-2r. 
V.11a Pedo Thalesio, Arte de canto chão (Coimbra: Diogo Gomez de Loureyro, 1628 [1618]), portada. Coimbra, Biblioteca Geral de la Universidade de Coimbra, CF C-2-26.

V.11b Domingo Marcos Durán, Lux bella de canto llano aprobada corregida e emendada (Salamanca: [Juan Gysser; ¿Pablo de Colonia?], 1509 [1492]), portada y verso de la portada. Lisboa, Biblioteca Nacional de Portugal, Res. 378P.

V.12a "Memoria de los libros que se enbian al marques mi Señor que se allaron en su aposento", f. 1v. Madrid, Archivo de los Duques de Alba, C. 241-3. Inventario de bienes del VII Conde de Lemos que incluye "arte de musica de fran ${ }^{\circ}$ de montanos".

V.12b "Memoria de la ropa que yo Juan de Enciso entrego a mi señora doña Leonor de Beltrán por mandado de mi señora la condesa de Lemos y de Castro, la qual ropa es de su Excelencia, que vino de Galicia, en Madrid, a 18 de junio de 1639”, ff. 2v-3r. Madrid, Archivo de los Duques de Alba, C. 197-10. Inventario de bienes del VII Conde de Lemos que incluye "un lio con una guitarra cubierto con dos sabanas de estopa para colchones yntitulada $\mathrm{n}^{\circ}$ 11 ”.

V.13 “Dónde son estas serranas? Del pinar de Ávila son”, en Juan Bermudo, El arte Tripharia (Osuna: Juan de León, 1550), f. 38v.

V.14 Nicolai Doizi de Velasco, Nueuo modo de cifra para tañer la guitarra con variedad, y perfeccion (Nápoles: Egidio Long, 1640), portada. Madrid, Biblioteca Nacional de España, R/4042.

VI.1 Conditor alme de Gracia Baptista. Tablatura original de Luis Venegas de Henestrosa, Libro de cifra nueua para tecla, harpa, y vihuela (Alcalá de Henares: Juan de Brocar, 1557), f. 56v. Madrid, Biblioteca Nacional de España, R/598.

VI.2 Juan Enríquez de Zúñiga, Amor con vista (Madrid: Iuan Delgado, 1625), portada y décima de Isabel de Aguiar y Saavedra. Barcelona, Biblioteca del Ateneu Barcelonès, GOc 84.

VI.3 Dotación de libros de Catalina de Zúñiga entregados al Monasterio de Franciscanas Descalzas de Monforte de Lemos y a algunos religiosos jesuitas. Madrid, Archivo de los Duques de Alba, C. 216-11, ff. 1v-2r.

VI.4 Retrato de Ángela Sigea conservado en la Biblioteca de Castilla-La Mancha en Toledo; reproducido en: Aurea María del Carmen Martín Tordesillas, El Renacimiento y las humanistas españolas: discurso de apertura del año académico 1961-62 (Toledo: Publicaciones del Instituto Nacional de Enseñanza Media de Toledo, 1961), p. 61.

VI.5 Francisco de Montanos, Arte de canto llano (Salamanca: Susana Muñoz, 1616 [1594]). Baviera, Bayerische Staatsbibliothek, Mus.th. 7349.

VI.6 Miscelánea, MS (siglo XIX), Barcelona, Biblioteca de Reserva de la Universitat de Barcelona, MS/1023. 
VII.1 Juan Sorapán de Rieros, Medicina española contenida en proverbios vulgares de nuestra lengua muy provechosa para todo genero de estados, para Philosophos, y Medicos, para Theologos, y Iuristas, para el buen regimiento de la salud, y mas larga vida (Granada: Martín Fernández Zambrano, 1616), portada y p. [502]. Munich, Bayerische Staatsbibliothek, 4 Path. 352.

VII.2 Oliva Sabuco, Nueva filosofia de la naturaleza del hombre no conocida ni alcanzada de los grandes filosofos antiguos: la cual mejora la vida y salud humana (Madrid: P. Madrigal, 1587), portada. Madrid, Biblioteca Nacional de España, R/4599.

VII.3 "Ejecutoria del pleito litigado por Isabel Ortiz, viuda de Gonzalo Hernández de Plazaola, Blas Carrillo, como curador de Isabel de Plazaola, hija de los primeros, todos vecinos de Guadalajara, con Diego de la Cueva, marqués de La Adrada, Juana de la Lama, duquesa de Alburquerque, Juana Portocarrero, viuda de Antonio de la Cueva, y consortes sobre pago de 400 ducados por despedir a su hija antes de cumplir los seis años al servicio de la duquesa como constaba en cierta escritura de obligación" (1575) [MINISTERIO DE CULTURA, Archivo de la Real Chancillería de Valladolid, ES.47186.ARCHV/1.1.1//REGISTRO DE EJECUTORIAS,CAJA 1314,80, f. 1r].

VII.4 Libros de música en el inventario post-mortem de Isabel de Aragón, IV Duquesa del Infantado (1491-1564) [MINISTERIO DE CULTURA, Sección Nobleza del Archivo Histórico Nacional, ES.41168.SNAHN/121.4.12//OSUNA,C.1834,D.2, f. xii].

VII.5 Instrumentos musicales en el inventario post-mortem de Isabel de Aragón, IV Duquesa del Infantado (1491-1564). [MINISTERIO DE CULTURA, Sección Nobleza del Archivo Histórico Nacional, ES.41168.SNAHN/121.4.12//OSUNA,C.1834,D.2, f. 13].

\section{Volumen II}

El Apéndice 2 presenta ilustraciones de las portadas de todas las artes de canto estudiadas.

El Apéndice 3 contiene ilustraciones de todos los cantos incluidos por Francisco de Montanos en su Arte de canto llano (Sevilla, 1594) y reutilizados por Antonio Ventura Roel del Río en su Institucion harmonica (Madrid, 1748).

El Apéndice 13 incluye las ilustraciones de todos los ejemplos musicales del Arte de canto llano (Sevilla, 1530) de Juan Martínez, tomadas de los ejemplares del siglo XVI conservados (incompletos y correspondientes a diferentes ediciones).

El Apéndice 14 presenta un catálogo de algunas de las manos musicales y escalas incluidas en las artes de canto estudiadas. 



\section{Lista de tablas}

1 Ubicación de los ejemplares consultados de las ediciones de artes de canto

2 Documentos de archivo consultados

I.1 Artes de canto de pequeño formato impresas en la Península Ibérica entre 1492 y 1626 . Lista abreviada

I.2 Citas a autores de artes de canto por parte de autores de este tipo de obras

I.3 Distribución de los autores de artes de canto por ámbito profesional

II.1 Licencias, pagadores y dedicatarios de las reimpresiones consultadas del Arte de canto llano (Valladolid, 1594) de Francisco de Montanos

II.2 Búsqueda de autoridad en las dedicatorias de las artes de canto

II.3 Dedicatarios de las artes de canto

II.4 Ejemplos de duración del privilegio real en las artes de canto

II.5 Ejemplos de documentos preliminares de las artes de canto

II.6 Ejemplos de artes de canto manuscritas

II.7 Comparación del tratado manuscrito de Fernand Estevan, el MS 14 de Silos y el Arte de canto llano de Juan Martínez

II.8 Fórmulas vinculadas a la oralidad en el manual R/14670(1) de la Biblioteca Nacional de España comparadas con el tratado de Juan Martínez

II.9 Valuación de artes de canto y artes de tañer

II.10 Poseedores de artes de canto y artes de tañer (siglos XVI y XVII)

II.11 Estrato social de los poseedores de artes de canto (siglos XV-XVII)

III.1 Variantes del nombre de Juan Martínez en la bibliografía

III.2 Cronologías asignadas a Juan Martínez en función de las ediciones conocidas de su libro

III.3 Ediciones del Arte de canto llano de Juan Martínez que se mencionan en la bibliografía

III.4 Comparación de los contenidos del Arte de canto llano de Juan Martínez y la Breue instrucion de Canto llano (Sevilla, 1565) de Luis de Villafranca

III.5 Listado abreviado de las reediciones del Arte de canto llano (Sevilla, 1530) de Juan Martínez

III.6 Transmisión del texto del Arte de canto llano (Sevilla, 1530) de Juan Martínez en los ejemplares en español que se conservan publicados con posterioridad

III.7 Conceptos introducidos en el primer capítulo del Arte de canto llano (Sevilla, 1530) de Juan Martínez, a partir de mi reconstrucción de este tratado 
IV.1 Imprenta y difusión de la religiosidad en Zaragoza y Granada

IV.2 Adiciones y correcciones en algunos ejemplares de artes de canto

IV.3 Indicaciones sobre el poseedor/a en algunos ejemplares de artes de canto

IV.4 Contenido general del manuscrito Barcelona, Biblioteca de Catalunya, MS. 1325

IV.5a Estructura del manuscrito Micel-lània de tractats musicals (1475-1525). Barcelona, Biblioteca de Catalunya, Ms. 1325/2

IV.5b Estructura del manuscrito Tractat de teoria musical (siglo XVIII). Barcelona, Biblioteca de Catalunya, Ms. 1325/3

IV.6 Presencia de la mano musical y la escala en las artes de canto

IV.7 Comparación de las lecciones de música de la Sé de Évora con el contenido de los manuales de canto llano de Mateo de Aranda y Juan Martínez

IV.8 Cotejo de las características de seises y mozos de coro en la Catedral de Sevilla

IV.9 Comparación de las ediciones en portugués (1550 y 1597) del Arte de canto llano (Sevilla, 1530) de Juan Martínez realizadas por Afonso Perea Bernal

V.1 Poemas incluidos en el material preliminar del Arte de musica theorica y pratica (Valladolid, 1592) de Francisco de Montanos

V.2 Comparación de las ediciones de 1594 y 1598 del Arte de canto llano (Valladolid, 1594) de Francisco de Montanos

VI.1 Mujeres del mundo ibérico vinculadas a la música mencionadas en el Capítulo VI

VI.2 Grabaciones del himno Conditor alme de Gracia Baptista

VI.3 Comparación de los métodos de elaboración del cantus firmus y cantus firmus estructural

VI.4 Comparación de las versiones de Gonzalo de Baena, Juan Bermudo y Gracia Baptista del himno Conditor alme

VII.1 Profesores de música de Isabel de Plazaola mencionados en el proceso inquisitorial de su madre Isabel Ortiz (1564-1565)

VII.2 Relación de las nobles para las que trabajó la música Isabel de Plazaola según los documentos del proceso inquisitorial de su madre Isabel Ortiz (1564-1565)

VII.3 Relaciones familiares de Juana de la Lama, V Duquesa de Alburquerque

VII.4 Protagonistas de las dos partes del pleito litigado por Isabel Ortiz en 1575

VII.5 Libros de música e instrumentos musicales en los inventarios de bienes de Diego Hurtado de Mendoza y Luna, III Duque del Infantado; Íñigo López de Mendoza y Pimentel, IV Duque del Infantado; y Diego Hurtado de Mendoza, primogénito del IV Duque

VII.6 Músicos del III Duque del Infantado mencionados en el "Proceso de fe de Rodrigo de Bivar" (1539)

VII.7 Esposas e hijas (en negrita) de los cuatro primeros Duques del Infantado

VII.8 Libros de música en el inventario post-mortem de Isabel de Aragón, IV Duquesa del Infantado (1491-1564). "Inventario de los bienes que dejaron los Duques del Infantado, Iñigo López de Mendoza e Isabel de Aragón". Toledo, Sección Nobleza del Archivo Histórico Nacional, Osuna, C.1834, D.2, f. xii 
VII.9 “Arpas viguelas y clavecinbanos" en el inventario post-mortem de Isabel de Aragón, IV Duquesa del Infantado (1491-1564).

"Inventario de los bienes que dejaron los Duques del Infantado, Iñigo López de Mendoza e Isabel de Aragón”, Toledo, Sección Nobleza del Archivo Histórico Nacional, Osuna, C.1834, D.2 (año 1564), ff. 13-14 



\section{Nota sobre el CD-ROM}

Esta Tesis Doctoral se complementa con un CD-ROM que, además de otro contenido interactivo, presenta los dos volúmenes del Trabajo en formato digital con el fin de facilitar la lectura, la búsqueda de términos y la introducción de marcas y comentarios. 



\section{INTRODUCCIÓN}

[...] porque se ve claramente que por ay van impressas unas Artezillas para sacristanes de Aldea; tan breues y tan ordinarias en sus reglas y materias, que (demas del muy poco prouecho que dellas se saca, pues harto mas vale el papel que gastan, que quanto dizen) por una parte nos dan à conocer que mas no sabian; y por otra, parece se quieren encubrir con el dicho de Oracio, Quidquid praecipias esto breuis; en todo lo que enseñares se breue $[\ldots]^{1}$

Las artes de canto impresas en el mundo ibérico renacentista eran libros de pequeño formato o "libros de faltriquera", normalmente en lengua vernácula, y por tanto accesibles a todo aquél que sabía leer, que recogían los rudimentos de la música y tenían un fin didáctico. La peyorativa concepción de estos libros como "artezillas para sacristanes de Aldea" presentada en textos como El Melopeo y Maestro (Nápoles, 1613) de Pietro Cerone ha quedado reflejada en la musicología moderna, ya que estos libros generalmente han pasado inadvertidos o han sido considerados carentes de interés, a pesar de que al menos entre los siglos XVI al XVIII eran los manuales habitualmente utilizados para iniciarse en la música. A su infravaloración ha contribuido el título de muchos de estos libritos, "arte de canto llano", que ha dado lugar a pensar que estaban dirigidos exclusivamente a la enseñanza del canto gregoriano, ocultando así su verdadero objetivo de servir de introducción a la práctica musical en general. Por ejemplo, en su Vergel de música (Burgo de Osma, 1570), Martín de Tapia describía el “A.B.C. de la latinidad" como "saber leer", mientras que definía el "A.B.C. de la musica" como "saber la arteçica de canto llano". ${ }^{2}$ Libros de música instrumental como el Libro de cifra

\footnotetext{
${ }^{1}$ Pietro Cerone, El Melopeo y Maestro (Nápoles: Iuan Bautista Gargano y Lucrecio Nucci, 1613), p. 337.

${ }^{2}$ Martín de Tapia, Vergel de musica spiritual speculatiua y actiua del qual muchas, diuersas y suaues flores se pueden coger (Burgo de Osma: Diego Fernández de Córdoba, 1570), f. 113r, "Tabla alphabetica de algunas cosas particulares que en este libro se contienen". Este libro, finalizado en 1559, es (con la excepción de algunos pasajes, como el aquí mencionado) un plagio de Comiença el libro primero de la declaracion de instrumentos (Osuna, 1549) de Juan Bermudo, como advirtieron Robert Stevenson y
} 
nueua para tecla, harpa, y vihuela (Alcalá de Henares, 1557) de Luis Venegas de Henestrosa y la Declaración de instrumentos (Osuna, 1555) de Juan Bermudo comienzan explicando el canto llano como base para cantar y tocar música tanto sacra como profana. El precio de las artes de canto era inferior al de las artes de tañer o manuales de música instrumental, por lo que las artes de canto podían ser adquiridas por un público muy amplio. Jessie Ann Owens señala que la historia y la teoría de la música occidental se han construido sobre libros de gran formato -como las obras de Heinrich Glareanus (1488-1563) o Gioseffo Zarlino (1517-1590)- que muy pocos podían adquirir o leer; ${ }^{3}$ la hipótesis central de esta investigación es que las artes de canto tuvieron un relevante papel (infravalorado en la historiografía) como agentes en la difusión del alfabetismo musical entre grupos hasta entonces excluidos del aprendizaje de los fundamentos de la música. Mi investigación presenta una panorámica de la cultura musical del mundo ibérico del siglo XVI a través del prisma de la doble alteridad que representan las artes de canto, como libros de música que han pasado generalmente inadvertidos en la bibliografía musicológica, y de su relación con las mujeres, un grupo cuya presencia en las narrativas de la música del período es mínima debido a su escasa representación en los documentos escritos que normalmente se utilizan como fuentes. Esta Tesis Doctoral continúa y desarrolla dos trabajos de investigación que realicé previamente: "Artes de canto en el mundo ibérico renacentista: producción, distribución-consumo y usos a través del Arte de canto llano (1530) de Juan Martínez" y "Women and Music Books in the Sixteenth-Century Iberian World". ${ }^{4}$

Francisco José León Tello. Véase Almonte Howell, “Tapia [Numantino], Martín de”, Grove Music Online. Oxford Music Online, 16 marzo 2012

$<$ http://www.oxfordmusiconline.com/subscriber/article/grove/music/27494>.

${ }^{3}$ Jessie Ann Owens, "You Can Tell a Book by Its Cover: Reflections on Format in English Music 'Theory"', en Music Education in the Middle Ages and the Renaissance: Reading and Writing the Pedagogy of the Past, ed. por Susan Forscher Weiss, Russell E. Murray y Cynthia J. Cyrus (Bloomington: Indiana University Press, 2010), pp. 347-385, p. 378.

${ }^{4}$ El primero es el Trabajo de Investigación Tutelada dirigido por el Prof. Emilio Ros-Fábregas con el que obtuve el Diploma de Estudios Avanzados en la Universidad de Granada en septiembre de 2009; el segundo es la Tesina del Master (MMus) en Estudios Musicales Avanzados en la especialidad de Musicología Histórica que completé en el Royal Holloway de la Universidad de Londres en agosto de 2010 bajo la supervisión del Prof. Stephen Rose. 


\section{OBJETIVOS Y METODOLOGÍA}

El propósito de esta Tesis Doctoral es estudiar las artes de canto llano, canto de órgano y contrapunto impresas en España y Portugal entre 1492 y 1626 y su relación con las mujeres de la época; se prestará especial atención a las artes de canto llano, por constituir el primer estadio del proceso de formación musical. ${ }^{5}$ La investigación de las vinculaciones entre artes de canto y mujeres tiene como objetivo la aproximación a la vida musical del mundo ibérico del siglo XVI ampliando la perspectiva con la exploración de la historia de las mujeres, que prácticamente no figuran en las historias de la música de que disponemos. ${ }^{6}$ En esta investigación se utiliza el concepto antropológico de cultura entendido como procesos activos, un concepto que surgió a finales del siglo XVIII en Inglaterra y Alemania, en oposición al significado ilustrado francés de cultura como formación. ${ }^{7}$ El concepto antropológico de cultura me ha llevado a entender la cultura musical del mundo ibérico renacentista como un conjunto de procesos de actividad musical en lugar de como productos, replanteando la idea de patrimonio musical y empleando la música y los libros de música como un medio para acercarme a la vida cotidiana de la época. ${ }^{8}$

\footnotetext{
${ }^{5}$ El enfoque adoptado supone la revalorización del canto llano como base del aprendizaje de la música en un período del que se ha estudiado primordialmente la polifonía vocal y, más recientemente, la música instrumental, con particular atención a la vihuela. Acerca del olvido historiográfico del canto llano en los estudios musicológicos sobre el siglo XVI, véase Juan Carlos Asensio Palacios, "El canto llano en la España del siglo XVI: de olvidos y protagonismos", en Politicas y prácticas musicales en el mundo de Felipe II: estudios sobre la música en España, sus instituciones y sus territorios en la segunda mitad del siglo XVI, ed. por John Griffiths y Javier Suárez Pajares (Madrid: ICCMU, 2004), pp. 253-284, p. 253: "La mayoría de los estudios y ediciones recientes que se han dedicado a la recuperación de la música de aquella centuria se han centrado sobre todo en la polifonía, obviando casi siempre la importancia que el canto llano llegó a tener en toda la liturgia de la época, al igual que la tuvo en momentos anteriores y que la tendría en el futuro".

${ }^{6}$ Jay S. Kleinberg, ed., Retrieving Women's History: Changing Perceptions of the Role of Women in Politics and Society (Oxford: Berg, 1988), p. xi, destaca la ampliación del campo de investigación histórica que conlleva explorar la historia de las mujeres. En esta Tesis Doctoral no se hablará de la mujer como categoría sino de "mujeres", en el sentido adoptado por Marck Bloch, Apologie pour l'histoire, ou Métier d'historien (París: A. Colin, 1949).

${ }^{7}$ Richard Middleton, "Introduction: Music Studies and the Idea of Culture", en The Cultural Study of Music. A Critical Introduction, ed. por Marin Clayton, Trevor Herbert y Richard Middleton (Nueva York: Routledge, 2003), pp. 1-15, p. 4. Véase también Josep Martí Pérez, "La idea de 'cultura' y sus implicaciones para la musicología", en Campos interdisciplinares de la musicología: V Congreso de la Sociedad Española de Musicología (Barcelona, 25-28 de octubre de 2000), ed. por Begoña Lolo (Madrid: SEdeM, 2001), vol. 2, pp. 1409-1422, p. 1415.

${ }^{8}$ John Shepherd, Music as Social Text (Cambridge: Polity Press, 1991); Josep Martí Pérez, "Hacia una Antropología de la Música", Anuario musical, XLVII (1992), pp. 195-225.
} 
Conocemos únicamente dos ejemplos de mujeres dedicatarias de libros de música impresos en la Península Ibérica en el siglo XVI (curiosamente, ambos son artes de canto), y un solo ejemplo de mujer autora de una pieza musical publicada en ese contexto, lo que pone de manifiesto que las mujeres tenían muchas limitaciones para expresarse musicalmente en el ámbito oficial. Por este motivo, la aproximación a las vinculaciones que se produjeron entre mujeres y libros de música requiere abordar la historia de la música desde otras perspectivas, como la historia de la vida cotidiana y la historia de la vida privada. ${ }^{9}$ En esta investigación se utilizan tales aproximaciones no sólo porque permiten estudiar la relación entre mujeres y música, sino porque además amplían las perspectivas desde las que afrontamos el estudio de la música del Renacimiento. Esta investigación intenta en la medida de lo posible trascender metodológicamente los límites tradicionales de la musicología, ${ }^{10}$ ya que, sin olvidar las perspectivas de la musicología histórica y el análisis musical, ${ }^{11}$ adopta metodologías tomadas de los historiadores del libro y de los historiadores de la cultura popular como una aportación más a la visión de la música en el Renacimiento ibérico, que otros muchos trabajos han ido modelando desde diferentes perspectivas.

Puesto que "en los últimos años la alfabetización se ha convertido en uno de los temas más explorados por la historiografía española", ${ }^{12}$ un estudio del alfabetismo musical, entendido como el conocimiento básico de la música, supondría una contribución

\footnotetext{
${ }^{9}$ Philippe Ariès y Georges Duby, eds., A History of Private Life (Cambridge, Mass.: Belknap Press of Harvard University Press, 1987-1994), 5 vols.

${ }^{10}$ Kevin Korsyn, Decentering Music. A Critique of Contemporary Musical Research (Oxford: Oxford University Press, 2003), p. 40, aboga por unos estudios musicales "post-disciplinarios", rechazando términos tan extendidos como interdisciplinariedad y multidisciplinariedad, puesto que éstos sugieren que "las disciplinas tienen límites definidos que pueden cruzarse o violarse, que están constituidas primero como entidades distintas y sólo subsecuentemente combinadas" ["Music studies will become postdisciplinary. I prefer this term to others such as interdisciplinary, transdisciplinary, crossdisciplinary, or multidisciplinary, all of which suggest that disciplines have definite boundaries that can be crossed or violated, that they are first constituted as distinct entities and only subsequently combined"]. Las traducciones en esta Tesis Doctoral son mías.
}

${ }^{11}$ Rob C. Wegman, "Historical Musicology: Is It Still Possible?", en The Cultural Study of Music. A Critical Introduction, ed. por Marin Clayton, Trevor Herbert y Richard Middleton (Nueva York: Routledge, 2003), pp. 136-145, p. 144, señala que hay una cierta arrogancia en la depreciación de la musicología histórica simplemente por el hecho de que no puede alcanzar la perfección: "There is a certain arrogance in depreciating a worthwhile endeavour, in this case historical musicology, merely because we cannot attain perfection in it".

${ }^{12}$ José Manuel Prieto Bernabé, Lectura y lectores: la cultura del impreso en el Madrid del Siglo de Oro (1550-1650) (Mérida: Editora Regional de Extremadura, 2004), p. 107, indica que los trabajos sobre alfabetización se "han centrado, principalmente, en ámbitos geográficos muy localizados". 
a la historia de la cultura musical, paralela a las aportaciones que se están llevando a cabo en otras disciplinas. Los historiadores del libro señalaban hace décadas que "los repertorios bibliográficos de las imprentas locales [...] representan el mejor índice para testimoniar el grado de cultura de una ciudad a través de los libros que se imprimen en ella". ${ }^{13}$ Los manuales de música en lengua vernácula impresos y vendidos a bajo precio son testimonio del grado de difusión del conocimiento de la música en el mundo ibérico del siglo XVI. Siguiendo la metodología de los historiadores del libro, ${ }^{14}$ las artes de canto se estudiarán como bienes de consumo a través del examen de diversos aspectos: sus características físicas, los métodos de producción, los medios de diseminación y las redes de distribución en la Península Ibérica y el Nuevo Mundo, su mercado potencial y los propósitos para los que fueron utilizadas. Estas cuestiones serán exploradas a través del estudio del material preliminar de los propios libros (el paratexto) y de la extracción de información de inventarios de bienes (publicados e inéditos) y catálogos bibliográficos (tanto catálogos de la época como aquéllos elaborados por bibliógrafos modernos). ${ }^{15}$ Siguiendo la conexión establecida por Roger Chartier entre la historia del libro y la historia de la educación, esta investigación intenta relacionar la historia de los libros de música con la historia de la enseñanza musical. ${ }^{16}$ El Arte de canto llano (Sevilla, 1530) de Juan Martínez, maestro de los mozos de coro en la Catedral de Sevilla, recibirá particular atención, puesto que, a pesar de su escasa presencia en la bibliografía musical, debió de ser un libro muy respetado en la época (a juzgar por las numerosas reediciones, correcciones, ampliaciones, traducciones y citas como autoridad de las que fue

\footnotetext{
${ }^{13}$ Francisco López Estrada, "Prólogo", en Aurora Domínguez de Guzmán, El libro sevillano durante la primera mitad del siglo XVI (Sevilla: Diputación Provincial de Sevilla, 1975), p. IX. Véanse también Manuel Peña Díaz, Cataluña en el Renacimiento: libros y lenguas (Lleida: Milenio, 1996); y El laberinto de los libros: historia cultural de la Barcelona del Quinientos (Madrid: Fundación Germán Sánchez Ruipérez, Ediciones Pirámide, 1997).

${ }^{14}$ Entre los estudios pioneros en historia del libro cabe destacar los siguientes: Lucien Febvre y HenriJean Martin, L'apparition du livre (París: Albin Michel, 1958); Henri-Jean Martin y Roger Chartier, Histoire de l'édition française (París: Promodis, 1982-1986), 4 vols.; y Robert Darnton, "What Is the History of Books?", Daedalus, CXI/3 (1982), pp. 65-83.

${ }^{15}$ Fermín de los Reyes Gómez, "El valor de los paratextos", en Precio y valor del libro antiguo (textos y materiales): Jaca, 2-6 de septiembre de 2004, coord. por Manuel José Pedraza Gracia (Zaragoza: Universidad de Zaragoza, Prensas Universitarias de Zaragoza, 2004), pp. 133-168.

${ }^{16}$ Roger Chartier, Cultura escrita, literatura e historia: coacciones transgredidas y libertades restringidas. Conversaciones de Roger Chartier con Carlos Aguirre Anaya, Jesús Anaya Rosique, Daniel Goldin y Antonio Saborit (Ciudad de México: Fondo de Cultura Económica, 2000), p. 101.
} 
objeto) y ofrece una serie de particularidades que lo convierten en un ejemplo paradigmático para aproximarse a la cultura musical del mundo ibérico renacentista.

Se ha dicho que las mujeres se hacen visibles en la historia cuando ésta se estudia desde la perspectiva de la vida cotidiana. ${ }^{17}$ Las metodologías usadas para documentar la cultura popular, como lo que Peter Burke llama "aproximaciones indirectas u oblicuas" (ver a través de los ojos de otro), parecen especialmente apropiadas para visibilizar al Otro; la historia de las mujeres es "una presa huidiza", tal y como calificaba Burke a la cultura popular. ${ }^{18}$ Las metodologías tomadas de la microhistoria, caracterizadas por la "reducción de la escala" y "el rol de lo particular", serán utilizadas no sólo para analizar la posición musical de las mujeres del siglo XVI, sino también la presencia de la música en la vida cotidiana. ${ }^{19}$ Mi hipótesis es que las mujeres no se mantienen completamente invisibles o "silenciosas" en documentos escritos como los libros de música, sino que se ven reflejadas indirectamente, como "en un espejo de tres lunas, cuando lo que uno ve es un reflejo de un reflejo de un reflejo". ${ }^{20}$ En consecuencia, estudiar la presencia documental de las mujeres requiere metodologías diferentes a las em-

\footnotetext{
${ }^{17}$ Mariló Vigil, La vida de las mujeres en los siglos XVI y XVII (Madrid: Siglo XXI de España Editores, 1994), p. 2.

${ }^{18}$ Peter Burke, Popular Culture in Early Modern Europe (Londres: Temple Smith, 1978), p. 65. Helen Nader, ed., Power and Gender in Renaissance Spain: Eight Women of the Mendoza Family, 1450-1650 (Urbana: University of Illinois Press; Bristol: University Presses Marketing, 2003), p. 19, llama la atención sobre la necesidad de las aproximaciones oblicuas para estudiar a las mujeres de la época (en particular a ocho mujeres de la familia Mendoza): "La mayoría de los autores han encontrado y descifrado cartas, memorias y documentos notariales de las mujeres. Algunos han reconstruido las vidas de las mujeres analizando la poesía y las cartas de sus maridos, padres y admiradores. Esta aproximación oblicua, a través de testimonios en segunda y tercera persona, es una práctica estándar para los historiadores, que frecuentemente deben depender de la lectura crítica de crónicas y documentos oficiales para reconstruir las vidas y las ideas de los hombres" ["Most of the authors have found and deciphered the women's letters, memoirs, and notarial documents. Some have reconstructed the women's lives by analysing the poetry and letters of husbands, fathers, and admirers. Such oblique approach, through second-and thirdperson accounts, is standard practice for historians, who frequently must depend on critical reading of chronicles and official documents to reconstruct the lives and ideas of men"].
}

${ }^{19}$ Éstas son dos de las características comunes de los estudios microhistóricos que señala Giovanni Levi, "On Microhistory", en New Perspectives on Historical Writing, ed. por Peter Burke (Cambridge: Polity Press, 1991), pp. 93-113, p. 110. Véanse también Peter Burke, "Unity and Variety in Cultural History", en Varieties of Cultural History, ed. por Peter Burke (Cambridge: Polity Press, 1997), pp. 183-212; y "The Microhistory Debate", en New Perspectives on Historical Writing, ed. por Peter Burke (Cambridge: Polity Press, 2001 [1991]), pp. 115-117.

${ }^{20}$ Axel Erdmann, My Gracious Silence: Women in the Mirror of 16th Century Printing in Western Europe (Lucerna: Gilhofer \& Ranschburg, 1999), p. xxi: "Taken as a whole, the reflection of women in sixteenth-century printed sources in Europe is an indirect one, somewhat like that in a three-way mirror, when what one sees is a reflection of a reflection of a reflection". 
pleadas en una musicología centrada en composiciones musicales y en grandes libros de teoría de la música. La tesis defendida en esta investigación es que las áreas en que se produce una superposición entre lo privado y lo público, o entre lo oral y lo escrito, permiten vislumbrar prácticas musicales (femeninas y masculinas) y vestigios de la cultura musical de la época invisibles de otro modo a los ojos del historiador, algo similar a lo que el teórico del postcolonialismo Homi K. Bhabha denomina espacios "inbetween". 21

Partiendo de la controversia en torno a "la posición de las mujeres" en el Renacimiento, en esta investigación se analiza el estatus cultural y musical de las mujeres a través del examen de su relación con los libros de música. ${ }^{22}$ En su muy citado trabajo “Did Women Have a Renaissance?”, Joan Kelly-Gadol utiliza la noción de amor en literatura como un medio de explorar la cambiante posición social de las mujeres entre la Edad Media y el Renacimiento. Mi aproximación conlleva transferir la metodología de Kelly-Gadol al campo de la música: el contenido de los libros de música, ¿podría ser un indicador de la posición cultural y musical de las mujeres? Las artes de canto son examinadas en busca de "pistas de implicación femenina que podrían haber pasado desapercibidas a los estudiosos modernos", e interpretadas como artefactos derivados de la cultura material de la época. ${ }^{23}$

${ }^{21}$ Homi K. Bhabha, The Location of Culture (Londres: Routledge, 1994), p. 2: "Lo que es innovador
desde el punto de vista teórico y políticamente crucial es la necesidad de pensar más allá de las narrativas
de subjetividades originarias e iniciales y centrarse en aquellos momentos o procesos que se producen en
la articulación de las diferencias culturales. Estos espacios 'in-between' proporcionan el terrero para ela-
borar estrategias de individualidad - singular o comunal- que inician nuevos signos de identidad, y luga-
res innovadores de colaboración, y lucha, en el acto de definir la idea de la sociedad en s'́ "“What is
theoretically innovative, and politically crucial, is the need to think beyond narratives of originary and
initial subjectivities and to focus on those moments or processes that are produced in the articulation of
cultural differences. These 'in-between' spaces provide the terrain for elaborating strategies on selfhood -
singular or communal- that initiate new signs of identity, and innovative sites of collaboration, and con-
testation, in the act of defining the idea of society itself"].

${ }^{22}$ La tesis de Jacob Burckhardt, The Civilisation of the Period of the Renaissance in Italy, trans. por Samuel G. C. Middlemore (Londres: Kegan Paul \& Co., 1878 [1860]), 2 vols., según la cual los sexos se consideraban iguales en el Renacimiento fue cuestionada por primera vez por Joan Kelly-Gadol, "Did Women Have a Renaissance?", en Becoming Visible: Women in European History, ed. por Renate Bridenthal y Claudia Koonz (Boston: Houghton Mifflin, 1977), pp. 137-164, que afirma que las mujeres perdieron estatus social en el Renacimiento con respecto a la Edad Media. Posteriormente, la creencia de Kelly-Gadol en la pérdida de estatus por parte de las mujeres en el Renacimiento también ha sido cuestionada; para referencias sobre esta controversia, véase Mary Beth Rose, ed., Women in the Middle Ages and the Renaissance: Literary and Historical Perspectives (Syracuse: Syracuse University Press, 1986), pp. xvi-xvii.

${ }^{23}$ Kimberly Marshall, ed., Rediscovering the Muses. Women's Musical Traditions (Boston: Northeastern University Press, 1993), p. xxiii: "Women are often considered accessories to the act of musical creation: 


\section{ESTADO DE LA CUESTIÓN}

Puesto que a lo largo de este trabajo se presentará un estado de la cuestión detallado acerca de los aspectos tratados en cada una de las secciones, en esta introducción llevaré a cabo una primera aproximación a ciertas cuestiones generales y metodológicas. En la bibliografía musicológica del siglo XX las artes de canto se han infravalorado como fuente para la historia de la teoría musical por considerar su contenido falto de interés, demasiado breve y carente de innovaciones; esto no es extraño en una musicología que se ha centrado en teóricos de la música que fueron innovadores y, sobre todo, en compositores. Por ejemplo, el único estudio de conjunto sobre la tratadística musical española, llevado a cabo por Francisco José León Tello, pone énfasis en el contenido y celebración de las innovaciones, por lo que no estudia algunas de las artes de canto analizadas en esta Tesis Doctoral que explícitamente califica de "muy breves" y carentes de interés. ${ }^{24}$ Esta perspectiva ya se había evidenciado antes en el trabajo sobre los teóricos españoles del siglo XVI llevado a cabo por Henri Collet, donde el propósito era poner de relieve "algunas figuras principales" y obras "dignas de atención especial". ${ }^{25}$ El estudio de Samuel Rubio sobre los tratados españoles de canto llano de los siglos XV al XVIII contiene un estudio de Ana Serrano Velasco que aporta una breve descripción de los contenidos de algunas artes de canto que son objeto de mi investigación. ${ }^{26}$ Las artes de canto llano del siglo XVII usadas con fines didácticos por órdenes religiosas han sido

performers of music written by others, or enthusiastic sponsors, assisting composers through financial patronage or personal encouragement [...] late medieval accounts of women 'inspiring' male creativity or sponsoring musical endeavors should be scrutinized for clues to female involvement that may have been overlooked by order scholars".

${ }^{24}$ Francisco José León Tello, Estudios de historia de la teoría musical (Madrid: CSIC, Instituto Español de Musicología, 1962), p. 197: "Podrá notarse el elevado número de autores de canto llano que figura en nuestra exposición. Aún deberíamos añadir dos anónimos conservados en la Biblioteca Nacional y otro que aparecía en la Catedral de Valencia: son, sin embargo, muy breves y carecen de interés”.

${ }^{25}$ Henri Collet, “Contribution à l'étude des théoriciens espagnols de la musique au XVIe siècle", L'Année Musicale, II (1912), pp. 1-63, p. 1: "Nous nous proposons seulement de faire apparaitre en relief quelques figures principales, de mettre en valeur - par des analyses et des extraits- un certain nombre d'ouvrages dignes d'une attention spéciale $[\ldots]$ ".

${ }^{26}$ Samuel Rubio, ed., Estudios sobre los teóricos españoles del canto gregoriano de los siglos XV al XVIII (Madrid: SEdeM, 1980), especialmente Ana Serrano Velasco, "Tratadistas españoles de canto llano. Breve biografía. Descripción y estudio de los tratados” (pp. 9-84). 
examinadas por María Sanhuesa. ${ }^{27}$ Estudios más recientes han mostrado el potencial de las artes de canto como fuente para acercarse a la cultura musical del mundo ibérico renacentista y para estudiar el contenido de las lecciones de música de la época. Un estudio pionero en este sentido es el trabajo de Tess Knighton sobre la propiedad de libros de canto en la Zaragoza de inicios del siglo XVI, que incluye un apartado sobre el mercado de las artes de canto. ${ }^{28}$ La tratadística portuguesa ha sido estudiada recientemente por Manuel Pedro Ferreira y Bernadette Nelson. ${ }^{29}$ Sin embargo, no encontramos ningún trabajo de conjunto en el que se estudien las artes de canto del mundo ibérico renacentista como fuente de la cultura musical de la época siguiendo las metodologías de los historiadores del libro.

La relación de las mujeres con los libros de música en el mundo ibérico renacentista ha pasado generalmente inadvertida en la bibliografía. ${ }^{30} \mathrm{Sin}$ embargo, existen trabajos sobre la relación de la mujer con el libro en general, tanto en el ámbito español como en el contexto europeo, que han sido de gran utilidad para enmarcar teóricamente esta investigación. ${ }^{31}$ Pilar Ramos ha apuntado tres propuestas con respecto a la musico-

\footnotetext{
${ }^{27}$ María Sanhuesa Fonseca, “...Laconice Scribunt: Artes de canto llano en las órdenes religiosas españolas del siglo XVII”, Revista de ciencias de las religiones, IV (1999), pp. 257-278.

${ }^{28}$ Tess Knighton, "Libros de canto: The Ownership of Music Books in Zaragoza in the Early Sixteenth Century", en Early Music Printing and Publishing in the Iberian World, ed. por Iain Fenlon y Tess Knighton (Kassel: Reichenberger, 2006), pp. 215-240, especialmente la sección titulada "The market for 'artes de..."” (pp. 227-231).

${ }^{29}$ Manuel Pedro Ferreira, "Mateus de Aranda: o Tractado de cãto llano (1533) -Notas de leitura", Revista Portuguesa de Musicologia, 14-15 (2004-2005), pp. 131-186; y "O tratado musical de Leiria", en Tratados de arte em Portugal / Art Treatises in Portugal, coord. por Rafael Moreira y Ana Duarte Rodrigues (Lisboa: Scribe, 2011), pp. 179-196; y Bernadette Nelson, “Music Treatises and 'artes para tanger' in Portugal Before the 18th Century: An Overview”, en el mismo volumen colectivo, pp. 197-222.
}

${ }^{30}$ Por ejemplo, en el reciente trabajo Mujer versus música. Itinerancias, incertidumbres y lunas (Valencia: Rivera Editores, 2011), editado por Rosa Iniesta Masmano, no encontramos ningún estudio sobre el tema. Tampoco se hace alusión a esta cuestión en el dossier "Música y estudios sobre las mujeres", editado por Susan Campos Fonseca y Josemi Lorenzo Arribas y publicado en Trans-Revista Transcultural de Música, 15 (2011) < http://www.sibetrans.com/trans/> con motivo del XX Aniversario de la publicación de Feminine Endings. Music, Gender, and Sexuality (Minnesota: University of Minnesota Press, 1991) de Susan McClary; ni en el número "Women and the Sacred" de Early Music, XXXIX/3 (2011). Los estudios sobre las mujeres y la música han proliferado en las últimas décadas, lo que se refleja en la publicación de libros de referencia tales como Julie C. Dunbar, ed., Women, Music, Culture: An Introduction (Nueva York: Routledge, 2010). Algunos aspectos sobre mujeres y libros de música son tratados en mi artículo "Women as Dedicatees of Artes de canto in the Early-Modern Iberian World: Imposed Knowledge or Women's Choice?”, Early Music, XL/2 (2012) [en prensa].

${ }^{31}$ En el contexto español, véase Pedro Manuel Cátedra García y Anastasio Rojo Vega, Bibliotecas y lecturas de mujeres: $s$. XVI (Salamanca: Instituto de Historia del Libro y de la Lectura, 2004). Sobre el ámbito italiano, véase Gabriella Zarri, ed., Donna, disciplina, creanza cristiana dal XV al XVII secolo 
logía de género -interdisciplinariedad, imaginación (dejar a un lado las fuentes "más trilladas") y estudio del público-, y ha señalado el modo en que el estudio de la historia de las mujeres puede contribuir a los estudios musicológicos en general, en línea con la perspectiva desde la que abordo el estudio de la historia de las mujeres. ${ }^{32}$

La mayor parte de los trabajos sobre las mujeres músicas en el mundo ibérico se han centrado hasta ahora en el ámbito conventual, destacando las investigaciones de Colleen R. Baade y Soterraña Aguirre sobre el siglo XVII y Alfonso de Vicente acerca de los siglos XVI al XVIII. ${ }^{33}$ En el contexto europeo disponemos de estudios dedicados específicamente a la cultura musical en los conventos, ${ }^{34} \mathrm{y}$ de estudios generales sobre la vida de las religiosas que muestran la importancia de la música en la clausura. ${ }^{35}$ Algu-

(Roma: Edizioni di Storia e Letteratura, 1996). Acerca de Francia, los territorios borgoñones y los estados italianos, véase Anne-Marie Legaré, ed., Livres et lectures de femmes en Europe entre Moyen Âge et Renaissance (Turnhout: Brepols, 2007). Sobre Francia e Italia, véase Dominique de Courcelles y Carmen Val Julián, Des femmes et des livres: France et Espagnes, XIVe-XVIIe siècle: Actes de la Journée d'Étude organisée par l'École Nationale des Chartes et l'École Normale Supérieure de Fontenay Saint-Cloud (Paris, 30 avril 1998) (París: École des Chartes, 1999).

${ }^{32}$ Pilar Ramos, "Luces y sombras en los estudios sobre las mujeres y la música", Revista musical chilena, LXIV/213 (2010), pp. 7-25, p. 18: “Algunos tópicos o lugares comunes se resquebrajan a la luz de las aportaciones de la historia de las mujeres. Por ejemplo, el estudiar a las mujeres me ha llevado a ahondar en una visión de la música como práctica baja y despreciable en el Siglo de Oro, que poco tiene que ver con el paraíso de mística musical imaginado por tantos musicólogos". Véase también su artículo "Los estudios de género y la música ibérica del siglo XVII”, Revista de Musicología, XX/1 (1997), pp. 231243.

${ }^{33}$ Véanse, por ejemplo, Colleen R. Baade, "Two Centuries of Nun Musicians in Spain's Imperial City", Trans-Revista Transcultural de Música, 15 (2011) [Dossier: "Música y estudios sobre las mujeres", ed. por Susan Campos Fonseca y Josemi Lorenzo Arribas; consultado 1 de diciembre de 2011] $<$ http://www.sibetrans.com/trans/a349/two-centuries-of-nun-musicians-in-spains-imperial-city>;

Soterraña Aguirre Rincón, Un manuscrito para un convento. El 'Libro de Música' dedicado a Sor Luisa de la Ascensión en 1633 (Valladolid: Fundación Las Edades del Hombre, 1998); y "Sonido en el silencio: monjas y músicas en la España de 1550 a 1650", en Políticas y prácticas musicales en el mundo de Felipe II: estudios sobre la música en España, sus instituciones y sus territorios en la segunda mitad del siglo XVI, ed. por John Griffiths y Javier Suárez Pajares (Madrid: ICCMU, 2004), pp. 285-318; y Alfonso de Vicente Delgado, La música en el Monasterio de Santa Ana de Ávila siglos XVI-XVIII: catálogo (Madrid: SEdeM, 1989); y "Diez años de investigación musical en torno al Monasterio de Santa Ana de Ávila”, Revista de Musicología, XXIII/2 (2000), pp. 509-562.

\footnotetext{
${ }^{34}$ Véanse, entre otros, Craig A. Monson, Disembodied Voices: Music and Culture in an Early Modern Italian Convent (Berkeley y Londres: University of California Press, 1995); y Robert Kendrick, Celestial Sirens: Nuns and Their Music in Early Modern Milan (Oxford: Clarendon Press, 1996), sobre el ámbito italiano; Anne Bagnall Yardley, Performing Piety: Musical Culture in Medieval English Nunneries (Nueva York: Palgrave Macmillan, 2006), para el contexto ingles; y Barbara Eichner, "Sweet Singing in Three Voices: A Musical Source from a South German Convent?”, Early Music, XXXIX/3 (2011), pp. 335-348, sobre el ámbito alemán.

${ }^{35}$ Véanse Electa Arenal y Stacey Schlau, Untold Sisters: Hispanic Nuns in Their Own Works (Albuquerque: University of New Mexico Press, 1989); Craig A. Monson, The Crannied Wall: Women, Religion and the Arts in Early Modern Europe (Ann Arbor, Michigan: University of Michigan Press, 1992); y
} 
nos estudios generales sobre mujeres muestran especial interés por las místicas. Stephen Haliczer señala que el misticismo alcanzó en la España de la temprana Edad Moderna una importancia superior a la de otros países, ${ }^{36}$ no sólo contamos con trabajos cuyo objeto de estudio son las místicas, sino que el misticismo tiene una importante presencia en los estudios generales sobre las religiosas y también sobre las mujeres en general. ${ }^{37}$ Otra característica común de muchos estudios generales sobre mujeres es el énfasis en las mujeres escritoras; la voz de la mujer se identifica predominantemente con la voz literaria, probablemente como consecuencia de que las fuentes que nos han llegado son principalmente escritos literarios y correspondencia. ${ }^{38}$ Estos estudios muestran la superación de la "postura victimista" y la creencia en que las mujeres tenían más opciones

Silvia Evangelisti, Nuns: A History of Convent Life, 1450-1700 (Nueva York: Oxford University Press, 2007).

${ }^{36}$ Stephen Haliczer, Between Exaltation and Infamy. Female Mystics in the Golden Age of Spain (Oxford: Oxford University Press, 2002), p. 8.

${ }^{37}$ Véanse, por ejemplo, Rosalynn Voaden, God's Words, Women's Voices: The Discernment of Spirits in the Writing of Late-Medieval Women Visionaries (Suffolk y Rochester: York Medieval Press, 1999); y Alastair Minnis y Rosalynn Voaden, eds., Medieval Holy Women in the Christian Tradition c.1100c.1500 (Turnhout: Brepols, 2010), que incluye un apartado dedicado a la Península Ibérica a cargo de Ronald Surtz. Sobre el misticismo en la historia de la música española, véanse Henri Collet, Le mysticisme musical espagnol au XVIe siècle (París: Éditions d'Aujourd'hui, 1979 [1913]); Emilio RosFábregas, "Historiografía de la música en las catedrales españolas. Positivismo y nacionalismo en la investigación musicológica", CODEXXI, Revista de la Comunicación Musical, I (1998), pp. 41-105, pp. 7477; y "Cristóbal de Morales: A Problem of Musical Mysticism and National Identity in the Historiography of the Renaissance", en Cristóbal de Morales: Sources, Influences, Reception, ed. por Owen Rees y Bernadette Nelson (Woodbridge, Suffolk: Boydell Press, 2007), pp. 215-233; Samuel Llano, "El Hispanismo y la cultura musical en París: 1898-1931", Tesis Doctoral (Ph.D.), Universidad Complutense de Madrid, 2007; y Whose Spain? Negotiating Spanish Music in Paris, 1908-1929 (Oxford: Oxford University Press, [2012]); y Pilar Ramos, "Mysticism as a Key Concept of Spanish Early Music Historiography", en Early Music. Context and Ideas. II International Conference in Musicology (Cracovia: Universidad de Cracovia, 2008), pp. 1-14. Véase también Carol A. Hess, Manuel de Falla and Modernism in Spain, 1898-1936 (Chicago y Londres: University of Chicago Press, 2001), p. 4: "Sin embargo, como Emilio Ros-Fábregas ha argumentado, la idea de misticismo musical como inherentemente española no era un cliché simplista impuesto por extranjeros irreflexivos. También fue alentada por los esfuerzos de musicólogos y críticos españoles (Rafael Mitjana, Adolfo Salazar, Higini Anglès) para diferenciar a Morales, Victoria y Guerrero de compositores de la 'importada' escuela de los Países Bajos" ["Yet as Emilio Ros-Fábregas has argued, the idea of musical mysticism as inherently Spanish was by no means a simplistic cliché imposed by unreflective foreigners. It was also fueled by the efforts of Spanish musicologists and critics (Rafael Mitjana, Adolfo Salazar, Higini Anglès) to differentiate Morales, Victoria, and Guerrero from composers of the "imported' Netherlands school"].

${ }^{38}$ Véanse Lisa Vollendorf, The Lives of Women. A New History of Inquisitional Spain (Nashville: Vanderbilt University Press, 2005); y Arenal y Schlau, Untold Sisters, p. 1, donde explícitamente se señala que "este libro cuenta la historia de monjas que escribieron" ["This book tells the story of nuns who wrote"]. Un libro que "vuelve a la voz audible" y no utiliza la voz como metáfora de la autoridad textual es Leslie C. Dunn y Nancy A. Jones, Embodied Voices: Representing Female Vocality in Western Culture (Cambridge: Cambridge University Press, 1994). 
de acceso a la cultura de lo que previamente se pensaba; pero, a la vez, advierten de la necesidad de evitar una "postura triunfalista". 39

Los usos que se hicieron de los libros de música en contextos didácticos de la iglesia, la universidad y el ámbito privado permanecen en gran medida sin aclarar, ${ }^{40} \mathrm{a}$ pesar de que José Augusto Alegria ha estudiado la enseñanza de la música en las catedrales portuguesas, y María Sanhuesa Fonseca, como mencionaba anteriormente, ha analizado los usos de las artes de canto llano en el siglo XVII en el contexto monástico. ${ }^{41}$ Aunque se han publicado los estatutos y libros de claustros de las universidades

\footnotetext{
${ }^{39}$ Cristina Segura Graíno, "Algunas cuestiones a debatir sobre la historia de las mujeres", en Historia a Debate. Tomo II: Retorno del sujeto. Actas del Congreso Internacional "A historia a debate" celebrado el 7-11 de julio de 1993 en Santiago de Compostela, coord. por Carlos Barros Guimerans (Santiago de Compostela: Historia a Debate, 1995), pp. 299-304, p. 299; Vollendorf, The Lives of Women, p. 5: "La investigación reciente sugiere que, más que compadecer a las mujeres por su falta de opciones, su relegación al hogar, y su posición subordinada, necesitamos reconocer que las mujeres tuvieron más opciones de lo que previamente se creía" ["Recent research suggests that, rather than merely pity women their lack of options, their relegation to the home, and their subordinate position, we need to recognize that women had more options than previously believed"]; y Nader, ed., Power and Gender in Renaissance Spain, p. 5: "El denominado sistema de patriarcado en la España de la temprana Edad Moderna era mucho más flexible y dependiente del contexto histórico de lo que se pensaba previamente" ["The so-called system of patriarchy in early modern Spain was much more flexible and dependent on historical context than previously thought"]. Otro ejemplo reciente es Dagmar Eichberger et al., eds., Women at the Burgundian Court: Presence and Influence (Turnhout: Brepols, 2011). Trabajos centrados en períodos más tardíos también reivindican la importancia de las mujeres en la configuración de discursos generales; por ejemplo, Theresa Ann Smith, The Emerging Female Citizen: Gender and Enlightenment in Spain (Berkeley: University of California Press, 2006), se basa en el papel fundamental que desempeñaron las mujeres en la Ilustración española y analiza la manera en que los debates de género "fueron centrales para reconfigurar España como una nación ilustrada" ["This book argues that gender debates are not merely a window through which scholars today can view Enlightenment principles at work, but rather that these debates were central to reconfiguring Spain as an enlightened nation" (p. 7)]. Son abundantes los estudios sobre las mujeres en el ámbito británico; véanse Retha Warnicke, Women of the English Renaissance and Reformation (Westport: Greenwood, 1983); Sara Mendelson, The Mental World of Stuart Women: Three Studies (Amherst: University of Massachusetts Press, 1987); Patricia Crawford, Women and Religion in England, 1520-1720 (Londres: Routledge, 1993); Sara Mendelson y Patricia Crawford, Women in Early Modern England, 1550-1720 (Oxford: Oxford University Press, 1998); y Amy Froide, Never Married Women: Single Women in Early Modern England (Oxford: Oxford University Press, 2005).
}

${ }^{40}$ En el ámbito internacional, destacan los trabajos de Bernarr Rainbow sobre educación musical, tales como Music in Educational Thought and Practice: A Survey from 800 BC (Aberystwyth: Boethius Press, 1989) y Four Centuries of Music Teaching Manuals, 1518-1932 (Woodbridge, Suffolk: Boydell Press, 2009); en el último no se estudia ningún manual del ámbito ibérico.

${ }^{41}$ José Augusto Alegria, "Prefácio", "Notícia biográfica" y "Notícia bibliográfica", en Mateo de Aranda, Tractado de Cãto Llano (1533), ed. facsímile con introd. y notas de José Augusto Alegria (Lisboa: Insti. De Alta Cultura, 1962); História da escola de música da Sé de Évora (Lisboa: Fundação Calouste Gulbenkian, 1973); "Introdução", en Mateo de Aranda, Tractado de canto mensurable, ed. facsímile con introd. y notas de José Augusto Alegria (Lisboa: Fundação Calouste Gulbenkian, 1978); "Mateus d'Aranda, Mestre da capela da Sé de Évora e lente de música dos estudos Gerais de Coimbra", Anais da Academia Portuguesa da História, 27 (1982), pp. 107-127; O ensino e prática da música nas Sés de Portugal: da reconquista aos fins do século XVI (Lisboa: Instituto de Cultura e Língua Portuguesa, 1985); y O Colégio dos Moços do Coro da Sé de Evora (Lisboa: Fundação Calouste Gulbenkian, 1997); Sanhuesa Fonseca, "Artes de canto llano en las órdenes religiosas españolas del siglo XVII". Los numerosos estu- 
españolas renacentistas y se ha estudiado la historia de estas instituciones, los contenidos de las clases universitarias de música no han sido detallados. ${ }^{42}$ Dos trabajos colectivos recientes incluyen investigaciones sobre la educación musical en el contexto ibérico: Young Choristers 650-1750 y Music Education in the Middle Ages and the Renaissance. ${ }^{43}$ Los ensayos de este último trabajo plantean asuntos centrales para la investigación de la enseñanza y aprendizaje de la música: los métodos pedagógicos usados, qué se aprendía y qué materiales se usaban para ello, quiénes eran los maestros y quiénes los alumnos, dónde y cuándo se aprendía y la razón por la cual se aprendía música.

Recientes investigaciones se han centrado en el lugar que ocupaba la música en la vida cotidiana, en particular, en el entorno urbano. $^{44}$ Esta perspectiva enlaza con el concepto de geografía musical propuesto por Robert Kendrick, que lleva a estudiar la música como parte del espacio físico de la ciudad y a abordar la conexión entre espacios y actitudes (marco cultural). ${ }^{45}$ Este concepto también está latente en el volumen colecti-

dios sobre la música en catedrales españolas también contienen referencias a la enseñanza de los mozos de coro.

${ }^{42}$ Sobre la Universidad de Salamanca, véanse Dámaso García Fraile, "La vida musical en la Universidad de Salamanca durante el siglo XVI", Revista de Musicología, XXIII/1 (2000), pp. 9-74; y Tess Knighton, "Gaffurius, Urrede and Studying Music at Salamanca University Around 1500", Revista de Musicología [en prensa]. Sobre la Universidad de Coimbra, véase Maria do Amparo Carvas Monteiro, "Da Música na Universidade de Coimbra (1537-2002)", Tesis Doctoral (Ph.D.), Universidad de Coimbra, 2002, 2 vols. Acerca de la música en el contexto universitario europeo, véase Nan Cooke Carpenter, Music in the Medieval and Renaissance Universities (Norman: University of Oklahoma Press, 1958).

${ }^{43}$ Susan Boynton y Eric N. Rice, eds., Young Choristers, 650-1700 (Woodbridge, Suffolk: Boydell Press, 2008); y Susan Forscher Weiss, Russell E. Murray y Cynthia J. Cyrus, eds., Music Education in the Middle Ages and the Renaissance: Reading and Writing the Pedagogy of the Past (Bloomington: Indiana University Press, 2010). El segundo volumen incluye varios trabajos sobre la educación musical femenina: Colleen R. Baade, "Nun Musicians as Teachers and Students in Early Modern Spain", en pp. 262-283; Cynthia J. Cyrus, "The Educational Practices of Benedictine Nuns: A Salzburg Abbey Case Study", en pp. 249-261; y Kristine K. Forney, “A Proper Musical Education for Antwerp’s Women”, en pp. 84-125. El libro es fruto del proyecto de colaboración titulado "Reading and Writing the Pedagogy of the Renaissance: Students, Teachers, and Materials of Musical Learning, 1520-1650", que también dio como resultado una base de datos online de libre acceso llamada MIML (http://miml.library.vanderbilt.edu/); esta base de datos contiene bibliografía sobre la enseñanza y aprendizaje de la música entre 1450 y 1650.

${ }^{44}$ Un ejemplo en el ámbito hispano son los artículos recogidos en Early Music, XXXVII/3 (2009), derivados de un Proyecto de Investigación sobre la música en el medio urbano de la España renacentista cuyos investigadores son John Griffiths, Soterraña Aguirre Rincón, Juan Ruiz Jiménez, Cristina Diego Pacheco y José Antonio Gutiérrez.

45 Robert Kendrick, The Sounds of Milan, 1585-1650 (Oxford y Nueva York: Oxford University Press, 2002). El estudio de Kendrick enlaza con una larga tradición de estudios sobre la música en ciudades europeas, entre los que destacan, por ejemplo: Lewis Lockwood, Music in Renaissance Ferrara, 14001505: The Creation of a Musical Center in the Fifteenth Century (Cambridge, Mass.: Harvard University Press, 1984); Reinhard Strohm, Music in Late Medieval Bruges (Oxford: Clarendon Press, 1985); y Allan W. Atlas, Music at the Aragonese Court of Naples (Cambridge: Cambridge University Press, 1985). 
vo Music and Urban Society in Colonial Latin America (Cambridge, 2011), editado por Geoffrey Baker y Tess Knighton. El estudio de la cultura musical como procesos musicales activos en lugar de como productos encuentra un paralelismo en trabajos llevados a cabo en otras disciplinas, como la historia de la ciencia. ${ }^{46}$

Aunque los historiadores del libro ya habían reparado en la importancia de los inventarios de bienes para el estudio de los patrones de posesión de libros y la difusión del alfabetismo, ${ }^{47}$ los inventarios de bienes han sido utilizados en el ámbito musicológico como fuente de la cultura musical renacentista sólo en las últimas décadas. ${ }^{48} \mathrm{Si}$ bien bastante explotados en otras disciplinas, los documentos inquisitoriales han sido raramente utilizados por los musicólogos como fuentes para el estudio de la cultura musical. ${ }^{49}$ Por el contrario, los relatos de viaje constituyen una fuente documental muy im-

\begin{abstract}
${ }^{46}$ Por ejemplo, José Pardo Tomás, El tesoro natural de América. Colonialismo y ciencia en el siglo XVI (Madrid: Nivola Libros Ediciones, 2002), p. 17, señala que no podemos basar el nacimiento y desarrollo de la ciencia moderna en "la gloria de un panteón de grandes pensadores, sino en los procesos sociales, culturales, económicos" en los que intervinieron multitud de individuos. Es interesante la similitud de esta aproximación con las conclusiones presentadas anteriormente por Ramos, "Los estudios de género y la música ibérica del siglo XVII", p. 232, con respecto a los estudios de género y la música ibérica del siglo XVII: "No se trata de acumular nuevos datos, esta vez sobre las mujeres, o de construir un panteón de mujeres ilustres. La musicología feminista se pregunta sobre el papel de la mujer en la música (lo que en épocas antiguas implica acercarse más que a los compositores, a los intérpretes y al público), y por las cuestiones de representación (¿qué imagen se presenta de la mujer en la música? ¿qué repercusiones tiene esta imagen?)".
\end{abstract}

${ }^{47}$ Véase el estudio pionero de José María Madurell y Marimón, comp., Documentos para la historia de la imprenta y librería en Barcelona (1474-1553), anotados por Jordi Rubió i Balaguer (Barcelona: Gremios de Editores y Libreros y de Maestros Impresores, 1955). Un ejemplo más reciente es María del Carmen Álvarez Márquez, La impresión y el comercio de libros en la Sevilla del Quinientos (Sevilla: Universidad de Sevilla, 2007), donde se examina la impresión y el comercio de libros, así como la presencia de la mujer en este negocio utilizando como fuente principal los protocolos notariales.

${ }^{48}$ Un trabajo pionero en el uso de inventarios como fuente musicológica es José María Madurell y Marimón, "Documentos de archivo: libros de canto (s. XIV-XVI)", Anuario musical, XI (1956), pp. 219-232. Véanse también Emilio Ros-Fábregas, The Manuscript Barcelona, Biblioteca de Catalunya, M.454: Study and Edition in the Context of the Iberian and Continental Manuscript Traditions, Tesis Doctoral (Ph.D.), The City University of New York, 1992, vol. 1, pp. 314-390; y "Libros de música en bibliotecas españolas del siglo XVI", Pliegos de Bibliofilia, XV (2001), pp. 37-62; XVI (2001), pp. 33-46; XVII (2002), pp. 17-54; Knighton, "Libros de canto"; y "La circulación de la polifonía europea en el medio urbano: libros impresos de música en la Zaragoza del siglo XVI”, en Música y cultura urbana en la Edad Moderna, ed. por Andrea Bombi, Juan José Carreras y Miguel Ángel Marín (Valencia: Universitat de València, 2005), pp. 337-350. El historiador del libro británico Trevor J. Dadson ha estudiado sobre todo inventarios de la nobleza y ha publicado en los últimos años una incursión en el ámbito de la bibliografía musical; véase Trevor J. Dadson, "Music Books and Instruments in Spanish Golden-Age Inventories: The Case of Don Juan de Borja (1607)", en Early Music Printing and Publishing in the Iberian World, ed. por Iain Fenlon y Tess Knighton (Kassel: Reichenberger, 2006), pp. 95-116.

${ }^{49}$ Un completo estado de la cuestión se incuye en Clive Griffin, Journeymen-Printers, Heresy, and the Inquisition in Sixteenth-Century Spain (Oxford: Oxford University Press, 2005), pp. 14 and ss. En este estudio se utilizan documentos inquisitoriales con el propósito de reconstruir la historia de un número de impresores que trabajaban en la Península Ibérica en el siglo XVI y, a través de estas historias, arrojar luz 
portante a la que los musicólogos suelen recurrir frecuentemente; en mi investigación he utilizado especialmente la recopilación de viajes de extranjeros por España y Portugal de José García Mercadal, que incluye numerosas referencias musicales. ${ }^{50}$ También la documentación sobre vidas de monjas es relevante. Colleen R. Baade utiliza varios ejemplos de vidas de monjas en su estudio sobre la educación musical de las religiosas de la España de la temprana Edad Moderna; ${ }^{51}$ Electa Arenal y Stacey Schlau mencionan vidas de monjas con referencias musicales. ${ }^{52}$

Los historiadores del libro subrayan la necesidad de llevar a cabo un estudio del libro "como un objeto completo, dentro de sus características tanto materiales como históricas". ${ }^{53}$ Rogier Chartier alude a la omisión de que han sido objeto los libros de

sobre el mundo de la producción del libro. En su reseña de tres libros sobre tradiciones orales, Stephen Rose hace alusión a la falta de trabajos musicológicos basados en documentos inquisitoriales: "Herl y Fisher iluminan las tradiciones orales con fuentes raramente empleadas por los historiadores de la música, incluyendo actas de juicios e informes de visitas". Véase Stephen Rose, "Performances and Popular Culture in the German Reformation", Early Music, XXXIII/2 (2005), pp. 295-303, p. 302: "Both Herl [Joseph Herl, Worship Wars in Early Lutheranism: Choir, Congregation and Three Centuries of Conflict (New York: Oxford University Press, 2004)] and Fisher [Alexander J. Fisher, Music and Religious Identity in Counter-Reformation Augsburg, 1580-1630 (Aldershot: Ashgate, 2004)] illuminate oral traditions with sources rarely employed by music historians, including trial records and visitation reports". Un ejemplo reciente del uso de documentos inquisitoriales como fuente musicológica es el trabajo de Javier Marín López, "A Conflicted Relationship: Music, Power and the Inquisition in Vice-regal Mexico City", en Music and Urban Society in Colonial Latin America, ed. por Geoffrey Baker y Tess Knighton (Cambridge: Cambridge University Press, 2011), pp. 43-63.

${ }^{50}$ José García Mercadal, Viajes de extranjeros por España y Portugal: desde los tiempos más remotos hasta comienzos del siglo XX (Madrid: Aguilar, 1952-1962).

${ }^{51}$ Baade, "Nun Musicians as Teachers and Students in Early Modern Spain". Se trata de las vidas de María Vela (1561-1617), Isabel de la Encarnación (siglo XVI) y Ana de la Cruz Ribera (1606-1650); véanse Miguel González Vaquero, La mujer Fuerte, Por otro titulo La Vida de Doña Maria Vela, monja de San Bernardo, en el convento de Santa Ana de Avila (Barcelona: Pedro Lacavallería, 1640); "Vida de Sor Isabel de la Encarnacion", en Fray Juan Carrillo, O.F.M., Relacion historica de la Real fundacion de las Descalças de Santa Clara de la villa de Madrid (Madrid: Luis Sánchez, 1616); y Sor Ana de la Cruz Ribera, "Quaderno Principal", en Escritoras Clarisas españolas, ed. por María Victoria Triviño, O.S.C. (Madrid: Biblioteca de Autores Cristianos, 1992).

${ }^{52}$ Arenal y Schlau, Untold Sisters.

${ }^{53}$ José Luis Gonzalo Sánchez-Molero, "Lectura y bibliofilia cortesanas en la España del Quinientos”, en Libro y lectura en la Península Ibérica y América (siglos XIII al XVI), ed. por Antonio Castillo Gómez (Madrid: Junta de Castilla y León, Consejería de Cultura y Turismo, 2003), pp. 129-164, p. 164. También Jacques Lafaye, Albores de la imprenta. El libro en España y Portugal y sus posesiones de ultramar (siglos XV y XVI) (Ciudad de México: Fondo de Cultura Económica, 2002), p. 15, ha abogado por una historia del libro interdisciplinar, por considerar que el libro es un "producto híbrido" que depende "a la par del medio cultural, del capital y del mercado". Véase también María José Osorio Pérez, María Amparo Moreno Trujillo y Juan María de la Obra Sierra, Trastiendas de la cultura: librerías y libreros en la Granada del siglo XVI (Granada: Universidad de Granada, 2001), p. 10: “[ ...] apenas si se han producido unas cuantas monografías que considerando el libro como una perfecta síntesis entre la producción (lo impreso), distribución (comercio) y difusión (lecturas), han venido a llenar un vacío considerable en el 
música en los trabajos sobre historia del libro. ${ }^{54}$ En el ámbito español e hispanoamericano, los trabajos sobre producción y difusión de libros de música impresos se han centrado en los libros que contienen repertorio musical, principalmente en libros de polifonía litúrgica y música instrumental. ${ }^{55}$ La imprenta y publicación musical en España ha sido prácticamente olvidada en la bibliografía internacional, ${ }^{56}$ en la cual se ha enfatiza-

que se halla inmerso [sic] la historiografía española". Entre los estudios citados como suplidores de este vacío se encuentran Philippe Berger, Libro y lectura en la Valencia del Renacimiento (Valencia: Institució Valenciana d'Estudis i Investigació Alfons el Magnànim, 1987), 2 vols.; Peña Díaz, Cataluña en el Renacimiento; y El laberinto de los libros; y la colección El libro antiguo español (1988-) dirigida por María Luisa López-Vidriero y Pedro Manuel Cátedra García. Véanse también Maxime Chevalier, Lectura y lectores en la España de los siglos XVI y XVII (Madrid: Turner, 1976); y Roger Chartier, Libros, lecturas y lectores en la Edad Moderna (Madrid: Alianza, 1993).

${ }^{54}$ Roger Chartier, “Afterword: Music in Print”, en Music and the Cultures of Print, ed. por Kate van Orden (Nueva York y Londres: Garland, 2000), pp. 325-342, p. 325: "The publication of music -and, more generally, the published forms of musical scores and the texts associated with them- has long been neglected by historians of the book".

${ }^{55}$ El XV Congreso de la Sociedad Internacional de Musicología (Madrid, 3-10/04/1992) llamado "Culturas musicales del Mediterráneo y sus ramificaciones" dedicó la "Study session I" a "La publicación y difusión de la música en el mundo ibérico", presidiendo la sesión Robert Stevenson y Luis Merino. Véanse también Robert Stevenson, Renaissance and Baroque Musical Sources in the Americas (Washington: General Secretariat, Organization of American States, 1970); y María Gembero Ustárroz, "Circulación de libros de música entre España y América (1492-1650): notas para su estudio”, en Early Music Printing and Publishing in the Iberian World, ed. por Iain Fenlon y Tess Knighton (Kassel: Reichenberger, 2006), pp. 147-180, donde se incluye una completa bibliografía. Sobre libros de polifonía litúrgica, véanse, entre otros, Màrius Bernadó, "Impresos litúrgicos: algunas consideraciones sobre su producción y difusión", en Fuentes Musicales en la Península Ibérica (ca. 1250-1550), ed. por Maricarmen Gómez y Màrius Bernadó (Lleida: Universitat de Lleida-Institut d'Estudis Ilerdencs, 2001), pp. 253-270; y Alejandro Luis Iglesias, "El maestro de capilla Diego de Bruceña (1567/71-1623) y el impreso perdido de su libro de Misas, Magnificats y Motetes (Salamanca: Susana Muñoz, 1620)", en Encomium musicae: Essays in Memory of Robert J. Snow, ed. por David Crawford (Hillsdale: Pendragon, 2002), pp. 435-469; y Tess Knighton, "Morales in Print: Distribution and Ownership in Renaissance Spain", en Cristóbal de Morales: Sources, Influences, Reception, ed. por Owen Rees y Bernadette Nelson (Woodbridge, Suffolk: Boydell Press, 2007, pp. 161-175. Sobre libros de música instrumental, algunos ejemplos son John M. Ward, "The vihuela de mano and Its Literature (1536-1576)", Tesis Doctoral (Ph.D.), New York University, 1953; Barry Ife, "La imprenta y la música instrumental del Renacimiento español", en El libro antiguo español: actas del primer Coloquio Internacional (Madrid, 18 al 20 de diciembre de 1986) [El libro antiguo español, 1], dir. por María Luisa López López-Vidriero y Pedro Manuel Cátedra García (Salamanca: Universidad de Salamanca, 1988), pp. 225-236; Jack Sage, "A New Look at Humanism in 16th-Century Lute and Vihuela Books", Early Music, XX/4 (1992), pp. 633-641; John Griffiths y Warren E. Hultberg, "Santa María and the Printing of Instrumental Music in Sixteenth-Century Spain", en Livro de homenagem a Macário Santiago Kastner, ed. por Maria Fernanda Cidrais Rodrigues, Manuel Morais y Rui Vieira Nery (Lisboa: Fundação Calouste Gulbenkian, 1992), pp. 343-360; John Griffiths, "The Printing of Instrumental Music in Sixteenth-Century Spain”, Revista de Musicología, XVI/6 (1993), pp. 3309-3321; Juan Ruiz Jiménez, "Insights into Luis de Narváez and Music Publishing in Sixteenth-Century Spain", Journal of the Lute Society of America, XXVI-XXVII (1993-1994), pp. 1-12; y John Griffiths, "The Transmission of Secular Polyphony in Renaissance Spain: Esteban Daza and Rodrigo de Ceballos", en Encomium musicae: Essays in Memory of Robert J. Snow, ed. por David Crawford (Hillsdale: Pendragon, 2002), pp. 321 340 .

${ }^{56}$ La presencia de los impresos musicales españoles en los estudios sobre los aspectos técnicos de la imprenta musical es escasa o nula; por ejemplo, la única referencia a España en la entrada "Printing and 
do el contexto italiano. ${ }^{57}$ Entre los primeros estudiosos de la imprenta musical en España cabe destacar a José María Madurell y Marimón, Antonio Odriozola, Ángel San Vicente Pino y Robert Stevenson. ${ }^{58}$ Buena parte de los trabajos sobre la imprenta musical

Publishing of Music" de The New Grove Dictionary es que "los Compañeros Alemanes produjeron un Antiphonarium Ord. S. Hieronymi en Sevilla"; véase Stanley Boorman et al., "Printing and Publishing of Music", Grove Music Online. Oxford Music Online, 7 mayo 2012

$<\mathrm{http}$ ://www.oxfordmusiconline.com/subscriber/article/grove/music/40101>. Véanse también Geoffrey Richard Hill, "Music Printing and Publishing: The Transition from Movable Type to Copper- and PewterPlate Engraving", Tesis Doctoral (Ph.D.), University of Newcastle upon Tyne, 1978; Stanley Boorman, "Early Music Printing: Working for a Specialised Market", en Print and Culture in the Renaissance: Essays on the Advent of Printing, ed. por Gerald P. Tyson y Sylvia S. Wagonheim (Newark: University of Delaware Press, 1986), pp. 222-245; Donald William Krummel y Stanley Sadie, eds., Music Printing and Publishing (Londres: Macmillan, 1990); y Stanley Boorman, Studies in the Printing, Publishing, and Performance of Music in the 16th Century (Burlington: Ashgate, 2005).

${ }^{57}$ Véanse Mary Kay Duggan, Italian Music Incunabula: Printers and Type (Berkeley: University of California Press, 1992); Stanley Boorman, "Printed Music Books of the Italian Renaissance from the Point of View of Manuscript Study", Revista de Musicología, XVI/5 (1993), pp. 2587-2602; Iain Fenlon, Music, Print and Culture in Early Sixteenth-Century Italy (Londres: British Library, 1995); y "Thoughts on the Popularity of Printed Music in the 16th-Century Italy", Fontes artis musicae, XLVIII/2 (2001), pp. 129144; Iain Fenlon y Patricia dalla Vecchia, eds., Venecia 1501: Petrucci e la stampa musicale: catalogo della mostra (Mariano del Friuli: Edizioni della Laguna, 2001); y los siguientes trabajos de Jane A. Bernstein: "Girolamo Scotto and the Venetian Music Trade", en Atti del XIV Congresso della Società Internazionale di Musicologia, Bologna, 27 agosto-1 settembre 1987, coord. por Angelo Pompilio (Turín: EDT, 1990), vol. 1, pp. 295-305; "Printing and Patronage in Sixteenth-Century Italy", Revista de Musicología, XVI/2 (1993) [Actas del XV Congreso de la Sociedad Internacional de Musicología "Culturas musicales del Mediterráneo y sus ramificaciones" (Madrid, del 3 al 10 de abril de 1992)], pp. 2603-2613; "Buyers and Collectors of Music Publications: Two Sixteenth-Century Music Libraries Recovered", en Music in Renaissance Cities and Courts: Studies in Honor of Lewis Lockwood, ed. por Jessie Ann Owens y Anthony Cummings (Warren, Michigan: Harmonie Park Press, 1997), pp. 21-34; y Music Printing in Renaissance Venice: The Scotto Press (1539-1572) (Nueva York y Oxford: Oxford University Press, 1998). Sobre la imprenta musical en Francia, véase Pierre-Simon Fournier, Traité historique et critique sur l'origine et les progrè des caractéres de fonte pour l'impression de la musique (Génova: Minkoff Reprint, 1972). Véanse también los siguientes trabajos sobre los principales impresores de música franceses e italianos: Daniel Heartz, Pierre Attaingnant, Royal Printer of Music (Berkeley y Los Ángeles: University of California Press, 1969); Kristine K. Forney, "Tielman Susato, Sixteenth-Century Music Printer: An Archival and Typographical Investigation", Tesis Doctoral (Ph.D.), University of Kentucky, 1978; Suzanne G. Cusick, Valerio Dorico, Music Printer in Sixteenth-Century Rome (Ann Arbor, Michigan: University of Michigan Research Press, 1980); Mary S. Lewis, Antonio Gardano, Venetian Music Printer, 1538-1569: A Descriptive Bibliography and Historial Study (Nueva York y Londres: Garland Pub., 1988-2005), 3 vols.; Tess Knighton, "Petrucci’s Books in Early Sixteenth-Century Spain", en Venezia 1501: Petrucci e la stampa musicale: Atti del convegno internazionale di studi, Venezia, Palazzo Giustinian Lolin, 10-13 ottobre 2001, o Venice 1501, Petrucci, Music, Print, and Publishing, ed. por Giulio Cattin y Patrizia Dalla Vecchia (Venecia: Edizioni Fondazione Levi, 2005), pp. 623-642; y Stanley Boorman, Ottaviano Petrucci: catalogue raisonne (Oxford: Oxford University Press, 2006). Sobre impresores venecianos concretos, véanse Martin Lowry, The World of Aldus Manutius: Business and Scholarship in Renaissance Venice (Ithaca: Cornell University Press, 1979); Nicholas Jenson and the Rise of Venetian Publishing in Renaissance Europe (Oxford: Blackwell, 1991); y Book Prices in Renaissance Venice: The Stockbook of Bernardo Giunti (Los Ángeles: Department of Special Collections, University Research Library, University of California, Los Ángeles, 1991).

${ }^{58}$ José María Madurell y Marimón, "La imprenta musical en España: documentos para su estudio", Anuario musical, VIII (1953), pp. 230-236; y "Documentos de archivo: manuscritos e impresos musicales (siglos XV-XVI)", Anuario musical, XXIII (1968), pp. 199-221; Antonio Odriozola, "Un incunable más y un incunable menos", Gutenberg-Jahrbuch, XXXV (1960), pp. 156-164; y "Los tipógrafos alemanes y 
del siglo XVI se han centrado en la impresión de la música instrumental; sin embargo, contamos con un volumen colectivo sobre la impresión, publicación y difusión de la música en España e Hispanoamérica, editado por Iain Fenlon y Tess Knighton. ${ }^{59}$

Aunque en los estudios de los historiadores del libro se encuentra frecuentemente la perspectiva interdisciplinar, ${ }^{60}$ los trabajos musicológicos que interrelacionan la historia de la música con la historia de la cultura y la historia del libro son todavía escasos. ${ }^{61}$ Trabajos como Music and the Cultures of Print (Nueva York, 2000), editado por Kate van Orden, permiten entrever las posibilidades de la metodología de los historiadores del libro en la historia de la música. ${ }^{62}$ Seis estudios han constituido referentes paradigmáticos para mi investigación: 1) el trabajo de Jane Bernstein sobre la imprenta musical en la Venecia del Renacimiento, que analiza el comercio de libros de música impresos en los talleres venecianos de Scotto para obtener información sobre la historia

la iniciación en España de la impresión musical (1485-1504)", Gutenberg-Jahrbuch, XXXVI (1961), pp. 60-70; Ángel San Vicente Pino, Tiento sobre la música en el espacio tipográfico de Zaragoza anterior al siglo XX (Zaragoza: Institución Fernando el Católico, Sección de Música Antigua, 1986); y Robert Stevenson, "Martín de Montesdoca: Spain's First Publisher of Sacred Polyphony (1550's), Chantre in Guatemala Cathedral (1570's)", Inter-American Music Review, XII/2 (1991-1992), pp. 5-26.

${ }^{59}$ Iain Fenlon y Tess Knighton, Early Music Printing and Publishing in the Iberian World (Kassel: Reichenberger, 2006).

${ }^{60}$ Sobre el libro en el ámbito sevillano, véanse, por ejemplo: Klaus Wagner, Martín de Montesdoca y su prensa: contribución al estudio de la imprenta y de la bibliografia sevillanas del siglo XVI (Sevilla: Universidad de Sevilla, 1982); y "Los libros del canónigo y vihuelista Alonso Mudarra", Bulletin hispanique, XCII (1990), pp. 655-675; y María del Carmen Álvarez Márquez, El mundo del libro en la iglesia Catedral de Sevilla en el siglo XVI (Sevilla: Diputación Provincial de Sevilla, 1992); "La enseñanza de las primeras letras y el aprendizaje de las artes del libro en el siglo XVI en Sevilla", Historia, instituciones, documentos, XXII (1995), pp. 39-86; "El escribano de letra de libros 'versus' el cajista: supervivencia y circulación del libro a mano en la Sevilla del Quinientos", en La memoria de los libros: estudios sobre la historia del escrito y de la lectura en Europa y América, coord. por Pedro Manuel Cátedra García, María Isabel Páiz Hernández y María Luisa López-Vidriero (Salamanca: Instituto de Historia del Libro y de la Lectura, 2004), vol. 1, pp. 87-176; "Mujeres lectoras en el siglo XVI en Sevilla", Historia, instituciones, documentos, XXXI (2004), pp. 19-40; y La impresión y el comercio de libros en la Sevilla del quinientos.

${ }^{61}$ No obstante, en su Catàlech de la Biblioteca Musical de la Diputació de Barcelona: ab notes històriques, biogràfiques y critiques (Barcelona: Palau de la Diputació, 1908-1909), Felip Pedrell ya prestó gran atención al paratexto de las obras catalogadas; Pedrell estuvo en contacto con el bibliógrafo Cristóbal Pérez Pastor. Véase Felip Pedrell, Tomás Luis de Victoria abulense. Biografia, bibliografia, significado estético de todas sus obras de arte polifónico-religioso (Valencia: Manuel Villar, 1918), p. 190.

${ }^{62}$ Véanse Stephen G. Nichols y Siegfried Wenzel, The Whole Book: Cultural Perspectives on the Medieval Miscellany (Ann Arbor, Michigan: University of Michigan Press, 1996); Seth Lerer, "Medieval English Literature and the Idea of the Anthology", Proceedings of the Modern Language Association, 118 (2003), pp. 1251-1267; Stephen Kelly y John J. Thompson, eds., Imagining the Book (Turnhout: Brepols, 2005). 
cultural, política y económica de la Europa del siglo XVI; ${ }^{63}$ 2) el estudio de Cristle Collins Judd sobre los contextos culturales en que se leían los tratados renacentistas de teoría de la música, tomando como punto de partida sus ejemplos musicales; ${ }^{64}$ 3) el trabajo de Kate van Orden, que observa la forma material de los libros como fuente de la cultura musical; ${ }^{65}$ 4) el análisis de Màrius Bernadó sobre las ediciones en Zaragoza del Intonario Caragoçano (1542) de Pedro Ferrer, que utiliza la investigación bibliográfica como vía para aclarar el contexto cultural en que surgió el libro y los usuarios a los que la obra iba dirigida; ${ }^{66}$ ) el estudio de Jessie Ann Owens sobre la tratadística musical inglesa, con sus hipótesis sobre la influencia del formato en la historiografía musical y su estudio de los libros como medios para descubrir su contexto y mercado potencial; ${ }^{67}$ y 6) la aproximación de Jane Alden a los "chansonniers" del Valle del Loira como "textos sociales", en la que presta particular atención a la recepción de los libros, el estudio de su contexto cultural, producción, destinatarios y usos. ${ }^{68}$

Las prácticas microhistóricas y las aproximaciones indirectas que se intentan emplear en esta investigación han sido utilizadas sólo recientemente y de forma limitada en la investigación musical. ${ }^{69}$ Para la historia de la cultura popular, la propuesta de Ro-

\footnotetext{
${ }^{63}$ Bernstein, Music Printing in Renaissance Venice.

${ }^{64}$ Cristle Collins Judd, Reading Renaissance Music Theory: Hearing with the Eyes (Cambridge: Cambridge University Press, 2000). De los libros de teóricos españoles sólo se estudia Musica practica (1482) de Bartolomé Ramos de Pareja.
}

${ }^{65}$ Kate van Orden, "Children's Voices: Singing and Literacy in Sixteenth-Century France”, Early Music History, 25 (2006), pp. 209-256.

${ }^{66}$ Màrius Bernadó, "Las ediciones zaragozanas del Intonario de Pedro Ferrer: contexto y nota bibliográfica", en Early Music Printing and Publishing in the Iberian World, ed. por Iain Fenlon y Tess Knighton (Kassel: Reichenberger, 2006), pp. 23-94.

${ }^{67}$ Owens, "You Can Tell a Book by Its Cover".

${ }^{68}$ Jane Alden, Songs, Scribes, and Society. The History and Reception of the Loire Valley Chansonniers (Oxford: Oxford University Press, 2010), p. 7: "My aim here is to show how the social, cultural, and intellectual world in which chansonniers were produced determined the meaning and significance of these objects".

69 James S. Amelang, "Looking Back: Books and Their Impact. The Cheese and the Worms: The Cosmos of a Sixteenth-Century Miller. Carlo Ginzburg. Trans. John Tedeschi and Anne Tedeschi”, The Sixteenth Century Journal, XL/1 (2009), pp. 31-34, p. 32, señala que Il formaggio e $i$ vermi (Florencia, 1976) de Carlo Ginzburg "es uno de los pocos libros con los que los historiadores de la temprana Edad Moderna esperan que sus colegas de otros campos y disciplinas estén familiarizados" ["It struck me some years ago that The Cheese and the Worms is one of the very few books (...) that early modern historians expect their colleagues in other fields and disciplines to be familiar with. It is, to use today's jargon, a default text"]. Véase también Aldo Colonnello y Andrea Del Col, eds., Uno Storico, Un Mugnaio, Un libro: 
bert Darnton de relacionar los documentos con el mundo significativo que los rodea se ha considerado en algunos trabajos musicológicos. ${ }^{70}$ El aviso de Darnton contra la "familiaridad con el pasado" ya se advierte en los sesenta del siglo XX en trabajos de Carl Dahlhaus cuando considera que la historia que escribimos refleja nuestro presente, y posteriormente en Richard Taruskin, que rechaza la autenticidad en relación al pasado como un objetivo alcanzable; en Leo Treitler, que considera la historia como una interacción entre presente y pasado, o más bien una narración sobre el pasado desde las sensibilidades del presente; y en los llamados musicólogos posmodernos, que parten de la premisa de que nuestras experiencias influyen en lo que escribimos. ${ }^{71}$ Darnton sugiere que podría ser de utilidad orientar la historia hacia la antropología y adoptar el concepto de "cultura como lenguaje". En el ámbito musical, una orientación similar fue propuesta en los ochenta del siglo XX por Joseph Kerman cuando reivindicaba conexiones más pronunciadas entre musicología y etnomusicología, como una consecuencia lógica de su opinión de que los musicólogos debían prestar más atención al contexto de la música

Carlo Ginzburg, Il formaggio e I Vermi, 1976-2002 (Montereale Valcellina: Circolo Culturale Menocchio, 2002).

${ }^{70}$ Robert Darnton, The Great Cat Massacre (Londres: Peguin, 1984), p. 6: "Debería ser posible por tanto
para el historiador descubrir la dimensión social del pensamiento y extraer significado de los documentos
relacionándolos con el mundo significativo que los rodea, pasando del texto al contexto y volviendo de
nuevo hacia atrás hasta que ha despejado el camino a través de un mundo mental extraño" ["It therefore
should be possible for the historian to discover the social dimension of thought and to tease meaning from
documents by relating them to the surrounding world of significance, passing from text to context and
back again until he has cleared a way through a foreign mental world"]. En el campo musicológico, la
historia de la cultura popular se refleja, por ejemplo, en Gary Tomlinson, Music in Renaissance Magic:
Toward a Historiography of Others (Chicago: University of Chicago Press, 1993). También en la década
de los noventa del siglo XX, Andrew Wathey, "Musicology, Archives and Historiography", en Musicolo-
gy and Archival Research, ed. por Barbara Haggh et al. (Bruselas: Archives et Bibliothèques de Belgique,
1994), pp. 3-26, señalaba que las aproximaciones musicológicas a los documentos se hallaban en algunos
aspectos todavía en un "estadio Rankeano" (en referencia a Leopold von Ranke y su aproximación a los
documentos como "textos sagrados") como consecuencia del aislamiento de la disciplina, y proponía
tratar los documentos como textos a través del planteamiento de algunas cuestiones básicas relacionadas
con el contexto de la creación de los mismos.

${ }^{71}$ Carl Dahlhaus, "What Is a Fact of Music History?", en Foundations of Music History (Cambridge: Cambridge University Press, 1983 [1967]), pp. 33-43, pp. 35-37; Richard Taruskin, Text and Act: Essays on Music and Performance (Oxford: Oxford University Press, 1995), especialmente pp. 3-49; y Leo Treitler, Music and the Historical Imagination (Cambridge, Mass.: Harvard University Press, 1990), p. 1. El volumen de Treitler parte de la premisa de que el contenido del pensamiento histórico sobre la música es comprender "la música a través de todos sus presentes, desde el momento de su creación hasta el presente del historiador" ["The meaningfulness of music through all its presents, from the moment of its creation to the historian's present, is the content of historical thought about it"]. 
que examinaban. ${ }^{72}$ Una orientación hacia una etnomusicología-antropología según la idea de Clifford Geertz de "descripción densa" ("thick description") ${ }^{73}$ estaba en la raíz del cambio de paradigma que tuvo lugar en la disciplina musicológica en los ochenta que, tomando Contemplating Music como hito, condujo a la proliferación de publicaciones "posmodernistas". 74

En su crítica de la investigación musical contemporánea, Kevin Korsyn argumenta que la investigación musical en el contexto estadounidense está afrontando "una crisis de discurso" que, en última instancia, es una crisis ética. ${ }^{75}$ Esta crisis está causada por la ruptura de la comunicación, tanto entre los investigadores de la música como entre éstos y el público ("la investigación musical se está convirtiendo en una Torre de Babel"), y por el falso consenso ("la investigación musical se está convirtiendo en un Ministerio de la Verdad"). Es muy interesante que, en el centro de la solución a la crisis de la investigación musical, Korsyn sitúe el concepto de alteridad:

Lo que la investigación musical necesita ahora más urgentemente no es otra teoría de la estructura musical, ni más trabajo de campo etnográfico, ni más crítica histórica -por muy valiosas que estas cosas sean- sino más bien una transformación ética que nos hará, en palabras de Mark Bracher, "más capaces de aceptar y alimentar la alteridad" en nosotros mismos y en los otros. ${ }^{76}$

${ }^{72}$ Véase Joseph Kerman, "How We Got into Analysis, and How to Get Out", Critical Inquiry, VII (1980), pp. 311-331; y Contemplating Music: Challenges to Musicology (Cambridge, Mass.: Harvard University Press, 1985), publicado en Reino Unido como Musicology (Londres: Fontana, 1985).

${ }^{73}$ Clifford Geertz, "Thick Description: Toward an Interpretive Theory of Culture", en The Interpretation of Cultures: Selected Essays (Nueva York: Basic Books, 1973), pp. 3-30.

${ }^{74}$ En una discusión teórica sobre los estudios musicológicos, Gary Tomlinson, "The Web of Culture: A Context for Musicology", Nineteenth-Century Music, VII/3 (1984), pp. 350-362, p. 351, explícitamente aplica el manifiesto de Geertz según el cual "para comprender las acciones humanas individuales necesitamos interpretar el contexto cultural del que surgen" a su propia visión de la musicología: "las obras del arte musical son las codificaciones o reflexiones inscritas de las acciones creativas humanas, y de ahí que deberían entenderse a través de una interpretación similar del contexto cultural" ["musical art works are the codifications or inscribed reflections of human creative actions, and hence should be understood through a similar interpretation of cultural context"]. Tomlinson examina los análisis llevados a cabo por Kerman y Treitler de las limitaciones del positivismo y establece las consecuencias que la aplicación de las ideas de Geertz tendría para la musicología. Para un examen de los trabajos de los ochenta que relacionan la música con su contexto cultural, véase Philip V. Bohlman, "On the Unremarkable in Music", Nineteenth-Century Music, XVI/2 (1992), pp. 203-216. Alastair Williams, Constructing Musicology (Aldershot: Ashgate, 2001), pp. viii-ix y 7, considera que algunos de los "nuevos" temas propuestos por la denominada "New Musicology" estaban en circulación mucho antes de la década de 1980 y, por tanto, antes de la publicación del libro de Kerman. Por este motivo, Williams incluye en su libro secciones sobre Adorno y Dahlhaus, mencionados sólo brevemente por Kerman.

${ }^{75}$ Korsyn, Decentering Music, p. 5.

${ }^{76}$ Korsyn, Decentering Music, p. 176: "What musical research now needs most urgently is neither another theory of musical structure, nor more ethnographic fieldwork, nor more historical criticism -however 
El concepto de alteridad ha sido central en numerosos trabajos en campos tan diversos como la historia de la ciencia, ${ }^{77}$ la antropología, ${ }^{78}$ la historia medieval ${ }^{79}$ y los estudios etnomusicológicos. ${ }^{80}$ Generalmente el concepto de alteridad se relaciona con el otro cultural y se considera un elemento primordial en la configuración del pensamiento, como muestran los siguientes ejemplos en los estudios musicológicos: 1) Gary Tomlinson reivindica la importancia de la alteridad en la configuración de la modernidad musical en el siglo XVIII; ${ }^{81}$ 2) Vanessa Agnew señala la relevancia de la alteridad en la configuración de Alemania como "la nación de la música" mediante la literatura de viaje, ${ }^{82}$ y 3) David R. M. Irving pone de manifiesto la noción de alteridad en la configuración del pensamiento musical en referencia a la temprana Edad Moderna y a los

valuable such things may be- but rather an ethical transformation that will make us, in the words of Mark Bracher, 'more capable of accepting and nurturing otherness' both in ourselves and in others". Véase Mark Bracher, Lacan, Discourse, and Social Change: A Psychoanalytic Cultural Criticism (Ithaca: Cornell University Press, 1993), p. 100.

${ }^{77}$ Un ejemplo es Pardo Tomás, El tesoro natural de América. Véanse también José Pardo Tomás, “Anatomías del Nuevo Mundo: Saberes y prácticas anatómicas en Nueva España en el siglo XVI", en Segundo Simposio "Ciencia y cultura entre dos mundos". Fuentes documentales y sus diversas interpretaciones [Actas del Simposio celebrado los días 2, 3 y 4 de diciembre de 2010, en Cholula, Estado de Puebla, México], coord. por José L. Montesinos Sierera y Sergio Toledo Prats (La Orotava [Publicación electrónica], 2011) < http://www.gobcan.es/educacion/3/usrn/fundoro/web_fcohc/005_publicaciones/

actas_congresos/Symposio_Cholula2010.html>; y Álvaro Girón Sierra, "La mirada occidental hacia el otro: dos siglos de difíciles encuentros" (introducción al dossier "Médicos, naturalistas y alteridad desde la Ilustración al siglo XX” coordinado por Girón Sierra), Dynamis, 29 (2009), pp. 17-28.

${ }^{78}$ Véase, por ejemplo, Deborah Poole, Vision, Race \& Modernity. A Visual Economy of the Andean Image World (Princeton: Princeton University Press, 1997), pp. 25-57.

${ }^{79}$ Roser Salicrú, "Crossing Boundaries in Late Medieval Mediterranean Iberia: Historical Glimpses of Christian-Islamic Intercultural Dialogue", International Journal of Euro-Mediterranean Studies, I/1 (2008), pp. 33-51.

${ }^{80}$ Ramón Pelinski, “'Yo es Otro': reflexiones sobre el encuentro musical entre Europa y América”, Re-
vista de Musicología, XVI/1 (1993), pp. 287-297; Laurent Aubert, The Music of the Other: New Chal-
lenges for Ethnomusicology in a Global Age (Aldershot: Ashgate, 2007 [2001]).
${ }^{81}$ Gary Tomlinson, "Self, Other, and the Emergence of Musical Modernity”, en Music and Historical
Critique. Selected Essays (Aldershot: Ashgate, 2007). Sobre el papel de la ideología europea en la com-
prensión de la canción en las sociedades del Nuevo Mundo indígena, véase Gary Tomlinson, "Ideologies
of Aztec Song”, Journal of American Musicological Society, XLVIII/3 (1995), pp. 343-379. Un ejemplo
temprano que implica el concepto de alteridad en los estudios musicales es Roger Savage, "Rameau's
American Dancers”, Early Music XI/4 (1983), pp. 441-452, que hace referencia a la alteridad cultural que
se refleja en las obras musicales de Rameau.

${ }^{82}$ Vanessa Agnew, Enlightenment Orpheus: The Power of Music in Other Worlds (Nueva York y Oxford: Oxford University Press, 2008). 
instrumentos musicales no europeos. ${ }^{83}$ En mi investigación, los pequeños tratados de música infravalorados en la historiografía y su relación con las mujeres emergen como una forma de alteridad cultural. ${ }^{84}$

\section{FUENTES}

Las fuentes primarias más importantes utilizadas en esta investigación son libros de música impresos y manuscritos (especialmente artes de canto), inventarios de bienes, documentación de procesos de la Inquisición, registros de ejecutorias, expedientes de viajeros a Indias, correspondencia, relatos de viaje, manuales de conducta, cuentos populares, libros de poesía y vidas de monjas. Las artes de canto constituyen la fuente principal. Se ha prestado especial atención a sus características materiales, los indicios de uso encontrados en los ejemplares analizados y los materiales preliminares (licencias, tasas, dedicatorias y prólogos). Aunque la colección Viejos libros de música publicó en edición facsímile doce de las artes de canto objeto de mi investigación, la mayoría de las artes de canto continúa dispersa en archivos y bibliotecas o bien se desconoce su paradero actual. ${ }^{85}$ He consultado un total de 112 ejemplares de artes de canto publicadas entre 1492 y 1626; estos ejemplares corresponden a 28 títulos diferentes (cinco de ellos no incluidos en RISM) y a un total de 66 ediciones (algunas no mencionadas hasta ahora). ${ }^{86}$ La Tabla 1 muestra la distribución geográfica de los ejemplares consultados.

\footnotetext{
${ }^{83}$ David R. M. Irving, "Comparative Organography in Early Modern Empires”, Music and Letters, XC/3 (2009), pp. 372-398; véase también su libro Colonial Counterpoint: Music in Early Modern Manila (Oxford y Nueva York: Oxford University Press, 2010).

${ }^{84}$ El dossier temático "Musical Otherness in the Iberian World, 1500-1800", coord. por María Gembero Ustárroz y Emilio Ros-Fábregas, en Early Music, XL/2 (2012), presenta algunos ejemplos de alteridad en el ámbito hispano.

${ }^{85}$ Entre los proyectos más recientes, encontramos Traités Musicaux en Espagnol, una base de datos de acceso público en Internet de tratados musicales escritos en español llevada a cabo por la Université Paris IV-Sorbonne y cuya responsable es Cristina Diego Pacheco. Este recurso ofrece actualmente transcripciones del Tractado de canto mensurable et contrapuncto (Lisboa, 1535) de Mateo de Aranda y de El arte Tripharia (Osuna, 1550) de Juan Bermudo, además de transcripciones de las artes de tañer de Joan Carles Amat (1626), Gonzalo de Baena (1540), Francisco Correa de Araujo (1626) y Miguel de Fuenllana (1554). Véase <http://www.pm.paris4.sorbonne.fr/LMR/indexEspagnol.html>.

${ }^{86}$ Véase el Capítulo I.
} 
Tabla 1. Ubicación de los ejemplares consultados de las ediciones de artes de canto *Los ejemplares consultados mediante digitalizaciones o solicitud de reproducción aparecen precedidos de asterisco.

\begin{tabular}{|c|c|c|}
\hline País & Ciudad y biblioteca & $\begin{array}{l}\text { Edición de la que se han consultado } \\
\text { uno o varios ejemplares }\end{array}$ \\
\hline Alemania & Munich, Bayerische Staatsbibliothek & $\begin{array}{l}\text { *Bermudo } 1549 \\
* \text { Montanos } 1616[1594]\end{array}$ \\
\hline Canadá & Toronto, University of Toronto Library & *Martínez de Bizcargui 1538 [1508] \\
\hline \multirow[t]{6}{*}{ España } & $\begin{array}{l}\text { Barcelona, Biblioteca de la Abadía de } \\
\text { Montserrat }\end{array}$ & $\begin{array}{l}\text { *Monserrate } 1614 \\
* \text { Montanos } 1694 \text { [1594] }\end{array}$ \\
\hline & Barcelona, Biblioteca de Catalunya & $\begin{array}{l}\text { Artufel } 1614 \\
\text { Cervera } 1595 \\
\text { Martínez de Bizcargui } 1538 \text { [1508] } \\
\text { Monserrate } 1614 \\
\text { Montanos } 1610 \text { [1594] } \\
\text { Montanos } 1648[1594] \\
\text { Montanos } 1670[1594] \\
\text { Montanos } 1756[1594]\end{array}$ \\
\hline & $\begin{array}{l}\text { Barcelona, Biblioteca Pública Episcopal del } \\
\text { Seminari }\end{array}$ & Martínez de Bizcargui 1538 [1508] \\
\hline & $\begin{array}{l}\text { Barcelona, Biblioteca de la Universitat } \\
\text { Autònoma de Barcelona }\end{array}$ & Martínez 1560? [1530] \\
\hline & $\begin{array}{l}\text { Barcelona, Biblioteca de la Universitat de } \\
\text { Barcelona }\end{array}$ & $\begin{array}{l}\text { Artufel } 1614 \\
\text { Cervera } 1595 \\
\text { Martínez de Bizcargui } 1541 \text { [1508] } \\
\text { Monserrate } 1614 \\
\text { Montanos } 1665 \text { [1594] } \\
\text { Montanos } 1670 \text { [1594] } \\
\text { Montanos } 1693 \text { [1594] } \\
\text { Montanos } 1694 \text { [1594] }\end{array}$ \\
\hline & $\begin{array}{l}\text { Las Palmas de Gran Canaria, Biblioteca de la } \\
\text { Universidad de Las Palmas de Gran } \\
\text { Canaria }\end{array}$ & $\begin{array}{l}* \text { Montanos } 1643[1594] \\
* \text { Torres } 1554[1544]\end{array}$ \\
\hline
\end{tabular}




\begin{tabular}{lc}
\hline País Ciudad y biblioteca & $\begin{array}{c}\text { Edición de la que se han consultado } \\
\text { uno o varios ejemplares }\end{array}$
\end{tabular}

(España) Madrid, Biblioteca Nacional de España

Artufel 1614

Bermudo 1549

Bermudo 1550 [facs. Barbieri]

Espinosa 1520

Fernandes 1626

Marcos Durán 1492

Marcos Durán 1498

Marcos Durán c. 1504

Martínez? c. 1512-1515?

Martínez? c. 1515-1519?

Martínez 1598 [1530]

Martínez de Bizcargui 1509 [1508]

Martínez de Bizcargui 1511 [1508]

Martínez de Bizcargui 1515 [1508]

Martínez de Bizcargui 1528 [1508]

Martínez de Bizcargui 1531 [1508]

Martínez de Bizcargui 1543 [1508]

Monserrate 1614

Montanos 1592

Montanos 1598 [1594]

Montanos 1610 [1594]

Montanos 1625 [1594]

Montanos c. 1640 [1594]

Montanos 1648 [1594]

Montanos 1665 [1594]

Montanos 1693 [1594]

Montanos 1712 [1594]

Montanos 1728 [1594]

Montanos 1734 [1594]

Montanos 1756 [1594]

Puerto 1504

Spañón c. 1500

Villafranca 1565

Villegas 1604

Madrid, Biblioteca de la Universidad Complutense de Madrid

*Montanos 1592

*Montanos 1705 [1594]

Oviedo, Biblioteca Central de la Universidad de Oviedo

Bermudo 1549

Bermudo 1550

Montanos 1592

Salamanca, Biblioteca de la Universidad de Salamanca

*Montanos 1648 [1594]

Sevilla, Biblioteca de la Universidad de Sevilla

*Montanos 1686 [1594]

Valencia, Biblioteca Històrica de la Universitat de València

Cervera 1595

Martínez 1562 [1530]

Montanos 1727 [1594]

Zaragoza, Biblioteca de la Universidad de

*Monserrate 1614 Zaragoza

*Torres 1566 [1544] 


\begin{tabular}{lll}
\hline País & Ciudad y biblioteca & $\begin{array}{c}\text { Edición de la que se han consultado } \\
\text { uno o varios ejemplares }\end{array}$ \\
\hline Francia & París, Bibliothèque nationale de France & *Guevara 1582 \\
Portugal & Coimbra, Biblioteca Geral de la Universidade & *Martínez $1559[1530]$ \\
de Coimbra & *Montanos 1594 \\
& & *Thalesio $1628[1618]$ \\
& Évora, Biblioteca Pública de Évora & Aranda 1533 \\
& & Aranda 1535 \\
& & Cervera 1595 \\
& Martínez $1597[1530]$ \\
& Martínez $1621[1530]$ \\
& Lisboa, Biblioteca Nacional de Portugal & Fernandes 1626 \\
& & Marcos Durán $1509[1492]$ \\
& & Martínez $1612[1530]$ \\
& & Martínez $1614[1530]$ \\
& & Martínez $1625[1530]$ \\
& & Thalesio 1618 \\
& & Montanos 1592 \\
\hline
\end{tabular}

Los inventarios de bienes, abundantes en los archivos notariales de España (en parte como consecuencia del control ejercido por la Inquisición), suponen una fuente de primer orden para el análisis de los propietarios de las artes de canto, además de constituir un testimonio de ediciones de las que no se conserva ningún ejemplar en la actualidad. Los diferentes tipos de inventarios (post-mortem, inventarios hechos en vida de la persona, partición de bienes y testamentos) contienen a veces valiosa información sobre el precio de los libros (valuación) y sobre la identidad de los propietarios (por ejemplo, los nombres de los herederos de los bienes o de los compradores), ${ }^{87}$ aunque estas fuentes presentan limitaciones. ${ }^{88}$ Los inventarios se confeccionaban generalmente como re-

\footnotetext{
${ }^{87}$ Trevor J. Dadson, Libros, lectores y lecturas. Estudios sobre bibliotecas particulares españolas del Siglo de Oro (Madrid: Arco libros, 1998); Bartolomé Bennassar, "Los inventarios post-mortem y la historia de las mentalidades", en La documentación notarial y la historia. Actas del II Coloquio de Metodología Histórica Aplicada, ed. por Antonio Eiras Roel (Santiago de Compostela: Junta de Decanos de los Colegios Notariales de España-Universidad, 1984), vol. 2, pp. 139-146.

${ }^{88}$ Sara T. Nalle, Trevor J. Dadson y Maxime Chevalier, entre otros, han advertido de lo engañosa que puede resultar la utilización de los inventarios como índice de alfabetismo o posesión de libros. Véanse Sara T. Nalle, "Literacy and Culture in Early Modern Castile", Past and Present, CXXV (1989), pp. 6595; Dadson, Libros, lectores y lecturas, p. 24; y Chevalier, Lectura y lectores en la España de los siglos XVI y XVII, p. 42.
} 
sultado de actos económicos, por lo que se realizaban para personas pertenecientes a clases más o menos elevadas (es decir, cuando había algo que inventariar), ${ }^{89}$ y sólo se anotaba en ellos información detallada de lo económicamente valioso, ${ }^{90}$ faltando en ocasiones la llamada "biblioteca devaluada", es decir, "escritos no considerados de valor para el registro desde el punto de vista de su soporte material” y que, sin embargo, podían ser las lecturas más frecuentes del propietario. ${ }^{91}$ También había inventarios de personas pertenecientes a estratos socioeconómicos más bajos, como los derivados de procesos inquisitoriales o los inventarios de bienes de difuntos que se hacían de la persona que "moría sin deudos ni parientes al otro lado del Atlántico". 92 La falta de precisión característica de los inventarios de la época estudiada hace difícil identificar muchos de los libros mencionados. Como resultado de estas limitaciones, las artes de canto, por su bajo precio, en muchos casos no eran inventariadas o bien aparecían con títulos genéricos que no permiten su identificación exacta. Además, la posesión de un libro no indica necesariamente su utilización, puesto que éste podía ser un objeto decorativo, ${ }^{93}$ y algunos inventarios realizados como consecuencia de procesos inquisitoriales o inspecciones no incluían material controvertido. ${ }^{94}$

${ }^{89}$ Manuel José Pedraza Gracia, Lectores y lecturas en Zaragoza (1501-1521) (Zaragoza: Prensas Univer-
sitarias de Zaragoza, 1998), p. 17; Francisco M. Gimeno Blay y José Trenchs Ódena, "Libro y bibliotecas
en la Corona de Aragón (siglo XVI)", en El libro antiguo español: actas del II Coloquio Internacional
[El libro antiguo español, 2], ed. por María Luisa López-Vidriero y Pedro Manuel Cátedra García (Sala-
manca: Universidad de Salamanca, Servicio de Archivos y Bibliotecas, 1992), pp. 207-239, p. 210.

${ }^{90}$ Un ejemplo lo encontramos en el inventario recogido en José Luis Barrio Moya, "La librería del abo-
gado burgalés don Juan de Vallejo Barcelona, relator de los Consejos de guerra e Indias en tiempos de
Carlos II (1692)", Anuario de historia del derecho español, 72 (2002), pp. 381-398, p. 394: "mas diez y
ocho libros de a quarto tambien viexos que por tener poco valor no se sientan cada uno de por si, 27 rs.".

${ }^{91}$ Isabel Beceiro Pita, "La relación de las mujeres castellanas con la cultura escrita (siglo XIII-inicios del XVI)", en Libro y lectura en la Península Ibérica y América (siglos XIII al XVI), ed. por Antonio Castillo Gómez (Madrid: Junta de Castilla y León, Consejería de Cultura y Turismo, 2003), pp. 15-52, p. 17. Véanse también Víctor Infantes, "Las ausencias en los inventarios de libros y bibliotecas", Bulletin hispanique, XCIX (1997), pp. 281-292; y Antonio Blanco Sánchez, "Inventario de Juan de Ayala, gran impresor toledano (1556)", Boletín de la Real Academia Española, LXVII (1987), pp. 207-250.

${ }^{92}$ Carlos Alberto González Sánchez, "Emigrantes y comercio de libros en el virreinato del Perú, siglos XVI y XVII", Revista de Indias, LVI/206 (1996), pp. 7-47, p. 3.

${ }^{93}$ Chevalier, Lectura y lectores en la España de los siglos XVI y XVII, p. 42; Roger Chartier, El orden de los libros. Lectores, autores, bibliotecas en Europa entre los siglos XIV y XVIII (Barcelona: Gedisa, 1996 [1992]), pp. 23-40.

${ }^{94}$ Por ejemplo, los inventarios de monjas estudiados por Pedro Manuel Cátedra fueron llevados a cabo como consecuencia de inspecciones "por parte de visitadores masculinos" o formaban parte de documentos públicos como las dotaciones; véase Pedro Manuel Cátedra García, "Lectura femenina en el claustro 
En esta investigación he llevado a cabo un vaciado de inventarios de bienes de instituciones y personas, de hombres y mujeres que fueron posibles usuarios de libros y de profesionales del negocio del libro. Los inventarios revelan detalles del mercado, circulación, propiedad y valuación de las artes de canto; he intentado suplir sus limitaciones complementándolos con otra información, como por ejemplo el material preliminar de las artes de canto. He utilizado inventarios ya publicados y otros inéditos consultados en archivos; véase la Tabla 2, apartado 1. Además de las artes de canto y los inventarios de bienes, en esta investigación he consultado como fuente primaria cuatro procesos de la Inquisición conservados en la Sección Inquisición del Archivo Histórico Nacional en Madrid, dos registros de litigios del Archivo de la Real Audiencia y Chancillería de Valladolid (ambos con músicos como protagonistas), tres expedientes de viajeros a Indias del Archivo General de Indias de Sevilla relativos a músicos, y correspondencia conservada en el Archivo de los Duques de Alba en Madrid (Palacio de Liria) y la Biblioteca Nacional de España, entre otros documentos de archivo; véase la Tabla 2.

(España, siglos XIV-XVI)", en Des femmes et des livres: France et Espagnes, XIVe-XVIIe siècle: Actes de la Journée d'Étude organisée par l'École Nationale des Chartes et l'École Normale Supérieure de Fontenay Saint-Cloud (Paris, 30 avril 1998), ed. por Dominique de Courcelles y Carmen Val Julián (París: École des Chartes, 1999), pp. 7-60, p. 10. 
Tabla 2. Documentos de archivo consultados

\begin{tabular}{|c|c|c|}
\hline & Documento & Localización \\
\hline \multirow[t]{6}{*}{ 1. Inventarios } & $\begin{array}{l}\text { "Inventario de los bienes que dejaron } \\
\text { los Duques del Infantado, Íñigo Ló- } \\
\text { pez de Mendoza e Isabel de Ara- } \\
\text { gón” (1564 y 1566). }\end{array}$ & $\begin{array}{l}\text { Toledo, Sección Nobleza del } \\
\text { Archivo Histórico Nacional, } \\
\text { Osuna, C.1834, D.1-2. }\end{array}$ \\
\hline & $\begin{array}{l}\text { "Inventario de los bienes de doña Cata- } \\
\text { lina de Zúñiga y Sandoval, 1628". }\end{array}$ & $\begin{array}{l}\text { Madrid, Archivo Histórico de } \\
\text { Protocolos, } \mathrm{P}^{\mathrm{o}} 2300 .\end{array}$ \\
\hline & $\begin{array}{l}\text { "Dotación de libros de Catalina de } \\
\text { Zúñiga entregados al monasterio de } \\
\text { Franciscanas Descalzas de Monfor- } \\
\text { te de Lemos y a algunos religiosos } \\
\text { jesuitas" (1630). }\end{array}$ & $\begin{array}{l}\text { Madrid, Archivo de los Duques } \\
\text { de Alba, C. 216-11. }\end{array}$ \\
\hline & $\begin{array}{l}\text { "Memoria de la ropa que yo Juan de } \\
\text { Enciso entrego a mi señora doña } \\
\text { Leonor de Beltrán por mandado de } \\
\text { mi señora la condesa de Lemos y de } \\
\text { Castro, la qual ropa es de su Exce- } \\
\text { lencia, que vino de Galicia, en Ma- } \\
\text { drid, a } 18 \text { de junio de } 1639 " .\end{array}$ & $\begin{array}{l}\text { Madrid, Archivo de los Duques } \\
\text { de Alba, C. 197-10. }\end{array}$ \\
\hline & $\begin{array}{l}\text { "Memoria de los libros que se enbian al } \\
\text { marques mi Señor que se allaron en } \\
\text { su aposento". }\end{array}$ & $\begin{array}{l}\text { Madrid, Archivo de los Duques } \\
\text { de Alba, C. 241-3. }\end{array}$ \\
\hline & $\begin{array}{l}\text { "Convento de Nuestra Señora de la } \\
\text { Piedad". }\end{array}$ & $\begin{array}{l}\text { Madrid, Archivo Histórico } \\
\text { Nacional, Clero-Secular } \\
\text { Regular, 2057/2070 (años } \\
\text { 1458-s. XIX). }\end{array}$ \\
\hline \multirow[t]{4}{*}{$\begin{array}{l}\text { 2. Documentos de la } \\
\text { Inquisición }\end{array}$} & $\begin{array}{l}\text { "Proceso de fe de Rodrigo de Bivar" } \\
\text { (1539). }\end{array}$ & $\begin{array}{l}\text { Madrid, Archivo Histórico } \\
\text { Nacional, Sección } \\
\text { Inquisición, legajo 213, } \\
\text { expediente } 7 .\end{array}$ \\
\hline & $\begin{array}{l}\text { "Proceso de fe de Isabel Ortiz" (1564- } \\
\text { 1565). }\end{array}$ & $\begin{array}{l}\text { Madrid, Archivo Histórico } \\
\text { Nacional, Sección } \\
\text { Inquisición, legajo 104, } \\
\text { expediente 5. }\end{array}$ \\
\hline & $\begin{array}{l}\text { "Proceso de fe de Antonio de Torres, } \\
\text { músico que tiene escuela de danza } \\
\text { en la calle de Barrio Nuevo de Ma- } \\
\text { drid y vecino del Burgo de Osma, } \\
\text { por deshonestidad" (1570). }\end{array}$ & $\begin{array}{l}\text { Madrid, Archivo Histórico } \\
\text { Nacional, Sección } \\
\text { Inquisición, legajo } 75, \\
\text { expediente } 16 .\end{array}$ \\
\hline & $\begin{array}{l}\text { "Confesión y abjuración de Juan Sher- } \\
\text { win, inglés, natural de Auxmesta, } \\
\text { tierra de Londres, y estante en la vi- } \\
\text { lla de Madrid, músico de violones y } \\
\text { flautas, por anglicano" (1583). }\end{array}$ & $\begin{array}{l}\text { Madrid, Archivo Histórico } \\
\text { Nacional, Sección } \\
\text { Inquisición, legajo 108, } \\
\text { expediente 11. }\end{array}$ \\
\hline 3. Litigios & $\begin{array}{l}\text { "Ejecutoria del pleito litigado por Gi- } \\
\text { nés Bezón, músico, con Antonio de } \\
\text { Fonseca, vecino y regidor de Toro } \\
\text { (Zamora), sobre deuda" (1560). }\end{array}$ & $\begin{array}{l}\text { Valladolid, Real Audiencia } \\
\text { Chancillería de Valladolid, } \\
\text { Registro de Ejecutorias, Caja } \\
\text { 968-39. }\end{array}$ \\
\hline
\end{tabular}




\section{Expedientes de viajeros a Indias}

\section{Correspondencia}

\section{Documento}

"Ejecutoria del pleito litigado por Isabel Ortiz, viuda de Gonzalo Hernández de Plazaola, Blas Carrillo, como curador de Isabel de Plazaola, hija de los primeros, todos vecinos de Guadalajara, con Diego de la Cueva, marqués de La Adrada, Juana de la Lama, duquesa de Alburquerque, Juana Portocarrero, viuda de Antonio de la Cueva, y consortes sobre pago de 400 ducados por despedir a su hija antes de cumplir los seis años al servicio de la duquesa como constaba en cierta escritura de obligación" (1575).

"Real Cédula a los oficiales de la Casa de la Contratación para que den licencia a Vicente Espi, músico de tecla, natural de Burgos, para pasar al Perú, obligándose a ejercer su oficio" $(1553,1555)$.

"Expediente de concesión de licencia para pasar a México a favor de Diego de Ayala, músico, vecino de México en compañía de su mujer Luciana Suárez hija de Pedro Suárez e Isabel de Contreras" (1567).

"Expediente de concesión de licencia para pasar a México a favor de Juan de Villarrubia, clérigo, músico para la Catedral de México” (1591).

"Carta del Infante D. Enrique de Aragón a su hija Isabel. Segorbe, 15 diciembre 1514".

"Carta del rey Felipe II a Gabriel de la Cueva, gobernador del estado de Milán, después V duque de Alburquerque, en la que le avisa haber nombrado capitán general de la mar a García de Toledo, virrey de Cataluña, y le ordena apreste la mayor cantidad de gente de armas que pueda, para embarcarla en la escuadra" (16-04-1564).

"Carta de El amigo a la condesa de Lemos, 1594".

“Carta de Diego García al Padre Gaspar Moro datada a 15 de mayo de $1595 ”$.

\section{Localización}

Valladolid, Real Audiencia y Chancillería de Valladolid, Registro de Ejecutorias, Caja 1314-80.

Sevilla, Archivo General de Indias, Indiferente, 1965, L.12, F.55; Indiferente, 1965 , L.12, F.71; y Pasajeros, L.3, E.2644.

Sevilla, Archivo General de Indias, Indiferente, 2051, N.41.

Sevilla, Archivo General de Indias, Indiferente, 2065, N.88.

Madrid, Biblioteca Nacional de España, MSS/12978/15.

Madrid, Biblioteca de la Real Academia de la Historia, Colección de don Luis de Salazar y Castro, M-24, ff. 141-143.

Madrid, Archivo de los Duques de Alba, C. 28-9.

Madrid, Archivo de los Duques de Alba, C. 152-47. 


\begin{tabular}{|c|c|c|}
\hline & Documento & Localización \\
\hline \multirow[t]{3}{*}{ (5. Correspondencia) } & $\begin{array}{l}\text { "Correspondencia de la condesa de } \\
\text { Lemos con su marido, 1592-1596". }\end{array}$ & $\begin{array}{l}\text { Madrid, Archivo de los Duques } \\
\text { de Alba, C. } 40-65 \text { a C. } 40- \\
132 .\end{array}$ \\
\hline & $\begin{array}{l}\text { “Carta del P. Diego García de la Com- } \\
\text { pañía de Jesús, Prefecto de estudios } \\
\text { del Colegio de Monforte, a D. Ro- } \\
\text { drigo de Castro y Osorio, Arzobis- } \\
\text { po de Sevilla, sobre la peste de Ga- } \\
\text { licia en 1598. Camba, } 26 \text { de Agosto } \\
\text { de } 1598 " .\end{array}$ & $\begin{array}{l}\text { Madrid, Biblioteca Nacional de } \\
\text { España, MSS/18552/16. }\end{array}$ \\
\hline & $\begin{array}{l}\text { "Correspondencia familiar de la Casa } \\
\text { del Infantado". }\end{array}$ & $\begin{array}{l}\text { Madrid, Biblioteca Nacional de } \\
\text { España, MSS/11157. }\end{array}$ \\
\hline 6. Cédulas & $\begin{array}{l}\text { "Noticia de la cédula del rey Felipe II } \\
\text { por la que nombra gobernador del } \\
\text { estado de Milán a Gabriel de la } \\
\text { Cueva, después V duque de Albur- } \\
\text { querque" (18-01-1564). }\end{array}$ & $\begin{array}{l}\text { Madrid, Biblioteca de la Real } \\
\text { Academia de la Historia, Co- } \\
\text { lección de don Luis de Sala- } \\
\text { zar y Castro, M-20, f. } 213 \text {. }\end{array}$ \\
\hline \multirow[t]{3}{*}{ 7. Testamentos } & $\begin{array}{l}\text { "Testamento de María de Mendoza, } \\
\text { [futura III marquesa del Cenete], hi- } \\
\text { ja de Rodrigo de Mendoza Vivar, } \\
\text { [I] marqués del Cenete y María de } \\
\text { Fonseca, [(I)] marquesa de Cenete" } \\
\text { (Burgos, 1535). }\end{array}$ & $\begin{array}{l}\text { Toledo, Sección Nobleza del } \\
\text { Archivo Histórico Nacional, } \\
\text { Osuna, C.424, D.16. }\end{array}$ \\
\hline & $\begin{array}{l}\text { "Testamento original y copias autori- } \\
\text { zadas de Isabel de Aragón" (Guada- } \\
\text { lajara, 1563). }\end{array}$ & $\begin{array}{l}\text { Toledo, Sección Nobleza del } \\
\text { Archivo Histórico Nacional, } \\
\text { Osuna, C.1763, D.14. }\end{array}$ \\
\hline & $\begin{array}{l}\text { "Testamento otorgado por doña Catali- } \\
\text { na de la Cerda, condesa de Coruña" } \\
\text { (Guadalajara, 1580). }\end{array}$ & $\begin{array}{l}\text { Madrid, Biblioteca de la Real } \\
\text { Academia de la Historia, Co- } \\
\text { lección de don Luis de Sala- } \\
\text { zar y Castro, M-41, ff. 164- } \\
169 .\end{array}$ \\
\hline 8. Libros de cuentas & $\begin{array}{l}\text { "Nóminas y cuentas de la Casa del } \\
\text { Infantado, v.3: años 1596-1739". }\end{array}$ & $\begin{array}{l}\text { Madrid, Biblioteca Nacional de } \\
\text { España, MSS/11148. }\end{array}$ \\
\hline
\end{tabular}

Junto a esta variedad de documentos inéditos, he empleado diversos tipos de libros impresos: relatos de viajes, manuales de conducta, libros de poesía, cuentos populares y vidas de monjas (algunas manuscritas). He utilizado los datos de interés musical en relatos de viajeros recogidos en Viajes de extranjeros por España y Portugal (Madrid, 1952-1962) de José García Mercadal. En cuanto a los manuales de conducta, he prestado particular atención a los que tratan sobre las mujeres, tanto del siglo XVI como 
alguno posterior, ${ }^{95}$ sin olvidar los libros destinados a un público sin distinción de género. ${ }^{96}$ Los juicios sobre la música en manuales tan conocidos como los de Juan Luis Vives, Fray Luis de León y Juan de la Cerda han sido examinados "indirectamente", cotejándolos con las opiniones emitidas en los mismos acerca de la conveniencia de que las mujeres leyeran. Los libros de poesía se han utilizado para estudiar la vida musical de la época por las referencias que en ellos encontramos a mujeres músicas y, sobre todo, a la práctica de la época de cantar poesía "al tono de...", es decir, con melodías conocidas que no se copiaban. En cuanto a los cuentos populares, he estudiado las referencias musicales que aparecen en los recogidos a comienzos del siglo XVII en Cuentos muy mal escritos que notó Juan de Arguijo (MSS/19380 de la Biblioteca Nacional de España), así como de los Cuentos españoles de los siglos XVI y XVII (Madrid, 1982) editados por Maxime Chevalier, que define el cuento breve en esa época como relatos "de intención jocosa y de carácter oral”. He analizado las vidas de siete monjas de la época conservadas en la Biblioteca Nacional de España en Madrid; ${ }^{97}$ se trata de biografías y autobio-

\footnotetext{
${ }^{95}$ Francesc Eiximenis, Libre de les dones (Barcelona: Iohan Rosenbach, 1495); Martín de Córdoba, Jardin de nobles doncellas (Madrid: Joyas bibliográficas, 1953 [1500]); Christine de Pisan, Aqui comença o liuro chamado espelho de Cristina o qual falla de tres estados de molheres e he partydo em tres partes (Lisboa: Campos, 1518); Juan Luis Vives, Instruccion de la muger christiana: obra compuesta en latin por el célebre Juan Luis Vives, que traduxo á la lengua castellana Juan Justiniano (Madrid: en la imprenta de don Benito Cano, 1793 [1523]); Luis de León, La perfecta casada (Madrid: Centro General de Administración, 1865 [1584]); Gaspar Astete, Tratado del gouierno de la familia y estado de las viudas y doncellas (Burgos: Iuan Baptista Varesio en la imprenta de Philippe de Iunta, 1603 [1597]); y Fray Juan de la Cerda, Libro intitulado vida politica de todos los estados de mugeres (Alcalá de Henares: Juan Gracián, 1599). También se inserta en esta categoría el tratado De como ordenar y ocupar el tiempo, incluido en Hernando de Talavera, Breve y muy provechosa doctrina cristiana Confesional. Del restituir daños y males. Del comulgar. Contra el murmurar y el maldecir. De las ceremonias de la misa. Del vestir y calzar. De como ordenar y ocupar el tiempo (Granada: Meinardo Ungut y Juan Pegnitzer, c. 1496). Aunque de fecha posterior al siglo XVI, también me ha sido útil la consulta del tratado de Josefa Amar y Borbón, Discurso sobre la educacion fisica y moral de las mugeres (Madrid: Imprenta de D. Benito Cano, 1790).
}

${ }^{96}$ Rodrigo Sánchez de Arévalo, Verjel de los príncipes: códice del siglo XV, ed. por Francisco Rafael Uhagon y Guardamino (Madrid: Vda. e hijos de Tello, 1900); Juan Luis Vives, Diálogos sobre la educación (Madrid: Alianza, 1987 [1538]); Cristóbal de Villalón, El scholástico, ed. por José Miguel Martínez Torrejón (Barcelona: Crítica, 1997 [Manuscritos: c. 1538, 1542]); Pedro de Luján, Coloquios matrimoniales (Sevilla: Dominico de Robertis, 1550); Pedro López de Montoya, Libro de la buena educación y enseñanza de los nobles, en que se da muy importantes avisos a los padres para enseñar y criar bien a sus hijos (Madrid: P. Madrigal, 1595).

${ }^{97}$ Son las vidas de Sor Margarita de la Cruz, del Real Monasterio de las Descalzas de Madrid; María de Toledo, fundadora del Monasterio de Santa Isabel de los Reyes de Toledo; Sor Estefanía de la Encarnación, monja en el Monasterio de Franciscanas de Descalzas de la Ascensión de Lerma; Sor Catharina Thomasa, monja en el Monasterio de Santa María Magdalena de Palma; María Clemente, monja en el Convento de San Nicolás Obispo de La Orotava (Tenerife); Ana Ponce de Leon, Condesa de Feria y monja en el Monasterio de Santa Clara de Montilla (Córdoba); y Mariana de S. Ioseph priora del Real Convento de la Encarnación. 
grafías, impresas y manuscritas, en las que se exalta el misticismo y la santidad de las religiosas (los milagros que les ocurrían, los favores que Dios les hizo, etc.), con escasas pero interesantes referencias a la música. ${ }^{98}$

\section{ESTRUCTURA DEL TRABAJO}

Esta Tesis Doctoral consta de dos volúmenes. El volumen I se estructura en dos partes de cuatro y tres capítulos, respectivamente; cada capítulo incluye al final un resumen de las principales aportaciones del mismo. En la Parte I se lleva a cabo una aproximación a las artes de canto impresas en la Península Ibérica como producto de consumo. El Capítulo I contiene una descripción de las artes de canto que son objeto de la investigación, un examen de sus características físicas, y un análisis de sus aspectos medievales y modernos que sirve para revalorizar estos libros de música hasta ahora infravalorados en la historiografía musical. En el Capítulo II, las artes de canto se estudian como un producto comercial, con particular atención a los procesos de producción y distribución, la valuación, las formas de consumo y el mercado potencial de esta categoría libresca. Este análisis tiene como objetivo determinar el grado de circulación de estos pequeños tratados que contenían los fundamentos de la música y dilucidar si pudieron contribuir a extender y difundir estos conocimientos a un amplio espectro de la población. El Capítulo III presenta un estudio en profundidad del arte de canto llano más difundido en el mundo hispánico del siglo XVI, pero que es poco conocido en la actualidad: el Arte de canto llano (Sevilla, 1530) de Juan Martínez, maestro de los mozos de coro de la Catedral de Sevilla. La historia de este libro sirve como ejemplo de buena parte de los aspectos tratados en el capítulo anterior y aporta evidencias sobre el uso de las artes de canto como herramienta docente en contextos educativos diferenciados. El Capítulo IV explora los usos que se dieron a las artes de canto a partir de un análisis de evidencias externas de los ejemplares consultados. Esta exploración complementa el estudio del mercado de estos libros presentado en el Capítulo II y refuerza, desde una nueva perspectiva, la hipótesis de que las artes de canto no eran manuales

\footnotetext{
${ }^{98}$ Esto podría relacionarse con los gustos del mercado potencial de estos libros en un contexto en que el misticismo era predominante; véase Haliczer, Between Exaltation and Infamy.
} 
usados exclusivamente en instituciones eclesiásticas para aprender a cantar la Misa y el Oficio Divino, sino que tuvieron una difusión en otros contextos (como la universidad y el ámbito privado) y entre muy diversos usuarios (profesionales del canto eclesiástico y aficionados, principiantes y maestros).

La aproximación al lugar de la música en la cultura del mundo ibérico renacentista a través de las artes de canto se complementa en la Parte II con el estudio de las vinculaciones entre estos libros de música y las mujeres, un grupo que, como las artes de canto, generalmente ha pasado desapercibido en las historias de la música española renacentista. La Parte II consta de tres capítulos. El Capítulo V presenta un estudio del papel desempeñado por las mujeres como dedicatarias y mecenas de libros de música, y se explora si las mujeres son "representadas" en los libros de música que aparentemente están dirigidos específicamente a un público femenino, como El arte Tripharia (Osuna, 1550) de Juan Bermudo. En el Capítulo V se estudia en detalle la relación entre Catalina de Zúñiga y Sandoval, VI Condesa de Lemos, y el Arte de canto llano (Valladolid, 1594) que le dedicó Francisco de Montanos.

El Capítulo VI consta de dos partes. La primera se centra en las mujeres como autoras de música e impresoras de libros de música. Se argumenta que la usual distinción entre lo privado y lo público, que consigna a las mujeres a la esfera privada, no es lo suficientemente clara, y que es en los lugares de superposición entre estas esferas donde las evidencias de la conexión de las mujeres con los libros de música se hacen visibles. La segunda parte del Capítulo VI muestra ejemplos menos obvios de actividades musicales femeninas y que por tanto requieren aproximaciones creativas o indirectas para documentarlos. Partiendo de un vaciado de inventarios de bienes de mujeres, cancioneros poéticos y artes de canto son analizados como "libritos de mujeres" y explorados como artefactos materiales en los que lo escrito y lo oral coexisten, para penetrar en prácticas musicales no documentadas. En el Capítulo VII estudio fuentes diferentes a los libros de música, tales como tratados de conducta femenina, documentos de la Inquisición, literatura e inventarios, que proporcionan pistas hasta ahora inexploradas de los conocimientos musicales que se esperaban de las mujeres. Los documentos derivados del proceso inquisitorial contra Isabel de Ortiz entre 1564 y 1565 se analizan desde una perspectiva musicológica con el propósito de conocer la formación y las vicisitudes profesionales de la música Isabel de Plazaola, hija de la procesada. La documentación consultada es especialmente relevante en relación al mecenazgo musical de Isabel de 
Aragón, IV Duquesa del Infantado, y de un grupo de mujeres establecidas en torno a Guadalajara. El segundo volumen de esta Tesis Doctoral contiene la Bibliografía y veinte Apéndices cuyo contenido se detalla en el Índice general. 



\section{Parte I}

LAS ARTES DE CANTO COMO PRODUCTO DE CONSUMO EN

EL MUNDO IBÉRICO RENACENTISTA:

LOS OTROS LIBROS DE MÚSICA 



\section{CAPÍTULO I \\ LAS ARTES DE CANTO IMPRESAS EN EL MUNDO IBÉRICO DEL SIGLO XVI: DESCRIPCIÓN E HISTORIOGRAFÍA}

Este Capítulo, dividido en dos secciones, presenta en la primera sección una descripción de las artes de canto impresas en la Península Ibérica entre 1492 y 1626 para analizarlas como producto de consumo siguiendo la metodología de los historiadores del libro. Este análisis servirá para realizar, en la segunda sección, una crítica a la posición historiográfica asignada a estos libros y para determinar si los rasgos estudiados constituyen peculiaridades de este género libresco o si, por el contrario, responden a un fenómeno cultural más general del Renacimiento. Curiosamente, aunque algunas de las causas principales del desinterés mostrado por la historiografía hacia las artes de canto sean su pequeño formato, su extrema brevedad y su carácter eminentemente práctico, estas características no son ajenas a la modernidad y al humanismo.

\section{LAS ARTES DE CANTO COMO TIPOLOGÍA LIBRESCA: UNA HISTORIA CONTADA POR "OCTAVOS”}

Las referencias a las artes de canto en los escritos de los siglos XVI y XVII enfatizan su pequeño formato (se las denomina “artezillas") y este rasgo juega un papel fundamental en el escaso valor que se ha dado a estos libros a lo largo de la historia. En su estudio de la conexión entre formato y función en los tratados musicales, Jessie Ann Owens ha señalado que la historia y la teoría de la música occidental se han construido sobre libros de gran formato (como las obras de Glareanus o Zarlino) que, sin embargo, muy pocos podían adquirir o leer, y aboga por escribir una historia de la teoría musical desde la perspectiva del formato: "la historia contada por octavos sería muy diferente de 
la contada por los folios". "El formato es esencial en la determinación del precio de un libro y, en consecuencia, en su mercado potencial. En esta sección delimitaré el objeto de mi estudio y analizaré las características físicas de las artes de canto como un primer paso hacia la valoración de estos libros como producto de consumo en el mundo ibérico renacentista.

\subsection{Definición y origen de las artes de canto. Delimitación del objeto de estudio}

Las artes (artezillas, artiçelas o sumas) de canto llano, canto de órgano o contrapunto son libros de pequeño formato y pocas hojas, similares a nuestros "libros de bolsillo", normalmente escritos en lengua vernácula, que presentan de forma sintética las principales reglas del canto (la mayoría únicamente del canto llano) con un propósito didáctico (véase Ilustración I.1). El Diccionario de la lengua castellana (1726) señala como primer significado del término arte "la facultad que prescribe reglas y preceptos para hacer rectamente las cosas" y, como última acepción, indica que se llama también arte al "mismo libro en que están escritas las reglas y preceptos del arte". ${ }^{2}$ Como tipología libresca, las "artes" no sólo tuvieron el canto como tema, sino que constituyeron un fenómeno general posiblemente relacionado con el aumento del alfabetismo y la existencia de un amplio mercado potencial. Encontramos artes de bien vivir, de bien morir, de bien confesar, de criar la seda, de navegar, de orar, de ingenio, de cocina, de amar a Dios y de servir a Dios, entre muchas otras. El concepto de "arte" se vincula por tanto al de "cartilla", como "tratado breve y elemental de algún oficio o arte". 3

\footnotetext{
${ }^{1}$ Owens, "You Can Tell a Book by Its Cover", p. 378: "We take figures such as Glarean and Zarlino to be the pillars of 'music theory'; we can't help but be influenced by their heft. But are we writing a history of books bought by few and read by even fewer? It would be interesting to write a 'history of theory' from the perspective of format: the story told by octavos would be far different from that by the folios".

${ }^{2}$ Real Academia Española, Diccionario de la lengua castellana, en que se explica el verdadero sentido de las voces, su naturaleza y calidad, con las phrases o modos de hablar, los proverbios o refranes, y otras cosas convenientes al uso de la lengua (Madrid: Imprenta de Francisco del Hierro, 1726), vol. 1 [AB], p. 422, col. 2. En el Diccionario de la lengua española (Madrid: Real Academia Española, 2001), p. 148 , se incluye la definición de arte como "conjunto de preceptos y reglas necesarios para hacer bien algo"; sin embargo, como género libresco, el significado de "arte" se reduce a las artes de gramática: "Libro que contiene los preceptos de la gramática latina".

${ }^{3}$ Diccionario de la lengua española, p. 316. Otra acepción del término "cartilla" que podría aplicarse a las "artes de..." es la siguiente: "Cuaderno pequeño, impreso, que contiene las letras del alfabeto y los primeros rudimentos para aprender a leer”.
} 
Ilustración I.1: Juan Martínez, Arte de canto llano (Sevilla: Juan Gutiérrez, 1560? [1530]), ff. A7vA8r. Barcelona, Biblioteca de Comunicació de la Universidat Autònoma de Barcelona, Res. XVI/56.

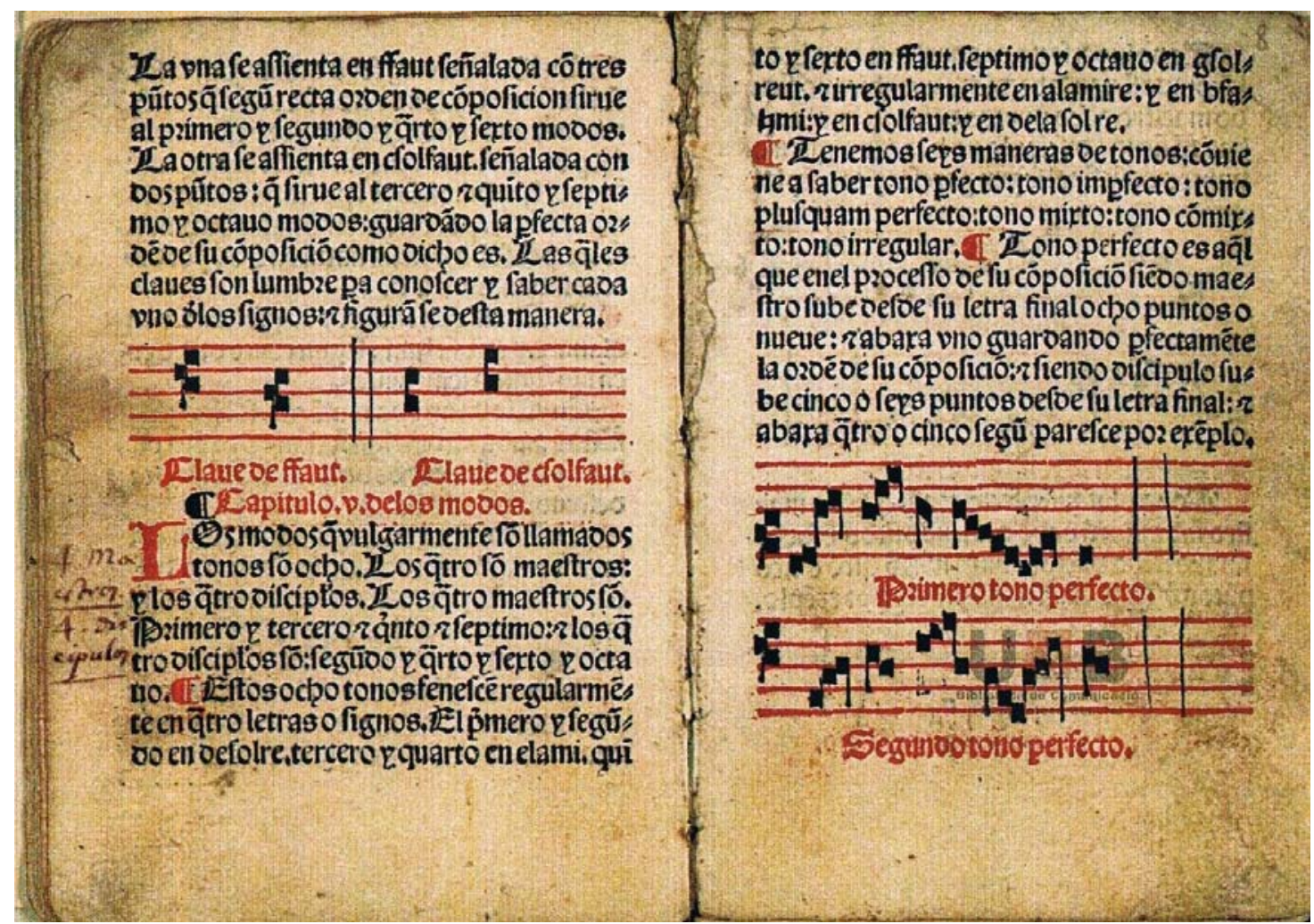

El origen de las artes de canto llano en particular se ha situado en los intonarios o cantorinos, libros en latín que suponían una "prolongación de los antiguos tonales o tonarios en los que todas las piezas del repertorio gregoriano aparecían agrupadas por tonos" y a los que más tarde se añadió una pequeña introducción con las principales reglas derivadas de los tratados especulativos medievales. ${ }^{4}$ Otros estudiosos utilizan el concepto de "tonarios de teórico", tomado del trabajo de Michel Huglo sobre los tonarios medievales, para definir las artes de canto como "una tradición literaria mixta", que combina "una información literaria derivada de los escritos especulativos medievales con una serie de elementos musicales prácticos (entonaciones, fórmulas, etc.) adaptados

\footnotetext{
${ }^{4}$ Pilar Escudero, "Tratados musicales. Estudio comparativo", en: Fernand Estevan, Reglas de canto plano è de contrapunto è de canto de órgano: primer tratado de música escrito en castellano (Sevilla: Conservatorio Superior de Música, 1984), pp. 33-45, p. 13. Véase también Ismael Fernández de la Cuesta, Los tratados de canto llano de Spañón, Martínez de Bizcargui y Molina (Madrid: Joyas bibliográficas, 1978), p. 24.
} 
de los Tonarios para el uso en la liturgia ordinaria". 5 Sin embargo, si comparamos las artes de canto con el Intonario Caragoçano (Zaragoza, 1542) de Pedro Ferrer, considerado por Màrius Bernadó muy parecido a los cantorinos que se imprimieron en Italia, se pueden apreciar claramente sus diferencias. ${ }^{6}$ El Intonario estaba destinado exclusivamente al clero, ya que: 1) presupone una base musical previa, puesto que no explica las letras, signos, claves y demás elementos que conforman el lenguaje del canto llano; ${ }^{7}$ y 2) contiene "una antología de cantos" cuya finalidad es el aprendizaje de un repertorio dado y su memorización. Los tonarios, por su carácter clasificatorio, eran una herramienta para memorizar los cantos del Oficio y la Misa. Por ejemplo, cuando un niño ingresaba en un monasterio debía memorizar todo el repertorio del Oficio, aunque el canto llano ya estuviese notado en los cantorales, y la duración de este aprendizaje oscilaba entre los seis meses y los dos o tres años. ${ }^{8}$ Tampoco parece totalmente apropiado identificar las artes de canto con los "tonarios de teórico", puesto que generalmente las artes eran libros totalmente prácticos carentes de cualquier contenido especulativo.

La presente investigación se centra en los tratados de canto (ya sea de canto llano, canto de órgano o contrapunto, aunque con una atención especial en el primer tipo por funcionar como base del resto de tratados) que dan prioridad a la vertiente práctica de la música y que cumplen tres condiciones que definen el fenómeno de "las artes de”: 1) están impresos, con todo lo que ello implica; 2) están escritos en lengua vernácula (español o portugués) y por tanto eran accesibles a todo aquél que sabía leer; y 3) tienen un formato pequeño, principalmente en octavo. Respecto a la primera condición, la impresión denota que había una demanda y permitía una difusión mayor del produc-

\footnotetext{
${ }^{5}$ Michel Huglo, Les Tonaires. Inventaire, Analyse, Comparaison (París: Soc. Française de Musicologie, Heugel et Cie, 1971), pp. 436-444; María del Carmen Rodríguez Suso, "Gonzalo Martínez de Bizcargui, y la música práctica”, Cuadernos de sección: Música, VI (1993), pp. 25-42, p. 33.

${ }^{6}$ Bernadó, "Las ediciones zaragozanas del Intonario de Pedro Ferrer”, pp. 45-46, sugiere que el propósito del Intonario Caragoçano fue seguramente restaurar la pureza del canto litúrgico en Zaragoza en el contexto de las reformas de Hernando de Talavera.

${ }^{7}$ Según Bernadó, "Las ediciones zaragozanas del Intonario de Pedro Ferrer”, p. 45, este Intonario es "un libro enteramente musical destinado al uso de la clerecía que contiene un extenso repertorio de entonaciones para diversas ocasiones litúrgicas e instrucciones detalladas sobre los principales problemas del canto llano".

${ }^{8}$ Anna Maria Busse Berger, Medieval Music and the Art of Memory (Berkeley: University of California Press, 2005), p. 47. Véase también su artículo "Mnemotechnics and Notre Dame Polyphony", The Journal of Musicology, XIV/3 (1996), pp. 263-298.
} 
to; ${ }^{9}$ además, requería una serie de trámites y una financiación, por lo que los autores debieron de considerar que sus obras merecían las costosas y lentas gestiones que conllevaba la imprenta. En cuanto a la segunda condición (la lengua vernácula), José Manuel Prieto Bernabé ha señalado que la multiplicación de las publicaciones en lengua vernácula en el siglo XVI respondía a estrategias editoriales motivadas por la "creciente demanda de hombres, mujeres y niños que estaban en condiciones de leer". ${ }^{10}$ En la bibliografía se hace alusión al "importante papel desempeñado por las mujeres en el desarrollo de traducciones en lengua vernácula" durante la Edad Media. ${ }^{11}$ En el proceso de delimitación de mi objeto de estudio, he encontrado dos obras en las que coexiste el latín con el castellano. Ars musicorum (Valencia, 1495) de Guillermo de Podio, escrito en latín aunque con algunas notas y las últimas páginas en castellano, no se incluye en este estudio por no compartir con las "artecillas" las características de brevedad y pequeño formato (consta de 136 páginas en folio). Portus musice (Salamanca, 1504) de Diego del Puerto, que contiene nueve hojas en latín con notas marginales impresas en castellano y tres hojas íntegramente en castellano, sí ha sido objeto de esta investigación por su formato y por la intención expresa de su autor de incluir el castellano con el propósito de hacer el libro accesible a un grupo más amplio de lectores: "Para que fuese nota y clara a todos asi vulgares como latinos, acorde tomar et clarar algunos principios necessarios para los nueuos, et otrosi otras dubdas que en la latinidad se contienen". ${ }^{2}$

Respecto al tercer requisito que cumplen las artes de canto aquí estudiadas (el pequeño formato), la mayor parte de ellas tienen un formato en octavo, aunque también se incluyen libros en formato cuarto. Por tanto, en esta investigación no se consideran "artes de" obras como Comiença el libro llamado declaracion de instrumentos musicales (Osuna, 1555) de Juan Bermudo o el Libro de cifra nueua para tecla, harpa, y vihuela (Alcalá de Henares, 1557) de Luis Venegas de Henestrosa, las cuales, aunque

\footnotetext{
${ }^{9}$ Sobre la transformación que conllevó la imprenta para "la producción y el consumo musicales", véase, por ejemplo, Bernadó, "Impresos litúrgicos", p. 254. Este tema se trata en detalle en el Capítulo II.

${ }^{10}$ Prieto Bernabé, Lectura y lectores, p. 77. Véase también Anastasio Rojo Vega, "Exportación de libros a América en el siglo XVI", en La medicina en el descubrimiento, ed. por Juan Riera Palmero (Valladolid: Universidad de Valladolid, 1991), pp. 65-78, p. 72.

${ }^{11}$ Susan Groag Bell, "Medieval Women Book Owners: Arbiters of Lay Piety and Ambassadors of Culture" [1982], en Women and Power in the Middle Ages, ed. por M. Erner y M. Kowaleski (Atenas: University of Georgia Press, 1988), pp. 149-187, pp. 149-150. Véase el Capítulo VI.

${ }^{12}$ Diego del Puerto, Portus musice (Salamanca: [Juan de Porras], 1504), f. A2r.
} 
comienzan explicando los principios del canto llano, fueron impresas en formato folio. No obstante, las referencias a estas dos obras serán constantes (sobre todo en los Capítulos V y VI, respectivamente). Desde el punto de vista del formato, el Arte de canto llano de Dámaso Artufel es especial, puesto que se trata de un manual anexado al final de su obra sobre el Oficio Divino Modo de rezar las horas canonicas conforme al Rezo de los Frayles Predicadores (Valladolid, 1614). No obstante, este Arte de canto llano es una obra independiente con su propia foliación, portada y material preliminar; consta de un total de 68 hojas, 4 de las cuales son material preliminar (portada, mano guidoniana, erratas, tasa, prólogo y tabla de los capítulos). Cabe preguntarse si el Arte de canto llano de Dámaso Artufel se vendería por separado y circularía como una obra independiente. En la Biblioteca de Catalunya en Barcelona se conserva un ejemplar de este Arte de canto llano como documento independiente. ${ }^{13}$ La inclusión de artes de canto llano en manuales de pequeño formato en lengua vernácula dirigidos a religiosos aparece también en un libro francés de finales del siglo XVII: el Processional, ou sont contenus les Offices communs \& particuliers [...] Et une petite méthode au commencement pour apprendre le Plainchant (París, 1694).

El ámbito geográfico en el que se enmarca esta investigación es el mundo ibérico renacentista, aceptando la complejidad que ello supone. Por ejemplo, Owen Rees señala la necesidad de estudios que aborden la cultura musical de la Península Ibérica en conjunto sin excluir a Portugal. ${ }^{14}$ Aunque todas las artes de canto aquí estudiadas fueron impresas en la Península Ibérica, el escenario de circulación analizado incluye las posesiones de España y Portugal, que incluían los territorios de Flandes, los territorios de la Corona de Aragón en la Italia meridional, las "Indias de Castilla", Brasil, y las tierras portuguesas en Japón, China e India; ${ }^{15}$ no se han conservado ejemplares de este género libresco impresos en el Nuevo Mundo en esta época. ${ }^{16}$ Las artes de canto impre-

\footnotetext{
${ }^{13}$ Barcelona, Biblioteca de Catalunya, Res 1407-12º (ex-libris de la Colección Teatral Arturo Sedó).

${ }^{14}$ Owen Rees, "Relaciones musicales entre España y Portugal", en Políticas y prácticas musicales en el mundo de Felipe II: estudios sobre la música en España, sus instituciones y sus territorios en la segunda mitad del siglo XVI, ed. por John Griffiths y Javier Suárez Pajares (Madrid: ICCMU, 2004), pp. 455-487.

${ }^{15}$ Lafaye, Albores de la imprenta, p. 15.

${ }^{16}$ Se tiene noticia de que el jesuita mexicano Juan de Tovar obtuvo permiso para imprimir un "Arte de la música" en 1602; véase Ernest J. Burrus, "Two Lost Mexican Books of the Sixteenth Century", Hispanic American Historical Review, XXXVII/3 (1957), pp. 330-339, p. 331, nota 5: "But by 1600 or slightly earlier Tovar had mastered a second Indian language, the difficult Otomí [...], wrote a catechism in it and
} 
sas en Nápoles no han sido objeto de estudio aquí, dada su vinculación con la imprenta italiana y los importantes estudios de que ésta ha sido objeto. Se ha evitado la focalización en una sola ciudad o un único taller de imprenta, puesto que la finalidad de esta investigación es histórica y cultural y los historiadores han enfatizado que "la historia del libro no es una historia local". ${ }^{17}$

La delimitación del contexto cronológico supone otra dificultad, derivada sin duda de la controversia historiográfica acerca del Renacimiento musical y sus límites temporales. ${ }^{18}$ No obstante, por su utilidad para los propósitos de la investigación, he optado por adoptar una de las opciones más consensuadas y estudiar el período com-

shortly afterwards requested authorization from his Jesuit general to have it also printed; at the same time he asked for permission to publish a music manual that he had used among his Indian charges. On March 15, 1602, his Jesuit general, Claudio Aquaviva, wrote the Mexican provincial superior, Ildefonso de Castro, 'Lo que el Padre Juan de Tovar quiere estampar en la lengua que ha aprendido, vuestra reverencia lo haga ver; que yo se lo remito para que lo haga imprimir, si ansí le pareciere; y lo mismo digo del Arte de la música"”.

${ }^{17}$ Anastasio Rojo Vega, "Comercio e industria del libro en el noroeste peninsular. Siglo XVI", en El libro antiguo español: actas del II Coloquio Internacional [El libro antiguo español, 2], ed. por María Luisa López-Vidriero y Pedro Manuel Cátedra García (Salamanca: Universidad de Salamanca, Servicio de Archivos y Bibliotecas, 1992), pp. 425-430, p. 430; Jaime Moll, "Del libro español del siglo XVI”, en el mismo volumen colectivo, pp. 325-338, p. 338.

${ }^{18}$ Acerca de la controversia en torno al Renacimiento musical, véanse Allan W. Atlas, La música del Renacimiento: la música en la Europa occidental, 1400-1600 (Madrid: Akal, 2002 [1998]), p. 782, "El Renacimiento y su negación"; Lewis Lockwood, "Renaissance", Grove Music Online. Oxford Music Online, 24 septiembre 2008

$<$ http://www.oxfordmusiconline.com/subscriber/article/grove/music/23192>; y Jessie Ann Owens, "Music Historiography and the Definition of 'Renaissance"”, Music Library Association Notes, 47 (1990), pp. 305-330. Sobre el caso concreto de la música portuguesa, véase Manuel Carlos de Brito, "Renascença, maneirismo, barroco: o problema de periodização histórica na música portuguesa dos séculos XVI e XVII", en De musica hispana et aliis. Miscelánea en honor al Prof. Dr. José López-Calo, S. J., en su 65 cumpleaños, ed. por Emilio Casares Rodicio y Carlos Villanueva (Santiago de Compostela: Universidad de Santiago de Compostela, 1990), vol. 1, pp. 539-554. Según Josep Maria Gregori i Cifré, Música universal, Història de la Música Catalana, Valenciana i Balear, dir. por Xosé Aviñoa, vol. 8 (Barcelona: Edicions 62, 2002), p. 39, se perfilan dos criterios cronológicos en la periodización del Renacimiento; el primero asignaría al Renacimiento un período extenso entre 1430 y 1600 , mientras que el segundo centraría el Renacimiento entre 1430 y 1530, y describiría como Manierismo la época entre 1530 y 1630 . Aunque el primer criterio es el más aceptado, Gregori prefiere el segundo. Más recientemente, Richard Taruskin, The Oxford History of Western Music (Oxford: Oxford University Press, 2005), vol. 1, p. 586, se refiere con ironía a "aquéllos que creen en el Renacimiento" ["those who believe in the Renaissance"]. Sobre la problemática en torno a la idea general de Renacimiento en el caso de la Península Ibérica, véase José Luis Abellán, Historia crítica del pensamiento español. II: La Edad de Oro (Madrid: Espasa Calpe, 1986), pp. 20-22, en particular, p. 22: "La conclusión que a nosotros nos interesa extraer de todo esto es la siguiente: el que nuestro país no se ajuste a un modelo de Renacimiento, previamente establecido sobre el ejemplo de uno o varios países, nada indica en contra de su existencia". 
prendido entre la segunda mitad del siglo XV y aproximadamente $1625 .{ }^{19}$ Por tanto, las artes de canto estudiadas son aquéllas publicadas entre 1492, año de la impresión en Sevilla de la primera obra de este tipo, Lux bella de Domingo Marcos Durán, y 1626, cuando se publicó en Lisboa el Arte de musica de canto dorgam, e canto cham, \& proporções de António Fernandes. La Tabla I.1 presenta un listado abreviado de las cuarenta artes de canto que son objeto de este estudio, mientras que el Apéndice 1 contiene el listado exhaustivo que incluye el título completo, todas las ediciones de las cuarenta artes de canto, así como la localización de todos los ejemplares existentes en las bibliotecas de Europa y América. RISM no menciona las siguientes cinco artes: Portus musice (Salamanca, 1504) de Diego del Puerto; Tractado de principios de musica practica e theorica (Toledo, 1520) de Juan de Espinosa; Breue instrucion de Canto llano (Sevilla, 1565) de Luis de Villafranca; Suma de todo lo que contiene el Arte de Canto llano (Sevilla, 1604) de Sebastián Vicente Villegas; y Arte de canto llano (Valladolid, 1614) de Dámaso Artufel. ${ }^{20}$ En el transcurso de mi investigación, he encontrado reediciones desconocidas de los libros de canto llano de Juan Martínez y Francisco de Montanos, así como ejemplares no mencionados hasta ahora. Un caso curioso es el hallazgo de un ejemplar completo conservado en la Biblioteca de la Universidad de Las Palmas de Gran Canaria de una edición de 1554 del Arte ingeniosa de musica (Alcalá de Henares, 1544) de Melchor de Torres que en trabajos bibliográficos anteriores se había considerado como edición fantasma. ${ }^{21}$

\footnotetext{
${ }^{19}$ Loockwood, "Renaissance". Véase también Howard Mayer Brown, Music in the Renaissance (Englewood Cliffs, Nueva Jersey: Prentice-Hall, 1976), donde se lleva a cabo una periodización del Renacimiento musical comprendida entre 1420 y 1600.

${ }^{20}$ François Lesure, dir., Écrits imprimés concernant la musique (Munich: G. Henle, 1971), 2 vols.

${ }^{21}$ Véase el Capítulo IV (Apartado 2.3.1).
} 
Tabla I.1. Artes de canto de pequeño formato impresas en la Península Ibérica entre 1492 y 1626. Lista abreviada ${ }^{22}$

\begin{tabular}{|c|c|c|}
\hline Primera edición & Autor & Título \\
\hline $\begin{array}{l}\text { Sevilla: Cuatro Alemanes } \\
\text { Compañeros, } 1492\end{array}$ & Marcos Durán, Domingo & Lux bella \\
\hline Salamanca: Porras, 1498 & Marcos Durán, Domingo & Comento sobre Lux bella \\
\hline $\begin{array}{l}\text { Salamanca: Impresor de la } \\
\text { Gramática de Nebrija, c. } \\
\mathbf{1 4 9 8}^{23}\end{array}$ & Escobar, Cristóbal & $\begin{array}{l}\text { Introduction muy breue de canto } \\
\text { llano }\end{array}$ \\
\hline Sevilla: Pedro Brun, c. 1500 & Spañón, Alonso de & $\begin{array}{l}\text { Introduccion muy util e breve de } \\
\text { canto llano }\end{array}$ \\
\hline $\begin{array}{l}\text { Valladolid: Diego Gumiel, } \\
\mathbf{1 5 0 3}\end{array}$ & Molina, Bartolomé de & $\begin{array}{l}\text { Arte de canto llano Lux videntis } \\
\text { dicha }\end{array}$ \\
\hline *Salamanca, 1503 [Fétis] & Rodríguez, Juan & Tratado de canto llano \\
\hline $\begin{array}{l}\text { Salamanca: [Juan de Porras], } \\
1504\end{array}$ & Puerto, Diego del & Portus musice \\
\hline $\begin{array}{l}\text { Salamanca: Juan Gysser, c. } \\
1504\end{array}$ & Marcos Durán, Domingo & $\begin{array}{l}\text { Sumula de canto de organo, con- } \\
\text { trapunto y composicion }\end{array}$ \\
\hline $\begin{array}{l}\text { *Salamanca, 1504? } \\
\text { [Carpenter, Collet, Mitjana] }\end{array}$ & Castillo, Alonso del & [Tratado de canto llano] \\
\hline Zaragoza: Jorge Coci, 1508 & $\begin{array}{l}\text { Martínez de Bizcargui, } \\
\text { Gonzalo }\end{array}$ & $\begin{array}{l}\text { Arte de canto llano et contrapunto } \\
\text { et canto de organo }\end{array}$ \\
\hline $\begin{array}{l}\text { *Barcelona: s.n., 1512? } \\
\text { [Mitjana, Cahner, León Tello] }\end{array}$ & Soto, José de & Tratado de Canto llano \\
\hline $\begin{array}{l}\text { [Sevilla: Jacobo Cromberger, } \\
\text { c. 1512-1515?] }\end{array}$ & [Martínez, Juan?] & Arte de cantollano \\
\hline $\begin{array}{l}\text { [Sevilla?: Juan Varela, c. } \\
\text { 1515-1519?] }\end{array}$ & [Martínez, Juan?] & [Arte de canto llano] (incompleto) \\
\hline $\begin{array}{l}\text { Toledo: Arnao Guillén de } \\
\text { Brocar, } 1520\end{array}$ & Espinosa, Juan de & $\begin{array}{l}\text { Tractado de principios de musica } \\
\text { practica e theorica }\end{array}$ \\
\hline
\end{tabular}

\footnotetext{
${ }^{22}$ En este listado de títulos abreviados se indica únicamente la primera edición de cada obra. En caso de discrepancias con respecto a la datación, se ha indicado la fecha recogida en RISM. Obras no conservadas o de existencia incierta aparecen precedidas por un asterisco y seguidas de los documentos en los que se hace referencia a las mismas. El listado completo con todas las ediciones y ejemplares existentes aparece en el Apéndice 1.

${ }^{23}$ Jesús Martín Galán, "Escobar, Cristóbal de", en Diccionario de la música española e hispanoamericana, ed. por Emilio Casares Rodicio (Madrid: Sociedad General de Autores y Editores, 1999-2002), vol. 4, p. 718: "Estudios tipográficos datan este tratado hacia 1490-91 (corrigiéndose la fecha tradicionalmente dada de $c a$. 1496) [...] La única copia existente fue adquirida por la Staatsbibliothek Preußischer Kulturbesitz de Berlín en 1924, procedente de la librería anticuaria de Victoria Vindel". Mário de Sampaio Ribeiro, A "Arte de Cantollano", de autor desconhecido, (R. 14670), da Biblioteca Nacional de Madrid e a "Arte" de Juan Martinez (Coimbra: [Coimbra Editora Ltda.], 1963), p. 9, señala que la obra de Escobar fue ignorada por la bibliografía hasta que un ejemplar se anunció para la venta en el catálogo de Victoria Vindel.
} 


\begin{tabular}{|c|c|c|}
\hline Primera edición & Autor & Título \\
\hline Sevilla: Juan de León, 1604 & Villegas, Sebastián Vicente & $\begin{array}{l}\text { Suma de todo lo que contiene el } \\
\text { Arte de Canto llano }\end{array}$ \\
\hline $\begin{array}{l}\text { Valencia: Pedro Patricio Mey, } \\
1614\end{array}$ & Monserrate, Andrés de & $\begin{array}{l}\text { Arte breve y compendiosa de las } \\
\text { dificultades que se ofrecen en la } \\
\text { musica practica del canto llano }\end{array}$ \\
\hline $\begin{array}{l}\text { Valladolid: Juan Godínez de } \\
\text { Millis, } \mathbf{1 6 1 4}\end{array}$ & Artufel, Dámaso & $\begin{array}{l}\text { Modo de rezar las horas canonicas } \\
{[\ldots] \text { Con un arte de canto llano }}\end{array}$ \\
\hline $\begin{array}{l}\text { Coimbra: Diogo Gomez de } \\
\text { Loureyro, } \mathbf{1 6 1 8}\end{array}$ & Thalesio, Pedro & Arte de canto chão \\
\hline $\begin{array}{l}\text { Lisboa: Pedro Craesbeeck, } \\
1626\end{array}$ & Fernandes, António & $\begin{array}{l}\text { Arte de musica de canto dorgam, e } \\
\text { canto cham, \& proporções }\end{array}$ \\
\hline *[Biblioteca de João IV] & Brito, Estêvão de & Arte de música [?] \\
\hline *[Biblioteca de João IV] & Escobar, Fr. João de & $\begin{array}{l}\text { Arte de musica Theorica, \& prati- } \\
\text { ca [?] }\end{array}$ \\
\hline *[Biblioteca de João IV] & Mendes, Manuel & Arte de música [?] \\
\hline *[Biblioteca de João IV] & Thalesio, Pedro & $\begin{array}{l}\text { Compendio de canto de orgão } \\
\text { contraponto, composiçao, fugas, \& } \\
\text { outras cousas }\end{array}$ \\
\hline *[Biblioteca de João IV] & Villena, Diogo Dias de & $\begin{array}{l}\text { Arte de canto cham para principi- } \\
\text { antes }\end{array}$ \\
\hline
\end{tabular}

\subsection{Características de las artes de canto}

Los rasgos que definen las artes de canto analizadas están íntimamente relacionados entre sí y son consecuencia de la utilidad didáctica de estas obras. Mateo de Aranda, en el prólogo de su Tractado de canto llano (Lisboa, 1533), mencionaba la necesidad de escribir para enseñar cuando advertía "que ninguno por scientifico que sea en qualquier arte o sciençia puede mostrar ni enseñar enteramente: si no escriue: e haze muestra de aquello que en su facultad alcança". ${ }^{27}$ Las artes de canto son libros de pequeño formato en los que se alude frecuentemente a su brevedad y claridad como mues-

\footnotetext{
${ }^{26}$ León Tello, Estudios de historia de la teoría musical, p. 198, no menciona a Juan Francisco Cervera, pero sí una obra con el mismo título e indicaciones tipográficas: "Tampoco conocemos si figura en alguna colección un 'Arte y suma de canto llano' (Valencia, 1595)”. Ricart i Matas, Diccionario biográfico de la música (Barcelona: Iberia, 1966 [1956]), p. 219, indica que Cervera es "autor de varios tratados musicales".

${ }^{27}$ Aranda, Tractado de canto llano, f. A2r.
} 
tras de un "nuevo estilo". Así, Melchor de Torres creía que su Arte ingeniosa de musica (Alcalá de Henares, 1544) sería "muy necessaria y prouechosa a todos los que en esta facultad de la musica pratica quisieren ser aprovechados con facilidad: como parecera en su nueuo estilo". 28

\subsubsection{PeQUeÑo FORMATO}

Las artes de canto analizadas tienen un formato en cuarto u octavo y da la impresión de que la tendencia general en este tipo de libros fue hacia la reducción del tamaño. Es curioso el hecho de que libros como el de Gonzalo Martínez de Bizcargui, cuya edición príncipe se hizo en cuarto, fuesen reeditados años después en octavo. Por su formato, las artes de canto encajan en los denominados "libros de faltriquera". ${ }^{29}$ Jane Alden considera que los libros pequeños denotan uso personal (podían llevarse consigo); ${ }^{30}$ Jessie Ann Owens señala que el formato en octavo era el usual "para libros didácticos destinados a amateurs consistentes principalmente en prosa en lugar de composiciones musicales" y que constituían manuales dirigidos a un "mercado de masas". ${ }^{31}$

Los formatos pequeños de las artes de canto podrían considerarse un indicio de modernidad, mientras que la utilización del tipo gótico, presente en buena parte de las artes de canto analizadas, cuando ya se había impuesto en Europa el romano se ha visto como signo de conservadurismo (véase Apéndice 1). ${ }^{32}$ No obstante, el tipo gótico siguió usándose hasta finales del siglo XVII en impresos legales y también en aquéllos de tipo popular como la literatura de cordel, que guarda notables similitudes con las artes de canto en cuanto a sus características físicas: ${ }^{33}$

\footnotetext{
${ }^{28}$ Torres, Arte ingeniosa de musica, f. 1v.

${ }^{29}$ Isabel Vega Vázquez, ed., El libro de motes de damas y caballeros de Luis de Milán (Santiago de Compostela: Universidade de Santiago de Compostela, 2006), p. 13.

${ }^{30}$ Alden, Songs, Scribes, and Society, p. 170. Alden titula un apartado de su libro "The Culture of Small Books". El más pequeño de los "chansonniers" que analiza mide 126 x 90-94 mm.

${ }^{31}$ Owens, "You Can Tell a Book by Its Cover", p. 357: “Octavo became the standard format for instruction books intended for amateurs consisting primarily of prose rather than of musical compositions".

${ }^{32}$ Lafaye, Albores de la imprenta, p. 44.

${ }^{33}$ Véanse Francisco Mendoza Díaz-Maroto, "Impresos de 1551 a 1600 en una biblioteca de Albacete", Al-Basit: revista de estudios albacetenses, XXXIX (1996), pp. 217-266, p. 217; y María Luisa LópezVidriero y Pedro Manuel Cátedra García, La imprenta y su impacto en Castilla (Salamanca: Cervantes Ind. Gráf., 1998), p. 17. Sobre el concepto de "literatura de cordel", véase Francisco Mendoza DíazMaroto, Panorama de la literatura de cordel española (Madrid: Ollero y Ramos, 2001), p. 25. Acerca de
} 
[...] con la propagación de la imprenta surge un mundo de cuadernillos breves, de cuatro, ocho folios a lo sumo destinados al gran público: son lo que en la jerga bibliográfica se llama pliegos sueltos. De costo mínimo ponen al alcance de la masa lectora, de la colectividad, millares de obras literarias en infinito número de ediciones, distribuidas por toda la geografía ibérica. ${ }^{34}$

En consecuencia, por su formato, las artes de canto podrían asociarse con el fenómeno de los pliegos sueltos, representado en España por los "pliegos de cordel". Este fenómeno no ocurrió únicamente en el mundo ibérico, sino que se manifestó en otros contextos geográficos. Entre otros ejemplos se encuentran los "donatos" o "libros de pobre" usados en Alemania ("unos mementos que utilizaban los estudiantes como resúmenes o syllabus" y que eran básicamente grabados xilográficos), ${ }^{35}$ los "penny chapbooks" del contexto británico estudiados por Tessa Watt, ${ }^{36}$ y la "bibliothèque bleue” del ámbito francés que examinó Roger Chartier ("libros baratos impresos en grandes cantidades y distribuidos por vendedores ambulantes"). ${ }^{37}$

Libros como el de Cristóbal Escobar, con cuatro hojas, el de Alonso de Spañón, con doce, o la edición de 1517 del Arte de canto llano et contrapunto et canto de organo de Gonzalo Martínez de Bizcargui, con tres pliegos (numerados a, b y c) se asemejan a la literatura de cordel no sólo por su formato, sino también por su idoneidad para transmitir "un mensaje de modo rápido y eficaz a amplias capas de la población". 38 Además, en las artes de canto se produjo un fenómeno similar al de la literatura de cordel con respecto a las formas de consumo: dentro del género literario existían relaciones, pasillos y sumarios de los libros, los cuales podían ser adquiridos a bajo precio por

las características de la literatura de cordel y de su tipología, véanse Mendoza Díaz-Maroto, Panorama de la literatura de cordel española, p. 27; Antonio Rodríguez Moñino, Diccionario bibliográfico de pliegos sueltos poéticos (siglo XVI) (Madrid: Castalia, 1970), p. 11; y Julio Caro Baroja, Ensayo sobre la literatura de cordel (Madrid: Istmo, 1990 [1969]).

34 Antonio Rodríguez Moñino, Construcción crítica y realidad histórica en la poesía española de los siglos XVI y XVII (Madrid: Castalia, 1968), pp. 45-46.

${ }^{35}$ Lafaye, Albores de la imprenta, p. 25.

36 Tessa Watt, Cheap Print and Popular Piety, 1550-1640 (Cambridge: Cambridge University Press, 1991).

${ }^{37}$ Roger Chartier, The Cultural Uses of Print in Early Modern France (Princeton: Princeton University Press, 1987), p. 240: “inexpensive books printed in large quantities and sold by peddlers".

${ }^{38}$ María del Mar Fernández Vega, "Política y propaganda en los pliegos sueltos poéticos catalanes (siglo XVI)”, eHumanista, III (2003), pp. 77-90, p. 77. 
aquellas personas que no podían permitirse pagar la obra original. ${ }^{39}$ De la misma manera, las artes de canto eran en su esencia la síntesis, en un volumen de pequeño formato, de contenidos extraídos de otros libros; encontramos al menos tres ejemplos ilustrativos: 1) Juan de Espinosa manifestaba en su Tractado breue de principios de canto llano (Toledo, c. 1521) haber incluido brevemente "todo lo que de necessidad conuiene y es menester saber al principio para no poder errar" aunque, para informarse de "los verdaderos principios de la musica” y encontrar autoridades y ejemplos, el lector debía acudir a su Tractado de principios de musica practica e theorica sin dexar ninguna cosa atras (Toledo, 1520); ${ }^{40}$ 2) el Arte de canto llano (Valladolid, 1594) de Francisco de Montanos consistía en la publicación por separado del primer libro de su anterior obra titulada Arte de musica theorica y practica (Valladolid, 1592); como muestra el Apéndice 1, fue el Arte de canto llano (y no el más amplio Arte de musica theorica y practica) la obra que fue reeditada en numerosas ocasiones durante un siglo y medio; y 3) Pedro de Loyola Guevara presentaba su Arte para componer canto llano (Sevilla, 1582) como un "tratadillo" para "que todos entiendan breuissimamente este Canto llano, dexando aparte tantas opiniones y Theorica" y remitía a los lectores a su más amplio tratado en seis libros titulado De la verdad si deseaban "saber de rayz las partes de la Musica":

Y aquel tratado [De la verdad], sera para saber todas las opiniones de todos los Auctores, assi prathicos, como theoricos, y la conclusion de cada vna dellas. Para los que quisieren saber de rayz las partes de la Musica, y dificultades della. Para la Canturia que agora tienen compuesta. Y este presente tratadillo sera vna Recopilacion para la canturia nueua que aqui ordenamos, para que esto se tenga por suma, y dechado. Para que todos entiendan breuissimamente este Canto llano, dexando aparte tantas opiniones y Theorica. De manera, que con este presente, no sera menester otro ninguno, y en este quitamos todas las dificultades que puede auer, y vamos por vn camino seguido, y tan llano que no abra lugar ninguno donde poder herrar. ${ }^{41}$

A pesar de las ventajas que la imprenta ofrecía para la conservación de libros frente a las del manuscrito ("la información manuscrita tuvo que ser transmitida mediante textos cambiantes y manuscritos evanescentes"), ${ }^{42}$ las artes de canto que han lle-

\footnotetext{
${ }^{39}$ Rodríguez Moñino, Diccionario bibliográfico de pliegos sueltos poéticos, pp. 11-12.

${ }^{40}$ Espinosa, Tractado breue de principios de canto llano, ff. A1v-A2r.

${ }^{41}$ Guevara, Arte para componer canto llano, f. 10r.

${ }^{4}$ Elizabeth Lewisohn Eisenstein, The Printing Revolution in Early Modern Europe (Cambridge: Cambridge University Press, 1983), p. 83.
} 
gado hasta la actualidad se califican como "rarezas bibliográficas", ${ }^{43}$ puesto que varios factores, entre ellos su pequeño formato, han podido dificultar su supervivencia. Por ejemplo, en el Incunable 2165 de la Biblioteca Nacional de España, el cual reúne un grupo de artes de canto encuadernadas en un solo volumen en 1753, encontramos una nota de Francisco Javier de Santiago y Palomares en la que se enumeran los motivos de la encuadernación. La primera razón es "por ser cada una de por sí de poco volumen, y ser fácil el perderse". Otros factores que han dificultado la conservación de las artes de canto son los siguientes: 1) su bajo precio y su fácil acceso; ${ }^{44}$ y 2) el uso que recibieron, ya que probablemente muchas fueron utilizadas por niños. ${ }^{45}$

Las características físicas de "libros de faltriquera" como las artes de canto plantean dificultades para la investigación, puesto que no podemos saber hasta qué punto los libros que se conservan, con seguridad en un número muy inferior al que circuló en la época, son representativos y, en consecuencia, nuestras conclusiones siempre serán provisionales (sujetas al hallazgo de ejemplares de nuevas obras o reimpresiones desconocidas):

Este tipo de libros "de faltriquera", pequeños y rústicos, en octavo o dieciseisavo, entre cuatro y cuarenta y ocho páginas, fueron muy populares, pero hoy han desaparecido en su mayor parte: de las ocho ediciones y 12.000 ejemplares que se imprimieron en un solo año en Alcalá de Henares de los Enfados a lo divino de Juan López de Úbeda, no se conoce ni un solo ejemplar conservado. Es por ello difícil hacerse una idea de lo que pudieron significar, si bien el hecho de que se reeditaran numerosas veces es de por sí elocuente. ${ }^{46}$

\footnotetext{
${ }^{43}$ Marcelino Menéndez y Pelayo, Historia de las ideas estéticas en España (Madrid: M. Tello, 1909-1923 [1883-1891]), vol. 2, p. 951.

${ }^{44}$ Rodríguez Moñino, Diccionario bibliográfico de pliegos sueltos poéticos, p. 12: "La misma posibilidad de adquisición [de los pliegos sueltos] ha hecho que nadie sintiera deseos de coleccionar lo contemporáneo. El letrado, el hombre de libros, desdeñaba en general cosa tan baladí y pasajera; el soldado, la moza o el estudiante, no tenían bibliotecas. En los conventos o Universidades, a nadie se le hubiera ocurrido conservar tales y tan nimias producciones".
}

${ }^{45}$ Carlos Romero de Lecea, Introducción a los viejos libros de música (Madrid: Joyas bibliográficas, 1976), p. 52: "Antonio Rodríguez Moñino [...] insiste en que a los pliegos, por ser utilizados por los niños en las escuelas, amén de ser usados por otro público poco cuidadoso, les ocurrió lo que a dos tipos de edición más, destinados a un público semejante: los catones o cartillas para aprender a leer y los compendios de doctrina cristiana que, impresos por millones durante el siglo XVI, pueden contarse con los dedos de la mano los que sobreviven".

${ }^{46}$ Alfonso de Vicente Delgado, "Música, propaganda y reforma religiosa en los siglos XVI y XVII: cánticos para la 'gente del vulgo' (1520-1620)", Studia Aurea, I (2007)

<URL: http://www.studiaaurea.com/articulo.php?id=47>. 


\subsubsection{BREVEDAD: PORQUE EL TIEMPO ES “COSA MUY PRECIOSA"}

Las artes de canto analizadas son por lo general breves, característica vinculada con su propósito didáctico y de utilidad. El concepto de brevedad aparece ya en el título en las obras de Cristóbal Escobar, Gonzalo Martínez de Bizcargui, Andrés de Monserrate, Alonso de Spañón, Pedro Thalesio, Melchor de Torres, Luis de Villafranca, en el tratado de canto llano de Juan de Espinosa y en la reedición de 1509 de Lux bella (Sevi1la, 1492) de Domingo Marcos Durán (Lux bella del canto llano corregida e emendada e aprouada puesta en orden e estilo muy breue e copioso). Además, se alude a la brevedad como una característica de la que se carecía anteriormente y que ahora se vuelve relevante.

La búsqueda de un "estilo muy breue" sugiere un cambio cultural en relación a la idea que se tenía del tiempo y que, por tanto, los libros de este tipo, no sólo los de canto, venían a satisfacer una necesidad. La preocupación por el tiempo se percibe en el tratado publicado por Hernando de Talavera a petición de María Pacheco, titulado De como se ha de ordenar el tiempo para que sea bien expendido (Granada, c. 1496) y motivado por la consideración del tiempo como "cosa muy preciosa". ${ }^{47}$ Sería interesante relacionar el "nuevo estilo" de los libros con un cambio en la concepción del tiempo, quizás como consecuencia del uso del reloj mecánico, que había surgido a finales del siglo XIII. Gerald J. Whitrow, cuando traza la influencia social del reloj mecánico, señala que "la clase media pronto se percató de que 'el tiempo es dinero' y en consecuencia se debía distribuir con cuidado y emplear de manera económica". ${ }^{48}$ Whitrow cita un fragmento de una carta escrita en 1399 por la mujer del "Mercader de Prato" (Francesco di Marco Datini) en el que se habla del tiempo en términos muy similares a como lo haría un siglo después Hernando de Talavera: "En vistas a todo lo que hay que hacer, cuando pierdes una hora, me parecen mil... Pues considero que no hay nada tan precioso, tanto para el cuerpo como para el alma, como el tiempo y me parece que lo valoras

\footnotetext{
${ }^{47}$ El primer capítulo del libro se titula "Demuestra que la peticion desta muy noble señora es deuota necessaria e prouechosa: porque el tiempo es cosa muy preciosa".

${ }^{48}$ Gerald James Whitrow, El tiempo en la historia (Barcelona: Crítica, 1990 [1988]), p. 146. Véase también su libro The Natural Philosophy of Time (Oxford: Clarendon Press, 1961).
} 
tan poco". ${ }^{49}$ Otra muestra de esta preocupación por el tiempo es la popularización de los libros de Horas (antes sólo encargados por la realeza y la alta nobleza) en el siglo XV. ${ }^{50}$

La búsqueda de brevedad es una referencia constante en las obras en que se trata la música desde la perspectiva especulativa. En este sentido, Alfonso de la Torre en su Visión deleytable (Burgos, 1480-1483) declaraba estar cumpliendo la voluntad de Juan de Biamonte: “[...] queriades por mi vos fuese fecho un breve compendio del fin de cada çiencia, que quasy proemialmente conteniese la esençia de aquello que en las çiençias era tractado [...]". ${ }^{51}$ El Vergel de musica (Burgo de Osma, 1570) de Martín de Tapia contiene entre su material preliminar una "Cedula del excelente musico Balthasar Ruyz, dignissimo maestro de capilla de la sancta yglesia de Osma, en la qual demuestra la breuedad y claridad de la musica contenida en este libro"; en ella se señala que el autor ha sido capaz de "sacar" de la música "su verdad abreuiada" y que no ha encontrado quien "ansi la aya reduzido y declarado". 52

La brevedad de las artes de canto se relaciona con el ámbito didáctico en el que se insertan estas obras: "nuestra intencion siempre fue y es de abreuiar porque los que algo dessean saber no quieren otra cosa”, señalaba Gonzalo Martínez de Bizcargui. ${ }^{53}$ Por ejemplo, en el "Prologo primero al discreto lector" de su Arte breve y compendiosa (Valencia, 1614), Andrés de Monserrate exponía los motivos que le llevaron a elaborar su libro y el tercero fue "el ver la grande falta que ay de vn Arte que sea manual y breue, con la qual pueda qualquiera cantor Ecclesiastico entender de raiz las dificultades del canto". ${ }^{54}$ Martínez de Bizcargui atribuía la brevedad al poner por escrito los preceptos de la misma manera en que los maestros los enseñaban adaptándose a las necesidades de sus educandos:

\footnotetext{
${ }^{49}$ Iris Origo, The Merchant of Prato (Londres: Jonathan Cape, 1957), p. 177; citado en Whitrow, El tiempo en la historia, p. 147.

${ }^{50}$ Whitrow, El tiempo en la historia, p. 146.

${ }^{51}$ Alfonso de la Torre, Visión deleytable, ed. crítica y estudio de Jorge García López (Salamanca: Universidad de Salamanca, Servicio de Archivos y Bibliotecas, 1991 [1480-1483]), vol. 1, p. 101.

52 Tapia, Vergel de musica, f. iir, “Aprobacion del libro". El elogio de Baltasar Ruiz resulta irónico si se tiene presente que el Vergel de musica es un "plagio" de Comiença el libro primero de la declaracion de instrumentos (Osuna, 1549) de Juan Bermudo.

${ }^{53}$ Martínez de Bizcargui, Arte de canto llano et contrapunto et canto de organo (1511 [1508]), f. A2v.

${ }^{54}$ Monserrate, Arte breve y compendiosa, p. 6.
} 
[...] como los ingenios de los hombres no son todos de vna qualidad assi los maestros que enseñan como los discipulos que aprenden reciben mucha fatiga con muchos dellos que no pueden tan presto caer en ello, acordamos de ponerlos por escrito como en otras partes los enseñan. ${ }^{55}$

Sin embargo, la brevedad ha sido el principal motivo de crítica a las artes de canto. El Melopeo y Maestro incluye entre su material preliminar un texto titulado "A los amigos de la brevedad" en el que Cerone señalaba que las artes de canto que circulaban por España eran breves en detrimento de la claridad, por lo que era imposible que un principiante las encontrara útiles:

[...] y como quieren que vn principiante en la Musica, entienda lo que lee en vnas Artecillas muy breues de palabras, y muy escasas de exemplos, si ay Maestros que por las mesmas razones, no las entienden? Assi como no todos pueden çabullirse à sacar las perlas, si no los maestros y buenos officiales; assi por las mayor [sic] parte, no entienden bien los documentos musicales (escriuiendolos digo con tanta breuedad como escriuen,) si no los que en la Musica son muy versados, y muy praticos. ${ }^{56}$

Curiosamente, a pesar de su crítica a las artes de canto, Cerone había publicado previamente un libro en italiano bastante similar a éstas en características y propósito ("que qualquiera de mediana habilidad, con poco trabajo, alcançarà esta profession") titulado Le regole piu necessarie per l'introduttione del canto fermo (Nápoles, 1609). La publicación de este libro coincide con la fecha en que Cerone comenzó a enseñar canto llano a los diáconos de la iglesia de Santa Annunziata en Nápoles. ${ }^{57}$

\subsubsection{ENSEÑANZA DE LO SUFICIENTE Y OPTIMIZACIÓN DEL TIEMPO DE APRENDIZAJE}

La preocupación por el tiempo también se manifestaba en el deseo de enseñar lo suficiente, es decir, enseñar sólo lo necesario y lo que es útil, con el fin de evitar la “confusión”, porque, en palabras de Juan Bermudo, “cosa contra razon es enseñar a vn principiante lo que no ha menester ni en todo canto llano se halla". ${ }^{58}$ Las artes de canto

\footnotetext{
${ }^{55}$ Martínez de Bizcargui, Arte de canto llano et contrapunto et canto de organo (1511 [1508]), f. A2v.

${ }^{56}$ Cerone, El Melopeo y Maestro, s.f., “A los amigos de la brevedad”.

${ }^{57}$ Barton Hudson, "Cerone, Pietro", Grove Music Online. Oxford Music Online, 23 febrero 2009

$<$ http://www.oxfordmusiconline.com/subscriber/article/grove/music/05304>.

${ }^{58}$ Bermudo, El arte Tripharia, f. 4r.
} 
contienen "todo lo que de necessidad conuiene y es menester saber al principio para no poder errar". ${ }^{59}$ Por ejemplo, el concepto de utilidad es mencionado por Martínez de Bizcargui cuando, después de enumerar sus autoridades, advertía: "por abreuiar muy magnifico señor no entiendo de meterme mucho a declarar la opinion e lo que cada vno destos doctores dize sino aquello que yo conosciere que mas vtil sea a los nouicios que la dessean saber" ${ }^{60}$ También Pedro de Loyola Guevara declaraba haber escrito una obra "con la cual sin dificultad, ni prolixidad se sepa lo que es necessario". ${ }^{61}$ A causa de esta aspiración, se eliminan los contenidos insuficientes, como se refleja en el proemio de la edición de 1509 de Lux bella, promovida por el Obispo de Salamanca ("di forma de corregir e sellar el canto llano en cierta e sufficiente perfecion. [...] Assi quitadas opiniones frustratorias insufficientes e sofisticas: puse las ciertas e suficientes"), ${ }^{62}$ o en el Arte ingeniosa de musica (Alcalá de Henares, 1544) de Melchor de Torres (“[ ...] tambien pone ciertas difficultades cerca de las species de diapente y diatessaron probando y declarando lo que se deue tener y guardar sin gastar tiempo en teoricas desaprovechadas"). ${ }^{63}$ Además, se suprimía aquello que ya no se consideraba útil, como muestra el Arte y suma de canto llano (Valencia, 1595) de Juan Francisco Cervera:

\begin{abstract}
Aunque tambien pudiera tratar de los tres generos, que dizen que ay, es a saber Diatonico, Cromatico, y Enarmonico. Todavia me ha parecido no tratar dellos, por dos cosas. La vna por ver yo que en el dia de oy no se vsan, ni los enseñan los maestros, y theoricos, que he visto en España, que son muchos, y buenos. La segunda porque veo no son necessarios, para saber cantar, que sin ellos puede ser qualquiera buen Theorico, o a lo menos diestro cantor: que si cosa necessaria fuera, creo yo que lo huuiera visto enseñar a alguno de los maestros que he tenido o a lo menos me lo vuieran enseñado, pero siempre he visto dezirme ser cosa superflua y assi no hago mension dellos. ${ }^{64}$
\end{abstract}

\footnotetext{
${ }^{59}$ Espinosa, Tratado breue de principios de canto llano, f. A1v.

${ }^{60}$ Martínez de Bizcargui, Arte de canto llano et contrapunto et canto de organo, f. A1v.

${ }^{61}$ Guevara, Arte para componer canto llano, f. A3v.

${ }^{62}$ Domingo Marcos Durán, Lux bella de canto llano aprobada, corregida e emendada (Salamanca: Juan Gysser, 1509), f. A1v.

${ }^{63}$ Torres, Arte ingeniosa de musica, f. 10v.

${ }^{64}$ Cervera, Arte y suma de canto llano, pp. 43-44.
} 
La finalidad de las artes de canto era que "en breue tiempo y con menos trabajo se pudiesse alcançar" el arte, ${ }^{65}$ lo que requiere no sólo brevedad, sino también la eficiencia del aprendizaje. Una vez más, las artes de canto reflejan una propensión general de la época: Francisco Correa de Araujo, tratando el origen de la tablatura, aludía a la eficiencia de este mecanismo que consigue "que personas tiernas y de poca edad, alcancen en breve tiempo, lo que en otros siglos, aun no se conseguia con largos años de estudio". ${ }^{66}$ Según Sebastián Vicente Villegas, la claridad de las artes de canto hacía que no costase más de dos meses aprender canto llano:

[...] assi que a los floxos no les queda ya camino por donde huyr, y si dixeren que es dificultoso, cansarse an en balde, porque ya se contentan los coros con que sepan canto llano solamente, y para esto ay ya tanta claridad que no cuesta dos meses de trabajo en saberlo, que por esso sacamos a luz este arte, donde fuera del trabajo que se à puesto en recopilarlo a brevedad, se à procurado poner por el modo mas claro que se à podido. ${ }^{67}$

\subsubsection{USO DE RECURSOS DIDÁCTICOS}

Los aspectos utilitarios de las artes de canto (brevedad, enseñanza de lo suficiente, optimización del tiempo de aprendizaje) vinculados con su utilización como material en el proceso de enseñanza y aprendizaje de la música se unen a los recursos didácticos que presentan estos manuales, entre los que se encuentran la simplificación, la síntesis, las referencias a experiencias didácticas propias y el uso de tablas y ejemplos musicales.

\section{a) Simplificación}

Según Ismael Fernández de la Cuesta, el contenido de las artes de canto sugiere que "el canto ya no era más que una caricatura del primitivo canto litúrgico monódico o gregoriano, con su multitud de neumas, de infinitos matices rítmicos, dinámicos, que hacían de la música gregoriana todo menos un canto plano". ${ }^{68}$ María Sanhuesa relaciona

\footnotetext{
${ }^{65}$ Artufel, Arte de canto llano, f. 3r.

${ }^{66}$ Francisco Correa de Araujo, Libro de tientos y discursos de musica practica, y theorica de organo: intitulado Facultad organica (Alcalá de Henares: Antonio Arnao, 1626), f. [4r].

${ }^{67}$ Villegas, Suma de todo lo que contiene el Arte de Canto llano, s.f.,"Prologo al Christiano lector".

${ }^{68}$ Fernández de la Cuesta, Los tratados de canto llano de Spañón, Martínez de Bizcargui y Molina, p. 25. Sin embargo, véanse los comentarios de Robert Stevenson, Spanish Music in the Age of Columbus (La Haya: Martinus Nijhoff, 1960), p. 50, sobre el grupo de cantos llanos con constantes alteraciones acciden-
} 
las artecillas del siglo XVII con el concepto de reforma como simplificación, planteando la cuestión de si la simplificación indicaba una menor competencia musical de los destinatarios. ${ }^{69}$ Las artes, desde sus primeras ediciones, no sólo tratan de exponer brevemente los preceptos fundamentales de la música, sino también de hacerlo de forma simplificada, por ejemplo con respecto al vocabulario musical empleado. Así, Juan de Espinosa y después Gaspar de Aguilar sustituyeron el término conjunta por el de división. ${ }^{70}$ Sebastián Vicente Villegas era elogiado por Juan Baptista Camacho en un soneto publicado entre el material preliminar de su libro por apuntar en "facil methodo" los preceptos de la música. ${ }^{71}$ La simplificación se muestra como un objetivo general que también se vincula al origen de la tablatura: ${ }^{72}$

[...] y viendo assi mismo la dificultad tan grande [...] que avia en poner cualquier obra, de canto de organo en la tecla, por pequeña y facil que fuesse: proveyendo del remedio necesario, acordaron divinamente de inventar un nuevo modo de señales, que causando los mismos efectos (en tanta perfeccion y primor como los de canto de organo, y sin que la musica perdiesse un punto de sus quilates) reduxesse aquella dificultad y desabrimiento, a grande facilidad y dulzura, haziendo camino llano y facil, el que antes era en extremo dificultoso y agro. ${ }^{73}$

tales incorporados en el tratado de Luis de Villafranca de 1565; véase más abajo la sección 1.2.5. PRIORIDAD A LA PRÁCTICA.

${ }^{69}$ Sanhuesa Fonseca, “Artes de canto llano en las órdenes religiosas españolas del siglo XVII”, p. 278.

${ }^{70}$ Miguel Alonso, Cuatro tratados de principios de canto llano: los de Espinosa, Aguilar, Escobar y el anónimo (Madrid: Joyas bibliográficas, 1983), p. 67. El término conjunta tiene diferentes acepciones. Paloma Otaola González, Tradición y modernidad en los escritos musicales de Juan Bermudo: del "Libro primero" (1549) a la "Declaración de instrumentos musicales" (1555) (Kassel: Reichenberger, 2000), p. 131, distingue tres etapas en la evolución del significado del término conjunta, procedente del latín coniuncta: 1) "división de un tono en dos semitonos"; 2) "hexacordo transportado o deducción accidental"; y 3$)$ "sistema cromático". Véase también Oliver Ellsworth, "The Origin of the Coniuncta: A Reappraisal", Journal of Music Theory, XVII/1 (1973), pp. 86-109.

${ }^{71}$ Villegas, Suma de todo lo que contiene el Arte de Canto llano, s.f., "Soneto en alabança de la obra, y del auctor, por el Licenciado Iuan Baptista Camacho": "Aqui quedò la citara templada / De Apolo, y el diuino movimiento / De la harpa de Orfeo, y tierno acento / En proporcion mas blanda y acordada. / De Euterpe la invencion mas entonada / De Terpsicore el concauo instrumento / Mas dulce, y con mas alto sentimiento / Quedo la voz de Amphion requebrada. / Al fin ya desde oy mas claro suena / Qualquier musico punto y armonia / Despues que en facil methodo apuntaste / El modo (o gran Villegas) que encadena / Las reglas de la dulce melodia / Y de passo cus[roto]".

${ }^{72}$ Griffiths, "The Transmission of Secular Polyphony in Renaissance Spain”, p. 323.

${ }^{73}$ Correa de Araujo, Libro de tientos y discursos de musica practica, y theorica de organo, f. [4r]. 
La simplificación en las artes de tañer y en las artes de canto impresas favoreció el que la competencia musical se extendiera y debió de suponer una mayor difusión no sólo del repertorio tanto monódico como polifónico contenido en los libros de vihuela, sino también del que aparecía en las artes de canto a modo de ejemplos ("cantos llanos diversos en que se exercite el que aprende"). ${ }^{74}$

\section{b) Síntesis}

La síntesis en una sola obra de principios que se encuentran dispersos en otras muchas es el propósito expreso de buena parte de los autores de artes de canto. Gaspar de Aguilar proclamaba que en su tratado puede encontrarse "en breue volumine co[m]pilado lo que por muchos libros está esparzido", 75 Juan de Espinosa manifestaba haber reducido en cuatro libros los principios de la música de los que otros habían escrito ${ }^{76}$ y Pedro de Loyola Guevara afirmaba haber "resumido en tan pequeño volumen, lo que esta escripto en tanta diuersidad de libros, y Autores",77 mientras que Sebastián Vicente Villegas usaba el concepto de "reducción" ya desde el título de su obra ("reduzida a toda claridad"). También en el soneto, hasta ahora desconocido, de Lope de Vega impreso entre el material preliminar del libro de Juan Francisco Cervera se enfatiza el concepto de "reducción". ${ }^{78}$ De nuevo, como ocurría con la característica de simplificación, la tendencia al compendio no es exclusiva de las artecillas, sino que también se da en libros más extensos. Por ejemplo, en su Vergel de musica, Martín de Tapia declaraba

\footnotetext{
${ }^{74}$ Montanos, Arte de canto llano, f. $12 \mathrm{v}$.

75 Aguilar, Arte de principios de canto llano, f. A1v. Alonso, Cuatro tratados de principios de canto llano, p. 203, manifiesta que "la claridad y transparencia" del lenguaje de Aguilar "y al mismo tiempo su carácter tradicional, pudieran estar motivados por el propósito del autor de escribir, a la vista de varios textos de canto llano ya publicados, un resumen de los mismos que facilitase su aprendizaje".

${ }^{76}$ Espinosa, Tractado de principios de musica practica e theorica, f. A2r.

${ }^{77}$ Guevara, Arte para componer canto llano, f. 10v.

${ }^{78}$ Cervera, Arte y suma de canto llano, [s.f.]: "Los altos Cielos hizo y fabricolos / De fuerte al Architecto, Auctor del dia / ques musica, concierto y armonia / quanto sustentan, los Celestes Polos / En esta imitación, raros Apolos / han reduzido, a boz y melodia / el mouimiento que imitar solia, / Quien no solo mouio los hombres solos / Iuan Francisco Ceruera Valenciano / del cielo, que por parte le ha cabido / reduze a tal principio el Canto llano, / Que como Orpheo del laurel ceñido / dexa su diestra, pluma boz y mano / el mouimiento Celestial vencido".
} 
haber recopilado lo sustancial de los libros antiguos y contemporáneos sobre música; ${ }^{79}$ como ya se ha señalado, hoy en día la obra de Tapia se considera un plagio del Libro primero (1549) de Juan Bermudo.

\section{c) Referencias a experiencias pedagógicas propias}

Puesto que, como se indicará más abajo, casi todos los autores de las artes de canto analizadas se insertan en el contexto profesional de la docencia de la música, es frecuente encontrar en sus obras referencias no sólo a sus experiencias como maestros, sino también a sus vivencias como estudiantes y a las prácticas docentes contemporáneas. Ejemplo de los dos primeros casos es Juan Francisco Cervera, quien explicaba de qué manera su experiencia como maestro había determinado los contenidos de su manual. En el Capítulo X de su Arte y suma de canto llano, titulado "En que se muestra saber hazer las mudanças que ay en los signos de dos bozes, y en los de tres quales se han de hazer primeras, y quales postreras", aparece entre paréntesis:

[...] que digo con verdad muchas vezes enseñando yo en çaragoça, y en en [sic] esta ciudad de Valencia, y en otras muchas partes, como lo saben muchos, me han venido algunos de los que yo enseñaua, en esta difficultad, o por mejor dezir ignorancia. ${ }^{80}$

Más adelante, en el Capítulo XX ("De las consonancias y disonancias”), Cervera hacía referencia a su experiencia como estudiante de música:

Digo con verdad, que siendo yo niño he sido reprehendido por mi maestro por lleuarle en el principio o medio, o en el fin de la licion del contrapunto alguna falta como quarta o septima; pues si consonancias fueran, no hauia necesidad de reprehension. ${ }^{81}$

Juan Bermudo y Andrés de Monserrate hacían alusión a la reticencia de los maestros a enseñar cuanto sabían. El caso de Bermudo es emblemático, puesto que

\footnotetext{
${ }^{79}$ Tapia, Vergel de musica, f. $2 \mathrm{v}-3 \mathrm{r}$ : "Esto pues, incito y mouio mi voluntad a que epitomase y sumasse este breue tratado sacado y tomado de graues, varios y diuersos doctores antiquísimos y modernos que larga y diffusamente la materia de musica trataban, y assi mesmo he mudado en romance (con sufficiente declaracion) todo aquello que a los cantores (y aun tañedores) podia seruir y aprouechar [...]”.

${ }^{80}$ Cervera, Arte y suma de canto llano, p. 21.

${ }^{81}$ Cervera, Arte y suma de canto llano, p. 37.
} 
construyó todo el "Prologo general de toda la obra para el lector" del Libro primero (Osuna, 1549) en torno a la idea de que la causa de que en España estén "todas las artes muertas" es la "codicia y auaricia" de los maestros que se niegan a comunicar lo que saben: "Tengo para mi, que si en España se comunicassen los secretos, que los musicos alcançan, como lo hazen en otras naciones: en mayor perfection estaria la Musica en nuestras tierras, que en las estrañas: porque hay mejores entendimientos". ${ }^{82}$ Andrés de Monserrate señalaba como primer motivo de la publicación de su libro el que eran pocos los que enseñaban el canto llano con "los verdaderos fundamentos que este diuino canto requiere". ${ }^{83}$ Esta razón es igualmente apuntada por Pietro Cerone en El Melopeo y Maestro ("porque [quienes quieren aprender música] carecen de Maestros ò si los tienen no todos les quieren enseñar lo poco ò mucho que saben"), incluso como el motivo que condujo al título de su libro:

Lo primero pues que me mouio intitularle assi, fue el ser las Aldeas y lugares de España tan faltos de Maestros de Musica; y el considerar que los pocos que hay en ellas por la mayor parte, no saben cumplidamente lo que es necessario saber: y si saben, no todos quieren enseñar fielmente (como dixe en el Preambulo) à quien de ueras desea saber esta Arte. El presente libro pues suple à todo lo que los dichos Maestros hazen falta; porque el enseña liberalmente, lo que ellos callan maliciosamente: el descubre con amor, lo que ellos (quiça) encubren por odio; y finalmente porque el enseña con mucha claridad, lo que ellos muestran con diuersas oscuridades. ${ }^{84}$

Aunque cronológicamente posterior, uno de los testimonios más sorprendentes en cuanto a referencias a experiencias docentes es el de Manuel Nunes da Silva, quien, debido a que los doctos en la música se mostraban reticentes a comunicar sus talentos, elaboró su Arte minima (Lisboa, 1685) atendiendo a las lecciones del coro de la Catedral de Lisboa y preguntando a los maestros. Presento a continuación el segundo párrafo del "Preámbulo al lector" de Manuel Nunes da Silva por su interés para captar el origen de las artes de música y su vinculación con la enseñanza:

Poco después empecé a enseñar a algunos estudiantes canto de órgano, los cuales crecieron bastante en número y, para ahorrar el trabajo de escribir un arte, hice un resumen del Arte de canto de órgano, vulgarmente llamado Mano, para que por él lo copiaran; y, puesto que las copias sa-

\footnotetext{
${ }^{82}$ Bermudo, Libro primero, f. 9r.

${ }^{83}$ Monserrate, Arte breve y compendiosa, p. 5.

${ }^{84}$ Cerone, El Melopeo y Maestro, pp. 1 y 9.
} 
lían tan distintas del original [...], hice diligencia por algún arte impreso, para por él estudiar, y no hallé noticia sino del Arte de António Fernandes, que no me contentó, por parecerme difícil para que los niños lo estudien de memoria. Antes de ser sacerdote me dieron una cátedra de canto llano en el Seminario del Arzobispado y luego escribí una Summa da Arte de Canto Chão, para los colegiales del dicho Seminario y, aunque de canto llano escribe en nuestro idioma el insigne catedrático de Coimbra Pedro Thalesio, son tan pocas las artes, que solamente se hallan en bibliotecas, finalizado el Resumo de Canto de Orgão, y una Summa de Canto Chão, empecé las explicaciones de estas Artes, para que más por extenso enseñase lo que tenía estudiado, y no ocultase el talento que recibí, que aunque uno solo he comunicado, se podrá multiplicar, y así me libro de la culpa que Plutarco impone a los que no comunican lo que saben, que la evalúa por mayor que la de los que no aprenden lo que ignoran. Por último ordené el Compendio da Arte de Contraponto, \& Compostura, al que no hice particulares explicaciones, y me remito a la Explanaçaõ do Canto Multiforme que le pertenece, y prometo continuar el estudio con explicaciones particulares, siendo aceptado lo que ofrezco habiendo dado cuenta de los motivos que tuve para hacer este Arte, que se titula Minima, por ser en comparación con las que se tienen escritas así en el volumen como en la forma muy pequeña, por acomodarme con un verso que dice: Derivata solent leges servare parentum. ${ }^{85}$

De este relato se extraen varias conclusiones: 1) que las artes circulaban manuscritas como "apuntes de clase" entre los estudiantes; ${ }^{86}$ 2) que las artes eran un material de estudio en las lecciones de canto catedralicias; 3) que Manuel Nunes da Silva consideraba demasiado difícil para sus estudiantes el Arte de mvsica de canto dorgam, e canto cham, \& proporções de musica diuididas harmonicamente (Lisboa, 1626) de António Fernandes; ${ }^{87}$ y 4) que el autor acudió a la imprenta para proporcionar fidelidad a las

\footnotetext{
${ }^{85}$ Manuel Nunes da Silva, Arte minima que com semibreve prolaçam tratta em tempo breve, os modos da Maxima, \& Longa sciencia da Musica (Lisboa: Na officina de Joam Galram, 1685), f. A3: "Pouco despois principiei a ensinar alguns estudantes Canto de Orgaõ, os quaes cresceraõ em bastante numero, \& para forrar o trabalho lhe escrever a Arte, fiz o Resumo da Arte de Canto de Orgaõ, vulgarmente chamada, Maõ, para por elle a copiarem; \& porque as copias sahiaõ taõ dessemelhantes do original, que lhe accumulavaõ mil testemunhos; fiz diligencia por alguna Arte impressa, para por ella estudarem, \& naõ achei noticia, senaõ da Arte de Antonio Fernandes, que me naõ contentou, por me parecer difficil para mininos estudarem de còr. Antes de ser Sacerdote me deraõ a Cadeira de Canto Chaõ, em o Seminario de Arcebispado, \& logo escrevi a Summa da Arte de Canto Chaõ, para os Collegiaes do ditto Seminario; \& supposto, que de Canto chaõ, no nosso idioma escreveo o insigne Cathedratico de Coimbra Pedro Talesio, saõ taõ poucas as Artes, que só em livrarias se achaõ; finalizado o Resumo de Canto de Orgaõ, \& a Summa de Canto Chaõ, principiei as Explanações a estas Artes, para que mais por extenso ensinasse, o que tinha estudado, \& naõ occultasse o talento que recebi, que supposto he hum só, communicado, poderá ser se multiplique, \& assim me livro da culpa, que Plutarco impõem aos que naõ communicaõ o que sabem, que a avalia por mayor, que a dos que naõ aprendem o que ignoraõ. Ultimamento ordenei o Cõpendio da Arte de Contraponto, \& Compostura; ao qual naõ fiz particulares Explanações, \& me aremetto á Explanaçaõ do Canto Multiforme, que lhe pertence, \& prometto continuar o estudo com Explanações particulares, sendo aceito, o que offereço: tenho dado conta dos motivos, que tive para fezer esta Arte, que em titulo Minima, por ser em comparação das que se tem escritto, assim no volume, como em a forma, muito pequena, por em accomodar com hum verso, que diz: Derivata solent leges servare parentum". Son llamativas también en el título de este tratado las referencias a la brevedad, la simplificación y el compendio.
}

${ }^{86}$ Por ejemplo, Carlos Romero de Lecea, "Las más antiguas imprentas musicales hispanas III", en Juan José Rey Marcos, Portus Musicae de Diego de Puerto: introducción, comentario y traducción (Madrid: Joyas bibliográficas, 1978), pp. 83-95, p. 89, sostiene que Portus musice funcionó como apuntes de clase.

${ }^{87}$ Robert Stevenson, "Fernandes, António”, Grove Music Online. Oxford Music Online, 31 octubre 2008 
copias de su texto. Por tanto, las artes trataban de arrojar luz sobre dificultades concretas expuestas por los discípulos a sus maestros y también de atender peticiones provenientes de personas que deseaban iniciarse en la música. Por ejemplo, Martínez de Bizcargui en su dedicatoria señalaba haber publicado su libro "incitado e muchas vezes requerido por algunos desseosos de hauer regla e doctrina para mejor poder deprender la musica". ${ }^{88}$ Es más, como sugiere el comentario de Manuel Nunes de Silva y como señalaba directamente Andrés de Monserrate, la publicación de artes de canto pudo constituir un intento de facilitar a los alumnos y a los maestros la tarea de "estar siempre trasladando y escriuiendo artes y preceptos de canto llano". ${ }^{89}$

\section{d) Uso de tablas "para mayor declaracion del canto llano" y ejemplos musicales}

Otro recurso didáctico constante en las artes de canto es el uso de ejemplos musicales y de tablas. No obstante, la inclusión de ejemplos musicales y material gráfico como la mano guidoniana dependía fundamentalmente del formato del libro y por tanto de su valuación y su mercado potencial. Es decir, en ocasiones no se incluían ejemplos musicales ni divisiones en el cuerpo del texto, de manera que éste discurría sin solución de continuidad, para así reducir la cantidad de papel utilizada en el ejemplar y por tanto su precio, en una época en la que más del $70 \%$ del coste del libro dependía de la cantidad y calidad del papel utilizado. ${ }^{90}$ Este tipo de disposición del texto se analizará en el Capítulo II en relación a las artes de canto llano R/14670 de la Biblioteca Nacional de España.

\footnotetext{
$<$ http://www.oxfordmusiconline.com/subscriber/article/grove/music/09489>, atribuye otros tres libros a Fernandes: Arte da musica de canto de orgã̃ composta por hum modo muito differente do costumado por hum velho de 85. annos dezejoso de evitar o ocio; Theorica do manicordio, e sua explicaçaõ; y Mappa universal. Ricart i Matas, Diccionario biográfico de la música, p. 341, los titula A explicaçao dos segredos da muzica; Teorica do manicordio; y Arte de muzica de canto de orgão e hum mapa oniversal de qualquer couza... que se contem na arte de muzica com os seus generos e demostrações matematicas. Un libro de António Fernandes titulado Especulação de segredos de Musica aparece en el índice de la biblioteca de música del rey João IV de Portugal realizado en Lisboa en 1649; véase Primeira parte do Index da Livraria de mvsica do muyto alto, e poderoso Rey Dom Joao o IV. Nosso Senhor (Lisboa: Paulo Craesbeck, 1649), p. 118, n 501. Este libro perdido también es mencionado en João de Freitas Branco, História da música portuguesa (Lisboa: Publicações Europa-América, 1995 [1959]), p. 131.

${ }^{88}$ Martínez de Bizcargui, Arte de canto llano et contrapunto et canto de organo (1511 [1508]), f. A1v.

${ }^{89}$ Monserrate, Arte breve y compendiosa, p. 6.

${ }^{90}$ Watt, Cheap Print and Popular Piety, p. 1; véanse también André Blum, Les origines du papier, de l'imprimerie et de la gravure (París: Ed. de la Tournelle, 1935); y Oriol Valls i Subirá, La historia del papel en España (Madrid: Empresa Nacional de Celulosa, 1978).
} 
Los ejemplos musicales irrumpen en el contenido textual enriqueciéndolo y, como sugiere Cristle Collins Judd, constituyen "imágenes auditivas" que deben ser interpretadas por el ojo y reconstruidas por el oído interno. ${ }^{91}$ Por su propósito pedagógico, la organización espacial del contenido de las artes juega un papel fundamental, puesto que una distribución cuidadosa del texto y los ejemplos musicales contribuía a una simultaneidad entre el discurso verbal y su representación visual. Esto enlaza con lo que Emma Dillon llama "el teatro de la página" en el contexto de los manuscritos musicales medievales: la disposición de música, imagen y texto contribuye al significado musical. ${ }^{92}$ En el mismo sentido, pero en el ámbito literario, Sylvia Hout habla de la cualidad teatral e incluso "cinematográfica" del libro medieval. ${ }^{93}$

Las ilustraciones captan la atención de los lectores y suponen una ayuda para la memorización de los contenidos conceptuales. Las imágenes eran usadas con el mismo fin en otras impresiones de la época como las estampas (en este sentido consideradas por Claude Fleury "la escritura de los ignorantes") y la literatura de cordel. ${ }^{94}$ Con respecto a esta última modalidad, María del Mar Fernández Vega indica que, "cuanto menor es el nivel cultural del público al que un impreso se dirige, mayor número de ilustraciones requiere, ya que éstas facilitan la lectura y la comprensión del texto". 95 También en el caso de los manuales de música, Susan F. Weiss señala que las imágenes servían para "estimular las memorias de aquéllos que confiaban en el alfabetismo de otros para acceder a los textos". 96

\footnotetext{
${ }^{91}$ Judd, Reading Renaissance Music Theory, pp. 8-10.

92 Emma Dillon, Medieval Music-Making and the Roman de Fauvel (Cambridge: Cambridge University Press, 2002), p. 80.

${ }^{93}$ Sylvia Huot, From Song to Book: The Poetics of Writing in Old French Lyric and Lyrical Narrative Poetry (Ithaca y Londres: Cornell University Press, 1987), p. 3.

${ }^{94}$ Claude Fleury, "Discours du dessein et de l'usage de ce catéchisme", en Catéchisme historique contenant en abrégé l'histoire sainte et la doctrine chrétienne (Madrid: Imprimerie de l'administration du royal arbitre de la bienfaisance, 1803 [1683]), pp. 13-64. Véase Dominique Julia, "Lecturas y Contrarreforma", en Historia de la lectura en el mundo occidental, dir. por Guglielmo Cavallo y Roger Chartier (Madrid: Taurus, 1997), pp. 367-412, p. 367.
}

${ }^{95}$ Fernández Vega, "Política y propaganda”, p. 77.

96 Susan Forscher Weiss, "Vandals, Students, or Scholars? Handwritten Clues in Renaissance Music Textbooks", en Music Education in the Middle Ages and the Renaissance: Reading and Writing the Pedagogy of the Past, ed. por Susan Forscher Weiss, Russell E. Murray y Cynthia J. Cyrus (Bloomington: Indiana University Press, 2010), pp. 207-246, p. 208: "In this context, images could stimulate the memories of those who relied on the literacy of others for access to texts". 
Frente al tradicionalismo, la falta de originalidad y el carácter conservador que, como se estudiará en la segunda parte de este Capítulo, se les han imputado a las artecillas de canto de la España renacentista, debemos tener en cuenta que el uso de materiales ilustrativos a modo de ejemplos dentro de discursos tanto escritos como orales ha sido señalado por Cristle Collins Judd como una característica del pensamiento humanista por su vinculación con los "exempla" de los tratados retóricos de la Antigüedad clásica. $^{97}$

\section{e) Otros recursos didácticos}

Otros recursos didácticos que presentan las artes de canto objeto de este estudio son los siguientes: 1) en los dos tratados de Mateo de Aranda se incluye como último apartado un resumen de la totalidad de la obra; 2) los capítulos del libro de António Fernandes comienzan en ocasiones con una frase breve que contiene la idea fundamental o una definición; 3) todas las artes analizadas presentan sus contenidos organizados en orden de dificultad creciente; por ejemplo, Andrés de Monserrate divide su obra en dos tratados, el primero de los cuales está dirigido únicamente a "principiantes"; 4) Francisco de Montanos, en su Arte de musica theorica y pratica, aconseja a los principiantes pasar por alto las definiciones hasta que las necesiten, lo que según Dan Murdock Urquhart supone anteponer la comprensión de la sustancia a la memorización de las definiciones; Urquhart señala además que, aislando los conceptos de altura y ritmo, Montanos logra el procedimiento pedagógico de dividir un tema en sus componentes básicos y tratarlos por separado; ${ }^{98}$ y 5 ) la mayor parte de las artes de canto llano analizadas incluyen al final los íncipits de las entonaciones de los principales cantos de la Misa y el Oficio en los ocho modos como una ayuda a la práctica de lo aprendido.

\subsubsection{PRIORIDAD A LA PRÁCTICA}

Las artes de canto se muestran poseedoras de un carácter tanto terminal, puesto que recogen todo lo "necesario", como preparatorio, ya que son el fundamento para emprender el aprendizaje de otros contenidos. Juan de Espinosa, en la introducción de

\footnotetext{
${ }^{97}$ Judd, Reading Renaissance Music Theory, pp. 126-128.

${ }^{98}$ Dan Murdock Urquhart, "Francisco de Montanos's Arte de musica theorica y pratica: A Translation and Commentary", Tesis Doctoral (Ph.D.), The University of Rochester, Eastman School of Music, 1969, p. 22 .
} 
su Tractado de principios de musica practica y teorica (Toledo, 1520), mostraba una orientación práctica de la enseñanza musical al manifestar que presentaría en ese tratado la práctica, puesto que sin ella era imposible pasar a la especulación y la teoría. La consecuencia es que los contenidos teóricos de las artes analizadas son mínimos y prolifera el repertorio musical para practicar lo aprendido. La huida de la prolijidad es también el propósito expreso de Juan Francisco Cervera, quien prefería basarse en "la experiencia y platica":

Que digo con verdad, que si se vuiessen de hazer reglas para todas las difficultades, que se offrecen, y pueden offrecerse en la platica y theorica del canto llano, seria impossible hazerlas, sin que huuiesse mucha prolixidad; la qual es de ningun prouecho para todos, y mas a los principiantes y assi lo remito todo a la experiencia y platica, porque como maestra en toda cosa pueda enseñar a los que necessitaren de su ayuda en esta arte y façultad del canto llano. ${ }^{99}$

El contenido principalmente práctico de las artes de canto convierte a estos libros en una importante fuente musical. Nan Cooke Carpenter señaló hace décadas que la fuente de información más fiable sobre la práctica musical del siglo XVI no son los tratados teóricos, sino los libros de música práctica y especialmente las secciones diseñadas para principiantes. ${ }^{100}$ Por ejemplo, Robert Stevenson indicaba que, con el grupo de cantos llanos con constantes alteraciones accidentales incorporados en su tratado, Luis de Villafranca “quizás no estaba invocando el estilo preferido por los especialistas en canto gregoriano actuales, sino que al menos estaba describiendo las lecturas extremadamente cromatizadas que los cantores sevillanos hacían del repertorio tradicional en 1565". ${ }^{101}$ Se ha considerado que el libro Reglas de canto plano, e contrapunto, e de canto de organo (1410) de Fernand Estevan y el manuscrito escurialense (signatura cIII-23) Ars cantus mensurabilis et inmensurabilis (1480) son fuentes teóricas muy im-

\footnotetext{
${ }^{99}$ Cervera, Arte y suma de canto llano, pp. 53-54.

${ }^{100}$ Hoyle Carpenter, "Tempo and Tactus in the Age of Cabezón”, Anuario musical, XXI (1966), pp. 123130 , p. 123.

101 Stevenson, Spanish Music in the Age of Columbus, p. 50: "When Luys de Villafranca reprinted a choice group of plainchants with constant accidentals, he was not perhaps invoking a style that would be favored by present-day plainsong specialists, but at least he was describing the highly chromaticized readings which Sevillian singers gave the traditional repertory in 1565 ".
} 
portantes de música ficta, ${ }^{102}$ y que el Arte de melodia sobre canto lano y canto d'organo (Barcelona, Biblioteca de Catalunya, Ms. 1325) es "la fuente más valiosa acerca del Canto melódico de Toledo". ${ }^{103}$ Las peculiaridades locales o regionales constituyen una faceta de las artes de canto que trataré en la siguiente sección.

\title{
1.2.6. ELEMENTOS LOCALES
}

En su Institucion harmonica (Madrid, 1748) Antonio Ventura Roel del Río señalaba respecto al canto llano que "cada uno lo canta segun el uso del Pais". ${ }^{104}$ Las artes de canto contienen elementos locales y por tanto suponen una valiosa fuente de información acerca de la vida musical y las prácticas interpretativas de las instituciones de las que emanaron. Encontramos una crítica a este rasgo localista en el Arte para componer canto llano (Sevilla, 1582) de Pedro de Loyola Guevara:

\begin{abstract}
Tambien es razon que la Canturia sea toda vna, y las yglesias seran mejor seruidas. Y no que los de Seuilla, digan que no saben los de Toledo, y los de Toledo que los de Burgos, y los de Burgos que los de Granada y Leon. Mas si emos de dezir verdad, los vnos ni los otros no se an entendido, como claramente vemos, por lo compuesto, y lo que tiene escripto sobre ello. Para remedio de lo qual é querido tomar cuydado de hazer esta Arte para componer Cantollano [...]. ${ }^{105}$
\end{abstract}

La inclusión de elementos locales característica de las artes de canto se evidencia de varias formas. En primer lugar, se manifiesta mediante alusiones en los títulos de los libros, siendo ejemplo claro la intención local manifestada por Luis de Villafranca ("para cantar epistolas, leciones, prophecias y evangelios y otras cosas que se cantan conforme al estilo de la sancta yglesia de Sevilla"). En segundo lugar, el carácter local se hace evidente a través del repertorio incluido en los libros, como ocurre en el Arte de canto llano (Sevilla, 1530) de Juan Martínez y la Breue instrucion de Canto llano (Sevi1la, 1565) de Luis de Villafranca. Ambos libros contienen la letra (quizás porque la mú-

\footnotetext{
${ }^{102}$ Kart-Werner Gümpel, "Gregorian Chant and Music Ficta: New Observations from Spanish Theory of the Renaissance”, Recerca Musicologica, VI-VII (1986-1987), pp. 5-27.

103 Kart-Werner Gümpel, "El canto melódico de Toledo: algunas reflexiones sobre su origen y estilo", Recerca Musicologica, VIII (1988), pp. 25-45, p. 30.

104 Antonio Ventura Roel del Río, Institucion harmonica, ó Doctrina musical theorica y practica, que trata del canto llano, y de organo (Madrid: Herederos de la viuda de Juan García Infanzón, 1748), p. 118.

${ }^{105}$ Guevara, Arte para componer canto llano, p. 8.
} 
sica era lo suficientemente conocida) de "Sanctissimae Trinitatis", antífona que cantaban los mozos de coro desde 1498 por una dotación de Pedro Mejía, archidiácono de Écija y canónigo de Sevilla, y hasta 1960, cuando se cerró el Colegio de San Isidoro: ${ }^{106}$

En el capítulo de intervenciones y costumbres de los mozos de coro de Sevilla debemos subrayar el canto diario de la antífona Sanctissimae Trinitatis, a la que alude ya Juan Martínez en su libro de canto llano en 1532. Esta pieza, dividida en dos partes, fue de gran tradición en la catedral de Sevilla, donde se cantó desde el siglo XV a 1960 en que se cerró el colegio de San Isidoro situado dentro del solar de San Miguel. La cantaban al principio los seises, los mozos de coro y los cantores adultos todos los días después de Prima y antes de Vísperas, excepto en el Triduo Pascual. Luego pasó a ser interpretada por los seises, y se ha conservado escrita en notación mensural típica del canto llano mixto. ${ }^{107}$

En tercer lugar, los elementos locales se ponen de manifiesto por medio de la declaración de intenciones contenida en los prólogos e introducciones, como se evidencia en el caso de Juan de Espinosa, que destinaba su Tractado breue de principios de canto llano a quienes deseaban aprender "tomando la muy cierta doctrina de la musica de la nueua manera que en esta insigne ciudad de Toledo se sigue ya de poco tiempo aca". 108

\subsubsection{BÚSQUEDA DE PRECEPTOS OBJETIVOS PARA NO GUIARSE POR EL OÍDO}

José Augusto Alegria sostiene que Mateo de Aranda organizó la enseñanza en la Claustra (Canonjía) de la Catedral de Évora de manera que se hizo necesario formar a cuatro mozos de coro para unirlos con otros cuatro que ya había pero que "musicalmen-

\footnotetext{
${ }^{106}$ Herminio González Barrionuevo, Francisco Guerrero (1528-1599): Vida y obra. La música en la Catedral de Sevilla a finales del siglo XVI (Sevilla: Cabildo Metropolitano de la Catedral de Sevilla, 2000), p. 150, nota 141; Juan Ruiz Jiménez, "From Mozos de coro Towards Seises: Boys in the Musical Life of Seville Cathedral in the Fifteenth and Sixteenth Centuries", en Young Choristers, 650-1700, ed. por Susan Boynton y Eric N. Rice (Woodbridge: Boydell Press, 2008), pp. 86-103, p. 97. González Barrionuevo y Ruiz Jiménez indican que el Arte de canto llano de Juan Martínez incluía "la melodía" "Sanctissimae Trinitatis" aunque en los ejemplares consultados se incluye únicamente la letra, al igual que ocurre en Villafranca, Breue instrucion de Canto llano, f. E4r. Resulta ilustrativo que la letra del "Sanctissimae Trinitatis" aparezca al final en las ediciones de Coimbra en 1550 (por ser una traducción literal del libro en español) del libro de Martínez y de Alcalá de Henares en 1598, pero sin embargo se omita en el resto de las ediciones portuguesas.

${ }^{107}$ González Barrionuevo, Francisco Guerrero (1528-1599), p. 695.

${ }^{108}$ Espinosa, Tratado breue de principios de canto llano, f. A1v.
} 
te" no sabían nada porque sólo aprendían de oído. ${ }^{109}$ La mayoría de las artes son evidencia de una búsqueda de la "objetividad" en las reglas establecidas, siendo la corroboración más clara de esta hipótesis los prólogos prácticamente idénticos de las artes publicadas por Andrés de Monserrate en 1614 y por António Fernandes en 1626. Monserrate, en su "Prologo segundo, y exortacion a los principiantes que dessean ser perfectos Musicos Ecclesiasticos, para que no se rijan, ni guien por su propio parecer, ni por sus oydos (si van fuera del arte), sino por los preceptos y reglas ciertas de la Musica, que son el verdadero camino y guia cierta", se lamentaba de que las personas ignorasen los términos, principios y causas de la ciencia de la música y se basasen en sus oídos mal ejercitados, "que cualquiera por barbaro que sea tiene". ${ }^{110}$ Fernandes incluía el mismo prólogo en su libro de 1626, pero traducido al portugués ("Prologo aos principiantes que deseiam ser perfeitos mestres, pera que nam se guiem nem gouernem por seu proprio parecer, nem por seus ouuidos se vam fora da Arte, senam pellos preceitos \& regras certas da Arte da Musica, que sam o verdadeiro caminho, \& guia certa pera não errarem"). ${ }^{111}$ Otro ejemplo se encuentra en la dedicatoria, firmada por el impresor Juan de Ibar, de la edición de 1665 del Arte de canto llano (1594) de Montanos: ${ }^{112}$

[...] oy dia ay algunos, que con este mismo santo zelo no admiten a los sacros Ordenes a los que no estàn diestros por lo menos en el Canto llano, aunque en lo demas tengan mucha suficiencia: y no se contentan porque en el se guien por solo el sentido (en que ay algunos muy eminentes) sino que quieren lo canten cientificamente porque esto es lo seguro [...].

La búsqueda de preceptos objetivos ha sido vista en la bibliografía como opuesta al llamado "sensualismo estético". ${ }^{113}$ En el lado opuesto encontramos a Martínez de Bizcargui, que fue acusado por Espinosa de anteponer su oído "a todos los passados e presentes"; para Espinosa, "el sentido del oyr sin el arte no puede ser juez de las conso-

\footnotetext{
${ }^{109}$ José Augusto Alegria, "Inéditos musicais de Mateus d'Aranda”, Colóquio-artes: Revista de artes visuais, música e bailado, XV/12 (1973), pp. 71-72, p. 72.

${ }^{110}$ Monserrate, Arte breve y compendiosa, p. 8.

${ }^{111}$ Fernandes, Arte da musica de canto de orgaõ, s.f.

${ }^{112}$ Véase el Capítulo II.

${ }^{113}$ Francisco José León Tello, La teoría española de la música en los siglos XVII y XVIII (Madrid: CSIC, Instituto Español de Musicología, 1974), p. 527.
} 
nancias ni dissonancias". ${ }^{114}$ Sin duda, en esta polémica subyace la infravaloración del "siervo de la música" (el cantor o instrumentista) frente al "músico" (el teórico de la música); Espinosa decía de Bizcargui que "se sabe de muy cierto que es cantor e tañedor a los quales todos aquellos [los teóricos] a quien el con tanta osadia e poco temor contradize llaman en muchos lugares sieruos de la musica". ${ }^{115}$ Es sumamente interesante la manera en que la imprenta musical se utilizó como vehículo de esta controversia. Espinosa publicó sus Retractaciones de los errores e falsedades que escrivio Gonçalo Martinez de Viscargui en su arte de canto llano (Toledo, 1514) "por mandado del muy magnifico señor don Francisco de Bouadilla obispo de Salamanca"; Martínez de Bizcargui respondió en 1515 con unas Intonaciones [...] segun el uso de los modernos, consistentes en un pliego que se vendió con la reimpresión de ese año de su libro, pero también como documento independiente que se reimprimiría tras agotarse la tirada; en la edición de 1517 de su Arte de canto llano et contrapunto et canto de organo, Martínez de Bizcargui insertaba un párrafo final (justo antes del colofón) en referencia a Espinosa:

\begin{abstract}
Algunos naturales hablando mas a su voluntad que con razon dizen y ponen objectos contra este breue tratado: diciendo que es muy oscuro: y otras cosas que a ellos plaze: es verdad que su reprehension los condena a que no le entienden. Ninguno puede ser maestro sin que primero sea discipulo. Porque esta breuemente ordenado por la pura theorica: y aprouado por mucha experiencia: assi de la pratica como de la cuerda. Y assi a ningun bueno es dado decir mal de lo bueno. Y si algunos con la nueba suficiencia que tienen quisieren algo contradecir: como es de costumbre entre los theoricos: placer hauremos de estar a dar razon de lo que pidieren, y assi quedara esta breue collocacion aprouada por muy buena: y mas prouechosa como esta. ${ }^{116}$
\end{abstract}

Espinosa, en su Tractado de principios de musica practica e theorica de 1520, incluía un último capítulo titulado "Retractacion contra Bizcargui". La edición de 1538 del libro de Martínez de Bizcargui contenía un párrafo final en que se evidencia el uso que se estaba haciendo de la imprenta musical en este debate:

Porque ninguno pretenda ignorancia vn Joannes de spinosa presumio de nos contradezir ciertos capitulos de la nuestra Arte primera: e respondimos en esta presente Arte a sus injustas e no rec-

\footnotetext{
${ }^{114}$ Espinosa, Tractado de principios de musica practica e theorica, f. C1r.

${ }^{115}$ Espinosa, Tractado de principios de musica practica e theorica, f. C1v.

${ }^{116}$ Martínez de Bizcargui, Arte de canto llano et contrapunto et canto de organo (1517 [1508]), f. C8r.
} 
tas contradicciones en el año de mil y quinientos y quinze que antes no vino a nuestra memoria. Assi mismo respondimos en especial en vn pliego de papel en que se imprimieron mil pliegos y todos mil es vno de manera que el quedo bien satishecho. E a los que ternan desseo de lo ver se dara juntamente con esta nuestra arte para que por ella: y por el vean la justa y verdadera causa que defiendo.

\subsubsection{VIGENCIA DEL CONTENIDO}

El Apéndice 2 presenta un listado de las tablas de contenidos de cada una de las artes de canto que han sido objeto de mi investigación. Salta a la vista que el contenido de esta tipología libresca varía muy poco, sobre todo en el caso de las artes de canto llano, y que las mayores alteraciones se producen en función de la extensión del libro. Los tratados explican el sistema hexacordal y la solmización y comienzan presentando los elementos del canto llano: las letras y signos, las seis voces (ut-la), las dos claves (fa y do), las cinco reglas (líneas del pentagrama), las vírgulas (líneas que separan grupos de signos), el guión (custos), las propiedades (becuadro, natura y bemol) y los movimientos de la música (deduccional, igual y disjuntivo). A continuación se tratan otros aspectos básicos para iniciarse en el canto llano: las mudanzas (o modulación de un modo a otro), las disjuntas (quinta, sexta, séptima y octava), los géneros (diatónico, cromático y enarmónico; Bermudo incluye además el semicromático), las consonancias, las doce especies de intervalos (unísono, semitono, tono, semidítono, ditono, diatesarón, diapente, hexacordo menor, hexacordo mayor, heptacordo menor, heptacordo mayor y diapasón), los ocho tonos o modos, las cláusulas, las proporciones y las conjuntas. Finalmente, se suele incluir un tonario y el repertorio musical que es fundamental aprender. ${ }^{117}$ En el Capítulo III analizaré en detalle el contenido del Arte de canto llano (1530) de Juan Martínez.

José Augusto Alegria, como ya había hecho Francisco José León Tello, ha indicado que "quien pretendiese ser clérigo, por riguroso imperativo de las circunstancias, no tenía alternativa: la música de la Iglesia era aquélla y sólo aquélla. No estaba sujeta a improvisaciones. Era, pura y simplemente, materia de enseñanza". ${ }^{118}$ Las artecillas de

\footnotetext{
${ }^{117}$ Acerca de la historia, el repertorio y su clasificación, y la notación manuscrita del canto gregoriano, véase Juan Carlos Asensio, El canto gregoriano: historia, liturgia, formas... (Madrid: Alianza Música, 2003).

${ }^{118}$ Alegria, O ensino e prática da música nas Sés de Portugal, p. 26: "Quem pretendesser ser clérigo, por rigoroso imperativo das circunstâncias, não tinha alternativa: a música da Igreja era aquela e só aquela. Não estava sujeita às improvisões. Era, pura e simplesmente, matéria de ensino"; León Tello, Estudios de historia de la teoría musical, p. 197.
} 
canto han sido calificadas de tradicionales e incluso de pasadas de moda $\mathrm{y}$, como causas de esta carencia de originalidad, se han señalado las limitaciones del tema, el hecho de que los reformadores fuesen despreciados en la época, y la consideración de la música en su sentido más técnico. El "tradicionalismo" de las artes de canto se desprende de los estudios de Kathleen E. Nelson. La musicóloga explica cómo, a finales del siglo XV, los teóricos españoles comenzaron a considerar las duraciones en el canto gregoriano y el concepto de plica (una línea que, añadida a cualquier nota o ligadura, influye en su duración); ${ }^{119}$ sin embargo, es curioso comprobar que los autores de las artes que son objeto de la presente investigación no siguieron esta innovación. También con respecto al ritmo, Nelson analiza la notación utilizada por cada teórico y distingue dos grupos en función de su tratamiento de la interpretación rítmica del canto llano (Juan Bermudo es estudiado independientemente): 1) la escuela "equalist", que aboga por la interpretación de todas las notas con igual valor (Aguilar, Martínez de Bizcargui, Marcos Durán, Molina, Spañón); y 2) la escuela "non-equalist" (Ars cantus plani de la Biblioteca de Catalunya, Ferrer y Podio). ${ }^{120}$ Por tanto, todos los autores de las artes de canto estudiadas se insertan en el primer grupo.

Francisco José León Tello sostiene que, por ejemplo, el Arte de canto llano de Montanos es el libro menos interesante de los seis que constituyen su Arte de musica debido a la falta de originalidad. La causa de esta carencia, según León Tello, debemos buscarla en las limitaciones del tema. ${ }^{121}$ En la misma línea, Samuel Rubio afirma que surgirán discrepancias "sólo per accidens" puesto que "la teoría gregoriana estaba muy sistematizada, exceptuando quizás la definición del semitono natural". ${ }^{122}$ Otros han visto esta falta de originalidad como consecuencia del desprecio con el que eran tratados los reformadores en la época. Así, Miguel Alonso sostiene que los autores de las artes de canto llano seguían a Guido d'Arezzo e ignoraban a Ramos de Pareja alegando que

\footnotetext{
${ }^{119}$ Kathleen E. Nelson, "The Plica and Plainchant Notation as Discussed by Spanish Musical Theorists c. 1490-1550", en All Kinds of Music: In Honour of Andrew D. McCredie, ed. por Graham Strahle y David Swale (Wilhelmshaven: Noetzel Wilhelmshaven, 1998), pp. 20-24.

${ }^{120}$ Véase Kathleen E. Nelson, Medieval Liturgical Music of Zamora (Ottawa: The Institute of Mediaeval Music, 1996), pp. 41-75.

${ }^{121}$ León Tello, Estudios de historia de la teoría musical, p. 197.

${ }^{122}$ Samuel Rubio, Historia de la música española 2: Desde el "ars nova” hasta 1600 (Madrid: Alianza Música, 1983), pp. 247-248.
} 
en el Método Teórico-Práctico de Cantollano simplificado (Palencia, 1858) de Evaristo García Torres se dice que el canto llano se conservaba en el mismo estado en que lo había dejado Guido porque los reformadores eran despreciados. ${ }^{123}$ Por otro lado, Álvaro Zaldívar considera que la pervivencia de la solmisación en los tratados musicales españoles de los siglos XV y XVI no responde "al mero cumplimiento aparente de una tradición", sino a que la solmisación había mantenido su utilidad para los compositores y, por tanto, era consecuencia de una concepción de la música "en su sentido más técnico". 124

Tanto las breves artecillas de canto como los manuales de música en general y de música instrumental en particular han sido criticados por su "conservadurismo". Al trazar la influencia del Arte de musica theorica y pratica de Montanos entre 1592 y 1748, Urquhart concluyó que la mayoría de los tratados escritos en España entre estas fechas podrían calificarse de conservadores ya que cubren los mismos temas, en el mismo orden y reconocen haber usado el libro de Montanos; según Urquhart, ponen mucho énfasis en la polifonía vocal sacra y apenas contienen alusiones a las prácticas interpretativas instrumentales. ${ }^{125}$ Respecto al tradicionalismo atribuido a la música instrumental, destaca la crítica de Macario Santiago Kastner a Tomás de Santa María por haber presentado ideas más conservadoras que otros tratadistas de tecla contemporáneos. ${ }^{126}$ También José Rada atribuye a Santa María un "conservadurismo que en distintos momentos se da de bruces con la música de la época". ${ }^{127}$ Sin embargo, más recien-

\footnotetext{
${ }^{123}$ Alonso, Cuatro tratados de principios de canto llano, p. 24.

124 Álvaro Zaldívar Gracia, "La pervivencia de la solmisación en los tratados musicales españoles de los siglos XV y XVI", en Fuentes Musicales en la Península Ibérica (ca. 1250-1550), ed. por Maricarmen Gómez y Màrius Bernadó (Lleida: Universitat de Lleida-Institut d'Estudis Ilerdencs, 2001), pp. 321-337, pp. 332 y 337.

${ }^{125}$ Urquhart, "Francisco de Montanos's Arte de musica theorica y pratica”, p. 56-94. Urquhart estudió cinco obras sobre música de tratadistas españoles publicadas entre 1592 y mediados del siglo XVIII: El porque de la musica (Alcalá de Henares, 1672) de Andrés Lorente, Fragmentos musicos (Zaragoza, 1683) de Pablo Nassarre, Medula de la musica theorica (Salamanca, 1707) de Antonio de la Cruz Brocarte, Escuela musica (Zaragoza, 1723) de Pablo Nassare, e Institucion harmonica (Madrid, 1748) de Antonio Ventura Roel del Río.
}

\footnotetext{
${ }^{126}$ Macario Santiago Kastner, "La teoría de Tomás de Santa María comparada con la práctica de algunos de sus contemporáneos", en III Semana de Música Española. El Renacimiento (Madrid: Comunidad de Madrid, 1988), pp. 111-129, p. 114.

127 José Rada, "La enseñanza de la tecla en el siglo XVI", en III Semana de Música Española. El Renacimiento (Madrid: Comunidad de Madrid, 1988), pp. 130-136, p. 134.
} 
temente, Miguel A. Roig-Francolí ha señalado que el libro de Santa María no ha sido bien comprendido y ha puesto de manifiesto los procedimientos compositivos utilizados en las obras de Antonio de Cabezón tomando como fuente el tratado de Santa María:

Aparte de su indiscutible valor pedagógico para tañedores de la época, vemos en este resumen que el Arte es un detallado tratado de composición sobre las mismas técnicas y los mismos géneros instrumentales practicados por Cabezón y otros compositores contemporáneos [...]. El Arte es, por tanto, un importante documento sobre las técnicas compositivas y las estructuras tonales y musicales de la época. ${ }^{128}$

La falta de innovaciones en las artes de canto alegada por algunos estudiosos es más bien consecuencia del propósito didáctico de los libros. Por ejemplo, Christopher Page señala en la voz "Universities" de The New Grove Dictionary que el hecho de que De musica de Boecio fuese el libro de texto utilizado en las aulas de música universitarias hasta bien entrado el Renacimiento sugiere que el requerimiento fundamental para una disciplina universitaria en la Edad Media y el Renacimiento era que su material fuese apreciado como universal. ${ }^{129}$ Este "tradicionalismo" tuvo como efecto que las artes de canto no fuesen un producto desechable y tuvieran vigencia durante siglos. ${ }^{130}$ Esto explica las reediciones, revisiones, ampliaciones y traducciones de las artes de canto y que, por ejemplo, el Arte de canto llano (Sevilla, 1530) de Juan Martínez se reimprimiera en 1621 simplemente "emendada de algunos yerros que antes auia". Según León Tello, la visión más controvertida de Juan Martínez fue el permitir hasta diez accidentes en el canto, cuestión sobre la que discreparía Pedro Thalesio en su Arte de can-

\footnotetext{
${ }^{128}$ Miguel A. Roig-Francolí, "Procesos compositivos y estructura musical: teoría y práctica en Antonio de Cabezón y Tomás de Santa María”, en Políticas y prácticas musicales en el mundo de Felipe II: estudios sobre la música en España, sus instituciones y sus territorios en la segunda mitad del siglo XVI, ed. por John Griffiths y Javier Suárez Pajares (Madrid: ICCMU, 2004), pp. 393-414, p. 398. La misma idea se percibía ya en Francisco José León Tello, "La teoría de la música de Tomás de Santa María”, en III Semana de Música Española. El Renacimiento (Madrid: Comunidad de Madrid, 1988), pp. 89-110, p. 91: "Su desarrollo de los temas referentes a la técnica del solfeo, ejecución y composición nos proporciona conocimientos insustituibles para la transcripción, análisis e interpretación de las obras de aquel período".

${ }^{129}$ Christopher Page, "Universities" [I. Middle Ages and Renaisance, to 1600], Grove Music Online, ed. por L. Macy (consultado 06-10-2007) <http://www.grovemusic.com>.

${ }^{130}$ Sobre la cualidad desechable de los libros, véase Lafaye, Albores de la imprenta, p. 14.
} 
to chão de $1618 .{ }^{131}$ Con anterioridad a Thalesio, Juan Bermudo había señalado los errores de Martínez (y los de Espinosa, como también haría Thalesio):

\begin{abstract}
Assi que, el genero diatonico procede por los tres interualos ya dichos. Segun el signo de adonde començamos a formar el diatessaron: assi hallaremos primera, segunda, o tercera specie del dicho diatessaron. En el artezica intitulada al venerando Joan martinez [al margen: "cap. 10"] quando estos dos interualos tracta: dize, que son tonos compuestos. Error fue, y no se cuyo: o del dicho author, o del impressor. Esto quise señalar (contra mi stylo) por auisar a los nueuos en la Musica. ${ }^{132}$
\end{abstract}

Un contenido estable era sin embargo constantemente corregido, transformado, adaptado a las costumbres de determinadas instituciones, a la época, ¿al gusto?, y usado como base sobre la que añadir nuevos repertorios y contenidos. Por ejemplo, Antonio Ventura Roel del Río utilizó en su Institucion harmonica (Madrid, 1748) los cantos para practicar que había recopilado Francisco de Montanos en su Arte de canto llano de 1594:

[...] Pero en orden a la Practica entendi no deber omitir para el exercicio del Canto Llano, la que puso el Maestro Montanos de Missas comunes con la exactitud, y estension (aunque mejoradas en los acentos, y algo aumentada) que se vè en su impression del año de 1594, assi por ser la mas conforme con la de las Santas Iglesias, como porque necesitando los que empiezan de corta edad muchos exemplares de ella, los hallen aqui promptos $[\ldots] .{ }^{133}$

El Apéndice 3 muestra un cotejo entre los cantos que incluyó Roel del Río en su tratado (en la sección titulada "Cantos llanos diversos, en que se exercite el nuevo Cantor") y aquéllos que había recogido Montanos en su libro de 1594 (sección "Cantos llanos diuersos en que se exercite el que aprende") como un estudio de caso que refleja la vigencia del contenido de las artes de canto. Roel del Río modificó ligeramente la orga-

\footnotetext{
${ }^{131}$ Francisco José León Tello, “Martínez, Juan”, Grove Music Online, ed. por L. Macy (consultado 06-102007) <http://www.grovemusic.com>; Stevenson, Spanish Music in the Age of Columbus, p. 95.
${ }^{132}$ Bermudo, Libro primero, f. 94r. Además, Bermudo no incluye a Martínez ni a Espinosa en su lista de autoridades, como ha notado Robert Stevenson, aunque los cita en el cuerpo del texto; véase Robert Ste- venson, Juan Bermudo (La Haya: Martinus Nijhoff, 1960), p. 33: "En los ff. 85 y 94 de la Declaración de 1549 él [Bermudo] llama a otros dos predecesores hispanos a ser amonestados por sus errores: Juan de Espinosa y Juan Martínez. No se digna a incluir sus nombres en la lista de 'autoridades' del f. ++4v" ["At fols. 85 and 94 of the 1549 Declaración he calls two other predecessor Spaniards to book for their errors: Juan de Espinosa and Juan Martínez. He does not condescend to include either name in his list of 'author- ities' at fol. $\left.++4 v^{\prime \prime}\right]$.

${ }^{133}$ Roel del Río, Institucion harmonica, s.f., prólogo -nota; véase también p. 118. 
nización de los cantos de Montanos, comenzando con los himnos Veni Creator, Pange lingua, Ave Maris Stella y Regina Coeli. Montanos insertó cada himno en el contexto de la misa de la festividad: Veni creator en la misa De Spiritu Sancto, Pange lingua en la misa In festo Corporis Christi y Ave Maris Stella en la Missa In festo Assumptionis Virginis Maria. De las piezas incluidas en el libro de Montanos, Roel del Río únicamente omite Asperges me Domine (f. 13v), Vidi aquam (f. 14v) y la Missa Defunctorum (f. 55r). El propósito de Roel del Río es poner a disposición del usuario de su libro una colección de los cantos más útiles: las "Missas comunes que se cantan en los Choros de las Santas Iglesias", los himnos y las salves. ${ }^{134}$ Es interesante determinar qué piezas no tomadas del Arte de canto llano de Montanos introduce Roel del Río: la salve de Adviento Alma Redemptoris Mater (p. 123); Ave Regina Coelorum (p. 125); el alleluia (p. 182), el ofertorio (p. 183) y la comunión (p. 184) de la Missa Confesoris non Pontificis; y la Missa Commune non Virginum (p. 193).

El cotejo de las melodías impresas en 1594 por Montanos con las correspondientes publicadas por Roel del Río en 1748 muestra una serie de diferencias. En primer lugar, en el libro de Roel del Río se logra una mayor precisión en la colocación del texto con respecto a la música. En segundo lugar, en los cantos del libro de Roel del Río se produce un acortamiento de los melismas: los melismas sobre la palabra "Alleluia" de los cantos de 1594 se dividen en dos grupos de notas, en el segundo de los cuales se repite el texto "Alleluia". Por último, en el libro de Montanos las notas carecen de indicación de duración relativa (sería una muestra de la escuela "equalist" que distinguía Kathleen E. Nelson), mientras que Roel del Río utiliza plicas; Roel del Río afirmaba recoger las piezas del libro de Montanos “mejoradas en los acentos". La comparación entre los dos libros indica, no obstante, las escasas modificaciones de la línea melódica. El repertorio del Arte de canto llano de Montanos es reimpreso con muy pocas modificaciones por Roel del Río a mediados del siglo XVIII, lo cual pone en evidencia la vigencia del mismo. No sólo el repertorio, sino también el contenido didáctico de las artes de canto impresas en el siglo XVI tenía vigencia en el siglo XVIII, como muestran las reimpresiones del Arte de canto llano de Montanos preparadas por Sebastián López de

\footnotetext{
${ }^{134}$ Roel del Río, Institucion harmonica, p. 118.
} 
Velasco $(1635,1640,1643,1648,1665,1670,1686,1687 ?, 1693,1694,1727,1756)$ у Joseph de Torres $(1705,1712,1728,1734) .{ }^{135}$

\subsubsection{LIMITADA PRESENCIA DE AUTORIDADES}

El propósito didáctico de las artecillas de canto hacía prescindible la inclusión de controversias especulativas así como la cita de autoridades. ${ }^{136}$ Por ejemplo, una de las características fundamentales del Arte de canto llano de Juan Martínez es que, además de comenzar directamente con el primer capítulo sin ningún tipo de prefacio o dedicatoria, no contiene citas a otros teóricos; este último rasgo es también característico de El arte Tripharia de Juan Bermudo y del Arte de canto llano de Francisco Montanos. Es probable que la ausencia de citas de teóricos, con lo que ello supone para la simplificación de la exposición, contribuyera a que las artes de canto llano de Martínez y Montanos fuesen reimpresas durante un extenso período de tiempo (un siglo y un siglo y medio, respectivamente). Dámaso Artufel únicamente mencionaba a San Agustín, y lo hacía en el prólogo, no en el cuerpo del texto. Tampoco António Fernandes citaba a otros teóricos fuera del prólogo, y Juan de Espinosa sólo nombraba a Guido. En contraste, la obra más extensa de Pedro Thalesio presenta una lista de "teóricos y prácticos", quizás debido a que su libro tenía como destino un contexto universitario. ${ }^{137}$ No obstante, las citas de autoridades consisten, por lo general, en nombrar a los teóricos sin exponer o discutir sus ideas (véase Ilustración I.2), lo que supone una muestra más del uso de estas obras como "libros de texto" en las lecciones de música, como ha advertido José Augusto Alegria con respecto al Tractado de canto mensurable y contrapuncto de Mateo de Aranda:

[...] es indispensable tener presente que el pequeño tratado de canto mensurable es un manual de estudio que recoge lo esencial de la enseñanza impartida por su autor en la Canonjía de la Catedral de Évora, a partir de 1528. La prueba de que se trata de un libro auxiliar de estudio reside en el hecho de que Mateo de Aranda nunca cita en sus páginas una autoridad en la materia expuesta $[\ldots]$ No le interesó alardear de erudición y prefirió la enseñanza directa y personal [...]. ${ }^{138}$

\footnotetext{
${ }^{135}$ Véanse el Apéndice 1 y el Capítulo IV (Apartado 1.4).

${ }^{136}$ Véase Suzannah Clark y Elizabeth Eva Leach, eds., Citation and Authority in Medieval and Renaissance Musical Culture: Learning from the Learned (Woodbridge, Suffolk: Boydell Press, 2005).

${ }^{137}$ Véase el Capítulo IV.

${ }^{138}$ Alegria, "Introdução", p. 10: “[...] é indispensável ter presente que o pequeño tratado de Canto mensurável e um manual de estudo que recohe o essencial do ensino propinado pelo seu Autor na Claustra da Sé
} 


\section{Ilustración I.2: Juan Martínez (Ioão Martinz) es citado por Pedro Thalesio en su Arte de canto chão} (Coimbra: Diogo Gomez de Loureyro, 1618), p. 39. Lisboa, Biblioteca Nacional de Portugal, M. 428 P.

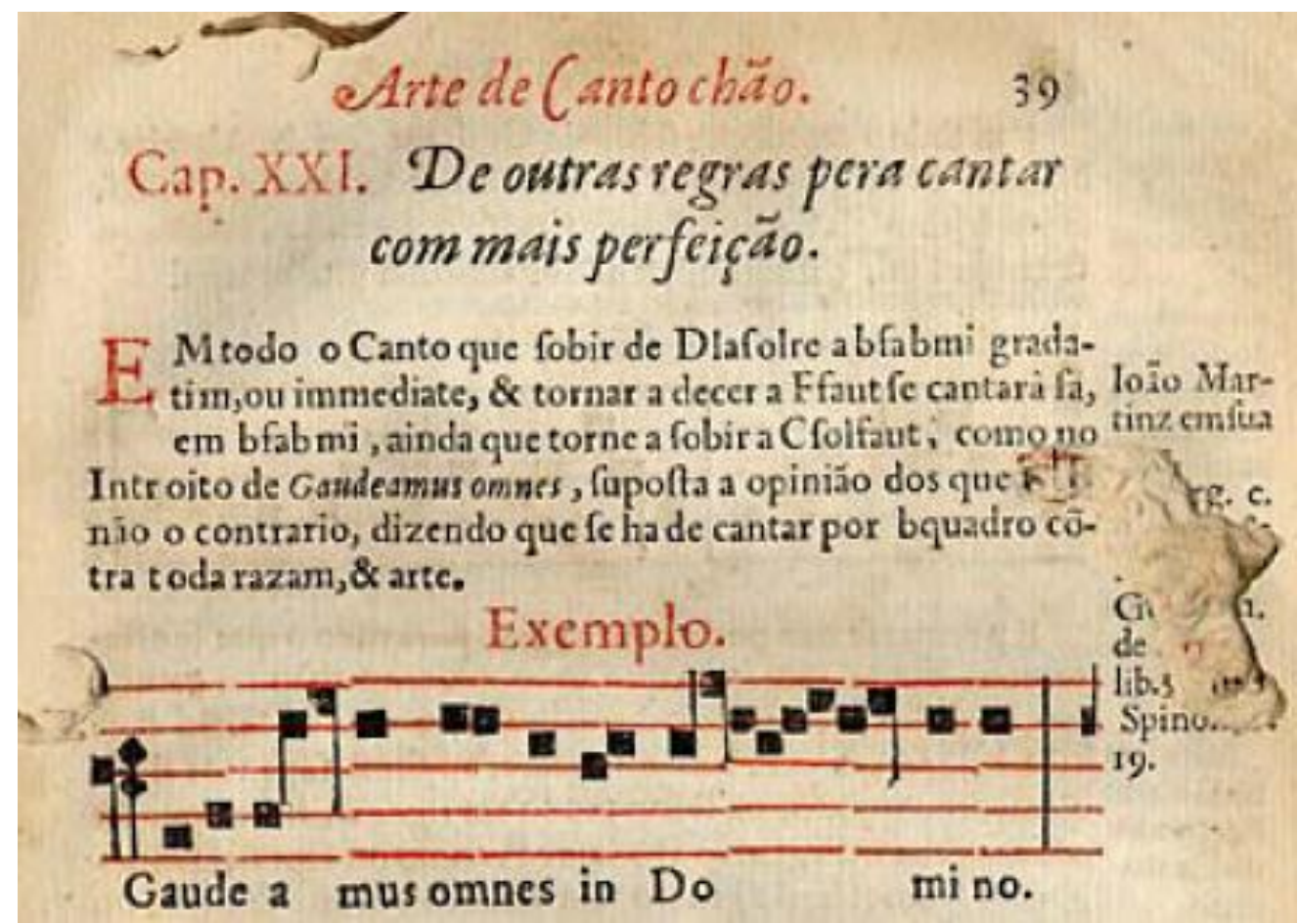

Aunque se ha considerado "práctica común del Renacimiento" citar únicamente las fuentes clásicas, "que son las que dan prestigio a una obra", ${ }^{139}$ en las artes de canto analizadas encontramos que, a partir de la segunda década del siglo XVI, y en concreto a partir de la publicación del Tractado de principios de musica practica e theorica (1520) de Espinosa, los autores de artes de canto citaban a los autores de libros del mismo género publicados previamente (véase Tabla I.2). Esto supone en ocasiones el posicionamiento en uno de los bandos de la polémica entre Espinosa y Martínez de Bizcargui. Por ejemplo, se ha sostenido que Gaspar de Aguilar y Mateo de Aranda se posicionaron a favor de Espinosa, ${ }^{140}$ mientras que Pedro de Loyola Guevara parece des-

de Évora, a partir de 1528. A prova de que se trata de livro auxiliar de estudo reside no facto de Mateus d'Aranda nunca citar nas suas páginas uma autoridade na materia exposta [...]. Não the interessou alardear erudição e preferiu o ensino directo e pessoal [...]".

${ }^{139}$ José Miguel Martínez Torrejón, "Prólogo”, en Cristóbal de Villalón, El scholástico (Barcelona: Crítica, 1997), p. xxxi.

${ }^{140}$ Alonso, Cuatro tratados de principios de canto llano, p. 67; Alegria, "Notícia bibliográfica", p. 60. 
aprobar las polémicas (“otros se andan tras el Monacordio, y la Vihuela, quebrandose las cabeças, escriuiendo vnos contra otros"). ${ }^{141}$ El elemento geográfico también desempeñó un papel importante en las citas a otros autores. Así, Juan Martínez es citado por casi todos los autores de artes de canto posteriores, pero son los autores que publicaron en Sevilla los que le mencionan reiteradamente: en el libro de Guevara "Iuan Martinez" aparece citado cinco veces y en el de Sebastián Vicente Villegas “Martinez” se menciona en seis ocasiones.

Tabla I.2: Citas a autores de artes de canto por parte de autores de este tipo de obras

\begin{tabular}{rll}
\hline Publicación & Autores de artes de canto citados \\
\hline 1492 & Marcos Durán & - \\
1496 & Escobar & - \\
c. 1500 & Spañón & - \\
1503 & Molina & - \\
1508 & Martínez de Bizcargui & - \\
1520 & Espinosa & Martínez de Bizcargui \\
c. 1521 & Espinosa & - \\
1530 & Martínez & - \\
1533 & Aranda & Espinosa \\
c. 1535 & Aguilar & Espinosa \\
1544 & Torres & - \\
1549 & Bermudo & Espinosa, Marcos Durán, Martínez, Martínez de Bizcargui \\
1550 & Bermudo & - \\
1565 & Villafranca & Bermudo, Espinosa, Martínez de Bizcargui, Torres \\
1572 & Artufel & - \\
1582 & Guevara & Martínez, Espinosa, Martínez de Bizcargui, Bermudo, \\
& & Villafranca, Torres \\
1594 & Montanos & - \\
1595 & Cervera & Marcos Durán, Martínez de Bizcargui, Martínez, Torres \\
1604 & Villegas & Bermudo, Cervera, Marcos Durán, Martínez, Martínez de \\
& & Bizcargui, Villafranca, Torres \\
1614 & Monserrate & Aranda, Bermudo, Espinosa, Marcos Durán, Martínez, \\
& & Martínez de Bizcargui, Montanos, Torres \\
1618 & Thalesio & Bermudo, Espinosa, Marcos Durán, Martínez, Martínez de \\
& & Bizcargui, Monserrate, Montanos, Torres \\
\hline 1626 & Fernandes & - \\
\hline & & \\
\hline
\end{tabular}

La coexistencia de autores antiguos, medievales y modernos entres las autoridades de las artes de canto renacentistas podría considerarse una muestra de modernidad. José Antonio Maravall opina que en el siglo XVI se apelaba a los autores contemporá-

\footnotetext{
${ }^{141}$ Guevara, Arte para componer canto llano, f. 7.
} 
neos junto con los anteriores "no como muestra de un admirable ejercicio de sobrepujamiento, sino como fuentes vivas, de aprovechamiento normal, en la formación del propio saber"; Maravall señala la música como "una materia en la que muy pronto se constituye un criterio favorable a los presentes". ${ }^{142}$

\subsubsection{LOS AUTORES Y SU CONEXIÓN CON LA ENSEÑANZA DE LA MÚSICA}

El Apéndice 4 contiene una tabla en la que se presentan los datos biográficos fundamentales sobre el ámbito profesional de los autores de las artes de canto estudiadas. De esos datos se pueden extraer dos conclusiones: 1) todos los autores son varones insertos en el contexto eclesiástico al menos en algún momento de su carrera; y 2) consecuentemente, ninguno se dedicó exclusivamente a la enseñanza en el ámbito universitario o a la docencia a título privado, sino que todos tenían un bagaje previo en el marco eclesiástico (véase Tabla I.3).

Tabla I.3: Distribución de los autores de artes de canto por ámbito profesional

\begin{tabular}{|c|c|}
\hline & Ámbito eclesiástico \\
\hline Cantores & $\begin{array}{l}\text { Artufel, Espinosa, ¿Fernandes?, Marcos Durán, } \\
\text { Martínez de Bizcargui, Puerto, Rodríguez, Villafranca, Villegas }\end{array}$ \\
\hline Ministriles & Espinosa \\
\hline Maestros de capilla & $\begin{array}{l}\text { Aranda, Brito, Castillo, Marcos Durán, ¿Martínez de Bizcargui?, } \\
\text { Mendes, Montanos, Thalesio, Torres }\end{array}$ \\
\hline "Maestros de la música" & Espinosa, Fernandes, ¿Monserrate?, Velez \\
\hline Maestros de los mozos de coro & Mendes, Martínez, Villafranca \\
\hline "Maestros de canto llano" & Villegas \\
\hline Compositores & $\begin{array}{l}\text { Aranda, Brito, Fr. João de Escobar, Mendes, Montanos, } \\
\text { Monserrate, Thalesio, Villegas }\end{array}$ \\
\hline Cargo no definido & Aguilar, ¿Cervera?, Molina \\
\hline No ocuparon un puesto musical & Bermudo \\
\hline
\end{tabular}

\section{Ámbito universitario}

Profesores Aranda, Thalesio

Estudiantes

¿Bermudo?, Castillo, ¿Escobar?, Espinosa, Marcos Durán, Molina, ¿Puerto?, Spañón, Villegas

${ }^{142}$ José Antonio Maravall, Antiguos y modernos: la idea de progreso en el desarrollo inicial de una sociedad (Madrid: Sociedad de Estudios y Publicaciones, 1966), p. 370. 


\section{Ámbito privado}

Al servicio de los cardenales Pedro González de Mendoza, Arzobispo de Toledo, y Diego Hurtado de Mendoza, Arzobispo de Sevilla

Espinosa

Al servicio de Fernando Ruiz de Castro, VI Conde de Lemos

Montanos

Al servicio del cardenal infante Henrique, Arzobispo de Évora desde 1575

Mendes

Puesto no definido

¿Cervera?

No es un dato sorprendente que todos los autores de artes de canto se inserten de alguna manera en un contexto religioso. ${ }^{143}$ Aunque de Alonso de Spañón sólo se conoce su condición de "bachiller", dedica su libro al arzobispo Fonseca, de lo que se deduce su vinculación con el ámbito religioso. Exceptuando el caso de Bermudo y tal vez el de Guevara, tenemos noticia de que todos los autores ocuparon un puesto relacionado con la música. Respecto a Guevara, Robert Stevenson señala que, aunque Francisco López Capillas mencione a Guevara como su predecesor en el cargo de maestro de capilla de la Catedral de Ciudad de México, en los documentos catedralicios no se encuentran referencias que lo confirmen. ${ }^{144}$

Es curioso que, quizás debido a las fuentes conservadas, los autores de artes de canto hayan pasado a los anales de la historia como teóricos y no como compositores, a pesar de los indicios acerca del prestigio que algunos tuvieron en el ámbito de la composición. Por ejemplo, en el Palacio Episcopal de Murcia existe un manuscrito (signatura A-4/8) de 1844 que contiene las siguientes composiciones de Andrés de Monserrate: "Regem praecursoris Dominum" de quinto tono a cuatro voces, "Regem apostolorum Dominum" de undécimo tono para coro de cuatro voces, y "Christum regem adoremos" de tercer tono para dos coros. En el manuscrito SP 26 del Archivo de la Catedral de Palma de Mallorca, datado entre 1651 y 1700, se encuentra otra composición de Monse-

\footnotetext{
${ }^{143}$ León Tello, "La teoría de la música de Tomás de Santa María", p. 91: "Desde el punto de vista sociológico, al comprobar la biografía de los tratadistas españoles de este período se advierte que pertenecen a una orden religiosa, están adscritos bien a una catedral u otro tipo de templos o al servicio de las Casas Reales o nobiliarias".

${ }^{144}$ Robert Stevenson, "Rumbos de la investigación sobre música colonial latinoamericana", Revista musical chilena, XXX/134 (1976), pp. 5-8, p. 6. Véanse también Leshter D. Brothers, "Musical Learning in Seventeenth-Century Mexico: The Case of Francisco López Capillas", Revista de Musicología, XVI/5 (1993), pp. 2814-2834, p. 2820; y Marín López, “Música y músicos entre dos mundos”, vol. 1, p. 202.
} 
rrate: la pieza para tres coros "Ay que mi niño llora" de undécimo tono. También se conserva una obra musical de Monserrate en el manuscrito Mus.ms. 2926 de la Bayerische Staatsbibliothek de Munich, datado hacia 1680: "El ave la planta", para dos coros. ${ }^{145}$ Contamos con obras de Estêvão de Brito, ${ }^{146}$ y sabemos de la existencia de motetes y de 31 villancicos de Navidad compuestos por él en la biblioteca de música del rey João IV de Portugal; tanto esa música de Brito como su tratado desaparecieron en el terremoto de Lisboa de $1775 .{ }^{147}$ También se conservan composiciones de Mateo de Aranda, Gaspar de Aguilar, Juan Bermudo, Juan de Espinosa y Pedro Thalesio. Otro compositor considerado principalmente como teórico es Francisco de Montanos, cuyo caso se tratará en detalle en el Capítulo V. Manuel Mendes, por el contrario, es conocido como polifonista, aunque es posible que, de haberse conservado su tratado Arte de música mencionado en el inventario de la biblioteca de João IV de Portugal, hubiera sido también catalogado como tratadista. ${ }^{148}$

\footnotetext{
${ }^{145}$ La información sobre las composiciones de Monserrate en el Palacio Episcopal de Murcia, la Catedral de Palma de Mallorca y la Bayerische Staatsbibliothek de Munich ha sido extraída del "Online Catalogue of Musical Sources" de RISM <http://www.rism.info/en/home.html>.
}

${ }^{146}$ Se conserva un Officium defunctorum, 9 psalmos, 25 motetes y tres lamentaciones; véanse Rui Cabral, "Brito, Estêvão de", en Die Musik in Geschichte und Gegenwart: allgemeine Enzyklopädie der Musik, ed. por Ludwig Finscher (Kassel: Bärenreiter, 1994-2007), vol. 3 (2000), cols. 915-916; y Estêvão de Brito, Estêvão de Brito: Obras diversa, trad. por Miquel Querol i Gavaldà (Lisboa: Fundação Calouste Gulbenkian, 1976).

${ }^{147}$ Primeira parte do Index da Livraria de mvsica, pp. 136 y 246-248. Además de la edición que hizo de este catálogo Joaquim de Vasconcellos (Oporto: Imprensa Portugueza, 1874), véase su Ensaio crítico sobre o catálogo d'El-Rey D. João IV (Oporto: Imprensa Portuguesa, 1873), así como Francisco Marques de Sousa Viterbo, A livraria de música de D. João IV e o seu index (Lisboa: Typographia da Academia Real das Sciencias, 1900 [1865]), y A Livraria Real especialmente no reinado de D. Manuel: memoria apresentada à Academia Real das Sciências de Lisboa (Lisboa: Typ. da Academia, 1901); Mário de Sampaio Ribeiro, Livraria de Música de el-Rei D. João IV. Estudo musical, histórico e bibliográfico (Lisboa: Academia Portuguesa da História, 1967), 2 vols.; Manuel Carlos de Brito, Estudos de história da música em Portugal (Lisboa: Estampa, 1989); Rui Vieira Nery, The Music Manuscripts in the Library of King D. Joaõ IV of Portugal (1604-1656): A Study of Iberian Music Repertoire in the Sixteenth and Seventeenth Centuries (Ann Arbor, Michigan: University of Michigan Press, Dissertation Information Service, 1992); y Calvin Elliker, "Reconstruction of the Printed Music in the Library of João IV", Midwest Note-book, I/1 (1992), pp. 9-11.

${ }^{148}$ De las obras de Mendes se han conservado dos misas (Missa Ferialis y Missa Pro Defunctis), Asperges me a 8, y un Alleluia a 4; véanse Stevenson, Renaissance and Baroque Musical Sources in the Americas, p. 209; Mário de Sampaio Ribeiro, Sete Alleluias inéditos (dum códice do Mosteiro de Arouca) (Oporto: Tip. Porto Médico, 1949), pp. 20-21; y João Pedro d'Alvarenga, "Manuscript Évora, Biblioteca Pública, Cód. CLI/1-3: Its Origin and Contents, and the Stemmata of Late-Sixteenth- and EarlySeventeenth-Century Portuguese Sources", Anuario musical, LXVI (2011), pp. 137-158. En el catálogo de la biblioteca de música de João IV se hace referencia a los siguientes motetes de Mendes: Doleo super te a 5 (p. 458), Peeccauia a 5 (p. 459), Responde mihi a 8 (p. 389), Tu est Petus a 6 (p. 466) y Ductus est Jesus a 5 (p. 455). En la biblioteca de João IV también aparecen composiciones perdidas de Fr. João de Escobar: Missas con huma de diffunctus, Liçoens, \& Salmo de Completas a 8 a 12 y a 16 ( $\left.\mathrm{n}^{\circ} 567\right)$; y 
Es interesante constatar la vinculación de algunos autores de artes de canto a la universidad y al ámbito privado. De la biografía de Cristóbal Escobar no poseemos datos, pero se ha señalado que quizás fuese bachiller de la Universidad de Salamanca. ${ }^{149}$ La Sumula de canto de organo de Domingo Marcos Durán fue mandada imprimir por Alfonso de Castilla, Rector del Estudio de Salamanca. Como cantor del Colegio de San Bartolomé de Salamanca, Diego del Puerto tenía relación también con el ámbito universitario. Juan Bermudo también estuvo vinculado a la universidad, puesto que había estudiado música en las clases de matemáticas de la Universidad de Alcalá de Henares; ${ }^{150}$ además, en El arte Tripharia se incluye una carta de "Francisco Ceruantes de Salazar", catedrático de retórica de la Universidad de Osuna, en la que éste hablaba de su amistad con Bermudo. Mateo de Aranda y Pedro Thalesio fueron catedráticos de música de la Universidad de Coimbra.

De la vinculación de los autores de artes de canto con el ámbito de la docencia privada existen menos indicios. Únicamente Cervera y Montanos dedican sus libros a figuras no relacionadas con el ámbito eclesiástico: Felipe III y los VI Condes de Lemos, respectivamente. Sobre Cervera sólo se sabe, por datos que el propio autor aportaba en su libro, que enseñó canto en Zaragoza y Valencia, pero ignoramos en qué contexto. Montanos trabajó como maestro de capilla para Fernando Ruiz de Castro, VI Conde de Lemos, en Galicia; aunque es difícil determinar si enseñó música a la familia de su patrón, la evidencia sugiere, como se estudiará en el Capítulo $\mathrm{V}$, una vinculación de su Arte de canto llano con el contexto gallego. La conexión de algunos autores a la universidad y al ámbito docente privado desmentiría la consideración de las artes de canto como un producto dirigido exclusivamente a "sacristanes de Aldea". 151

Mottetes, ou Modulorum a 5 y a 6, libro 1 ( $\mathrm{n}^{\mathrm{o}}$ 36). Ribeiro, Livraria de Música de el-Rei D. João IV, vol. 1, p. 83, menciona asimismo la publicación de una colección de motetes de Escobar en Lisboa en 1620. Otro teórico de quién también había música en la biblioteca de João IV es Pedro Thalesio: en el apartado "Cançoens" se hace referencia a "Varias cousas de Pedro Talesio, \& outros. a 4. 5. 6. \& mais vozes" $\left(n^{\circ}\right.$ 478) y al motete a 8 Iam de somno (p. 456). Se conservan tres salmos de Thalesio en el Libro de Coro 11 de Vila Viçosa, Fundação da Casa de Brangança, Biblioteca do Paço Ducal, Arquivo Musical.

\footnotetext{
${ }^{149}$ Martín Galán, "Escobar, Cristóbal de”, p. 718.

150 Juan Bermudo, Comiença el libro llamado declaracion de instrumentos musicales [a partir de ahora Declaración de instrumentos] (Osuna: Juan de León, 1555), f. 1r.

${ }^{151}$ Cerone, El Melopeo y Maestro, p. 337.
} 


\section{POSICIÓN HISTORIOGRÁFICA DE LAS ARTES DE CANTO IMPRESAS EN EL MUNDO IBÉRICO: LOS OTROS LIBROS DE MÚSICA}

Aunque el estudio de la historia de la música en España durante el siglo XVI se ha centrado en las "grandes instituciones", quedan muchos aspectos sin investigar en este ámbito. ${ }^{152}$ Las artes de canto han sufrido un olvido historiográfico, quizás por considerarse "cosa de poca sustancia" a pesar de haber emanado de autores cuyo espacio profesional se situaba en las principales catedrales y universidades de la Península. ${ }^{153}$ Esta omisión podría vincularse en general a las peculiaridades de la imprenta española en lo referente al formato: "en estas primeras batallas de impresos a escala europea, España y Portugal, grandes consumidores de pliegos sueltos, pero modestos productores de libros, no hicieron un papel de protagonistas, a pesar de su posición hegemónica en el mundo contemporáneo". ${ }^{154}$ La hipótesis fundamental de María Sanhuesa en su estudio de las artes de canto llano del siglo XVII usadas con fines didácticos por órdenes religiosas es que las artecillas fueron "muy despreciadas", probablemente por transmitir una "ideología didáctica y/o religioso-política". ${ }^{155}$ Mário de Sampaio Ribeiro señala que, quizás por su pequeño formato y su elevado consumo, estos libros fuesen tratados con poco aprecio material (lo que no implica desprecio intelectual). ${ }^{156}$ En este apartado estudiaré el corpus de ideas que pudieron determinar la recepción e historiografía de las artes de canto.

\footnotetext{
${ }^{152}$ Véase, por ejemplo, John Griffiths y Javier Suárez Pajares, eds., Politicas y prácticas musicales en el mundo de Felipe II. Estudios sobre la música en España, sus instituciones y sus territorios en la segunda mitad del siglo XVI (Madrid: ICCMU, 2004), p. 9.

${ }^{153}$ En la licencia de la Inquisición firmada por Francisco de Meneses y Ioão Aluares Brandão para la edición portuguesa de 1614 del Arte de canto llano de Juan Martínez, se advierte que estos libros no suponen ningún peligro por "ser cousa de pouca substancia".

${ }^{154}$ Lafaye, Albores de la imprenta, p. 19.

${ }^{155}$ Sanhuesa Fonseca, "Artes de canto llano en las órdenes religiosas españolas del siglo XVII", p. 278. Esta idea ya aparecía en María Sanhuesa Fonseca, "El tratado Falsas practicables para músicos (manuscrito, 1651) de Jayme de Ciervo", Revista de Musicología, XIX/1-2 (1996), pp. 329-353, p. 330: "Pero el pensamiento musical del XVII no sólo se plasmó en grandes tratados -en las distintas acepciones del término-, sino que vino a reflejarse en las muy despreciadas 'artecillas' de canto llano y canto de órgano, breves prontuarios con carácter de compendio, sin espíritu enciclopédico y de utilidad práctica inmediata $[\ldots] "$.

${ }^{156}$ Ribeiro, A "Arte de Cantollano", de autor desconhecido, p. 21.
} 
A juzgar por la influencia que se ha atribuido a Cerone como historiador, ${ }^{157}$ podría pensarse que la indiferencia que han sufrido las artes de canto tiene su origen en $E l$ Melopeo y Maestro. Sin embargo, encontramos invectivas a las artes de canto en escritos anteriores, incluso de los propios autores de las mismas, como Pedro de Loyola Guevara y Juan Bermudo. Paradójicamente, en el Arte para componer canto llano (1582) de Guevara se culpa a los autores de "artecillas" de los "hierros y faltas que agora ay":

[...] y los que mas an dañado, son los que an escripto tantas Artezillas, que no a quedado nadie que no se a puesto a escreuir lo que se le à antojado. Y pueden lo bien hazer, porque quando no se entendieren ay esta el remedio de la prima regla a la quinta, que no les puede faltar. Estas Artezillas, en parte es affrenta sufrirlas, porque an hecho mucho daño, y an sido causa de tanta confusion como vemos, y se auia de poner remedio para que no se imprimiessen sin corregirlas, y enmendarlas. ${ }^{158}$

Este fragmento evidencia un menosprecio hacia las artes de canto, pero también pone de manifiesto la pronta y casi incontrolable difusión de las mismas ("se auia de poner remedio para que no se imprimiessen sin corregirlas, y enmendarlas"). No sólo es paradójico encontrar una crítica a las artes de canto dentro de un arte de canto, sino que también ésta suponga responsabilizar a los propios autores de los errores que se estaban produciendo en el canto cuando, como se comentará en el Capítulo IV, uno de los usos de estos manuales fue el evitar tales errores.

Dejando a un lado la acusación de Pedro de Loyola Guevara, las críticas contemporáneas a las artes de canto aludían a dos cuestiones íntimamente relacionadas: 1) contenían únicamente cuestiones prácticas, lo que se consideraba insuficiente para que uno pudiera convertirse en "músico"; y 2) eran breves en extremo, carentes de claridad $\mathrm{y}$, consecuentemente, ineficaces desde el punto de vista pedagógico para que un principiante aprendiera canto usando este producto. Críticas del primer tipo aparecen en $\mathrm{Co}$ -

\footnotetext{
${ }^{157}$ Enrique Alberto Arias sostiene que la musicología en su forma moderna empezó con los grandes tratados sistemáticos de inicios del XVII, siendo el primero el de Pietro Cerone. Véase Enrique Alberto Arias, "Cerone as Historian", Anuario musical, LVIII (2003), pp. 87-110. Sobre la posición historiográfica ocupada por Cerone, véase Robert Stevenson, "Pedro Cerone (1566-1625): Imposter or Defender of the Faith", Inter-American Music Review, XVI/1 (1997), pp. 1-27.

${ }^{158}$ Guevara, Arte para componer canto llano, ff. 6v-7r.
} 
miença el libro llamado declaracion de instrumentos musicales (Osuna, 1555) de Juan Bermudo cuando éste mencionaba a "Bizcargui y otros barbaros":

Si pensays, que basta auer leydo a Bizcargui y a otros barbaros para ser theoricos: es engaño. Guido compara el musico practico al pregonero, y el theorico al corregidor. Para que el pregonero haga bien su officio, no puede dezir mas, ni menos de lo que manda el corregidor $[\ldots] .{ }^{159}$

Si nos basamos en el testimonio de Bermudo, percibimos que la repulsa a las artes de canto es consecuencia del conocido y permanente menosprecio al músico práctico porque sólo el teórico es verdaderamente "músico". Paradójicamente, Bermudo había publicado cinco años antes El arte Tripharia, donde expresaba su decisión de "quitar toda sophisteria" y escribir "tres artezicas breues" con el propósito de que "en breue tiempo" se pudiera formar una monja. ${ }^{160}$ En la Declaración de instrumentos (1555), Bermudo animaba a sus lectores a que mirasen "los quatro tractados primeros del libro sexto, donde escriuo contra quatorze artes de canto, y lo que dexe de decir en mis libros, mouido y occasionado de lo que las dichas artes dizen: copiosamente tracte". ${ }^{161}$ Sin embargo, este libro sexto anunciado en el prólogo y en la tabla de contenidos no se incluye en el libro impreso. ${ }^{162}$ Más de un siglo después, Andrés Lorente se lamentaba de la necesidad de fundamentar científicamente, a través de la teoría, los conocimientos musicales:

[...] muchos (aun los que se tienen por mas doctos en ella) tratando solo de la Practica, dando de mano a lo cientifico de la Teorica, quando ven algo escrito que no entienden, luego al punto lo reprueban, no aguardando la razon para conuencerse en las cosas que hazen fuera de Arte: estos tales han estudiado la Musica materialmente, y muy de passo. Adviertan, pues, que para saber la

\footnotetext{
${ }^{159}$ Bermudo, Declaración de instrumentos, f. 68r.

${ }^{160}$ Véase el Capítulo V.

${ }^{161}$ Bermudo, Declaración de instrumentos, s.f., "Prologo segundo para el piadoso lector".

${ }^{162}$ Bermudo, Declaración de instrumentos, s.f., "Cathalogo de los libros contenidos en el presente volumen, y de que tracta cada vno dellos": "En el sexto libro copile algunos errores de Musica, de los que en esta facultad escriuieron en nuestro materno lenguaje, y suficientemente los confute, y enseñe la verdad y lo diuido por tractados, y contiene quatro: en fin de los quales hago otros dos, en el vno hablo de los generos de Musica, y en otro pongo el modo de tañer mis instrumentos, y ay cosas nueuas en todos seys tractados: especialmente de affinacion de los instrumentos".
} 
Musica con fundamento, y de raiz, es necessario gastar mucho tiempo en ella. No se adquiere esta Ciencia en breve tiempo (como algunos piensan) $[\ldots] .{ }^{163}$

El testimonio de Lorente alude específicamente a la insuficiencia de la práctica y a la imposibilidad de aprender música en poco tiempo. Cerone se sitúa en los dos frentes de ataque y su concepción se puede sintetizar del siguiente modo: 1) elegancia no es sinónimo de brevedad, sino de "brevedad y claridad", por lo que no hay que escatimar en palabras en beneficio de la transparencia; 2) los principiantes no pueden entender las artecillas españolas porque parecen destinadas a entendidos en música; y 3) aunque para los principiantes la extrema prolijidad tampoco es apropiada, para "ser deueras Musico" hay que acudir a los largos tratados teóricos. Cerone señalaba que no escribía su obra "como pratico ordinario, el qual escriue breue y sucintamente, sino como quien tracta y discure [sic] en largo". ${ }^{164}$ Por tanto, detrás de las críticas contemporáneas a las artes de canto se encuentra sin duda la controversia en torno al verdadero músico (el teórico) frente al siervo de la música (el práctico), como indicaba la metáfora del corregidor y el pregonero citada por Bermudo. La música como ciencia no se podía aprender en poco tiempo, de ahí que las artes de canto, según sus críticos, no sirvieran para convertirse en músico.

El estudio del canto gregoriano desde una perspectiva científica iniciado por la escuela de Solesmes en 1889 supuso una infravaloración de los tratados de canto llano. En un apartado de su introducción a la Paléographie musicale titulado "Les traités de musique et les manuscrits notés; leur importance respective au point de vue de la restauration archéologique du chant", Dom André Mocquereau distingue tres categorías de fuentes para restaurar el canto gregoriano: 1) "los textos musicales o manuscritos con notación musical"; 2) "los tratados de la Edad Media"; y 3) "las obras de los Padres, liturgistas, gramáticos latinos; las crónicas de iglesias y monasterios, etc.". ${ }^{165}$ Las artes

\footnotetext{
${ }^{163}$ Andrés Lorente, El porque de la musica: en que se contiene los quatro artes de ella, canto llano, canto de organo, contrapunto y composicion, y en cada uno de ellos nuevas reglas... tocantes a la Harmonia Musica (Alcalá de Henares: en la Imprenta de Nicolas de Xamares, 1672), s.f., "Epistola recomendatoria de la presente Obra, para los que desean saber la Ciencia de la Musica, y para los Maestros que la enseñan".

${ }^{164}$ Cerone, El Melopeo y Maestro, p. 2.

165 Dom André Mocquereau, "Introduction générale”, en Paléographie musicale (Solesmes: Imprimerie de St. Pierre, 1889), vol. 1, pp. 3-50, p. 18. Véase también Katherine Bergeron, "A Life of Chants", en
} 
de canto no se mencionan y parecen incluirse en la tercera categoría, que queda completamente descartada “como la menos útil” para la restauración del canto gregoriano. ${ }^{166}$ Según Mocquereau, los tratados medievales no constituyen fuentes legítimas para estudiar el canto gregoriano puesto que implican la especulación del historiador (lo que Mocquereau llama "fantasie"); son los manuscritos de música notada las únicas fuentes fiables para llevar a cabo esta investigación:

Estos monumentos tienen, sobre los tratados de música, la ventaja inapreciable para el arqueólogo de ser la primera materia de sus investigaciones. En sí mismos contienen todo lo que queremos saber sobre la versión, la modalidad, el ritmo y la notación de las melodías eclesiásticas. No son la exposición de los principios del canto, pero los contienen substancialmente y la teoría y la práctica; no son los maestros antiguos de los que querríamos entender las enseñanzas, sino que son la traducción por escrito de lo que estos maestros enseñan y ejecutan y hablan, para quienes saben leer y comprender esta escritura, la expresión más perfecta de las cantilenas litúrgicas $[\ldots]$. $^{167}$

La revalorización de las artes de canto que propongo conllevaría, por tanto, reexaminar también su interés como fuentes para el estudio de la interpretación musical del canto gregoriano, tema que no abordaré en esta Tesis Doctoral. Es curioso constatar, sin embargo, cómo desde el comienzo de la investigación moderna sobre el canto llano a finales del siglo XIX en la Abadía de Solesmes, los tratados utilizados para enseñarlo han sido relegados, por lo que no es extraño que durante el siglo XX no hayan recibido la atención que merecen.

Es sorprendente notar que el mismo debate que encontrábamos en los escritos de Cerone y Lorente se desprende de la reprobación de las artes de canto en los estudios de historia de la música y no sólo en los escritos de la época. Una interesante crítica de la

Disciplining Music. Musicology and Its Canons, ed. por Katherine Bergeron y Philip V. Bohlman (Chicago y Londres: University of Chicago Press, 1992), pp. 182-196.

${ }^{166}$ Mocquereau, "Introduction générale", p. 18: "Il faut d'abord écarter, comme la moins utile, la troisième catégorie de monuments".

167 Mocquereau, "Introduction générale”, p. 23: "Ces monuments ont, sur les traités de musique, l'avantage inappréciable pour l'archéologue d'être la matière première de ses recherches. En eux-mêmes ils renferment tout ce que nous voulons savoir sur la version, sur la modalité, sur le rythme \& la notation des mélodies ecclésiastiques. Ils ne sont pas l'exposé des principes du chant, mais ils en contiennent substantiellement \& la théorie \& y la pratique; ils ne sont pas les anciens maîtres dont nous voudrions entendre les enseignements, mais ils sont la traduction par l'écriture de ce que ces maîtres enseignaient \& exécutaient, \& partant, pour qui sait lire \& comprendre cette écriture, l'expression la plus parfaite des cantilènes liturgiques $[\ldots]$ ”. 
cual han sido objeto los autores de artes de canto en la bibliografía es su condición de aficionados y en ella subyace la consideración de que el músico era el teórico y no el práctico. Por ejemplo, Samuel Rubio señala que los autores de artes de canto "no eran auténticos profesionales del arte musical, sino meros aficionados y hasta autodidactas, a excepción, claro es, de Montanos"; y apunta que estos libros "fueron escritos no por grandes músicos, sino por meros cantollanistas, clérigos todos ellos, sin pretensiones especulativas". ${ }^{168}$ Rubio parece seguir a Cerone cuando señala que algunas de las artes de canto "son tan breves que no alcanzamos a comprender su utilidad"; y opina que, por sus características, estos libros "parecen desconectados de la realidad" y "son ajenos al ambiente musical en el que viven y operan". ${ }^{169}$

Wolfgang Freis, en un controvertido artículo en el que trata de desmitificar la imagen de Bermudo como "príncipe de la teoría musical" y le acusa sin pruebas de falsificar la carta de Cristóbal de Morales que aparece en su tratado, afirma que Bermudo no poseía una gran formación musical, no practicó la música profesionalmente y no era un teórico, sino un estudioso de la ciencia de la música para contribuir a la comunidad cristiana. ${ }^{170}$ Aunque Bermudo declaraba haberse "abscondido y criado desde los quinze años en la obseruancia de la religion franciscana, donde no ay exercicio de la Musica" y que la música no era su profesión, también afirmaba haber estudiado música en las clases de matemáticas de la Universidad de Alcalá de Henares. ${ }^{171}$ Además, la licencia firmada por Frater Gómez de Llanos impresa en el Libro primero (1549) sugiere que

\footnotetext{
${ }^{168}$ Rubio, Historia de la música española 2, pp. 251-252 y 247.

${ }^{169}$ Rubio, Historia de la música española 2, pp. 251-252.

${ }^{170}$ Wolfgang Freis, "Becoming a Theorist: The Growth of The Bermudo's Declaración de instrumentos musicales", Revista de Musicología, XVIII/1-2 (1995), pp. 27-112, en particular, p. 34: "as far as can be gathered from his three publications, music did not play an important role in it [his education]. In fact, it is not even clear whether he ever received any substantial practical training in music. He never counts himself among the professionals and actually never states explicitly that he even played the instruments he discusses in his treatises"; p. 39: "Due to the lack of any data that would evidence a professional involvement in music, one can call Bermudo nothing but essentially an amateur"; y p. 40: "As Bermudo put it himself, as a member of a religious community he felt obligated to occupy himself in some manner according to his vows and for the benefit of the Order; and, not being able to continue as superior of his convent, it does not surprise that he devoted his time studying the science of music". Según RosFábregas, "Historiografía de la música en las catedrales españolas. Positivismo y nacionalismo en la investigación musicológica", p. 90, nota 28, "aunque Freis afirma en sus conclusiones que no es su intención devaluar la figura de Bermudo, describirle como un amateur y fraile provinciano con poca instrucción musical, y justificar la hipotética falsificación de la carta de Morales -comparando esta acción con el plagio que Martín Tapia hizo de la propia obra de Bermudo- resulta desafortunado".
}

${ }^{171}$ Bermudo, Declaración de instrumentos, s.f., "Prologo segundo para el piadoso lector", y f. 1r. 
Bermudo era conocido en su época por su talento musical: "Siendo yo assaz informado de muy singulares y eminentes varones en la sciencia y arte de la Musica, de la especial gracia y talento que de nuestro señor aueys, padre, en esta facultad recebido, y que teneys compuestos tres libros de mucha vtilidad [...]". La desmitificación de la figura de Bermudo por parte de Freis basada en la idea de que su relación con la música no era "profesional" muestra cómo se trata de desvincular a Bermudo, como un Otro, de la corriente principal de una historia de la música basada en compositores y teóricos profesionales.

El énfasis en la práctica y la minimización de la especulación medieval que caracterizaban a las artes de canto constituyen indicios de modernidad. Curiosamente, en el Vergel de musica (1570) -en uno de los pasajes no plagiados del Libro primero (1549) de Bermudo- Martín de Tapia manifestaba estar "engastando, como cosa nueva, la theorica en la pratica", algo que desde la mentalidad actual de los derechos de autor podría considerarse como un ejercicio de cinismo por parte del plagiador. ${ }^{172}$ Sin embargo, también debe tenerse en cuenta que el deseo de Tapia por "engastar" o encajar "la teoría en la práctica" respondía a una nueva demanda ("cosa nueva") de su tiempo. La referencia de Tapia a Justino y Lucio Floro como autores de resúmenes (epítomes) de obras clásicas extensas de Trogo Pompeyo y Tito Livio, respectivamente, le sirve no sólo para ensalzar la "brevedad" como cualidad de su época ("somos en nuestro tiempo tan amigos de brevedad"), sino también para presentar su propio tratado, como epítome, "sacado y tomado de graves, varios y diversos doctores antiquísimos y modernos":

...y assimesmo son tantos y tan prolixos los libros que estan escritos, y cada dia se escriben, que Mathusalen no bastaba para los pasar, siquiera como de corrida, a cuya causa Iustino epitomo la historia larga de Trogo Pompeyo, y Lucio Floro la del suauissimo Tito Liuio, porque en este poco tiempo que viuimos tubiesemos lugar de ver y pasar alguna cosa que fuese prouechosa para nuestra correccion, y sustentacion spiritual de nuestra anima; y paresceme que no es poco acertado segun somos en nuestro tiempo, tan amigos de breuedad.

Esto, pues, incito y mouio mi voluntad a que epitomase y sumasse este breue tratado sacado y tomado de graues, varios y diuersos doctores antiquisimos y modernos que larga y diffusamente la materia de musica trataban, y assimesmo he mudado en romance (con sufficiente declaracion) todo aquello que a los cantores (y aun tañedores) podia seruir y aprouechar engastando (como cosa nueua) la theorica en la pratica [El énfasis es mío]. ${ }^{173}$

\footnotetext{
172 Tapia, Vergel de musica, f. $3 r$.

173 Tapia, Vergel de musica, ff. 2v-3r. Tapia distinguía dos categorías de consumidores de su libro: los cantores "que desean canto llano, canto de organo y contrapuncto, cuyas tres artes van faciles y abreuiadas para quien en suma verdadera las quisiere", y aquellos que desean ser "musicos consumados", a quienes dirigía "las theoricas sobre canto llano y de organo" (f. 8r).
} 
La brevedad, más que causa de la ineficacia pedagógica del producto, es muestra de su utilidad didáctica como "libro de texto" y complemento de las explicaciones del maestro. Zarlino afirmaba en Le istitutioni harmoniche (Venecia, 1558) que el saber de los libros era insuficiente, aunque los valoraba. ${ }^{174}$ La brevedad también era una muestra de la actualidad del producto, puesto que satisfacía la demanda a la que hacían referencia varios textos de la época. Además, la proliferación de estos manuales breves y por tanto de bajo coste indica la amplia difusión y accesibilidad de la música en España, lo que contrasta con la idea de Cerone:

[...] vemos que en España muy pocos son los Caualleros que gustan saber Musica, antes muchos la aborecen, y desechan, y destierran de sus casas, como cosa vil, vituperosa, y dañosa: y parece ser inuentada solo para los Ecclesiasticos y Religiosos [...]. ${ }^{175}$

La brevedad y el contenido eminentemente práctico de las artes de canto han sido también alabados en la bibliografía. Por ejemplo, Marcelino Menéndez y Pelayo consideró estos libritos como una reacción contra los "indigestos libros especulativos":

\begin{abstract}
Por fortuna, y como reacción y contrapeso a estos indigestos libros especulativos, que ni eran de Música ni de Matemáticas, erizados con aquellos hórridos términos de Diapente y Diatessaron, los cantores y músicos prácticos, los organistas y maestros de capilla, comenzaron a imprimir ciertos epítomes o cartillas, casi enteramente libres (como advierte el matemático Pedro Ciruelo) de la influencia de la música especulativa: cuadernos puramente prácticos, sumas de canto llano y canto de órgano. ${ }^{176}$
\end{abstract}

La profusión de libros breves de música práctica ha sido utilizada como evidencia del importante papel que desempeñó la música en la sociedad española renacentista no sólo por Francisco A. Barbieri en su conocido discurso de $1874,{ }^{177}$ sino también por Guillermo Furlong Cardiff, Francisco José León Tello y Carlos Romero de Lecea:

\footnotetext{
${ }^{174}$ Judd, Reading Renaissance Music Theory, p. 181.

${ }^{175}$ Cerone, El Melopeo y Maestro, p. 9.

${ }^{176}$ Menéndez y Pelayo, Historia de las ideas estéticas en España, vol. 2, p. 945. En el mismo sentido, Carmen Rodríguez Suso, "Gonzalo Martínez de Bizcargui, y la música práctica”, p. 32, considera que los libros destinados "al uso práctico de los músicos de oficio" pertenecían a "una línea más avanzada" que aquéllos que prolongaban la especulación medieval.

${ }^{177}$ Francisco Asenjo Barbieri, "Discurso leído en la Academia de Bellas Artes de San Fernando en la sesión pública y extraordinaria del día 10 de mayo de 1874 para solemnizar la agregación de la sección de música, por el Excmo. Sr. D. Francisco Asenjo Barbieri académico de número", en Francisco Asenjo
} 
[Portus musice] Viene a ratificarnos en aquellas características expuestas en la Introducción a los Viejos Libros de Música, de que en los mencionados siglos hispanos nuestra patria era un pueblo cantor. Por ello, junto a los tratados teóricos de notorio nivel científico, innovadores de preceptos y normas, como en el caso de Bartolomé Ramos de Pareja, surgen a su lado y gozan de amplia audiencia a otros niveles más populares el sumario elemental y el humilde vademécum, en los que se desarrollan los principios musicales vigentes en aquellos tiempos [...]. ${ }^{178}$

El análisis de las características de las artes de canto españolas presentado en la primera parte de este Capítulo desvela que éstas no son fruto de un aislamiento cultural, sino la manifestación de un fenómeno general. Rafael Mitjana afirmaba erróneamente que el fenómeno de los tratados en lengua vernácula se dio exclusivamente en España y era prueba de la "independencia del arte español". ${ }^{179}$ Carlos José Gosálvez Lara señala respecto a los cinco tratados de música impresos en España en el siglo XV que la mayoría son "de gran brevedad y escritos en lengua vernácula, característica de nuestra imprenta nacional que contrasta con las prácticas seguidas en otros países". ${ }^{180}$ Encontramos, sin embargo, tratados de música impresos en Italia en lengua vernácula en el siglo XV, como el Tractato vulgare di canto figurato (Milán, 1492) de Francesco Caza, un resumen traducido al italiano de Musices practicabilis libellus (escrito hacia 1480), que se convertiría en el segundo libro de Practica musicae (1496) de Gaffurio; y Breviloquium musicale (Brescia, 1497) de Bonaventura da Brescia, con los títulos en latín y el texto en italiano.

Algunos trabajos indican que la proliferación de la tratadística española de contenido práctico tuvo lugar en un momento "en que el intercambio musical entre Italia y

Barbieri. 2. Escritos, ed. por Emilio Casares Rodicio (Madrid: ICCMU, 1994), pp. 324-339. Una crítica al discurso de Barbieri basándose en datos históricos y no en los estéticos puede verse en F. Adolpho Coelho, Bibliographia critica de Historia e Litteratura (Oporto: Impr. Litterario-Commercial, 18731875), vol. 2, no 57.

${ }^{178}$ Romero de Lecea, "Palabras previas", en Juan José Rey Marcos, Portus Musicae de Diego de Puerto: introducción, comentario y traducción (Madrid: Joyas bibliográficas, 1978), pp. 11-12. Véanse también Guillermo Fúrlong Cardiff, Músicos argentinos durante la dominación hispánica (Buenos Aires: Huarpes, 1945), p. 19; y León Tello, Estudios de historia de la teoría musical, p. ix.

${ }^{179}$ Rafael Mitjana, Historia de la música española (Madrid: INAEM, Centro de Documentación Musical, 1993 [1920]), p. 59.

${ }^{180}$ Carlos José Gosálvez Lara, La edición musical española hasta 1936 (Madrid: Asociación Española de Documentación Musical, 1995), p. 19. Los cinco tratados de música a los que hace referencia Gosálvez Lara son Lux bella (1492) y Comento sobre Lux bella (1498) de Domingo Marcos Durán; Ars musicorum (1495) de Guillermo de Podio; Introduccion muy util e breve de canto llano (datado por Gosálvez Lara en 1498) de Alonso Spañón; e Introduction muy breue de canto llano (c. 1498) de Cristóbal Escobar. 
España se incrementó notablemente", y que fue "en el ámbito de los contactos con el mundo italiano" donde surgieron algunos de estos libros prácticos. ${ }^{181}$ La publicación en Roma (1553) y Venecia (1558 y 1561) de Introduttione facilissima, \& nouissima de canto Fermo de Vicente Lusitano, teórico y compositor probablemente nacido en Olivenza (Badajoz), ejemplifica esta conexión. Este libro, que estaba dedicado a Marc Antonio Colonna, Duque de Marsi, fue incluso traducido al portugués por Bernardo da Fonseca en 1603 en Lisboa, versión que no llegó a imprimirse. ${ }^{182}$ Otro caso interesante que muestra el transnacionalismo de las artes de canto es el ejemplar de Compendiolo di molti dvbbi, segreti et sentenze intorno al canto fermo et figvrato, da molti eccellenti \& consumati musici dichiarate (Milán, c. 1545) de Pietro Aaron que se conserva en la Biblioteca de Reserva de la Universitat de Barcelona, puesto que perteneció a la Congregación de la Misión de Barcelona. ${ }^{183}$

El Apéndice 5 presenta un listado de 121 libros similares a las artes de canto publicados en Alemania, Francia, Inglaterra e Italia en el mismo período (entre 1492 y

\footnotetext{
${ }^{181}$ Antonio Moreno, "La teoría musical antigua en el Renacimiento español: introducción al estudio de la tradición textual", en Fuentes Musicales en la Península Ibérica (ca. 1250-1550), ed. por Maricarmen Gómez y Màrius Bernadó (Lleida: Universitat de Lleida-Institut d'Estudis Ilerdencs, 2001), pp. 339-358, p. 346. Más recientemente, María Gembero ha llamado la atención acerca de la abundancia de compositores y de impresos italianos que llegaban al Nuevo Mundo, lo que contrasta con cualquier visión de aislamiento cultural nacionalista; véase Gembero Ustárroz, "Circulación de libros de música entre España y América (1492-1650)", p. 155. Emilio Ros-Fábregas ha enfatizado en sus trabajos las consecuencias del rechazo de la musicología española a "estudiar y reconocer el relevante papel de la música y de los músicos foráneos en nuestro país": "la visión que actualmente se tiene de la vida musical en la España del siglo XVI no sólo es incompleta, fragmentada y en gran parte aislacionista, sino a todas luces contradictoria"; véase Emilio Ros-Fábregas, "Música y músicos extranjeros en la España del siglos XVI", en La Capilla Real de los Austrias: música y ritual de Corte en la Europa moderna, ed. por Juan José Carreras y Bernardo J. García García (Madrid: Fundación Carlos de Amberes, 2001), pp. 101-126, p. 101, donde se analiza la historiografía musical española desde el siglo XIX y se estudia la presencia de música y músicos extranjeros en la España del siglo XVI. Ros-Fábregas, "Historiografía de la música en las catedrales españolas", estudia la influencia del nacionalismo y sus consecuencias en la historia de la música en las catedrales españolas. También en el ámbito divulgativo, Juan Goytisolo ha criticado los estudios sobre la España medieval y renacentista por haber rechazado "el influjo 'contaminador' de los elementos y factores juzgados 'alógenos"; véase Juan Goytisolo, "Historiadores y mitólogos", El País (31-011996), p. 1.
}

${ }^{182}$ Robert Stevenson, "Vicente Lusitano: New Light on His Career", Journal of the American Musicological Society, XV/1 (1962), pp. 72-77, p. 72. Véanse también Maria Augusta Alves Barbosa, Vicentius Lusitanus: ein Portugiesischer Komponist und Musiktheortiker des 16. Jahrhunderts (Lisboa: Secretaria de Estado da Cultura, Direcção Geral do Património Cultural, 1977); y Philippe Canguilhem y Alexander Stalarow, "Singing upon the Book According to Vicente Lusitano", Early Music History, 30 (2011), pp. $55-103$.

${ }^{183}$ Se trata de un volumen en cuarto con la signatura 07 XVI-1767-1, encuadernado en pergamino con cintas, que contiene el libro de Pietro Aaron (38 folios) junto a otras dos obras. En la portada encontramos la siguiente anotación: "Congregationy Missiony Barcelona". 
1626); el listado se ha llevado a cabo a partir de un vaciado en RISM. ${ }^{184}$ Los libros incluidos en este Apéndice tratan de los fundamentos del lenguaje musical (no se han incluido libros que tratan exclusivamente sobre instrumentos o danza) y cumplen los siguientes criterios: formato en cuarto u octavo y contenido eminentemente práctico. Este vaciado de manuales publicados en el contexto internacional muestra que, sobre todo en Italia, pero también en Francia, Alemania e Inglaterra, se encuentran libros de similares características a las de las artes de canto españolas de la época, como por ejemplo Scala di musica molto necessaria per principianti (Venecia, 1585) de Orazio Scaletta, Instruction pour apprendre à chanter à quatre parties, selon le plain-chant, les pseaumes et cantiques (Caen, 1582) de Bénédic Macé, Ein Kurtz deudsche Musica (Wittenberg, 1528) de Martin Agricola, y A Briefe Introduction to the Skill of Song (Londres, 1596) de William Bathe. ${ }^{185}$ Además, de las palabras de Juan Bermudo en El arte Tripharia deducimos que en España había conciencia de que el énfasis en la práctica no era exclusivo ni de los libros de música, ni de los libros españoles:

Querria de esta arte de Musica, quitar toda sophisteria como lo ha hecho el estudiosissimo y muy curioso padre fray Francisco Titelman en la logica y phisica, y el doctissimo padre fray Luys de Caruajal, guardian de sanct francisco en seuilla en la theulogia, y como ya lo hazen todos los doctos en lo que scriuen. ${ }^{186}$

Puesto que la utilización de fuentes clásicas aparece en la historiografía como la principal característica del humanismo, ${ }^{187}$ tratadistas como Ramos de Pareja y Salinas

${ }^{184}$ Lesure, dir., Écrits imprimés concernant la musique.

185 Sobre el ultimo, véase Jeremy Smith, Thomas East and Music Publishing in Renaissance England (Oxford: Oxford University Press, 2003).

${ }^{186}$ Bermudo, El arte Tripharia, f. A4v.

${ }^{187}$ Claude V. Palisca, Humanism in Italian Renaissance Musical Thought (New Haven y Londres: Yale University Press, 1985); James Haar, "Humanism", Grove Music Online. Oxford Music Online, 15 octubre $2008<$ http://www.oxfordmusiconline.com/subscriber/article/grove/music/40601>.

Sobre el reflejo del humanismo en los libros de vihuela, véase Sage, “A New Look at Humanism”, p. 633; acerca del lugar ocupado por la música en el pensamiento humanista, véanse Luis Robledo Estaire, "La música en el pensamiento humanista español", Revista de Musicología, XXI/2 (1998), pp. 385-430; y "El lugar de la música en la educación del príncipe humanista", en Música y literatura en la España de la Edad Media y del Renacimiento, coord. por Virginie Dumanoir (Madrid: Casa de Velázquez, 2003), pp. 1-19. Véanse también Miquel Querol i Gavaldà, "El humanismo musical de la escuela sevillana del Renacimiento", Anuario musical, XXXI-XXXII (1976-1977), pp. 51-64; y "El humanismo musical español", Nassarre, IV/1-2 (1988), pp. 213-225, que supone un estudio del humanismo en la escuela sevillana basado en la problemática de la unión de música y poesía. Véase también Paloma Otaola, "Las fuentes en el De musica libri septem de Francisco Salinas (1577)”, en Fuentes Musicales en la Península Ibérica (ca. 
se han vinculado a este movimiento intelectual, mientras que se ha señalado que la "incidencia de la tradición clásica" en las artes de canto es "extremadamente escasa". ${ }^{188}$ Las artes de canto no estuvieron desconectadas de la realidad y eran reflejo del humanismo por varios motivos. Daban respuesta a una demanda popular motivada por la difusión de la alfabetización y por la mayor accesibilidad a estos productos consecuencia del desarrollo de la imprenta. Obviamente, las artes de canto allanaban el camino para saber cantar, algo recomendado en los tratados de educación de la época. Sánchez de Arévalo presentaba "el cordial, alegre e artifiçioso exerçiçio de melodias e modulaçiones musicales, las cuales alegran e esfuerçan al coraçon humano exçitandole a actos de virtud" como uno de los tres "deleytes e honestos exerçiçios en que los inclitos Reyes e Prinçipes, e los nobles e virtuosos varones se pueden e deuen honestamente exerçitar e occupar". ${ }^{189}$ Baldassarre Castiglione explicaba en el décimo capítulo de $I l$ libro del Cortegiano "cómo al perfecto Cortesano le pertenece ser músico, así en saber cantar y entender el arte, como en tañer diversos instrumentos" y enfatizaba que al cortesano le "conviene la música, no sólo por un ornamento bueno, mas de pura necesidad". 190

Algunos de los autores de artes de canto, como Domingo Marcos Durán, debieron de relacionarse con humanistas de la época, a juzgar por las dedicatorias de sus tratados. ${ }^{191}$ Las artes de canto contienen en ocasiones discursos apologéticos de la música con referencias a la Antigüedad clásica en los documentos preliminares, como por

1250-1550), ed. por Maricarmen Gómez y Màrius Bernadó (Lleida: Universitat de Lleida-Institut d'Estudis Ilerdencs, 2001), pp. 359-384.

\footnotetext{
${ }^{188}$ Moreno, "La teoría musical antigua en el Renacimiento español”, p. 346. Según León Tello, "Significación del Renacimiento en la música española del siglo XVI", Boletín de la Real Academia de Bellas Artes de San Fernando, 86 (1998), pp. 355-378, p. 361, además de los tratados antiguos, "el nexo que une la antigüedad y la edad media no fue otro que el canto gregoriano", éste nos queda como "un testimonio vivo de la música de la antigüedad". El libro que prepara Louise K. Stein, Humanism and Anti-Humanism in Spanish Musical Theory and Practice, aportará nuevas reflexiones aplicables al estudio de la influencia humanista en España.

${ }^{189}$ Sánchez de Arévalo, Verjel de los principes, p. 15.

${ }^{190}$ Baldassarre Castiglione, El cortesano (Madrid: Espasa Calpe, 1967 [1528]), pp. 68 y 71.

${ }^{191}$ Domingo Marcos Durán dedicó sus tratados a Domingo Jiménez de Préjamo $(† 1495)$ y Alfonso de Fonseca (†1534). Véanse María José Vega, ed., Comento sobre Lux Bella, introd. de María José Vega y Álvaro Zaldívar (Cáceres: Institución Cultural "El Brocense", 1998), p. 12; y María Pilar Barrios Manzano, "Domingo Marcos Durán. Un teórico musical extremeño del Renacimiento. Estado de la cuestión", Revista de Musicología, XXII/1 (1999), pp. 91-128, p. 94
} 
ejemplo el soneto hasta ahora desconocido de Lope de Vega que aparece en el Arte y suma de canto llano (1595) de Cervera, y las referencias a la Antigüedad en algunos de los catorce poemas que se incluyen en el Arte de musica theorica y pratica de Montanos firmados por Jerónimo de Lomas Cantoral (2 sonetos), el licenciado Neyra, el licenciado Miguel Sanchez, don Francisco de la Cueba, Christobal Maço de la Madriz, el licenciado Pedro Salgado de Ribadeneyra, Bernardo Prego, el licenciado Iuan Ortiz, Fernelio Huraneo y Alonso Bezerra. La mayor parte de las artes de canto contiene ejemplos musicales que se vinculan con los "exempla" de la tratadística clásica. En las autoridades citadas en las artes de canto se produce una fusión de tradición medieval y pensamiento moderno, como, por ejemplo, la coexistencia de autoridades de teóricos medievales con autores contemporáneos, y la conjunción de un contenido medieval (el canto gregoriano) con la búsqueda del "nuevo estilo breve". ${ }^{192}$

La utilización de la lengua vernácula es otra característica de las artes de canto relacionada con el humanismo. El humanismo conllevó el rechazo de la lengua vernácula y el gusto por un lenguaje latinizante. El latín era la lengua de la ciencia y de las universidades; por ejemplo, José Luis Abellán indica que los Estatutos de la Universidad de Salamanca de 1538 prohibían a los estudiantes que cantasen acompañándose de la guitarra canciones que no fueran en latín o en griego. ${ }^{193}$ Simultáneamente, una de las características del Renacimiento fue la aparición de tendencias nacionalistas que contribuyeron al desarrollo de las lenguas vernáculas; además, se ha destacado el papel que desempeñó la literatura religiosa en la consolidación de la lengua vernácula. ${ }^{194}$ En el ámbito musical, Leofranc Holford-Strevens señala que el humanismo requería que la música fuese explicada en un lenguaje digno de un arte liberal y que este requisito no lo cumplía el latín de finales de la Edad Media, de forma que finalmente se impusieron las lenguas vernáculas, y añade: “como en otros proyectos, el humanismo, habiendo purga-

192 Paloma Otaola, La pensée musicale espagnole à la Renaissance. Héritage antique et tradition médiévale (Barcelona: Tritó, 2008), p. 10, ha indicado que el humanismo musical español presenta ciertas particularidades con respecto al italiano o el francés, siendo la principal la alianza de la tradición medieval con el pensamiento moderno.

193 Abellán, Historia crítica del pensamiento español II, pp. 165-166: "Por eso el latín era también la lengua de las Universidades, entendiendo por ello no sólo que fuese la lengua de la cátedra, sino también la impuesta en los claustros a los estudiantes, a quienes se prohibía entonar a la guitarra las canciones de que tanto gustaban, a menos que fuera en latín o en griego. Así lo establecen, por ejemplo, los estatutos de la Universidad de Salamanca de 1538, norma que mantienen todavía en 1561”.

${ }^{194}$ Abellán, Historia crítica del pensamiento español II, pp. 165-166. 
do y vestido al Latín de su miseria gótica, elevó las diferentes lenguas vernáculas para competir con él; ahora encontramos tratados musicales en italiano, español, francés, holandés, alemán, inglés y escocés". 195

Por último, el género libresco de las artes de canto se relaciona significativamente con los conceptos neoplatónicos de "luz" e "iluminar" por ser en esencia conjuntos de reglas "objetivas" frente a lo especulativo. Por ejemplo, Artufel manifestaba que “el arte es la guía y la luz", y encontramos títulos de tratados con alusiones expresas a la luz, tales como Lux bella y Lux videntis. ${ }^{196}$ El concepto de luz unido a las artes de canto no es exclusivo del mundo ibérico, como muestran, por ejemplo, los manuales publicados en Venecia por Aiguino (Illuminato) da Brescia, La Illuminata de tutti $i$ tuoni di canto Fermo (1562) y Il tesoro illuminato di tutti i tuoni di canto figurato (1581). El filósofo italiano Eugenio Garin señala que fue en el Renacimiento cuando se configuró la imagen de las "tinieblas medievales" y, en su arte de canto, Guevara hablaba del pasado en estos términos: "Antes parece que lo que se a escripto a sido causa de mayor confusion, y para mas escurecerlo". 197

Siguiendo la metodología de los historiadores del libro, en este Capítulo se ha llevado a cabo un estudio de las características físicas de las artes de canto, lo cual ha servido como punto de partida para una reflexión acerca de la posición historiográfica ocupada por esta tipología libresca. El siguiente paso consistirá en analizar la producción de las artes de canto, su circulación y mercado potencial, para arrojar luz sobre el grado de integración de la música en la vida cotidiana del mundo ibérico renacentista.

\footnotetext{
${ }^{195}$ Holford-Strevens, Leofranc. "Humanism and the Language of Music Treatises", Renaissance Studies, XV/4 (2001), pp. 415-449, p. 445: "As in other endeavours, humanism, having cleansed and clothed Latin from its Gothic squalor, elevated the various vernaculars to compete with it; we now find musical treatises in Italian, Spanish, French, Dutch, German, English, and Scots".

${ }^{196}$ Artufel, Modo de rezar las horas canonicas, f. 3r.

197 Eugenio Garin, La revolución cultural del Renacimiento (Barcelona: Crítica, 1981 [1967]), p. 41; Guevara, Arte para componer canto llano, f. A4v.
} 


\section{RESUMEN DEL CAPÍTULO I}

La Parte I de esta Tesis Doctoral consta de cuatro capítulos en los que llevo a cabo un estudio de las artes de canto en lengua vernácula impresas en España y Portugal entre 1492 y 1626 siguiendo la metodología de los historiadores del libro. El Capítulo I presenta el resultado de un estudio completo de las artes de canto publicadas en el mundo ibérico renacentista. Como se aprecia en el Apéndice 1, que contiene un listado de las artes de canto estudiadas con todas las ediciones, la ubicación de los ejemplares conocidos y sus características físicas, en esta investigación se incluyen artes de canto no mencionadas en RISM, ediciones desconocidas hasta el momento y ejemplares a los que no se había hecho referencia en la bibliografía previa; véase también el Apéndice 2, que presenta las portadas y el índice de contenidos de las artes de canto estudiadas. Tras la delimitación del objeto de estudio, en el Capítulo I se examinan en detalle las características de las artes de canto como tipología libresca, estableciendo un paralelismo con la literatura de cordel y la "bibliothèque bleue", mostrando el contraste entre sus aspectos medievales y renacentistas, y destacando la relevancia de las artes de canto como el primer libro que se utilizaba para aprender música en general (no sólo el canto gregoriano). Este análisis sirve para revalorizar unos libros de música que hasta ahora han sido infravalorados por la historiografía musical.

El análisis de las características de las artes de canto que se lleva a cabo en la primera parte del Capítulo I refleja que estos libros respondían a un fenómeno general e internacional: 1) la búsqueda de brevedad, anunciada ya desde el título en buena parte de las artes de canto, y la necesidad de optimizar el tiempo de aprendizaje se asocian con un cambio cultural en relación a la concepción que se tenía del tiempo en aquella época; 2) las artes de canto muestran una orientación hacia la enseñanza de la práctica musical y no hacia la especulación teórica; 3) ocasionalmente, las artes de canto incluyen entre su material preliminar poemas apologéticos con referencias a la Antigüedad clásica; por ejemplo, en el libro de Cervera aparece un soneto desconocido hasta ahora de Lope de Vega; 4) las artes de canto se relacionan con los conceptos neoplatónicos de luz e iluminar, al igual que tratados musicales publicados en el contexto italiano; 5) las artes de canto respondían a un fenómeno internacional, puesto que existían pequeños tratados musicales similares en lengua vernácula publicados en Italia y otros países desde el siglo XV; véase el Apéndice 5 que presenta los resultados de un vaciado en RISM de libros similares a las artes de canto publicados en Alemania, Francia, Inglaterra e Italia entre 1492 y 1626 ; y 6) el tradicionalismo atribuido a las artes de canto es un resultado de su propósito didáctico (el Apéndice 4 muestra que casi todos los autores se insertaban en el contexto profesional de la docencia de la música) y causa de que estos libros fuesen reimpresos durante siglos sin apenas cambios, o como una base a la que añadir nuevos contenidos y repertorio. Por ejemplo, Antonio Ventura Roel del Río utilizó en su Institucion harmonica de 1748 los cantos para practicar que había recopilado Francisco de Montanos en su Arte de canto llano de 1594; en el Apéndice 3 se cotejan ambas versiones: Roel del Río mantiene la línea melódica prácticamente sin cambios, divide en dos partes algunos melismas y logra una mayor precisión en la indicación de la duración que en la versión de Montanos.

En la segunda parte del Capítulo I se pone en evidencia que la fusión de un contenido de herencia medieval (aunque se establecen diferencias entre las artes de canto y los tonarios medievales) y características nuevas (pequeño formato, brevedad, prioridad de la práctica, uso de lenguas vernáculas) ha determinado la recepción de las artes de 
canto y su posición historiográfica. La "alteridad" que representan estas artes de canto se debe al hecho de haber sido discriminadas hasta ahora, por dos causas principales: su pequeño formato en el marco de una historia de la teoría musical basada en libros en formato folio, y su brevedad y contenido eminentemente práctico en el contexto de una tradición que consideraba músico únicamente al teórico y una historia de la música basada en teóricos y, sobre todo, en compositores. Encontramos invectivas contra las artes de canto por parte de los propios autores de los libros de este tipo publicados en España, como Guevara y Bermudo. Varios autores publicaron un libro ambicioso de contenido teórico-práctico y, poco después (en contra de su propio criterio), publicaron un libro más breve, de menor alcance temático (dedicado casi siempre únicamente al canto llano) y enfoque totalmente práctico; como ejemplo de estas parejas de libros se pueden citar: Espinosa con Tractado de principios de musica practica e theorica (1520) y Tractado breue de principios de canto llano (c. 1521); Bermudo con el Libro primero (1549) y El arte Tripharia (1550); Guevara con De la verdad (antes de 1582) y Arte para componer canto llano (1582); y Montanos con Arte de musica theorica y pratica (1592) y Arte de canto llano (1594). Esto muestra una respuesta a la demanda de pequeños tratados para aprender los fundamentos de la música. Las artes de canto, en particular las de canto llano, raramente presentaban innovaciones en su contenido, por lo que no han sido suficientemente valoradas y han pasado generalmente inadvertidas en la bibliografía musicológica. Curiosamente, los rasgos considerados en la época como propios de un nuevo estilo (principalmente la brevedad y el énfasis en la práctica) son los que aparecen criticados tanto en los textos de su época como en la bibliografía musicológica del siglo XX. 


\section{CAPÍTULO II \\ ARTES DE CANTO: \\ PRODUCCIÓN, DISTRIBUCIÓN, MERCADO}

Los estudios que relacionan la imprenta de artes de canto en España con el comercio del libro en general son inexistentes, con la excepción del trabajo de Tess Knighton sobre el mercado de las artes de canto en Zaragoza. ${ }^{1}$ El comercio de libros con repertorio musical ha recibido mayor atención, sobre todo el de aquéllos que surgieron en el contexto italiano; un ejemplo es el trabajo Music Printing in Renaissance Venice de Jane Bernstein, que presenta un estudio socioeconómico en el que la transmisión de música se entiende principalmente como un fenómeno comercial. ${ }^{2}$ El propósito de este Capítulo es, siguiendo la metodología de los historiadores del libro, analizar la producción, distribución y consumo de las artes de canto como un producto comercial para determinar en qué medida la formación musical básica era accesible en la vida cotidiana del mundo ibérico renacentista.

Los libros de música en español no se mencionan en las primeras historias de la música a nivel europeo, donde sólo se cita a Bartolomé Ramos de Pareja y a Francisco Salinas, que eligieron el latín. ${ }^{3}$ Es una muestra más de una teoría de la música construida con volúmenes de gran formato (como advertía Jessie Ann Owens) y en latín a los

\footnotetext{
${ }^{1}$ Knighton, "Libros de canto".

${ }^{2}$ Bernstein, Music Printing in Renaissance Venice; véase también Tim Carter, "Music-Selling in Late Sixteenth-Century Florence: The Bookshop of Pîero di Giuliano Morosi", Music \& Letters, LXX/4 (1989), pp. 483-504.

${ }^{3}$ John Hawkins, A General History of the Science and Practice of Music (Londres: Printed for T. Payne and son, 1776); Charles Burney, A General History of Music, from the Earliest Ages to the Present Period. To Which is Prefixed, a Dissertation on the Music of the Ancients (Londres: Printed for the author, 1776-1789), 4 vols.; y Hugo Riemann, Catechism of Musical History. Second Part: History of Musical Forms with Biographical Notices of the Most Illustrious Composers (Londres: Augener \& Co; Nueva York: G. Schirmer, 1892).
} 
que muy pocos podían acceder y entender. ${ }^{4}$ Sin embargo, según Robert Stevenson, los tratados en lengua vernácula tienen una ventaja: "son testigo de la cultura musical tal y como era y no de la cultura ideal de los sabios". 5 La principal tesis de este Capítulo es que, debido a que tenían un precio inferior al de los libros de vihuela y las "artes de tañer" y por tanto personas de bajo poder adquisitivo podían acceder a ellas, las artes de canto han pasado inadvertidas como contribuidoras al incremento y la difusión de la competencia musical en grupos sociales hasta entonces excluidos del aprendizaje de la música.

\section{LA PRODUCCIÓN}

Como indica Roger Chartier, "los autores no escriben los libros, sino que éstos son objetos que requieren de numerosas intervenciones". ${ }^{6}$ Por ejemplo, una de las hipótesis de Jane Alden en Songs, Scribes, and Society es que el papel de los copistas en la construcción del repertorio de la chanson fue mayor que el de los mecenas y los compositores. ${ }^{7}$ En esta sección se analizarán las gestiones que debían realizarse desde que el autor de un arte de canto elaboraba un manuscrito que sirviera como modelo hasta que éste llegaba a la imprenta, así como los aspectos técnicos que afectaron a la impresión de las artes de canto, el tamaño de las tiradas, los motivos de las reediciones y las conexiones que se produjeron entre sus impresores.

\subsection{El proceso de publicación}

Desde que el autor elaboraba un modelo manuscrito de su libro hasta que éste llegaba a la imprenta tenían lugar una serie de trámites, a menudo bastante costosos en cuanto a tiempo y dinero. Los principales estadios del proceso de publicación de un libro en la época, aunque variaban según la legislación vigente en la fecha concreta,

\footnotetext{
${ }^{4}$ Owens, "You Can Tell a Book by Its Cover", p. 378.

${ }^{5}$ Stevenson, Spanish Music in the Age of Columbus, p. 50: "They bear witness to music culture as it existed, not the ideal culture of savants".

${ }^{6}$ Chartier, Cultura escrita, literatura e historia, p. 10.

${ }^{7}$ Alden, Songs, Scribes, and Society, pp. 137-166.
} 
eran los siguientes: 1) obtención de licencia real; 2) aprobación de la Inquisición; 3) obtención del privilegio; 4) obtención de una licencia eclesiástica expedida por el Vicario General del Obispado (requisito necesario únicamente en algunas diócesis); 5) búsqueda de patrocinadores, en ocasiones a cambio de la dedicatoria del libro, lo que suponía el envío de una copia manuscrita al posible patrocinador, quien, si accedía, enviaba dinero al autor para que iniciara la impresión; 6) búsqueda de una imprenta que tuviera los tipos necesarios; 7) estipulación entre autor e impresor del papel y los tipos que se iban a utilizar, el tamaño del libro y el de la plana, el precio de la impresión y el tamaño de la tirada; y 8) corrección de las pruebas de imprenta. ${ }^{8}$ Este laborioso y costoso procedimiento hizo que algunos autores desistieran, ${ }^{9}$ por lo que encontramos manuscritos preparados para la imprenta que, sin embargo, no llegaron a imprimirse. ${ }^{10}$ Tenemos también noticia de otros libros para cuya impresión se obtuvo el debido privilegio real pero de los que, si finalmente fueron impresos, no se ha conservado ningún ejemplar. Dos ejemplos de este caso son el Tratado de canto chão e cimco cordas e de huma e de camto dorguão e contra ponto de Francisco Velez, sucesor de Mateo de Aranda en el maestrazgo de capilla de la Canonjía de la Catedral de Évora, ${ }^{11}$ del que sólo se conserva el privilegio, firmado en Lisboa en la chancillería de D. Sebastião el 8 de marzo de 1563; y el Arte de musica de reformação e perfeição do cantochão e de toda a musica cantada e tangida de João Rodrigues que obtuvo una licencia de impresión por diez años firmada por D. Sebastião en $1576 .^{12}$

\footnotetext{
${ }^{8}$ Agustín González de Amezúa y Mayo, Cómo se hacía un libro en nuestro Siglo de Oro (Madrid: Magisterio Español, 1946); Fermín de los Reyes Gómez, El libro en España y América: legislación y censura, siglos XV-XVIII (Madrid: Akal, 2000), 2 vols.; Luis Iglesias, "El maestro de capilla Diego de Bruceña”.

${ }^{9}$ Véase Alejandro Luis Iglesias, "Manuscritos e impresos con polifonía en la catedral de Palencia (15351633)", en Actas del II Congreso de Historia de Palencia, 27, 28 y 29 de abril de 1989, coord. por María Valentina Calleja González (Palencia: Diputación Provincial de Palencia, 1990), vol. 5, pp. 293-304, p. 304.

${ }^{10}$ Sobre los casos de Cesare Negri y Juan Ruiz de Robledo, véase María Sanhuesa Fonseca, "Manuscritos teóricos del siglo XVII español. Las letras y las voces", en Estudios sobre el barroco musical hispánico: en torno a la figura del Dr. Miguel Querol, coord. por Antonio Ezquerro, Marc Heilbron Ferrer y Luis Antonio González Marín (Barcelona: CSIC, Departamento de Musicología, Institución Milá y Fontanals, 2006), pp. 169-181, p. 178.

${ }^{11}$ Alegria, "Introdução", p. 9; e História da escola de música da Sé de Évora, p. 32.

${ }^{12}$ Nelson, “Music Treatises and 'artes para tanger' in Portugal Before the 18th Century”, p. 201.
} 


\subsubsection{LA BÚSQUEDA DE FINANCIACIÓN, AUTORIDAD Y DIFUSIÓN:}

\section{MECENAS Y DEDICATARIOS}

Como consecuencia de la importante inversión inicial que suponía la edición de un libro, buena parte de los autores buscaron un mecenas que financiara la edición y a quien, como muestra de agradecimiento, pudieran dedicar su libro. Como ha señalado Jaime Moll, el mecenas y el dedicatario no coincidían en todos los casos, puesto que se dieron otras modalidades de financiación: 1) el propio autor podía financiar su obra, independientemente o con ayuda de otra persona; ${ }^{13}$ 2) si el autor pertenecía a una orden religiosa, ésta podía afrontar los gastos de edición; y 3) el impresor/editor en ocasiones tomaba la iniciativa para editar una obra y corría con los costes.

La financiación de la publicación de libros por parte del editor/impresor es una modalidad particularmente interesante en el caso de las artes de canto. Jane Bernstein sugiere que los libros de música con propósito didáctico (como las artes de canto) fueron probablemente iniciativa del impresor/editor debido a la popularidad de este género y su consecuente comerciabilidad. ${ }^{14}$ Bernstein establece distintos tipos de acuerdos financieros a los que podía llegar el impresor: producción independiente, asociación y obra patrocinada (el impresor publicaba la obra por un dinero fijado sin riesgo financiero en la publicación). Por ejemplo, fue la impresora María Ramírez quien solicitó licencia para reimprimir en 1598 el Arte de canto llano (Sevilla, 1530) de Juan Martínez en Alcalá de Henares, lo que muestra la popularidad del libro y su éxito editorial. ${ }^{15}$ Las reimpresiones del Arte de canto llano (1594) de Francisco de Montanos nos servirán como un estudio de caso (véase Tabla II.1).

\footnotetext{
${ }^{13}$ Jaime Moll, "Para el estudio de la edición española del Siglo de Oro", en Livres et libraires en Espagne et au Portugal (XVIe-XXe siècles). Actes du Colloque Internacional de Bordeaux (25-27 avril 1986) (París: Éditions du Centre Nacional de la Recherche Scientifique, 1989), pp. 15-25, p. 17.

${ }^{14}$ Jane A. Bernstein, "Financial Arrangements and the Role of Printer and Composer in SixteenthCentury Italian Music Printing", Acta Musicologica, LXIII/1 (1991), pp. 39-56, p. 40.

${ }^{15}$ Encontramos la licencia impresa al final del único ejemplar conocido (incompleto) de esta edición del libro de Juan Martínez, que se encuentra en Madrid, Biblioteca Nacional de España, M/850. La licencia está firmada por Gonçalo de la Vega. Sobre la impresora María Ramírez, véase el Capítulo VI.
} 
Tabla II.1: Licencias, pagadores y dedicatarios de las reimpresiones consultadas del Arte de canto llano (Valladolid, 1594) de Francisco de Montanos

\begin{tabular}{|c|c|c|c|}
\hline Edición & $\begin{array}{l}\text { Tenedor de la licencia } \\
\text { de impresión }\end{array}$ & Pagador de la impresión & Dedicatario \\
\hline $\begin{array}{l}1594 \\
\text { Valladolid }\end{array}$ & Francisco de Montanos & - & $\begin{array}{l}\text { Catalina de Zúñiga, } \\
\text { VI Condesa de Lemos }\end{array}$ \\
\hline $\begin{array}{l}1598 \\
\text { Valladolid }\end{array}$ & Francisco de Montanos & - & Beata Virgen \\
\hline $\begin{array}{l}1610 \\
\text { Salamanca }\end{array}$ & Francisco de Córdoba & $\begin{array}{l}\text { Andrés López, mercader de } \\
\text { libros }\end{array}$ & Beata Virgen \\
\hline $\begin{array}{l}1616 \\
\text { Salamanca }\end{array}$ & $\begin{array}{l}\text { Andrés López, merca- } \\
\text { der de libros }\end{array}$ & $\begin{array}{l}\text { Andrés López, mercader de } \\
\text { libros }\end{array}$ & Beata Virgen \\
\hline $\begin{array}{l}1625 \\
\text { Salamanca }\end{array}$ & Antonio Vázquez & $\begin{array}{l}\text { Antonio López Calderón, } \\
\text { mercader de libros }\end{array}$ & Beata Virgen \\
\hline $\begin{array}{l}1635 \\
\text { Madrid }\end{array}$ & - & $\begin{array}{l}\text { Juan Antonio Bonet, } \\
\text { mercader de libros }\end{array}$ & - \\
\hline $\begin{array}{l}1640 \\
\text { Zaragoza }\end{array}$ & - & - & San Pedro de Arbues \\
\hline $\begin{array}{l}1643 \\
\text { Madrid }\end{array}$ & - & $\begin{array}{l}\text { Antonio Ribero, mercader } \\
\text { de libros }\end{array}$ & Beata Virgen \\
\hline $\begin{array}{l}1648 \\
\text { Madrid }\end{array}$ & - & - & - \\
\hline $\begin{array}{l}1665 \\
\text { Zaragoza }\end{array}$ & Juan de Ybar & - & Fr. Francisco de Gamboa \\
\hline $\begin{array}{l}1670 \\
\text { Zaragoza }\end{array}$ & - & - & San Pedro de Arbues \\
\hline $\begin{array}{l}1686 \\
\text { Madrid }\end{array}$ & - & [¿Antonio Ribero?] & $\begin{array}{l}\text { Nuestra Señora de la } \\
\text { Concepción }\end{array}$ \\
\hline $\begin{array}{l}1693 \\
\text { Madrid }\end{array}$ & - & - & - \\
\hline $\begin{array}{l}1694 \\
\text { Zaragoza }\end{array}$ & - & $\begin{array}{l}\text { Herederos de Gabriel de } \\
\text { León }\end{array}$ & San Pedro de Arbues \\
\hline $\begin{array}{l}1705 \\
\text { Madrid }\end{array}$ & Joseph de Torres & - & - \\
\hline $\begin{array}{l}1712 \\
\text { Madrid }\end{array}$ & Joseph de Torres & - & - \\
\hline $\begin{array}{l}1727 \\
\text { Zaragoza }\end{array}$ & - & - & Santo Dominguito de Vul \\
\hline $\begin{array}{l}1728 \\
\text { Madrid }\end{array}$ & [Joseph de Torres] & - & - \\
\hline $\begin{array}{l}1734 \\
\text { Madrid }\end{array}$ & [Joseph de Torres] & - & - \\
\hline $\begin{array}{l}1756 \\
\text { Zaragoza }\end{array}$ & - & - & - \\
\hline
\end{tabular}


Mientras que las dos primeras ediciones (1594 y 1598) del Arte de canto llano de Montanos contienen una licencia de impresión concedida al autor, la edición de 1610 fue publicada con una licencia dada al impresor Francisco de Córdoba; la edición de 1616 incluye una licencia otorgada a “Andrés López, mercader de libros”. El tenedor de la licencia en 1625 fue el impresor Antonio Vázquez, y el titular del permiso de impresión en 1665 fue de nuevo el impresor, en este caso Juan de Ibar (“Aviendo pues de sacar yo a la luz esta Arte de canto llano, para facilitar el trabajo, assi de los Maestros, que enseñan la musica, como de los Discipulos, que la aprenden"). ${ }^{16}$ Las ediciones de 1610 y 1616 se imprimieron "a costa de” Andrés López, mercader de libros; Antonio López Calderón y Juan Antonio Bonet, de nuevo mercaderes de libros, corrieron con los gastos de las reimpresiones de 1625 y 1635, respectivamente. El también mercader de libros Antonio Ribero cubrió los costes de la reimpresión de 1643, a la que no he encontrado referencias en la bibliografía (véase Ilustración II.1); y los herederos de Gabriel de León costearon la edición de 1694. Es Juan de Ibar, el impresor del libro, la persona que firma la amplia dedicatoria de la edición de 1665 "Al ilvstrissimo, y reverendissimo Señor D. Fr. Francisco de Gamboa”. La licencia concedida a Antonio Vázquez en 1625 es sumamente interesante, puesto que da permiso al impresor para imprimir por diez años no sólo el Arte de canto llano de Montanos, sino también "los demas artes de canto que huuiere, sin privilegio":

\footnotetext{
Por la presente damos licencia y facultad a Antonio Vazquez impressor de libros, vezino de Salamanca, para que pueda imprimir el Arte de canto llano, sin incurrir en pena alguna, por diez años: y los demas artes de canto que huuiere, sin priuilegio, reseruando no toquen al nueuo rezado, ni à ninguno de Orden alguna, como sean de canturia de buena casta, \&c. Dada en Madrid à catorze de Febrero, de mil y seyscientos y veynte años. El Licenciado don Martin de Cordoua. Por mandado de su Señoria. El Licenciado Martin de Quintanilla. ${ }^{17}$
}

\footnotetext{
${ }^{16}$ Montanos, Arte de canto llano (1665 [1594]), s.f., [dedicatoria].

${ }^{17}$ Montanos, Arte de canto llano (1625 [1594]), s.f., "Licencia del licenciado don Martin de Cordoua, Comissario general de la santa Cruzada, y juez Apostolico, y Real, para lo tocante a las impresiones del nuevo rezado".
} 
Ilustración II.1: Francisco de Montanos, Arte de canto llano (Madrid: Imprenta Real, 1643 [1594]). Las Palmas de Gran Canaria, Biblioteca de la Universidad de Las Palmas de Gran Canaria, BIG XVII MON art.

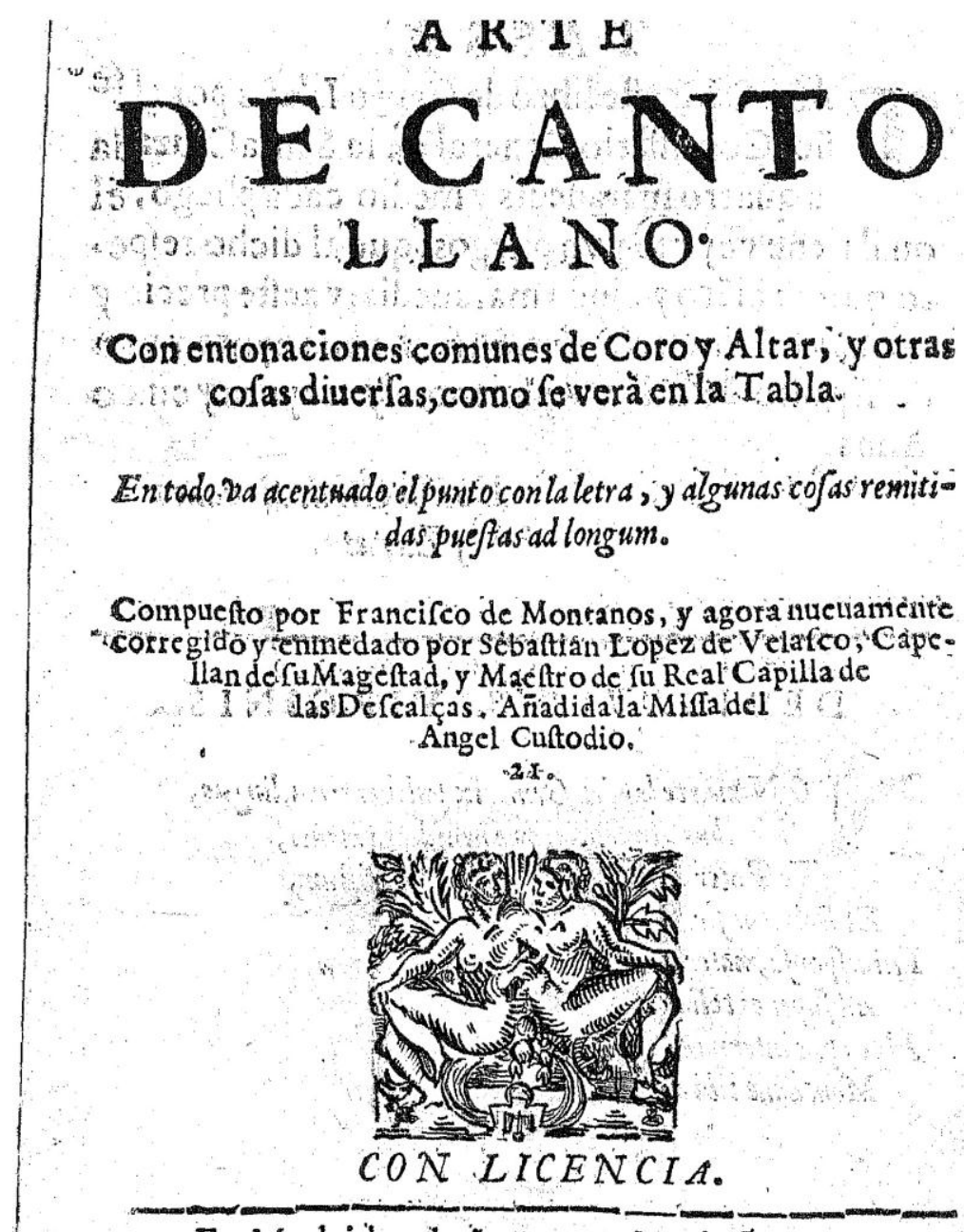

En Madriden la Imprenta Real año 1643 . A coftáde Antonio Ribero, mercader de libro

La licencia concedida a Antonio Vázquez en 1625 actúa por tanto como evidencia de que las artes de canto eran tan demandadas que un impresor pidió licencia para imprimir no sólo una obra en concreto, sino este tipo de libros en general. Este dato indica, como la crítica de Pedro de Loyola Guevara que citaba en el Capítulo I, que las artes de canto tenían una enorme proliferación y difusión. No sólo los impresores y libreros tomaron la iniciativa en la reimpresión de artes de canto, sino también músicos posteriores como Joseph de Torres (c. 1670-1738), que llevó a cabo reediciones del li- 
bro de Montanos tras obtener un privilegio en 1705. El caso de la reimpresión de Lux bella en 1509 sugiere que también figuras no ligadas al comercio del libro ni a la música promovieron reimpresiones de artes de canto, puesto que fue el Obispo de Salamanca la persona que ordenó revisar Lux bella para su publicación en Salamanca en 1509. ${ }^{18}$ Casos como el del Arte de canto llano de Montanos actúan como evidencia de que, como ha señalado Natalie Zemon Davis, en el siglo XVI "la propiedad del libro impreso era aún difusa". ${ }^{19}$

Además de buscar una financiación inicial, algunos autores (o impresores) trataron de dedicar sus libros a figuras ligadas al ámbito intelectual o insertas en un contexto que facilitara la difusión del libro y lo situara en una posición ventajosa en el mercado. ${ }^{20}$ No obstante, la elección de una figura a quien dedicar la obra no tenía únicamente un fin económico; buena parte de las dedicatorias de las artes de canto analizadas hacen referencia a la búsqueda de "autoridad", como muestra la Tabla II.2.

\footnotetext{
${ }^{18}$ Marcos Durán, Lux bella (1509 [1492]), s.f. [Colofón]: "fue impressa la presente obra en la muy noble ciudad de Salamanca a .xvi. dias del mes de Julio de mill e quinientos e nueve años, fue emendada e corrigida e añadida de nuevo, e fue examinada por mandado del muy reverendo señor obispo de la dicha ciudad de Salamanca".

${ }^{19}$ Natalie Zemon Davis, The Gift in Sixteenth-Century France (Oxford: Oxford University Press, 2000), pp. 76-77: "La propiedad en el libro impreso era todavía difusa: el editor o impresor a menudo adquiría el privilegio real, o derecho exclusivo para publicar el libro durante un número específico de años, pero a veces lo hacían los autores o el editor. El autor estaba muy identificado con su libro en su dedicatoria, pero no tenía derechos de autor, y muchos libros impresos del siglo XVI no tenían un autor conocido, sino sólo un traductor o editor" ["Property in the printed book was still diffuse: the publisher or printer often acquired the royal privilege, or exclusive right to publish the book for a specified number of years, but sometimes the authors or editor did. The author was closely identified with his or her book in its dedication, but had no formal copyright, and many sixteenth-century printed books had no known author, but only a translator or editor"].

${ }^{20}$ Bernstein, Music Printing in Renaissance Venice, p. 20: "The Venetian printers understood that their liaisons with the patriciate and the intellectual world provided them with advantageous business opportunities".
} 
Tabla II.2: Búsqueda de autoridad en las dedicatorias de las artes de canto

Arte de canto y dedicatario

Spañón, Introduccion muy util e breve de canto llano (c. 1500).

Juan Fonseca, Obispo de Córdoba

Espinosa, Tratado breue de principios de canto llano (c. 1521).

Don Martín de Mendoza, Archidiácono de Talavera y Guadalajara

Aranda, Tractado de canto llano (1533).

D. Afonso, cardenal infante de Portugal, Arzobispo de Lisboa y Obispo de Évora

Aguilar, Arte de principios de canto llano (c. 1535).

Pedro Manrique, Obispo de Ciudad Rodrigo y capellán mayor de la capilla de los Reyes Nuevos de Toledo

Guevara, Arte para componer canto llano (1582).

D. Hernando de Rueda, Obispo de Gran Canaria

Cervera, Arte y suma de canto llano (1595).

Felipe III

Thalesio, Arte de canto chão (1618).

D. Affonso Furtado de Mendoça, Obispo de Coimbra, Conde de Arganil, del Consejo de Estado del Rey

Torres, Arte ingeniosa de musica (1566 [1544]).

Gutierre de Carvajal, Obispo de Plasencia (Cáceres)

Fernandes, Arte de musica de canto dorgam, e canto cham (1626).

Duarte Lobo, maestro de música de la Catedral de Lisboa
Fragmento de la dedicatoria

"Non es cosa nueua muy reuerendo et magnifico señor, mas antes es mucho vsada acerca de los antiguos, los que fazen algunas obras las intitulen a los principes o grandes señores, no porque les den doctrina mas por que de la auctoridad de aquellos a quien la obra se endereça la obra reciba auctoridad".

“[...] suplico a vuestra señoria pues que sabe que todas mis obras de musica las imprimidas y por imprimir estan debaxo de su fauor y amparo que reciba esta muy pequeño hecha por las causas arriba dichas".

“[...] suplico resciba este pequeño: porque debaxo de su grandeza sea el authorizado".

"[...] no faltandome voluntad y entera aficion para que con el favor de vuestra illustre señoria comience otra mayor obra".

"Y para que esto lleue el sabor y amparo que semejantes cosas an menester, yo la he dedicado a vuestra Señoria Illustrissima, como a singular señor mio, Assi para que con el nombre de vuestra Señoria, la obra tenga mayor auctoridad [...]."

"Porque si el principe es inclinado a caça todos caçan; si armas, todos tornean y justan; si a letras todos deprenden, y si a musica, todos cantan y tañen [...]".

Agradece a su dedicatario que siendo Obispo de Guarda le escogiera como maestro de capilla y le diera "premios y salarios" en su mayor parte para que lograra el puesto de profesor de música en la Universidad de Coimbra.

"Y pues con las migajas que caen de la mesa de la grandeza de vuestra señoria sobrara fauor a esta presente obra: vuestra Señoria ampare y favorezca, para que debaxo de tan grandes alas ninguna cosa aya que temer".

Alaba la labor pedagógica de su maestro Duarte Lobo en la Catedral de Lisboa. 
Arte de canto y dedicatario

Silva, Arte minima (1685).

Beata Virgen María
Fragmento de la dedicatoria
"Os Authores dedicaõ seus livros, ou aos mais obrigados, au aos mais poderosos, ou aos mais sabios da sciencia de que escrevem. Aos mais obrigados, para que com a offerta lhe lisongeem a vontade, \& se confesen agradecidos. Aos mais poderosos, para que com seu poder lhe grangeem creditos, \& tributem dispendios. A os mais sabios, para que contra os murmuradores sejã̃ invencivel escudo a suas settas: E como em vòs tenho todos estes titulos unidos com taõ excessiva grandesa, a quem a podia eu dedicar? A quem mais obrigado? [...]".

El análisis de las dedicatorias de las artes de canto revela que la mayoría de los dedicatarios ocupaban una posición religiosa de elevado rango (véase Tabla II.3). No obstante, también encontramos figuras ajenas al ámbito religioso. Así, Juan Francisco Cervera dedicó su tratado a Felipe III y Francisco de Montanos dedicó sus libros de 1592 y 1594 a Fernando de Castro, VI Conde de Lemos, y a la esposa de éste, Catalina de Zúñiga y Sandoval, respectivamente. ${ }^{21}$ Además, es interesante que Diego del Puerto dedicase su arte de canto llano a Alfonso de Castilla, Rector del Estudio salmantino, y que únicamente Fernandes dedicase su libro a un músico, el compositor Duarte Lobo.

Tabla II.3: Dedicatarios de las artes de canto

\begin{tabular}{ll}
\hline \multicolumn{1}{c}{ Libro } & \multicolumn{1}{c}{ Dedicatario } \\
\hline $\begin{array}{l}\text { Marcos Durán, Lux bella (1492). } \\
\text { Escobar, Introduction muy breue de canto } \\
\quad \text { llano (c. 1496). }\end{array}$ & Pedro Ximénez de Préxano, Obispo de Coria \\
$\begin{array}{l}\text { Marcos Durán, Comento sobre Lux bella } \\
\text { (1498). }\end{array}$ & Alfonso III de Fonseca, primado de España \\
$\begin{array}{l}\text { Spañón, Introduccion muy util e breve de } \\
\text { canto llano (c. 1500). }\end{array}$ & Juan Fonseca, Obispo de Córdoba \\
Molina, Lux videntis (1503). &
\end{tabular}

\footnotetext{
${ }^{21}$ Acerca de la dedicatoria del Arte de canto llano de Montanos a Catalina de Zúñiga, véase el Capítulo $\mathrm{V}$.
} 


\begin{tabular}{c} 
Libro \\
\hline Puerto, Portus musice $(\mathbf{1 5 0 4})$
\end{tabular}

Puerto, Portus musice (1504).

Marcos Durán, Sumula de canto de órgano, contrapunto y composicion (c. 1504).

Martínez de Bizcargui, Arte de canto llano et contrapunto et canto de organo (1508).

Marcos Durán, Lux bella (1509 [1492])

Martínez de Bizcargui, Arte de canto llano et contrapunto et canto de organo (1515 [1508]).

Espinosa, Tractado de principios de musica practica e theorica (1520).

Espinosa, Tratado breue de principios de canto llano (c. 1521).

Martínez, Arte de canto llano (1530).

Aranda, Tractado de canto llano (1533).

Aranda, Tractado de canto mensurable y contrapuncto (1535).

Aguilar, Arte de principios de canto llano (c. 1535).

Bermudo, Libro primero (1549).

Bermudo, El arte Tripharia (1550).

Villafranca, Breue instrucion de Canto llano (1565).

Torres, Arte ingeniosa de musica (1566 [1544]).

Guevara, Arte para componer canto llano (1582).

Montanos, Arte de musica therica y pratica (1592).

Montanos, Arte de canto llano (1594).

Cervera, Arte y suma de canto llano (1595).

Montanos, Arte de canto llano (1598; 1610; 1616; 1625 [1594]).

Villegas, Suma de todo lo que contiene el Arte de Canto llano (1604).

Monserrate, Arte breve y compendiosa (1614).

Artufel, Modo de rezar las horas canonicas (1614).

\section{Dedicatario}

Alfonso de Castilla (†1504), Rector del Estudio en la Universidad de Salamanca

Alfonso de Fonseca, Arzobispo de Santiago

Fray Pascual, Obispo de Burgos

D. Bernardino Manrique de Lara

Juan Rodríguez de Fonseca, Arzobispo de Rosano y Obispo de Burgos

Don Martín de Mendoza, Archidiácono de Talavera y Guadalajara

Don Martín de Mendoza, Archidiácono de Talavera y Guadalajara

D. Afonso, cardenal infante de Portugal, Arzobispo de Lisboa y Obispo de Évora

D. Afonso, cardenal infante de Portugal, Arzobispo de Lisboa y Obispo de Évora

Pedro Manrique, Obispo de Ciudad Rodrigo y capellán mayor de la capilla de los Reyes Nuevos de Toledo

João III de Portugal

Doña Isabel Pacheco, Abadesa del Convento de Santa Clara de Montilla

Juan Ovando, canónigo

Gutierre de Carvajal, Obispo de Plasencia (Cáceres)

D. Hernando de Rueda, Obispo de Gran Canaria

Fernando Ruiz de Castro, VI Conde de Lemos

Catalina de Zúñiga y Sandoval, VI Condesa de Lemos

Felipe III

Beata Virgen

D. Fernando Niño de Guevara, Cardenal de la Santa Iglesia de Roma, Arzobispo de Sevilla, y del Consejo de Estado del Rey

Virgen María

Ambrosio de Lanchares, predicador general y prior del Convento de San Pablo de Valladolid 


\begin{tabular}{|c|c|}
\hline Libro & Dedicatario \\
\hline Thalesio, Arte de canto chão (1618 y 1628). & $\begin{array}{l}\text { D. Affonso Furtado de Mendoça, Obispo de Coimbra, } \\
\text { Conde de Arganil, del Consejo de Estado del Rey }\end{array}$ \\
\hline $\begin{array}{l}\text { Fernandes, Arte de musica de canto dorgam, } \\
\quad \text { e canto cham } \mathbf{( 1 6 2 6 )} \text {. }\end{array}$ & $\begin{array}{l}\text { Duarte Lobo "Quartanario, \& mestre de Musica na S. Sé } \\
\text { de Lisboa" }\end{array}$ \\
\hline Montanos, Arte de canto llano (1665 [1594]). & Fr. Francisco de Gamboa \\
\hline Montanos, Arte de canto llano (1670 [1594]). & $\begin{array}{l}\text { "Invicto Martir San Pedro de Arbues, primer Inquisidor } \\
\text { del Rey de Aragon y Canonigo de la Santa Iglesia } \\
\text { Metropolitana" }\end{array}$ \\
\hline Montanos, Arte de canto llano (1694 [1594]). & San Pedro de Arbues \\
\hline Montanos, Arte de canto llano (1727 [1594]). & $\begin{array}{l}\text { Invicto Mártir Santo Dominguito de Vul, Infante de la } \\
\text { Santa Iglesia Metropolitana Cesaraugustana }\end{array}$ \\
\hline
\end{tabular}

\title{
1.1.2. APROBACIONES, LICENCIAS Y PRIVILEGIOS
}

\begin{abstract}
Mientras que un incunable o un libro actual nos ofrecen con ningún o poco aditamentos la obra del escritor, un libro del Siglo de Oro antepone numerosas piezas, por lo general breves, en uno o varios idiomas, en prosa o en verso, de carácter administrativo o literario, con tal variedad de tonos, que traen a la memoria la algarabía de las plazas mayores de las ciudades en días de mercado $[\ldots .]^{22}$
\end{abstract}

El potencial de la imprenta para la difusión de ideas motivó que los gobernantes trataran de someterla a un control, lo que derivó en la proliferación de una legislación que, comenzando con la Real Pragmática de Isabel y Fernando (Toledo, 8 de julio de 1502), introdujo técnicas de intervención, principalmente prohibiciones y licencias. ${ }^{23}$

\footnotetext{
${ }^{22}$ José Simón Díaz, El libro español antiguo. Análisis de su estructura (Kassel: Reichenberger, 1983), p. 1.

23 “D. Fernando y D a Isabel en Toledo, por pragmática de 8 de julio de 1502”, en Códigos españoles concordados y anotados. Novísima recopilación de las Leyes de España (Madrid: Rivadeneyra, 1850), tomo IX, pp. 95-96; José Manuel Lucía Megías, Imprenta, libros y lectura en la España del "Quijote” (Madrid: Artes Gráf. Municipales, 2006), p. 160; y "La Pragmática de 1558 o la importancia del control del Estado en la imprenta española”, Indagación, IV (1999), pp. 195-220. Sobre la legislación que afectaba a la imprenta, véase Reyes Gómez, El libro en España y América. Véanse también Enrique Gómez-Reino y Carnota, Aproximación histórica al derecho de imprenta y de la prensa en España (1480-1966) (Madrid: Instituto de Estudios Administrativos, 1977); y Eugenio de Eguizábal, Apuntes para una historia de la legislación sobre imprenta desde el año 1480 al presente (Madrid: Impr. de la Revista de Legislación, 1879). Las disposiciones concernientes a la regulación de la imprenta se recogen en la Novísima recopilación (Libro VIII, títulos XV, XVI, XVII y XVIII). Para un recorrido por la legislación que ha afectado a la imprenta a lo largo de la historia, véase Francisco Javier Paredes Alonso, Mercaderes de libros: cuatro siglos de historia de la Hermandad de San Gerónimo (Madrid: Fundación Germán Sánchez Ruipérez, 1988). Sobre los motivos que llevaron a establecer mecanismos de control, véase Carlos Alberto Gonzá-
} 
Las medidas legislativas también tuvieron el efecto de diferenciar el libro impreso del manuscrito, puesto que suponían la inclusión de una serie de documentos antepuestos al cuerpo del texto ${ }^{24}$ por ejemplo, con la Pragmática de 1502 se hacía imprescindible la licencia en Castilla (aunque no en Aragón ni en las posesiones italianas), siendo el Arzobispado de Sevilla la autoridad encargada de tramitarla, mientras que, como consecuencia de la Pragmática de 1558, se convirtieron en requisitos la aprobación, el privilegio, la tasa y la fe de erratas. ${ }^{25}$ Algunas de las artes de canto estudiadas contienen el privilegio real, documento que autorizaba la impresión de un libro con derechos de publicación exclusivos durante un período de tiempo y sólo para una zona geográfica definida, ${ }^{26}$ lo que llevó en ocasiones a la aparición de "ediciones pirata". ${ }^{27}$ La Tabla II.4 muestra algunos ejemplos de obtención del privilegio real para imprimir artes de canto y evidencia que, en la mayoría de las ocasiones, tras la obtención de la licencia se requerían varios años para completar el proyecto; por ejemplo, Dámaso Artufel obtuvo el privilegio para imprimir su libro nueve años antes de que se produjera la publicación del mismo.

lez Sánchez, "Cerco a la imaginación: lectura y censura ideológica en la España del siglo XVI", en Libro y lectura en la Península Ibérica y América (siglos XIII al XVI), ed. por Antonio Castillo Gómez (Madrid: Junta de Castilla y León, Consejería de Cultura y Turismo, 2003), pp. 77-106, p. 84. Es de sumo interés en este sentido el ya mencionado trabajo de Clive Griffin, Journeymen-Printers, que explica cómo se desmanteló una red de inmigrantes trabajando en la industria de la imprenta en la Península Ibérica durante las décadas de 1560 y 1570 .

${ }^{24}$ Lafaye, Albores de la imprenta, p. 50. Sobre las partes integrantes del libro, véase Simón Díaz, El libro español antiguo, p. 33.

${ }^{25}$ Eduardo Torres Corominas, Literatura y facciones cortesanas en la España del siglo XVI: estudio y edición del "Inventario" de Antonio Villegas (Madrid: Polifemo, 2008).

${ }^{26}$ En el ámbito musical y sobre el caso veneciano, véase Richard J. Agee, "The Privilege and Venetian Music Printing in the Sixteenth Century", Tesis Doctoral (Ph.D.), Princeton University, 1982; y "The Venetian Privilege and Music-Printing in the Sixteenth Century", Early Music History, 3 (1983), pp. 142.

${ }^{27}$ Don W. Cruickshank, "Some Aspects of Spanish Book Production in the Golden Age", Gutenberg Jahrbuch, XXV (1950), pp. 203-204, p. 203, nota 14: "Un factor que posiblemente condujo a una mayor suma de impresiones piratas en España fue la separación judicial de Aragón y Portugal de Castilla, lo que significaba que un privilegio concedido para Castilla no era válido en Aragón o Portugal (y viceversa)" ["One factor which possibly led to a greater amount of piratical printing in Spain was the judicial separation of Aragón and Portugal from Castile, which meant that a privilege granted for Castile was not valid in Aragón or Portugal (and vice-versa)"]. Véanse también Jaime Moll, De la imprenta al lector: estudios sobre el libro español de los siglos XVI al XVIII (Madrid: Arco Libros, 1994); y Problemas bibliográficos del libro del Siglo de Oro (Madrid: Arco Libros, 2011); y Reyes Gómez, El libro en España y América. 
Tabla II.4: Ejemplos de duración del privilegio real en las artes de canto

\begin{tabular}{lll}
\hline Arte de canto & Concesión del privilegio & Duración del privilegio \\
\hline $\begin{array}{l}\text { Aranda, Tractado de canto llano (1533). } \\
\text { Aranda, Tractado de canto mensurable y } \\
\text { contrapuncto (1535). }\end{array}$ & 7 de julio de 1534 & 3 años \\
$\begin{array}{l}\text { Bermudo, Libro primero (1549). } \\
\begin{array}{l}\text { Guevara, Arte para componer canto } \\
\quad \text { llano (1582). }\end{array}\end{array}$ & $\begin{array}{l}18 \text { de noviembre de } 1549 \\
\text { Villegas, Suma de todo lo que contione de } 1575\end{array}$ & 6 años \\
$\quad$ el Arte de Canto llano (1604). & 11 de julio de 1602 & 6 años \\
$\begin{array}{c}\text { Artufel, Modo de rezar las horas } \\
\text { canonicas (1614). }\end{array}$ & 17 de agosto de 1605 & 10 años \\
\hline
\end{tabular}

En ocasiones, encontramos que las artes de canto contienen aprobaciones de músicos de reconocido prestigio. Por ejemplo, el libro de Luis de Villafranca contiene la aprobación de Pedro Fernández y Francisco Guerrero, mientras que Philippe Rogier, maestro de la Capilla Flamenca entre 1588 y 1599, daba su aprobación para que la obra de Juan Francisco Cervera fuese publicada, y Hernando de Cabezón firmaba a 10 de septiembre de 1593 su aprobación para que saliera a la luz el Arte de canto llano de Francisco de Montanos. Se ha dicho que el libro perdido de Fray João Rodrigues, vicario de la iglesia de Santa María en Marvão, fue aprobado en Roma por Antonio Boccapadula, maestro de capilla y secretario del Papa Gregorio XIII, y por Palestrina. ${ }^{28}$ La Tabla II.5 recoge otros ejemplos de materiales preliminares en las artes de canto analizadas.

\footnotetext{
${ }^{28}$ Branco, História da música portuguesa, p. 131; Nelson, "Music Treatises and 'artes para tanger' in Portugal Before the 18th Century", p. 201.
} 
Tabla II.5: Ejemplos de documentos preliminares de las artes de canto

\begin{tabular}{|c|c|}
\hline Arte de canto & Material preliminar \\
\hline $\begin{array}{l}\text { Marcos Durán, Sumula } \\
\text { de canto de organo, } \\
\text { contrapunto y } \\
\text { composicion (c. 1504). }\end{array}$ & Dedicatoria; prólogo. \\
\hline $\begin{array}{l}\text { Bermudo, Libro primero } \\
\text { (1549). }\end{array}$ & $\begin{array}{l}\text { Privilegio; licencia de Gómez de Llanos, ministro provincial de la Orden } \\
\text { de los frailes menores de observancia en la provincia de Andalucía; Epís- } \\
\text { tola de Figueroa, maestro de la capilla real de Granada, a João de Portu- } \\
\text { gal; "Prologo general de toda la obra para el lector"; carta de Figueroa a } \\
\text { Gómez de Llanos. }\end{array}$ \\
\hline $\begin{array}{l}\text { Bermudo, El arte } \\
\text { Tripharia (1550). }\end{array}$ & $\begin{array}{l}\text { Privilegio; licencia de Gómez de Llanos; carta de Francisco Cervantes de } \\
\text { Salazar, catedrático de retórica de la Universidad de Osuna, a Isabel Pa- } \\
\text { checo; "Prologo epistolar del author"; prólogo al lector. }\end{array}$ \\
\hline $\begin{array}{l}\text { Montanos, Arte de musi- } \\
\text { ca theorica y pratica } \\
\text { (1592). }\end{array}$ & $\begin{array}{l}\text { Aprobación; privilegio; dedicatoria; prologo; "A los maestros de capilla y } \\
\text { musicos doctos"; "Discurso de diuersas maneras de Musica". }\end{array}$ \\
\hline $\begin{array}{l}\text { Montanos, Arte de canto } \\
\quad \text { llano (1594). }\end{array}$ & $\begin{array}{l}\text { Tasa; aprobación; privilegio; soneto "al avthor de vn su amigo"; dedicato- } \\
\text { ria. }\end{array}$ \\
\hline $\begin{array}{l}\text { Monserrate, Arte breve y } \\
\text { compendiosa (1614). }\end{array}$ & $\begin{array}{l}\text { Licencia del oficial Pedro Antonio Serra; aprobación de Nicolas Mariner y } \\
\text { de Alagon; "Pregunta de vn amante de las Musas a Apollo"; "Prologo } \\
\text { primero al discreto lector"; "Prologo segundo y exortacion a los princi- } \\
\text { piantes }[\ldots] \text { ". }\end{array}$ \\
\hline $\begin{array}{l}\text { Thalesio, Arte de canto } \\
\text { chão (1618). }\end{array}$ & $\begin{array}{l}\text { Tasa; licencias de Bartolomeu da Fonseca, Antonio Diaz Cardoso, Frey } \\
\text { Antonio Freire, Ioao Alvares Brandao, A. Bispo Conde, Luis Machado de } \\
\text { Gouuea y Francisco Vaz Pinto; dedicatoria; "Ao benevolo e pio leitor”; } \\
\text { poemas. }\end{array}$ \\
\hline $\begin{array}{l}\text { Fernandes, Arte de } \\
\text { mvsica de canto } \\
\text { dorgam, e canto cham } \\
\text { (1626). }\end{array}$ & $\begin{array}{l}\text { Licencias de Fr. Thomas de S. Domingos Magister y del Obispo Inquisi- } \\
\text { dor Geral; aprobación; tasa; dedicatoria; prólogo. }\end{array}$ \\
\hline
\end{tabular}

Además de los documentos requeridos por la legislación, las portadas suponen una de las diferencias más visibles entre el manuscrito y el impreso, y su desarrollo discurre paralelo al de la historia de la imprenta. ${ }^{29}$ Las portadas contribuían a la comercialización de los libros al proporcionar los datos necesarios para que los consumidores decidieran si comprarlos o no. En la Ilustración II.2 se cotejan a modo de ejemplo la portada del Arte de cantollano anónimo R/14670(1) de la Biblioteca Nacional de Espa-

${ }^{29}$ Sigrid Henry Steinberg, Five Hundred Years of Printing (Harmondsworth, Middlesex: Penguin Books, 1955), p. 105. 
ña, que sólo contiene el título del libro, con la portada del Arte de canto chão (1618) de Pedro Thalesio, la cual incluye el título del libro, el nombre del autor, el propósito de la publicación, la posición profesional del autor, la persona a la que está dedicado y su escudo de armas, y los datos tipográficos (lugar de la impresión, nombre del impresor y fecha).

\section{Ilustración II.2: Cotejo de las portadas de un arte de canto de principios del siglo XVI y otro de principios del XVII.}

Portada del anónimo Arte de cantollano

[Sevilla: Jacobo Cromberger, c. 1512-1515?].

Madrid, Biblioteca Nacional de España, R/14670(1).
Portada de Pedro Thalesio, Arte de canto chão

(Coimbra: Diogo Gomez de Loureyro, 1618).

Lisboa, Biblioteca Nacional de Portugal, M.428P.

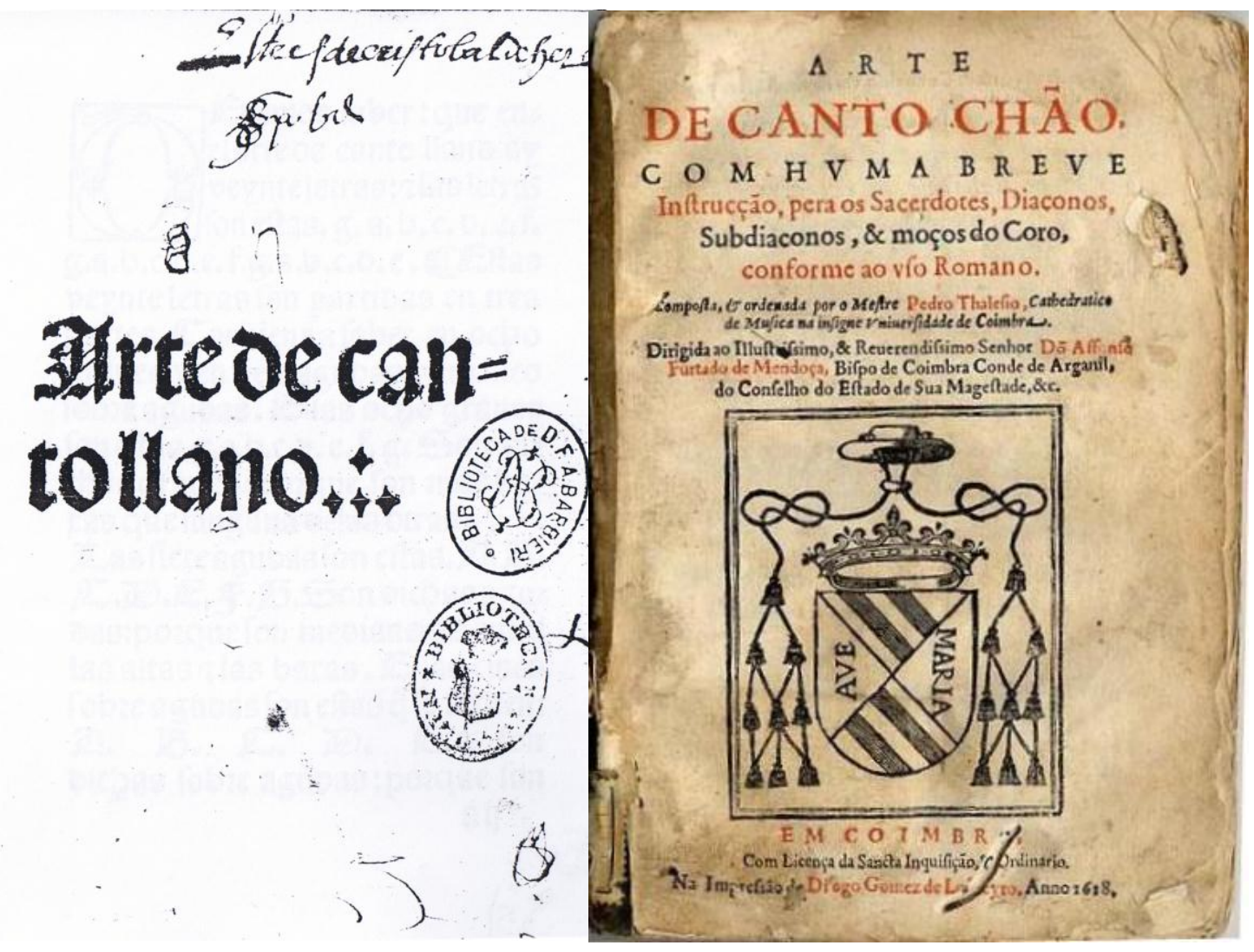

\subsection{La imprenta de artes de canto}

La imprenta musical española no ha recibido la suficiente atención en los trabajos sobre imprenta musical, en los cuales se han enfatizado los contextos italiano, ale- 
mán y anglosajón, ${ }^{30}$ lo cual podría deberse a que: 1) ningún impresor se especializó en la producción de libros de música; ${ }^{31}$ 2) la impresión musical se hallaba dispersa en diferentes ciudades sin que hubiese un verdadero centro de impresión musical; y 3) las artes de música en castellano o portugués no tenían como propósito introducirse en el mercado europeo. ${ }^{32}$ En la historiografía musical portuguesa, no obstante, se ha prestado más atención a estos libros didácticos, tal vez por considerarse inauguradores de la imprenta musical lusitana. ${ }^{33}$

\subsubsection{LAS ARTES DE CANTO EN EL ÁMBITO DE LA CULTURA DE LA IMPRENTA}

$\mathrm{Si}$, como mostraba el texto de Manuel Nunes da Silva, las artes de canto tuvieron una difusión manuscrita como "apuntes de clase" o "libros de texto" entre los estudiantes todavía en $1685,{ }^{34}$ debió de producirse una coexistencia entre manuscritos e impresos en el mundo de las artes de canto renacentistas. Por ejemplo, en su estudio de la circulación del libro manuscrito en Sevilla, María del Carmen Álvarez Márquez ha

${ }^{30}$ Por ejemplo, Kathi Meyer-Baer, Liturgical Music Incunabula: A Descriptive Catalogue (Londres: The Bibliographical Society, 1962), contiene descripciones de música impresa en incunables litúrgicos conservados en las grandes bibliotecas de Inglaterra, Francia y Estados Unidos. Ejemplos de impresos españoles sí habían aparecido en Toledo Museum of Art, The Printed Note: 500 Years of Music Printing and Engraving (Toledo, Ohio: The Museum, 1957). Alexander Hyatt King, Four Hundred Years of Music Printing (Londres: British Museum, 1964), se limita a los países de o cerca de "la corriente principal" (Alemania, Italia, Francia, Inglaterra y Países Bajos), menciona los principales hitos de la imprenta musical en el Nuevo Mundo y da prominencia a los desarrollos en Inglaterra. El volumen Fenlon y Knighton, eds., Early Music Printing and Publishing in the Iberian World, constituye una excepción.

${ }^{31}$ Carlos José Gosálvez Lara et al., "Editores e impresores", en Diccionario de la Música española e hispanoamericana, ed. por Emilio Casares Rodicio (Madrid: Sociedad General de Autores y Editores, 1999-2002), vol. 4, pp. 606-629, p. 606; véase también Gosálvez Lara, La edición musical española hasta 1936, p. 24: "En la España renacentista no concurrieron las condiciones necesarias para que se diera en este campo un proceso similar al de otros países y, a pesar del progreso indudable de nuestro arte tipográfico, tardaría todavía casi trescientos años en cuajar aquí una actividad de impresión y edición de música verdaderamente significativa y diferenciada".

${ }^{32}$ López-Vidriero y Cátedra García, La imprenta y su impacto en Castilla, p. 35.

${ }^{33}$ Manuel Carlos de Brito, "Edições musicais em Portugal nos séculos XVII e XVIII: distribuição e significado", Revista de Musicología, XVI/2 (1993) [Actas del XV Congreso de la Sociedad Internacional de Musicología "Culturas musicales del Mediterráneo y sus ramificaciones" (Madrid, del 3 al 10 de abril de 1992)], pp. 1137-1142, p. 1137: "Hay dos aspectos de estas primeras ediciones que encontraremos repetidamente en la edición musical portuguesa de los siglos XVII y XVIII: por un lado, la importancia de los tratados y manuales con finalidad predominantemente didáctica; por otro, el papel que en ella desempeñaron los editores extranjeros establecidos en Portugal" ["Há dois aspectos destas primeiras ediçoes que iremos encontrar repetidamente na ediçao musical portuguesa dos séculos XVII e XVIII: de um lado a importancia dos tratados e manuais com finalidade predominantemente didáctica, do outro o papel que nela irao desempeñar os editores estrangeiros fixados em Portugal'].

${ }^{34}$ Silva, Arte minima, f. A3. Véase el Capítulo I (Apartado 1.2.4.c). 
señalado la coexistencia de manuscritos e impresos en el inventario de bienes de 1588 de Alonso Mudarra:

[...] se halla "vn libro de çifras de musica de mano viejo", que pudiera tratarse del original de su obra Tres libros de Musica de cifra para vigüela, que había impreso en Sevilla Juan de León en 1546. Es posible que los dos siguientes asientos se refieran también a cuadernos de musica de su propia inspiración: "otros quadernicos de musica encuadernados de pergamino blanco" y "otros cuadernos sueltos de musica", como las "muchas fantasias y composturas en una nueua manera de cifra para harpa y organo", que no se imprimieron "pues mis preocupaciones no me dieron lugar a que imprimiese el dicho libro". ${ }^{35}$

Además, se han hallado conexiones entre copistas e impresores en el ámbito de la profesión del libro, ${ }^{36}$ y una relación de dependencia recíproca entre el libro manuscrito y el impreso, es decir, que no sólo el manuscrito fue modelo para la elaboración del impreso, sino que también se copiaban manuscritos a partir de un modelo impreso. ${ }^{37}$ Carlos Romero de Lecea ha comparado los dos primeros tratados de Domingo Marcos Durán concluyendo que en el segundo se percibe que "el propio estilo del autor se ha dejado ganar por los nuevos principios que presiden al impreso respecto de los imperantes en la era del manuscrito". ${ }^{38}$ El propósito de este apartado es determinar en qué medida las artes de canto llano son consecuencia de lo que se ha denominado "cultura de la imprenta". 39

Como ya advirtió Marcelino Menéndez y Pelayo, "la tradición de este género de libros de canto, por lo común en lengua vulgar, era muy antigua en España". ${ }^{40}$ Se conservan artes de canto manuscritas anteriores a las artes impresas analizadas, como por ejemplo: 1) el conocido Reglas de canto plano è de contrapunto è de canto de organo (Sevilla, 1410) de Fernand Estevan, del que sobrevive una copia procedente de la colec-

\footnotetext{
35 Álvarez Márquez, “El escribano de letra de libros 'versus' el cajista”, p. 109.

${ }^{36}$ María del Carmen Álvarez Márquez y Margarita Gómez Gómez, "Un pleito la para impresión de libros corales con destino a las Indias”, Historia, instituciones, documentos, XXV (1998), pp. 13-42, p. 32.

${ }^{37}$ Bernadó, "Impresos litúrgicos”, p. 264.

${ }^{38}$ Véase Romero de Lecea, Introducción a los viejos libros de música, p. 101.

${ }^{39}$ Judd, Reading Renaissance Music Theory, p. 17.

${ }^{40}$ Menéndez y Pelayo, Historia de las ideas estéticas en España, vol. 2, p. 951.
} 
ción Borbón-Lorenzana que contiene únicamente la sección de canto llano; ${ }^{41}$ 2) el Arte de canto llano del Monasterio de Silos que data de antes de 1436 (aunque posiblemente reproduce un original de finales del siglo XIV o inicios del XV); ${ }^{42}$ 3) el Ars cantus mensurabilis et inmensurabilis datado en Sevilla a 7 de julio de 1480, en latín y caste1lano, de la Real Biblioteca del Monasterio de San Lorenzo de El Escorial; ${ }^{43}$ 4) el Ars cantus plani, versión en catalán del manuscrito de Silos; ${ }^{44}$ y 5) un breve tratado de contrapunto del Archivo Capitular de Girona, datado en el segundo tercio del siglo XV. ${ }^{45}$ También se han conservado artes de canto manuscritas que coexistieron con las impresas, como por ejemplo: 1) el tratado de canto llano en portugués más antiguo que se conoce (datado en 1494), que se encuentra en la Biblioteca Pública de Évora; ${ }^{46}$ 2) el

\footnotetext{
${ }^{41}$ Para su transcripción y facsímile, véase Fernand Estevan, Reglas de canto plano è de contrapunto è de canto de órgano: primer tratado de música escrito en castellano, trans. y estudio de Pilar Escudero (Sevi1la: Conservatorio Superior de Música, 1984); véase también Maricarmen Gómez Muntané, La música medieval en España (Kassel: Reichenberger, 2001), p. 275.
}

${ }^{42}$ El MS 14 del Archivo de Santo Domingo de Silos se inserta entre los folios 100r y 107r de un ceremonial monástico de 149 folios de la congregación de San Benito de Valladolid. Véanse Ernesto Zaragoza i Pascual, "Un manual de canto llano del siglo XV hasta hoy inédito", Tesoro Sacro Musical, 637 (1976), pp. 79-85; y P. Bernardo-Recaredo García, O.S.B., "Un tratado de canto llano del siglo XV", Glosas silenses, VI (1991), pp. 54-62.

${ }^{43}$ Encontramos ediciones del tratado, la segunda en facsímile, en Luis Villalba Muñoz, "Un tratado de música inédito del siglo XV", La Ciudad de Dios, 70 (1906), pp. 118-123 y 531-543; y "Un tratado de música inédito del siglo XV", Biblioteca Sacro Musical, V (1915), pp. 64-71 y 74-77. En la Biblioteca Nacional de España (signatura M/1282) se conserva una transcripción manuscrita realizada por Francisco A. Barbieri, digitalizada en:

$<$ http://bibliotecadigitalhispanica.bne.es:80/webclient/DeliveryManager?pid=2680726\&custom_att_2=si mple_viewer>.

${ }^{44}$ Art del can plà, ed. por Felip Pedrell (Barcelona: Tip. de l'Acadèmia, 1912) [Recull de textes catalans antichs, XVII]; Kart-Werner Gümpel, "Zur Frühgeschichte der vulgärsprachlichen spanischen und katalanischen Musiktheorie", en Spanische Forschungen der Görresgesellschaft, Erste Reihe: Gesammelte Aufsätze zur Kultugeschichte Spaniens, 24, ed. por Johannes Vincke (Münster: Aschendoffshe Verlagsbuchhandlung, 1968), pp. 257-336; y "Zwei unbeachtete Fragmente der altkatalanischen Art del cant pla”, en De Musica Hispana et aliis. Miscelánea en honor del Prof. José López-Calo, ed. por Emilio Casares y Carlos Villanueva (Santiago de Compostela: Universidade de Santiago de Compostela, 1990) vol. 1, pp. 111-144. Ferreira, "Mateus de Aranda", p. 134, lo llama "Anónimo de Barcelona e Silos, Art del cant pla / Arte de canto llano (s. XIVex-1435)"'.

${ }^{45}$ Gómez Muntané, La música medieval en España (Kassel: Reichenberger, 2001), pp. 275-276.

${ }^{46}$ Para una edición del manuscrito, véase Harvey L. Sharrer, "A Late Fifteenth-Century Portuguese Plainchant Treatise", Revista Portuguesa de Musicología, 14-15 (2004-2005), pp. 101-130. Otros manuscritos portugueses (algunos conservados y otros perdidos) son listados en Nelson, "Music Treatises and 'artes para tanger' in Portugal Before the 18th Century"; véase también Ferreira "O tratado musical de Leiria". 
Tratat molt util de la art de can pla (1500-1525) de la Biblioteca de Catalunya; $\left.{ }^{47} 3\right)$ el Arte de melodia sobre canto lano y canto d'organo (principios del siglo XVI) también en la Biblioteca de Catalunya; y 4) el Tractat de música del siglo XVI conservado en la Biblioteca de Reserva de la Universidad de Barcelona. Véase a continuación la Tabla II.6 en la que se presentan de forma esquemática estos ejemplos de artes de canto manuscritas anteriores y coexistentes con las artes impresas.

Tabla II.6: Ejemplos de artes de canto manuscritas

\begin{tabular}{|c|c|c|c|c|}
\hline \multirow{6}{*}{ 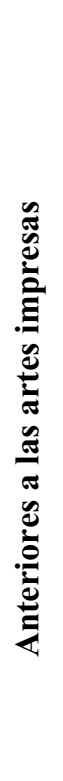 } & & Fecha & Tratado & Localización \\
\hline & 1 & $\begin{array}{l}1410, \\
\text { Sevilla }\end{array}$ & $\begin{array}{l}\text { Fernand Estevan, Reglas de } \\
\text { canto plano è contrapunto ̀̀ } \\
\text { de canto de organo fechas e } \\
\text { ordenadas para informacion } \\
\text { y declaracion de los inorantes }\end{array}$ & $\begin{array}{l}\text { Toledo, Biblioteca de Castilla-La } \\
\text { Mancha / Biblioteca Pública del } \\
\text { Estado, Ms. } 329 .\end{array}$ \\
\hline & 2 & $\begin{array}{l}\text { Antes de } \\
1436\end{array}$ & $\begin{array}{l}\text { Arte de canto llano, en Cere- } \\
\text { monial Monástico }\end{array}$ & $\begin{array}{l}\text { Santo Domingo de Silos, Biblioteca } \\
\text { de la Abadía de Santo Domingo } \\
\text { de Silos, MS 14, ff. 100r-106r. }\end{array}$ \\
\hline & 3 & $\begin{array}{l}1480, \\
\text { Sevilla }\end{array}$ & $\begin{array}{l}\text { Ars cantus mensurabilis et } \\
\quad \text { inmensurabilis }\end{array}$ & $\begin{array}{l}\text { San Lorenzo de El Escorial, Real } \\
\text { Biblioteca del Monasterio de San } \\
\text { Lorenzo de El Escorial, c-III-23. }\end{array}$ \\
\hline & 4 & Siglo XV & Ars cantus plani, en Cantoral & $\begin{array}{l}\text { Barcelona, Biblioteca de Catalunya, } \\
\text { M } 1327 \text { G. Fol, ff. 72v-89r. }\end{array}$ \\
\hline & 5 & $\begin{array}{l}2^{\circ} \text { tercio del } \\
\text { siglo XV }\end{array}$ & Tratado de contrapunto & $\begin{array}{l}\text { Girona, Archivo Capitular, Ms. 91, } \\
\text { ff. } 118 \mathrm{r}-119 \mathrm{v} .\end{array}$ \\
\hline \multirow{4}{*}{ 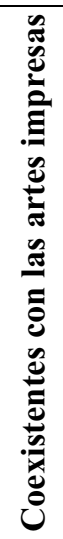 } & 6 & 1494 & $\begin{array}{l}\text { [Tratado dos Tons das antifonas } \\
\text { e Arte do cantochão] }\end{array}$ & $\begin{array}{l}\text { Évora, Biblioteca Pública de Évora, } \\
\text { Códice CXIII/1-40. }\end{array}$ \\
\hline & 7 & $1500-1525$ & $\begin{array}{l}\text { Tractat molt util de la art de } \\
\quad \text { can pla }\end{array}$ & $\begin{array}{l}\text { Barcelona, Biblioteca de Catalunya, } \\
\text { Ms. 1325/1. }\end{array}$ \\
\hline & 8 & $\begin{array}{l}\text { Inicios del } \\
\text { siglo XVI }\end{array}$ & $\begin{array}{l}\text { Arte de melodia sobre canto } \\
\text { lano y canto d'organo, en } \\
\text { Micel-lània de tractats musi- } \\
\text { cals }\end{array}$ & $\begin{array}{l}\text { Barcelona, Biblioteca de Catalunya, } \\
\text { Ms. 1325/2. }\end{array}$ \\
\hline & 9 & Siglo XVI & Tractat de música & $\begin{array}{l}\text { Barcelona, Biblioteca de Reserva } \\
\text { de la Universidad de Barcelona, } \\
\text { Ms } 2044 .\end{array}$ \\
\hline
\end{tabular}

\footnotetext{
${ }^{47}$ Higini Anglès, "Un tractat de cant plà d'autor anònim del segle XVI", Spanische Forschungen der Görresgessellschaft, I/2 (1963), pp. 277-293.
} 
Carlos Romero de Lecea señala que Portus musice (Salamanca, 1504) de Diego del Puerto emana de la cultura manuscrita puesto que nace "como un catón o una carti1la musicales manuscritos para uso del maestro cantor". 48 Jacques Lafaye indica que los primeros impresos se consideraron "ante todo como un medio más rápido de copiar textos, un truco técnico, algo como la fotocopia cuando se inventó y se difundió en la segunda mitad del siglo XX". ${ }^{49}$ Mientras que los manuscritos correspondientes a los números 7, 8 y 9 de la Tabla II.6 (Tractat molt útil de la art de can pla; Arte de melodia sobre canto lano y canto d'organo; y Tractat de música) se analizarán en el Capítulo IV como fuente de información acerca de los usos de las artes de canto impresas, los manuscritos 1, 2 y 4 (el tratado de Estevan; el Arte de canto llano de Silos; y Ars cantus plani) se utilizarán en esta sección para determinar hasta qué punto las artes de canto son consecuencia de la cultura de la imprenta.

Pilar Escudero, editora del libro de Estevan, califica a éste de revolucionario por escribir en lengua vulgar en un momento en que "los saberes de todo tipo se transmitían en latín"; Escudero vincula esta característica al propósito de Estevan de formar musicalmente al pueblo y no sólo a "clérigos y eruditos" que sí podían leer en latín (Escudero habla de "afán democratizador"). ${ }^{50}$ El tratado de Estevan y el manuscrito de Silos poseen buena parte de las características de los libros que son objeto de esta investigación, como muestra la Tabla II.7, en la que se comparan los dos manuscritos con la edición de 1562 del Arte de canto llano de Juan Martínez. ${ }^{51}$ Parece que estos libros manuscritos no constituyen ejemplos aislados sino que por el contrario reflejan una tendencia generalizada que derivó en las artes impresas.

\footnotetext{
${ }^{48}$ Romero de Lecea, "Las más antiguas imprentas musicales hispanas III”, p. 90.

${ }^{49}$ Lafaye, Albores de la imprenta, p. 17.

${ }^{50}$ Escudero, “Tratados musicales”, pp. 7 y 44.

${ }^{51}$ Escudero, "Tratados musicales", pp. 44-45, ha comparado el tratado de Estevan con los de Guillermo del Podio, el anónimo de Silos, y los libros de Marcos Durán, Aguilar, Spañón, Puerto, Tovar, Martínez de Bizcargui, Montanos, Bermudo y Villafranca.
} 
Tabla II.7: Comparación del tratado manuscrito de Fernand Estevan, el MS 14 de Silos y el Arte de canto llano de Juan Martínez

\begin{tabular}{|c|c|c|c|}
\hline & $\begin{array}{l}\text { Fernand Estevan, Reglas de } \\
\text { canto plano è de contra- } \\
\text { punto è de canto de organo } \\
\text { (Sevilla, 1410). }\end{array}$ & $\begin{array}{l}\text { Arte de canto llano, MS } 14 \\
\text { de Silos (antes de 1436). }\end{array}$ & $\begin{array}{l}\text { Juan Martínez, Arte de } \\
\text { canto llano (Zaragoza: } \\
\text { viuda de Bartholome de } \\
\text { Nagera, } 1562[1530]) \text {. }\end{array}$ \\
\hline Formato & $4^{\mathrm{o}}, 41 \mathrm{f}$., gótico & $24,3 \times 16,5 \mathrm{~cm}, 8$ f., gótico & $8^{\circ}, 35$ f., gótico \\
\hline Tinta & Negra y roja & Negra, azul y roja & Negra y roja \\
\hline Idioma & Castellano & Castellano & Castellano \\
\hline Estilo & Conciso & Preguntas y repuestas & Conciso \\
\hline Estructura & División en reglas & Texto sin divisiones & División en capítulos \\
\hline Contenido & $\begin{array}{l}\text { Origen del canto llano, } \\
\text { letras, signos, claves, } \\
\text { deducciones, propiedades, } \\
\text { conjuntas, voces, mudan- } \\
\text { zas, disjuntas, tonos. }\end{array}$ & $\begin{array}{l}\text { Letras, signos, voces, } \\
\text { deducciones, propiedades, } \\
\text { mudanzas, disjuntas, con- } \\
\text { juntas, tonos. }\end{array}$ & $\begin{array}{l}\text { Letras, signos, mudanzas, } \\
\text { claves, modos, disjuntas, } \\
\text { consonancias, géneros de } \\
\text { música. }\end{array}$ \\
\hline
\end{tabular}

El Ars cantus plani en catalán de la Biblioteca de Catalunya también apoya la hipótesis de que las artes de canto en lengua vernácula proliferaron en forma manuscrita. Este arte de canto llano ocupa los folios $72 \mathrm{v}$ a $89 \mathrm{r}$ de un cantoral que perteneció al Convento de Clarisas de la Santísima Trinidad de Valencia y después formó parte de la biblioteca particular de mossen Roc Chabàs, canónigo de la Catedral de Valencia; Felip Pedrell lo tomó de esta biblioteca particular para publicar en 1912 el Ars cantus plani como Art del cant plà en la colección Recull de textes catalans antichs. ${ }^{52} \mathrm{El}$ cantoral en su totalidad está en latín y el arte de canto llano es el único texto en lengua vernácula. Es más, el arte de canto llano va precedido por un "ars musice qui apellatur liberalis" (f. 71) y seguido por unas definiciones musicales en formato de pregunta-respuesta también en latín. El arte de canto llano consta de los siguientes apartados: "Seguexense los signes", "Sigueixsense les mudances", "Segueixse la noticia de les dues claus del cant", "Sequitur de tonis", "Seguitur de coniunctis", "Sequitur de difiunctis" y "Altra diffinitio de disienta"; además, contiene una mano guidoniana y una escala (véase Ilustración II.3).

\footnotetext{
${ }^{52}$ Pedrell, ed., Art del can plà.
} 
Ilustración II.3: Ars cantus plani, MS (siglo XVI), f. 80r. Barcelona, Biblioteca de Catalunya, M 1327 G. Fol, ff. 72v-89r.

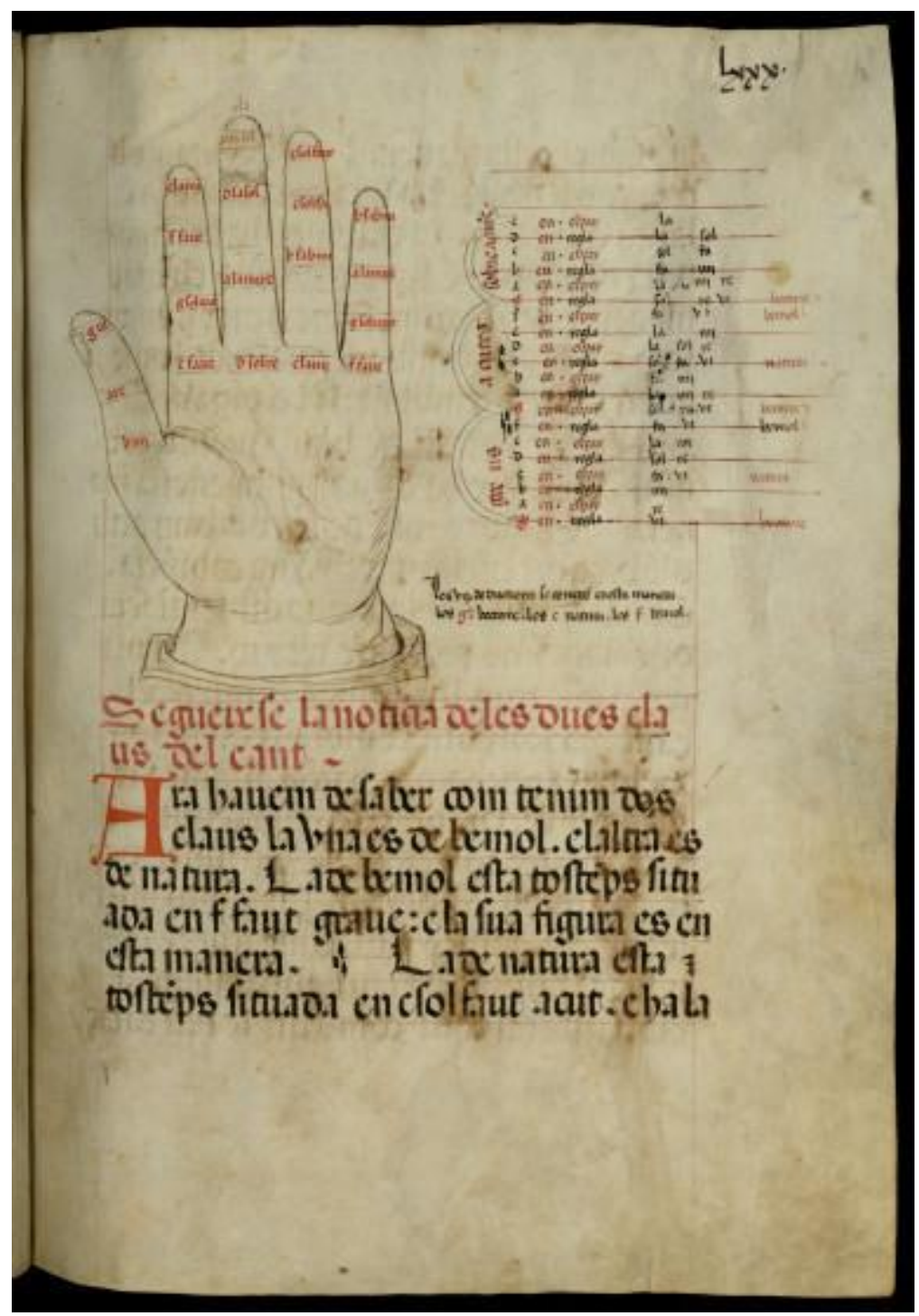

Por tanto, las artes de canto en lengua vernácula no surgieron como producto de la cultura de la imprenta, puesto que existían con anterioridad en forma manuscrita, modalidad en la que se mantuvieron incluso cuando ya había obras impresas de este tipo. Quizás el Arte de cantollano anónimo R/14670 de la Biblioteca Nacional de España, como veremos en el Capítulo III, se encuentre más cerca de la tradición manuscrita, sin indicaciones tipográficas o de autoría ni materiales preliminares. Las fórmulas que utiliza para pasar de un tema a otro son muy similares a las del arte de canto llano ma- 
nuscrito del Monasterio de Silos. ${ }^{53}$ Esto sugiere que desde la Edad Media hasta el Renacimiento se produjo una continuidad a la que se incorporaron las peculiaridades que ofrecía la imprenta. Si bien encontramos una tradición de artes de canto previa a la difusión de la imprenta, este nuevo medio de reproducción proporcionó a los autores nuevas vías para lograr viejos fines. ${ }^{54}$ La imprenta no sólo permitió mantener la fidelidad del texto original y dio autoridad a las obras, sino que indudablemente facilitó el acceso al producto y su difusión en grandes cantidades, convirtiendo las artes de canto en un fenómeno "de masas". Además, la imprenta era un negocio y por tanto debieron de imprimirse los productos que la gente demandaba; ${ }^{55}$ por ejemplo, Emilio Pujol hace alusión a la decisión de Luis de Narváez de esperar la reacción del público y por tanto el grado de éxito de su libro antes de publicar otras obras "de más fundamento". ${ }^{56}$ Pero también, como descubriremos más abajo, se formularon estrategias de venta, y los editores influyeron en la configuración de los gustos de los compradores. ${ }^{57}$

\footnotetext{
${ }^{53}$ Gómez Muntané, La música medieval en España, p. 275, sugiere incluso que el tratado impreso de la Biblioteca Nacional de España y el manuscrito del Monasterio de Silos fueron elaborados a partir de una fuente común, que también utilizó Fernand Estevan, aunque sin especificar por qué: "Aunque ofrezcan variantes entre ellos, los tres tratados derivan de otro desconocido que fue el que debió utilizar Fernand Estevan. Su autor, activo hacia 1400, tanto pudo ser Remón de Cacio como cualquier otro experto en los entresijos del canto llano [...]". La semejanza de estos tratados en cuanto a sus contenidos no es sorprendente, puesto que, como se señaló en el Capítulo I, el contenido de las artes de canto es bastante estable. A esto hay que añadir el que el impreso de la Biblioteca Nacional de España fue impreso en Sevilla, donde también había sido copiado el tratado de Estevan, por lo que ambos deben reflejar la tradición de aprendizaje del canto llano en el ámbito de la Catedral de Sevilla. El Arte de canto llano (Sevilla, 1530) de Juan Martínez, maestro de los mozos de coro de la Catedral de Sevilla, presenta la misma ordenación de los contenidos que el anónimo de la Biblioteca Nacional (véase el Capítulo III).
}

${ }^{54}$ Elizabeth Lewisohn Eisenstein, The Printing Press as an Agent of Change: Communications and Cultural Transformations in Early-Modern Europe (Cambridge: Cambridge University Press, 1979), p. 684.

${ }^{55}$ Ife, "La imprenta y la música instrumental del Renacimiento español”, p. 225, menciona las dos principales tesis defendidas por los estudiosos con respecto a la invención y desarrollo de la imprenta: la evolucionista, según la cual se publicó lo que la gente necesitaba (de modo que la imprenta sirvió para mantener vivo el pensamiento medieval en el mundo renacentista); y la revolucionaria, que mantiene que existió una relación de causa-efecto entre la llegada de la imprenta y la revolución intelectual que produjo el pensamiento científico moderno.

${ }^{56}$ Emilio Pujol, Luys de Narváez: Los seys libros del Delphin de música de cifra para tañer vihuela (Valladolid, 1538) [Monumentos de la Música Española, 3] (Barcelona: CSIC, 1944), p. 112.

${ }^{57}$ Por ejemplo, Bian Richardson, Print Culture in Renaissance Italy: The Editor and the Vernacular Text, 1470-1600 (Cambridge: Cambridge University Press, 1994), p. 183, sostiene que los editores contribuyeron a la evolución de una erudición vernácula paralela a la clásica. 


\subsubsection{CUESTIONES TÉCNICAS: LA CONFIGURACIÓN DEL PRODUCTO}

Al igual que la legislación y el fin comercial determinaron la apariencia física de las artes de canto, las cuestiones técnicas también influyeron en las características de estos libros. ${ }^{58}$ El primer determinante de la configuración de los primeros libros impresos era el diseño del modelo manuscrito, por lo que basta con analizar las características de los libros manuscritos para cotejarlas con sus "imitaciones" impresas. ${ }^{59}$ Por ejemplo, Juan José Rey Marcos señala con respecto a Portus musice: "Don Carlos Romero de Lecea me ha hecho notar la similitud que ofrece la distribución de la página con los códices medievales de tipo doctrinal, en cuyos márgenes se acumulan las anotaciones que cada nuevo lector cree conveniente añadir". ${ }^{60}$ Las notaciones cuadrada y mensural, los sistemas de tablatura y las alteraciones accidentales ya existían, y el uso de tintas negra y roja era común en los manuscritos.

Aunque encontramos artes de canto sin ejemplos musicales, no podemos hablar de un desarrollo progresivo desde ediciones sin música a ediciones con música, puesto que la inclusión de música impresa no sólo era cuestión de habilidad técnica, sino que también atendía a consideraciones económicas. El anónimo R/14670(1) de la Biblioteca Nacional de España no incluye ejemplos musicales y el texto discurre casi sin solución de continuidad quizás por tratarse de un pequeño resumen con pocas hojas, y por tanto de bajo precio, destinado a un amplio grupo de compradores. Tampoco encontramos ejemplos musicales en el tratado de Aguilar ni en el Tractado breue de principios de canto llano (c. 1521) de Espinosa, quien, como indicaba anteriormente, ilustrativamente remitía a su libro más amplio de 1520 para que el lector se informase "de las autoridades, demostraciones y exemplos para no dexar ninguna cosa atras". ${ }^{1}$ Estas "versiones" más breves y, por tanto, incluso más baratas de las artes de canto recuerdan a la teoría

\footnotetext{
${ }^{58}$ Por ejemplo, con respecto a la impresión de música instrumental, Ife, "La imprenta y la música instrumental del Renacimiento español", p. 236, sospecha que podría haber una correlación entre las posibilidades técnicas de la imprenta española y las formas musicales desarrolladas: “Es que los organistas españoles no conocían la tocata y no la tocaban, o es que los impresores españoles no lograron representarla en letras de molde?"

${ }^{59}$ Hipólito Escolar Sobrino, Historia del libro (Madrid: Ediciones Pirámide, 1986), pp. 301-306.

${ }^{60}$ Rey Marcos, Portus Musicae de Diego de Puerto, p. 76.

${ }^{61}$ Espinosa, Tratado breue de principios de canto llano, ff. A1v-A2r, "Al reuerendo et muy magnifico señor”.
} 
de Roger Chartier de la "bibliothèque bleue" que mencioné en el Capítulo I (resúmenes de obras más amplias vendidos a bajo precio). ${ }^{62}$

El principal problema del impresor musical era la correcta distribución de notas, pautado y texto de manera que los tres elementos se correspondieran. Así, según el propósito del libro y sus contenidos, más que como efecto del grado de competencia técnica del impresor o del desarrollo técnico de la imprenta, se resolvió esta cuestión y se seleccionó la clase de impresión a llevar a cabo: xilografía o tipos móviles. Aunque la impresión xilográfica podría concebirse como una técnica más temprana y simple que la tipografía, Kathi Meyer-Baer señala que esta concepción es cierta sólo en un sentido muy restringido, puesto que "hay impresión xilográfica en la mayoría de los incunables de teoría de la música e impresión tipográfica en casi todos los incunables litúrgicos". ${ }^{6}$ En Occidente algunos libros de pequeño formato continuaron incluyendo impresión xilográfica hasta entrado el siglo XIX. ${ }^{64}$ Puesto que los contenidos de las artes de canto (por ejemplo, la inclusión de una mano guidoniana) apenas diferían de edición en edición e incluso entre un autor y otro debido a su propósito didáctico, la técnica que se solía utilizar, tanto en el período de los incunables como ya entrado el siglo XVI, era la xilografía o impresión a partir de planchas de madera grabadas. Los ejemplos musicales de Lux bella fueron realizados con xilografía, pero también los de tratados posteriores aunque ya hubieran avanzado las técnicas de impresión en el mundo ibérico. ${ }^{65}$ Antes de la invención de la imprenta, se utilizaba ya un conato del método xilográfico en Europa (principalmente en los Países Bajos y Alemania) para estampar imágenes piadosas que después se unieron formando libros caracterizados por su bajo precio y por la importancia otorgada a la imagen, los cuales parecen destinados "a sacerdotes que deseaban utilizarlos para la enseñanza de la doctrina religiosa". ${ }^{66}$ Por tanto, no es sorprendente que

\footnotetext{
${ }^{62}$ Chartier, The Cultural Uses of Print in Early Modern France, p. 240.

${ }^{63}$ Kathi Meyer-Baer, Liturgical Music Incunabula: A Descriptive Catalogue (Londres: The Bibliographical Society, 1962), p. xxiii: "There is printing from woodblocks in most of the incunabula on the theory of music and there is printing from type in almost all the liturgical incunabula".

${ }^{64}$ Boorman et al., "Printing and Publishing of Music".

${ }^{65}$ Romero de Lecea, Introducción a los viejos libros de música, p. 101. Reproducciones de fragmentos de Lux bella se incluyen en Francisco Vindel, El arte tipográfico en España durante el siglo XV (Madrid: Ministerio de Asuntos Exteriores, Relaciones Culturales, 1945-1951), vol. 4, p. 147, no 47.

${ }^{66}$ Escolar Sobrino, Historia del libro, p. 281.
} 
las artes de canto, de similares características y propósito, utilizaran el método xilográfico para los ejemplos musicales e ilustraciones, puesto que éste "hacía posible la impresión de libros de teoría de la música en ausencia de tipos mensurales caros o fuentes complejas para los neumas del canto llano". ${ }^{67}$

Las notas musicales solían imprimirse en negro y el pautado en rojo, como en algunos manuscritos, aunque también podían imprimirse todos los elementos en negro; por ejemplo, las ediciones españolas de los siglos XVI y XVII del libro de Juan Martínez combinan tinta roja y negra, mientras que en las ediciones portuguesas, con la excepción de la primera, sólo se utiliza tinta negra. Al principio, el método xilográfico fue utilizado para imprimir primero el pautado y, a continuación, las notas se insertaban a mano o, en orden inverso, primero se escribían las notas y después se estampaba el pautado (véase Ilustración II.4). El uso de tipos móviles para la impresión de la música cambió la apariencia de los ejemplos musicales. Tras un primer estadio en que se requería que el pliego pasara por la imprenta varias veces (una para imprimir cada elemento: pautado, música y texto) en lo que se conoce como impresión múltiple, el siguiente paso fue tallar la nota y su segmento de pentagrama correspondiente en el mismo tipo, de manera que nota y pentagrama eran impresos en una sola operación, resultando discontinuidades en las líneas del pautado. ${ }^{68}$ La investigación en este ámbito podría clarificar si las artes de canto funcionaron para los impresores establecidos en la Península Ibérica a modo de ensayo de cómo imprimir música.

\footnotetext{
${ }^{67}$ Judd, Reading Renaissance Music Theory, p. 19: "Woodcut music illustrations made possible the printing of music theory books in the absence of expensive mensural types or complex fonts for plainchant neumes". Sobre las condiciones financieras de la imprenta (el elevado coste de los punzones, las matrices y el papel; la cuantiosa inversión inicial; y la lentitud que conllevaba la amortización del capital invertido), véase Lafaye, Albores de la imprenta, pp. 28-31. Para un estudio de caso acerca del funcionamiento de una imprenta musical y sus costes, véase Bernstein, Music Printing in Renaissance Venice, sobre el taller de Scotto.

${ }^{68}$ William Gamble, Music Engraving and Printing: Historical and Technical Treatise (Londres: Pitman, 1923), p. 22; Donald William Krummel y Stanley Sadie, eds., Music Printing and Publishing (Londres: Macmillan, 1990).
} 
Ilustración II.4: Música manuscrita sobre pentagrama impreso en Guillermo del Podio, Ars musicorum (Valencia: Peter Hagenbach \& Leonhard Hutz, 1495), f. 54r. Barcelona, Biblioteca de Catalunya, 11-VII-15.

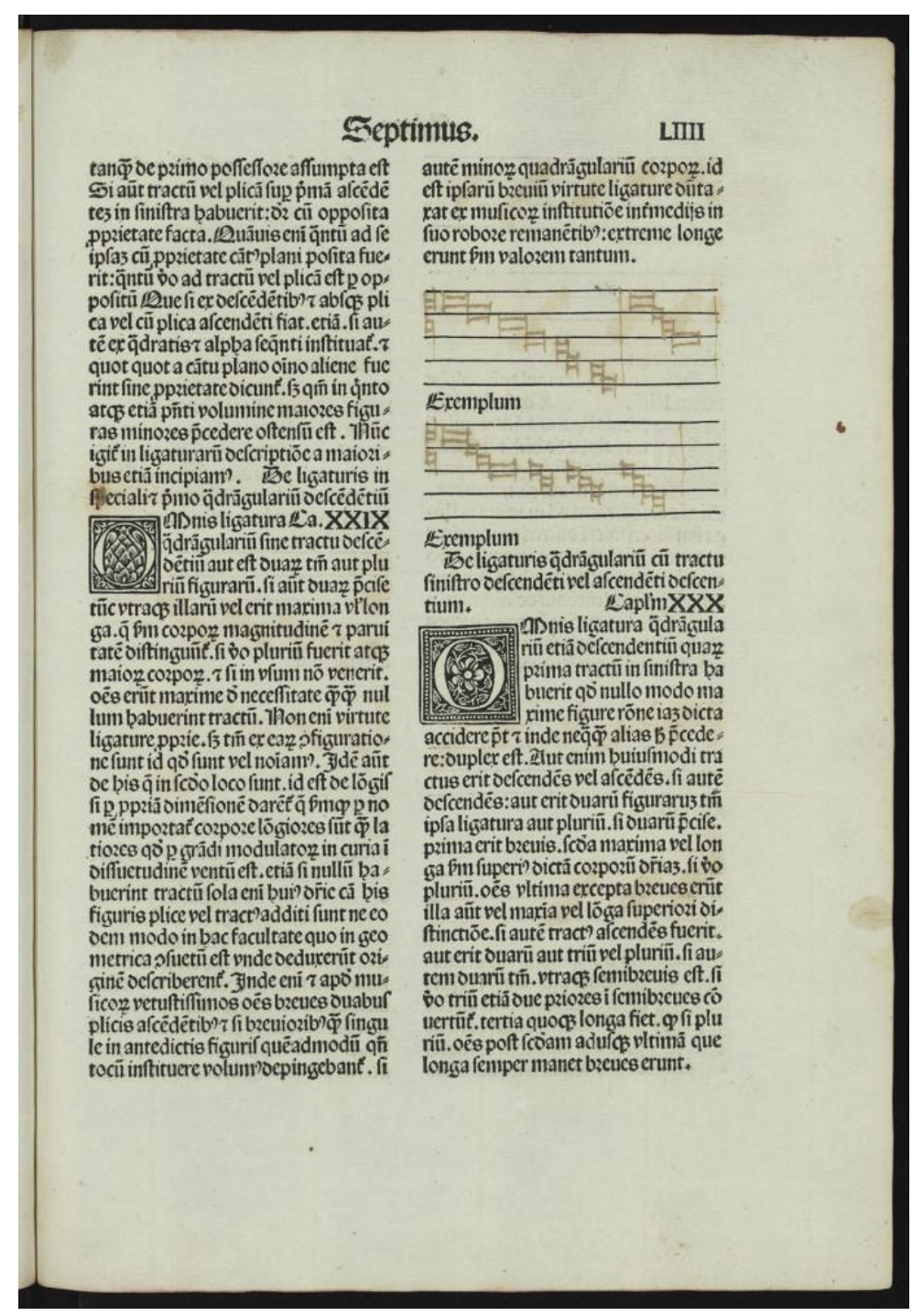

$\mathrm{Si}$, como indica Jacques Lafaye, los impresores españoles y portugueses preferían imprimir géneros librescos que "exigían escasa inversión y corto tiempo de trabajo y se vendían rápido en gran cantidad", 69 no es sorprendente que, como muestran los inventarios, las "artes de..." (no sólo de canto) fuesen un producto muy popular entre los impresores. ${ }^{70} \mathrm{Al}$ igual que los pliegos sueltos, las "artes de..." y otros libros de estas características debieron funcionar como un "estabilizador económico" para las impren-

\footnotetext{
${ }^{69}$ Lafaye, Albores de la imprenta, p. 31.

${ }^{70}$ Knighton, “Libros de canto", p. 227.
} 
tas. María del Carmen Álvarez Márquez ha señalado que, puesto que el objetivo de la imprenta era generalmente económico, se trataba de editar "obras cuyo mercado estuviese, más o menos, asegurado porque el éxito de la obra o del autor se diese por descontado". ${ }^{71}$ Por tanto, volúmenes de pequeño formato y gran demanda como las artes debieron desempeñar un importante papel en el equilibrio de los balances económicos de estas empresas. Por ejemplo, en el inventario de libros en stock de Jorge Coci en 1537 aparece una distinción entre "artes de canto llano" (3 dineros) y "artes de canto de órgano" (6 dineros) y posiblemente ambas entradas hagan referencia al Arte de canto llano et contrapunto et canto de organo de Martínez de Bizcargui. Esto podría sugerir que Coci reprodujo pliegos sueltos que contenían las diferentes partes de la obra. ${ }^{72}$

Característica de la imprenta es que en cierto modo proporciona autoridad; el autor en ocasiones estaba presente durante todo el proceso y a veces corregía las pruebas asumiendo la responsabilidad de la calidad del texto. Una de las conclusiones presentadas por John Griffiths tomando como base el Arte de tañer fantasía de Tomás de Santa María es que los autores de los libros de música tenían un papel directo en la publicación. ${ }^{73}$ La misma idea es planteada por Tess Knighton con respecto al libro de Gonzalo de Baena, Arte nouamente inuentada pera aprender a tanger (Lisboa, 1540): “dada la naturaleza pionera de la publicación (al menos en Portugal) y la exclusiva tablatura para tecla usada por Baena, éste debió haber trabajado cerca del impresor para producir un volumen de su satisfacción". ${ }^{74}$ El contrato entre Hernando de Cabezón y el impresor Francisco Sánchez para la publicación de las Obras de musica para tecla, arpa y vihuela (Madrid, 1578) de Antonio de Cabezón estipulaba incluso que Hernando se quedaría con los punzones, matrices, puntos y reglas utilizados en la impresión. ${ }^{75}$ No obstante, la

\footnotetext{
${ }^{71}$ Álvarez Márquez, La impresión y el comercio de libros en la Sevilla del quinientos, p. 16.

${ }^{72}$ Véase Knighton, “Libros de canto”, p. 229.

${ }^{73}$ Griffiths, "The Printing of Instrumental Music in Sixteenth-Century Spain”, p. 3310.

74 Tess Knighton, “A Newly Discovered Keyboard Source (Gonzalo de Baena's Arte nouamente inuentada pera aprender a tanger, Lisbon, 1540): A Preliminary Report", Plainsong and Medieval Music, V/1 (1996), pp. 81-112, p. 95: "Given the pioneering nature of the publication (at least in Portugal) and the unique keyboard tablature used by Baena, he must have worked closely with the printer in order to produce the volume to his satisfaction".

${ }^{75}$ Nicolás Álvarez Solar-Quintes, "Nuevas noticias de músicos de Felipe II, de su época, y sobre la impresión de música", Anuario musical, XV (1960), pp. 195-217, p. 209.
} 
impresión de artes de canto no implicaba las dificultades de imprenta que acarreaban libros de música instrumental como los de Santa María, Baena y Cabezón.

Según Clive Griffin, “un impresor nos ofrece interés porque sus productos son libros, y el estudio de los mismos puede proporcionar pruebas del ambiente cultural y espiritual de una época". ${ }^{76}$ Màrius Bernadó ha advertido cierta especialización entre los impresores dentro de dos tipologías de música impresa como son los tratados teóricos y los libros litúrgicos. ${ }^{77}$ Las reediciones de las artes de canto a veces las realizaba el impresor de la edición príncipe, pero en otras ocasiones se llevaban a cabo en talleres de imprenta diferentes. ${ }^{78}$ De la tabla recogida en el Apéndice 7, en la que se relacionan los impresores de artes de canto, las ciudades en que trabajaron y los títulos que imprimieron dentro de esta tipología, se deduce que no había impresores especializados en este género libresco (como tampoco los hubo dedicados exclusivamente a la música), puesto que imprimieron un solo título o a lo sumo dos. Esta circunstancia ponía en una difícil situación a los autores de libros de música; según José Augusto Alegria, "Mateo de Aranda hizo imprimir su tratado de canto llano en Lisboa, sólo porque en Évora no había impresor de esa altura o si lo había, no tenía los caracteres musicales para la impresión". ${ }^{79}$ Francisco de Montanos hacía referencia también a las dificultades técnicas de la impresión musical en su Arte de música (1592): “en los exemplos de contrapunto sobre tiple, y en los exemplos de contrapunto, sobre canto de Organo ay algunas figuras mal

\footnotetext{
${ }^{76}$ Clive Griffin, Los Cromberger: la historia de una imprenta del siglo XVI en Sevilla y Méjico (Madrid:
} Cultura Hispánica, 1991 [1988]), p. 16.

${ }^{77}$ Bernadó, “Impresos litúrgicos”, p. 255.

${ }^{78}$ Sobre los impresores que trabajaron en el mundo ibérico renacentista, véase Juan Delgado Casado, Diccionario de impresores españoles (Madrid: Arco Libros, 1996), 3 vols. Véanse también Joaquín Hazañas y la Rúa, La imprenta en Sevilla: ensayo de una historia de la tipografía sevillana y noticias de algunos de sus impresores desde la introducción del arte tipográfico en esta ciudad hasta el año de 1800 (Sevilla: Imp. de la Revista de Tribunales, 1892); Francisco Escudero y Perosso, Tipografia hispalense: anales bibliográficos de la ciudad de Sevilla desde el establecimiento de la imprenta hasta fines del siglo XVIII (Madrid: Sucesores de Rivadeneyra, 1894); Konrad Haebler, The Early Printers of Spain and Portugal (Londres: Chiswick Press, 1897); Marcelino Gutiérrez del Cano, "Ensayo de un catálogo de impresores españoles desde la introducción de la imprenta hasta fines del siglo XVIII", Revista de Archivos Bibliotecas y Museos, III (1899), pp. 662-671; y IV (1900), pp. 77-85; Augusto Jurado, La imprenta y el libro en España: desde los inicios hasta el principio de las actuales técnicas. Las artes gráficas en el umbral del siglo XXI (Madrid: Comunicación Gráfica, 2001), pp. 136-137; y María Marsá Vilá, Materiales para una historia de la imprenta en Valladolid (siglos XVI y XVII) (León: Universidad de León, 2007).

${ }^{79}$ Alegria, "Notícia bibliográfica", p. 49: "Mateus de Aranda fez imprimir o seu tratado de canto chão na cidade de Lisboa, só porque em Évora não havia impresor nessa altura ou se o havia, faltavam-lhe os caracteres musicais para a impressão". 
señaladas por falta de tinta con poco que aduiertan, se entendera lo que es en la segunda Estampa abra emienda en todo". ${ }^{80}$ En su Arte y suma de canto llano (1595), Juan Francisco Cervera hacía alusión al retraso que estaba sufriendo la publicación de otro tratado que tenía preparado por la falta de los moldes necesarios:

Como las desseo salgan, para que el amado lector se aproueche, y aproueche a otros, que confio en Dios, y tuuiendo salud no sera mucho antes de poco tiempo salga otra arte de canto de organo y contrapunto, como ya he dicho: que si no ha salido y tarda, es por la falta de los moldes que me dizen se han perdido, o por mejor dezir no los hay. ${ }^{81}$

Los impresores que imprimieron más de un arte de música son Juan de Porras en Salamanca (Lux Bella y Portus musice), Pedro Patricio Mey en Valencia (los libros de Cervera y Monserrate), Juan Gysser en Salamanca (la Sumula de Marcos Durán y la reimpresión de Lux bella del mismo autor) y Jacobo Cromberger en Sevilla (el Arte de cantollano anónimo de la Biblioteca Nacional de España y una reimpresión de Lux bella). La impresión de varias artes de canto en una misma imprenta, el carácter itinerante de los primeros impresores que trabajaron en la Península Ibérica, ${ }^{82}$ los acuerdos de intercambio de materiales entre talleres, y la endogamia característica del gremio ${ }^{83}$ son circunstancias que llevan a preguntarse de qué manera circularon los materiales tipográficos entre los impresores de artes de canto. El Arte de canto llano de Juan Martínez, que será el foco del Capítulo III, constituirá un caso paradigmático para aproximarse a la cuestión de la circulación de los materiales tipográficos.

\footnotetext{
${ }^{80}$ Montanos, Arte de musica, f. 50r, "Lugares comunes".

${ }^{81}$ Cervera, Arte y suma de canto llano, pp. 60-61. José Ruiz de Lihory, La música en Valencia: diccionario biográfico y crítico (Valencia: Librerías París-Valencia, 1987 [1903]), p. 213, señala que el tratado que anunciaba Cervera "dudamos mucho llegara á imprimirse; pero su original manuscrito está en poder de los PP. Dominicos”. Podría referirse al Real Convento de Santo Domingo de Valencia, actualmente Capitanía General de Valencia.

${ }^{82}$ López-Vidriero y Cátedra García, La imprenta y su impacto en Castilla, p. 29; Clive Griffin, "La carrera del impresor en la Edad Moderna: Pierre Regnier, peripecias de un impresor en la Barcelona del siglo XVI", en La memoria de los libros: estudios sobre la historia del escrito y de la lectura en Europa y América, coord. por María Isabel de Páiz Hernández, Pedro Manuel Cátedra García y María Luisa LópezVidriero (Salamanca: Instituto de Historia del Libro y de la Lectura, 2004), vol. 1, pp. 383-403, p. 384.

${ }^{83}$ Véase el Capítulo VI.
} 


\subsubsection{LA INTERACCIÓN PRODUCCIÓN-DEMANDA:}

\section{EL TAMAÑO DE LAS TIRADAS Y LAS REEDICIONES}

En su estudio del libro durante el Siglo de Oro, Agustín González de Amezúa y Mayo señala que la tirada estándar oscilaba entre los 1000 y los 2000 ejemplares, "salvo cuando se trata de cartillas, catecismos, breviarios y otras obras de liturgia y enseñanza, excediendo entonces de los 3000 y más cuerpos". ${ }^{84}$ Las tiradas de las artes de canto llano tuvieron que ser elevadas como muestra el número de estos ejemplares que aparecen en los inventarios de los Cromberger. Por ejemplo, en el "Inventario de los bienes que dejó a su muerte Jacobo Cromberger", realizado en 1529, encontramos 1.038 “cartillas d[e] arte" (2.076 maravedíes el lote, 2 maravedíes el ejemplar), 2.355 “artesycas de canto llano" (4.610 maravedíes el lote, 2 maravedíes el ejemplar) y 324 "artes d[e] canto d[e] la mano" (2.025 maravedíes el lote, 6,25 maravedíes el ejemplar). ${ }^{85}$ El tamaño de las tiradas de las artes de canto indica que existía una importante demanda y también que el mercado iba más allá de un ámbito regional; ${ }^{86}$ aunque parece que no existía un propósito de introducir las artes de canto impresas (en lengua vernácula) dentro de los circuitos del mercado europeo, sí debieron de tener una importante presencia en el mercado con el Nuevo Mundo.

Además de la producción en grandes tiradas, otra muestra de la importante demanda que tuvieron las artes de canto es que algunas fueron reeditadas una y otra vez, no sólo en la misma imprenta de donde salió la edición príncipe, sino también en imprentas situadas en otros reinos. Respecto al primer caso, Rudolf Hirsch opina que, con bastante seguridad, "un libro no se volvía a imprimir, y no lo hacía ciertamente el mismo tipógrafo, más que en el caso de que hubiera una evidente demanda no satisfecha". ${ }^{87}$

\footnotetext{
${ }^{84}$ González de Amezúa y Mayo, Cómo se hacía un libro en nuestro Siglo de Oro, p. 29.

${ }^{85}$ José Gestoso y Pérez, Noticias inéditas de impresores sevillanos (Sevilla: Gomez hnos., 1924), pp. 3656; Clive Griffin, "Un curioso inventario de libros de 1528", El libro antiguo español: actas del primer Coloquio Internacional (Madrid, 18 al 20 de diciembre de 1986) [El libro antiguo español, 1], dir. por María Luisa López-Vidriero y Pedro Manuel Cátedra García (Salamanca: Universidad de Salamanca, 1988), pp. 189-224 ( ${ }^{\text {os }} 8,34$ y 114); y Ros-Fábregas, "Libros de música en bibliotecas españolas del siglo XVI" (II), p. 36, nº 18 .

${ }^{86}$ Sobre esta circunstancia en el caso de la música instrumental, véanse Griffiths, "The Printing of Instrumental Music in Sixteenth-Century Spain”, p. 3315; y “La vihuela en la época de Felipe II”, p. 425.

${ }^{87}$ Rudolf Hirsch, "Imprenta y lectura entre 1450 y 1550", en Libros, editores y público en la Europa Moderna, ed. por Armando Petrucci (Valencia: Edicions Alfons el Magnànim, 1990 [1977]), pp. 27-70, p. 30. Véanse también sus trabajos Printing, Selling and Reading, 1450-1550 (Wiesbaden: Harrassowitz,
} 
Según los datos del Apéndice 7, varios impresores llevaron a cabo varias ediciones de un mismo libro: Nicolao Carvalho del libro de Juan Martínez; Fadrique Alemán de Basilea, Juan de Junta y Jorge Coci del libro de Gonzalo Martínez de Bizcargui; Pedro Brun del de Alonso de Spañón; Pascual Bueno, Juan de Ibar, la Imprenta de Música y la Imprenta Real del Arte de canto llano de Francisco de Montanos; Diego Gómez de Loureyro del libro de Pedro Thalesio; y Atanasio Salcedo del Arte ingeniosa de musica de Melchor de Torres. En cuanto al segundo caso (la reimpresión de artes de canto en imprentas situadas en diferentes reinos), la complejidad administrativa de la Península Ibérica durante el período estudiado (debido a su división en reinos con legislación, mercados y redes de distribución propios), así como el requerimiento de privilegios reales únicamente válidos para un reino, provocaron que los libros que tenían éxito fuesen reeditados en otros reinos previa solicitud del privilegio correspondiente. ${ }^{88}$ Como mostraré en el Capítulo III, una de las características más remarcables del Arte de canto llano de Juan Martínez e indicio de su popularidad es que fue reeditado en los reinos de Castilla (Sevilla, Alcalá de Henares, Salamanca y Madrid), Aragón (Zaragoza y Barcelona) y Portugal (Coimbra).

\section{LA DISTRIBUCIÓN}

Tras analizar algunos aspectos de la producción de artes de canto, el siguiente estadio conlleva un estudio de su distribución. La difusión real de las artes de canto es un aspecto a considerar si se pretende una aproximación a la cultura musical del mundo ibérico renacentista, puesto que un libro, independientemente de su interés intrínseco, no pudo influir en la vida cotidiana si no tuvo una amplia circulación. En palabras de Eugenio Garin, "si se quiere comprender una época, no se pueden situar en el mismo plano los libros que todos han leído y apreciado y aquéllos que casi por milagro han sobrevivido en el silencio universal" ${ }^{89}$ Las artes de canto se distribuían en grandes can-

1967); y The Printed Word: Its Impact and Diffusion (Primarily in the 15th-16th) (Londres: Variorum Reprints, 1978).

${ }^{88}$ Moll, "Para el estudio de la edición española del Siglo de Oro", p. 22.

${ }^{89}$ Eugenio Garin, La educación en Europa, 1400-1600: problemas y programas (Barcelona: Crítica, 1987 [1957]), pp. 11-12. 
tidades (lo que indica la existencia de una fuerte demanda) con medios diferentes a aquéllos por los que circulaban los libros manuscritos, pero también a los utilizados para otras tipologías de libros de música; las artes de canto tuvieron una difusión más extensa al entrar de forma más acusada en los circuitos comerciales de los empresarios del libro.

\subsection{La venta}

La imprenta de artes de canto era un negocio con un propósito lucrativo y los verdaderos beneficios económicos se conseguían en el proceso de distribución más que en la impresión propiamente dicha. Buena parte de los grandes impresores del siglo XVI fueron ante todo empresarios para quienes la imprenta era una parte de sus negocios. Hipólito Escolar Sobrino en su Historia del libro indica que "el desarrollo de la industria y comercio del libro, conviene no olvidarlo, fue un negocio dirigido a la obtención de beneficios económicos a través de la satisfacción de las necesidades de lectura de la gente"; ${ }^{90}$ Jacques Lafaye señala que el fin de la imprenta "fue el provecho mercantil; la cultura se ha aprovechado también, pero ha sido como de añadidura". ${ }^{91}$ Un indicio de este afán comercial aparece en los litigios entre libreros o impresores, como por ejemplo el pleito que tuvo lugar en 1559 entre Alonso Pérez, clérigo beneficiado de Rodilana de la diócesis de Medina del Campo y escritor de libros de iglesia, y Francisco Fernández de Córdoba, impresor vallisoletano que antes también había sido escritor de libros; ${ }^{92}$ y la causa de 1524 de Juan Varela de Salamanca y Jácome Alemán contra las exclusivas que se habían otorgado a los talleres de Juan de Brocar y Miguel de Eguía. ${ }^{93}$

Escritas en lengua vernácula, las artes de canto eran productos destinados a un mercado nacional y no afrontaban una competencia internacional. Precisamente éstas son las características de las obras promovidas por la industria editorial ibérica de la época. Como producto de mercado, las artes de canto incluían fórmulas comerciales,

\footnotetext{
${ }^{90}$ Escolar Sobrino, Historia del libro, p. 306.

${ }^{91}$ Lafaye, Albores de la imprenta, p. 15.

92 Álvarez Márquez y Gómez Gómez, "Un pleito para la impresión de libros corales con destino a las Indias"; Emilio Ros-Fábregas, "Libros de música para el Nuevo Mundo en el siglo XVI", Revista de Musicología, XXIV/1-2 (2001), pp. 39-66.

93 Álvarez Márquez y Gómez Gómez, “Un pleito para la impresión de libros corales con destino a las Indias", pp. 23-24, nota 45.
} 
similares a los eslóganes publicitarios actuales que, sin duda, tenían como finalidad atraer la atención de los consumidores para que compraran precisamente ese libro y no otro de similares características. Por ejemplo, las reediciones conimbricenses del Arte de canto llano (Sevilla, 1530) de Juan Martínez impresas en 1597, 1612, 1614 y 1625 incluyen en la portada el lema "a que mais se vsa em toda a Christandade" ("la que más se usa en toda la Cristiandad").

Aunque el impresor realizaba el trabajo de imprenta, el editor era el responsable financiero de la publicación y la distribución, y el librero vendía los libros, ${ }^{94}$ estos roles no se muestran claramente delimitados en la realidad del negocio del libro, de manera que encontramos familias de impresores que desempeñaban los tres papeles, como por ejemplo los Cromberger y los Junta. Jane Bernstein sostiene que "relaciones familiares y personales a menudo formaban la base de las actividades comerciales". ${ }^{95}$ Un ejemplo es la conexión entre Benito Boyer y Francisco del Canto: "Benito Boyer se casó con Isabel Delgado del Canto, hija de Francisco del Canto, impresor de Medina del Campo; de ahí que encontremos muchas ediciones con el siguiente pie de imprenta: Medina del Campo, Francisco del Canto a costa de Benito Boyer". 96 Además, aunque a principios del siglo XVI los principales centros urbanos del mundo ibérico estaban ya provistos de librerías, destacaban en número las regentadas por un librero-impresor, frente a las que no tomaban parte en la producción del libro y a aquéllas que, aunque no disponían de imprenta propia, sí tenían medios económicos para costear las ediciones que luego vendían (Trevor J. Dadson introduce el concepto de "libreros costeadores"). ${ }^{97}$

\footnotetext{
${ }^{94}$ Véase Jordi Rubió i Balaguer, Llibreters i impressors a la Corona d'Aragó (Barcelona: Departament de Cultura de la Generalitat de Catalunya, Abadía de Montserrat, 1993), p. 56. Este texto se publicó originalmente en 1955 como el prólogo a Madurell y Marimón, comp., Documentos para la historia de la imprenta y librería en Barcelona.

95 Bernstein, Music Printing in Renaissance Venice, p. 16: "Familial and personal relationships often formed the basis for commercial activities".

96 Trevor J. Dadson, "La librería de Cristóbal López (1606): estudio y análisis de una librería madrileña de principios del siglo XVII", Coleccionismo y Bibliotecas (siglos XV-XVIII) [El libro antiguo español, 4], dir. por María Luisa López-Vidriero y Pedro Manuel Cátedra García (Salamanca: Universidad de Salamanca, 1988), pp. 167-234, p. 167.

${ }^{97}$ Dadson, “La librería de Cristóbal López”, p. 167. Nelson, "Music Treatises and 'artes para tanger' in Portugal Before the 18th Century", p. 199, señala que había 54 libreros activos en Lisboa a mediados del siglo XVI: "As many as fifty-four livreiros (primarily booksellers) were calculated in the list of 'Gente doficios que há em Lizboa' in Christovão d'Oliveira's Summario of c. 1551-55, for example, and by that time there were about half a dozen printers working in Lisbon".
} 
Trevor J. Dadson señala que "un estudio de los inventarios de impresores y libreros [...] proporciona un cuadro bastante exacto del mercado de libros y las posibilidades de compra durante el siglo XVI español". ${ }^{98}$ Para lograr una panorámica del mercado de las artes de canto durante el Renacimiento, he acudido a los inventarios de existencias de los impresores, libreros y otros distribuidores. El análisis de estas fuentes muestra que, al igual que en el caso de los impresores, tampoco hubo libreros especializados en libros de música. ${ }^{99}$ A la vista del Apéndice 8 de este Trabajo, que presenta los resultados de un vaciado de inventarios de libreros, podemos concluir que las artes de canto se distribuían en grandes cantidades y que tenían una importante presencia en las librerías, por lo que debieron de ser un producto no sólo demandado, sino también requerido en grandes cantidades, sin duda como consecuencia de su uso didáctico.

\subsection{Medios de difusión}

Las vías de difusión del repertorio musical manuscrito consistían en envíos a una institución religiosa para darse a conocer y obtener una gratificación, transporte de las obras por los propios músicos en sus desplazamientos, peticiones expresas, y copias. ${ }^{100}$ Por ejemplo, en cuanto a la formación de su biblioteca, el historiador Lope García de Salazar (1399-1476) decía haber obtenido sus libros haciéndolos buscar "por las provincias e casas de reyes e príncipes cristianos", "con mercaderes e mareantes", y por él mismo. ${ }^{101}$ Cabe preguntarse si, como ocurría con los impresos litúrgicos de polifonía, los autores de artes de canto enviaban ejemplares a las instituciones religiosas para que

\footnotetext{
${ }^{98}$ Dadson, Libros, lectores y lecturas, p. 30. Para una bibliografía de inventarios de libreros, véase Antonio Rodríguez Moñino, Historia de los catálogos de librería españoles (1661-1840): estudio bibliográfico (Madrid: [s.n.]; Valencia: Graf. Soler, 1966).

${ }^{99}$ Véanse María José Osorio Pérez, María Amparo Moreno Trujillo y Juan María de la Obra Sierra, "El mercado del libro en Granada en el s. XVI", en La imprenta en Granada, ed. por José Antonio Cordón García (Granada: Universidad de Granada, 1997), pp. 43-72; Julián Martín Abad, "Talleres de imprenta y mercaderes de libros en España", en Creadores del libro del Medievo al Renacimiento, ed. por José María Fernández Catón (Madrid: Dirección General del Libro y Bibliotecas, Fundación Central Hispano, 1994), pp. 51-66; Knighton, "Petrucci's Books in Early Sixteenth-Century Spain"; y Dadson, "La librería de Cristóbal López”, p. 176.

${ }^{100}$ Sobre la circulación de manuscritos en general, véase Fernando Jesús Bouza Álvarez, Corre manuscrito. Una historia cultural del Siglo de Oro (Madrid: Marcial Pons Historia, 2001).

${ }^{101}$ Gemma Avenoza, "Lope García de Salazar: la formación de un bibliófilo y de su biblioteca", en $M e$ dieval and Renaissance Spain and Portugal: Studies in Honor of Arthur L-F. Askins, ed. por Martha Schaffer y Antonio Cortijo Ocaña (Woodbridge, Suffolk: Tamesis, 2006), pp. 1-22, p. 8.
} 
los cabildos, asesorados por sus maestros de capilla, decidieran si quedarse con el libro y remitir el pago al autor (el precio era establecido por los compradores tras analizar la "utilidad" del libro) o bien devolverlo. ${ }^{102}$ No obstante, no tenemos ningún testimonio que confirme que en el caso de las artes de canto funcionase este mecanismo que Juan Ruiz Jiménez ha denominado "donación remunerada", ${ }^{103}$ por lo que debemos considerar que, a diferencia de los libros litúrgicos de música impresa, las artes de canto tuvieron como principal vía de difusión la venta a través de un librero o en el mercado de segunda mano.

Como muestra el Apéndice 8, las artes de canto tuvieron una importante presencia en los catálogos e inventarios de libreros, impresores y otros distribuidores. Esta circunstancia es relevante puesto que, mientras que los principales centros de recepción del repertorio musical tanto impreso como manuscrito tuvieron que ser centros subsidiarios al lugar de trabajo del autor, ${ }^{104}$ las artes de canto debieron de tener una difusión más extensa al entrar de manera más acusada en los circuitos comerciales y las redes de distribución de los empresarios del libro. Antonio Rodríguez Moñino aseguraba que los impresores vendían la literatura de cordel en conjuntos de muchos volúmenes y no como ejemplares sueltos. ${ }^{105}$ En el caso de las artes de canto, esta compra "al por mayor" debió de realizarse por parte de los libreros pero también de las órdenes religiosas. Además del mecanismo de compra-venta entre un librero y un particular o una institución, ${ }^{106}$ el mercado de segunda mano era bastante potente y se basaba en almonedas y subastas.

\footnotetext{
${ }^{102}$ Sobre el caso de Cristóbal de Morales, véase Knighton "Morales in Print". Sobre Diego de Bruceña, véase Luis Iglesias, "El maestro de capilla Diego de Bruceña".

103 Juan Ruiz Jiménez, La Librería de Canto de Órgano. Creación y pervivencia del repertorio del Renacimiento en la actividad musical de la Catedral de Sevilla (Granada: Junta de Andalucía, 2007), p. 143.

104 Juan Ruiz Jiménez, "Difusión del repertorio de los maestros de capilla de Granada en el siglo XVI", Revista de Musicología, XX/1 (1997), pp. 171-184, pp. 173-174.

${ }^{105}$ Rodríguez Moñino, Diccionario bibliográfico de pliegos sueltos poéticos, p. 16.

${ }^{106}$ Sobre el proceso de compra de libros para la Biblioteca de la Universidad de Salamanca, véase Vicente Bécares Botas, "Compras de libros para la Biblioteca Universitaria salmantina del Renacimiento", en Coleccionismo y Bibliotecas (siglos XV-XVIII) [El libro antiguo español, 4], dir. por María Luisa LópezVidriero y Pedro Manuel Cátedra García (Salamanca: Universidad de Salamanca, 1988), pp. 83-135.
} 
Las artes de canto no sólo fueron un producto comercial, sino que debieron circular por otros medios. ${ }^{107}$ Las artes de canto pudieron circular como parte de un legado o herencia; por ejemplo, Isabel Beceiro Pita asegura que hubo "un uso social en todo el Occidente europeo consistente en legados femeninos de libros de devoción a una hija, en defecto de ésta a la nuera y, en general, a otra mujer". ${ }^{108}$ Puesto que eran usadas a modo de "apuntes de clase", las artes de canto debieron circular también como copias personales elaboradas a partir de una o varias artes de canto impresas. ${ }^{109}$ Así, como muestra el Apéndice 9, los clérigos Bartolomé Cañar y Cristóbal de Alcubierre eran poseedores de artes de canto manuscritas. Por ejemplo, en el inventario de Alcubierre, realizado en Zaragoza en 1515, encontramos "otro libro de arte de canto plano de mano", "Hun libro pequenyo de abezar a cantar" y "Hun arte de musica de mano bieja"; ${ }^{110}$ Tess Knighton sugiere que este clérigo pudo haber impartido clases de música en alguna de las parroquias de Zaragoza. ${ }^{111}$ No obstante, tras la invención de la imprenta,

\begin{abstract}
${ }^{107}$ Sobre mecanismos de distribución del libro impreso en general, véase Prieto Bernabé, Lectura y lectores, p. 343. Acerca del caso particular de los libros de música, véase Tess Knighton, "Los libros de música de Felipe II: la formación de una colección real", en Políticas y prácticas musicales en el mundo de Felipe II: estudios sobre la música en España, sus instituciones y sus territorios en la segunda mitad del siglo XVI, ed. por John Griffiths y Javier Suárez Pajares (Madrid: ICCMU, 2004), pp. 47-68, p. 53: Felipe II adquirió su biblioteca "a través de mecanismos generalmente bien establecidos en la Península: comprando a libreros o en almonedas (normalmente a través de un intermediario que pertenecía a la capilla), otros adquiridos como obsequios, y por herencia". Dadson, Libros, lectores y lecturas, pp. 28-29, establece cuatro rutas "para la adquisición o consulta de libros": la compra a un librero, la compra de segunda mano en almonedas, el regalo o el préstamo y la copia manuscrita.
\end{abstract}

${ }^{108}$ Beceiro Pita, "La relación de las mujeres castellanas con la cultura escrita", p. 40. Véase también Sandra Penketh, "Women and Book of Hours", en Women and the Book. Assessing the Visual Evidence, ed. por Jane H. M. Taylor y Lesley Smith (Londres: British Library; Toronto: University of Toronto Press, 1997), pp. 266-281, pp. 275-276.

${ }^{109}$ Véase el Capítulo I (Apartado 1.2.4.c).

${ }^{110}$ Manuel José Pedraza Gracia, Documentos para el estudio de la historia del libro en Zaragoza (Zaragoza: Institución Fernando el Católico, 1993), p. 241, nº 1038; y Knighton, “Libros de canto”, p. 232.

${ }^{111}$ Knighton, "Libros de canto", p. 237: "Este clérigo de rango medio, sobre el que tan poco se sabe hoy día, debe de haber tenido un fuerte interés musical; posiblemente era el responsable de la música en una de las iglesias parroquiales de la ciudad, quizás la de Santa María del Portillo, y posiblemente impartía lecciones de música a los mozos de coro o a otros miembros de la clerecía allí. Varios de sus otros libros, algunos de ellos descritos como viejos o usados, podrían sugerir que estaba involucrado en alguna medida en la enseñanza más general. Podría igualmente haber estado en activo como copista de música: parece que tenía un libro de música con el pautado manuscrito [...] y un libro en blanco [...], así como algunas de las herramientas del oficio" ["This middle-ranking clergyman, about whom so little is known at present, must have had a strong musical interest; possibly he was responsible for the music in one of the city's parish churches, perhaps that of Santa María del Portillo, and possibly he gave music lessons to the choirboys or other members of the clergy there. Several of his other books, some of them described as old or used, might suggest that he was involved to some degree in more general teaching. He might equally 
mientras que el repertorio musical seguía circulando con frecuencia en manuscritos, los manuales didácticos (como las artes de canto) tuvieron una mayor difusión en versión impresa, como han señalado Stanley Boorman con respecto a los libros de música, ${ }^{112} \mathrm{y}$ Miguel Ángel Pallarés Jiménez con respecto al libro en general:

Pensamos que [la imprenta] hizo desaparecer, en los primeros años, un mercado no especializado, que cubría el trabajo de copiar manuales de estudio, gramáticas e incluso pequeños libros religiosos que no tenían por qué ser reproducidos por un profesional, y para lo que valía cualquiera que supiera escribir: estudiantes, religiosos, criados alfabetizados, etc. ${ }^{113}$

Las artes de canto debieron circular como parte del bagaje de los maestros de capilla, maestros de los mozos de coro y otros docentes cuando cambiaban de institución. Los maestros que escribieron artes de canto llevarían consigo sus libros; aquéllos que no habían publicado ningún libro transportarían los manuales que utilizaban en sus clases. ${ }^{114}$ Las artes de canto posiblemente tuvieran también una diseminación como regalos u obsequios. Natalie Zemon Davis ha estudiado cómo los libros impresos formaban parte del sistema de obligaciones y obsequios en el siglo XVI más allá de las transacciones de compra-venta y distingue, además del legado, dos tipos de circunstancias en que se regalaban libros: la dedicatoria o "regalo público" y el obsequio del autor o impresor a otra persona como parte del sistema de obligaciones o como signo de amistad. ${ }^{115}$ Puesto que los libros eran apreciados como productos del "arte divino", no se consideraban como objetos susceptibles de tenerse en propiedad: "“el conocimiento es un regalo de Dios, y no puede venderse' era el aforismo medieval, que se remontaba al ideal griego" y que se transmitió al siglo XVI. ${ }^{116}$ Por tanto, "como objetos físicos, los

well have been active as a music scribe: he would appear to have had one music book ruled by hand (...) and a blank book (...), as well as some of the tools of the trade"].

${ }^{112}$ Boorman et al., "Printing and Publishing of Music".

${ }^{113}$ Miguel Ángel Pallarés Jiménez, La imprenta de los incunables de Zaragoza y el comercio internacional del libro a finales del siglo XV (Zaragoza: Institución Fernando el Católico, 2003), p. 254.

${ }^{114}$ Véase Luis Iglesias, "Manuscritos e impresos con polifonía en la Catedral de Palencia”, p. 293.

115 Natalie Zemon Davis, "Beyond the Market: Books as Gifts in Sixteenth-Century France", Transactions of the Royal Historical Society, XXXIII (1984), pp. 69-88; Davis, The Gift in Sixteenth-Century France.

${ }^{116}$ Davis, The Gift in Sixteenth-Century France, p. 75: "Knowledge is a gift of God, and cannot be sold' was the medieval aphorism, itself going back to a Greek ideal". 
libros impresos del siglo XVI operaban bajo el signo de la venta y del regalo", ${ }^{117}$ lo que enlaza con el solapamiento que, según Rob C. Wegman, se producía en el Renacimiento entre una "economía del regalo" y una "economía de mercado". 118

\subsection{Redes de distribución en la Península Ibérica y el Nuevo Mundo}

Las secciones anteriores sugieren que no sólo había formas de distribución diferenciadas entre manuscritos e impresos, ${ }^{119}$ sino también entre libros con música y libros sobre música (o libros con repertorio musical y artes de canto). ${ }^{120}$ Es posible, en consecuencia, que las artes de canto establecieran unas rutas comerciales que después aprovecharan otros manuales de música con propósito didáctico como los libros de vihuela. Los libros en general se difundían en contextos urbanos, ${ }^{121}$ y lo hacían en resma, sin encuadernar, salvo que su destino fuese el Nuevo Mundo en cuyo caso eran encuadernados en Salamanca, "centro de la encuadernación española durante el XVI", antes del embarque, debido a la falta de personal cualificado en el lugar de destino. ${ }^{122}$ Las rutas eran marítimas o terrestres y, en éste último caso, los libros eran transportados a lomos

\footnotetext{
${ }^{117}$ Davis, The Gift in Sixteenth-Century France, p. 78: “As physical objects, sixteenth-century printed books operated under the sign both of sale and of gift. The publisher's address was on the title page for potential buyers; the dedication of author, editor, or translator was on the inside, inserting the book into a gift relation".

${ }^{118}$ Rob C. Wegman, "Musical Offerings in the Renaissance”, Early Music, XXXIII/3 (2005), pp. 425437.

${ }^{119}$ Chartier, Cultura escrita, literatura e historia, p. 23. Sobre la problemática de la difusión de la música manuscrita, véase Alejandro Luis Iglesias, En torno al barroco musical español: el oficio y la misa de difuntos de Juan García de Salazar (Salamanca: Ediciones Universidad de Salamanca y Colegio Universitario de Zamora, 1989), p. 47.

${ }^{120}$ Para poder comparar la difusión de un libro de vihuela con un libro de repertorio polifónico, véase Alejandro Luis Iglesias, "Andanzas y fortunas de algunos impresos musicales españoles del siglo XVI: Fuenllana y Pedro Guerrero", en Coleccionismo y Bibliotecas (siglos XV-XVIII) [El libro antiguo español, 4], dir. por María Luisa López-Vidriero y Pedro Manuel Cátedra García (Salamanca: Universidad de Salamanca, 1988), pp. 461-503. Acerca de la diferenciación entre libros de polifonía y libros de canto en cuanto a producción, distribución y mercado, véase Knighton, "Libros de canto", p. 227.

${ }^{121}$ Prieto Bernabé, Lectura y lectores, p. 80.

122 Anastasio Rojo Vega, “El negocio del libro en Medina del Campo, ss. XVI y XVII”, Investigaciones Históricas, VII (1987), pp. 17-26, p. 23.
} 
de animales de carga por "mercaderes andantes", que los ofrecían en las ferias, contaban con el favor real y disfrutaban de importantes exenciones fiscales. ${ }^{123}$

Frente al aislamiento con respecto a Europa atribuido tradicionalmente a la vida musical española, tenemos constancia de una importante presencia de repertorio musical internacional en los catálogos de libreros como Joan Guardiola $(\dagger 1561)$ en Barcelona, entre cuyas existencias encontramos música impresa en París, Amberes, Venecia (ediciones de Petrucci) y, sobre todo, Lyon. Barcelona era un centro distribuidor de primer orden debido a sus estrechas relaciones con el sur de Francia; ${ }^{124}$ pero también se han hallado libros de música impresa de procedencia internacional (principalmente de Venecia y, en menor medida, de Amberes) en el inventario del librero de Valladolid Gaspar Trechsel $(\dagger 1571) .{ }^{125}$

Medina del Campo funcionaba como un "inmenso almacén de libros donde se acumulaba el género recién importado". ${ }^{126}$ Los libros procedentes de Lyon llegaban a Medina del Campo por la ruta cantábrica a través de Bilbao, Laredo o Santander, ${ }^{127}$ siendo Burgos la ciudad más importante del trayecto, ${ }^{128}$ y desde Medina del Campo

${ }^{123}$ Torres Corominas, Literatura y facciones cortesanas en la España del siglo XVI, p. 207.

${ }^{124}$ Emilio Ros-Fábregas, "Orígenes e inventario de un manuscrito catalán del Renacimiento con repertorio polifónico internacional: Barcelona, Biblioteca del Orfeó Català, Ms.5”, en Fuentes musicales en la Península Ibérica (ca. 1250-ca. 1550), ed. por Maricarmen Gómez y Màrius Bernadó (Lleida: Institut d'Estudis Ilerdencs-Universitat de Lleida, 2001), pp. 141-176, pp. 142-143: “Girona se encontraba en el 'camino real' utilizado por viajeros para entrar y salir de la Península". Para una transcripción del inventario y valoración de los libros de la herencia del librero Joan Guardiola en 1562, véase Ros-Fábregas, "Libros de música en bibliotecas españolas del siglo XVI" (III), pp. 23-24, no 47.

${ }^{125}$ Sobre la difusión en España de repertorio musical internacional, véanse Ros-Fábregas, The Manuscript Barcelona, Biblioteca de Catalunya, M.454, vol. 1, pp. 115-347; Henri Vanhulst, "Plantin et le commerce international des éditions de musique polyphonique 1566-1578", Revista de Musicología, XVI/3 (1993), pp. 2630-2640; y Knighton, "Transmisión, difusión y recepción de la polifonía franco-neerlandesa en el Reino de Aragón a principios del siglo XVI", Artigrama, XII (1996-1997), pp. 19-38; y "Petrucci’s Books in Early Sixteenth-Century Spain".

${ }^{126}$ Torres Corominas, Literatura y facciones cortesanas en la España del siglo XVI, p. 209; Rojo Vega, "El negocio del libro en Medina del Campo", pp. 19 y 21. Véase también Vicente Bécares Botas, La librería de Benito Boyer (Medina del Campo, 1592) (Valladolid: Consejería de Cultura y Turismo, 1992).

${ }^{127}$ Rojo Vega, "El negocio del libro en Medina del Campo", p. 22; Torres Corominas, Literatura y facciones cortesanas en la España del siglo XVI, p. 209.

${ }^{128}$ María Asenjo González, "Vida económica y sociedad en la Segovia de los Dávila", Arias Dávila: obispo y mecenas. Segovia en el siglo XV, ed. por Ángel Galindo García [Actas del Congreso] (Salamanca: Universidad Pontificia de Salamanca, 1998), pp. 39-76. Véase también Marcel Bataillon, Erasmo y España. Estudios sobre la historia espiritual del siglo XVI (Ciudad de México: Fondo de Cultura Económica, 1966 [1937]), p. 215. 
alcanzaban Sevilla por la "vía de la plata". ${ }^{129}$ La importancia de Castilla como centro de comercio internacional ha sido destacada frecuentemente en la bibliografía; ${ }^{130}$ se ha señalado que el objetivo de la fundación de la Compañía de Libreros de Salamanca era “importar del extranjero los libros que demandaba el mercado y que la industria nacional no alcanzaba a suplir". ${ }^{131}$ Zaragoza se situaba en la ruta comercial de libros entre Lyon y Medina del Campo, además de tener una localización cercana a Barcelona y Valencia, de manera que los impresores y libreros de Zaragoza estaban en contacto con Venecia a través de estos puertos mediterráneos. ${ }^{132}$ Los libros procedentes de Lyon con destino Sevilla o Lisboa llegaban a través del Mediterráneo. ${ }^{133}$ La conexión entre Lyon y Barcelona era directa, como muestra la importante presencia de libros procedentes de Lyon que había en la tienda del librero Joan Guardiola, ${ }^{134}$ y el caso de Pierre Régnier, librero activo en Barcelona que fue procesado por la Inquisición tras comprar material tipográfico en Lyon a un protestante. ${ }^{135}$

Las artes de canto tuvieron una significativa presencia no sólo en los reinos de la Península Ibérica, sino también en el mercado con el Nuevo Mundo, como evidencian los inventarios de bienes y los registros de ida y de vuelta de navíos. ${ }^{136}$ Sin embargo, es

\footnotetext{
${ }^{129}$ Torres Corominas, Literatura y facciones cortesanas en la España del siglo XVI, p. 210: en Sevilla "terminaba la ruta comercial que, desde la costa cantábrica, atravesaba Castilla de parte a parte".

${ }^{130}$ María Luisa López-Vidriero y Pedro Manuel Cátedra García, "La imprenta y su impacto en Castilla", en Historia de una cultura: la singularidad de Castilla, ed. por Agustín García Simón (Valladolid: Junta de Castilla y León, 1995), vol. 2, pp. 463-542, p. 509.

${ }^{131}$ Vicente Bécares Botas, La Compañía de Libreros de Salamanca (1530-1534) (Salamanca: Seminario de Estudios Medievales y Renacentistas, 2003), p. 9. Además, una muestra más frente a la visión aislacionista es que la compañía de libreros de Salamanca tuvo su precedente en la compañía de libreros de Lyon; véase Marta de la Mano, Mercaderes e impresores de libros en la Salamanca del siglo XVI (Salamanca: Universidad de Salamanca, 1998), pp. 253-254.
}

${ }^{132}$ Knighton, “Libros de canto", p. 216.

${ }^{133}$ Rojo Vega, "El negocio del libro en Medina del Campo”, p. 22.

${ }^{134}$ Ros-Fábregas, "Libros de música en bibliotecas españolas del siglo XVI” (III), pp. 23-24, n 47; Peña Díaz, Cataluña en el Renacimiento, en particular, pp. 97-98; y El laberinto de los libros.

${ }^{135}$ Griffin, "La carrera del impresor en la Edad Moderna"; y Journeymen-Printers, Heresy, and the Inquisition in Sixteenth-Century Spain, pp. 133-155.

${ }^{136}$ Sobre el libro en general en la carrera de Indias, véanse Irving Leonard, “One Man’s Library, Manila, 1583”, Hispanic Review, XV/1 (1947), pp. 84-100; y Los libros del conquistador (Ciudad de México: Fondo de Cultura Económica, 1996 [1949]); Rojo Vega, "Exportación de libros a América en el siglo XVI"; y Pedro J. Rueda Ramírez, "Libros a la mar: el libro en las redes comerciales de la carrera de Indias", en Libro y lectura en la Península Ibérica y América (siglos XIII al XVI), ed. por Antonio Castillo 
difícil determinar de qué obra en concreto se trata puesto que se registran con el nombre genérico de "artes de canto llano". María Gembero señala que "en casi todos los envíos había un importante número de libros litúrgicos (que solían contener canto llano) y Artes de canto llano (tratados)". ${ }^{137}$ Jania Sarno, en su estudio sobre el Archivo General de Indias, indica que "las memorias que contienen Artes de Canto llano" en Contratación 674 , se encuentran en las carpetas $11,13,16,64-72,73,210-212,110,181-183 .{ }^{138} \mathrm{Al}-$ fred Lemmon da noticia de tres artes de canto llano enviadas a México desde Sevilla en 1576 y en $1583,{ }^{139}$ de diez artes de canto llano enviadas a la Catedral de México en $1584,{ }^{140} \mathrm{y}$ de otras diez artes de canto llano inventariadas entre las aproximadamente 40 cajas de libros enviadas por Benito Boyer desde Medina del Campo a Diego Navaro

Gómez (Madrid: Junta de Castilla y León, Consejería de Cultura y Turismo, 2003), pp. 189-208. Los registros de ida y de vuelta de navíos han sido estudiados por Carlos Alberto González Sánchez en varios trabajos: "El libro y la Carrera de Indias: Registro de ida de navíos", Archivo hispalense: revista histórica, literaria y artística, LXXII/220 (1989), pp. 93-104; "Los libros de los españoles en el Virreinato del Perú, siglos XVI y XVII"; Los mundos del libro: medios de difusión de la cultura occidental en las Indias de los siglos XVI y XVII (Sevilla: Diputación de Sevilla, Universidad de Sevilla, Secretariado de Publicaciones, 1999); "Emigrantes y comercio de libros en el virreinato del Perú", Biblios: revista electrónica de bibliotecología, archivología y museología, VI (2000 [1993])

$<$ http://dialnet.unirioja.es/servlet/articulo?codigo=283291>; y Carlos Alberto González Sánchez y Natalia Maillard Álvarez, Orbe tipográfico: el mercado del libro en la Sevilla de la segunda mitad del siglo XVI (Gijón: Trea, 2003). Respecto a la circulación de libros de música entre la Península Ibérica y el Nuevo Mundo, véanse Stevenson, Renaissance and Baroque Musical Sources in the Americas; Jorge Velazco, "Edición y circulación de publicaciones musicales entre México y Europa", Revista de Musicología, XVI/2 (1993) [Actas del XV Congreso de la Sociedad Internacional de Musicología (Madrid, 310/04/1992): "Culturas musicales del Mediterráneo y sus ramificaciones”], pp. 1181-1192; Ros-Fábregas, "Libros de música para el Nuevo Mundo en el siglo XVI"; Gembero Ustárroz, "Circulación de libros de música entre España y América (1492-1650)"; y "Migraciones de músicos entre España y América (siglos XVI-XVIII): estudio preliminar”, en La Música y el Atlántico, coord. y ed. por María Gembero Ustárroz y Emilio Ros-Fábregas (Granada: Universidad de Granada, 2007), pp. 17-58; y Marín López, "Música y músicos entre dos mundos". Acerca de la distribución de libros de música en Asia, véase David R. M. Irving, "The Dissemination and Use of European Music Books in Early Modern Asia", Early Music History, 28 (2009), pp. 39-59; véase también su libro ya mencionado Colonial Counterpoint.

${ }^{137}$ Gembero Ustárroz, “Circulación de libros de música entre España y América (1492-1650)”, p. 154.

${ }^{138}$ Jania Sarno, "El tráfico de instrumentos y libros musicales de España al Nuevo Mundo a través de los documentos del Archivo General de Indias de Sevilla: notas para el comienzo de una investigación", en The Brussels Museum of Musical Instruments. Bulletin. Musiques et influences culturelles réciproques entre l'Europe et l'Amérique Latine du XVIème au XXème siècle, ed. por René de Maeyer (Bruselas: The Brussels Museum of Musical Instruments, 1986), pp. 95-108, p. 98, nota 6.

139 Alfred E. Lemmon, "Towards an Inventory of Music Theory Books in Colonial Mexico", Anuario musical, XXXIII-XXXV (1978-1980), pp. 131-139, p. 132. El dato se toma de José Torre Revello, “Algunos libros de música traídos a América en el siglo XVI”, Boletín Interamericano de Música, I (1957), p. 13.

${ }^{140}$ Lota M. Spell, "Music in the Cathedral of Mexico", Hispanic American Historical Review, XXVI (1949), pp. 293-310. 
Maldonado que estaba en México. ${ }^{141}$ Lemmon señala a Gabriel Saldívar como el primer historiador que inventarió libros de música en el México colonial, entre ellos el Arte de canto llano de Dámaso Artufel, el de Juan Martínez y el Arte de musica theorica y pratica de Francisco de Montanos. ${ }^{142}$

El envío de artes de canto llano al Nuevo Mundo se explica por la utilización de la música como instrumento evangelizador y por la fundación de las catedrales hispanoamericanas, de modo que las artes de canto debieron de ser muy demandadas en las Indias como herramienta en el proceso de enseñanza-aprendizaje de la música. ${ }^{143}$ Por ejemplo, Alfred Lemmon da noticia de la Relación de Antonio Sepp, un misionero jesuita en Paraguay, donde éste explica "cómo otro sacerdote alemán le había preparado un pequeño panfleto instructivo antes de que partiera hacia el Nuevo Mundo para ayudarle en la enseñanza de la música". ${ }^{144}$ Las nuevas ediciones alcanzaban rápidamente el Nuevo Mundo, como muestra Javier Marín en su análisis del inventario de 1589 de la Catedral de México, ${ }^{145}$ y desde el Nuevo Mundo se demandaban libros que fuesen "de la ùltima imprission". ${ }^{146}$ Juan Bermudo señalaba en la Declaración de instrumentos (Osuna, 1555) que una de las razones que le habían llevado a imprimir su libro era que se lo habían requerido desde las Indias (según Robert Stevenson, posiblemente a través de su vínculo con Cervantes de Salazar en México): ${ }^{147}$

\footnotetext{
${ }^{141}$ Francisco Fernández del Castillo, Libros y libreros en el siglo XVI (Ciudad de México: Archivo General de la Nación, 1914), pp. 267, 268 y 270.

${ }^{142}$ Lemmon, "Towards an Inventory of Music Theory Books in Colonial Mexico", pp. 132-133.

${ }^{143}$ Véase Geoffrey Baker, Imposing Harmony: Music and Society in Colonial Cuzco (Durham: Duke University Press, 2008). Para algunos ejemplos, véase Gabriel Saldívar, Historia de la Música en México (Ciudad de México: Secretaría de Educación Pública, 1934), pp. 129-130.

${ }^{144}$ Lemmon, "Towards an Inventory of Music Theory Books in Colonial Mexico", p. 132: "Sepp, a most articulate writer, recalled how another German priest had prepared for him a little instruction booklet, prior to his departure for the New World, to aid him in the instruction of music". Para una edición de la Relación del P. Antonio Sepp, véase Antonio Sepp, Relación de viaje a las misiones jesuíticas, ed. por Werner Hoffmann (Buenos Aires: Editorial Universitaria de Buenos Aires, 1971), pp. 208-209.

145 Javier Marín López, “The Musical Inventory of Mexico Cathedral, 1589: A Lost Document Rediscovered”, Early Music, XXXVI/4 (2008), pp. 575-596.

${ }^{146}$ Sobre la demanda de las últimas ediciones y las prácticas fraudulentas a las que esto condujo, véase Rojo Vega, "Exportación de libros a América en el siglo XVI", p. 75.

${ }^{147}$ Stevenson, Juan Bermudo, p. 25.
} 
Bien tengo entendido auer en España mucha y Buena musica de la qual se pueden los tañedores aprouechar, y assi no auia necessidad de la mia: pero he sido importunado de amigos, que imprimiesse alguna hecha aposta para tañer, mayormente que de indias me han rogado por ella: $\mathrm{y}$ pareciome cosa iusta hazerlo. ${ }^{148}$

Ante la escasez de libros de música impresos en territorio hispanoamericano, el comercio con Europa debió de ser de extrema necesidad y las copias manuscritas probablemente proliferaron como medio de reproducción y difusión; por ejemplo, se ha hecho referencia en la bibliografía a un tratado posterior procedente de Santa Eulalia (Guatemala) escrito en lengua náhuatl y copiado en torno a $1679 .{ }^{149}$ Muestra de esta situación son las dificultades que encontró Juan Pérez Materano (†1561), músico de la Catedral de Cartagena de Indias (Colombia) para imprimir su Libro de canto de órgano y canto llano (c. 1554) por falta de papel. ${ }^{150}$ Otro caso es el del jesuita Juan de Tovar, quien tampoco logró imprimir un Arte de música que había preparado para su publicación en México en 1602. ${ }^{151}$ Aparte de las transacciones comerciales, las migraciones de músicos favorecieron la movilidad de libros de música de todo tipo. ${ }^{152}$ Como ejemplo, citaré tres licencias para pasar al Nuevo Mundo concedidas a músicos que se conservan en el Archivo General de Indias: 1) el "Expediente de concesión de licencia para pasar a México a favor de Diego de Ayala, músico, vecino de México en compañía de su mujer Luciana Suárez hija de Pedro Suárez e Isabel de Contreras" (1567); 2) el "Expediente de concesión de licencia para pasar a México a favor de Juan de Villarrubia, clérigo, músico para la Catedral de México" (1591); y 3) la "Real Cédula a los oficiales de la Casa de la Contratación para que den licencia a Vicente Espi, músico de tecla, natural

\footnotetext{
${ }^{148}$ Bermudo, Declaración de instrumentos, f. 113v.

${ }^{149}$ Alfred E. Lemmon y Fernando Horcasitas, "Manuscrito teórico musical de Santa Eulalia: un estudio de un tesoro musical y lingüístico de Guatemala colonial”, Revista musical chilena, XXXIV/152 (1980), pp. 37-79.

${ }^{150}$ Gembero Ustárroz, "Circulación de libros de música entre España y América”, pp. 160-161; Marín López, "Música y músicos entre dos mundos”, p. 412.

${ }^{151}$ Marín López, "Música y músicos entre dos mundos”, p. 412.

${ }^{152}$ Gembero Ustárroz, "Migraciones de músicos entre España y América”, p. 48; véase también su trabajo "El compositor español Hernando Franco (1532-85) antes de su llegada a México: trayectoria profesional en Portugal, Santo Domingo, Cuba y Guatemala", Latin American Music Review, XXVI/2 (2005), pp. 273-317.
} 
de Burgos, para pasar al Perú, obligándose a ejercer su oficio" $(1553,1555) .{ }^{153}$ Estos documentos suponen una valiosa fuente de información acerca de la movilidad de los músicos y la música a través del Atlántico. En cualquier caso, Javier Marín ha indicado que "uno de los aspectos más sorprendentes y fascinantes de los archivos hispanoamericanos radica en el alto porcentaje de piezas de compositores españoles que nunca viajaron al Nuevo Mundo". ${ }^{154}$ En el Capítulo siguiente, dedicado a un estudio en detalle del Arte de canto llano de Juan Martínez, se presentará como un caso paradigmático la circulación de este libro en Portugal y el Nuevo Mundo.

\section{VALUACIÓN Y MERCADO POTENCIAL}

El análisis de la distribución de las artes de canto se complementa con un estudio del consumo de éstas como producto comercial con el propósito de determinar el grado de accesibilidad a la formación musical en la vida cotidiana del mundo ibérico renacentista y la contribución de estos manuales a la difusión de la competencia musical dentro un amplio espectro socioeconómico. Por sus características materiales (examinadas en el Capítulo I), las artes de canto eran relativamente asequibles en comparación con las artes de tañer y con los libros de repertorio musical, de manera que las artes de canto debieron de contribuir a que la competencia musical se extendiese a un espectro socioeconómico más amplio. ${ }^{155} \mathrm{Al}$ margen de la valuación de las artes y de las tasas de alfabetismo de la época, encontramos formas de consumo que no implican propiedad ni lectura, como la asistencia a las lecciones públicas de las capillas eclesiásticas en las que se seguían estos manuales.

A pesar de sus limitaciones, los inventarios de bienes (complementados con la información proporcionada por los textos preliminares de las propias artes de canto)

\footnotetext{
${ }^{153}$ Sobre Diego de Ayala, véase Sevilla, Archivo General de Indias, Indiferente, 2051, N.41. Acerca del caso de Juan de Villarubia, véase Indiferente, 2065, N.88. Sobre Vicenti Espi, véanse Indiferente, 1965, L.12, F.55; Indiferente, 1965, L.12, F.71; y Pasajeros, L.3, E.2644.

${ }^{154}$ Marín López, “Música y músicos entre dos mundos”, p. 409.

${ }^{155}$ Esto contrasta con libros manuscritos como los "chansonniers" del Valle de Loira, que surgieron como una respuesta a la demanda de libros personales de fina artesanía por parte de la nobleza; véase Alden, Songs, Scribes, and Society, p. 178.
} 
permiten determinar que el mercado potencial (particular e institucional) de las artes abarcaba un amplio abanico de usuarios: religiosos y laicos (es decir, profesionales del canto eclesiástico y aficionados), principiantes y maestros. Además, los inventarios de bienes proporcionan información sobre ediciones de artes de canto de las que no se conserva ningún ejemplar en la actualidad y sobre los libros que estaban en circulación en una época determinada. Por ejemplo, como se vio en la delimitación del objeto de estudio de esta investigación y muestra el Apéndice 9, el inventario de la biblioteca de música de João IV de Portugal proporciona no sólo referencias a artes de canto desconocidas hoy, sino también a una coexistencia de artes de canto creadas en prensas ibéricas con artes de canto procedentes del contexto italiano, como Introduttione facilissima, \& nouissima de canto (Roma, 1553) de Vicente Lusitano, Introduttorio abbreviato di musica piana o vero canto fermo (Venecia, 1555) de Pietro Cinciarino, y Scala di musica (Venecia, 1585) de Orazio Scaletta. ${ }^{156}$ Debido a las limitaciones que presentan los inventarios como fuente, las artes de canto halladas a partir del vaciado de inventarios podrían constituir sólo una mínima parte del total difundido y consumido; véase el Apéndice 9. ${ }^{157}$

Además de los inventarios de bienes, otra fuente muy valiosa es el catálogo de la biblioteca de Hernando Colón puesto que incluye información sobre el precio de los libros y acerca de las condiciones de la publicación y el comercio de estos productos en la época. ${ }^{158}$ No es extraño que, por estos motivos, la Biblioteca Colombina se haya considerado "única en su género". ${ }^{159}$ Prueba de la importancia del catálogo bibliográfico de Hernando Colón para esta investigación es que el único ejemplar conservado del Arte de principios de canto llano de Gaspar de Aguilar perteneció a Hernando Colón y continúa localizándose en la Sala Noble de la Biblioteca Capitular y Colombina de Sevilla.

\footnotetext{
${ }^{156}$ Primeira parte do Index da Livraria de mvsica, p. 122, $\mathrm{n}^{\text {os }} 524$ a 526.

${ }^{157}$ Sobre los aspectos metodológicos del estudio de las bibliotecas particulares, véase Fernando Huarte Morton, "Las bibliotecas particulares españolas de la Edad Moderna", Revista de Archivos, Bibliotecas y Museos, LXI/2 (1955), pp. 555-576. Véase también Francisco Vindel, Los bibliófilos y sus bibliotecas desde la introducción de la imprenta en España hasta nuestros días (Madrid: Imp. Góngora, 1934).
}

\footnotetext{
${ }^{158}$ Por tanto, no es sorprendente que en Fenlon y Vecchia, eds., Venecia 1501, catálogo de la exposición sobre la imprenta musical de Petrucci, se incluya un apartado dedicado a la Biblioteca Colombina dentro de la sección "Diffusione e consumo nel Cinquecento". Véase también Catherine Weeks Champman, "Printed Collections of Polyphonic Music Owned by Ferdinand Columbus", Journal of the American Musicological Society, XXI/1 (1968), pp. 34-84.

${ }^{159}$ Lafaye, Albores de la imprenta, p. 70.
} 


\subsection{Formas de consumo, valuación y accesibilidad}

Al igual que la posesión de un libro no presupone su uso, los libros podían ser utilizados sin necesidad de tenerlos en propiedad e incluso sin tener que leerlos: "los antiguos no profesaban nuestro culto del libro; veían en el libro un sucedáneo de la palabra oral". ${ }^{160}$ Es aplicable a las artes de canto lo establecido por María del Mar Fernández Vega para los pliegos sueltos poéticos catalanes, dadas las similitudes entre los dos géneros librescos:

La proliferación de este tipo de impreso nos induce a especular sobre la existencia de cuantiosos circuitos de difusión, puesto que el número de lectores lo suficientemente avezados no justifica las numerosas tiradas y múltiples ediciones; contamos con quienes compran y leen por su cuenta pero también con cuantos escuchan leer y, a su vez, propagan lo oído por vía oral. ${ }^{161}$

Aunque no existe un acuerdo acerca de la extensión del alfabetismo en los reinos peninsulares durante el siglo XVI, ${ }^{162}$ la lectura en voz alta de un texto nuevo es considerada por Chartier una forma de edición. ${ }^{163}$ En el ámbito musical, Alfonso de Vicente ha señalado la importancia de la oralidad en el caso de los cantos devotos, de modo que "la difusión de estas obras es, por tanto, infinitamente mayor que lo que el número de ejemplares impresos o de libros conservados pudieran hacernos sospechar, lo mismo que los índices de alfabetización, que excluirían a la mayor parte de la población". ${ }^{164}$ Leo Treitler subraya la importancia de la memoria en la transmisión del canto gregoriano incluso cuando éste se escribía, ${ }^{165}$ así como el lugar de la oralidad en la historia de

\footnotetext{
160 Jorge Luis Borges, Borges oral (Buenos Aires: Emecé, 1979 [1978]), citado en Chartier, Cultura escrita, literatura e historia, p. 9.

${ }^{161}$ Fernández Vega, “Política y propaganda en los pliegos sueltos poéticos catalanes”, p. 77.

${ }^{162}$ Para un estado de la cuestión, véase Nalle, "Literacy and Culture in Early Modern Castile”, pp. 66-76. Por ejemplo, Richard L. Kagan, Universidad y sociedad en la España moderna (Madrid: Tecnos, 1981 [1974]), pp. 65-66, propuso una tasa de alfabetización para la Castilla del siglo XVI del 15\% de la población. Véanse también Hirsch, "Imprenta y lectura entre 1450 y 1550", p. 64; y Antonio Castillo Gómez, Entre la pluma y la pared: una historia de la cultura escrita en los Siglos de Oro (Madrid: Akal, 2006), p. 20.

${ }^{163}$ Chartier, Cultura escrita, literatura e historia, pp. 60-61.

${ }^{164}$ Vicente Delgado, “Música, propaganda y reforma religiosa en los siglos XVI y XVII”, p. 19.

165 Véanse Leo Treitler, “The 'Unwritten' and 'Written' Transmission of Medieval Chant and the StartUp of Musical Notation”, The Journal of Musicology, X (1992), pp. 131-191, pp. 161-162, donde se propone el concepto de "performance from memory" como sustitutivo del término "improvisation"; y "Ho-
} 
la escritura musical. ${ }^{166}$ También la memoria tenía un importante papel en la transmisión de la polifonía: los niños eran formados para cantar "alla mente" (interpretar un contrapunto improvisado sobre una línea dada). ${ }^{167}$ Según Malcolm Parkes, en la Edad Media la escritura se percibía menos como un registro de la palabra hablada que como un medio para transmitir las autoridades del pasado; ${ }^{168}$ Isidoro de Sevilla consideraba las letras signos sin sonido. ${ }^{169}$ Cristle Collins Judd señala que en las escuelas de latín los alumnos no compraban libros de música, sino que copiaban y memorizaban los materiales que el profesor mostraba sobre la pizarra. ${ }^{170}$

mer and Gregory: The Transmission of Epic Poetry and Plainchant", The Musical Quarterly, LX/3 (1974), pp. 333-372, en que se considera la memoria el medio de transmisión de la música y la interpretación el medio de composición de la misma. Véase también "What Kind of Thing Is Musical Notation?", en Reflections on Musical Meaning and Its Representations (Bloomington e Indianapolis: Indiana University Press, 2011), pp. 107-160, p. 107, donde se amplía el concepto de notación musical al de "un sistema de signos entre otros a través del cual representamos aspectos de nuestra experiencia" ["one sign system among others through which we represent aspects of our experience"].

${ }^{166}$ Leo Treitler, "Oral, Written, and Literate Process in the Music of the Middle Ages", en With Voice and Pen: Coming to Know Medieval Song and How It Was Made (Oxford: Oxford University Press, 2003), pp. 230-251.

167 Jessie Ann Owens, Composers at Work: The Craft of Musical Composition 1450-1600 (Nueva York: Oxford University Press, 1997), pp. 68-69: "La improvisación era importante no sólo para aprender si no también para interpretar una variedad de repertorios diferentes, tanto instrumentales como vocales [...]. Componer primero 'alla mente' no habría sido difícil para músicos que se habían formado para cantar 'alla mente'. Aunque hay importantes diferencias entre cantar alla mente (cantar un contrapunto improvisado a una línea dada) y componer alla mente (concebir toda la estructura de una nueva composición), ambos reflejan un mundo en que las distinciones entre música escrita y música improvisada no eran grandes" ["Improvisation was important not only for learning but also for performing a variety of different repertories, both instrumental and vocal (...). Composing first 'alla mente' would not have been difficult for musicians who were trained to sing 'alla mente'. While there are important differences between singing alla mente (singing an improvised counterpoint to a given line) and composing alla mente (conceiving the entire fabric of a new composition), both reflect a world in which the distinctions between improvised and written music were not great"]. Véanse también Berger, Medieval Music and the Art of Memory; y "Mnemotechnics and Notre Dame Polyphony". Sobre el contexto español, véase Giuseppe Fiorentino, "Con ayuda de nuestro Señor': Teaching Improvised Counterpoint in 16th-Century Spain", en Recent Research on Early Iberian Music in an International Context, ed. por Tess Knighton y Emilio Ros-Fábregas (Kassel: Reichenberger [en prensa]). Acerca de la importancia de la memoria en la cultura del Renacimiento, véase Laura Bolzoni, La stanza della memoria: modelli litterari e iconographici nell'eta della stampa (Turín: Einaudi, 1995).

${ }^{168}$ Malcolm Parkes, "Reading, Copying and Interpreting a Text in the Early Middle Ages", en A History of Reading in the West, ed. por Guglielmo Cavallo y Roger Chartier, trad. por Lydia G. Cochrane (Cambridge: Polity Press, 1999), pp. 90-102, p. 93.

${ }^{169}$ Blair Sullivan, “The Unwritable Sound of Music: The Origins and Implications of Isidore's Memorial Metaphor”, Viator: Medieval and Renaissance Studies, 30 (1999), pp. 1-14.

${ }^{170}$ Judd, Reading Renaissance Music Theory, p. 95: "No había una tradición por la que los estudiantes de las escuelas de latín compraran libros de música, los cuales claramente eran muy caros. Más bien copiaban y memorizaban materiales proporcionados por su profesor. Generalmente el profesor proporcionaba estos materiales escribiéndolos en una gran pizarra delante de la clase" ["There was not a tradition of 
Las artes de canto eran utilizadas por los maestros en sus clases, que en el caso de las capillas eclesiásticas solían ser públicas, de manera que incluso una audiencia iletrada podía convertirse en consumidora de libros mediante la audición de sus contenidos en las lecciones de las capillas eclesiásticas. ${ }^{171}$ Por ejemplo, Carlos Romero de Lecea considera que Lux bella "aparenta ser el guión que llevara consigo el maestro para servir de pauta a la explicación docente":

El cuadro de combinación de las voces, en la primera página, viene a ser el apunte que escribirá en la pizarra, para exponer la doctrina y teoría musicales, y, al tiempo, retener la atención de los alumnos, en una época en que se inicia la lectura visual, pero en la que todavía está viva la lectura oral y su explicación se efectúa, en voz alta, para un grupo que le escucha. [...] [Comento sobre Lux bella] pone de manifiesto que el autor ha comprendido la necesidad de no dirigirse a un auditorio a modo de lectura oral, sino a un lector individual cuya lectura es visual, necesitado de que la redacción sea más detenida y desarrollada, fácil de comprender, y con las pautas precisas para que resulte ameno el ejercicio de la lectura. ${ }^{172}$

Es llamativo entonces que fuese Lux bella y no el Comento la obra que se reeditó en numerosas ocasiones, porque sugeriría que estos libros eran utilizados en mayor medida como guión de clase que para ser leídos de manera personal. Quizás por su conexión con el mundo religioso, la imprenta no supuso el abandono de la lectura en voz alta en el caso de las artes de canto; ${ }^{173}$ como señala Roger Chartier, la lectura en una comu-

students in Latin schools buying music books, which from all the evidence were very expensive. Rather they copied out and memorized materials provided by their teacher. Generally the teacher supplied these materials by writing them out on a large board in the front of the room"].

${ }^{171}$ Gimeno Blay y Trenchs Ódena, "Libro y bibliotecas en la Corona de Aragón (siglo XVI)”, pp. 210211, afirman que las "clases subalternas" no recibían los mensajes directamente de los libros, sino mediante lecturas públicas.

${ }^{172}$ Romero de Lecea, Introducción a los viejos libros de música, pp. 101-102.

173 Paul Saenger, Space Between Words: The Origin of Silent Reading (Stanford: Stanford University Press, 1997), p. 6, relaciona la lectura silenciosa con la introducción por parte de los escribas de separaciones entre las palabras: "En Occidente, la habilidad de leer en silencio y rápidamente es un resultado de la evolución histórica de la separación de las palabras que, empezando en el siglo VII, cambió el formato de la página escrita, la cual tenía que leerse oral y lentamente para ser comprendida" ["In the West, the ability to read silently and rapidly is a result of the historical evolution of word separation that, beginning in the seventh century, changed the format of the written page, which had to be read orally and slowly in order to be comprehended"]. Véanse también Paul Saenger, "Silent Reading: Its Impact on Late Medieval Script and Society", Viator: Medieval and Renaissance Studies, 13 (1982), pp. 367-414; y Margit Frenk, Entre la voz y el silencio. La lectura en tiempos de Cervantes (Alcalá de Henares: Centro de Estudios Cervantinos, 1997). 
nidad religiosa es la "lectura de la mascullación" porque se vincula a la plegaria y la oración. ${ }^{174}$

Un indicio más de la estrecha conexión de las artes de canto con la enseñanza oral es que en esta época los tratados de música tomaban como modelo los libros de retórica clásica. ${ }^{175}$ Por ejemplo, Alexis Luko ha analizado los enlaces sistemáticos que se producen en la tercera parte del Liber de arte contrapuncti (manuscrito de 1477) de Johannes Tinctoris entre las teorías antiguas sobre retórica y las teorías de Tinctoris acerca del contrapunto; ${ }^{176}$ Luko muestra cómo Tinctoris emulaba en sus reglas del contrapunto los principios contenidos en De oratore (c. 55 a. C.) de Cicerón. Es ilustrativo en este sentido comparar las artes de canto llano R/14670 de la Biblioteca Nacional de España (datadas 1512-1515? y c. 1515-1519?, respectivamente) con el Arte de canto llano (Sevilla, 1530) de Juan Martínez. Aunque coinciden en contenidos (estos breves manuales de la Biblioteca Nacional han sido atribuidos a Juan Martínez), ${ }^{177}$ el Arte de canto llano de Martínez se muestra más ligado a un "estilo escrito", por ejemplo utilizando títulos que encabezan cada capítulo, mientras que los tratados más tempranos de la Biblioteca Nacional se organizan como un discurso oral en el que se emplean determinadas fórmulas para realizar la transición de un tema a otro (véase Tabla II.8). A pesar de la importancia de la oralidad en la vida musical del siglo XVI, cabe preguntarse si una textualidad beneficiada por la imprenta incrementó la difusión del alfabetismo musical en ese contexto. El alfabetismo puede entenderse como la disponibilidad de libros para los lectores sin que ello suponga la sustitución de la oralidad. ${ }^{178}$

\footnotetext{
${ }^{174}$ Chartier, Cultura escrita, literatura e historia, pp. 51-52.

175 Margaret Bent, "The Grammar of Early Music: Preconditions for Analysis", en Tonal Structures in Early Music, ed. por Cristle Collins Judd (Nueva York: Garland, 1998), pp. 15-59.

${ }^{176}$ Alexis Luko, “Tinctoris on Varietas”, Early Music History, 27 (2008), pp. 99-136.

${ }^{177}$ Ribeiro, A “Arte de Cantollano”, de autor desconhecido, p. 30. Véase el Capítulo III.

178 Erick A. Havelock, The Literate Revolution in Greece and Its Cultural Consequences (Princeton: Princeton University Press, 1982), p. 57. Véase Mary Carruthers, The Book of Memory: A Study of Memory in Medieval Culture (Cambridge: Cambridge University Press, 2008 [1990]), p. 18. Acerca de las diferencias entre alfabetismo y oralidad, véase Walter Ong, Orality and Literacy: The Technologizing of the World (Londres: Routledge, 1995).
} 
Tabla II.8: Fórmulas vinculadas a la oralidad en el manual R/14670(1) de la Biblioteca Nacional de España comparadas con el tratado de Juan Martínez

\section{Anónimo, Arte de cantollano [Sevilla: Jacobo Cromberger, c. 1512-1515?]. Madrid, Biblioteca Nacional de España, R/14670(1).}

Juan Martínez, Arte de canto llano (Sevilla: Juan Cromberger, 1530).

\begin{abstract}
Agora vengamos a los signos e veamos que cosa es signo.

Pues auemos dicho de suso de los signos e sus bozes como se cantan e de sus propiedades: agora vengamos a las mutanças: y veamos que cosa es mutança.
\end{abstract}

Capitulo segundo de los signos.

Capitulo .iii. de las mutanças.

Agora vengamos a la platica del canto llano. Capitulo quarto de las claues.

Una de las controversias más reiteradas en los estudios sobre la historia del libro es si la imprenta supuso una democratización en el acceso a los libros al disminuir su coste o si por el contrario éstos seguían siendo demasiado caros como para poder ser adquiridos por una mayoría. ${ }^{179}$ En cualquier caso, debe de tenerse en cuenta que en las almonedas y otras modalidades del activo mercado de segunda mano los precios se reducían considerablemente. Quizás la clave esté en la tipología de los libros y sus características físicas, ${ }^{180}$ puesto que, aunque es cierto que los libros en general no llegaron a ser lo suficientemente baratos como para que cualquier persona pudiera comprarlos, las artes de canto, como la literatura de cordel, tenían un coste relativamente asequible. ${ }^{181}$ Por ejemplo, Jacques Lafaye rechaza la concepción según la cual la imprenta fue de inmediato un medio de educación y emancipación popular porque tanto el analfabetismo como el costo del libro "fueron obstáculos insuperables hasta muy entrado el siglo

\footnotetext{
${ }^{179}$ Acerca de la evolución del precio de los libros en general, véase el apéndice "La evolución de los precios de los libros en la España del siglo diecisiete" en Dadson, Libros, lectores y lecturas, p. 513.
${ }^{180}$ La relación entre el formato de los libros y la extensión de su difusión a nuevas clases sociales ya ha sido señalada por Cristle Collins Judd (como uno de los logros de Petrucci) y, más recientemente, por Jessie Ann Owens; véanse Judd, Reading Renaissance Music Theory, p. 31: “Aunque los libros eran ca- ros, ponían sin embargo la notación musical en manos de una nueva clase de lectores de música en volú- menes de tamaño conveniente y fácilmente manejables" ["Although the books were expensive, they ne- vertheless placed music notation in the hands of a new class of music readers in conveniently sized, easily manipulated volumes"]; y Owens, "You Can Tell a Book by Its Cover".

${ }^{181}$ Sobre la accesibilidad de las diferentes tipologías librescas, véase Osorio Pérez et al., Trastiendas de la cultura, pp. 141-142. 
XX en las sociedades hispánicas”, pero más adelante argumenta que los pliegos sueltos "fueron el instrumento principal de la democratización de la cultura impresa". ${ }^{182}$

El Apéndice 10 muestra una tabla que incluye el valor monetario de diferentes artes de canto (a menudo sin identificar) tomando como fuentes la tasa incluida en los propios libros (precio fijo establecido por el Consejo Real en función del coste de producción estimado) o bien información extraída de inventarios de bienes y catálogos bibliográficos en un ámbito cronológico comprendido entre 1529 (el inventario postmortem de Jacobo Cromberger) y 1743 (el inventario de la biblioteca de don Juan Mateo de Somalo, secretario de Felipe V). Si las comparamos con otros libros didácticos como los manuales de vihuela, las artes de canto eran mucho más asequibles. Por ejemplo, el Libro de musica para vihuela intitulado Orphenica lyra (Sevilla, 1554) de Miguel de Fuenllana fue impreso en una tirada de 1000 ejemplares, cada uno de los cuales se tasó para la venta en 28 reales (952 maravedíes), mientras que, como muestra el Apéndice 10, en 1557 el "Arte de Canto llano in $8^{\circ}$ Alcala y Salamanca" incluido en el inventario de Juan de Junta y que podría ser un ejemplar del Arte de canto llano de Juan Martínez tenía un valor de 14 maravedís, nada menos que 68 veces más barato (véase Tabla II.9). En general, las artes de tañer eran más voluminosas y su precio era más elevado. Por ejemplo, cada ejemplar de las Obras de musica para tecla, arpa y vihuela (Madrid, 1578) de Antonio de Cabezón fue tasado en 563 maravedíes, y en el registro de embarque de los libros de Antonio Dávalos (documento otorgado en Sevilla a 1 de enero de 1582) encontramos un "arte de tañer fantasia", seguramente un ejemplar del Libro llamado Arte de tañer fantasia (Valladolid, 1565) de Tomás Luis de Santa María, tasado en 750 maravedíes. ${ }^{183}$ Incluso libros más económicos como el Libro de Musica en cifras para Vihuela, intitulado el Parnasso (Valladolid, 1576) de Esteban Daza, tasado en 136 maravedíes, tenían un precio mucho más elevado que el de las artes de canto.

\footnotetext{
${ }^{182}$ Lafaye, Albores de la imprenta, pp. 16 y 30.

${ }^{183}$ Teodoro Hampe-Martinez, "Libros profanos y sagrados en la biblioteca del tesorero Antonio Davalos", Revista de Indias, XLVI/178 (1986), pp. 385-402, p. 396, nº 9.
} 
Tabla II.9: Valuación de artes de canto y artes de tañer

* 1 real $=34$ maravedíes

\begin{tabular}{|c|c|c|c|}
\hline & & Precio & Fecha y fuente \\
\hline \multirow{2}{*}{ 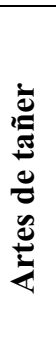 } & $\begin{array}{l}\text { Miguel de Fuenllana, Libro de musica } \\
\text { para vihuela intitulado Orphenica lyra } \\
\text { (Sevilla: Martín de Montesdoca, 1554). }\end{array}$ & $\begin{array}{l}28 \text { reales }[=952 \\
\text { maravedíes }]\end{array}$ & Sevilla, 1557; tasa impresa \\
\hline & $\begin{array}{l}\text { Arte de tañer fantasia [identificado como } \\
\text { Tomás Luis de Santa María, Libro lla- } \\
\text { mado Arte de tañer fantasia (Vallado- } \\
\text { lid: Francisco Fernández de Córdoba, } \\
\text { 1565)]. }\end{array}$ & 750 maravedíes & $\begin{array}{l}\text { Sevilla, 1582; registro de } \\
\text { embarque de los libros de } \\
\text { Antonio Dávalos }\end{array}$ \\
\hline \multirow{2}{*}{ 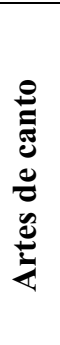 } & $\begin{array}{l}\text { Juan Martínez, Arte de canto llano (Alcalá } \\
\text { de Henares: Miguel de Eguía, 1532). }\end{array}$ & 10 maravedíes & $\begin{array}{l}\text { Alcalá de Henares, 1534; } \\
\text { anotación en la copia ante- } \\
\text { riormente conservada en la } \\
\text { Biblioteca Colombina de } \\
\text { Sevilla }^{184}\end{array}$ \\
\hline & $\begin{array}{l}\text { Arte de Canto llano in } 8^{\circ} \text { Alcalá y Sala- } \\
\text { manca [identificado como el Arte de } \\
\text { canto llano de Juan Martínez]. }\end{array}$ & 14 maravedíes & $\begin{array}{l}\text { Burgos, 1557; inventario } \\
\text { del impresor Juan de Junta }\end{array}$ \\
\hline
\end{tabular}

Los cuentos populares de la época nos ayudan a estimar estos precios en su contexto. Así, por ejemplo, en "La porfía de los recién casados" del Fabulario (1613) de Sebastián Mey, se indica que un huevo valía 3 blancas y cinco huevos costarían aproximadamente 7,5 maravedíes. ${ }^{185}$ Por tanto, un arte de canto llano de 10 maravedíes era muy asequible. En consecuencia, mientras que las artes de tañer "suponían un gasto razonable pero no excesivo" y por tanto podían ser adquiridas por una emergente clase media, ${ }^{186}$ las artes de canto parecen diseñadas para ajustarse a los medios económicos de un espectro social mucho más amplio. Mário de Sampaio Ribeiro sugiere que incluso

\footnotetext{
${ }^{184}$ La anotación con la valuación del ejemplar es de Hernando Colón. Este ejemplar fue consultado por Bartolomé José Gallardo, que pudo copiar la anotación; véase su Ensayo de una biblioteca española de libros raros y curiosos (Madrid: Gredos, 1968 [1888]), vol. 3, p. 646, nº 2933.

${ }^{185}$ Sebastián Mey, Fabulario (Valencia: Felipe Mey, 1613), n ${ }^{\circ} 51$.

${ }^{186}$ Griffiths, "La vihuela en la época de Felipe II", p. 425: "Desde la perspectiva del consumidor, los libros suponían un gasto razonable pero no excesivo. En términos actuales, un real de la época de Felipe II tendría un valor de alrededor de mil pesetas. Medido así, los cuatro reales que costaba El Parnasso representarían un gasto modesto mientras que Orphenica lyra era más comparable con lo que hoy en día sería una edición cara, si no de lujo". Según la Tabla II.9, el libro de Fuenllana se tasó en 28 reales que, siguiendo la correspondencia de Griffith, hoy en día equivaldrían aproximadamente a 168 euros.
} 
pudo haber un tipo de tratados musicales de precio aún más reducido, caracterizado por utilizar poco papel de manera que el texto discurría sin solución de continuidad, sin espacios en blanco y sin ejemplos musicales. ${ }^{187}$ Este es el caso del Arte de cantollano anónimo R/14670(1) de la Biblioteca Nacional de España.

\subsection{El mercado potencial: artes de canto, nuevas categorías de lectores y difusión del alfabetismo musical}

Trevor J. Dadson ha subrayado que "los libros no existen en el vacío" sino que "pertenecen a ciertos individuos en determinados momentos de la historia" y que, por tanto, "si queremos entender la importancia de aquéllos, tenemos que saber más acerca de éstos". ${ }^{188}$ El propósito de esta sección es delimitar el mercado potencial de las artes de canto en el mundo ibérico renacentista siguiendo dos métodos: el análisis de los documentos preliminares de las propias artes de canto, donde los autores en ocasiones mencionaban a qué tipo de público estaban destinadas sus obras, y el vaciado de inventarios de bienes que presenta el Apéndice 9.

El estudio de los textos preliminares de las artes de canto permite concluir que estos manuales estaban destinados a un amplio mercado y fueron diseñados para ello; sus usuarios no eran sólo religiosos, sino también laicos, y no exclusivamente principiantes, sino también maestros. Gonzalo Martínez de Bizcargui dirigía su obra a los "novicios" y el Arte de canto llano de Francisco de Montanos estaba ideado "para que se animen y ocupen los que profesan el hábito Sacerdotal”. En los tratados de la época encontramos constantes referencias a la obligación que tenían los religiosos de saber cantar, según Juan Bermudo, por varias razones: "para emplear la musica en el seruicio y alabanças de Dios", porque "mandamiento tenemos en muchas partes de la sacra scriptura para cantar", y "tambien es obligado el hombre a saber cantar: quando prome-

${ }^{187}$ Ribeiro, A “Arte de Cantollano”, de autor desconhecido, p. 9.

${ }^{188}$ Dadson, Libros, lectores y lecturas, p. 48. Para un estudio de la cultura de una ciudad, en particular Santiago de Compostela, utilizando como fuente el contenido de las bibliotecas de sus habitantes, véase Juan Eloy Gelabert González, "La cultura libresca de una ciudad provincial del Renacimiento", en $L a$ documentación notarial y la Historia. Actas del II Coloquio de Metodología Histórica Aplicada, ed. por Antonio Eiras Roel (Santiago de Compostela: Junta de Decanos de los Colegios Notariales de EspañaUniversidad, 1984), vol. 2, pp. 147-163. Véanse también Anastasio Rojo Vega, Ciencia y cultura en Valladolid. Estudio de las bibliotecas privadas de los siglos XVI y XVII (Valladolid: Universidad, 1985); y Prieto Bernabé, Lectura y lectores. Acerca del caso de Barcelona, véanse Peña Díaz, Cataluña en el Renacimiento; y El laberinto de los libros. 
tio dezir el officio diuino". ${ }^{189}$ Cerone criticaba a los eclesiásticos que no sabían cantar porque "todos los Religiosos son tenidos saber cantar a lo menos Cantollano, para poder satisfazer al obligo que tienen de dezir el officio cantando las fietas solennes en el Choro". ${ }^{190}$ Por ejemplo, Vicente Espinel fue nominado a medio beneficio por el Dean y Cabildo de la Iglesia de Málaga en 1587 por ser "clerigo presuitero, buen latino y buen cantor de canto llano y de canto de organo". ${ }^{191}$ Como consecuencia, en la época proliferaron normativas que regulaban la instrucción del clero a este respecto. Un temprano ejemplo es la Sinodal de Aguilafuente de 1472, mediante la cual se pretendía poner remedio a la ignorancia de algunos clérigos "que no saben leer ni cantar". ${ }^{192}$ Otros ejemplos se encuentran en el Nuevo Mundo: en las constituciones del Primer Concilio Mexicano, donde se enfatizó la necesidad de conocer al menos el canto llano y se ordenó que los candidatos a los distintos grados eclesiásticos superaran un examen de canto; y en las Ordenanzas para el coro de la Catedral de México, en que se estipuló que "los clérigos que no cantaran adecuadamente el oficio divino serían penalizados". ${ }^{193}$ No es extraño, por tanto, que buena parte del mercado potencial de las artes de canto estuviese constituido por clérigos y aspirantes a ello.

Según reflejan los materiales preliminares de las artes de canto, no todos los consumidores de esta tipología libresca pertenecían al ámbito eclesiástico. La idea de un mercado no profesional para las artes aparece ya en los trabajos de Tess Knighton: "no se pensaba que estos manuales fueron necesariamente diseñados para aquéllos con alguna implicación profesional, sino que estaban dirigidos, a través del agente de la im-

\footnotetext{
${ }^{189}$ Bermudo, El libro primero, ff. 49v-51v; Tapia, Vergel de musica, ff. 21r-22r. Véanse también Manuel Barra Rodríguez, "La música entre los jerónimos de Bornos (Cádiz)”, Revista de Musicología, V (1982), pp. 235-285; y Alfonso de Vicente Delgado, "Los cargos musicales y las capillas de música en los monasterios de la orden de San Jerónimo (siglos XVI-XIX)", Tesis Doctoral (Ph.D.), Universidad Complutense de Madrid, 2010.

${ }^{190}$ Cerone, El Melopeo y Maestro, pp. 20-24.

191 "Nominacion de medio beneficio de Ronda a Vizente Spinel" (4 de mayo de 1587); citado en Juan Pérez de Guzmán, "Vicente Espinel y su obra", en Vicente Espinel, Vida del escudero Marcos de Obregón (Barcelona: Biblioteca “Arte y Letras”, 1883), p. 23.

192 Romero de Lecea, Introducción a los viejos libros de música, p. 79.

193 Gonzalo Roldán Herencia, "La música eclesiástica en Nueva España según documentos papales y episcopales del siglo XVI", en La Música y el Atlántico, coord. y ed. por María Gembero Ustárroz y Emilio Ros-Fábregas (Granada: Universidad de Granada, 2007), pp. 277-309, pp. 294 y 303.
} 
prenta, a un consumo más general". ${ }^{194}$ En el transcurso de la presente investigación he encontrado indicios que apoyan esta hipótesis. El ejemplo más emblemático quizás se encuentre en el Arte y suma de canto llano de Juan Francisco Cervera que incluye el término "aficionados" en dos ocasiones: 1) en la aprobación firmada por el Doctor Pedro Ioan Assensio, consultor del Santo Oficio de la Inquisición en Valencia, quien daba el visto bueno a la obra "entendiendo que ha de ser muy vtil y de prouecho para los aficionados a dicha arte, por la necesidad que dizen que ay de semejante libro"; y 2) en lo escrito por el propio Cervera más adelante: “començare la presente Arte de Canto llano, para que con mucha facilidad se aprouechen todos los afficionados y desseosos de saber dicha façultad". 195

Los indicios apuntan a que se produjo un solapamiento entre poseedores de artes de canto y usuarios de artes de tañer; véase Tabla II.10. La interconexión que se producía en la época entre la música vocal y la instrumental ha sido señalada por John Griffiths como muestra de la incongruencia que supone que la música instrumental del período haya ocupado un lugar secundario en la historiografía con respecto a la vocal. ${ }^{196}$ Al final del ejemplar del libro de Cervera conservado en la Biblioteca Històrica de la Universitat de València, encontramos anexado un "desplegable" repleto de ilustraciones de gran atractivo visual que funcionan como tablatura para guitarra (véase Ilustración II.5). ${ }^{197}$ El formato de la tablatura ("los dedos que tienen sortija”), así como el tono y el vocabulario usados en la concisa explicación de la tablatura ("el que no entienda la Musica") muestran que este pliego iba dirigido a aficionados. Además, se señala que para entender las obras del autor del pliego no se "necesita ser Matematico basta saber leer":

\footnotetext{
${ }^{194}$ Knighton, "Libros de canto", p. 229: "Clearly, the demand for a plainchant and polyphony manual must have come largely from members of the clergy, and it would be premature to assume at this stage that there was a widespread general interest in acquiring some literacy in music. Yet such manuals were not necessarily thought of as applying to those with some professional involvement, but were intended, through the agent of printing, for more general consumption".

${ }^{195}$ Cervera, Arte y suma de canto llano, p. 1.

${ }^{196}$ John Griffiths, "Juan Bermudo, Self-Instruction and the Amateur Instrumentalist", en Music Education in the Middle Ages and the Renaissance: Reading and Writing the Pedagogy of the Past, ed. por Susan Forscher Weiss, Russell E. Murray y Cynthia J. Cyrus (Bloomington: Indiana University Press, 2010), pp. 126-137, p. 127.

${ }^{197}$ Este documento con tablatura para guitarra no aparece en el resto de ejemplares del libro de Cervera consultados (Biblioteca Pública de Évora, Biblioteca de la Universitat de Barcelona, Biblioteca de Catalunya en Barcelona).
} 
Nueva Demonstracion de los Puntos de la Guitarra para saberlos excutar muy facilmente sin Maestro. Los dedos que tienen sortija no pisan cuerda algun y las que hay puntitos se han de pisar con las puntas, o yemas de los dedos sin tocar otras teniendolos arqueados y el index pisa todas las de los numeros $6,7,8$, etc. Los 12 , primeros son con $3^{\mathrm{a}}$ mayor $5^{\mathrm{a}}$ natural, y $8^{\mathrm{a}}$ y $\operatorname{los} 12$ ultimos son con $3^{\text {a }}$ menor [...]. El que no entienda la Musica, llame a estos Puntos el 1, el 2, el 3, el 4, etc. naturales, y bmolados. Si quiere saber mas, mire los Trastes de este instrumento y de los demas, el Labyrinto, y sus Clausulas [...] que he sacado.

En Madrid, a casa del autor, se venden todas sus obras muy utiles | curioso, y para entenderlas, no necesita ser Matematico basta saber leer.

Tabla II.10: Poseedores de artes de canto y artes de tañer (siglos XVI y XVII)

\begin{tabular}{|c|c|c|c|c|}
\hline \multicolumn{2}{|c|}{$\begin{array}{l}\text { Datos del } \\
\text { inventario }\end{array}$} & \multirow{2}{*}{$\begin{array}{l}\text { Propietario } \\
\text { Juan Bernal Díaz de } \\
\text { Luco, Obispo de } \\
\text { Calahorra }\end{array}$} & \multirow{2}{*}{$\begin{array}{l}\text { Artes de canto } \\
\text { "Iten otro libro de } \\
\text { Mollina letra D" } \\
\text { [¿Lux videntis?] }\end{array}$} & \multirow{2}{*}{$\begin{array}{l}\text { Artes de tañer } \\
\text { "Dos tratados de Musica en } \\
\text { cifra" [Alonso de Mudarra, } \\
\text { Tres libros de musica en cifras } \\
\text { para vihuela] }\end{array}$} \\
\hline 1556 & Logroño $^{198}$ & & & \\
\hline 1580 & Sevilla $^{199}$ & Alonso Mudarra & $\begin{array}{l}\text { "Arte yngeniosa de } \\
\text { musica de Melchor } \\
\text { de Torres" }\end{array}$ & $\begin{array}{l}\text { "Un libro de cifra de vihuela } \\
\text { impreso" [Posiblemente su } \\
\text { propia publicación] y "un libro } \\
\text { de cifras de musica, de mano, } \\
\text { viejo" }\end{array}$ \\
\hline 1630 & Madrid $^{200}$ & $\begin{array}{l}\text { Diego de Silva y } \\
\text { Mendoza, Conde de } \\
\text { Salinas (poeta y } \\
\text { político) }\end{array}$ & $\begin{array}{l}\text { "Veynte y cinco } \\
\text { libros de canto muy } \\
\text { bajos encuadernados } \\
\text { en pergamino" }\end{array}$ & $\begin{array}{l}\text { "Vn libro encuadernado en } \\
\text { pergamino con flores doradas } \\
\text { yntitulado flores de musica } \\
\text { para instruccion de arpa" }\end{array}$ \\
\hline 1699 & $\begin{array}{l}\text { Ciutadella } \\
\text { (Menorca) }^{201}\end{array}$ & $\begin{array}{l}\text { Bernat Josep Olives, } \\
\text { noble }\end{array}$ & "Lu & rte musical",202 \\
\hline
\end{tabular}

198 Tomás Marín Martínez, "La biblioteca del obispo Juan Bernal Díaz de Luco (1495-1556)”, Hispania sacra, V/2 (1952), pp. 263-326; VII/1 (1954), pp. 47-84; María Isabel Hernández González, "Suma de inventarios de bibliotecas del siglo XVI (1501-1560)", en Coleccionismo y Bibliotecas (siglos XV-XVIII) [El libro antiguo español, 4], dir. por María Luisa López-Vidriero y Pedro Manuel Cátedra García (Salamanca: Universidad de Salamanca, 1998), pp. 375-446, p. 442, n 52; y Ros-Fábregas, "Libros de música en bibliotecas españolas del siglo XVI” (III), pp. 19-20, nº 42.

199 Wagner, "Los libros del canónigo y vihuelista Alonso Mudarra”, pp. 656-658; Álvarez Márquez, "El escribano de letra de libros 'versus' el cajista”, p. 109; y Ruiz Jiménez, La Librería de Canto de Órgano, p. 148.

${ }^{200}$ Dadson, Libros, lectores y lecturas, p. 408, n 150.

${ }^{201}$ Miquel-Àngel Casasnovas i Camps, Biblioteques, llibres i lectors: la cultura a Menorca entre la Contrareforma i el Barroc (Barcelona: L’Abadia de Montserrat, 2001), p. 333.

202 Seguramente Luz y norte musical para caminar por las cifras de la guitarra española y arpa, tañer, y cantar a compas por canto de organo; y breve explicacion del arte (Madrid: M. Álvarez, 1677), obra de Lucas Ruiz de Ribayaz, nacido en Santa María Ribarredonda, Burgos, antes de 1650. Este libro encajaría por tanto en ambas categorías (artes de canto y artes de tañer). 


\section{Ilustración II.5: "Nueva Demonstracion de los Puntos de la Guitarra" al final del ejemplar de Valencia, Biblioteca Històrica de la Universitat de València, Z-13/32 del libro de Juan Francisco Cervera, Arte y suma de canto llano (Valencia, 1595).}
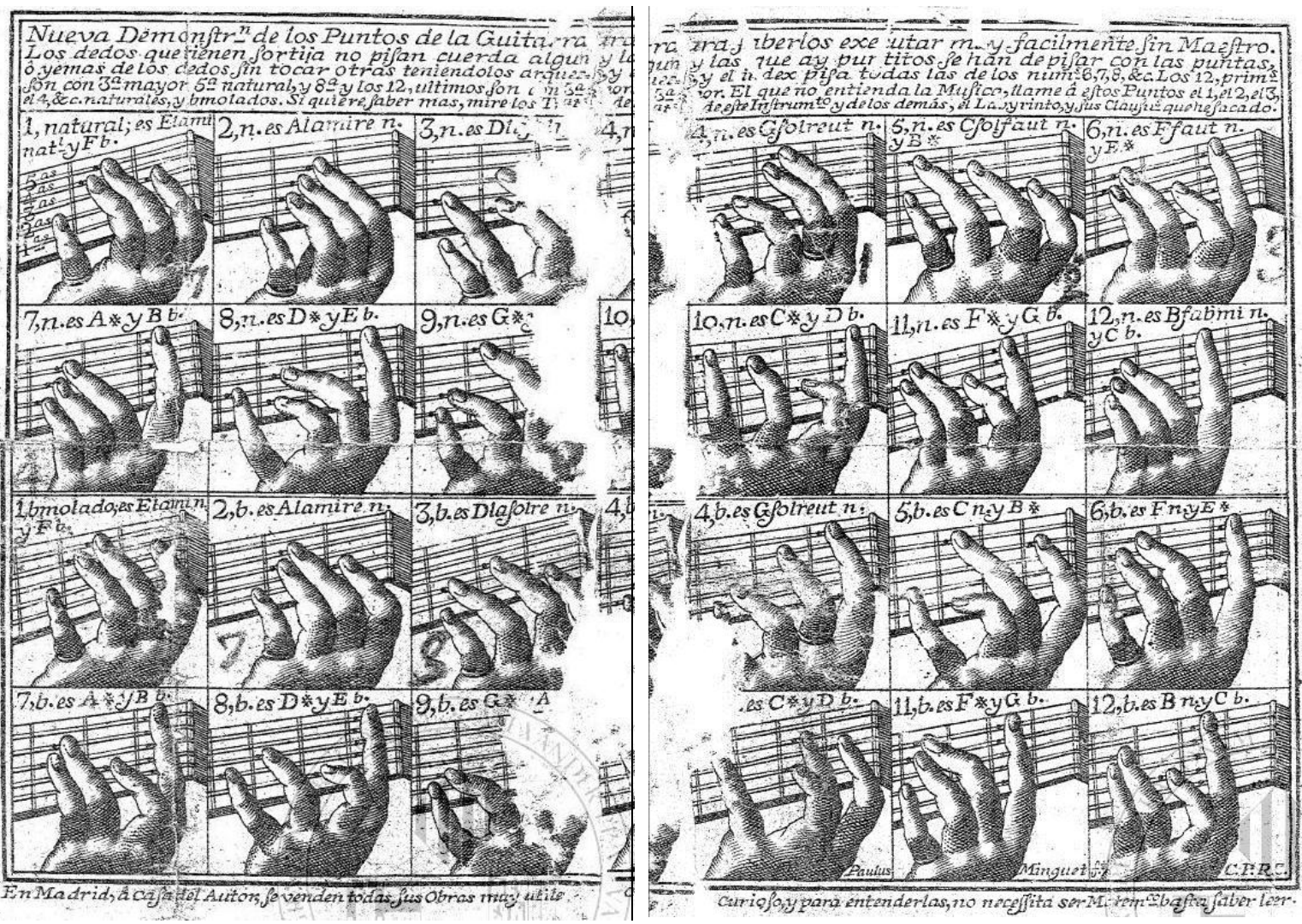

Este formato ("broadside"), según Jessie Ann Owens, "no ha sido lo suficientemente estudiado como un método de instrucción musical elemental, quizás porque el porcentaje de superviviencia es muy bajo y la pista bibliográfica difícil de seguir". ${ }^{203}$ Owens distingue varios tipos de pliegos a partir de los ejemplos que han sobrevivido en el contexto inglés: los que proporcionan instrucción sobre un instrumento particular, a veces conteniendo una ilustración del instrumento que muestra la digitación (algo similar al caso del pliego de Valencia); los que presentan los rudimentos de la música; y aquéllos que tratan temas más avanzados como contrapunto y bajo continuo. Además, la musicóloga advierte la conexión entre libros en octavo y pliegos, ambos concebidos para un uso pedagógico, debido sobre todo a que ambos eran "medios asequibles de

${ }^{203}$ Owens, "You Can Tell a Book by Its Cover", p. 361: "This format has not been sufficiently studied as a method of elementary music instruction, perhaps because the survival rate is poor and the bibliographical trail hard to follow". 
proporcionar instrucción musical elemental". ${ }^{204}$ El pliego hallado en el ejemplar de Valencia del Arte y suma de canto llano de Cervera no se encuentra registrado independientemente en el catálogo de la Biblioteca sino que pasa desapercibido entre las hojas del libro de Cervera. Aunque es difícil alcanzar conclusiones en este sentido, este caso podría indicar que el usuario del arte de canto de Cervera poseía asimismo el pliego con tablatura para guitarra.

Encontramos otros indicios de este solapamiento entre el mercado de artes de canto y el de artes de tañer en la Breue instrucion de Canto llano de Luis de Villafranca, puesto que en este manual de canto gregoriano se encuentran alusiones al órgano, el monacordio y la vihuela, alabando la perfección de este último instrumento, ${ }^{205} \mathrm{y}$ en el Libro de cifra nueua para tecla, harpa, y vihuela (Alcalá de Henares, 1557) de Luis Venegas de Henestrosa, dirigido a sacristanes y futuras monjas:

Bien tengo entendido, que ha dilatar un año, o dos la impresion deste libro, fuera mas perfecto; pero tengo en mucho mas el prouecho que en este tiempo podia sacar el otro que esta recogido tañendo, o oyendo tañer un psalmo, para leuantar su spiritu a Dios, o del otro sacristan, que por no saber tañer un poco no lo reciben, o de la otra que quiere ser monja, etc., que lo que me podria succeder es que saliesse muy limado y en perfection. ${ }^{206}$

Es interesante que Venegas señalase que los sacristanes tenían la necesidad de saber tañer al mencionar el provecho de su libro para el "sacristan, que por no saber tañer un poco no lo reciben". El propio Venegas era sacerdote (“cura de la villa de Hon-

\footnotetext{
${ }^{204}$ Owens, "You Can Tell a Book by Its Cover", p. 368: "Whatever the borrowing may tell us about how literally we should take any of Playford's statements, it surely reinforces the kinship between the small octavos and the large broadsides for pedagogical use. The close connection between the contents should not be surprising because both are inexpensive ways of providing elementary instruction in music".

${ }^{205}$ Villafranca, Breue instrucion de Canto llano, f. B5r: "Desta quinta diuision assi hecha caresce el Organo, mas no la boz por ser instrumento mas perfecto que otro ninguno hecho de manos. Eccepto la vihuela y aunque el organo no la tiene ningun impedimento tiene la boz para no hazella todas las vezes que subiere o descendiere de la tercera diuision a alamire. La horden del juego del Organo, o Monacordio es limitada aunque tiene lo que ha menester, y vsa de lo que puede: pero la boz humana es tan abundante que lo vno y lo otro sojuzga y puede hazer". En los ff. c1v-c2r: “[...] sino porque el monacordio muestra ser mayor, y esto viene de estar mal repartido el diapasson en el, pues vemos que despues de bien templado es menester abaxar las quintas para poder tañer: de donde se manifiesta el contrario: tambien vemos que la vihuela haze el semitono de vn traste a otro, y si estuuiessen puestos por mano de musico, quedaria el vno menor que el otro: y de estar assi se manifiesta ser este instrumento mas perfecto que todos los otros".
}

${ }^{206}$ Luis Venegas de Henestrosa, Libro de cifra nueua para tecla, harpa, y vihuela (Alcalá de Henares: Juan de Brocar, 1557), f. 3v, "Prologo y argumento de este libro". 
tova”, Guadalajara), ${ }^{207}$ como también lo fue el vihuelista Alonso Mudarra. Los propios tratados dirigidos a religiosos hacen referencia a la conveniencia de que éstos sepan, además de cantar, tañer:

\begin{abstract}
No os basta harto, dixo dessear a Dios, ni os aueys de tener por contento en saber solamente cantar: pues el señor os dio disposicion, tiempo, y habilidad para saber tañer: que mucho plaze al señor el que sabe bien tañer, principalmente organos. Y tambien os quiero auisar, que aqui en casa ninguno sale buen cantor, si no es tambien tañedor: porque lo vno ayuda a lo otro, y lo confirma. Y por esso pues vos teneys ya aquellos dos libricos de canto llano, y de canto de organo de Sant Agustin, para cantar delante del señor, yo os quiero agora mostrar a tañer, porque el Señor me lo mando: y dize que si os regis bien y os guardays de agraz y de cosas verdes (esto es) de cosas estrañas a su amor, y mucho mas de las azedas, que son delytes malos: que terneys buena voz de afficion spiritual, y sereys buen cantor, y mostrareys despues a los otros el canto. ${ }^{208}$
\end{abstract}

En los tratados de educación contemporáneos encontramos referencias a la necesidad que tenían todas las personas, no sólo los clérigos, de saber cantar. Tapia lo expresaba así: "Allende de tener obligacion a saber cantar, los que ya tengo dicho, aun me parece que a todos generalmente incumbe, y conuiene procurar tan sublimada sciencia, y efectuarse, a mi opinion, por el bien que de la musica se nos sigue". ${ }^{209}$ También Cristóbal de Villalón dedicaba un capítulo a los motivos por los cuales tiene el "scholástico" que saber cantar. $^{210}$

En conclusión, las artes de canto estaban diseñadas para alcanzar un mercado tanto religioso como laico en una época en que ambos ámbitos estaban en íntima relación, ${ }^{211}$ lo cual favoreció la existencia de un mercado "no profesional" interesado en estos manuales. Barry Ife ha señalado que el surgimiento de un mercado de aficionados para los libros de música debió de promover la impresión de música instrumental con

\footnotetext{
${ }^{207}$ Carta de poder de 8 noviembre 1543 otorgada por el doctor Bonifacio "al muy reverendo señor Luys de Ynestrosa, cura de la villa de Hontova"; véase Jaime Moll, "Músicos de la corte del cardenal Juan Tavera (1523-1545): Luis Venegas de Henestrosa", Anuario musical, VI (1951), pp. 155-178.

${ }^{208}$ Miguel de Comalada, Tratado llamado el Desseoso, y por otro nombre, Espejo de Religiosos: agora de nuevo corregido, y añadida la Sexta parte, que hasta agora no ha sido impressa (Salamanca: Alonso de Terranoua y Neyla, 1580), f. 191v.

${ }^{209}$ Tapia, Vergel de musica, f. 24r.

${ }^{210}$ Villalón, El scholástico, ed. de José Miguel Martínez Torrejón (Barcelona: Crítica, 1997 [ms. c. 1538 y 1542$])$, p. 306.

${ }^{211}$ Miguel Batllori, Humanismo y Renacimiento: estudios hispano-europeos (Barcelona: Ariel, 1987), p. 104.
} 
fines pedagógicos puesto que los profesionales de la época sabían improvisar (algunos eran ciegos). ${ }^{212}$ De la misma manera, si el canto se enseñaba de forma oral en las lecciones públicas de las iglesias y en las universidades, la impresión de artes de canto debió de responder en parte a las demandas de un público aficionado, además de a la necesidad de una herramienta docente para la impartición de las clases.

Es interesante examinar la información que aporta la dedicatoria del Comento sobre Lux bella (Salamanca, 1498) de Domingo Marcos Durán:

[...] acorde tomar haldas en cinta para abrir este camino que nos guie a la gloriosa ciudad de musica: el qual a mi ver fuera de toda soberuia es para hazer muy mas breue la jornada y a menos costa de fatiga no solamente a los sotiles de ingenio mas avn a los que son de muy baxa ralea. ${ }^{213}$

El vocablo "ralea" hace referencia despectiva a las personas de muy baja condición social. La terminología utilizada por Marcos Durán y, en particular, el concepto "sotiles de ingenio", recuerda a la proliferación que ha tenido lugar a partir de la década de los noventa del siglo XX de manuales "para torpes" tales como "Ofimática para torpes" o "Bricolaje para torpes".

Los textos preliminares contenidos en las artes de canto también muestran que estos manuales no estaban ideados únicamente para estudiantes, sino también para que los entendidos en la materia pudiesen utilizarlos como herramienta docente. En la Suma de todo lo que contiene el Arte de Canto llano (Sevilla, 1604) de Sebastián Vicente Villegas encontramos dos alusiones a este solapamiento: 1) ya en el título se menciona que la finalidad del libro es enseñar a cantar pero también a "regir bien el Coro"; y 2) en la aprobación firmada por Pedro de Cotes el 6 de junio de 1602 se considera que la obra "sera de mucha utilidad y provecho, assi para todos los que entienden de canto llano, como también para los que tratan de saberlo". Otro ejemplo de la finalidad plural de las artes de canto se localiza al comienzo del prólogo del Tratado breue de principios de canto llano (Toledo, c. 1521) de Juan de Espinosa: el libro está dirigido a "todos los que muestran tener gana de començar a deprender los principios del canto llano", pero también servirá para que "los que en el dicho tiempo se han dado al exercicio della [la mú-

\footnotetext{
${ }^{212}$ Ife, "La imprenta y la música instrumental del Renacimiento español”, p. 226.

${ }^{213}$ Marcos Durán, Comento sobre Lux bella, f. A2r, [dedicatoria].
} 
sica] la puedan mostrar a los que la dessean saber con menos dificultad". ${ }^{214}$ Esta dualidad no es exclusiva ni de las artes de canto españolas, ni de las artes de canto renacentistas. En primer lugar, también se percibe en el ámbito internacional: por ejemplo, en su portada, Cerone encomendaba el libro primero de El Melopeo y Maestro tanto "a los maestros de capilla y musicos eccelentes, como à gente docta [...] para que con su buena razon, los demas la conozcan y estimen”, pero más adelante advertía no escribir para "los ya professos" ni para "los famossos y eccelentes Maestros", sino para "los principiantes y nueuos en la Musica". ${ }^{215}$ En segundo lugar, esta dualidad también se percibe en obras posteriores; por ejemplo, en El porque de la musica (1672), Andrés Lorente incluía una "Espistola recomendatoria de la presente Obra, para los que desean saber la Ciencia de la Musica, y para los Maestros que la enseñan”. El Capítulo IV, que se centra en los usos de las artes de canto a la luz de las evidencias externas encontradas en los ejemplares consultados, aporta nueva información que apoya la hipótesis de que estos libros eran usados tanto por maestros como por principiantes.

Además de los receptores individuales, encontramos un mercado institucional para las artes de canto, principalmente los monasterios y las universidades. ${ }^{216}$ Por ejemplo, el Apéndice 9 muestra que una edición salmantina del Arte de canto llano de Juan Martínez aparece en el inventario de libros de 1642 del Convent de Jesús de Maó (Menorca). No sólo los monasterios y universidades disponían de estos manuales de canto, sino también las catedrales, como queda reflejado en el inventario de 1542 de los libros de música de la Catedral de Guatemala y el inventario de libros de música de la Catedral de Cuzco en 1546 (véase Apéndice 9).

La creación de libros en lengua vernácula y el abaratamiento de los precios que supuso la imprenta tuvieron como consecuencia la aparición de nuevas categorías de lectores y de este proceso se beneficiaron, como ha indicado Prieto Bernabé, "los lecto-

\footnotetext{
${ }^{214}$ Espinosa, Tractado breue de principios de canto llano, f. A1v.

${ }^{215}$ Cerone, El Melopeo y Maestro, p. 10.

${ }^{216}$ Para un estudio de las artes de canto llano en las órdenes religiosas españolas del siglo XVII, véase Sanhuesa Fonseca, "Artes de canto llano en las órdenes religiosas españolas del siglo XVII". Vicente Bécares Botas ha estudiado la propiedad institucional de los libros en general en la España renacentista, tanto en el ámbito monacal como en el universitario. Para un listado de las bibliotecas monásticas en la provincia de Zamora y una clasificación de sus fondos, véase su trabajo Las bibliotecas monásticas y la desamortización en la provincia de Zamora (Zamora: Semuret, 1999), pp. 28 y 36. Acerca de los mecanismos de adquisición de libros en la Biblioteca de la Universidad de Salamanca, véase su ya mencionado "Compras de libros para la Biblioteca Universitaria salmantina del Renacimiento".
} 
res de estratos sociales menos favorecidos". ${ }^{217}$ En principio, las únicas personas letradas eran aquéllas cuyo oficio exigía saber leer y escribir (clero, nobleza, funcionarios, maestros y mercaderes) ${ }^{218}$ por lo que los aldeanos, el "proletariado" urbano y una fracción de los artesanos quedaban al margen. ${ }^{219}$ No obstante, en su estudio sobre la cultura vallisoletana en el siglo XVI, Bartolomé Bennassar señala la aparición de libros en casa de un sastre, dos plateros, un pasamanero, un cerero, un pastelero y un zapatero, ${ }^{220}$ mientras que Hipólito Escolar Sobrino indica que "los artistas, los artesanos, los comerciantes y los labradores" poseían libros en sus casas. ${ }^{221}$ Las personas que únicamente habían recibido una enseñanza de tipo primario no sabían leer latín, ${ }^{222}$ por lo que las artes (tanto de canto como de tañer) en lengua vernácula alcanzaron un espectro de mercado más amplio que otros libros sobre música escritos en latín (véase Tabla II.11).

\footnotetext{
${ }^{217}$ Prieto Bernabé, Lectura y lectores, p. 77.

${ }^{218}$ Véase Wagner, "El siglo de Gutenberg y la imprenta en el siglo XVI", p. 33.

${ }^{219}$ Henri-Jean Martin, Livre, pouvoirs et société à Paris au XVIIe siècle (1598-1701) (Génova: Droz, 1969), p. 14.

${ }^{220}$ Bartolomé Bennassar, Valladolid au siècle d'Or: une ville de Castille et sa campagne au XVIe siècle (París: Mouton \& Co., 1967), p. 511.

${ }^{221}$ Hipólito Escolar Sobrino, Historia del libro español (Madrid: Gredos, 1998), p. 114.

${ }^{222}$ Escolar Sobrino, Historia del libro español, p. 114.
} 
Tabla II.11: Estrato social de los poseedores de artes de canto (siglos XV-XVII)

\begin{tabular}{|c|c|c|c|}
\hline Realeza & Nobleza & Clero & $\begin{array}{c}\text { Funcionarios y } \\
\text { profesionales liberales }\end{array}$ \\
\hline $\begin{array}{l}\text { - Isabel la } \\
\text { Católica } \\
\text { - Juana I de } \\
\text { Castilla } \\
\text { - Juana de } \\
\text { Austria } \\
\text { - João IV de } \\
\text { Portugal }\end{array}$ & $\begin{array}{l}\text { - Leonor Pimentel } \\
\text { - Juan de Guzmán } \\
\text { - Don Fadrique } \\
\text { Enríquez de Ribera, } \\
\text { I Marqués de Tarifa } \\
\text { - Diego Hurtado de } \\
\text { Mendoza, I Conde } \\
\text { de Mélito } \\
\text { - Antonia de Ulloa, } \\
\text { Condesa de Salinas } \\
\text { - Diego de Silva y } \\
\text { Mendoza, Conde de } \\
\text { Salinas } \\
\text { - Bernat Josep Olives }\end{array}$ & $\begin{array}{l}\text { - Bartolomé Cañar, clérigo } \\
\text { - Cristóbal de Alcubierre, } \\
\text { clérigo } \\
\text { - Juan Picart, sacerdote } \\
\text { - Pere Monjo, presbítero } \\
\text { - Antoni Cabrera, } \\
\text { canónigo } \\
\text { - Juan Bernal Díaz de } \\
\text { Luco, Obispo } \\
\text { - Arzobispo Carranza } \\
\text { - Pedro Cerbuna, Obispo } \\
\text { - Jaume Fábrega, antes } \\
\text { rector de la iglesia } \\
\text { parroquial de Santa } \\
\text { María de Corcó y el día } \\
\text { de su óbito beneficiado } \\
\text { de Santa María del Mar } \\
\text { de Barcelona } \\
\text { - Alonso Mudarra }\end{array}$ & $\begin{array}{l}\text { - Yolanda de Soria, esposa } \\
\text { del mercader Mateo } \\
\text { Belsequer } \\
\text { - Bartomeua Riera, } \\
\text { madre del librero Miquel } \\
\text { Riera } \\
\text { - Hernando Colón } \\
\text { - Isabel de Santisteban } \\
\text { - Benito Arias Montano } \\
\text { - Miguel Climent Gurrea, } \\
\text { protonotario del Consejo } \\
\text { Supremo de Aragón } \\
\text { - “Trebiña" (¿Juan de } \\
\text { Treviño?) } \\
\text { - Melchor Pérez de Soto, } \\
\text { arquitecto } \\
\text { - D. Martín Martínez de } \\
\text { Medrano, funcionario de } \\
\text { Felipe IV }\end{array}$ \\
\hline
\end{tabular}

En conclusión, la creación de libros de bajo coste en lengua vernácula llevó a la emergencia de nuevas categorías de lectores. ¿Cómo encajan las artes de canto en este marco general? En este Capítulo, he hecho referencia al debate sobre la conexión entre imprenta y acceso popular a los libros, concluyendo que no es posible generalizar porque había categorías librescas muy diferentes en formato y, en consecuencia, en precio. En general, las artes en lengua vernácula podían alcanzar un mercado más amplio que el de los tratados escritos en latín. Por su precio, las artes de tañer podían ser adquiridas por la emergente clase media y, por tanto, tuvieron un lugar en las casas burguesas y no sólo en la Corte, ${ }^{223}$ convirtiéndose en "un pasatiempo de las clases acomodadas". ${ }^{224}$ Las

${ }^{223}$ John Griffiths, "La vihuela en la época de Felipe II", en Políticas y prácticas musicales en el mundo de Felipe II: estudios sobre la música en España, sus instituciones y sus territorios en la segunda mitad del siglo XVI, ed. por John Griffiths y Javier Suárez Pajares (Madrid: ICCMU, 2004), pp. 415-446, pp. 427428 , diferencia el contexto cortesano en el que se inserta el libro de Fuenllana del ámbito burgués urbano del que emerge el libro de Daza.

${ }^{224}$ Ife, "La imprenta y la música instrumental del Renacimiento español”, p. 226. Véanse también Margit Frenk, "Música y poesía en el Renacimiento español (1490-1560)", en III Semana de Música Española. El Renacimiento (Madrid: Comunidad de Madrid, 1988), pp. 29-45, p. 42; y John Griffiths, "At Court and at Home with the Vihuela de Mano", Journal of the Lute Society of America, XXII (1989), pp. 1-27; "The Printing of Instrumental Music in Sixteenth-Century Spain"; y "The Transmission of Secular Polyphony in Renaissance Spain”. 
artes de canto, a causa de su pequeño formato y muy bajo coste en comparación con las artes de tañer, tuvieron una circulación similar a la de la literatura de cordel y un mercado potencial con análogo poder adquisitivo. Por tanto, el fenómeno de las artes de canto seguramente dio lugar a una ampliación del alfabetismo musical o, en palabras de Roger Chartier, a un "entrecruzamiento entre la historia del libro y la historia de la educación". ${ }^{225}$ Si un público amplio podía acceder a las artes de canto, cada vez más personas conocerían las reglas básicas de la música. Así, el análisis de una categoría libresca a menudo infravalorada como fuente musicológica ofrece una ventana a la cultura del mundo ibérico renacentista que muestra que la música iba más allá de la Corte y las catedrales, puesto que estaba íntimamente integrada en el entramado cultural de la época.

\section{RESUMEN DEL CAPÍTULO II}

El Capítulo II se complementa con los Apéndices 6 al 10 y se divide en tres secciones dedicadas a la producción, la distribución y el mercado de las artes de canto como bien de consumo. En la primera, se analizan los trámites requeridos en el proceso de publicación y las cuestiones técnicas y comerciales que afectaron a la imprenta de artes de canto. Estos libros no fueron una consecuencia de la cultura de la imprenta, ya que tratados en lengua vernácula con las principales reglas del canto proliferaron en forma manuscrita antes y después de que aparecieran artes impresas, produciéndose una coexistencia entre ambas modalidades. En este Capítulo se sugiere que las artes de canto pudieron servir a los impresores para experimentar cómo imprimir música. Aunque no había impresores especializados en la producción de artes de canto, en varias ocasiones un mismo impresor volvió a imprimir un arte de canto determinado, lo que indica que había una demanda por satisfacer. El estudio de la influencia de las cuestiones técnicas de la imprenta en las características de las artes de canto y el examen de las tiradas y las frecuentes reediciones sugieren que estos libros fueron muy populares entre los impresores. Puesto que su producción era relativamente poco costosa y su demanda elevada, las artes de canto debieron funcionar como un "estabilizador económico" para las imprentas. Las licencias de impresión, mecenas y dedicatarios de todas las reimpresiones del Arte de canto llano (1594) de Montanos muestran que en ocasiones fue el impresor quien tomaba la iniciativa de publicar artes de canto debido al atractivo comercial de estos libros; las artes de canto eran tan demandadas que Antonio Vázquez consiguió una licencia en Salamanca para imprimir en 1625 el libro de Montanos y cualquier otra arte de canto. La mayoría de los dedicatarios de estos libros ocupaba una posición religiosa de elevado rango, pero también encontramos figuras ajenas al ámbito religioso. La legislación y el fin comercial determinaron la apariencia física de las artes de canto.

\footnotetext{
${ }^{225}$ Chartier, Cultura escrita, literatura e historia, p. 102.
} 
En las dos últimas secciones de este Capítulo se lleva a cabo un análisis de la distribución y el consumo de las artes de canto para determinar el grado de presencia de la música en la vida cotidiana del mundo ibérico renacentista y la contribución de estos manuales a la difusión de la competencia musical en un amplio espectro socioeconómico. Mientras que los principales centros de recepción del repertorio musical impreso y manuscrito tuvieron que ser centros relacionados con el lugar de trabajo del autor, las artes de canto se vendieron sobre todo a través de un librero o en el mercado de segunda mano, por lo que entraron de forma más pronunciada en las rutas comerciales de los empresarios del libro y su difusión fue mayor que la de otros libros de música impresa. Los inventarios de impresores y libreros indican que las artes de canto eran demandadas en grandes cantidades. En este Capítulo se sugiere que las artes de canto pudieron establecer unas rutas comerciales que después aprovecharan otros manuales de música con propósito didáctico, como los libros de vihuela, y se pone de manifiesto la importante presencia que tuvieron las artes de canto en el mercado con el Nuevo Mundo.

Mediante un estudio de los precios de las artes de canto, se concluye que, por sus características físicas, estos libros eran mucho más asequibles que las artes de tañer, de manera que, mientras las últimas podían ser adquiridas por la emergente clase media (que también poseía artes de canto), las primeras eran accesibles a personas de menor poder adquisitivo, y debieron de contribuir a extender el alfabetismo musical a un espectro socioeconómico muy amplio. Había además otras formas de consumo que no implicaban propiedad ni lectura, como la asistencia a las lecciones abiertas al público de las capillas eclesiásticas de las que emergieron estos manuales; por ejemplo, el Arte de cantollano R/14670(1) anónimo de la Biblioteca Nacional de España presenta fórmulas vinculadas a la oralidad, en lugar de un estilo escrito. Los inventarios de bienes (complementados con la información proporcionada por los textos preliminares de las propias artes de canto) permiten determinar que el mercado potencial (particular e institucional) de las artes abarcaba una amplia gama de lectores: religiosos y laicos (es decir, profesionales del canto eclesiástico y aficionados), principiantes y maestros, y que se produjo un solapamiento entre poseedores de artes de canto y artes de tañer. Por ejemplo, he localizado un pliego con tablatura para guitarra anexo al ejemplar del arte de canto llano de Cervera conservado en la Biblioteca Històrica de la Universitat de València. Este pliego, que no está catalogado independientemente en esa biblioteca, había pasado desapercibido entre las hojas del libro de Cervera, y sugiere que el usuario del arte de canto de Cervera poseía también el pliego con tablatura para guitarra. El fenómeno de las artes de canto dio lugar a una ampliación de la competencia musical (a un “entrecruzamiento entre la historia del libro y la historia de la educación”, en palabras de Chartier). Las artes de canto habían pasado inadvertidas como contribuidoras al incremento y la difusión de la competencia musical en grupos sociales hasta entonces excluidos del aprendizaje de la música. 



\section{CAPÍTULO III}

\section{LA RECUPERACIÓN DEL ARTE DE CANTO LLANO (SEVILLA, 1530) DE JUAN MARTÍNEZ}

La historia del Arte de canto llano (Sevilla, 1530) de Juan Martínez, maestro de los mozos de coro de la Catedral de Sevilla, ofrece una serie de particularidades que lo convierten en un objeto de estudio paradigmático para aproximarse a la cultura musical del mundo ibérico renacentista. Las primeras ediciones de 1530 y 1532 se han perdido y los ejemplares de las primeras ediciones conocidas tanto en portugués (1550) como en castellano (1598) son incompletos. Este libro ejemplifica la mayor parte de las cuestiones planteadas en el Capítulo II sobre los procesos de producción, distribución, valuación y consumo de las artes de canto, y sirve como enlace al Capítulo IV, dados sus claros vínculos con la enseñanza de la música en contextos educativos diferenciados. Este Capítulo se estructura en cinco secciones enmarcadas por una parte introductoria, que presenta el estado de la cuestión sobre el Arte de canto llano de Juan Martínez, y una parte conclusiva. Los objetivos de este Capítulo son los siguientes: 1) explorar las reediciones de las que fue objeto el Arte de canto llano de Juan Martínez durante casi un siglo en los reinos de Castilla, Aragón y Portugal, con la aportación del hallazgo de ediciones desconocidas hasta el momento y de ejemplares conservados a los que no se había hecho referencia en la bibliografía; 2) analizar la importante difusión de este libro en los reinos peninsulares y el Nuevo Mundo siguiendo la metodología de los historiadores del libro; y 3) presentar una reconstrucción del texto del libro de Juan Martínez a partir de los ejemplares incompletos conservados (correspondientes a diferentes ediciones), posibilitando así la recuperación completa de las características didácticas de la obra de este tipo más difundida en el mundo hispánico de aquella época, pero menos conocida en la actualidad. 


\section{CUESTIONES DE HISTORIOGRAFÍA NACIONALISTA EN LA HISTORIA DE UN LIBRO}

El Apéndice 11 recoge las referencias a Juan Martínez y a su libro en los catálogos bibliográficos y en la bibliografía general. Los datos biográficos sobre Juan Martínez son mínimos, en ocasiones contradictorios y marcados por la polémica respecto a su nacionalidad. Seguramente como consecuencia de que no se conocían ejemplares de ediciones españolas de su Arte de canto llano y las primeras referencias a este músico aparecen en las traducciones portuguesas de su libro, donde se le llama Ioão Martinz (aunque no se menciona su nacionalidad), algunos historiadores lo contextualizan entre los músicos portugueses. Por ejemplo, Joaquim Martins de Calvalho y José Mazza señalan erróneamente que la primera edición del libro de Juan Martínez es una edición portuguesa impresa en Coimbra en $1603 .{ }^{1}$ Simplemente con respecto a su nombre encontramos múltiples variantes, como muestra la Tabla III.1.

Tabla III.1: Variantes del nombre de Juan Martínez en la bibliografía

\begin{tabular}{|c|c|}
\hline Variantes & Referencias \\
\hline João / Ioão Martinz & $\begin{array}{l}\text { Portadas de las ediciones portuguesas del tratado }(1550,1597,1603 \text {, } \\
\quad 1612,1614 \text { y 1625) }\end{array}$ \\
\hline Ioannes Martínez & Antonio, Bibliotheca Hispana Nova, vol. 1, p. 734. \\
\hline Ioão Martins & $\begin{array}{l}\text { Barbosa Machado, Bibliotheca Lusitana Historica, Critica, e } \\
\text { Cronologica, vol. 2, p. } 692 .\end{array}$ \\
\hline João Martins & $\begin{array}{l}\text { Silva, Diccionario bibliographico portugués, vol. 3, p. 415; Vasconcellos, } \\
\text { Os musicos portuguezes, vol. 1, p. 225; Pinto de Mattos, Manual bi- } \\
\text { bliographico portugués de livros raros, classicos e curiosos, p. } 380 ; \text { y } \\
\text { Catálogo online de la Biblioteca Nacional de Portugal. }\end{array}$ \\
\hline Jean Martínez & Fétis, Biographie universelle des Musiciens, vol. 5, p. 479. \\
\hline $\begin{array}{l}\text { João Martins o Juan } \\
\text { Martínez }\end{array}$ & $\begin{array}{l}\text { Vieira, Diccionario biographico de musicos portuguezes, vol. 2, pp. 66- } \\
\quad 67 .\end{array}$ \\
\hline Juan Martínez Clérigo & Pereira Salas, Los orígenes del arte musical en Chile, p. 10. \\
\hline João Miz. ${ }^{2}$ & Mazza, Dicionário biográfico de músicos portugueses, p. 29. \\
\hline \multicolumn{2}{|c|}{$\begin{array}{l}1 \text { Joaquim Martins de Carvalho, “Apontamentos para a historia da typographia em Coimbra, desde a sua } \\
\text { introdução nesta cidade em } 1531 \text { até o presente”, O Conimbricense: jornal politico, instructivo e com- } \\
\text { mercial (22-07-1867/11-08-1868), 17-09-1867, p. 1; y José Mazza, Dicionário biográfico de músicos } \\
\text { portugueses, prefacio y notas de José Augusto Alegria (Lisboa: Editorial Império, 1944-1945), p. } 29 \text {. }\end{array}$} \\
\hline
\end{tabular}




\begin{tabular}{|c|c|}
\hline Variantes & Referencias \\
\hline Juan Martinez de Rigo ${ }^{3}$ & $\begin{array}{l}\text { Eitner, Biographisch-bibliographisches Quellen Lexikon der Musiker und } \\
\text { Musikgelehrten christlicher Zeitrechnung bis Mitte des neunzehnten } \\
\text { Jahrhunderts, vols. } 5 \text { y 6, p. 354; Straeten, La musique aux Pays-Bas } \\
\text { avant le XIXe siécle, vol. 8, p. 465, nota 1. }\end{array}$ \\
\hline Juan Martínez de Sevilla & Martín Moreno, Historia de la música andaluza, p. 182. \\
\hline Juan Martínez & $\begin{array}{l}\text { Mitjana, "La musique en Espagne", p. 1965; Stevenson, Spanish Music in } \\
\text { the Age of Columbus, p. 94; León Tello, "Martínez, Juan"; Martín Ga- } \\
\text { lán, "Martínez Juan"; y Gümpel, "Martínez, Martinz, Juan". }\end{array}$ \\
\hline
\end{tabular}

Aunque ya en la Bibliotheca Hispana Nova (Roma, 1672) de Nicolás Antonio Juan Martínez aparece enmarcado en el ámbito sevillano, ${ }^{4}$ el primer diccionario de músicos portugueses incluye a "João Martins" y menciona que la duda respecto a su nacionalidad no es un caso aislado, sino que es muy frecuente entre los músicos portugueses que residieron en España durante los siglos XVI y XVII ("porque no ha aparecido como en España, un Soriano Fuertes, o un Eslava que abra los ojos a la ceguera universal”, señalaba Joaquim de Vasconcellos). ${ }^{5}$ Realmente existe confusión sobre el origen de buena parte de los músicos que trabajaron en Portugal, como en el caso de dos catedráticos de música de la Universidad de Coimbra: Afonso Perea Bernal aparece en los diccionarios de músicos portugueses aunque posiblemente fuera español, ${ }^{6}$ y Pedro Thalesio, "tal vez español", tuvo su actividad profesional únicamente en el reino de Portugal. ${ }^{7}$ En cualquier caso, este afán nacionalista tiene poco sentido si tenemos en cuenta los nexos que hubo en la época entre los reinos de Portugal y Castilla. ${ }^{8}$ Como Thalesio, el

\footnotetext{
${ }^{3}$ Quizás se deba a un error en la lectura de "Juan Martinez Cle/rigo".

${ }^{4}$ Nicolás Antonio, Bibliotheca Hispana Nova: sive Hispanorum scriptorum qui ab anno MD ad MDCLXXXIV floruere noticia (Madrid: Apud Joachimum de Ibarra Typographum Regium, 1783-1788 [1672]), vol. 1, p. 734.

5 Joaquim de Vasconcellos, Os musicos portuguezes. Biographia-bibliographia (Oporto: Imprensa Portugueza, 1870), vol. 1, p. 226.

${ }^{6}$ Ribeiro, A “Arte de Cantollano”, de autor desconhecido, p. 27, nota 35.

${ }^{7}$ Branco, História da música portuguesa, p. 131; y Ernesto Vieira, Diccionario biographico de musicos portuguezes: historia e bibliographia da musica em Portugal (Lisboa: Typographia Mattos Moreira \& Pinheiro Lambertini, 1900), vol. 2, p. 348.

${ }^{8}$ Manuel Fernández Álvarez, “Objetivo: Lisboa. La unión de Portugal y Castilla bajo Felipe II”, en Las relaciones entre Portugal y Castilla en la época de los descubrimientos y la expansión colonial [Actas
} 
compositor Hernando Franco, de origen extremeño, posiblemente fuese maestro de capilla del Hospital Real de Todos los Santos en Lisboa en un período situado entre 1549 y antes de 1561. ${ }^{9}$ También encontramos el caso contrario: Pedro do Porto y Pedro de Escobar, ambos de origen portugués, fueron respectivamente cantor de la Capilla de Isabel la Católica entre 1489 y 1499, y maestro de los mozos de coro de la Catedral de Sevilla. ${ }^{10}$ Además, Mateo de Aranda, a quien se atribuye origen castellano, se considera una figura central en la historia de la música portuguesa por su contribución a la génesis de la enseñanza musical. ${ }^{11}$

Quizás la atribución de nacionalidad portuguesa a Juan Martínez se deba a una confusión historiográfica, puesto que François-Joseph Fétis, Joaquim de Vasconcellos y Mário de Sampaio Ribeiro señalan que Diogo Barbosa Machado en su Bibliotheca Lusitana Historica, Critica, e Cronologica calificaba a Martínez de portugués. ${ }^{12}$ No obstante, si acudimos a la fuente original, vemos que Barbosa Machado no hacía referencia alguna a la procedencia de "Ioão Martins". ${ }^{13}$ No deja de ser llamativo cómo en la historiografía española se añade "de Sevilla” al nombre de Juan Martínez. ${ }^{14}$

del Congreso "Las relaciones entre Portugal y España en la época de los descubrimientos y la expansión colonial" (Salamanca, del 15 al 17 de octubre de 1992)], ed. por Ana María Carabias Torres (Salamanca: Ediciones Universidad de Salamanca, Sociedad V Centenario del Tratado de Tordesillas, 1994), pp. 327 336. En el ámbito musical, véase Ruiz Jiménez, La Librería de Canto de Órgano, p. 199.

${ }^{9}$ Gembero Ustárroz, "El compositor español Hernando Franco (1532-85) antes de su llegada a México", p. 277.

${ }^{10}$ La hipótesis mantenida hasta el momento de que Pedro de Escobar y Pedro do Porto son la misma persona se refuta en Francesc Villanueva, "La identificación de Pedro de Escobar con Pedro do Porto: una revisión a la luz de nuevos datos sobre el magisterio de capilla de Pedro do Porto, alias de Sosa, en la catedral de Valencia (1509-1514)", Revista de Musicología [en prensa].

${ }^{11}$ Véase Alegria, “Inéditos musicais de Mateus d’Aranda”, p. 72.

${ }^{12}$ Diogo Barbosa Machado, Bibliotheca Lusitana Historica, Critica, e Cronologica: Na qual se comprende a noticia dos Authores Portuguezes, e das Obras, que compuseraõ desde o tempo da promulgação da Ley da Graça até o tempo prezente (Lisboa: Na officina de Aut. Isid da Fauce, 1741-1759), vol. 2, p. 692; François-Joseph Fétis, Biographie universelle des Musiciens, et Bibliographie Générale de la Musique (París: H. Fournier, 1860-1880 [1835-1844]), vol. 5, p. 479; Vasconcellos, Os musicos portuguezes, p. 226; Ribeiro, A “Arte de Cantollano”, de autor desconhecido, p. 15, nota 13.

\footnotetext{
${ }^{13}$ Stevenson, Spanish Music in the Age of Columbus, pp. 94-96, ya advirtió acerca de este malentendido.

${ }^{14}$ Antonio Martín Moreno, Historia de la música andaluza (Sevilla: Editoriales Andaluzas Unidas, 1985), p. 182, presenta al autor como "Juan Martínez de Sevilla", sin hacer referencia al posible origen portugués. La información parece tomada de Rafael Mitjana, "La musique en Espagne: art réligieux et art profane", en Encyclopédie de la musique et dictionnaire du Conservatoire, dir. por Albert Lavignac y Lionel de Laurencie (París: Librairie Delagrave, 1920), vol. 4 (Espagne-Portugal), pp. 1913-2400, p. 1965,
} 
La Tabla III.2 muestra que hasta hace poco no ha habido un acuerdo con respecto a la cronología de Juan Martínez, estando ésta íntimamente ligada a la fecha de las ediciones de su libro que se han ido conociendo; es decir, cada historiador situaba a Juan Martínez en un ámbito cronológico en función del año de la edición de su libro de la que tenía noticia.

Tabla III.2: Cronologías asignadas a Juan Martínez en función de las ediciones conocidas de su libro

\begin{tabular}{|c|c|c|}
\hline Referencia & $\begin{array}{l}\text { Ediciones } \\
\text { conocidas }\end{array}$ & $\begin{array}{l}\text { Cronología de Juan } \\
\text { Martínez propuesta }\end{array}$ \\
\hline $\begin{array}{l}\text { Fétis, Biographie universelle des musiciens, vol. 5, p. } \\
\quad 479 \text {. }\end{array}$ & 1560 & Fl. mediados del siglo XVI \\
\hline $\begin{array}{l}\text { Vasconcellos, Os musicos portuguezes, vol. 1, p. } \\
225 .\end{array}$ & 1560 & $\begin{array}{l}\text { "Viveu no meado do seculo } \\
\text { XVI (1558)" }\end{array}$ \\
\hline $\begin{array}{l}\text { Pinto de Mattos, Manual bibliographico portugués } \\
\text { de livros raros, classicos e curiosos, p. } 380 \text {. }\end{array}$ & 1603 & Fl. finales del siglo XVI \\
\hline $\begin{array}{l}\text { Silva, Diccionario bibliographico portugués, vol. } 3 \text {, } \\
\text { p. } 415 .\end{array}$ & 1603 & Fl. segunda mitad del XVI \\
\hline $\begin{array}{l}\text { Méndez Bejarano, Diccionario de escritores, maes- } \\
\text { tros y oradores naturales se Sevilla y su actual } \\
\text { provincia, vol. } 2 \text {, p. } 28 .\end{array}$ & $\begin{array}{l}1532 \text { ("Debe de } \\
\text { haber alguna edi- } \\
\text { ción anterior") }\end{array}$ & Fl. siglo XVI \\
\hline $\begin{array}{l}\text { Stevenson, Spanish Music in the Age of Columbus, p. } \\
\quad 94 .\end{array}$ & 1532 & Fl. 1532 \\
\hline $\begin{array}{l}\text { Catálogo online de la Biblioteca Nacional de } \\
\text { Portugal }\end{array}$ & $\begin{array}{l}1530 ?, 1612,1614 \\
1625\end{array}$ & Fl. $1530^{15}$ \\
\hline
\end{tabular}

Todas las fuentes consultadas coinciden en atribuir a Juan Martínez un gran prestigio y reconocimiento en su época. Nicolás Antonio le llama "sacerdos almae ecclesiae Hispalensis" y Diogo Barbosa Machado lo identifica como un "sacerdote de ejemplar procedimento, e muito perito na Arte do Canto Chaõ". ${ }^{16}$ Mário Méndez Beja-

aunque Mitjana no dice que fuera oriundo de Sevilla: "JUAN MARTINEZ, prête, maître des enfants de choeur à la Cathédrale de Séville".

${ }^{15}$ Durante el transcurso de esta investigación, el catálogo de la Biblioteca Nacional de Portugal ha modificado el registro de autoridad "Martins, João fl. 1612" a "Martins, João fl. 1530".

${ }^{16}$ Antonio, Bibliotheca Hispana Nova, vol. 1, p. 734; Barbosa Machado, Bibliotheca Lusitana Historica, Critica, e Cronologica, vol. 2, p. 692. Mazza, Dicionário biográfico de músicos portugueses, p. 29, utiliza prácticamente las mismas palabras que Barbosa Machado: "Presbitero de exemplar procedimento, foi muito perito na Arte do Cantochão". 
rano, siguiendo a Barbosa Machado, lo califica de "sacerdote ejemplar", ${ }^{17}$ mientras que Mário de Sampaio Ribeiro manifiesta que fue "prestigiosissimo". ${ }^{18}$

\section{LA EDICIÓN PRÍNCIPE DEL LIBRO DE JUAN MARTÍNEZ}

El estudio del Arte de canto llano de Juan Martínez permite indagar en la historia de un libro del que se sabía muy poco. Tal vez por no conocerse ningún ejemplar de la edición de Alcalá de Henares de 1532, considerada la edición príncipe en obras de referencia como el Diccionario de la música española e hispanoamericana y The New Grove Dictionary, ${ }^{19}$ ni tampoco de ninguna reedición española del tratado, éste no ha tenido una presencia en los estudios sobre la teoría musical de la España renacentista; por ejemplo, no forma parte de la colección Viejos libros de música, ni tampoco aparece en el trabajo de historia de la teoría musical de Francisco José León Tello, que es la obra de referencia por antonomasia sobre teoría de la música española. ${ }^{20}$

Se tiene constancia de que un ejemplar de este Arte de canto llano impreso en Alcalá de Henares en 1532 fue adquirido por Hernando Colón en 1534 en Alcalá de Henares por 10 maravedíes, como indica una anotación manuscrita del propio Colón en la hoja de guarda final del ejemplar que se conservaba en la Biblioteca Colombina de Sevilla, pero que se encuentra desaparecido en la actualidad. ${ }^{21}$ Quizás no sea casual que un ejemplar de esta edición de 1532 aparezca en el catálogo del anticuario Leo Liepmannssohn en Berlín como subastado en 1899 por 180 marcos. $^{22}$ En 1888 Edmond

\footnotetext{
${ }^{17}$ Mario Méndez Bejarano, Diccionario de escritores, maestros y oradores naturales de Sevilla y su actual provincia (Sevilla: [s.n.], 1922-1925), vol. 2, p. 28.

${ }^{18}$ Ribeiro, A “Arte de Cantollano”, de autor desconhecido, p. 23.

${ }^{19}$ Jesús Martín Galán, "Martínez, Juan (II)”, en Diccionario de la música española e hispanoamericana, ed. por Emilio Casares Rodicio (Madrid: Sociedad General de Autores y Editores, 1999-2002), vol. 7, p. 263: "Se publicó, en primer lugar, en Alcalá de Henares (Madrid) en 1532 [...]”; y Francisco José León Tello, "Martínez, Juan”, en Grove Music Online, ed. por L. Macy (consultado 06-10-2007) $<$ http://www.grovemusic.com>.

${ }^{20}$ León Tello, Estudios de historia de la teoría musical. No obstante, León Tello es el autor de la entrada "Martínez, Juan" de The New Grove Dictionary.

${ }^{21}$ Gallardo, Ensayo de una biblioteca española de libros raros y curiosos, vol. 3, p. 646, nº 2933.

${ }^{22}$ Robert Eitner, Biographisch-bibliographisches Quellen Lexikon der Musiker und Musikgelehrten christlicher Zeitrechnung bis Mitte des neunzehnten Jahrhunderts (Graz: Akademische Druck U. Ver-
} 
vander Straeten mencionaba este ejemplar de Liepmannssohn y señalaba que había sido examinado en busca de referencias a autores neerlandeses. ${ }^{23}$ En cualquier caso, en el catálogo de libros impresos de la Biblioteca Colombina de 1888 ya no se hace referencia al ejemplar. ${ }^{24}$ En un artículo de 1947, Higini Anglès señalaba que la signatura antigua del libro era G. 37-31, pero reconocía que no había tenido tiempo para comprobar si realmente existía. ${ }^{25}$ En 1963, Mário de Sampaio Ribeiro relataba cómo se dirigió al director de la Biblioteca Capitular Colombina, quien le informó de que el libro de Juan Martínez, aunque figure en el Manual del librero hispanoamericano (Barcelona, 19231927) de Antonio Palau y Dulcet (tal vez porque éste tomó la referencia del Ensayo de una biblioteca española de libros raros y curiosos de 1888 de Bartolomé Gallardo), no se encontraba en los fondos de la Biblioteca cuando se preparó el material para la impresión del Catálogo a finales del siglo XIX. ${ }^{26}$ Afortunadamente, Bartolomé Gallardo tuvo acceso al ejemplar de la Colombina y desglosó su contenido, aportando una valiosa

lagsantstalt, 1959 [1900]), vols. 5 y 6, p. 354; y Francisco Javier Romero Naranjo, "La circulación de manuscritos de compositores portugueses en el anticuario de Leo Liepmannssohn en París y Berlín", Nassarre: revista aragonesa de musicología, XVII/1-2 (2001), pp. 339-356; y "Der Umlauf der Spanischen Handschriften aus dem Antiquariat Leo Liepmannssohns in Paris und Berlin", Anuario musical, LIX (2004), pp. 191-210.

${ }^{23}$ Edmond vander Straeten, La musique aux Pays-Bas avant le XIXe siécle: documents inedits et annotés, compositeurs, virtuoses, théoriciens, luthiers; opéras, motets, airs nationaux, académies, maîtrises, livres, portraits, etc., avec planches de musique et table alphabétique (Bruselas: C. Muquardt, 18671888), vol. 8, p. 465, nota 1: "Poco antes de que Guerrero iniciara el aprendizaje de su arte, apareció en Alcalá de Henares el Arte de canto llano de Juan Martínez de Rigo [sic] maestro de los mozos de coro de la Catedral de Sevilla. El ejemplar, por así decirlo, único, que el librero berlinés M. Léon Liepmannssohn ha lanzando al mercado (véase su catálogo, $\mathrm{n}^{\circ} 45$ ) ha sido examinado infructuosamente desde el punto de vista de la mención de autores neerlandeses" ["Peu avant l'époque où Guerrero a dû faire l'apprentissage de son art, parut, à Alcala de Henarès, l'Arte de canto llano de Juan Martinez de Rigo, maître des enfants de chœur de la cathédrale de Séville. L'exemplaire, pour ainsi dire unique, que le libraire berlinois, M. Léon Liepmannssohn, a lancé dans le commerce (voy. son catalogue, $\mathrm{n}^{\mathrm{o}} 45$ ), a été examiné infructueusement, au point de vue de la mention d'auteurs néerlandais"].

24 Biblioteca Capitular y Colombina (Sevilla), Biblioteca Colombina: Catálogo de sus libros impresos (Madrid: CSIC, 1948 [Sevilla: Imp. de E. Rasco, 1888]), 7 vols. El libro no aparece tampoco en el posterior catálogo de Antonio Segura Morera y Pilar Vallejo Orellana, Catálogo de los impresos del siglo XVI de la Biblioteca Colombina de Sevilla (Sevilla: Catedral de Sevilla, Cabildo, 2001), 5 vols. Este último catálogo muestra la abundancia de obras impresas por Miguel de Eguía entre 1524 y 1530 ahora en la Biblioteca Colombina.

${ }^{25}$ Higini Anglès, "La música conservada en la Biblioteca Colombina y en la Catedral de Sevilla", Anuario musical, II (1947), pp. 3-39, p. 21. Anglès (p. 5) data las desapariciones de libros en la Biblioteca Colombina en los siglos XVIII y XIX.

${ }^{26}$ Ribeiro, A “Arte de Cantollano”, de autor desconhecido, p. 18. 
información que ha servido como punto de partida para hallar otras ediciones del Arte de canto llano de Juan Martínez:

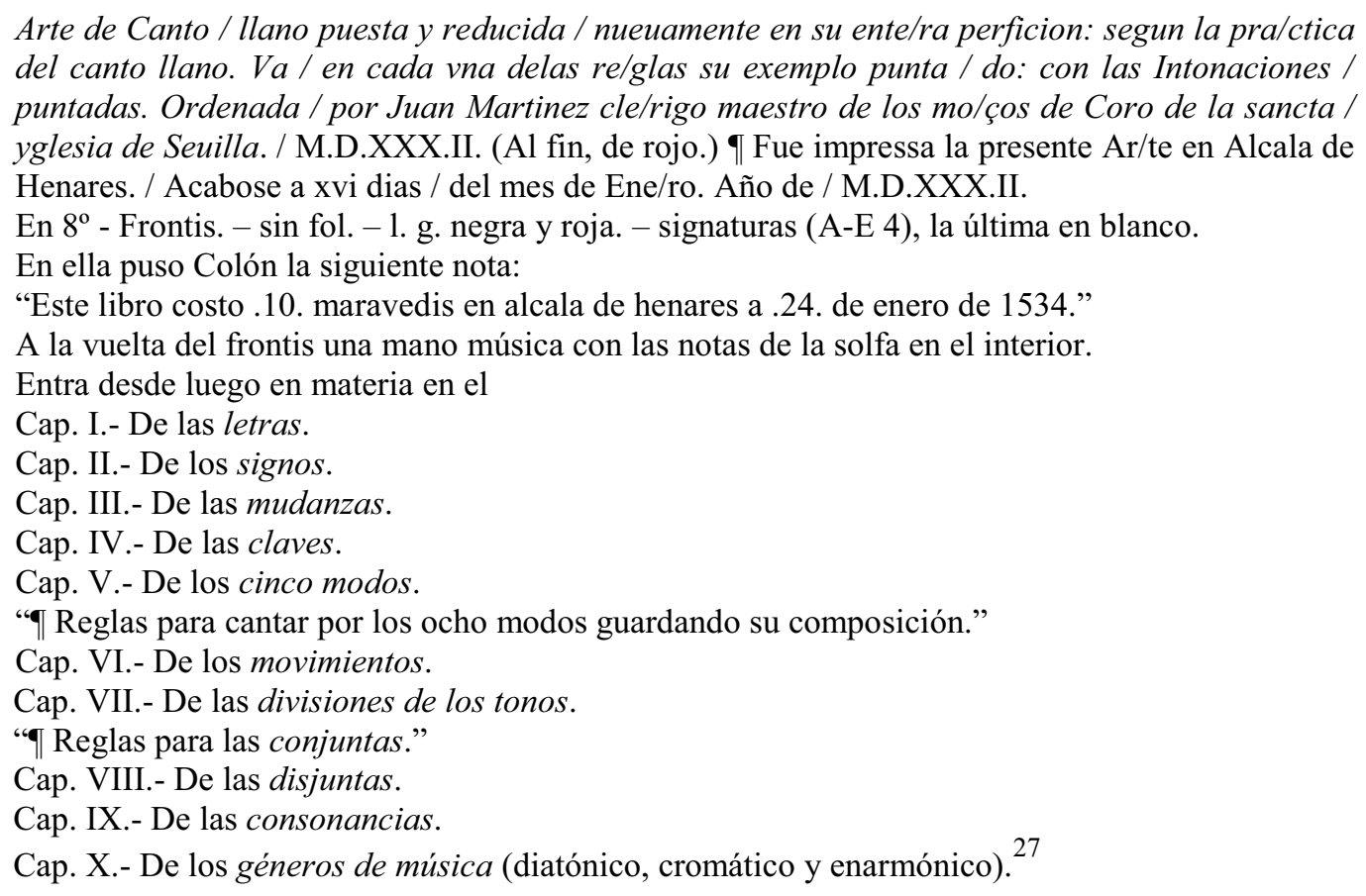

Una de las cuestiones que emergen a la vista de las obras de referencia es el motivo de la publicación del Arte de canto llano de Juan Martínez en Alcalá de Henares en 1532 si su autor trabajaba en una ciudad como Sevilla, donde en esos años continuaba activo el impresor Juan Cromberger, quien en 1530 había imprimido un libro de las mismas características; si acudimos a la "Lista cronológica de ediciones impresas en Sevilla por la familia Cromberger" publicada por Clive Griffin, encontramos que se incluye un Arte de canto llano (sin autor) impreso por Juan Cromberger en 1530. Griffin indica que no se conoce ningún ejemplar de esta edición y cita el trabajo bibliográfico de 1913 de Konrad Burger como su fuente. ${ }^{28}$ Sorprendentemente, si acudimos al trabajo de Konrad Burger que cita Griffin, encontramos que Burger atribuye el Arte de canto llano a Juan Martínez y señala como fuente $A$ imprensa portugueza no seculo XVI seus representantes e suas producções (Oporto, 1873) de Tito de Noronha, donde efec-

\footnotetext{
${ }^{27}$ Gallardo, Ensayo de una biblioteca española de libros raros y curiosos, vol. 3, p. 646.

${ }^{28}$ Griffin, Los Cromberger, p. 328; Konrad Burger, Die Drucker und Verleger in Spanien und Portugal von 1501-1536: mit chronologischer Folge ihrer Druck- und Verlagswerke (Leipzig: Kart W. Hiersemann, 1913), p. 26.
} 
tivamente se incluye el Arte de canto llano de 1530 de Juan Martínez entre las impresiones de Juan Cromberger. ${ }^{29}$ El Arte de canto llano de Juan Martínez podría ser una de las artes de canto llano registradas en grandes cantidades en el inventario del almacén de libros de Juan Cromberger elaborado en Sevilla en 1540; véase el Apéndice $8 .{ }^{30}$ La investigación bibliográfica que he llevado a cabo permite determinar que ya en 1871 António de Sousa Teles de Matos hacía referencia a la edición de Sevilla de 1530; además, certificaba la existencia de un ejemplar de esta edición en la Biblioteca Pública de Évora antes de $1870 .{ }^{31}$ En 1900, Ernesto Vieira mencionaba de nuevo el ejemplar de Évora e incluso citaba el texto de la portada y las características físicas del libro:

La edición original, de la que existe un ejemplar en la Biblioteca Pública de Évora, fue impresa en Sevilla en 1530 por Juan Cromberger. Dice así el respectivo título: "Arte de canto llano puesta y reduzida nuevamete en su entera pfeciõ según la pratica d'l cãto. Va en cada vna de las reglas su exemplo puntado. Con las intonationes puntadas. Ordenada por Juan martinez clerigo: maestro de los moços d'l coro d'la sancta yglesia de Seuilla. Impressa est Hispali per Joãnem crõberger. Anno humanae salutis Mdxxx". Es un $8^{\circ}$ pequeño con 79 páginas sin numerar, impreso en tipo gótico, en rojo y negro. ${ }^{32}$

Posteriormente, Mário de Sampaio Ribeiro señalaba que no hay ningún hilo conductor que permita averiguar el paradero actual del ejemplar del Arte de canto llano de Juan Martínez impreso en Sevilla en 1530 que se conservaba en la Biblioteca Pública

${ }^{29}$ Tito de Noronha, A imprensa portugueza no seculo XVI seus representantes e suas producções: ordenações do Reino (Oporto: Imp. Portugueza, 1873), p. 92; véase también su trabajo A imprensa portugueza durante o seculo XVI (Oporto: Imprensa portuguesa, 1874).

${ }^{30}$ Clive Griffin, "El inventario del almacén de libros del impresor Juan Cromberger: Sevilla 1540", en Coleccionismo y Bibliotecas (siglos XV-XVIII) [El libro antiguo español, 4], dir. por María Luisa LópezVidriero y Pedro Manuel Cátedra García (Salamanca: Universidad de Salamanca, 1988), pp. 257-373, $\mathrm{n}^{\circ}$ 137.

${ }^{31}$ Joaquim António de Sousa Teles de Matos, "Additamentos ao livro do sr. Joaquim de Vasconcellos os Musicos Portugueses", O conimbricense: jornal politico, instructivo e commercial, XXIV/2458 (14-021871), pp. 1-2.

${ }^{32}$ Vieira, Diccionario biographico de musicos portuguezes, vol. 2, p. 66: “A edição original, cuja existe um exemplar na bibliotheca publica de Evora, foi impressa em Sevilha em 1530, por João Cromberger. Diz assim o respectivo titulo: 'Arte de canto llano puesta y reduzida nuevamete en su entera pfeciõ según la pratica d'l cãto. Va en cada vna de las reglas su exemplo puntado. Con las intonationes puntadas. Ordenada por Juan martinez clerigo: maestro de los moços d'l coro d'la sancta yglesia de Seuilla. Impressa est Hispali per Joãnem crõberger. Anno humanae salutis Mdxxx'. E’ um 8º pequeño com 79 paginas não numeradas, impresso em typo gothico, a vermelho e preto". 
de Évora. ${ }^{33}$ La Tabla III.3 presenta de forma esquemática las fechas que se han dado al Arte de canto llano de Juan Martínez en la bibliografía y muestra que, aunque en la bibliografía portuguesa se había hecho referencia a la edición de Sevilla de 1530 ya en el siglo XIX, en los estudios musicológicos españoles y anglosajones se había ignorado este dato: que el libro de Juan Martínez fue impreso por el propietario de la que se ha considerado la imprenta más productiva de Sevilla “y quizás de toda la Península Ibérica". ${ }^{34}$

Tabla III.3: Ediciones del Arte de canto llano de Juan Martínez que se mencionan en la bibliografía *Las casillas sombreadas corresponden a estudios musicales; las casillas blancas corresponden a trabajos generales o bibliográficos

\begin{tabular}{lll}
\hline $\begin{array}{l}\text { Fecha del } \\
\text { estudio }\end{array}$ & Estudioso & Ediciones del libro de Juan Martínez mencionadas \\
\hline 1672 & N. Antonio & Sevilla, 1560 \\
$1741-59$ & D. Barbosa Machado & Coimbra, 1603, 1612, 1625 \\
1792 & J. N. Forkel & Coimbra, 1603, 1612, 1625 \\
$1835-44$ & F.-J. Fétis & Sevilla, 1560; Coimbra, 1603, 1612, 1625 \\
$1855-59$ & M. Soriano Fuertes & Sevilla, 1560 \\
1859 & I. F. da Silva & Coimbra, 1603, 1614, 1625 \\
$1867-68$ & J. Martins de Carvalho & Coimbra, 1603, 1612, 1614, 1625 \\
1870 & J. de Vasconcellos & Sevilla, 1560; Coimbra, 1603, 1612, 1625 \\
1871 & A. de S. T. de Matos & Sevilla, 1530 \\
1872 & P. Salvá y Mallén & Salamanca, s. XVI; Sevilla, 1560 \\
1873 & T. de Noronha & Sevilla, 1530 \\
1874 & F. A. Barbieri & Alcalá de Henares, 1532 \\
1878 & R. Pinto de Matos & Coimbra, 1603, 1614, 1625 \\
1887 & J. F. Riaño & Alcalá de Henares, 1512; ${ }^{35}$ Sevilla, 1560 \\
\hline
\end{tabular}

\footnotetext{
${ }^{33}$ Ribeiro, A "Arte de Cantollano", de autor desconhecido, p. 24.

${ }^{34}$ Griffin, "El inventario del almacén de libros del impresor Juan Cromberger”, p. 257.

${ }^{35}$ Juan Facundo Riaño, Critical and Bibliographical Notes on Early Spanish Music (Londres: Bernard Quaritch, 1887), p. 81, hizo alusión a la publicación del Arte de Martínez en Alcalá de Henares en 1512. Puesto que Riaño no indicó la localización del ejemplar que consultó, no es posible comprobar si se trata de una edición real. En cualquier caso, no se cita en Juan Catalina García López, Ensayo de una tipografia complutense (Pamplona: Analecta, 2000 [1889]); ni tampoco entre las ediciones complutenses recogidas en Julián Martín Abad, La imprenta en Alcalá de Henares (1502-1600) (Madrid: Arco Libros, 1991), 3 vols. Ribeiro, A "Arte de Cantollano", de autor desconhecido, p. 23, ha aventurado que podría tratarse
} 


\begin{tabular}{|c|c|c|}
\hline $\begin{array}{l}\text { Fecha del } \\
\text { estudio }\end{array}$ & Estudioso & Ediciones del libro de Juan Martínez mencionadas \\
\hline 1888 & E. vander Straeten & Alcalá de Henares, 1532 \\
\hline 1888 & B. J. Gallardo & Alcalá de Henares, 1532 \\
\hline 1894 & F. Escudero y Perosso & Sevilla, 1560 \\
\hline 1900 & E. Vieira & Sevilla, 1530; Coimbra, 1597 \\
\hline 1900 & R. Eitner & Alcalá de Henares, 1532 \\
\hline 1904 & S. de Rosa López & Alcalá de Henares, 1532 \\
\hline 1912 & H. Collet & Alcalá de Henares, 1532 \\
\hline 1913 & K. Burger & Sevilla, 1530; Alcalá de Henares, 1532 \\
\hline 1920 & R. Mitjana & $\begin{array}{l}\text { Alcalá de Henares, 1532; Sevilla, 1560; Coimbra, 1603, } \\
\text { 1612, } 1625\end{array}$ \\
\hline $1915-22$ & J. Cejador y Frauca & Sevilla, 1530; Alcalá de Henares, 1532; Sevilla, 1560 \\
\hline $1922-25$ & M. Méndez Bejarano & Alcalá de Henares, 1532; Sevilla, 1560; Barcelona, 1586 \\
\hline 1926 & A. Anselmo & Coimbra, 1597 \\
\hline $1923-27$ & A. Palau y Dulcet & Alcalá de Henares, 1532; Sevilla, 1560; Barcelona, 1586 \\
\hline $1944-45$ & J. Mazza & Coimbra, 1603, 1612 \\
\hline 1947 & H. Anglès & Alcalá de Henares, 1532 \\
\hline 1947 & I. Leonard & Sevilla, 1560 \\
\hline 1953 & R. Stevenson & Alcalá de Henares, 1532 \\
\hline 1956 & J. Ricart i Matas & Coimbra, 1612 \\
\hline 1960 & R. Stevenson & $\begin{array}{l}\text { Alcalá de Henares, 1532; Sevilla, 1560; Barcelona, 1586; } \\
\text { Salamanca, s. XVI; Coimbra, 1603, 1612, } 1625\end{array}$ \\
\hline 1962 & J. A. Alegria & Alcalá de Henares, 1532 \\
\hline 1963 & M. de S. Ribeiro & $\begin{array}{l}\text { Sevilla, 1530, 1560; Alcalá de Henares, 1532, 1598; } \\
\quad \text { Coimbra, 1550, 1612, } 1625\end{array}$ \\
\hline 1977 & J. A. Alegria & Coimbra, 1597; Madrid, 1621 \\
\hline 1978 & J. M. Llorens Cisteró & $\begin{array}{l}\text { Alcalá de Henares, 1532; Sevilla, 1560; Coimbra, 1603, } \\
\text { 1612, } 1625\end{array}$ \\
\hline 1978 & A. Domínguez Guzmán & Sevilla, 1560 \\
\hline 1980 & M. L. Lemos & Coimbra, 1550 \\
\hline 1985 & A. Martín Moreno & $\begin{array}{l}\text { Alcalá de Henares, 1532; Sevilla, 1560; Coimbra, 1603, } \\
\text { 1612, } 1625\end{array}$ \\
\hline 1988 & T. J. Dadson & Sevilla, 1560 \\
\hline $1960-88$ & RISM & Alcalá de Henares, 1532; Coimbra, 1597, 1612, 1625 \\
\hline
\end{tabular}

de una errata, de manera que aparece impresa la cifra 1512 en lugar de 1532. También Julián Martín Abad, Post-incunables ibéricos (Madrid: Ollero \& Ramos, 2001), p. 363, hace referencia a un posible error de imprenta indicando que la edición de 1512 "está [en Riaño] por la edición de Alcalá de Henares, [Miguel de Eguía], 16 en. 1532”. 


\begin{tabular}{|c|c|c|}
\hline $\begin{array}{l}\text { Fecha del } \\
\text { estudio }\end{array}$ & Estudioso & Ediciones del libro de Juan Martínez mencionadas \\
\hline 1991 & J. Martín Abad & Alcalá de Henares, 1532 \\
\hline $1950-93$ & J. Simón Díaz & $\begin{array}{l}\text { Alcalá de Henares, 1532; Sevilla, 1560; Barcelona, 1586; } \\
\text { Salamanca, s. XVI; Coimbra, 1612, } 1614\end{array}$ \\
\hline 1995 & W. Pettas & Alcalá de Henares, 1532 \\
\hline 1998 & C. Griffin & Alcalá de Henares, 1532 \\
\hline 1998 & F. Binder y P. Castaga & Alcalá de Henares, 1512 \\
\hline 1999 & A. González Sánchez & Sevilla, 1560 \\
\hline 2000 & H. González Barrionuevo & Alcalá de Henares, 1532 \\
\hline 2001 & F. J. León Tello & Alcalá de Henares, 1532; Coimbra, 1603, 1612, 1625 \\
\hline 2001 & R. Stevenson & Alcalá de Henares, 1532; Coimbra, 1550, 1597 \\
\hline 2001 & $\begin{array}{l}\text { M.-A. Casasnovas i } \\
\text { Camps }\end{array}$ & Salamanca, 1599 \\
\hline 2002 & J. Martín Galán & $\begin{array}{l}\text { Alcalá de Henares, 1532; Sevilla, 1560; Barcelona, 1586; } \\
\text { Coimbra, 1603, 1612, } 1625\end{array}$ \\
\hline 2002 & L. Jambou & Alcalá de Henares, 1532 \\
\hline 2004 & E. Martínez Miura & Alcalá de Henares, 1532 \\
\hline 2004 & K.-W. Gümpel & $\begin{array}{l}\text { Alcalá de Henares, 1532; Coimbra, 1550, 1597, 1603, } \\
\text { 1612, 1625; Sevilla, 1560; Barcelona, 1586; Salaman- } \\
\text { ca, } 1625\end{array}$ \\
\hline 2004-05 & M. P. Ferreira & Sevilla, 1530 \\
\hline 2008 & J. Ruiz Jiménez & Alcalá de Henares, 1532 \\
\hline 2009 & $\begin{array}{l}\text { M. del C. Álvarez Már- } \\
\text { quez }\end{array}$ & Sevilla, 1560 \\
\hline 2010 & A. S. Wilkinson & Alcalá de Henares, 1532; Coimbra, 1597 \\
\hline
\end{tabular}




\section{JUAN MARTÍNEZ EN LA CATEDRAL DE SEVILLA (ANTES DE 1525 - DESPUÉS DE 1545): LOS TRATADOS DE CANTO LLANO R/14670 DE LA BIBLIOTECA NACIONAL DE ESPAÑA}

Juan Martínez ocupó un puesto eclesiástico en la Catedral de Sevilla, siguiendo la norma general que se desprendía del análisis del ámbito profesional de los autores de las artes de canto; véanse el Capítulo I y el Apéndice 4. Mientras que Ricardo Pinto de Mattos lo califica de "presbítero secular", Robert Stevenson alude a Martínez como clérigo y racionero. ${ }^{36}$ Como ocurría con respecto a su nacionalidad y su cronología, la actividad profesional de Juan Martínez en el ámbito de la Catedral de Sevilla ha sido objeto de múltiples interpretaciones. Aunque por el título de su libro sabemos que fue maestro de los mozos de coro, algunos estudiosos le atribuyen el puesto de maestro de capilla de la Catedral de Sevilla, ${ }^{37}$ mientras que otros le consideran "maestro de música sacra". ${ }^{38}$ A pesar de que no se tiene noticia de composiciones atribuidas a Juan Martínez, José Mazza asegura que compuso algunas obras. ${ }^{39}$ Del mismo modo, aunque, según el título de su libro trabajó en la Catedral de Sevilla, Diogo Barbosa Machado y José Mazza, quienes seguramente no tenían noticia de las ediciones españolas del libro de Juan Martínez, señalan que tuvo “escola pública” sin especificar dónde. ${ }^{40}$ Finalmen-

\footnotetext{
${ }^{36}$ Ricardo Pinto de Mattos, Manual bibliographico portuguez de livros raros, classicos e curiosos, ed. revisada por Joaquim Ferreira (Madrid: Ollero y Ramos, 2004 [1878]), p. 380; Robert Stevenson, La música en la Catedral de Sevilla, 1478-1606: documentos para su estudio (Madrid: SEdeM, 1985 [1954]), p. 99.

${ }^{37}$ Mariano Soriano Fuertes, Historia de la música española: desde la venida de los fenicios hasta el año de 1850 (Madrid: ICCMU, 2007 [1855-1859]), vol. 1, tomo 2, p. 157; Fétis, Biographie universelle des musiciens, vol. 5, p. 479: "maître de chapelle à l'église cathédrale de Séville"; Vasconcellos, Os musicos portuguezes, vol. 1, p. 225, atribuye a Martínez además la condición de "poeta y músico"; Vieira, Diccionario biographico de musicos portuguezes, vol. 1, p. 101; y Méndez Bejarano, Diccionario de escritores, maestros y oradores, vol. 2, p. 28.
}

${ }^{38}$ Pinto de Mattos, Manual bibliographico portuguez de livros raros, classicos e curiosos, p. 380; e Inocêncio Francisco da Silva, Diccionario bibliographico portuguez. Estudos de Inocencio Francisco da Silva applicaveis a Portugal e ao Brasil continuados e ampliados por Brito Aranha e Alvaro Neves (Lisboa: Imp. Nacional, 1858-1923), vol. 3, p. 415.

${ }^{39}$ Mazza, Dicionário biográfico de músicos portugueses, p. 29: “[...] compos algumas obras em $\mathrm{Mu}$ zica".

40 Barbosa Machado, Bibliotheca Lusitana Historica, Critica, e Cronologica, vol. 2, p. 692; y Mazza, Dicionário biográfico de músicos portugueses, p. 29. Vasconcellos, Os musicos portuguezes, vol. 1, p. 225, sí sitúa a Juan Martínez en Sevilla: "Teve aula publica de Cantochão que foi fecundissima nos seus resultados, sahindo d'ella numerosos discipulos que, com os seus conhecimentos apregoavam a pericia do 
te, otros autores afirman que Juan Martínez fue propuesto como organista de la Catedral de Burgos en 1492 para los días que no fuesen fiesta principal. ${ }^{41}$

En la portada del libro de Juan Martínez se le identifica como maestro de los mozos de coro de la Catedral de Sevilla. Acerca de su actividad en este cargo, encontramos información bastante relevante en la recopilación de documentos para el estudio de la música en la Catedral de Sevilla realizada por Robert Stevenson. Los datos presentados por Stevenson permiten datar a 1 de septiembre de 1525 el nombramiento de Juan Martínez como maestro de los mozos de coro: "Este dia sus merçedes resçibieron para maestro para enseñar moços de coro desta santa iglesia a juan martinez clerigo desde primero de setiembre deste año en adelante con el salario que tenia". ${ }^{42}$ De la expresión "con el salario que tenia" se deduce que antes de ser nombrado maestro de los mozos de coro, Martínez debió desempeñar alguna otra función en la Catedral. La última referencia a Juan Martínez en los documentos recogidos por Robert Stevenson data del 9 de diciembre de 1536 y alude a un aumento de salario en reconocimiento al trabajo del maestro en la institución:

\begin{abstract}
En este dia los dichos señores llamados de ante dia para lo yuso escripto e platicando en ello e votando verbalmente mandaron dar e dieron a juan martinez racionero de los niños de canto llano tres mill maravedises e vn cahiz de trigo sobre el salario que tenia de manera que sea por todo doze mill e dos cahizes attento lo mucho que ha seruido en esta santa yglesia el qual dicho salario sea durante su vida e no mas e este conmiençe desde primero dia de enero proximo venidero del año de 1537 años lo qual cometieron a los señores qontadores que asi lo pague e cunplan el dicho salario e a los tiempos segun y en la manera que se suele pagar. ${ }^{43}$
\end{abstract}

Según Stevenson, este aumento de salario, que comenzaría a ser efectivo a inicios de 1537, unido al hecho de "lo mucho que ha seruido en esta santa yglesia", y que el salario iba a durar "durante su vida e no mas", hace pensar que Juan Martínez ya

\footnotetext{
mestre. Viveu no meado do seculo XVI (1558) e publicou em Sevilha, onde fôra Mestre de Capella, a seguinte obra, que em 20 annos teve nada menos que tres ediçoes em Portugal”.

${ }^{41}$ Rubio, Historia de la música española 2, p. 39; Martín Galán, "Martínez, Juan (II)”, p. 263: "Previamente, en 1492, se le había propuesto como organista de la catedral de Burgos para los días del año que no fuesen fiesta principal (ya que en éstas tañería Juan de Burgos)"; y Gümpel, "Martínez, Martinz, Juan", en Die Musik in Geschichte und Gegenwart: allgemeine Enzyklopädie der Musik, ed. por Ludwig Finscher (Kassel: Bärenreiter, 1994-2007), vol. 11 (2004), col. 1191.

${ }^{42}$ Stevenson, La música en la Catedral de Sevilla, p. 26, doc. 140.

${ }^{43}$ Stevenson, La música en la Catedral de Sevilla, p. 31, doc. 197.
} 
tenía una edad avanzada. ${ }^{44}$ Puesto que en las voces dedicadas a Juan Martínez en The New Grove Dictionary, el Diccionario de la música española e hispanoamericana y Die Musik in Geschichte und Gegenwart se establece que éste desempeñó el puesto de maestro de los mozos de coro durante el período comprendido entre 1525 y al menos 1536, probablemente estas obras de referencia tengan su fuente en la recopilación de Stevenson. Un nuevo documento, citado en el trabajo de Herminio González Barrionuevo sobre Francisco Guerrero, aporta información original según la cual Juan Martínez ocupó el puesto desde el 1 de septiembre de 1525 (cuando fue elegido debido a la defunción del maestro Vega) y estaba en activo en la Catedral de Sevilla todavía a finales de febrero de $1545 .^{45}$

Como indicaba antes, a juzgar por la documentación, en el momento de ser nombrado maestro de los mozos de coro, Juan Martínez debía de estar desempeñando algún otro puesto en la Catedral de Sevilla, por lo que cabe preguntarse si se trataba de algún cargo vinculado a la música. Tomando como fuente los documentos aportados por Stevenson no podemos resolver esta cuestión puesto que únicamente se menciona el estatus eclesiástico de Martínez. ${ }^{46}$ En 1963, Mário de Sampaio Ribeiro (1898-1966), que también fue el precursor de las primeras investigaciones en torno a Mateo de Aranda, hizo un importante descubrimiento que le llevó a sugerir que, antes de ser nombrado maestro de los mozos de coro, Martínez ya desempeñaba algún tipo de actividad en el ámbito de la docencia de la música. Ribeiro advirtió que el Arte de cantollano existente

\footnotetext{
${ }^{44}$ Stevenson, Spanish Music in the Age of Columbus, p. 95, nota 115: "Como razón del aumento, el cabildo señaló 'lo mucho que ha seruido en esta santa yglesia'. El aumento se iba a hacer efectivo el 1 de enero de 1537. Puesto que el nuevo 'salario' iba a durar 'durante su vida e no mas' podría suponerse que Martínez era ya mayor y tenía herederos que esperaban "pagos de consuelo" de la Catedral tras su muerte" ["As reason for the increase, the chapter noted lo mucho que ha seruido en esta santa yglesia. The increase was to become effective January I, 1537. Since the new salario was to last durante su vida e no mas (during his life and no longer) he was already old -one may suppose- and surrounded with heirs who hoped for "consolation payments" from the cathedral after his death"].

45 "A Juan Martínez, maestro que fue de los moços de coro, de un salario desde primero de henero hasta fin de febrero VIIII fanegas de trigo"; en Nóminas y Salarios de la Catedral de Sevilla, 322, f. 5v (año 1545), Sevilla, Archivo Capitular, Sección IV: Fábrica, Serie de Nóminas y Salarios (1446-1826). Citado en González Barrionuevo, Francisco Guerrero (1528-1599), p. 696.

${ }^{46}$ Cuando se le nombra maestro de los mozos de coro se le menciona como "juan martínez clérigo", mientras que en 1536 se le cita como "juan martínez racionero". En el último estadio de la presente investigación se ha publicado un estudio sobre la música en la Catedral de Sevilla entre 1434 y 1517, que no menciona referencias a la labor de Juan Martínez; véase Juan Ruiz Jiménez, “The Sounds of the Hollow Mountain': Musical Tradition and Innovation in Seville Cathedral in the Early Renaissance", Early Music History, 29 (2010), pp. 189-239.
} 
en la Biblioteca Nacional de España catalogado como anónimo con la signatura R/14670(1) y el Arte de canto llano incompleto que le sigue encuadernado en el mismo volumen con signatura $\mathrm{R} / 14670$ (2) son dos ediciones diferentes de un pequeño epítome destinado a principiantes cuyo contenido en español coincide con el del Arte de canto llano de Juan Martínez (en su edición en portugués de 1550, que es la que conocía Ribeiro). ${ }^{47}$ Es esta coincidencia la evidencia que utiliza Ribeiro para concluir que Juan Martínez estaba llevando a cabo una función docente en la Catedral de Sevilla (con anterioridad a su nombramiento de 1525 como maestro de los mozos de coro), quizás consistente en la instrucción de manera provisional de los propios mozos de coro, ${ }^{48}$ y que estas dos ediciones anónimas de la Biblioteca Nacional, la segunda más moderna que la primera (como muestra la corrección de la ortografía de algunas palabras), deben ser atribuidas a Juan Martínez. ${ }^{49}$ Higini Anglès y José Subirá ya habían advertido en su catalogación de los fondos musicales de la Biblioteca Nacional de España que el segundo tratado incompleto "es idéntico al anterior, pero corresponde a otra edición. Se trata de una reproducción exacta por el lenguaje y por el orden expositivo de las materias". 50 No obstante, parece que Ribeiro fue el primero en advertir la coincidencia del contenido de estos libros con el del Arte de canto llano de Juan Martínez. Respecto a dónde y cuándo fueron publicados, Ribeiro considera que nada permite determinarlo. ${ }^{51}$

Las artes de canto R/14670(1) y (2) de la Biblioteca Nacional han pasado prácticamente desapercibidas en la historiografía musical. Francisco José León Tello, al mencionar estos manuales, advierte de que son "muy breves y carecen de interés". 52 Aunque

\footnotetext{
${ }^{47}$ Ribeiro, A “Arte de Cantollano”, de autor desconhecido, p. 30.

${ }^{48}$ Ribeiro, A “Arte de Cantollano”, de autor desconhecido, p. 16, nota 14: “[...] e não é inverosimil admitir que ela consistisse na leccionaçao, mas a título experimental, ou provisório, dos mesmos rapazes".

${ }^{49}$ Ribeiro, A “Arte de Cantollano”, de autor desconhecido, p. 8.

${ }^{50}$ Higini Anglès y José Subirá, Catálogo musical de la Biblioteca Nacional de Madrid, II (Barcelona: CSIC, 1949), p. 123.

51 Jane A. Bernstein, "The Burning Salamander: Assigning a Printer to Some Sixteenth-Century Music Prints", Notes, XLII/3 (1986), pp. 483-501, p. 483: "Uno de los problemas más difíciles a los que se enfrenta un bibliógrafo de la música del siglo XVI es la identificación de un impresor que ha omitido su nombre en una publicación musical" ["One of the most challenging problems facing a bibliographer of sixteenth-century music is the identification of a printer who has omitted his name from a music publication"].

${ }^{52}$ León Tello, Estudios de historia de la teoría musical, p. 197.
} 
en la colección Viejos libros de música encontramos una edición facsímile del primero, ${ }^{53}$ Carlos Romero de Lecea evade el estudio de Ribeiro y afirma que "carecemos de toda noticia en cuanto a su autor". ${ }^{4}$ Alusiones más recientes al Arte de cantollano anónimo de la Biblioteca Nacional han sido hechas por Maricarmen Gómez Muntané, quien, sin relacionarlo con el de Juan Martínez, opina que tanto este libro como el manuscrito de Silos y el Art del cant plà de la Biblioteca de Catalunya "reproducen" las Reglas de canto plano è de contrapunto è de canto de organo (Sevilla, 1410) de Fernand Estevan y "derivan de otro desconocido que fue el que debió utilizar Estevan". 55 Posteriormente, Manuel Pedro Ferreira ha denominado "Anónimo de Madrid" a este Arte de cantollano de la Biblioteca Nacional de España y lo data entre 1490 y $1520 .{ }^{56}$

El volumen R/14670 de la Biblioteca Nacional de España tiene una encuadernación moderna, el canto de las hojas en rojo y una hoja de guarda inicial con anotaciones del bibliófilo Pascual de Gayangos (1809-1897) y de Francisco A. Barbieri (18231894). En la portada del tratado R/14670(1) sólo aparece el título "arte de cantollano", los sellos de Barbieri y de la Biblioteca Nacional de España, la anotación manuscrita "Este es de cristobal de her" y la firma de este antiguo propietario. Consta de portada más 14 folios, faltando la última hoja. No contiene ejemplos musicales y el texto, en tipo gótico, está dispuesto sin solución de continuidad. Al final encontramos la anotación manuscrita "Herrera" a modo de firma; por tanto, cuando el libro estaba en posesión de Cristóbal de Herrera ya le faltaba el último folio. Le siguen 13 hojas en blanco tras las cuales aparece el documento R/14670(2), un fragmento de otro arte de canto llano sin principio ni final, por lo que desconocemos si se publicó con atribución de

\footnotetext{
${ }^{53}$ Anónimo, Arte de canto llano (Madrid: Joyas bibliográficas, 1978).

${ }^{54}$ Carlos Romero de Lecea, "Las más antiguas imprentas musicales hispanas VI", en Miguel Alonso, Cuatro tratados de principios de canto llano: los de Espinosa, Aguilar, Escobar y el anónimo (Madrid: Joyas bibliográficas, 1983), pp. 183-225, p. 221. Romero de Lecea (p. 224) señala que "la obra anónima del Arte de Canto Llano se nos presenta como un catecismo, como un catón musical, en el que pueden aprender lo indispensable quienes han de participar en los cantos litúrgicos [...]. Para nosotros es evidente que con esta obrita estaban muy familiarizados los cantores diocesanos. Nos parece verosímil que se hicieran sucesivas ediciones y no solamente las dos que conocemos".

${ }^{55}$ Gómez Muntané, La música medieval en España, p. 275. Robert Stevenson, "Estevan, Fernand”, Grove Music Online, ed. por L. Macy (consultado 06-10-2007) < http://www.grovemusic.com>, aunque señala que los tres libros dan las mismas reglas, no menciona esta derivación de una fuente común.

${ }^{56}$ Ferreira, "Mateus de Aranda", p. 135, hace alusión a la identificación de Mário de Sampaio Ribeiro, pero no ofrece su opinión al respecto.
} 
autoría. Las cuatro hojas que se conservan de este ejemplar fueron encontradas por Pascual de Gayangos usadas como encuadernación de un libro de $1534 .{ }^{57}$ Las hojas son igual de anchas, pero más de un centímetro más cortas que las del documento $\mathrm{R} / 14670(1)$. Tampoco tiene ejemplos musicales, pero el texto se dispone de manera más fragmentada. ${ }^{58}$

Como se detallaba en el Capítulo II, en el anónimo R/14670(1) el texto no está estructurado en capítulos ni párrafos, sino que discurre sin solución de continuidad y aparecen expresiones coloquiales que sirven como enlace entre temas diferentes, características de un estilo íntimamente conectado con la oratoria y la oralidad. ${ }^{59}$ En el incompleto R/14670(2) el texto está estructurado en párrafos más breves y apartados con títulos. El contenido es exactamente el mismo que el de R/14670(1), únicamente varía la ortografía de algunas palabras. El Apéndice 12 presenta una comparación entre los contenidos de los dos manuales R/14670 de la Biblioteca Nacional y el Arte de canto llano de Juan Martínez, evidenciando que los contenidos de los tres libros coinciden.

Aunque Ribeiro indicaba que nada permitía determinar el lugar y fecha de publicación de los tratados R/14670 de la Biblioteca Nacional, mediante la consulta de catálogos bibliográficos posteriores al estudio de Ribeiro es posible determinar los datos tipográficos de las dos ediciones. Frederick John Norton y Clive Griffin señalan que el Arte de cantollano anónimo fue impreso c. 1512-1515? por Jacobo Cromberger en Sevilla y que constaba de 16 hojas en octavo. ${ }^{60} \mathrm{El}$ cotejo permite determinar que los tipos del ejemplar R/14670(1) coinciden con los descritos por Norton y Griffin y que la letra “d” inicial que aparece al comienzo coincide con la "q" del alfabeto de iniciales utilizadas por la familia Cromberger, pero rotada 180 grados. ${ }^{61}$ Siendo Jacobo Cromberger el

\footnotetext{
${ }^{57}$ Frederick John Norton, A Descriptive Catalogue of Printing in Spain and Portugal 1501-1520 (Cambridge: Cambridge University Press, 1978), p. 358, nº 985.

${ }^{58}$ Ribeiro, A “Arte de Cantollano”, de autor desconhecido, p. 11, opina que debía tener un total de 12 hojas.

${ }^{59}$ Véase el Capítulo II (Apartado 3.1).

${ }^{60}$ Norton, A Descriptive Catalogue, p. 321, n 877; y Griffin, Los Cromberger, p. 316, nº 140. Véase también Knighton, "Libros de canto", p. 228. Acerca de la datación de las impresiones de Jacobo Cromberger, Álvarez Márquez, La impresión y el comercio de libros en la Sevilla del quinientos, p. 26, ha advertido tras estudiar el inventario de bienes de este impresor que quizás haya que "precisar más en el tiempo la fecha de edición atribuida a algunas obras e, incluso, añadir otras a su producción tipográfica".

${ }^{61}$ El alfabeto puede verse en Griffin, Los Cromberger, p. 294.
} 
impresor de la edición (y puesto que sólo imprimió otro libro de estas características, como es la edición de 1518 de Lux bella de Domingo Marcos Durán), este Arte de cantollano anónimo podría ser la "cartilla de arte", la "artesyica de canto llano" o el "arte de canto de la mano" que aparecen en grandes lotes en su inventario post-mortem datado a 7 de junio de 1529; por ejemplo, el Arte de cantollano anónimo podría ser la "artesyca de canto llano" vendida a 2 maravedíes que aparece en el inventario en un lote de 2355 ejemplares. ${ }^{62}$ No parece una coincidencia que Jacobo Cromberger imprimiese el Arte de cantollano anónimo R/14670(1) de la Biblioteca Nacional de España y que después, en 1530, su hijo Juan imprimiera el Arte de canto llano puesta y reduzida nuevamente en su entera perfecion de Juan Martínez. Como mostraré más abajo, debió de ocurrir lo mismo en el caso de las ediciones portuguesas del libro de Martínez impresas por João Barreira y su hijo António. Respecto al Arte de canto llano incompleto R/14670(2), Norton apunta que fue impreso c. 1515-1519? por Juan Varela posiblemente en Sevilla y advierte, como ya habían hecho Ribeiro y Anglès/Subirá, que el texto coincide con el del Arte de cantollano impreso por Jacobo Cromberger. ${ }^{63}$ La datación propuesta por Norton se basa en la posesión del tipo $81 \mathrm{G}$ por parte de Varela, ya que dejó de utilizarlo en 1520, sustituyéndolo por el 80G.

En el catálogo de la biblioteca de João IV de Portugal llevado a acabo en 1649 se incluye un "Arte de cantollano" (sin espacio entre las palabras "canto" y "llano") de "Iuan Martines". ${ }^{64}$ ¿Se atribuía a Juan Martínez un ejemplar como el anónimo de la Biblioteca Nacional de España? Una posibilidad es que los libros R/14670 fuesen obra de Juan Martínez, que los escribió con un propósito utilitario a modo de apuntes de clase tal vez como auxiliar o ayudante del maestro Vega, maestro de los mozos de coro de la Catedral de Sevilla anterior a Martínez, y los publicó como muestra de su competencia para ocupar el puesto de maestro de los mozos de coro. Esta hipótesis coincidiría con lo establecido por Cristle Collins Judd con respecto a la publicación de Le istitutioni harmoniche (Venecia, 1558) de Gioseffo Zarlino, que es anterior a su nombramiento como maestro de capilla y coincide con el debilitamiento de la salud de Adrian Willaert, por

\footnotetext{
${ }^{62}$ Véanse el Capítulo II (Apartado 1.2.3) y el Apéndice 8.

${ }^{63}$ Ribeiro, A “Arte de Cantollano”, de autor desconhecido, p. 30; Anglès y Subirá, Catálogo musical de la Biblioteca Nacional de Madrid, p. 126.

${ }^{64}$ Primeira parte do Index da Livraria de mvsica, p. 124, nº 539.
} 
lo que quizás responda al deseo de Zarlino de conseguir un puesto como el de San Marco. ${ }^{65}$ En el mismo sentido, pero en el caso de los compositores, Manuel Carlos de Brito señala que muchas veces en los siglos XVI y XVII el interés de los compositores en publicar sus obras respondía esencialmente a consideraciones de fama y prestigio. ${ }^{66}$ Además, la ausencia de colofón u otras indicaciones tipográficas en el Arte de cantollano anónimo podría indicar que Martínez financió la edición, de ahí que, al igual que las ediciones de su Arte de canto llano, no tenga dedicatoria. También la primera edición del libro de Zarlino carece de colofón y la ausencia del nombre del impresor (que se ha identificado como Pietro da Fino) podría indicar, según Cristle Collins Judd, que Zarlino financió la edición. ${ }^{67}$ Sin embargo, el Arte de cantollano se publicó sin indicación de autoría, lo que no encaja con la hipótesis de una publicación con el propósito de conseguir fama y prestigio.

Los tratados R/14670 de la Biblioteca Nacional sin duda reflejan los contenidos de la formación musical que recibían los mozos de coro de la Catedral de Sevilla y constituyen el material didáctico utilizado por los maestros de los mozos de coro anteriores a Martínez: Fernando Solís desde 1504, Francisco Hernández desde 1510 y el maestro Vega. ${ }^{68}$ El propio Martínez antes de ser nombrado maestro de los mozos de coro o alguno de sus predecesores en el cargo pudieron haber preparado los dos libros para su publicación en 1512-1515 y 1515-1519, respectivamente. En cualquier caso, Martínez, siendo ya maestro de los mozos de coro, publicó su propia ordenación de estos apuntes en lo que fue su Arte de canto llano de 1530. Fuera quien fuese el autor de los manuales de la Biblioteca Nacional, el que se publicaran sin indicación de autoría (al menos el primero, puesto que del segundo no se conserva la portada) apoya la hipótesis

\footnotetext{
${ }^{65}$ Judd, Reading Renaissance Music Theory, pp. 191-192.

${ }^{66}$ Brito, "Edições musicais em Portugal nos séculos XVII e XVIII”, p. 1139.

${ }^{67}$ Judd, Reading Renaissance Music Theory, p. 191.

${ }^{68}$ Para un listado de los maestros de coro de la Catedral de Sevilla, véase Josep Maria Llorens Cisteró, "Francisco Guerrero y su mundo catedralicio. Trayectoria humana y artística del maestro", en: Francisco Guerrero, Opera omnia (Barcelona: CSIC, Instituto Español de Musicología, 1955-2005), vol. 3 (1978), p. 41 .
} 
de que funcionaban como apuntes de clase, con un contenido neutral, no controvertido. ${ }^{69}$

\section{EL ARTE DE CANTO LLANO: UN SIGLO DE REEDICIONES}

Debido a los problemas de conservación que presentan los libros de pequeño formato, tenemos noticia de algunas artes de canto únicamente por medio de catálogos, inventarios y bibliografías, que en ocasiones pueden presentar ediciones "fantasma" que quizás nadie haya conocido de primera mano. ${ }^{70}$ Aunque la situación está cambiando, todavía hoy se encuentran dificultades para localizar y acceder a las fuentes en los archivos y bibliotecas españoles y portugueses. ${ }^{71}$ Por consiguiente, es difícil determinar con certeza el número exacto de reediciones de un libro de esta época. La Tabla III.3 mostraba las ediciones del Arte de canto llano de Juan Martínez a las que se había hecho referencia en la bibliografía. Durante el transcurso de esta investigación, he podido localizar ejemplares y referencias de otras ediciones del libro de Juan Martínez que se desconocían y que contribuyen a trazar la historia editorial de este libro.

Si el Arte de canto llano de Juan Martínez ya había sido publicado en Sevilla en 1530 (edición hoy desaparecida), la edición de 1532 en Alcalá de Henares (también desaparecida) es una reedición que responde a una demanda motivada por la utilidad y el éxito comercial del libro; además, fue impresa por Miguel de Eguía, impresor de la

\footnotetext{
${ }^{69}$ En este sentido, véase Michel Foucault, “Qu'est-ce qu'un auteur?”, Bulletin de la Société Française de Philosophie, III (1969), pp. 73-104: "Los textos, los libros y los discursos empezaron a tener realmente autores (distintos de los personajes míticos, distintos de las grandes figuras sacralizadas y sacralizadoras) en la medida en que podían ser transgresivos". Citado en Roger Chartier, Entre poder y placer: cultura escrita y literatura en la Edad Moderna (Madrid: Cátedra, 2000), p. 92.

${ }^{70}$ Keith Whinnom, “The Problem of the 'Best-Seller' in Spanish Golden-Age Literature”, Bulletin of Hispanic Studies, LVII (1980), pp. 189-198, p. 191: “Quizás la única edición de la que uno puede estar seguro es la que se ha visto y manejado. Los catálogos, ya sean de bibliotecas o de libreros, deben de ser relegados a un segundo rango. Y en tercer lugar vienen bibliografías y monografías" ["Perhaps the only edition one can be quite certain of is one which one has seen and handled. Catalogues, whether of libraries or book-sellers, have to be assigned to a second rank. And in third place come bibliographies and monographs"].

${ }^{71}$ Véase Tess Knighton, "Iberian Masses Catalogued” [Recensión de: Cristina Urchueguía, Mehrstimmige Messen in Quellen aus Spanien, Portugal und Lateinamerika ca. 1490-1630. Drucke, Handschriften und verlorene Quellen (Munich: Henle, 2005)], Early Music, XXXVI/2 (2008), pp. 309-310, p. 309, acerca de la utilidad en este sentido del catálogo que recoge Urchueguía.
} 
Universidad de Alcalá de Henares, lo que sugiere la conexión del libro con el contexto universitario (véase el Capítulo IV). Según Clive Griffin, antes de imprimir un título, Miguel de Eguía "solía dirigirse a un grupo de estudiosos de Alcalá que le decían qué libros no se encontraban en España y también, sin duda, cuáles tendrían éxito". ${ }^{72}$

Tras la publicación de Alcalá de Henares de 1532, encontramos una reedición de esta versión en Portugal, concretamente en Coimbra, en 1550. Como muestra la Tabla III.3, el primer estudioso en mencionar esta edición fue Mário de Sampaio Ribeiro en 1963. El Arte de canto llano de Juan Martínez fue traducido al portugués por Afonso Perea Bernal como Arte de canto chão posta \& reducida em sua inteira perfeiçao, segundo a pratica delle [...] Ordenada por Joao Martinz Sacerdote [...] e trasladada em linguagem portugues por Afonso Perea. La traducción debió de hacerse a partir de la edición de Alcalá de Henares de 1532, siendo prueba de ello que, según los datos que se conocen, la edición de Sevilla de 1530 difería levemente en el título ("segun la pratica del canto", en lugar de "segun la practica del canto llano"). ${ }^{73}$ El número de hojas es otro indicio de que para la traducción se utilizó la edición de 1532; se conservan 31 hojas y falta la portada, por lo que el total sería de 32 folios y por tanto cercano a los 35 folios que se atribuyen a la edición de Alcalá de Henares de 1532. En la impresión portuguesa del Arte de canto llano de Martínez se utilizaron tintas roja y negra como en las ediciones españolas. Que en la biblioteca de João IV aparezca un ejemplar de una de las ediciones españolas del libro muestra que en Portugal circulaba también la versión en español, lo que conduce a preguntarse las razones de la traducción. ${ }^{74}$ Podrían plantearse dos hipótesis: 1) aunque la corte portuguesa era bilingüe, seguramente las traducciones iban dirigidas a un público ajeno al ámbito cortesano que tenía dificultades para leer el castellano; y 2) la traducción del libro de Juan Martínez podría relacionarse con el deseo de leer en la lengua propia (como ya ocurría en Italia y Castilla) que señala António Ribeiro dos Santos. ${ }^{75}$ El único ejemplar conocido de esta edición portuguesa de 1550, al

\footnotetext{
${ }^{72}$ Griffin, Los Cromberger, p. 26.

${ }^{73}$ Ribeiro, A “Arte de Cantollano”, de autor desconhecido, pp. 28-29.

${ }^{74}$ Primeira parte do Index da Livraria de mvsica, p. 124, n 539.

75 António Ribeiro dos Santos, "Memoria sobre a historia da typographia portuguesa do seculo XVI", en Memorias da litteratura portugueza, ed. por la Academia Real das Ciencias de Lisboa (Lisboa: na Officina da mesma Academia, 1792-1814), vol. 8, pp. 77-147, p. 77.
} 
cual he tenido acceso, se conserva en la Biblioteca Geral de la Universidade de Coimbra. Aunque carece de la hoja que contenía la portada en el anverso y la mano guidoniana en el reverso, parece probable que la edición fuese impresa por João Barreira, lo que explicaría que su hijo António Barreira solicitara licencia para reeditar el libro en $1597 .^{76}$

La siguiente edición del libro de Martínez de la que tenemos noticia tuvo lugar en Sevilla en 1560, impresa por Juan Gutiérrez (de la misma imprenta y el mismo año salió a la luz la Recopilacion de sonetos y villancicos a quatro y cinco de Juan Vázquez). Esta edición fue "corregida y enmendada" por Luis de Villafranca, que sucedió a Juan Martínez como maestro de los mozos de coro de la Catedral de Sevilla hasta 1579. ${ }^{77}$ Esto sugiere que el libro de Juan Martínez era el que se seguía utilizando para instruir a los mozos de coro de la Catedral de Sevilla y que, en consecuencia, Villafranca decidió reimprimirlo corregido en $1560 .^{78}$ Puesto que cinco años más tarde Villafranca publicaría su propio manual Breue instrucion de Canto llano, cabe preguntarse si hay alguna relación en el contenido de ambos libros. ${ }^{79}$ Como muestra la Tabla III.4, contenido y organización resultan similares, aunque el libro de Villafranca es más extenso y, curiosamente, en él no se cita a Martínez como autoridad.

\footnotetext{
${ }^{76}$ Ribeiro, A “Arte de Cantollano”, de autor desconhecido, p. 21.

${ }^{77}$ Stevenson, Spanish Music in the Age of Columbus, p. 95. Stevenson, La música en la Catedral de Sevilla, documentos 367, 409, 536 y 538, ofrece información sobre Villafranca en el período 1562-1579.

${ }^{78}$ González Barrionuevo, Francisco Guerrero (1528-1599), p. 678.

${ }^{79}$ La edición del libro de Martínez corregida por Villafranca ha sido objeto de confusión en Ricart i Matas, Diccionario biográfico de la música, p. 1072, donde se atribuye a Villafranca el Arte de canto de Martínez de 1560 y no se cita la Breue instrucion de Canto llano de 1565.
} 
Tabla III.4: Comparación de los contenidos del Arte de canto llano de Juan Martínez y la Breue instrucion de Canto llano (Sevilla, 1565) de Luis de Villafranca

Juan Martínez, Arte de canto llano (Sevilla, 1530) [Contenido tomado de las ediciones de 1562 y 1598].

[Portada]

[Mano guidoniana]

Capitulo primero de las letras

Capitulo segundo de los Signos

Capitulo.iii.de las mutanças

Capitulo quarto de las claues

Capitulo. v.de los modos

Capitulos .vi. de los mouimientos

Capitulo septimo de las diuisiones delos tonos

Capitulo .viii. de las disjuntas

Capitulo .ix. de las consonancias

Capitulo .x. de los generos de musica

[Tabla]

[Ejemplo musical: "las bozes musicales" (primeras, segundas, terceras, quartas, quintas y sextas)]

Incipiunt intonaciones Psalmorum e de Magnificat

Incipiunt Introitus misse

Incipiunt Glorie responsoriorum

Sequitur canticum, quod in Ecclesia cantatur in laudem Beatisimae Virginis

[Letra de Sanctissimae Trinitatis]
Luis de Villafranca, Breue instrucion de Canto llano (Sevilla, 1565).

[Portada]

[Dedicatoria en latín]

[Mano guidoniana y ejemplo musical sobre pentagrama]

Capit. primero de las letras, bozes y propiedades

Capitulo .ii. de las mutanças

[El "Capitulo primero de las letras, bozes y propiedades" incluye las claves]

Cap. De los modos de cantar

Capitulo .v. para cantar por los ocho modos

[Cap .iii. de los mouimentos de la musica]

Cap .vi. de la diuision del tono

Cap .vii. de las consonancias

[Tabla]

[Ejemplo musical: "las bozes musicales" (primeras, segundas, terceras, quartas, quintas y sextas)]

Cap .viii. para entonar los psal.

Cap .ix. para entonar los psalmos [...] sus sequencias vengan todas a vn tono, aunque sean de diuersos modos

Incipiunt Psalmorum intonationes secundum hordinem beati Gregorium et etiam glorie

Responsoriorum et glorie introitus Misse

Sequitur canticum quod ab eclesia cantatur in laudem Beatissime Virginis Marie

[Letra de Sanctissimae Trinitatis]

Cap .x. de la diuision: y diffinicion de accento para cantar epistolas, y euangelios

[Aprobación de Pedro Fernández y Francisco Guerrero]

[Licencia de impresión firmada por Juan de Ovando y Francisco Aragonés] 
En la Biblioteca de Comunicació de la Universitat Autònoma de Barcelona se conservan 17 hojas sin encuadernar (recogidas en una carpeta) del Arte de canto llano de Juan Martínez. Este ejemplar, que hasta ahora no se había mencionado en la bibliografía, procede de la Colección Capdevila, un fondo de manuscritos litúrgicos que pertenecieron a Felip Capdevila i Rovira de Barcelona. ${ }^{80}$ Según la catalogación de la Biblioteca, este ejemplar data del siglo XVI y podría corresponder a la edición de 1560. La carpeta contiene al principio una hoja mecanografiada correspondiente a la ficha catalográfica que se hizo en su momento para el Catàleg Col·lectiu del Patrimoni Bibliogràfic de Catalunya; ${ }^{81}$ esta ficha recoge los datos de la edición de 1530 :

\author{
Arte de cãto \\ llano puesta y reducida \\ nuevamente en su entera \\ pfeciõ segun la pratica$$
\text { d'l cãto }
$$$$
\text { Va en cada una de las }
$$ \\ reglas su ejemplo puntado: \\ Con las Intonaciones puntadas. \\ Ordenada por Juan Martinez \\ clerigo: maestro de los moços \\ d'l coro d'la sancta yglesia \\ de Sevilla \\ (Impressa en Sevilla por Ioãnem \\ Cromberger. Anno humanae salutatis \\ Mdxxx) \\ En $8^{\circ}$, letra gotica, en rojo y \\ Negro. 40 hojas sin numerar. \\ Signaturas seguramente a-e.
}

En la Biblioteca Històrica de la Universitat de València se encuentra un ejemplar de una edición del libro de Juan Martínez de la que no se da noticia en la bibliografía, impresa en Zaragoza por María de Solórzano, viuda de Bartolomé de Nájera, en

\footnotetext{
${ }^{80}$ Véase Alexander Olivar, "Notas sobre manuscritos", Hispania sacra, VIII/16 (1955), pp. 429-446, p. 439, "El fondo particular Capdevila Rovira, de Barcelona". Puesto que en la edición provisional del Catálogo colectivo de 1976 todavía no se hace referencia a este ejemplar, debió de pasar a formar parte de los fondos de esta biblioteca después de esa fecha. Véase Biblioteca Nacional, Catálogo colectivo de obras impresas en los siglos XVI al XVIII existentes en las bibliotecas españolas. Sección I: siglo XVI (Madrid: Instituto Bibliográfico Hispánico, 1976).

${ }^{81}$ Agradezco esta información a M. Antònia Galceran de la Biblioteca de Comunicació i Hemeroteca General de la Universitat Autònoma de Barcelona.
} 
1562 (véase Ilustración III.1). ${ }^{82}$ El libro, incompleto, consta de 32 hojas y está encuadernado en pergamino junto con otros dos libros de contenido devocional. ${ }^{83}$ El Arte de canto llano de Martínez aparece en tercer lugar. El hallazgo de esta edición del tratado de Martínez impresa en Zaragoza en 1562, de la que no se tenía ninguna referencia, es de sumo interés por tratarse de una reimpresión llevada a cabo en el reino de Aragón. Además, el ejemplar de la misma que se conserva contiene el texto completo de los diez capítulos que conforman el libro, aunque carece de las últimas hojas de repertorio musical.

Ilustración III.1: Juan Martínez, Arte de canto llano (Zaragoza: viuda de Bartholome de Nagera, 1562 [1530]), portada. Valencia, Biblioteca Històrica de la Universitat de València, BH Q/224(3).

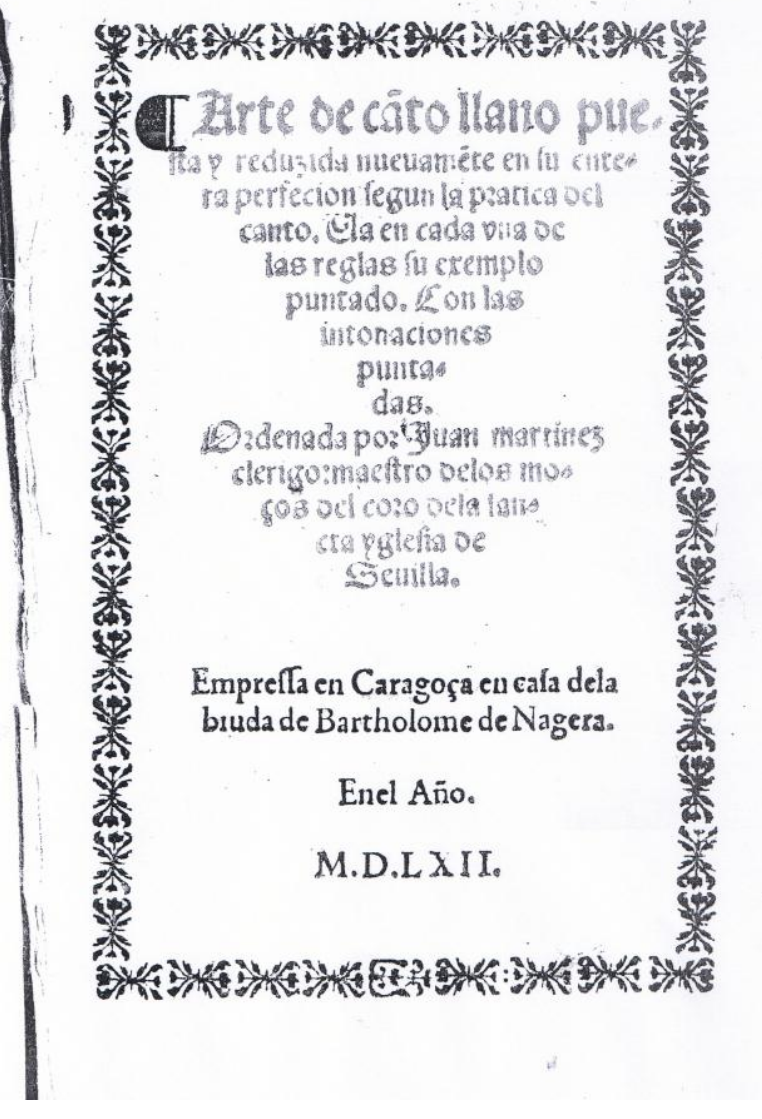

\footnotetext{
${ }^{82}$ Por ejemplo, esta edición zaragozana de 1562 del libro de Martínez no se menciona en Gerónimo Borao, La imprenta en Zaragoza (Zaragoza: Vicente Andrés, 1860), entre las impresiones de la viuda de Nájera. Sobre el tema de las mujeres impresoras de libros de música, véase el Capítulo VI (Apartado 1.2).

${ }^{83}$ La primera es el Tratado de las ceremonias de la Missa Rezada, y solemne (Valencia: Imprenta de Iayme de Bordazar, 1692 [3 $3^{\text {a }}$ ed.]) de Iuan Bautista Almanza, presbítero de la Real Congregación de San Felipe Neri de Valencia; y la segunda es el Apendice de las missas votivas conforme al Missal romano, Decretos de la Sacra Congregacion de Ritos y Autores, que tratan de ellas (Valencia: en la Imp. de la viuda de Benito Macè, por Iayme Bordazar, 1682) de Alexandro Valencia, presbítero beneficiado y maestro de ceremonias en la Santa Iglesia Metropolitana de Valencia.
} 
Existen varias referencias a una edición en cuarto de la obra de Juan Martínez llevada a cabo en Barcelona en 1586 bajo el título de Compendio de canto llano. ${ }^{84}$ Aunque Antonio Palau y Dulcet ubica un ejemplar en la Biblioteca del Seminario de Barcelona, no aparece en el catálogo de esta institución. ${ }^{85}$ Kart-Werner Gümpel hace referencia a una edición de este Compendio de canto llano llevada a cabo en Salamanca en 1625 de la que no he encontrado información en catálogos bibliográficos ni tampoco ejemplares conservados de la misma. La siguiente publicación de la que se tiene noticia y de la que se conservan dos ejemplares, en la Biblioteca Geral de la Universidade de Coimbra y en la Biblioteca Pública de Évora, respectivamente, es una versión portuguesa ya no sólo traducida sino también "accrescentada" por Afonso Perea Bernal siendo catedrático de música de la Universidad de Coimbra, e impresa en esa ciudad por António Barreira en 1597 (véase Ilustración III.2). La ampliación de Bernal se mantendrá en las siguientes ediciones portuguesas del libro de Juan Martínez revisadas por António Cordeiro, así como la mutación del lugar ocupado por las tablas y ejemplos musicales con respecto a las ediciones anteriores; en las ediciones españolas se sitúan al final del libro, mientras que en las portuguesas, exceptuando la de 1550, este material aparece al final del cuarto capítulo. Puesto que Afonso Perea falleció en 1593, se trata de una edición póstuma, en la que se utiliza únicamente tinta negra como en todas las ediciones portuguesas posteriores, en lugar de tintas negra y roja como en todas las ediciones españolas.

\footnotetext{
${ }^{84}$ Antonio Palau y Dulcet, Manual del librero hispanoamericano: bibliografía general española e hispanoamericana desde la invención de la imprenta hasta nuestros tiempos (Barcelona: Librería anticuaria de A. Palau, 1948-1977 [1923-1927]), vol. 8, p. 268, nº 154417; José Simón Díaz, Bibliografía de la literatura hispánica (Madrid: CSIC, Instituto Miguel de Cervantes de Filología Hispánica, 1950-1993), vol. 14, p. 300; Martín Galán, "Martínez, Juan (II)", p. 263; y Stevenson, Spanish Music in the Age of Columbus, p. 94.

${ }^{85}$ La bibliotecaria, Isabel de Colmenares Brunet, ha confirmado que actualmente no existe este ejemplar.
} 
Ilustración III.2: Juan Martínez / Afonso Perea, Arte de Canto chão (Coimbra: Antonio Barreira, 1597), portada. Évora, Biblioteca Pública, Res. 294.

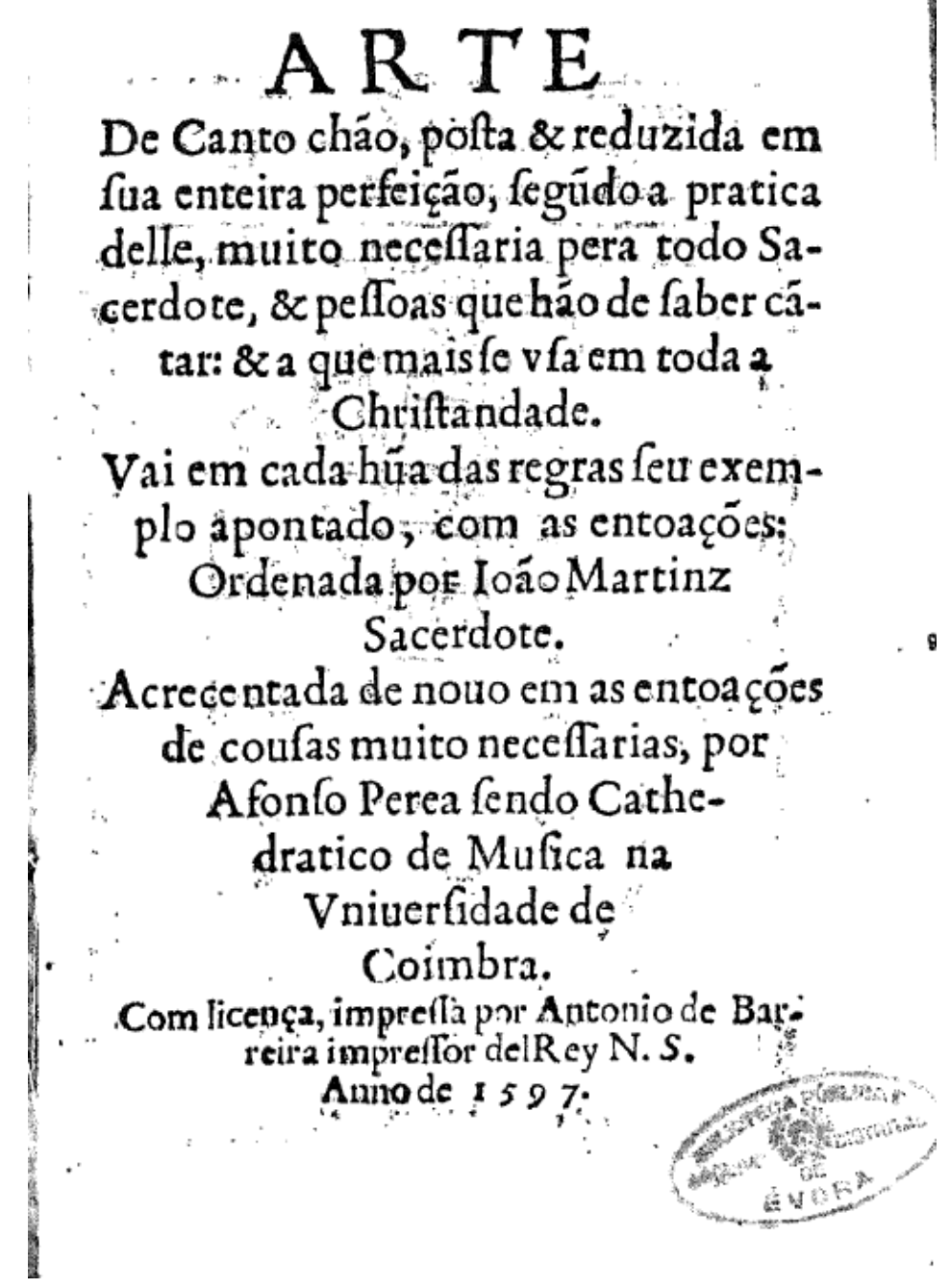

El libro de Martínez se reimprimió de nuevo en Alcalá de Henares con una licencia concedida a la impresora María Ramírez, viuda de Juan Gracián, el 22 de agosto de 1598. Se conserva un ejemplar de esta edición en la Biblioteca Nacional de España con la signatura $\mathrm{M} / 850$, el cual permaneció catalogado como anónimo durante los primeros meses de la presente investigación: cuando fue revisado para su digitalización fue atribuido a Juan Martínez. ${ }^{86}$ Aunque en su estudio de la imprenta en Alcalá de He-

\footnotetext{
${ }^{86}$ Información aportada por José María Soto, Bibliotecario de la Sala Barbieri de la Biblioteca Nacional de España.
} 
nares Julián Martín Abad incluye esta edición sin indicar autoría, ${ }^{87}$ ya en 1963 Mário de Sampaio Ribeiro había asegurado que su autor era Juan Martínez, basándose en la comparación de este ejemplar con las versiones portuguesas de la obra y con las indicaciones que Bartolomé Gallardo daba sobre el contenido de la edición de Alcalá de Henares de $1532 .^{88}$

Pedro Salvá y Mallen decía en 1872 tener "un fragmento del frontis" de una edición salmantina del Arte de canto llano de Juan Martínez. ${ }^{89}$ Sin embargo, no aparece ninguna edición del libro de Juan Martínez en el catálogo descriptivo de libros impresos en Salamanca entre 1501 y 1600 de Lorenzo Ruiz Fidalgo. ${ }^{90}$ En el transcurso de mi investigación he hallado la referencia a una edición de Salamanca impresa por Juan Fernández en 1599, registrada en el inventario del Convent de Jesús de Maó (Menorca) hecho a requerimiento del Santo Oficio en $1642 .{ }^{91}$ Muy probablemente, la edición mencionada por Salvá sea esta publicación de 1599 en Salamanca de la que se preservaba un ejemplar entre los fondos del Convent de Jesús de Maó.

En una obra bibliográfica publicada por Alexander S. Wilkinson en 2010 que recoge libros impresos en la Península Ibérica antes de 1601, sólo se registran dos (1532 y 1597) de las nueve ediciones del siglo XVI del Arte de canto llano de Juan Martínez $\left(1530,1532,1550,1560,1562,1586,1597\right.$, c. 1598, 1599). ${ }^{92}$ Es sumamente interesante que la totalidad de las artes de canto llano citadas como anónimas por Wilkinson son de Juan Martínez o atribuibles a él (Sevilla, Jacobo Cromberger, 1512-1515?; Sevilla, Juan Varela de Salamanca, 1515-1519?; Sevilla, Juan Cromberger, 1530; y Alcalá de Henares, María Ramírez, c. 1598). ${ }^{93}$

\footnotetext{
${ }^{87}$ Martín Abad, La imprenta en Alcalá de Henares, p. 1313, nº 1156.

${ }^{88}$ Ribeiro, A “Arte de Cantollano”, de autor desconhecido, p. 31.

${ }^{89}$ Pedro Salvá y Mallen, Catálogo de la biblioteca de Salvá (Valencia: Ferrer de Orga, 1872), vol. 2, p. 348. Véanse también Stevenson, Spanish Music in the Age of Columbus, p. 94; y Simón Díaz, Bibliografía de la literatura hispánica, vol. 14, p. 300.

${ }^{90}$ Lorenzo Ruiz Fidalgo, La imprenta en Salamanca (1501-1600) (Madrid: Arco Libros, 1994), 3 vols.

${ }^{91}$ Casasnovas i Camps, Biblioteques, llibres i lectors, p. 284.

92 Alexander S. Wilkinson, ed., Iberian Books: Books Published in Spanish or Portuguese or on the Iberian Peninsula Before 1601 = Libros ibéricos: libros publicados en español o portugués o en la Península Ibérica antes de 1601 / edited by Alexander S. Wilkinson (Leiden y Boston: Brill, 2010), p. 490, $\mathrm{n}^{\text {os }}$ 12478 y 12479 .

${ }^{93}$ Wilkinson, ed., Iberian Books, p. 95.
} 
La primera reimpresión del libro de Martínez en el siglo XVII de la que tenemos constancia tuvo lugar en Coimbra por Manoel de Araujo en 1603. No se tiene constancia de la conservación de ningún ejemplar de esta edición, aunque Inocêncio Francisco da Silva menciona uno desaparecido de la biblioteca del extinto Convento de Jesús en Lisboa. ${ }^{94}$ Cuando no se conocían ediciones españolas de la obra de Martínez, se consideraba que ésta era la edición príncipe y que su autor era el portugués Ioão Martins; Diogo Barbosa Machado, quizás por no tener noticia de las ediciones españolas previas, presentaba esta edición como la primera publicada por Ioão Martins, lo que, como señalé anteriormente, llevó a atribuir la nacionalidad portuguesa a este autor. Barbosa Machado menciona una reimpresión en 1612, y cita la edición de 1625 como la primera publicación de António Cordeiro. También Ricardo Pinto de Mattos alude a la publicación de 1603 como obra del P. João Martins, quien estaba por tanto activo a finales del siglo XVI, y considera que se publicó una segunda versión revisada por António Cordeiro en 1614 y después en 1625, sin mencionar la edición de 1612. Ernesto Vieira hace referencia a la edición de 1603 citando a Barbosa Machado, pero confiesa no haberla visto (véase Tabla III.3). ${ }^{95}$ Este caso muestra un ejemplo de cómo una edición que quizás nadie haya conocido de primera mano puede llevar a confusiones respecto a la procedencia y cronología de un autor.

En 1612 y 1614, Nicolao Carvalho, impresor de la Universidad de Coimbra llevó a cabo dos reediciones del libro de Juan Martinez, en este caso "revisadas y enmendadas" por António Cordeiro, sochantre de la Sé de Coimbra, las cuales he podido estudiar a través de los ejemplares conservados en la Biblioteca Nacional de Portugal. Ambas ediciones contienen al final la ampliación de Afonso Perea Bernal "Seguense algunas cousas muyto necessarias, acresentadas, \& emmendadas agora de nouo nesta impreçao", aunque no se nombra al catedrático como autor de la ampliación.

El Arte de canto llano de Juan Martínez fue reeditado en España en el siglo XVII. La impresión, llevada a cabo en Madrid por Tomás Junta en 1621, preserva las características de las ediciones españolas: formato en octavo, 32 hojas (incompleto) y tintas roja y negra (véase Ilustración III.3). Citada por José Augusto Alegria en su catá-

\footnotetext{
${ }^{94}$ Silva, Diccionario bibliographico portuguez, vol. 3, p. 415.

${ }^{9}$ Barbosa Machado, Bibliotheca Lusitana Historica, Critica, e Cronologica, vol. 2, p. 692; Pinto de Mattos, Manual bibliographico portuguez de livros raros, classicos e curiosos, p. 380; y Vieira, Diccionario biographico de musicos portuguezes, vol. 2, pp. 66-67.
} 
logo de fondos musicales de la Biblioteca Pública de Évora, ${ }^{96}$ no aparece en el listado de impresiones de la familia Junta publicado por William Pettas, ni tampoco en el listado de bibliografía madrileña de los siglos XVI y XVII de Cristóbal Pérez Pastor. ${ }^{97}$ El ejemplar conservado en la Biblioteca Pública de Évora, al cual he tenido acceso, proviene de una biblioteca particular, la "Biblioteca da Manizola", cuyo último propietario fue José Bernardo Gama Lobo, Visconde da Esperança, que murió en 1931 habiendo manifestado su deseo de donar la colección a la Biblioteca Pública de Évora. Puesto que esta voluntad no estaba concretada en el testamento, los libros no se integraron a los fondos de la Biblioteca Pública de Évora hasta 1955, tras años de negociaciones con los herederos. ${ }^{98}$ Hay que destacar el hecho de que se produjese una reedición del Arte de canto llano de Juan Martínez en 1621 únicamente "enmendada de algunos errores que antes había" por el impresor que estaba al frente de la Imprenta Real, Tomás Junta. ${ }^{99}$ Quizás los motivos de esta reedición haya que buscarlos en la demanda de los centros de enseñanza que estaban proliferando en Madrid (como el Estudio de la Villa y el Colegio de los Padres de la Compañía de Jesús), “cuyos alumnos necesitaban libros de texto para sus estudios". 100

\footnotetext{
${ }^{96}$ José Augusto Alegria, Biblioteca Pública de Évora: Catálogo dos Fundos Musicais (Lisboa: Fundação Calouste Gulbenkian, 1977).

${ }^{97}$ William Pettas, A History \& Bibliography of the Giunti (Junta) Printing Family in Spain 1526-1628 (New Castle, Delaware: Oak Knoll Press, 2005); y Cristóbal Pérez Pastor, Bibliografía madrileña de los siglos XVI y XVII. Descripción de las obras impresas en Madrid desde el establecimiento de la imprenta en Madrid en el año 1566 al 1625 con anotaciones analíticas e históricas (Pamplona: Analecta, 2000 [1891]), 3 vols.
}

${ }^{98}$ Agradezco esta información a José Chitas, Bibliotecario de la Sala de Reservados de la Biblioteca Pública de Évora.

${ }^{99}$ Delgado Casado, Diccionario de impresores españoles, vol. 1, p. 359; William Pettas, A SixteenthCentury Spanish Bookstore: The Inventory of Juan de Junta (Philadelphia: American Philological Society, 1995); y A History \& Bibliography of the Giunti. Para un listado de direcciones de las imprentas madrileñas entre los siglos XVI y XIX, véase Ricardo Donoso-Cortés y Mesonero-Romanos, Señas de las imprentas de Madrid (1568-1850) según constan en las portadas o colofones (Madrid: Instituto de Estudios Madrileños, 2007).

${ }^{100}$ Ricardo Valladares Roldán, Origen y cultura de la imprenta madrileña (Madrid: Diputación Provincial de Madrid, 1981), p. 47. 
Ilustración III.3: Juan Martínez, Arte de canto llano (Madrid: Tomas Iunti Impresor del Rey nuestro señor, 1621 [1530]), portada. Évora, Biblioteca Pública de Évora, Nuevo Res. Maniz. № 821.

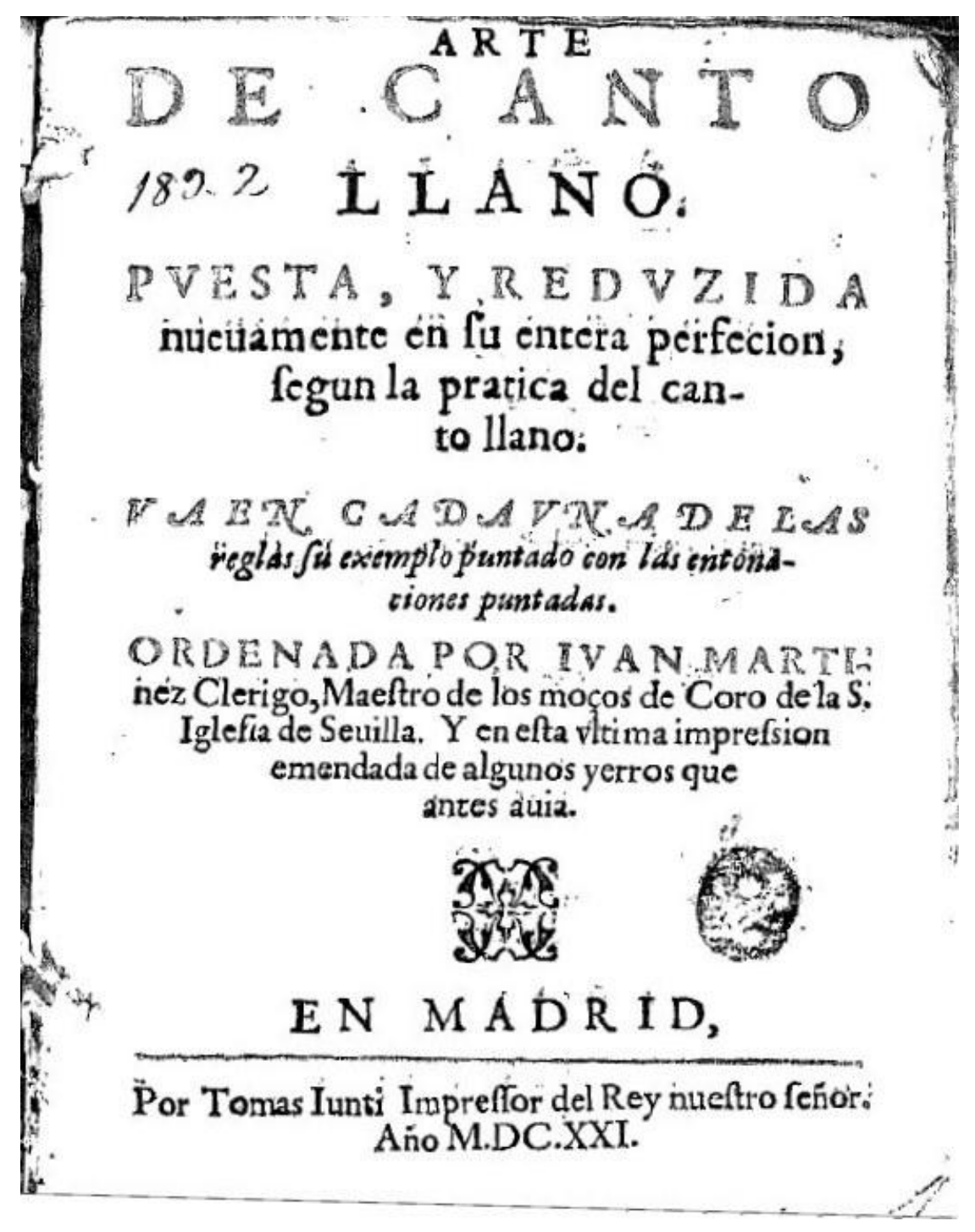

La última edición del Arte de canto llano de Juan Martínez de la que se tiene constancia fue impresa en Coimbra por Nicolao Carvalho en 1625 y es una reimpresión de nuevo "revisada y enmendada" por António Cordeiro. Aunque Robert Stevenson señala que esta edición fue "aumentada" por António Cordeiro, ${ }^{101}$ el añadido es el mismo que aparece en las ediciones de 1612 y 1614 y había sido escrito por Afonso Perea Bernal y publicado en la edición de Coimbra de 1597. Probablemente la confusión se

\footnotetext{
${ }^{101}$ Stevenson, Spanish Music in the Age of Columbus, p. 94.
} 
deba a que Stevenson desconocía entonces las ediciones portuguesas de 1550 y 1597 , aunque años después las cite en la voz "Bernal, Afonso Perea" de The New Grove Dictionary. ${ }^{102}$

Aunque las estadísticas bibliográficas siempre sean provisionales y sujetas a nuevos hallazgos, con los datos que tenemos podemos concluir que el Arte de canto llano et contrapunto et canto de organo (Zaragoza, 1508) de Gonzalo Martínez de Bizcargui y el Arte de canto llano (Sevilla, 1530) de Juan Martínez fueron los libros más reeditados de los de su tipología en el mundo ibérico del siglo XVI. Sin embargo, mientras que el libro de Martínez de Bizcargui ha recibido mayor atención, ${ }^{103}$ el de Juan Martínez había pasado casi desapercibido en la historiografía, quizás por desconocerse ejemplares conservados, si bien en los estudios portugueses se había hecho alusión a las numerosas ediciones de la obra. ${ }^{104}$ Las reediciones del Arte de canto llano de Juan Martínez que han surgido a lo largo de esta investigación permiten afirmar que supera al de Gonzalo Martínez de Bizcargui en cuanto a "popularidad", por dos diferencias: 1) el libro de Martínez de Bizcargui fue impreso únicamente en Burgos y Zaragoza, mientras que el de Martínez se publicó en Sevilla, Alcalá de Henares, Coimbra (traducido al portugués), Barcelona, Zaragoza, Salamanca y Madrid; y 2) si la obra de Martínez de Bizcargui fue objeto de reediciones entre 1508 y 1550, la de Juan Martínez fue reeditada a lo largo de casi un siglo (entre 1530 y 1625), sin contar los manuales anónimos R/14670 de la Biblioteca Nacional de España (de la segunda década del siglo XVI) que podrían atribuirse también a Juan Martínez. A modo de resumen, la Tabla III.5 contiene un listado simplificado de las versiones y reediciones del Arte de canto llano de Juan Martínez que he podido recopilar; para más información, véase el Apéndice 1.

\footnotetext{
102 Robert Stevenson, "Bernal, Afonso Perea", Grove Music Online. Oxford Music Online, 31 octubre $2008<$ http://www.oxfordmusiconline.com/subscriber/article/grove/music/02839>.

${ }^{103}$ Véanse, por ejemplo, Albert Seay, ed., Arte de canto llano, by Gonçalo Martinez de Biscargui (Colorado Springs: Colorado Collage Music Press, 1979); y Fernández de la Cuesta, Los tratados de canto llano de Spañón, Martínez de Bizcargui y Molina.

${ }^{104}$ Véase, por ejemplo, Vieira, Diccionario biographico de musicos portuguezes, vol. 1, p. 102: Afonso Perea Bernal "amplió un 'Arte de cantochão do padre Joao Martins', obra que tuvo gran boga en la Península durante casi todo el siglo XVI y principios del XVII, publicándose numerosas ediciones tanto en español como en portugués" [Afonso Perea Bernal "accrescentou a "Arte de cantochão do padre João Martins', obra que teve grande voga na peninsula durante quasi todo o seculo XVI e ainda principios do XVII, publicando-se numerosas edições tanto em hespanhol como em portuguez”].
} 
Tabla III.5: Listado abreviado de las reediciones del Arte de canto llano (Sevilla, 1530) de Juan Martínez ${ }^{105}$

* Ediciones incluidas en RISM

$[\mathrm{P}]$ Ediciones perdidas

Juan Martínez, Arte de canto llano puesta y reducida nuevamente en su entera perfecion segun la pratica del canto (Sevilla: Juan Cromberger, 1530) [P].

\section{REEDICIONES:}

- 1532, Alcalá de Henares, [Miguel de Eguía] *[P]

- 1550, Coimbra, [João Barreira?] [traducido al portugués por Afonso Perea Bernal]

- 1560, Sevilla, Juan Gutiérrez [corregido por Luis de Villafranca] [P]

- 1562, Zaragoza, Viuda de Bartholome de Nagera [María de Solórzano]

- 1586, Barcelona [como Compendio de canto llano] [P]

- 1597, Coimbra, António Barreira [traducido y ampliado por Afonso Perea Bernal] *

- 1598 (aprox.), Alcalá de Henares, María Ramírez

- 1599, Salamanca, Juan Fernández [P]

- 1603, Coimbra, Manoel de Araujo [traducido y ampliado por Afonso Perea Bernal] [P]

- 1612, Coimbra, Nicolao Carvalho, imprensa da Uniuersidade [versión de Perea Bernal revisada por António Cordeiro] *

- 1614, Coimbra, Nicolao Carualho, Impressor da Vniuersidade de Coimbra [versión de Perea Bernal revisada por António Cordeiro]

- 1621, Madrid, Tomas Iunti

- 1625, Coimbra, Nicolao Carvalho [versión de Perea Bernal revisada por António Cordeiro] *

- 1625, Salamanca [como Compendio de canto llano] [?] [P]

\section{La impresión del Arte de canto llano de Juan Martínez y la movilidad de materiales tipográficos}

Como maestro de los mozos de coro de la Catedral de Sevilla, Martínez se encontraba en el momento y lugar indicados para imprimir un libro: Sevilla era "el primer centro productor de libros del país" y las primeras décadas del siglo XVI suponen su período más brillante. ${ }^{106}$ Además, María del Carmen Álvarez Márquez ha señalado que esta ciudad era "el lugar propicio donde buscar la mano de obra que se necesitaba para imprimir en otros lugares de la Península”. ${ }^{107}$ Puesto que Juan Martínez estuvo vinculado de alguna forma con el Arte de cantollano R/14670(1) de la Biblioteca Nacional de

\footnotetext{
${ }^{105}$ No se incluyen en esta lista los dos tratados anónimos impresos en la segunda década del siglo XVI y conservados en la Biblioteca Nacional de España, aunque su contenido coincide con el tratado de Juan Martínez.

${ }^{106}$ Domínguez Guzmán, El libro sevillano durante la primera mitad del siglo XVI, p. 3; y Wagner, Martín de Montesdoca y su prensa, p. 19.
}

107 Álvarez Márquez, La impresión y el comercio de libros en la Sevilla del quinientos, p. 32. 
España impreso por Jacobo Cromberger y su Arte de canto llano de 1530 sería impreso por Juan Cromberger, Martínez debió de guardar relación con esta importante familia de impresores. Jacobo Cromberger consta en 1503 como vecino de Sevilla (vecino suponía en principio siete años de residencia), fue aprendiz en el taller de Meinard Ungut y, a la muerte de éste, se casó con su viuda y se hizo cargo de la imprenta. Se ha dicho que "la imprenta fue sólo una parte, no la principal" de los negocios de los Cromberger. ${ }^{108}$ Por consiguiente, quizás debamos buscar los motivos de algunas reediciones del Arte de Martínez en los intercambios, acuerdos y transacciones comerciales efectuados por esta familia de empresarios.

El impresor del arte de canto llano incompleto R/14670(2) de la Biblioteca Nacional de España (cuyo contenido coincide con el del libro de Juan Martínez) es Juan Varela, que "se había asociado con Jacobo Cromberger en varias aventuras comerciales" y ambos probablemente intercambiaron material tipográfico. Además, se ha sugerido que Varela traspasó después a Juan Cromberger, impresor del Arte de canto llano de 1530 de Martínez, parte de sus existencias. ${ }^{109}$ Tampoco es sorprendente que en 1532 se reimprimiese el libro en el taller complutense de Miguel de Eguía, impresor de la Universidad de Alcalá de Henares (cargo en el que sucedió a Arnao Guillén de Brocar), puesto que ya en 1525 éste había firmado un acuerdo de intercambio de productos con la imprenta Cromberger de Sevilla. ${ }^{110}$ El acuerdo debía de ser ventajoso para los Cromberger, puesto que Alcalá estaba situada en el camino natural hacia Aragón. Además, se ha apuntado que hacia 1540 el foco comercial de la imprenta castellana comenzó a desplazarse de Sevilla al norte de Castilla. ${ }^{111}$

La edición de Alcalá de Henares de 1532 del libro de Martínez se produjo en un momento en que Miguel de Eguía estaba en prisión procesado por la Inquisición acusado de erasmista, aunque su taller seguía funcionando "gracias a un amigo suyo que se

\footnotetext{
${ }^{108}$ Lafaye, Albores de la imprenta, p. 92. Sobre la imprenta de los Cromberger, véanse Cristóbal Bermúdez Plata, "Relaciones entre Jacobo Cromberger y Hernán Cortés, con noticias de imprentas en Sevilla", Anuario de Estudios Americanos, IV (1947), pp. 665-688; Domínguez Guzmán, El libro sevillano durante la primera mitad del siglo XVI, pp. 13-33; y Griffin, "Un curioso inventario de libros de 1528"; The Crombergers of Seville; y "El inventario del almacén de libros del impresor Juan Cromberger".

${ }^{109}$ Griffin, "El inventario del almacén de libros del impresor Juan Cromberger”, p. 264.

${ }^{110}$ Dadson, "La librería de Cristóbal López", p. 167.

${ }^{111}$ Griffin, "El inventario del almacén de libros del impresor Juan Cromberger", p. 264.
} 
había hecho cargo del negocio". ${ }^{112}$ Miguel de Eguía había llevado a cabo una serie de ediciones erasmistas en 1525 bajo el patrocinio de Alonso de Fonseca y Ulloa, Arzobispo de Toledo; en palabras de Marcel Bataillon esta serie de ediciones "constituye la primera manifestación en masa del erasmismo español". ${ }^{113}$ Miguel de Eguía estaba vinculado al menos con otro impresor de libros de música, ya que se formó en Logroño en el taller de Arnao Guillén de Brocar (que imprimió en Toledo en 1520 el Tractado de principios de musica practica e theorica de Juan de Espinosa); en 1518 se casó con la hija de éste y a partir de 1523 se hizo cargo de su taller (y por tanto de los materiales tipográficos) de Alcalá de Henares. ${ }^{114}$

También encontramos relaciones de los Cromberger con Portugal. Dada la notable reputación de Jacobo Cromberger, el rey Manoel de Portugal invitó al impresor a trasladar su taller a Lisboa a cambio de concederle un título de nobleza. Aunque a partir de 1521 llevó a cabo impresiones en Évora y Lisboa, se sospecha que Jacobo Cromberger no aceptó la oferta, ya que prefería Sevilla como centro de su industria. ${ }^{115}$ Desconocemos si existe alguna conexión entre las relaciones de Cromberger con el reino de Portugal y las reediciones coimbricenses del Arte de canto llano de Juan Martínez. Si, como se ha sugerido, el impresor de la primera edición portuguesa del Arte de canto llano en 1550 fue João da Barreira (que posiblemente era de origen español y llevó a cabo su aprendizaje en Lisboa), ${ }^{116}$ no deja de ser una interesante coincidencia que fuese impresor de la Universidad de Coimbra, como Miguel de Eguía lo fue de la Universidad de

\footnotetext{
${ }^{112}$ Ramón González Navarro, "El impresor navarro Miguel de Eguía, en Alcalá de Henares”, Príncipe de Viana, XLII/162 (1981), pp. 307-322, p. 318.

${ }^{113}$ Bataillon, Erasmo y España, p. 164. Véase Martín Abad, La imprenta en Alcalá de Henares, vol. 1, p. 82; José Goñi Gaztambide, "El impresor Miguel de Eguía procesado por la Inquisición (c. 1495-1546)", Hispania sacra, I (1948), pp. 35-54; Luís Fernández Martín, La Real Imprenta del Monasterio de Nuestra Señora de Prado (1481-1835) (Salamanca: Junta de Castilla y León, 1992); Delgado Casado, Diccionario de impresores españoles, vol. 1, p. 200; y María Ángeles Santos Quer, "Las iniciales en libros impresos en Alcalá de Henares por Miguel de Eguía hasta 1537”, Anales complutenses, IV (2002), pp. 51-60.
}

114 María Dolores Ruiz Negrillo, Impresos del s. XVI en Toledo (Madrid: Universidad Complutense, 1992), p. 108; y Martín Abad, La imprenta en Alcalá de Henares, vol. 1, p. 56: las "tres prensas con sus cajas" que Arnao Guillén de Brocar legó a su hija fueron vendidas por Miguel de Eguía a sus cuñados Juan y Pedro de Brocar.

${ }^{115}$ Lafaye, Albores de la imprenta, p. 89; Santos, "Memoria sobre a historia da typographia portuguesa do seculo XVI", p. 119; Griffin, Los Cromberger, p. 73.

${ }^{116}$ Francisco Marquez de Sousa Viterbo, O movimiento tipográfico em Portugal no século XVI. Apontamentos para a sua história (Coimbra: Imp. da Universidade, 1924), p. 155. 
Alcalá de Henares, puesto que apoyaría la hipótesis de la demanda del libro de Juan Martínez en el ámbito de la docencia universitaria (véase el Capítulo IV). También el hijo de João Barreira, António Barreira, que imprimió la edición de 1597 del Arte de canto llano de Juan Martínez, obtuvo en 1587 el privilegio de impresor de la Universidad de Coimbra. ${ }^{117}$

Además de mostrar la difusión de las artes de canto en el mundo ibérico del siglo XVI, el Arte de canto llano de Juan Martínez constituye también un prototipo para ejemplificar la cuestión de la circulación de los materiales tipográficos entre impresores. Aunque no conocemos ningún ejemplar de la edición, el Arte de canto llano de Alcalá de Henares de 1532 tenía una mano guidoniana en el vuelto de la portada que Henri Collet calificó de "magnífica", lo que no deja de ser llamativo dada la frecuente inclusión de tal ilustración en los libros sobre canto llano. ${ }^{118}$ El análisis y comparación que he realizado de todos los ejemplares existentes del libro de Martínez muestran que la edición impresa en Zaragoza por María de Solórzano, viuda de Bartolomé de Nájera, en 1562 contiene una mano guidoniana casi idéntica a la que aparece en el libro de Villafranca de 1565 impreso en Sevilla por Sebastián Trujillo. La única diferencia es el texto que aparece en el recuadro de la palma de la mano, lo que sugiere la posible reutilización de esta ilustración a partir de una plancha con el recuadro en blanco. La mano musical utilizada en las ediciones de Martínez (1562) y Villafranca (1565) había sido impresa previamente en dos ediciones del Arte de canto llano et contrapunto et canto de organo de Gonzalo Martínez de Bizcargui: 1) en la última hoja del ejemplar R/31259 de la Biblioteca Nacional de España que corresponde a la edición del libro de Martínez de Bizcargui impresa en Zaragoza por Jorge Coci en 1531; y 2) en la portada de la edición impresa en Burgos por Juan de Junta en 1543 (véase Ilustración III.4a). Esta última edición del libro de Martínez de Bizcargui es el único arte de canto que he encontrado en que la mano guidoniana aparece impresa en la portada (en el lugar que usualmente ocupa el escudo de armas del dedicatario o una ilustración religiosa) y no en el interior del libro.

\footnotetext{
117 António Joaquim Anselmo, Bibliografía das obras impressas em Portugal no século XVI (Lisboa: Biblioteca Nacional, 1977 [1926]), p. 29.

${ }^{118}$ Henri Collet, Un tratado de canto de órgano (siglo XVI) manuscrito en la Biblioteca Nacional de París. Edición y comentarios (Madrid: Librería Gutenberg de José Ruiz, 1913), p. 23. Como mostraré en el Capítulo IV, el Arte de canto llano de Juan Martínez debió de ser uno de los primeros del mundo ibérico en incluir una mano musical impresa.
} 
Ilustración III.4a: Manos guidonianas contenidas en la edición de 1562 del Arte de canto llano de Juan Martínez, en la Breue instrucion de Canto llano (1565) de Luis de Villafranca y en la edición de 1543 del Arte de canto llano et contrapunto et canto de organo de Gonzalo Martínez de Bizcargui

Juan Martínez, Arte de canto llano (Zaragoza: María de Solórzano, 1562 [1530]), f. A1v.

Valencia, Biblioteca Històrica de la Universitat de València, Q/224 (3).

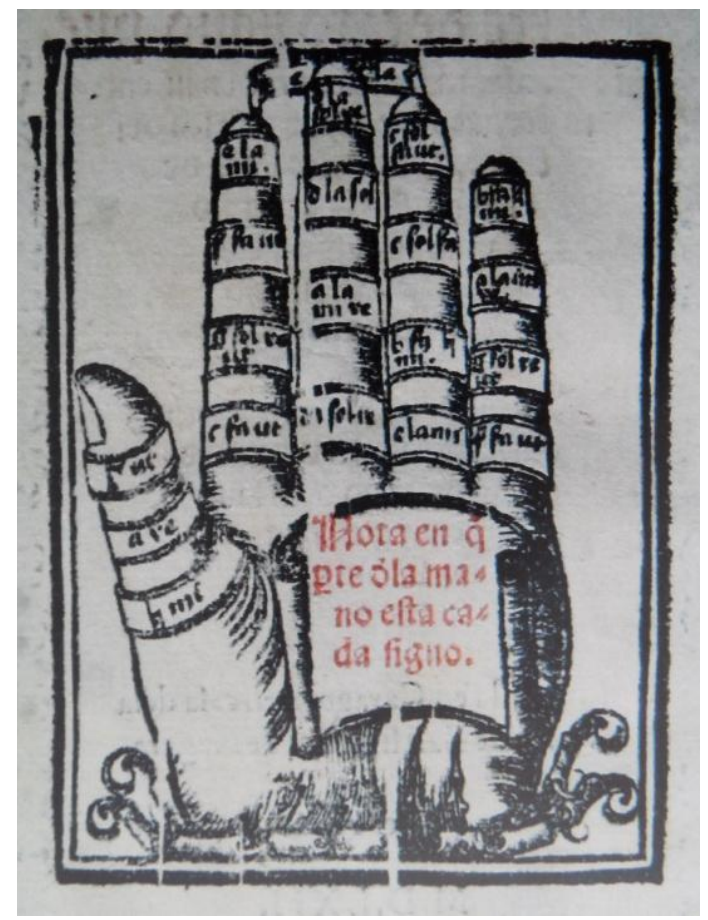

Luis de Villafranca, Breue instrucion de Canto llano (Sevilla: Sebastián Trujillo, 1565), f. A2r. Madrid, Biblioteca Nacional de España, R/14651.

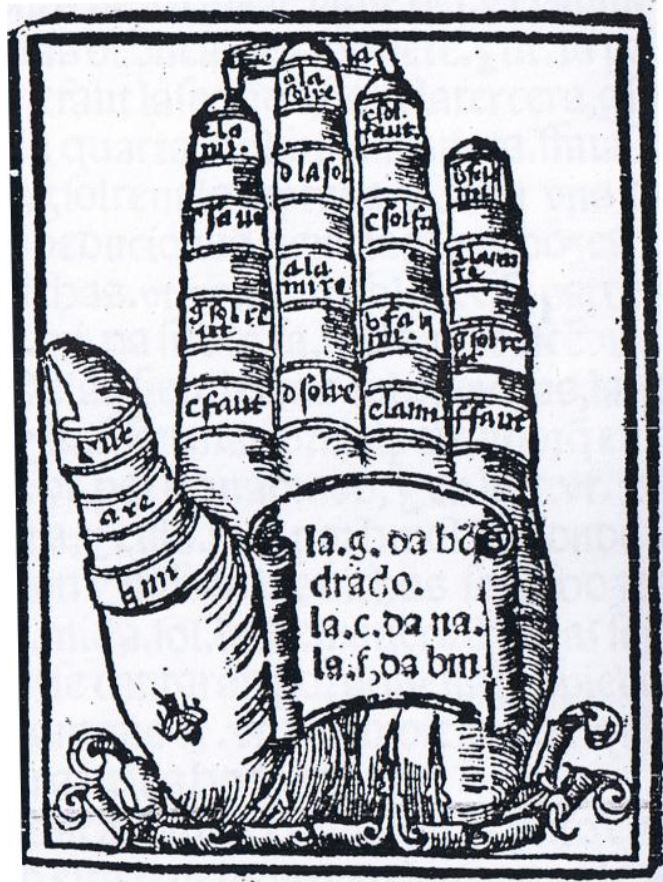

Gonzalo Martínez de Bizcargui, Arte de canto llano et contrapunto et canto de organo (Burgos: Juan de Junta, 1543 [1508]), portada. Madrid, Biblioteca Nacional de España, R/31625.

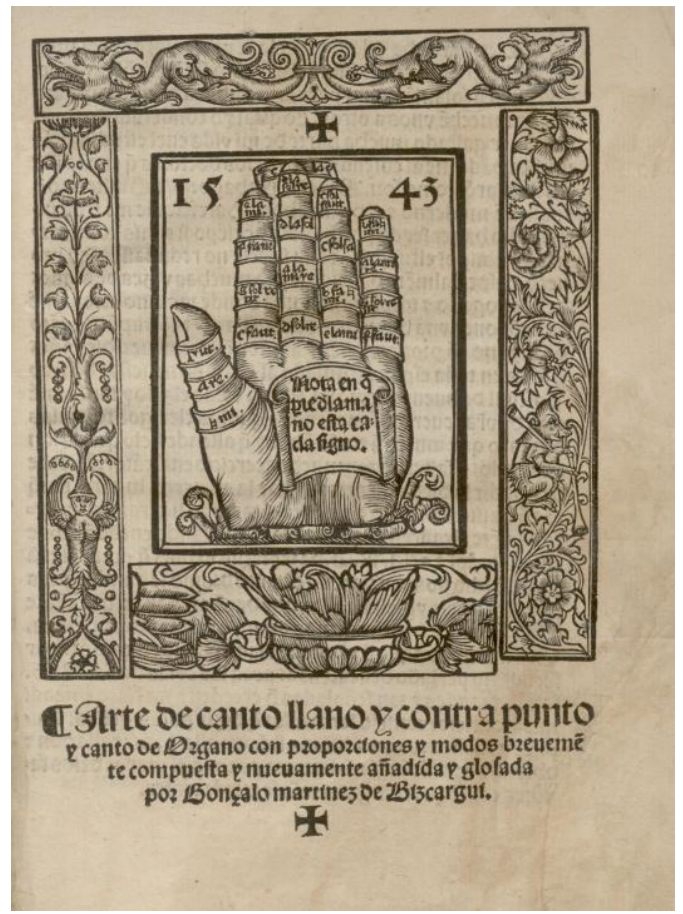


En la edición portuguesa del libro de Juan Martínez llevada a cabo por António Barreira en 1597 encontramos una nueva mano musical que reaparece en el resto de ediciones portuguesas de las que se conserva algún ejemplar con la primera hoja (las impresas por Nicolao Carvalho en 1612, 1614 y 1625). Con respecto a esta mano musical encontramos otra correspondencia, puesto que la misma se utiliza en el Arte de canto chão (Coimbra, Diogo Gomez de Loureyro, 1618) de Pedro Thalesio (véase Ilustración III.4b).

\section{Ilustración III.4b: Manos guidonianas contenidas en la edición de 1597 del Arte de canto llano de} Juan Martínez y en el Arte de canto chão (1618) de Pedro Thalesio.

Juan Martínez / António Cordeiro, Arte de Canto chão (Coimbra: Nicolao Carvalho, 1625).

Lisboa, Biblioteca Nacional de Portugal, M. 307 P.

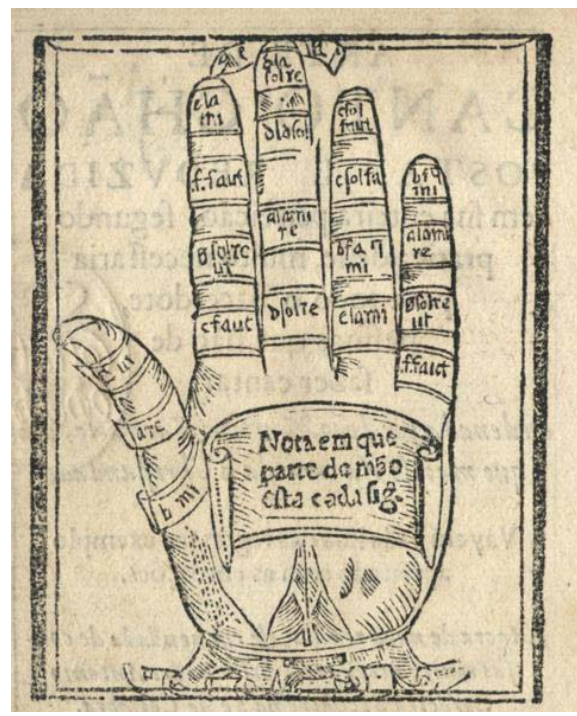

Pedro Thalesio, Arte de canto chão (Coimbra: Diogo Gomez de Loureyro, 1618). Lisboa, Biblioteca Nacional de Portugal, M.428P.

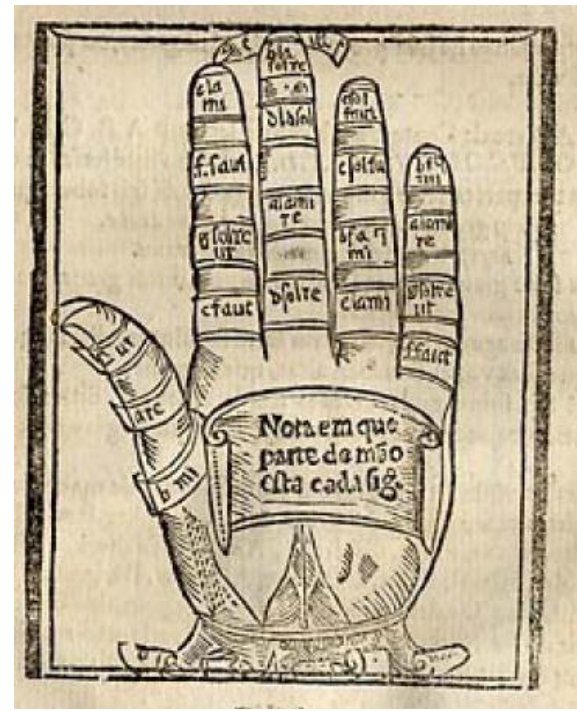

\section{DIFUSIÓN DEL LIBRO DE JUAN MARTÍNEZ}

\section{EN PORTUGAL Y EL NUEVO MUNDO}

El Arte de canto llano de Juan Martínez tuvo una importante difusión relacionada sin duda con el hecho de que los Cromberger surtían de libros a una amplia red de libreros que Clive Griffin ha clasificado en tres mercados: "Sevilla y el resto de Anda- 
lucía: Écija, Jerez, Jaén y Granada; Portugal, incluyendo Évora, Lisboa e incluso una ciudad tan septentrional como Guimaraes; y el norte de Castilla: Salamanca, Toledo y, por supuesto, Medina del Campo". ${ }^{119}$

El Arte de canto llano de Juan Martínez tuvo que ser conocido en Portugal de manera que se generase una demanda que condujese a las ediciones traducidas de Coimbra. Acerca de los mecanismos por los que el libro llegó a Portugal, caben varias posibilidades que pudieron suceder simultáneamente. Es posible que lo llevara a Portugal el autor de la traducción portuguesa y posterior catedrático de música de la Universidad de Coimbra, Afonso Perea Bernal. Según Mário de Sampaio Ribeiro, posiblemente Perea Bernal fuese natural de Sevilla y alumno de Juan Martínez en la Catedral de esa ciudad; ${ }^{120}$ sin embargo, su nombre no aparece en los documentos de esta institución compilados por Robert Stevenson. ${ }^{121}$ El libro de Martínez pudo llegar al país vecino mediante las importantes transacciones comerciales que mantuvieron Jacobo y Juan Cromberger en Portugal; es más, los Cromberger imprimieron específicamente para el mercado lusitano e incluso tenían un representante portugués, Luis Rodrigo, que distribuía sus libros en Lisboa. ${ }^{122}$ Julián Martín Abad ha subrayado la importancia que tienen actualmente los fondos de la Biblioteca Nacional de Lisboa y de la Biblioteca Pública de Évora para conocer la producción de las imprentas de Sevilla y Alcalá de Henares en el siglo XVI. ${ }^{123}$

Entre las numerosas artes de canto tanto españolas como portuguesas que formaban parte de la biblioteca del rey João IV de Portugal se encontraba, como señalaba anteriormente, un "Arte de cantollano" de "Iuan Martines", tratándose por tanto de un

\footnotetext{
${ }^{119}$ Griffin, Los Cromberger, p. 110.

${ }^{120}$ Ribeiro, A “Arte de Cantollano”, de autor desconhecido, p. 26.

${ }^{121}$ Stevenson, La música en la Catedral de Sevilla.

${ }^{122}$ Griffin, Los Cromberger, p. 74.

${ }^{123}$ Julián Martín Abad, "Raros impresos complutenses del siglo XVI en bibliotecas portuguesas", Anales del Instituto de Estudios Madrileños, XXV (1988), pp. 507-533, p. 508. En la recopilación elaborada por Francisco Aguilar Piñal de los impresos sevillanos del siglo XVI localizados en bibliotecas de Lisboa y Coimbra no encontramos ningún libro de música; véase Francisco Aguilar Piñal, "Impresos sevillanos del siglo XVI localizados en las Bibliotecas de Lisboa y Coimbra”, Cuadernos bibliográficos, XXX (1973), pp. 159-170. Acerca de los libreros portugueses activos en esta época, véase José Joaquim Gomes de Brito, Noticia de livreiros e impressores em Lisboa na $2^{a}$ metade do seculo XVI (Lisboa: Imprensa Libanio da Silva, 1911).
} 
ejemplar de alguna de las ediciones españolas de la obra en un momento en que estaban disponibles traducciones al portugués (véase Apéndice 9). ${ }^{124}$ João IV (1604-1656), Duque de Braganza y desde 1640 Rey de Portugal, estudió música con el compositor inglés Roberto Tornar (1587-1629), un alumno de Géry Ghersem en la Capilla Flamenca de Madrid que había sido contratado por el padre de João IV, Teodósio II (1568-1630), VII Duque de Braganza, en el palacio ducal de Vila Viçosa. El compositor portugués João Lourenço Rebelo (1610-1661) también recibió clases de Roberto Tornar en el Colégio dos Santos Reis de Vila Viçosa junto al propio João IV. ${ }^{125}$ Además, Mateo Romero (c. 1575-1647), cantor de la Capilla Flamenca de Felipe II y después maestro de capilla para Felipe III, fue invitado a Vila Viçosa por el propio João IV (antes de ascender al trono) y después nombrado capellán de la Corona Portuguesa. Otra muestra de la alta estima de que disfrutaban los músicos de la Capilla Flamenca en Vila Viçosa es la solicitud que se hizo a Philippe Rogier de que proporcionara música a la capilla ducal. ${ }^{126}$ Estos casos muestran los lazos musicales existentes entre Castilla y Portugal a través del mecenazgo musical del ducado de Braganza en Vila Viçosa y el intercambio de música y músicos (con el subsecuente establecimiento de una actividad docente), por lo que no es sorprendente la circulación de materiales didácticos como las artes de canto.

Las artes de canto no sólo circularon en los reinos peninsulares. Como indicaba en el Capítulo II, la presencia de artes de canto en el Nuevo Mundo fue muy significativa y, en particular, el Arte de canto llano de Juan Martínez tuvo una enorme difusión al otro lado del Atlántico. Carlos Alberto González Sánchez señala que el libro de Martínez aparece en ocho ocasiones en los once registros con libros de flotas y galeones de 1583 y 1584 conservados en el Archivo General de Indias que ha analizado. El autor lo incluye en su desglose de los libros litúrgicos: "en 1583-84 [la liturgia] se compone de 11 Breviarios, 15 Diurnos, 5 misales y, de canto gregoriano, 8 del Arte de canto llano,

${ }^{124}$ Primeira parte do Index da Livraria de mvsica, p. 124, n 539.

${ }^{125}$ El ensayo de João IV, Defensa de la musica moderna, contra la errada opinion del Obispo Cyrilo Franco (Lisboa: s.n., 1649), fue dedicado a Rebelo. Sobre la enseñanza de la música en esta institución, véase José Augusto Alegria, História da Capela e Colégio dos Santos Reis de Vila Viçosa (Lisboa: Fundação Calouste Gulbenkian, Serviço de Música, 1983). Véanse también Mário de Sampaio Ribeiro, ElRei D. João IV príncipe-músico e príncipe da música (Lisboa: Academia Port. da História, 1958); y Michael Ryan, "John IV of Portugal, King and Musician: An Anniversary Assessment", The Musical Times, CXLV/1887 (2004), pp. 58-62.

${ }^{126}$ Rui Fernando Vieira Nery y Paulo Ferreira de Castro, Historia da música (Lisboa: Europália - Imprensa Nacional, 1991), p. 61; Rees, "Relaciones musicales entre España y Portugal”, p. 481. 
publicado en Sevilla en 1560, de Juan Martínez y 3 del Oficio de la Semana Santa". ${ }^{127}$ Esto indica que la edición del libro de Martínez que había preparado Luis de Villafranca no sólo se usaba como material didáctico en las lecciones de música de la Catedral de Sevilla sino que también se exportó al Nuevo Mundo.

El Arte de canto llano de Juan Martínez aparece en el inventario de 1655 de Melchor Pérez de Soto, arquitecto criollo procesado por la Inquisición de México (véase Apéndice 9), circunstancia que, según Robert Stevenson, demuestra la estima en que se tenía la obra en el Nuevo Mundo más de un siglo después de su primera aparición. ${ }^{128}$ También encontramos un ejemplar del libro de Martínez en la memoria de libros llevados por un tal "Trebiña" desde México a Manila en 1583 (la relación marítima de la Península Ibérica con Manila se llevaba a cabo a través de México). ${ }^{129}$ Este documento está recogido en un artículo de Irving Leonard, donde se sugiere que el propietario podría ser el mercader de libros activo en Ciudad de México Juan de Treviño, y se considera que esta "Memoria de los libros sig ${ }^{\text {tes }}$ que traygo yo trebiña-1583" es uno de los archivos coloniales españoles más interesantes para el estudio de la difusión de la cultura literaria en el siglo XVI. ${ }^{130}$

El Arte de canto llano de Juan Martínez también estuvo presente en el Virreinato del Perú. En un análisis de los libros españoles difundidos en este territorio llevado a

\footnotetext{
${ }^{127}$ González Sánchez, Los mundos del libro, p. 88.

${ }^{128}$ Stevenson, Spanish Music in the Age of Columbus, p. 94. Véase también Eugenio Pereira Salas, Los origenes del arte musical en Chile (Chile: Publicaciones de la Universidad de Chile, 1941), p. 9; Fúrlong Cárdiff, Músicos argentinos, p. 22; y Enrique Martínez Miura, La música precolombina: un debate cultural después de 1492 (Barcelona: Paidós Ibérica, 2004), p. 47.

${ }^{129}$ Lafaye, Albores de la imprenta, p. 105.

${ }^{130}$ Leonard, “One Man's Library”, p. 85; y Los libros del conquistador, p. 454. Sobre la posesión de libros en la América colonial véanse también Agustín Millares Carlo, "Bibliotecas y difusión del libro en Hispanoamérica colonial: intento bibliográfico", Boletín Histórico, VIII/22 (1970), pp. 25-72; Guillermo Lohmann Villena, "Libros, libreros y bibliotecas en la época virreinal", Fénix, XXI (1971), pp. 17-24, que constituye una investigación sobre libros, libreros y bibliotecas en Lima durante el período virreinal tomando como fuente inventarios recogidos en protocolos; Francisco de Solano, "Fuentes para la historia cultural: libros y bibliotecas de la America colonial", en Ensayos de metodología histórica en el campo americanista, ed. por Fermín del Pino Díaz (Madrid: CSIC, Centro de Estudios Históricos, 1985), pp. 6971 , que trata aspectos metodológicos e incluye una amplia bibliografía sobre el tema; Teodoro HampeMartínez, "The Diffusion of Books and Ideas in Colonial Peru: A Study of Private Libraries in the Sixteenth and Seventeenth Centuries", Hispanic American Historical Review, LXXIII/2 (1993), pp. 211-233, que representa un estudio de bibliotecas privadas del Perú colonial durante los siglos XVI y XVII; y González Sánchez, "Los libros de los españoles en el Virreinato del Perú", que utiliza los libros españoles en el Virreinato del Perú durante los siglos XVI y XVII como un instrumento para reconstruir el mundo cultural de los inmigrantes.
} 
cabo por Carlos Alberto González Sánchez tomando como fuente los inventarios de bienes de difuntos ("aquella clase especial de bienes pertenecientes a los españoles fallecidos en el Nuevo Mundo sin herederos”), encontramos que el libro de Martínez aparece en seis de los inventarios examinados y supone el único ítem de temática musical contenido en los mismos: "el grupo de varios" (un subgrupo dentro del conjunto de libros de temática religiosa) está constituido por "un conjunto de obras y autores de diversas materias que no cuadraban en los apartados anteriores. De todos, por su número, resalta el Arte de canto llano de Juan Martínez". ${ }^{131}$ En un trabajo más amplio, González Sánchez muestra que el Arte de canto llano de Juan Martínez aparece en nueve de los autos de bienes de difuntos entre 1558 y 1697 examinados. ${ }^{132}$

Cabe preguntarse cuáles fueron las razones de la enorme "popularidad" del Arte de canto llano de Juan Martínez en el Nuevo Mundo. Como indiqué en el Capítulo I, una característica de las artes de canto es la inclusión de características locales; así, el libro de Martínez, como el de Villafranca, contenía la letra del "Sanctissimae Trinitatis", una pieza polifónica que se cantaba desde 1498 en la Catedral de Sevilla. Buena parte de las iglesias americanas siguieron el modelo litúrgico de la Catedral de Sevilla, de manera que el Arte de canto llano de Juan Martínez sería especialmente adecuado como herramienta docente. Además, los Cromberger fueron un elemento fundamental en la distribución de libros al Nuevo Mundo, al menos por tres motivos: 1) Jacobo Cromberger (y Lázaro Nürnberger) consiguieron en 1525 "las primeras licencias que fueron concedidas a un extranjero para viajar a las Indias y comerciar allí"; ${ }^{133}$ 2) el 12 de junio de 1539, Juan Cromberger y Juan Pablos (uno de sus operarios) firmaron un contrato según el cual el segundo fundaría en México una imprenta (la primera del Nuevo Mundo) con materiales aportados por el primero; ${ }^{134}$ y 3) en 1542 el Emperador otorgó a Juan Cromberger y sus herederos "el monopolio de la venta e impresión de libros y cartillas y cualquier impreso en la Nueva España". ${ }^{135}$ Por tanto, una de las cau-

\footnotetext{
${ }^{131}$ González Sánchez, "Los libros de los españoles en el Virreinato del Perú”, pp. 9 y 31.

${ }^{132}$ González Sánchez, Los mundos del libro, p. 250.

${ }^{133}$ Lafaye, Albores de la imprenta, p. 91.

${ }^{134}$ Gestoso y Pérez, Noticias inéditas de impresores sevillanos, p. vii; Griffin, "El inventario del almacén de libros del impresor Juan Cromberger", p. 257; Lafaye, Albores de la imprenta, p. 91.

${ }^{135}$ Lafaye, Albores de la imprenta, p. 96.
} 
sas de la importante difusión del Arte de canto llano de Juan Martínez en los reinos peninsulares y el Nuevo Mundo fueron sin duda las transacciones comerciales de los Cromberger.

\section{RECONSTRUCCIÓN DEL TEXTO DEL ARTE DE CANTO LLANO DE JUAN MARTÍNEZ}

Aunque en su Ensayo de una biblioteca española de libros raros y curiosos Bartolomé Gallardo proporcionó los títulos de los capítulos de la edición perdida de 1532 del Arte de canto llano de Juan Martínez, ${ }^{136}$ y Mário de Sampaio Ribeiro estudió las versiones portuguesas, es de sumo interés conocer el contenido completo y exacto de las ediciones españolas del libro, dada la difusión geográfica y cronológica de éste y la influencia que, como veremos en el Capítulo IV, ejerció tanto sobre la práctica educativa dentro de ámbitos docentes diferenciados como sobre posteriores autores de artes de canto y tratados musicales en general.

Como señalé anteriormente, la investigación bibliográfica más detallada realizada hasta ahora sobre el Arte de canto llano de Juan Martínez la llevó a cabo Mário de Sampaio Ribeiro, que utilizó los ejemplares que conocía de ediciones portuguesas para atribuir el anónimo M/850 de la Biblioteca Nacional de España a Martínez. La edición de Coimbra de 1550 descubierta por Ribeiro es muy relevante por constituir una edición más temprana simplemente "traducida", sin ningún tipo de ampliación, y que incluso mantiene las particularidades tipográficas de las ediciones españolas, así como la letra del "Sanctissimae Trinitatis", que se omite en todas las ediciones portuguesas posteriores del Arte de canto llano de Juan Martínez de las que se conservan ejemplares (1597, 1612, 1614 y 1625). Durante el transcurso de esta investigación he podido encontrar ejemplares de dos ediciones españolas hasta ahora desconocidas, una del siglo XVI (1562) y otra del XVII (1621) que contribuyen a trazar la historia de este libro. Aunque ninguno de los ejemplares de ediciones españolas está completo, los correspondientes a las publicaciones de Zaragoza en 1562 y de Madrid en 1621 contienen todos los capítulos, mientras que en el ejemplar de la edición de Alcalá de Henares de c. 1598, conser-

\footnotetext{
${ }^{136}$ Gallardo, Ensayo de una biblioteca española de libros raros y curiosos, vol. 3, p. 646.
} 
vado en la Biblioteca Nacional de España, se conservan todos los "apéndices musicales"; véase la Tabla III.6, en que las casillas sombreadas indican los fragmentos conservados.

Tabla III.6: Transmisión del texto del Arte de canto llano (Sevilla, 1530) de Juan Martínez en los ejemplares en español que se conservan publicados con posterioridad

Se indican Portada, capítulos y secciones de música (Salmos, Introito, Gloria y Beata Maria Virgine).

\begin{tabular}{|c|c|c|c|c|c|c|c|c|c|c|c|c|c|c|c|}
\hline & $P$ & c. 1 & c. 2 & c. 3 & c. 4 & c. 5 & c. 6 & c. 7 & c. 8 & c. 9 & c. 10 & Sal. & Intr. & Glo. & BMV \\
\hline $1560 ?$ & & & & & & & & & & & & & & & \\
\hline 1562 & & & & & & & & & & & & & & & \\
\hline c. 1598 & & & & & & $T$ & & & & & & & & & \\
\hline 1621 & & & & & & & & & & & & & & & \\
\hline
\end{tabular}

Por consiguiente, es posible reconstruir la versión española del Arte de canto llano de Juan Martínez, edición que presento en el Apéndice 13, y para cuya elaboración he utilizado el ejemplar hasta ahora desconocido que he encontrado en la Biblioteca Històrica de la Universitat de València de la edición impresa en 1562 en Zaragoza por María de Solórzano, y el ejemplar de la Biblioteca Nacional de España de la edición impresa en Alcalá de Henares por María Ramírez hacia 1598 (sólo Ribeiro la menciona en la bibliografía). Esta reconstrucción permite llevar a cabo un análisis de la distribución de los contenidos del libro. En primer lugar, llama la atención la ausencia de cualquier material preliminar al cuerpo del texto; el libro de Martínez carece de dedicatoria y de prólogo, documentos que permitirían obtener información acerca de la finalidad del libro y del contexto en que surgió, e incluso aportar algunos datos biográficos del autor. Por el contrario, en el vuelto de la portada aparece ya una mano musical con la anotación "Nota en que parte de la mano esta cada signo" y en el folio siguiente se entra directamente en materia con la introducción del primer capítulo dedicado a las letras del canto llano. En este capítulo se explican brevemente los conceptos de letra, signo, deducción, propiedad y voces utilizando la herramienta pedagógica de presentar cada concepto como consecuencia de uno explicado anteriormente (véase Tabla III.7). 
Tabla III.7: Conceptos introducidos en el primer capítulo del Arte de canto llano (Sevilla, 1530) de Juan Martínez, a partir de mi reconstrucción de este tratado

\begin{tabular}{|c|c|}
\hline Conceptos & Nexos \\
\hline \multirow[t]{2}{*}{$\begin{array}{l}\text { Las letras y su clasificación en graves, agudas } \\
\text { y sobreagudas. }\end{array}$} & \\
\hline & "Destas veynte letras se siguen veynte signos" \\
\hline \multirow[t]{2}{*}{$\begin{array}{l}\text { Los signos y su clasificación: "los diez en } \\
\text { regla" y "los diez en espacio" }\end{array}$} & \\
\hline & $\begin{array}{l}\text { "Destos veynte signos se siguen siete dedu- } \\
\text { ciones por las cuales son regidos" }\end{array}$ \\
\hline \multicolumn{2}{|l|}{ Enumeración de las deducciones } \\
\hline & $\begin{array}{l}\text { "Estas siete deducciones se cantan y rigen por } \\
\text { tres propiedades" }\end{array}$ \\
\hline \multicolumn{2}{|l|}{ Las propiedades } \\
\hline & $\begin{array}{l}\text { "Cada vna destas siete deduciones trahe seys } \\
\text { vozes naturales" }\end{array}$ \\
\hline $\begin{array}{l}\text { Las voces y su división (para subir y para des- } \\
\text { cender) }\end{array}$ & \\
\hline
\end{tabular}

La concisión en las explicaciones y la organización didáctica de los contenidos, conectando los nuevos conceptos con los ya aclarados, son los principales rasgos definitorios del estilo de Juan Martínez. De este modo, en el capítulo segundo se enumeran las letras y las voces que hay en cada signo y en el tercer capítulo se introduce la definición de mutanza como "ayuntamiento y departimiento de dos bozes yguales de diuersas propiedades de vn signo", utilizando por tanto términos ya explicados. En el capítulo cuarto se presentan las claves, también relacionándolas con el concepto de signo ("para conoscimiento de los signos tenemos dos claues"). El capítulo de contenido más "teórico" es el dedicado a los tonos o modos, su clasificación en maestros (auténticos) y discípulos (plagales) y las "seys maneras de tonos": perfecto, imperfecto, pluscuamperfecto, mixto, comixto e irregular. Se explican los términos diapasón, diapente, diatesaron y las especies de los dos últimos. No obstante, la exposición teórica es mínima y se pasa rápidamente a la práctica con las reglas "para cantar por los ocho modos". Efectivamente, de las palabras de Juan Martínez se deduce que su libro estaba destinado a principiantes que pretendían adquirir unos conocimientos básicos y que, por tanto, era preferible huir 
de la prolijidad, aunque ello supusiese "corromper algunas vezes el modo o la consonancia":

[...] es imposible cantarse bien sin corromper algunas vezes el modo o la consonancia: y sin mucha experiencia con el arte de manera que estas sobredichas reglas por la mayor parte seran infalibles segun lo que se tiene en costumbre y en pratica: porque si se houiessen de hazer reglas para todas las cosas que desta causa se offrescen en el canto llano seria impossible comprehenderlo sin que houiesse mucha prolixidad. De la qual se ha de huyr principalmente para los que toman los principios del canto llano. ${ }^{137}$

En los siguientes capítulos del libro de Martínez se explican lacónicamente los tres movimientos de la música (deduccional, igual y disjuntivo), las diez divisiones de los tonos o conjuntas y sus reglas, las disjuntas, las consonancias y los géneros de la música (diatónico, cromático y enarmónico). Una tabla ejemplifica lo explicado y a modo de anexo se incluyen los íncipits de las entonaciones de los salmos, magnificats, introitos y responsorios del Gloria en cada uno de los ocho tonos, algunos cantos en alabanza a la Virgen María y la letra del "Sanctissimae Trinitatis". Dadas las características didácticas de la obra de Martínez, cabe preguntarse qué conexión tenían los libros de este tipo con los contenidos de las lecciones de música en los contextos didácticos en que se utilizaron. Éste es el objeto del Capítulo IV.

\section{APORTACIONES DE LA INVESTIGACIÓN SOBRE EL LIBRO DE MARTÍNEZ}

La musicología española se ha caracterizado por la importancia otorgada a las fuentes, de manera que la ausencia de éstas ha impedido el estudio del Arte de canto llano de Juan Martínez, un tratado cuyas dos primera ediciones (1530 y 1532) no se conservan y del que únicamente tenemos ejemplares incompletos correspondientes a diferentes ediciones en portugués y castellano. Además, por su carácter didáctico, el libro de Martínez no presenta contenidos polémicos ni innovadores, lo que podría conducir a considerarlo carente de un valor musicológico intrínseco. A esto hay que añadir cuestiones nacionalistas; la ausencia de datos sobre el origen del autor ha tenido como

\footnotetext{
${ }^{137}$ Juan Martínez, Arte de canto llano (Zaragoza: viuda de Bartholome de Nagera, 1562), f. B5v.
} 
consecuencia que a este músico no se le haya ubicado firmemente ni en la historia de la música española ni en la historia de la música portuguesa.

A pesar de su escasa presencia en la historiografía musical, el Arte de canto llano de Juan Martínez fue el manual de canto llano más difundido en el mundo hispánico del siglo XVI a juzgar por las numerosas reediciones, correcciones, ampliaciones, traducciones y citas como autoridad de las que fue objeto. Juan Martínez fue maestro de los mozos de coro en la Catedral de Sevilla desde 1525 y seguía en activo en la institución hasta al menos 1545. Como indica la documentación catedralicia, en el momento de ser nombrado para el cargo estaba desempeñando alguna otra función en la misma institución, y ésta podría vincularse a la docencia de la música puesto que el Arte de cantollano anónimo (Sevilla: Jacobo Cromberger, c. 1512-1515?) y el Arte de canto llano (Sevilla?: Juan Varela, c. 1515-1519) incompleto conservados en la Biblioteca Nacional de España son ejemplares de dos ediciones de un mismo tratado cuyo contenido coincide con el de Martínez. Aunque la coincidencia de contenidos no es una prueba definitiva para atribuirle estos libros, sí constituye una muestra de que el autor estuvo relacionado de algún modo con estas publicaciones que en la bibliografía se habían considerado hasta ahora carentes de interés. Como mostré en el Capítulo II, estos libros contienen fórmulas orales que los vinculan con la retórica y la enseñanza oral de la música, frente al estilo más "escrito" de artes de canto posteriores. Las artes de canto llano de la Biblioteca Nacional, el Arte de canto llano de 1530 de Juan Martínez y la reimpresión de este último por Luis de Villafranca en 1560 muestran la transmisión de una tradición estable de enseñanza de la música en la Catedral de Sevilla que se remonta al menos al manuscrito de Fernand Estevan de 1410.

El libro de Juan Martínez fue impreso en Sevilla por Juan Cromberger, lo que supone la vinculación de Juan Martínez con la imprenta de los Cromberger, una de las más productivas de la Península Ibérica y con más conexiones internacionales. El Arte de canto llano de Juan Martínez se reeditó en los reinos de Castilla (Alcalá de Henares, Sevilla, Salamanca y Madrid), Aragón (Zaragoza y Barcelona) y Portugal (Coimbra). Durante el transcurso de esta investigación he encontrado referencias a ediciones desconocidas hasta el momento (Zaragoza, viuda de Nájera, 1562; Salamanca, Juan Fernández, 1599; y Madrid, Tomás Junta, 1621), así como ejemplares de los que no se tenía noticia (posiblemente de la edición de Sevilla, Juan Gutiérrez, 1560; de la edición de Zaragoza, María de Solórzano, 1562; y de la edición de Madrid, Tomás Junta, 1621). 
Buena parte de estas reediciones fueron propiciadas probablemente por los intercambios de materiales tipográficos, los acuerdos y las transacciones comerciales efectuadas por la familia Cromberger. Además, esta empresa distribuía libros a una amplia red de libreros de toda la Península y el Nuevo Mundo. La popularidad del tratado de Juan Martínez propició su traducción al portugués en 1550; la versión en castellano también se siguió utilizando en Portugal, a juzgar por la Biblioteca del rey João IV. El libro tuvo que ser demandado en el Nuevo Mundo para que sea el libro de arte de canto llano más representado en registros de flotas y aparezca en inventarios de los siglos XVI y XVII procedentes de México, Manila y Perú.

La transcripción del Arte de canto llano de Juan Martínez, mediante la reconstrucción de sus diferentes apartados a partir de los ejemplares en castellano que he encontrado, me ha permitido analizar el contenido y las características de una obra tan difundida geográfica y cronológicamente. Pese a que carece de cualquier documento preliminar capaz de aportar alguna información acerca de la biografía del autor o sobre la finalidad del libro, salta a la vista la calidad didáctica de la obra, cualidad donde posiblemente reside la razón de su éxito. El libro de Juan Martínez fue publicado por los impresores de la Universidad de Alcalá de Henares (Miguel de Eguía) y la Universidad de Coimbra (Nicolao Carvalho y João da Barreira) y reimpreso con ampliaciones del catedrático de música de esta última institución (Afonso Perea Bernal), lo que sugiere una utilización del Arte de canto llano de Juan Martínez en el contexto universitario. Estas cuestiones son objeto de estudio en el Capítulo IV, donde sostendré que, como la historia del libro de Juan Martínez sugiere, las artes de canto en general son reflejo del contenido de las lecciones de música en ámbitos docentes diferenciados, en contraste con la generalización de que fueron utilizadas como material didáctico exclusivamente en las capillas eclesiásticas.

\section{RESUMEN DEL CAPÍTULO III}

El Capítulo III traza la historia del que emerge como el tratado con mayor difusión geográfica durante el siglo XVI y principios del XVII: el Arte de canto llano (Sevi1la, 1530) de Juan Martínez, maestro de los mozos de coro de la Catedral de Sevilla desde el 1 de septiembre de 1525, y que seguía en activo en la institución a finales de febrero de 1545 . Puesto que hasta ahora no se habían estudiado ejemplares en castellano 
del libro (con la excepción de las alusiones de Mário da Sampaio Ribeiro al ejemplar M/850 de la Biblioteca Nacional de España, hasta entonces catalogado como anónimo), el Arte de canto llano de Martínez no ha recibido la atención que merece en los estudios de conjunto de la tratadística española. La edición príncipe del libro (de la que existía un ejemplar en la Biblioteca Pública de Évora, hoy desaparecido) fue impresa en Sevilla en 1530 por Juan Cromberger, lo que relaciona el libro con la imprenta más productiva del mundo ibérico de la época. Además, podría tratarse de una de las artes de canto llano registradas en grandes lotes ("1150 artes de canto llano de a 2 pligos") en el inventario del almacén de libros de Juan Cromberger elaborado en Sevilla en 1540. En este Capítulo presento los resultados de un vaciado de las referencias a Juan Martínez en la bibliografía desde el siglo XVII hasta la actualidad (véase el Apéndice 11) y analizo la confusión en torno a su nacionalidad y las cronologías que se le han asignado en función de las ediciones de su libro que se conocían. Por la cronología, difícilmente es posible que Juan Martínez se pueda identificar con la persona de mismo nombre que trabajó como organista en la Catedral de Burgos en 1492, como se ha afirmado en la bibliografía previa.

Al comparar las dos artes de canto R/14670(1) y (2) de la Biblioteca Nacional de España (ambas anónimas) con el ejemplar hasta ahora desconocido del Arte de canto llano (Zaragoza, 1562) de Juan Martínez es posible corroborar que los contenidos coinciden, tal y como ya advirtió Ribeiro (que utilizó la traducción portuguesa del tratado de Martínez); véase el Apéndice 12. Aunque Ribeiro no fechaba los tratados de la Biblioteca Nacional, mediante la consulta de catálogos bibliográficos he podido determinar sus datos tipográficos: el Arte de cantollano R/14670(1) fue impreso en Sevilla por Jacobo Cromberger c. 1512-1515?, y el Arte de canto llano R/14670(2) fue impreso c. 1515-1519? por Juan Varela, posiblemente en Sevilla. El Arte de cantollano anónimo podría ser la "artesyca de canto llano" vendida a 2 maravedíes que aparece en el inventario post-mortem de Jacobo Cromberger en un lote de 2355 ejemplares. Las grandes tiradas en las que debieron imprimirse los manuales de la Biblioteca Nacional y el Arte de canto llano de 1530 de Juan Martínez sugieren que éste era el material didáctico con el que se aprendía música en la Catedral de Sevilla. La reedición del libro de Martínez de 1560 (hoy perdida) promovida por Luis de Villafranca, maestro de los mozos de la Catedral de Sevilla, sugiere que el libro se seguía utilizando para la enseñanza a los mozos de coro en la institución.

La historia del Arte de canto llano de Juan Martínez ilustra buena parte de las cuestiones estudiadas en los capítulos anteriores acerca de las artes de canto como fuente de la cultura musical del mundo ibérico renacentista: las características de las artes de canto, la vinculación de sus autores con la enseñanza de la música, la multiplicidad de reediciones de las que estos libros eran objeto, el intercambio de materiales tipográficos entre talleres de imprenta (por ejemplo, las ilustraciones de la mano musical utilizadas en las ediciones del libro de Martínez aparecen en otras artes de canto de la época), y la distribución y difusión de las artes de canto. El Arte de canto llano et contrapunto et canto de organo (Zaragoza, 1508) de Gonzalo Martínez de Bizcargui y el Arte de canto llano (Sevilla, 1530) de Juan Martínez fueron los libros más reeditados de los de su tipología en el mundo ibérico del siglo XVI. Sin embargo, el libro de Martínez de Bizcargui, actualmente considerado entre los más conocidos, fue impreso únicamente en Burgos y Zaragoza, mientras que el de Juan Martínez se publicó en Sevilla, Alcalá de Henares, Coimbra, Barcelona, Zaragoza, Salamanca y Madrid. El libro de Martínez de Bizcargui fue objeto de reediciones entre 1508 y 1550, mientras que el de Juan Martínez fue reeditado a lo largo de casi un siglo (entre 1530 y 1625), incluso sin contar los 
manuales anónimos de la Biblioteca Nacional publicados en la segunda década del siglo XVI que se le atribuyen. Un vaciado de inventarios de bienes muestra que el Arte de canto llano de Juan Martínez tuvo también una enorme difusión en el Nuevo Mundo.

Este Capítulo presenta también una reconstrucción del Arte de canto llano de Juan Martínez a partir de ejemplares incompletos conservados de diferentes ediciones del siglo XVI; la reconstrucción del texto completo del tratado se recoge en el Apéndice 13. He documentado ediciones del siglo XVI y ejemplares desconocidos del libro en la Biblioteca de Comunicació i Hemeroteca General de la Universitat Autònoma de Barcelona y la Biblioteca Històrica de la Universitat de València. He dado noticia de otra edición desconocida impresa en Salamanca en 1599 registrada en el inventario del Convent de Jesús de Maó (Menorca) realizado a petición del Santo Oficio en 1642 (podría tratarse de la edición de Salamanca mencionada por Salvá); y he encontrado una edición desconocida del siglo XVII (Madrid por Tomás Junta en 1621), y un ejemplar de la misma (Biblioteca Pública de Évora). La reconstrucción del libro que he llevado a cabo permite analizar su contenido y su calidad didáctica. Es un tratado que muestra los elementos básicos de la educación musical que se impartía a los mozos de coro de la Catedral de Sevilla y, posiblemente, a los alumnos de la cátedra de música de la Universidad de Coimbra, puesto que fue traducido al portugués y ampliado por Afonso Perea Bernal, catedrático de música de esta institución. Además, el libro de Martínez fue reimpreso en otras ciudades universitarias como Alcalá de Henares (por el impresor de la universidad, Miguel de Eguía) y Salamanca. La historia de este libro sugiere, por tanto, que las artes de canto fueron utilizadas como herramienta docente en ámbitos diferenciados, lo que requiere el análisis de los usos de estos manuales y de su vinculación con la enseñanza que se llevará a cabo en el Capítulo IV. 



\section{CAPÍTULO IV \\ USOS DE LAS ARTES DE CANTO: "MAESTROS MUDOS"1}

El propósito de este Capítulo es analizar el papel de las artes de canto como herramienta en el proceso de enseñanza-aprendizaje de la música en ámbitos docentes diferenciados, para lograr así una aproximación a las prácticas de la enseñanza musical y al grado de accesibilidad a la formación musical en la Península Ibérica durante el siglo XVI. Por tanto, siguiendo la conexión establecida por Roger Chartier entre historia del libro e historia de la educación, se pretende aquí relacionar la historia de la enseñanza de la música con la historia de las artes de canto como tipología libresca: "a través de los textos impresos se fijan y transmiten las normas pedagógicas". ${ }^{2}$ Chartier distingue tres campos de estudio en la historia de la educación que he aplicado a la enseñanza musical: 1) "la sociología de las poblaciones educadas"; 2) "la historia de los programas y de los materiales que definen a la educación"; y 3) "las prácticas pedagógicas". Mientras que el primer elemento ya ha sido tratado en el Capítulo II, este Capítulo presenta un análisis de los campos de estudio segundo y tercero, con el propósito de determinar "la relación o la distancia" entre la práctica pedagógica y los impresos que podrían reflejarla o definirla. Para ello, tras un examen de las funciones de las artes de canto y de los indicios de uso hallados en los ejemplares que he consultado, analizaré el contenido de estos manuales con el fin de relacionarlo con las lecciones de música impartidas en distintos ámbitos docentes: las instituciones eclesiásticas, las escuelas de latín, la uni-

\footnotetext{
${ }^{1}$ Iñigo López de Mendoza y Pimentel, IV Duque del Infantado, comenta en el prólogo dirigido a su hijo de Memorial de cosas notables (Guadalajara: Pedro de Robles y Francisco de Cormellas, 1564), f. A3v, el bien que hacen los libros a las personas de su condición "que pocas vezes hallan, quien fielmente les digan las verdades: como los libros (que se llaman maestros mudos) se las enseñan".

${ }^{2}$ Chartier, Cultura escrita, literatura e historia, p. 101. Algunos de los resultados de esta investigación se presentan en Ascensión Mazuela-Anguita, "Artes de canto and Music Teaching in the Renaissance Iberian World", en en Recent Research on Early Iberian Music in an International Context, ed. por Tess Knighton y Emilio Ros-Fábregas (Kassel: Reichenberger [en prensa]).
} 
versidad y la esfera privada. Según José García Oro y María José Portela Silva, “una de las realidades culturales más positivas en la España del siglo XVI es la multiplicación de las instituciones educativas". ${ }^{3}$ Eugenio Garin, al estudiar la enseñanza escolástica, distinguía entre los autores, que "enuncian afirmaciones propias, originales” y los lectores o maestros “que exponen e ilustran las 'sentencias' de los autores". 4 En las artes de canto renacentistas encontramos un solapamiento entre ambos papeles, puesto que, como se mostró en el Capítulo I, los autores estuvieron vinculados a la docencia de la música y, seguramente, la elaboración de sus libros fue consecuencia de esta actividad, de manera que los textos reflejan (aunque no de forma directa) los contenidos de las lecciones de música y/o fueron utilizados como material para el desarrollo de las mismas.

\section{LOS USOS DE LAS ARTES DE CANTO}

En el contexto del libro en general, los historiadores han advertido la importancia de estudiar "los usos, el estatus o los espacios propios" del libro para trazar el panorama de la historia de la cultura. ${ }^{5}$ En la historiografía musical, los estudios de este tipo han emergido más recientemente. ${ }^{6} \mathrm{Si}$ antes de la llegada de la imprenta los libros de música eran objetos "de lujo" encargados por nobles y aristócratas o bien objetos consumidos con fines principalmente utilitarios como el estudio, la liturgia y la docencia, en el siglo XVI, como vimos en el Capítulo II, aficionados pertenecientes a diferentes estratos socioecónimos también accedían a estos libros, quizás como entretenimiento, y

\footnotetext{
${ }^{3}$ José García Oro y María José Portela Silva, Monarquía y escuela en la España del Renacimiento. Escuelas, colegios y universidades en la Corona de Castilla (Santiago de Compostela: Editorial El Eco Franciscano, 2003), p. 15.

${ }^{4}$ Garin, La educación en Europa, p. 59. Véase también Eugenio Garin, Il pensiero pedagogico dell'umanesimo (Florencia: Coedizioni Giuntine-Sansoni, 1958).

${ }^{5}$ Véase Fernando Jesús Bouza Álvarez, "El mecenazgo real y el libro: impresores y bibliotecas en la corte de Felipe II", en Las sociedades ibéricas y el mar a finales del siglo XVI. Tomo I: La Corte. Centro e imagen del poder [Actas del Congreso Internacional "Las sociedades ibéricas y el mar a finales del siglo XVI" (Lisboa, 1998)] (Madrid: Sociedad Estatal para la Conmemoración de los Centenarios de Felipe II y de Carlos V, 1998), pp. 131-155, p. 132.

${ }^{6}$ Véanse, por ejemplo, Ros-Fábregas, "Libros de música en bibliotecas españolas del siglo XVI”, y Knighton, "Los libros de música de Felipe II", pp. 47-48.
} 
las publicaciones respondían en ocasiones a estrategias editoriales. ${ }^{7}$ En esta sección se estudiarán las finalidades que tenía en la cultura de la época el aprendizaje del canto y se llevará a cabo un examen de las artes de canto en su materialidad mediante el análisis de la evidencia externa de su uso encontrada en los ejemplares consultados y de los materiales gráficos que incluían.

\title{
1.1. Artes de canto: usos y costumbres
}

\begin{abstract}
El primer cantor, que es bendicion, es tiple: y este canta y bendize al señor por la su alta potencia. El segundo, que es honor, y es contra alto, canta y da honor al señor por la su infinita sapiencia. El tercero, que es loor, es tenor, canta y alaba al señor por su inestimable bondad, y por todas sus virtudes, noblezas y excellencias, y por lo que el señor es en si mesmo. El quarto (que es hazimiento de gracias) es contrabaxo, y canta y da gracias al señor, por las cosas que ha criado, y por todos los beneficios que ha hecho a toda criatura. ${ }^{8}$
\end{abstract}

Aunque, como se mostrará a lo largo de este Capítulo, las artes de canto eran utilizadas principalmente como herramienta pedagógica, encontramos otras funciones que pudieron ser atribuidas a esta tipología libresca: principalmente, la difusión de la religiosidad, con lo que se relacionan estrechamente otros dos usos, como son la contribución al ceremonial de la Iglesia y el deseo de evitar errores en el canto; sin embargo, encontramos también constantes referencias en las artes de canto a su uso como honesto pasatiempo y alguna alusión a la publicación de libros didácticos sobre música como una forma de enaltecimiento de la nación.

\footnotetext{
${ }^{7}$ Escolar Sobrino, Historia del libro español, p. 114: “[En el XVI] La baratura del libro, la aparición de colecciones de libros entre las personas privadas y la variada oferta de los impresores orientada en gran parte a los libros en castellano, facilitó el crecimiento de la lectura que se fue abriendo camino junto al estudio y la consulta, anteriormente los únicos motivos de aproximación al libro". Véase también Louis Jambou, "La función del órgano en los oficios litúrgicos del Monasterio de El Escorial a finales del siglo XVI", en Música en el Monasterio del Escorial: Actas del Simposium (1,4-IX-1992), coord. por Francisco Javier Campos y Fernández de Sevilla (San Lorenzo de El Escorial: Ediciones Escurialenses, 1992), pp. 391-426, pp. 412-413: "No deja de extrañar, en el repertorio organístico de la península del XVI que ha llegado hasta nosotros, la inexistencia de libros impresos o manuscritos que respondan por completo a un uso litúrgico. Pese a las declaraciones de Venegas de Henestrosa y pese a las alabanzas de Cabezón, de Hernando o de un humanista desconocido, al órgano como instrumento al servicio exclusivo de culto divino, causa asombro el que en sus libros no nos ofrezcan una 'diferencia', un juego completo de versos que ilustren las partes del ordinario de la misa o de otro oficio. La impresión de estos libros respondían por cierto a variadas preocupaciones: la docencia, la técnica del teclado y la composición, el ocio, la liturgia, la estrategia editorial o impresorial, entre otras".

${ }^{8}$ Comalada, Tratado llamado el Desseoso, ff. 113v-114r.
} 
La música se entendía como un instrumento para servir a Dios y, por tanto, que a todos incumbía. La mayor parte de los autores de artes de canto mencionaban este uso como justificación de sus publicaciones. Juan Bermudo señalaba que quien supiese cantar debía ejercitarse en este arte para alabar a Dios y, quien no supiese, "tiene obligacion de saberlo: trabaje de aprenderlo para pagar la deuda y seruir a Dios, que de Musica se quiso seruir"; 9 Bermudo reprendía a los maestros que no querían enseñar lo que sabían “a los que pueden seruir a Dios, dador de todos los bienes". ${ }^{10}$ En la licencia que otorgó Fray Gómez de Llanos a Juan Bermudo para publicar su Libro primero (1549), se señala que los libros de Bermudo son útiles para que "en la sabrosa y sancta lection de ellos sean las gentes despertadas a alabar a nuestro señor en himnos y psalmos y cantos spirituales". ${ }^{11}$ Dámaso Artufel indicaba que es "mucho el prouecho que del canto se deriua en las almas de los fieles: porque oyendola se encienden en douocion y reuerencia de su Magestad diuina". ${ }^{12}$ Pietro Cerone afirmaba que "la potentissima y principal causa, porque hauiamos de saber cantar es, para emplear la Musica en el seruicio y alabanças de Dios". ${ }^{13}$ Pedro Thalesio manifestaba que la importancia de su obra radicaba en que servía al culto divino. ${ }^{14}$

En los tratados destinados a religiosos se consideraba el canto una herramienta al servicio de Dios. El séptimo capítulo del Tratado del officio ecclesiastico canonico (Toledo, 1568) de Bernardino de Sandoval se titula "De la quinta consideracion: que por la institucion de los canticos eclesiasticos se entiende, que se deuen cantar, y oyr los officios diuinos attenta, y deuotamente. Tratase el ministerio de los cantores, y como deuan vsar del, y del vso de los instrumentos musicos". Sandoval afirmaba que "los canticos eclesiasticos se han instituydo, para que los que cantan, y los que oyen, se mueuan a deuocion, y conpuncion", de modo que "el cantor (segun dizen los sanctos padres) ha de tener buena boz, y ha de ser sabio en el arte: para que con la suavidad de

\footnotetext{
${ }^{9}$ Bermudo, Libro primero, f. 58r; Tapia, Vergel de musica, f. 27v: "si sabes cantar, exercitate en este officio sancto, y si no lo sabes, deprendelo para alabar al que es digno de toda alabança”.

${ }^{10}$ Bemudo, Libro primero, f. 8r, "Prologo general de la obra al lector".

${ }^{11}$ Bemudo, Libro primero, f. 2r.

${ }^{12}$ Artufel, Modo de rezar las horas canonicas, f. $3 \mathrm{r}$.

${ }^{13}$ Cerone, El Melopeo y Maestro, p. 21.

${ }^{14}$ Thalesio, Arte de canto chão, s.f., "Ao benevolo \& pio Leitor”.
} 
la boz mueua los animos de los oyentes". ${ }^{15}$ Otro ejemplo del siglo XVI es el Tratado llamado el Desseoso, y por otro nombre, Espejo de Religiosos (Salamanca, 1580), en que se apremia a los clérigos para que aprendan a cantar con el propósito de servir a Dios:

Y por ende trabajad quanto pudieredes en este camino de aprender bien el canto, porque alla do ys [sic] en la casa de amor de Dios, no tienen otro officio sino cantar: porque quando esteys alla sepays bien cantar. Ca el que en el camino tiene buena voz y la exercita, y no la pierde ni se le muda, y quanto mas puede por el camino no dexa de cantar quando llega alla, le es confirmada del todo la voz, y mucho mejorada: ca no la puede ya mudar. Y segun que en el camino alguno aprende mejor a cantar por el mucho vso y exercicio, ansi es mayor cantor y perece a los otros. ${ }^{16}$

Se consideraba que el canto cumplía mejor la función de servir a Dios que la música instrumental, porque la voz es percibida por todos, se inserta en el alma y "despierta sus afectos", mientras que "la del instrumento, es voz muerta":

La musica de la vihuela, o de otro qualquier instrumento, y la de la voz, toda es musica, y todas son vozes; pero con gran diferencia, que la del instrumento, es voz muerta, sin vida, no se entra tanto en el alma, ha de ser gran musico, el que la ha de entender y gustar della; los demas si el musico no acompaña lo que tañe con algun cantar, le diremos que lo dexe; la voz del hombre es la forma del instrumento, todos la perciben, entrase en el alma, y despierta sus afectos: desta manera se han Dios y el Predicador. Habla el hombre, dize lo que conuiene, predica la Escriptura sagrada, musica es, y que lleua artificio del cielo; pero si no và acompañada con la voz de Dios, que hable interiormente al alma, es cosa muerta y sin vida: en hablando Dios, luego hay gusto de la musica, conocimiento afectivo que llega a hazer lo que entiende. ${ }^{17}$

Las artes de canto contribuyeron en consecuencia a la difusión de la religiosidad, quizás como una modalidad más de las artes para servir a Dios, lo que implicaría una necesaria conexión entre la educación musical y la educación general en esta época. Kate van Orden señala la importancia del canto (tanto monódico como polifónico) en el aprendizaje de la lectura en la Francia del siglo XVI tomando como evidencia, por ejemplo, la inclusión de música en los catecismos y la emergencia de colecciones de

15 Bernardino de Sandoval, Tratado del officio ecclesiastico canonico (Toledo: Francisco de Guzmán, 1568), p. 193.

${ }^{16}$ Comalada, Tratado llamado el Desseoso, f. 91 r.

${ }^{17}$ Fray Alonso de Cabrera, De Consideraciones en los Euangelios de los Domingos de Aduiento, y Festiuidades que en este tiempo caen, hasta el Domingo de la Septuagesina. Tomo II (Barcelona: Lucas Sánchez, 1609), pp. 90-91. 
arreglos a cuatro voces de los textos de la cartilla en latín en traducciones a lengua vernácula. ${ }^{18}$ La aparición en el ámbito francés de manuales como Méthodes pour apprendre à lire, à escripre, chanter le plain chant, et compter (Paris, 1633) de Jacques Cossard, apoya la hipótesis de que el aprendizaje del canto llano no era materia exclusiva de clérigos y monjas, sino que formaba parte de la enseñanza general, que la música estaba estrechamente imbricada en la cultura de la época en un amplio espectro socioeconómico, y que las artes de canto no eran "Artezillas para sacristanes de aldea", sino manuales para aprender los rudimentos de la música. Libros de música instrumental como el Libro de cifra nueua para tecla, harpa, y vihuela (1557) de Henestrosa y la Declaración de instrumentos (1555) de Bermudo comienzan explicando el canto llano como base para cantar y tocar música tanto sacra como profana.

Las artes de canto podrían vincularse con la denominada "vulgarización de la Escritura", un fenómeno acontecido tanto en el ámbito católico como en el protestante consistente en la impresión de libros religiosos en lengua vernácula con el propósito de que se difundiesen fuera de los contextos propiamente eclesiásticos. ${ }^{19}$ Muestra de esta relación entre la imprenta y la difusión de la religiosidad es la labor de Hernando de Talavera en Granada o de Hernando de Aragón en Zaragoza ${ }^{20}$. Así, por ejemplo, las ediciones zaragozanas del Intonario de Pedro Ferrer en 1542, 1548, 1559 (no quedan ejemplos) y 1564 surgieron en este contexto quizás como ediciones oficiales promovidas por el Arzobispo Hernando de Aragón (véase Tabla IV.1).

\footnotetext{
${ }^{18}$ Orden, “Children's Voices”, p. 209.

${ }^{19}$ Bataillon, Erasmo y España, p. 49; Carlos Alberto González Sánchez, "Cerco a la imaginación”, p. 82; Vicente Bécares Botas, Arias Montano y Plantino: el libro flamenco en la España de Felipe II (León: Secretariado de Publicaciones de la Universidad de León, 1999), p. 98. Sobre la utilización de la música en el ámbito contrarreformista en Augsburgo, véase Alexander J. Fisher, Music and Religious Identity in Counter-Reformation Augsburg 1580-1630 (Aldershot: Asghate, 2004).

${ }^{20}$ Sobre Hernando de Talavera, véanse Bataillon, Erasmo y España, p. 58; Frederick John Norton, Printing in Spain, 1501-1520 (Cambridge: University Press, 1966), p. 16; María José López-Huertas Pérez, Bibliografia de impresos granadinos de los siglos XVII y XVIII (Granada: Universidad de Granada, 1997), p. 9; y Álvarez Márquez y Gómez Gómez, "Un pleito para la impresión de libros corales con destino a las Indias", p. 18. Acerca de Hernando de Aragón, véase Bernadó, "Las ediciones zaragozanas del Intonario de Pedro Ferrer".
} 
Tabla IV.1: Imprenta y difusión de la religiosidad en Zaragoza y Granada

\begin{tabular}{lll}
\hline & \multicolumn{1}{c}{ Zaragoza } & \multicolumn{1}{c}{ Granada } \\
\hline $\begin{array}{l}\text { "Mecenas editorial” } \\
\text { Objetivo }\end{array}$ & $\begin{array}{l}\text { Arzobispo Hernando de Aragón } \\
\text { Restablecimiento de la uniformidad } \\
\text { y la pureza litúrgica }\end{array}$ & $\begin{array}{l}\text { Arzobispo Hernando de Talavera } \\
\text { Adoctrinamiento de los conversos }\end{array}$ \\
$\begin{array}{l}\text { Impresor } \\
\text { Libros que mandó } \\
\text { imprimir }\end{array}$ & $\begin{array}{l}\text { Pedro Bernuz } \\
\text { notado, 2 graduales }\end{array}$ & Juan Varela de Salamanca \\
& & $\begin{array}{l}\text { Rationale de Guillermo Durando; } \text { Arte } \\
\text { para ligeramente saber la lengua aráui- } \\
\text { ga; } \text { Vocabulista arábigo en letra caste- } \\
\text { llana; un Breviarium de Camera; } \text { un } \\
\text { Gradual; un Antifonario. }\end{array}$ \\
\hline
\end{tabular}

Tal como advirtió Chartier, la escritura didáctica en general se convirtió en esta época en "un instrumento fundamental del ejercicio del poder, de la imposición de los controles y de la inculcación de las conductas". ${ }^{21}$ Pero no sólo las obras didácticas actuaron como vehículo de propaganda religiosa, sino también la música y, en particular, el canto monódico. Alfonso de Vicente ha llevado a cabo un estudio de la utilización de cantos monódicos en lengua vernácula como instrumento de propaganda religiosa por parte de movimientos reformistas católicos entre 1520 y $1620 .{ }^{22}$ También Kate van Orden ha mostrado cómo los niños de la Francia del siglo XVI cantaban canciones devotas sin saber apenas leer, de modo que, cuando aprendían a leer los textos catequísticos, éstos "activaban una matriz de conocimiento de base almacenada en formas musicales". ${ }^{23}$

Con las artes de canto también se pretendía contribuir al ceremonial y ornamento de la Iglesia, uso íntimamente vinculado con la difusión de la religiosidad. Encontramos un ejemplo en la licencia otorgada por Fray Tomás de Santo Domingo a António Fernandes para imprimir su libro, en la que se alegaba que la obra "sera para los que apren-

\footnotetext{
${ }^{21}$ Chartier, Entre poder y placer, p. 11; Luis Miguel Fernández, La seducción de los sueños: el libro en la Europa Moderna (siglo XV al XVIII) [Catálogo de exposición] (A Coruña: Diputación Provincial de A Coruña, 1994), p. 19, "La mano de la Iglesia"; Kagan, Students and Society in Early Modern Spain, p. xvii.

${ }^{22}$ Vicente Delgado, "Música, propaganda y reforma religiosa en los siglos XVI y XVII".

${ }^{23}$ Orden, "Children's Voices", p. 216: "More recollection than true discovery, reading catechistic texts activated a matrix of background knowledge stored in musical forms".
} 
den musica de mucha utilidad y para la iglesia en que se cantan glorias a Dios en la tierra de no pequeño ornamento". ${ }^{24}$ También es ilustrativo el caso de Sebastián Vicente Villegas, maestro de ceremonias de la Catedral de Sevilla, autor de la Suma de todo lo que contiene el Arte de Canto llano (1604) y del que se conserva un manuscrito de 1633 sobre el Orden del tañido de las campanas y officio de campanero de esta Iglesia Metropolitana de Sevilla. ${ }^{25}$ El caso de Villegas muestra la imbricación de las artes de canto en el entramado del ceremonial de la Iglesia. En el Tratado del officio ecclesiastico canonico de Bernardino de Sandoval se justificaba el uso de los instrumentos (proporcionando detalles de las plantillas instrumentales usadas en las catedrales del siglo XVI) únicamente como un medio para proporcionar solemnidad al culto divino:

Lo mismo se ha de entender de los otros instrumentos musicos, que en las yglesias cathedrales se tocan, celebrandose fiestas solennes, como son flautas, cornetas, chirimias, y ministriles altos, y baxos de diuersas maneras, harpas, y vihuelas, choros, y otros diuersos instrumentos musicos [...]. Pero porque esta ya recebido el vso dellos: y el intento de recebirse, fue, para celebrar mas solennemente las fiestas: deuese tolerar: con que no se permittan abusos. Y conforme a esto se proue yo en vn Concilio de Braccarense. ${ }^{26}$

El afán por evitar errores en el canto es otra de las utilidades de las artes de canto. En este sentido, encontramos tres ejemplos ilustrativos. Juan de Espinosa decía incluir en su libro "todo lo que de necesidad conuiene y es menester saber al principio para no poder errar". ${ }^{27}$ Paradójicamente, Pedro de Loyola Guevara se lamentaba en su libro ya desde el título (Arte para componer canto llano y para corregir y emendar la Canturia) de los "hierros y faltas" que tenía el canto llano señalando que "los que mas an dañado, son los que an escripto tantas Artezillas, que no a quedado nadie que no se a puesto a escreuir lo que se le à antojado"; ${ }^{28}$ Guevara citaba a otros autores de artes de

\footnotetext{
${ }^{24}$ Fernandes, Arte de musica de canto dorgam, e canto cham, \& proporções, s.f., "Licencia": "serà pera os que apremdem Musica de muita vtilidade: \& pera a Igreja em que se cantam glorias a Deos na terra de não pequeño ornamento".

${ }^{25}$ Sebastián Vicente Villegas, Orden del tañido de las campanas y officio del campanero de esta Santa Iglesia Metropolitana de Sevilla: por mandado de los Illustrissimos Señores Dean y Cabildo della: recogido todo de los Estatutos y Reglas antiguas, y de otros instrumentos que hablan desta materia, MS (1633), Madrid, Biblioteca Nacional de España, MSS/23095.

${ }^{26}$ Sandoval, Tratado del officio ecclesiastico canonico, p. 200.

${ }^{27}$ Espinosa, Tratado breue de principios de canto llano, f. A1v, “Al euerendo et muy magnifico señor".

${ }^{28}$ Guevara, Arte para componer canto llano, f. 6v.
} 
canto en el prólogo al lector y en el último folio, pero no en el cuerpo del texto, "porque los mas Cantollanos que hasta agora estan compuestos: tienen grandissimas faltas, y assi mesmo en lo que tienen escripto sobre ello". ${ }^{29}$ Se ha señalado que la actitud de Guevara parece consecuencia de la adopción en España del misal y breviario del papa Pío V de $1570 .^{30}$ Encontramos un último ejemplo en el soneto al autor incluido entre el material preliminar del libro de Pedro Thalesio, que hace referencia en el último verso a la utilidad de la obra para evitar cantar errores ("E se[m] ella, mil error cantaria"). ${ }^{31}$ Así, el aprendizaje del canto al que estaban destinadas las "artezillas" se entendía en la cultura del mundo ibérico renacentista como una herramienta inigualable para servir a Dios y proporcionar solemnidad al culto divino, libre de errores y faltas musicales.

Pero en los materiales preliminares de las artes de canto, sobre todo en dedicatorias y licencias, también encontramos abundantes referencias al uso de estos libros como un honesto pasatiempo para huir de la temida ociosidad. ${ }^{32}$ Por ejemplo, en la dedicatoria de su libro al Obispo de Burgos Fray Pascual de Ampudia, Gonzalo Martínez de Bizcargui señalaba como primer motivo de su publicación la conveniencia de que "siempre el enemigo en alguna buena obra nos vea ejercitar" con el fin de "no ser reprehendidos de la ociosidad". ${ }^{33}$ En la licencia otorgada a Bermudo para la publicación del Libro primero (1549), Fray Gómez de Llanos apuntaba que su deber era "repremir y castigar a los ociosos" y "promouer, y dar graciosos fauores a los que en sanctos exercicios se ocupan", y que los libros de Bermudo eran "de mucha vtilidad para los que en este loable exercicio se quisieren occupar". ${ }^{34}$ En el mismo libro encontramos una "epistola que Figueroa maestro dignissimo de capilla de la Real de Granada, examinador de

\footnotetext{
${ }^{29}$ Guevara, Arte para componer canto llano, f. 10v.

${ }^{30}$ Almonte Howell, "Guevara, Pedro de Loyola", Grove Music Online. Oxford Music Online, 7 octubre $2008<$ http://www.oxfordmusiconline.com/subscriber/article/grove/music/11943>; y Pedro Koegel, "Guevara Loyola, Pedro de [Pedro de Loyola Guevara]”, en Diccionario de la música española e hispanoamericana, ed. por Emilio Casares Rodicio (Madrid: Sociedad General de Autores y Editores, 1999-2002), vol. 6, p. 56.

${ }^{31}$ Thalesio, Arte de canto chão, s.f., "Ao avtor Soneto".

${ }^{32}$ Véase Pilar Ramos, "Musical Practice and Idleness: a Moral Controversy in Renaissance Spain", Acta Musicologica, LXXXI (2009), pp. 255-274.

${ }^{33}$ Martínez de Bizcargui, Arte de canto llano et contrapunto et canto de organo, f. A1v, "Muy magnifico et reverendo señor".

${ }^{34}$ Bermudo, Libro primero, f. 2 r.
} 
este libro embio al clementissimo Rey de Portugal”, en la que se señala que los libros de Bermudo fueron escritos "para que los que dessean gastar el tiempo fuera de juegos perjudiciales, y en otras cosas que dañan el alma y cuerpo: se pueda dar a entender qualquier genero de instrumentos con poco trabajo con el arte de cifrar, y auisos que en ellos pone". ${ }^{35}$ Precisamente en los libros de Bermudo se encuentra una alusión a otra función de las artes de canto que radica en la vinculación de la música (y en particular su didáctica) con el enaltecimiento de la nación:

Por las entrañas de Christo suplico a los musicos, y cantores de España, que en esta materia scriuan largo. Principalmente por el seruicio de Dios: y despues por la honra y prouecho de España. No auia musico de morir, que no dexasse el trabajo de toda su vida debuxado en papeles. Y si esto en España se hiziesse: seria la nacion mas rica del mundo en Musica. No hay gente que no se precie de honrrar su nacion: sino somos los descuydados españoles. ${ }^{36}$

\subsection{Indicios de uso en los ejemplares consultados}

La importancia de examinar la evidencia externa del uso de los libros como una herramienta musicológica para adquirir información acerca de la cultura musical ha sido subrayada recientemente por Màrius Bernadó, quien aboga por un estudio de la tratadística musical "desde el punto de vista de su soporte material". ${ }^{37}$ Susan F. Weiss considera las anotaciones en los manuales de música, y en concreto los manuales de canto llano, "interacciones" entre los lectores y los libros que actúan como fuente del "alfabetismo musical” del Renacimiento. ${ }^{38}$ Aunque James Haar señala que los manuales didácticos iban dirigidos principalmente a los maestros, puesto que los estudiantes adquirían

\footnotetext{
${ }^{35}$ Bermudo, Libro primero, ff. 2v-3r.

${ }^{36}$ Bermudo, Libro primero, ff. 142v-143r.

${ }^{37}$ Bernadó, "Impresos litúrgicos", p. 225. También existe una larga tradición sobre el estudio de la evidencia externa de manuscritos musicales para resolver problemas relacionados con su datación, procedencia, destinatarios, propietarios y aspectos relativos a la interpertación musical; véanse por ejemplo, Allan W. Atlas, The Cappella Giulia chansonnier (Rome, Biblioteca Apostolica Vaticana, C.G.XIII.27) (Brooklyn: Institute of Mediaeval Music, 1975); Howard Mayer Brown, A Florentine chansonnier from the Time of Lorenzo the Magnificent: Florence, Biblioteca nazionale centrale, MS Banco rari 229 (Chicago: Chicago University Press, 1983); y Margaret Bent, Bologna Q15: The Making and Remaking of a Musical Manuscript (Lucca: Libreria Musicale Italiana, 2008).
}

${ }^{38}$ Weiss, "Vandals, Students, or Scholars?", p. 208. 
conocimientos musicales de forma oral, ${ }^{39}$ Weiss asegura que eran usados por ambos, maestros y alumnos. Mateo de Aranda tituló de forma significativa la última sección de su Tractado de canto llano "Manera de como el canto se a de enseñar y entender".

En mi investigación he consultado más de 100 ejemplares de artes de canto y las evidencias externas de uso encontradas indican que estos libros fueron utilizados tanto para enseñar como para aprender los fundamentos de la música; también servían como libros de repertorio musical. Sin embargo, hay que tener presente que las artes de canto, debido a sus características físicas, fueron una literatura efímera, de manera que la mayoría de los ejemplares no se ha conservado y buena parte de los ejemplares que han llegado hasta nosotros carecen de indicios de uso y presentan un excelente estado de conservación (un ejemplo es Artufel 1614 BC Res 1407-12 $\left.{ }^{\circ}\right){ }^{40}$ Es llamativo el caso de Artufel 1614 BU 07 XVII-1297, puesto que en este completo Modo de rezar las horas canonicas únicamente encontramos anotaciones en la sección Arte de canto llano, lo que sugiere que posiblemente el tratado se adquiriera únicamente para usar especialmente esa sección relativa a la música.

\subsubsection{ANOTACIONES QUE INDICAN USO POR PARTE DE MAESTROS O POSTERIORES ESTUDIOSOS DE LA MÚSICA: CORRECCIONES, AMPLIACIONES Y REFERENCIAS BIBLIOGRÁFICAS Y/O MUSICALES}

Las correcciones que hallamos en las artes de canto indican una lectura crítica por parte de un usuario con formación musical, como un maestro de capilla, y por tanto con un fin práctico, o bien son fruto de la lectura crítica posterior de un estudioso de la música. Ejemplos de estas enmiendas son la sustitución de notas en los ejemplos musicales, la modificación de las claves y la corrección de las erratas (reiteración de palabras, confusiones en la foliación, etc.) del texto impreso. Casos paradigmáticos son Montanos 1648 BNM R/14492, Torres BUZ An-7-5-13(2) y Monserrate 1614 BUZ An7-5-13(1). En Montanos 1648 BNM R/14492 las hojas de guarda inicial y final están completamente anotadas por varias manos, mostrando una lectura crítica y utilitaria:

\footnotetext{
39 James Haar, "Lessons in Theory from a Sixteenth-Century Composer", en Essays on Italian Music in the Cinquecento, ed. por Richard Charteris (Sydney: Fredrick May Foundation for Italian Studies, 1990), pp. 51-81.

${ }^{40}$ Para referir a los diferentes ejemplares de forma abreviada en el análisis de los indicios de su uso, utilizaré el sistema Autor-Fecha-Biblioteca-Signatura (véanse las abreviaturas del Apéndice 1).
} 
encontramos anotaciones en latín, un resumen en español bajo el título "Llaue real para solphear, quando ay mutanças en el canto", el nombre de las voces ("vaxo, tenor, tiple, alto; contralto, falsete") y una referencia a la práctica de la época ("Nota como los nueuos solphistas de ahora al baxar de el canto dicen como los antiguos fa, sol, la: en las mutanzas"), entre numerosas anotaciones. En el cuerpo del libro son frecuentes las anotaciones en los márgenes comentando y ampliando lo establecido en el texto de Montanos y las correcciones de los ejemplos musicales (como en la p. 16 y ss., incluso indicando "error de imprenta"). Los inidicios de uso hallados en Torres y Monserrate 1614 BUZ An-7-5-13 (principalmente en el tratado de Monserrate), encuadernados juntos y anotados por la misma mano, muestran una lectura altamente crítica, con numerosas correcciones y ampliaciones, y más reciente, como evidencia la aparición de las claves modernas (véase Ilustración IV.1). Los casos de correcciones en los ejemplares de artes de canto consultados son muy numerosos; la Tabla IV.2 presenta algunos ejemplos. 
Ilustración IV.1: Anotaciones que amplían y actualizan el contenido en Andrés de Monserrate, Arte breve y compendiosa de las dificultades que se ofrecen en la musica practica del canto llano (Valencia: Pedro Patricio Mey, 1614), p. 59.

Zaragoza, Biblioteca de la Universidad de Zaragoza, An-7-5-13(1).

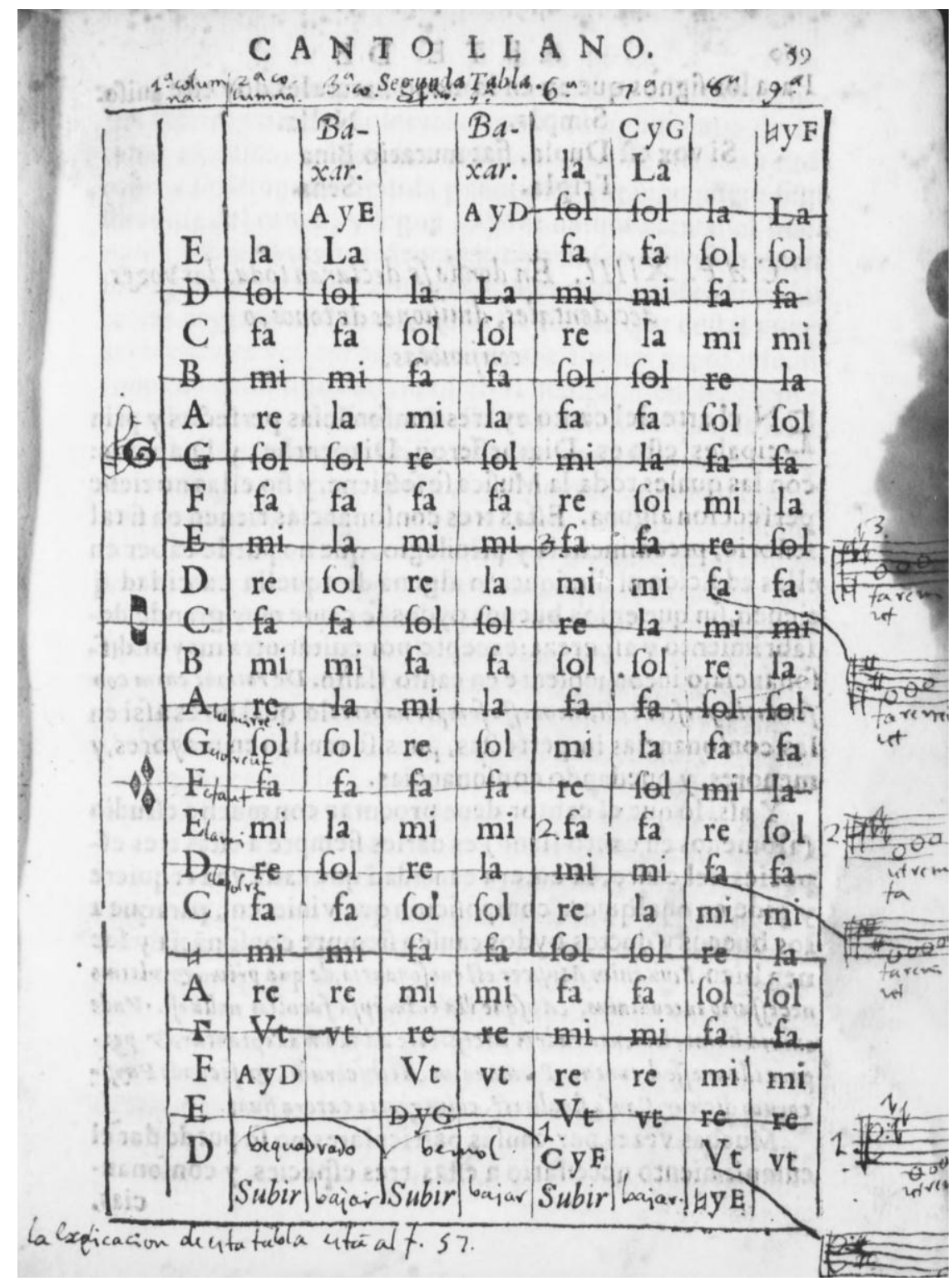


Tabla IV.2: Adiciones y correcciones en algunos ejemplares de artes de canto

\begin{tabular}{ll}
\hline Ejemplar & Correcciones \\
\hline
\end{tabular}

Bermudo 1550

BUO A-178

[Miscelánea]

BNM INC/2165

Cervera 1595

BC M1324

Monserrate 1614

BNM R/9666

Montanos 1592

BNM M/2831

Montanos 1592

BNM R/9503

Montanos 1592

BUO A-208
Anot. al margen: "siendo las dos para subir, i si las dos son para descender, la primera es de Bmol" (f. 7r).

[El volumen perteneció a Barbieri]

Maño señalando dibujada a plumilla (a veces palabras subrayadas) a lo largo de todo el volumen (ej. ff. 80r-83v, 86v-88v, 177v-120v).

Añadido de T capital en rojo (f. 91v).

3 pautados manuscritos con notación manuscrita (pp. 4, 7).

Corrección de la clave (p. 32).

En una hoja inserta con bolígrafo negro se han copiado los íncipits de primer tono que faltan.

Anotación al principio de los íncipits tertiux tonus (p. 67).

Se añaden alteraciones accidentales a algunas notas (pp. 70, 75).

Anot. en el margen superior: "las llabes" (p. 71).

Se completan los signos (p. 16).

En el texto se señalan dos párrafos, en el margen inferior se anota "diapason de $8^{\circ}$ Diapente de $5^{\circ}$ diatesaron de $4^{\prime \prime}$ (p. 19).

Anot. en el margen izquierdo: " $1^{\circ}, 3^{\circ}, 5^{\circ}, 7^{\circ}$ maestros los demas son discipulos" (p. 22).

En el ejemplo musical se anota sobre cada fragmento "b [becuadro], natura, bmol" (p. 42).

Anot. en el margen izquierdo con respecto al ejemplo musical (p. 84).

Anot.: "longo" (p. 111).

Corrección de errata en "Quando": tachado "ndo", escrito "tro" (se refiere a los "quatro maestros" y los "quatro discipulos") (Canto llano, f. 20).

Corrección de la notación de las figuras en el ejemplo musical (Canto de órgano, f. 4).

Correcciones en la notación musical (Contrapunto, ff. 25v, 26, 27).

Corrección: se tacha "darla, pues" (Prólogo, f. 4v): [...] no se desdeñen de leer authores, y saber darla, pues raçones mias y agenas, para saber dar la, pues dize el Sabio en los Prouerbios: Audiens sapiens sapientior erit $[\ldots] "$.

A partir del f. 20 se corrige el número de folio $(16 \rightarrow 20$, etc.).

Corrección de las claves en el ejemplo musical (f. $4 \mathrm{v}$ ).

Se escribe re en lugar de si en el ejemplo musical (f. 14r).

Tachado en el margen: "Tethracordos que sean" (f. 30v).

Anot. en la hoja de guarda a lápiz: "edicion principe Salva 2535 es muy notable en este arte el tratado de compostura (Menendez Pelayo (ciencia [...]) first edition".

Anot. en el verso de la hoja de guarda a plumilla: "Este Montanos creo que fue quien publico parte del Romanzero General". Se hace una lista de algunos de los autores de los sonetos en alabanza de Montanos incluidos en el Arte de musica. 


\begin{tabular}{|c|c|}
\hline Ejemplar & Correcciones \\
\hline $\begin{array}{l}\text { Montanos } 1640 \\
\text { BNM M/42 }\end{array}$ & $\begin{array}{l}\text { Anot. en el verso de la hoja de guarda con letra de Barbieri: “(¿Publicado } \\
\text { sobre el 1640?)”. Las hojas están cortadas y no se ve el año en la porta- } \\
\text { da. } \\
\text { Añadido entre líneas a la lectio prima del ofico de difuntos: "pecaui quid } \\
\text { faci [...]” (p. 135). } \\
\text { Corrección de palabras en latín (p. 137). }\end{array}$ \\
\hline $\begin{array}{l}\text { Montanos } 1648 \\
\text { BC M912 }\end{array}$ & $\begin{array}{l}\text { Corrección de la música y añadido de bemol (p. 17). } \\
\text { Corrección de la música y anot. al margen inferior: "Endos Endos End" } \\
\text { (p. } 65) \text {. } \\
\text { Corrección de la música (p. } 70) \text {. } \\
\text { Corrección de las claves (p. } 87 \text { ). } \\
\text { Frecuente corrección del custos (ej. p. 89). }\end{array}$ \\
\hline $\begin{array}{l}\text { Montanos } 1648 \\
\text { BNM R/9505 }\end{array}$ & $\begin{array}{l}\text { Anot. en la hoja de la tasa: "Primus cum sexto fa, sol, la semper habetur } \\
\text { Tertius et octauos ut re mi fa atque seuinous fa fa quintus, la quartus ut } \\
\text { sol septimus etc". }\end{array}$ \\
\hline $\begin{array}{l}\text { Montanos } 1665 \\
\text { BNM R/31415 }\end{array}$ & Se cambia la clave de do por la de fa en dos ejemplos musicales (p. 8). \\
\hline $\begin{array}{l}\text { Montanos } 1665 \\
\text { BUB XVII-1616 }\end{array}$ & $\begin{array}{l}\text { Tachado un neuma de tres notas y desplazamiento del texto al neuma } \\
\text { anterior (p. 65). }\end{array}$ \\
\hline $\begin{array}{l}\text { Montanos } 1712 \\
\text { BNM M/1781 }\end{array}$ & $\begin{array}{l}\text { Anot. en la hoja de guarda: “Consonancias y proporciones"; [diagrama]; } \\
\text { [lista]: } \\
-\quad \text { tercera menor }-6 / 5 \\
-\quad \text { tercera mayor }-5 / 4 \\
-\quad \\
-\quad \text { quarta }-4 / 3 \\
-\quad \text { quinta }-6 / 4 \\
-\quad \text { sexta mayor }-5 / 3 \\
\text { octava }-6 / 3\end{array}$ \\
\hline
\end{tabular}

Otras evidencias que presuponen conocimientos musicales por parte del usuario son la inserción de ejemplos musicales manuscritos (Montanos 1592 BNM R/9503) y la indicación de referencias bibliográficas, en ocasiones muy posteriores a la fecha de publicación del ejemplar en el que aparecen, lo que demuestra el uso prolongado de estos libros. Por ejemplo, en Monserrate 1614 BUZ An-7-5-13(1) se añaden a mano constantes referencias a otros autores y repertorios musicales: Melchor de Torres, Arte ingeniosa de música (1544, reimp. 1554, 1559, 1566; en p. 56); “Antifonario impreso en Venecia año 1579" (en el verso de la portada), ${ }^{41}$ Pietro Cerone, El Melopeo y Maestro (1613; en pp. 85-87 y 118, véase Ilustración IV.2a); Pablo Nassarre, Fragmentos musicos

${ }^{41}$ Podría tratarse del Antiphonarium sacrosancte Romane Ecclesie integami et completimi iuxta ordinem novi Breviarii ex decreto sacrosancti Concilii Tridentini restituii (Venecia: Peter Liechtenstein, 1579). 
(1683 y 1700; en p. 102) y Escuela musica (1723-1724; en pp. 83 y 104; véase Ilustración IV.2b); y Antonio de la Cruz Brocarte, Medula de la musica theorica (1707; en p. 47).

Ilustración IV.2a: Andrés de Monserrate, Arte breve y compendiosa (1614), p. 85. Una anotación en el margen derecho ("Cerone trae esto mismo f. 448 y 438 ") refiere al tratado de Pietro Cerone, El Melopeo y Maestro (1613).

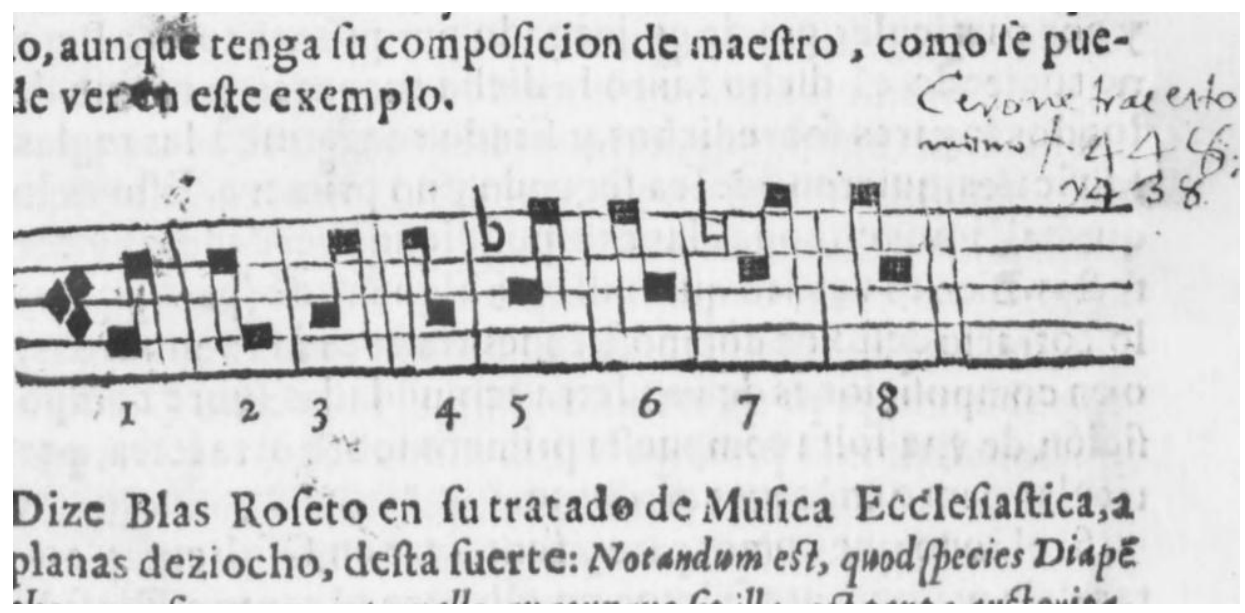

Ilustración IV.2b: Andrés de Monserrate, Arte breve y compendiosa (1614), p. 102. Una anotación en el margen superior ("vide fragmentos musicos f. 27") refiere a la obra de Pablo Nassarre, Fragmentos musicos (1683 y 1700).

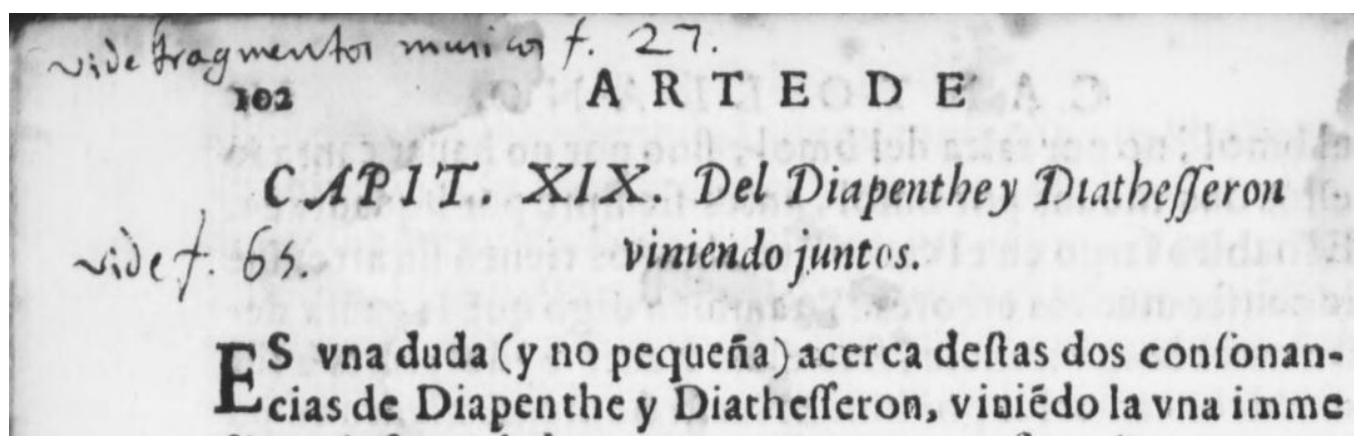

En Montanos 1648 BNM R/14492 encontramos un ejemplo emblemático del uso de artes de canto por parte de usuarios con conocimientos musicales; en una anotación en la hoja de la tasa se hace referencia a otra edición, más correcta, de la misma obra: 
“el bueno es el impreso en Salamanca año de 1610 porque este tiene muchos yerros de Imprenta". Además, en la hoja de guarda, anotada por varias manos, se leen títulos y autores de tratados de música: "Ceron de Musica. el Porque de la musica tobar, ziruelo, franchino, Tapia Vergel de Musica Numantino Impreso en Osma / P. Athanasio Kircherio Jesuita dos tomos Musurgia / Antiphonario [...] el P. Fr. Antonio Martin y coll”. Estas anotaciones no sólo confirman el uso de los tratados de Tovar, Ciruelo y Tapia hasta al menos el siglo XVIII -puesto que se hace referencia al Arte de canto llano (Madrid, 1714) de Antonio Martín y Coll- sino también al uso de tratados internacionales de Franchino Gaffurius y Athanasius Kircher. De particular interés es el comentario que hizo el anónimo lector a la mano guidoniana de este ejemplar (f. 1v; véase Ilustración IV.3), ya que confirma la vigencia del tratado de 1530 de Juan Matínez en el siglo XVIII: "Esta explicacion no corresponde con la mano, ni la Musica de Guidon Aretino; porque se hizo con fin de quitar al canto llano las vozes Graues; Vease el Arte del Seuillano Juan Martinez”. En las anotaciones de los ejemplares de artes de canto analizados también encontramos referencias a Palestrina (Montanos 1592 BNM R/9503, f. 15), Boecio (Montanos 1592 BNM M/M2831, f. 8v; Monserrate 1614 BUB 07 XVII-6259, p. 13); Guido (Bermudo 1549 BNM R/3646, f. 68r; Monserrate 1614 BUB 07 XVII6259, pp. 32 y 36); y Monserrate (Torres 1566 BUZ An-7-5-13). 
Ilustración IV.3: Indicios de uso en Francisco de Montanos, Arte de canto llano (Madrid: Imprenta Real, 1648 [1594]), f. 2v. Madrid, Biblioteca Nacional de España, R/14492.

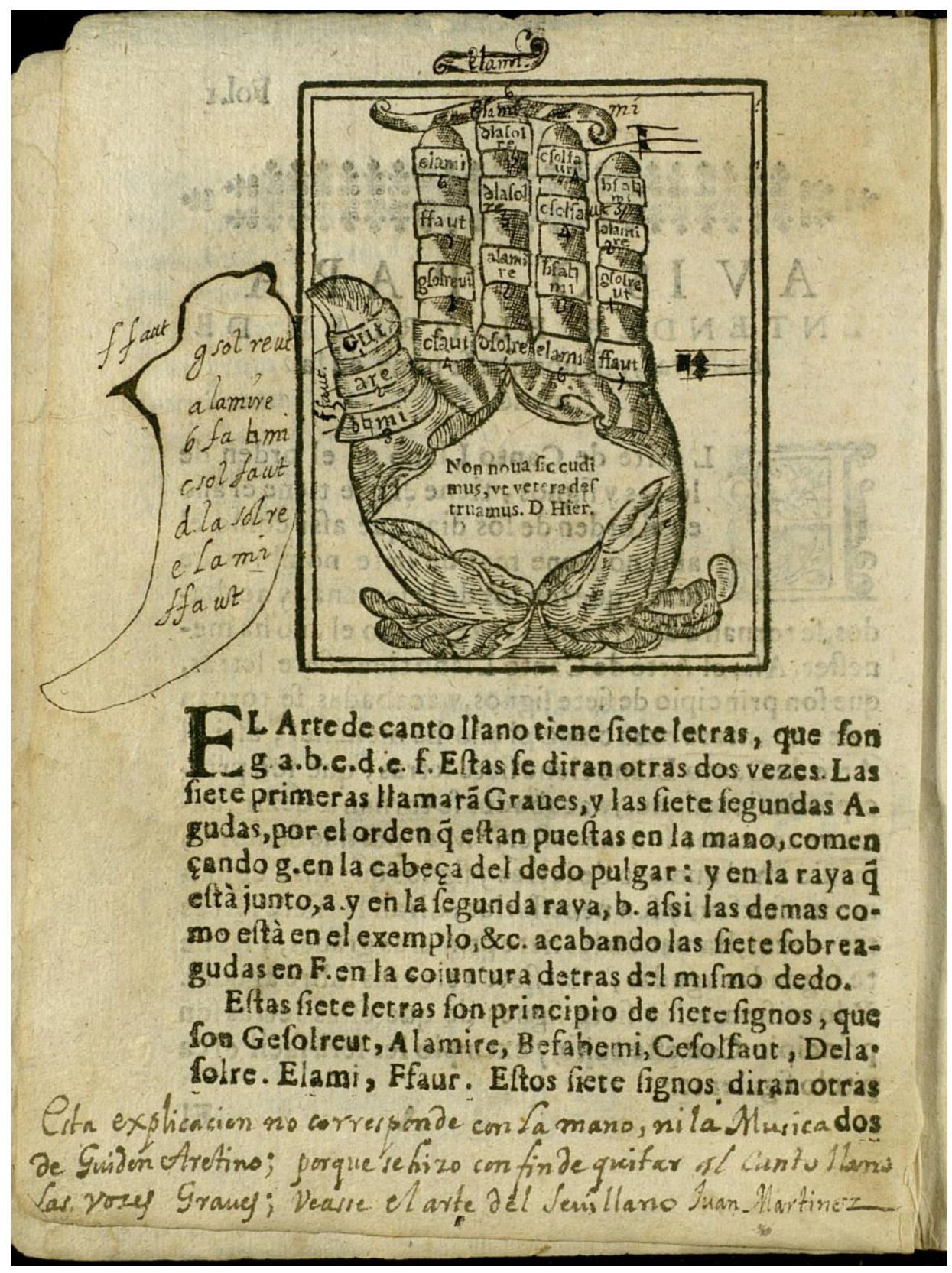

Indicios de uso que indican el empleo de las artes de canto como material didáctico son los subrayados y la inserción de hojas con ideas clave a modo de marca páginas. Encontramos ejemplos de subrayados en Martínez de Bizcargui 1528 BNM R/9702 (ff. D6v, D5, A8r, A7v, A7r, A6v, A6r, A5v, A3, A2v y A2r), Montanos 1648 BNM R/14492 (en el f. 1r se rodean dos líneas y media) y Montserrate BU 07 XVII-6259 (pp. 12 y 13). Son sumamente frecuentes las anotaciones de palabras clave manuscritas en 
los márgenes que permiten descifrar el contenido del texto y sus ideas fundamentales con un simple golpe de vista (Aranda 1533 BPE Res. $n^{\circ} 402$ y Villegas 1604 BNM $\mathrm{R} / 37433$ ). En ocasiones, estas palabras se acompañan de trazos que abarcan varias líneas de texto; una muestra aparece en Artufel 1614 BNM R/13944. También Guevara 1582 BNP RES-V-2478 contiene numerosas anotaciones a modo de comentarios al margen y subrayados. En los ejemplares de artes de canto se conservan a menudo pequeñas hojitas usadas como marca páginas o como leyenda. Por ejemplo, en Monserrate 1614 BUB 07 XVII-7515 encontramos dos de estas hojas con sus respectivas anotaciones, la segunda en catalán: 1) "G sol re ut / A la mi re / B fa mi / C sol fa ut / D la sol re / E la mi / F fa ut"; y 2) "Se pregunta: Si hi ha Jindulgencia [sic] Plenaria concedida para los que asistira als 4 sermons dels 5 missionals f.".

\subsubsection{ANOTACIONES QUE INDICAN USO PRÁCTICO POR PARTE DE PRINCIPIANTES}

En ocasiones, encontramos evidencia externa de uso en las artes de canto que sugiere que los usuarios se estaban iniciando en la música: indicación de números en la mano guidoniana (Monserrate 1614 BNM R/12147); escritura de los nombres de las notas en los ejemplos musicales (Artufel 1614 BNM R/13944; Montanos 1648 BNM R/14492, pp. 7 y ss.); anotaciones en los márgenes a modo de pruebas de caligrafía de las notas musicales (Martínez de Bizcargui 1515 BNM R/9405, ff. C8v, D1r y D8v); y líneas que unen las notas de un ejemplo musical con su correspondiente sílaba de texto cuando la línea textual ha quedado ligeramente desplazada con respecto al ejemplo musical (Torres 1566 BUZ An-7-5-13[1]). Estos indicios apoyan la tesis de Susan F. Weiss según la cual los manuales de canto llano no fueron utilizados únicamente por maestros como herramienta docente sino también por los estudiantes (véanse Ilustraciones IV.3a y IV.3b). 
Ilustración IV.4a: Anotaciones de estudiantes en Dámaso Artufel, Arte de canto llano, en Modo de rezar las horas canonicas (Valladolid: Iuan Godinez de Millis, 1614), f. 17v. Madrid, Biblioteca Nacional de España, R/13944.

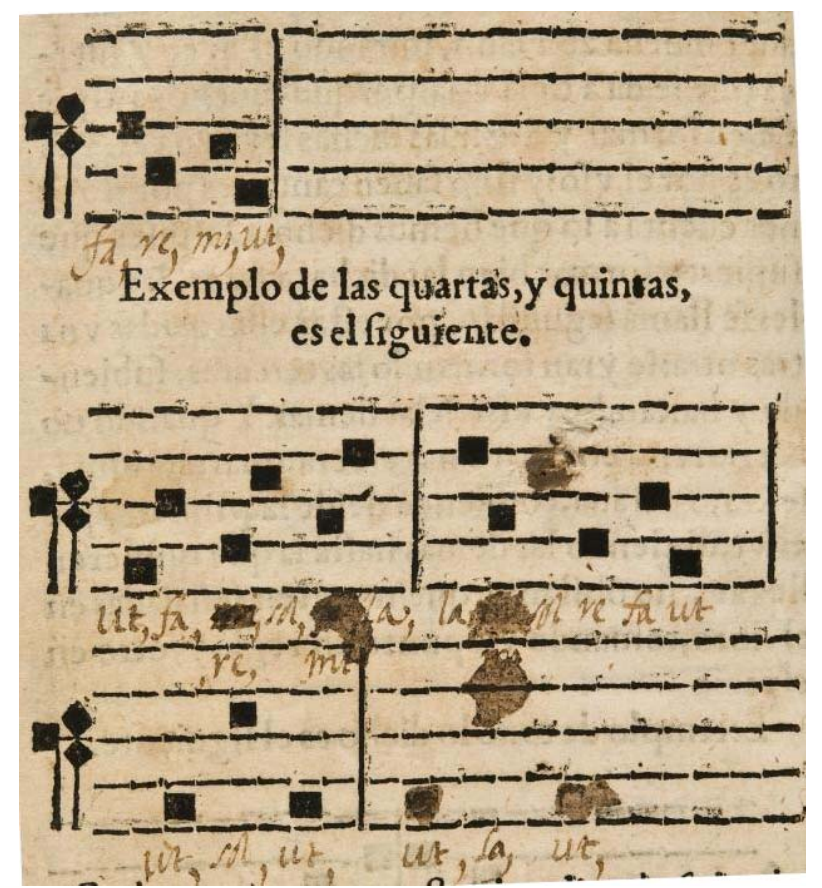

Ilustración IV.4b: Evidencia de uso por parte de principiantes en Melchor de Torres, Arte ingeniosa de musica (Alcalá de Henares: Pedro de Robles y Juan de Villanueva, 1566 [1544]), f. 6 r. Zaragoza, Biblioteca de la Universidad de Zaragoza, An-7-5-13(2).

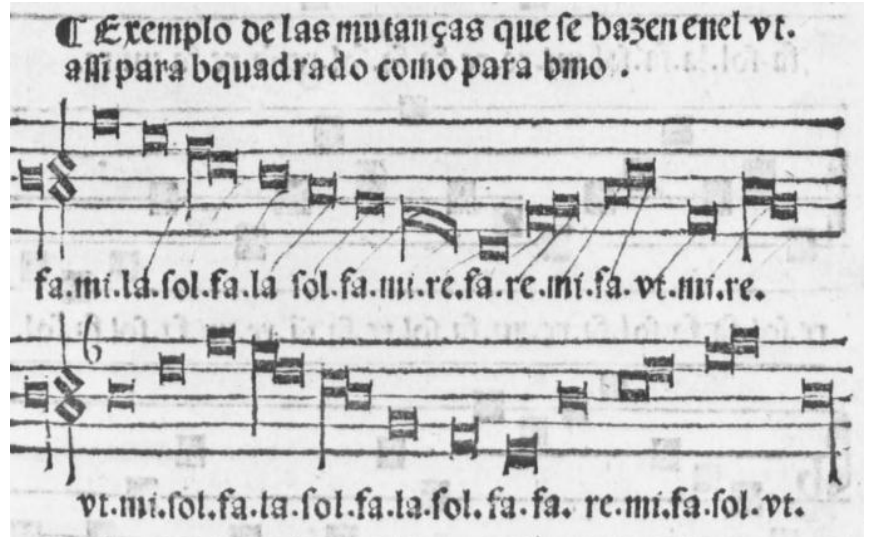

\subsubsection{USO COMO FUENTE DE REPERTORIO MUSICAL}

Las evidencias de uso de algunos ejemplares muestran que las artes de canto no sólo se utilizaron para aprender los fundamentos de la música y para enseñarlos, sino también como soporte material de un determinado repertorio musical. Por ejemplo, en 
Montanos 1640 BNM R/4054 no encontramos vestigios de uso en el "arte de canto llano" en sí, sino en los cantos anexados para practicar y, de ellos, en secciones muy concretas; las anotaciones corrigen algunos sonidos (pp. 37, 45, 50, 54, 57, 58, 69, 73, 77, 81 y 82). Esto no es sorprendente, ya que, como se indicó en el Capítulo I, precisamente con respecto a las reediciones del Arte de canto llano (1594) de Montanos, el “arte de canto llano" se usó como una introducción a la que ir añadiendo nuevo repertorio. Es bastante ilustrativo el que los únicos indicios de uso hallados en Montanos 1648 BNM M/1780 estén localizados en la "Missa del Angel Custodio" (en las pp. 62-64 se corrigen tres notas, mientras que en la p. 65 se corrige el texto reemplazando la "s" final de "himnus" por una "m"), anunciada desde la portada como la novedad de estas nuevas ediciones a partir de 1616.

\subsubsection{PISTAS SOBRE EL POSEEDOR/A DEL EJEMPLAR}

Los vestigios del uso de las artes de canto también proporcionan indicaciones del propietario del ejemplar y, en ocasiones, de su contexto institucional, como el ejemplar Montanos 1686 BUS A 133/045, propiedad del Convento de San Diego de Sevilla (véase Ilustración IV.5). Por tanto, el análisis de la evidencia externa de uso de los libros constituye una metodología apta para complementar el estudio del mercado potencial de las artes de canto (llevado a cabo mediante el vaciado de inventarios de bienes en el Capítulo II) e incluso para determinar la valuación de estos libros gracias a anotaciones en las que se indica el precio. 
Ilustración IV.5. Ejemplar que perteneció a la biblioteca del Convento de San Diego de Sevilla. Francisco de Montanos, Arte de canto llano (Madrid: Iuan Garcia Infanzon, 1686 [1594]), portada y tasa. Sevilla, Biblioteca de la Universidad de Sevilla, A 133/045.
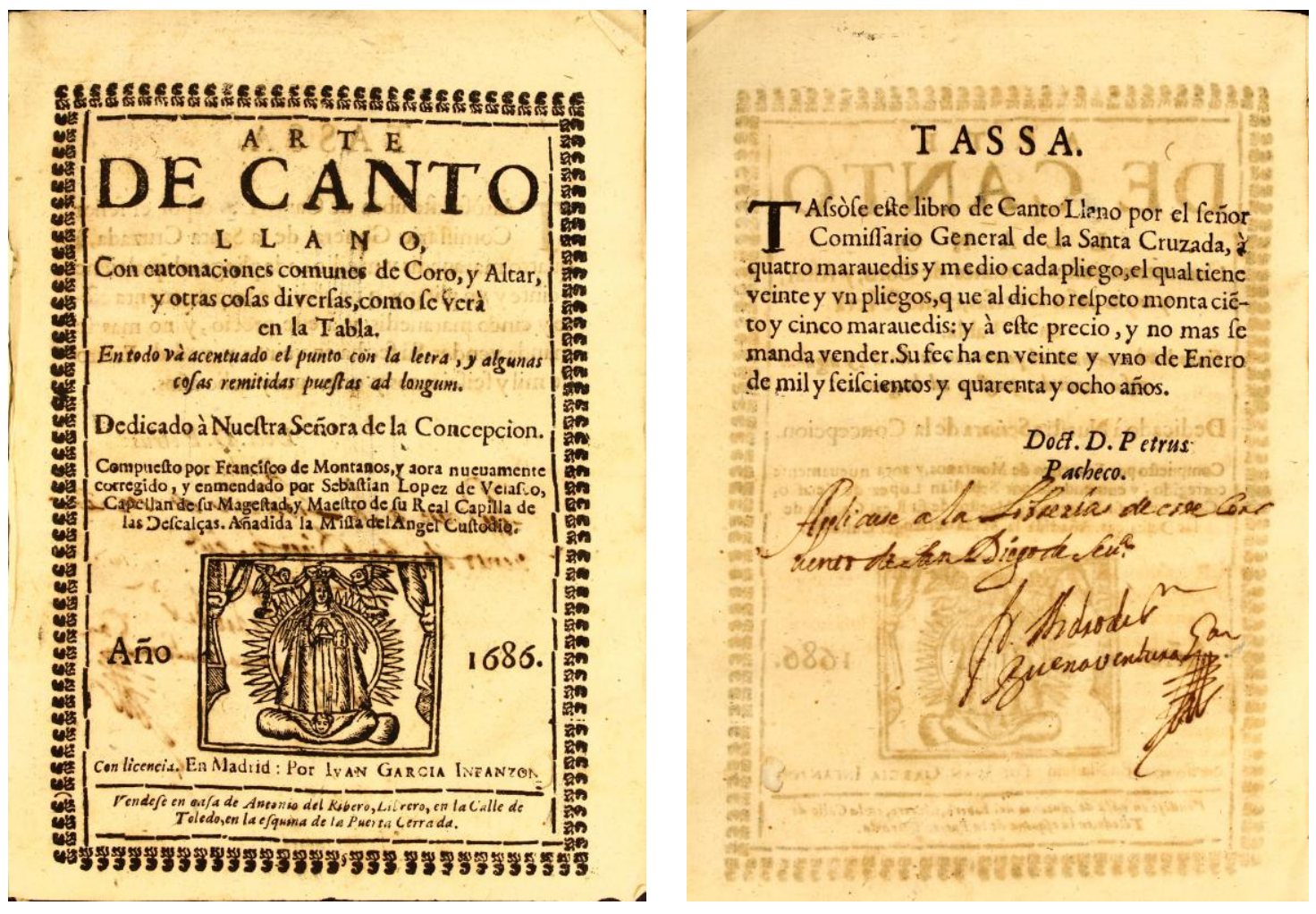

La Tabla IV.3 muestra que muchas de las artes de canto que se han conservado hasta la actualidad pertenecían a coleccionistas, estudiosos o bibliófilos (como Bartolomé Gallardo o Francisco A. Barbieri), pero también a usuarios de ambos géneros y a congregaciones religiosas. Por ejemplo, encontramos los nombres de las religiosas Sor Teresa y Sor Maria Benita Bassecourt en copias del libro de Artufel de 1614 y el de "Rossa Maria de Samo y Serna" en un ejemplar de la edición de 1648 del Arte de canto llano (1594) de Francisco de Montanos. ${ }^{42}$

\footnotetext{
${ }^{42}$ En el caso de Sor Maria Benita Bassecourt, podría tratarse de Sor Maria Benita Bassecourt y Briás, religiosa del Convento de Nuestra Señora de los Ángeles de Barcelona, que firmó un documento fechado en 1772 recogido en Josep Climent, Coleccion de las obras del Ilustrisimo señor don Joseph Climent del Consejo de su magestad y Obispo de Barcelona (Madrid: Imprenta Real, 1788), p. 158.
} 
Tabla IV.3: Indicaciones sobre el poseedor/a en algunos ejemplares de artes de canto

\begin{tabular}{|c|c|}
\hline Ejemplar & Anotación \\
\hline Artufel 1614 BC M1317 & Anot. f. 20v al margen: "Sorteresa". \\
\hline Artufel 1614 BC R(2)-8-484 & $\begin{array}{l}\text { Anot. hoja de guarda: "Es per us de Sor Maria Benita } \\
\text { Bassecourt". }\end{array}$ \\
\hline Bermudo 1549 BUO A-178 & $\begin{array}{l}\text { Anot. verso de la hoja de guarda inicial: "Escritor sesu- } \\
\text { do, castizo i profundo filosofo. Esta calificacion es de } \\
\text { D. Bartolome Gallardo a quien pertenecio este libro". } \\
\text { Anot. f. } 11 \mathrm{v} \text { del material preliminar: "\#Bernardino de". } \\
\text { Anot. f. 12r del material preliminar: "\# D. Juan Tellez } \\
\text { Jiron, Conde de Urueña". } \\
\text { Anot. hoja de guarda final: "Compró mi padre este libro } \\
\text { en Toledo al heredero de D. Bartolomé Gallardo hacia } \\
\text { el año de } 1861 . \text { / Labra } 1869 \text { S. de Soto". }\end{array}$ \\
\hline Cervera 1595 BC M1324 & $\begin{array}{l}\text { Anot.: "Joseph Escobar Infançon", } \\
\text { Anot. p. 135: "Michail Jangallo?". } \\
\text { Anot. verso del último folio: "de la mano y pluma de } \\
\text { Joseph [...]". }\end{array}$ \\
\hline Cervera 1595 BC M2237 & $\begin{array}{l}\text { Anot. hoja de guarda: "Mahon [Menorca] Junio } 1809 \text { / } \\
\text { Antonio Pruby y Somila". } \\
\text { Anot. hoja de licencias (margen inferior): "nombre aqui } \\
\text { bajo lo pondre Pablo angles de Cenfis [?]". }\end{array}$ \\
\hline Cervera 1595 BUB 07 CM-2364 & $\begin{array}{l}\text { Anot. portada: “ex Congregationy Sti Philipi }[\ldots] \text { Bar- } \\
\text { cin”. }\end{array}$ \\
\hline Cervera 1595 BUV Z-13/32 & $\begin{array}{l}\text { "Legado por D. Vicente Hernandez y Mañez a la biblio- } \\
\text { teca de la universidad literaria de Valencia". }\end{array}$ \\
\hline Espinosa 1520 BNM R/15124 & $\begin{array}{l}\text { Sello de las hojas de guarda: "Comisario General de la } \\
\text { Santa Cruzada D. Patricio Minz de Bustos", año de } \\
\text { 1796, "Sumario de tercera clase". }\end{array}$ \\
\hline Fernandes 1626 BNM M/184 & $\begin{array}{l}\text { Anot. hoja de guarda: "Lisboa } 20 \text { de Setiembre / P. de } \\
\text { Gayangos / Me lo reg[a]ló el mismo Gayangos en } 16 \\
\text { de Enero de } 1868 \text { / Barbieri”. } \\
\text { Anot. portada: "Del Beneficiado Bartolomeu Guerrero } \\
\text { Banadar [?] / Costou 250". }\end{array}$ \\
\hline Marcos Durán 1509 BNL Res. 378P & Perteneció a los monjes de Santiago de Palmela. \\
\hline Marcos Durán 1518 LC 23-4270 & Perteneció a la biblioteca de Juan M. Sánchez. \\
\hline Martínez de Bizcargui 1515 BNM R/9405 & $\begin{array}{l}\text { Firmas de "Fray Melchior" (portada, ff. B8v, C1r, C8v, } \\
\text { D1r) y "Almeyda" (f. D4v). }\end{array}$ \\
\hline Molina 1503 BUV U/Bc IyR 265 (1-3) & $\begin{array}{l}\text { "Es de la Casa professa de la Comp[añi]a de Vall[adoli]d } \\
\text { y su librería" }\end{array}$ \\
\hline Monserrate 1614 BUB 07 XVII-1715 & Anot. hoja de guarda: "Nos don f. Julian de [...]". \\
\hline
\end{tabular}




$\overline{\text { Ejemplar }}$ Anotación

Monserrate 1614 BUB 07 XVII-6259

Monserrate 1614 BNM R9666

Monserrate 1614 BUZ An-7-5-13

Monserrate 1614 BC M235

Montanos $1592 \mathrm{BNM} \mathrm{M/2831}$

Montanos 1598 BNM R/9503

Montanos 1610 BC M1009

Montanos 1640 BNM M/42

Montanos 1640 BNM R/4054

Montanos 1648 BC M912

Montanos 1648 BUS BG/29166

Montanos 1665 BU XVII-1616

Montanos 1670 BC M249
Anot. portada: "Es de la biblioteca mariana del convento de San Francisco de Barcelona".

Anot. portada: "Pedro"

Anot. p. 124: "Juan".

Anot. verso de la hoja de guarda final: "Fray Andres Matheos Ibañez y Baena Dia 9 de diciembre de 1762 años. Dominico".

Anot. portada: "fr. Sebastián de Arizaleta".

Anot. hoja de guarda: "Don Antonio [...] / De Don Joseph Don[oro?] / Juan Villel Don Ro[roto] / Don Manuel Don Jua[roto] / Miguel Entrena / Joseph Sanchez".

Anot. p. 82: "Antonio San antonio de la Don Joseph Donoro y Gobierno".

Anot. hoja de guarda inicial: "Es de Salvador Farriols Musich".

Anot. verso de la portada: "Lisboa 1846".

Sello: "Livraria da alcoba ca".

Anot. hoja de guarda 1: "Del $[\ldots]$ por $[\ldots]$ concejo de $[\ldots]$ parroquia sanante $[. .$.$] en el lugar de [. .$.$] que$ adeven almia $[\ldots]$ fran[...] diez y [...] diez y ie[...]"; "Luis casado" (otra mano).

Anot. hoja de guarda 2: "Si estte lybro se perdiere como suele acontezer sepase que es de Ysidoro [...] Natural de launadalga [¿Laguna Dalga (León)?]” [Firma].

Anot. dedicatoria: "Soy del uso de fray [...]"; "fr. Salvador" (otra mano).

Anot. hoja de guarda: "Aques llibre es de Don [...] de Cancer 16 de Junio 1693".

Anot. portada: "De Cancer n ${ }^{\circ} 20$ "

Anot. última página (margen derecho): "Martin".

Anot. verso de la hoja de guarda: "Este 'arte' de cantollano es de Manuel Phelipe de Otea".

Anot. portada: "Es de Thomas Garcia de la [...]". Firmas de "Joseph Izquierdo Clerigo de Prados" (pp. $104,130,131,136,138,163)$.

Anot. portada: "D ${ }^{a}$ Rossa Maria de Samo y Serna".

Anot. portada: "ex libris franci[...] de A[... 1727".

Marca páginas inserto con anot.: "Señor Bruno Parera Escola de cant de la Capella de Sta Maria".

Anot. hoja de guarda final: "Anton [...] escola de Montserrat". 


\begin{tabular}{|c|c|}
\hline Ejemplar & Anotación \\
\hline Montanos 1686 BUS A 133/045 & Anot. bajo la tasa: "Convento de San Diego de Sevilla". \\
\hline Montanos 1693 BNM R/14484 & $\begin{array}{l}\text { Anot. hoja de guarda: "Llibre de Solfa de Joseph Serrali- } \\
\text { d"”, "Llibre de Campla [...] de Joseph Serra [...]". }\end{array}$ \\
\hline Montanos 1712 BNM M/1781 & Anot. p. 42: "Don Francisco Muñoz". \\
\hline Montanos 1712 BNM R/9525 & $\begin{array}{l}\text { Anot. verso de la portada: "licinciado [...] de cortazar". } \\
\text { Anot. hoja de la tabla: "licinciado [...] de cortazar". } \\
\text { Anot. p. } 15 \text { (margen superior): "de los padres de la [...]". } \\
\text { Anot. p. 252: "Don Juan de Casti". }\end{array}$ \\
\hline Montanos 1756 BC M163 & $\begin{array}{l}\text { Anot. hoja de guarda: "Jose Val, Antonio Cattar?"; "En } \\
21 \text { de mayo de } 1799 \text { se colocaron estas lineas prosice". } \\
\text { Anot. verso de la portada: "De Mariano Aznarez natural } \\
\text { de [palabra con mancha de tinta] de los Caballeros re- } \\
\text { sidente en Huesca". } \\
\text { Anot. hoja de guarda final: "Lorenzo Soler, Pepe Soler, } \\
\text { Josef, Carlos, Pedro Juan, Serbia con paciencia". }\end{array}$ \\
\hline Villegas 1604 BNM R/37433 & $\begin{array}{l}\text { Anot. p. 80: "Don Pedro delgadillo Arriola"; "don Jorge } \\
\text { Delgadillo Arriola". }\end{array}$ \\
\hline
\end{tabular}

Por tanto, las evidencias que indican a quién pertenecieron estas artes de canto complementan la información presentada en el Capítulo II acerca de su mercado potencial y apoyan la hipótesis de que estos libritos eran manuales de música de nivel básico y no solamente libros para aprender a cantar el Oficio Divino. Por ejemplo, la Tabla IV.3 mostraba una anotación encontrada en Montanos 1693 BNM R/14484 en la cual se describe el libro como "Llibre de Solfa". Encontramos vestigios de uso que apoyan otras hipótesis presentadas anteriormente en este trabajo, puesto que suponen indicios de intersección entre lo profano y lo religioso, indicaciones de valuación, y evidencia de la amplia vigencia cronológica del contenido de estos manuales. Por ejemplo, Cervera 1595 BC M1324 incluye poemas profanos anotados por uno de sus propietarios a continuación del poema impreso de San Gregorio dedicado a la música:

Dime papel que te bas Amanos por quien jo muero Dile papel que tal quedo Pues jo quedo y tu te bas De dios nos bino el bien De las salinas la sal 


\begin{abstract}
De las abexas la miel
De las mugeres el mal

B. si para tu padre no dime para quien
\end{abstract}

El propietario del libro vuelve a anotar la cuarteta ("De dios nos bino...") en la página 62 (no impresa), seguida de un poema que se localiza en fuentes italianas de poesía musicada:
A las espaldas de un monte
Y el monte no tiene espaldas
Llorava un Pastorcito
Porque se le ivan las Cabras ${ }^{43}$

Otro ejemplo de la incursión de elementos profanos en las artes de canto se encuentra en Montanos 1648 R14492, puesto que en este ejemplar aparece una referencia al repertorio popular no litúrgico; en la hoja de guarda inicial encontramos la anotación "interpretaran ba la burra". Además, en las artes de canto localizamos indicaciones de valuación en diferentes épocas. Por ejemplo, en Martínez de Bizcargui 1515 BNM R/9405 aparece anotado: "la edicion de Burgos (1515) se ha vendido en Paris (en 1878) en 905 frs (col. Miró)". En Fernandes 1626 BNM M/184 se indica que "Costou 250". Por último, en los ejemplares analizados encontramos indicios de que las artes de canto renacentistas han sido utilizadas durante un largo período temporal, en particular las artes de canto llano, por la vigencia de su contenido. Además de los casos ya presentados en la Tabla IV.3 y de las anotaciones de fechas que llegan hasta el siglo XIX (por ejemplo, “Año 1812” en Monserrate 1614 BUZ An-7-5-13[1]), señalaremos dos casos más: 1) Cervera 1595 BUV Z-13/32 tiene páginas manuscritas que contienen las claves modernas y la notación actual; y 2) Montanos 1610 BNM M/95 contiene en su interior dos trozos de papel sueltos a modo de marca páginas con anotaciones; en la primera

\footnotetext{
${ }^{43}$ El primer verso de este poema ("A las espaldas de un monte”) aparece en cinco ocasiones en Mariano Lambea, Nuevo Íncipit de Poesía Española Musicada (NIPEM), con la colaboración de Lola Josa y Francisco A. Valdivia (Alicante: Biblioteca Virtual Miguel de Cervantes, 2010), p. 41. Según el catálogo de Lambea, este íncipit aparece en cinco fuentes italianas: cuatro manuscritos de Florencia (con cifra), el Libro dell'ill.mo Conte Paolo Canossi, y en María Teresa Cacho, "Manuscritos españoles en la Biblioteca Civica de Verona", Quaderni di lingue e letterature, 18 (1993), pp. 211-224. Véase también María Teresa Cacho, Manuscritos hispánicos en las bibliotecas de Florencia: descripción e inventario (Firenze: Alinea, 2001), vol. 2, p. 489. Una variante de este poema aparece en Pedro Vacas Moreno, Romancero de pastores (Madrid: Editorial Visión Libros, 2008), p. 185: “A las espaldas de un monte, / que hasta el monte tiene espaldas, / está llorando un cabrero, / que se le han perido las cabras".
} 
nota se lee: "Este Arte se encontro en la libreria de este de Nuestro P. S. Joseph de Avila, y por el se empezo a aprehender el Canto llano año de 1784"; el papel de la segunda nota parece más moderno, la caligrafía es diferente y la anotación remite al "Ritual blanco" de la congregación como complemento del libro:

El modo de concluir los salmos tanto en la estrella, como en el fin de los Versos vease nuestro Ritual blanco desde la pagina 194, hasta 201: esto es, quando al medio o al fin de los versos acaba la letra en me, te hoc, Ysrrael, Sion, sunt, fac y todas las que no tienen mas que una silaba, le hace como alli lo dice con especialidad en la pagina 200.

Procurese evitar la conclusion de otro modo porque es muy fea. ${ }^{44}$

\subsubsection{APUNTES, RESÚMENES Y TRADUCCIONES: LOS CASOS DEL TRACTAT DE MÚSICA}

(BArcelona, Biblioteca de Reserva de la Universitat de BArCelona, MS2044) Y LA MiCEL·LÀNIA DE TRACTATS MUSiCALS (BARCELONA, BiBlioteCA DE CATALUNYA, Ms. 1325/2)

Además de los indicios de uso que encontramos en los ejemplares de artes de canto tal y como se conservan en la actualidad, contamos con manuscritos que en su día estuvieron relacionados con determinados ejemplares de artes de canto pero que hoy se conservan como documentos independientes. Por ejemplo, se ha advertido el parecido del manuscrito de Santa Eulalia (c. 1679) en lengua náhuatl con las artes de canto peninsulares, en especial, con el Arte de canto llano de Dámaso Artufel y con el Arte de canto llano e contrapunto e canto de organo de Gonzalo Martínez de Bizcargui. ${ }^{45} \mathrm{El}$ caso más evidente que he podido encontrar es el del Tractat de música, un manuscrito datado en el siglo XVI conservado en la Biblioteca de Reserva de la Universitat de Barcelona con la signatura MS2044 (véase Ilustración IV.6). Se trata de un libro en octavo encuadernado en pergamino en cuya hoja de guarda inicial se indica: "Estava relligat al final de B-14/5/18/2367 Gonzalo MARTÍNEZ DE BIZCARGUI Arte de Canto llano. Saragossa, Coci, 1512. NORTON 653. Restaurat taller BUB (Tana Andrades) juny

\footnotetext{
${ }^{44}$ Anotación en hoja de papel inserta en Montanos 1610 BNM M/95.

${ }^{45}$ Lemmon y Horcasitas, "Manuscrito teórico musical de Santa Eulalia", pp. 45-49. Este tratado manuscrito incluye una mano guidoniana y explicaciones sobre los signos, las mutanzas, las claves, los modos y el tempus, y lo que parece el comienzo de una sección sobre polifonía.
} 
1996". ${ }^{46}$ Es decir, el Tractat de música, a pesar de conservarse hoy como un documento independiente, estuvo encuadernado a continuación del Arte de canto llano et contrapunto et canto de organo de Gonzalo Martínez de Bizcargui y, por tanto, pudieron ser propiedad de la misma persona o institución. ${ }^{47}$ Cabe preguntarse si existe alguna relación entre el ejemplar del libro de Martínez de Bizcargui y las anotaciones manuscritas que componen el Tractat de música que aporten nueva información sobre los usos de las artes de canto.

Ilustración IV.6: Tractat de música, MS (siglo XVI), ff. 32v-33r. Barcelona, Biblioteca de Reserva de la Universitat de Barcelona, MS2044.

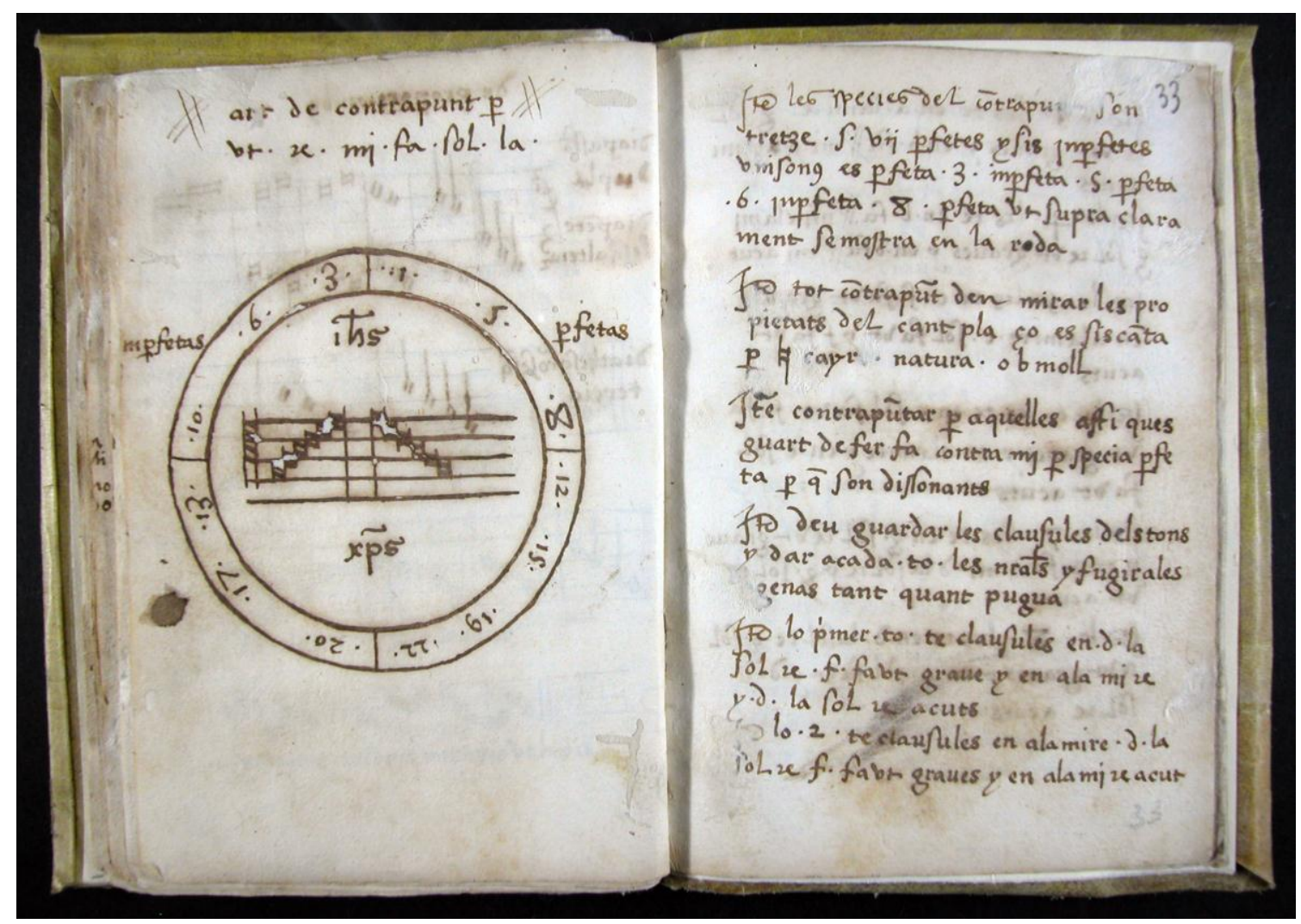

\footnotetext{
${ }^{46}$ En realidad, la signatura 07 CM-2367 corresponde a una edición del libro de Martínez de Bizcargui fechada en 1541.

${ }^{47}$ Isabel Astals Forn, de la Biblioteca de Reserva de la Universidat de Barcelona, indica que estas dos obras se encuadernaron separadamente en 1996. El taller de encuadernación no conservaba entonces las encuadernaciones originales, en contraste con el procedimiento que se sigue actualmente, en que todo el proceso está documentado y se conservan los restos de materiales que se han tenido que sustituir durante la restauración. Por este motivo, se desconoce la procedencia del volumen.
} 
El Tractat de música consta de 4 hojas +1 hoja en blanco +32 hojas con varios tipos de papel y la escritura de diversos copistas. En el recto del primer folio encontramos una mano guidoniana manuscrita, y en su verso la explicación de los tonos (primo, secundus, etc.) y un ejemplo musical con saltos de $4^{\mathrm{a}}, 5^{\mathrm{a}}, 6^{\mathrm{a}}$ y $8^{\mathrm{a}}$. El folio $2 \mathrm{r}$ está escrito en catalán por otra mano y trata de los tonos y semitonos. Los folios $2 \mathrm{v}$ y $3 \mathrm{r}$ contienen ejemplos musicales con las entonaciones de Ite missa est, Benedicamus Domino y Gloria. En los folios $3 \mathrm{v}$ y $4 \mathrm{r}$ encontramos ejemplos musicales sin texto y con notación cuadrada sin rellenar. Los folios $4 \mathrm{v}$ a $5 \mathrm{v}$ están en blanco. Los folios 6r a $11 \mathrm{v}$ fueron escritos por otro copista y en esta sección (en latín y catalán sin ejemplos musicales) comienza a tratarse el contrapunto, en lo que parece la copia o resumen de un manual, puesto que se introducen encabezados concretos correspondientes a capítulos; el texto se organiza en párrafos muy breves: "Capitol primer de las specias del contrapunt quantas y quales son" (f. 8v); "Capitulo iij quantes maneres y a de contrapunt" (f. 9r); "Capitol segon de la subdiuisio de les species" (f. 10r). Al final del folio $12 \mathrm{r}$ se introduce el encabezado "Reglas per saber ordenar la solfa ab la letra" y se continúa con la misma estructuración del texto en párrafos muy breves o ítems a modo de listado. En los folios 13v a 16r, bajo el título "triplex es musica", otra mano señala los tres tipos de géneros, las tres clases de compositio, etc., y se dibuja la escala, así como las claves y los signos de "natural" y “accidental"; en los folios 16v a 27r encontramos de nuevo ejemplos musicales. En los folios $27 \mathrm{v}$ a $28 \mathrm{v}$ se anotan explicaciones de los tipos de tonos, las entonaciones de los salmos, Glorias de responso, Glorias de Oficio, los nombres de los tonos y definiciones según los griegos. El folio 29r está en blanco. Entre los folios 29v y 32r se tratan las figuras del canto de órgano, y entre los folios $32 \mathrm{v}$ y $37 \mathrm{r}$ se vuelve al "arte de contrapunto".

Una primera aproximación al manuscrito sugiere que el Tractat de música podría consistir en un resumen en catalán del Arte de canto llano et contrapunto et canto de organo de Gonzalo Martínez de Bizcargui, puesto que coinciden en la distribución general de los contenidos (canto llano, contrapunto y canto de órgano). Sin embargo, una referencia clara para tomar como punto de partida en la búsqueda de las posibles fuentes utilizadas por el copista de este manuscrito es la indicación de la numeración y títulos de tres capítulos ("Capitol primer de las specias del contra punt quantas y quales son", "Capitulo iij quantes maneres y a de contrapunt" y "Capitol segon de la subdiuisio 
de les species"). ${ }^{48}$ Estas indicaciones coinciden exactamente con los correspondientes capítulos de la Sumula de canto de organo, contrapunto y composicion (Salamanca, c. 1504) de Domingo Marcos Durán: "Capitulo primero de las species del contrapunto quantas y quales son y de su diuision por las CC como el viso"; "Capitulo segundo de la subdiuision de las species"; y “Capitulo iij quantas maneras ay de contrapunto". Una detallada comparación de los textos del Tractat de música y de la Sumula de Marcos Durán muestra que: 1) el primer capítulo y el segundo de la Sumula se han traducido literalmente al catalán en el manuscrito (reproduciendo incluso el diagrama del segundo capítulo); 2) el copista empezó a hacer lo mismo con el tercer capítulo (aunque se interrumpe la escritura y el resto de la página queda en blanco); y 3) estos contenidos aparecen intercalados con otros materiales tanto en catalán como en latín. Las "Reglas per saber ordenar la sol fa ab la letra" del Tractat de música (f. 12r) son muy similares a las "Reglas para ordenar la letra" que encontramos al final de Lux Bella y del Comento sobre Lux Bella de Marcos Durán.

Además de los contenidos tomados de libros concretos y reagrupados de un nuevo modo, el Tractat de música contiene resúmenes esquemáticos sobre los temas habituales en las artes de canto e incluso comienza dibujando una mano guidoniana; véase Apéndice 14. Todo esto sugiere que el manuscrito pudo surgir en el contexto de lecciones de música en las que también se utilizaban artes de canto (con seguridad, la Sumula de Marcos Durán). El Tractat de música se asemeja a lo que Cristle Collins Judd ha denominado "el cuaderno del humanista". Según la musicóloga, el libro corriente representaba un sector especializado dentro de la más amplia cultura del "cuaderno", consistente en transcribir a mano, bajo encabezados preestablecidos, citas tomadas de textos impresos; el rol del maestro en este proceso era el de guía y filtro, "determinando lo que era moralmente edificante y pragmáticamente útil para su inclusión en el cuaderno". ${ }^{4}$ Por sus características y la estructuración de sus contenidos, también la mayor parte de las "artecillas" de canto impresas guardan similitud con "el cuaderno del humanista".

Encontramos un caso similar al del Tractat de música entre los tratados musicales reunidos en otro manuscrito, Barcelona, Biblioteca de Catalunya, Ms. 1325, un vo-

\footnotetext{
${ }^{48}$ En el manuscrito aparece el capítulo segundo a continuación del tercero.

${ }^{49}$ Judd, Reading Renaissance Music Theory, p. 129.
} 
lumen de 36 folios en $4^{\circ}$ encuadernado en pergamino con la indicación en el lomo "Art del cant pla", cuyo contenido general aparece en la Tabla IV.4.

Tabla IV.4: Contenido general del manuscrito Barcelona, Biblioteca de Catalunya, MS. 1325

\begin{tabular}{lllll}
\hline & Folios & Signatura & Título & Fecha \\
\hline 1 & ff. 1-12v & Ms. 1325/1 & Tractat molt util de la art de can pla & $1500-1525$ \\
2 & ff. 13r-25v & Ms. 1325/2 & Micel lània de tractats musicals & $1475-1525$ \\
3 & ff. 26r-36 & Ms. 1325/3 & Tractat de teoria musical & Siglo XVIII \\
\hline
\end{tabular}

$\mathrm{Al}$ arte de canto llano en catalán Tractat molt util de la art de can pla (Ms. 1325/1) con que se inicia el manuscrito, le sigue una Micel·lània de tractats musicals (Ms. 1325/2), que consiste en una recopilación de fragmentos de textos y notación musical sobre diferentes tipos de papel (con marcas de agua distintas). Como muestra la Tabla IV.5a, tras una primera hoja en la que encontramos un ejemplo musical, la $M i$ cel·lània incluye a su vez dos tratados de canto, uno en catalán (ff. $14 \mathrm{r}-20 \mathrm{v}$ ) y otro en castellano titulado Arte de melodia sobre canto lano y canto dorgano (ff. 21v-24r) y una hoja con ejemplos musicales y su explicación en italiano (véase Ilustración IV.7). 
Tabla IV.5a: Estructura del manuscrito Micel-lània de tractats musicals (1475-1525).

Barcelona, Biblioteca de Catalunya, Ms. 1325/2

\begin{tabular}{|c|c|c|c|}
\hline Folios & Material & Contenido & Idioma \\
\hline $13 r$ & Ejemplo musical & $\begin{array}{l}\text { Figuras (maxima, longa, breu, semibreu, minima) } \\
\text { tiempo y prolación }\end{array}$ & Catalán \\
\hline $13 \mathrm{v}$ & En blanco & & \\
\hline $14 \mathrm{r}-20 \mathrm{v}$ & $\begin{array}{l}\text { Texto y ejemplos } \\
\text { musicales }\end{array}$ & $\begin{array}{l}\text { [Apartados:] } \\
\text { - } \text { de les propietats perfetas } \\
\text { - } \text { de les propietats imperfetas } \\
\text { - } \text { de accidens de les proprietats perfetas e } \\
\text { imperfetas } \\
\text { - } \quad \text { de quatre maneras de su nominacio que te } \\
\text { - lo punt en cant dorga } \\
\text { - de la perfectio de les figuras imperfetas per } \\
\text { aphracio de punt aquascuna de les } \\
\text { - de alteracione } \\
\text { - de alteracionis impedimento } \\
\text { - de alteracione per punctum non } \\
\text { impedienda } \\
\text { - de proprietatum perfectarum e } \\
\text { - imperfectione } \\
\text { - de perfeccione figurarum secundum partes } \\
\text { - de sincopa proprie sumpta } \\
\text { - de colore figurarum } \\
\text { de pausis }\end{array}$ & Catalán \\
\hline $21 \mathrm{r}-24 \mathrm{v}$ & $\begin{array}{l}\text { Texto y ejemplos } \\
\text { musicales }\end{array}$ & 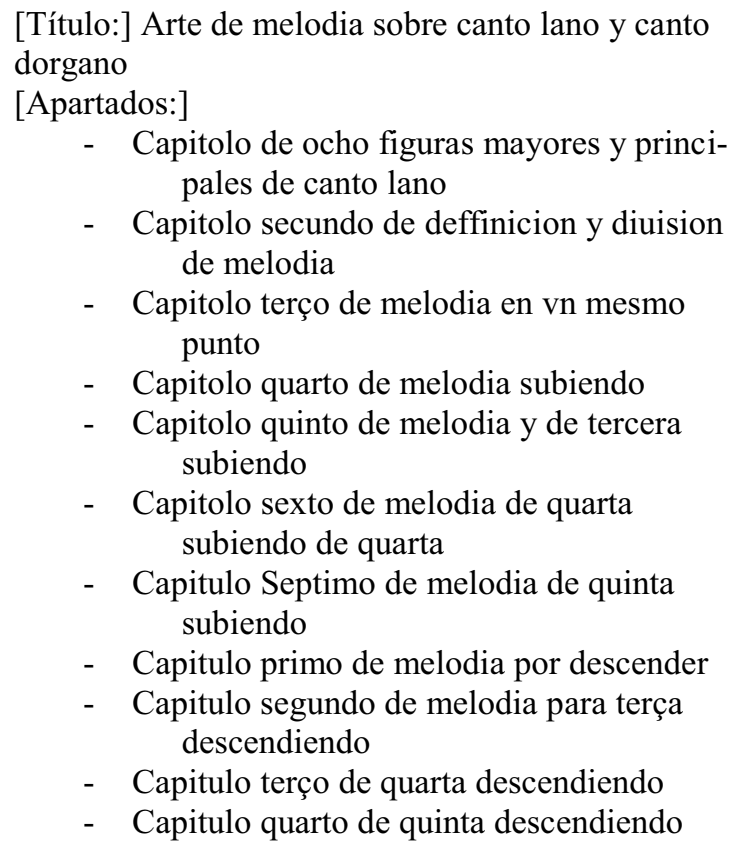 & Castellano \\
\hline $25 \mathrm{r}-\mathrm{v}$ & $\begin{array}{l}\text { Ejemplos } \\
\text { musicales y su } \\
\text { explicación }\end{array}$ & & Italiano \\
\hline
\end{tabular}


Ilustración IV.7: Micel·lània de tractats musicals, MS (1475-1525), última página del Arte de melodia sobre canto lano y canto dorgano y recto de la hoja en italiano (ff. $24 \mathrm{v}-25 \mathrm{r}$ ).

Barcelona, Biblioteca de Catalunya, Ms. 1325/2.

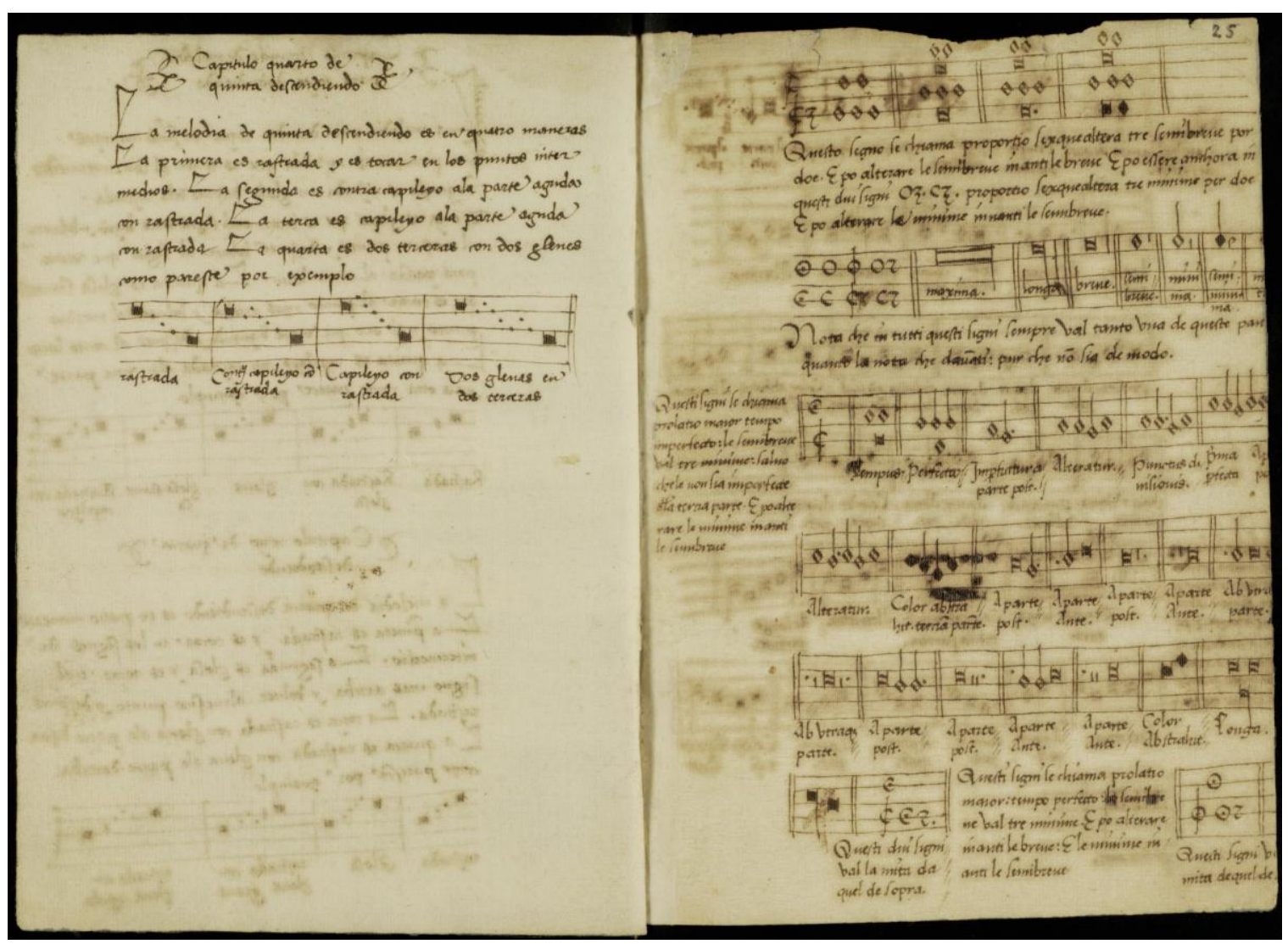

Como ocurría en el caso del Tractat de música, el tratado en catalán de la Micel-lània de tractats musicals se ha identificado como la traducción de un tratado de Guillermo de Podio que Higini Anglès encontró encuadernado a continuación del manuscrito In Enchiridion de principiis musice discipline (Bologna, Biblioteca Musicale, Ms. Sezione II, N. 51): "se trata simplemente de una obra desconocida de Guillermo de Podio, en la cual el autor resume y aclara los capítulos VIII-XXXVI del Liber Septimus del Ars musicorum". 50

Encuadernado a continuación de la Micel-lània de tractats musicals encontramos un Tractat de teoria musical (Ms. 1325/3) de 11 hojas datado en el siglo XVIII (véase

\footnotetext{
${ }^{50}$ Higini Anglès, "La notación musical española de la segunda mitad del s. XV: un tratado desconocido de Guillermus de Podio", Anuario musical, II (1947); pp. 151-173, p. 160. Véase también Karl-Werner Gümpel, "Eine Katalanische Version der Mensurallehre des Guillermus de Podio", Orbis Musicae: Studies in Musicology, II (1974-1975), pp. 41-52.
} 
Tabla IV.5b). Esta Micel·lània, como el Tractat de música de la Biblioteca de la Universitat de Barcelona, se asemeja a lo que Cristle Collins Judd denomina "el cuaderno del humanista", es decir, la copia a mano a partir de textos impresos bajo encabezados preestablecidos por el maestro. Estos tratados manuscritos semejantes al "cuaderno del humanista" son una evidencia de los usos que se hicieron en Cataluña de las artes de canto impresas.

Tabla IV.5b: Estructura del manuscrito Tractat de teoria musical (siglo XVIII). Barcelona, Biblioteca de Catalunya, Ms. 1325/3

\begin{tabular}{|c|c|c|c|}
\hline Folios & Material & Contenido & Idioma \\
\hline $26 r-33 v$ & $\begin{array}{l}\text { Texto con la } \\
\text { estructura pregun- } \\
\text { ta }(\mathrm{M}) \text { - respuesta } \\
\text { (D) [¿Maestro y } \\
\text { Discípulo?] }\end{array}$ & $\begin{array}{ll}\text { [División en } 4 \text { capítulos:] } \\
\text { - } & \text { De la Musica en General Capitulo primero } \\
\text { - } & \text { De quantas Maneras ni ha de Musica Cap. } 2^{\circ} \\
\text { - } & \text { De la Musica Plana i Uniforme Cap. } 3 \\
\text { - } & \text { De la Musica Organica i Mensural Cap. } 4\end{array}$ & Catalán \\
\hline $33 v-36 r$ & Texto & $\begin{array}{l}\text { [Título:] De la Musica del cant Pla comensan los } \\
\text { vuyt tons } \\
\text { [Apartados:] } \\
\text { - } \quad \text { Ahont tenen son aciento } \\
\text { - } \quad \text { De las deduccions i quantas ni ha } \\
\text { - } \quad \text { La deduccio de natura sempre deualla } \\
\text { - } \\
\text { Ara be ya que auen aribat a tractar [mu]dansa } \\
\text { direm alguna cosa de[...] com s pren i de } \\
\text { quina manera se }[\ldots] \\
\text { - Com se te de formar lo Diapason pera saber } \\
\text { pendrer la Mudansa }\end{array}$ & Catalán \\
\hline
\end{tabular}

\subsection{El contenido gráfico de las artes de canto. La cuestión de la mano guidoniana y la escala}

La inclusión u omisión de un determinado material como la mano musical puede arrojar luz sobre los usos de las artes de canto. En su artículo "Disce Manum Tuam si vis bene discere cantum: Symbols of Learning Music in Early Modern Europe", Susan F. Weiss traza la trayectoria de la mano musical desde el siglo XI hasta el XX estudiando las transformaciones relacionadas con el contexto social y musicológico que han 
afectado a esta ilustración. ${ }^{51} \mathrm{Su}$ estudio muestra que la ausencia de la mano guidoniana tiene normalmente dos motivos. El primero es la naturaleza del tratado: cuanto más teórico sea un texto menos probable será que contenga la mano guidoniana, puesto que "la presencia de una mano en un libro implicaba sentido práctico". ${ }^{52}$ La segunda razón de omisión de la mano musical es la asociación simbólica entre la mano izquierda levantada y la religión católica: en el siglo XVI se produjo un cambio en las prácticas educativas musicales en los países protestantes, de manera que en la enseñanza de la música se enfatizaron los ejercicios escritos sobre los orales/mnemotécnicos y pasó a usarse la escala en detrimento de la mano guidoniana, quizás por considerarse ésta asociada con la religión católica. ${ }^{53}$ En este sentido es interesante el caso de la Instruction méthodique et fort facile pour apprendre la musique practique, sans aucune gamme ou main (Lyon, 1573) de Corneille Blockland de Montfort, puesto que ya en el título indica la no inclusión de la mano ni de la escala en su tratado; es tentador relacionar esta ausencia con la posibilidad que ha señalado Frank Dobbins de que Blockland fuese sospechoso de Protestantismo. $^{54}$

Por consiguiente, la presencia o la ausencia de la mano musical en las artes de canto impresas en el mundo ibérico (católico) del siglo XVI debe estar determinada principalmente por la naturaleza del tratado. Más recientemente, Susan F. Weiss ha señalado que la inclusión de la mano guidoniana en los tratados musicales "es a menudo indicio de que un texto estaba destinado a la enseñanza de la música a principiantes". 55 La omisión de la ilustración no siempre implica lo contrario, ya que puede deberse a

\footnotetext{
${ }^{51}$ Susan Forscher Weiss, "Disce Manum Tuam si vis bene discere cantum: Symbols of Learning Music in Early Modern Europe", Music in Art, 30 (2005), pp. 35-75. Véase también Karol Berger, "The Hand and the Art of Memory", Musica Disciplina, XXXV (1981), pp. 87-120.

${ }^{52}$ Weiss, "Disce Manum Tuam si vis bene discere cantum", p. 36: "The presence of a hand in a book implied practicality".

${ }^{53}$ Weiss, "Disce Manum Tuam si vis bene discere cantum”, pp. 47. En p. 55: "Otros escritores que seguían la Reforma substituyen la escala por la mano porque el simbolismo de la última evoca convenciones y símbolos del Catolicismo y de sistemas más antiguos de aprendizaje por repetición de memoria" ["Other writers following the Reformation substitute the scale for the hand because the latter's symbolism evokes conventions and symbols of Catholicism and of the older ways of learning by rote memory"].
}

${ }^{54}$ Frank Dobbins, Music in Renaissance Lyons (Oxford: Oxford University Press, 1992), pp. 92-93 y $207-$ 254.

${ }^{55}$ Weiss, "Vandals, Students, or Scholars?", p. 207: "The presence of the hand is often a clue that a text was intended for teaching music to beginners". 
cuestiones técnicas de la imprenta o simplemente al hecho de que el funcionamiento de la mano se explicaba oralmente y no siempre era necesario contar con un soporte visual en papel. Encontramos clara evidencia de ello en el Arte breve y compendiosa (1614) de Andrés de Monserrate, puesto que no incluía la ilustración de la mano, pero sí una página titulada "La mano del canto" antes de comenzar el tratado en sí. Es muy interesante el modo en que en esta introducción se expone con palabras el funcionamiento de la mano guidoniana, enumerando los signos y explicando en qué parte de la mano se halla cada uno. Además de esta particularidad (omisión de la ilustración y explicación de la misma de modo textual), Monserrate comienza su exposición explicando que la finalidad de la mano es enseñar los signos musicales a los principiantes:

Los Musicos (segun tiene Nicolao Vuollico) no hallaron instrumento mas apto, prompto, ni mejor (por donde enseñassen a los principiantes los veynte signos de la Musica) que la mano. Y escogieron la yzquierda, que para esto viene mas a proposito. $\mathrm{Y}$ assi lo primero que el principiante en Canto llano ha de saber es, los veynte signos desta mano, que dizen assi $\left[\ldots .{ }^{56}\right.$

Los tratados dirigidos a religiosos apoyan la hipótesis de que la presencia de la mano musical en un tratado indica que estaba dedicado a la enseñanza de la música a principiantes. Por ejemplo, en el ya mencionado Tratado llamado el Desseoso, y por otro nombre, Espejo de Religiosos (1580), se hace alusión a la mano musical como herramienta para iniciarse en el canto: "Pero es menester para que vamos por arte, que primero ayamos conocimento del canto, y pues tenemos las vozes, es menester que aprendamos la mano del cantar". ${ }^{57}$ En el Arte de canto llano et contrapunto et canto de organo de Gonzalo Martínez de Bizcargui no aparece la mano musical, exceptuando las ediciones de 1531 y 1543 en que sí encontramos la ilustración (véase Tabla IV.6). Esto muestra quizás que la inclusión u omisión de la ilustración dependía de cuestiones técnicas; la Tabla IV.6 refleja que es a partir de la década de 1530 (curiosamente coincidiendo con la publiación del libro de Juan Martínez), cuando la inclusión de la mano guidoniana en las artes de canto se convierte en una constante. Como muestra el Apéndice 14, la mano musical era grabada de forma xilográfica y en las ediciones de 1531 (Zaragoza, Jorge Coci) y 1543 (Burgos, Juan de Junta) del libro de Martínez de Bizcar-

\footnotetext{
${ }^{56}$ Monserrate, Arte breve y compendiosa, p. 16.

${ }^{57}$ Comalada, Tratado llamado el Desseoso, f. 90r.
} 
gui se utiliza la misma plancha de madera. También es significativo que algunas artes de música incluyan tanto la mano musical como la escala; por ejemplo, el tratado de Juan Francisco Cervera, además de la mano guidoniana, incorporaba la escala en forma de árbol (véase Apéndice 14). Esta ilustración se asemeja al "árbol de la memoria" que aparece en el tratado Bellum musicale (Estrasburgo, 1563) de Claudius Sebastiani. ${ }^{58}$

Tabla IV.6: Presencia de la mano musical y la escala en las artes de canto

\begin{tabular}{|c|c|c|}
\hline & Mano guidoniana & Escala \\
\hline Marcos Durán 1492 y 1498 & & $\checkmark$ \\
\hline \multicolumn{3}{|l|}{ Escobar c. 1498} \\
\hline \multicolumn{3}{|l|}{ Spañón c. 1500} \\
\hline Molina 1503 & & $\checkmark$ \\
\hline \multicolumn{3}{|l|}{ Puerto 1504} \\
\hline \multicolumn{3}{|l|}{ Espinosa 1520 y 1521} \\
\hline Martínez 1532 [1530] & $\begin{array}{l}\checkmark \text { [Excepto las ediciones de } \\
\text { António Cordeiro] }\end{array}$ & $\checkmark$ \\
\hline $\begin{array}{l}\text { Martínez de } 1531 \text { y } 1543 \\
\text { [1508] }\end{array}$ & $\checkmark$ & \\
\hline Aranda 1533 & & $\checkmark$ \\
\hline \multicolumn{3}{|l|}{ Aguilar c. 1535} \\
\hline Torres 1544 & & $\checkmark$ \\
\hline Bermudo 1549 y 1550 & & $\checkmark$ \\
\hline Villafranca 1565 & $\checkmark$ & $\checkmark$ \\
\hline \multicolumn{3}{|l|}{ Guevara 1582} \\
\hline Montanos 1592 & $\checkmark$ & \\
\hline Montanos 1594 & $\checkmark$ & \\
\hline Cervera 1595 & $\checkmark$ & $\checkmark$ \\
\hline Villegas 1614 & $\checkmark$ & \\
\hline Monserrate 1614 & $\begin{array}{l}\text { [No aparece la ilustración } \\
\text { pero sí la explicación] }\end{array}$ & $\checkmark$ \\
\hline \multicolumn{3}{|l|}{ Artufel 1614} \\
\hline Thalesio 1618 & $\checkmark$ & $\checkmark$ \\
\hline Fernández 1626 & & \\
\hline
\end{tabular}

${ }^{58}$ Véase Weiss, "Disce Manum Tuam si vis bene discere cantum”, pp. 50 y 59. 
De las artes de canto estudiadas, el Arte de canto llano (1530) de Juan Martínez podría haber sido el primero en incluir una mano musical impresa. Aunque desconocemos si la edición príncipe de 1530 contenía la ilustración, la de 1532 incluía una mano musical que, como señálé en el Capítulo III, Collet calificó de "magnífica". 59 De las ediciones de este libro que se conservan completas, todas contienen la mano musical, con la excepción de las publicadas por António Cordeiro e impresas en el taller de Nicolao Carvalho. Es significativo que incluso la edición de Coimbra de 1597, publicada por el catedrático de música de la Universidad de esa ciudad, Afonso Perea Bernal, incluyera la mano guidoniana, puesto que implicaría una enseñanza de la práctica de la música desde el nivel básico en el ámbito universitario. No sólo El arte Tripharia (1550) de Bermudo incluye la escala, sino también su más teórico Libro primero (1550). De la misma forma, Montanos incorporaba la mano guidoniana en su ambicioso Arte de musica theorica y pratica (1592), dirigido a "músicos doctos y maestros de capilla", y en su Arte de canto llano (1594), dirigido a clérigos que necesitaban aprender a cantar el Oficio Divino. Ya fuesen dirigidas a maestros o a alumnos, la inclusión de la mano guidoniana sugiere el uso de las artes de canto en el proceso de enseñanza-aprendizaje de la música desde un nivel elemental hasta alcanzar un amplio espectro de grados de competencia musical, según la extensión y los contenidos del libro. Incluso los aspirantes a maestro de capilla debían ser capaces de improvisar un contrapunto a dos o tres voces sobre un cantus firmus cantando una de las voces e indicando la otra o las otras dos en la mano. ${ }^{60}$

La mano musical debió estar lo bastante imbricada en la cultura de la época como para ser usada a modo de metáfora en textos dramáticos:

\footnotetext{
${ }^{59}$ Collet, Un tratado de canto de órgano (siglo XVI), p. 23.

${ }^{60}$ Fiorentino, “'Con ayuda de nuestro Señor"”, [en prensa]: "El 21 de mayo de 1604, el cabildo de la Catedral de Toledo estableció los exámenes que debían pasar los aspirantes a la vacante de maestro de capilla. De las 20 pruebas diferentes, 15 estaban directamente relacionadas con diferentes tipos de contrapunto improvisado [...]. Por ejemplo, sobre diferentes tipos de cantus firmus [...] el candidato tenía que improvisar un contrapunto a una voz y un 'contrapunto concertado' a dos voces: en el primer caso el aspirante cantaría la melodía improvisada; en el segundo, cantaría la primera melodía, indicando la segunda sobre la mano (guidoniana). También tenía que improvisar un contrapunto a tres voces sobre un cantus firmus, cantando una voz e indicando las otras dos en la mano" ["On 21 May 1604, the chapter of Toledo Cathedral established the examinations that aspirants to the vacant office of chapel master would have to take. Of the 20 different tests, 15 were directly related to different kinds of improvised counterpoint (...) For example, over different types of cantus firmus (...) the candidate had to improvise both a single-voice counterpoint and a two-voice 'contrapunto concertado': in the first case he would sing the improvised melody; in the second, he would sing the first melody indicating the second on the (Guidonian) Hand. He also had to improvise a three-voice counterpoint over a cantus firmus, singing one voice and indicating the other two voices on the Hand"].
} 


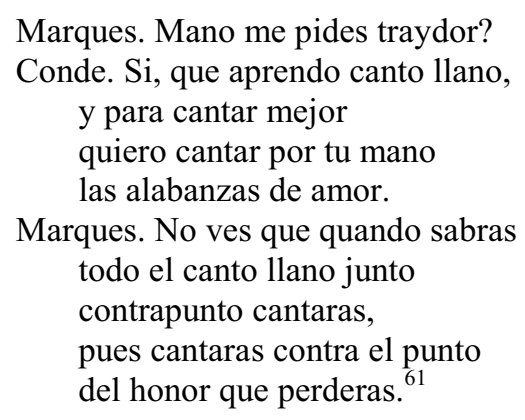

Como muestra el Apéndice 14, la inclusión de la mano musical en los tratados de música del contexto ibérico se ha mantenido a lo largo de los siglos, en contraste con lo ocurrido en el ámbito protestante. Evidencia de ello es que en 1748 Antonio Ventura Roel del Río justificara su omisión de la mano en la Institucion harmonica por considerarla "cosa superflua", pero indicase que su inclusión era una práctica común entre los autores:

La Mano, que llaman Musical, y dibujan comunmente los Autores al principio escritos en ella los signos, para que los principiantes los tomen de memoria, la he omitido como cosa superflua, respecto de haver puesto las progressiones de los tres mas principales por sus Claves correspondientes y respecto no entenderse su dibujo, sino despues de sabida por las articulaciones de los dedos. $^{62}$

\subsection{Las artes de canto llano como base del aprendizaje de la música: el caso del}

\section{Arte de canto llano (Valladolid, 1594) de Francisco de Montanos}

El análisis de los indicios de uso de las artes de canto y el estudio de las implicaciones de la inclusión de un determinado material gráfico como la mano musical indican que las artes de canto se utilizaban como material didáctico por maestros y principiantes y que constituían una herramienta para enseñar/aprender los fundamentos del lenguaje musical, pero también una base sobre la que cimentar contenidos más complicados. El Arte de canto llano (Valladolid, 1594) de Francisco de Montanos constituye un ejemplo. Este tratado fue reimpreso a iniciativa de impresores y libreros, lo que muestra su

\footnotetext{
${ }^{61}$ Gaspar Aguilar, "Comedia famosa de la fuerza del interés", en Norte de la poesía española. Illvstrado del sol de doze Comedias (que forman Segunda parte) de Laureados Poetas Valencianos: y de doze escogidas Loas, y otras Rimas a varios sugetos, ed. por Aurelio Mey (Valencia: Felipe Mey, 1616), f. B5v.

${ }^{62}$ Roel del Río, Institucion harmonica, s.f., Prólogo -Nota.
} 
éxito comercial, pero también fue reimpreso por músicos como una base del aprendizaje de la música a la que se fueron añadiendo repertorio (como la Misa del Ángel Custodio) y materiales didácticos más avanzados (como el Arte de canto de organo de Joseph de Torres en el siglo XVIII). En el transcurso de esta investigación he consultado ejemplares de las ediciones del tratado de Montanos de 1594, 1598, 1610, 1616, 1625, 1640, $1643,1648,1665,1670,1686,1693,1694,1705,1712,1727,1728,1734$ y 1756, lo que me ha permitido analizar en profundidad el contenido de las distintas reediciones y la manera en que éste se fue modificando a lo largo de un siglo y medio; véase Apéndice 2 .

Dos músicos prepararon ediciones del Arte de canto llano de Montanos: Sebastián López de Velasco en 1635 (reimpresiones en 1640, 1643, 1648, 1665, 1670, 1686, 1687?, 1693, 1694, 1727 y 1756) y Joseph de Torres a partir de 1705 (reimpresiones en 1712, 1728 y 1734). Cantor, maestro de capilla y compositor, Sebastián López de Velasco (1584-1659) reimprimió el Arte de canto llano de Montanos tal y como se venía haciendo desde la edición de 1616 por iniciativa del mercader de libros Andrés López, es decir, con la añadidura de la Misa del Ángel Custodio, y simplemente "corregido, y enmendado por Sebastian Lopez de Velasco, Capellan de su Magestad, y Maestro de su Real Capilla de las Descalzas". López de Velasco se retiró de su puesto de maestro de capilla de Doña Juana en las Descalzas Reales de Madrid en 1636 por cuestiones de salud y pasó el resto de su vida como racionero de la Catedral de Granada. Esto sugiere que las subsecuentes reimpresiones de la edición de 1635 que López de Velasco había preparado fueron iniciativa de libreros e impresores.

Joseph de Torres y Martínez Bravo (1670-1738) fue, además de compositor y organista, editor; ${ }^{63}$ junto con otros dos miembros de la Real Capilla (Pedro París y Royo y Miguel Martín), fundó en 1699 la Imprenta de Música de Madrid, que obtuvo el privilegio para la impresión de música en la España de la época. La defensa de este privilegio debió de ser efectiva, dado que la mayor parte de los impresos musicales producidos fuera de la Imprenta de Música eran manuales de canto llano que no usaban la tipografía musical moderna y, por tanto, no suponían una violación del privilegio. ${ }^{64}$ En esta im-

\footnotetext{
${ }^{63}$ Véase Begoña Lolo, La Música en la Real Capilla de Madrid: José de Torres y Martínez Bravo, h.1670-1738 (Madrid: Universidad Autónoma de Madrid, 1990).

${ }^{64}$ Juan José Carreras, "José de Torres and the Spanish Musical Press in the Early 18th Century (16991736)", Eighteenth-Century Music [en prensa]: "La defensa de Torres de su privilegio parace haber sido
} 
prenta, Torres publicó sus ediciones del libro Montanos, además de otros tratados musicales (el primero que publicó fue Fragmentos musicos de Pablo Nassarre en 1699) y obras de repertorio musical. Juan José Carreras ha señalado que "el impacto principal" de la Imprenta de Música "estaba relacionado con best-sellers como el Arte de canto llano de Montanos y Torres". ${ }^{65}$ A diferencia de Sebastián López de Velasco, Torres usó el Arte de canto llano de Montanos como una base didáctica a la que añadió su propio tratado, titulado El arte practico de canto de organo, así como repertorio musical con carácter acumulativo, de forma que cada reimpresión era más amplia que la anterior:

- 1712: “con motetes, o lecciones diversas, por todos los tiempos, y Claves".

- 1728: “con Motetes, ò Lecciones diversas, por todos los Tiempos, y claves, nuevamente corregidos. Y aora novissimamente en esta vltima impression aumentadas las tres Antiphonas de tiempo, Ave Regina Coelorum, Alma Redemptoris, y la Salve Regina Mater, las dos primeras al fin del Canto Llano, à fol. 129. y la vltima al Canto de Organo, à fol. 251. con su voz, y acompañamiento".

- 1734: “con Motetes, y Lecciones diversas, nuevamente corregidos: Y ahora aumentadas novissimamente en esta vltima Impression: en el Canto Llano, las dos Sequencias Victima Paschali, \&C. Y Veni Sante Spiritus. Y en el Canto de Organo vn Admirable, con Voz, y Acompañamiento, y vna Salve à Duo, à Tres, y à Quatro segun la oportunidad de las voces".

Las ediciones de 1728 y 1734 de Joseph de Torres muestran de forma clara que su novedad radicaba en el repertorio, al indicar ya en la portada los folios exactos donde podían encontrarse las piezas nuevas. Por tanto, la historia del Arte de canto llano de Montanos muestra que, como se percibía mediante el estudio de las evidencias de uso

muy efectiva durante su vida. La mayoría de impresos musicales conocidos que se produjeron fuera de la imprenta son manuales de canto llano que no usan la tipografía musical moderna y, por tanto, no están protegidos por el privilegio" ["Torres defense of his privilege seems to have been very effective during his lifetime. Most music prints known to have been produced outside the press belong to plain chant tutors which do not use modern music typography and therefore are not protected by the privilege"]. Sobre la Imprenta de Música, véase también Juan José Carreras, “Conducir a Madrid estos moldes': Producción, dramaturgia y recepción de la fiesta teatral Destinos vencen finezas", Revista de Musicología, XVIII (1995), pp. 113-143.

${ }^{65}$ Carreras, "José de Torres and the Spanish Musical Press in the Early 18th Century (1699-1736)", [en prensa]: "The main impact of the press was related to best-sellers like Montano's and Torres's Arte de Canto llano with its four editions in less than thirty years". 
de las artes de canto, estos libros funcionaron como fuente de repertorio musical, pero también como una introducción a la que añadir contenidos más avanzados.

\section{LAS ARTES DE CANTO COMO VESTIGIO DE LECCIONES DE MÚSICA EN ÁMBITOS DOCENTES DIFERENCIADOS}

En la primera parte de este Capítulo he mostrado que las artes de canto se utilizaron como herramienta docente y que testimonian un solapamiento entre la tradición oral de la docencia musical y la cultura escrita; Juan Bermudo, al referirse al aprendizaje de instrumentos, advertía en el Libro primero (1549) que no pretendía "enseñar a tañer" porque esto no podía enseñarse "por letras", sino que su objetivo era que sus lectores entendiesen "los instrumentos de fundamento: lo qual es camino de saber tañer". 66 No hay duda de que la práctica musical se aprendía oralmente: "No auia musico de morir, que no dexasse el trabajo de toda su vida debuxado en papeles", recomendaba Bermudo. ${ }^{67}$ La evidencia externa que he encontrado en las artes de canto, el caso del Tractat de música y los contenidos incluidos en estos libros sugieren que las artes de canto permiten vislumbrar vestigios de los procesos de enseñanza de la música en ámbitos docentes diferenciados, como estudiaré a continuación.

\footnotetext{
${ }^{66}$ Bermudo, Libro primero, f. 11v. En el contexto de la enseñanza instrumental, Griffiths, "Juan Bermudo, Self-Instruction and the Amateur Instrumentalist", p. 129, ha señalado que hubo "probablemente un cierto grado de congruencia entre pedagogías orales e impresas" en el ámbito de la música instrumental, tomando como evidencia los libros de Luis de Milán -quien expresaba "su deseo de replicar la práctica de la vida real en los manuales que publicó"-, y Juan Bermudo, posiblemente "un informante certero de la práctica pedagógica establecida" ["We know very little about what they [teachers] did, and the methods they used. At the same time, there is probably a certain degree of congruence between oral and print pedagogies, and we can only be reassured by the indications given by writers such as Luis Milán who confirm their desire to replicate real-life practice in their published manuals"; p. 134: "The congruence between Bermudo's writings and those of other authors who ventured to discuss early instrumental music suggests him to be an accurate reporter of established pedagogical practice"].

${ }^{67}$ Bermudo, Libro primero, ff. 142v-143r.
} 


\subsection{Vinculación de las artes de canto con las lecciones públicas de música en las instituciones eclesiásticas}

Diversas constituciones sinodales mencionan la obligación que tenían los clérigos de saber canto llano. Por ejemplo, en la segunda de las Constituciones synodales del Obispado de Auila (Madrid, 1617) se establecía que "el que huuiere de ordenarse de epistola" debía saber "razonablemente" canto llano, y se añadía: "mandamos a nuestro secretario no admita a nadie a este orden, aunque estè aprouado por los examinadores, sin que trayga aprobacion del dicho canto llano de la persona a quien por nos fuere cometido el examen del". ${ }^{68}$ En el ámbito de la enseñanza musical en las capillas eclesiásticas la evidencia invita a rechazar el aislamiento atribuido tradicionalmente a la música española en la bibliografía musicológica. Giuseppe Fiorentino destaca que la formación de los mozos de coro en las capillas catedralicias del mundo ibérico "es idéntica a la formación que Adrianus Petit Coclico recibió de su maestro Josquin" y que la enseñanza de las técnicas del contrapunto improvisado "seguía modelos comunes en toda Europa" ${ }^{69}$ En la investigación de la conexión entre las artes de canto y el aprendizaje de la música en instituciones religiosas he tomado como guía el contexto catedralicio y monacal, sin olvidar, no obstante, que la docencia de la música también se llevaba a cabo en otras instituciones eclesiásticas como parroquias y abadías. ${ }^{70}$

Además de la obligación de instruir a los mozos de coro, los maestros de capilla tenían el deber de enseñar canto a todos los clérigos y laicos que quisieran aprender. Richard Kagan señala que en la Castilla del siglo XVI se pagaron subsidios a catedrales y conventos para que abrieran al público las clases hasta el momento privadas, como

${ }^{68}$ Francisco de Gamarra, Constituciones synodales del Obispado de Auila (Madrid: Juan de la Cuesta, 1617), f. 41.

${ }^{69}$ Giuseppe Fiorentino, "Música española del Renacimiento entre tradición oral y transmisión escrita: el esquema de folía en procesos de composición e improvisación", Tesis Doctoral (Ph.D.), Universidad de Granada, 2009, p. 543. Véanse también "Folía": el origen de los esquemas armónicos entre tradición oral y trasmisión escrita [DeMusica, 17] (Kassel: Reichenberger [en prensa]); y “"Con ayuda de nuestro Señor"”.

${ }^{70}$ Acerca de la música en parroquias españolas, véanse María Gembero Ustárroz, "El patronazgo ciudadano en la gestión de la música eclesiástica: la Parroquia de San Nicolás de Pamplona (1700-1800)", Nassarre: revista aragonesa de musicología, XIV/1 (1998), pp. 269-362; y Juan Cruz Labeaga Mendiola, "La capilla de música de Santa María de Viana, Navarra (siglos XVI-XIX)", Príncipe de Viana, LXVII/238 (2006), pp. 389-424. Para un trabajo sobre la música en las parroquias del Cuzco colonial, véase Baker, Imposing Harmony. Sobre la música en la Abadía del Sacromonte (Granada), véase Mercedes Castillo Ferreira, "Música y ceremonia en la Abadía del Sacromonte de Granada (Siglos XVII-XIX)", Tesis Doctoral (Ph.D.), Universidad de Granada, 2009. 
consecuencia de la toma de conciencia por parte de las autoridades municipales de la necesidad de invertir en educación primaria pública. ${ }^{71}$ Algunas actas capitulares establecen la gratuidad de estas lecciones, aunque en las horas libres el maestro podía impartir clases particulares remuneradas. En las lecciones gratuitas, el público ajeno a la vida eclesiástica no estaba constituido únicamente por adultos, sino también por niños; ${ }^{72}$ por ejemplo, en el Primer Concilio Mexicano (1555) se acordó que "los Niños y Niñas fuessen todos los días a la Iglesia guiados de algún grande, para que aprendiessen la Doctrina, y a el mismo tiempo la Música, para lo que se les pusieron Maestros". ${ }^{73}$ Herminio González Barrionuevo ha estudiado el tipo de público que asistía a las lecciones de los maestros de capilla exponiendo varios casos: 1) entre las obligaciones de Bernardino Pirris, maestro de capilla de la Catedral de Mallorca desde 1472, estaba la de enseñar "a los canónigos, a los familiares de éstos y a los del obispo, además de los niños de coro y sacristanes"; 2) los deberes de Bernardo de Villalba en Sevilla en 1540 incluían la enseñanza "a los señores beneficiados mancebos (= jóvenes) y los otros señores del Cabildo que quisieran aprender a cantar"; y 3) a las lecciones del maestro de capilla en Badajoz en 1534 “debían asistir todos los que de una manera directa o indirecta tenían relación no sólo con la música, sino con la celebración del culto de la catedral: ‘capellanes, clerizontes, sacristanes, mozos de coro (= acólitos), beneficiados y oficiales de la iglesia'". ${ }^{74}$ Por consiguiente, es posible que los maestros escribieran manuales como las artes de canto (en lengua vernácula y, por tanto, accesibles a clérigos y laicos) con el fin de facilitar el proceso de aprendizaje de la música a una audiencia tan heterogénea.

\footnotetext{
${ }^{71}$ Kagan, Students and Society in Early Modern Spain, p. 18: “A los profesores se les pagaba y las escuelas se construían del presupuesto municipal, mientras que los subsidios que se ofrecían a catedrales y conventos abrieron las clases, hasta entonces privadas, al público" ["Teachers were paid and schools built out of the municipal budget, while subsidies offered to cathedrals and convents opened hitherto private classes to the public"].

${ }^{72}$ González Barrionuevo, Francisco Guerrero (1528-1599), pp. 168-169.

${ }^{73}$ Roldán Herencia, “La música eclesiástica en Nueva España”, p. 291.

${ }^{74}$ Herminio González Barrionuevo, Los seises de Sevilla (Sevilla: Castillejo, 1992), p. 66.
} 


\subsubsection{LA ENSEÑANZA DE LA MÚSICA EN LAS CATEDRALES DE}

\section{ÉVORA, SEVILLA Y COIMBRA}

La necesidad de una investigación que aclare la posible relación entre las artes de canto y el contenido de las lecciones públicas y diarias sobre contrapunto y polifonía impartidas por los maestros de capilla en las catedrales ya ha sido advertida por Tess Knighton. ${ }^{75}$ Para lograr una aproximación a las prácticas docentes en las capillas catedralicias, trataré los casos de Sevilla, Évora y Coimbra por ser instituciones conectadas con el Arte de canto llano de Juan Martínez (véase el Capítulo III), y estableceré el grado de vinculación de este manual con la historia de la enseñanza de la música en Coimbra.

Las relaciones musicales y el intercambio de músicos entre las catedrales portuguesas y la Catedral de Sevilla debieron de ser bastante importantes en la época a juzgar por lo reflejado en la documentación; por ejemplo, Francisco de Herrera, procedente de Coimbra, fue admitido como seise de la Catedral de Sevilla en $1642 .{ }^{76}$ Aunque en todas las iglesias los niños que cantaban canto llano y polifonía se llamaban "mozos de coro" o "niños cantores", 77 en la Catedral de Sevilla hubo una distinción entre los mozos de coro, que cantaban canto llano, y los seises, que cantaban polifonía. ${ }^{78}$ Esta circunstancia conllevó la existencia de dos puestos docentes diferenciados: maestro de seises y maestro de los mozos de coro. ${ }^{79}$ Los puestos de maestro de capilla y maestro de los seises estaban íntimamente conectados, puesto que a veces el maestro de capilla asumía el cargo de maestro de los seises y en otras ocasiones el maestro de los seises ocupaba el cargo de maestro de capilla temporalmente (el puesto de maestro de los seises surgió

\footnotetext{
${ }^{75}$ Knighton, “Libros de canto”, pp. 229-230.

${ }^{76}$ González Barrionuevo, Los seises de Sevilla, p. 42.

77 Sobre las obligaciones de Juan de Arenzana como maestro de capilla desde 1514 en la Catedral de Sigüenza, véase Louis Jambou, "La capilla de música de la Catedral de Sigüenza en el siglo XVI. Ordenación del tiempo musical litúrgico: del Renacimiento al Barroco", Revista de Musicología, VI (1983), pp. 271-298, p. 275: “además del canto 'gregoriano', tendrá que iniciar a los mozos de choro, según sus disposiciones naturales, al Canto de Organo e contrapunto". Para un recorrido histórico del papel de los niños de coro de la Catedral de Palencia, véase María Pilar Cabeza Rodríguez y María Antonia Virgili Blanquet, "La enseñanza musical y las escuelas catedralicias: los niños de Coro en la Catedral de Palencia", en Actas del II Congreso de Historia de Palencia, 27, 28 y 29 de abril de 1989, coord. por María Valentina Calleja González (Palencia: Diputación Provincial de Palencia, 1990), vol. 5, pp. 293-304.

${ }^{78}$ Stevenson, Spanish Music in the Age of Columbus, p. 95.

${ }^{79}$ González Barrionuevo, Los seises de Sevilla, p. 68.
} 
como "maestro auxiliar" del maestro de capilla). ${ }^{80}$ A este respecto, Herminio González Barrionuevo establece dos etapas delimitadas por la escolarización de los niños en el Colegio de San Isidoro: en la primera etapa, los niños vivían con el maestro de capilla y el maestro de los seises tenía una "labor de sustitución"; en la segunda etapa, el maestro de los seises adquirió más independencia aunque su cargo siempre fue considerado de "segunda categoría" con respecto al de maestro de capilla. ${ }^{81}$

Como mostraba en el Capítulo II, Mateo de Aranda, Estêvão de Brito, Alonso del Castillo, Domingo Marcos Durán, Manuel Mendes, Francisco Montanos, Pedro Thalesio, Melchor de Torres y quizás Gonzalo Martínez de Bizcargui ocuparon el puesto de maestro de capilla. ${ }^{82}$ Las obligaciones docentes de Mateo de Aranda como maestro de capilla de la Sé de Évora entre 1528 y 1544 pueden servir como ejemplo de las prácticas educativas en el ámbito catedralicio; todos los días (excepto domingos y festivos) debía impartir tres horas de clase, una por la mañana y dos por la tarde, en las cuales enseñaba a cantar canto llano y canto de órgano y a leer música. ${ }^{83}$ En la Sé de Évora los mozos de coro no podían superar los diez años de edad en el momento de ser admitidos y recibían una paga a cambio de asistir a clase y cantar en las celebraciones. No sólo aprendían a cantar, sino que algunos eran iniciados en la práctica del órgano y de los instrumentos de viento utilizados en las capillas. ${ }^{84}$ En la última sección de su Trac-

\footnotetext{
${ }^{80}$ González Barrionuevo, Los seises de Sevilla, p. 74.

${ }^{81}$ González Barrionuevo, Los seises de Sevilla, p. 297.

${ }^{82}$ Aunque no era un requisito, en las oposiciones de maestro de capilla se dio preferencia a los clérigos, como ha señalado Louis Jambou usando como fuente bulas o decretos papales fundacionales de plazas de músicos de los siglos XV y XVI. Véase Louis Jambou, "Reflexiones y documentos sobre dinastías de maestros de capilla y organistas de los siglos XVI-XVIII", Nassarre: revista aragonesa de musicología, XII/2 (1996), pp. 161-184, p. 166.
}

\footnotetext{
${ }^{83}$ Alegria, História da escola de música da Sé de Évora, p. 29. Véanse también Alegria, O ensino e prática da música nas Sés de Portugal; y O Colégio dos Moços do Coro da Sé de Evora.
}

\footnotetext{
${ }^{84}$ Alegria, História da escola de música da Sé de Évora, p. 55. Véase también Branco, História da música portuguesa, pp. 143-144: "Relevante para la historia de la enseñanza de la música en Portugal es el hecho de que los mozos no aprendiesen solamente música vocal, sino también la ejecución de algunos instrumentos, incluyendo, naturalmente, el órgano. El primer reglamento de la capilla de la Catedral de Évora (1565) no deja dudas en cuanto a la posibilidad de que el chantre o director del coro mandara 'algún cantor o mozo de coro u otra persona de fuera al órgano o las flautas cuando se tocaran"” ["Relevante para a história do ensino da música em Portugal é o facto de os moços não terem aprendido apenas música vocal, senão que tambén a execução nalguns instrumentos, incluindo, naturalmente, o órgão. O primeiro regimento da capela da sé de Évora (1565) não deixa dúvidas quanto à possibilidade de o chantre ou presidente do coro mandar 'algum cantor ou moço do coro ou outra pessoa de fora ao órgão ou às frautas quando se tangerem"'].
} 
tado de canto llano (1533) Mateo de Aranda señalaba que "todo aquello que auemos dicho es para conocimiento de todo lo cantado y tañido". ${ }^{85}$ La combinación de música vocal e instrumental en la enseñanza que recibían los mozos de coro no es una particularidad de las capillas portuguesas, como muestran estos dos ejemplos: 1) Luis de Villafranca, maestro de los mozos de coro de la Catedral de Sevilla, hablaba en su Breue instrucion de Canto llano (1565) del órgano, el monacordio y la vihuela; ${ }^{86}$ y 2 ) en las Actas Capitulares de la Catedral de las Palmas se presenta con fecha de 28 de mayo de 1599 el encargo a Bartolomé Cairasco de Figueroa de comprar un monocordio y que "se embie a Sevilla a Jheronimo de Medina por un ynstrumento burolote para que se enseñen los moços a tecla o sacabuche para suplir algunas faltas que suele haver por ausencia de los offiçiales de organo y baxon". ${ }^{87}$ La instrucción de los mozos de coro se iniciaba con el aprendizaje del canto llano, usando como material didáctico el monocordio. La descripción que hace Alegria de los contenidos de las primeras lecciones de música que recibían los mozos en Évora (muy similar a la que aparece en la História da música portuguesa de João de Freitas Branco) evidentemente coincide en buena parte con los contenidos conceptuales del manual de canto llano de Aranda, ${ }^{88}$ pero también con los del Arte de canto llano de Martínez, como muestra la Tabla IV.7. ${ }^{89}$

\footnotetext{
${ }^{85}$ Aranda, Tractado de canto llano, f. C4r.

${ }^{86}$ Villafranca, Breue instrucion de Canto llano, ff. B5r, C1v-C2r. Véase el Capítulo II.

${ }^{87}$ Lola de la Torre, La música en la Catedral de Las Palmas, 1514-1600: documentos para su estudio (Madrid: SEdeM, 1983), p. 70, nº 561.

${ }^{88}$ Alegria, História da escola de música da Sé de Évora, p. 60; Branco, História da música portuguesa, p. 144.

${ }^{89}$ Vieira, Diccionario biographico de musicos portuguezes, vol. 2, pp. 66-67, asegura que el libro de Juan Martínez fue utilizado en el Seminario de Évora.
} 
Tabla IV.7: Comparación de las lecciones de música de la Sé de Évora con el contenido de los manuales de canto llano de Mateo de Aranda y Juan Martínez

\section{Contenido de Aranda, Tractado de canto llano (Lisboa, 1533).}

\author{
Contenido de las lecciones de \\ música en la Sé de Évora en la \\ época de Mateo de Aranda según \\ Alegria, História da escola de \\ música da Sé de Évora, p. 60.
}

Contenido de Martínez, Arte de canto llano (Sevilla, 1530).
Conclusion primera de las siete letras del canto

Conclusion segunda de las propiedades y vozes y signos y deduciones

[Tabla]

Conclusion tercera de las claues

Conclusion quarta de la voz que se ha de tomar en principio del canto

Conclusion quinta de las mutanças

Conclusion sexta de vnisonus: y de los interuallos: que hazen consonançias y disonançias: que el canto muestra por sus mouimientos

Conclusion septima de ocho modos de cantar

Conclusion octaua de tres generos de melodia: y orden y manera de diuisiones

[Tablas]

Manera de como el canto se a de enseñar y entender

Declaracion de algunas cosas que en este tractado se contienen
El primer material didáctico era la mano del alumno.

El maestro recalcaba las tres letras más importantes (sol, do y fa), por las que introducía al educando en las propiedades, voces, signos y deducciones. Esta iniciación conllevaría días de repeticiones constantes, así como la memorización de una tabla.

Los mozos de coro utilizaban los libros litúrgicos para conocer las claves, los nombres de las notas y la justificación de las mutanzas.

Los mozos de coro aprendían el sistema de intervalos y los ocho modos, lo cual exigía bastante tiempo.

El maestro impartía lecciones sobre los géneros de la música (lecciones teóricas en las que se utilizaba un cuadro de tonos demostrados matemáticamente).

Ahora el cantor podía comenzar a leer la música en sus respectivos modos.
[Mano guidoniana]

Capitulo primero de las letras Capitulo segundo de los Signos

Capitulo .iii. de las mutanças Capitulo quarto de las claues

Capitulo .v. de los modos Capitulos .vi. de los mouimientos Capitulo septimo de las diuisiones de los tonos

Capitulo .viii. de las disjuntas

Capitulo .ix. de las consonancias

Capitulo .x. de los generos de musica

[Tabla]

[Ejemplo musical: "las bozes musicales" (primeras, segundas, terceras, quartas, quintas y sextas)]

Incipiunt intonaciones Psalmorum e de Magnificat Incipiunt Introitus misse Incipiunt Glorie responsoriorum Sequitur canticum, quod in Ecclesia cantatur in laudem Beatisimae Virginis

[Letra de Sanctissimae trinitati] 
Al mismo tiempo que aprendían el canto llano, los mozos podían comenzar a estudiar la teoría del canto de órgano (polifonía). Con respecto a los infantes de la Catedral de México, también se aprecia un solapamiento temporal en la enseñanza de canto llano y polifonía; los infantes "daban dos clases diarias de canto llano, canto de órgano y contrapunto con el maestro de capilla, desde las seis y media hasta las siete y media (inicio de prima) y desde las ocho (fin de prima) hasta las nueve (inicio de tercia)". ${ }^{90}$ Los Capítulos de Burgos contienen un programa de estudios con indicaciones temporales: durante cuatro meses, los niños sólo aprenden canto llano; después, sin abandonar esta materia, se inician en el canto de órgano aprendiendo las figuras y realizando ejercicios de copia de obras hasta a cuatro voces en sus cuadernos; a continuación, se inician en el canto de estos ejercicios; después, se les enseña contrapunto; y, por último, quienes tienen cualidades para ello, aprenden el arte de la "compostura". ${ }^{91}$ En Sevilla, sin embargo, la distinción entre seises y mozos de coro llevó a una diversificación de las enseñanzas (véase Tabla IV.8). El maestro de canto de órgano (después llamado "catedrático de canto de órgano”) era el encargado de enseñar esta disciplina a los cantores, mientras que el maestro de los mozos de coro, elegido mediante un concurso oposición en el cual solía intervenir el maestro de capilla, era el experto en canto gregoriano e impartía esta materia (enseñanza que se llamó durante un período “cátedra de melodía"). ${ }^{92}$ Esta especialización contrasta con la tendencia general según la cual el experto en polifonía lo era también en monodia; por ejemplo, Alegria sostiene la complementariedad de los tratados de canto llano y canto de órgano de Mateo de Aranda como dos partes de un sistema único. ${ }^{93}$

\footnotetext{
${ }^{90}$ Marín López, “Música y músicos entre dos mundos”, p. 70.

91 González Barrionuevo, Francisco Guerrero (1528-1599), p. 174. El mismo proceso se describe en Fiorentino, "Música española del Renacimiento entre tradición oral y transmisión escrita", p. 541.

92 González Barrionuevo, Francisco Guerrero (1528-1599), p. 170.

93 Alegria, "Prefácio", p. 12.
} 
Tabla IV.8: Cotejo de las características de seises y mozos de coro en la Catedral de Sevilla

\begin{tabular}{|c|c|c|}
\hline & Seises & Mozos de coro \\
\hline $\begin{array}{l}\text { Requisitos de } \\
\text { acceso }\end{array}$ & $\begin{array}{l}\text { No tener más de } 10 \text { años. } \\
\text { Saber leer y escribir. } \\
\text { Demostrar voz y oído musical ante } \\
\text { el cabildo o una comisión elegida } \\
\text { para ello. }\end{array}$ & $\begin{array}{l}\text { Tener entre } 10 \text { y } 16 \text { años. } \\
\text { Saber leer y escribir. }\end{array}$ \\
\hline Elección & $\begin{array}{l}\text { Eran "preseleccionados" por el } \\
\text { maestro de capilla (o por un re- } \\
\text { presentante de éste) y el cabildo } \\
\text { tenía la última palabra. }\end{array}$ & $\begin{array}{l}\text { Dos terceras partes eran nombradas por el } \\
\text { cabildo y una tercera parte por el chan- } \\
\text { tre. }\end{array}$ \\
\hline Número & Entre 4 y 10 , normalmente 6 . & Aproximadamente 20 . \\
\hline Alojamiento & Vivían con el maestro de capilla. & $\begin{array}{l}\text { Salvo en el período comprendido entre } \\
1532 \text { y } 1538 \text {, en que vivieron en el Co- } \\
\text { legio de San Isidoro fundado por Alon- } \\
\text { so Manrique, vivían en sus respectivas } \\
\text { casas (eran "manteistas"). }\end{array}$ \\
\hline Salario & No recibían salario. & Recibían un salario mensual. \\
\hline $\begin{array}{l}\text { Contenido de las } \\
\text { clases que recibían }\end{array}$ & $\begin{array}{l}\text { Canto llano, canto de órgano, con- } \\
\text { trapunto y gramática. }\end{array}$ & Canto llano y gramática. \\
\hline Funciones & $\begin{array}{l}\text { Interpretaban las voces agudas de } \\
\text { las obras polifónicas y algunos } \\
\text { versos de canto llano en el Ofi- } \\
\text { cio. }\end{array}$ & $\begin{array}{l}\text { Servían en el altar y en el coro como } \\
\text { acólitos. } \\
\text { Participaban en el canto del Oficio Di- } \\
\text { vino. } \\
\text { Algunos eran miembros del grupo de } \\
\quad \text { cantores de canto llano. }\end{array}$ \\
\hline
\end{tabular}

De los autores de artes de canto que he estudiado, Manuel Mendes, Juan Martínez y Luis de Villafranca ocuparon el puesto de maestro de los mozos de coro, mientras que Sebastián Vicente Villegas desempeñó un cargo quizás similar, ya que en la portada de su libro se identifica como maestro de canto llano. Fuentes de primer orden para determinar las obligaciones docentes del maestro de los mozos de coro son los estatutos

\footnotetext{
94 Avenoza, "Lope García de Salazar", p. 2: "Los términos mozo y mocedad se refieren a una época capital en la formación de los jóvenes que, superada la niñez, aún no están capacitados para intervenir activamente en los asuntos de la vida adulta". Según Avenoza, la mocedad se sitúa entre los siete y los catorce años.

${ }^{95}$ Simón de Rosa y López, Los seises de la Catedral de Sevilla: ensayo de investigación histórica (Sevilla: Francisco de P. Díaz, 1904), p. 41.
} 
del arzobispo Fernando Valdés (1546-1568) y el "Reglamento de Bartolomé Olalla de Rojas" (1598, aunque debió funcionar con anterioridad). ${ }^{96}$ Fuera del ámbito de la Catedral de Sevilla encontramos documentos semejantes; en la Catedral de Badajoz, el cabildo elaboró en 1534 un reglamento por el que se regiría Juan Vásquez; ${ }^{97}$ y en la Catedral de México existe un manuscrito titulado "Instrucción tocante a la enseñanza y crianza de los infantes", elaborado por el deán Pedro de Vega Sarmiento y copiado en 1615. ${ }^{98}$ González Barrionuevo indica que los mozos de coro recibían por la mañana clase de canto llano, latín, doctrina cristiana y ceremonias, y que por la tarde se repetían las lecciones de la mañana y se practicaba escritura y lectura. ${ }^{99}$ Los estatutos del arzobispo Fernando Valdés, los cuales desvelan que estas lecciones, como las de los maestros de capilla, eran "abiertas al público"; el maestro de los mozos de coro debía "dar lección de canto llano, por persona, todos los días que no fuese domingo o fiesta de guardar, así a los mozos de coro como a todos cuantos quisieren tomarlo, lo cual haga sin interés alguno, tarde y mañana”. Carecemos de información acerca del programa de estas clases de música, pero González Barrionuevo remite precisamente a los tratados de Juan Martínez y Luis de Villafranca para determinar los contenidos de las lecciones de canto llano; puesto que eran los manuales que se "solían seguir", "nada mejor que dirigirse a estas obras para hacernos una idea del programa seguido por estos maestros en las clases de canto llano en el siglo XVI". ${ }^{100}$

Antes de la aparición del puesto específico de maestro de los mozos de coro, el sochantre era el encargado de enseñar canto y ceremonias a los mozos de coro, de manera que cuando se instauró el nuevo cargo, éste solía ser ocupado por el sochantre; ${ }^{101}$ encontramos un ejemplo en la Catedral de México, donde se instituyó el puesto de

\footnotetext{
${ }^{96}$ Este último documento se encuentra transcrito en González Barrionuevo, Los seises de Sevilla, pp. 293296, y es citado en Rosa y López, Los seises de la Catedral de Sevilla, p. 56.

${ }^{97}$ Carmelo Solís Rodríguez, "Datos para una biografía”, en Juan Vázquez. Agenda Defunctorum. Sevilla, 1556. Estudio técnico-estilístico y transcripción, ed. por Samuel Rubio (Madrid: Real Musical, 1975), p. $\mathrm{X}$.

${ }^{98}$ Marín López, “Música y músicos entre dos mundos”, p. 69.

${ }^{99}$ González Barrionuevo, Francisco Guerrero (1528-1599), pp. 693-695.

${ }^{100}$ González Barrionuevo, Francisco Guerrero (1528-1599), p. 695; véase también Ruiz Jiménez, "From Mozos de coro Towards Seises", p. 92.

${ }^{101}$ González Barrionuevo, Francisco Guerrero (1528-1599), p. 696.
} 
maestro de lo mozos de coro en $1584 .{ }^{102}$ Además, en los lugares donde no se creó el puesto de maestro de los mozos de coro, el sochantre como tal siguió encargándose de impartir estas enseñanzas. Una circunstancia que corrobora este último caso es la publicación en 1612, 1614 y 1625 de ediciones del Arte de canto llano de Juan Martínez revisadas por António Cordeiro, sochantre de la Sé de Coimbra. ${ }^{103}$ Entre las obligaciones del sochantre recogidas en El Melopeo y Maestro no se hace referencia a función docente alguna, estableciéndose que la labor del sochantre era "emendar las composiciones falsas" y "mantener el Choro en tono y consonante". ${ }^{104}$ En el caso mexicano se menciona la misma labor de dirección del coro en una solicitud de plazas de sochantre, "ya que, aunque los chantres estuvieran bien instruidos en la teoría musical, era excepcional que tuvieran la voz adecuada para dirigir el canto llano". ${ }^{105}$ También en la Catedral de Sigüenza se señala que el sochantre desempeñaba la función de dirigir el coro, pero que no tenía obligaciones docentes, las cuales eran desempeñadas por el maestro de capi1la. ${ }^{106}$ Sí encontramos una muestra de funciones docentes entre las obligaciones de Juan Vázquez cuando fue nombrado sochantre de la Catedral de Badajoz, cargo que ocupó entre 1535 y 1538: “e le mandaron que haga su oficio de sochantre y enseñe los moços de coro conforme a la constitución y que aliende del salario que le da el chantre aya de cada moço de choro cada año dosyentos maravedis". ${ }^{107}$ También existen referencias a las obligaciones docentes del sochantre en la Abadía del Sacromonte de Granada: "los colegiales habían de colaborar en el coro de clérigos y asistir a las clases de música que

\footnotetext{
${ }^{102}$ Marín López, "Música y músicos entre dos mundos”, p. 68. En el Diccionario de la música española e hispanoamericana, vol. 9, p. 1102, se define "sochantre" como "director de coro en el Oficio divino", mientras que, en The New Grove Dictionary, "succentor", el término inglés para sochantre, se define como "miembro de la clerecía de la Iglesia Anglicana". Para un reglamento sobre el oficio de sochantre en el caso de la Catedral de Granada, véase Casares Hervás, Archivo Catedral, p. 37 (año 1537, legajo 23/24).

${ }^{103}$ Sobre António Cordeiro, véanse Barbosa Machado, Bibliotheca Lusitana Historica, Critica, e Cronologica, vol. 1, p. 246; y Ricart i Matas, Diccionario biográfico de la música, p. 239.

${ }^{104}$ Cerone, El Melopeo y Maestro, p. 479, Libro V, Cap. 100: "Del oficio del sochantre o cantoral y como se ha de auer en el choro".

${ }^{105}$ Roldán Herencia, “La música eclesiástica en Nueva España”, p. 286.

${ }^{106}$ Jambou, "La capilla de música de la Catedral de Sigüenza en el siglo XVI”, pp. 284-285.

${ }^{107}$ Solís Rodríguez, "Datos para una biografía”, p. x, nota 22.
} 
impartía el sochantre". ${ }^{108}$ António Cordeiro, como sochantre de la Sé de Coimbra, debió de desempeñar labores docentes y utilizar como manual el Arte de canto llano de Juan Martínez, puesto que lo revisó para su reedición en tres ocasiones. Sin duda, en un principio, Cordeiro utilizó en sus lecciones la edición traducida al portugués y ampliada por Afonso Perea Bernal en 1597, ya que las reediciones que preparó contienen tal cual la ampliación escrita por Perea Bernal.

\subsubsection{LA PUBLICACIÓN DE MANUALES DE CANTO EN EL CONTEXTO MONÁSTICO}

Las artes de canto no sólo reflejan las prácticas docentes en las capillas catedralicias, sino que también tuvieron una importante presencia en la docencia musical desarrollada por las órdenes religiosas. Como se examinará en el Capítulo V a propósito de El arte Tripharia de Juan Bermudo, una de las funciones de los religiosos de una Orden era el canto del Oficio Divino y debían ser instruidos para ello. María Sanhuesa Fonseca ha trabajado en este ámbito, centrándose en las artes de canto gregoriano, ${ }^{109} \mathrm{o}$ bien en los libros de música empleados por órdenes religiosas concretas como la Orden de San Jerónimo ${ }^{110}$ o la Orden de la Merced. ${ }^{111}$ De los estudios de esta musicóloga se desprende un afán por parte de los músicos del ámbito monástico de escribir manuales de música, pero también se deduce que en el siglo XVI muchos de estos libros no llegaron a la imprenta, quizás porque no respondían a una estrategia editorial ni pretendían una difusión más allá de los muros del monasterio.

\footnotetext{
${ }^{108}$ Mercedes Castillo Ferreira, "Patronazgo musical indiano en Granada: la familia Vaca de Castro y la Abadía del Sacromonte en el siglo XVII”, en La Música y el Atlántico, coord. y ed. por María Gembero Ustárroz y Emilio Ros-Fábregas (Granada: Universidad de Granada, 2007), pp. 69-87, p. 78.

${ }^{109}$ Sanhuesa Fonseca, “Artes de canto llano en las órdenes religiosas españolas del siglo XVII”.

${ }^{110}$ María Sanhuesa Fonseca, "La teoría musical en los monasterios jerónimos (siglos XV-XIX): notas bio-bibliográficas", en La orden de San Jerónimo y sus monasterios: actas del simposium (II), 1/5-IX1999, coord. por Francisco Javier Campos y Fernández de Sevilla (San Lorenzo del Escorial: Estudios Superiores de El Escorial, 1999), vol. 1, pp. 575-591. Sobre los libros de música utilizados por la orden de San Jerónimo, véanse Samuel Rubio, "Los jerónimos de El Escorial, el canto gregoriano y la liturgia", La Ciudad de Dios, CLXXXII (1969), pp. 225-231; José López-Calo, "La música en el rito y en la orden jeronimianos", en Studia Hieronymiana: VI Centenario de la Orden de San Jerónimo (Madrid: Orden de San Jerónimo, 1973), vol. 1, pp. 123-138, donde únicamente se citan artes de canto publicadas en el siglo XIX; y Vicente Delgado, "Los cargos musicales y las capillas de música en los monasterios de la orden de San Jerónimo (siglos XVI-XIX)".

${ }^{111}$ María Sanhuesa Fonseca, "Libros litúrgicos y teóricos musicales en la Orden de la Merced", en Campos interdisciplinares de la musicología: V Congreso de la Sociedad Española de Musicología (Barcelona, 25-28 de octubre de 2000), coord. por Begoña Lolo (Madrid: SEdeM, 2001), vol. 2, pp. 841-859.
} 
De los autores de las artes de canto impresas que son objeto de mi investigación, únicamente Dámaso Artufel se inserta en el contexto monástico como cantor en monasterios dominicos en Francia y los reinos de Aragón y Castilla; su Arte de canto llano no es una obra independiente, sino que constituye un fragmento de una obra mayor titulada Modo de rezar las horas canonicas conforme al rezo de los Frailes Predicadores. Las órdenes religiosas también utilizaron artes de canto de autores externos. Como mostraba el Capítulo II, las artes de canto debieron tener un mercado institucional constituido principalmente por monasterios y universidades. Buena parte de los ejemplares de artes de canto que he consultado pertenecieron a congregaciones religiosas; por ejemplo, algunas de las artes de canto conservadas actualmente en la Biblioteca de Reserva de la Universitat de Barcelona pertenecieron a monasterios de Barcelona y fueron traspasadas a la Biblioteca entre los documentos procedentes de la desamortización de Mendizábal en el siglo XIX. Los inventarios de los conventos y monasterios también proporcionan evidencia en este sentido: el Arte de canto llano de Juan Martínez aparece inventariado en el catálogo de libros que en 1642 pertenecían al Convent de Jesús de Maó (Menorca), por lo que es posible que se utilizara como instrumento docente en esta institución; ${ }^{112}$ otro ejemplo paradigmático es El arte Tripharia de Bermudo, dedicado a Doña Isabel Pacheco, Abadesa del Convento de Santa Clara de Montilla (Córdoba) y que se estudiará separadamente en el Capítulo V.

Si las artes de canto han servido como fuente para aproximarse a las prácticas pedagógicas del mundo ibérico renacentista y al lugar de la música en las capillas catedralicias y los conventos, otras fuentes complementan este estudio. Encontramos referencias al papel desempeñado por la música en las instituciones religiosas en cuentos populares y en libros de historia de las instituciones religiosas. Algunos de los cuentos populares anotados en las primeras décadas del siglo XVII y conservados en un manuscrito de la Biblioteca Nacional de España bajo el título Cuentos muy mal escritos que notó don Juan de Arguijo recogen vestigios de la formación de un determinado sacristán, de las obligaciones de un corneta de la Catedral de Sevilla y, sobre todo, proporcionan una valiosa información sobre el lugar de la música en la vida cotidiana y su imbricación en la cultura de la época:

\footnotetext{
${ }^{112}$ Casasnovas i Camps, Biblioteques, llibres i lectors, p. 284.
} 
[Cuento 199] Un sacristán de una aldea, en los oficios divinos cantaba siempre por la posta, tras de pronunciar mal como quien no sabía latín; y así, farfullando el Credo, en lugar de decir "Credo in unum Deum", decía siempre "credo non in Deum".

[Cuento 430] A Peraza el corneta, estando en Sevilla en un día de agosto de grandísimo calor, envió el chantre a decir que subiese al órgano a tañer. Respondió que estaba calurosísimo, que no podía. Replicó el chantre que so pena de descontarle cuatro días. Respondiólo que si los días eran tales, le hacía grandísimo favor en quitarle ocho.

[Cuento 657] Estaba oyendo fray Juan de la Barrera, el agustino, una maldita música, y dijo por alabarla, con gran mesura:

- ¡Válgame Dios! Si esto hay en la tierra, ¿qué habrá en el infierno?

[Cuento 686] Farfán, oyendo a un fraile organista de su orden que, a cada cosa que tañía no se hartaba de alabarlo, diciendo:

- Oiga esto V.P., que es lo mejor que se ha tañido en el mundo-, y otras alabanzas semejantes, le dijo muy mensurado:

- Padre, no lo trabaje todo V.R., sólo tañed[1]o bien, y nosotros lo alabaremos. ${ }^{113}$

Además de estos cuentos breves o chistes populares que se dice surgieron en las tertulias convocadas en Sevilla por el poeta y músico Juan de Arguijo (1567-1623), el Libro de la Historia y Milagros hechos a inuocacion de nuestra Señora de Montserrate (Barcelona, 1582) de Pedro de Burgos actúa como fuente de prácticas de docencia musical en la vida monacal. En el quinto capítulo de la obra, que se titula "De la gente y compaña que residen en la camara angelical de nuestra señora de Montserrate, y de los exercicios dellos", se explican las labores de los 17 ó 18 niños escolares que servían en la institución:

[...] tienen el cargo cada mañana antes del dia de cantar y oficiar la missa de nuestra Señora que llaman alli la missa matutinal, a vezes a canto llano y a vezes a canto de organo, tienen cargo tambien de dezir a canto de organo o canto llano cada noche [...] los gozos y salues, profas, y otras muchas deuociones y cantos muy devotos de la virgen Maria, y seruir tambien a las missas, que se dizen continuamente en aquella iglesia. Y estos son alli adoctrinados en leer, y escriuir, y en cantar canto llano, y canto de organo, y en los mandamientos de Dios y finalmente en toda buena doctrina, y costumbre. ${ }^{114}$

${ }^{113}$ Cuentos muy mal escritos que notó don Juan de Arguijo, MS (siglo XVII), Madrid, Biblioteca Nacional de España, MSS/19380. Tomado de la transcripción de Beatriz Chenot y Maxime Chevalier, Cuentos recogidos por Juan de Arguijo y otros (Sevilla: Excma. Diputación Provincial, 1979).

${ }^{114}$ Pedro de Burgos, Libro de la Historia y Milagros hechos a inuocacion de nuestra Señora de Montserrate (Barcelona: Pedro Malo, 1582), f. 20; véase también Xose Aviñoa, dir., Història de la música catalana, valenciana i balear (Barcelona: Edicions 62, 2000), vol. 1, p. 228. 


\section{2. ¿Artes de canto en las escuelas de latín?}

La escuela de gramática o colegio era la institución encargada de la "educación secundaria" en el mundo ibérico de la época y en ella la materia principal era la gramática latina, ${ }^{115}$ por lo que fueron causa de la proliferación de las llamadas "artes de Antonio", muy frecuentes en los inventarios de bienes de la época. ${ }^{116}$ Como ha señalado Cristle Collins Judd, algunos autores de tratados de teoría de la música en el contexto europeo estuvieron vinculados a escuelas latinas, por lo que contamos con numerosos estudios sobre el lugar de la música en estas instituciones, si bien circunscritos al ámbito protestante. ${ }^{117}$ Los libros Musica (1507), un tratado de 15 folios con las notas añadidas a mano, y Tetrachordum musices (1511) de Johannes Cochlaeus (1479-1552) son ejemplos de tratados de música vinculados a escuelas de latín; otros ejemplos son Musica stoicheiōsis (Nuremberg, 1532), ${ }^{118}$ Musica, id est Artis canendi, libri duo (Nuremberg, 1537), y De arte canendi, ac vero signorum in cantibus usu, libri duo (Nuremberg, 1540) de Sebald Heyden (1499-1561). Tanto Johannes Coechlaeus como Sebald Heyden estaban afiliados a escuelas latinas de Nuremberg y sus tratados se utilizaban como libros de texto en estas instituciones; la mayor parte de los ejemplares conservados de estos tratados eran propiedad de las escuelas latinas de Nuremberg. ${ }^{119}$ Por la información que aporta sobre el lugar de la música en las escuelas latinas, tanto Cristle Collins Judd como Susan F. Weiss recogen la ilustración xilográfica que aparece en la portada del libro de gramática latina de Paulus Naivis, Latinum idioma pro parvulis editum $(\mathrm{Nu}-$

\footnotetext{
${ }^{115}$ Kagan, Students and Society in Early Modern Spain, p. 31.

${ }^{116}$ Antonio de Nebrija, Introductiones latinae (Salamanca: [Tip. epónima], 1481).

117 Véanse Bruce A. Bellingham, "The Bicinium in the Lutheran Latin Schools During the Reformation Period", Tesis Doctoral (Ph.D.), University of Toronto, 1971, sobre el uso de composiciones a dos voces como herramienta didáctica en las escuelas luteranas desde c. 1520 a 1560; J. Kevin Waters, "Handbook of Two Musical Practices: Plainsong. An English Translation and Annotation of Georg Rhaw's Enchiridion utriusque musicae practicae (musica plana)", Tesis Doctoral (DMA), University of Washington, 1970, acerca de la utilización de Enchiridion utriusque musicae practicae (1538) de Georg Rhaw en las escuelas latinas de la Alemania del Renacimiento; y Klaus Wolfgang Niemöller, Untersuchungen zu Musikpflege und Musikunterricht an den deutschen Lateinschulen vom ausgehende Mittelalter bis um 1600 (Regensburg: Bosse, 1969), para una historia de la pedagogía musical que incluye el análisis de más de treinta libros de texto.

${ }^{118}$ Reedición del tratado perdido Rudimenta [Institutiones musices] (Nuremberg, 1529).

${ }^{119}$ Judd, Reading Renaissance Music Theory, p. 95.
} 
remberg, 1494), que muestra un aula con una pizarra al fondo que contiene notación musical; véase Ilustración IV.8. ${ }^{120}$

Ilustración IV.8: La presencia de la música en las escuelas de latín. Paulus Naivis, Latinum idioma pro parvulis editum (Nuremberg: Friedrich Creussner, 1494), portada.

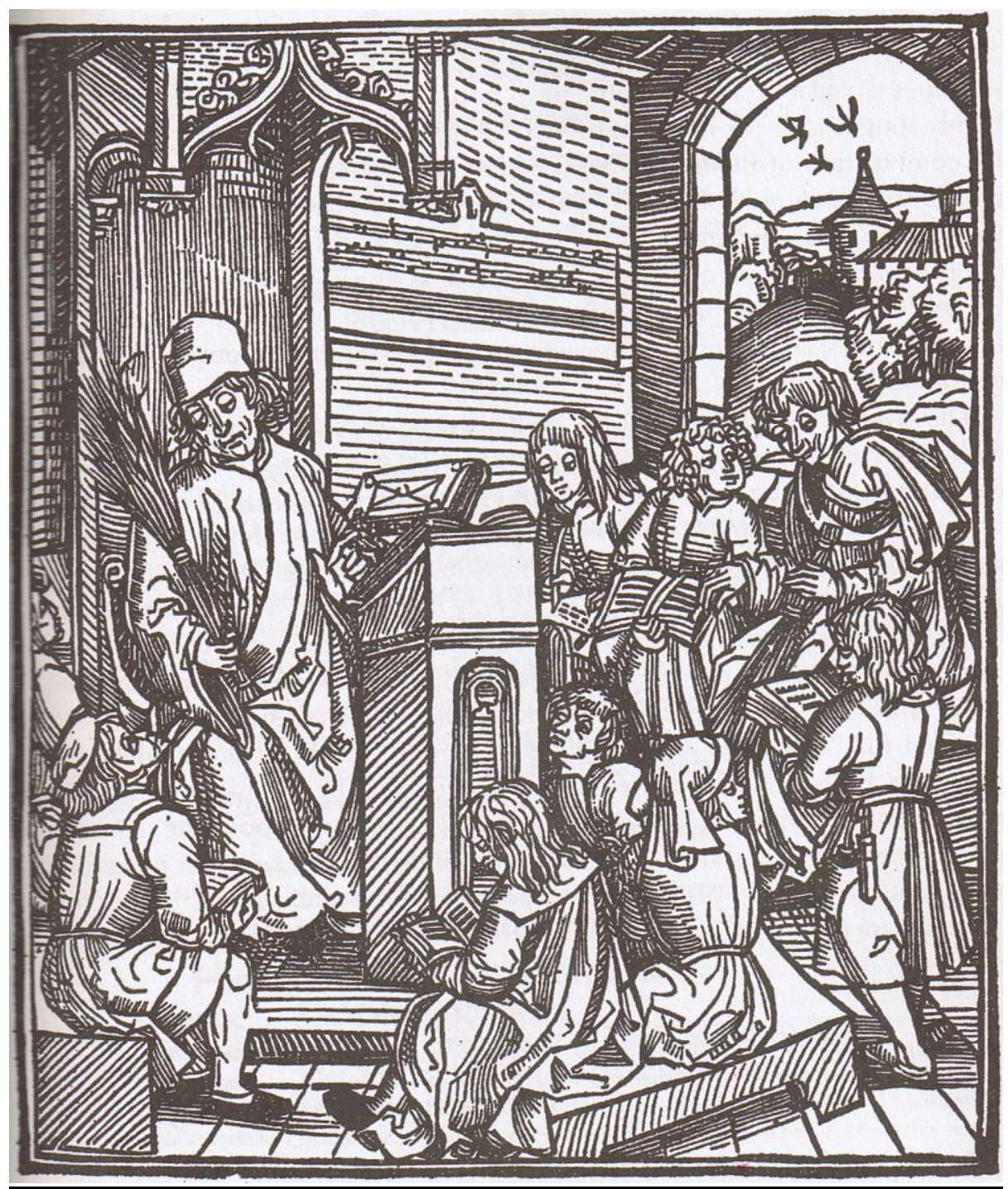

${ }^{120}$ Judd, Reading Renaissance Music Theory, p. 85; Weiss, "Disce Manum Tuam si vis bene discere cantum", p. 58. 
Encontramos información acerca del contenido de las lecciones en las escuelas latinas del mundo ibérico renacentista en las fuentes literarias de la época. Vicente Espinel declaraba que estudió latín en Ronda en las aulas del bachiller de la gramática Juan Cansino, que le enseñó también "un poco de música". ${ }^{121}$ Desconocemos más casos que nos permitan establecer si la introducción de contenidos musicales en las escuelas de latín era un fenómeno generalizado en el mundo ibérico, pero del testimonio de Espinel se deduce que la investigación en este ámbito podría conducir a hallazgos relevantes. Además, no sería un hecho insólito que, como en el caso europeo, en estas escuelas se utilizaran artes de canto como libros de texto. La conexión entre música y escuelas latinas es un signo de la conexión de la enseñanza musical con la enseñanza de la retórica. Por ejemplo, De oratione libri septem (Basilea, 1558) de Antonio Lull (Mallorca, c. 1510 - Besançon, 1582) es una obra sobre retórica surgida en el contexto de las lecciones de teología que impartía el autor desde 1535 en la Universidad de Dôle, en la cual incluyó la música como una de las disciplinas necesarias en la formación del orador. Lull explicaba la relación entre retórica y música en términos de elocutio, cuyos componentes, numerus y melos, son empleados por los oradores, los poetas y los músicos. ${ }^{122}$

Susan F. Weiss ha señalado que, ya desde la época de Carlomagno, el currículum monástico requería un maestro versado a la vez en gramática, música y cómputo, de manera que el aprendizaje de la gramática y la música estuvieron ligados desde la

\footnotetext{
${ }^{121}$ Vicente Espinel, Relaciones de la vida del escudero Marcos de Obregon (Madrid: Juan de la Cuesta, a costa de Miguel Martínez, 1618), p. 35. Acerca de la posible identificación de Juan Cansino con el gramático Juan de Aguilar, véase Dámaso Alonso, "Juan de Aguilar y el Juan Cansino del 'Marcos de Obregón"”, Revista de Dialectología y Tradiciones Populares, XXXII/1 (1976), pp. 13-16.

${ }^{122}$ Klaus Wolfgang Niemöller, "Ars musica - ars poetica - musica poetica”, en Bericht über den internationalen musikwissenschaftlichen Kongreß, ed. por Walter Gerstenberg, Harald Heckmann y Heinrich Husmann (Kassel: Bärenreiter-Verlag, 1957), pp. 170-171; Heinrich Hüschen, "Die Musik im Kreise der artes liberales", en el mismo volumen colectivo, pp. 117-123; y Lawrence Gushee, "Questions of Genre in Medieval Treatises on Music", en Gattungen der Musik in Einzeldarstellungen. Gedenkschrift Leo Schrade, ed. por Wulf Arlt, Ernst Lichtenhahn, Hans Oesch y Max Haas (Bern, Munich: Francke, 1973), vol. 1, pp. 365-433; José-Vicente González Valle, "Música y retórica: una nueva trayectoria de la 'ars musica' y la 'música práctica' a comienzos del Barroco", Revista de Musicología, X (1987), pp. 811-841; y "Relación música y lenguaje en los teóricos españoles de música de los siglos XVI y XVII", Anuario musical, XLIII (1988), pp. 95-109; Karen Desmond, "Sicut in grammatica: Analogical Discourse in Chapter 15 of Guido's Micrologus", The Journal of Musicology, XVI/4 (1998), pp. 467-493; y Joseph Dyer, "The Place of Music in Medieval Classifications of Knowledge", The Journal of Musicology, XXIV/1 (2007), pp. 3-71.
} 
Edad Media, ${ }^{123}$ siendo evidencia de ello el hecho de que en ocasiones un mismo autor escribía manuales de música y gramática. ${ }^{124}$ Aunque no he encontrado conexiones de los autores de artes de canto impresas con la enseñanza de la gramática en el mundo ibérico renacentista, quizás futuras investigaciones en este campo conduzcan al descubrimiento de relaciones similares a las que se produjeron en el mundo protestante.

\subsection{La presencia de manuales prácticos en las aulas universitarias}

Las múltiples reimpresiones de artes de canto en ciudades con universidad muestra la demanda de estos libros en el contexto universitario. Como muestra el Apéndice 6, en Salamanca salieron a la luz el Comento sobre Lux bella (1498) de Domingo Marcos Durán, la Introduction muy breue de canto llano (c. 1498) de Cristóbal Escobar, el Tratado de Canto llano (1503) perdido de Juan Rodríguez, la Sumula de canto de organo (c. 1504) de Marcos Durán, el tratado de canto llano perdido de 1504 de Alonso del Castillo, Portus musice (1504) de Diego del Puerto, la reedición de 1509 de Lux bella de Marcos Durán, la reedición de 1599 del libro de Juan Martínez y las reediciones de 1610, 1616 y 1625 del Arte de canto llano de Montanos. En Alcalá de Henares se imprimió en 1532 y 1598 el Arte de canto llano de Martínez, y en 1544, 1554, 1559 y 1566 el Arte ingeniosa de musica de Melchor de Torres. En Coimbra se publicó el Arte de canto llano de Juan Martínez en 1550, 1597, 1603, 1612, 1614 y 1625, y el Arte de canto chão de Pedro Thalesio en 1618 y 1628.

En el ámbito europeo, Nan Cooke Carpenter ha estudiado la vinculación de los tratados musicales medievales y renacentistas "diseñados para o resultantes de los estudios universitarios" con la enseñanza de la música. ${ }^{125}$ Tras completar el curso en gramática latina, quien tenía la oportunidad continuaba sus estudios en una institución que se

\footnotetext{
${ }^{123}$ Weiss, "Disce Manum Tuam si vis bene discere cantum", p. 42. Sobre las conexiones entre la mano musical, el sistema guidoniano y el arte antiguo de la retórica, véase Berger, "The Hand and the Art of Memory".

${ }^{124}$ Weiss, "Disce Manum Tuam si vis bene discere cantum", p. 72. Véanse Charles Atkinson, "Glosses on Music and Grammar and the Advent of Music Writing in the West", en Western Plainchant for the First Millennium: Studies in the Medieval Liturgy and Its Music, ed. por Sean Gallagher et al. (Aldershot: Ashgate, 2003), pp. 199-215; y Haar, "Lessons in Theory from a Sixteenth-Century Composer”, p. 150.

${ }^{125}$ Carpenter, Music in the Medieval and Renaissance Universities, p. vi. Un trabajo más reciente sobre la Universidad de París es Joseph Dyer, "Speculative Music and the Medieval University of Paris", Music \& Letters, XC/2 (2009), pp. 177-204.
} 
llamó Estudio General hasta el siglo XVII y Universidad a partir de entonces. ${ }^{126}$ Aunque no todos los autores identifican Estudio General y Universidad (algunos consideran que en el Estudio General tenían lugar unos estudios previos a los universitarios), ${ }^{127}$ parece que se produjo una transformación a lo largo del siglo XVI en las instituciones de las ciudades castellanas, de manera que las "cátedras de gramática" se convirtieron en Estudios Generales y éstos en Universidades. ${ }^{128}$ Carecemos de programas de estudio que permitan determinar los contenidos concretos de las lecciones de música en las aulas universitarias, pero en los Estatutos de 1529 de la Universidad de Salamanca encontramos referencias a la combinación de contenidos teóricos y prácticos, disposición que se mantiene en los Estatutos de 1551 y 1561:

El catedratico de musyca lehera una parte de su hora de la especulacion de la musyca y otra parte que hexercite los oyentes en cantar, que hasta el mes de março muestre canto llano y de alli a la fiesta de San Juan canto de horgano, y de alla a bacaciones el o su sostituto contrapunto les muestre. $^{129}$

Como también señala Dámaso García Fraile, "se estructura la docencia musical en la Universidad de Salamanca en dos grandes bloques: la música especulativa y la música práctica, y ésta a su vez, en tres géneros: canto llano, canto de órgano y contrapunto"; según este investigador, los dos bloques constituían materias independientes

\footnotetext{
${ }^{126}$ Kagan, Students and Society in Early Modern Spain, p. 62.

${ }^{127}$ Sobre el Estudio segoviano fundado por Juan Arias Dávila, véanse Mariano Sanz González, "La reforma de la Iglesia en los sínodos de Juan Arias Dávila”, en Arias Dávila: obispo y mecenas. Segovia en el siglo XV, ed. por Ángel Galindo García [Actas del Congreso] (Salamanca: Universidad Pontificia de Salamanca, 1998), pp. 417-453, p. 439; y Bonifacio Bartolomé Herrero, "La actividad eclesiástica del obispo de Segovia Juan Arias Dávila (1461-1497)", en el mismo volumen colectivo, pp. 495-511, p. 504. Romero de Lecea, Introducción a los viejos libros de música, p. 98, ha asegurado que a esta institución debían acudir "los clérigos de aquella diócesis que sean habidos inhábiles de leer latín y cantar" y que en ella se aprendía el canto llano.

${ }^{128}$ García Oro y Portela Silva, Monarquía y escuela en la España del Renacimiento, p. 21.

${ }^{129}$ Universidad de Salamanca, Estatutos de la Universidad de Salamanca, 1529: mandato de Pérez de Oliva, rector, ed. por José Luis Fuertes Herreros (Salamanca: Universidad de Salamanca, 1984), p. 144. Acerca de los estatutos de 1551, véase María Fernández Ugarte, "Estatutos de la Universidad de Salamanca: la reforma de 1550-1551”, Studia historia. Historia moderna, VII (1989), pp. 687-705. Para los Estatutos de 1561, véase Enrique Esperabé Arteaga, Historia pragmática e interna de la Universidad de Salamanca (Salamanca: F. Núñez Izquierdo, 1914), vol. 1, p. 162: "El cathedratico de canto ha de leer media hora de musica speculativa, y otra media hora de practica". Sobre los Estatutos de 1594, véase Francisco Javier Alejo Montes, La reforma de la Universidad de Salamanca a finales del s. XVI: los estatutos de 1594 (Salamanca: Universidad de Salamanca, 1990).
} 
"con programas específicos y alumnado diferente", y para el bloque de música especulativa durante la época de Francisco Salinas (1513-1590) se utilizó su De musica libri Septem (Salamanca, 1557) como libro de texto. ${ }^{130}$ Las artes de canto que emergieron en el contexto universitario podrían clarificar, al menos parcialmente, los contenidos impartidos por el catedrático de canto en el bloque práctico. Por ejemplo, en el "Prologo al lector" de El arte Tripharia (1550) Juan Bermudo señalaba con referencia a sus tratados que, "aunque sean libros para leerse en cathedras: el que guardare los auisos en los prologos y en otros lugares puestos: se aprovechara de todos ellos". ${ }^{131}$ La Declaración de instrumentos (1555) de Bermudo que, como se detallará en el Capítulo V, incluía casi todo el contenido de El arte Tripharia en sus páginas, se dirigía probablemente (por sus amplios contenidos especulativos) al contexto universitario.

La vinculación de las artes de canto con las enseñanzas universitarias conduce a descartar la concepción de estos manuales prácticos como destinados exclusivamente al alumnado de las capillas eclesiásticas:

Estos tratados de Canto Llano, en realidad, no tenían como función el servir de manual para la enseñanza de la música en la universidad, sino para ayudar al cantor de las iglesias importantes a entonar bien los salmos y demás piezas contenidas en los libros de canto, cantorales, situados en un gran atril o facistol en medio del coro. ${ }^{132}$

\footnotetext{
${ }^{130}$ Dámaso García Fraile, "La cátedra de música de la universidad de Salamanca durante diecisiete años del siglo XV (1464-1481)”, Anuario musical, XLVI (1991), pp. 57-101, pp. 60-61; "El acceso a una cátedra universitaria de música en el siglo XVI", en Miscel-lània Oriol Martorell, ed. por Xosé Aviñoa (Barcelona: Universidat de Barcelona, 1998), pp. 35-58, pp. 42-43; y "La música en la vida universitaria del Quinientos: la capilla de S. Jerónimo de Salamanca", en Las Universidades hispánicas: de la monarquía de los Austrias al centralismo liberal. V Congreso Internacional sobre Historia de las Universidades Hispánicas. Salamanca, 1998, ed. por Luis E. Rodríguez-San Pedro Bezares (Salamanca: Universidad de Salamanca, Junta de Castilla y León, Consejería de Educación y Cultura, 2000), vol. 1, pp. 207-232, p. 208. Sobre la música en la universidad española medieval, véase Maricarmen Gómez Muntané, "La prehistoria de la enseñanza musical en las universidades españolas", en De musica hispana et aliis. Miscelánea en honor al Prof. Dr. J. López-Calo, ed. por Emilio Casares Rodicio y Carlos Villanueva (Santiago de Compostela: Universidade de Santiago de Compostela, 1990), pp. 77-89.

${ }^{131}$ Bermudo, El arte Tripharia, f. 5v. El término cátedra también podría aludir a la enseñanza de la música en el ámbito catedralicio (en la Catedral de Sevilla encontrábamos la cátedra de canto de órgano y la cátedra de melodía).

${ }^{132}$ Escudero, “Tratados musicales. Estudio comparativo”, p. 1.
} 
Esta generalización (el uso de manuales de música práctica en el ámbito eclesiástico y de tratados especulativos en el contexto universitario) es frecuente en la bibliografía:

Los tratados de Domingo Marcos Durán presentan un compendio de lo que son los tratados altomedievales y renacentistas en sus dos aspectos, teórico-prácticos y filosófico-especulativos (más brevemente). Los teórico-prácticos se utilizan para enseñar el canto llano y la polifonía desde el punto de vista del estudio y la composición, más dedicado a un alumnado eclesiástico de las capillas catedralicias. La tratadística filosófico-especulativa se utilizó más en las aulas universitarias. ${ }^{133}$

Para analizar la conexión de las lecciones de música en las universidades y los contenidos de las artes de canto, me centraré en los casos de Alcalá de Henares, Salamanca y Coimbra, puesto que se tiene constancia de la presencia de la música en estas instituciones (y de la existencia de una cátedra específicamente de música en los dos últimos casos). La investigación en este campo podría arrojar luz sobre la enseñanza de la música en otras universidades peninsulares; por ejemplo se ha descubierto que la Universidad de Oviedo tuvo desde sus orígenes en 1608 una cátedra de música que, como en el caso de Salamanca, estaba ligada al cargo de maestro de capilla de la Catedral. $^{134}$

\subsubsection{LA UNIVERSIDAd de AlCALÁ DE HENARES}

Puesto que no se tiene noticia de la existencia de una cátedra de música como tal en la Universidad de Alcalá de Henares, Luis Jambou ha manifestado la problemática en torno a la presencia de esta disciplina en la institución: "no cabe duda de que la enseñanza musical debía pasar por las clases de matemáticas, que tenían desde el principio

\footnotetext{
${ }^{133}$ Barrios Manzano, “Domingo Marcos Durán”, p. 95.

${ }^{134}$ Louis Jambou, “Alcalá de Henares”, en Diccionario de la música española e hispanoamericana, ed. por Emilio Casares Rodicio (Madrid: Sociedad General de Autores y Editores, 1999-2002), vol. 1, pp. 218-224, p. 219. La primera referencia a este descubrimiento aparece en García Fraile, "La vida musical en la Universidad de Salamanca durante el siglo XVI", p. 11: "Recientemente me han confirmado que ya se ha encontrado documentación en la Universidad de Oviedo que demuestra que también la universidad asturiana, desde sus orígenes, se ocupó de la docencia y de la práctica musical". Sobre los orígenes de la Universidad de Oviedo, véase Jorge Uría y Carmen García, eds., Historia de la Universidad de Oviedo (Oviedo: Universidad de Oviedo, 2008), vol. 1. Mediante la consulta de bibliografía sobre otras universidades peninsulares, como por ejemplo la de Sevilla, no he encontrado referencias a la existencia de cátedras de música; véanse José Antonio Ollero Pina, La Universidad de Sevilla en los siglos XVI y XVII (Sevilla: Universidad de Sevilla, 1993); y Ramón María Serrera Contreras y Rafael Sánchez Montero, La Universidad de Sevilla, 1505-2005: V centenario (Sevilla: Universidad de Sevilla, 2005).
} 
una cátedra, o por una de las cátedras de artes, mal conocidas". ${ }^{135}$ Jambou propone el "estudio de las provisiones de canónigos o raciones de la iglesia magistral de los Santos Justo y Pastor" como una vía de investigación de la cuestión de la cátedra de música complutense. Para demostrar la enseñanza musical en la Universidad de Alcalá de Henares y ubicarla en el contexto de las clases de matemáticas basta con acudir al prólogo de una de las artes de canto objeto de esta investigación, puesto que Mateo de Aranda aseguraba en su Tractado de canto llano que se había formado en música especulativa con Pedro Ciruelo, catedrático de matemáticas de la Universidad de Alcalá de Henares:

Acorde mediante Jhesu e maria con aquella doctrina en musica speculatiua que en Alcala de henares del doctor Ciruelo: y en Italia de musica pratica recebi: criar este presente tractado de canto llano: por el qual deprenden los que no saben: y se auisen los que algo supieren asi en musica vocal como en instrumental. ${ }^{136}$

Por tanto, el material preliminar de un arte de canto demuestra que la parte especulativa de la música se estudió durante el período renacentista en la Universidad de Alcalá de Henares en las clases de Pedro Ciruelo, quien ocupó en 1510 una cátedra por invitación del Cardenal Cisneros tras estudiar en esta ciudad, en Salamanca y en París. ${ }^{137}$ Ciruelo publicó Cursus quatuor mathematicarum artium liberalium (Alcalá de Henares, 1516), tratado que probablemente refleje los contenidos de sus clases. El libro de Ciruelo incluye una sección musical que supone una simplificación y reducción (por considerarlo demasiado difícil para sus estudiantes) de la primera parte de Musica libris demonstrata quattuor (París, 1496) de Jacobus Faber Stapulensis o Jacques Lefèvre d'Etaples. ${ }^{138}$ También Juan Bermudo mencionaba en la Declaración de instrumentos (1555) su formación musical en las clases de matemáticas de la Universidad de Alcalá de Henares: "Dios por su infinita bondad me auia dado alguna inteligencia en Musica

\footnotetext{
135 Jambou, “Alcalá de Henares”, p. 219. Véase también José García Oro, La Universidad de Alcalá de Henares en la etapa fundacional (1458-1578) (Santiago de Compostela: Independencia Editorial, 1992).

${ }^{136}$ Aranda, Tractado de canto llano, f. A2r.

${ }^{137}$ Acerca del papel de Cisneros en la fundación de la Universidad de Alcalá de Henares, véase Bataillon, Erasmo y España, pp. 10-15.

${ }^{138}$ María Sanhuesa Fonseca, "Sánchez Ciruelo, Pedro [Maestro Ciruelo]”, en Diccionario de la música española e hispanoamericana, ed. por Emilio Casares Rodicio (Madrid: Sociedad General de Autores y Editores, 1999-2002), vol. 9, pp. 674-675.
} 
mayormente despues que en la famosa y doctissima vniuersidad de Alcala oy las mathematicas". 139

Tenemos noticia de otros materiales didácticos más tardíos que el libro de Ciruelo ligados a las clases de música especulativa en la Universidad de Alcalá de Henares y Salamanca durante el período renacentista. Se trata de los tratados de Juan Pérez de Moya, Aritmetica practica y especulativa (Salamanca, 1562), reeditado en 27 ocasiones, y Tratado de Mathematicas (Alcalá de Henares, 1573), los cuales han sido estudiados y editados modernamente por Luis Robledo Estaire. ${ }^{140}$ Robledo señala que Pérez de Moya estudió en Salamanca y que se desconoce si ejerció la docencia, aunque se sabe que no pudo haber obtenido una cátedra puesto que no pasó del grado de bachiller. En particular, el segundo tratado está íntimamente ligado a la enseñanza de la música como parte de las matemáticas en la Universidad de Alcalá de Henares, al menos por dos motivos: 1) el ejemplar autógrafo a partir del cual se elaboró la versión impresa (conservado en la Biblioteca Nacional de España con la signatura MSS/19301, ff. 88r-98v) contiene el visto bueno de Juan Segura, catedrático de Matemáticas de la Universidad de Alcalá de Henares; y 2) Robledo ha mostrado las correspondencias de este tratado con el de Salinas en cuanto a organización de los contenidos. Robledo concluye que la influencia de Pérez de Moya fue enorme, como queda demostrado por el hecho de que Francisco de Montanos cite a este autor y no a Salinas en el apartado "De proporcione" de su Arte de musica theorica y pratica (1592). La novedad de los tratados de Pérez de Moya con respecto a los de Ramos de Pareja, Salinas y Ciruelo es que están escritos en lengua vernácula.

Es evidente, por tanto, que en la Universidad de Alcalá de Henares se estudiaba la vertiente especulativa de la música, pero desconocemos si las lecciones de música incluían una parte práctica que propiciara, por ejemplo, las ediciones complutenses del Arte de canto llano de Juan Martínez en 1532 (por Miguel de Eguía, impresor de la Universidad de Alcalá de Henares) y 1598. El único arte de canto publicado en Alcalá de Henares entre esas fechas es el Arte ingeniosa de musica (1544) de Melchor de Torres, de quien sólo se conoce su condición de maestro de capilla en Alcalá de Henares.

\footnotetext{
${ }^{139}$ Bermudo, Declaración de instrumentos, f. 1r.

${ }^{140}$ Véase Luis Robledo Estaire, "Del pitagorismo a la justa entonación: los tratados musicales de Juan Pérez de Moya y de Juan Segura”, Revista de Musicología, XIX (1996), pp. 289-328, p. 291.
} 
Este libro se reimprimiría en la misma ciudad en 1554,1559 y 1566 . El caso del Arte ingeniosa de musica ejemplifica que una de las dificultades del estudio de las artes de canto es la carencia de fuentes. Por ejemplo, la voz sobre Melchor de Torres en The New Grove Dictionary consiste en un breve párrafo en el que se describe el contenido del Arte ingeniosa (haciendo referencia únicamente a las ediciones de 1544 y 1559) a través de las referencias que teóricos posteriores hicieron al tratado. Julián Martín Abad, estudioso de la imprenta en Alcalá de Henares, dedica un artículo al Arte ingeniosa que inicia lamentándose de "la rareza de los ejemplares" del libro de Torres. ${ }^{141}$ En este artículo, Martín Abad lleva a cabo un detallado estado de la cuestión sobre las referencias que se han hecho en la bibliografía al tratado de Melchor de Torres en función del conocimiento de ejemplares de las tres ediciones que se conocían del mismo (1544, 1559, 1566).

En el transcurso de mi investigación he podido consultar un ejemplar incompleto de la edición de 1566 del Arte ingeniosa que se conserva en la Biblioteca de la Universidad de Zaragoza encuadernado a continuación del Arte breve y compendiosa (1614) de Andrés de Monserrate y, lo que es todavía más interesante, un ejemplar completo conservado en la Biblioteca de la Universidad de Las Palmas de Gran Canaria de una edición de 1554 que en los trabajos bibliográficos se había considerado una edición fantasma (véase Ilustración IV.9). La edición príncipe del tratado de Torres fue datada en 1554 (en lugar de 1544) por Nicolás Antonio, Baltasar Saldoni, François-Joseph Fétis y Felip Pedrell (Saldoni y Fétis lo llaman Arte de la música). ${ }^{142}$ Sin embargo, Julián Martín Abad consideró que la de 1554 era una edición fantasma y que la de 1559 era la segunda edición del libro de Melchor de Torres. ${ }^{143}$

\footnotetext{
${ }^{141}$ Julián Martín Abad, "Melchor de Torres y su Arte de música", Anales Complutenses, II (1988), pp. 103-106, señala que la rareza de los ejemplares del Arte ingeniosa de musica podría incluso haber conducido al error en el nombre de una de las calles de Alcalá de Henares y de la escuela de música, que se llaman "Mateo de Torres", en lugar de Melchor de Torres.

${ }^{142}$ Antonio, Bibliotheca Hispana Nova, vol. 2, p. 126; Baltasar Saldoni, Efemérides de músicos españoles así profesores como aficionados (Madrid: Imprenta de la Esperanza, 1860), p. 223; Fétis, Biographie universelle des musiciens, vol. 8, p. 243 (indica formato en folio); y Felip Pedrell, Los músicos españoles antiguos y modernos en sus libros o escritos sobre música (Barcelona: Torres y Seguí, 1888), p. 16.

${ }^{143}$ Martín Abad, La imprenta en Alcalá de Henares (1502-1600), vol. 1, p. 86.
} 
Ilustración IV.9: Edición que hasta ahora se consideraba "fantasma" de Melchor de Torres, Arte ingeniosa de musica (Alcalá de Henares: en casa de Salzedo Librero, 1554 [1544]), portada y colofón (f. 36v). Las Palmas de Gran Canaria, Biblioteca de la Universidad, BIG XVI TOR art.
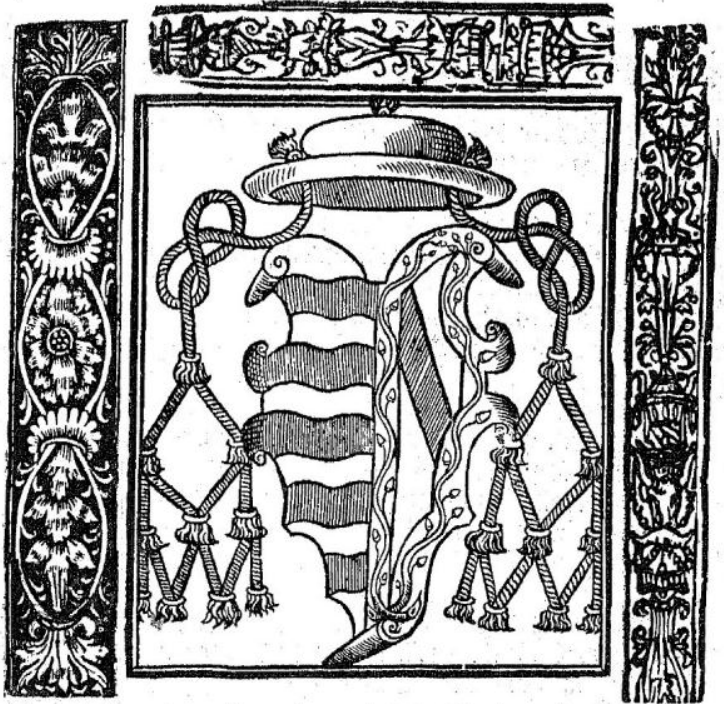

TEftapzefente obza bzene y muy compen. diofa oe mufica pzatica: affi oe cantollano/ $y$ canto oe ozg? no/como o contrapunto sue impzefia enla muy noble villa/ y flozentifima viniuerfidad oe Zalcala oe. If

bolea vepnte be Jumio/zaño oela en carnació oe nueltro feñoz yefu Lbzito oe ABil Y quinien tos $y$ cincuenta $y$ quatro.

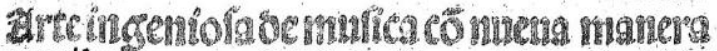
De auiros/breties y côpẻdioros robze toda la facultad silla: âgozanueuamente reformada/ 7 cozregida poz fit mefino

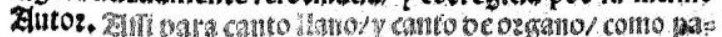
la contrapunts: oonde re ballaran rëglag en bzene compze

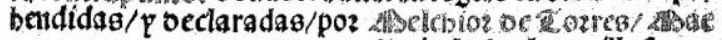
firo ac Copilla oe zilcalai Gntitulada al inuy illuftre

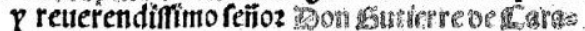

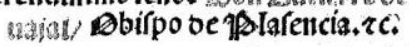

En alcala oe lbenares, en cafa oe Salzedo 2 ibze

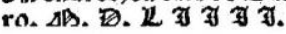

El Arte ingeniosa de musica se publicó por primera vez en 1544 en la imprenta de Juan de Brocar, reimprimiéndose en 1554 y 1559 por Atanasio de Salcedo, quien ejerció principalmente como librero y "sus impresiones son escasas y salteadas". ${ }^{144} \mathrm{Su}$ labor como impresor se sitúa entre 1554 y 1562. Martín Abad ha sugerido que posiblemente Salcedo utilizase parte del material tipográfico de Juan de Brocar, que fue el impresor de la edición príncipe del libro de Melchor de Torres. ${ }^{145}$ El colofón de las tres primeras ediciones del Arte ingeniosa (1544, 1554 y 1559) sitúa la impresión en la propia Universidad de Alcalá de Henares y es una clara evidencia del surgimiento de artes de canto en el contexto universitario:

\footnotetext{
${ }^{144}$ Delgado Casado, Diccionario de impresores españoles, vol. 2, pp. 623-624.

${ }^{145}$ Martín Abad, La imprenta en Alcalá de Henares (1502-1600), vol. 1, p. 86.
} 
Esta presente obra breue y muy compendiosa de musica pratica: assi de canto llano y canto de organo como de contrapunto fue impressa en la muy noble villa y florentissima vniuersidad de Alcala de Henares en casa de Salzedo Librero. Acabose a veynte de Junio Año de la encarnacion de nuestro señor Jesu Christo de Mil y quinientos y cincuenta y quatro. ${ }^{146}$

El que no hubiera una cátedra específicamente de música en la Universidad de Alcalá de Henares ha conducido a pensar que la música sólo se estudiaba en su parte especulativa dentro de las aulas universitarias como parte de las matemáticas, pero la universidad tenía su capilla-iglesia de San Ildefonso, que contaba con cantor, organista y ministriles. ${ }^{147}$ Desconocemos si en el contexto estricto de las clases de matemáticas se estudiaba la música en su vertiente práctica. Sin embargo, las reediciones complutenses del Arte de canto llano de Juan Martínez y del Arte ingeniosa de musica de Melchor de Torres sugieren su uso como material didáctico práctico en la Universidad de Alcalá.

\subsubsection{LA UNIVERSIDAD DE SALAMANCA}

Si acudimos a las artes de canto publicadas en el contexto de la Universidad de Salamanca, podemos extraer información de interés para determinar el contenido de las lecciones de música práctica que se impartían en esta institución. Un ejemplo es Portus musice (1504) de Diego del Puerto, estudiante en Salamanca y cantor del Colegio de San Bartolomé. Aunque al parecer no ocupó ninguna cátedra universitaria, su Portus musice, según Juan José Rey Marcos, fue escrito con la intención de ayudar a los estudiantes de música de la Universidad de Salamanca. ${ }^{148}$ El carácter utilitario del tratado queda demostrado por la inclusión de unas reglas de cronología al final del libro. Mostrando una finalidad práctica en su organización, Portus musice se considera un tratado pionero en dos sentidos: 1) incluye una reproducción del mástil de la vihuela; y 2) contiene notación mensural.

Rey Marcos asegura que "las enseñanzas universitarias eran [...] fundamentalmente teóricas, por lo que no es extraño que los estudiantes anduviesen necesitados de

\footnotetext{
${ }^{146}$ Torres, Arte ingeniosa de musica (1554 [1544]), f. 36v. La reimpresión de 1566, llevada a cabo por Pedro de Robles y Juan de Villanueva, no hace referencia a la Universidad de Alcalá de Henares.

147 Sobre la organización del Colegio de San Ildefonso como cabeza de la Universidad, véase Kagan, Students and Society in Early Modern Spain, p. 110.

${ }^{148}$ Rey Marcos, “Introducción”, p. 15.
} 
los consejos de un músico práctico para completar su formación". ${ }^{149}$ Sin embargo, Nan Cooke Carpenter indica que los estudiantes de la Universidad de Salamanca con poco poder adquisitivo en ocasiones se mantenían dando lecciones de canto, un medio de vida que se dio en otras universidades, especialmente en las germánicas. ${ }^{150}$ Las fuentes literarias confirman la existencia de lecciones de este tipo:

Estauamos despues desto tres compañeros al barrio de san Vicente, tan abundantes de necessidad, que el menos desamparado de las armas Reales era yo, por ciertas lecciones de cantar que yo daua, y aun las daua, porque se pagauan tan mal, que antes eran dadas que pagadas, y aun dadas al diablo. ${ }^{151}$

En los reglamentos de los colegios mayores encontramos la provisión de profesores que enseñaban canto a los alumnos durante los meses de verano: "estatuimos y ordenamos que en algunos meses de verano haya quien les enseñe canto llano y, estando algunos suficientes, canto de organo". ${ }^{152}$ Hubo figuras que ocuparon simultáneamente los puestos de maestro de capilla de la Catedral y catedrático de música de la Universidad, aunque Álvaro Torrente ha manifestado que esta coincidencia no se dio "tan a menudo como se ha creído". ${ }^{153}$ En cualquier caso, el acceso a la cátedra requería la superación de un examen doble, teórico y práctico, y en esta última parte los aspirantes debían demostrar sus conocimientos en canto gregoriano, canto de órgano y contrapunto. ${ }^{154}$

Frente a la imposibilidad de llevar a cabo un estudio cuantitativo acerca de los asistentes a las lecciones de música de las capillas catedralicias, en el caso de las clases universitarias contamos con libros de visitas que recogen información sobre el número

\footnotetext{
${ }^{149}$ Rey Marcos, “Introducción”, pp. 15-16.

${ }^{150}$ Carpenter, Music in the Medieval and Renaissance Universities, p. 102.

${ }^{151}$ Espinel, Relaciones de la vida del escudero Marcos de Obregon, f. 42r.

${ }^{152}$ García Fraile, "La vida musical en la Universidad de Salamanca durante el siglo XVI”, p. 47.

153 Álvaro Torrente, "Salamanca", en Diccionario de la música española e hispanoamericana, ed. por Emilio Casares Rodicio (Madrid: Sociedad General de Autores y Editores, 1999-2002), vol. 9, pp. 551562 , p. 556. El primer caso constatado es el de Juan de Oviedo, quien compaginó ambos cargos hasta su muerte en 1566; fue catedrático desde 1542 (sucesor de Lucas Fernández) y en 1545 obtuvo la media ración de maestro de capilla de la Catedral (sucediendo a Diego del Castillo). Después encontramos a Roque de Salamanca (†1593), catedrático entre 1590 y 1593 (sucediendo a Francisco Salinas) y previamente (desde 1574) mozo de coro, capellán y maestro de capilla de la Catedral de Salamanca.
}

${ }^{154}$ García Fraile, "El acceso a una cátedra universitaria de música en el siglo XVI”, p. 37. 
de estudiantes. Según el Libro de Visitas de Cátedra de 1564, asistían a las clases de música de la Universidad de Salamanca entre 40 y 50 "oyentes cantantes" en el período de Juan de Oviedo (1542-1566) y se han localizado los nombres de 45 alumnos de Francisco Salinas. ${ }^{155}$ Según Dámaso García Fraile, buena parte de los estudiantes de la Universidad de Salamanca durante el siglo XVI pertenecían a la nobleza. Los vínculos de la Universidad de Salamanca con el extranjero son notables: no sólo esta nobleza "tenía o había tenido alguno de sus miembros destinados en los dominios españoles en la península italiana a lo largo del quinientos", sino que también algunos catedráticos como Francisco Salinas y Bernardo Clavijo habían pasado algún período en la Península Itálica. ${ }^{156}$

Además de Portus musice, varias artes de canto emergieron en el mundo universitario salmantino en esta época, como los libros de Domingo Marcos Durán (estudiante de artes liberales y filosofía en Salamanca) y Cristóbal Escobar. ${ }^{157}$ En la bibliografía se menciona la publicación en 1504 de un tratado de canto llano ahora perdido de Alonso del Castillo, que fue "doctor en Salamanca". ${ }^{158}$ También Juan de Espinosa se graduó en la Universidad de Salamanca, aunque sus libros fueron publicados en Toledo. Además, en Salamanca se reeditaron el Arte de canto llano de Juan Martínez en 1599 y el homónimo de Francisco de Montanos en 1610, 1616 y 1625, lo que indica una importante demanda universitaria de este tipo de libros.

\subsubsection{LA UNIVERSIDAD DE COIMBRA}

Tanto Salamanca como Coimbra albergaron al menos dos instituciones de enseñanza musical de primer orden, la catedral y la universidad, y ambas ciudades coinciden en el establecimiento de relaciones catedral-universidad en el ámbito de la docencia

\footnotetext{
${ }^{155}$ García Fraile, "La cátedra de música en la universidad de Salamanca". Véase también su trabajo "Salinas, catedrático de la universidad de Salamanca", en Livro de Homenagem a Macario Santiago Kastner, ed. por Maria Fernanda Cidrais Rodrigues, Manuel Morais y Rui Vieira Nery (Lisboa: Fundação Calouste Gulbenkian, 1992), pp. 431-462. Sobre el Archivo Histórico de la Universidad de Salamanca, véase Agustín Vivas Moreno, Archivo Histórico de la Universidad de Salamanca (Gijón: Trea, 2003).

${ }^{156}$ García Fraile, “La vida musical en la Universidad de Salamanca durante el siglo XVI”, p. 45.

${ }^{157}$ Véase Knigghton, “Gaffurius, Urrede and Studying Music at Salamanca University Around 1500”.

${ }^{158}$ Collet, "Contribution à l'étude des théoriciens espagnols de la musique", p. 19; Carpenter, Music in the Medieval and Renaissance Universities, p. 220. Mitjana, Historia de la música española, p. 60, considera que "Alfonso del Castillo [...] quizá fue el corrector del Portus Musicae", puesto que los datos editoriales del tratado perdido de Alonso del Castillo coinciden con los del tratado de Diego del Puerto.
} 
musical. Esto no es una coincidencia si tenemos en cuenta que entre las dos ciudades se produjo una "transferencia de pautas universitarias" que ha sido analizada por Marciano Sánchez Rodríguez. Este historiador menciona tres cauces de intercambio: por ósmosis, por personal y por libros. En ocasiones las vías de influencia coinciden; pensar que "los estudiantes volvían de vacío a su país sin llevar, sus propios apuntes o notas, algunos libros y hasta una pequeña biblioteca personal en el caso de los más pudientes, es desconocer la realidad". ${ }^{159}$ Además, Manuel Augusto Rodrigues ha analizado los contactos que se produjeron entre las universidades de Salamanca y Coimbra desde la Edad Media señalando una intensificación de los mismos a partir del siglo XVI; la Universidad de Coimbra también mantuvo contactos con otros centros universitarios españoles como Sigüenza, Alcalá de Henares y Sevilla. ${ }^{160}$

Los Estudios Generales de Lisboa se trasladaron a Coimbra en 1537 por voluntad de João III. ${ }^{161}$ Los Estatutos de 1597 marcan el final de la fijación normativa que comenzó con la implantación de la Universidad en Coimbra y son el texto por el que se regiría la institución hasta la reforma del Marqués de Pombal en 1772. ${ }^{162}$ José Augusto Alegria ha indicado que la música aparece entre las disciplinas impartidas al menos desde 1323 en el Estudio General de Lisboa, pero no cita ningún maestro o programa. ${ }^{163}$

\footnotetext{
${ }^{159}$ Marciano Sánchez Rodríguez, "Coimbra y Salamanca. Transferencia de pautas universitarias", en Las relaciones entre Portugal y Castilla en la época de los descubrimientos y la expansión colonial [Actas del Congreso "Las relaciones entre Portugal y España en la época de los descubrimientos y la expansión colonial" (Salamanca, del 15 al 17 de octubre de 1992)], ed. por Ana María Carabias Torres (Salamanca: Ediciones Universidad de Salamanca, Sociedad V Centenario del Tratado de Tordesillas, 1994), pp. 207222, p. 210.
}

${ }^{160}$ Manuel Augusto Rodrigues, "Relações científico-culturais entre as universidades de Coimbra e Sala-
manca", en Las Universidades hispanicas: de la monarquía de los Austrias al centralismo liberal. V
Congreso Internacional sobre Historia de las Universidades Hispánicas. Salamanca, 1998, ed. por Luis
E. Rodríguez-San Pedro Bezares (Salamanca: Universidad de Salamanca, Junta de Castilla y León, Con-
sejería de Educación y Cultura, 2000), vol. 1, pp. 409-431, p. 410: "Mas convém referir que também
houve relações científico-culturais com outras universidades de Espanha: Sigüenza, Alcalá, Sevilha, etc.".
${ }^{161}$ Sobre este período, véase Francisco Leitão Ferreira, Noticias chronologicas da Universidade de
Coimbra, dedicadas à Magestade del Rey nosso Senhor D. João V. Escritas pelo Beneficiado Francisco
Leitao Ferreira, Académico real do numero. Primeira parte, que comprende os annos que discorren
desde o de 1288 até principio do de 1537 (Lisboa: Off. de Joseph Antonio da Sylva, 1729).

${ }^{162}$ Para un análisis del paradigma pedagógico reflejado en esta normativa, véase Fernando Taveira da Fonseca, "Os estatutos da universidade de Coimbra de 1597: a consolidação de um paradigma educativo", en Las Universidades hispánicas: de la monarquía de los Austrias al centralismo liberal. V Congreso Internacional sobre Historia de las Universidades Hispánicas. Salamanca, 1998, ed. por Luis E. Rodríguez-San Pedro Bezares (Salamanca: Universidad de Salamanca, Junta de Castilla y León, Consejería de Educación y Cultura, 2000), vol. 1 [siglos XVI y XVII], pp. 191-205.

${ }^{163}$ Alegria, História da escola de música da Sé de Évora, p. 29. 
De la Universidad de Coimbra, el "centro cultural universitario" de Portugal según Fernández Álvarez, ${ }^{164}$ tenemos más datos, desde los nombres de los profesores a los libros que posiblemente se utilizaron en las clases de música. En el listado de profesores de la Universidad de Coimbra desde 1537 hasta 1728 que aparece en el diccionario de 1728 de Francisco Leitão Ferreira, encontramos que el total de profesores de música asciende a 9 , frente a los 84 profesores de medicina, los 184 profesores de leyes, los 118 profesores de derecho canónico y los 118 profesores de teología. ${ }^{165}$ Aunque no recoge información acerca de los contenidos de las clases, el estudio más reciente sobre el lugar de la música en la Universidad de Coimbra es la Tesis Doctoral de Maria do Amparo Carvas Monteiro. $^{166}$

Tres músicos que publicaron o reeditaron artes de canto fueron catedráticos de música en la Universidad de Coimbra: Mateo de Aranda entre 1544 y 1548, ${ }^{167}$ Afonso Perea Bernal entre 1553 y 1593, y Pedro Thalesio entre 1613 y 1629 . Los tres son muestra de la conexión típica de esta época entre las capillas eclesiásticas y la universidad con respecto a la enseñanza de la música, puesto que, antes de convertirse en catedráticos, Aranda y Thalesio trabajaron como maestros de capilla, ${ }^{168}$ mientras que a Perea Bernal se le identifica como "cantor" en la documentación institucional (en las Actas de los Consejos de la Universidad aparece como "Afonso Perea, cantor"). ${ }^{169}$ Esto indica que los catedráticos de música de Coimbra eran en primer lugar profesionales del canto. Además, a diferencia de los catedráticos de matemáticas de Alcalá de Henares y de los catedráticos de música de Salamanca, los profesores de música de la Universidad

\footnotetext{
${ }^{164}$ Fernández Álvarez, “Objetivo: Lisboa”, p. 328.

${ }^{165}$ Francisco Leitão Ferreira, Alphabeto dos lentes da insigne Universidade de Coimbra desde 1537 em diante (Coimbra: Universidade de Coimbra, 1937 [MS de 1728]).
}

${ }^{166}$ Maria do Amparo Carvas Monteiro, "Da Música na Universidade de Coimbra (1537-2002)", Tesis Doctoral (Ph.D.), Universidad de Coimbra, 2002, 2 vols.

${ }^{167}$ Maria do Amparo Carvas Monteiro presenta la transcripción de la licencia real de 26 de julio de 1544 que aseguraba el nombramiento de Mateo de Aranda a título vitalicio con el salario anual de 70.000 reis; véase Monteiro, "Da Música na Universidade de Coimbra (1537-2002)", vol. 1, p. 348. Aunque no se conoce documentación sobre el final de su actividad docente, es posible que concluyera en 1548, año en que Pedro de Trigueiros (posiblemente sustituto de Aranda) tomó posesión del cargo, puesto que no se conoce otro nombre que pueda situarse entre ellos; véase Monteiro, "Da Música na Universidade de Coimbra (1537-2002)", vol. 1, p. 352.

\footnotetext{
${ }^{168}$ Véase el Apéndice 4.

${ }^{169}$ Monteiro, "Da Música na Universidade de Coimbra (1537-2002)”, vol. 1, p. 366.
} 
de Coimba escribieron (o reeditaron, en el caso de Perea Bernal) artes de canto, en lugar de tratados de música de tipo teórico-especulativo. Este fenómeno es sumamente interesante, puesto que las publicaciones son a su vez reflejo de los contenidos de las clases que se impartían o tal vez respuesta a las necesidades de los estudiantes.

Mateo de Aranda publicó sus tratados de canto llano y de canto de órgano en 1533 y 1535, respectivamente, como maestro de capilla de la Sé de Évora. Si en su período como catedrático de la Universidad de Coimbra no publicó ningún otro tratado conocido, se podría pensar que quizás no sintió la necesidad de hacerlo, puesto que contaba con el favor del rey João III de Portugal y tal vez hubiese podido conseguir financiación, además de poseer la formación necesaria en música especulativa al haber sido alumno de Pedro Ciruelo en la Universidad de Alcalá de Henares. Pedro Thalesio publicó su Arte de canto chão siendo catedrático en Coimbra y lo dedicó a Afonso Furtado de Mendoza, Obispo de Coimbra, figura que ejemplifica las relaciones IglesiaUniversidad, puesto que también fue Rector de la Universidad de Coimbra entre 1597 y 1605 y Obispo de la Sé de Guarda a partir de $1610 .{ }^{170}$

Afonso Perea Bernal no publicó un libro propio, sino que tradujo y después amplió el Arte de canto llano de Juan Martínez. Aunque en la bibliografía se supone de origen sevillano, los únicos datos fehacientes que tenemos de Afonso Perea Bernal le sitúan en Coimbra, donde publicó al menos en dos ocasiones (1550 y 1597) el Arte de canto llano de Juan Martínez (primero traducido al portugués y después también revisado y ampliado), en cuya Universidad fue nombrado profesor ("lente") de música por provisión de João III en 1553, y donde murió antes del 6 de octubre de 1593. ${ }^{171}$ Mário de Sampaio Ribeiro apuesta por el origen sevillano de Perea Bernal basándose en los

\footnotetext{
${ }^{170}$ Para un estado de la cuestión acerca de Pedro Thalesio, véase Monteiro, "Da Música na Universidade de Coimbra", vol. 1, p. 388 y ss.

${ }^{171}$ Ferreira, Alphabeto dos lentes, p. 195; Vieira, Diccionario biographico de musicos portuguezes, vol. 1, p. 101; y Stevenson, "Bernal, Afonso Perea". Para un estado de la cuestión detallado, véase Monteiro, "Da Música na Universidade de Coimbra (1537-2002)", vol. 1, p. 364 y ss., donde se aportan nuevos datos tomando como fuente las Actas de los Consejos de la Universidad del período 1553-1557. A pesar de que el Consejo ya se había provisto de un sustituto (António de Bivar), Afonso Perea presentó una provisión real por la que se le otorgaba el puesto dejado vacante por Baltazar Teles con el salario anual de 40.000 reis, primero en régimen de sustitución y después como profesor principal. Del estudio de los documentos, Monteiro concluye que el período de Baltazar Teles debió de ser bastante agitado puesto que se disputaban el cargo António de Bivar y Ambrósio de Pino. No obstante, finalmente sería Afonso Perea quien lo conseguiría utilizando el favor real. Además, Monteiro deduce que, por el prestigio de Perea y su largo período dedicado a la docencia, debió de tener sustitutos, aunque no se ha encontrado documentación concluyente en este sentido; véase Monteiro, "Da Música na Universidade de Coimbra (15372002)", vol. 1, p. 371.
} 
"castellanismos" hallados en su uso del portugués; además, lanza la hipótesis de que habría sido mozo de coro de la Catedral de Sevilla y alumno de Juan Martínez. ${ }^{172}$ Sin embargo, su nombre no está en la lista de mozos de coro de la Catedral de Sevilla presentada por Robert Stevenson en La música en la Catedral de Sevilla, por lo que provisionalmente no podemos corroborar la hipótesis de Ribeiro. La nacionalidad de Perea ha sido objeto de controversia. Como en el caso de Juan Martínez, existen diferentes versiones de su nombre: Alfonso, Alonso, Pérez, Pereira, etc. Mientras que Mário de Sampaio Ribeiro y Robert Stevenson le atribuyen origen español, Ernesto Vieira asegura que era "legitimamente portuguez" aunque quizás tuviera ascendientes castellanos. ${ }^{173}$ Desconocemos si Perea es el autor del romance "A las armas moriscote" recogido en el libro de vihuela de Miguel de Fuenllana bajo el título "Romance viejo de bernal", ${ }^{174}$ dato que vincularía más certeramente al músico al contexto sevillano. En la bibliografía, esta pieza ha sido atribuida a Francisco (o José) Bernal González (fl. c. 1550), maestro de capilla de la iglesia colegiata de San Salvador de Sevilla. En el Diccionario de la música española e hispanoamericana aparecen dos compositores apellidados Bernal: Antonio Bernal y Francisco Bernal González, atribuyéndosele el romance al último. Sin embargo, en The New Grove Dictionary se considera que ambos son una misma persona: aparece una entrada para "Bernal Gonçalez, José?" y se indica que antes se creía que su nombre era Antonio. ${ }^{175}$

Perea Bernal publicó la primera traducción al portugués del manual de Juan Martínez en 1550, cuando aún no había sido nombrado catedrático. No se sabe qué puesto desempeñaba con anterioridad, pero sí se le atribuye ser "cantor", por lo que probablemente trabajase en una capilla. Como indiqué en el Capítulo III, Perea Bernal

\footnotetext{
${ }^{172}$ Ribeiro, A "Arte de Cantollano", de autor desconhecido, p. 27, nota 35: "debía ser español -tal vez sevillano- quizás antiguo mozo de coro de la catedral hispalense y alumno del famoso Juan Martínez. Perea sería el apellido paterno y Bernal el materno" ["devia ser espanhol -tal vez sevilhano- porventura antigo menino de coro da catedral hispalense e aluno do famoso Juan Martinez. Perea seria o apelido paterno e Bernal o materno"]. Según Ribeiro, testimonio de ello es que en el portugués de Perea Bernal se encuentren castellanismos, ya que "linguagem portugues" era una expresión obsoleta en 1550, fecha en la que ya se utilizaba "lenguaje portugues".

173 Ribeiro, A "Arte de Cantollano", de autor desconhecido, p. 27, nota 35; Stevenson, "Bernal, Afonso Perea"; Vieira, Diccionario biographico de musicos portuguezes, vol. 1, p. 104.

${ }^{174}$ Miguel de Fuenllana, Libro de musica para vihuela intitulado Orphenica lyra (Sevilla: Martín de Montesdoca, 1554), V, f. 145.

${ }^{175}$ Robert Stevenson, "Bernal Gonçález, ?José”, Grove Music Online. Oxford Music Online, 1 mayo 2012 $<$ http://www.oxfordmusiconline.com/subscriber/article/grove/music/02840>.
} 
debió de utilizar para su traducción de 1550 la edición de 1532 del libro de Martínez. El que Perea Bernal no utilizase la edición sevillana de 1530, sino la impresa por Miguel de Eguía, impresor de la Universidad de Alcalá de Henares, conduce a especular sobre la relación de Perea Bernal con la Universidad de Alcalá de Henares, y acerca de la transferencia de materiales didácticos de esta institución a la Universidad de Coimbra (fue el impresor de la Universidad de Coimbra, João Barreira, quien sacó a la luz la traducción de Pera Bernal). Ernesto Vieira y Mário de Sampaio Ribeiro aseguran que las ediciones conimbricenses del Arte de canto llano de Juan Martínez se deben a su adopción como libro de texto en las aulas de la Universidad de Coimbra; ${ }^{176}$ Manuel Pedro Ferreira señala que Afonso Perea prefirió el tratado de Juan Martínez cuando sucedió a Mateo de Aranda en la cátedra. ${ }^{177}$ El examen que he llevado a cabo de la ampliación incluida en la edición póstuma de 1597 permite determinar los contenidos que Perea Bernal estimó oportuno incorporar siendo catedrático de música de la Universidad de Coimbra. Dicho de otro modo, las "cousas muito necessarias, acrecentadas nesta Arte, por Afonso Perea de Bernal sendo lente de Musica na Vniversidade de Coimbra" podrían reflejar su experiencia de cuarenta años en la enseñanza de la música práctica en la Universidad de Coimbra; véase la Tabla IV.9.

\footnotetext{
${ }^{176}$ Vieira, Diccionario biographico de musicos portuguezes, vol. 2, pp. 66-67; Ribeiro, A "Arte de Cantollano", de autor desconhecido, p. 2.

${ }^{177}$ Ferreira, "Mateus de Aranda", p. 164.
} 
Tabla IV.9: Comparación de las ediciones en portugués (1550 y 1597) del Arte de canto llano (Sevilla, 1530) de Juan Martínez realizadas por Afonso Perea Bernal

\begin{tabular}{|c|c|c|}
\hline & Coimbra, João Barreira, 1550 & Coimbra, António Barreira, 1597 \\
\hline $\begin{array}{l}\text { Intervención de } \\
\text { Perea Bernal }\end{array}$ & "trasladada em linguagem portugues" & "accrescentada de nouo" \\
\hline Tinta & Tinta negra y roja & Tinta negra \\
\hline \multirow{13}{*}{$\begin{array}{l}\text { Organización de } \\
\text { los contenidos }\end{array}$} & \multirow{5}{*}{$\begin{array}{l}\text { Mano guidoniana } \\
\text { [Capitulo primeiro das letras] }{ }^{178} \\
\text { [Capitulo segundo dos Signos] } \\
\text { [Capitulo terceiro das mutanças] } \\
\text { [Capitulo iiij das Chaues] }\end{array}$} & Mano guidoniana \\
\hline & & Capitulo primeiro das letras \\
\hline & & Capitulo segundo dos Signos \\
\hline & & Capitulo terceiro das mutanças \\
\hline & & $\begin{array}{l}\text { Capitulo iiij das Chaues } \\
\text { [Tabla y ejemplos musicales (las voces)] }\end{array}$ \\
\hline & [Capitulo .v. de los modos] & Capitulo v. dos modos \\
\hline & Capitulo .vi. dos mouimentos & Capit. sexto, dos mouimentos \\
\hline & Capitulo .vii. das diuisones dos tonos & Capit. vij. Das diuisones dos tonos \\
\hline & Capitulo .viii. das disjuntas & Capitulo viij Das disjuntas \\
\hline & [Capitulo .ix. das consonancias] & Capit. nono das Consonancias \\
\hline & $\begin{array}{l}\text { [Capitulo .x. de los generos de } \\
\text { musica] }\end{array}$ & Capitulo decimo, dos generos da musica \\
\hline & $\begin{array}{l}\text { Tabla y ejemplos musicales } \\
\quad \text { (las voces) }\end{array}$ & \\
\hline & & $\begin{array}{l}\text { Seguemse algunas cousas muito necessarias, } \\
\text { acrecentadas nesta Arte, por Afonso Perea de } \\
\text { Bernal sendo lente de Musica na Vniversida- } \\
\text { de de Coimbra }\end{array}$ \\
\hline \multirow[t]{13}{*}{$\begin{array}{l}\text { Repertorio } \\
\text { musical }\end{array}$} & \multirow[t]{9}{*}{$\begin{array}{l}\text { Incipiunt intonationes Psalmorum, \& } \\
\text { de Magnificat }\end{array}$} & $\begin{array}{l}\text { Incipiunt intonationes psalmorum simplicium } \\
\text { Incipiunt psalmi solennes }\end{array}$ \\
\hline & & In festis duplicibus [Gloria] \\
\hline & & In diebus Dominicis [Gloria] \\
\hline & & In festis ix lectionum [Gloria] \\
\hline & & Infra octauas [Gloria] \\
\hline & & In solemnitatibus Virgine Mariae [Gloria] \\
\hline & & In duplicibus \& solennibus [Gloria] \\
\hline & & $\begin{array}{l}\text { Instrução pera a entoação do Credo, duplex } \\
\text { solenne }\end{array}$ \\
\hline & & $\begin{array}{l}\text { In diebus Dominicis, in octauas [Credo, Ite } \\
\text { Missa est] }\end{array}$ \\
\hline & Incipiunt introitus misse & Incipiunt versus Introitus missae \\
\hline & Incipiunt Gloria responsoriorum & Incipiunt Gloria Responsoriorum \\
\hline & $\begin{array}{l}\text { Sequitur canticum quod ab ecclesia } \\
\text { cantatus in laudem beatissimae } \\
\text { virginis marie }\end{array}$ & $\begin{array}{l}\text { Sequitur canticum quod ab ecclesia cantatus in } \\
\text { laudem Beatissimae Virginis Mariae }\end{array}$ \\
\hline & [Letra "Sanctissimae Trinitatis"] & \\
\hline
\end{tabular}

${ }^{178}$ Los títulos de algunos capítulos (indicados entre corchetes), en tinta roja, no están impresos en el ejemplar consultado, conservado en la Biblioteca Geral de la Universidade de Coimbra con signatura M.I. 254. 
La Tabla IV.9 muestra que la ampliación de Perea Bernal publicada póstumamente en 1597 aparece a modo de apéndice, totalmente desgajada del cuerpo del texto, el cual sigue siendo una traducción fiel de la versión castellana de Martínez. El contenido de la ampliación es el siguiente: 1) "Regras para solfar perfeitamente em Canto chão"; 2) "Declaração dos pontos que commuummente se echão em Canto chão, \& de como se ha de poer a letra nelles"; 3) "Breue \& necessario modo, pera saber de que tono sam as Antiphonas que vienem antes dos Psalmos em todas as horas Canonicas, per estes versiculos"; 4) "Entoações dos Psalmos \& Canticos"; 5) "A differença que ha dos Canticos solemnes aos simples"; y 6) "Meditações dos Psalmos \& canticos". Se trata, por tanto, de un contenido enteramente práctico, repleto de ejemplos musicales. Por ejemplo, las "Regras para solfar perfeitamente em Canto chão" hacen referencia a los pasos concretos a seguir en el momento de comenzar a cantar. ${ }^{179}$

Frente al carácter teórico de lo que en principio podría esperarse de un tratado destinado a una universidad, Perea Bernal, como catedrático de música de la Universidad de Coimbra, añadió contenidos totalmente prácticos a un manual ya de por sí práctico. El propio Perea Bernal al final de su ampliación no dejaba duda acerca del uso del libro de Juan Martínez como material didáctico: "Todo lo que está dicho se puede ver por sus ejemplos en sus lugares y, lo que falta para la perfecta declaración de las cosas sobredichas, el Maestro lo podrá declarar enteramente". ${ }^{180}$

\footnotetext{
${ }^{179}$ Juan Martínez / Afonso Perea, Arte de Canto chão (Coimbra: António Barreira, 1597), f. B3: "Primeira regra / Antes que comecemos a cantar, auemos de olhar tres cousas. Primeiramente, se he a claue de Ffaut, ou de Csolfaut: \& depois se esta o ponto onde começão em regra, ou em espaço. Finalmente que voz das seis tomamos, guardando a regra, ut, re, mi, para subir: fa, sol, la, para decer. / Segunda regra / Em principio de Canto auemos de escusar Bmol \& mutança: \& deuemos de ver se cantamos natural, ou accidentalmente, quero dizer, por Bmol, ou $\natural$ quadrado, ou natura. Porque cuando cantamos por Bmol cantamos accidentalmente \& quando por $\mid$ quadro ou natura, cantamos naturalmente. E o que dissemos da mutança, que se ha de escusar em principio de canto, ha se de entender, que auemos antes de cantar deducionalmente, que dando saltos per diuersas propriedades, nomeando vozes pera sobir ou decer, sem serem necessarias. / Terceira regra / Nam daremos fa, contra mi, nem mi contra fa, em quarta, nem em quinta, nem oitaua \& se algumas vezes se corromper esta regra por causa da letra, o por estar falsa a compostura do canto chão: em tal caso antes se corrompa em Quinta, que em Quarta, nem oitaua, por escusar. Tritono dissonacia em a Quarta, \& dissonancia de septima maior, ou menor em oitaua".

${ }^{180}$ Martínez / Perea, Arte de Canto chão, f. B6r: "Tudo o que esta dito se pode ver por os seus exemplos em seus lugares, \& o que faltar pera perfeita declaração das cousas sobreditas o Mestre o poderá declarar enteiramente".
} 


\title{
2.4. La enseñanza musical en el ámbito doméstico
}

El estudio de las actividades educativas en el ámbito familiar supone, como ha advertido Richard Kagan, una interpretación subjetiva basada en información muy escasa referente a una élite, por lo que las clases populares están poco representadas. ${ }^{181} \mathrm{Sin}$ embargo, a través de las artes de canto podemos aproximarnos a los procesos de enseñanza y aprendizaje de la música en un espectro socioeconómico más amplio.

\subsubsection{TUTORÍAS}

\author{
Entré una sala do ví enseñar \\ todos los pages á un gran maestro, \\ porque fuese cada vno diestro \\ de ser enseñado y saber enseñar, \\ en leer, escriuir, tañer y cantar, \\ dançar y nadar, luchar, esgrimir \\ arco y ballesta, llatinar y dezir, \\ xedrez y pelota saber bien iugar. ${ }^{182}$
}

Por sus características de brevedad y compendio de lo necesario y fundamental, las artes de canto se presentan como una opción adecuada para el aprendizaje de la música por parte de la realeza, si tenemos en cuenta los preceptos contenidos en los tratados de educación de la época: ${ }^{183}$

También puede [el príncipe] aprender desde niño la música, pero no la de flauta ni de otros instrumentos que se tañen con la boca, ya que es propia de hombres de baja suerte por los gestos y visajes que hacen, sino la de voces y cuerdas. Y esto siempre, al igual que la poesía, sin que se aficione excesivamente a ella y se distraiga de asuntos más importantes. Y así como por la majestad de su estado puede tener todo género de cantores que colaboren en los oficios divinos y le distraigan y amenicen sus fiestas, él se guardará de tañer y cantar en público. Y del mismo modo que no compondrá poesías y sobre todo no presumirá de poeta, conviene que aunque sea muy primoroso en sonar y cantar se limite a hacerlo para su propio regalo o entre los muy domésticos. $^{184}$

\footnotetext{
${ }^{181}$ Kagan, Students and Society in Early Modern Spain, p. 5.

${ }^{182}$ Noticia recogida en Crianza y virtuosa doctrina, obra atribuida a Juan de Lucena, sobre Pedro Mártir, maestro de los jóvenes de la Casa Real tras la conquista de Granada. Citado en Adolfo Bonilla y San Martín, "El Renacimiento y su influencia en España”, La España Moderna, XIV/158 (1902), pp. 84-100, p. 97.

${ }^{183}$ Véanse Robledo Estaire, "El lugar de la música en la educación del príncipe humanista"; y Knighton, "Los libros de música de Felipe II".

${ }^{184}$ Varela, Modos de educación en la España de la Contrarreforma, p. 79.
} 
Según Tess Knighton, "la enseñanza musical, tanto de música teórica como de música práctica, formó parte de la educación de los príncipes según el modelo establecido desde al menos el siglo XIV"; siguiendo el paradigma de la casa de Borgoña, los príncipes se iniciaban en la práctica musical a los siete años, al tiempo que comenzaba su educación general. ${ }^{185}$ Knighton ha identificado dos figuras docentes en la formación de Felipe II: el tutor (Juan Martínez Silíceo) y el ayo (Juan de Zúñiga). ${ }^{186}$ María Sanhuesa Fonseca ha analizado el papel de la música en la educación de Felipe III como parte de la llamada "pedagogía de la templanza" identificando dos figuras similares: el ayo (Gómez Dávila y Toledo, Marqués de Velada), que era el encargado de la enseñanza de la música, y el maestro (García de Loaysa). ${ }^{187}$

Numerosas artes de tañer fueron dedicadas a los reyes: El primero (-sesto) libro del Delphin de musica para tañer vihuela (Valladolid, 1538) de Luis de Narváez, el Libro de musica de vihuela (Salamanca, 1552) de Diego Pisador y el Libro de musica para vihuela intitulado Orphenica lyra (Sevilla, 1554) de Miguel de Fuenllana fueron dedicados a Felipe II. João III es el dedicatario del Libro de musica de vihuela (Valencia, 1536) de Luis de Milán y el Libro primero (Osuna, 1549) de Juan Bermudo. Fueron dedicados a Felipe III El Melopeo y Maestro (Nápoles, 1613) de Pietro Cerone y Flores de musica para o instrumento de tecla \& harpa (Lisboa, 1620) de Manoel Rodrigues Coelho. Algunas artes de tañer estuvieron vinculadas posiblemente con la educación de los príncipes, como el Arte nouamente inuentada pera aprender a tanger (Lisboa, 1540) de Gonzalo de Baena, músico al servicio de la corte portuguesa:

Es interesante especular si, como era a menudo el caso, las obligaciones de Baena habrían incluido la instrucción de los niños reales, entre ellos Isabel de Portugal, quien en 1526 se casó con Carlos V y consecuentemente llegó a ser mecenas del más famoso de los organistas españoles del siglo XVI, Antonio de Cabezón. Si esto fuera cierto, entonces el Arte de Baena podría de he-

\footnotetext{
${ }^{185}$ Tess Knighton, "La música en la casa y capilla del príncipe Felipe (1543-1556): modelos y contextos", en Aspectos de la cultura musical en la corte de Felipe II, ed. por Luis Robledo Estaire, Tess Knighton, Cristina Bordas Ibáñez y Juan José Carreras (Madrid: Fundación Caja Madrid, Editorial Alpuerto, 2000), pp. 35-97, pp. $65,67$.

${ }^{186}$ Knighton, “La música en la casa y capilla del príncipe Felipe”, p. 61.

${ }^{187}$ Carta manuscrita sobre la educación de un noble [Obligaciones del ayo de un noble], MS (finales del XVI o principios del XVII), Madrid, Biblioteca Nacional de España, Mss. 12951, ff. 286-295. Citado en María Sahuesa Fonseca, "El 'Vicio Templado' de Felipe El Piadoso: música y educación para Felipe III”, en Politicas y prácticas musicales en el mundo de Felipe II: estudios sobre la música en España, sus instituciones y sus territorios en la segunda mitad del siglo XVI, ed. por John Griffiths y Javier Suárez Pajares (Madrid: ICCMU, 2004), pp. 69-94, pp. 78-79.
} 
cho haberse compilado con sus obligaciones reales en mente, aunque no hace mención de esto en su libro. ${ }^{188}$

La vinculación de la educación musical de los príncipes con las artes de canto es elusiva. Carlos Romero de Lecea ha aventurado que la publicación del Arte de cantollano anónimo de la Biblioteca Nacional de España, cuyo contenido coincide con el libro de Juan Martínez, podría haber sido promovida por Diego de Deza (posterior Arzobispo de Sevilla, teólogo y profesor de la Universidad de Salamanca), preceptor del príncipe don Juan, con la finalidad de que sirviera en la educación musical de éste. ${ }^{189}$ Tenemos noticias de la educación musical del príncipe don Juan gracias a la conocida descripción del cronista Gonzalo Fernández de Oviedo:

Fue su maestro de capilla Johanes de Anchieta e él le enseñó el arte. E tenía por costumbre en las siestas (en especial en verano) que iban a Palacio el dicho Johanes con cinco o seis muchachos de la capilla de Su Alteza de lindas vozes e diestros, de los cuales fue uno Corral, que después fue muy excelente cantor e tiple, e cantaba el Príncipe con ellos dos horas o lo que le placía e les hacía tenor, e era bien diestro en el arte. ${ }^{190}$

Debemos descartar la hipótesis de Romero de Lecea, que relaciona el Arte de cantollano anónimo de la Biblioteca Nacional con la educación del hijo de los Reyes Católicos, puesto que el príncipe don Juan falleció en 1497 y la publicación de ese libro se ha datado entre c. 1512 y 1515. Más allá de la posesión de libros que muestra el Apéndice 9, la investigación de la vinculación de las artes de canto con la formación musical de la realeza no ha dado suficientes resultados que permitan asociar un libro concreto con algún miembro de la realeza. Por ejemplo, el Arte y suma de canto llano (Valencia, 1595) de Juan Francisco Cervera está dedicado al príncipe Felipe, más tarde

\footnotetext{
${ }^{188}$ Knighton, “A Newly Discovered Keyboard Source”, p. 90: "It is interesting to speculate whether, as was often the case, Baena's duties would have included instruction of the royal children, among them Isabel of Portugal, who in 1526 married Charles $\mathrm{V}$ and subsequently became a patron of the most famous of sixteenth-century Spanish organists, Antonio de Cabezon. If this were true, then Baena's Arte may indeed have been compiled with his royal charges in mind, although he makes no mention of this in his book".

${ }^{189}$ Romero de Lecea, "Las más antiguas imprentas musicales hispanas VI”, p. 224.

${ }^{190}$ Gonzalo Fernández de Oviedo, Oficios de la Casa Real de Castilla Dividido en dos partes, MS (siglo XVII), Madrid, Biblioteca Nacional de España, MSS/1027. Citado en Luis Robledo Estaire, "La música en la corte madrileña de los Austrias. Antecedentes: las casas reales hasta 1556", Revista de Musicología, X/3 (1987), pp. 753-796.
} 
Felipe III; sin embargo, como se mostrará en el Capítulo V, la dedicatoria de un libro no implicaba el uso del mismo por parte del dedicatario.

La aproximación a la educación musical de otros estratos sociales en relación con las artes de canto ha sido más fructífera. Respecto a la enseñanza de las primeras letras (lectura y escritura en lengua vernácula, cálculos matemáticos sencillos y recitado del Catecismo), ${ }^{191}$ el medio de instrucción más prestigioso lo constituía el tutor personal privado. Una alternativa a las clases particulares individuales era la tutoría privada fuera de casa y en este caso el tamaño de la clase dependía de la popularidad del maestro y del precio que cobraba, pero las clases solían ser relativamente amplias, lo que sugiere que la atención individual era mínima y que se hacía necesaria la utilización de cartillas impresas. Por ejemplo, Alonso Martín de Canto, residente en Salamanca durante la década de 1530, enseñaba a 150 alumnos al día, mientras que el tamaño de las clases en el Madrid de 1642 era de entre 38 y 140 educandos. ${ }^{192}$ En consecuencia, si la música formaba parte de estas lecciones a grandes grupos, las artes de canto impresas debieron utilizarse como instrumento didáctico, lo que explicaría los lotes de miles de ejemplares de artes de canto localizados en inventarios de empresarios del libro. Un caso del siglo XVIII presentado por Juan José Carreras apoya esta hipótesis. ${ }^{193}$ En 1743, Francisco Díaz de Guitián, segundo trompeta de la Capilla Real de Madrid, solicitó al Rey un privilegio para imprimir un libro titulado Arte de cantar. Carreras indica que este libro debió ultimarse en 1707 ó principios de 1708, ya que se conserva una aprobación firmada el 16 de abril de 1708 por Juan Bonet García de Paredes, maestro de capilla de la Catedral de Toledo, y una segunda aprobación firmada el 9 de mayo de 1710 por Juan Pérez de los Cobos, maestro de capilla de Lorca. Puesto que el libro implicaba un nuevo tipo de tablatura, el autor requería permiso para imprimirlo en su propia casa, lo que supuso una disputa con Joseph de Torres, cuya Imprenta de Música (1699-1736), como señalaba anteriormente, tenía privilegio para imprimir todo lo concerniente a la música.

\footnotetext{
${ }^{191}$ Véase Kagan, Students and Society in Early Modern Spain, p. 9: "El arte de aprender a leer y escribir en lengua vernácula, a interpretar cálculos aritméticos sencillos, y a recitar partes del Catecismo y unas cuantas oraciones simples eran las primera responsabilidades que muchos niños de seis y siete años tenían que afrontar" ["The art of learning how to read and to write in the vernacular, to perform simple arithmetic calculations, and to recite parts of the Catechism and a few simple prayers were the first responsibilities which many new six- and seven-year-olds had to face"].

${ }^{192}$ Kagan, Students and Society in Early Modern Spain, p. 10.

${ }^{193}$ Carreras, "José de Torres and the Spanish Musical Press in the Early 18th Century (1699-1736)".
} 
Otra de las razones que aportaba Díaz de Guitián para instalar una imprenta en su casa era proveer de impresos a los numerosos alumnos que acudían a su casa a recibir clases de música:

[...] el numeroso concurso de discípulos que asisten a mi casa, a fin de conseguir el objeto de atribución de dicha facultad [...], después de conseguido éste, necesitan de tener obras divinas y humanas, puestas en la serie y debajo de las reglas de dicho methodo, asi para su mayor adelantamiento y ejercicio así como para la enseñanza de otros. Para cuyo fin, es el medio mas conveniente permitirme tener imprenta en mi casa $[\ldots] .{ }^{194}$

Aunque en la bibliografía no he encontrado referencias a contratos de aprendizaje entre un tutor de canto y un alumno, sí se conservan contratos de lecciones privadas de vihuela, ${ }^{195}$ lo que lleva a sospechar que la investigación en este campo podría conducir al descubrimiento de documentos contractuales. Mediante el examen de los indicios de uso de las artes de canto he hallado clara evidencia de la utilización de estos libros en lecciones privadas de música. El ejemplar de la edición de 1648 del Arte de canto llano (1594) de Francisco de Montanos conservado en la Biblioteca de la Universidad de Salamanca perteneció a "Rossa Maria de Sam y Serna", como indica una anotación sobre la portada del ejemplar; véase la Ilustración IV.10.

\footnotetext{
${ }^{194}$ Madrid, Archivo Histórico Nacional, Consejos 26565-12; citado en Carreras, "José de Torres and the Spanish Musical Press in the Early 18th Century (1699-1736)".

195 Véase Griffiths, "La vihuela en la época de Felipe II", p. 428, donde se menciona un contrato de aprendizaje musical datado en Zaragoza en 1583 entre el músico Antonio Mayayo y el niño Juanico de Ágreda residente en el Hospital de los Niños Desamparados de Zaragoza.
} 
Ilustración IV.10: Francisco de Montanos, Arte de canto llano (Madrid: Imprenta Real, 1648 [1594]), portada. Salamanca, Biblioteca de la Universidad de Salamanca, BG/29166. Las anotaciones en la portada de este ejemplar indican que perteneció a "Rossa Maria de Sam" y Serna", que lo utilizó para recibir lecciones de canto en su casa.

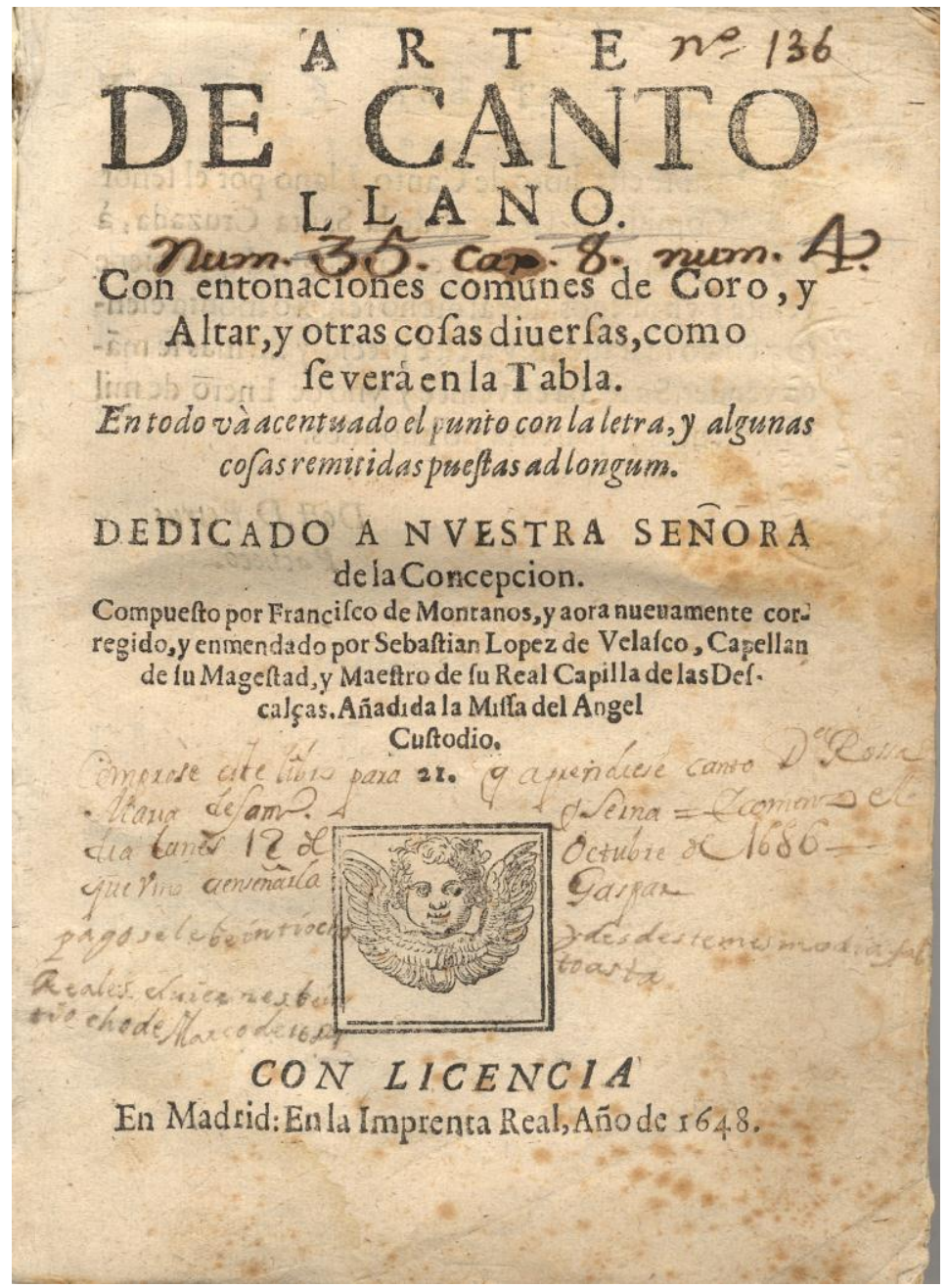

Texto de la inscripción: "Comprose este libro para que aprendiese canto Da Rossa Maria de Sam y Serna y comenzo el dia lunes 12 de Octubre de 1686 que vino a enseñarla Gaspar pagosele veintiocho Reales y desde este mesmo dia falto asta el viernes veintiocho de Março de 1687”.

Las anotaciones en la portada muestran que el ejemplar de la edición de 1648 del Arte de canto llano (1594) de Francisco de Montanos conservado en la Biblioteca de la Universidad de Salamanca se compró para ser utilizado en el marco de lecciones privadas de canto que tenían lugar en el ámbito doméstico de la alumna ("vino a enseñarla") y que eran impartidas por un profesor particular llamado Gaspar que cobraba 28 reales. Como se detallará en la Parte II de esta Tesis Doctoral, el estudio de la formación musical de las mujeres requiere fuentes que van más allá de los libros de música, tales como fuentes literarias y documentos de la Inquisición. Por tanto, aunque según sus materiales 
preliminares las artes de canto no parecen concebidas para ser utilizadas en el contexto de lecciones privadas de música, existe evidencia de la compra de artes de canto para ser usadas como herramienta docente también en este ámbito.

\subsubsection{ACADEMIAS Y TERTULIAS}

Más allá de la utilización de artes de canto impresas, en el intercambio de conocimientos musicales (ya fuese remunerado o "amistoso") surgieron artes de canto que, por su empleo en círculos privados, no llegaron a imprimirse. María Sanhuesa Fonseca delimita un tipo de artecillas insertas en el ámbito doméstico, al cual pertenece el tratado manuscrito de 1651 Falsas practicables para músicos de Jayme de Ciervo; se trata de manuales escritos por "aficionados con conocimientos musicales" y destinados "a la información y aprendizaje de un círculo reducido de personas, como los familiares y amigos del autor". ${ }^{196}$ Falsas practicables para músicos "es un pequeño prontuario de contrapunto" escrito por Jayme del Ciervo para sus amigos, posiblemente en el contexto de una academia reunida en su casa mallorquina e integrada por aficionados a la creación musical:

La finalidad de este tratado manuscrito es procurar un pequeño resumen donde se pudiera consultar de forma rápida la resolución de las disonancias en la composición, sin necesidad de recurrir a obras de mayor extensión. Nos hallamos de lleno en la filosofía y el estilo de la artecilla: es el tratado conciso, de manejo rápido, que no contiene pasajes superfluos y que solamente recoge la doctrina musical indispensable para ser puesta en práctica de manera inmediata. ${ }^{197}$

Roberto Weiss opina que fueron las academias y no las universidades las transmisoras del saber humanista. ${ }^{198}$ Aunque no tenemos noticia de la existencia de academias exclusivamente musicales, en España existieron tertulias en las que la música es-

\footnotetext{
${ }^{196}$ Sanhuesa Fonseca, "El tratado Falsas practicables para músicos", pp. 330-331. Jayme del Ciervo era un "Caballero Flamengo" que residía en Mallorca. Sanhuesa Fonseca ha llevado a cabo la edición crítica de este y otros dos tratados manuscritos también datados en torno a 1651 que emergieron en el mismo círculo, Reglas de música práctica y Contrapuntos dobles. Véase María Sanhuesa Fonseca, "Reglas de música práctica y Contrapuntos dobles (manuscritos, ca. 1651): más textos teóricos del círculo del caballero Jayme de Ciervo", Revista de Musicología, XXI/1 (1998), pp. 247-282. De los miembros del círculo, Sanhuesa Fonseca ha identificado a Jayme del Ciervo, Vicente Mut y, posiblemente, el jesuita P. Joseph Zaragoza y Vilanova.

${ }^{197}$ Sahuesa Fonseca, "El tratado Falsas practicables para músicos”, pp. 336, 338-339.

${ }^{198}$ Roberto Weiss, "Italian Humanism in Western Europe: 1460-1520", en Italian Renaissance Studies, ed. por Ernest Fraser Jacob (Londres: Faber and Faber, 1960), pp. 69-93.
} 
tuvo presente. ${ }^{199}$ Los discursos en alabanza de la música recogidos en las actas de la Academia de los Nocturnos (Valencia, 1591-1594), y los músicos que se hallan entre sus contertulios evidencian la existencia de academias literarias en el siglo XVI en las que la música ocupaba un importante lugar. En la sesión 14 (1 de enero de 1592) de la Academia de los Nocturnos, Recogimiento (Manuel Ledesma) leyó "un discurso alabando la música” y Horror (Fabián de Cucalón), “2 redondillas en alabança de la vihuela"; uno de los académicos era el poeta Juan López Maldonado, “doméstico, secretario y músico de doña Tomasa de Borja y Enríquez señora de las villas de Grajar y Valverde y familiar de los duques de Gandía”, que había llegado a Valencia en 1592 “acompañando a su ama" ${ }^{200}$ La existencia de academias con presencia de la música en la Península Ibérica desmentiría la concepción de Cerone según la cual la proliferación de academias en Italia era unas de las causas por las cuales la música floreció más en ese país que en España: $:^{201}$

\footnotetext{
${ }^{199}$ La presencia de la música en las academias literarias del siglo XVII ha sido examinada por María Sanhuesa y por Andrea Bombi; véanse María Sanhuesa Fonseca, "Armería del ingenio y recreación de los sentidos: la música en las academias literarias españolas del siglo XVII", Revista de Musicología, XXI/2 (1998), pp. 497-530; Andrea Bombi, "Entre tradición y modernización: el italianismo musical en Valencia (1685-1738)", Revista de Musicología, XXVI/1 (2003), pp. 296-302; y "Pedagogy and Politics: Music and the Arts in the Valencian Academy (1690-1705)", Early Music, XXXVI (2008), pp. 557-574. Griffiths, "La vihuela en la época de Felipe II", p. 426, basándose en fuentes literarias, ha investigado la presencia de la vihuela en el ámbito de las academias y ha asegurado que este instrumento era usado "en tertulias y reuniones sociales semejantes, o incluso en veladas organizadas con un específico propósito musical".
}

${ }^{200}$ Academia de los Nocturnos, Actas de la Academia de los Nocturnos, ed. por José Luis Canet, Evangelina Rodríguez y José Luis Sirera (Valencia: Edicions Alfons el Magnànim, 1988), vol. 1, pp. 343-354, 364-365. Tomasa Enríquez de Borja (c. 1565-1634) era esposa de Juan de Vega y Toledo, I Conde de Grajal.

${ }^{201}$ La entrada "Academias" del Diccionario de la música española e hispanoamericana comienza con la Academia Española de Historia, Arqueología y Bellas Artes en Roma, creada en 1873, eludiendo la importancia anterior de la academia en el ámbito musical; véase Alfonso de Vicente Delgado et al., "Academias", en Diccionario de la música española e hispanoamericana, ed. por Emilio Casares Rodicio (Madrid: Sociedad General de Autores y Editores, 1999-2002), vol. 1, pp. 19-25. Por su parte, en la voz "Academy" de The New Grove Dictionary no se hace ninguna referencia a España; véase Howard Mayer Brown e Iain Fenlon, “Academy", en The New Grove Dictionary of Music and Musicians, ed. por Stanley Sadie (Londres: Macmillan, 2001), vol. 1, pp. 41-45. Acerca de las academias literarias españolas, véanse Juan Pérez de Guzmán, "Las academias literarias del siglo de los Austrias", La Ilustración española y americana, XXIV/31-32-33 (1880), pp. 106-107, 125-126, 139-140; y "Bajo los Austrias. Academias literarias de ingenios y señores", La España Moderna, LXXI (1894), pp. 68-107; José Enrique Serrano Morales, "Noticia de algunas academias que existieron en Valencia en el siglo XVI", Revista de Valencia, I (1880-1881), pp. 441-452; Joaquín Hazañas y la Rúa, Noticia de las academias literarias, artísticas y cientificas de los siglos XVII y XVIII (Sevilla: en la oficina de D. Carlos de Torres y Daza, 1888); Javier de Salas, "Una academia toledana del tiempo de Felipe III", Archivo Español de Arte y Arqueología, VII (1931), pp. 178-81; y Julia Barella, "Bibliografía: Academias literarias", Edad de Oro, VII (1988), pp. 189-195. Sobre las academias literarias en México y su influencia española, véase José Sánchez, Academias y sociedades literarias en Méjico (Chapel Hill: University of North Carolina, 1951). 
La quinta causa es, por las muchas comodidades que ay para deprender; porque en muchas ciudades de Italia ay vnas casas, que llaman Academias; deputadas solo para juntarse ay los Cantores, Tañedores y Musicos à hazer dos ó tres horas de exercicio. De ordinario aqui suelen acudir los Compositores mas nombrados del lugar, los quales despues de auer hecho prouar sus composiciones, y despues de acabada la Musica acostumbran discurrir sobre de alguna materia musical, diziendo cada uno su parecer con mucha concordia, y concluyendo sus disputas con prouecho de todos. De mas destas Academias publicas, ay diuersas otras casas de Caualleros particulares à onde se haze lo mesmo [...] Parte desto que voy agora diziendo auran visto hazer otras vezes en Madrid, en casa del Señor Cauallero de Gracia Modenes [...] De todas estas occasiones y comodidades para mas facilmente deprender y mas depresto, la España es harto falta. ${ }^{202}$

La Academia de los Nocturnos no constituye un fenómeno aislado. ${ }^{203}$ Las academias españolas se insertaban en un contexto urbano y seguramente tuvieran su precedente en las academias italianas. El Apéndice 15 presenta un listado de academias activas durante el siglo XVI y, en su caso, el grado de presencia de la música en las mismas. Las fuentes para el análisis de la posición de la música en estas reuniones son los libros de actas (si existen) y los testimonios literarios (poesía y, en palabras de Willard King, “novelas académicas”). ${ }^{204}$ Como se aprecia en el Apéndice 15, la música estuvo presente de alguna manera en las siguientes academias: la Academia de Cristóbal de Sandoval (Osuna, 1567-1570), las reuniones musicales y poéticas de Doña Agustina de Torres (Salamanca, c. 1572), la “Academia del Jardín” de Bartolomé Cairasco de Figueroa (Las Palmas de Gran Canaria, 1580-1600), ${ }^{205}$ la Academia Real Matemática (Madrid, 1582), la Academia de los Nocturnos (Valencia, 1591-1594), la Academia de Gonzalo de Córdoba (Loja, fines del siglo XVI y comienzos del XVII), la Academia de Juan de Borja (finales del siglo XVI), la Academia del Caballero de Gracia (finales del siglo XVI), las reuniones de músicos en casa del maestro Bernardo Clavijo (Madrid, finales del siglo XVI e inicios del XVII), la Academia de Juan de Arguijo (Sevilla, 1600-1628), y la Academia de Francisco Pacheco (Sevilla, 1600-1650).

\footnotetext{
${ }^{202}$ Cerone, El Melopeo y Maestro, p. 151.

${ }^{203}$ Nieves Baranda Leturio, “Actas de la Academia de los Nocturnos”, Ínsula: revista de letras y ciencias humanas, 510 (1989), pp. 4-5, p. 5.

204 Willard F. King, Prosa novelística y academias literarias en el siglo XVII (Madrid: RAE, 1963 [Anexo X del Boletín de la Real Academia Española]), p. 113.

${ }^{205}$ Oswaldo Guerra Sánchez, Bartolomé Cairasco de Figueroa: contexto y sentido (Las Palmas de Gran Canaria: Gobierno de Canarias, 2007).
} 
Aunque, como indicaba anteriormente, no tenemos noticia de artes de canto originadas en el contexto de las academias ni de la utilización en estos círculos de manuales ya publicados, los hallazgos de María Sanhuesa Fonseca para el siglo XVII son muestra de la conexión de tratados de música y academias. No sería extraño que surgieran artes de canto en los círculos académicos si tenemos en cuenta que las frecuentaban músicos prácticos y que estos libros se utilizaban como base en el aprendizaje de la música tanto vocal como instrumental. Esta circunstancia se dio por ejemplo en la "Academia del Jardín" (1580-1600), tertulia consagrada a “Apolo Délfico" que reunía a intelectuales, poetas y músicos en la casa de Las Palmas de Gran Canaria de Bartolomé Cairasco de Figueroa, puesto que a esta tertulia acudían Ambrosio López y Francisco de la Cruz, maestros de capilla de la Catedral, y Juan de Centellas, cantor, autor dramático y compositor. $^{206}$

Un tipo de academia frecuente en el mundo ibérico renacentista fue la academia bíblica, consistente en la reunión de un grupo de amigos para leer pasajes de la Biblia. Marcel Bataillon hace referencia a la academia bíblica reunida por el Cardenal Cisneros en 1502, pero también a las reuniones que tenían lugar en casa de Rodrigo de Bivar, "cantor temple" de la capilla del III Duque del Infantado y amigo íntimo del impresor Miguel de Eguía. ${ }^{207}$ No sería insólito que en este ambiente amistoso se hubiesen dado lecciones informales de canto. Encontramos una relación más indirecta entre artes de canto y academias. Pedro Fernando de Castro, VII Conde de Lemos y Virrey de Nápoles, hijo de Fernando Ruiz de Castro y de Catalina de Zúñiga y Sandoval, dedicatarios respectivamente del Arte de musica theorica y pratica (1592) y del Arte de canto llano (1594) de Montanos, mantuvo una academia literaria llamada “de los ociosos" en Nápoles entre 1611 y 1616. Contamos además con otras instituciones de enseñanza musical quizás semejantes a las academias, como son las “escuelas públicas”. Bernadette Nelson

\footnotetext{
${ }^{206}$ María Sanhuesa Fonseca, "El Templo Militante de Cayrasco de Figueroa: los instrumentos musicales del 'Sacro Consistorio", en Actas del I Encuentro Tomás Luis de Victoria y la música española del siglo XVI: los instrumentos musicales en el siglo XVI (Ávila, Mayo de 1993) (Ávila: Fundación Cultural Santa Teresa-Diputación de Ávila, 1997), pp. 197-205, p. 198.

${ }^{207}$ Rodrigo de Bivar fue condenado por la Inquisición en 1539 por alumbrado. Véase "Proceso de fe de Rodrigo de Bivar", Madrid, Archivo Histórico Nacional, Inquisición, legajo 213, expediente 7. Para una transcripción de este expediente inquisitorial, véase Alastair Hamilton, El proceso de Rodrigo de Bivar (1539) (Madrid: Fundación Universitaria Española, 1979), p. 56. Véanse también Bataillon, Erasmo y España, pp. 24, 212; y Antonio Márquez, Los alumbrados. Orígenes y filosofía 1525-1559 (Madrid: Taurus, 1972). Véase el Capítulo VII.
} 
menciona la existencia de 13 "escolas pubricas de canto dorgão" en la Lisboa de mediados del siglo XVI; Nelson considera este dato como una prueba de que el aprendizaje del arte del contrapunto era "una actividad popular entre las clases educadas". ${ }^{208}$ No sería sorprendente, por tanto, el uso de artes de canto llano y contrapunto en el contexto de estas "escuelas públicas”.

\subsubsection{ARTES DE CANTO Y FORMACIÓN AUTODIDACTA:}

\section{¿“NO HA MENESTER MAESTRO EL CANTOR”?}

Juan Bermudo aseguraba en El arte Tripharia que para "entender" sus libros "no ha menester maestro el cantor". ${ }^{209}$ Se plantea, por tanto, la cuestión de la posible autosuficiencia de las artes de canto para el aprendizaje de los fundamentos del canto. ${ }^{210}$ Como señalé en el Capítulo I, una de las principales críticas que han recibido las artes de canto en la historiografía alude a su extrema brevedad y a su ineficacia para el aprendizaje por parte de principiantes; indicaba que el objetivo de estos manuales era servir como herramienta docente y, por tanto, como un complemento a la explicación del maestro o como un resumen de la misma. El análisis de la afirmación de Bermudo en su contexto sugiere que la enseñanza de los rudimentos de la música se llevaba a cabo de forma oral usando como material artes de música como El arte Tripharia, pero que, una vez "introducido" en la música, el estudiante podría entender por sí sólo libros más avanzados:

Digo, que para entender mis libros: no ha menester maestro el cantor. El que introduzido estuviere en la Musica por este arte [El arte Tripharia] y en traer las manos en los instrumentos: entendera todos mis libros estudiandolos.

\footnotetext{
${ }^{208}$ Nelson, "Music Treatises and 'artes para tanger' in Portugal Before the 18th Century", p. 200: "That learning the art of counterpoint was apparently a popular activity among the educated classes in Lisbon by the mid $16^{\text {th }}$ century, for example, may be testified by a piece of information provided in Oliveira's Summario: here, it was reported that in addition to as many as fourteen 'escolas pubricas' for dancing (not counting those individuals who taught privately in the houses of the nobility), there were apparently as many as thirteen 'escolas pubricas de canto dorgão'. It is not certain how the term 'escola pubrica' in this document should be interpreted, nor whether such schools, or small academies, were independent of other established and larger institutions associated with choral foundations, for example".

${ }^{209}$ Bermudo, El arte Tripharia, f. 5v, "Prologo al lector". Barrios Manzano, "Domingo Marcos Durán", p. 95, sostiene que las artes de canto gregoriano se utilizaban "siempre contando con la ayuda y explicaciones del maestro de canto llano o del sochantre"

${ }^{210}$ John Griffiths considera que los libros de vihuela dirigidos a aficionados se relacionan con el autoaprendizaje. Véase Griffith, "Juan Bermudo, Self-Instruction and the Amateur Instrumentalist".
} 
Cerone planteaba una complementariedad entre el maestro y los libros para convertirse en "músico" cuando señalaba que "demas de los Maestros, es menester leer diuersas artes y tractados de Musica: y ver muchas obras en practica”, de manera que "casi señal cierta es de perfeto Musico el tener grande libreria". ${ }^{211}$ De nuevo, la identificación del músico con el teórico de la música se hace evidente. Las artes de canto, por su contenido y su estilo, se presentan como un instrumento auxiliar, ligado a las lecciones de música, como las impartidas en instituciones religiosas y universidades, pero también las de carácter privado que tenían lugar en el ámbito doméstico. Es decir, como refleja el estudio del mercado potencial de estos libros llevado a cabo en el Capítulo II, las artes de canto eran consumidas no sólo por un público profesional, sino también por los aficionados, aunque es difícil determinar si con estos libros "no ha[bía] menester maestro el cantor".

A través del estudio de las artes de canto que he presentado en la Parte I de esta Tesis Doctoral, siguiendo la metodología de los historiadores del libro, han surgido los nombres de varias mujeres como dedicatarias, impresoras y usuarias de artes de canto. Esta circunstancia, unida al replanteamiento de la discriminación que la historiografía musicológica había establecido entre los materiales musicales a los que tenían acceso las mujeres para aprender música y aquéllos utilizados para enseñar a los hombres, me ha conducido a estudiar las diferentes conexiones entre las artes de canto y las mujeres de la época, relacionando así estas dos alteridades. Los resultados de este análisis se presentan en la Parte II de esta Tesis Doctoral, constituida por los Capítulos V al VII.

\section{RESUMEN DEL CAPÍTULO IV}

El Capítulo IV, el último de la Parte I, se estructura en dos secciones. En la primera se exploran diferentes empleos de las artes de canto más allá de su propósito didáctico (como instrumento de difusión de la religiosidad, contribución al ceremonial de la Iglesia, ayuda para evitar errores en el canto, honesto pasatiempo y forma de enaltecimiento de la nación) y se estudian las evidencias externas halladas en los ejemplares consultados. En la segunda sección, siguiendo a Roger Chartier, se estudia el grado de conexión entre las artes de canto como categoría libresca y el proceso de tradición oral de enseñanza-aprendizaje de la práctica de la música en ámbitos docentes diferenciados (eclesiástico, universitario, doméstico).

\footnotetext{
${ }^{211}$ Cerone, El Melopeo y Maestro, p. 87.
} 
La aparición en el ámbito francés de manuales como Méthodes pour apprendre à lire, à escripre, chanter le plain chant, et compter (París, 1633) de Jacques Cossard, apoya las hipótesis perfiladas en capítulos anteriores de que el aprendizaje del canto llano no era materia exclusiva de clérigos y monjas, sino que formaba parte de la enseñanza general, y de que las artes de canto no eran "Artezillas para sacristanes de aldea", sino manuales para aprender los rudimentos de la música. Libros de música instrumental como el Libro de cifra nueua para tecla, harpa, y vihuela (1557) de Venegas de Henestrosa y la Declaración de instrumentos (1555) de Bermudo comienzan con un arte de canto llano como base para cantar y tocar música tanto sacra como profana. Además, las artes de canto contribuyeron a la difusión de la religiosidad, quizás como una modalidad más de las artes para servir a Dios, lo que implicaría la conexión entre educación musical y educación general en esa época. Las artes de canto podrían vincularse con la denominada "vulgarización de la Escritura", mediante la impresión de libros religiosos en lengua vernácula para difundirlos fuera de los contextos propiamente eclesiásticos.

Las evidencias externas de uso que he encontrado en más de 100 ejemplares de artes de canto sugieren que estos libros se utilizaron tanto para enseñar como para aprender los fundamentos de la música y que también servían como libros de repertorio musical. Las anotaciones en un ejemplar a menudo ofrecen información sobre su precio y sobre su poseedor/a, por lo que contribuyen al estudio del mercado de estos libros llevado a cabo en el Capítulo II. Muchas de las artes de canto conservadas acabaron en manos de coleccionistas, estudiosos o bibliófilos (como Bartolomé Gallardo o Francisco A. Barbieri), pero también contienen información sobre los iniciales poseedores. La evidencia externa de los ejemplares de artes de canto apoya otras hipótesis presentadas anteriormente en este trabajo, puesto que se encuentran indicios de intersección entre lo profano y lo religioso y evidencias de la amplia vigencia cronológica del contenido de estos manuales.

En este Capítulo analizo el Tractat de música, un manuscrito datado en el siglo XVI conservado en la Biblioteca de Reserva de la Universitat de Barcelona y no estudiado hasta ahora. El manuscrito pudo surgir en el contexto de lecciones orales en las que también se utilizaban artes de canto, puesto que contiene una traducción al catalán de los dos primeros capítulos y parte del tercero de la Sumula de canto de organo (c. 1504) de Domingo Marcos Durán (una de las primeras artes de canto conocidas). El Tractat de música sigue el mismo procedimiento denominado por Cristle Collins Judd "cuaderno del humanista", consistente en transcribir a mano citas tomadas de textos impresos bajo encabezados preestablecidos. Otro caso similar es el manuscrito $\mathrm{Mi}$ cel-lània de tractats musicals (1475-1525) de la Biblioteca de Catalunya.

La inclusión de la mano guidoniana en las artes de canto es otro aspecto tratado en el Capítulo IV (véase el Apéndice 14). Aunque dependía de cuestiones técnicas de la imprenta, la inclusión de la mano musical en un libro indica que era dedicado a la enseñanza de la música a principiantes. Un caso especial fue el del tratado de Monserrate, que no incluyó la ilustración de la mano guidoniana pero sí su explicación verbal. La mano musical se empleaba además en la cultura de la época como metáfora en textos dramáticos.

La historia del Arte de canto llano (Valladolid, 1594) de Montanos se estudia en profundidad. La consulta de ejemplares de las diferentes ediciones del libro hasta el siglo XVIII me ha permitido analizar cómo se fue modificando a lo largo de un siglo y medio. Este tratado fue reimpreso a iniciativa de impresores y libreros, lo que muestra su éxito comercial, pero también por músicos, que fueron añadiendo repertorio y materiales didácticos más avanzados; por ejemplo, Joseph de Torres publicó el Arte de canto 
llano de Montanos en 1705, 1712, 1728 y 1734, añadiendo a los contenidos de Montanos su propio tratado titulado El arte practico de canto de organo y repertorio musical.

Las artes de canto reflejan de modo indirecto el contenido de las lecciones públicas y gratuitas impartidas en las capillas eclesiásticas, en las que estos manuales debieron de utilizarse para facilitar el aprendizaje a un público heterogéneo. Se sirvieron de estos libros en sus clases maestros de capilla (Aranda, Brito, Castillo, Marcos Durán, Mendes, Montanos, Thalesio, Torres y tal vez Martínez de Bizcargui), maestros de los mozos de coro (Martínez, Villafranca y Villegas) y sochantres (António Cordeiro). Además, a juzgar por la procedencia de los ejemplares conservados y los inventarios de libros conventuales, las artes debieron tener una importante presencia en el ámbito monacal.

Frente a la hipótesis de que las artes de canto eran utilizadas exclusivamente por clérigos, monjas y aspirantes a la carrera eclesiástica para aprender a cantar la Misa y el Oficio Divino, esta investigación demuestra que la proyección de las artes de música transciende el ámbito eclesiástico. Las fuentes literarias sugieren que las artes de canto pudieron utilizarse en las escuelas de latín como ocurría en el contexto protestante. Además, las artes de canto tuvieron una presencia en las aulas universitarias. Las múltiples reediciones de que fueron objeto algunas artes de canto en ciudades con universidad como Salamanca, Alcalá de Henares y Coimbra indican su uso en el contexto universitario; véase el Apéndice 6. Por ejemplo, el Arte de canto llano de Juan Martínez fue reimpreso en 1532 por Miguel de Eguía, impresor de la Universidad de Alcalá de Henares, y el colofón de la edición de 1554 del Arte ingeniosa de musica de Melchor de Torres (considerada hasta ahora una edición fantasma) indica que la impresión fue llevada a cabo en la propia imprenta de la Universidad de Alcalá de Henares. Dos autores de artes de canto fueron catedráticos de música en Coimbra: Aranda y Thalesio. Sin embargo, la muestra más evidente de la conexión entre artes de canto y enseñanza musical universitaria es el caso de Afonso Perea Bernal, quien como catedrático de música de la Universidad de Coimbra no escribió un libro de música teórico-especulativa como habían hecho en Alcalá de Henares Pedro Ciruelo en 1516 (Cursus quatuor mathematicarum artium liberalium) y en Salamanca Francisco Salinas en 1577 (De musica libri Septem), sino que preparó una edición traducida, revisada y ampliada (con más contenidos prácticos) del Arte de canto llano (Sevilla, 1530) de Juan Martínez.

Las artes de canto no sólo se utilizaban en las enseñanzas oficiales. En este Capítulo aporto evidencias de la utilización de artes de canto en lecciones privadas en el ámbito doméstico; un ejemplar de la edición de 1648 del Arte de canto llano (1594) de Montanos tiene una anotación en la portada que indica que perteneció a "Rossa Maria de Sam ${ }^{\circ}$ y Serna" y que se compró para que recibiera lecciones de canto en su casa por un profesor particular. Este Capítulo estudia la posible conexión de las artes de canto con las academias (véase el Apéndice 15) y la educación de la realeza. Aunque Carlos Romera de Lecea sugiere que el Arte de cantollano anónimo R/14670(1) de la Biblioteca Nacional pudo ser promovido por Diego de Deza, preceptor del príncipe don Juan, para la educación musical de éste, esta hipótesis debe descartarse, puesto que el Príncipe había fallecido en 1497 y el libro se ha datado entre c. 1512 y 1515. Finalmente, el Capítulo IV muestra que no existe una relación evidente entre las artes de canto y la autoenseñanza, puesto que los indicios apuntan a que la enseñanza de la música a nivel introductorio se llevaba a cabo de forma oral usando como material las artes de canto llano. En la Parte I de esta Tesis Doctoral han surgido los nombres de varias mujeres como dedicatarias, impresoras y usuarias de artes de canto, lo que conduce al análisis 
que se lleva a cabo en la Parte II de las diferentes conexiones que se establecieron entre las artes de canto y las mujeres de la época. 

Parte II

MUJERES Y ARTES DE CANTO EN LA CULTURA MUSICAL 



\title{
INTRODUCCIÓN
}

\begin{abstract}
Y lamento mucho el hecho de que el libro [Feminine Endings] y su recepción tuvieran el efecto de clausurar la empresa de la crítica feminista en los estudios musicales antes de que realmente consiguiera empezar. Yo misma dejé de trabajar en el área por lo general, dado que parecía estar causando más problemas que soluciones. En retrospectiva, tendría que decir que $\mathrm{Fe}$ minine Endings tuvo un impacto completamente negativo en el subcampo de la musicología feminista. ${ }^{1}$
\end{abstract}

La exploración de la vida musical del mundo ibérico renacentista a través de la alteridad de las artes de canto -libros de música que, por su brevedad y por la falta de originalidad de sus contenidos, habían pasado desapercibidos en los estudios musicológicos- se complementa con la ampliación del campo de miras que proporciona otra manifestación de alteridad: la historia de las mujeres. El estudio de las relaciones entre libros de música y mujeres (como mecenas, impresoras y propietarias de los mismos) requiere el uso de tácticas diferentes a las utilizadas por la musicología tradicional. Las metodologías tomadas de los estudios de la cultura popular resultan fructíferas para afrontar el "fenómeno de invisibilidad de las mujeres" en documentos históricos; ${ }^{2}$ estas metodologías conducen a vislumbrar vestigios no sólo de la cultura musical de las mujeres de la época sino también del lugar de la música en la vida cotidiana. Partiendo de una serie de conexiones entre mujeres y artes de canto, en la Parte II de esta Tesis Doctoral se plantea que las áreas en que se produce una superposición entre lo privado y lo público y entre lo oral y lo escrito permiten visibilizar prácticas musicales (femeninas) y

\footnotetext{
${ }^{1}$ Susan McClary, "Feminine Endings at Twenty", Trans-Revista Transcultural de Música, 15 (2011) [Consultado 1 de diciembre de 2011] <http://www.sibetrans.com/trans/a348/feminine-endings-attwenty>: "And I very much regret the fact that the book [Feminine Endings] and its reception had the effect of closing down the enterprise of feminist criticism in music studies before it really got started. I myself stopped working in this area for the most part, given that I appeared be causing more problems than solutions. In retrospect, I would have to say that Feminine Endings had an overwhelmingly negative impact on the subfield of feminist musicology".

${ }^{2}$ Kleinberg, ed., Retrieving Women's History, p. ix.
} 
vestigios de la cultura musical de la época invisibles desde perspectivas y metodologías tradicionales.

James S. Amelang llama la atención acerca de la importancia que tiene el "estudio de la religión para la historia de las mujeres en España", puesto que "la religión puso a disposición de las mujeres un vocabulario rico y expresivo, y sirvió como sistema de comunicación social, en el que, por diversas razones, las mujeres se distinguieron como participantes especialmente eficaces". ${ }^{3}$ No es extraño, por tanto, que en la esfera pública encontremos múltiples conexiones entre mujeres y libros de música que, como las artes de canto, se concebían como un instrumento para servir a Dios. La Parte II comienza con un análisis de la vinculación de Catalina de Zúñiga y Sandoval, VI Condesa de Lemos, con el Arte de canto llano (Valladolid, 1594) de Francisco de Montanos, obra de la que es dedicataria; este estudio conduce a pensar que la dedicatoria de un arte de canto sirvió como una forma de demostración pública de la religiosidad de la Condesa (Capítulo V). Las artes de canto guardan notables similitudes con los "libritos de mujeres”, una categoría libresca específica en el mercado del libro del siglo XVI constituida por libros de temática principalmente religiosa; no resulta sorprendente, en consecuencia, que las artes de canto sean los libros de música mejor representados en los inventarios de bienes de mujeres del siglo XVI que he examinado (Capítulo VI). La particular vinculación de las mujeres con la religión que señala James S. Amelang también se refleja en la posición que la música ocupaba en los tratados de conducta femenina, en los que se rechazaba la música en asociación con los "convites"; sin embargo, esta panorámica "pública" (dedicatorias de libros impresos, preceptos incluidos en manuales de conducta) contrasta con la imagen ofrecida por otras fuentes como los cuentos populares y los documentos de la Inquisición (Capítulo VII).

La hipótesis de Amelang no sólo vincula la religión especialmente con las mujeres, sino que lo hace en concreto con las mujeres en España. Cabe preguntarse por consiguiente si en España la relación mujeres-religión era más determinante que en otros lugares. En los capítulos que siguen se aportará nueva evidencia que conduce al rechazo de la visión aislacionista de la vida musical en el mundo ibérico renacentista. Por ejemplo, el caso de Catalina de Zúñiga, virreina de Nápoles y camarera mayor en la Corte

\footnotetext{
${ }^{3}$ James S. Amelang, "Los usos de la autobiografía: monjas y beatas en la Cataluña Moderna”, en Historia y género: las mujeres en la Europa moderna y contemporánea, ed. por James S. Amelang y Mary Nash (Valencia: Universidad de Valencia, 1990), pp. 191-214, p. 191.
} 
española, mostrará que los contactos culturales transnacionales que determinaban el pensamiento de la época convierten en artificial y arbitrario el estudio de la vida musical dentro de marcos nacionales. ${ }^{4}$ La corte napolitana funcionó como conexión entre el mundo ibérico y el resto de Europa con respeto a la música, ${ }^{5}$ y en cuanto a modelos de conducta para la nobleza femenina: se ha argumentado que las napolitanas (muchas de origen ibérico, como Eleonora de Toledo) fueron tomadas como modelo por otras nobles italianas. ${ }^{6}$ Los capítulos siguientes no tienen como objetivo estudiar "una parte mínima de un todo ya conocido" de la historia de la música, ${ }^{7}$ sino intentar aproximarse a un todo cultural del que sólo conocemos una parte mínima (compositores, música escrita, "grandes" libros de música).

\footnotetext{
${ }^{4}$ Sobre la matriz transnacional que subyace la formación del pensamiento musical europeo del siglo XVIII, véase Agnew, Enlightenment Orpheus. Este aspecto ha sido subrayado por Olivia A. Bloechl en su reseña del libro en Eighteenth-Century Music, VII/1 (2010), pp. 105-107. Véase también Emilio RosFábregas, "Musicological Nationalism or How to Market Spanish Olive Oil", Newsletter of the International Hispanic Music Study Group, IV/2 (1998), pp. 6-15.

${ }^{5}$ Tess Knighton, "Isabel of Castile and Her Music Books: Franco-Flemish Song in Fifteenth-Century Spain", en Queen Isabel I of Castile: Power, Patronage, Persona, ed. por Barbara F. Weissberger (Woodbridge: Tamesis, 2008), pp. 29-52, p. 49, indica que el cancionero polifónico del siglo XV conservado en El Escorial (MS IV.a.24) "refleja la importancia de la conexión napolitana para la difusión del repertorio internacional de canciones hacia la Península Ibérica".

${ }^{6}$ Bruce L. Edelstein, "Nobildonne napoletane e committenza: Eleonora d'Aragona ed Eleonora di Toledo a confronto", Quaderni Storici, CIV/2 (2000), pp. 295-330.

${ }^{7}$ María Luisa Bueno Domínguez, "Reflexiones en torno a la historia de las mujeres. ¿Una historia coyuntural?", en Historia a Debate. Tomo II: Retorno del sujeto. Actas del Congreso Internacional “A historia a debate" celebrado el 7-11 de julio de 1993 en Santiago de Compostela, coord. por Carlos Barros Guimerans (Santiago de Compostela: Historia a Debate, 1995), pp. 285-297.
} 



\section{CAPÍTULO V \\ MUJERES DEDICATARIAS DE ARTES DE CANTO}

Sólo dos libros de música impresos en el mundo ibérico del siglo XVI fueron dedicados a mujeres y ambos encajan en la categoría de las artes de canto: El arte Tripharia (Osuna, 1550) de Juan Bermudo y el Arte de canto llano (Valladolid, 1594) de Francisco de Montanos. ${ }^{1}$ El primero, dedicado a la noble Isabel Pacheco, abadesa del Convento de Santa Clara de Montilla (Córdoba), estaba dirigido a sus monjas. E1 segundo, dedicado a la noble Catalina de Zúñiga y Sandoval (1555-1628), era un manual consistente en la publicación por separado de la primera sección del Arte de musica theorica y pratica (Valladolid, 1592) del mismo autor, que había sido dedicado al marido de Catalina, Fernando Ruiz de Castro (1548-1601), VI Conde de Lemos. Historiadores del libro establecen que la mayoría de los libros del siglo XVI dedicados a mujeres "son libros para mujeres en su sentido amplio, y la destinataria es mera punta de iceberg representativa con la que se identifican las de su género". ${ }^{2}$ Como veremos en este Capítulo, estos dos libros de música dedicados a dos mujeres distan mucho de ser libros "para mujeres".

Tratados breves y prácticos dirigidos a mujeres como El arte Tripharia se han tomado frecuentemente como evidencia para argumentar que en la tratadística musical del mundo ibérico renacentista las mujeres eran consideradas estudiantes intelectualmente inferiores y, por tanto, estaban consignadas a aprender pasivamente sólo la ver-

\footnotetext{
${ }^{1}$ A principios del siglo XVII, un libro de repertorio polifónico litúrgico fue dedicado a una mujer. Tomás Luis de Victoria dedicó su última publicación, Officium defunctorum: in obitu et obsequiis sacrae imperatricis, a 6 voces (Madrid, 1605) a la infanta archiduquesa Margarita de Austria, hija de la Emperatriz y monja en el Real Monasterio de las Descalzas de Madrid como Sor Margarita de la Cruz. Véase Alfonso de Vicente Delgado, "El entorno femenino de la dinastía: el complejo conventual de las Descalzas Reales (1574-1633)", en Tomás Luis de Victoria y la cultura musical en la España de Felipe III, dir. por Alfonso de Vicente y Pilar Tomás (Madrid: Centro de Estudios Europa Hispánica, 2012), pp. 197-246, p. 200.

${ }^{2}$ Cátedra García y Rojo Vega, Bibliotecas y lecturas de mujeres, p. 87.
} 
tiente práctica de la música. ${ }^{3}$ Sin embargo, debido a las distintas motivaciones que inducían a dedicar un libro a una persona, las dedicatorias presentan problemas de interpretación cuando se emplean como fuente para determinar la conexión precisa entre un libro y su dedicatario, de manera que se requieren documentos adicionales para poder analizarlas con mayor profundidad. ${ }^{4}$ En este Capítulo argumentaré que estos libros que Bermudo y Montanos dedicaron a mujeres no se diseñaron como libros para la categoría "mujer" (independientemente de que El arte Tripharia estuviese explícitamente dirigido a un grupo de mujeres), ni se consideraron en la época como tales. Tras cuestionar previas lecturas de El arte Tripharia tomando como punto de partida controversias más generales sobre la representación de las mujeres en las obras de arte, este Capítulo se centrará en las conexiones (hasta ahora inadvertidas) entre Catalina de Zúñiga y el Arte de canto llano de Montanos. La dedicatoria de Montanos, el material preliminar de otros libros dedicados a la Condesa de Lemos y las características y acontecimientos del entramado cultural en que se insertaban estos personajes apoyan la hipótesis de que esta noble promovió la publicación del Arte de canto llano, y de que lo hizo como parte de su programa de mecenazgo religioso en lugar de como una potencial usuaria del libro.

\section{PUNTO DE PARTIDA: CONTEXTUALIZACIÓN DE EL ARTE TRIPHARIA}

\section{(OSUNA, 1550) DE JUAN BERMUDO EN EL DEBATE HISTORIOGRÁFICO}

El surgimiento de lecturas musicológicas de El arte Tripharia de Juan Bermudo desde perspectivas de género puede entenderse en el contexto de debates más amplios en torno al papel de las mujeres en la creación y transmisión de la cultura y, sobre todo,

\footnotetext{
${ }^{3}$ Maria Therese Annoni y Kathleen E. Nuccio, "Gender as Text and Subtext: The Case of Renaissance Music Pedagogy”, Revista de Musicología, XVI/4 (1993) [Actas del XV Congreso de la Sociedad Internacional de Musicología (Madrid, del 3 al 10 de abril de 1992)], pp. 2210-2228; María Sanhuesa Fonseca, "Música de señoras: las religiosas y la teoría musical española del siglo XVII", en La clausura femenina en España: actas del simposium (1/4-IX-2004), coord. por Francisco Javier Campos y Fernández de Sevilla (San Lorenzo del Escorial: RCU Escorial-M ${ }^{a}$ Cristina, 2004), vol. 1, pp. 167-180.

${ }^{4}$ Véase el Capítulo II (Apartado 1.1.1). En el ámbito literario, Nieves Baranda Leturio, Cortejo a lo prohibido: lectoras y escritoras en la España moderna (Madrid: Arco, 2005), pp. 60-61, ha advertido estas cuestiones metodológicas al señalar que las dedicatorias son "un material que tiene muchos problemas de valoración, al encontrarse entre la adulación, la imagen proyectada o ideal, las deudas o esperanzas en el poder y la posible realidad lectora, pero ello no debe llevar a desecharlo, sino a sopesarlo con cuidado".
} 
en el ámbito de los estudios acerca de la "representación" de la mujer en obras artísticas y literarias. Puesto que El arte Tripharia es el único libro de música del mundo ibérico del siglo XVI del que disponemos que cumple el doble requisito de estar dedicado a una mujer y dirigido explícitamente a mujeres como potenciales usuarias del mismo, no es extraño que se haya interpretado como prueba del grado de destreza musical que se esperaba de las mujeres de este contexto. Sin embargo, cabe preguntarse si en $\mathrm{El}$ arte Tripharia la "mujer" es representada como una categoría diferenciada desde la perspectiva de género. En 1960, Robert Stevenson señalaba en el prefacio de su monografía sobre Bermudo que éste fue un pionero al escribir "el primer tratado específicamente diseñado para uso femenino". 5 Esta afirmación, descontextualizada, podría haber conducido a lecturas de género de El arte Tripharia. Aparte de esta frase en el prefacio, Stevenson no hace ninguna valoración de género de El arte Tripharia, sino que, al contrario, alude al hecho de que Bermudo había concebido el libro no sólo para las monjas de Santa Clara, sino para ser usado por un público más amplio. ${ }^{6}$

\subsection{Controversias generales transferidas a los libros de música}

En el contexto de la Florencia de la temprana Edad Moderna, Kelley A. Harness considera que es difícil determinar el grado de elección del que disfrutaban las mujeres como mecenas de arte, puesto que, en una época en que el silencio era una de las virtudes femeninas, el mecenazgo constituía una oportunidad de comunicación, lo que significa que "una variedad de individuos, algunos de ellos en competición, tomaban parte en la conversación". ${ }^{7}$ La tesis de Harness es que el análisis de una obra de arte permite distinguir el género de su mecenas y, lo que es más importante para mi argumento, que "las mujeres aristócratas en Florencia ejercían control sobre las representaciones de su género en las obras que patrocinaban"; por ejemplo, las protagonistas femeninas pre-

\footnotetext{
${ }^{5}$ Stevenson, Juan Bermudo, p. v: "He pioneered with the first treatise specifically designed for female use".

${ }^{6}$ Stevenson, Juan Bermudo, p. 12: "Él [Bermudo] esperaba que [El arte Tripharia] haría bien no sólo a la sobrina, sino que se encontraría útil en general en toda España" ["He hoped that it would do not only the niece good, but would be found generally useful throughout Spain"].

${ }^{7}$ Kelley Ann Harness, Echoes of Women's Voices: Music, Art and Female Patronage in Early Modern Florence (Chicago: University of Chicago Press, 2006), p. 3: "If, as I propose, patronage might be viewed as a means of communication, then it is important to remember that a variety of individuals, some of them in competition, took part in the conversation".
} 
dominaban en las obras artísticas y literarias patrocinadas por la Archiduquesa María Magdalena. ${ }^{8}$ En la misma línea, Susan G. Bell opina que en la Edad Media las mujeres que financiaron libros para la educación de sus hijos o como regalos para sus hijas ejercieron poder e influencia cultural al elegir el tema de los mismos. ${ }^{9}$ Joan Kelly-Gadol, conocida por cuestionar el que las mujeres tuvieran un Renacimiento, representa la otra cara de la moneda al argumentar que las obras patrocinadas por las nobles italianas no muestran relación alguna con sus intereses como mujeres. ${ }^{10}$ En referencia a la España renacentista, Elisa Garrido González también afirma que "el Renacimiento intentó que las relaciones de las mujeres con la cultura fueran superficiales y se limitaran a la protección de los artistas y a la recepción pasiva de conocimientos", lo cual condujo a la consolidación de la mentalidad masculina. ${ }^{11}$

Las controversias sobre el mecenazgo femenino se han reflejado en estudios musicológicos centrados en el contexto italiano. William Prizer identifica dos pautas de mecenazgo musical femenino en Mantua y Ferrara a finales del siglo XV basándose en los casos de Isabella d'Este y Lucrezia Borgia: 1) las nobles no patrocinaban música sacra, sino música vocal secular (frottola) y música devota (lauda); y 2) estas mujeres no contrataban cantores de música sacra ni tañedores de instrumentos de música alta,

\footnotetext{
${ }^{8}$ Harness, Echoes of Women's Voices, p. 9: "Pero, ¿es posible también en estos objetos de mecenazgo distinguir el género de sus mecenas? Yo me propongo argumentar que lo es y que, además, las mujeres aristócratas en Florencia ejercían control sobre las representaciones de su género en las obras que patrocinaban" ["But is it also possible for these objects of patronage to distinguish the gender of their patrons? I intend to argue that it is and that, furthermore, aristocratic women in Florence exercised control over the depictions of their gender in the works they commissioned"]. Sobre el caso de la Archiduquesa María Magdalena, véase el capítulo 2 (pp. 40-61) del mismo libro.

${ }^{9}$ Bell, "Medieval Women Book Owners", p. 163: "Es importante considerar también el poder y la influencia que las mujeres, como patrocinadoras de volúmenes educativos, podían ejercer en su elección del tema. Mediante el patrocinio de libros y la instrucción de los niños podían influenciar los desarrollos artísticos e ideológicos" ["It is important to consider as well the power and influence that women, as commissioners of educational volumes, were able to exercise in their choice of subject matter. By commissioning books and by instructing children they were able to influence both artistic and ideological developments"].

${ }^{10}$ Kelly-Gadol, "Did Women Have a Renaissance?", p. 152: "De acuerdo con los nuevos valores culturales, el mecenazgo de las mujeres Este, Sforza, Gonzaga y Montefeltro iba mucho más allá de la literatura y el arte del amor y las maneras, pero las obras que patrocinaban, compraban o se les dedicaban no muestran correspondencia consistente con sus preocupaciones como mujeres" ["In accordance with the new cultural values, the patronage of the Este, Sforza, Gonzaga, and Montefeltro women extended far beyond the literature and art of love and manners, but the works they commissioned, bought, or had dedicated to them do not show any consistent correspondence to their concerns as women"].
}

${ }^{11}$ Elisa Garrido González et al., Historia de las mujeres en España (Madrid: Síntesis, 1997), p. 235. 
sino cantores solistas, tañedores de instrumentos de cuerda, maestros de danza y tamborileros. ${ }^{12}$ Podría argumentarse que la elección de estas mujeres estaba determinada por las normas sociales de la época, según las cuales "de las nobles se esperaba que no tuvieran en sus hogares ni instrumentos de música alta, los legítimos atributos de un príncipe bélico, ni una capilla personal". ${ }^{13}$ Otro ejemplo es el trabajo de Suzanne Cusick sobre Francesca Caccini (1587-c. 1640). Cusick argumenta que la música compuesta por Caccini reflejaba la cultura femenina de su época $y$, en particular, era consecuencia de los objetivos políticos de la Duquesa Christine de Lorraine. ${ }^{14}$ Si transferimos este debate al análisis de la relación entre mujeres y libros de música en el mundo ibérico del siglo XVI, surgen tres cuestiones: 1) ¿la representación de la mujer en libros de música patrocinados por mujeres y dirigidos a mujeres podría considerarse una negociación (o “conversación”, en palabras de Kelly A. Harness)?; 2) ¿podemos identificar pautas en el mecenazgo femenino de libros de música en el contexto ibérico renacentista?; y 3 ) si es así, ¿en qué medida serían estas pautas fruto de la elección de las mujeres?

\subsection{El caso de El arte Tripharia}

Una conexión explícita entre libros de música y la formación femenina se encuentra en El arte Tripharia (1550) de Juan Bermudo. Aunque el único ejemplar conocido hasta ahora del libro había sido la reproducción en facsímile realizada aproximadamente en 1892 por Francisco Asenjo Barbieri que se conserva en la Biblioteca Nacional de España con la signatura M/1366, en el transcurso de mi investigación he localizado el ejemplar original de la edición de 1550 a partir del cual Barbieri llevó a cabo la copia. Este ejemplar hasta ahora desconocido de El arte Tripharia se encuadernó junto con un ejemplar del Libro primero (1549) de Bermudo, que es el documento catalogado

\footnotetext{
${ }^{12}$ William Prizer, "Isabella d'Este and Lucrezia Borgia as Patrons of Music: The Frottola at Mantua and Ferrara", Journal of the American Musicological Society, XXXVIII (1985), pp. 1-33; y "Renaissance Women as Patrons of Music: The North-Italian Courts", en Rediscovering the Muses: Women's Musical Traditions, ed. por Kimberly Marshall (Boston: Northeastern University Press, 1993), pp. 186-205.

${ }^{13}$ Prizer, "Renaissance Women as Patrons of Music", p. 197: "noblewomen were expected to have in their households neither loud instruments, the rightful attributes of the warlike prince, nor a personal chapel". Para un trabajo reciente sobre mecenazgo musical femenino en España, véase Vicente Delgado, "El entorno femenino de la dinastía".

${ }^{14}$ Suzanne Cusick, Francesca Caccini at the Medici Court: Music and the Circulation of Power (Chicago: University of Chicago Press, 2009).
} 
con la signatura A-178 en la Biblioteca de la Universidad de Oviedo. ${ }^{15}$ En la hoja de guarda final del volumen encontramos la siguiente anotación: "Compró mi padre este libro en Toledo al heredero de D. Bartolomé Gallardo hacia el año de 1861. / Labra 1869 S. de Soto". Dentro del libro se inserta una hoja suelta en la que se narran las vicisitudes de este ejemplar de El arte Tripharia:

\section{ARTE TRIFARIA}

ESTE LIBRO DE MUSICA ESCRITO POR JUAN BERMUDO RELIGIOSO FRANCISCANO Y MUSICO ESPAÑOL ES INDISCUTIBLEMENTE UNO DE LOS LIBROS ESPAÑOLES DE MAYOR RAREZA COMO ASI LO RECONOCIO EL GRAN MUSICO Y BIBLIOFILO D. FRANCISCO ASENJO BARBIERI QUE POSEYENDO LOS MAS RAROS NUNCA PUDO CONSEGUIR ESTE, TENIENDO QUE CONTENTARSE CON UNA REPRODUCCION QUE EL MISMO HIZO DEL UNICO EJEMPLAR CONOCIDO Y QUE PROCENTE [sic] DE LA LIBRERIA DE D. BARTOLOME J. GALLARDO GUARDABA EL SR. SOTO POSADA Y HOY FIGURA EN MI BIBLIOTECA. - SE HALLA ENCUADERNADO JUNTAMENTE CON LA $1^{\text {a }}$ EDICION DE LA DECLARACION DE INSTRUMENTOS. - DEL MISMO AUTOR Y DE IGUAL RARZA [sic]. EN LA FOTOGRAFIA APARECE LA ULTIMA HOJA CON EL COLOFON DE ESTA OBRA.

En contraste con las mujeres instruidas únicamente en lo doméstico, las monjas tenían la obligación de aprender música, al menos hasta el grado de ser capaces de cantar el Oficio Divino. ${ }^{16}$ Encontramos un ejemplo en la "vida” de Mariana de San José, quien, recodando su niñez en el Convento de Santa Cruz de Ciudad Rodrigo, comentaba:

Fuime inclinando a todo lo que era Religion; en particular me aficionè a los Oficios Diuinos, y assi seguia el Coro como las demas Monjas, y gustauan como era tan niña, de verme dezir en el

\footnotetext{
${ }^{15}$ Una confusión del mismo tipo tuvo lugar con respecto a los dos tratados de Mateo de Aranda, puesto que los ejemplares de los mismos conservados en la Biblioteca Pública de Évora están encuadernados conjuntamente, de manera que el segundo podría haber pasado desapercibido a los estudiosos. Tito de Noronha, Ensaios sobre a história da imprensa (Lisboa: Typ. Franco-Portugueza de Lallemant, 1857), p. 57, data los dos tratados de Aranda en 1533: "Germão Garlhard: Dois -tractados, um de contra-ponto e outro de canto-chão por Matheus de Arauda. Lisboa, 1533". También en Monteiro, "Da Música na Universidade de Coimbra", vol. 1, p. 348, se mencionan los tratados de Aranda como un solo libro titulado "Tratado de Cantollano e contrapuncto". Sin embargo, esta confusión ya había sido advertida en 1900 por Vieira, Diccionario biographico de musicos portuguezes, vol. 1, p. 41: “Correram incorporadas n'um só volume, e assim se encontram os rarissimos exemplares que hoje existem, de sorte que para alguns escriptores tem passado desapercebida a divisão, confundido-as n'uma só”.

${ }^{16}$ Estudios paradigmáticos de la música en los conventos en el ámbito internacional son los ya mencionados de Kendrick, Celestial Sirens; y Monson, Disembodied Voices. En el contexto ibérico, son destacables las aportaciones de Colleen R. Baade, como por ejemplo su ya citado "Nun Musicians as Teachers and Students in Early Modern Spain", así como las contribuciones de Alfonso de Vicente, Soterraña Aguirre, Matilde Olarte, Julieta Vega, Geoffrey Baker y María Gembero (sobre el siglo XVIII).
} 
oficio los versos, y lecciones, y yo que del todo no estaua libre de vanagloria, olgaua saberlo mejor que ninguna. Con esto aprendi presto a cantar, y reçar lo que era menester para aquel estado. $^{17}$

Se ha dicho que "las monjas constituían una parte importante de las mujeres de nivel cultural alto y las enclaustradas tenían un nivel cultural desproporcionadamente alto en el contexto femenino de la época". ${ }^{18}$ Efectivamente, se ha aludido a un mayor florecimiento musical en los monasterios y conventos que en las colegiatas y parroquias, quizás como consecuencia de la clausura. ${ }^{19}$ Las religiosas podían aprender música una vez en el convento, pero debemos tener presente que las únicas vías que eximían del pago de la dote de ingreso eran el ser descendiente de los fundadores del convento y la posesión de una formación musical, de manera que las monjas músicas probablemente fueron instruidas desde una edad temprana "porque sus familias no tenían otro medio de pagar la dote de una monja". ${ }^{20}$ Colleen R. Baade hace una distinción entre el estatus de estas músicas “contratadas”, que debieron ser consideradas en la época como el resto de músicos profesionales, es decir, casi como "sirvientas", y las monjas de clase alta que, incluso teniendo conocimientos musicales, habían pagado su dote. ${ }^{21}$ Nicolás Gon${ }^{17}$ Mariana de San José, Vida de la venerable M. Mariana de S. Ioseph fundadora de la Recoleccion de
monjas augustinas, priora del Real Convento de la Encarnacion: hallada en unos papeles escritos de su
mano: sus virtudes obseruadas por sus hijas dedicadas al Rey nuestro Señor. Publicalas de orden de las
mismas Religiosas El Licenciado Luis Muñoz, MS (1645), Madrid, Biblioteca Nacional de España,
2/37970, p. 12 .

${ }^{18}$ Margaret L. King, "La mujer en el Renacimiento", en P. Burke et al., El hombre del Renacimiento (Madrid: Alianza, 1990 [1988]), pp. 261-307, p. 282.

${ }^{19}$ Aguirre Rincón, "Sonido en el silencio", p. 317.

${ }^{20}$ Colleen R. Baade, “'Hired' Nun Musicians in Early Modern Castile”, en Musical Voices of Early Modern Women. Many-Headed Melodies, ed. por Thomasin K. LaMay (Aldershot: Ashgate, 2005), pp. 287310, p. 307: "He sugerido que la mayoría de las chicas que recibían exención de la dote debido a su habilidad musical fueron probablemente preparadas desde la temprana infancia para convertirse en monjas músicas porque sus familias no tenían otro medio de pagar la dote de una monja, mucho menos posibilidad de asegurar un matrimonio conveniente" ["I have suggested that the majority of girls who received dowry waivers on the basis of their musical ability were likely prepared from early childhood to become nun musicians because their families had no other means of paying a nun's dowry, let alone any prospects for securing a suitable marriage"]. Baade, "Two Centuries of Nun Musicians in Spain's Imperial City", ofrece información sobre más de cien monjas músicas de conventos de Toledo de los siglos XVII y XVIII. Véase también Aguirre Rincón, Un manuscrito para un convento, p. 106.

${ }^{21}$ Baade, “'Hired' Nun Musicians in Early Modern Castile”, p. 303: "A pesar de su (somera) promesa de 'cantar y tocar y barrer', por virtud de haber pagado una dote completa, a Doña Alfonsa González de Salazar se le habría dado un estatus social más alto -tanto dentro de su comunidad religiosa como en la comunidad exterior- que el de las monjas músicas (probablemente anónimas) que 'trabajaban por un precio"" ["Despite her (cursory) promise to 'sing and play and sweep', by virtue of having paid a full 
zález, en su Historia del monasterio de la Encarnación de Ávila, señala que, además de no pagar dote, las monjas músicas "tenían derecho a percibir un pequeño salario", y ofrece referencias a ello halladas en los libros de cuentas, dotaciones y libros de profesiones. $^{22}$

El proceso de enseñanza musical de las monjas músicas pudo tener lugar en un contexto informal y doméstico, como sugiere la selección de casos que presento a continuación. Encontramos referencias a monjas con parientes músicos que les sirvieron como maestros. Un ejemplo es la organista y arpista Bernardina Clavijo, hija del compositor, organista y profesor de la Universidad de Salamanca Bernardo Clavijo del Castillo (1545-1626). ${ }^{23}$ También contamos con "vidas" de monjas que actúan como fuente de una formación musical doméstica premeditada por unos padres sin los medios económicos necesarios para afrontar el pago de una dote. El ejemplo más claro que he encontrado es la "Vida de Doña Eugenia Clara y Doña Clara Eugenia, hermanas" que recoge María Pinel (1685-1707) en un manuscrito recopilatorio de "vidas" de monjas carmelitas. Las dos hermanas, nacidas en la última década del siglo XVI, ingresaron en el Convento de la Encarnación de Ávila exentas del pago de la dote en calidad de bajonista y organista/arpista, respectivamente:

[...] de Padres virtuosos y pobres, que, deseosos de dar a nuestro Señor dos hijas que su Magestad les había dado, no teniendo dote que poder darlas para que entrasen religiosas, con la ayuda de un hermano que tenía en un curato, las enseñó música. Doña Clara Eugenia, que era la mayor aprendió órgano y arpa; y la menor, que era Doña Eugenia Clara, bajón. Por estos instrumentos las recibieron de valde en el convento de la Encarnación. ${ }^{24}$

dowry, Doña Alfonsa González de Salazar would have been afforded a higher social status -both within her religious community and in the external community- than those (likely anonymous) nun musicians who 'labored for a price"']. Aguirre Rincón, "Sonido en el silencio", p. 298, afirma que la música "democratizó" los conventos al permitir el acceso a mujeres de clase media. En el contexto italiano, Monson, Disembodied Voices, p. 2, menciona dotes menores para las monjas con conocimientos musicales.

${ }^{22}$ Nicolás González, Historia del monasterio de la Encarnación de Ávila (Madrid: Editorial Espiritualidad, 1995 [1976-1977]), p. 202, nota 12.

${ }^{23}$ Espinel, Relaciones de la vida del escudero Marcos de Obregon, p. 174.

${ }^{24}$ María Pinel, Retablo de Carmelitas, ed. por Nicolás González (Madrid: Editorial Espiritualidad, 1981), p. 200. Ésta es una edición moderna del códice de María Pinel, Noticias del santo convento de la Encarnación de Ávila, casa primera de mi Madre Santa Teresa, y biografía de algunas monjas contemporáneas, MS (finales siglo XVII o comienzos del XVIII), Ávila, Archivo del Monasterio de la Encarnación, f. 222. Las vidas de Clara y Eugenia son citadas por Nicolás González tomando como fuente el manuscrito de María Pinel y por Antonio Baciero tomando como fuente el libro de Nicolás González; véase González, Historia del monasterio de la Encarnación de Ávila, p. 200; y Antonio Baciero, El Órgano de cámara del Convento de la Encarnación de Ávila (Madrid: Poniente, 1982), pp. 27-28. Colleen R. Baade 
En el prólogo de De musica libri Septem (Salamanca, 1577) Francisco Salinas explicaba que, cuando era un niño, dio lecciones de órgano a una mujer que quería ser monja, a cambio de que ella le enseñase gramática latina. ${ }^{25}$ Tess Knighton menciona el caso de un cantor de la Catedral de Granada que solicitó algunos libros de Cristóbal de Morales con el propósito de enseñar música a sus sobrinas, probablemente para que "pudieran ingresar en un convento como monjas músicas". ${ }^{26}$ Además de esta formación doméstica previa al ingreso en el convento, es interesante la posibilidad que tenían las niñas de entrar "seglares" en un convento y formarse musicalmente antes de profesar para convertirse en monjas músicas y quedar libres del pago de la dote. Las "vidas" de otras dos hermanas que recoge María Pinel actúan como evidencia de ello. Hijas de “padres nobles”, Mariana Rosa (c. 1602-1650) e Isabel de Velasco (c. 1602-1669) eran hermanas gemelas. Su madre murió cuando tenían cuatro años y medio y su padre "las trajo seglares" al Convento de la Encarnación de Ávila, donde fueron educadas por María de León:

\begin{abstract}
Esmeróse la sierva del Señor en su crianza, y enseñólas desde luego a cantar canto llano, y canto de órgano, porque tenían buenas voces, para dedicarlas a las divinas alabanzas. Y doña Mariana aprendió a tocar órgano, arpa, guitarra y cítara. Doña Isabel empezó a deprender bajón, pero no tuvo fuerza en el estómago para ello. Desde luego empezaron las niñas a seguir el coro, sirviendo en todo como religiosas, por no hallarse su padre con caudal para darlas el hábito [...]. ${ }^{27}$
\end{abstract}

Según Bermudo, Isabel Pacheco, dedicataria de El arte Tripharia, necesitaba un breve manual para que sus monjas, y en particular su sobrina, aprendieran los rudimentos de la música. ${ }^{28}$ Bermudo, atendiendo esa necesidad, publicó un breve resumen en

presenta la "vida" de María Vela (1561-1617) como fuente de una formación musical previa al ingreso en un convento; véase Baade, "Nun Musicians as Teachers and Students", p. 263.

${ }^{25}$ Francisco Salinas, De musica libri Septem (Salamanca: Mathias Gast, 1577), f. 5r.

${ }^{26}$ Knighton, "Morales in Print", p. 174. José Goñi Gaztambide, "La Capilla Musical de la Catedral de Pamplona en el siglo XVII", Música en la Catedral de Pamplona, V (1986), pp. 3-97, p. 19, presenta un caso similar en el siglo XVII: Mateo Calvente, maestro de capilla de la Catedral de Pamplona, enseñaba canto a su sobrina "porque está destinada a ser monja y de otra suerte no podrían entrar en religión por falta de dote". Baade, "Nun Musicians as Teachers and Students", y "Two Centuries of Nun Musicians in Spain's Imperial City", proporcionan evidencia documental de otros casos de monjas instruidas en la música antes de ingresar en el convento.

${ }^{27}$ Pinel, Retablo de carmelitas, pp. 187-188, "Vida de Doña Isabel de Velasco y de Doña Mariana Rosa".

${ }^{28}$ Isabel Pachedo era hija de Pedro Fernández de Córdoba, I Marqués de Priego; su sobrina, Teresa Manrique, era hija de los IV Condes de Osorno. 
tres partes sobre canto llano, música mensural y órgano (véase Apéndice 2), que debía ser suficiente "para dar en alguna manera noticia de la Musica: mayormente a religiosas, que son estudiosas, y no pretenden saber sino el officio diuino". ${ }^{29}$ La dedicatoria de Bermudo evidencia, por tanto, que El arte Tripharia contenía lo necesario para la formación musical de las religiosas cuyo cometido era cantar el Oficio Divino, pero quizás sólo funcionara como un manual introductorio para las monjas músicas, puesto que, como indicaban las "vidas", los conocimientos musicales de estas mujeres iban más allá de los contenidos de El arte Tripharia.

La existencia de un libro dirigido explícitamente a mujeres como El arte Tripharia se ha interpretado frecuentemente como testimonio de las diferencias entre el material didáctico diseñado para las mujeres y aquél concebido para los hombres y, por tanto, como fundamento para la discusión de cuestiones de género en la pedagogía musical. En los años noventa del siglo XX Maria Therese Annoni y Kathleen Nuccio llevaron a cabo una comparación entre el Libro primero (1549) y El arte Tripharia de Bermudo. El primero, un libro extenso y que incluía contenidos filosóficos, se tomó como fuente de información acerca de la enseñanza musical que recibían los hombres; el segundo, tres veces más breve y con contenidos totalmente prácticos, se interpretó como ejemplo de texto utilizado para la formación musical femenina. ${ }^{30}$ La comparación se concebía como "una excelente oportunidad para determinar cómo Bermudo, y quizás otros escritores de este período, podrían haber percibido la enseñanza de la música para hombres y para mujeres", y como evidencia de "los prejuicios de género de la instrucción musical del Renacimiento español". ${ }^{31}$ La conclusión del cotejo de los dos tratados de Bermudo llevado a cabo por Annoni y Nuccio fue que, a diferencia del hombre, la mujer estaba relegada a aprender conceptos musicales simples y métodos prácticos; “de las mujeres se esperaba simplemente que tocaran el instrumento o cantaran la canción sin conocer

\footnotetext{
${ }^{29}$ Bermudo, El arte Tripharia, f. 3v.

${ }^{30}$ Los contenidos de ambos libros se desglosan en el Apéndice 2.

31 Annoni y Nuccio, “Gender as Text and Subtext", p. 2215: "The gender bias of Spanish Renaissance musical instruction is most evident in Bermudo's first two treatises, El libro primero and El arte tripharia [...]. The existence of treatises such as these provides an excellent opportunity to determine how Bermudo, and perhaps other writers of this period, may have perceived the teaching of music to men and to women".
} 
los fundamentos teóricos". ${ }^{32}$ En su estudio de la educación musical de las religiosas en el siglo XVII, María Sanhuesa Fonseca afirma que las mujeres eran consideradas por tratadistas como Pablo Nassarre en Fragmentos musicos (Zaragoza, 1683) "alumnos de segunda fila, que ofrecen más problemas a la hora de emprender su educación musical, en la que siempre alcanzarán peores resultados que un discípulo del sexo masculino"."33 Según la musicóloga, esto derivaba de la inferioridad de las mujeres planteada en la teoría musical renacentista, y se refleja en el hecho de que el interlocutor de los libros no sea la mujer, sino el maestro encargado de instruirla.

Contrariamente a la interpretación de Annoni y Nuccio, mi hipótesis sostiene que Bermudo no tenía en mente las categorías de género en sus libros, sino el uso de los mismos por parte de personas con distintos niveles de formación musical e insertas en ámbitos educativos diferenciados como la universidad y el convento. Cantar y tocar sin conocer los fundamentos teóricos no se esperaba de la categoría "mujer", sino de personas como clérigos, mozos de coro, monjes y monjas que necesitaban conocer la práctica musical para desempeñar sus funciones religiosas (personas que no pretendían "saber sino el officio diuino"). La enseñanza de lo suficiente y la prioridad de la práctica eran dos de las características generales de las artes de canto que destaqué en el Capítulo I. Frente la idea de Sanhuesa Fonseca de que el interlocutor de los tratados de teoría musical del Renacimiento no era una mujer, sino el maestro que debía enseñarla, hay que tener presente que en los conventos (y en otros contextos) las mujeres ejercían la docencia musical, como se detallará en el Capítulo VI.

Las interpretaciones de género de libros como El arte Tripharia demuestran las dificultades halladas en el proceso de valoración de las dedicatorias como fuente musicológica. El análisis del material preliminar de El arte Tripharia muestra que el manual no fue diseñado exclusivamente para las monjas de Isabel Pacheco, ${ }^{34}$ que su impresión

\footnotetext{
32 Annoni y Nuccio, "Gender as Text and Subtext", p. 2227: "Women were expected to simply play the instrument, or sing the song without knowing the theoretical foundations".

${ }^{33}$ Sanhuesa Fonseca, "Música de señoras", p. 177. Véase también Álvaro Zaldívar Gracia, "Unos dicen y otras hacen: de la misógina teoría histórica española renacentista y barroca”, en Actas del VII Congreso Internacional de Mujeres en la Música (Bilbao: Real Sociedad Vascongada de Amigos del País, 1994), pp. 159-167.

${ }^{34}$ Freis, "Becoming a Theorist", p. 44, apuntaba la misma idea con un propósito diferente: la desmitificación de la figura de Bermudo como príncipe de la teoría musical española.
} 
no fue sufragada por ella sino por "parientes y amigos" de Bermudo, ${ }^{35}$ y que el libro tampoco fue un encargo explícito de la abadesa ("comence a pensar el modo de poner en obra, lo que, señora, por palabra no me mandastes: pero de mi fue cognoscido, que lo teniades en voluntad", explicaba Bermudo), sino el más básico de una serie de libros que Bermudo ya había compuesto. ${ }^{36}$ La evidencia más clara de este punto es que ya en 1549, en el "Prologo general de toda la obra para el lector" del Libro primero, Bermudo hacía referencia a un volumen dirigido a principiantes, ya compuesto y en circulación, cuyas tres primeras secciones coincidían con las de El arte Tripharia: "Para introduzir los nueuos en Musica tengo vnas artezicas breues de canto llano, organo, monachordio, y de vihuela. Todas estas quatro andan en vn libro por si". ${ }^{37}$ Bermudo comenzaba el Libro primero con una glosa de su "arte para principiantes":

Presuponiendo que auia artezicas para introducir a los nueuos en el canto, quisiera començar: a screuir en Musica para hombres, que tenian alguna noticia de los terminos musicales. Pero viendo, que en todas partes no tenian artezicas, y a la que ay se puede abreuiar, y poner en stylo mas claro: pareciome hazer vna breue introducion para entender facilmente mis libros de Musica. Si vno entrasse sin ver algunos principios de Musica en estos libros: seria infuscarse. El mesmo arte que pusiere para principiantes: glosare para los curiosos. ${ }^{38}$

Además, Bermudo explicaba en El arte Tripharia que aquellos principiantes que quisieran utilizar sus "quatro libros de la declaración de instrumentos musicales" debían empezar con El arte Tripharia, puesto que había sido diseñado como una introducción:

\footnotetext{
Suplico a los doctos maestros, que algunas imperfecciones que en este libro hallaren, miren que es para principiantes, y que auemos de introduzirlos poco a poco, començando como naturaleza de lo imperfecto a lo perfecto. Pues començaran por este libro pequeño, y acabaran con perfection en quatro libros de la declaracion de instrumentos musicales. ${ }^{39}$
}

\footnotetext{
${ }^{35}$ Bermudo, El arte Tripharia, f. 2v: "no solo trabaxo en componer y empremir la dicha obra: mas para ello se ha prouecho de los dineros de parientes y amigos".

${ }^{36}$ Bermudo, El arte Tripharia, f. 3v. Aguirre Rincón, "Sonido en el silencio", p. 287, ha señalado, en contraste, que Isabel Pacheco, "tía de la duquesa de Arcos y 'mecenas por derecho propio', impulsó a Juan Bermudo a escribir” El arte Tripharia.

${ }^{37}$ Bermudo, Libro primero, f. 11v.

${ }^{38}$ Bermudo, Libro primero, f. 1r.

${ }^{39}$ Bermudo, El arte Tripharia, ff. 39v-40r.
} 
Las alusiones que hacía Bermudo a la ampliación de conocimientos mediante el uso de sus otros libros a lo largo de El arte Tripharia descartaría la hipótesis según la cual el autor estaba limitando la educación musical de las mujeres a los contenidos de ese manual. Por ejemplo, Bermudo aconsejaba que "el que tuuiere necesidad de mayor claridad para la intelligencia del monachordio, y la manera de cifrar vea mis libros, y sera largamente informado". ${ }^{40}$ Además, el autor indicaba en el "Prologo epistolar del autor" su intención de que El arte Tripharia fuese usado en toda España: "y porque tanto mejor es el bien, quanto es mas comunicado: trabaje (no sin falta de costa) de imprimirlos, para el prouecho de nuestra España". ${ }^{41}$

En cualquier caso, no existen fuentes que permitan establecer cuál fue el uso real de El arte Tripharia, ni si llegó a utilizarse en el Convento de Santa Clara de Montilla, ni en qué medida fue un libro difundido. Por lo que se sabe hasta el momento, no fue reimpreso como volumen independiente tras su primera edición. No obstante, su contenido se incluyó como parte integrante del más ambicioso tratado Declaración de instrumentos musicales publicado por Bermudo en 1555 (véase Ilustración V.1). “Algunas vezes hallareys vn capitulo en dos libros: lo qual hize por no obligar a comprar vn libro por sola vna cosa", advertía Bermudo. ${ }^{42}$ En este sentido, Robert Stevenson critica que Henri Collet calificara El arte Tripharia de "seco" y "vulgar" y a la vez elogiase la Declaración de instrumentos puesto que los dos libros tienen contenidos comunes. ${ }^{43}$

\footnotetext{
${ }^{40}$ Bermudo, El arte Tripharia, f. 39r.

${ }^{41}$ Bermudo, El arte Tripharia, f. 4r.

${ }^{42}$ Bermudo, El arte Tripharia, f. 5v.

${ }^{43}$ Stevenson, Juan Bermudo, p. 6. Véase Collet, "Contribution à l'étude des théoriciens espagnols", p. 34: "El Arte Tripharia [...] es una obra esencialmente práctica, de muy mal estilo, un manual seco y vulgar, una tentativa desafortunada de simplificación científica" ["L'Arte Tripharia (...) est une ouvre essentiellement pratique, de fort mauvais style, un manuel sec et vulgaire, une tentative malheureuse de simplification scientifique"]. Stevenson, Juan Bermudo, p. 5, explica que los capítulos 1 a 12 de El arte Tripharia reaparecen en el Libro II de la Declaración de instrumentos y que 26 de los 28 capítulos restantes de El arte Tripharia también se repiten en la Declaración de instrumentos según las siguientes concordancias:
}

\begin{tabular}{ll}
\hline El arte Tripharia (1550) & Declaración de instrumentos (1555) \\
\hline Capítulo 13 & Capítulo 19 del Libro III \\
Capítulo 14 & Capítulo 13 del Libro II \\
Capítulos 15 a 28 & Capítulos 16 a 29 del Libro II \\
Capítulo 29 ("De la composicion de los modos") & - \\
Capítulo 30 & Capítulo 25 del Libro IV \\
Capítulos 31 a 33 & Capítulos 37 a 39 del Libro IV \\
Capítulo 34 & Capítulo 26 del Libro IV \\
Capítulo 35 & Capítulo 35 del Libro IV
\end{tabular}


Ilustración V.1: Juan Bermudo, Comiença el arte Tripharia (S.I.: s.n., c. 1892 [Facsímile de la ed. de Osuna, Juan de León, 1550]), f. 6r, Madrid, Biblioteca Nacional de España, M/1366; y Declaración de instrumentos (Osuna: Juan de León, 1555), f. 20v,

Madrid, Biblioteca Nacional de España, R/5256.

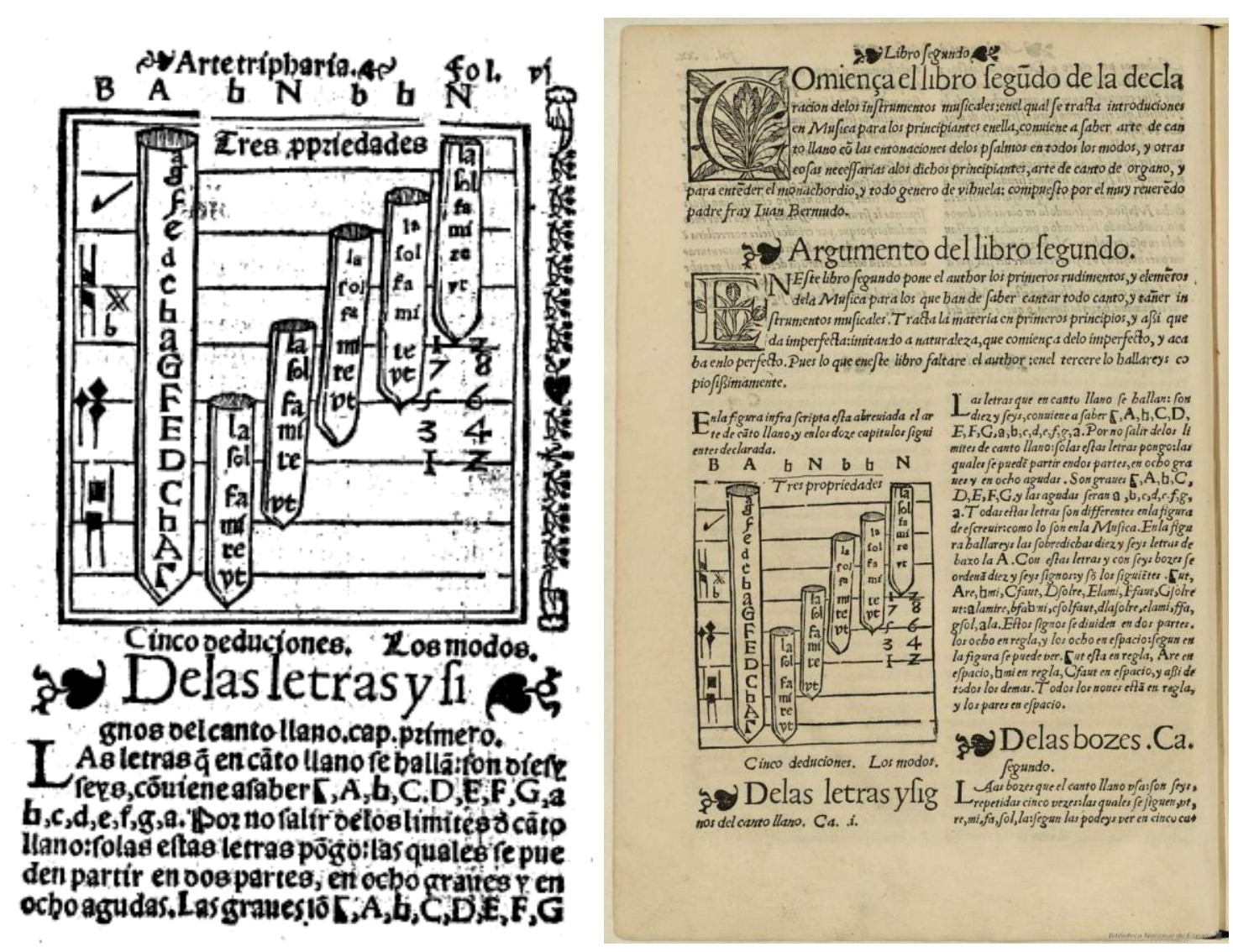

Quizás por iniciativa del propio Bermudo, los primeros once capítulos de El arte Tripharia se tradujeron al catalán para insertarse en el Ordinarium Barcinonense (Barcelona, 1569), un libro litúrgico publicado por el Obispo de Barcelona Guillem Caçador con el propósito de perfeccionar la formación de las monjas y los clérigos de su diócesis. ${ }^{44}$ La evidencia sugiere que Bermudo no distinguía entre los géneros de sus lectores,

\begin{tabular}{ll}
\hline Capítulo 36 & Capítulo 40 del Libro IV \\
Capítulo 37 & Capítulo 48 del Libro IV \\
Capítulo 38 (“Que bozes tiene cada signo en el monachordio”) & - \\
Capítulos 39 y 40 & Capítulo 41 del Libro IV \\
\hline
\end{tabular}

\footnotetext{
${ }^{44}$ María Asunción Ester Sala, "Difusió en català de l'obra de J. Bermudo a l'Ordinarium Barcinonense de 1569", Recerca Musicològica, V (1985), pp. 13-43, señala que el propio Bermudo podría haber enviado El arte Tripharia al organista catalán Mosén Pere Alberch Vila; véase también Otaola, Tradición y modernidad en los escritos musicales de Juan Bermudo, pp. 37-38.
} 
sino más bien entre los diferentes niveles de habilidad (principiantes/iniciados) y los ámbitos en que se formaban musicalmente (monasterio/universidad). Como atestigua el Ordinarium Barcinonense, El arte Tripharia no fue concebido ni visto en la época como un "libro para mujeres", sino como un manual introductorio para usuarios de ambos géneros. ${ }^{45}$ En conclusión, los mozos de coro y los monjes, siendo hombres, habrían adquirido una formación musical similar a la proporcionada por El arte Tripharia, obra cuyo contenido es semejante al del resto de artes de canto que son objeto de esta investigación.

\section{CATALINA DE ZÚÑIGA Y EL ARTE DE CANTO LLANO (VALLADOLID, 1594)}

\section{DE FRANCISCO DE MONTANOS}

Las referencias a la conexión entre Isabel Pacheco y El arte Tripharia son numerosas en la bibliografía, pero la dedicatoria del Arte de canto llano (1594) de Francisco de Montanos a la noble Catalina de Zúñiga y Sandoval ha pasado prácticamente desapercibida. El Arte de canto llano consiste en la publicación por separado de la primera de las seis partes (canto llano, canto de órgano, contrapunto, composición, proporciones y "lugares comunes") del Arte de musica theorica y pratica (Valladolid, 1592) de Montanos, que había sido dedicado al marido de Catalina de Zúñiga, Fernando Ruiz de Castro, VI Conde de Lemos. El Apéndice 1 muestra un listado de las ediciones conocidas y de los ejemplares conservados de los libros de Montanos. Hasta ahora, la edición príncipe del Arte de canto llano (la única que incluye la dedicatoria a Catalina de Zúñiga entre su material preliminar) ha pasado generalmente inadvertida en los estudios musicológicos, quizás por desconocerse tanto el único ejemplar existente de la misma, conservado en la Biblioteca Geral de la Universidade de Coimbra, ${ }^{46}$ como las dos referencias que a esta edición hizo en el siglo XVIII Antonio Ventura Roel del Río en su trata-

\footnotetext{
${ }^{45}$ Baade, "Nun Musicians as Teachers and Students", p. 268, apunta que considera dudoso que El arte Tripharia proporcione testimonio directo de desigualdades en la formación musical de hombres y mujeres: "Es incierto, sin embargo, que El arte proporcione evidencia directa de inequidades en la formación musical de mujeres y hombres, respectivamente" ["It is uncertain, however, whether El arte provides direct evidence of inequities in the respective music training of females and males"].

${ }^{46}$ María Luisa Lemos, Impressos musicais da Biblioteca Geral da Universidade de Coimbra (Coimbra: Coimbra Editora, 1980), p. 27.
} 
do Institucion harmonica (Madrid, 1748) cuando afirmaba haber copiado algunas piezas del Propio de la Misa de una obra de Montanos impresa en Valladolid en $1594{ }^{47}$

El desconocimiento de la edición príncipe del Arte de canto llano de Montanos ha conducido a que en las entradas sobre el músico que encontramos en obras de referencia como The New Grove Dictionary, el Diccionario de la Música Española e Iberoamericana y la Historia de la música española 3: Siglo XVII de José López-Calo, se afirme que el Arte de canto llano es una reedición de 1610 (reimpresa en numerosas ocasiones) de la primera parte del Arte de musica theorica y pratica, y no una publicación independiente de 1594 concebida por Montanos con un propósito determinado. El bibliógrafo Antonio Palau y Dulcet sostenía que, si bien las licencias de la edición de 1610 indicaban que el libro ya había sido impreso con anterioridad, probablemente se tratase sólo de la segunda edición de una parte del Arte de musica theorica y pratica. ${ }^{48}$ En su Tesis Doctoral de 1969 sobre el Arte de musica de Montanos, Dan Murdock Urquhart señala 1625 como el año en que por primera vez se reimprimió por separado el Arte de canto llano. ${ }^{49}$ Sin embargo, en el siglo XIX Francisco A. Barbieri describía el ejemplar de la edición de 1598 del Arte de canto llano conservado hoy en la Biblioteca Nacional de España y mencionaba la posible existencia de una edición previa de 1594 ó 1595 de la misma obra. ${ }^{50}$ Aunque, según las indicaciones bibliográficas que la Biblioteca General de la Universidad de Coimbra adjunta al ejemplar de 1594 conservado en esta institución, esta edición es "citada en Riaño", no he encontrado referencias a los libros de Montanos en Critical and Bibliographical Notes on Early Spanish Music (Londres, 1887) de Juan Facundo Riaño. La edición príncipe de 1594 del Arte de canto llano de Montanos sí aparece citada en Écrits imprimés concernant la musique (Munich y Duisburg, 1971) de RISM indicando la existencia de un ejemplar de la misma en

\footnotetext{
${ }^{47}$ Véase el Capítulo I (Apartado 1.2.8).

${ }^{48}$ Véase Palau y Dulcet, Manual del librero hispanoamericano, vol. 3, p. 322.

${ }^{49}$ Urquhart, "Francisco de Montanos's Arte de musica theorica y pratica", p. 9, hace referencia a la edición de 1610 pero dice no haber podido confirmarla.

${ }^{50}$ Francisco A. Barbieri, Apuntes biográficos de diversas personas, cartas y otros documentos, MS (siglo XIX), Madrid, Biblioteca Nacional de España, MSS/14037/1-55, n 47: "Jesús de Monasterio tiene ejemplar de este libro, pero falto de las cuatro primeras hojas de Portada, preliminares, mano musical grabados, y primer párrafo del texto. Debe existir edición anterior á esta, quizás de los años 1594 al 95, porque la primera aprobación tiene fecha de Madrid, 10 de Set. de 1593, firmada por Hernando de Cabezon; aprobación reproducida en la edición de Salamanca, 1610”.
} 
Coimbra. ${ }^{51}$ También se cita en la segunda edición de Die Musik in Geschichte und Gegenwart de 2004. ${ }^{52}$ En los trabajos más recientes de María Marsá Vila y Alexander S. Wilkinson también se menciona la edición de 1594 del Arte de canto llano de Montanos a partir del ejemplar conservado en Coimbra, aunque sin referencia a la dedicatoria. ${ }^{53}$ La única mención a la edición de 1594 del Arte de canto llano y a su dedicatoria a Catalina de Zúñiga que he encontrado en la bibliografía musicológica aparece en la nota al pie de un ensayo de Alejandro Luis Iglesias. ${ }^{54}$

\subsection{Francisco de Montanos y los VI Condes de Lemos}

Francisco de Montanos (década de 1520 - después de 1595) debió de haber sido una importante figura en el mundo cultural del Renacimiento. En el Arte de musica (1592) proliferan los poemas introduciendo cada uno de sus seis libros y un examen de este material poético aporta más datos acerca de la biografía de Montanos; véase la Tabla V.1. El epigrama de Alonso Becerra que introduce la última sección ("Tratado ultimo de los lugares comunes") del Arte de musica se ha tomado frecuentemente como testimonio de la distinguida ascendencia de Montanos. Robert Stevenson alude a otro de los poetas, Bernardo Prego de Montanos, como pariente del compositor. ${ }^{55}$ Más recientemente, Juan Bautista Varela de Vega ha utilizado ambos poemas como un indicio que apunta al origen gallego de Francisco de Montanos: Alonso Becerra habla del linaje de Montanos junto al de Bermúdez, Pregos y Silvanos. ${ }^{56}$ Narciso Alonso señala que "la familia de Montanos residió indudablemente en Valladolid" y proporciona documenta-

\footnotetext{
${ }^{51}$ Lesure, dir., Écrits imprimés concernant la musique, vol. 2, p. 592.

52 SL (Miguel Querol), "Montanos, Francisco de", en Die Musik in Geschichte und Gegenwart: allgemeine Enzyklopädie der Musik, ed. por Ludwig Finscher (Kassel: Bärenreiter, 1994-2007), vol. 12 (2004), cols. 370-371.

${ }^{53}$ Marsá Vila, Materiales para una historia de la imprenta en Valladolid, p. 167; y Wilkinson, ed., Iberian Books, p. 518.

${ }^{54}$ Luis Iglesias, "El maestro de capilla Diego de Bruceña”, p. 461, nota 123.

55 Robert Stevenson, La música en las catedrales españolas del Siglo de Oro (Madrid: Alianza Música, 1993), p. 364.

${ }^{56}$ Juan Bautista Varela de Vega, "El origen noble de Francisco de Montanos, maestro de capilla (15641576) en la Colegiata de Santa María de Valladolid", Boletín de la Real Academia de Bellas Artes de la Purísima Concepción, 39 (2004), pp. 69-74.
} 
ción parroquial del bautizo de su sobrino Francisco en 1594, hijo de Marcelo de Montanos y Úrsula de Nápoles y de la matrícula en la Universidad de Valladolid de éste último en $1583 .^{57}$ Estos datos sugieren que este Marcelo de Montanos podría ser el conocido platero del siglo XVII (fallecido en 1633) que, procedente de Valladolid, se afincó en Orense "para colaborar con Juan de Nápoles en la obra de las arquetas de San Rosendo y de San Torcuato del Monasterio de Celanova". 58

Tabla V.1: Poemas incluidos en el material preliminar del Arte de musica theorica y pratica (Valladolid, 1592) de Francisco de Montanos

\begin{tabular}{ll}
\hline Ubicación en el libro & Poemas \\
\hline Comienzo del libro & $\begin{array}{l}\text { "Soneto del licenciado Neyra al maestro de capilla Francisco } \\
\text { de Montanos" } \\
\text { "Soneto. De Hieronymo de Lomas Cantoral. Al autor"59 }\end{array}$ \\
Comienzo del libro de canto de órgano & $\begin{array}{l}\text { "Soneto del licenciado Neyra, al maestro de capilla Francis- } \\
\text { co de Montanos" } \\
\text { "Soneto. Del licenciado Miguel Sanchez al autor" }\end{array}$ \\
Comienzo del libro de contrapunto & $\begin{array}{l}\text { "Soneto de don Francisco de la Cueba, al autor" } \\
\text { "Soneto. De Christobal Maço de la Madriz"60 }\end{array}$ \\
Comienzo del libro de composición & $\begin{array}{l}\text { Poema en latín "Del licenciado Pedro Salgado, de Ribade- } \\
\text { neyra. Al autor" }\end{array}$ \\
Epigrama de Bernardo Prego de Montanos \\
Comienzo del libro "De proporcione" & $\begin{array}{l}\text { Soneto de Jerónimo de Lomas Cantoral } \\
\text { Soneto del licenciado Juan Ortiz }\end{array}$ \\
& $\begin{array}{l}\text { Soneto de Fernelio Huraneo } \\
\text { Soneto de Alonso Becerra }\end{array}$ \\
\hline
\end{tabular}

\footnotetext{
${ }^{57}$ Narciso Alonso Cortés, Noticias de una corte literaria (Madrid y Valladolid, 1906), p. 12, nota 1: "Francisco.- en 26 de junio año de 1594 Baptice a francisco hijo de marçelo de montanos y hursola de napoles su muger fueron padrinos el doctor phelipe baca de santiago y Juana Sanchez y por verdad lo firme. El Doctor Diego Gomez -Parroquia del Salvador, libro $2^{\circ}$. de bautismos, f. 187. Este sería, probablemente, sobrino. Marcelo de Montanos estudió también en la Universidad por 1583, matriculándose en Gramática el día 3 de noviembre de aquel año. (Libro de matrículas de 1567 á 1575, f. 131 v. ${ }^{\circ}$ )”.

${ }^{58}$ Miguel Ángel González García. Los dos testamentos del platero de Ourense Marcelo de Montanos (siglo XVII) (Orense: Archivo Capitular Ourense, 2010), p. 5. En sus testamentos, Marcelo de Montanos nombra a Úrsula de Nápoles como su esposa (pp. 15-16): "Iten digo que yo tengo cuatro hijos míos y de Ursula de Nápoles mi mujer legítima que se falesio, como postremos que son y se llaman el uno Isidro de Montanos y el otro Rosendo de Montanos y el otro Juan de Montanos y una hija que llaman Bernarda de Montanos [...]". Sin embargo, no menciona a Francisco, a cuyo bautismo hacía referencia Alonso Cortés, Noticias de una corte literaria, p. 12, nota 1.

${ }^{59}$ Este soneto se cita en Cerone, El Melopeo y Maestro, p. 222.

${ }^{60}$ Este soneto se cita en Cerone, El Melopeo y Maestro, p. 156.
} 
Si bien ha pasado a los anales de la historia como teórico de la música, Montanos ejerció también como compositor, poeta y maestro de capilla. El propio Arte de musica proporciona testimonio de su labor compositiva, puesto que en el libro Montanos comentaba el estilo que había usado en sus motetes y mencionaba su plan de publicar un volumen de música. ${ }^{61}$ Más allá de estas referencias en el tratado, contamos con otros documentos que corroboran la faceta compositiva de Montanos: 1) dos motetes a 4 de Montanos, "O Domine Jesu Christe" y "Interveniat pro nobis", se conservan en el códice de la Parroquia de Santiago de Valladolid (ff. 2v-3r y 3v-4r, respectivamente) entre piezas de Cristóbal de Morales, Juan Navarro, Francisco Guerrero y Rodrigo de Ceballos, entre otros (véase Ilustración V.2); ${ }^{62}$ 2) el Manuscrito 18 del Archivo de Música de la Catedral de Valladolid (copiado en el siglo XVII) contiene las partes de bassus y tenor de piezas compuestas por Montanos intercaladas con composiciones anónimas; ${ }^{63} \mathrm{y}$ 3) Cristiana Diego da noticia del descubrimiento en el Archivo General de Simancas de una licencia de 1565 otorgada a Montanos en Valladolid para imprimir "cuatro libros de música de letras españolas intitulados madrigales". 64 Aunque Cristina Diego señala que se desconoce si llegaron a imprimirse, he podido encontrar en el inventario de 1575 de Francisco de Aguilar, librero de Sevilla, "vno madrigales de Montano a quatro boçes",

\footnotetext{
${ }^{61}$ Montanos, Arte de musica, "Lugares comunes", f. 50v: "Mucho ha que en parte de mis motetes vse este estylo, mas no sale con la claridad que las demas imitaciones"; "Compostura", f. 25r: "No canten siempre todos, para que mexor sea entendida la letra, y el artificio que lleuan, mas a veces tres solas, para que con esta diuersidad sea mas apacible con algun passo de buena consonancia, o imitacion especial en las obras de a cinco, o mas voces, \&c. como vsan muchos buenos compositores, y como veran en mis obras, que quan presto pueda saldran a luz".

${ }^{62}$ El manuscrito fue copiado por Diego Sánchez, maestro de los mozos de coro de la Catedral de Sevilla entre 1596 y 1598 y, posteriormente, maestro de capilla de la Parroquia de Santiago de Valladolid. Para una edición y estudio del códice, véase Juan Bautista de Elústiza y Gonzalo Castrillo Hernández, Antología musical. Siglo de Oro de la música litúrgica de España. Polifonía vocal, siglos XV y XVI (Barcelona: Rafael Casulleras, 1933). Para un estudio posterior del códice que pretende corregir y completar el anterior, véase Pedro Aizpurúa Zalacaín, "El códice musical de la parroquia de Santiago de Valladolid", Revista de Musicología, IV (1981), pp. 51-59.

${ }^{63}$ Véase Higini Anglès, "El Archivo Musical de la Catedral de Valladolid", Anuario musical, III (1948), pp. 59-108, pp. 86-87. Aunque Anglès había señalado que de las piezas sólo se conservaba la voz del bassus, Cristina Diego Pacheco, "Circulación y producción del madrigal en España durante el siglo XVI: el caso de Francisco de Montanos", Revista de Musicología, XXXII/2 (2009), pp. 35-49, p. 46, nota 61, indica que se copia también la voz del tenor.
}

${ }^{64}$ Simancas (Valladolid), Archivo General de Simancas, Registro General de Sello, 1565, no 518 . Véase Diego Pacheco, "Circulación y producción del madrigal en España durante el siglo XVI”, p. 42. 
entre una serie de libros de música impresa, lo que sugiere que los madrigales de Montanos se imprimieron y entraron en los circuitos comerciales de los libreros. ${ }^{65}$

Ilustración V.2: Comienzo de "O domine Jesu Christe", motete a 4 de Francisco de Montanos conservado en el Códice de la Parroquia de Santiago de Valladolid (ff. 2v-3r).

Transcripción de Juan Bautista de Elústiza y Gonzalo Castrillo Hernández, Antología musical. Siglo de Oro de la música litúrgica de España. Polifonía vocal, siglos XV y XVI (Barcelona: Rafael Casulleras, 1933), p. 100.

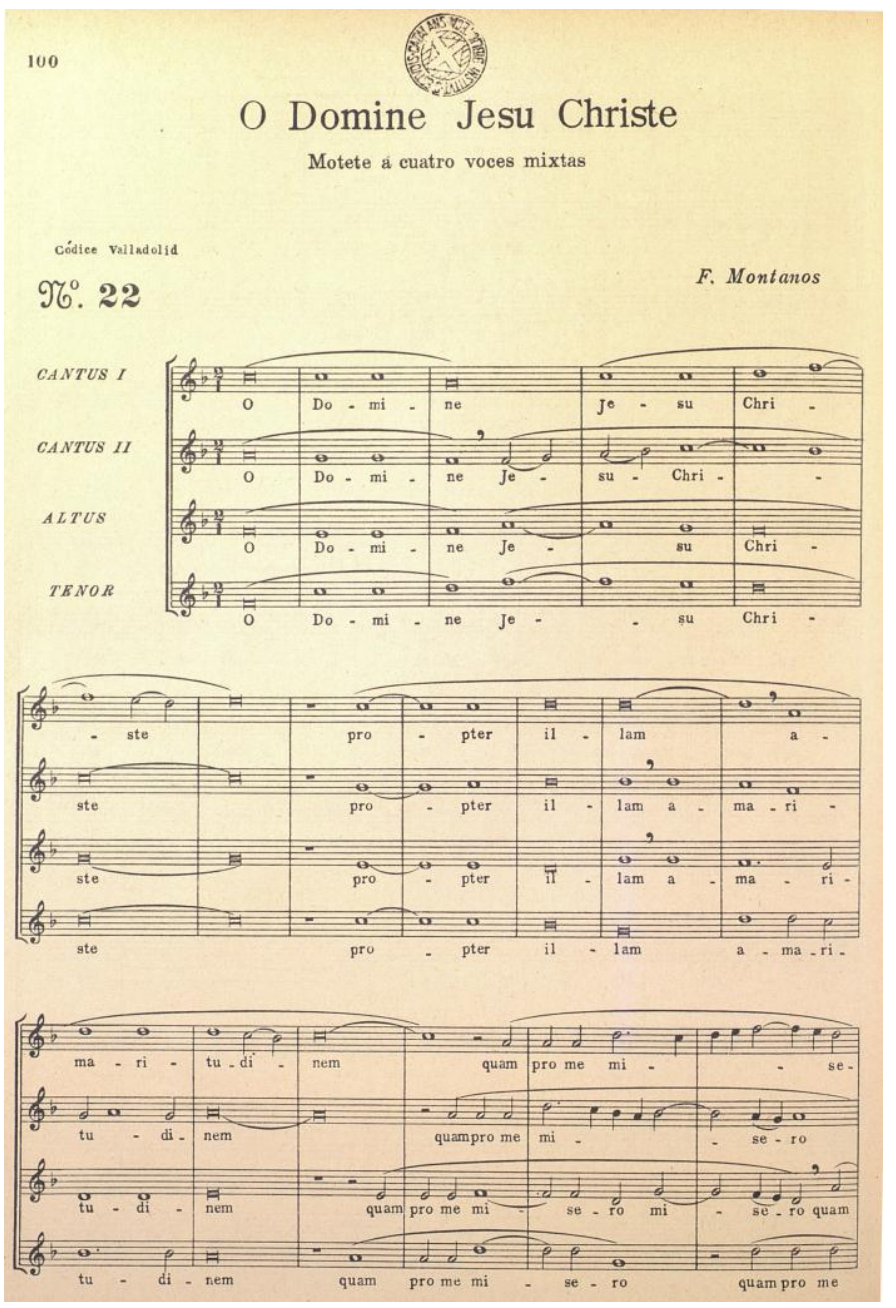

\footnotetext{
${ }^{65}$ González Sánchez y Maillard Álvarez, Orbe tipográfico, p. 188, nº 689. Véase el Apéndice 9.
} 
En su Arte de musica Montanos aseguraba haber trabajado como maestro de capilla durante treinta y seis años, y hay evidencia de su labor en la Iglesia Colegiata de Toro (en 1562), en la Iglesia Colegiata (catedral desde 1595) de Santa María la Mayor de Valladolid (desde 1564) y en la casa del VI Conde de Lemos. ${ }^{66}$ Robert Stevenson señala que Montanos comenzó a trabajar al servicio del Conde en torno a 1574, coincidiendo con el matrimonio entre éste y Catalina de Zúñiga. ${ }^{67}$ Esta hipótesis parece plausible, puesto que, según las Actas Capitulares de Valladolid, en 1576 "se despidió Francisco de Montanos, maestro de capilla”, quizás porque ya estaba trabajando para Fernando de Castro. ${ }^{68}$ Como se mostrará más abajo, el Arte de canto llano de Montanos proporciona evidencia del trabajo de éste en Monforte de Lemos (Lugo) al servicio del Conde Lemos, desvelando una etapa gallega de Montanos desconocida hasta el momento. Esto explicaría también el que aspirase al puesto de maestro de capilla de la Catedral de Santiago de Compostela en 1581. Montanos vuelve a aparecer en las Actas Capitulares en 1588 como maestro de capilla suplente en Valladolid y de nuevo se despide en febrero de 1595; la última referencia al músico en los libros de actas data de octubre de 1595 cuando se le paga por ejercer como miembro del tribunal en el concurso-oposición a maestro de capilla. ${ }^{69}$ Además, en el Arte de musica, Montanos explicaba: "el año que dexe el Magisterio [¿en la catedral de Valladolid?], propuse hazer estos seys tratados de musica, y diuersas ocupaciones [¿su labor al servicio del Conde de Lemos y su trabajo

\footnotetext{
${ }^{66}$ Pedro Aizpurúa Zalacaín, "El vallisoletano Francisco de Montanos (s. XVI), teórico musical y polifonista”, Revista de Musicología, VI (1983), pp. 109-120, p. 113; y Robert Stevenson, "Montanos, Francisco de", Grove Music Online. Oxford Music Online, 27 abril 2010

$<$ http://www.oxfordmusiconline.com/subscriber/article/grove/music/18998>.

${ }^{67}$ Stevenson, "Montanos, Francisco de". Aizpurúa Zalacaín, "El vallisoletano Francisco de Montano", p. 113, sugiere que Montanos trabajó para el Conde de Lemos a partir de 1540 (lo que no parece posible dado que el Conde nació en 1548) hasta 1564 (año en que aparece por primera vez en las actas capitulares de Valladolid) y después pasó trece años como maestro de capilla de la Catedral de Valladolid.
}

${ }^{68}$ Alonso Cortés, Noticias de una corte literaria, p. 12, señala que "Francisco de Montanos fue durante más de treinta años maestro de capilla en varias iglesias y últimamente en la catedral de Valladolid". Alonso Cortés, Miscelánea vallisoletana (Valladolid: Miñón, 1955 [1920-1944]), vol. 1, pp. 314-315, nota I, aporta noticias extraídas de los documentos catedralicios de Valladolid: en 1564 se le recibe en la Catedral como maestro de capilla con media ración, en 1571 el cabildo dispuso que diera lecciones de canto en público y en 1576 "se despidió Francisco de Montanos, maestro de capilla”.

${ }^{69}$ Stevenson, "Montanos, Francisco de"; Diego Pacheco, "Circulación y producción del madrigal en España durante el siglo XVI", pp. 44-45. 
esporádico en la Catedral?] no me han dado lugar a cumplir mi desseo con mas breuedad". 70

Una correspondencia literaria apoya la afirmación de Robert Stevenson de que Montanos comenzó a trabajar al servicio del Conde en torno a 1574. Montanos pertenecía a un grupo literario activo en Valladolid en la segunda mitad del siglo XVI. ${ }^{71} \mathrm{El}$ único indicio de la existencia de este grupo es la publicación de las obras de uno de sus componentes, Jerónimo de Lomas Cantoral, en un volumen titulado Las obras de Hieronimo de Lomas Cantoral, en tres libros diuididas (Madrid, 1578) que contiene poemas escritos por otros miembros del grupo (entre ellos, dos sonetos de Montanos), así como poemas escritos por Lomas Cantoral sobre sus compañeros, Montanos incluido. ${ }^{72}$ Un claro vínculo entre el libro de Lomas Cantoral y el Arte de musica de Montanos es que el soneto LVIII del primero también aparece al inicio de la quinta sección ("De proporcione") del libro de Montanos (véase Tabla V.1):

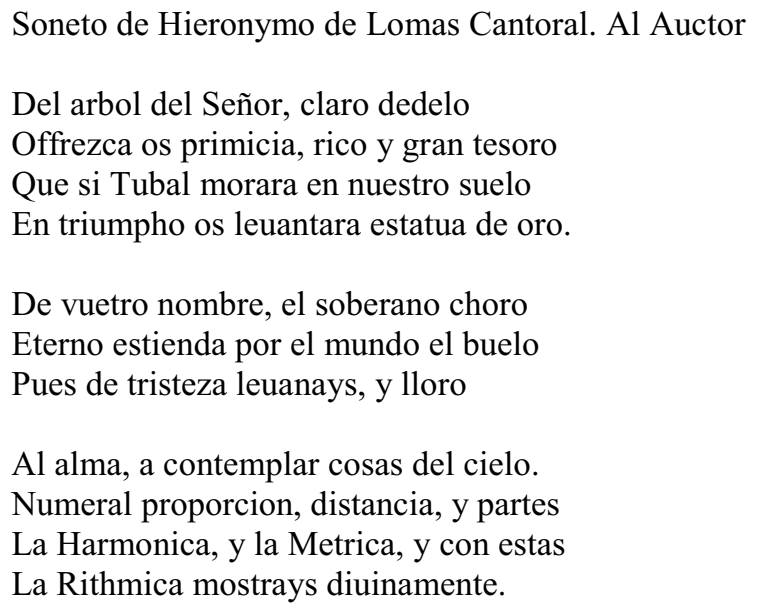

\footnotetext{
${ }^{70}$ Montanos, Arte de musica, f. 5v, "A los maestros de capilla y musicos doctos".

${ }^{71}$ Antonio Prieto, La poesía española del siglo XVI. II: Aquel valor que respetó el olvido (Madrid: Cátedra, 1998), p. 654.

72 Jerónimo de Lomas Cantoral, Las obras de Jerónimo de Lomas Cantoral, ed. por Lorenzo Rubio González (Valladolid: Servicio de Publicaciones de la Diputación Provincial, 1980 [1578]). José Ignacio Díez Fernández, "Disposición y ordenación de las obras de Jerónimo de Lomas Cantoral”, Boletín de la Biblioteca de Menéndez Pelayo, 69 (1993), pp. 53-85, pp. 71-72, señala que Montanos es omnipresente en el libro de Lomas Cantoral, puesto que es el destinatario implícito de buena parte de los poemas, principalmente los que tratan sobre la amistad.
} 
Pincia os celebre con eternas fiestas

Leuanten os estatua en cien mil partes,

Con Daphne, Apolo ciña vuestra frente. ${ }^{73}$

No queda claro si, con la expresión "La Harmonica, y la Metrica, y con estas / La Rithmica mostrays diuinamente", Lomas Cantoral se refería al manual de Montanos o a la labor docente de éste. En el caso de que Lomas Cantoral hubiese escrito el soneto elogiando el libro de Montanos, cabría suponer que Montanos estaba trabajando en su Arte de musica antes de 1578 (fecha de publicación del libro de Lomas Cantoral en que aparece el soneto) y que, por tanto, había dejado "el Magisterio" para esa fecha. ${ }^{74}$ Otro documento apoya la idea de que Montanos no era maestro de capilla en Valladolid cuando publicó su Arte de musica en 1592. El ejemplar del Arte de musica conservado en la Biblioteca de la Universidad Complutense de Madrid (signatura BH FLL 27938) incluye entre su material preliminar un documento en que se explica cómo Francisco Montero, envió en nombre de Montanos un ejemplar del Arte de musica a su maestro George de Santa María, compositor y racionero en la Iglesia Mayor de Toledo, y se incluye la alabanza de éste a Montanos y a su tratado, en la que se señala que el libro hace a Montanos merecedor del título de "Maestro de los maestros" (véase Ilustración V.3). La alabanza de George de Santa María a Francisco de Montanos no aparece en el resto de ejemplares consultados del Arte de musica. En este documento se hace referencia a Francisco Montero como maestro de capilla de la Catedral de Valladolid. Montero debió de ocupar este puesto al menos desde 1589 y antes había trabajado como maestro de capilla en la Colegiata de Talavera de la Reina, como muestra un documento conservado en el Archivo de esta institución bajo el título "Información sobre la autenticidad de dos cartas escritas por Francisco Montero, maestro de capilla de Valladolid y antes de la Colegiata de Talavera, a petición del deán y cabildo de dicha Colegiata. 1589 Origs. Caja 257, núm. $45{ }^{\prime}{ }^{75}$

\footnotetext{
${ }^{73}$ Montanos, Arte de musica, s.f. [verso de la portada del libro "De proporcione"]; y Lomas Cantoral, Las obras de Jerónimo de Lomas Cantoral, p. 259.

${ }^{74}$ La licencia de impresión y el privilegio real datan de 1587.

${ }^{75}$ Mercedes Mendoza Eguaras y Carmen Torroja Menéndez, eds., Catálogo analítico del Archivo de la Colegiata de Talavera de la Reina (1204-1900) (Toledo: Diputación Provincial, 1969), p. 177, nº 1173.
} 
Ilustración V.3: Alabanza de George de Santa María a Francisco de Montanos en Francisco de Montanos, Arte de musica theorica y pratica (Valladolid: Diego Fernández de Córdoba y Oviedo, 1592), s.f. Madrid, Universidad Complutense, BH FLL 27938.

Este documento indica que en 1592 el maestro de capilla de la Catedral de Valladolid era Francisco Montero.

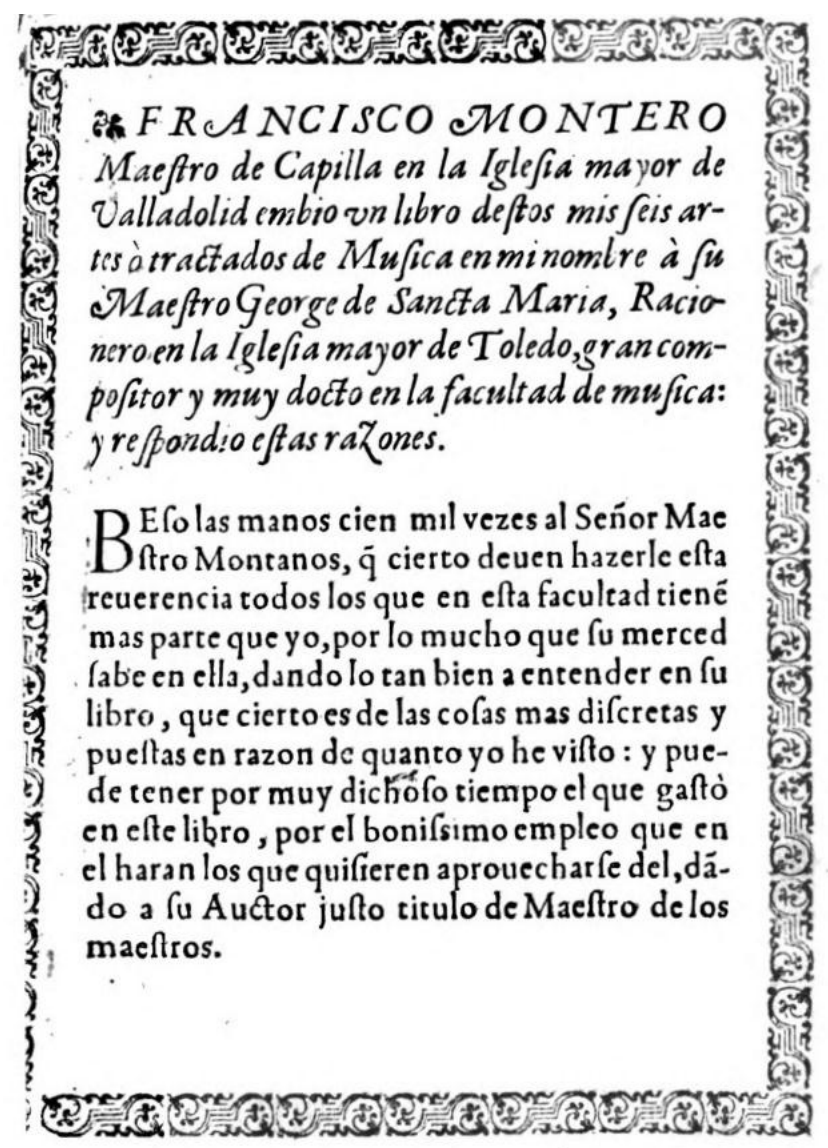

Cristina Diego ha encontrado en documentos del Archivo Histórico de Protocolos de Valladolid referencias a algunos detalles de la capilla de música de Fernando Ruiz de Castro antes de su matrimonio con Catalina de Zúñiga: en 1571 el Conde de Lemos contrató a dos cantores (contralto y contrabajo) y pagó a Jerónimo de Torres 442 maravedíes por haber "cantado madrigales"; en 1572 el Conde regaló dos camisas al vihuelista Antonio Álvarez. ${ }^{76}$ En mi investigación en la Sección Inquisición del Archivo Histórico Nacional localicé un expediente que proporciona nueva información sobre

\footnotetext{
${ }^{76}$ Diego Pacheco, “Beyond Church and Court:”, pp. 367-368; y “Circulación y producción del madrigal en España durante el siglo XVI”, p. 44.
} 
una capilla de música que el Conde de Lemos mantenía en Galicia, al frente de la cual trabajó Montanos. Se trata de la confesión y abjuración de la "secta anglicana" en 1583 del músico inglés Juan Sherwin, "violon de sus altezas" (véase Ilustración V.4). ${ }^{77}$ Cuando se le preguntó por su profesión, Juan Sherwin "dixo que el es musico de biolones de arco y flautas" y que antes había trabajado en Galicia para el Conde de Lemos y después nueve meses en Portugal "a donde le seruia de musico". Este documento inquisitorial aporta por tanto información sobre la capilla del Conde de Lemos en Galicia y más detalles de la plantilla instrumental de la misma. ${ }^{78}$

\footnotetext{
77 "Confesión y abjuración de Juan Sherwin, inglés, natural de Auxmesta, tierra de Londres, y estante en la villa de Madrid, músico de violones y flautas, por anglicano" (1583), Madrid, Archivo Histórico Nacional, Sección Inquisición, legajo 108, expediente 11.

${ }^{78}$ En las cartas de Catalina de Zúñiga, Condesa de Lemos, encontramos referencia a otro músico; en una carta sin fechar, probablemente de la última década del siglo XVI, Catalina de Zúñiga hace referencia al "discurso del corneta por su traslado". Véase "Correspondencia de la condesa de Lemos con su marido, 1592-1596”, Madrid, Archivo de los Duques de Alba, C. 40-66, f. 2r.
} 
Ilustración V.4: “Confesión y abjuración de Juan Sherwin, inglés, natural de Auxmesta, tierra de Londres, y estante en la villa de Madrid, músico de violones y flautas, por anglicano" (1583). En este documento, Juan Sherwin, "violón de sus altezas", afirma haber trabajado para el Conde de Lemos en Galicia [MINISTERIO DE CULTURA, Archivo Histórico Nacional, ES.28079.AHN/1.1.49.3//INQUISICIÓN,108,EXP.11, f. 3r].

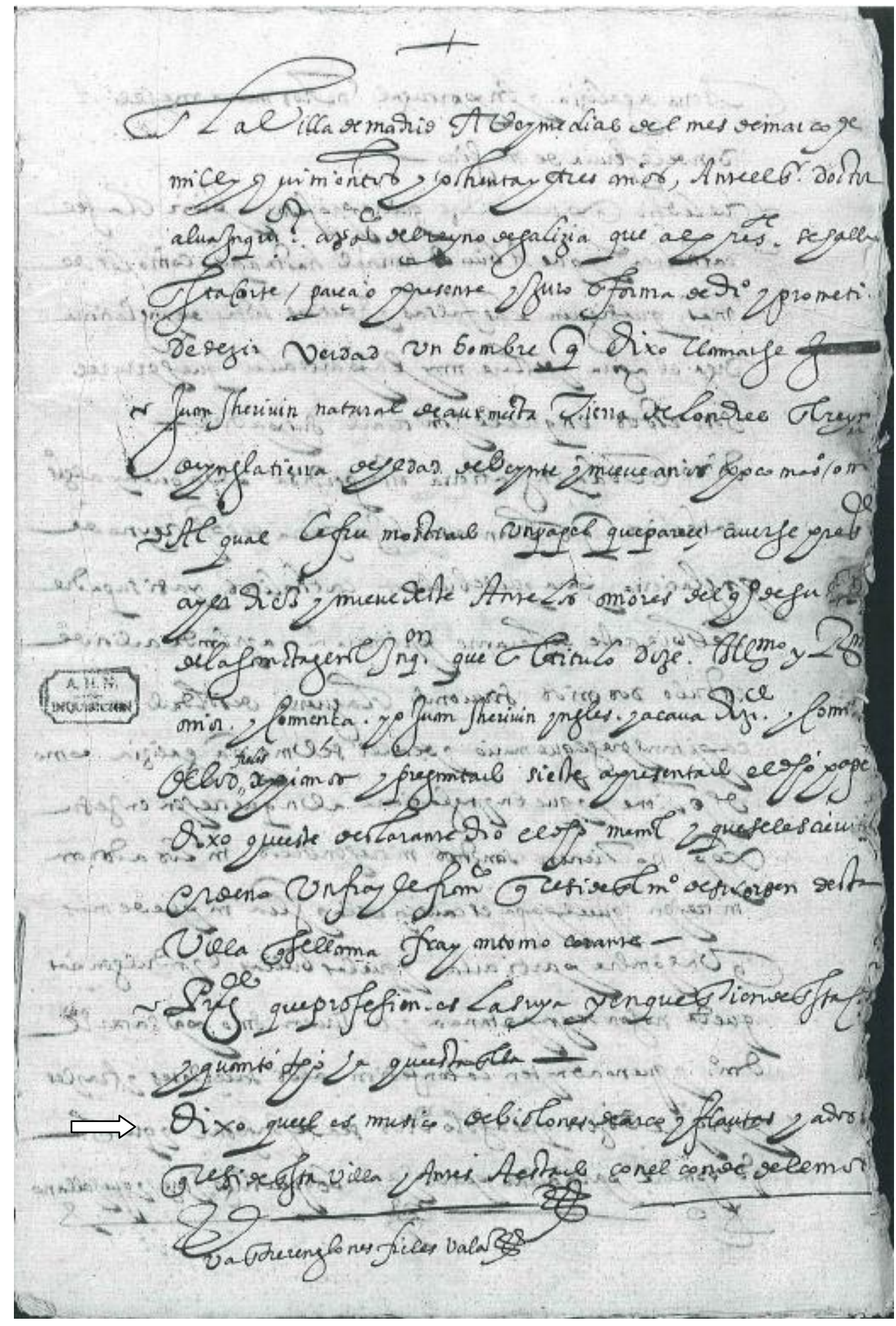


Además de su capilla particular en Galicia, los Condes de Lemos debieron de disfrutar de la Capilla Real de Nápoles cuando Fernando Ruiz de Castro fue nombrado Virrey en 1599. El maestro de esta capilla desde ese año y hasta su muerte en 1614 fue el flamenco Giovanni Di Macque, que hasta entonces y desde 1594 había sido organista de la misma. Isabel Enciso da noticia de un documento que recoge las reformas que en 1610 hizo el VII Conde de Lemos a la Capilla Real de Nápoles y que, por tanto, puede ofrecer una visión general de las características de la formación musical de la que dispusieron los VI Condes durante su virreinato entre 1599 y 1601 :

[...] ha parecido que para que los divinos officios se puedan hazer en aquella Real Capilla, con la deçencia que conviene ha de aver de cada voz cinco, porque si ha de cantar a tres coros (como suele hazerse muchas vezes) no puede estar el coro lleno, con menos de dos vozes por parte, y los coros del órgano, y de los instrumentos una voz por parte, aunque el capellán mayor le paresce que bastaría que fuesen quatro vozes por parte, que huviera dos o tres sacerdotes para aiudar a cantar las pasiones y los demás officios de Cuaresma y Semana Santa, que fuesen en todo diez y ocho vozes (siendo estos sacerdotes más útiles y necesarios para este efecto que todos los demás), a cada uno de los quales se les puede señalar doze ducados al mes, y a las vozes particulares y mucho más que ordinarias, a veinte ducados al mes a cada uno [...], dos organistas con cada quinze ducados al mes, un laud, un corneta, un trombón, un arpa, con cada diez ducados al mes a cada uno, cinco violines con el mismo sueldo, un maestro de capilla con treinta ducados al mes; porque se halle eminente y sepa mucho de composición, un sacristán mayor con diez ducados al mes, dos ayudantes con ocho ducados al mes cada uno [...], seis capellanes de altar, los quales han de decir cada día misa por V. Md con obligación de las vísperas y las misas cantadas, con cada seys ducados al mes, un diacono para aiudar a las missa y limpiar la plata con quatro ducados al mes, otro para adereçar los órganos con tres ducados al mes [...]. ${ }^{79}$

Montanos dedicó al Conde de Lemos su Arte de musica, un libro publicado como la culminación de su carrera docente. El Arte de musica se divide en seis partes ("arte de canto llano", "canto de organo", "contrapunto", "de compostura", "de proporcione" y "tratado ultimo de los lugares comunes") e incluye un prólogo con abundantes referencias a los clásicos y a la vertiente especulativa de la música en que dice proporcionar a los maestros de capilla de forma clara "la razon de lo que professan" aconsejándoles que "no se contenten con solo vso". ${ }^{80}$ A continuación encontramos un prefacio

\footnotetext{
${ }^{79}$ Consulta sobre la reformacion de la Capilla Real de Napoles (Nápoles, 12 de noviembre de 1610), Simancas (Valladolid), Archivo General de Simancas, S.P., leg. 11, f. 1r; citado en Isabel Enciso AlonsoMuñumer, "Linaje, poder y cultura. El virreinato de Nápoles a comienzos del siglo XVII. Pedro Fernández de Castro, VII Conde de Lemos", Tesis Doctoral (Ph.D.), Universidad Complutense de Madrid, 2002, p. 839; esta Tesis Doctoral ha sido publicada como Nobleza, poder y mecenazgo en tiempos de Felipe III: Nápoles y el Conde de Lemos (San Sebastián de los Reyes: Actas, 2007).

${ }^{80}$ Montanos, Arte de musica, f. 4v, "Prologo".
} 
en que el autor encomienda el libro a "maestros de capilla y músicos doctos", a través de los cuales el resto de personas deberían abordar el manual ("para que con su buena raçon los demas le conozcan y estimen"), ${ }^{81}$ lo que indica que el libro fue concebido como una herramienta didáctica. En el cuerpo del texto, Montanos hacía referencia en varias ocasiones a "la gente moça": "la gente moça, y los no latinos no se detengan ni ocupen mucho con diffiniciones, sino passen lo demas, y a su tiempo las veran los que quisieren dar raçon de lo que saben"; "la gente moça (como ya dixe) no se detenga en diffiniciones hasta que vea le conuiene saberlas". ${ }^{82}$ La dedicatoria del libro al Conde de Lemos no sólo expresa la gratitud de Montanos hacia su protector, sino que también indica la búsqueda de prestigio para su obra:

\begin{abstract}
Si los que pretenden sacar a la luz sus obras, con cuydado solicitan fauor para dirigirlas a quien las faborezca y haga merced: a quien tiene la ocasion que yo con V.S. tantos años de seruicio en su casa, y conocer siempre en V. S. voluntad de hazerme merced, no se atribuyra a demasiado atreuimiento el dirigir a V.S. estos seys artes o tratados de musica, que con tanto cuydado he compuesto, para que con facilidad entienda esta facultad quien fuere aficionado a ella. Reciba V.S. con ellos la mayor voluntad a su seruicio, que puedo dezir, que con ampararlos V.S. tendran lustre y ser para parecer en toda parte. ${ }^{83}$
\end{abstract}

Como muestra la Ilustración V.5a, el escudo de armas impreso en la portada es el del condado de Lemos, con los tres rasgos que lo caracterizan (los seis roeles de azur, los dos lobos puestos en palo y la bordadura con ocho escudetes), ${ }^{84}$ y aparece coronado por una figura alada, quizás de Fernando Ruiz de Castro; véase un retrato posterior del Conde de Lemos en la Ilustración V.5b. No sabemos si el Conde patrocinó la publicación, aunque no sería sorprendente dado el precedente existente en su familia: en 1557, su tío, el Cardenal Rodrigo de Castro, había sido el dedicatario del libro de Francisco

\footnotetext{
${ }^{81}$ Montanos, Arte de musica, f. 6r, "A los maestros de capilla y musicos doctos".

${ }^{82}$ Montanos, Arte de musica, “Arte de canto llano", f. 10r; "De contrapunto", f. 4r.

${ }^{83}$ Montanos, Arte de musica, f. 3v [dedicatoria].

${ }^{84}$ Francisco Fernández de Béthencourt, Historia genealógica y heráldica de la monarquía española, casa real y grandes de España (Sevilla: Fabiola de Publicaciones Hispalenses, 2001-2003 [1897-1912]), vol. 4, p. 353.
} 
Salinas, De Musica libri septem, y probablemente corrió con los gastos de la publicación (véase Ilustración V.6). ${ }^{85}$

Ilustración V.5a: Francisco de Montanos, Arte de musica theorica y pratica (Valladolid: Diego Fernández de Córdoba y Oviedo, 1592), portada. Madrid, Biblioteca Nacional de España, R/9503.

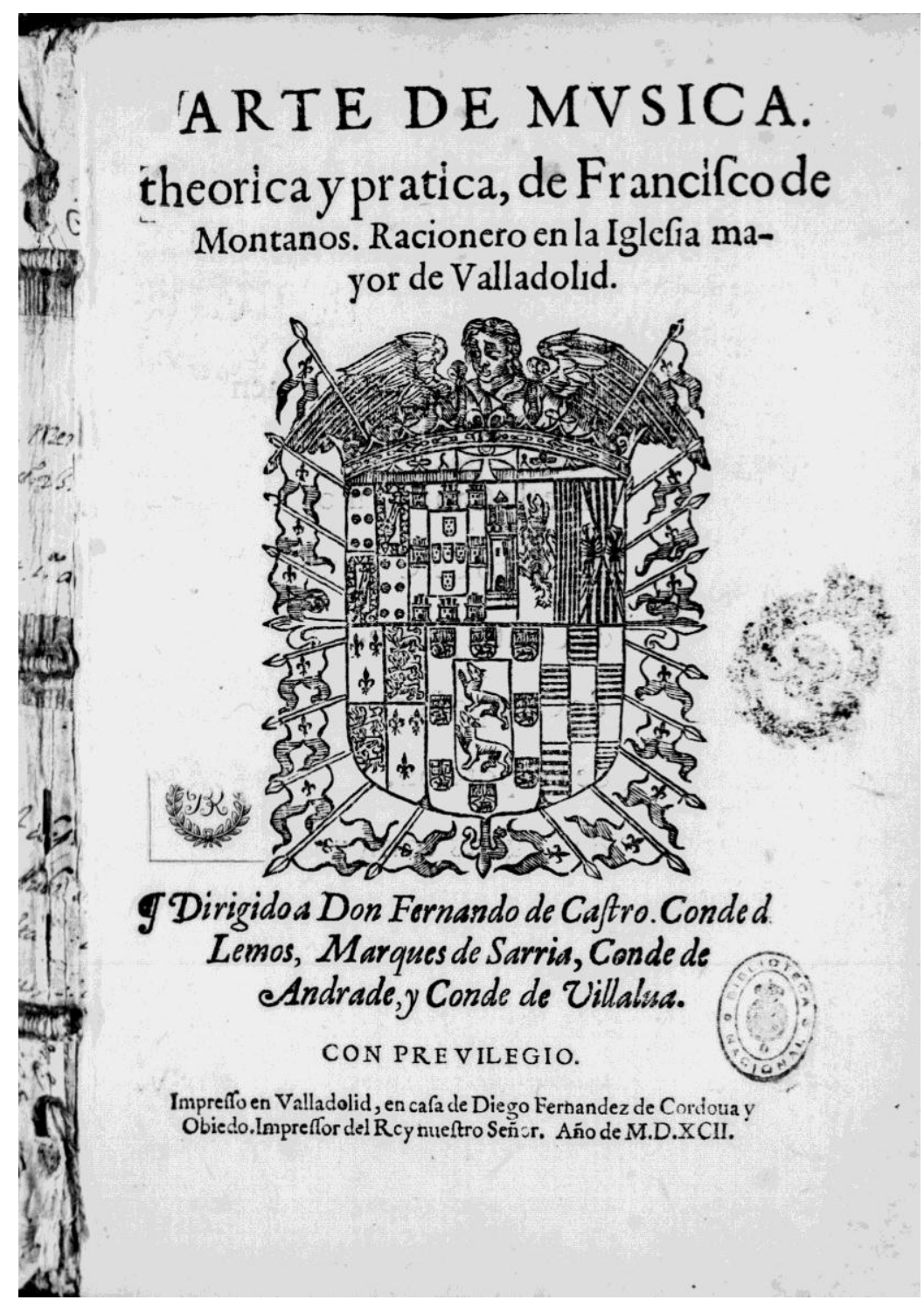

\footnotetext{
${ }^{85}$ Véase Armando Cotarelo Valledor, El Cardenal Don Rodrigo de Castro y su fundación en Monforte de Lemos (Madrid: Magisterio Español, 1945 y 1946), vol. 1, p. 100: "Había conocido DON RODRIGO en Salamanca al famoso ciego Francisco Salinas [...]. Y como el de CASTRO amaba también la música, ambos fueron amigos y, según parece, el magnate protegió al artista y acaso le apoyaría para la cátedra musical que regentó en aquella gran escuela por más de veinte años. En el de 1575 terminó Salinas de componer 'siete libros de harmonía y ritmo', y dos más tarde los dio a la imprenta en Salamanca. Tan célebre monumento de la musicología española va dedicado a nuestro DON RODRIGO DE CASTRO, quien costearía la impresión, pues lleva su escudo en la portada".
} 
Ilustración V.5b: Retrato de Fernando Ruiz de Castro, VI Conde de Lemos, en Domencio-Antonio Parrino, Teatro Eroico, e Politico de' Governi de' Vicere del Regno de Napoli Dal tempo del Re Ferdinando il Cattolico Fino al Presente

(Nápoles: Nella nuova Stampa Del Parrino, e del Mutii, 1692), vol. 2, s.f.

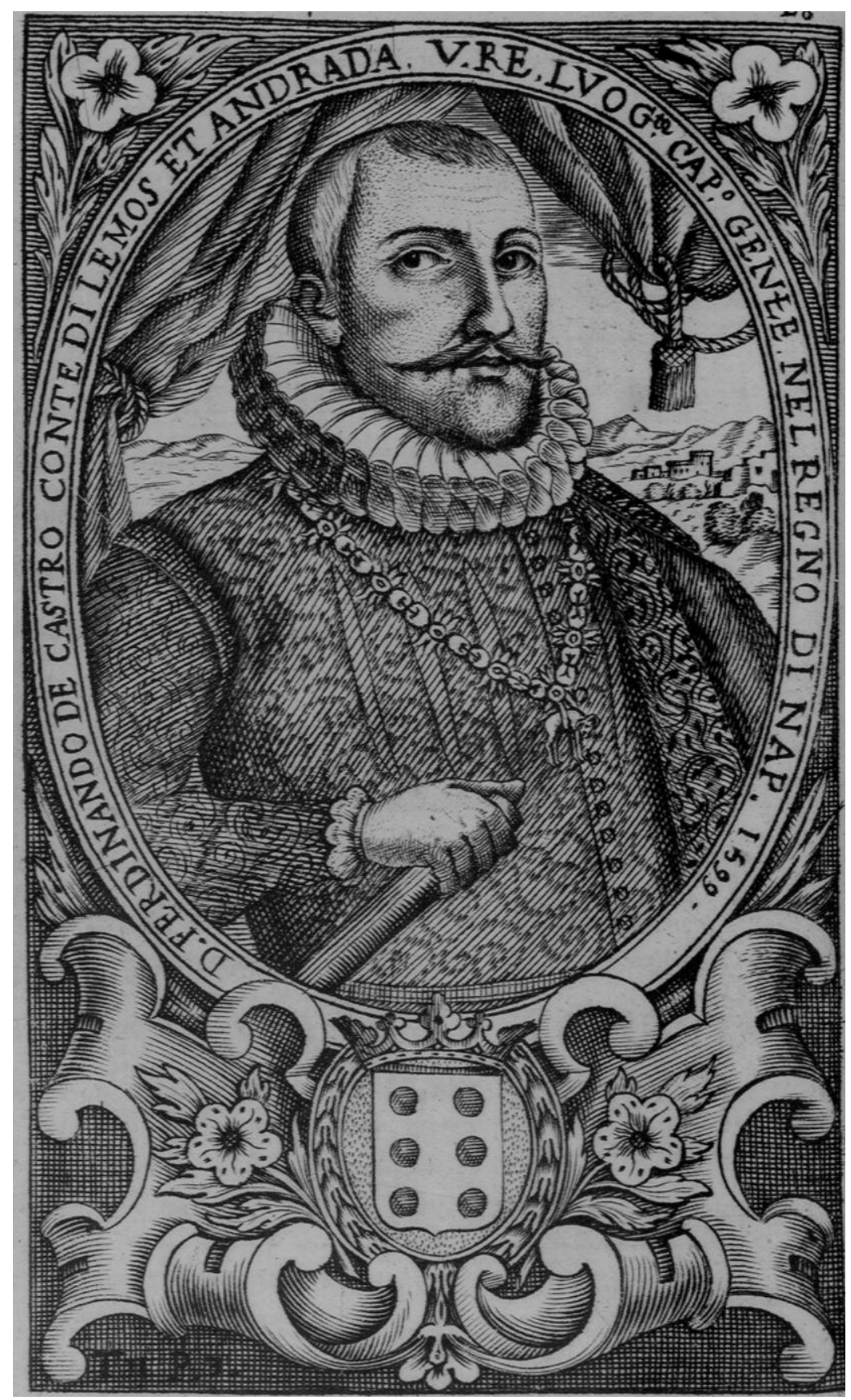


Ilustración V.6: Francisco Salinas, De Musica libri Septem (Salamanca: Mathias Gastius, 1557), portada y dedicatoria (página 1 de 2). Madrid, Biblioteca Nacional de España, R/9298.
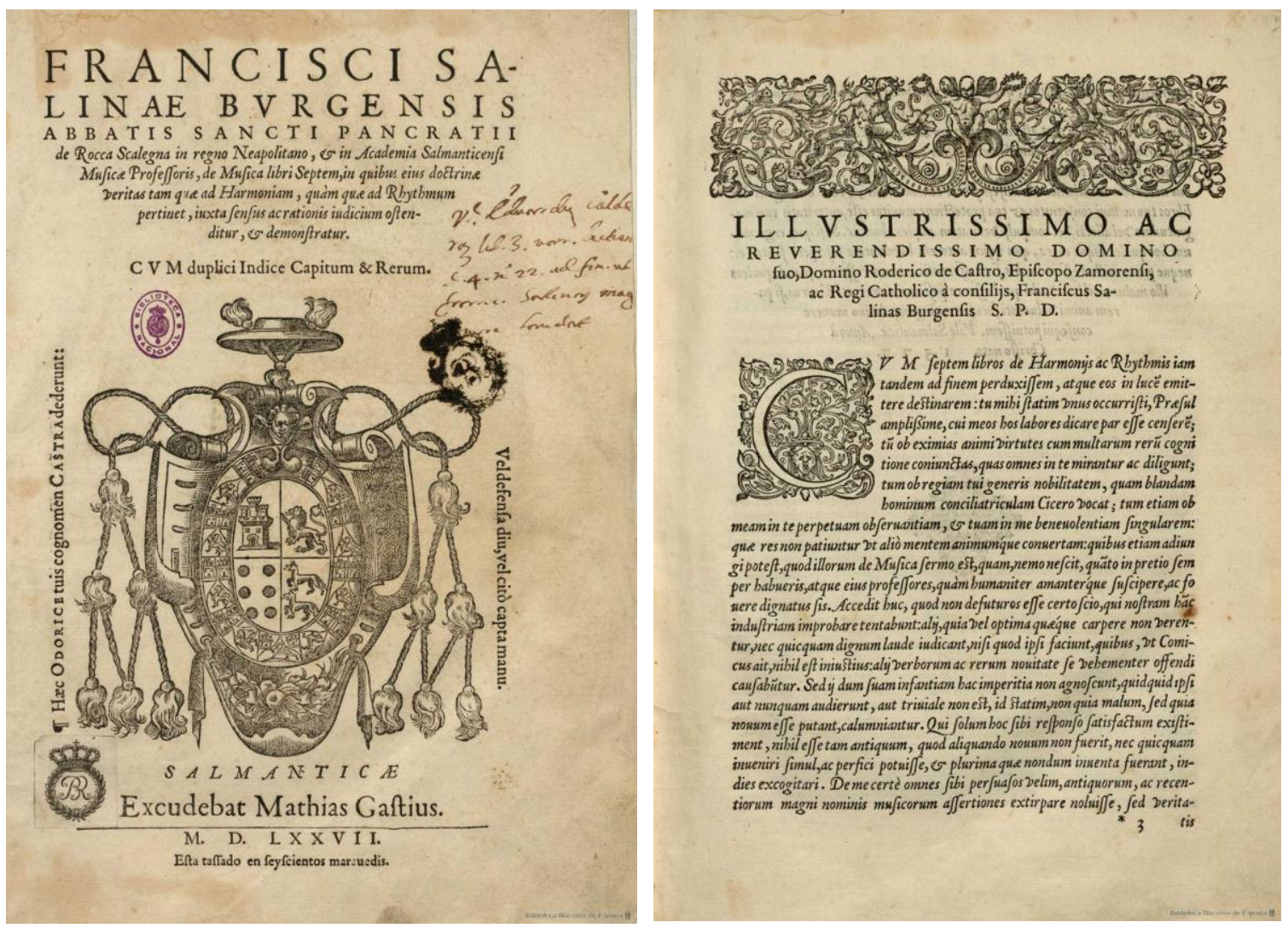

En 1594, Montanos publicó la primera sección del Arte de musica, el "arte de canto llano", como un volumen independiente constituido únicamente por contenidos prácticos (en contraste con el Arte de musica, evitando la "razon" y centrándose en el "uso") y lo dedicó a la esposa de su patrón. El Arte de canto llano consta de dos secciones: 1) "Arte de canto llano y todo lo a el tocante" (23 páginas), que consiste en una exposición concisa de las reglas básicas del canto llano utilizando numerosos ejemplos musicales (sólo 4 de las 23 páginas contienen únicamente texto); y 2) "Cantos diuersos en que se exercite el que aprende" (al menos 89 páginas), ${ }^{86}$ que es una recopilación de piezas para practicar lo aprendido. Como hacía Bermudo en El arte Tripharia, Montanos concebía su libro como una introducción y remitía a los lectores a su libro más extenso, el Arte de musica, para ampliar conocimientos; entre las dos secciones, es decir,

${ }^{86}$ El ejemplar analizado en Coimbra carece de las últimas páginas. 
cuando acaba el "arte de canto llano" propiamente dicho, Montanos indicaba: "Deffiniciones y cotas [sic] de authores graues latinos, y declaracion de muchas difficultades de musica, se hallaran en mis seis artes impressos de canto llano, canto de organo, contrapunto, compostura y proporciones, y lugares communes". ${ }^{87}$ Es decir, como Juan de Espinosa, tanto Bermudo como Montanos publicaron un libro más extenso $\mathrm{y}$, en segundo lugar, otro más breve en que remitían al primero. Cabría preguntarse si, debido a su utilidad, la sección sobre canto llano del Arte de musica estaba circulando en manuscritos y Montanos o Catalina de Zúñiga decidieron publicarla como un volumen independiente debido a su atractivo comercial. Mi hipótesis es que el Arte de canto llano de Francisco de Montanos constituye una publicación solicitada por una mujer para satisfacer sus propios intereses en el marco de la labor de mecenazgo religioso que estaba desempeñando.

\section{2. "Una señora muy varón": el mecenazgo de Catalina de Zúñiga}

Catalina de Zúñiga mantuvo una importante posición política en la Corte durante toda su vida. Era hija de Francisco Gómez de Sandoval y Rojas, IV Marqués de Denia, embajador de Felipe II en Portugal, y hermana de Francisco Gómez de Sandoval Rojas y Borja, I Duque de Lerma y valido de Felipe III. ${ }^{88}$ Tanto en los escritos de su época como en los posteriores se han destacado su inteligencia y su fuerte carácter. Cuando se casó en 1574, Catalina trabajaba ya como camarera de la reina Ana de Austria, cuarta esposa de Felipe II: ${ }^{89}$

[...] ya a los veinticuatro años de edad que contaba la novia se veía en ella resplandecer las condiciones de inteligencia y enérgico carácter de que hartas pruebas dio [...] desde el elevado car-

\footnotetext{
${ }^{87}$ Montanos, Arte de canto llano, f. 12 r.

${ }^{88}$ Sobre la Capilla musical del hermano de Catalina de Zúñiga en la iglesia colegiata de San Pedro de Lerma, véase Douglas Kirk, "Instrumental Music in Lerma, c.1608”, Early Music, XXXIII/3 (1995), pp. 393-408. El Duque de Lerma controlaba las arcas reales y por este motivo era el receptor de las peticiones de los músicos que prentendían publicar bajo patronazgo real. Es dedicatario de libros de música de Pedro Ruimonte, Antonio Mogavero, Stefano Limido y Giovanni Pietro Flaccomio.

${ }^{89}$ Catalina de Zúñiga estuvo al servicio de Ana de Austria entre 1572 y 1580.
} 
go que dignamente ocupó muchos años de Camarera Mayor de la Reina Da . Margarita de Austria, mujer de Felipe III. ${ }^{90}$

La Condesa dejó la Península Ibérica para acompañar a su marido cuando éste fue nombrado Virrey de Nápoles en $1599 .{ }^{91}$ Dos años después, enviudó y regresó a la Corte para ocupar el puesto de camarera mayor de la reina Margarita de Austria, permaneciendo en la Corte al servicio de las sucesivas reinas hasta su muerte en $1628 .{ }^{92} \mathrm{Su}$ abuela materna, la Duquesa Doña Leonor de Castro, había ocupado el puesto de camarera mayor de la Emperatriz Isabel de Portugal, y su madre, Isabel de Borja y Castro (1532-1558), fue dama de Juana la Loca en Tordesillas y estaba acordada su entrada al servicio de la princesa María, primera mujer de Felipe II (sin embargo, Isabel de Borja murió prematuramente a los 26 años de edad). ${ }^{93}$ La vida de Catalina de Zúñiga, como la de su madre y la de su abuela, muestra cómo las mujeres podían ejercer poder político incluso en contextos relativamente privados, ${ }^{94}$ puesto que su trabajo como camarera

\footnotetext{
${ }^{90}$ Alfonso Pardo y Manuel de Villena, Marqués de Rafal, Un mecenas español del siglo XVII. El conde de Lemos: noticias de su vida y de sus relaciones con Cervantes, Lope de Vega, los Argensola y demás literatos de su época (Madrid: Imprenta de Jaime Ratés Martín, 1911), pp. 11-12.
}

${ }^{91}$ Sobre esta etapa, véase Parrino, Teatro Eroico, e Politico de' Governi de' Vicere del Regno de Napoli, vol. 2 , f. A2.

${ }^{92}$ Cuando murió el Conde, Felipe III y su esposa Margarita de Austria esperaban con impaciencia la llegada de Catalina de Zúñiga a la Corte, como muestra el siguiente extracto de una carta de 4 de julio de 1602 de Felipe III a la Condesa: "Muy largo se nos hace este vuestro camino, por lo mucho que deseo veros y teneros cerca de mi, que yo os prometo, Condesa, que me debeis toda la buena voluntad que me mostrais, y que la Reina os espera contando las horas de vuestra llegada. Y por todo, os pido que os deis prisa [...]". Madrid, Archivo de los Duques de Alba, C. 88-98; transcripción tomada de María Isabel Barbeito Carneiro, Escritoras madrileñas del siglo XVII: estudio bibliográfico-crítico (Madrid: Universidad Complutense, 1986), vol. 2, pp. 881-882. La carta también se cita en María Isabel Barbeito Carneiro, Mujeres del Madrid barroco: voces testimoniales (Madrid: Horas y Horas, 1992), pp. 31-32. En una relación atribuida a Miguel de Cervantes encontramos referencias a la labor de Catalina de Zúñiga como camarera mayor; véase Miguel de Cervantes, atrib., Relacion de lo sucedido en la ciudad de Valladolid, desde el punto del felicisimo nacimiento del principe don Felipe Dominico Victor nuestro señor, hasta que se acabaron las demostraciones de alegria que por el se hicieron, reimp. con prólogo de Narciso Alonso Cortés (Valladolid: Imprenta del Colegio Santiago, 1916 [1605]), pp. 7 y 57.

${ }^{93}$ Fernández de Béthencourt, Historia genealógica y heráldica de la monarquía española, vol. 4, pp. $112-$ 113. Encontramos una referencia a Isabel de Borja en la "Oda VI - En el nacimiento de Doña Tomasina, hija del Marques de Alcañices, D. Alvaro de Borja, y Doña Elvira Enriquez" de Fray Luis de León: "la tia, de quien vuela / la fama, en quien la dura / muerte mostro lo poco que el bien dura"; véase Fray Luis de León, Obras del M. Fr. Luis de Leon de la Orden de San Agustin reconocidas y cotejadas con varios manuscritos por el P. M. Fr. Antolin Merino de la misma órden. Tomo VI. Las poesias (Madrid: por Ibarra, impresor de cámara de S. M., 1816), p. 19.

${ }^{94}$ Sobre nuestro limitado concepto de poder como "autoridad pública", véase Mary Erner y Maryanne Kowaleski, Women and Power in the Middle Ages (Atenas: University of Georgia Press, 1988), p. 2. 
mayor tenía un componente extremadamente político al permitir a su familia el acceso a información privilegiada. ${ }^{95}$ Las cartas de Catalina conservadas en el Archivo de los Duques de Alba en Madrid apoyan este argumento, puesto que algunas dirigidas a su hijo cuando éste ocupaba el cargo de embajador de la Santa Sede en Roma muestran un sistema por el que determinados números sustituían palabras como "Reina", "Rey" o "Papa". ${ }^{96}$ Según Isabel Enciso, la significación de la trayectoria política de la Condesa de Lemos reside en su éxito para mantener su poder en la Corte incluso tras el fracaso político de su hermano el Duque de Lerma y de su hijo Pedro Fernández de Castro. ${ }^{97}$

Es interesante que la "inteligencia y carácter energético" de Catalina de Zúñiga fuesen calificados de "varoniles" tanto por sus contemporáneos como por posteriores biógrafos del Conde de Lemos. La Condesa fue descrita por Orazio Della Rena en 1602

Nader, ed., Power and Gender in Renaissance Spain, p. 5, señala que "el denominado sistema de patriarcado en la España de la temprana Edad Moderna era mucho más flexible y dependiente del contexto histórico de lo que se había pensando previamente" ["The so-called system of patriarchy in early modern Spain was much more flexible and dependent on historical context than previously thought"]. Véase también Grace E. Coolidge, Guardianship, Gender and the Nobility in Early Modern Spain (Aldershot: Ashgate, 2010), p. 160. Para un estudio del poder femenino en el contexto italiano, véase Natalie Tomas, The Medici Women: Gender and Power in Renaissance Florence (Aldershot: Ashgate, 2003).

${ }^{95}$ Patricia Marín Cepeda, "La cultura cortesana, devocional y literaria de una mujer poderosa del Siglo de Oro: la VI condesa de Lemos, doña Catalina de Zúñiga y Sandoval", en Vivir al margen. Mujer, poder e institución literaria, ed. por María Pilar Celma Valero y Mercedes Rodríguez Pequeño (Burgos: Instituto Castellano y Leonés de la Lengua), 2009, pp. 163-173, pp. 165-166, señala que, puesto que "tener acceso directo a la reina era una vía fundamental para ganarse y sobre todo mantener el favor del rey”, los sucesivos Duques de Lerma (el padre de Catalina y después su hermano), intentaron rodear a la reina "de sus propios familiares para no perder el control y el conocimiento de todos los resortes del juego".

${ }^{96}$ Muestra de ello es el siguiente fragmento de una carta datada en San Lorenzo a 29 de agosto de 1611 y conservada en Madrid, Archivo de los Duques de Alba, C. 58-166: "He reçiuido tu carta de 5 de agosto con la copia de la carta de tu hermano para ti de 2 del mesmo; y con gran raçon pusiste en çifra los renglones que en ella vienen, porque eran endeablados, pero lindos, y tal vez me toma tanbien la rauia como a el y escriuo sin cifra [...]". Esta carta se transcribe en Barbeito Carneiro, Escritoras madrileñas del siglo XVII, p. 887; y Mujeres del Madrid barroco, p. 36. Además de las cartas de Catalina de Zúñiga fechadas en el siglo XVII que transcribe María Isabel Barbeito, en el Archivo de los Duques de Alba se conserva un conjunto de cartas de la Condesa a su marido (datadas entre 1592 y 1596), así como dos cartas del Conde de Lemos a su esposa (datadas el 18 y 19 de febrero de 1594) en las que la Condesa responde escribiendo en los márgenes y espacios en blanco de las hojas; véanse "Correspondencia de la condesa de Lemos con su marido, 1592-1596", Madrid, Archivo de los Duques de Alba, C. 40-65 a C. 40-132; y "Cartas de El amigo a la condesa de Lemos, 1594", Madrid, Archivo de los Duques de Alba, C. 28-9. Enciso Alonso-Muñumer, "Linaje, poder y cultura", p. 64, explica la razón de la actual conservación de estos documentos en el Palacio de Liria: la herencia de los Lemos se incorporó a la Casa de Berwick y Alba en el siglo XVIII por descendencia de Fernando, tercer hijo de Catalina de Zúñiga.

${ }^{97}$ Enciso Alonso-Muñumer, “Linaje, poder y cultura”, p. 326. 
como "una mujer de ánimo viril y gran sinceridad", 98 y calificada como "una señora muy varón" en uno de los 691 breves cuentos populares recogidos aproximadamente entre 1619 y 1625 y conservados en el ya mencionado manuscrito Madrid, Biblioteca Nacional de España, MSS/19380, titulado Cuentos muy mal escritos que notó don Juan de Arguijo (véase Ilustración V.7):

La condesa de Lemos, camarera maior, es una señora mui baron i que tiene acsiones de tal embio a sauer de la duquesa de Medina sidonia, $\mathrm{D}^{\mathrm{a}}$ Ana de silva que se hallaua en Madrid como lo auia pasado una tarde que hubo gran tempestad Porque ella confesaua de si gran miedo Respondio la de Medina, que la uesaba las manos, i que echase de uer pues su excelencia auia estado tal, como estarian las mugeres. ${ }^{99}$

98 Orazio Della Rena, Osservazioni della Spagna et della sua casa e corte, MS (1602), París, Bibliothèque nacionale de France, clase XXIV, no 223, f. 134r: "una donna d'animo virile et di gran sincerità".

${ }^{99}$ Cuentos muy mal escritos que notó don Juan de Arguijo, MS (siglo XVII), Madrid, Biblioteca Nacional de España, MSS/19380, f. 6r, cuento $n^{\circ}$ 33. Para ediciones modernas de los cuentos, véanse Eduardo Barriobero y Herrán, Los viejos cuentos españoles: elegidos en las colecciones de Arguijo, Garibay, Pinedo y el Duque de Frías (Madrid: Mundo Latino, 1930); Antonio Paz y Meliá, comp., Sales españolas o agudezas del ingenio nacional (Madrid: s.n., 1890-1902), 2 vols.; Juan Arguijo, Obras completas, ed. por Rafael Benítez Claros (S.1.: s.n., 1968); y Cuentos recogidos por Juan de Arguijo y otros, ed. por Beatriz Chenot y Máxime Chevalier (Sevilla: Diputación Provincial de Sevilla, 1979). 
Ilustración V.7: Cuento sobre Catalina de Zúñiga recogido en Cuentos muy mal escritos que notó don Juan de Arguijo, MS (siglo XVII), f. 6r, cuento no 33. Madrid, Biblioteca Nacional de España, MSS/19380.

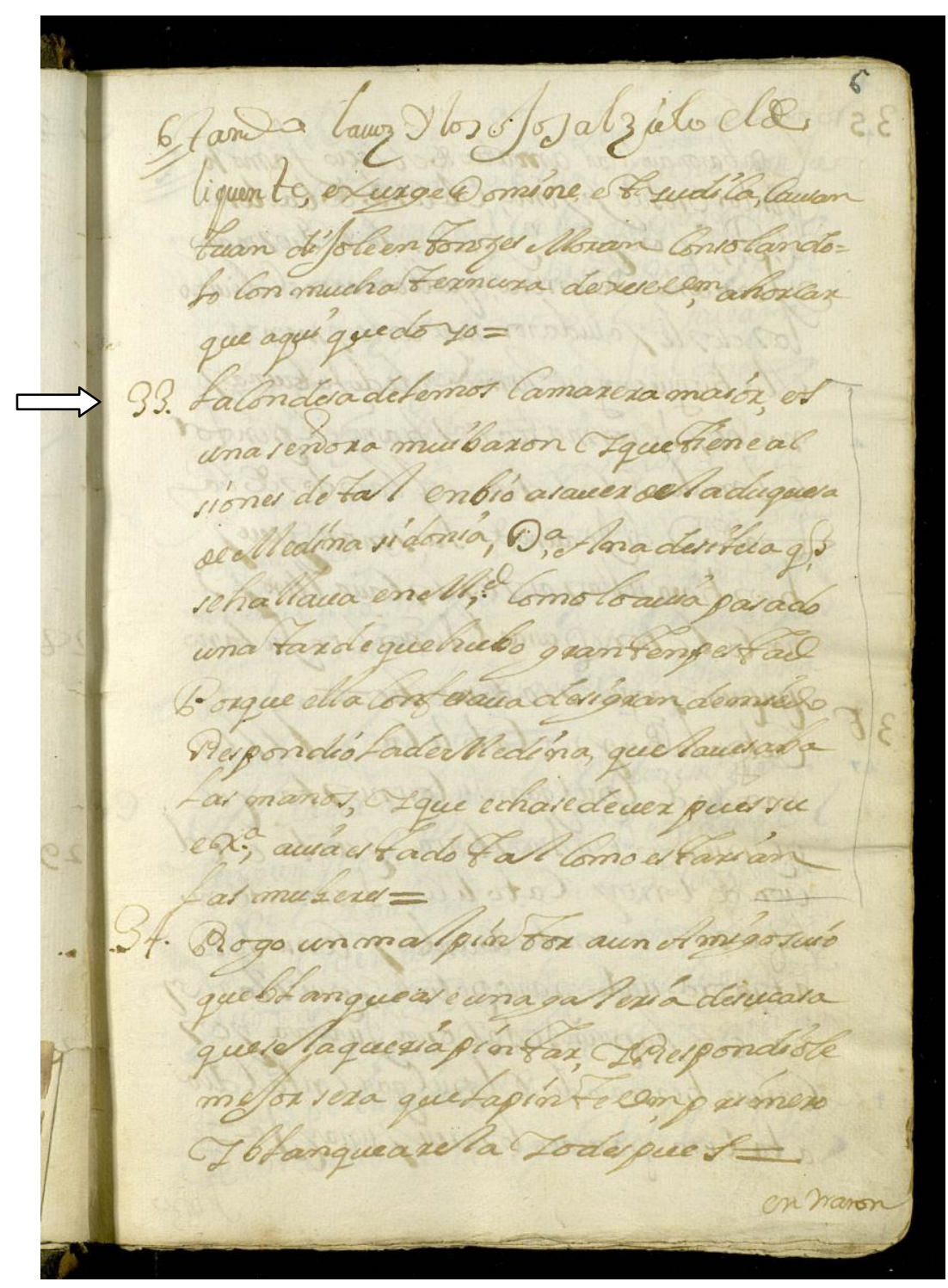

La lectura de estos cuentos, los cuales reproducen las expresiones cotidianas de los sevillanos, constituye, en palabras de Carlos Martínez Shaw, una manera de penetrar "en los recovecos de las mentalidades colectivas que existían en la Andalucía del Siglo de Oro". ${ }^{100}$ Beatriz Chenot y Maxime Chevalier señalan que los cuentos de este manuscrito eran "conocidos por todos por transmisión oral como queda demostrado por las

\footnotetext{
${ }^{100}$ Carlos Martínez Shaw, "Los cuentos de Arguijo. Chistes andaluces del Siglo de Oro", Andalucía en la historia, 10 (2005), pp. 84-90, pp. 85 y 90.
} 
variantes que ofrecen en distintas fuentes", y asocian la brevedad de los mismos al hecho de que "el que los apuntaba se los sabía de memoria", de manera que, "más de una vez, únicamente se cuidó de notar, a vuelapluma, los rasgos esenciales de ellos". ${ }^{101}$ Aunque en estos cuentos la consideración de Catalina de Zúñiga como "una señora muy varón" probablemente busque "el chascarrillo y la risa", ${ }^{102}$ el calificativo "varonil" atribuido a una mujer tenía en algunos contextos una connotación positiva, como evidencia la introducción que hizo Luis Muñoz a la "vida" de la religiosa Mariana de San José (1568-1638), en la que, entre otras alabanzas, la describía como "muger solo en el sexo, en lo demas varon". ${ }^{103}$ A inicios del siglo XX, el Marqués de Rafal se refería a Catalina como "la varonil Camarera, cuya entereza de carácter era proverbial en su época". ${ }^{104}$

¿Cuál fue la conexión exacta entre Catalina de Zúñiga y el Arte de canto llano de Montanos? Si bien no hay referencias explícitas en el Arte de canto llano para probar que la Condesa financió la publicación (como tampoco las había en el Arte de musica ni en el tratado de Salinas para asegurar que fueron patrocinados por el Conde de Lemos y por el Cardenal Rodrigo de Castro, respectivamente), algunas pistas halladas en el material preliminar de la obra sugieren que podría haber actuado como mecenas. ${ }^{105}$

\subsubsection{ANÁLISIS DEL MATERIAL PRELIMINAR DEL ARTE DE CANTO LLANO DE FRANCISCO DE}

\section{MONTANOS}

El material preliminar del Arte de canto llano, que será analizado a continuación, consiste en la documentación legal exigida, un soneto "al avthor de vn su amigo"

\footnotetext{
${ }^{101}$ Chenot y Chevalier, eds., Cuentos recogidos por Juan de Arguijo y otros, pp. 18 y 8. Respecto a la autoría del manuscrito, los editores señalan que la evidencia apunta a que los copistas fueron "varios hombres de buen humor, amigos sin duda, contertulios acaso, entre los cuales hubo de figurar, en un principio, el propio Juan de Arguijo" (p. 10). Véase el Apéndice 15.

${ }^{102}$ Juan de Arguijo, Poesía, ed. por Gaspar Garrote Bernal y Vicente Cristóbal López (Sevilla: Fundación José Manuel Lara, 2004), pp. LIII-LIV.

${ }^{103}$ San José, Vida de la venerable M. Mariana de S. Ioseph, p. 2.

${ }^{104}$ Pardo y Manuel de Villena, Un mecenas español del siglo XVII, p. 35.

${ }^{105}$ Utilizo el concepto de mecenazgo como el encargo y pago de una obra, si bien algunos estudios han extendido el término patrón o mecenas a "una persona o grupo de personas que el artista asumía que iban a ser potenciales compradores y usuarios". Véase Sheryl E. Reiss y David G. Wilkins, eds., Beyond Isabella: Secular Women Patrons of Art in Renaissance Italy (Kirksville: Truman State University Press, 2001), p. 1: "To advance our discussion, let me propose that we also consider as patrons a person or group of persons who were assumed by the artist to be potential buyers and users".
} 
y la dedicatoria de Montanos a Catalina de Zúñiga. Los documentos legales son los siguientes: la tasa firmada por Cristóbal de León, la aprobación firmada por Hernando de Cabezón (ambos documentos datados en 1593), y el privilegio real de 22 de septiembre de 1594, distinto al que aparecía en el Arte de musica (que había sido concedido en 1587). Por el nuevo privilegio se otorgaba licencia a Montanos para imprimir el Arte de canto llano (se le llama "libro de Canto llano y organo") durante ocho años. El escudo de armas impreso en la portada no es el del Conde de Lemos, como ocurría en el Arte de musica de 1592, ni una combinación de los escudos de los cónyuges, sino el escudo de la familia Zúñiga, que consiste en una banda de gules sobre campo de oro (armas primitivas del linaje) o plata; véase la Ilustración V.8. ${ }^{106}$ El libro es introducido por un soneto escrito por un amigo anónimo de Montanos en el que se señala que el libro "assaz va encomendado / Del Patron, del Author y del subjecto", indicando por tanto que la obra contaba con la protección de un patrón; véase la Ilustración V.9.

\footnotetext{
${ }^{106}$ Endika de Mogrobejo, Diccionario hispanoamericano de heráldica, onomástica y genealogía: adición al "Diccionario heráldico y genealógico de apellidos españoles y americanos", por Alberto y Arturo García Carraffa (Bilbao: Mogrobejo-Zabala, 1995-2009), vol. 15, p. 234 y lámina 7 (escudos 338 y 339). Aunque el escudo de la portada del libro de Montanos fue teñido a posteriori con acuarela, el uso de "líneas sutiles perpendiculares, consideradas siempre desde lo alto del jefe del escudo a la punta" indica que se trata de una banda de gules. Véase Alberto y Arturo García Carraffa, Enciclopedia heráldica y genealógica hispano-americana, vol 1: Ciencia heráldica o del blasón según el método de los más insignes tratadísticas (Madrid: Imprenta de Antonio Marzo, 1919), p. 32.
} 
Ilustración V.8: Francisco de Montanos, Arte de canto llano (Valladolid: Andrés de Merchan, 1594), portada. Coimbra, Biblioteca Geral de la Universidade de Coimbra, R-11-36.

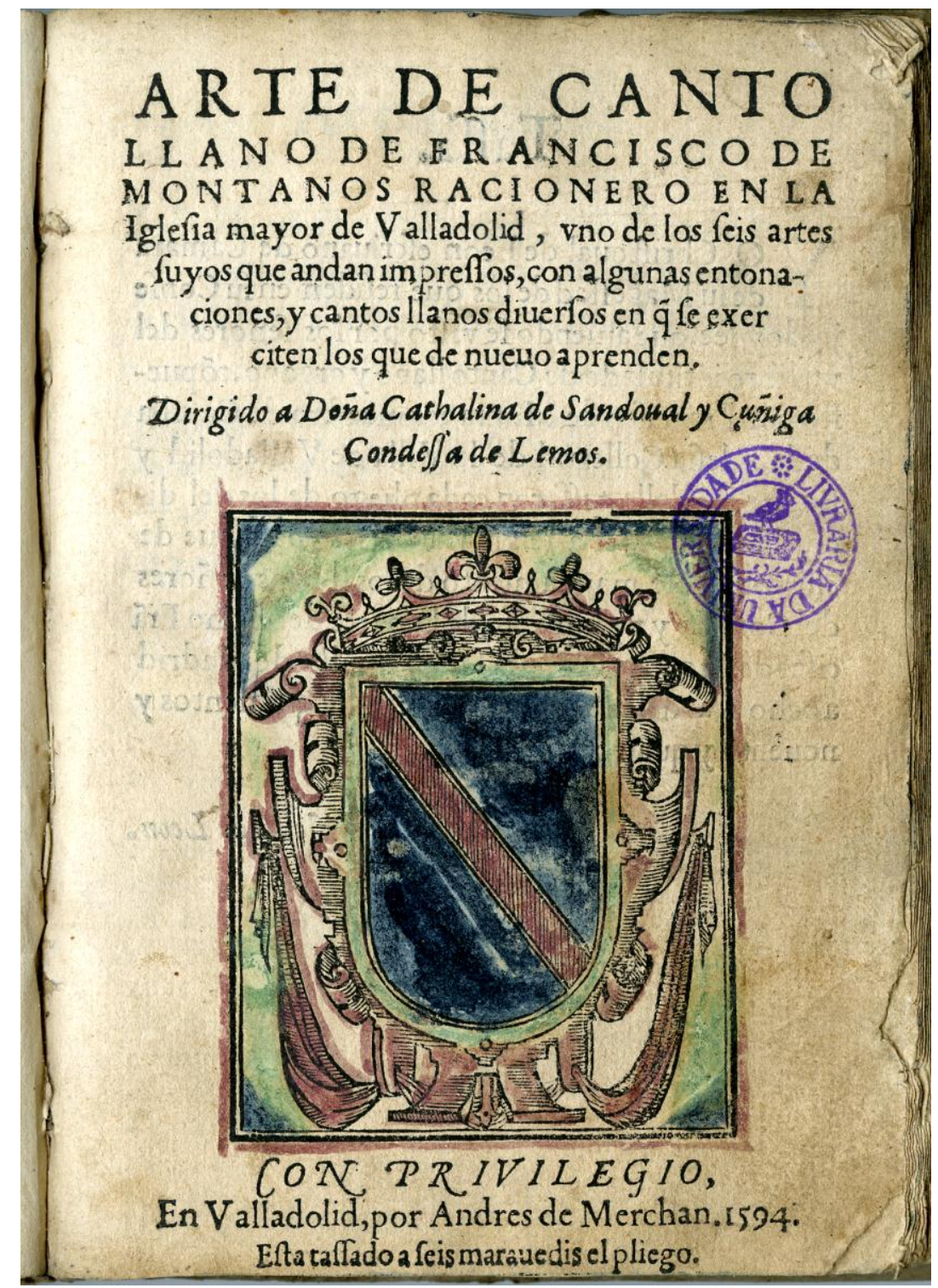


Ilustración V.9: Francisco de Montanos, Arte de canto llano (Valladolid: Andrés de Merchan 1594), Soneto escrito por un amigo anónimo y dedicatoria. Coimbra, Biblioteca Geral de la Universidade de Coimbra, R-11-36.

\begin{tabular}{|c|c|}
\hline 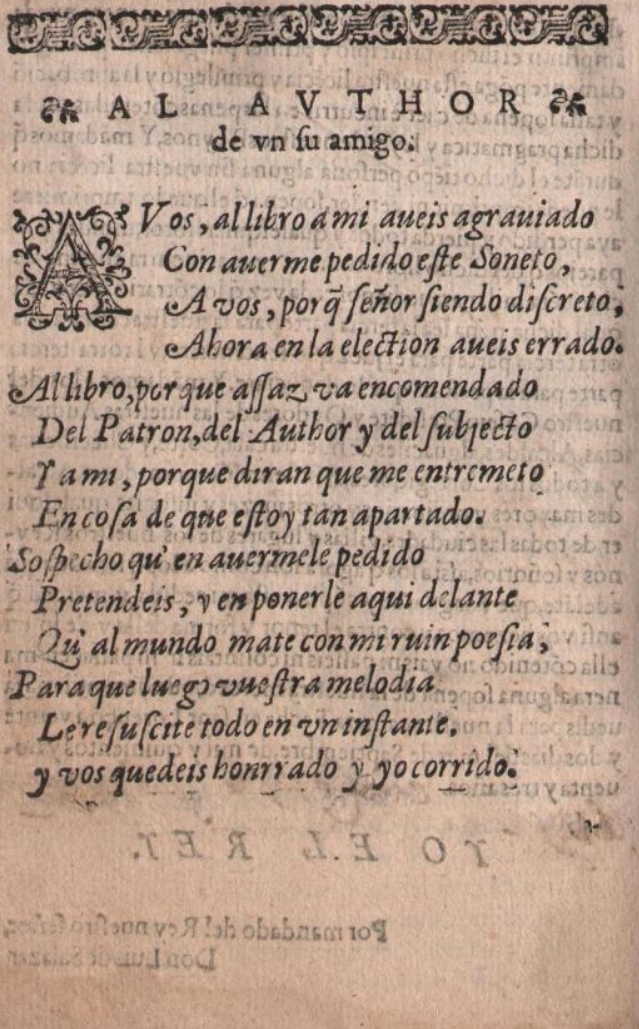 & 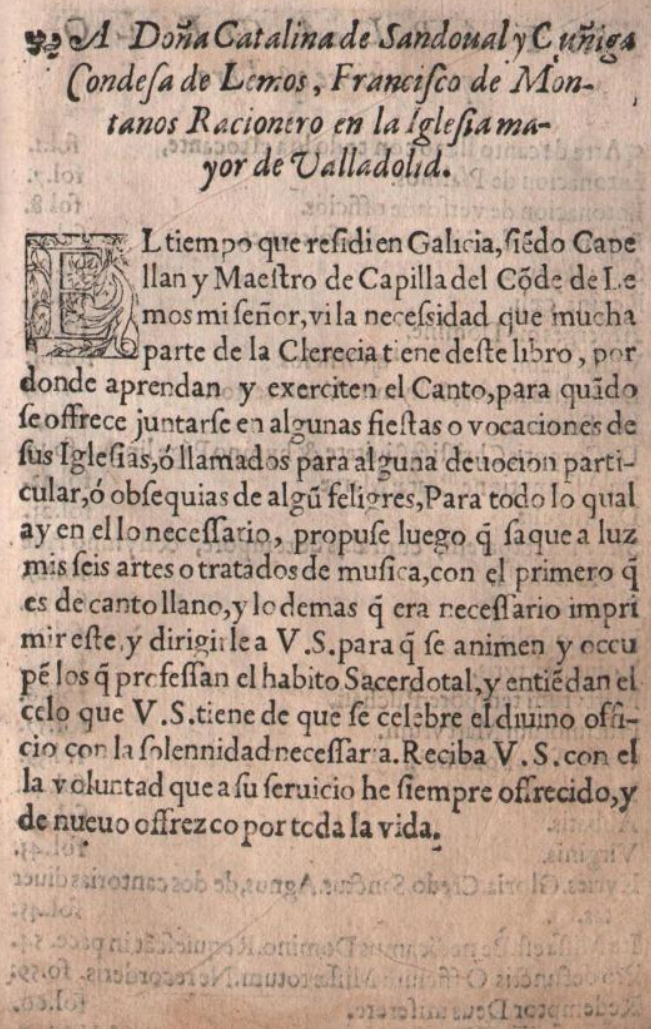 \\
\hline
\end{tabular}

El Arte de canto llano carece de un prólogo dedicado a la "razón" de la música como el que encontrábamos en el Arte de música de 1592, así como de cualquier material introductorio escrito por Montanos a excepción de la dedicatoria. Ésta es algo más amplia que la del Arte de musica y hace simultáneamente las funciones de dedicatoria y de prólogo, puesto que indica los motivos de la publicación del libro. Un análisis pormenorizado de la dedicatoria del Arte de canto llano también sugiere la posibilidad de que Catalina de Zúñiga actuó como mecenas. Montanos explicaba que, tras publicar su Arte de musica, decidió imprimir separadamente la primera sección, porque mientras trabajaba en Galicia como capellán y maestro de capilla para el Conde de Lemos había notado la necesidad que el clero tenía de un manual para aprender y practicar el canto. Montanos dirigía su libro por tanto a "los que professan el habito Sacerdotal”, y lo dedicaba a Catalina de Zúñiga con el propósito de que los clérigos entendieran el "celo" de 
la noble por la celebración del Oficio Divino con la "solemnidad necessaria". Los términos utilizados por Montanos en su dedicatoria a la Condesa de Lemos son muy similares a los que había utilizado Martínez de Bizcargui en la dedicatoria de su Arte de canto llano et contrapunto et canto de organo a Juan Rodríguez de Fonseca, Obispo de Burgos desde 1515 (las ediciones previas contienen otra dedicatoria al anterior Obispo de Burgos Fray Pascual de Ampudia):

[...] Agora viendo el zelo y santa yntencion de vuestra reuerendissima señoria que los clerigos sean en las obras lo que muestra en el nombre: y que allende de lo que mas son obligados a saber: tengan mucho exercicio en el cantar, acorde de añadir la dicha mi arte y glosarla en ciertos lugares porque los que quisieren por ella deprender cantar mas ligeramente y perfectamente alcançen lo que desean. Pensando en ello aprouechar a todos e a. V.R.S. hazer seruicio pues que tanta vigilancia y estudio pone en hazer que el culto diuino se augmente y los ministros de la yglesia sean los que deuen e sepan lo que cumple a su officio, que bien podemos dezir y affirmar concurrir en. V.R.S. todo aquello que el apostol sant Pablo en qualquier perfectissimo perlado desea [Mi cursiva]. ${ }^{107}$

La dedicatoria a Catalina de Zúñiga es aún más parecida a la que escribió Melchor de Torres en su Arte ingeniosa de musica (Alcalá de Henares, 1544) para Gutierre de Carvajal, Obispo de Plasencia:

\begin{abstract}
Como vuiesse [sic] gastado mucho tiempo, muy illustre y reuerendissimo señor, en procurar el fin y remate de mi desseo cerca desta presente obra de musica: tuue osadia para presentarla a vuestra Señoria creyendo ser muy necessaria y prouechosa a todos los que en esta facultad de la musica pratica quisieren ser aprovechados con facilidad: como parecera en su nueuo estilo. Para lo qual el zelo grande que vuestra Señoria del culto diuino tiene da animo: porque la musica principalmente fue dedicada a los diuinos officios: como parece por muchas autoridades de la sagrada escriptura [...] [Mi cursiva]. ${ }^{108}$
\end{abstract}

Estas similitudes muestran que la dedicatoria de Montanos a Catalina de Zúñiga utiliza los mismos términos que habían usado otros autores de artes de canto en sus dedicatorias a altos miembros de la jerarquía eclesiástica (concretamente obispos, en los casos de las dedicatorias de Martínez de Bizcargui y Torres).

\footnotetext{
${ }^{107}$ Martínez de Bizcargui, Arte de canto llano et contrapunto et canto de organo (1515 [1508]), f. A1v [dedicatoria].

${ }^{108}$ Torres, Arte ingeniosa de musica, f. 1v.
} 


\subsubsection{ANÁLISIS DEL MATERIAL PRELIMINAR DE OTROS LIBROS DEDICADOS}

\section{A CATALINA DE ZÚÑIGA}

Además de los indicios del mecenazgo de Catalina de Zúñiga encontrados en el propio libro de Montanos, la acción de la Condesa como mecenas en otro caso apoya la hipótesis de que fue ella quien promovió la publicación del Arte de canto llano en 1594. Catalina de Zúñiga es también la dedicataria de las Fiestas de Denia (Valencia, 1599) de Lope de Vega (secretario de su marido y posteriormente de su hijo Pedro), Las bodas de los Catolicos Reyes de España Don Felipe III y Doña Margarita de Austria celebradas en la Ciudad de Valencia (Sevilla, 1599) de Luis Vélez de Guevara, ${ }^{109}$ y el Tratado espiritual de los soberanos mysterios y ceremonias santas del diuino sacrificio de la Missa (Madrid, 1604) de Fray Juan de los Ángeles. En estos libros encontramos tres aspectos interesantes. En primer lugar, las tres obras pueden agruparse en dos categorías librescas; las dos primeras publicaciones pertenecen al género de las relaciones, mientras que la tercera es un tratado de devoción. Curiosamente, Nieves Baranda Leturio señala que la mayoría de los libros dedicados a mujeres fueron "de materia religiosa diversa" y que "el segundo género de preferencia" estuvo constituido por relaciones, normalmente debido a "la vinculación de la dama con los hechos relatados, ya fueran por razones geográficas, de parentesco o sociales". ${ }^{110}$ Por ejemplo, Lope de Vega dedicaba su relación de las fiestas de Denia a Catalina de Zúñiga, porque ésta no había podido asistir a los festejos por encontrarse indispuesta: "Estas fiestas, señora, justamente / os cuento a vos, pues que faltaste de ellas / por culpa de aquel subito accidente, / que pudo entristecer lustras estrellas". En segundo lugar, estos tres autores, en contraste con Montanos, dedicaron sus libros a la Condesa de Lemos una vez que ésta se había convertido en Virreina de Nápoles. Por último, es llamativo que sólo en el caso del libro de

\footnotetext{
${ }^{109}$ Antonio, Bibliotheca Hispana nova, vol. 2, p. 69. Enciso Alonso-Muñumer, "Linaje, poder y cultura", p. 956, señala que el poema fue dedicado a Catalina de Zúñiga y que la publicación se hizo a instancias del Cardenal Rodrigo de Castro.

${ }^{110}$ Baranda Leturio, Cortejo a lo prohibido, pp. 59-61. Debe señalarse que Catalina de Zúñiga y Sandoval no era la hija de los Marqueses de Aguilafuente como afirma Baranda (p. 61), y que la dedicataria de Amaçona cristiana. Vida de la B. M. Theresa de J-H-S (Valladolid: Francisco Fernández de Córdoba, 1619) de Bartolomé de Segura no era Catalina de Zúñiga y Sandoval, sino su sobrina y nuera Catalina de la Cerda y Sandoval, VII Condesa de Lemos (p. 59, nota 46). Prueba de esto último es que, en su dedicatoria, dirigida "A D. CATALINA DE / Sandoual, y la Cerda Condesa / de Lemos de Andrade, y / Villalua Marquesa de Sarria, etc.", Bartolomé de Segura señala que "el conde, que Dios guarde muchos años, se ha empeñado en fayorecer [sic] los partos de mi pobre ingenio"; Segura debe referirse al VII Conde de Lemos, puesto que el VI Conde, el marido de Catalina de Zúñiga, ya había fallecido en 1619.
} 
Fray Juan de los Ángeles, la única obra religiosa de las tres, existe evidencia de que Catalina de Zúñiga actuó como mecenas cubriendo los gastos de la publicación (“à su cuenta ha de salir en publico"). ${ }^{111}$ Según el material preliminar del libro, Catalina de Zúñiga, además de pagar la impresión, ordenó la creación del libro y determinó sus contenidos como una potencial usuaria del mismo:

[...] en este tratado, que de los mysterios soberanos de la Missa tengo escrito, no he hecho mi voluntad, sino la de V. Ex ${ }^{\text {a }}$. que desseosa de tener de mi mano, lo que las ceremonias santas significan, y algunos sentimientos espirituales acerca del diuino sacrificio, para ocupar con aprouechamiento el tiempo que à el assiste, me mandò dexasse otras ocupaciones, y tomasse esta. ${ }^{112}$

El Tratado espiritval de los soberanos mysterios y ceremonias santas del diuino sacrificio de la Missa indica que el mecenazgo de Catalina de Zúñiga fue probablemente un medio para expresar públicamente su celo religioso ("un lugar de comunicación", en palabras de Kelley A. Harness). Los paralelismos entre los objetivos del libro de Fray Juan de los Ángeles y el Arte de canto llano de Montanos son claros. El primero, un librito en octavo que "puede andar en manos de los más ocupados, y tan acomodado à toda suerte de gente", ${ }^{113}$ explica a los fieles el significado de la ceremonia de la Misa, mientras que por medio del segundo se pretendía que los clérigos comprendieran la solemnidad de la ceremonia del Oficio Divino y se formaran para ello. La comparación entre las dedicatorias de Fray Juan de los Ángeles y Francisco de Montanos a Catalina de Zúñiga indica que, mientras que la Condesa iba a usar el Tratado espiritval como un libro de devoción personal, el manual de Montanos estaba dirigido a clérigos y no encontramos referencias a Catalina como una potencial usuaria de la obra.

Sería interesante saber si la Condesa influyó en la elección de los contenidos concretos del Arte de canto llano de Montanos, como ocurrió en el caso del libro de Fray Juan de los Ángeles. Un ejemplo anterior es el de la noble María de Tovar y de

\footnotetext{
111 Fray Juan de los Ángeles, Tratado espiritval de los soberanos mysterios y ceremonias santas del diuino sacrificio de la Missa (Madrid: Imprenta Real, 1604), s.f., “Al lector”.

${ }^{112}$ Ángeles, Tratado espiritval, s.f. [dedicatoria].

113 Ángeles, Tratado espiritval, s.f., “Aprobación de la Orden firmada por F. Antonio Viues, Difinidor y Letor”. Aquí se percibe no sólo la búsqueda de un mercado potencial diversificado, sino también que el afán de brevedad que caracteriza a las artes de canto era un fenómeno generalizado, quizás motivado por un cambio en el estilo de vida. Véase el Capítulo I (Apartado 1.2.2).
} 
Vivero $(\dagger 1527)$ que, como mecenas del popular confesionario Memorial de pecados $e$ aviso de la vida christiana (Burgos, 1515) de Pedro de Covarrubias, dirigió el discurso del teólogo de acuerdo con sus propias preferencias como futura usuaria del libro. ${ }^{114} \mathrm{Si}$ Catalina influyó de algún modo en los contenidos de un libro de música dirigido a sacerdotes, estaríamos ante un caso en que una mujer determinó cuál iba a ser la formación musical de un grupo de hombres (y no a la inversa, como se señala generalmente en los estudios de género de la tratadística musical renacentista). Catalina de Zúñiga patrocinó el Tratado espiritval siendo viuda, mientras que la publicación del Arte de canto llano habría sido promovida por la Condesa en su condición de mujer casada. Esto constituiría otra particularidad del caso, puesto que el mecenazgo femenino y la viudedad estaban íntimamente asociados en la época. ${ }^{115}$

\subsubsection{El arte de CANTO LLANO de Francisco de Montanos EN El CONTEXto dE \\ MONFORTE DE LEMOS}

En la dedicatoria del Arte de canto llano (1594), Montanos hablaba en pasado del "tiempo que residi en Galicia, siendo Capellan y Maestro de Capilla del Conde de Lemos". Esto sugiere que el Arte de canto llano no sería usado por los clérigos de Monforte bajo la supervisión de Montanos, lo que lleva a preguntarse si el libro se vinculaba a alguna institución educativa de Monforte de Lemos. El libro de Montanos fue publicado en 1594, cuando los hijos de Catalina de Zúñiga comenzaron sus estudios en el Colegio Jesuita de Monforte de Lemos (aunque también tenían maestros en la Corte), fundado por el Cardenal Rodrigo de Castro (dedicatario del libro de Salinas) y en cuya instauración la Condesa había desempeñado un papel trascendental. Fue la propia Catalina de Zúñiga quien, según Pedro de Ribadeneira (1527-1611), “puso al Cardenal en

\footnotetext{
${ }^{114}$ María Jesús Framiñán de Miguel, "Mecenazgo intelectual femenino en el Renacimiento español: a propósito de María de Tovar y el Memorial de Pecados de Pedro de Covarrubias (1515)", en Mujeres y cultura escrita. Del mito al siglo XXI, ed. por María del Val González de la Peña (Gijón: Trea, 2005), pp. $147-166$.

${ }^{115}$ El tercer capítulo del libro De como ordenar y ocupar el tiempo (Granada, c. 1496) de Hernando de Talavera, dedicado a María Pacheco, se llama "Que tener la dicha orden es mas grave á las dueñas casadas, porque no tienen libertad para hacer su voluntad; mas han se de conformar al buen querer de sus maridos". Harness, Echoes of Women's Voices, p. 8, afirma que "las viudas tendían a ser mecenas más prolíficas, posiblemente debido a la tradición, pero también como consecuencia de un mayor acceso al dinero" ["widows tended to be the most prolific patrons, possibly due to tradition but also stemming from their increased access to money"].
} 
que hiciese esta fundacion". ${ }^{116}$ Las obras de construcción del Colegio comenzaron en 1593, justo cuando se obtuvieron el privilegio real y la aprobación para imprimir el Arte de canto llano de Montanos. Catalina de Zúñiga seguía el avance de las obras desde su palacio de Monforte, como queda demostrado por las referencias que hace a las mismas en las cartas que escribía a su marido. ${ }^{117}$

El historiador Esteban de Garibay y Zamalloa (1533-1600), que conoció a la Condesa de Lemos, la califica de "Señora de gran religion, y exemplo, en todo genero de virtud, y valor". ${ }^{118}$ En su estudio de las mujeres místicas del Siglo de Oro español, Stephen Haliczer ha señalado que "en ningún lugar de Europa el misticismo desempeñó un papel tan dominante como en España", donde "tomó el carácter de casi un movimiento de masas, al menos entre las clases medias y altas urbanas". ${ }^{119}$ En las cartas de Catalina de Zúñiga encontramos constantes referencias a su fervor por las reliquias de santos y este fervor, según Haliczer, es una muestra de la creencia en los milagros (creencia que existía principalmente entre los médicos). ${ }^{120}$

La atmósfera de religiosidad que rodeaba a los Condes de Lemos se hace evidente en dos documentos de archivo. En primer lugar, el ya mencionado Juan Sherwin, músico inglés al servicio del Conde de Lemos, declaró ante la Inquisición que se decidió a abjurar del anglicanismo y profesar la fe católica cuando estuvo en Galicia en la casa del Conde de Lemos, y que lo que le movió a ello fue "ber que todas las gentes con un

\footnotetext{
${ }^{116}$ Pedro de Ribadeneira, Historia de la Compañía de Jesús en las Provincias de España, libro VIII, capítulo 11, MS, Roma, Biblioteca del Institutum Historicum S. J.; citado en Evaristo Rivera Álvarez, Galicia y los Jesuitas: sus colegios y enseñanza en los siglos XVI al XVIII (A Coruña: Fundación Pedro Barrié de la Maza, 1989), p. 295. Otra de las fuentes manuscritas sobre el Colegio de Monforte de las que da noticia Evaristo Rivera es el primer capítulo de Luis de Valdivia, Historia de los colegios de la provincia de Castilla, manuscrito del que también se conserva una copia en la Biblioteca del Institutum Historicum de Roma.
}

${ }^{117}$ Un ejemplo son las menciones a Andrés Ruiz, director de la fábrica; véase, por ejemplo, la carta fechada en 1595 y conservada en Madrid, Archivo de los Duques de Alba, C. 40-130.

${ }^{118}$ Esteban de Garibay y Zamalloa, Obras, no impresas, de Estevan de Garibay chronista de los catholicos reyes de las Españas y del Nuebo Mundo, Philipes, segundo y tercero, MS (1790), 6 vols., Madrid, Biblioteca de la Real Academia de la Historia, 9/2110-2117; citado en Fernández de Bethencourt, Historia genealógica y heráldica de la monarquía española, vol. 4, p. 497.

${ }^{119}$ Haliczer, Between Exaltation and Infamy, p. 8: "But nowhere in Europe did mysticism come to play such a dominant role as in Spain, where it was not limited to a comparatively small number of devout individuals but took on the character of almost a mass movement, at least among the urban middle and upper classes".

${ }^{120}$ Haliczer, Between Exaltation and Infamy, p. 13. 
mismo corazon tenian estas cosas de la fe catholica"; cuando se le preguntó si se había confesado alguna vez, el músico "dixo que se a confesado tres bezes una bez en galizia por quaresma un poco despues que uino alli en Monforte de lemos con un frayle de la orden". ${ }^{121}$ En segundo lugar, una carta enviada por Diego García, prefecto de estudios, "lector de mayores" y posteriormente Rector del Colegio de Monforte, al Cardenal Rodrigo de Castro proporciona más evidencias del contexto de religiosidad en que se movían los Condes de Lemos. ${ }^{122}$ La carta, con fecha de 26 de agosto de 1598, explica que, ante la extensión de la epidemia de peste que azotaba Galicia, los Condes habían enviado a sus hijos a Madrid, que la Condesa también se trasladaría para asistir a una boda y que el Conde se había quedado solo con su hermano fray Juan de Castro:

Anda su señoria tan pio y tan deuoto que causa gran consuelo a toda la tierra manda hazer processiones y haze que toda la gente se confiesse y no aguarde al peligro y es el primero en todas las cosas de deuoçion y con los sermones del padre Hernando de Mendoça que es el lector de casos del colegio que ha estado con estos señores desde que uinieron a la Caldelas se haze y ha hecho mucho fruto. ${ }^{123}$

Fue también en 1594 cuando empezaron a impartirse clases de humanidades en el Colegio Jesuita de Monforte y cuando las escuelas de niños y gramática crecieron exponencialmente. ${ }^{124}$ En una carta datada en mayo de 1595, el mismo Diego García sugería al Padre Gaspar Moro, jesuita de Valladolid, la fundación de una cátedra de canto en el Colegio de Monforte, probablemente "un ignorado proyecto de don Rodrigo

\footnotetext{
121 “Confesión y abjuración de Juan Sherwin”, ff. 8v-9r.

${ }^{122}$ Diego García fue profesor de los tres hijos de los Condes de Lemos, Pedro, Francisco y Fernando. En el curso 1594-1595, junto a Diego García como lector de mayores, encontramos al también sacerdote Juan Pérez de Navarra ocupando el puesto de maestro de niños y a los escolares Diego de Poveda y Miguel Rubio como lectores de medianos y menores, respectivamente. Véase Rivera Álvarez, Galicia y los Jesuitas, p. 309. José Manuel Pita Andrade, "Noticias sobre el Colegio de la Compañía de Monforte y la formación del VII Conde de Lemos", Cuadernos de Estudios Gallegos, XV (1960), pp. 105-110, p. 106, da noticia de la consecución del cargo de rector por parte de Diego García: "No sabemos si al fin logró lo que pedía, pero desde luego consta que se quedó en Monforte por cuanto en 1613 era Rector del Colegio y daba una carta de pago al maestro de cantería, Simón de Monasterio".

123 “Carta del P. Diego García de la Compañía de Jesús, Prefecto de estudios del Colegio de Monforte, a D. Rodrigo de Castro y Osorio, Arzobispo de Sevilla, sobre la peste de Galicia en 1598. Camba, 26 de Agosto de 1598", Madrid, Biblioteca Nacional de España, MSS/18552/16.

${ }^{124}$ Rivera Álvarez, Galicia y los Jesuitas, p. 309-310, indica la existencia de 400 estudiantes de Latinidad y 300 niños que leían y escribían en el curso 1594/1595.
} 
para su obra", ${ }^{125}$ y proponía a su sobrino como candidato a la misma (véase Ilustración V.10):

[...] podra el Ilustrisimo fundar luego la catedra de canto que dizen que se ha de poner en este pueblo, y estudio, y començarse este San Lucas, y tomarla ya este clerigo, el qual fuera de las demas partes que tiene, sabe tambien lo que al canto que puede enseñarlo [...]. La institucion de la catedra es de suma importancia para hazer aqui clerecia perfecta en todo, y en cosa de canto ay extraordinaria falta [...] y qualquiera de los generales que agora ay puede seruir, pues esta licion no concurre a un mismo tiempo con la de latin, que asi se haze en el colegio nuestro de Leon. $^{126}$

Ilustración V.10: Carta de Diego García al Padre Gaspar Moro, datada a 15 de mayo de 1595, en la que se propone la fundación de una cátedra de canto en el Colegio de Monforte. Madrid, Archivo de los Duques de Alba, C. 152-47, ff. 1v-2r.

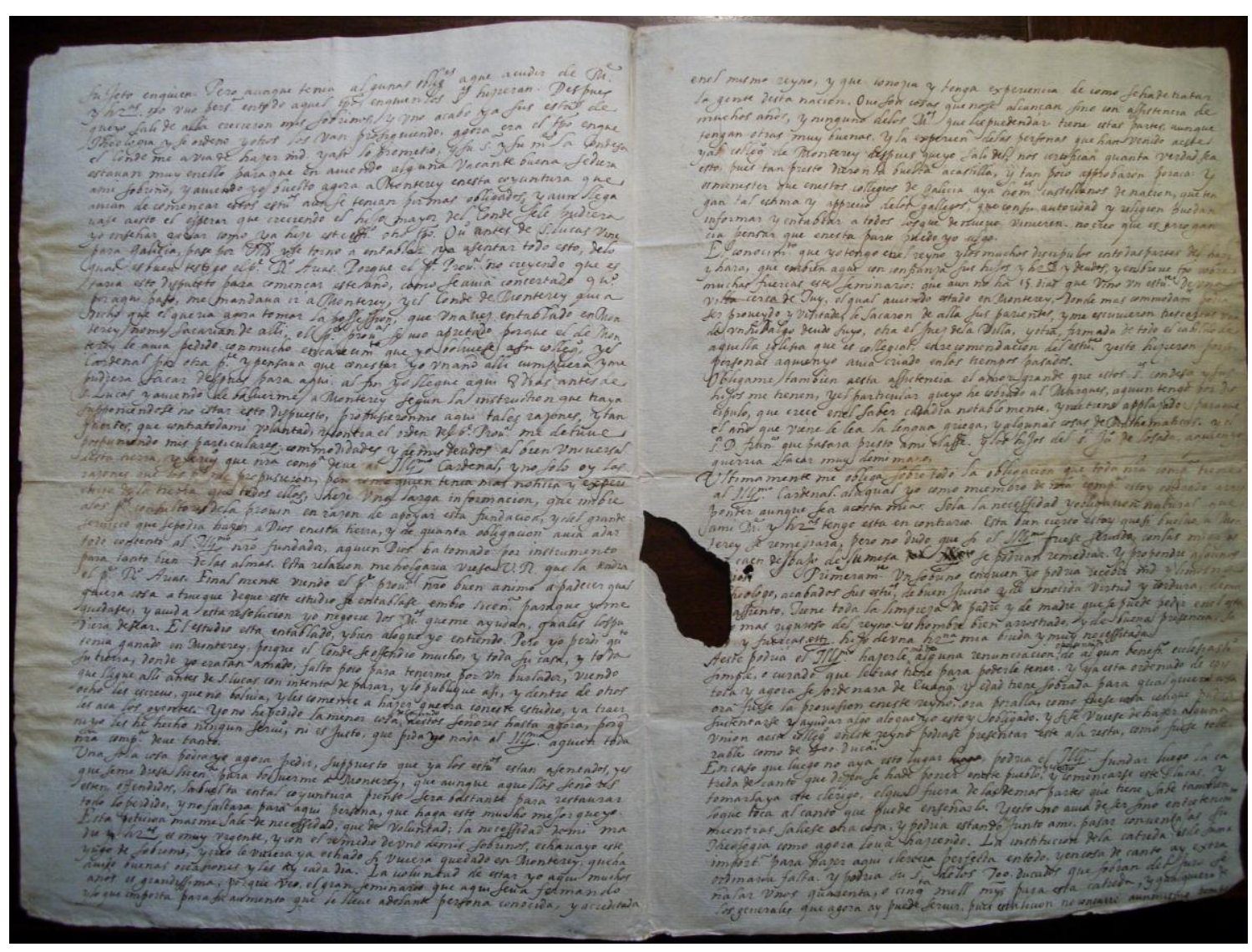

${ }^{125}$ Rivera Álvarez, Galicia y los Jesuitas, p. 321.

126 "Carta de Diego García al Padre Gaspar Moro" (15 de mayo de 1595), f. 2r, Madrid, Archivo de los Duques de Alba, C. 152-47. Para una transcripción de la carta, véase Pita Andrade, "Noticias sobre el Colegio de la Compañía de Monforte". 
Los motivos que señalaba Diego García para que hubiese necesidad de una cátedra de canto son los mismos a los que aludía Montanos en el Arte de canto llano, es decir, las carencias en la formación musical del clero gallego. Las similitudes entre los contenidos de la dedicatoria de Montanos y la carta de Diego García son notorias; Montanos señalaba que la razón de su publicación era la necesidad de aprender la práctica del canto que había notado cuando trabajaba en Galicia, mientras que García explicaba que una cátedra de canto era muy importante para mejorar la formación del clero gallego, la cual era insuficiente en materia de música. Las cartas de Catalina de Zúñiga muestran que, como ha indicado Evaristo Rivera Álvarez, "fue muy familiar su trato con el Prefecto de estudios, el P. Diego García". ${ }^{127}$ Aunque no existen documentos que permitan corroborar la realización de este proyecto de fundación de una cátedra de música, cabe preguntarse si hubo una conexión entre la publicación del Arte de canto llano de Montanos, su dedicatoria a Catalina de Zúñiga, la referencia que hace Montanos a los clérigos de Monforte como prospectivos usuarios de su libro, y la enseñanza de la música en el Colegio de Monforte de Lemos (con o sin cátedra de canto, dado el importante papel adjudicado a la música por parte de los jesuitas en las enseñanzas generales). ${ }^{128}$

En 1598 el cardenal Rodrigo de Castro otorgó a Catalina de Zúñiga “un poder para intervenir y coordinar la marcha de las obras" del Colegio de Monforte. ${ }^{129}$ Casualmente, el Arte de canto llano fue reimpreso por primera vez (que sepamos) en 1598. Esta nueva edición carece de la dedicatoria a la Condesa de Lemos y en su lugar encontramos una dedicatoria a la Virgen, en latín, en la que se hace referencia a Montanos en tercera persona, y que reaparece al menos en las ediciones de 1610, 1616, 1625 y 1643 (véase la Tabla V.2):

\footnotetext{
${ }^{127}$ Rivera Álvarez, Galicia y los Jesuitas, p. 295. En las cartas de Catalina de Zúñiga encontramos referencias a Diego García. Un ejemplo es la carta de 10 de junio de 1595 conservada en Madrid, Archivo de los Duques de Alba, C. 40-82.

${ }^{128}$ T. Frank Kennedy, Jesuits and Music: The European Tradition, 1547-1622, Tesis Doctoral (Ph.D.), University of California at Santa Barbara, 1982.

${ }^{129}$ Rivera Álvarez, Galicia y los Jesuitas, p. 295.
} 
DEDICATIO B. Virgini.

Non meate laudet Genitrix pulcherrima lingua,

Vocibus Angelicis qua benedicta manes.

Te Pater aternus nouit, tu filia Christum,

Et Spiritus saancti sponsa dicata Deo.

Filia, sponsa, mater, te tot monilibus, auctam,

Ad superos tollat mens mea grata tibi.

Hodc opus interna dulcedine captus amoris.

Montanus tibi dedicat alma parens.

Tabla V.2: Comparación de las ediciones de 1594 y 1598 del Arte de canto llano (Valladolid, 1594) de Francisco de Montanos

\section{Edición de 1594}

[Ejemplar: Coimbra, Biblioteca Geral de la Universidade de Coimbra, R-11-36]

\section{Edición de 1598}

[Ejemplar: Madrid, Biblioteca Nacional de España, M/7002]
Arte de canto llano de Francisco de Montanos racionero en la Iglesia mayor de Valladolid, vno de los seis artes suyos que andan impresos, con algunas entonaciones, y cantos llanos diversos en que se ejerciten los que de nuevo aprenden. Dirigido a Doña Cathalina de Sandoual y Çuñiga Condessa de Lemos.

[Escudo de Zúñiga]

Con privilegio.

En Valladolid, por Andres de Merchan. 1594.

Esta tassado à seys marauedis cada pliego.
Arte de canto llano con las diversas cosas. Como se vera en la Tabla, y discurso, y entonaciones comunes de Coro, y Altar.

En todo va accentuado el punto con la letra, y algunas cosas remitidas puestas ad longum. Compuesto por Francisco de Montanos.

[Ilustración de la Virgen]

Con privilegio.

Impresso en Valladolid, por Gaspar Hernandez, y Iuan de Bustillo. Año.1598.

Esta tassado à seys marauedis cada pliego.

ENMIENDAS firmadas por Doctor Alonso Vaca de Santiago "En Valladolid, a 23 dias de Deziembre, de 1599 años"

Dedicatoria a la Virgen

Tasa firmada por Cristóbal de León en Madrid a 8 de mayo de 1594

Tasa firmada por Cristóbal de León en Madrid a 8 de mayo de 1594

Aprobación de Hernando de Cabezón en Madrid a 10 de Septiembre 1593

Aprobación de Hernando de Cabezón en Madrid a 10 de septiembre 1593

Privilegio real en San Lorenzo a 22 de septiembre de 1593

de 1593

Soneto "Al avtor de vn su amigo"

Dedicatoria “A Doña Catalina de Sandoual y Çuñiga Condesa de Lemos, Francisco de Montanos Racionero en la Iglesia mayor de Valladolid"

[La dedicatoria a la Virgen aparece antes de la Tasa]

[La tabla está al final]

Tabla de lo que contiene este libro 


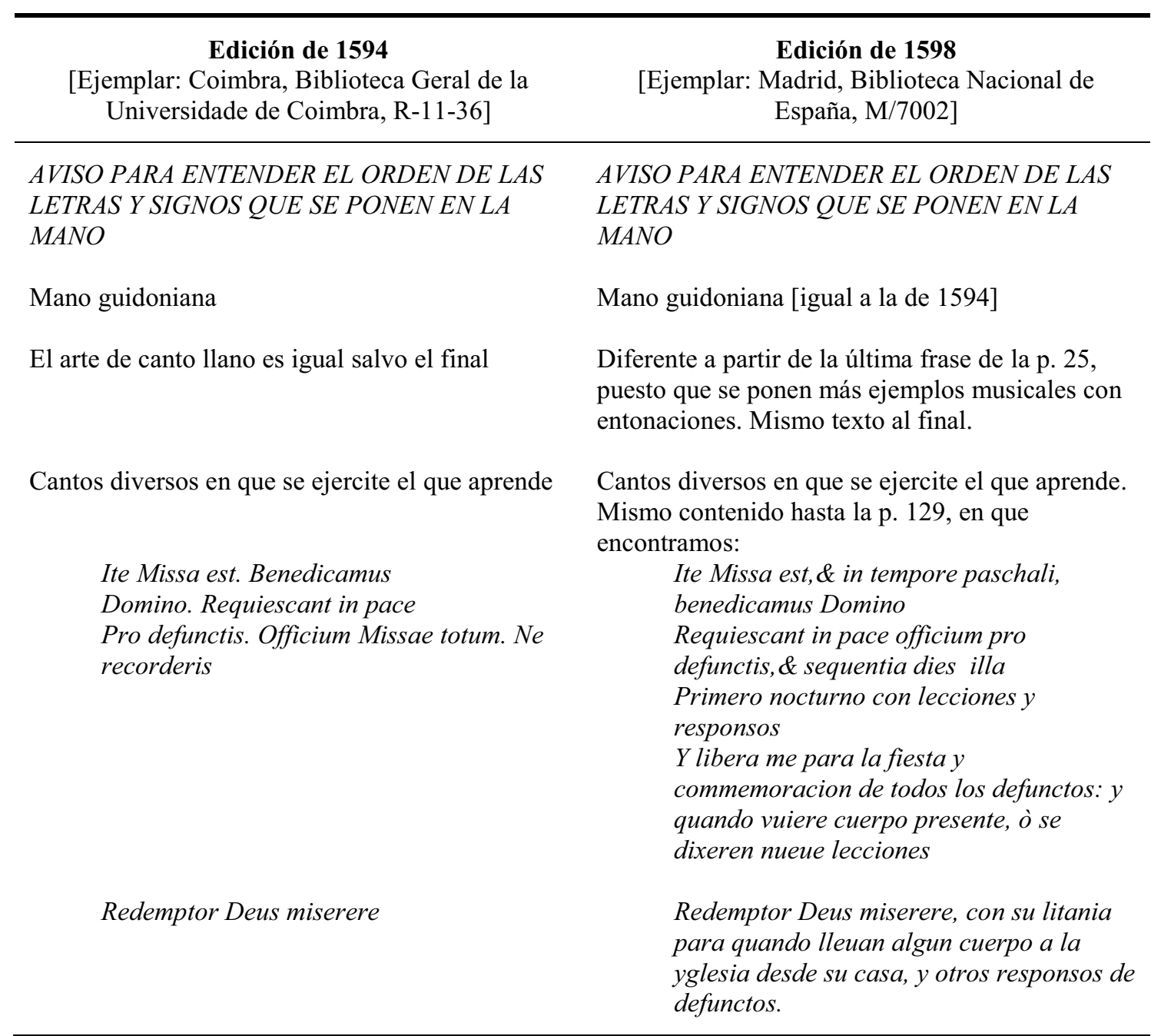

La no inclusión del soneto al autor o la dedicatoria a la Condesa de Lemos sugiere a simple vista que Montanos probablemente ya no vivía en 1598 y que la iniciativa de la publicación fue de otra persona. Quizás, debido a la demanda del Arte de canto llano en el mercado, los impresores (Gaspar Hernández y Juan de Bustillo) o algún librero decidieron reeditarlo, como ocurrió en las posteriores ediciones de Salamanca, Madrid y Zaragoza. Por ejemplo, la siguiente edición que conocemos salió a la luz en Salamanca en 1610 con una licencia nueva otorgada a Francisco de Córdoba "para que pueda imprimir y vender el libro". Sin embargo, la edición de 1598 fue publicada en Valladolid con el mismo privilegio real que encontrábamos en la edición príncipe de 1594 y por tanto con una licencia de impresión otorgada a Montanos "o a la persona que su poder ouiere", lo que sugeriría que la nueva edición fue impulsada por Montanos (y en este caso cabría preguntarse por qué no incluye la dedicatoria a Catalina de Zúñiga ni el so- 
neto de su amigo) o por otra persona a la que el autor hubiese transferido este poder. Dos casos apoyan la hipótesis de que la edición de 1598 del Arte de canto llano de Montanos no fue promovida por el autor. En primer lugar, la edición de 1628 del Arte de canto chão (1618) de Pedro Thalesio fue publicada con una nueva licencia otorgada en 1627 y a continuación encontramos impresas las licencias de la edición príncipe de 1618. Fue el propio Thalesio quien promovió la reedición y, por tanto, reimprimió la dedicatoria de la edición príncipe y los poemas que le habían sido dedicados y que formaban parte del material preliminar de la edición príncipe (véase Ilustración V.11a). El segundo caso es el de Lux bella (1492) de Domingo Marcos Durán. En 1509 apareció una edición en Salamanca promovida probablemente por el Obispo de esta ciudad y, en lugar de reimprimir la dedicatoria del autor a Pedro Ximénez de Préxano, esta nueva edición "va dedicada al muy noble cauallero don bernaldino manrique de Lara" (véase Ilustración V.11b). Estos casos apoyan la posibilidad de que el Arte de canto llano no fue reditado en 1598 por iniciativa del autor; es tentador especular si la propia Condesa podría haber impulsado esta reimpresión del libro. 
Ilustración V.11a: Pedo Thalesio, Arte de canto chão (Coimbra: Diogo Gomez de Loureyro, 1628 [1618]), portada. Coimbra, Biblioteca Geral de la Universidade de Coimbra, CF C-2-26.

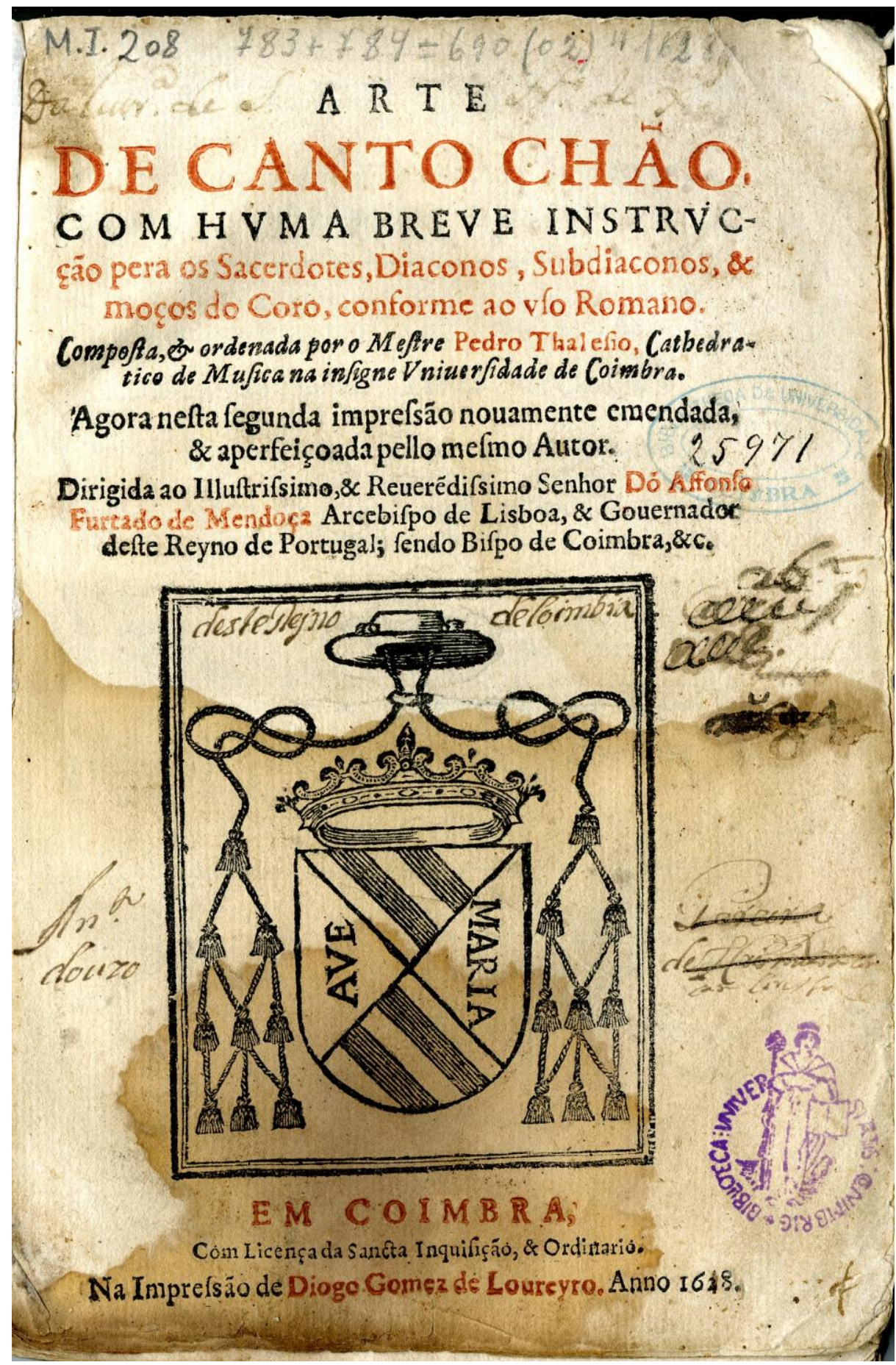


Ilustración V.11b: Domingo Marcos Durán, Lux bella de canto llano aprobada corregida e emendada (Salamanca: [Juan Gysser; ¿Pablo de Colonia?], 1509 [1492]), portada y verso de la portada. Lisboa, Biblioteca Nacional de Portugal, Res. 378P.

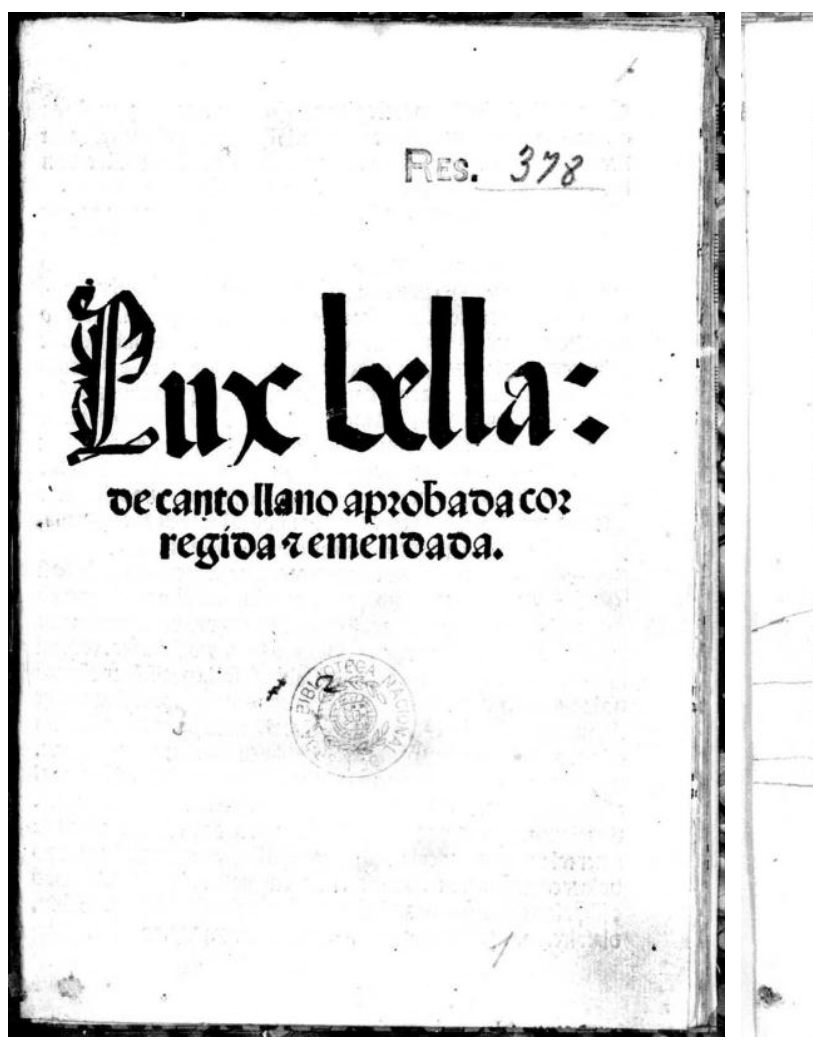

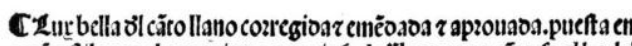
o:oé $\tau$ fitilo mų bzcue:cierto $\tau$ copiofo.lä̈l ozoeno z cöpufo el bacbi ller oomingo marcos ourã.va ocoicada al mue noble cauallero oon berualoinomärriq̄ólara. Ciprobentio.

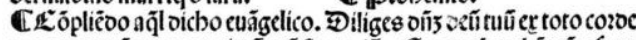

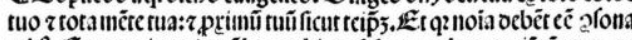
$\mathrm{reb}^{\circ}$. Émo mi ppzio nöbze z vitimo fobzcnombze conniēçă cll.o.co Imo cita dicion o b bo dare: oi fozma oc cozregir z fellar cl căro llano cu çerra z fufficiēere pfeció. ve veritas z cerrituoo ci' ac rotius mufice oeo

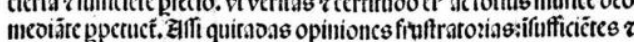
fofifticas:pufe las cicrtas $z$ fufficiētes.acquirioas $z$ puadas poz auto

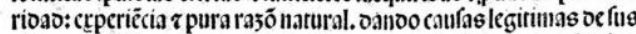
effectog. Ë öbunil reucrēcia fuplico a todos ă afuera rodo vliraic z murıunuraciō:quierärecebir efte mi pequeño äfi ppetuo. z fi fas ē oice

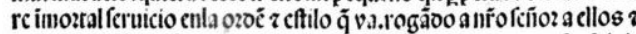

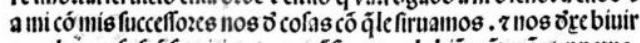
z acabàr en fúcóferuicio : como cöfiganos labiēauẽturäça ppetua. TEapitulopzimero. Đelos fignos z oeouciones.

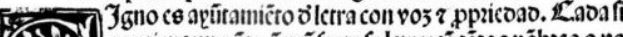
6.-. gnoticne vn púto q̃ ré̃fentafuletra:côtătos nöbzes o vo

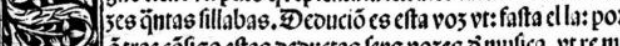
20. fa folla. Sö affi biprioas ve remi pafobir.fafolla pa ớcēoer cöparā oolas entre fi fienc boad efta regla en tooos los fighos: faluo enelve

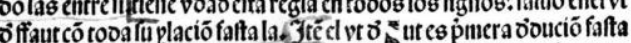

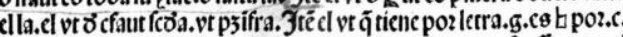

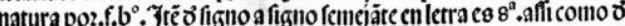

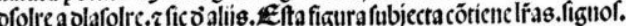
jouciones. ppeoades. Inutäças. $z$ fines ò tonos pfectamërc. bas de rener ral ozoen en ozoenar los fignos q̃óllegues affaut fobzeagudo boluer como pimero fafta ofolre. $z$ ölaletrapaftar alas vozesvirimas

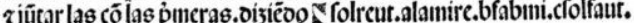
olafolrc.1.2.3.4.5.6.7.8.9.10.11.12,13,14,15,16.17,18,19,20.21,22,

En resumen, aunque no hay ninguna evidencia totalmente concluyente de que Catalina de Zúñiga costease la impresión u ordenase la publicación del Arte de canto llano de Francisco de Montanos, contamos con multitud de indicios que apuntan en esa dirección. El texto de la dedicatoria indica que con su Arte de canto llano Montanos cumplía los deseos de Catalina de Zúñiga relacionados con la formación musical del clero gallego, por lo que la publicación de un manual de canto llano extremadamente popular y reeditado repetidamente durante un siglo y medio podría haber sido promovida por la Condesa de Lemos. El mecenazgo de Catalina de Zúñiga sería consecuente con la hipótesis de Paula Higgins con respecto al período medieval tardío, según la cual las mujeres desempeñaron un importante papel "como agentes activos en la creación y propagación de la cultura musical". ${ }^{130}$ Higgins propone investigar a las magnates feme-

\footnotetext{
${ }^{130}$ Paula Higgins, "The 'Other Minervas': Creative Women at the Court of Margaret of Scotland", en Rediscovering the Muses: Women's Musical Traditions, ed. por Kimberly Marshall (Boston: Northeastern
} 
ninas y a sus camareras; Catalina de Zúñiga es un ejemplo paradigmático. Costease o no la impresión del libro, la publicación del Arte de canto llano contribuyó a que el celo religioso de la Condesa fuese reconocido públicamente.

La acción pública (religiosa) de la Condesa de Lemos en el campo musical contrastaba con sus actividades en el contexto privado. Es bastante ilustrativo que aunque la mayoría de los libros incluidos en los inventarios de bienes de Catalina de Zúñiga fuesen manuales de perfección cristiana, el único libro de música entre sus pertenencias no fuera el Arte de canto llano de Montanos ni ningún otro manual de canto religioso, sino un "libro en lengua ytaliana de Musica y Danza. Tassado en diez y seys reales". ${ }^{131}$ Según la identificación de Alejandro Luis Iglesias, podría tratarse de Nuove inventioni di balli, opera vaghissima... (Milán, 1604) de Cesare Negri, o bien de Nobiltà di dame... libro, altra volta, chiamato il ballarino (Venecia, 1605) de Fabritio Caroso. ${ }^{132}$ En el inventario post-mortem de Catalina de Zúñiga aparecen “organos pequeños". ${ }^{133}$ Por tanto, la actividad pública de Catalina de Zúñiga probablemente contrastaba con sus

University Press, 1993), pp. 169-185, p. 170: "In the discussion that follows I shall briefly highlight the cultural and historical contexts surrounding this little-known medieval princess, and use them to explore a broader spectrum of possibilities than has existed heretofore of the ways in which other female magnates and their ladies-in-waiting participated in the literary and musical culture of the late Middle Ages"; p. 180: "We need to gain deeper insight into the role of women as active agents in the creation and propagation of musical culture in the late Middle Ages".

${ }^{131}$ Este libro aparece en el inventario post-mortem de la Condesa realizado en Madrid a partir del 29 de febrero de 1628, el cual contiene un total de 202 libros. Véase "Inventario de los bienes de doña Catalina de Zúñiga y Sandoval, 1628”, Madrid, Archivo Histórico de Protocolos, Po 2300, f. 711v y ss. Los libros se listan a partir del f. 744v y el libro de música aparece en el f. 746r. Para una transcripción parcial de este inventario, véase Luis Vázquez Fernández, Documentos da historia de Monforte no Século de Ouro (Lugo: Servicio Publicaciones Diputación Provincial, 1991), p. 279, doc. 68. Para una corrección de algunos de los títulos de la transcripción de Vázquez Fernández y un estudio también parcial del inventario, véase Enciso Alonso-Muñumer, "Linaje, poder y cultura", p. 158, nota 463, y p. 161. Arantxa Mayo, "Los libros religiosos como posesiones personales en el Siglo de Oro español", en Materia crítica: formas de ocio y de consumo en la cultura áurea, ed. por Enrique García Santo-Tomás (Madrid: Iberoamericana; Frankfurt: Vervuert, 2008), pp. 149-168, p. 159, estima que el 72.27\% de la biblioteca de Catalina estaba constituido por libros religiosos. Marín Cepeda, "La cultura cortesana, devocional y literaria de una mujer poderosa del Siglo de Oro", p. 168, señala que los libros de Catalina muestran la afiliación de ésta con la tendencia antimaquiavélica que emergió en España en el último tercio del siglo XVI y abogaba por la reconciliación entre política y religión, frente a la superioridad de la política que promulgaba Maquiavelo. El libro de música y danza puede encontrarse en el inventario de 186 libros legados en 1630 por Catalina de la Cerda, sobrina de Catalina de Zúñiga, en nombre de la Condesa al convento de Franciscanas Descalzas de Monforte de Lemos; sobre esta dotación, véase María Isabel Barbeito Carneiro, "La biblioteca de la VI Condesa de Lemos", en Varia bibliographifica: homenaje a José Simón Díaz, ed. por Concepción Casado Lobato et al. (Kassel: Reichenberger, 1988), pp. 67-85, p. 78. Véase el Capítulo VI.

\footnotetext{
${ }^{132}$ Luis Iglesias, “El maestro de capilla Diego de Bruceña”, p. 461, nota 123.

${ }^{133}$ Diego Pacheco, "Beyond Church and Court", p. 368; y "Circulación y producción del madrigal en España durante el siglo XVI", p. 44.
} 
ocupaciones en la privacidad del hogar o de la cámara de la Reina. Se ha atribuido a la Condesa de Lemos un poema recogido en el Cancionero de Pedro de Rojas compilado por Pedro de Rojas Niño de Ayala, canónigo de la Catedral de Toledo, en un manuscrito datado en 1582 según una anotación en la hoja de guarda inicial, ${ }^{134}$ y conservado con el título Poesías varias en Madrid, Biblioteca Nacional de España, MSS/3924. ${ }^{135}$ Este poema se inserta en un contexto lúdico cortesano de preguntas y respuestas poéticas (contiene motes, como los del libro de Luis de Milán). ${ }^{136}$ En concreto, el poema atribuido a Catalina de Zúñiga (ff. 55v-56r del manuscrito) es una "Respuesta" a otro poema de Juan de Borja sobre "el diligente deseo" titulado "Pregunta que hizo don juan de

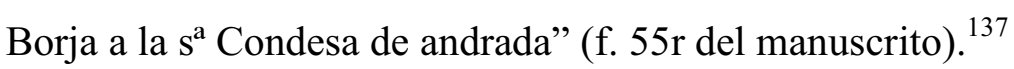

\section{3. ¿Un libro para mujeres?}

A simple vista, el hecho de que el Arte de musica de Francisco de Montanos, un completo tratado en seis libros, fuese dedicado al Conde de Lemos y su primera parte, despojada de cualquier contenido teórico, fuese dedicada a la Condesa, podría llevar a interpretaciones de género similares a las ya mencionadas acerca del Libro primero y El arte Tripharia de Juan Bermudo. Como hemos visto, dadas las diferentes razones de las dedicatorias, el dedicatario de un libro no tenía por qué haber sido considerado por el autor como un posible usuario del mismo. No sabemos el uso real que el Conde y la Condesa hicieron de los libros de Montanos, si es que los utilizaron de alguna manera. Cristina Diego plantea la hipótesis de que Montanos enseñase música al Conde de Le-

\footnotetext{
${ }^{134}$ Anotación: "Obras de diuersos Recopiladas / 1582 / Don Pedro de Rojas”.

${ }^{135}$ Cancionero de Pedro de Rojas, ed. por José J. Labrador Herraiz, Ralph A. DiFranco y María T. Cach, prólogo de José Manuel Blecua (Cleveland, Ohio: Cleveland State University, 1988), p. xvii: “Condesa de Andrade. Dama de la reina Isabel de Valois, que contrajo matrimonio con Felipe II en 1560, era una señora muy celebrada en la Corte por su discreción e ingenio. Se llamaba doña Catalina de Zúñiga y estaba casada con el conde de Aranda, don Fernando de Castro. Era nieta, por línea materna, del duque de Gandía. En nuestro manuscrito figura una "respuesta" a la pregunta que le hizo su pariente, don Juan de Borja. Este intercambio de preguntas y respuestas eran muy estimadas como juego de salón, cuya ascendencia encontramos ya en el Cancionero de Baena, pasatiempo poético que con mayor o menor intensidad continúa apareciendo en los cancioneros. Doña Catalina se muestra en esta contestación como digna de la fama que había alcanzado en el mundillo cortesano". Véase también Nieves Baranda Leturio, "Notas para un cancionerillo de poetas cortesanas del siglo XVI", Destiempos, IV/19 (marzo-abril 2009), pp. 8-27 (Dossier: Mujeres en la literatura. Escritoras) <http://www.destiempos.com/>.

${ }^{136}$ Luis de Milán, El libro de motes (Valencia: Francisco Díaz Romano, 1535). Véase el Capítulo VII.

${ }^{137}$ Ambos poemas se transcriben en Labrador Herraiz et al., Cancionero de Pedro de Rojas, pp. 82-84.
} 
mos (¿también a la Condesa y a sus hijos?). ${ }^{138}$ Entre los bienes del primogénito del matrimonio, Pedro Fernández de Castro, VII Conde de Lemos, ${ }^{139}$ se incluía un ejemplar del "arte de musica de francisco de montanos" junto a "cinco cuerpos de libros de musica" y "otros dos libros de musica" sin identificar (véase Ilustración V.12a), así como "un lio con una guitarra cubierto con dos sabanas de estopa para colchones yntitulada $\mathrm{n}^{\mathrm{o}}$ 11 " (véase Ilustración V.12b). ${ }^{140}$ En la distribución que Montanos hace de las dedicatorias de sus libros podría percibirse un matiz de género (es decir, el más ambicioso Arte de musica fue dedicado al Conde y su hijo poseía un ejemplar, mientras que la publicación independiente de su sección más básica se dedicó a la Condesa) que llevaría a especular sobre diferencias entre los conocimientos musicales que se esperaban de los hombres y de las mujeres.

\section{Ilustración V.12a: "Memoria de los libros que se enbian al marques mi Señor que se allaron en su aposento", f. 1v. Madrid, Archivo de los Duques de Alba, C. 241-3. Inventario de bienes del VII Conde de Lemos que incluye "arte de musica de fran" de montanos".}

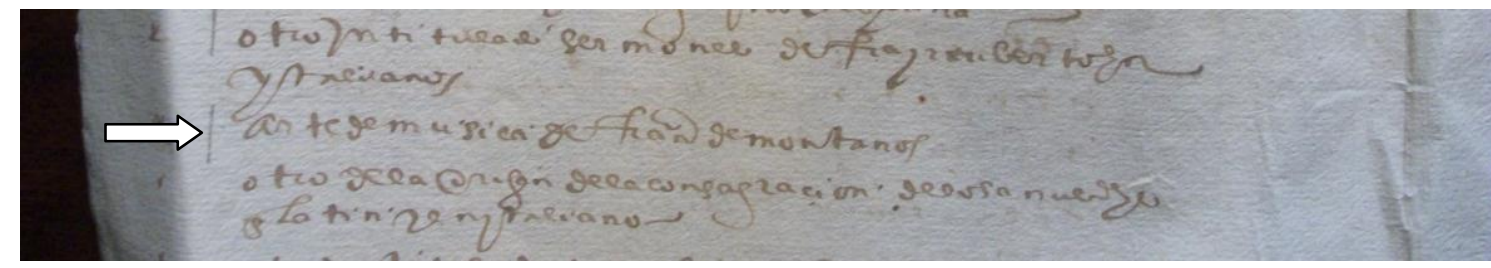

\footnotetext{
${ }^{138}$ Diego Pacheco, "Beyond Church and Court", p. 371: "Los músicos podían impartir clases a la nobleza como fue probablemente el caso de Montanos con el Conde de Lemos" ["Musicians could give lessons to the nobility as was probably the case of Francisco de Montanos with the Count of Lemos"].

${ }^{139}$ Sobre el VII Conde de Lemos, véanse Fernández de Bethencourt, Historia genealógica y heráldica de la monarquía española, vol. 4, pp. 498-504; e Enciso Alonso-Muñumer, Nobleza, poder y mecenazgo en tiempos de Felipe III.

140 "Memoria de los libros que se enbian al marques mi Señor que se allaron en su aposento", Madrid, Archivo de los Duques de Alba, C. 241-3, ff. 1v-2r. Otra fuente de la biblioteca del VII Conde es la "Memoria de la ropa que yo Juan de Enciso entrego a mi señora doña Leonor de Beltrán por mandado de mi señora la condesa de Lemos y de Castro, la qual ropa es de su Excelencia, que vino de Galicia, en Madrid, a 18 de junio de 1639", Madrid, Archivo de los Duques de Alba, C. 197-10, f. 6r: "Mas dos mill libros dos mas a menos grandes y pequeños de diferentes autores que son los que han quedado y estan en ser de la libreria del conde mi señor = no sson mas de mill y nouecientos y dos". En este último documento aparece la guitarra (f. 2v) entre la ropa "que vino de Galicia".
} 
Ilustración V.12b: "Memoria de la ropa que yo Juan de Enciso entrego a mi señora doña Leonor de Beltrán por mandado de mi señora la condesa de Lemos y de Castro, la qual ropa es de su Excelencia, que vino de Galicia, en Madrid, a 18 de junio de 1639", ff. 2v-3r. Madrid, Archivo de los Duques de Alba, C. 197-10. Inventario de bienes del VII Conde de Lemos que incluye "un lio con una guitarra cubierto con dos sabanas de estopa para colchones yntitulada no 11 ”.

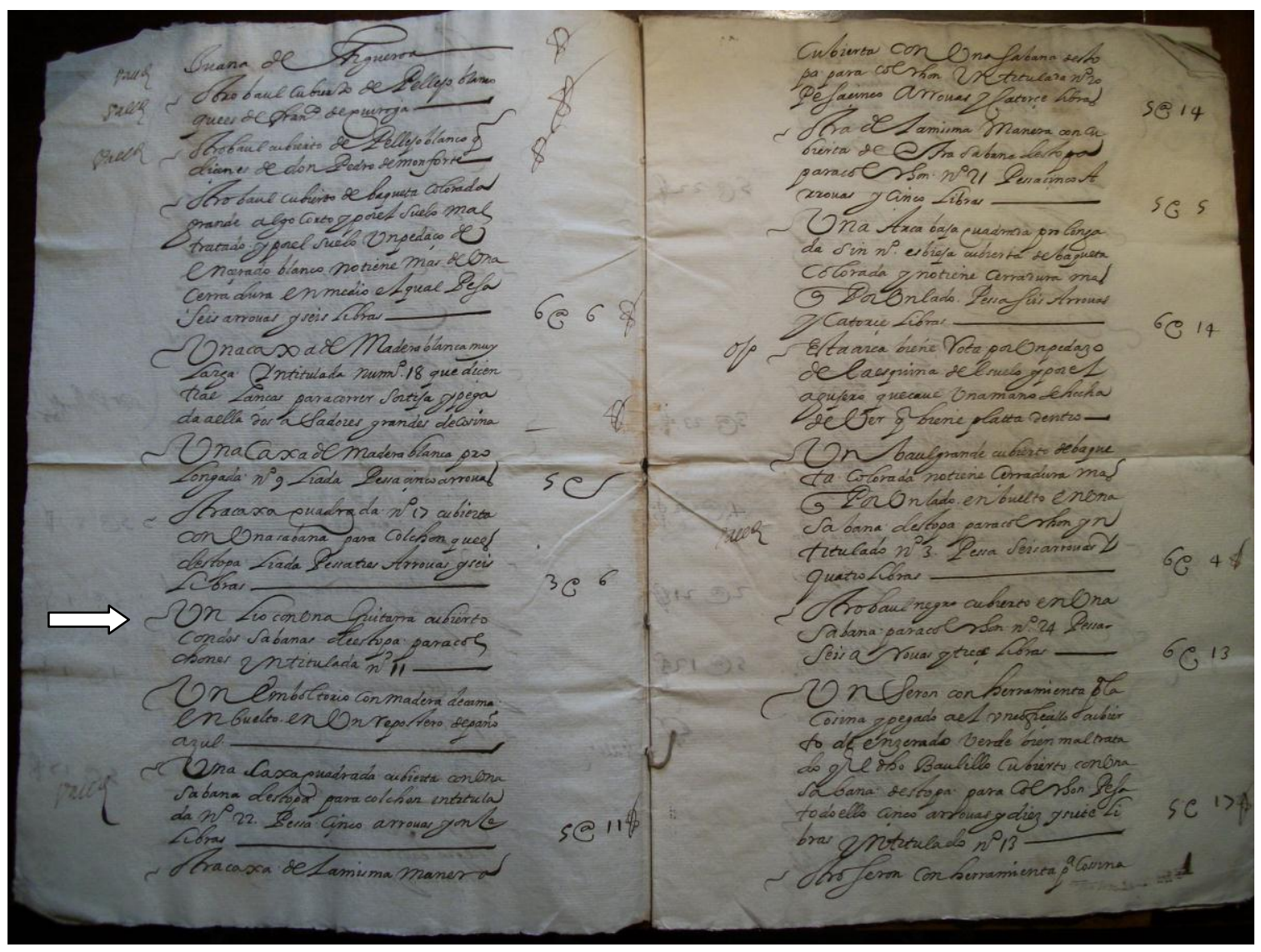

Como mostraba en el Capítulo IV, el ejemplar conservado en la Biblioteca de la Universidad de Salamanca de la edición de 1648 del Arte de canto llano de Montanos fue utilizado en el contexto doméstico de la educación femenina. Se ha sugerido que el tratado más completo, el Arte de musica, no se consideraba apropiado para la educación femenina. Para ello se ha utilizado como prueba el caso de Mariana de Jesús, una monja del Convento de Santa Clara de Vitoria que en una carta datada en 1676 y dirigida al compositor Miguel de Irízar decía guardar en secreto su ejemplar del Arte de musica de Montanos: "y si quisiere el libro de Montanos, le tengo dado a una persona para que me 
lo guardase, porque es mui secreto". ${ }^{141}$ Mariana de Jesús señalaba que su ejemplar del Arte de musica de Montanos "es mui secreto" sin explicar el motivo de ello. Soterraña Aguirre indica que Mariana de Jesús usaba el libro de Montanos en secreto "por tratarse de un libro que enseña "inteligencia del canto y compostura", por lo que "la explicación plausible de este hecho nos remite nuevamente a la innecesaria formación de la 'inteligencia del canto, y de la composición' en las mujeres". ${ }^{142}$ Matilde Olarte toma esta misma carta como prueba de que las religiosas efectivamente utilizaban tratados como el Arte de musica para componer. ${ }^{143}$

Por tanto, aunque una primera aproximación al caso de las dedicatorias de los dos libros de Montanos llevaría a una valoración similar a la que Annoni y Nuccio hacían de los dos libros de Bermudo (que la formación musical de las mujeres era más limitada que la de los hombres), el análisis en profundidad del material preliminar de los libros de Montanos a la luz de la evidencia proporcionada por otras fuentes y acontecimientos históricos muestra que el Arte de musica fue diseñado como un instrumento docente para ser usado por maestros de capilla y que el Arte de canto llano iba destinado originalmente al clero gallego y, por tanto, como El arte Tripharia, era un manual que contenía lo suficiente para quienes sólo pretendían cantar la Misa y el Oficio Divino.

El análisis del Arte de canto llano de Montanos desde una perspectiva de género (su relación con Catalina de Zúñiga) muestra cómo la exploración de la historia de las mujeres puede conducir al hallazgo de información relativa a controversias más generales. Este caso complementa las investigaciones que descartan la exclusiva asociación entre la música española renacentista y las capillas reales y eclesiásticas (al evidenciar

\footnotetext{
${ }^{141}$ La carta se recoge en Matilde Olarte, Miguel de Irízar y Domenzain (1635-1684?): biografia, epistolario y estudio de sus lamentaciones (Valladolid: Secretariado de Publicaciones, Universidad de Valladolid, 1996), vol. III, p. 444.

${ }^{142}$ Aguirre Rincón, "Sonido en el silencio", p. 298 y nota 58.

${ }^{143}$ Matilde Olarte Martínez, “Las 'monjas músicas' en los conventos españoles del Barroco. Una aproximación etnohistórica”, Revista de Folklore, 146 (1993), pp. 56-63

$<$ http://www.funjdiaz.net/folklore/07ficha.cfm?id=1149>: "También se constata a través de las peticiones de músicas que se hacen en los conventos, cómo las profesionales utilizaban para componer los tratados teóricos de música vocal (de canto llano y mensural) y tratados de música instrumental. Tenemos el ejemplo de la monja Mariana de Jesús, del convento de Santa Clara de Vitoria, que le pide a su maestro una obra a órgano que 'sea otavo tono, pero a de ser de famoso gusto, como vmd. le tiene en co[m]poner', ofreciéndole - para que lo utilice- el libro de Montanos, que 'le tengo dado a una persona para que me le guardase, porque es mui secreto"'. En cualquier caso, cabe preguntarse por qué Mariana de Jesús guardaba en secreto el libro de Montanos.
} 
una activa vida musical en las casas de los nobles y en su entorno), y la visión aislacionista de la vida musical en la España del Renacimiento. ${ }^{144}$ En contraste con la idea de que Valladolid era una ciudad aislada de la influencia italiana "en comparación con Valencia, Barcelona o incluso Sevilla", ${ }^{145}$ trabajos recientes demuestran la presencia de repertorio italiano en Valladolid y su asimilación por parte del propio Montanos, que publicó madrigales. ${ }^{146}$ Aunque Cristina Diego señala que se desconoce si llegaron a imprimirse, he podido encontrar en el inventario de 1575 de Francisco de Aguilar, librero de Sevilla, "vno madrigales de Montano a quatro boçes", entre una serie de libros de música impresa, lo que sugiere que los madrigales de Montanos se imprimieron y entraron en los circuitos comerciales de los libreros. ${ }^{147}$ La influencia musical entre España e Italia parece haber sido recíproca, puesto que en el El Melopeo y Maestro (Nápoles, 1613) Cerone citaba a Montanos y reproducía algunos de sus ejemplos musicales. Robert Stevenson señala que Cerone y Montanos podrían haber coincidido cuando el Conde y la Condesa de Lemos se trasladaron a Nápoles en 1599, si bien he presentado indicios que sugieren que Montanos ya había fallecido en $1598 .{ }^{148}$ En cualquier caso, parece que Montanos no necesitó viajar para conocer el repertorio extranjero, puesto que en la última frase de su Arte de musica declaraba haber visto durante sus años de maestro de capilla "gran summa de obras, de los mejores estrangeros de nuestros tiempos, y de los que ya fueron". 149

\footnotetext{
${ }^{144}$ La necesidad de que los musicológicos investiguen los archivos de las familias nobles españolas del siglo XVI ha sido señalada en Emilio Ros-Fábregas, "The Cardona and Fernández de Córdoba Coats of Arms in the Chigi Codex", Early Music History, 21 (2002), pp. 223-258, p. 258.

${ }^{145}$ Urquhart, "Francisco de Montanos's Arte de musica theorica y pratica", pp. 15-16, apunta esta idea para apoyar la hipótesis de que Montanos no leía italiano.

${ }^{146}$ Sobre la circulación de música extranjera en Valladolid; véanse Diego Pacheco, "Circulación y producción del madrigal en España durante el siglo XVI"; y Soterraña Aguirre Rincón, "The Formation of an Exceptional Library: Early Printed Music Books at Valladolid Cathedral”, Early Music, XXXVII/3 (2009), pp. 379-399.

${ }^{147}$ González Sánchez y Maillard Álvarez, Orbe tipográfico, p. 188, nº 689. Véase el Apéndice 9.

${ }^{148}$ Stevenson, "Montanos, Francisco de".

${ }^{149}$ Montanos, Arte de musica, "Lugares comunes", f. [50v]. Según Stevenson, "Montanos, Francisco de", Montanos "fue el primer teórico de la Península Ibérica en mostrar familiaridad con la música de Palestrina, y también conocía las obras de Lassus y Dominique Phinot" ["He was the first theorist from the Iberian Peninsula to show familiarity with the music of Palestrina, and also knew the works of Lassus and Dominique Phinot"].
} 
El estudio del Arte de canto llano abordado desde una perspectiva de género también permite vislumbrar la importancia que debió tener Francisco de Montanos en el ámbito cultural del mundo ibérico renacentista y la manera en que su figura integraba las facetas de sacerdote, músico (teórico, compositor y docente) y poeta. Aunque sabemos que Montanos compuso música, las fuentes que han llegado hasta nuestros días son mínimas, por lo que una investigación centrada en compositores y obras musicales impediría apreciar la posición que ocupó Montanos entre sus contemporáneos y el modo en que su actividad musical constituía sólo un hilo del rico entramado cultural del que el músico formaba parte.

\section{LA ACTIVIDAD MUSICAL DE LAS MUJERES EN LA ESFERA PÚBLICA}

El análisis de la edición príncipe del Arte de canto llano (1594) de Francisco de Montanos contribuye al menos en dos maneras a la historia de la música: 1) supone una aportación a la biografía de Montanos, puesto que confirma que ocupaba los puestos de “capellán” y "Maestro de Capilla" para el Conde de Lemos en Monforte y que había concluido esta actividad antes de 1594, dado que se refería en pasado al tiempo en que residió en Galicia; y 2) el Arte de canto llano de Montanos podría ser el único libro de música del siglo XVI que conocemos patrocinado o promovido por una mujer. Es significativo que los dos únicos libros impresos en el mundo ibérico del siglo XVI que se conocen dedicados a mujeres encajen en la misma categoría libresca. Ambos son artes de canto, con la particularidad de que la tercera sección de El arte Tripharia se dedica al "monacordio". El enlace entre Catalina de Zúñiga y el Arte de canto llano de Montanos sugiere que no sólo monjas, sino también mujeres nobles estuvieron conectadas con las artes de canto, una tipología libresca que, como argumentaré en el Capítulo VI, ciertamente cumplía los requisitos de religiosidad y espiritualidad prescritos en los tratados sobre conducta femenina publicados en esa época. En el caso de la Condesa de Lemos, la dedicatoria de un arte de canto (cuya impresión seguramente costeó) funcionó como una forma de reconocimiento público de su religiosidad. Así, en este Capítulo he llevado a cabo una aproximación a la cultura musical del mundo ibérico renacentista a través de la doble alteridad que supone el estudio de las artes de canto y de su conexión con las mujeres. 
El Apéndice 16 muestra que, por lo que se sabe hasta el momento, todos los manuales de música instrumental, los cuales contenían repertorio secular, publicados en el mundo ibérico del siglo XVI fueron dedicados a hombres. ${ }^{150}$ Es interesante que Bermudo incluyera como ejemplo de cifra en El arte Tripharia el íncipit de una pieza a dos voces con texto profano, “¿Dónde son estas serranas? Del pinar de Ávila son”, y a continuación indicase que la pieza incluida no es "tan buena" como quisiera, aunque "no se pone para que tengan codicia de tañerla sino por exemplo de ser imitado" (véase Ilustración V.13).

Ilustración V.13: “¿Dónde son estas serranas? Del pinar de Ávila son”, en Juan Bermudo, El arte Tripharia (Osuna: Juan de León, 1550), f. 38v.

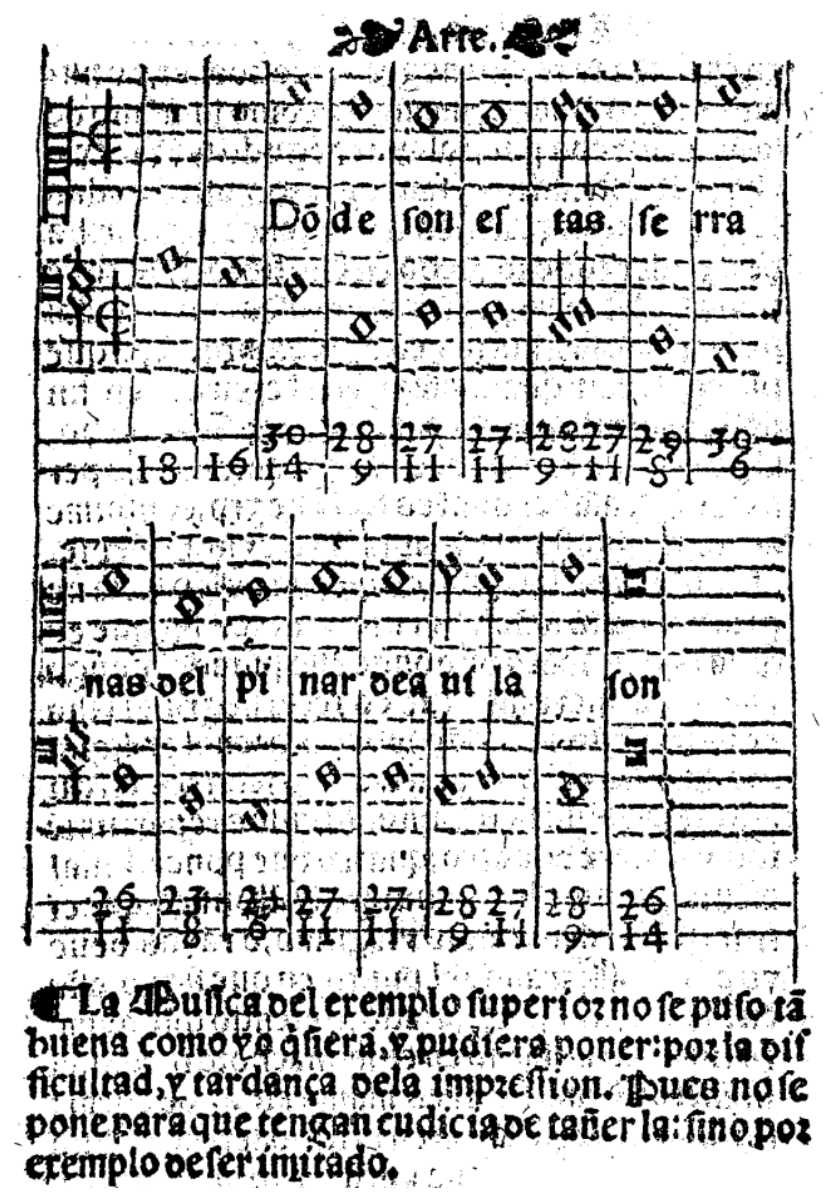

\footnotetext{
${ }^{150}$ Para una bibliografía, véase Howard Mayer Brown, Instrumental Music Printed Before 1600: A Bibliography (Cambridge, Mass.: Harvard University Press, 1965).
} 
Contamos con dos ejemplos posteriores relacionados con el mundo ibérico que indican el uso por parte de mujeres y el mecenazgo femenino de libros de música secular. El Metodo mui facilissimo para aprender a tañer la guitarra a lo español (París, 1626) del gallego Luis de Briceño está dedicado a "Madama de Chales", una noble francesa que se había iniciado en el estudio de la guitarra: ${ }^{151}$

[...] aunque es verdad que en poco tiempo VS. a comprendido casi todo lo que yo he podido componer y juntar, en el hallara nueuamente çifrado curiosos Romançes, Seguidillas, Chaconas, Çarauandas, Pasacalles, Gallardas romanescas, Satiras, Liras, Cançiones Zampa palos, guineos, Pauanas, Otauas y quartillas glosas y egnimas [sic], la morisca, las folias de ocho maneras, el rastreado el Ay ay ay, letrillas de teatro, la dança de el hacha, amorosas endechas, seguidillas, en Eco, el saltaren, y el cauallero Español, y otras cosas que son de gusto y no de mucha pena. A mi me pesa mucho de haçer presente a V S. de un metodo a la ora que saue casi todo lo que en el se ençierra, pero si he caido en esta falta, no a sido que por el contento que reçiuiran los curiosos y curiosas, en pasar el tiempo y la vista sobre estas liçiones, siguiendo a VS. en el gusto y en la curiosidad. [...] no la pese a V S. de auerse enbaraçado en el exerçiçio de la Guitarra, porque no hay exerçiçio, que no sea loable, quanto y mas, que este no es fuera de vso ni de raçon, que merezca, escarnio, ni titulo de grosero, yo he façilitado grandemente el tañer de la Guitarra, pero con todo eso, no lo es tanto que se puede aprender si no es ayudandose de la hauitud y del entendimiento, porque no bale mucho lo que poco questa. ${ }^{152}$

Otro método de guitarra, Nuevo modo de cifra para tañer la guitarra (Nápoles, 1640) de Nicolás Doizi de Velasco (c. 1590-1659), guitarrista portugués activo en Madrid y Nápoles, fue dedicado a Margarita de Austria Branciforte y Colonna (16041659), Princesa de Butera y nieta de Juan de Austria, que se había casado en 1619 con Felipe Colonna, Duque de Paliano y condestable del Reino de Nápoles (véase Ilustración V.14). Según la dedicatoria, 1) la publicación de este manual fue promovida por Margarita de Austria cuando pidió a Doizi de Velasco que proporcionase repertorio a tres de sus camareras con habilidades musicales; 2) el contenido del libro fue determinado por los deseos de la dedicataria (Doizi de Velasco puso en cifra las consonancias que Margarita consideró “propias”); y 3) los métodos y contenidos didácticos que Doizi de Velasco exponía en su libro habían sido puestos en práctica previamente en la privacidad del hogar de Margarita:

\footnotetext{
${ }^{151}$ La dedicataria ha sido identificada como Denise Naturel, nieta de Jan Godon, consejero de Luis XIII; véase Barton Hudson y Monica Hall, "Briçeño, Luis de", Grove Music Online, Oxford Music Online, 18 mayo $2010<\mathrm{http}$ ://www.oxfordmusiconline.com/subscriber/article/grove/music/03974>.

${ }^{152}$ Luis de Briceño, Metodo mui facilissimo para aprender a tañer la guitarra a lo español (Génova: Minkoff, 1972 [1626]), ff.a2r-[a3r], "A mi señora de Chales salvd y vida".
} 
Hauiendome V.E. mandado, que fuese a dar algunos tonos mios a tres criadas de V.E. diestras en musica, y excelentes en las bozes, y pasajes, a fin de que se perficionasen, cantando con el aire Español, a que V.E. por su Real sangre deue ser, y es aficionadissima, tal vez se me ofrecio hablar sobre la opinion, que ay de ser la Guitarra instrumento inperfeto, y tal poner en ella algunas consonancias, que por parecerle a la Señora Margarita propias, y no de las ordinarias, me obligò a darle señal particular, para conocerlas por no hallarse en ninguna de las Cifras, que comunmente se vssan. [...] A su casa de V.E. reconozco la ocasión de hauer puesto en platica este breue trabajo, por donde a nadie mas justamente deuo dedicarle, que a V.E. pues de la mucha estimacion, que haze de la noble arte, y singular virtud de la musica, me prometo hara la de este trabajuelo $[\ldots] .{ }^{153}$

Ilustración V.14: Nicolai Doizi de Velasco, Nueuo modo de cifra para tañer la guitarra con variedad, y perfeccion (Nápoles: Egidio Long, 1640), portada.

Madrid, Biblioteca Nacional de España, R/4042.

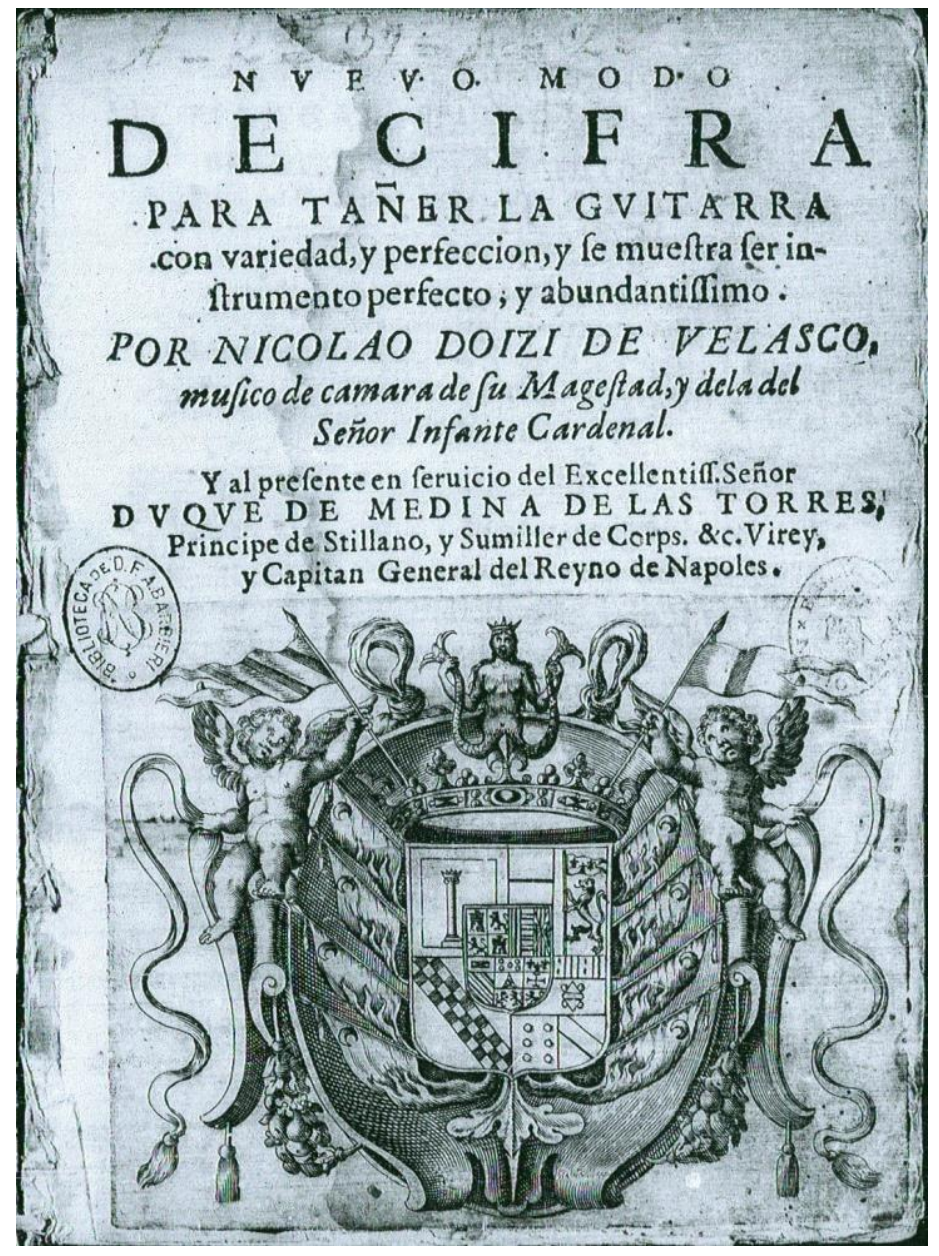

${ }^{153}$ Nicolai Doizi de Velasco, Nueuo modo de cifra para tañer la guitarra con variedad, y perfeccion, y se muestra ser instrumento perfecto, y abundantisimo. Por Nicolao Doizi de Velasco, musico de camara de su Magestad, y de la del Señor Infante Cardenal. Y al presente en seruicio del Excellentissimo Señor Duque de Medina de las Torres, Principe de Stillano, y Sumiller de Corps. \&c. Virrey, y Capitan General del Reyno de Napoles (Nápoles: Egidio Long, 1640), ff. a2r-a3r, "Dedicatoria". Dos ejemplares de este libro se conservan en la Biblioteca Nacional de España en Madrid con las signaturas R/4042 y R/101081. 
Es llamativo que estos dos libros de música instrumental dedicados a mujeres fueran impresos fuera de la Península Ibérica, si bien escritos por un músico gallego, Luis de Briceño, y por un portugués, Nicolai Doizi de Velasco, y dedicados a una aristócrata de la corte napolitana y de ascendencia española como Margarita de Austria. Estos casos muestran que en el mundo ibérico del siglo XVI, al menos en la esfera pública (dedicatorias de libros impresos y patrocinio de los mismos) las mujeres no se relacionaban de manera oficial con la música instrumental, lo que podría estar motivado por el bajo estatus que los moralistas de la época atribuían a la música. ${ }^{154}$ Sin embargo, en el Arte nouamente inuentada pera aprender a tanger (Lisboa, 1540) de Gonzalo de Baena encontramos referencias a su potencial uso por parte de "niñas", quizás pertenecientes a la nobleza y/o que se formaban para ser monjas. ${ }^{155}$ En el siglo XVIII encontramos una perspectiva diferente; Josefa Amar y Borbón, en su Discurso sobre la educacion fisica y moral de las mugeres (Madrid, 1790), sostenía que "la música instrumental es más útil que la vocal, porque se puede exercitar á solas", y que "quando se busca la propia utilidad en la instruccion, se ha de procurar tambien depender lo ménos que se pueda de los otros, y en las mugeres siempre es peligroso cultivar habilidades que requieren mucha comparsa". ${ }^{156}$ Como mostraré en el Capítulo VII, las fuentes documentales evidencian que la panorámica oficial de la vida musical femenina en el mundo ibérico renacentista estaba lejos de la realidad. Los inventarios de bienes muestran que algunas mujeres, al igual que Catalina de Zúñiga, poseían instrumentos musicales, y documentos de archivo evidencian que las mujeres músicas eran muy estimadas más allá de la Corte y el convento.

Ni El arte Tripharia de Bermudo ni el Arte de canto llano de Montanos cumplen a la vez los requisitos de ser libros patrocinados por mujeres y ser libros dirigidos exclusivamente a mujeres, por lo que carecemos de libros de música surgidos en el mundo

\footnotetext{
${ }^{154}$ Ramos, "Musical Practice and Idleness"; y "The Spanish Prohibition on Women Listening to Music: Some Reflections on Juan Luis Vives and the Jewish and Muslim Legacy", en Recent Research on Early Iberian Music in an International Context, ed. por Tess Knighton y Emilio Ros-Fábregas (Kassel: Reichenberger [en prensa]). Véase el Capítulo VII.

${ }^{155}$ Gonzalo de Baena, Arte pera tanger (Lisbon, 1540), ed. y estudio introductorio de Tess Knighton (Lisboa: Edições Colibri/CESEM, 2012): "todas esta reglas que son relatadas solamente para los que no son tanto engeñoses o que no tienen principios aprendidos. .s. los moços/ o niñas y otros semejantes. Porque para todo lo al solamente la primera regla basta".
}

${ }^{156}$ Amar y Borbón, Discurso sobre la educacion fisica y moral de las mugeres, p. 200. 
ibérico renacentista que nos sirvan como fuente para contribuir a los estudios sobre la representación de la mujer en obras artísticas y literarias. Los casos analizados sugieren que no podemos afirmar que las mujeres fueran "representadas" en estos libros dedicados a mujeres, puesto que éstos no estaban dirigidos a la mujer como categoría independiente, o como el "Otro" del autor. La interpretación que hace Colleen R. Baade de Fragmentos musicos (Zaragoza, 1683) de Pablo Nassarre, en fuerte contraste a la lectura de María Sanhuesa Fonseca, apoya esta misma hipótesis para el siglo XVII:

\begin{abstract}
Sería simplista [...] concluir de la disposición de contenidos que Nassarre relega a las niñas junto con los amateurs y los ciegos- a un estatus inferior como músicos, particularmente porque el propio Nassarre era ciego de nacimiento. Más bien, en este capítulo Nassarre aborda algunas de las dificultades particulares que él asocia con la enseñanza a este tipo de alumnos [...]. Los comentarios de Nassarre sugieren que muchas de las dificultades que él asociaba con la enseñanza de las niñas eran debidas al menos tanto a su inmadurez física y psicológica como a su sexo. ${ }^{157}$
\end{abstract}

Debe resistirse el impulso de tomar las dedicatorias de los dos libros de Montanos como indicio de los conocimientos musicales propios de los hombres y de las mujeres. La dedicatoria del Arte de canto llano muestra que Catalina de Zúñiga, más que una potencial usuaria del libro o una receptora pasiva del mismo, seguramente promovió la publicación, como la del Tratado espiritval de Fray Juan de los Ángeles, para satisfacer sus propios objetivos como mecenas religiosa. En consecuencia, los libros de Montanos y Bermudo no pueden tomarse como fuente del conocimiento musical que se esperaba de "la mujer" (como categoría) en el siglo XVI. Para abordar esta cuestión se requieren fuentes adicionales a los libros de música, que se presentarán en el Capítulo VII. Los dos libros analizados en este Capítulo llevan a cuestionarse hasta qué punto el género era un criterio que funcionaba en la categorización de lo usuarios de los libros de música o en la de los estudiantes de música, y si había criterios más importantes como la edad (tal y como apunta Baade) o el estatus social. En contraste con Juan Huarte de San Juan, que afirmaba en su ampliamente difundido Examen de ingenios para las ciencias

\footnotetext{
${ }^{157}$ Baade, "Nun Musicians as Teachers and Students", p. 260: "It would be simplistic, however, to conclude from the arrangement of subject matter that Nassarre relegates girls -along with amateurs and the blind - to an inferior status as musicians, particularly since Nassarre himself was blind from birth. Rather, in this chapter Nassarre addresses some of the particular difficulties he associates with teaching these three types of students [...]. Nassarre's comments suggest that many of the difficulties he associated with teaching little girls owed at least as much to their physical and psychological immaturity as to their sex".
} 
(Baeza, 1575) que "los padres que quisieren gozar de hijos sabios, y que tengan habilidad para letras, han de procurar que nazcan varones: porque las hembras por razon de la frialdad, y humedad de su sexo, no pueden alcanzar ingenio profundo", ${ }^{158}$ Fray Antonio de Guevara, señalaba que no existían diferencias en la capacidad de aprendizaje entre los hombres y "las princesas y grandes señoras":

No deben las princesas y grandes señoras dexar de enseñar todo lo que pueden enseñar a sus hijas y no se deben engañar diziendo que por ser mugeres para las ciencias son inabiles, ca no es regla general que todos los niños son de juyzio claro y todas las niñas de entendimiento obscuro; porque si ellos y ellas deprendiessen a la par, yo creo que avria tantas mugeres sabias como ay hombres necios. ${ }^{159}$

En el ámbito de la historia medieval, María Luisa Bueno Domínguez sostenía que en los estudios sobre mujeres "se está especificando el tema separando a la mujer como un elemento extraño a la historia" debido a que partimos "de nuestro concepto actual sobre la marginación femenina", y que la idea de que la mujer estaba "relegada" a determinados papeles infravalora el mundo femenino de la época, puesto que éste "no se movía por los conceptos de independencia, libertad e igualdad". La solución de esta historiadora consiste en "intentar reconstruir" el papel de las mujeres dentro de su entorno social. ${ }^{160}$ En este sentido, basándose en el Paradigma de la Complejidad de Edgar Morin, Ana Sánchez Torres señala que "no se es MUJER, se es mujer situada, con múltiples pertenencias: edad, etnia, clase social, género, situación geopolítica, etc.”. ${ }^{161}$

\footnotetext{
${ }^{158}$ Juan Huarte de San Juan, Examen de ingenios para las ciencias en el qual el lector hallara la manera de su ingenio, para escoger la ciencia en que mas ha de aprovechar: y la diferencia de habilidades que ay en los hombres, $y$ le genero de las letras, y artes que a cada vno responde en particular (Baeza: Juan Bautista de Montoya, 1575), p. 278.
}

${ }^{159}$ Fray Antonio de Guevara, Libro llamado Relox de Principes, en el qual va incorporado el muy famoso libro de Marco Aurelio (Valladolid: Nicolás Tierri, 1529), Lib. II, Cap. XXVII, f. 129.

${ }^{160}$ Bueno Domínguez, "Reflexiones en torno a la historia de las mujeres”, pp. 296-297.

${ }^{161}$ Ana Sánchez Torres, "Teoría feminista, complejidad y musicología”, en Mujer versus música. Itinerancias, incertidumbres y lunas, ed. por Rosa Iniesta Masmano (Valencia: Rivera Editores, 2011), pp. 409-427, p. 411. Esto enlaza con casos más recientes como el de la poeta afroamericana Phillis Wheatley (1753-1784). Robert Kendrick, "Re-membering America: Phillis Wheatley's Intertextual Epic", African American Review, XXX/1 (1996), pp. 71-88, p. 71, advierte que no se ha tratado lo suficiente la demanda que Wheatley hace en su obra para ser reconocida como una poeta madura y como un sujeto americano, independientemente de su raza o sexo: "El tema del reconocimiento es de crucial importancia en la poesía de Wheatley -pero una amplia evidencia en el cuerpo de su trabajo demuestra que su llamada a ser reconocida como una poeta madura y como un sujeto americano (independientemente de su raza o sexo) no ha sido respondida suficientemente" ["The matter of recognition is of crucial importance in Wheatley's 
Mientras que en su estudio de las españolas de la temprana Edad Moderna Lisa Vollendorf defiende que "el género era un factor tan determinante que, a pesar de las diferencias entre las mujeres, muchas tenían reacciones similares hacia una cultura que trataba de controlarlas y domesticarlas", ${ }^{162}$ en su trabajo sobre las mujeres de la familia Mendoza Helen Nader reconoce que es imposible "separar la influencia del género cuando se examinan las vidas de las mujeres". ${ }^{163}$

De los documentos conservados se desprende una imagen de Catalina de Zúñiga que aúna un fuerte carácter, curiosamente descrito como "varonil", y una profunda religiosidad, tal y como prescribían los tratados de conducta femenina publicados en su contexto. El análisis de su conexión con el Arte de canto llano de Montanos sugiere que las nobles del mundo ibérico del siglo XVI eran mecenas religiosas, independientemente de las actividades musicales que llevaran a cabo en el ámbito privado. No obstante, es difícil determinar si ésta era una decisión tomada por las mujeres, o una consecuencia del comportamiento femenino socialmente aceptado, o una negociación. Stephen Haliczer defiende que "el misticismo proporcionaba a las mujeres españolas un medio de trascender pero no perturbar el control de una Iglesia dominada por hombres", de manera que los logros de las místicas "sólo lograban reforzar el poder y control” de esta institución. ${ }^{164}$ Antonio Castillo Gómez señala que las cartas constituyen una apropiación de la escritura por parte de las mujeres, pero en el espacio aceptado: la escritura de cartas

poetry -but ample evidence in her body of work demonstrates that her call to be recognized as a mature poet and as an American subject (regardless of her race or sex) has not been sufficiently answered"].

${ }^{162}$ Vollendorf, The Lives of Women, p. 187: "The textual evidence examined in this book suggests that women experienced the world differently than men in the early modern period. Gender was such a compelling factor that, in spite of great differences among women, many had similar reactions to a culture that tried to control and domesticate them".

${ }^{163}$ Nader, ed., Power and Gender in Renaissance Spain, p. 5: "El género no era el único factor que determinaba el comportamiento de una persona. Más bien era un eje entre varios -riqueza, estatus marital, edad- que podía significar jerarquía en una sociedad corporativa. Aunque podría parecer imposible separar la influencia del género cuando se examinan las vidas de las mujeres, un análisis que incorpora riqueza, edad y estatus marital matiza más la comprensión de las experiencias de las mujeres de la temprana Edad Moderna" ["Gender was not the only factor that determined a person's behavior. It rather was one axis among several -wealth, marital status, age- that could signify hierarchy in a corporate society. Though it might seem impossible to separate the influence of gender when examining women's lives, an analysis that incorporates wealth, age, and marital status further nuances the understanding of the experiences of early modern women"].

${ }^{164}$ Haliczer, Between Exaltation and Infamy, pp. 292-293: "Mysticism provided Spanish women with a way to transcend but not disrupt the control of the male-dominate church [...]. During the post-Tridentine period, the spiritual transports and worldly achievements of Spain's women mystics succeeded only in reinforcing the power and control of the male-dominated church". 
“representa una práctica escrita, una actividad cultural, que, por sí misma, refleja la hegemonía de la ideología patriarcal". ${ }^{165}$ Igualmente, Catalina de Zúñiga podría considerarse la promotora de un influyente manual de canto llano; sin embargo, su acción "pública" en la creación de cultura musical tuvo lugar sólo en el espacio oficialmente aceptado, es decir, el religioso, reforzando de este modo el comportamiento femenino prescrito por los hombres en sus tratados de conducta femenina.

\section{RESUMEN DEL CAPÍTULO V}

Los Capítulos V, VI y VII constituyen la Parte II de esta Tesis Doctoral en la que se estudia la relación de las artes de canto con las mujeres. En el Capítulo V se examinan los dos únicos libros de música impresos en el mundo ibérico del siglo XVI dedicados a mujeres de los que tenemos noticia, ambos pertenecientes a la categoría de las artes de canto: El arte Tripharia (Osuna, 1550) de Juan Bermudo, dedicado a la abadesa Isabel Pacheco, y el Arte de canto llano (Valladolid, 1594) de Francisco de Montanos, dedicado a la VI Condesa de Lemos, Catalina de Zúñiga y Sandoval. El primero estaba dirigido a las monjas del Convento de Santa Clara de Montilla (Córdoba) y el segundo a los clérigos de Monforte de Lemos (Lugo). La revisión de las lecturas de género que se han llevado a cabo de El arte Tripharia en los estudios musicológicos y el análisis en profundidad de las conexiones entre Catalina de Zúñiga y el Arte de canto llano de Montanos sugieren que el género no era un criterio determinante en la categorización de los potenciales usuarios de estos libros de música, como hasta ahora se creía, y que, por tanto, libros como El arte Tripharia no pueden considerarse fuente del conocimiento musical esperable de la mujer del siglo XVI. Dado que ninguno de estos dos libros dedicados a mujeres iban dirigidos exclusivamente a mujeres, no pueden ser utilizados como fuente para contribuir a los debates en torno a la representación de la mujer en obras artísticas y literarias patrocinadas por mujeres.

En este Capítulo se da noticia de la existencia de un ejemplar de la edición príncipe de 1550 (que hasta ahora se pensaba perdida) de El arte Tripharia de Juan Bermudo en la Biblioteca de la Universidad de Oviedo, a partir del cual Barbieri realizó en el siglo XIX el facsímile que se conserva en la Biblioteca Nacional de España, única copia que se utilizaba hasta ahora. El Libro primero y El arte Tripharia de Juan Bermudo estaban diseñados para utilizarse en niveles educativos diferentes, por lo que no deberían tomarse como fuente del modo en que los tratadistas concebían la educación musical destinada a hombres y mujeres, respectivamente, ni como evidencia de prejuicios de género o de la inferioridad de las mujeres en la teoría musical renacentista. El arte Tripharia de Juan Bermudo no es un ejemplo de libro patrocinado o encargado por una mujer, puesto que fue publicado gracias a la ayuda de amigos y parientes de Bermudo y no

\footnotetext{
${ }^{165}$ Antonio Castillo Gómez, Escrituras y escribientes: prácticas de la cultura escrita en una ciudad del Renacimiento (Las Palmas de Gran Canaria: Gobierno de Canarias, Fundación de Enseñanza Superior a Distancia de Las Palmas de Gran Canaria, 1997), p. 333.
} 
fue un encargo explícito de Isabel Pacheco. Tampoco es un libro diseñado exclusivamente para mujeres, sino concebido como un manual introductorio para lectores de ambos géneros (por ejemplo, los primeros once capítulos de El arte Tripharia se tradujeron al catalán para insertarse en el Ordinarium Barcinonense de 1569). En El arte Tripharia Bermudo remite a los lectores a sus otros libros para ampliar conocimientos, lo que conduce a descartar la hipótesis de que el autor estaba limitando la educación musical de las mujeres (en este caso monjas) a los contenidos de este manual, como se ha señalado en la bibliografía previa. Las vidas de monjas muestran que los conocimientos musicales de algunas monjas músicas iban más allá de los contenidos elementales de $E l$ arte Tripharia de Juan Bermudo.

Este Capítulo presenta el primer estudio musicológico de la relación hasta ahora inadvertida de Catalina de Zúñiga con el Arte de canto llano de Montanos, y se analiza en profundidad la edición príncipe de este libro, raramente citada en la bibliografía musicológica moderna; Roel del Río afirmaba en su Institucion harmonica de 1748 haber copiado algunas piezas del Propio de la Misa de esta edición de 1594 del libro de Montanos. La publicación del Arte de canto llano de Montanos no fue una reimpresión con fin comercial de la parte más popular de su Arte de musica theorica y pratica llevada a cabo en el siglo XVII tras la muerte de Montanos, sino una publicación concebida por el propio autor con un propósito determinado: mejorar la formación musical del clero gallego. Como Bermudo en El arte Tripharia, Montanos concibió su Arte de canto llano de 1594 como una introducción, remitiendo a los lectores a su libro más extenso, el Arte de musica, para ampliar conocimientos. Como los libros de Bermudo, los de Montanos no pueden tomarse como evidencia de desigualdades en la educación musical de mujeres y hombres por el hecho de que el Arte de musica fuese dedicado al Conde de Lemos y la reedición de su primera parte, el Arte de canto llano, se dedicara a su esposa. Con la dedicatoria de Montanos se ponía de manifiesto el celo de la Condesa por la celebración del Oficio Divino con la solemnidad necesaria.

El texto de la dedicatoria de Montanos a Catalina de Zúñiga proporciona evidencia de una etapa gallega de Montanos desconocida hasta el momento en la que trabajó como capellán y maestro de la capilla del Conde de Lemos en Monforte. Además, a través de un documento inquisitorial de 1583, he identificado al inglés Juan Sherwin, "músico de violones de arco y flautas", como uno de los integrantes de la capilla musical del Conde de Lemos en Galicia. En este Capítulo sugiero que posiblemente Montanos fuese hermano de Marcelo de Montanos, el platero del siglo XVII que, procedente de Valladolid, se afincó en Orense para trabajar en las arquetas de San Rosendo y San Torcuato del Monasterio de Celanova. Un soneto de Lomas Cantoral que aparece en el Arte de musica theorica y pratica (1592) en alabanza al libro de Montanos había sido publicado previamente entre las obras de Lomas Cantoral en 1578. La reutilización en la obra de Montanos (1592) de un poema al cabo de catorce años de su publicación (1578) abre la ventana a la especulación sobre la fecha real en la que Montanos ya tenía listo su tratado, y sobre la posibilidad de que, debido a las dificultades en el proceso de publicación, tardase más de una década en salir a la luz. El ejemplar del Arte de musica theorica y pratica de la Universidad Complutense de Madrid incluye una página impresa (que no aparece en otros ejemplares) en la que Montanos se dirige a Francisco Montero, maestro de capilla de la Catedral de Valladolid. Montero debió de ocupar este puesto al menos desde 1589 y antes había trabajado como maestro de capilla en la Colegiata de Talavera de la Reina. Además de proporcionar detalles sobre la actividad de Montanos como maestro de capilla en Monforte, en este Capítulo menciono por primera vez la existencia de un libro de madrigales a cuatro voces de "Montano" que aparece en 
el inventario de 1575 del librero sevillano Francisco de Aguilar entre una serie de libros de música impresa; ese libro hasta ahora desconocido podría relacionarse con la licencia solicitada en 1565 por Montanos para imprimir cuatro libros de madrigales.

La exploración del material preliminar del Arte de canto llano de Montanos y de otros libros dedicados a Catalina de Zúñiga, así como el estudio del contexto en que fue publicada la obra, indican que la dedicataria debió de costear la impresión del libro. El escudo de la portada es el de la familia Zúñiga y no el de su marido, el Conde de Lemos. Los términos utilizados por Montanos en su dedicatoria a la Condesa son muy similares a los usados por Martínez de Bizcargui y Torres en las dedicatorias de sus libros a altos cargos de la jerarquía eclesiástica. Es curioso que la "inteligencia y carácter enérgico" de Catalina de Zúñiga fuesen calificados de "varoniles" en documentos de la época y en biografías posteriores del Conde de Lemos. Otros libros dedicados a Catalina de Zúñiga son relaciones y un tratado de devoción; sólo en el caso de este último, el Tratado espiritval (1604) de Fray Juan de los Ángeles, existe evidencia de que la Condesa costeó la publicación. Es posible sugerir que la Condesa también costease el libro de Montanos, dado que los libros de Montanos y Fray Juan de los Ángeles tenían objetivos similares (explicar a los fieles el significado de la ceremonia de la Misa, y que los clérigos comprendieran la solemnidad del Oficio Divino y se formaran para ello).

El Arte de canto llano de Montanos podría asociarse a una institución educativa en cuya fundación la Condesa desempeñó un papel importante: el Colegio Jesuita de Monforte de Lemos. Las obras de construcción del colegio comenzaron en 1593, justo cuando se obtuvieron el privilegio real y la aprobación para imprimir el libro de Montanos. En una carta de 1595, Diego García, prefecto de estudios del Colegio, sugirió la fundación de una cátedra de canto en el Colegio, alegando (como hacía Montanos en su dedicatoria) la falta de formación musical del clero gallego. El libro de Montanos se reimprimió en 1598, sin la dedicatoria a la Condesa, que es sustituida por una dedicatoria a la Virgen María en la que se hace referencia a Montanos en tercera persona; sugiero la posibilidad de que Catalina hubiese tomado la iniciativa de esta reimpresión de 1598, el mismo año en que asumió la tarea de coordinar las obras del Colegio. La relación de los Condes de Lemos y Montanos evidencia, por tanto, una activa vida musical en las casas nobles y su entorno.

Catalina de Zúñiga probablemente ordenó y patrocinó la publicación del Arte de canto llano de Montanos como parte de su programa de mecenazgo religioso. La dedicatoria de un arte de canto funcionó como una forma de manifestación pública de la religiosidad de la Condesa. En este Capítulo se compara el misticismo con el mecenazgo musical femenino. Los logros de las místicas reforzaban el control de la Iglesia. De modo similar, Catalina de Zúñiga seguramente promovió un influyente manual de canto llano reimpreso durante un siglo y medio (podría tratarse del único libro de música del siglo XVI que conocemos promovido o patrocinado por una mujer), pero esta acción "pública" en la creación de cultura musical tuvo lugar en el espacio religioso, es decir, el socialmente aceptado para las mujeres, lo que reforzaba el comportamiento prescrito por los hombres en sus tratados de conducta femenina. Excepto El arte Tripharia, todos los manuales conocidos de música instrumental (que contenían música secular) publicados en el mundo ibérico del XVI fueron dedicados a hombres (véase el Apéndice 16). Las mujeres eran mecenas religiosas, aunque esta actuación en el ámbito oficial no impidió poseyeran instrumentos musicales y trabajaran como instrumentistas más allá de la corte y el convento; por ejemplo, el único libro de música encontrado en el inventario de bienes de Catalina de Zúñiga no es un arte de canto, sino un libro de música y danza en italiano. 


\title{
CAPÍTULO VI \\ VISIBILIZAR AL OTRO: \\ ÁREAS DE SUPERPOSICIÓN COMO PUNTOS DE VISUALIZACIÓN
}

\begin{abstract}
[Isabel la Católica] hizo tocar a doña Juana en un claviórgano un himno religioso, y cantar a D. ${ }^{a}$ María, acompañándola su hermana, unos villancicos de Juan de la Encina [...]. ${ }^{1}$
\end{abstract}

La necesidad de buscar testimonios dispersos en fuentes documentales acerca del estatus musical femenino en el mundo ibérico renacentista se relaciona con el "fenómeno de invisibilidad de las mujeres", es decir, su omisión sistemática en documentos históricos como si, en palabras de Jay Kleinberg, "sólo los hombres hubiesen participado en eventos que merece la pena conservar". ${ }^{2}$ El propósito de este Capítulo es afrontar la invisibilidad femenina a través del estudio de conexiones entre mujeres y libros de música que van más allá de la dedicatoria (objeto del Capítulo anterior), como son: las mujeres como autoras, impresoras y propietarias de libros de música. Mi hipótesis es que las áreas en que se produce una superposición entre lo privado y lo público, o entre lo oral y lo escrito, permiten vislumbrar prácticas musicales femeninas y vestigios de la cultura musical de la época. Este Capítulo se estructura en dos partes. En la primera, mostraré que cuando los límites entre lo privado y lo público se difuminan aparecen indicios de mujeres trabajando en los campos tradicionalmente masculinos de la creación musical y la imprenta de libros de música. En la segunda sección presentaré

\footnotetext{
${ }^{1}$ Luis Coloma, Fray Francisco: narración histórica (Madrid: Editorial Razón y Fe, 1929), p. 172. Se trata de la narración de la visita del Cardenal Francisco Jiménez de Cisneros a las dependencias privadas de los hijos de Isabel la Católica.

${ }^{2}$ Kleinberg, ed., Retrieving Women's History, p. ix: "Historians searching for evidence about women's history have encountered the phenomenon of women's invisibility; women have been systematically omitted from accounts of the past. This has distorted the way we view the past; indeed it warps history by making it seem as though only men have participated in events thought worthy of preservation and by misrepresenting what actually happened".
} 
artes de canto y cancioneros poéticos como artefactos materiales que, por preservar el contemporáneo entrecruzamiento de tradición oral y cultura escrita, actúan como testimonio de la participación de la mujer en procesos musicales. En los últimos años han proliferado los estudios sobre mujeres y música, y este Capítulo reúne a mujeres que participaron activamente en diversas facetas de la cultura musical del mundo ibérico renacentista. La Tabla VI.1 presenta un listado de las mujeres mencionadas en este Capítulo; el Apéndice 20 reúne a todas las mujeres a las que se hace referencia en esta investigación.

Tabla VI.1: Mujeres del mundo ibérico vinculadas a la música mencionadas en el Capítulo VI

$\begin{array}{ll}\text { Apartados } & \text { Mujeres }\end{array}$

1. La superposición de los ámbitos privado y público: compositoras e impresoras

1.1. ¿Mujeres autoras de libros de música? El caso de Gracia Baptista

Gracia Baptista

1.1.1. El marco conceptual en torno al Libro de cifra nueua (Alcalá de Henares, 1557) de Luis Venegas de Henestrosa

1.1.2. "Gracia Baptista, monja"

Teresa de Jesús (1515-1582)

1.1.3. Gracia Baptista, compositora: las técnicas de cantus firmus en los himnos Conditor alme de Gonzalo de Baena (1540), Juan Bermudo (1555) y Gracia Baptista (1557)

1.1.4. Lo privado y lo público, lo religioso y lo secular en los conventos de

Aguiar y Saavedra, Isabel clausura: el Monasterio de la Piedad de Guadalajara

Arellano, María de

Cimbrón, Margarita

Clavijo, Ana María

Clavijo, María

Contreras, Antonia de

Encarnación, Mariana de la (1571-1657)

Mantilla, María

Martínez, Francisca

Martínez, Juana

Olivares, Antonia de

Toledo, Antonia de 


\begin{tabular}{|c|c|}
\hline Apartados & Mujeres \\
\hline $\begin{array}{l}\text { 1.1.5. Compositoras y maestras en otras } \\
\text { esferas femeninas }\end{array}$ & $\begin{array}{l}\text { Alba, Álvara de } \\
\text { Austria, Margarita de }(1480-1530) \\
\text { Borja, Tecla de (1435-1459) } \\
\text { Méndez de Zurita, Laurencia }(\dagger 1599 / 1600) \\
\text { Morella, Juana/Juliana (nacida c. 1595) } \\
\text { Morillas, Cecilia (c. 1530-1581) } \\
\text { Nacimiento, Sor Cecilia del }(1570-1646) \\
\text { Portugal, María de (1521-1577) } \\
\text { San Alberto, Sor María de }(1568-1640) \\
\text { Sigea, Ángela } \\
\text { Sigea, Luisa (1522-1560) } \\
\text { Vicente, Paula (1519-1576) }\end{array}$ \\
\hline 1.2. Mujeres impresoras de libros de música & $\begin{array}{l}\text { Muñoz, Susana } \\
\text { Ramírez, María } \\
\text { Solórzano, María de }\end{array}$ \\
\hline \multicolumn{2}{|l|}{$\begin{array}{l}\text { 2. La superposición de tradición oral y cultura } \\
\text { escrita: artes de canto y cancioneros }\end{array}$} \\
\hline 2.2. Libritos de mujeres y artes de canto & $\begin{array}{l}\text { Celenque, Ana } \\
\text { Fernández de Córdoba, Elvira }(\dagger 1524) \\
\text { Isabel I de Castilla (1451-1504) } \\
\text { Manrique, María, Duquesa de Terranova (†1527) } \\
\text { Monroy, Lucía } \\
\text { Sámano, Catalina de }\end{array}$ \\
\hline 2.3. Cancioneros poéticos como libros de música & $\begin{array}{l}\text { Clara Eugenia } \\
\text { Nacimiento, Sor Cecilia del }(1570-1646) \\
\text { Portugal, Isabel de }(1470-1498) \\
\text { Salazar, Alfonsa de }(† 1639 / 1641) \\
\text { Teresa de Jesús }(1515-1582)\end{array}$ \\
\hline
\end{tabular}




\section{LA SUPERPOSICIÓN DE LOS ÁMBITOS PRIVADO Y PÚBLICO: COMPOSITORAS E IMPRESORAS}

“Esfera pública” es una construcción teórica creada por Jürgen Habermas. ${ }^{3}$ Una de las críticas que ha recibido este marco teórico es su falta de reconocimiento de interconexiones entre lo privado y lo público. ${ }^{4}$ Autoría e impresión de libros son dos vinculaciones elusivas entre mujeres y libros de música que se vuelven visibles precisamente cuando se produce una superposición entre los ámbitos privado y público. En el apartado 1.1 de este Capítulo expondré las dificultades afrontadas cuando se lleva a cabo una aproximación a las mujeres del siglo XVI como compositoras, usando como ejemplo la excepcionalidad del caso de Gracia Baptista, la única mujer conocida en el mundo ibérico renacentista cuya producción musical llegó a la imprenta. Con este caso pretendo evidenciar la necesidad de reconocer la rareza del pasado, ${ }^{5}$ puesto que una de las razones de la invisibilidad de las mujeres músicas en registros históricos podría residir en la utilización de conceptos anacrónicos de compositor, autor y texto auténtico, así como en la excesiva concentración en producciones musicales escritas. Por ejemplo, Thomasin K. LaMay sugiere que la causa principal de que mujeres compositoras como Francesca Caccini y Barbara Strozzi hayan obtenido reconocimiento histórico es que "cogieron la pluma y se comportaron como hombres (los historiadores podían medir su producción), y no porque pudieran haber sido parte de una cultura musical más amplia que incluía a las mujeres". ${ }^{6}$ Cabe preguntarse qué tenía de especial Gracia Baptista para que una obra suya sea el único caso conocido de publicación de música compuesta por una mujer del mundo ibérico renacentista. En el apartado 1.2 examinaré la invisibilidad de las mujeres impresoras de artes de canto, argumentando que es problemático estimar el papel

\footnotetext{
${ }^{3}$ Jürgen Habermas, Strukturwandel der Öffentlichkeit: Untersuchungen zu einer Kategorie der bürgerlichen Gesellschaft (Neuwied: Luchterhand, 1962).

${ }^{4}$ Smith, The Emerging Female Citizen, p. 4.

${ }^{5}$ Darnton, The Great Cat Massacre, p. 4: "constantemente necesitamos sacudirnos un falso sentido de familiaridad con el pasado, administrarnos dosis de shock cultural" ["we constantly need to be shaken out a false sense of familiarity with the past, to be administered doses of culture shock"].

${ }^{6}$ Véase Thomasin K. LaMay, ed., Musical Voices of Early Modern Women. Many-Headed Melodies (Aldershot: Ashgate, 2005), p. 3: "I suspect that they were initially permitted the nod of historical acknowledgement primarily because they seized the pen and behaved like men (historians could measure their output), and not because they may have been part of a larger musical culture which included women".
} 
desempeñado por hombres y mujeres, respectivamente, en el negocio de la imprenta, dada la tradicional unión de hogar y negocio característica de los talleres artesanos.

\section{1. ¿Mujeres autoras de libros de música? El caso de Gracia Baptista}

[...] que se lleuo el dicho libro a el doctor majuelo y que dixo quel libro no tenia cosa mala mas que en ser obra de muger no era bien que se imprimiese $[\ldots]^{7}$

Lisa Vollendorf sostiene que en torno a 1580 se produjo un cambio en la vida de las mujeres españolas, puesto que a partir de entonces cada vez más escritoras publicaron sus libros y los introdujeron en el mercado. ${ }^{8}$ Parece que esta transformación no encontró una contrapartida en el ámbito musical, dado que todos los autores conocidos de artes de canto o de cualquier otra tipología de libros de música impresos en el mundo ibérico del siglo XVI son hombres. Sin embargo, parece probable que también mujeres, especialmente monjas, crearan o compilaran música y manuales de música. ${ }^{9}$ Un caso que sugiere esta posibilidad es el de la monja Gracia Baptista, considerada la primera mujer europea cuya música fue publicada y la autora de la más temprana pieza para tecla creada por una mujer que ha llegado hasta nosotros. ${ }^{10} \mathrm{Su}$ himno a tres voces Con-

\footnotetext{
7 "Proceso de fe de Isabel Ortíz", Madrid, Archivo Histórico Nacional, Sección Inquisición, legajo 104, expediente 5, f. 21r, Declaración del Licenciado Miguel Majuelo, 30 de mayo de 1564.

${ }^{8}$ Vollendorf, The Lives of Women, p. 3.

${ }^{9}$ Evangelisti, Nuns, p. 101, señala que había religiosas con los contactos sociales necesarios para publicar sus escritos ["Not surprisingly, the nuns who had the skill, motivation, and social connections to become published authors were members of the convent elite, and held the most prestigious offices"].

${ }^{10}$ Encontramos ejemplos de mujeres relacionadas con el mundo ibérico de las que se conserva música manuscrita, como Margarita de Austria (1480-1530), viuda del Príncipe Juan, de la que se conserva el motete-chanson "Se je souspire" en un "chansonnier" manuscrito creado para ella en torno a 1516, que también contiene algunos poemas escritos por ella con música de Pierre de la Rue; véase Martin Picker, "Margaret of Austria (1480-1530)", en Women Composers: Music Through the Ages, ed. por Sylvia Blickmand y Martha Furman Schleifer (Nueva York: G. K. Hall, 1996), vol. 1, pp. 88-97. Se trata del manuscrito Bruselas, Bibliothèque Royale, MS 228. Véase Herbert Kellman, ed., The Treasury of Petrus Alamire: Music and Art in Flemish Court Manuscripts, 1500-1535 (Ghent y Amsterdam: Ludion, 1999). Esta pieza apoya la hipótesis de Higgins, "The 'Other Minervas"”, p. 182, según la cual algunas mujeres nobles mostraban una comprensión de la música más allá de su imagen de "promotoras pasivas de la obra de hombres de talento" ["passive promoters of the work of gifted men"]. Un caso posterior es el de María Bárbara de Bragança (Lisboa, 1711-Madrid, 1758), Princesa de Asturias, hija de João V de Portugal y esposa de Fernando VI, que fue alumna de Domenico Scarlatti. Como anexo de su testamento se encuentra una lista de las doce piezas para tecla que compuso; véase el "Testamento e inventario de bienes de la reina María Bárbara de Portugal”, Madrid, Biblioteca del Palacio Real, II/305. En Pedro Vaz Rego, Armonico Lazo, con que se une una Metrica Correspondencia de Portugal a Castilla, sobre assumpto digno de la mas sublime estimacion. Recogido por un Apassionado de las Musas (s.1., [1731]), se recoge un
} 
ditor alme fue publicado por Luis Venegas de Henestrosa en su Libro de cifra nueua para tecla, harpa, y vihuela (Alcalá de Henares, 1557), una antología impresa consistente en música de compositores ibéricos y extranjeros activos en los ámbitos religioso y cortesano; véase la Ilustración VI.1. Las interpretaciones que se han hecho del Libro de cifra nueua en la bibliografía musicológica constatan en general que el aparato conceptual con el que se ha valorado muestra cierta "familiaridad con el pasado". En esta sección sostendré una doble hipótesis: 1) que el caso de Garcia Baptista se hace visible a los ojos del historiador porque su actividad musical en el ámbito privado se transfirió a la esfera pública de la imprenta, quizás debido a que los conventos eran lugares en que los límites entre lo público y lo privado se difuminaban; y 2) que si bien se ha señalado que sólo a las monjas se les permitía socialmente desempeñar trabajos de docencia y composición musical, la investigación incipiente en otros contextos privados demuestra que no sólo las religiosas podían enseñar música y componer de forma socialmente aceptada.

romance "en Alabanza de la Salve Regina, que compuso en Musica su Alteza Real la Serenissima Princesa de las Asturias (que Dios guarde)". Pedrell, Catàlech de la Biblioteca Musical de la Diputació de Barcelona, vol. 1, p. 328, describe a la princesa como una "cèlebre tocadora de clave y compositora distinguida". 
Ilustración VI.1: Conditor alme de Gracia Baptista. Tablatura original en Luis Venegas de Henestrosa, Libro de cifra nueua para tecla, harpa, y vihuela (Alcalá de Henares: Juan de Brocar, 1557), f. 56v. Madrid, Biblioteca Nacional de España, R/598.

La atribución del himno a Gracia Baptista aparece en el índice de contenidos del libro y no encabezando la tablatura.
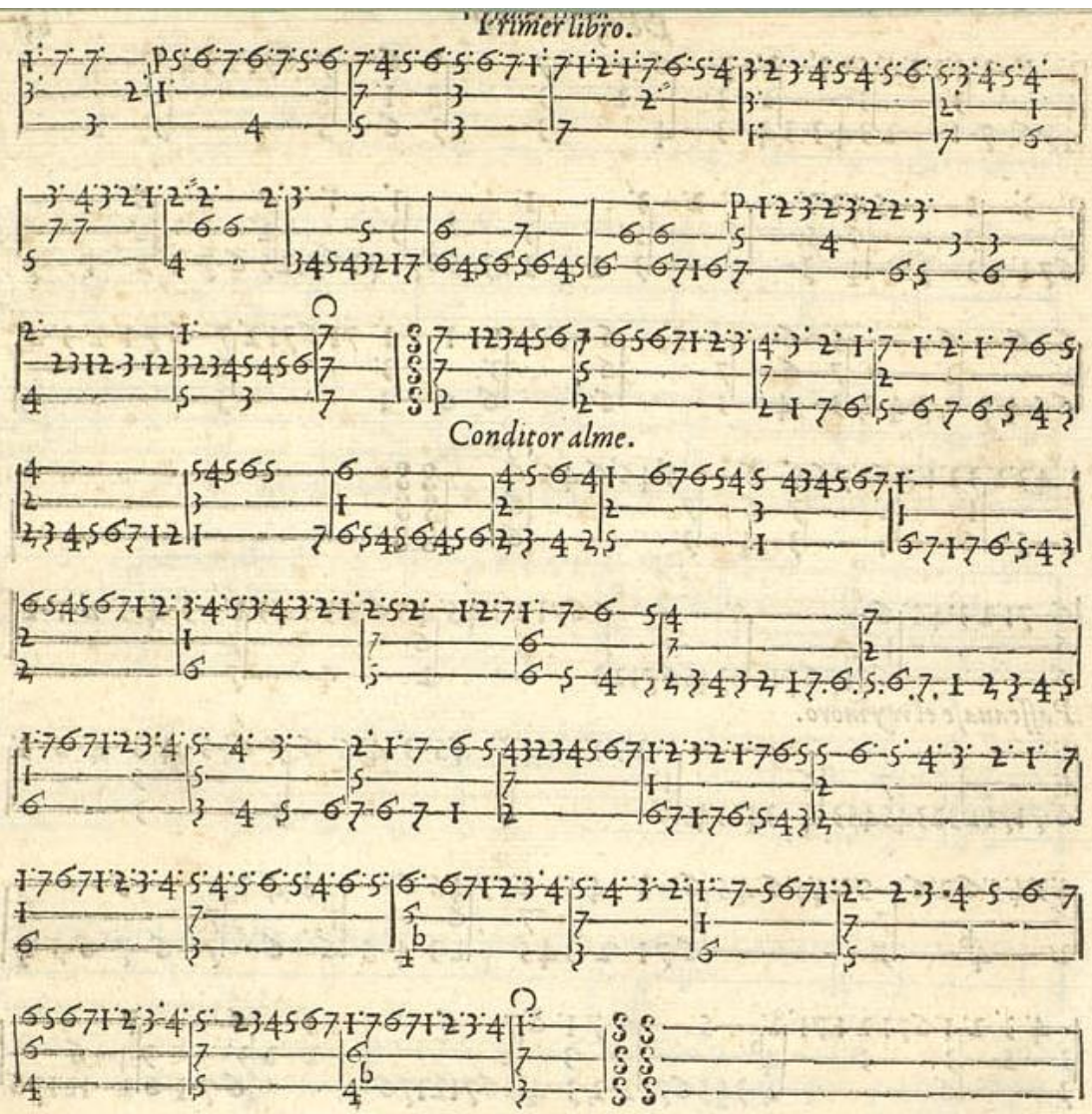

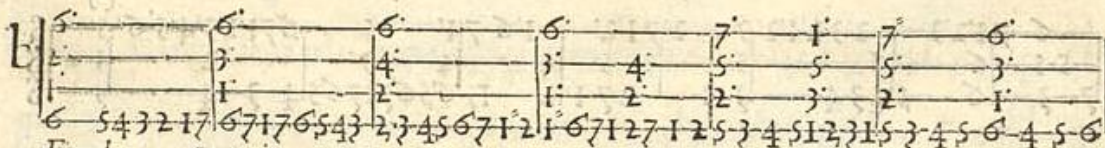
Finales, Antonio

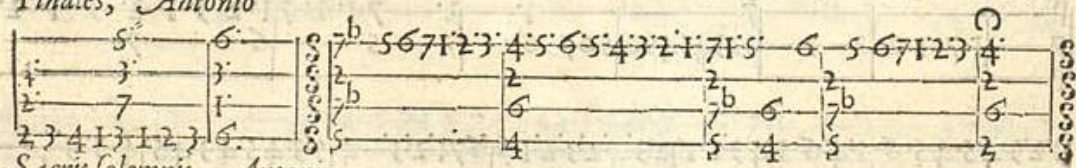

Sacrisfolemnis. Antonio,

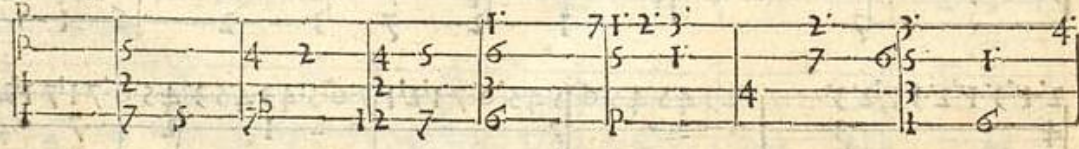




\subsubsection{EL MARCO CONCEPTUAL EN TORNO AL LIBRO DE CIFRA NUEUA}

\section{(Alcalá de Henares, 1557) de Luis Venegas de Henestrosa}

Luis Venegas de Henestrosa (c. 1510-1570), caballero al servicio del Cardenal Juan Tavera, ${ }^{11}$ presentó su Libro de cifra nueua (Alcalá de Henares, 1557) como el primero de siete libros de música que ya había preparado para llevar a la imprenta (incluso proporcionando una descripción general del contenido de los seis restantes) y señalaba entre los potenciales usuarios de su libro a sacristanes y a mujeres que deseaban ser monjas. ${ }^{12}$ Introducido por un conjunto de breves secciones didácticas a modo de artecillas sobre canto llano, canto de órgano, contrapunto, tablatura, vihuela, tecla y arpa, la antología incluye piezas explícitamente atribuidas a Antonio de Cabezón, Nicolás Gombert, Pedro Alberch y Vila, Julius de Modena, Cristóbal de Morales, Francisco Fernández Palero, Francisco de Soto, Josquin des Prez, Juan de Urreda, Luys Alberto, Gracia Baptista, Thomas Crecquillón, Jachet de Mantua, Philippe Verdelot, Jean Mouton y Rogier Patie.

John Ward afirmaba en los años cincuenta del siglo XX que los métodos editoriales de Venegas de Henestrosa iban "de lo respetable a lo irresponsable". ${ }^{13} \mathrm{Si}$, en su edición de 1944 del Libro de cifra nueua, Higini Anglès sugirió atribuir algunas de las piezas anónimas al propio Venegas, ${ }^{14}$ Ward mostró subsecuentemente que las piezas anónimas para vihuela del Libro de cifra nueua habían sido tomadas de los libros de Luis de Narváez, Alonso Mudarra y Enríquez de Valderrábano, y que una fantasía de Francesco da Milano también era incluida por Venegas como anónima. En los casos en que existían otras fuentes de las piezas que permitían el cotejo, Ward concluyó que Ve-

\footnotetext{
${ }^{11}$ Alejandro Luis Iglesias, "Luis Venegas de Henestrosa, Libro de Cifra Nueva", en El siglo de Fray Luis de León. Salamanca y el Renacimiento (Salamanca: Universidad de Salamanca, 1991), pp. 222-224; Cristina Diego Pacheco, "La musique à l'époque de l'empereur. Un nouvel éclairage sur Luis Venegas de Henestrosa et le répertoire pour clavier”, Ibérica, XIII (2001), pp. 65-79.

${ }^{12}$ Venegas de Henestrosa, Libro de cifra nueva para tecla, harpa, y vihuela, f. 3v, "Prologo y argumento de este libro". Es curioso, por tanto, que en su testamento Venegas pidiera a sus albaceas que publicasen "el armonya de los tres mundos", otro libro que decía estar ultimando, y no mencionase los restantes seis libros de tablatura; ¿habrían sido ya impresos? Para una transcripción del testamento de Venegas, véase Louis Jambou y François Reynaud, "Doble enigma en torno a la figura de Luis Venegas de Henestrosa (†1570): su testamento”, Revista de Musicología, VII (1984), pp. 420-430.

${ }^{13}$ John M. Ward, "The Editorial Methods of Venegas de Henestrosa”, Musica Disciplina, VI (1952), pp. 105-113, p. 108: "his editorial methods range from the respectable to the irresponsible".

${ }^{14}$ Higini Anglès, La música en la corte de Carlos V con la transcripción del "Libro de Cifra Nueva para tecla, harpa y vihuela” de Luys Venegas de Henestrosa (Alcalá de Henares, 1557) [Monumentos de la música española, 2] (Barcelona: CSIC, 1984 [1944]), vol. 1, p. 172, nº 27; p. 179, nº 112.
} 
negas había alterado la música introduciendo u omitiendo secciones, añadiendo ornamentos, insertando música nueva o uniendo fragmentos procedentes de piezas diferentes, lo cual "socava completamente la fe del estudioso en los textos conservados en el Libro de Cifra Nueva". ${ }^{15}$ En la misma línea que John Ward, Calvert Johnson, que transcribió y analizó el himno de Gracia Baptista en los años noventa del siglo XX, advertía que, "no habiendo otra fuente con la que comparar la versión del himno de Baptista publicada por Venegas, debemos aceptarla como él la conservó, siendo conscientes, sin embargo, de que ésta podría no ser una interpretación fiel del original”. ${ }^{16}$

Independientemente de las razones que llevaron a Venegas a utilizar procedimientos editoriales considerados "irresponsables" (se ha dicho que no incluyó los nombres de los autores y cambió la música en los casos en que extrajo piezas de libros ya publicados con privilegio real), ${ }^{17}$ cabe preguntarse si el interés por un "texto" original u “obra musical” es apropiado en el caso del Libro de cifra nueua, puesto que éste incluía un repertorio caracterizado por su naturaleza improvisatoria. Por ejemplo, Colleen R. Baade ha señalado para el siglo XVII que los usuarios del tratado Fragmentos musicos (1683) de Pablo Nassarre aprendían a "inventar contrapuntos sin tener que escribirlos" e indica que el himno de Gracia Baptista es "un ejemplo de lo que Nassarre habría llamado un concierto a tres". ${ }^{18}$ El concepto de texto auténtico subordina los deseos del editor a la voluntad del compositor en una época en la que "la propiedad en el libro impreso

\footnotetext{
${ }^{15}$ Ward, "The Editorial Methods of Venegas de Henestrosa", pp. 110-111: "And this, alas, completely undermines the scholar's faith in the texts preserved in the Libro de Cifra Nueva: which pieces are untouched by Venegas, which recast in part, and which are composites?"

${ }^{16}$ Calvert Johnson, "Gracia Baptista: Conditor alme", en Women Composers: Music Through the Ages, ed. por Sylvia Blickmand y Martha Furman Schleifer (Nueva York: G. K. Hall, 1996), vol. 1, pp. 118122, p. 118: "there being no other source with which to compare Venegas's version of Baptista's hymn, we must accept it as he preserves it yet be aware that it may not be a faithful rendition of the original".

${ }^{17}$ Josep Maria Llorens Cisteró, "Venegas de Henestrosa, Luis", en Diccionario de la música española e hispanoamericana, ed. por Emilio Casares Rodicio (Madrid: Sociedad General de Autores y Editores, 1999-2002), vol. 10, pp. 805-806, p. 806.

${ }^{18}$ Baade, "Nun Musicians as Teachers and Students", p. 275: "Like his predecessors, Nassarre applies the word contrapunto to counterpoint devised over a plainchant cantus firmus: contrapunto suelto refers to two-part counterpoint, and contrapunto a concierto to counterpoint involving three, four, or even five voices. Certainly, Nassarre's students were taught to invent contrapuntos without having to write them down: Gracia Baptista's Conditor alme [... -the only published musical work known to have been composed by a Spanish woman, and an example of what Nassarre would have called a concierto a tres- is the kind of piece the pupil described in Baraosain's letter would surely have been able to improvise".
} 
era todavía difusa". ${ }^{19}$ La supremacía decimonónica del genio creativo no funcionaba en esta época; ${ }^{20}$ por ejemplo, Musica Nova (Venecia, 1558-1559) de Adrian Willaert era conocido en Mantua como "La Pecorina", es decir, por el nombre de Polissena Pecorina, la cantante que probablemente popularizó los contenidos del libro en Venecia en la década de 1540, en lugar de por el nombre del compositor o por el título de su obra. ${ }^{21}$

El énfasis excesivo en producciones musicales escritas y en la fidelidad textual podría haber conducido a una infravaloración de la antología de Venegas como fuente musicológica, de modo que las interesantes cuestiones que podría plantear sobre la vida musical de la época habían pasado inadvertidas. Por ejemplo, Josemi Lorenzo Arribas sugiere que Venegas no ofrecía justificación alguna por incorporar música de una mujer, lo cual podría sugerir que incluir música de mujeres en antologías publicadas en el mundo ibérico no era una práctica extraordinaria, o bien que la cuestión del género de los compositores no era un tema al que se prestara el mismo tipo de atención que se le presta hoy. ${ }^{22}$ Esto lleva a pensar que quizás nuestras categorías contemporáneas de género no funcionaban de la misma manera en el siglo XVI o bien existían criterios más relevantes para categorizar a las personas, lo que enlazaría con la problemática planteada en el Capítulo V.

El himno de Gracia Baptista también ha sido estudiado desde una perspectiva feminista. Josemi Lorenzo Arribas lleva a cabo un análisis de los "procesos desautorizadores" que entran en juego en la pieza. Lorenzo Arribas sostiene que la ausencia del nombre de la compositora encabezando la tablatura (véase Ilustración VI.1) y los erro-

\footnotetext{
${ }^{19}$ Davis, The Gift in Sixteenth-Century France, pp. 76-77.

${ }^{20}$ Acerca de la controversia en torno al surgimiento de la idea de "obra musical", véanse Lydia Goehr, The Imaginary Museum of Musical Works: An Essay in the Philosophy of Music (Oxford: Clarendon Press, 1992); y Reinhard Strohm, "Looking Back at Ourselves: The Problem with the Musical WorkConcept", en The Musical Work. Reality or Invention?, ed. por Michael Talbot (Liverpool: University of Liverpool Press, 2000), pp. 128-152.

${ }^{21}$ David Butchart, “'La Pecorina' at Mantua, Musica Nova at Florence”, Early Music, XIII/3 (1985), pp. 359-366, p. 360: "Parece posible inferir de estas cartas que la colección manuscrita que Alfonso d'Este compró en diciembre de 1554 se llamaba, o era conocida como, 'la Pecorina' - como la cantante que probablemente había hecho famoso su contenido en Venecia durante la década de 1540" ["From these letters it seems possible to infer that the manuscript collection which Alfonso d'Este bought in December 1554 was called, or known as, 'la Pecorina' -named after the singer who had probably made its contents famous in Venice during the 1540 s"].

22 Josemi Lorenzo Arribas, "Gracia Baptista, una compositora española del siglo XVI", 8 de marzo, XXVIII (1997), pp. 27-30, p. 30.
} 
res de imprenta que se concentran en su himno dificultando la recepción de la pieza (error en una cifra, intercambio de dos trigramas y errata en la foliación) no son fortuitos, sino resultado del "desprecio" que existía en la época hacia las mujeres músicas y en especial hacia "las organistas religiosas". ${ }^{23}$ Desconocemos, no obstante, si las organistas religiosas eran despreciadas en la época y si realmente el impresor cometió estos errores adrede por este motivo. ${ }^{24}$

¿Cómo conoció Venegas el himno de Gracia Baptista? ¿Circulaba la pieza en manuscritos? ¿Se incluiría en otros libros impresos no conservados actualmente? ¿Se trataba de una música de transmisión no escrita? Si es así, ¿fue el propio Venegas quien la puso en cifra a partir de la interpretación que Gracia Baptista hizo de la pieza? ¿Puso Venegas el himno por escrito tras escucharlo interpretado por otro músico? Esta última posibilidad es de especial relevancia, puesto que indicaría que la pieza, circulara por escrito o por transmisión oral, tenía atribución de autoría, es decir, se conocía como un himno "de" Gracia Baptista. Sin embargo, aunque la investigación de la génesis del Libro de cifra nueua podría arrojar luz sobre las prácticas musicales en general y el estatus musical de las mujeres en particular, ésta se ve desafortunadamente frustrada por la carencia de fuentes documentales que puedan aclarar estas cuestiones.

\subsection{2. "GRACIA BAPTISTA, MONJA"}

El único dato biográfico que se conoce con respecto a Gracia Baptista es que era monja, lo cual se indica en la tabla de contenidos del Libro de cifra nueua de Venegas

\footnotetext{
${ }^{23}$ Josemi Lorenzo Arribas, "La historia de las mujeres y la historia de la música: ausencias, presencias y cuestiones teórico-metodológicas”, en Música y mujeres. Género y poder, comp. por Marisa Manchado Torres (Madrid: Horas y Horas, 1998), pp. 19-37.

${ }^{24}$ En su estudio sobre el virginal construido en 1578 por Hans Bos conservado en el Real Monasterio de Santa Clara de Tordesillas, John Koster señala que, aunque no poseemos información sobre su uso en el convento, la utilización de estos instrumentos en España "era probablemente similar" a la que se hacía en Amberes y en otros lugares de Europa: "los virginales comúnmente eran tañidos por mujeres y chicas de clase media y alta sujetas al ideal virginal de Santa Cecilia". Véase John Koster, "The Virginal by Hans Bos, Antwerp, 1578, at the Royal Monastery of Santa Clara, Tordesillas", en Música de tecla en los monasterios femeninos y conventos de España, Portugal y las Américas / Keyboard Music in the Female Monasteries and Convents of Spain, Portugal and the Americas, ed. por Luisa Morales (Almería: LEAL, 2011), pp. 67-89, p. 82: "We can say nothing about its use at the convent, except to suggest that the use of such instruments in Spain was probably similar to their use in the Spanish Netherlands. That is, in Antwerp and, indeed, in other parts of Europe, both Catholic and Protestant, virginals were commonly played by middle- and upper-class women and girls held to the virginal ideal of St. Cecilia".
} 
de Henestrosa. Aunque no sabemos su lugar de nacimiento, en fuentes secundarias se la describe como una organista española que vivió y trabajó en Ávila en la primera mitad del siglo XVI, y perteneció a la congregación de la escritora mística Santa Teresa de Jesús (1515-1582). ${ }^{25}$ Sin embargo, no he encontrado documento alguno para probarlo, y la idea de que procediera de Ávila podría proceder de un comentario de José Subirá: ${ }^{26}$

La religiosa Gracia Baptista [...] tenía tal habilidad como intérprete que, según ha referido Venegas de Henestrosa, quedó exceptuada por Santa Teresa de la prohibición que la mística doctora había impuesto a las monjas carmelitas, y, en consecuencia, podía tocar música profana al clave o al monacordio. ${ }^{27}$

No sabemos si, con la expresión "según ha referido Venegas de Henestrosa", Subirá podría estar haciendo referencia a una fuente desconocida independiente del propio Libro de cifra nueua, puesto que en éste no se encuentra tal información. Antonio Baciero estudió la vida musical del Convento de la Encarnación de Ávila, en el que Santa Teresa ingresó en 1533, y la vinculación de esta religiosa con la música, a propósito de la reconstrucción del órgano portativo del convento, que fue construido a finales del siglo XV o inicios del XVI y al que las monjas de la institución llamaban "el organito de la Santa". ${ }^{28}$ En este estudio no encontramos alusión a que Santa Teresa hiciera

\footnotetext{
${ }^{25}$ Meg Lota Brown y Kari Boyd McBride, Women's Roles in the Renaissance (Westport y Londres: Greenwood Press, 2005), p. 270; y Antonio Álvarez Cañibano et al., eds., Compositoras españolas: la creación musical femenina desde la Edad Media hasta la actualidad (Madrid: INAEM, Centro de Documentación de Música y Danza, 2008), p. 167. No hay entradas sobre Gracia Baptista en obras de referencia como The New Grove Dictionary o el Diccionario de la música española e hispanoamericana. Rubio, Historia de la música española 2, p. 238, únicamente cita el nombre de la monja entre los compositores incluidos en la antología de Venegas.

${ }^{26}$ Josemi Lorenzo Arribas, "Gracia Baptista, año 1557. La primera compositora europea con obra publicada", Audio Clasica, 146 (2009), pp. 80-85, p. 84, sugiere la posibilidad de que Gracia Baptista tuviera origen andaluz: "No hay ningún indicio que permita especular con procedencia alguna, aunque la abundancia de músicos de la escuela andaluza de teclado en el Libro de cifra nueva (Francisco Hernández Palero, Francisco Peraza...) quizás esté apuntando a una tímida posibilidad estadística".

${ }^{27}$ José Subirá, Historia de la música española e hispanoamericana (Barcelona: Salvat, 1953), p. 273.

${ }^{28}$ Baciero, El Órgano de cámara del Convento de la Encarnación de Ávila. Se conserva correspondencia del siglo XVII entre las monjas de la Encarnación y el compositor Gómez Camargo (1618-1690); véase Olarte, Miguel de Irízar y Domenzain (1635-1684?). El convento de Santa Ana de Ávila sí ha recibido mayor atención en los estudios musicológicos; véanse Vicente Delgado, La música en el Monasterio de Santa Ana de Ávila siglos XVI-XVIII; y "Diez años de investigación musical en torno al Monasterio de Santa Ana de Ávila"; y María Gembero Ustárroz, "De rosas cercada: Music by Francisco de la Huerta for the Nuns of Santa Ana de Ávila (1767-78)", en Devotional Music in the Iberian World, 1450-1800: The Villancico and Related Genres, ed. por Tess Knighton y Álvaro Torrente (Aldershot: Ashgate, 2007), pp. 321-362.
} 
referencias a la música instrumental, ni tampoco mención a Gracia Baptista. La única alusión a la compositora aparece en el comentario de Baciero de la grabación que él mismo hizo del himno en 1982 (véase Tabla VI.2): “'Gracia Baptista, monja' es todo lo que sabemos de su autora en la referencia de Venegas". ${ }^{29}$ Soterraña Aguirre señala que en un instrumento similar al de la Encarnación “debió de ejecutar y componer 'Gracia Baptista, monja' su himno de adviento titulado Conditor alme". ${ }^{30}$

Tabla VI.2: Grabaciones del himno Conditor alme de Gracia Baptista

\begin{tabular}{|c|c|c|c|c|}
\hline & Título & $\begin{array}{l}\text { Publicación y } \\
\text { formato }\end{array}$ & Intérprete & $\begin{array}{l}\text { Instrumento } \\
\text { utilizado }\end{array}$ \\
\hline 1978 & $\begin{array}{l}\text { Le Siècle d'Or du Clavier } \\
\text { Espagnol. Cabezon-Palero- } \\
\text { Mudarra-Soto }\end{array}$ & $\begin{array}{l}\text { Barcelona, } \\
\text { Edigsa; LP. }\end{array}$ & Pablo Cano & Clave \\
\hline 1982 & $\begin{array}{l}\text { Música organística española del } \\
\text { s. XVI }\end{array}$ & $\begin{array}{l}\text { Madrid, Hispa- } \\
\text { vox; LP. }\end{array}$ & $\begin{array}{l}\text { Antonio } \\
\text { Baciero }\end{array}$ & $\begin{array}{l}\text { Órgano del } \\
\text { monasterio de la } \\
\text { Encarnación de } \\
\text { Ávila }\end{array}$ \\
\hline 1993 & Go Tell It on the Mountain & $\begin{array}{l}\text { Ithaca, Calcante } \\
\text { Recordings; CD. }\end{array}$ & $\begin{array}{l}\text { Calvert } \\
\text { Johnson }\end{array}$ & Órgano \\
\hline 1997 & $\begin{array}{l}\text { Música de la Puebla de los } \\
\text { Ángeles: Music by Women of the } \\
\text { Mexican, Cuban, and European } \\
\text { Baroque }\end{array}$ & $\begin{array}{l}\text { Nannerl Re- } \\
\text { cords; CD. }\end{array}$ & $\begin{array}{l}\text { Ars Femina } \\
\text { Ensemble }\end{array}$ & Clave \\
\hline 1998 & $\begin{array}{l}\text { Venegas de Henestrosa-Libro } \\
\text { de Cifra Nueva }\end{array}$ & $\begin{array}{l}\text { Stradivarius; } \\
\text { CD. }\end{array}$ & Paola Erdas & Clave italiano \\
\hline 2006 & $\begin{array}{l}\text { Women Composers for Organ } \\
\text { Music Spanning Five Centuries }\end{array}$ & $\begin{array}{l}\text { Jaffrey, Gasparo } \\
\text { Records; CD. }\end{array}$ & $\begin{array}{l}\text { Barbara } \\
\text { Harbach }\end{array}$ & Órgano \\
\hline
\end{tabular}

\footnotetext{
${ }^{29}$ Baciero, El Órgano de cámara del Convento de la Encarnación de Ávila, p. 90.

${ }^{30}$ Aguirre Rincón, "Sonido en el silencio", p. 300.
} 
Mi investigación acerca de cuál podría ser la fuente de Subirá me ha llevado al estudio Les Clavecinistes, publicado por André Pirro en 1925. Parece probable que Subirá tomara la información de esta fuente secundaria, donde lo que realmente se señala es que "muchos artistas españoles fueron salvados del olvido" por Venegas: por ejemplo, "gracias a" él, "sabemos que Santa Teresa habría podido tolerar las obras de la monja Gracia Baptista cuando prohibió a sus carmelitas clavecinistas el permanecer ligadas a cantos profanos" [mi cursiva]. ${ }^{31}$ Podemos concluir, por tanto, que Venegas no proporcionaba ningún detalle biográfico de Gracia Baptista, con la excepción de su condición de monja. André Pirro vincula a Gracia Baptista muy hipotéticamente ("habría podido tolerar") con la orden Carmelita, y desconocemos si la prohibición de Santa Teresa a "sus carmelitas clavecinistas" figura en algún documento. En los “Avisos espirituales" (Madrid, 1647) de Santa Teresa no he encontrado ninguno referente a la música, y en las "Constituciones de las Carmelitas Descalzas" no aparece alusión alguna a la música instrumental, puesto que sólo se hace referencia al canto y, en concreto, a la prohibición de cantar polifonía (“jamás sea el canto por puntos”). ${ }^{32}$ Así, Santa Teresa prescribía lo siguiente en "Modos de visitar los conventos de religiosas":

\footnotetext{
${ }^{31}$ André Pirro, Les Clavecinistes (París: Henri Laurens, 1925), p. 27: "Beaucoup d'artistes espagnols ont été sauvés de l'oubli par le compilateur. Grâce à lui, nous savons que sainte Thérèse aurait pu tolérer les œuvres de la monja Gracia Baptista, quand elle défendait à ses carmélites clavecinistes de rester attachées aux chants profanes".

32 “Constituciones para las hermanas del Orden de nuestra Señora del Monte Carmelo de la primera regla sin relajación, dadas por el reverendísimo padre fray Juan Bautista Rubeo, general de la dicha Orden, año 1568", en Escritos de Santa Teresa, añadidos e ilustrados por Vicente de la Fuente (Madrid: M. Rivadeneyra, 1861), vol. 1, p. 273: "Los Domingos y dias de fiesta se cante Misa, Visperas y Maytines, y los dias primeros de Pascua, ó otros dias de solemnidad podran cantar Laudes, en especial el dia del glorioso san Alberto. Jamas sea el canto por puntos, sino en tono, las vozes iguales, lo ordinario sea rezado, y tambien la Misa [...]". Dos ejemplos más confirman la prohibición: 1) "Fundación del convento de Carmelitas Descalzas en Sevilla, y persecuciones que padecieron hasta la época de la muerte de Santa Teresa; por la venerable María de San José", en Escritos de Santa Teresa, p. 556: "Mandóse también en este Capítulo, que se le quitase á nuestra Madre las patentes y comisiones, que tenía para fundar, y estuviese reclusa sin salir de un monasterio, y que los Descalzos y Descalzas se calzasen, y cantasen por punto, y otras cosas así"; y 2) Ángel Justiano Carranza, "Ensayo sobre la genealogía de los Tejeda" [continuación], Revista de Buenos Aires: historia americana, literatura y derecho, XVI (1868), pp. 19-30, p. 27: "en la religión, regla y constituciones de la dicha Santa Teresa de Jesús, no se permite órgano ni su canto sino en tono, y habiéndose de conservar con integridad no se atreve su Señoría, á innovar en esto sin dar aviso á su Santidad, y que en el entre tanto que lo concede no se cante canto de órgano por las dichas Monjas aunque bien permite que se celebren las dichas fiestas con canto de órgano por cantores clérigos, o religiosos".
} 
Mirar lo que se dice en el coro ansí cantado, como rezado, y informarse si vá con pausa, y el cantado que sea en voz baja, conforme á nuestra profesion, que edifique, porque en ir altas, hay dos daños; el uno, que parece mal como no vá por punto, el otro, que se pierde la modestia y espíritu de nuestra manera de vivir. Y si en esto no se pone mucho, serlo há la demasia y quita la devocion á los que lo oyen, sino que vayan las voces mas con mortificacion, que con dar á entender que miran en parecer bien á los que las oyen, que esto es casi en general, y parece ya que no ha de tener remedio, sigun está la constumbre, y ansí es menester encargarlo mucho. ${ }^{33}$

Sin embargo, en el relato de su vida, la religiosa utilizaba el concepto de polifonía como metáfora, poniendo de manifiesto su conocimiento de la terminología musical:

Muchas veces lo digo, que por poco que sea el punto de honra, es como en el canto de organo, que un punto, ò compas que se yerre, disuena toda la musica, y es cosa que en todas partes hace harto daño al alma, mas en este camino de Oracion es pestilencia. ${ }^{34}$

La confirmación de un nexo entre Santa Teresa y Gracia Baptista sería fascinante, puesto que relacionaría a dos monjas que ejercieron como autoras en diferentes campos y cuyas obras fueron publicadas (si bien, al menos en el caso de Santa Teresa, póstumamente). No obstante, quizás la de Pirro constituya simplemente una referencia a la monja española más conocida coetánea de Baptista. Carezco de fuentes para confirmar si Gracia Baptista conoció a Santa Teresa, o si perteneció a la orden carmelita (de Ávila o de otro lugar).

Louis Joambou y Colleen R. Baade aportan evidencia documental de que en la mayoría de los conventos castellanos era una de las religiosas la encargada de tocar el órgano. ${ }^{35}$ Es interesante que, en el contexto del Cuzco colonial, Geoffrey Baker señale diferencias entre monasterios femeninos y masculinos con respecto a la existencia de organista: en contraste con los conventos femeninos, los monasterios masculinos no tenían un monje que supiera tocar el órgano, sino que contrataban a músicos externos

${ }^{33}$ Santa Teresa de Jesús, "Modos de visitar los conventos de religiosas", en Escritos de Santa Teresa, p. 296.

${ }^{34}$ Santa Teresa de Jesús, "La vida de la Santa Madre Teresa de Jesus y algunas de las mercedes que Dios le hizo; escritas por ella misma por mandado de su Confessor, à quien lo embia y dirige", en Obras de Santa Teresa de Jesús (Madrid: Editora de los Amigos del Círculo del Bibliófilo, Biblioteca Nacional, 1982), p. 269.

35 Louis Jambou, Evolución del órgano español: siglos XVI-XVIII (Oviedo: Universidad de Oviedo, 1988), 2 vols.; Colleen R. Baade, "Organs and Organists in Female Monasteries in Castilla, c. 14981616", en Cinco siglos de música de tecla española, ed. por Luisa Morales (Almería: Asociación Cultural Leal, 2007), pp. 195-206. 
para que lo hicieran en las ocasiones importantes. ${ }^{36}$ Josemi Lorenzo Arribas sugiere que Gracia Baptista pudo haber sido la maestra de música de su convento, puesto que la organista solía ser la música más cualificada. ${ }^{37}$ Las conclusiones que presenta Colleen R. Baade tras su examen de diversa documentación conventual de la España de la temprana Edad Moderna refuerzan la misma hipótesis: aunque en ocasiones músicos externos acudían al convento para dar lecciones de música, ${ }^{38}$ al no encontrar registros de pago a maestros externos por lecciones de órgano, Baade concluye que había una tradición establecida por la que las propias monjas organistas enseñaban a sus compañeras. ${ }^{39}$ Por ejemplo, Baade presenta el caso de dos organistas berberiscas que trabajaron como maestras en el Convento de San Leandro de Sevilla. ${ }^{40}$ En los conventos tenía lugar una enseñanza musical de carácter informal entre las religiosas, como evidencian las vidas de monjas; por ejemplo, Isabel de Velasco y su hermana Mariana "desde los ocho años enseñaban a leer y cantar a otras, que las llevaban muchos años, y en este santo ejercicio perseveraron hasta morir, porque decían que ellas alababan a Dios con todas aquellas almas, a quien enseñaban". ${ }^{41}$ Por tanto, carecemos de fuentes documentales que propor-

\footnotetext{
${ }^{36}$ Geoffrey Baker, "Music in the Convents and Monasteries of Colonial Cuzco", Latin American Music Review, XXIV/1 (2003), pp. 1-41, p. 13.

${ }^{37}$ Josemi Lorenzo Arribas, Una relación disonante: las mujeres y la música en la Edad Media hispana, siglos IV-XVI (Alcalá de Henares: Ayuntamiento de Alcalá de Henares, 1998), p. 135; y "Mères, muses et religieuses: transmission musicale et magistère féminin au Moyen Âge", L'histoire des femmes en revues: France/Europe, XVI (2002), pp. 167-193, pp. 188-189. Sobre los puestos musicales en los conventos femeninos, véase Luisa Morales, "Keyboards, Feast and Liturgy in Castilian Female Monasteries and Convents During the Early Modern Era", en Música de tecla en los monasterios femeninos y conventos de España, Portugal y las Américas / Keyboard Music in the Female Monasteries and Convents of Spain, Portugal and the Americas, ed. por Luisa Morales (Almería: LEAL, 2011), pp. 1-27.
}

${ }^{38}$ Aguirre Rincón, “Sonido en el silencio”, p. 299; María Julieta Vega García-Ferrer, La música en los conventos femeninos de clausura en Granada (Granada: Universidad de Granada, 2005), p. 215.

${ }^{39}$ Baade, "Nun Musicians as Teachers and Students", p. 265: "Es interesante que no haya encontrado en libros de cuentas registros de pago por lecciones de órgano o para maestros de órgano externos. Esto indica probablemente que, en el siglo XVII (y seguramente incluso antes), había una tradición bien establecida en los conventos de clausura de monjas organistas que enseñaban a otras monjas" ["Interestingly, I have encountered in account books no record of any payments made for organ lessons or for outside organ teachers. This probably indicates that, by the seventeenth century (and surely even earlier), there was a well-established tradition inside the cloister of nun organists teaching other nuns"].

${ }^{40}$ Baade, "Nun Musicians as Teachers and Students", p. 262.

${ }^{41}$ Pinel, Retablo de Carmelitas, p. 188. Véase también Manuel Ramos Medina, "Bibliothèques et lectures de femmes en Nouvelle-Espagne", en Des femmes et des livres: France et Espagnes, XIVe-XVIIe siècle: Actes de la Journée d'Étude organisée par l'École Nationale des Chartes et l'École Normale Supérieure de Fontenay Saint-Cloud (Paris, 30 avril 1998), ed. por Dominique de Courcelles y Carmen Val Julián (París: École des Chartes, 1999), pp. 55-60, p. 57: “Las niñas pequeñas a las que enseñaban las beatas o 
cionen información sobre Gracia Baptista en particular, aunque las investigaciones llevadas a cabo sobre otros casos muestran que había una tradición de monjas organistas y de docencia informal de la música en los conventos.

\subsubsection{GRACIA BAPTISTA, COMPOSITORA: LAS TÉCNICAS DE CANTUS FIRMUS EN LOS HIMNOS CONDITOR ALME DE GONZALO DE BAENA (1540), JUAN BERMUdo (1555) Y GRACIA BAPTISTA (1557)}

El ejemplo de Gracia Baptista sugiere que, como en el caso de los hombres, la labor de docencia musical femenina se relacionaba íntimamente con la creación musical. Usando como fuentes libros de profesiones, actas capitulares, correspondencia y vidas de monjas, Colleen R. Baade y Matilde Olarte han aportado valiosa información sobre las monjas músicas españolas en el siglo XVII que pone de manifiesto que las maestras encargadas de las capillas de música componían música al igual que lo hacían los maestros de capilla. ${ }^{42}$ En el ámbito de la historia del arte, Roberto Longhi muestra la manera en que "un examen profundo de los textos pictóricos puede subsanar la pobreza de la documentación externa". ${ }^{43}$ Debido a la ausencia de otros documentos que nos permitan detallar la biografía de Gracia Baptista, únicamente contamos con su música como fuente de información.

El himno de Gracia Baptista usa la técnica de cantus firmus, situándose éste en la voz del tenor en notas de igual duración. ${ }^{44} \mathrm{Su}$ estilo (preponderancia de movimiento conjunto, evasión de disonancias, cadencias internas y progresiones armónicas) ha sido calificado de "conservador" por Calvert Johnson y visto como "un producto de su tiem-

\footnotetext{
las religiosas eran formadas en la música del culto, en la lectura de las horas litúrgicas y en las prácticas de devoción, así como en los cuidados de la casa y de los niños" ["Les petites filles enseignées par les beatas ou par les religieuses sont formées à la musique cultuelle, à la lecture des heures liturgiques et aux pratiques de dévotion, ainsi qu'aux soins de la maison et des enfants"].

42 Olarte Martínez, “Las 'monjas músicas' en los conventos españoles del Barroco”; Baade, "Nun Musicians as Teachers and Students", p. 275.

${ }^{43}$ Carlo Ginzburg, Pesquisa sobre Piero. El Bautismo. El ciclo de Arezzo. La Flagelación de Urbino (Barcelona: Muchnik Editores, 1984 [1981]), p. xiv.

44 Transcripciones de Conditor alme pueden encontrarse en Anglès, La música en la corte de Carlos V, vol. 2, p. 155; Johnson, "Gracia Baptista"; y Calvert Johnson, ed., Organ Music by Women Composers Before 1800 (Pullman: Vivace Press, 1993), p. 8.
} 
po y lugar". ${ }^{45}$ A excepción del estudio de Calvert Johnson, el himno de Gracia Baptista no ha sido examinado desde una perspectiva analítica. Es más, la pieza fue descrita por Antonio Baciero como sigue: "si es verdad que la obra en cuestión no despliega especiales vuelos, presenta un lirismo amable a todas luces y un 'sentido' expresivo que, según el título de la misma, nos hace otorgarle aquí la atención que merece". ${ }^{46}$ La terminología usada por Baciero es muy similar, como veremos, a la empleada por cronistas del siglo XVII para describir la música de las religiosas basada en los conceptos de lirismo, amabilidad, sentimiento y expresión. La calidad técnica (el despliegue de “especiales vuelos"), por el contrario, se considera baja.

Con el propósito de valorar musicalmente el himno de Gracia Baptista llevaré a cabo en esta sección un análisis del mismo en su contexto musical. La pieza de Gracia Baptista consiste en la ornamentación (glosas) del cantus firmus de Conditor alme, himno para el Oficio de Vísperas de los domingos de Adviento. Aparte de la de Baptista, encontramos otras versiones instrumentales de este himno en fuentes del siglo XVI: 1) "Contrapunto sobre canto llano de la mano izquierda: Conditor alme" y "Contrapunto de la mano derecha sobre canto llano: Conditor alme" publicados en 1540 por Gonzalo de Baena; ${ }^{47}$ y 2) "Conditor alme siderum" publicado en 1555 por Juan Bermudo. ${ }^{48}$ La pieza no aparece en los anteriores libros de Bermudo el Libro primero (1549) y El arte Tripharia (1550), sino que se anexa al libro cuarto (que contiene "la verdadera intelligencia del organo") de la Declaración de instrumentos (1555) entre un conjunto de piezas hechas "aposta para tañer" (aunque se utiliza notación mensural y se indican los nombres de las cuatro voces) que le habían sido solicitadas a Bermudo principalmente "de indias":

\footnotetext{
${ }^{45}$ Johnson, "Gracia Baptista", p. 118: "Although perhaps late medieval in its cantus planus approach, the work is a product of its time and place, for liturgical music in Renaissance and Baroque Spain remained more conservative than elsewhere".

${ }^{46}$ Baciero, El Órgano de cámara del Convento de la Encarnación de Ávila, p. 90.

${ }^{47}$ Baena, Arte nouamente inuentada pera aprender a tanger, ff. 15v-16v. Se ha utilizado la edición de Tess Knighton ya citada.

${ }^{48}$ Bermudo, Declaración de instrumentos, f. 118v. Para una transcripción del himno de Bermudo, véase Stevenson, Juan Bermudo, p. 80.
} 
Digo esta musica ser hecha para tañer, y no para cantar, y que se ha de tañer por donde va puntada: porque a mudarse vna vez faltaran teclas, y otra vez manos. Las señales de teclas negras lleva puestas. El punto que tuuiere señal se porna en la tecla negra, y el otro no: aunque esten en vn signo. $^{49}$

También contamos con versiones vocales con acompañamiento instrumental del himno, como son los motetes a 3 (dos partes instrumentales) de Juan de Anchieta y Marturià Prats conservados en el llamado Cancionero de Segovia. ${ }^{50}$ Según el número de fuentes de que disponemos, parece que Conditor alme no era un canto que se tomase frecuentemente como base en la creación de piezas para tecla en el siglo XVI, como lo fue por ejemplo el himno Pange lingua $;{ }^{51}$ no obstante, se utilizó en numerosas composiciones de polifonía vocal, siendo ejemplos, aparte de los ya mencionados motetes de Anchieta y Prats, las versiones de Guillaume Du Fay, Antoine Busnoys, Jehan Titelouze, Tomás Luis de Victoria, Thomas Morley, Giovanni Pierluigi da Palestrina y Pietro Pontio. El propósito de esta sección es determinar el grado de competencia musical de Gracia Baptista mediante un análisis de su himno, en particular del tratamiento que se hace del cantus firmus, en comparación con las versiones de Gonzalo de Baena y Juan Bermudo. Puesto que el estudio más extensivo hasta la fecha sobre las técnicas de cantus firmus es el llevado a cabo por Edgar H. Sparks, tomaré su distinción entre "elaboración del cantus firmus" y "cantus firmus estructural" como punto de partida para examinar los procedimientos compositivos utilizados en las piezas. ${ }^{52}$

El himno Conditor alme siderum es un texto anónimo del siglo VII que tras la revisión del Breviario Romano en 1632 resultó bastante modificado convirtiéndose en Creator alme siderum, que es como aparece en el Liber usualis (véase Ejemplo musical VI.1). El texto "Conditor alme siderum / eterna lex credentium / Christe redemptor om-

\footnotetext{
${ }^{49}$ Bermudo, Declaración de instrumentos, f. $113 \mathrm{v}$.

${ }^{50}$ Los himnos de Anchieta y Prats se encuentran en el manuscrito Segovia, Archivo de la Catedral, s.s., f. 169 r.

${ }^{51}$ Por ejemplo, en los siete volúmenes de la Nueva biblioteca española de música de teclado: siglos XVI al XVIII (Madrid: Unión Musical Española, 1978-1984) de Antonio Baciero no aparece ninguna pieza sobre Conditor alme.

52 Edgar H. Sparks, Cantus firmus in Mass and Motet, 1420-1520 (Berkeley: University of California Press, 1963). Los estudios de Sparks acerca de los procedimientos de cantus firmus en el siglo XV han sido considerados los más esclarecedores hasta la fecha; véase M. Jennifer Bloxam, "Cantus firmus", en Grove Music Online, ed. por L. Macy (consultado 20-02-2008), <http://www.grovemusic.com>.
} 
nium / exaudir preces supplicum" pasó a ser "Creator alme siderum / Aeterna lux credentium / Jesu, Redemptor omnium / Intende votis supplicum”. Richard Sherr señala que, según Gaffurius, himnos y secuencias son ejemplos de cantos que podrían haberse escrito sin ritmo mensural pero haberse cantado con un ritmo mensural inspirado por la métrica del texto; Conditor alme se menciona como el ejemplo más claro de este fenómeno, puesto que aparece con valores iguales en un manuscrito de Laón del siglo XIII y con notación mensural en fuentes como la versión alternatim de Du Fay en Bolonia, Civico Museo Bibliografico Musicale, MS Q15. ${ }^{53}$ Sherr indica que el catálogo de himnos de Tom R. Ward muestra que prácticamente todas las versiones polifónicas de Conditor alme siderum empiezan haciendo referencia al ritmo ternario. ${ }^{54}$ En las piezas analizadas encontramos diferentes soluciones: Bermudo dispone la melodía Conditor alme en ritmo ternario, Baptista utiliza el canto en valores largos e iguales y Baena emplea valores muy largos pero repetidos, creando una sensación de ritmo ternario sobre el papel; véase el Ejemplo musical VI.2.

\footnotetext{
${ }^{53}$ Richard Sherr, "The Performance of Chant in the Renaissance and Its Interactions with Polyphony”, en Plainsong in the Age of Polyphony, ed. por Thomas Forrest Kelly (Cambridge: Cambridge University Press, 1992) pp. 178-209, p. 189. Véase también Lope de Vega, Laurel de Apolo: con otras rimas (Madrid: Iuan Gonçalez, 1630), silva IV, f. 38r: "En las Endechas muestra / Ser tambien imitado del Latino / El verso Castellano, / Como se vee en el Hymno / (Si bien sin los Esdruxulos mas llano) / Que se canta el Aduiento / En Dimetros, y Iambicos sonoros, / Versos de Ambrosio Santo"; y Richard Hoppin, Medieval Music (Nueva York: W. W. Norton, 1978), p. 111.

${ }^{54}$ Sherr, "The Performance of Chant in the Renaissance and Its Interactions with Polyphony", p. 191: "En realidad, como muestra el catálogo de himnos de Ward, prácticamente todas las versiones polifónicas de Conditor alme siderum empiezan haciendo referencia al ritmo de BolQ 15 y VatS 15" ["Indeed, as Ward's catalogue of hymns shows, practically every polyphonic setting of Conditor alme siderum begins by referring to the rhythm in BolQ 15 and VatS 15"]. Véase Tom R. Ward, The Polyphonic Office Hymn, 1400-1520: A Descriptive Catalogue (Stuttgart: American Institute of Musicology, 1980).
} 
Ejemplo musical VI.1: Creator alme en el Liber usualis, pp. 324-325.
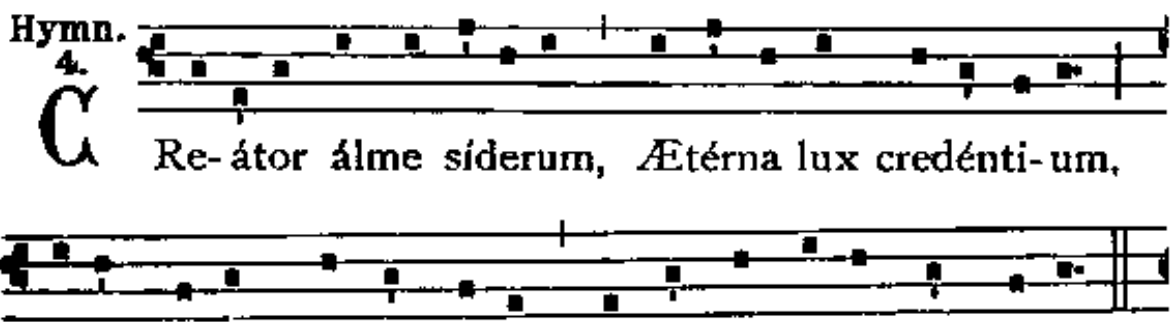

Jésu, Redémptor ómni- um, Inténde vó-tis súppli-cum.

Ejemplo musical VI.2a: Melodía Conditor alme en la versión de Juan Bermudo
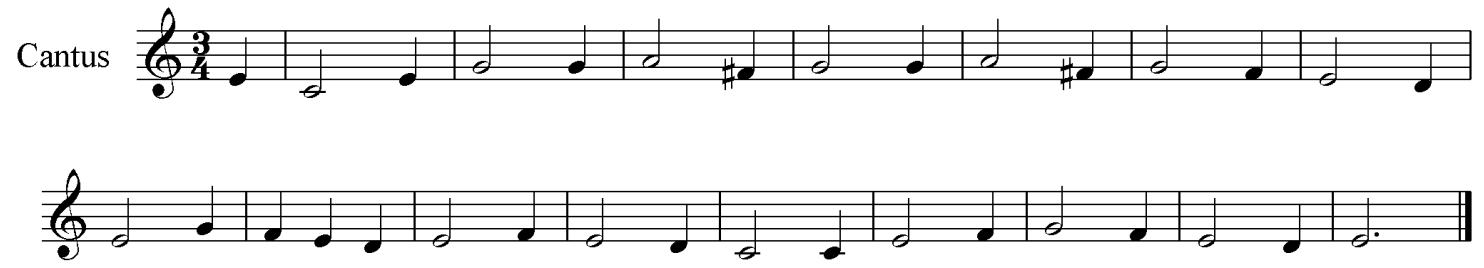

Ejemplo musical VI.2b: Cantus firmus del himno Conditor alme de Gracia Baptista
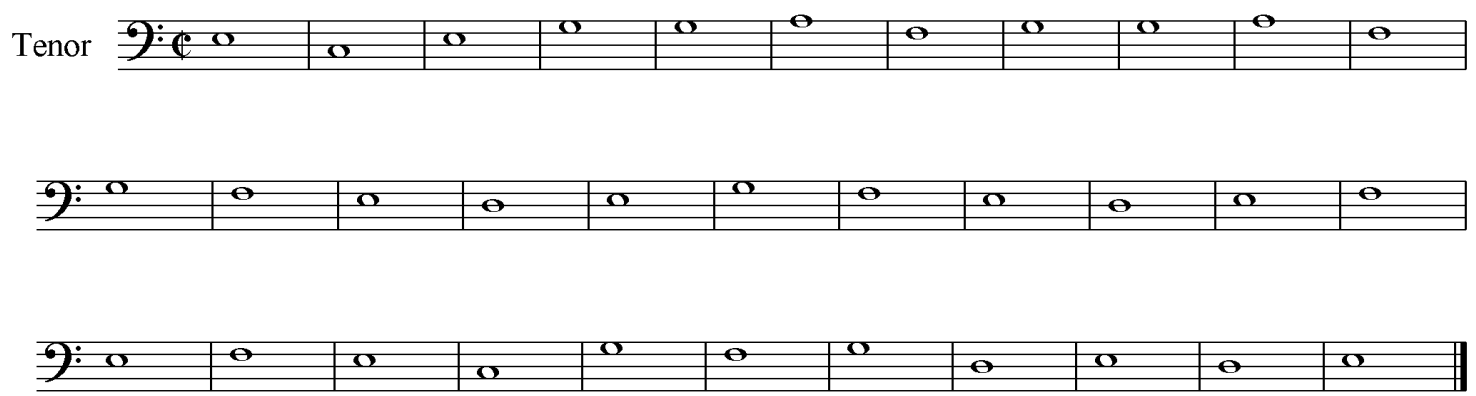
Ejemplo musical VI.2c:

Cantus firmi utilizados por Gonzalo de Baena en sus dos versiones de Conditor alme
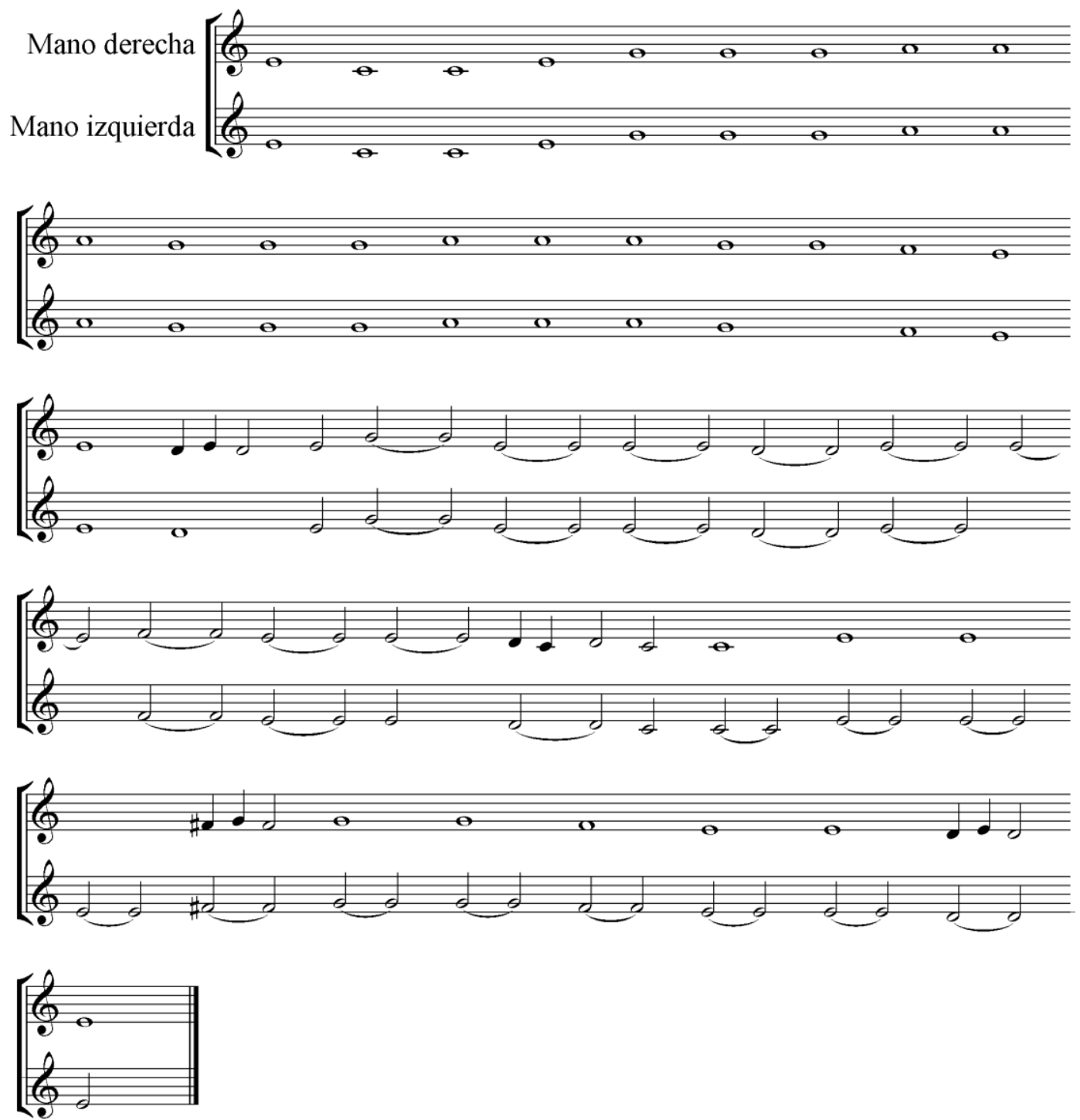
Ejemplo musical VI.2d: Comparación de los cantus firmi utilizados por Juan Bermudo y Gracia Baptista en sus versiones del himno Conditor alme
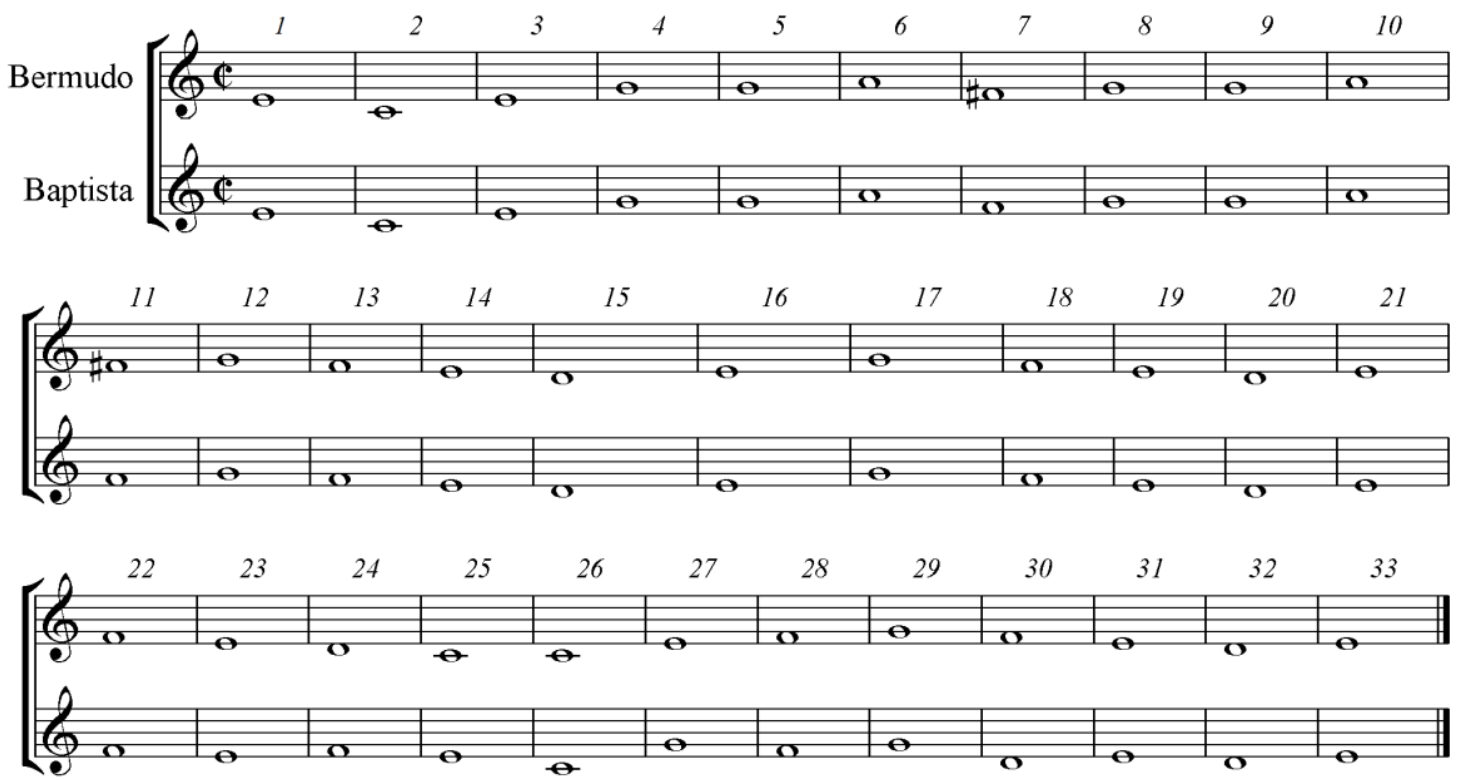

Edgar Sparks identifica dos modos básicos de tratar un cantus firmus en el siglo $\mathrm{XV}:$ 1) la "elaboración del cantus firmus", primero utilizada por compositores ingleses como Lionel Power y John Dunstaple; y 2) el "cantus firmus estructural", que es una práctica más antigua originada en la manipulación de fragmentos de canto llano en las cláusulas sustitutivas del siglo XIII. ${ }^{55}$ Jean-Marc Evans sigue la clasificación de Sparks y distingue dos métodos de tratar una melodía usada como cantus firmus, dependiendo de si ésta aparece en el superius o en el tenor. ${ }^{56}$ Tomando como fuente las distinciones de ambos autores, podemos caracterizar y comparar los dos métodos como muestra la Tabla VI.3.

\footnotetext{
${ }^{55}$ Sparks, Cantus firmus in Mass and Motet, 1420-1520, pp. 42-93.

${ }^{56}$ Jean-Marc Evans, "A Unique Cantus Firmus Usage in a 15th-Century English Mass Movement”, Early Music, XXVI/3 (1998), pp. 469-474, 476-477.
} 


\section{Tabla VI.3: Comparación de los métodos de elaboración del cantus firmus} y cantus firmus estructural

Elaboración del cantus firmus

Material usado como la melodía de una composición polifónica.

Normalmente, en la voz más aguda.

Melodía embellecida mediante el añadido de un ritmo y la interpolación de notas, figuraciones estilizadas y cadencias. Recreación del estilo de chanson.

Rango de aplicación: desde la cita casi literal de la melodía hasta la abundante ornamentación (oscurecimiento del material original). La elaboración del cantus firmus es menor al principio de la frase y crece hacia las cadencias.

Piezas: obras litúrgicas y pequeñas piezas de devoción como los himnos.

\section{Cantus firmus estructural}

Material usado como fundamento estructural de una composición polifónica.

Normalmente, en la voz del tenor.

Melodía tratada como una sucesión de alturas susceptible de manipulación: normalmente, la duración de las notas es alargada, la estructura de la frase es fracturada por extensas pausas, y el texto original se omite.

La integridad del canto no es un requisito. Técnicas de manipulación: repetición, aumentación, disminución, inversión, retrogradación.

Piezas: para ocasiones ceremoniales y festivas.

Estas dos técnicas no son mutuamente exclusivas y Sparks habla de "elaboración estructural", reconociendo que el tenor a veces es parafraseado. ${ }^{57}$ En las versiones de Conditor alme de Baena, Bermudo y Baptista encontramos varias soluciones también a este respecto. Bermudo dispone la melodía Conditor alme en la voz del cantus, la más aguda de la textura a 4, y la usa como melodía de la composición polifónica, lo que se corresponde con la técnica de ornamentación del cantus firmus. Baptista, en contraste, utiliza la melodía como fundamento estructural de la composición polifónica y la coloca en la voz del tenor; las notas son largas y a todas se les adjudica el mismo valor. De manera similar, Baena utiliza la técnica del cantus firmus estructural disponiendo la melodía de Conditor alme como base sobre la que introducir contrapunto en la mano derecha o en la mano izquierda. A diferencia de Baptista, Baena no da a todas las notas la misma duración y además introduce adornos (bordaduras) en el cantus firmus. Ve-

\footnotetext{
${ }^{57}$ Sparks, Cantus firmus in Mass and Motet, 1420-1520, p. 89. La clasificación de Sparks fue cuestionada por James Caldwell, quien propone llevar a cabo una distinción entre cantus firmi monorrítmicos, si los valores relativos de las notas se mantienen inalterados, y cantus firmi no monorrítmicos, en los cuales no hay una adhesión a las duraciones originales. Véase James Caldwell, "Cantus Firmus in Mass and Motet, 1420-1520 by Edgar H. Sparks (review)”, The Musical Times, CVI/1466 (1965), p. 274.
} 
mos, por tanto, que la melodía del himno sólo es fácilmente distinguible de modo auditivo en el caso de la composición de Bermudo, mientras que Baptista y Baena la utilizan como fundamento de un contrapunto (véase Tabla VI.4).

Tabla VI.4: Comparación de las versiones de Gonzalo de Baena, Juan Bermudo y Gracia Baptista del himno Conditor alme

\begin{tabular}{|c|c|c|c|c|}
\hline & & Baena 1540 & Bermudo 1555 & Baptista 1557 \\
\hline \multirow[t]{5}{*}{$\mathbf{C F}$} & Localización & $\begin{array}{l}\text { Mano derecha / } \\
\text { Mano izquierda }\end{array}$ & Cantus & Tenor \\
\hline & Ritmo & $\begin{array}{l}\text { Sonidos largos de } \\
\text { duración variable }\end{array}$ & Ternario & $\begin{array}{l}\text { Sonidos de igual } \\
\text { duración }\end{array}$ \\
\hline & Nota inicial & Mi & Mi & Mi \\
\hline & Modo & $\begin{array}{l}\text { Modo de Mi } \\
\text { (deuterus) plagal } \\
\text { (IV) }\end{array}$ & $\begin{array}{l}\text { Modo de Mi } \\
\text { (deuterus) plagal } \\
\text { (IV) }\end{array}$ & $\begin{array}{l}\text { Modo de Mi } \\
\text { (deuterus) plagal } \\
\text { (IV) }\end{array}$ \\
\hline & $\begin{array}{l}\text { Interpolación } \\
\text { de notas ajenas }\end{array}$ & Bordaduras & & \\
\hline Ritmo & & Binario & Ternario & Binario \\
\hline Notación & & Tablatura & $\begin{array}{l}\text { Notación mensu- } \\
\text { ral }\end{array}$ & Tablatura \\
\hline Textura & & a 2 & a 4 & a 3 \\
\hline
\end{tabular}

Una técnica con profundo efecto en la composición polifónica del siglo XVI fue la unificación de la estructura musical mediante la inclusión de motivos del cantus firmus en todas las voces. ${ }^{58}$ Esta técnica es la empleada en las llamadas misas "paráfrasis"; Baena, Bermudo y Baptista no emplean esta técnica. Aunque encontramos células que recuerdan a la melodía del himno en el resto de las voces, esto no se utiliza sistemáticamente ni en un grado que indique que ha sido concebido como un procedimiento para proporcionar unidad estructural. La pieza de Bermudo se estructura según los incisos del cantus firmus monódico. Encontramos una introducción de tres compases en que se producen las entradas en imitación del tenor, el bassus y el altus; a continuación cada

\footnotetext{
${ }^{58}$ Bloxam, "Cantus firmus".
} 
inciso de la melodía Conditor alme ocupa cuatro compases; los incisos 2 y 4 terminan con la misma cadencia. Las versiones de Gonzalo de Baena y Gracia Baptista tienen forma continua. El himno de Gracia Baptista tiene, sin embargo, contrastes de textura alternando pasajes en que el movimiento melódico se concentra en una de las voces y pasajes homorrítmicos a dos voces sobre el cantus firmus.

En resumen, la adherencia a un cantus firmus no lleva a producir soluciones similares desde las perspectivas del ritmo, estructural, textura y armonía. La congruencia estricta entre la división en incisos de la melodía original y la estructura de la composición polifónica derivada que se da en la versión de Bermudo muestra el carácter vocal de la melodía en esta composición, frente a la escritura idiomática para el teclado de las versiones de Baena y Baptista. Las de Baena son piezas claramente pedagógicas que trabajan determinadas destrezas técnicas: la ejecución de contrapunto en la mano izquierda y en la derecha, respectivamente. Según Bernadette Nelson, las texturas a tres partes se hicieron más frecuentes a finales del siglo XVII, de forma que el interés contrapuntístico era centrado en dos voces, o bien en una sola línea mientras que el canto se movía en terceras paralelas. ${ }^{59}$ Sorprendentemente, esta textura "más avanzada" se asemeja a la utilizada por Gracia Baptista. Por tanto, el análisis musical muestra que Gracia Baptista había recibido una formación contrapuntística y que es matizable el que su himno no despliegue "especiales vuelos".

\subsubsection{LO PRIVADO Y LO PÚBLICO, LO RELIGIOSO Y LO SECULAR EN LOS CONVENTOS DE Clausura: El Monasterio de la Piedad de Guadalajara}

Axel Erdmann indica, refiriéndose a la imprenta en general en la Europa Occidental, que era frecuente que las mujeres "no publicaran sus obras por sí mismas, sino que dejaran que fuesen publicadas por hombres editores". ${ }^{60}$ Con respecto al contexto italiano, Robert Kendrick sugiere que esto dependía de factores externos tales como la política episcopal. ${ }^{61}$ Es interesante que, al igual que Venegas de Henestrosa publicó la música de Gracia Baptista, fuese otro hombre, el poeta Fray Luis de León, quien dio a la

\footnotetext{
${ }^{59}$ Bernadette Nelson, "Juego de pangelinguas: A Source of Organ Music by José Elías at Montserrat", Anuario musical, L (1995), p. 75-85.

${ }^{60}$ Erdmann, My Gracious Silence, p. vii: "They did not publish their works on their own, but let them be published by male editors".

${ }^{61}$ Kendrick, Celestial Sirens, pp. 425-426.
} 
imprenta los escritos de Santa Teresa, ${ }^{62}$ lo que no significa que éstas no circulasen en manuscritos con anterioridad y fuesen de hecho ampliamente difundidas de este modo. ${ }^{63}$ Para el caso de España, en la bibliografía se han enfatizado las inquietudes relacionadas con la autoría femenina en general: "la obsesión española por la privacidad doméstica" prevenía las publicaciones de mujeres; ${ }^{64}$ las mujeres publicaban anónimamente o usaban pseudónimos; ${ }^{65}$ o bien se excusaban señalando que "sus obras eran realmente privadas pero que alguna fuerza externa había obligado a su publicación”. ${ }^{66}$ Es controvertido, no obstante, el que este afán por la privacidad doméstica de las mujeres fuera una particularidad española. $^{67}$

En esta sección presentaré la posibilidad de que Gracia Baptista se haga visible a los ojos del historiador porque su actividad musical en el ámbito privado se transfirió a la esfera pública de la imprenta quizás debido a que los conventos eran lugares en que los límites entre lo público y lo privado se difuminaban. En cualquier caso, si Conditor alme era parte de un repertorio improvisado (que presumiblemente habría consistido en un número mayor de "composiciones"), cabe preguntarse por qué esta pieza en particular se puso por escrito en tablatura y se publicó, o si este himno no constituye un caso aislado y se trata más bien de una cuestión de conservación de fuentes. Mi hipótesis es que los conventos eran lugares en que los límites entre lo privado y lo público se desdi-

\footnotetext{
${ }^{62}$ Santa Teresa de Jesús, Los libros de la madre Teresa de Ieusus fundadora de los monasterios de monjas y frayles Carmelitas desçalcos de la primera regla (Salamanca: Guillermo Foquel, 1588). Es necesario exceptuar la publicación previa, también póstuma, del Tratado que escriuio la madre Teresa de Iesus a las hermanas Religiosas de la orden de nuestra Señora del Carmen del Monasterio del Señor sanct Ioseph de Auila de donde a la sazon era Priora y fundadora (Évora: Viuda Muger que fue de Andres de Burgos, 1583).

${ }^{63}$ María del Mar Graña Cid, "Palabra escrita y experiencia femenina en el siglo XVI", en Escribir y leer en el siglo de Cervantes, ed. por Antonio Castillo Gómez (Barcelona: Paidós, 1999), pp. 211-242, p. 232.

${ }^{64}$ Gwyn Fox, Subtle Subversions: Reading Golden Age Sonnets by Iberian Women (Washington: Catholic University of America Press, 2008), p. 3: "For instance, Paul Julian Smith has claimed that there were even fewer women writing in Spain in the Counter-Reformation period than elsewhere in Europe as a result of the Spanish obsession with domestic privacy that also prevented the publication of memoirs and letters". Véase Paul Julian Smith, The Body Hispanic: Gender and Sexuality in Spanish and Spanish American Literatures (Oxford: Clarendon Press, 1989), p. 14.

${ }^{65}$ Erdmann, My Gracious Silence, p. xvii; y Castillo Gómez, Entre la pluma y la pared, p. 199.

${ }^{66}$ Erdmann, My Gracious Silence, p. xvi: "they often claimed that their works were really private, but that some external force had compelled their publication".

${ }^{67}$ Sobre la preocupación de las mujeres en general ante la creación musical es paradigmático el trabajo de Marcia J. Citron, Gender and the Musical Canon (Cambridge: Cambridge University Press, 1995).
} 
bujaban, permitiendo quizás la transferencia a un ámbito público (la imprenta) de una muestra de la música creada en la clausura (el himno de Gracia Baptista). Además, argumentaré que en los conventos se producía una superposición entre lo religioso y lo secular y que la música era un medio para ello.

Nobles y religiosas eran una categoría especial protegida del estigma de inmoralidad ligado a las mujeres que practicaban la música. Pilar Ramos ha señalado que según Francesc Eiximenis "una mujer debía comportarse del modo que más satisficiera a su marido" y que, si bien los "ciudadanos" preferían "esposas serias que evitaran las danzas", los caballeros optaban por esposas amables y simpáticas con los invitados. ${ }^{68}$ Por tanto, las nobles necesitaban cultivar destrezas musicales con el propósito de atraer y entretener a un marido; en contraste, la música de las religiosas se justificaba como un instrumento para alabar a Dios. Sin embargo, podría argumentarse que, incluso en el caso de las monjas de clausura, quienes estaban aparentemente operando en una esfera femenina (o "cultura de mujeres"), ${ }^{69}$ la música era concebida como un medio de comunicación con un público principalmente masculino.

La flexibilidad de las constricciones de la clausura y la permeabilidad de los conventos son aspectos tratados frecuentemente en la bibliografía. En su estudio sobre el Monasterio de la Encarnación de Ávila, Nicolás González señala que en esa época "pocas monjas guardaban la clausura", 70 de modo que se producía un traspaso bidireccional de los muros del convento. La movilidad de las beatas y la temática de la literatura escrita por religiosas son muestra de ello. ${ }^{71}$ Los estudios de Colleen R. Baade y Al-

\footnotetext{
${ }^{68}$ Eiximenis, Libre de les dones, f. 62v; citado en Ramos, "Musical Practice and Idleness", pp. 263-264: "He said that a woman should behave in the way that satisfies her husband most. According to him gentlemen preferred wives to be kind and friendly with guests whereas the citizens -lawyers, merchants, solicitors, ragmen, but not the artisans who were considered lower that citizens- liked more serious wives who avoided dances".

${ }^{69}$ Los conceptos de "esfera de mujeres" y "cultura de mujeres" se han tomado de los estudios históricos por Monson, Disembodied Voices, pp. 8-9, con el propósito de comprender "los conventos del mundo católico post-tridentino". Se considera que el concepto de "esfera de mujeres" fue determinado por el hombre, mientras que el concepto de "cultura de las mujeres" reconoce "algún elemento de acción de las mujeres en la historia".

${ }^{70}$ González, Historia del monasterio de la Encarnación de Ávila, p. 188.

${ }^{71}$ Ángela Muñoz Fernández titula "Las beatas, entre el monasterio y el mundo" el tercer capítulo de su trabajo Acciones e intenciones de mujeres. Vida religiosa de las madrileñas (ss. XV-XVI) (Madrid: Horas y Horas, 1995). Sobre el reflejo del exterior en la literatura escrita por religiosas, véase Vollendorf, The Lives of Women, p. 115.
} 
fonso de Vicente sobre España, Robert Kendrick, Colleen Reardon y Craig Monson acerca de Italia, y Geoffrey Baker sobre el Virreinato del Perú, entre otros, ponen de manifiesto que la música de las religiosas no era sólo un medio de honrar a Dios, sino también una forma de entretenimiento para la ciudad, y que constituía para las monjas una oportunidad de comunicación con la esfera pública. ${ }^{72}$ Por ejemplo, Geoffrey Baker señala que frente a "la imagen moderna de los conventos como islas de calma y silencio en medio de la ruidosa y ajetreada ciudad", los conventos del Cuzco colonial eran "ciudades dentro de la ciudad" en que la música se utilizaba como un medio de comunicación entre la esfera conventual y el medio urbano. ${ }^{73}$ Silvia Evangelisti usa como evidencia The Parlour, una pintura veneciana de c. 1740-50 de Giovanni Antonio Guardi, y los datos del Cuzco colonial presentados por Kathryn Burns para señalar que los locutorios de los conventos "no eran los espacios silenciosos y austeros que las autoridades hubiesen deseado", sino lugares para el entretenimiento donde las monjas "tocaban arpas y guitarras", "cantaban canciones profanas o incluso bailaban con sus hábitos frente a los visitantes, que hacían lo mismo al otro lado de las ventanas". ${ }^{74}$

Las hijas de familias nobles a menudo ingresaban como monjas en los conventos "de moda" tales como el Convento de la Inmaculada Concepción de Caracas, fundado en 1637 gracias a una licencia solicitada en 1590 por Juana de Villela, procedente de Palos (Huelva) y viuda del capitán y encomendero Lorenzo Martínez; para ingresar en

\footnotetext{
${ }^{72}$ Colleen R. Baade, "La 'música sutil' del Monasterio de la Madre de Dios de Constantinopla: aportaciones para la historia de la música en los monasterios femeninos de Madrid a finales del siglo XVI-siglo XVII", Revista de Musicología, XX/1 (1997), pp. 221-230, p. 222; "Music and Misgiving: Attitudes Towards Nuns' Music in Early Modern Spain", en Female Monasticism in Early Modern Europe: An Interdisciplinary View, ed. por Cordula van Wyhe (Aldershot: Ashgate, 2008), pp. 81-95, p. 82; y "Dos siglos de música y fiesta en los monasterios femeninos de Toledo", en Música de tecla en los monasterios femeninos y conventos de España, Portugal y las Américas / Keyboard Music in the Female Monasteries and Convents of Spain, Portugal and the Americas, ed. por Luisa Morales (Almería: LEAL, 2011), pp. 49-59, p. 58; Vicente Delgado "Diez años de investigación musical en torno al Monasterio de Santa Ana de Ávila", p. 525; Kendrick, Celestial Sirens, p. 425; Monson, ed., The Crannied Wall, pp. 3-4; y Disembodied Voices, p. 11; y Baker, "Music in the Convents and Monasteries of Colonial Cuzco", p. 4.

${ }^{73}$ Baker, "Music in the Convents and Monasteries of Colonial Cuzco", pp. 4-5.

${ }^{74}$ Evangelisti, Nuns, p. 51: "parlours were not the silent and austere spaces that the authorities would have liked them to be [...] well after Trent, nuns played harps and guitars in the parlour, sang profane songs, or even danced in their habits in front of the visitors, who did the same on the other side of the windows". Véase Kathryn Burns, Colonial Habits: Convents and the Spiritual Economy of Cuzco, Peru (Durham: Duke University Press, 1999).
} 
este convento se requería una alta dote y las monjas disponían de criadas a su servicio. ${ }^{75}$ Otro ejemplo es el Monasterio de la Piedad de Guadalajara. Fundado en 1524 por Brianda de Mendoza y Luna, hija de los II Duques del Infantado, Íñigo López de Mendoza y María de Luna, ${ }^{76}$ el Monasterio de la Piedad acogía por mandato de la fundadora a una mayoría de beatas procedentes de familias nobles y, buena parte de ellas, pertenecientes a la familia Mendoza. ${ }^{77}$ El historiador Francisco Layna Serrano describe este monasterio (y en menor medida los de Santa María y Santa Clara, también en Guadalajara) como lugares de encuentros sociales entre "grupos de elegantes y engolados caballeros" y "encopetadas damas llegadas al templo con el atavío de sus mejores galas y distribuyendo entre los galanes sus más delicadas sonrisas" y en cuyo locutorio los aristócratas ("con el pretexto de hacer una visita a las beatas de la Piedad sus amigas o parientas") se reunían para celebrar tertulias en las que las monjas eran puestas al corriente "no sólo de cuanto afectaba a las respectivas familias sino de todos los chismes y comadreos de vecindad, sin que faltara nunca la nota humorística y casi tampoco la algo picante a pesar de estar presente la silenciosa escuchadera". ${ }^{78}$

A la amalgama de las esferas privada y pública debemos sumar la ambigüedad relativa al estatus moral de la música que encontramos en el Monasterio de la Piedad. Aunque según las reglas del convento estaba prohibido cantar las misas y los oficios "por punto", ${ }^{79}$ Francisco Torres, regidor de Guadalajara entre 1635 y 1649, describe en

\footnotetext{
${ }^{75}$ Viana Cadenas, "El convento de la Inmaculada Concepción de Caracas: vida musical y educación de la mujer en la Caracas del siglo XVII", en IX Congreso Internacional de Historia de América, ed. por Fernando Serrano Mangas et al. (Mérida: Editora Regional de Extremadura, 2002), vol. 2, pp. 225-234.

${ }^{76}$ Para un retrato de Brianda de Mendoza y Luna, véase Cristina Arteaga y Falguera, La casa del Infantado cabeza de los Mendoza (Madrid: Duque del Infantado, 1930), Lámina XLIII.

${ }^{77}$ Véase el Capítulo VII.

${ }^{78}$ Las crónicas de Layna Serrano sobre el Monasterio de la Piedad en sus dos obras sobre la ciudad de Guadalajara son sumamente interesantes. Véanse Francisco Layna Serrano, Historia de Guadalajara y sus Mendozas, en los siglos XV y XVI (Madrid: Aldus, 1942), vol. 4, pp. 201-202; y Los conventos antiguos de Guadalajara: apuntes históricos a base de los documentos que guarda el Archivo Histórico Nacional (Madrid: CSIC, Instituto Jerónimo Zurita, 1943), p. 195. Fuentes primarias sobre el Monasterio de la Piedad se preservan en Madrid, Archivo Histórico Nacional, Clero-Secular Regular, 2057/2070.

79 "Testamento de Brianda de Mendoza" (Guadalajara, 19 de febrero de 1534), Toledo, Sección Nobleza del Archivo Histórico Nacional, Osuna, legajo 1763. Citado en Layna Serrano, Los conventos antiguos de Guadalajara, p. 187: “También prohibió [Brianda de Mendoza en su testamento] que en ningún tiempo se pudiera mudar el carácter del beaterio y el modo de vivir en él las religiosas así como cantar en el coro a misa ny a bísperas ny a otros ofiçios más de que los digan en tono y no por punto (con música)". Aunque Layna Serrano define "por punto" como "con música", las constituciones de las carmelitas descalzas que mencionaba anteriormente evidencian que "por punto" hacía referencia al canto de órgano, en con-
} 
su historia de la ciudad una activa vida musical en el Monasterio de la Piedad y da noticia de la existencia de una excelente capilla musical constituida por monjas:

Tiene el Combento vn buen patio, y en el goçan las Monjas algunas fiestas diferentes. En varias occassiones se an hecho alli grandes altares, y desde las Ventanas que estan altas, y con Zelosias) an cantado las Religiossas en las Processiones sonoras letras, y tal vez an sido alternadas, y correspondidas de la Capilla Real, que para este efecto viene a esta Ciudad. Y desta suerte se goça a un tiempo de dos acordes y diestras Capillas. La de esta cassa es tan perfecta que se puede decir son prodigios de suauidad, y sirenas diuinas pues al espiritu mas bronco con lo tierno, $\mathrm{y}$ dulce de sus acentos a un tiempo suspenden, y admiran. A juicio de Grandes mussicos desapasionados se lleban estas señoras la primacia de diestras, y suabes detodas las Capillas de mugeres que ay en el Orbe, con que viene aser el mas feliz este conuento de todos quantos tiene castilla pues en el esta abreuiado el Cielo. Dichossos los que le frequentan, y celebran. Mas las religiosas son tan modestas, y entendidas, que este aplauso no las desuanece; ni inquieta; ni por el an subido a la perfeccion de la musica, que lo que mas las alienta a este sagrado exercicio es la gloria y alabança de su Esposo: pues assi el culto diuino esta mas decente, y autoriçado. Las señoras Religiossas que en este tiempo mas se señalan en voz, y destreza son las siguientes. Doña Antonia de Toledo. Doña Margarita Zimbron. Doña Isabel de Aguiar (aguda Poeta) Doña Maria de Arellano, Doña Antonia de Olibares, Doña María Clauijo, y su hermana Doña Ana Maria grandes compositoras, y ynstrumentistas. Doña Juana Martinez, y su hermana Doña Francisca. Doña Maria Mantilla, y Doña Antonia de Contreras; y mas otras .26. de Capilla donde ay variedad de ynstrumentos. ${ }^{80}$

El párrafo de Francisco Torres posee una gran riqueza como fuente para la investigación musicológica por varios motivos. En primer lugar, Torres equipara en destreza a la capilla musical de monjas del Monasterio de la Piedad y a la Capilla Real y sugiere la posibilidad de interpretaciones conjuntas de ambas formaciones cuando la Capilla Real visitaba Guadalajara (¿el palacio del Infantado?). En segundo lugar, la crónica pone de manifiesto la existencia en Guadalajara de otras capillas musicales integradas por mujeres. En tercer lugar, esta descripción de la música de las religiosas de la Piedad se basa en los adjetivos "suave", "tierno" y "dulce", situando la crítica en un marco conceptual muy parecido al utilizado en el siglo XX para describir la música de

traste con "en tono", que aludía al canto llano. En la Hispanic Society of America de Nueva York se encuentran libros exclusivamente de canto llano (un Antifonario y 15 libros de coro) de los siglos XVI y XVII procedentes de Guadalajara; véanse Emilio Ros-Fábregas, "La biblioteca musical de Federico Olmeda (1865-1909) en la 'Hispanic Society of América' de Nueva York", Revista de Musicología, XX/1 (1997), pp. 553-570; y "Medieval and Renaissance Spanish Music Manuscripts at the Hispanic Society of America in New York", ponencia no publicada pronunciada en el Congreso Internacional "Medieval and Renaissance Music Conference", Royal Holloway, University of London, 5 de julio de 2010.

${ }^{80}$ Francisco Torres, Historia de la mui nobilissima ciudad de Guadalajara, MS (1647), Madrid, Biblioteca Nacional de España, MSS/1690, ff. 208v-209r. 
Gracia Baptista, como señalé antes. ${ }^{81}$ En cuarto lugar, la importancia de esta historia de Guadalajara para la historia de la música también reside en la inclusión de una lista con los nombres de once músicas y la referencia a la existencia de veintiséis más. Si esto ocurría en un solo monasterio y el mismo párrafo hace referencia a otras capillas de mujeres incluso en la misma ciudad, la creación musical femenina debió de ser un fenómeno más extendido de lo que las fuentes conservadas permiten vislumbrar.

Del listado de monjas de la capilla musical de la Piedad que proporciona Francisco Torres he podido obtener información sobre Margarita Cimbrón, Isabel de Aguiar y Saavedra, y María de Arellano. Margarita Cimbrón aparece en el "Libro quinto, linages, y apellidos de ciudadanos de Guadalaxara" de la Historia eclesiastica y seglar de la muy noble y muy leal ciudad de Guadalaxara de Alonso Núñez de Castro, en el apartado dedicado al apellido Cimbrón, que procedía "de los Cimbrones de Auila":

Gil Suarez Cimbron casò en Vzeda con D. Francisca de Acuña, en quien tuyo a D. Francisco Cimbron, que fue padre de don Gil Cimbron, y de D. Margarita Cimbron, Monja en la Piedad, su padre embiudò, y se ordenò de Orden Sascro, y muriò Sacerdote. ${ }^{82}$

He podido encontrar más datos de Isabel de Aguiar y Saavedra, puesto que ha pasado a los anales de la historia como poetisa, quizás debido a que las fuentes que se conservan de esta religiosa se relacionan con su producción poética. En la Biblioteca Nacional de España se encuentran algunos de sus poemas en manuscritos del siglo XVII; ${ }^{83}$ como muestra la Ilustración VI.2, una décima que escribió en alabanza de Juan Enríquez de Zúñiga se imprimió entre el material preliminar del libro de éste titulado

\footnotetext{
${ }^{81}$ El párrafo de Torres ha sido tomado como punto de partida por Colleen R. Baade en su estudio de las actitudes hacia la música de las monjas en la temprana Edad Moderna; véase Baade, "Music and Misgiving", p. 85.

${ }^{82}$ Alonso Núñez de Castro, Historia eclesiastica y seglar de la muy noble y muy leal ciudad de Guadalaxara (Madrid: Pablo de Val, 1653), pp. 332-333.

${ }^{83}$ Cancionero, MS (siglo XVII), Madrid, Biblioteca Nacional de España, MSS/3773: “A una Dama embiandola un galan unas pastillas de boca" (f. 87); "A una librea que saco en un juego de cañas un cauallero guarnecida de plata y las espaldas sin guarnicion" (ff. 80-81); "Romance del beso las manos de v.m., en que se queja le an dejado por el besso la mano" (ff. 109v-110); y "Soneto. Diciendole al marques de Montesclaros que era muy entendida Doña Isabel de Aguiar, pregunto si era mujer que diria una de las desnudeces del Paraiso, y ella hizo de repente este soneto" (f. 140). Para una transcripción de estos poemas, véase Manuel Serrano y Sanz, Apuntes para una biblioteca de escritoras españolas desde el año 1401 al 1833 (Madrid: Establecimiento tipolitográfico "Sucesores de Rivadeneyra", 1903-1905), vol. 1, p. 12.
} 
Amor con vista (Madrid, 1625). Aunque Layna Serrano (como también Francisco Torres) ubica a Isabel de Aguiar y Saavedra en el Monasterio de la Piedad e incluso relata cómo una de sus poesías ("algo mundana") surgió en las tertulias vespertinas que tenían lugar en el locutorio de este monasterio, ${ }^{84}$ Manuel Serrano y Sanz la describe como "monja de Santa Clara de Guadalajara". ${ }^{5}$

Ilustración VI.2: Juan Enríquez de Zúñiga, Amor con vista (Madrid: Iuan Delgado, 1625), portada y décima de Isabel de Aguiar y Saavedra. Barcelona, Biblioteca del Ateneu Barcelonès, GOc 84.
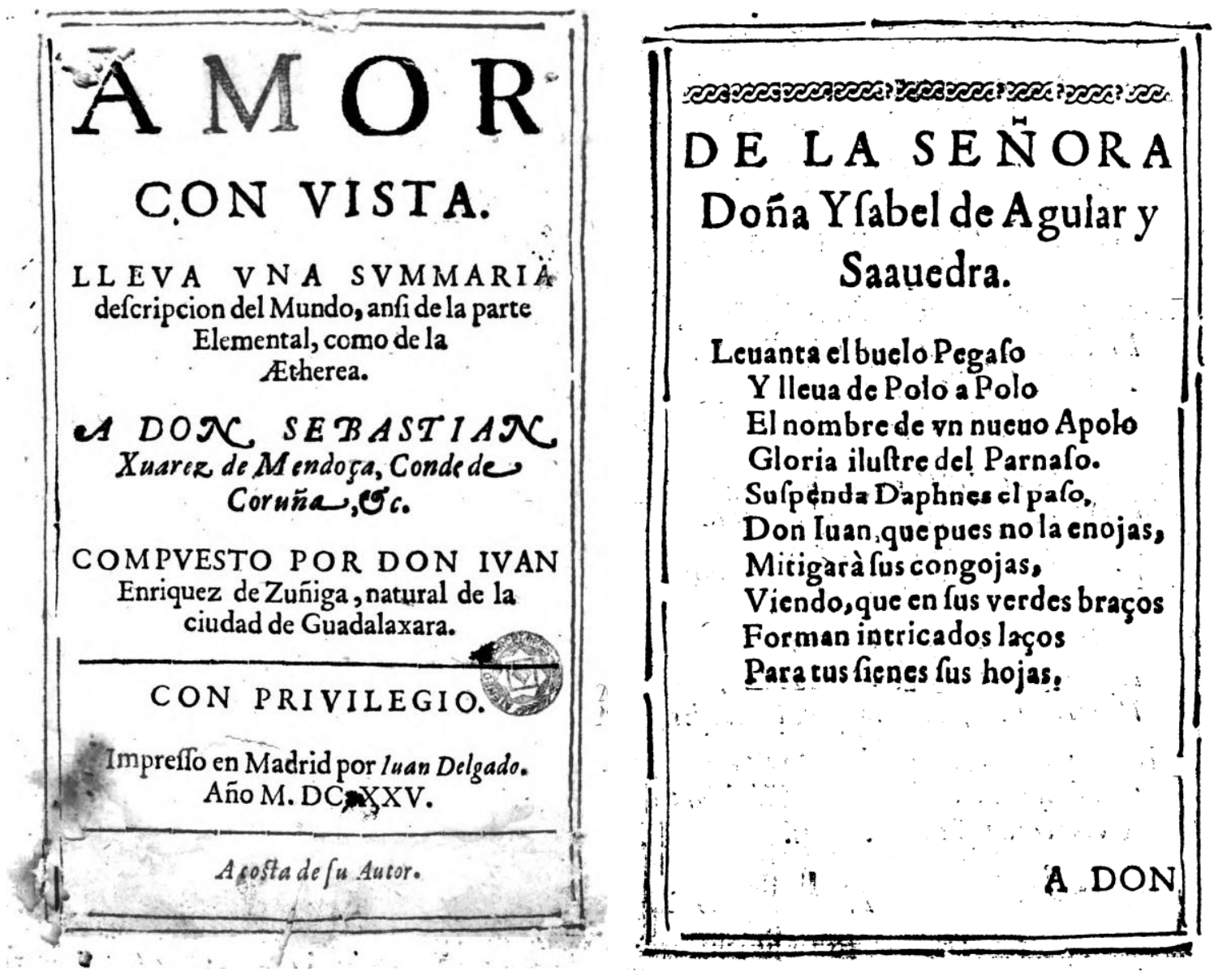

\footnotetext{
${ }^{84}$ Layna Serrano, Historia de Guadalajara y sus Mendozas, vol. 4, p. 202.

${ }^{85}$ Layna Serrano, Historia de Guadalajara y sus Mendozas, vol. 3, p. 302; Serrano y Sanz, Apuntes para una biblioteca de escritoras españolas, vol. 1, p. 12.
} 
Como en el caso de Margarita Cimbrón, encontramos en una genealogía nobiliaria la procedencia familiar de María de Arellano, hija de Juan Ramírez de Arellano y Leonor de Zúñiga, y hermana de Juana de Arellano (monja en la Concepción de Guadalajara). ${ }^{86}$ Como en el caso de Isabel de Aguiar, he podido localizar una décima de María de Arellano entre el material preliminar de un libro impreso. Se trata de un libro de cinco hojas de extensión perteneciente al género de las relaciones de fiesta y titulado Relacion de las fiestas reales con que la muy noble, y muy leal Ciudad de Salamanca, cabeza de Estremadura, celebro el feliz sucesso de la reduccion de Barcelona y su Condado, a la obediencia de el Rey N. Señor Phelipo IIII, el Grande (Salamanca, 1652), del protonotario Martín Ledesma y Herrera. ${ }^{87}$ La relación es introducida por cinco poemas en alabanza del autor, el primero de los cuales es una décima "De doña Maria de Arellano y Mendoza, religosa [sic] en el Convento Real de la Piedad de la Ciudad de Guadalagara $[$ sic]": 88

\author{
Mucho estimara alavaros \\ que fuera en prosa discreta, \\ pero en esto de poeta \\ no passo de un Conde Claros, \\ $\mathrm{y}$ alla entre ingenios tan raros \\ diran en qualquier quadrilla \\ que son versos de almoadilla, \\ y aunque el trueque era bien llano \\ me quitaran lo Arellano \\ llamandome Bovadilla.
}

Sólo se incluye un poema del autor, Martín de Ledesma, y constituye una contestación precisamente a la décima de María de Arellano. En el libro de Martín de Ledesma encontramos un poema de otra religiosa de la que no se tiene noticia, "Doña

\footnotetext{
${ }^{86}$ Alonso López de Haro, Nobiliario genealogico de los Reyes y Principes de España (Madrid: viuda de Fernando Corresa de Montengro, 1622), vol. 2, p. 57.

${ }^{87}$ He consultado el ejemplar localizado en Madrid, Biblioteca Nacional de España, R/30863. La edición moderna de ésta y otras dos relaciones del mismo festejo (el que se llevó a cabo en Salamanca con motivo de la "reducción" de Barcelona por las tropas de Felipe IV) puede encontrarse en Fernando Rodríguez de la Flor y Esther Galindo Blasco, Política y fiesta en el Barroco, 1652: descripción, oración y relación de fiestas en Salamanca con motivo de la conquista de Barcelona (Salamanca: Universidad de Salamanca, 1994).

${ }^{88}$ En su edición de esta relación, Fernando Rodríguez de la Flor y Esther Galindo Blasco señalan que "no disponemos de ninguna otra noticia de esta religiosa"; véase Rodríguez de la Flor y Galindo Blasco, Politica y fiesta en el Barroco, 1652, p. 96, nota 5.
} 
Margarita de Calzada y Santayana, religiosa en el Convento de Corpus Christi de Salamanca". Los ejemplos de las religiosas del Monasterio de la Piedad Isabel de Aguiar y María de Arellano muestran, por tanto, que los materiales preliminares de los libros impresos eran, como la música, una oportunidad de expresión pública para las religiosas puesto que constituían un lugar en el que publicar (quizás una pequeña muestra de) sus creaciones poéticas. Es llamativo que mujeres alabadas por sus destrezas musicales hayan pasado a los anales de la historia como poetisas debido a que sólo nos han llegado sus composiciones poéticas.

El aspecto de más relevancia para mi argumento de la descripción que hace Francisco Torres de la vida musical en la Piedad radica en sus referencias a la celebración de grandes festividades urbanas en que la música de las religiosas (a través de las ventanas con celosías) tenía un papel fundamental. Además, muestra que la música era un instrumento mediante el cual las monjas obtenían la admiración y el "aplauso" de un público externo. Estas características concuerdan con la hipótesis de que la música era un medio de intercambio y comunicación entre la esfera urbana y la conventual y, por tanto, un mecanismo por el que se superponían los ámbitos "privado" (convento) y público (ciudad) y los contextos religioso y secular. Es sumamente interesante el modo en que Torres se apresura a justificar estas prácticas musicales femeninas como "decentes" y "autorizadas" mediante el ensalzamiento de la modestia de las religiosas y la despreocupación de éstas por la admiración que despertaban: la música era para ellas un "sagrado ejercicio" cuyo propósito residía en "la gloria y alabanza de su Esposo".

Sin embargo, tenemos noticia de la interpretación de música profana en los conventos, y algunas crónicas, cuentos populares y vidas de monjas describen interpretaciones musicales conventuales dirigidas a personas concretas externas al convento, las cuales tenían como fin entretener o "divertir". Quizás el ejemplo más evidente de la primera cuestión sea la interpretación de cantos profanos "vueltos a lo divino", así como la utilización de música profana por parte de las monjas "para su recreo". ${ }^{89}$ Encontramos un ejemplo en la dotación de los libros de Catalina de Zúñiga al Monasterio de las

\footnotetext{
${ }^{89}$ Ramos, "Los estudios de género y la música ibérica del siglo XVII”, p. 239. Sobre el ámbito italiano, véanse los trabajos de Laurie Stras, "Musical Portraits of Female Musicians at the Northern Italian Courts in the 1570s", en Art and Music in the Early Modern Period: Essays in Memory of Franca Trinchieri Camiz, ed. por Katherine A. McIver (Aldershot: Ashgate, 2003), pp. 145-172; y "Le nonne della ninfa: Feminine Voices and Modal Rhetoric in the Generations Before Monteverdi", en Gender, Sexuality and Early Music, ed. por Todd Borgerding (Nueva York y Londres: Routledge, 2002), pp. 123-165.
} 
Descalzas de Monforte de Lemos llevada a cabo en 1630. Habiendo participado en su fundación, "la VI condesa tuvo como residencia el Monasterio de las Descalzas, lugar de recepción de las mujeres de la alta nobleza y de la realeza, durante algún tiempo". 90 También su sobrina y nuera Catalina de la Cerda (1580-1646), VII Condesa de Lemos, que había enviudado en 1622, ingresaría como monja en 1633 en este monasterio. ${ }^{91}$ Fue Catalina de la Cerda quien realizó la dotación en nombre de su tía. ${ }^{92}$ La dotación consistía en 186 libros, entre los cuales se encontraba el "libro en lengua ytaliana de Musica y Danza" mencionado en el Capítulo V (véase Ilustración VI.3). ${ }^{93}$ Patricia Marín Cepeda afirma que la dotación de Catalina al convento probablemente incluía la totalidad de su biblioteca en lugar de una selección, ${ }^{94}$ mientras que Isabel Barbeito asegura que los libros legados constituían sólo una parte de la biblioteca de Catalina seleccionada particularmente para las monjas. Isabel Enciso lleva a cabo en su Tesis Doctoral un listado de 16 libros que aparecen en el inventario general de Catalina, pero no fueron incluidos en el lote de libros donados. ${ }^{95}$ Si los libros destinados al convento fueron seleccionados teniendo en mente su fin, es sumamente interesante que el único libro de música legado fuese un libro de música y danza que, como se señaló en el Capítulo $\mathrm{V}$, probablemente iba dirigido a "cavalieri et dame" e incluía música secular y tablatura para laúd. Este ejemplo sugiere, por tanto, la introducción por parte de Catalina de Zúñiga de música secular italiana en el contexto conventual femenino de Galicia.

\footnotetext{
${ }^{90}$ Encisco Alonso-Muñumer, Nobleza, poder y mecenazgo en tiempos de Felipe III, p. 138.

${ }^{91}$ Manuel Hermida Balado, La condesa de Lemos y la corte de Felipe III (Madrid: Paraninfo Librería, 1949). Existe un trabajo biográfico previo sobre Catalina de la Cerda realizado por Sor María de la Concepción de San Francisco en el siglo XIX ganador de un certamen literario celebrado en Monforte en 1895; véase Sor María de la Concepción de San Francisco, Memoria sobre la vida de la fundadora del convento de franciscanas descalzas de la ciudad de Monforte y monja del mismo, Excma. Señora Doña Catalina de la Cerda y Sandoval [...] escrita por una religiosa del referido convento (Lugo: Imp. Gerardo Castro Montoya, 1896).

${ }^{92}$ La bibliografía enfatiza la cercanía de la relación existente entre tía y sobrina. Incluso un poema de Lope de Vega habla de las dos "Cathalinas". Véase Lope de Vega, Colección de las obras sueltas: assi en prosa, como en verso. Tomo III (Madrid: Impr. de A. de Sancha, 1776), p. 385. Véanse también Hermida Balado, La condesa de Lemos, pp. 23, 41; y Barbeito Carneiro, Mujeres del Madrid barroco, pp. 29-47.

${ }^{93}$ Barbeito Carneiro, “La biblioteca de la VI Condesa de Lemos”, p. 78.

${ }^{94}$ Marín Cepeda, "La cultura cortesana, devocional y literaria de una mujer poderosa del Siglo de Oro", p. 167.

${ }^{95}$ Enciso Alonso-Muñumer, “Linaje, poder y cultura”, p. 171.
} 
Ilustración VI.3: Dotación de libros de Catalina de Zúñiga al Monasterio de Franciscanas Descalzas de Monforte de Lemos y a algunos religiosos jesuitas.

Madrid, Archivo de los Duques de Alba, C. 216-11, ff. 1v-2r.

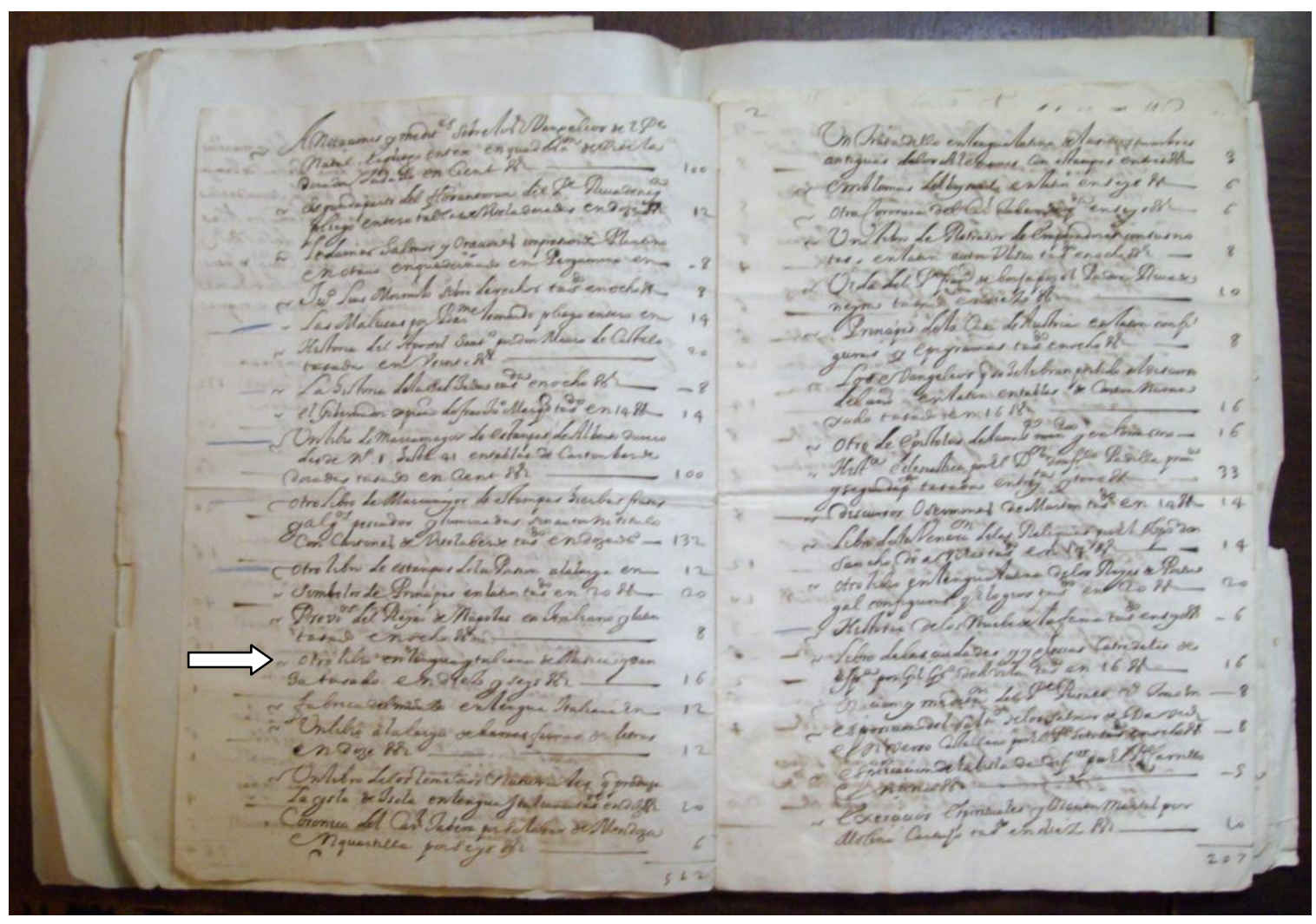

El ejemplar del Libro de musica de vihuela, intitulado silva de sirenas (Valladolid, 1547) de Enríquez de Valderrábano conservado en la Biblioteca de Reserva de la Universitat de Barcelona con la signatura CM-4125-3 perteneció al Convento de Santa Caterina de Barcelona, una institución masculina. ${ }^{96}$ El caso de Gracia Baptista aporta más indicios de la interpretación de música profana en los conventos: 1) si la restricción de Santa Teresa sobre las organistas mencionada por André Pirro pudiera confirmarse, ésta indicaría que las monjas organistas interpretaban repertorio profano, hasta el punto de que se hizo necesario prohibir esta práctica; y 2) el propio libro de Venegas de Henestrosa, que amalgamaba repertorio religioso y profano puesto en cifra iba dirigido explícitamente a sacristanes y futuras monjas.

\footnotetext{
${ }^{96}$ En el ejemplar encontramos los sellos del convento de Santa Caterina de Barcelona y una anotación manuscrita en la portada: "esta tassado en dos ducados".
} 
Existen ejemplos de interpretaciones musicales de las religiosas dirigidas a personas concretas externas al convento con el propósito de entretener. Jerónimo de Barrionuevo relata entre las "distracciones del duque de Lorena en Toledo" en 1654 sus visitas a los "conventos de monjas, donde le divierten y cantan". 97 Por tanto, tenemos noticias no sólo de prácticas musicales no estrictamente litúrgicas o de una actividad musical no relacionada con grandes festejos religiosos, sino también de una música más íntima inserta en el marco de la vida cotidiana de la que quedan muy pocos testimonios. Los cuentos populares de la época prueban que era común la asistencia de los caballeros a los conventos con el fin de escuchar las interpretaciones musicales de las religiosas: "En un monasterio de monjas, en Madrid, hay muchas voces excelentes. Preguntáronle a un caballero cuál era la que mejor cantaba de ellas, y respondió: -La que canta". ${ }^{98}$ También las vidas de religiosas actúan como fuente: Mariana de la Encarnación (15711657), como vicaria de coro en el Convento Carmelita de Puebla, debía enseñar a sus compañeras, encargarse de los ensayos y ordenar interpretaciones musicales en el locutorio, donde "la comida y la conversación con los invitados complementaban la música"; incluso se le requería que cantase acompañándose del órgano en estas ocasiones. ${ }^{99}$ El himno de Gracia Baptista debió de traspasar los muros del convento en una situación similar.

\subsubsection{COMPOSITORAS Y MAESTRAS EN OTRAS ESFERAS FEMENINAS}

Como argumentaré en el Capítulo VII, los tratados de conducta de la época mostraban una actitud ambivalente hacia las mujeres músicas y hacia las mujeres docentes, aunque las monjas constituían una excepción porque sus prácticas musicales eran “decentes" y "autorizadas", como ponía de manifiesto la crónica de Francisco Torres. Juan Luis Vives y Juan de la Cerda rechazaban la práctica de la música y la danza por parte de las mujeres, excepto el órgano en el caso de las monjas o futuras monjas. ${ }^{100}$ Vives

\footnotetext{
${ }^{97}$ Jerónimo de Barrionuevo, Avisos de don Jerónimo de Barrionuevo. 1654-1658, ed. por Arturo Paz y Meliá (Madrid: Atlas, 1968), vol. 1, p. 122. Citado en Vicente Delgado, "La actividad musical en los monasterios de monjas en Ávila durante la Edad Moderna”, p. 525.

${ }^{98}$ Cuentos muy mal escritos que notó don Juan de Arguijo, cuento 291a; transcripción tomada de Chenot y Chevalier, eds., Cuentos recogidos por Juan de Arguijo y otros, p. 199.

${ }^{99}$ Arenal y Schlau, Untold Sisters, p. 344.

${ }^{100}$ Vives, Instruccion de la muger christiana, p. 153; Cerda, Libro intitvlado vida politica de todos los estados de mugeres, f. $18 \mathrm{v}$.
} 
indicaba que las mujeres debían aprender para sí mismas o, como mucho, para sus hijos o para sus compañeras monjas:

\begin{abstract}
El tiempo que ha de estudiar yo no lo determino ni en el varón ni en la hembra, con la salvedad de que es más razonable que el varón se pertreche con mayores y más variados conocimientos, que luego habrán de ser de harto provecho a sí y a la República, utilizándolos en su propio bien y difundiendo y propagando esta su erudición en muchos otros. Yo quiero que la mujer se limite exclusivamente a aquella parte de la filosofía que se concretó a la formación y al mejoramiento de las costumbres. Y esto apréndalo para sí sola o, a lo más, para los hijos pequeños todavía o para sus hermanas en el Señor. Pues no parece bien que la mujer regente escuelas, ni alterne con varones, ni hable en público [...] Si es ella buena, le está mejor quedarse sentada en casa y de los otros desconocida. En las reuniones esté con los ojos bajos, vergonzosa y callada, de forma que la vean, así, algunos, pero no la oiga nadie. ${ }^{101}$
\end{abstract}

Parece por tanto que, como refleja el caso de Gracia Baptista, los conventos eran una esfera privilegiada donde las mujeres podían desempeñar roles inalcanzables para otras mujeres, como el de maestra de música y compositora. Cabe preguntarse si era la única. Las referencias a mujeres docentes relacionadas de alguna manera con la música en ámbitos públicos es bastante limitada. Lisa Vollendorf señala la necesidad de ampliar nuestras definiciones de educación incluyendo mecanismos informales con el fin de recuperar la historia de las mujeres. ${ }^{102}$ Álvara de Alba y Juana/Juliana Morella son dos ejemplos de mujeres españolas autoras de tratados teóricos que reflejan una docencia en contextos públicos. Procedente de Vitigudino (Salamanca), Álvara de Alba estudió en la Universidad de Salamanca (consta matriculada en 1546) y publicó en la misma ciudad un tratado de matemáticas perdido. ${ }^{103}$ Por su parte, Juliana Morella nació en Barcelona

${ }^{101}$ Juan Luis Vives, Obras completas (Madrid: Aguilar, 1947), vol. 1, p. 1001.

${ }^{102}$ Vollendorf, The Lives of Women, p. xiii: "la historia de la educación de las mujeres puede recuperarse sólo si ampliamos nuestras definiciones de educación para que tengan en cuenta los mecanismos formales e informales por los que las mujeres y otros grupos no dominantes se han apoyado e instruido entre sí a lo largo de los siglos" ["the history of women's education can be recovered only if we broaden our definitions of education to take into account the formal and informal mechanisms by which women and other nondominant groups have supported and instructed each other through the centuries"].

${ }^{103}$ Bernardo Dorado, Historia de la ciudad de Salamanca (Salamanca: Imprenta del Adelante, 1861), p. 291. Para un listado de las referencias a Álvara de Alba en la bibliografía, véase Therese Oettel, "Una catedrática en el siglo de Isabel la Católica: Luisa (Lucía) Medrano", Boletín de la Real Academia de Historia, CVII (1935), pp. 289-368, pp. 316-317. María de los Dolores Gómez Molleda, "La cultura femenina en la época de Isabel la Católica", Revista de Archivos, Bibliotecas y Museos, LXI/1 (1955), pp. 137-195, pp. 187-188, se lamenta de lo infructuoso de su investigación en torno a Álvara de Alba: "No hemos podido dar con más detalles acerca de esta personalidad tan interesante. El Ayuntamiento de Vitigudino contestó a mi pregunta diciendo que en los libros parroquiales no constaba dato alguno [...]. El mismo resultado negativo obtuvieron una pregunta dirigida al Archivo de la Duquesa de Alba, en Madrid, y mi busca por el Tratado de Matemáticas, publicado por Álvara de Alba". 
hacia 1595 y se formó en Lyon. Se dice que sabía filosofía, teología, música, dibujo, jurisprudencia y catorce lenguas. Cuando tenía 12 años, “defendió Conclusiones publicas en Philosofia", a los 17 años "entraba a disputar públicamente en el Colegio de los Jesuitas de León” y, finalmente, ingresó en el Convento de Santa Praxedis de Aviñón. ${ }^{104}$ En su Historia bibliográfica de la medicina española, Antonio Hernández añade que “escribió varias obras que estuvieron á punto de salir á luz; pero arrepintiéndose luego no quiso que se imprimiesen". ${ }^{105}$ Desconocemos si escribió algún libro de música, así como el motivo que la disuadió de publicar sus obras.

Si bien las fuentes documentales que poseemos son limitadas, la investigación en contextos privados diferentes al conventual y otras esferas femeninas podría conducir a vislumbrar vestigios de mujeres ajenas al ámbito conventual que interpretaron y escribieron música y ejercieron como maestras de música; estos indicios serían sólo las huellas visibles de una rica actividad musical en la vida cotidiana. Un ejemplo es la poetisa catalana Tecla de Borja (1435-1459), que "tocava la lira i poetitzava”, pero de la que sólo se ha conservado poesía. ${ }^{106}$ Otro ejemplo es Laurencia Méndez de Zurita $(† 1599 / 1600)$, procedente de Madrid y "versadísima [...] en tan distintas disciplinas como Matemáticas, Retórica, Música, Latín, que escribía y hablaba perfectamente y además notabilísima poetisa". ${ }^{107}$ Aurea María del Carmen Martín Tordesillas, que da noticia de Laurencia Méndez Zurita en su discurso de apertura del año académico 1961/1962 titulado El Renacimiento y las humanistas españolas, toma como fuente la Varia Historia de sanctas e ilustres mugeres (Madrid, 1583) de Juan Pérez de Moya: “y con esto la musica de Canto y de harpa; en la qual tañe y canta los versos de Homero

\footnotetext{
${ }^{104}$ Benito Jerónimo Feijoo, Theatro critico universal o Discursos varios en todo genero de materias, para desengaño de errores comunes (Madrid: Lorenzo Francisco Mojados, 1726-1740), p. 388; véase también Don Gregorio Mayans y Siscar, Cartas militares, civiles, i literarias, de varios autores españoles (Madrid: en la Imprenta de Música por Francisco Asensio, 1756), vol. 2, pp. 242-243.

105 Antonio Hernández Morejón, Historia bibliográfica de la medicina española (Madrid: Viuda de Jordan e Hijos, 1843), vol. 3, p. 341.

106 Jaume Massó Torrents, "Poetesses i dames intellectuals", Estudis Universitaris Catalans, XI (1936), pp. 405-417, p. 412. Véanse también Fidel Fita Colomé, "Tecla de Borja", Boletín de la Real Academia de la Historia, X (1897), pp. 221-228; y Gómez Molleda, "La cultura femenina en la época de Isabel la Católica", pp. 190-191. Se conserva un poema de Tecla de Borja en respuesta a otro de Ausiàs March (c. 1397-1459); véase Ausiàs March, Obras poéticas de Mosen Ausias March, MS (1546), Madrid, Biblioteca Nacional de España, MSS/3695.
}

${ }^{107}$ Martín Tordesillas, El Renacimiento y las humanistas españolas, p. 45. 
Ovidio y Vergilio y los psalmos de David y otros hymnos ecclesiasticos tan facilmente como otra qualquiera Romana y contar castellano segun saben todos aquellos que la han visto". ${ }^{108}$ En el ámbito italiano, el ejemplo de Tecla de Borja recuerda a la música de tradición oral o poesía cantada del siglo XV en la que destacó Pietrobono del Chitarino (1417?-1497), cantante y laudista que pasó la mayor parte de su carrera en Ferrara, y del que, a pesar de su excelente reputación, no se conserva música escrita. ${ }^{109}$ Laurencia Méndez de Zurita evoca la música de la seconda prattica de finales del siglo XVI.

Aunque se ha afirmado que el convento era el único escenario en que las mujeres podían ejercer la enseñanza musical, ${ }^{110}$ encontramos que las mujeres enseñaban música en los ámbitos cortesano y doméstico, como ejemplifican los casos de Ángela Sigea y Paula Vicente, y Cecilia Morillas, respectivamente. Los estudios realizados en otras disciplinas acerca de la corte de María de Portugal (1521-1577) muestran que la infanta se rodeó de un grupo de mozas de cámara o "Academia de mujeres doctas" en que la composición musical y la enseñanza de la música jugaban un importante papel, principalmente gracias a las figuras de Ángela Sigea y Paula Vicente. ${ }^{111}$ Procedentes de Tole-

\footnotetext{
108 Juan Pérez de Moya, Varia Historia de sanctas e ilustres mugeres (Madrid: Francisco Sánchez, 1583), f. 310; citado en Martín Tordesillas, El Renacimiento y las humanistas españolas, p. 46. Para otra bibliografía sobre Laurencia Méndez de Zurita, véanse: José Antonio Álvarez y Baena, Hijos de Madrid ilustres en Santidad, Dignidades, Armas, Ciencias, Artes (Madrid: Benito Cano, 1790), p. 339; Antonio, Bibliotheca Hispana Nova, vol. 2; p. 350; Vega, Laurel de Apolo, f. 10r, Silva I; y Pietro Paolo di Ribera, Le glorie inmortali Apologetiche de' trionfi et heroica imprese d'ottocento quarantacinque Donne ilustri antiche e moderne dotate di condicione e scienze segnalate: cioé in sacra Scrittura, Teologia, Profetia, Filosofia, Greco, Rettorica, Grammatica, Medicina, Astrologia, Leggi Civili, Pittura, Musica e Armi (Venecia: Deuchino, 1609), p. 331.
}

${ }^{109}$ Lewis Lockwood, "Pietrobono and the Instrumental Tradition at Ferrara in the Fifteenth Century", Rivista italiana di musicologia, 10 (1975), pp. 115-133; y Music in Renaissance Ferrara, pp. 103-118, "Pietrobono and the Improvisatory Tradition"; y Nino Pirrotta, Music and Culture in Italy from the Middle Ages to the Baroque: A Collection of Essays (Cambridge, Mass., y Londres: Harvard University Press, 1984), pp. 90-91 y 94-96. Aunque se había atribuido a Peri la invención del recitativo, teorías posteriores sostienen que el recitativo surgió antes del Barroco, puesto que se fue gestando en las obras monódicas con acompañamiento instrumental de la corte de Nápoles; véase John Water Hill, Roman Monody, Cantata and Opera from the Circles Around Cardinal Montalto (Oxford: Clarendon Press, 1997), vol. 1, pp. 119-120.

${ }^{110}$ Olarte Martínez, “Las 'monjas músicas' en los conventos españoles del Barroco", señala que "de los datos conocidos hasta el momento, se puede deducir que el único sitio donde las mujeres podían ejercer la enseñanza musical era en los conventos femeninos", puesto que "en todas las capillas nobiliarias las referencias son de maestros, siendo todos sus integrantes varones"; y Aguirre Rincón, "Sonido en el silencio", p. 299: "Recordemos además que el cenobio parece ser el único contexto en el que el ejercicio de la docencia por mujeres sí estaba bien visto".

${ }^{111}$ Carolina Michaëlis de Vasconcelos, A Infanta D. Maria de Portugal e as Suas Damas (Oporto: Typ. a Vapor Arthur José de Souza, 1902); Pedro Álvarez Cifuentes, “Juego de damas: una corte femenina en el 
do, Ángela Sigea y su hermana, la conocida escritora Luisa Sigea, fueron formadas en música y letras por su padre Diego Sigeo, que había estudiado en la Universidad de Alcalá de Henares y se había convertido en un reconocido preceptor de los hijos de las familias aristócratas. Ambas fueron llamadas a la corte de Catalina de Austria como "mozas de cámara" y a continuación pasaron al servicio de su sobrina, la infanta María, como preceptoras. ${ }^{112}$ Aunque Luisa y Ángela habían recibido la misma formación, la primera destacó en las letras y la última en la música, como reflejan los cronistas contemporáneos y los posteriores biógrafos de Luisa Sigea: ${ }^{113}$ "Angela Sigea, hermana de Luisa, fue también instruida en idiomas; pero en lo que mas sobresalió fue en la música, en la que era eminente profesora". ${ }^{114}$ Los estudios apuntan a que Ángela Sigea (véase Ilustración VI.4) ejerció como maestra de música y compositora en la corte femenina de la infanta María de Portugal: “y cuando se habla de esta 'ilustrada corte femenina', junto a Luisa aparece su hermana Ángela, dedicada fundamentalmente a la música, a dar clases, a componer piezas musicales y a interpretarlas". 115

\footnotetext{
quinhentismo portugués", en Las revolucionarias. Literatura e insumisión femenina, ed. por Estela González de Sande y Ángeles Cruzado Rodríguez (Sevilla: ArCiBel, 2009), pp. 41-57, p. 51.

112 Álvarez Cifuentes, “Juego de damas”, p. 47.

${ }^{113}$ Véanse las siguientes crónicas contemporáneas: Juan Vaseo, Chronica rerum memorabilium Hispaniae (Salamanca: Ioannes Iunta, 1552), p. 593; Andreas Schottus, Hispaniae biblioteca seu de Academiis ac Bibliothecis. Item Elogia et nomenclator clarorum Hispaniae scriptorum (Frankfurt: Claudium Marnium et haeredes Ioan Aubrii, 1608), p. 341; Frei Luis dos Anjos, Jardim de Portugal, em que se da noticia de algumas Santas, e outras mulheres ilustres em virtude, as quais nasceram ou viveram, ou estao sepultadas neste Reino, e suas conquistas (Coimbra: N. Carvalho, 1626); António de Sousa de Macedo, Flores de España excelencias de Portugal: en que breuemente se trata lo mejor de sus historias, y de todas las del mundo desde su principio hasta nuestros tiempos, y se descubren muchas cosas nueuas de prouecho, y curiosidad (Lisboa: Iorge Rodriguez, 1631), p. 69; Miguel Pacheco, Vida de la Serenissima Infanta Doña Maria hija del Rey D. Manoel, Fundador de la insigne Capilla mayor del Convento de N. Señora de la Luz, y de su Hospital, y otras muchas casas dedicadas al culto divino (Lisboa: Juan Costa, 1675), p. 84. Sobre la controvertida atribución a Luisa Sigea de una obra erótica de Aloisiae Sigeae Toletanae en latín publicada en Lyon en 1660, véanse Nicholas Chorier, The Dialogues of Luisa Sigea (North Hollywood: Brandon, 1965); y María Antonia Bel Bravo, Mujeres españolas en la historia moderna (Madrid: Sílex, 2002), p. 75.

${ }^{114}$ Hernández Morejón, Historia bibliográfica de la medicina española, vol. 3, p. 340, nota 1.

${ }^{115}$ Sigea, Epistolario latino, p. 58.
} 
Ilustración VI.4: Retrato de Ángela Sigea conservado en la Biblioteca de Castilla-La Mancha en Toledo; reproducido en: Aurea María del Carmen Martín Tordesillas, El Renacimiento y las humanistas españolas: discurso de apertura del año académico 1961-62 (Toledo: Publicaciones del Instituto Nacional de Enseñanza Media de Toledo, 1961), p. 61.

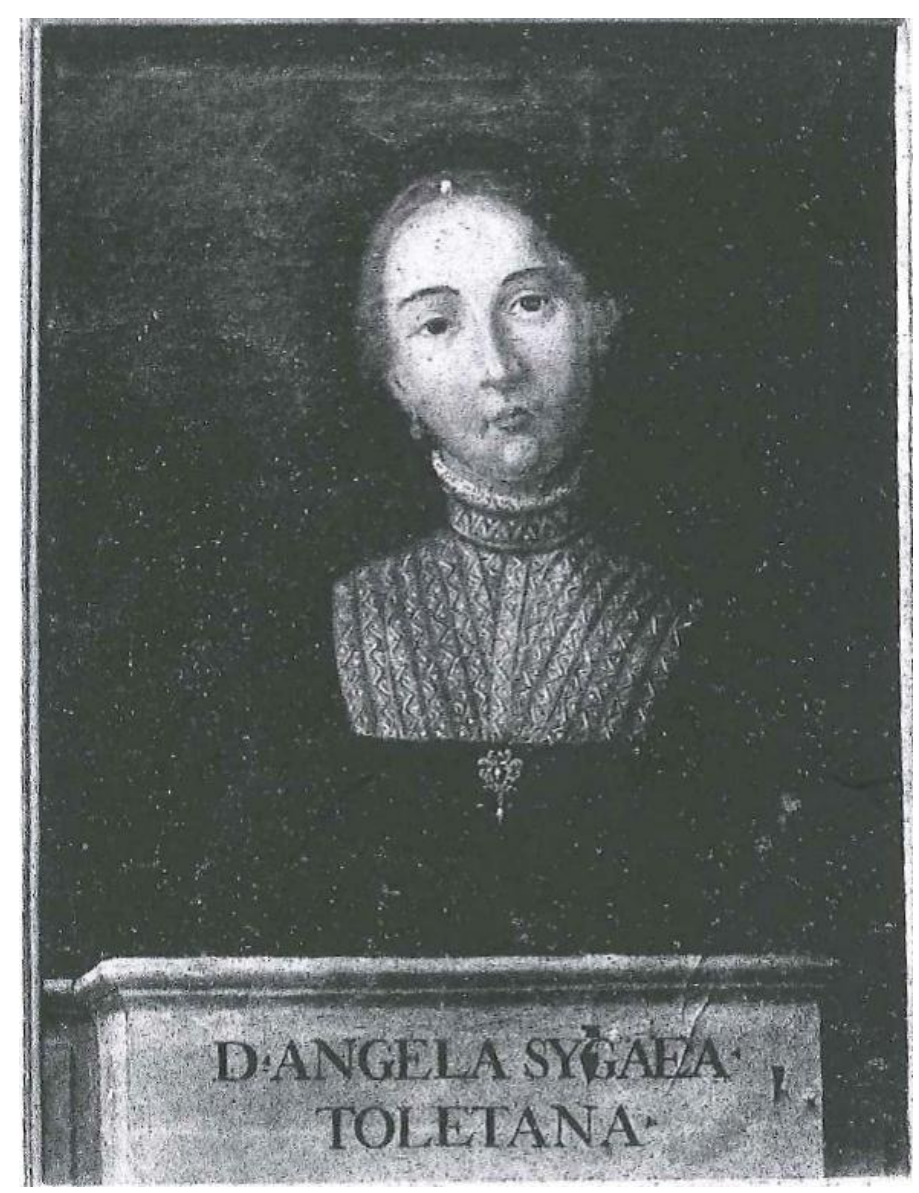

Desconocemos cuáles eran los contenidos exactos de las lecciones de música impartidas a María de Portugal por sus mozas de cámara. Se ha dicho que Luisa y Ángela Sigea enseñaron a la infanta "el arte de tocar varios instrumentos -entre ellos, el arpa y el órgano". ${ }^{116}$ Los contenidos musicales debieron de imbricarse en un conjunto formativo más amplio en el que la música constituía un componente más. También moza de cámara de la infanta María de Portugal, Paula Vicente (Lisboa, 1519-1576), hija del dramaturgo Gil Vicente, aparece en los registros de la Corte como "A Tangedora" y

${ }^{116}$ Álvarez Cifuentes, “Juego de damas”, p. 45. 
fue "maestra en este arte de las demás jóvenes". ${ }^{117}$ Las fuentes indican que no sólo impartía lecciones de música, puesto que escribió para María de Portugal un manual de inglés y holandés titulado Arte da lingua inglesa e holandesa para instrução dos seus naturais. ${ }^{118}$ No obstante, las facetas que más se han destacado de Paula Vicente son las de actriz y escritora de obras de teatro; ${ }^{119}$ junto a su hermano Luiz, editó la producción teatral de su padre y la publicó. ${ }^{120}$

Las mujeres podían ejercer como maestras de música no sólo en los ámbitos conventual y cortesano, sino también en el medio doméstico, como prueba el caso de Cecilia Morillas (Salamanca, c. 1530-Valladolid, 1581). Cecilia Morillas estudió en la Universidad de Salamanca a la vez que su hijo mayor con el propósito de poder hacerse cargo de la formación de sus hijos menores. Los cronistas indican que "convirtiò su Casa en Universidad, ocupando ella sola las Catedras de Gramatica latina y griega, de Retorica, de Musica, de Filosofia y Teologia", ${ }^{121}$ y Lope de Vega ensalza su labor docente. ${ }^{122}$ Se ha señalado que la reputación de Cecilia Morillas como profesora llegó a oídos de Felipe II y que éste "le ofreciò el cargo honroso de Maestra de las Infantas, pero ella rogò al Rey que se dignase relevarla de este honor, para poder perficionar la educación de sus hijos". ${ }^{123}$ Desconozco si existe algún documento que permita confir-

\footnotetext{
117 Thereza Leitão de Barros, Escritoras de Portugal. Génio revelado na literatura portuguesa (Lisboa: Antonio O. Aztur, B. Coelho da Rocha, 1924), pp. 75-78; Sigea, Epistolario latino, p. 27.

${ }^{118}$ Leitão de Barros, Escritoras de Portugal, p. 76; Álvarez Cifuentes, “Juego de damas”, p. 51.

${ }^{119}$ Reina Ruiz, Monstruos, mujer y teatro en el Barroco: Feliciana Enríquez de Guzmán, primera dramaturga española (Nueva York: Peter Lang, 2005), p. 2, nota 2: "Nicolás Antonio le atribuye [a Paula Vicente] una obra en portugués titulada $O$ cerco de Dio, y Menéndez Pelayo sostiene que ésta ayudaba a su padre a componer comedias. De ser ciertas estas conjeturas, Paula Vicente sería la primera escritora dramática de la Península”.
}

${ }^{120}$ Gil Vicente, Compilação de todas las obras de Gil Vicente (Lisboa: João Álvarez, 1562).

${ }^{121}$ Francisco Javier Lampillas, Ensayo historico-apologetico de la literatura Española contra las opiniones preocupadas de algunos Escritores modernos Italianos, trad. por Josefa Amar y Borbón (Zaragoza: Blas Miedes, 1782-1784), vol. 2, p. 363.

122 Lope de Vega, "Oración y discurso que para dar principio al certamen Poetico hizo LdV en alabanza de N. M. S. Teresa de Iesus", en Compendio de las solenes fiestas que en toda España se hicieron en la Beatificacion de N.M.S. Teresa de Iesus (Madrid: Viuda Alonso Martin, 1615), p. 5. Citado en Simón Anselmus Vosters, "Lope de Vega y las damas doctas", en Actas del Tercer Congreso Internacional de Hispanistas, coord. por Carlos H. Magis (Ciudad de México: El Colegio de México, 1970), pp. 909-921, pp. 915-916.

${ }^{123}$ Lampillas, Ensayo historico-apologetico, p. 363. 
mar esta oferta de Felipe II a Cecilia Morillas. Además de su labor docente, Cecilia Morillas ayudaba a su marido, el bachiller Antonio Sobrino, en sus tareas como administrador de la Universidad de Valladolid. La destreza de Cecilia Morillas como cantante e instrumentista, destacada en la bibliografía, se refleja en la formación que proporcionó a sus hijos. ${ }^{124}$ Tres de ellos sobresalieron como músicos: José Sobrino, capellán del archiduque Alberto y catedrático de la Universidad de Valladolid, "fué músico eminente y en tal concepto muy estimado por Felipe II", ${ }^{125}$ y Sor María de San Alberto (1568-1640) y Sor Cecilia del Nacimiento (1570-1646) destacaron como poetisas y músicas, como se detallará en el Capítulo VII. ${ }^{126}$

${ }^{124}$ Siete cartas de Cecilia Morillas y su testamento autógrafo fechado a 25 de julio de 1580 se conserva en Valladolid, Convento de la Concepción de Nuestra Señora del Carmen, OCD, K1, ff. 4r-16v. También disponemos de una biografía manuscrita de su hijo con referencias a ella: Diego de San Joseph, Relacion de cosas memorables de la vida y muerte del señor don Francisco Sobrino, Obispo de Valladolid, y de sus padres y hermanos. Dedicado al mismo señor Obispo [...] Por Fray Diego de San Joseph su hermano, Carmelita Descalzo, MS (1640), Valladolid, Convento de la Concepción de Nuestra Señora del Carmen (existe otro ejemplar en la Catedral de Valladolid); citado en Blanca Alonso-Cortés, Dos monjas vallisoletanas poetisas (Valladolid: Imprenta Castellana, 1944), p. 7, nota 5. Véanse también Lampillas, Ensayo historico-apologetico, p. 362-363; y Memorial literario instructivo y curioso de la Corte de Madrid (Madrid: Imprenta Real, 1785), vol. 5, p. 152-153; Amar y Borbón, Discurso sobre la educacion fisica y moral de las mugeres, p. 307; José Gefe de Villa, Manual de curiosidades, ó sea, Recopilacion de noticias históricas, geográficas, estadísticas, etc., útil á toda clase de personas (Madrid: Tomás Jordán, 1832), p. 83; Repertorio de literatura y variedades (Ciudad de México: Imprenta del Repertorio, 1841), vol. 1, p. 184; Hernández Morejón, Historia bibliográfica de la medicina española, vol. 3, p. 340, nota 1; Vicente Díez Canseco, Diccionario biografico universal de mujeres célebres: ó compendio de la vida de todas las mujeres que han adquirido celebridad en las naciones antiguas y modernas, desde los tiempos mas remotos hasta nuestros dias (Madrid: José Felix Palacios, 1845), vol. 3, p. 232; Francisco de Paula Mellado, Diccionario universal de historia y de geografía (Madrid: Francisco de Paula Mellado, 1848), vol. 7. p. 294; Dorado, Historia de la ciudad de Salamanca, p. 291-292: "El Seminario de Salamanca, periódico que se publicaba á fines del siglo próximo pasado, de donde tomamos estas noticias, hace los mayores elogios de aquella señora"; Juan Pérez de Guzmán, Bajo los Austrias: la mujer española en la minerva literaria castellana (Madrid: Escuela Tip. Salesiana, 1923), p. 58; Arenal y Schlau, Untold Sisters, pp. 131-141; María Dolores Pérez Lucas, Mujeres singulares salmantinas (220 a.C.-S. XIX) (Salamanca: Diputación Provincial de Salamanca, 1989), pp. 113-115; Javier Portús Pérez, Pintura y pensamiento en la España de Lope de Vega (Hondarribia, Guipuzkoa: Nerea, 1999), p. 62; Javier Burrieza Sánchez, "Una mujer moderna en el siglo XVI", Diario de Valladolid (6 de noviembre de 2004), p. 2; Vollendorf, The Lives of Women, p. 198; y Jesús Rebollo Prieto, "Las escritoras de Castilla y León (14001800). Ensayo bibliográfico", Tesis Doctoral (Ph.D.), Universidad Nacional de Educación a Distancia, 2006.

${ }^{125}$ Alonso-Cortés, Dos monjas vallisoletanas poetisas, p. 11.

${ }^{126}$ Elizabeth Teresa Howe, Education and Women in the Early Modern Hispanic World (Aldershot: Ashgate, 2008), p. 81: "Cecilia del Nacimiento demostró ser una artista, música y poeta consumadas, complementando los talentos de su hermana mayor como dramaturga" ["Cecilia del Nacimiento proved to be an accomplished artist, musician, and poet, complementing her elder sister's talents as a dramatist"]; Serrano y Sanz, Apuntes para una biblioteca de escritoras españolas, vol. 2, p. 473: "Cecilia Sobrino, que adquirió notables conocimientos en latín, humanidades, pintura y poesía y que profesó en el Carmen descalzo de Valladolid (m. 1646). Escribió la vida de su hermana, María de San Alberto, notable música, que falleció con fama de santidad en el año 1640". 
En conclusión, las mujeres componían música y ejercían como maestras de música en contextos diferentes al conventual. La corte femenina de María de Portugal, las monjas de la Piedad de Guadalajara María de Arellano y Isabel de Aguiar, y las poetas músicas Tecla de Borja y Laurencia Méndez de Zurita evidencian que, si bien disponemos de indicios para vislumbrar una participación activa de las mujeres en la vida musical, el registro escrito de la música parece no haber recibido en la época la misma atención que la conservación de producciones literarias. ${ }^{127}$ Es probable que la reputación como música de Ángela Sigea haya llegado hasta nosotros en parte como consecuencia de los numerosos trabajos llevados a cabo acerca de su hermana, reconocida escritora. ${ }^{128}$ Ambas recibieron la misma formación de su padre en música y letras; la diferencia es que Ángela fue sobresaliente en la música y no se han conservado muestras de su actividad musical, mientras que Luisa destacó en las letras dejando obras escritas para la posteridad. ${ }^{129}$ De manera similar, sabemos de la labor de Cecilia Morillas en la docencia de la música en parte debido a los estudios realizados sobre dos de sus hijas, María de San Alberto y Cecilia del Nacimiento, monjas Carmelitas Descalzas de Valladolid que destacaron como poetisas y autoras de textos místicos. ${ }^{130}$ Por consiguiente, si bien la

\footnotetext{
${ }^{127}$ Vasconcelos, A Infanta D. Maria de Portugal e as Suas Damas, p. 43: “Ángela y Paula, representantes de la tradición portuguesa o Escuela vieja, nos llevan del gabinete de estudio a las salas de recepción. Fiestas, íntimas o solemnes, sin el suave concierto de instrumentos músicos, tocados por damas gentiles, acompañando cantigas, 'vilancetes', chistes, elegías, églogas o danzas artísticamente ordenadas; saraos sin declamación de versos, juegos de espíritu, motes glosados; representaciones improvisadas sobre temas dados, o previamente estudiadas, ¿quién las podrá imaginar?" ["Angela e Paula, representantes da tradição portuguesa ou Escola velha, conduzem-nos do gabinete de estudo às salas de recepção. Festas, quer intimas, quer solemnes, sem o suave concerto de instrumentos músicos, tocados por damas gentis, acompanhando cantigas, vilancetes, chistes, elegias, eglogas ou danças artisticamente ordenadas; serões sem declamação de versos, jogos de espirito, motes glosados; representações improvisadas sobre themas dados, ou previamente estudadas, quem as poderá imaginar?"]. Ángela Sigea aparece como "musica da mesma Princesa" en el drama António Feliciano de Castilho, Camões, estudo historico-poetico liberrimanente fundado sobre um drama francez dos senhores Victor Perrot, e Armand du Mesnil (Ponta Delgada: Typographia da Rua das Artes 68, 1849).

${ }^{128}$ Serrano y Sanz, Apuntes para una biblioteca de escritoras españolas, vol. 2, pp. 394-401; Isabel Barbeito Carneiro, "Mujeres peninsulares entre Portugal y España", Península: revista de estudios ibéricos, 0 (2003), pp. 209-224; Sigea, Epistolario latino; y Miguel Ángel Pérez Priego, ed., Melchor Cano y Luisa Sigea. Dos figuras del Renacimiento español (Cuenca: Ayuntamiento / Centro Asociado de la UNED, 2008).

${ }^{129}$ Por ejemplo, la propia Laura Sigea relataba su experiencia en la corte en el manuscrito Duarum virginum Colloquium de vita aulica et privata (1552), Toledo, Biblioteca Provincial, Signatura BorbónLorenzana, $\mathrm{n}^{\circ}$ 335. Para una edición del relato, véase Luisa Sigea, Dialogue de deux filles sur la vie de cour et la vie de retraite (1552), ed. por Odette Sauvage (París: Presses universitaires, 1970).
} 
aproximación a la autoría femenina en el campo musical resulta problemática debido a la escasez de fuentes y a la necesidad de adentrarse en la esfera privada, la utilización de aproximaciones más indirectas, como por ejemplo las llevadas a cabo desde la perspectiva literaria, y el estudio de los puntos de superposición entre lo privado y lo público (como la publicación de una muestra de la música creada en la clausura) constituyen mecanismos para afrontar este fenómeno de invisibilidad, puesto que permiten vislumbrar vestigios no sólo de la existencia de una rica vida musical en esferas femeninas, sino también de la fuerte imbricación de la música en el entramado cultural de la época.

\subsection{Mujeres impresoras de libros de música}

La misma superposición entre lo privado y lo público se manifiesta en el caso de las mujeres impresoras de artes de canto, otro ejemplo de invisibilidad en documentos históricos. ${ }^{131}$ La bibliografía sobre impresoras consiste en su mayoría en estudios de figuras individuales, como Isabel de Basilea, viuda de Juan de Junta; ${ }^{132}$ Brígida Maldonado, viuda de Juan Cromberger; ${ }^{133}$ y Jerónima de Gales, viuda de Joan Mey y de Pedro Huete. ${ }^{134}$ En general, los testimonios de presencia femenina en la imprenta emergían sólo cuando el jefe del taller moría y su viuda asumía la responsabilidad del negocio.

\footnotetext{
${ }^{130}$ Véanse, por ejemplo, los ya mencionados estudios Alonso-Cortés, Dos monjas vallisoletanas poetisas; y Rebollo Prieto, "Las escritoras de Castilla y León (1400-1800)"; así como Isabelle Poutrin, Le voile et la plume: autobiographie et sainteté féminine dans l'Espagne moderne (Madrid: Casa de Velázquez, 1995).

${ }^{131}$ Encontramos un ejemplo similar de invisibilidad en otras artesanas vinculadas a la música: las mujeres constructoras de instrumentos musicales. Diego Pacheco, "Beyond Church and Court", p. 375, da noticia de un contrato de 1536 por el cual Alonso de las Moras de Burgos se obligaba con el violero de Valladolid Pedro de Arratia a entregarle "todas las cuerdas que mi mujer hiciere de su mano". El documento se encuentra en Valladolid, Archivo Histórico Provincial de Valladolid, legajo 92, f. 529r.
}

132 Aristide Rumeau, "Isabel de Basilea 'mujer impresora'?", Bulletin hispanique, LXXIII (1971), pp. 231-247.

${ }^{133}$ Clive Griffin, "Brígida Maldonado 'ynprimidora' sevillana, viuda de Juan Cromberger", Archivo hispalense, LXXVI (1993), pp. 83-120.

${ }^{134}$ María del Mar Fernández Vega, “Jerónima de Gales. Una impresora valenciana del siglo XVI”, en $L a$ memoria de los libros: estudios sobre la historia del escrito y de la lectura en Europa y América, coord. por María Isabel de Páiz Hernández, Pedro Manuel Cátedra García y María Luisa López-Vidriero (Salamanca: Instituto de Historia del Libro y de la Lectura, 2004), vol. 1, pp. 405-434. En este trabajo se hace referencia a la "escasa consideración que la crítica ha prestado al trabajo de las mujeres en la imprenta". Para un volumen colectivo sobre mujeres impresoras en el mundo ibérico, véase Marina Garone Gravier y Albert Corbeto i López, eds., Muses de la impremta: la dona i les arts del llibre. Segles XVI-XIX [Catálogo de la exposición] (Barcelona: Museu Diocesá, 2009). 
Sin embargo, incluso en tales circunstancias, los nombres de estas mujeres raramente aparecían en los colofones puesto que firmaban como "viuda de...". Juan Luis Vives recomendaba a las viudas volver a casarse o hacerse monjas con el fin de evitar la indeseable libertad asociada con la viudedad. ${ }^{135}$ En el caso de mujeres artesanas como las impresoras, casarse en segundas nupcias con otro impresor era un medio de continuar o fortalecer la empresa. La conexión entre mujeres impresoras y viudedad podría llevar a pensar que la implicación de la mujer con la imprenta era circunstancial y provisional. Sin embargo, puesto que estos talleres eran negocios familiares normalmente localizados dentro del hogar del impresor, las mujeres debían de haber estado trabajando en ellos en vida de sus maridos, si bien raramente quedaba documentado. En su estudio sobre la vida laboral de las mujeres del siglo XVII, Alice Clark comenta las dificultades que existen para determinar "cuánto trabajo de la mujer se destinaba al negocio y cuánto se confinaba al servicio de sus familias", dada la inexistencia de una línea clara que dividiera las ocupaciones domésticas de las de la empresa. ${ }^{136}$

Se ha dicho que se produjo una endogamia casi "programática" dentro del gremio de los impresores. La norma común era que el joven miembro de una familia de impresores procedente de Europa fuese enviado a España como aprendiz, se integrara en el negocio de uno de los socios de su padre y conviviera con su familia; el joven se casaría con la hija de su patrón y heredaría la empresa, o bien, si fallecía el dueño, se casaría con su viuda. ${ }^{137}$ A este significativo papel desempeñado por las mujeres en el progreso de la industria de la imprenta en el mundo ibérico debería añadirse su participación "en todos los aspectos del negocio". ${ }^{138}$ Por ejemplo, María del Carmen Álvarez

\footnotetext{
${ }^{135}$ Vives, Instruccion de la muger christiana, p. 460.

${ }^{136}$ Alice Clark, Working Life of Women in the Seventeenth Century (Londres: Routledge, 1992 [1919]), p. 290: "no hard and fast line dividing domestic occupations from other branches of industry, and thus it has not been possible to discover how much of women's labour was given to purposes of trade and how much was confined to the service of their families". Véase también Merry E. Wiesner-Hanks, Women and Gender in Early Modern Europe (Cambridge: Cambridge University Press, 1993), pp. 102-142.

${ }^{137}$ Lafaye, Albores de la imprenta, p. 34; Bernstein, Music Printing in Renaissance Venice, p. 17: "Oficiales y jóvenes aspirantes a impresores buscarían matrimonios estratéticos con las hijas de hombres del libro ya establecidos" ["Journeymen and aspiring young printers would seek strategic marriages to the daughters of established bookmen"].

${ }^{138}$ Nancy Joe Dyer, "Dowagers and Heiresses in the Printing Industry in Late Medieval Spain", en Women at Work in Spain: From the Middle Ages to Early Modern Times, ed. por Marilyn Stone y Carmen Benito-Vessels (Nueva York: Peter Lang, 1998), pp. 65-80, p. 65.
} 
Márquez proporciona indicios de presencia femenina en el negocio del libro en la Sevilla del siglo XVI, ${ }^{139}$ mientras que Pedro Cátedra y Anastasio Rojo señalan que algunas mujeres aprendieron a leer y escribir después de casarse con el propósito de participar en los negocios de sus maridos. ${ }^{140}$ Por tanto, los pocos casos en que existen referencias explícitas para relacionar a mujeres impresoras con libros de música podrían ser sólo el vestigio visible de años de trabajo invisible.

Como mencioné en el Capítulo III, dos mujeres imprimieron ediciones del Arte de canto llano (Sevilla, 1530) de Juan Martínez. La edición de 1562, hasta ahora desconocida, fue impresa en Zaragoza por María de Solórzano, viuda de Bartolomé de Nájera. María de Solórzano se había casado en 1545 y enviudó en 1561. La firma "biuda de Bartholome de Nagera" o "viuda de B. Naxera" aparece en libros impresos entre 1562 y 1572. ${ }^{141}$ Hacia 1598, otra edición (generalmente inadvertida en la bibliografía) del libro de Martínez fue impresa en Alcalá de Henares por María Ramírez, viuda de Juan Gracián. De esta imprenta habían salido obras como La Galatea (1585) de Miguel de Cervantes. María Ramírez continúo el negocio desde el fallecimiento de su marido en 1588 hasta 1624. A excepción de una edición de 1600 de Selva de aventuras de Jerónimo de Contreras, en la que incluyó su nombre en el colofón, María Ramírez siempre firmaba como "viuda de" o bien incluía alguna fórmula como "en casa de Juan Gracián, que sea en gloria". No sabemos qué apelativo aparece en el colofón del Arte de canto llano de Juan Martínez, puesto que el ejemplar conservado carece de la portada. En este caso encontramos el nombre de la impresora ("Maria Ramirez, viuda") sólo en la licencia de impresión firmada por el escribano Gonzalo de la Vega el 22 de agosto de 1598.

La última mujer relacionada con la imprenta de artes de canto entre 1492 y 1626 que he localizado es Susana Muñoz, viuda del prestigioso impresor de Amberes Artus Taberniel (†1609). Susana Muñoz trabajó en Salamanca y llevó a cabo la reimpresión de 1616 del Arte de canto llano de Francisco de Montanos (véase Ilustración VI.5) y la única edición del Libro de Misas Magnificats y Motetes (1620) de Diego de Bruceña, actualmente perdido. El caso de Susana Muñoz muestra que las viudas impresoras fre-

\footnotetext{
139 Álvarez Márquez, La impresión y el comercio de libros en la Sevilla del quinientos, pp. 283-295.

${ }^{140}$ Cátedra García y Rojo Vega, Bibliotecas y lecturas de mujeres, p. 38.

141 Ángel San Vicente Pino, Apuntes sobre libreros, impresores y libros localizados en Zaragoza entre 1545 y 1599. II: Los impresores (Zaragoza: Gobierno de Aragón, Departamento de Cultura y Turismo, 2003), p. 219.
} 
cuentemente se casaban con otro impresor y cualquier referencia a ellas en los colofones desaparecía de nuevo. La firma de Susana Muñoz aparece en colofones entre 1610 y 1621, primero como "viuda de Artus Taberniel” y después utilizando su propio nombre, en contraste con los dos casos presentados previamente. Esta impresora constituye un ejemplo del trabajo conjunto esposa-esposo esencial para el funcionamiento de un ta1ler-hogar. ${ }^{142}$ Alejandro Luis Iglesias ha señalado que Susana Muñoz ya era la heredera de "una rica tradición de impresos musicales" cuando imprimió el Libro de Misas, Magnificats y Motetes de Diego de Bruceña, ${ }^{143}$ puesto que bajo el nombre de Taberniel, su marido, se habían publicado tres libros de polifonía de Sebastián de Vivanco y dos de Juan Esquivel. ${ }^{144}$ Susana Muñoz tuvo que haber participado en la impresión de esos libros si cuando enviudó estaba cualificada para llevar a cabo la impresión del de Bruceña. Cabe preguntarse si esta impresora conocía la escritura musical o si era asistida por compositores y correctores de pruebas. Posteriormente, Susana Muñoz se casó en segundas nupcias con el también impresor Antonio Vázquez y el nombre incluido en los colofones pasó a ser el de éste, como muestra por ejemplo la edición de 1625 del Arte de canto llano de Montanos, que se llevó a cabo en la misma imprenta pero, en esta ocasión, bajo la firma de Antonio Vázquez.

\footnotetext{
${ }^{142}$ Clark, Working Life of Women in the Seventeenth Century, pp. 150-235.

${ }^{143}$ Luis Iglesias, "El maestro de capilla Diego de Bruceña”, p. 461.

144 Sebastián de Vivanco, Liber Magnificarum (1607), Libro de misas (1608) y Liber motectorum (1610); Juan Esquivel, Missarum [...] liber primus (1608) y Motecta festorum et dominicarum (1608). Véase Iain Fenlon, "Artus Taberniel: Music Printing and the Book Trade in Renaissance Salamanca”, en Early Music Printing and Publishing in the Iberian World, ed. por Iain Fenlon y Tess Knighton (Kassel: Reichenberger, 2006), pp. 117-146.
} 
Ilustración VI.5: Francisco de Montanos, Arte de canto llano (Salamanca: Susana Muñoz, 1616 [1594]). Baviera, Bayerische Staatsbibliothek, Mus.th. 7349.

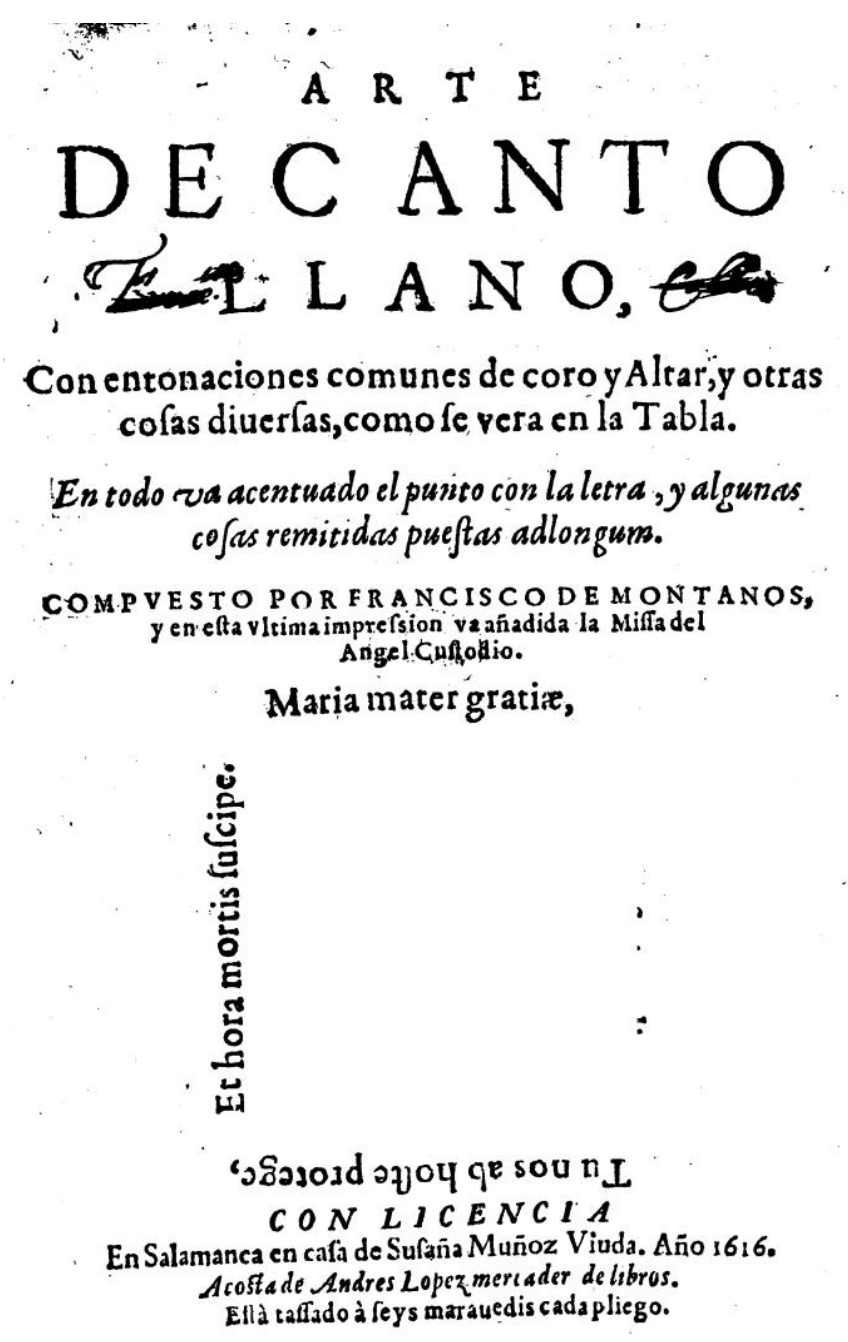

En resumen, vestigios ocasionales de mujeres trabajando en los campos tradicionalmente masculinos de la composición y la imprenta musical se hacen visibles en los contextos en que lo privado y lo público no son fácilmente distinguibles, como la música de los conventos y la mezcla de hogar y taller de imprenta. Además, en el caso del himno de Gracia Baptista percibimos que otro lugar de superposición permite vislumbrar la actividad musical en la vida cotidiana: las circunstancias en que prácticas orales o improvisatorias son registradas en documentos escritos. Éste es el objeto de la siguiente sección. 


\section{LA SUPERPOSICIÓN DE TRADICIÓN ORAL Y CULTURA ESCRITA:}

\section{ARTES DE CANTO Y CANCIONEROS}

Para evitar el "falso sentido de familiaridad con el pasado" del que advierte Robert Darnton, debemos tener presente que en el mundo ibérico renacentista la música escrita no tenía la misma significación que en la actualidad. Como se señaló en el Capítulo IV, la enseñanza de la música se basaba en prácticas orales y mnemotécnicas y los límites entre interpretación y composición no estaban claramente definidos. Por ejemplo, Soterraña Aguirre afirma que algunas monjas iletradas podían interpretar canto figurato e improvisarlo mnemotécnicamente. ${ }^{145}$ La importancia de la oralidad en la vida musical del siglo XVI se ha enfatizado en los trabajos musicológicos de Kate van Orden sobre el contexto francés, y en los estudios de Giuseppe Fiorentino (la polifonía de tradición oral y su influencia sobre los compositores) y Cristina Diego (la oralidad del madrigal como algo selecto) sobre casos ibéricos. ${ }^{146}$ La percepción del papel predominante de la oralidad en la historia de la música no sólo contrarresta el fuerte impacto atribuido a la imprenta, como ha señalado Kate van Orden, ${ }^{147}$ sino que también muestra el carácter fragmentario de los estudios musicológicos normalmente basados en música escrita.

Como se detalló en el Capítulo II, la creación de libros de música en lengua vernácula, el sensible descenso de los precios que conllevaba la imprenta y el diseño de volúmenes de pequeño formato como las artes de canto son factores que debieron conducir a un incremento de la propiedad individual de libros de música entre grupos previamente excluidos del aprendizaje de esta disciplina. Este apartado explora la vinculación de las mujeres con la utilización de artes de canto y cancioneros poéticos, categorías librescas que comparten dos rasgos relevantes. En primer lugar, sus características físicas y temáticas sugieren que podrían haber formado parte de una categoría comercial precisa, los "libritos de mujeres". En segundo lugar, constituyen artefactos materiales que preservan la contemporánea superposición de tradiciones musicales orales y cultura

\footnotetext{
${ }^{145}$ Aguirre Rincón, “Sonido en el silencio”, p. 298.

${ }^{146}$ Orden, "Children's Voices"; Giuseppe Fiorentino, "La música de 'hombres y mugeres que no saben de música': polifonía de tradición oral en el Renacimiento español", Revista de Musicología, XXXI/1 (2008), pp. 9-39; Diego Pacheco, "Circulación y producción del madrigal en España durante el siglo XVI".

${ }^{147}$ Orden, “Children’s Voices", p. 219.
} 
escrita. Es más, los cancioneros poéticos, muchos vinculados especialmente con las mujeres y con los niños, podrían haberse visto en la época como "libros de música", puesto que, si bien no contenían notación musical, sus versos estaban concebidos para ser cantados. Tal vocalización de la poesía apoyaría la hipótesis de que las mujeres del Renacimiento "participaron en la cultura musical de Europa más plenamente de lo que los registros escritos documentan". ${ }^{148}$

\subsection{Libritos de mujeres $y$ artes de canto}

Yten mando que den a Leonor Alvarez, mi muger, todos los libros de romance que yo tengo que no sean de leyes ni de derechos $\left[\ldots . .{ }^{149}\right.$

El Apéndice 17 presenta un vaciado de los libros de música que aparecen en los inventarios de bienes de diecinueve mujeres. A pesar de sus limitaciones, estos inventarios proporcionan testimonio de la propiedad de libros de música por parte de mujeres del ámbito religioso y del secular insertas en un amplio rango de estratos sociales y muestran, además, la prominencia de un género en particular: los libros de canto. ${ }^{150}$ Tres casos que Pedro Manuel Cátedra y Anastasio Rojo han sacado a la luz en su investigación de las bibliotecas de mujeres en el Valladolid del siglo XVI son especialmente interesantes desde la perspectiva musical. ${ }^{151}$ En primer lugar, la biblioteca de Ana de Mendoza, una mujer de la clase artesana, estaba constituida únicamente por dos ítems:

${ }^{148}$ Brown y McBride, Women's Roles in the Renaissance, p. 266: "It is certain, however, that women participated in the musical culture of Europe more fully than surviving records document".

${ }^{149}$ Fernando del Valle Lersundi, "Testamento de Fernando de Rojas, autor de La Celestina", Revista de filología española, XVI (1929), pp. 366-388, p. 369.

${ }^{150}$ Además de los inventarios de bienes, los escudos de armas incluidos en los manuscritos de música sirven para estudiar a sus propietarios. Por ejemplo, los escudos de armas de María Manrique, Duquesa de Terranova, esposa de El Gran Capitán, y de su hija Elvira Fernández de Córdoba se incluyen el f. 20r del Chigi Códex. La familia Fernández de Córdoba debió poseer este manuscrito en la última parte del siglo XVI. Véase Ros-Fábregas, "The Cardona and Fernández de Córdoba Coats of Arms in the Chigi Codex", especialmente pp. 244-251.

${ }^{151}$ Véase Cátedra García y Rojo Vega, Bibliotecas y lecturas de mujeres. Las fuentes de este estudio son inventarios datados entre 1529 y 1599 procedentes de la sección de Protocolos del Archivo Provincial de Valladolid. Sobre bibliotecas de mujeres, véanse, entre otros trabajos, Beceiro Pita, "La relación de las mujeres castellanas con la cultura escrita"; Álvarez Márquez, "Mujeres lectoras en el siglo XVI en Sevilla"; y Araceli Guillaume-Alonso, "Des bibliothèques féminines en Espagne (XVIe-XVII siècles)", en Des femmes et des livres: France et Espagnes, XIVe-XVIIe siècle: Actes de la Journée d'Étude organisée par l'École Nationale des Chartes et l'École Normale Supérieure de Fontenay Saint-Cloud (Paris, 30 avril 1998), ed. por Dominique de Courcelles y Carmen Val Julián (París: École des Chartes, 1999), pp. 61-75. 
"un libro de canto" y un libro de Petrarca. En segundo lugar, la biblioteca de Catalina de Sámano, una monja de clase alta, consistía en sesenta libros, entre los que encontramos "veinte libros pequeños de canto". En tercer lugar, exceptuando el libro en italiano de música y danza de Catalina de Zúñiga, los únicos libros de música instrumental aparecen en el inventario de 1570 de Lucía Monroy, quien probablemente también pertenecía a la nobleza. La biblioteca de Lucía Monroy estaba integrada por cinco libros: cuatro libros de vihuela y un "Flos sanctorum" (narración de las vidas de varios santos). Según Peter Burke, las bibliotecas pequeñas son más propensas a indicar uso que las de numerosos ejemplares. ${ }^{152}$ No obstante, es difícil determinar el ratio de alfabetismo de las mujeres del mundo ibérico renacentista; ${ }^{153}$ por ejemplo, Helen Nader señala que era muy variable, aunque era total entre las nobles. ${ }^{154}$

Se ha dicho que, mientras que los hombres tenían libros de temáticas diferentes, las mujeres poseían principalmente bibliotecas religiosas. ${ }^{155}$ Por ejemplo, como señalé en el Capítulo V, la gran mayoría de los libros de Catalina de Zúñiga eran manuales de perfección cristiana. Incluso los libros de Isabel la Católica han sido descritos por Elisa Ruiz García como una selección de textos considerados ejemplares para la formación y el perfeccionamiento religioso de una mujer, independientemente de su condición. ${ }^{156}$

\footnotetext{
${ }^{152}$ Peter Burke, Los avatares de El cortesano. Lecturas y lectores de un texto clave del espíritu renacentista (Barcelona: Gedisa, 1998), pp. 22-23.

${ }^{153}$ Guillaume-Alonso, "Des bibliothèques féminines en Espagne (XVIe-XVII siècles)", p. 61: "Históricamente, es muy difícil determinar el grado de alfabetización de las mujeres españolas de la época; pero era ciertamente débil, más aún que el de los hombres y, como el de éstos, desigual en función del medio social y geográfico" ["Historiquement, il est très difficile de déterminer le degré d'alphabétisation des femmes espagnoles de l'époque; mais il était certainement faible, plus encore que celui des hommes, et, comme pour ceux-ci, inégal en fonction du milieu social et géographique"].
}

${ }^{154}$ Nader, ed. Power and Gender in Renaissance Spain, p. 11: "El alfabetismo femenino variaba ampliamente, del $12 \%$ que Sara Nalle ha descubierto entre las ciudadanas de Cuenca, al total alfabetismo de las nobles de España; no hay ejemplos de mujeres aristócratas que no supieran firmar" ["Female literacy varied widely, from the 12 percent literacy rate that Sara Nalle has discovered among female citizens of the city of Cuenca to the total literacy of Spain's noblewomen; there are no instances of aristocratic women unable to sign their names"]. Véase Nalle, "Literacy and Culture in Early Modern Castile", p. 71.

${ }^{155}$ Rojo Vega, Ciencia y cultura en Valladolid, pp. 26-27, y "El libro religioso en las bibliotecas privadas vallisoletanas del siglo XVI", en Coleccionismo y Bibliotecas (siglos XV-XVIII) [El libro antiguo español, 4], dir. por María Luisa López-Vidriero y Pedro Manuel Cátedra García (Salamanca: Universidad de Salamanca, 1988), pp. 559-575, p. 560; y Mayo, "Los libros religiosos como posesiones personales en el Siglo de Oro español”, p. 159.

${ }^{156}$ Elisa Ruiz García desafía en este sentido la imagen historiográfica de la reina Isabel como protectora de los libros. Véase Elisa Ruiz García, "Los libros de Isabel la Católica: una encrucijada de intereses", en Libro y lectura en la Península Ibérica y América (siglos XIII al XVI), ed. por Antonio Castillo Gómez (Madrid: Junta de Castilla y León, Consejería de Cultura y Turismo, 2003), pp. 53-78; y Los libros de 
Otro ejemplo es el inventario de 1582 de Ana Celenque, viuda del oidor Luis Francés, que, como muestra el Apéndice 17, estaba constituido por un libro de Horas, algunos libros de canto, un "Flos sanctorum" en lengua vernácula, un libro pequeño de devoción en lengua vernácula y un libro de cocina manuscrito. ${ }^{157}$

Los libros de música encontrados más frecuentemente en los inventarios de mujeres consultados son libros de canto y artes de canto llano; ambas tipologías cumplen las características de los "libritos de mujeres", una categoría del mercado libresco del siglo XVI. ${ }^{158}$ Los libros de mujeres solían ser volúmenes de pequeño formato escritos en lengua vernácula, que se incorporaban a los ajuares y pasaban de madres a hijas. Aunque el rango temático era amplio, la mayor parte de ellos recogían material didáctico sobre devoción personal. Un ejemplo del primer rasgo (el pequeño formato) es $E l$ libro de motes (Valencia, 1535) de Luis de Milán, un volumen de bolsillo que contenía entretenimientos cortesanos y se dirigía "a las damas", protagonistas de los juegos. ${ }^{159}$ Respecto a la segunda característica (la lengua vernácula), se ha dicho que las mujeres, a menudo sin formación en latín, "desempeñaron un importante papel en el desarrollo de traducciones a las lenguas vernáculas" durante la Edad Media por dos motivos: 1) "de las mujeres se esperaba que leyesen literatura devocional"; y 2) las mujeres se encargaban de la educación de los niños. ${ }^{160}$ Por ejemplo, en 1413 Violant de Bar (13651431), Duquesa de Girona, pidió a fray Antoni Canals que llevase a cabo una traducción del Evangelio. ${ }^{161}$ Josemi Lorenzo Arribas sugiere que los libros didácticos de música en

Isabel la Católica. Arqueología de un patrimonio escrito (Salamanca: Instituto de Historia del Libro y de la Lectura, 2004).

${ }^{157}$ Cátedra García y Rojo Vega, Bibliotecas y lecturas de mujeres, p. 328.

158 Tiziana Plebani, "Nascita e caratteristiche del pubblico di lettrici tra medioevo e prima età moderna", en Donna, disciplina, creanza cristiana dal XV al XVII secolo. Studi e testi a stampa, ed. por Gabriella Zarri (Roma: Edizioni di Storia e Letteratura, 1996), pp. 23-44, p. 36.

${ }^{159}$ Véase el Capítulo VII.

${ }^{160}$ Bell, "Medieval Women Book Owners", p. 150.

${ }^{161}$ Isabel de Riquer, "Los libros de Violante de Bar", en Las sabias mujeres: educación, saber y autoría (siglos III-XVII), ed. por María del Mar Graña Cid (Madrid: Asociación Cultural Al-Mudayna, 1994), pp. 161-173, p. 170. Véase también Maria Rosa, Terés Tomàs, "Violant de Bar: les inclinacions artístiques d'una reina francesa a la Corona d'Aragó", en Capitula facta et firmata: inquietuds artístiques en el quatre-cents, coord. por Maria Rosa Terés Tomàs (Valls, Tarragona: Cossetània; Universitat de Barcelona, 2011), pp. 9-69. Otros trabajos sobre mecenazgo femenino publicados en el mismo volumen colectivo son: Teresa Vicens i Soler, “Aproximació al món artístic de la reina Maria de Castella” (pp. 193-262); y 
lengua vernácula estaban frecuentemente vinculados con conventos femeninos y cita como ejemplo el Ars cantus plani (manuscrito en catalán mencionado en el Capítulo II), puesto que pertenecía al Convento de Clarisas de Valencia. ${ }^{162}$ Aunque podían tratar una variedad temática, los materiales didácticos sobre devoción personal y perfeccionamiento cristiano destacan como los temas más comunes de los libros de mujeres. Susan G. Bell indica que "debido a que la participaron pública de las mujeres en la vida espiritual no era bienvenida por la organización jerárquica masculina, una íntima implicación con literatura devocional religiosa, inofensiva a causa de su privacidad, adquirió mayor importancia para las mujeres"; los libros de piedad relacionados con las mujeres que menciona Bell son evangelios, salterios, "Flos sanctorum" y, especialmente, libros de Horas. ${ }^{163}$ Los libros de devoción en lengua vernácula se relacionan con el espíritu de la Contrarreforma y, según Stephen Haliczer, "la nueva cultura religiosa que se estaba creando en la España postridentina era una cultura vernácula que incluía a las mujeres en mayor medida de lo que nunca lo hizo la cultura basada en el latín”. ${ }^{164}$

Las artes de canto reúnen todos los rasgos de los libros de mujeres. Como se detalló en el Capítulo I, las artes de canto eran libros de pequeño formato (normalmente en octavo) escritos en lengua vernácula que contenían las principales reglas del canto religioso y perseguían un propósito didáctico. Es interesante observar la similitud entre artes de canto y libros de Horas, dado que, según Sandra Penketh, estos últimos "estaban diseñados para ser leídos ocho veces al día en las horas canónicas [...] en la privacidad del hogar o en capillas familiares o personales, y se llevaban a la iglesia, donde

Teresa Vinyoles Vidal, "La dama que va fer pintar el retaule de les santes Clara i Caterina de la catedral de Barcelona" (pp. 263-279).

162 Josemi Lorenzo Arribas, “Una historia poco canónica de la música hispánica hasta 1557”, en Compositoras españolas: la creación musical femenina desde la Edad Media hasta la actualidad, ed. por Antonio Álvarez Cañibano et al. (Madrid: INAEM, Centro de Documentación de Música y Danza, 2008), pp. 3-42, p. 11.

163 Bell, "Medieval Women Book Owners", p. 160: "Because women's public participation in spiritual life was not welcomed by the hierarchical male establishment, a close involvement with religious devotional literature, inoffensive because of its privacy, took on a greater importance for women. [...] These books of piety included gospels, Psalters, lives of the saints, and, in large part, Books of Hours".

${ }^{164}$ Haliczer, Between Exaltation and Infamy, p. 46: "the new religious culture that was being created in post-Tridentine Spain was a vernacular culture that included women to a far greater extent than the old Latin-based culture ever did". 
podían usarse cuando se decía la Misa". ${ }^{165}$ Por tanto, artes de canto y libros de Horas compartían el propósito religioso, la asociación con determinadas ceremonias litúrgicas, y una dualidad entre lo privado y lo público, lo oral y lo escrito. Si bien los hombres también tenían libros de Horas, Penketh sostiene que los testimonios iconográficos indican un vínculo especial entre esta tipología libresca y las mujeres.

Las artes de canto, como los libritos de mujeres, satisfacían los requerimientos de brevedad y religiosidad asociados con los ideales de la educación femenina de la época. Como se mostró en el Capítulo I, las artes de canto eran generalmente breves como consecuencia de su propósito didáctico y práctico. Existen indicios que apuntan a una especial asociación entre mujeres y libros breves. Por ejemplo, en su manual de guitarra de 1626 Luis de Briceño señalaba que la dedicatoria de "libros pequeños" a “madama de Chales" era "cosa mecánica". ${ }^{166}$ Los tratados de conducta de la época enfatizan los requisitos de brevedad y simplicidad en la educación femenina. Ya a mediados del siglo XV, Martín de Córdoba sostenía en su Jardin de nobles doncellas que las mujeres comunes no necesitaban saber de artes ni de ciencias, aunque las futuras reinas constituían una excepción (el libro iba dirigido a Isabel la Católica) puesto que debían prepararse para gobernar. ${ }^{167}$ En el siglo XVI, Juan Luis Vives consideraba que así como "las leyes y constituciones de los varones son muchas y diversas; mas cierto es así que brevemente y en pocas palabras se pueden componer y instruir las costumbres de las mugeres"; la justificación de Vives es que "los hombres estan en casa y conversan en la plaza: tienen que hacer particularmente, y ocúpanse en la República: lo que no tienen las mujeres"; "la mujer", en cambio, "no ha de tener muchos cuidados; solo una cosa le han encargado, que es la castidad". ${ }^{168}$ Más tarde, Juan de la Cerda vinculaba el requisito

\footnotetext{
${ }^{165}$ Penketh, "Women and Books of Hours", p. 270: "were designed to be read eight times a day at the canonical hours $[\ldots]$ either in privacy at home, or in family or personal chapels, and they were taken into church, where they might be used as Mass was being said". Véase también Elizabeth L'Estrange, "Images de maternité dans deux livres d'heures appartenant aux duchesses de Bretagne", en Livres et lectures de femmes en Europe entre Moyen Âge et Renaissance, ed. por Anne-Marie Legaré (Turnhout: Brepols, 2007), pp. 35-47.

${ }^{166}$ Briceño, Metodo mui facilissimo para aprender a tañer la guitarra a lo español, f. A2r, "A mi señora de Chales salvd y vida": "se estima por cosa mecanica dedicar libros pequeños a tan grande y curioso sujeto como el suyo". Véase el Capítulo V.

${ }^{167}$ Martín de Córdoba, Jardin de nobles doncellas (Madrid: Joyas bibliográficas, 1953 [primera publicación en 1500, escrito en 1448-1449]), p. 83.

${ }^{168}$ Vives, Instruccion de la muger christiana, pp. xxxi-xxxii.
} 
de brevedad con "las muchas ocupaciones e impedimentos que las mugeres tienen", pero también con la inferior capacidad intelectual de éstas. ${ }^{169}$

La religiosidad era otra prescripción de los tratados de conducta que las artes de canto satisfacían. La mayoría de los autores de tales tratados educativos eran teólogos, "la Cristiandad era la fuente más importante de ideas sobre las mujeres para los europeos del siglo XVI", y "ninguno de los movimientos intelectuales relevantes de los siglos XV y XVI" (humanismo, Reforma y Contrarreforma) cambiaron "el ideal cristiano para las mujeres -silencio, obediencia y castidad". ${ }^{170}$ Finalmente, la enseñanza oral que se relaciona con las mujeres en los tratados de conducta también es un rasgo de las artes del canto, como se señalaba en el Capítulo II en relación a las formas de consumo de estos libros y en el Capítulo IV en referencia a la conexión de las artes de canto con la enseñanza de la música. Juan Luis Vives aconsejaba a las mujeres que leyesen obras devotas o bien escucharan su lectura en voz alta. ${ }^{171}$ Pedro Manuel Cátedra y Anastasio Rojo Vega sugieren que en las escuelas de labores domésticas, conocidas como "la amiga”, las mujeres aprendían a leer o escuchaban a otra mujer que leía en voz alta. ${ }^{172}$ Evidencia de la especial vinculación de la educación femenina con la oralidad es el relato del Cardenal Francisco Jiménez de Cisneros de su visita a las dependencias de las hijas de Isabel la Católica:

En medio de todas, y sentada en un escabel, una dama, ya madura [Beatriz Galindo], leía en voz alta acompasada un libro manuscrito con cubiertas de cuero amarillo y cerraduras de latón, que se titulaba Tercero tratado del libro de las mugeres, y que todas escuchaban religiosamente. ${ }^{173}$

La lectura en voz alta de libros de santos también formaba parte de las rutinas de los conventos. Stephen Haliczer presenta el caso del Convento de Santa Catalina en

\footnotetext{
${ }^{169}$ Cerda, Libro intitvlado vida politica de todos los estados de mugeres, f. $317 \mathrm{v}$.

${ }^{170}$ Erdmann, My Gracious Silence, pp. ix-xii. Véase también Sherrin Marshall, ed., Women in Reformation and Counter-Reformation Europe: Public and Private Worlds (Bloomington e Indianapolis: Indiana University Press, 1989), p. 2.

${ }^{171}$ Vives, Instruccion de la muger christiana, pp. 28-39.

${ }^{172}$ Cátedra García y Rojo Vega, Bibliotecas y lecturas de mujeres, p. 56.

${ }^{173}$ Coloma, Fray Francisco, p. 171. Podría hacer referencia al Libro de las claras e virtuosas mugeres escrito en la primera mitad del siglo XV por Álvaro de Luna $(\dagger 1453)$, valido de Juan II.
} 
Zaragoza, donde se tenía por costumbre la elección de "una de las monjas para leer un libro espiritual o hagiografía mientras las demás tejían o llevaban a cabo otra labor". ${ }^{174}$ Además, "la lectura en voz alta de las vidas de los santos era también un frecuente pasatiempo entre las jóvenes aristócratas". ${ }^{175}$ Por ejemplo, María de Mendoza y de la Cerda guardaba libros en su cesta de labores para leer en voz alta a sus compañeras y sirvientas mientras trabajaban. ${ }^{176}$ Hernando de Talavera, cuando en su tratado sobre la ordenación del tiempo hace referencia al que se tiene que dedicar María Pacheco a sí misma, iguala los conceptos de leer y oír leer:

\begin{abstract}
Para vuestra auisacion: deueys expender algo en leer o en oyr leer: y en comunicar algunas vezes con personas sabias e spirituales: que vos puedan auisar e informar de como vos aueys de saluar: para vuestra recreacion se deue algo gastar en algunos passa tienpos honestos que assi creen y esfuercen la carne que el alma no pierda nada. ${ }^{177}$
\end{abstract}

Esto encaja con la tesis de Roger Chartier según la cual la lectura de un texto en voz alta se considera una forma de publicación, y también con su concepto de un "uso colectivo del impreso". ${ }^{178}$ La enseñanza de la música se basaba en prácticas orales y mnemotécnicas y la mayoría de las artes de canto fueron escritas por maestros de capilla como material didáctico. ${ }^{179}$ Parece por tanto que, como los libritos de mujeres, las artes de canto podrían considerarse un entrecruzamiento entre cultura escrita y tradiciones orales.

\footnotetext{
${ }^{174}$ Haliczer, Between Exaltation and Infamy, p. 39: "Reading books written by or about Saints was incorporated into convent routines. In Zaragoza's aristocratic Convent of Santa Catalina [...] it was customary to choose one of the nuns to read a spiritual book or hagiography while the others sewed or performed other labor".

${ }^{175}$ Haliczer, Between Exaltation and Infamy, p. 40: "Reading aloud from the lives of the saints was also a frequent pastime among aristocratic girls".

${ }^{176}$ María del Carmen Vaquero Serrano, "Books in the Sewing Basket: María de Mendoza y de la Cerda", en Power and Gender in Renaissance Spain: Eight Women of the Mendoza Family, 1450-1650, ed. por Helen Nader (Urbana: University of Illinois Press; Bristol: University Presses Marketing, 2003), pp. 93112, p. 100.

${ }^{177}$ Talavera, De como ordenar y ocupar el tiempo, s.f. [cap. viii].

${ }^{178}$ Chartier, Cultura escrita, literatura e historia, pp. 60-61.

${ }^{179}$ Véase el Capítulo IV.
} 
Los libritos de mujeres se incorporaban a las dotes y formaban parte de legados de madres a hijas. ${ }^{180}$ Fuentes medievales como el Sachsenspiegel ("una colección de leyes consuetudinarias sajonas compiladas por Eike von Repgow en torno a 1215") indican que entre los bienes domésticos que pasaban de madres a hijas se incluían "libros conectados con la observancia religiosa". ${ }^{181}$ Susan G. Bell señala que tales costumbres se ponen de manifiesto en el caso de los libros de Horas, los cuales "eran regalos tradicionales para niñas aprendiendo a leer y a menudo se incluían en los ajuares de las novias". ${ }^{182}$ Bell menciona incluso la existencia de un libro de Horas holandés "inscrito con los nombres de seis generaciones de mujeres", y sugiere que la falta de referencias testamentarias de legados entre madres e hijas "podría sugerir que tales legados eran consuetudinarios (como en el Sachsenspiegel) y no requerían documentación alguna". ${ }^{183}$ Debido a las similitudes entre libros de Horas y libros de canto que he señalado anteriormente, no sería sorprendente que los últimos también se incluyeran en los ajuares como "libros de mujeres" y fuesen legados de una generación a la siguiente. Sin embargo, debido a la falta de evidencia testamentaria, es difícil corroborar tal hipótesis porque, en contraste con las lujosas características materiales de muchos de los libros de Horas, las artes de canto eran literatura efímera con menos probabilidad de conservación.

\subsection{Cancioneros poéticos como libros de música}

Además de las artes de canto, los cancioneros actúan como vestigios de prácticas musicales más allá de la música escrita. Debido al importante papel que desempeñaba la música como vehículo de la poesía, los cancioneros literarios podrían considerarse un tipo de libro de música sin notación musical, puesto que contenían versos para ser cantados. La vinculación entre poesía y música en la época ha llevado a los historiadores de

\footnotetext{
${ }^{180}$ Rojo Vega, Ciencia y cultura en Valladolid, pp. 26-27; Penketh, "Women and Books of Hours", pp. 275-276.

${ }^{181}$ Bell, “Medieval Women Book Owners”, pp. 156-157.

182 Bell, “Medieval Women Book Owners", p. 160.

${ }^{183}$ Bell, "Medieval Women Book Owners", p. 157.
} 
la música a prestar atención a la literatura como fuente musicológica, ${ }^{184}$ pero también a los estudiosos de la historia de la poesía a indagar en las fuentes musicales. Por ejemplo, José Manuel Blecua traza un esquema de la poesía de la Edad de Oro en España a partir de los poemas incluidos en los Tres libros de Musica en cifras para vihuela (Sevilla, 1546) de Alonso Mudarra. ${ }^{185}$ Quizás no sea casual el que en una miscelánea manuscrita del siglo XIX conservada en la Biblioteca de Reserva de la Universitat de Barcelona con la signatura MS/1023 encontremos una mano guidoniana y su explicación (ff. 5-12) a continuación de cuatro folios que contienen poesías (véase Ilustración VI.6). ${ }^{186}$

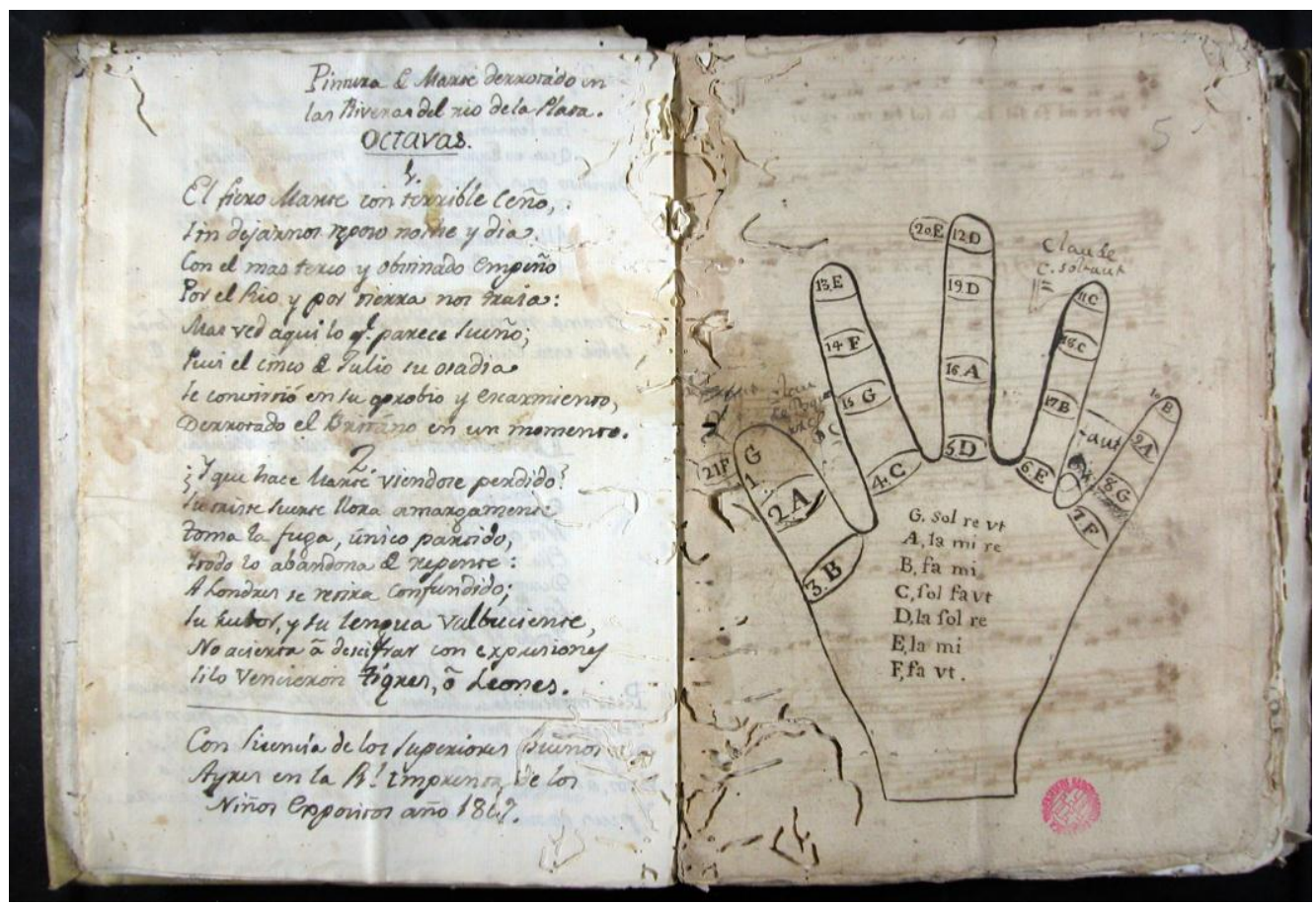

\footnotetext{
${ }^{184}$ Un ejemplo es Howard Mayer Brown, “Ut Musica Poesis': Music and Poetry in France in the Late Sixteenth Century”, Early Music History, 13 (1994), pp. 1-63.

${ }^{185}$ José Manuel Blecua, "Mudarra y la poesía del Renacimiento: una lección sencilla”, en Studia hispanica in honorem R. Lapesa, ed. por la Cátedra-Seminario Menéndez Pidal de la Universidad Complutense de Madrid (Madrid: Gredos, 1972), vol. 1, pp. 173-179.

${ }^{186}$ En el f. $5 \mathrm{r}$ encontramos la mano musical; en los ff. 5v-9r aparece notación musical sobre pentagrama: intervalos en notación cuadrada y a continuación lo que parecen ejercicios en orden creciente de dificultad en notación moderna (a partir de la mitad del f. 6v), muchos de ellos con un sostenido en la armadura; los ff. $8 \mathrm{v}-11 \mathrm{v}$ contienen sólo pautado; en el f. $12 \mathrm{r}$ se dibujan las claves y la escala y se explican en catalán las mudanzas; y en el f. 12v, que no tiene pautado, sólo texto en catalán, se explican las propiedades, las claves, las deducciones, las voces, los signos y los tonos.
} 
Los cantos de devoción, en particular, se dirigían a un amplio espectro social y con propósitos diferenciados: a niños que debían educarse en la doctrina cristiana, a trabajadores que debían "desterrar los malos cantares" y aprender cantos honestos para utilizar durante la faena, y a las religiosas de los conventos y a las mujeres de clase media y alta como un entretenimiento devoto. Este fenómeno no es exclusivo del mundo ibérico ni tampoco del Renacimiento. En el ámbito francés encontramos un marco conceptual similar, como muestra el Traicté du profit que toute personne tire de chanter en la doctrina chrestienne, et ailleurs les hymnes et chansons spirituells en vulgaire; et du mal qu'apportent les lascives et hérétiques, controuvés de Satan (Lyon, 1608) de Michel Coyssard. Es interesante que el mismo propósito se ponga de manifiesto en el cancionero del Llibre Vermell (última década del siglo XIV) de la Abadía de Montserrat:

Dado que a veces los peregrinos cuando velan en la iglesia de la Virgen María de Montserrat quieren cantar y bailar y también desean hacerlo de día en la plaza, y allí sólo deben cantarse canciones honestas y devotas, por tal razón hay escritas algunas antes y después de esta nota. ${ }^{187}$

Alfonso de Vicente cita la "Doctrina christiana que se canta: 'Oidnos vos, por amor de Dios"” de San Juan de Ávila:

La idea de sustituir cantares malos, torpes y deshonestos, le sirve al santo para buscar una nueva clientela entre los "hombres rudos o de mala memoria [...] especialmente para hombres del campo, como son pastores, gañanes, caminantes, trajineros, carreteros y trabajadores" a los que se les debe enseñar "cosa que canten, que es lo que a ellos más aplace para pasar sus trabajos, y así cada día lo cantarán y quitarán cantares malos y sabrán lo que son obligados; y de esto hay experiencia". 188

\footnotetext{
${ }^{187}$ Traducción del latín tomada de Gómez Muntané, La música medieval en España, p. 266. El cancionero ocupa los folios 21v-27r del Manuscrito 1 de la Biblioteca de la Abadía de Montserrat y la nota en latín está en el f. 22 r.

188 Vicente Delgado, "Música, propaganda y reforma religiosa en los siglos XVI y XVII"; San Juan de Ávila, "Doctrina christiana que se canta: 'Oidnos vos, por amor de Dios'. Hay añadido de nuevo el rosario de Nuestra Señora. Y una instruccion muy necesaria asi para los niños como para los mayores", en Obras completas del santo maestro Juan de Ávila, ed. por Luis Sala Balust y Francisco Martín Hernández (Madrid: Biblioteca de Autores Cristianos, 1971), vol. 6, pp. 454-481, pp. 478-480. Los refranes y cuentos populares proporcionan evidencia de que la gente cantaba mientras llevaba a cabo sus labores: "kien tiene suegra, zedo se le muera. -Kien tuviere nuera, kemada la vea. Lo primero kantava una kasada deskuidadamente enbolviendo una criatura delante de su suegra ke la kalentava los pañales, i lo segundo rrespondió la suegra; advirtió entonzes la nuera i dijo: “¡Ai, señora, esto es cantar!”; replikó la suega: -I esto es kopla"; véase Gonzalo Correas, Vocabulario de refranes y frases proverbiales (1627), ed. por Louis Combet (Burdeos: Institut d'Etudes Ibériques et Ibéroaméricaines, 1967), p. 412.
} 
Otro ejemplo es la tercera parte de Doctrina christiana y Espejo de bien vivir (Valladolid, 1554) de Gregorio Pesquera, que incluía “muchos cantares y coplas devotas para que los niños y otras personas canten y se alegren con devocion”. Los versos de Gregorio Pesquera estaban destinados a ser cantados, indicándose en algunos casos con qué tono se debían cantar: "Al tono de la gallarda", "Al tono de la pavana", "Cantar de los niños para el Nascimiento, al tono de la gallarda", etc. En su análisis del ejemplar de este cancionero conservado en la Biblioteca Nacional de Portugal (signatura F.R. 829), María Jesús Framiñán de Miguel señala la existencia de indicaciones tal vez musicales en algunas canciones, posiblemente añadidas con posterioridad, por lo que constituirían indicios de uso, "aprovechando los espacios en blanco, mediante varios puntos negros agrupados de diversas maneras: en forma de triángulos, triángulos invertidos, en forma de L, etc.". ${ }^{189}$ Los cantos devotos desempeñaban un importante lugar en la enseñanza de las primeras letras, como evidencian las indicaciones del jesuita Gaspar de Astete: "por esso quiso el señor mezclar la virtud de la diuina doctrina con algunas canciones agradables al oydo, para que deleytandose el oydo con la suauidad del verso que oye, se embaba en el alma el provecho de la palabra diuina". ${ }^{190}$

Varios autores publicaron versos y canciones devotas explícitamente destinadas a la infancia. Un ejemplo es Destierro de los malos cantares, con que nuestro Señor se ofende: y para que canten los niños en las calles y escuelas dejando los del mundo por los de Dios (Sevilla, 1621) de Francisco de Soto. ${ }^{191}$ Encontramos una muestra de la tradición del canto popular infantil en un romance que relata la "vida" de María Clemente, religiosa del Convento de San Nicolás de La Orotava (Tenerife). ${ }^{192}$ Aunque se trata de un texto poético y sin duda adornado, no sólo muestra la importancia atribuida al canto

\footnotetext{
${ }^{189}$ María Jesús Framinán de Miguel, "La Doctrina cristiana de Gregorio de Pesquera (Valladolid, 1554): esbozo de análisis y contextualización histórico-literaria”, Criticón, 96 (2006), pp. 5-46, p. 18.

190 Gaspar Astete, Tratado del gouierno de la familia y estado de las viudas y doncellas (Burgos: Iuan Baptista Varesio en la imprenta de Philippe de Iunta, 1603 [1597]), pp. 379-380.

${ }^{191}$ Varela, Modos de educación en la España de la Contrarreforma, p. 208.

${ }^{192}$ Antonio Correa Sanabria, La Flor del cielo Azuzena de Santa Maria, y Estrella de la tierra, la V. Maria Clemente, que trocando este nombre en aquel, entrò Monja en el Religioso Convento de San Nicolàs Obispo, del Orden de S. Catalina de Sena, de la Villa de la Orotaua, en la Isla de Tenerife [...] describese por mayor su marauillosa vida, y prodigiosa muerte, en vn Romance (S.1.: s.n., 1601). Se ha consultado el ejemplar de Madrid, Biblioteca Nacional de España, VE/104/17.
} 
infantil en las alabanzas divinas, sino también el lugar de la música (en particular, el canto motetes) en la cultura de la época y su importante papel en la vida cotidiana:

[...] Porque no ay en la Gomera

Monjas, y para que entrara

Monja Azuzena, era fuerça

Que à otra Isla se embarcara:

Con que esto supuesto aqui,

$\mathrm{Y}$ que todos ignorauan

El portento referido,

Hasta sus padres en casa,

Sino el Confessor, los niños

Ya en sabrosas consonancias

Por las calles del Lugar

Aquesta cancion cantauan:

Ya se parte la Azuzena

A la tierra agena.

Esta letra tan sucinta

Repetidamente daban

Al ayre, cuyo motete

Hasta el Cielo regalaua.

Vnos niños quiere Dios

Queeste fauor pregonaran,

Porque el canto de los niños

Es el que mas le alabaua.

Inocentes tantas dichas

Hizo desta Flor cantaran,

$\mathrm{Y}$ assi inocentes la fuerte

Del vaso de Dios le sacan.

Dize la cedula breue:

Monja sea. O que adequada!

Pues su vida recogida

Viene al encierro ajustada.

Bocas de inocentes eran

Las que la letra entonauan,

Que cantos de vna Flor pura

Solo à inocentes tocara.

En gorgeos el motete,

Ya lo empiezan, ya lo acaban,

I cessantes vno al otro

Dulcemente lo alternauan.

Mas diestros que Ruyseñores,

De Azuzena resonauan

Las dichas, que en el retiro

Solo de su pecho estauan $[\ldots] .^{193}$

Los cancioneros de devoción no sólo iban destinados a los niños y las madres encargadas de su educación, sino que también fueron concebidos por o para mujeres

\footnotetext{
${ }^{193}$ Correa Sanabria, La Flor del cielo Azuzena de Santa Maria, f. 16.
} 
como un tipo de "entretenimiento musical devoto". ${ }^{194}$ Existe evidencia de la lectura de libros religiosos acompañada por el canto por parte de grupos de mujeres de clase alta ya en las Cantigas de Santa María: "estavan todas no coro / e ben cantand' e leendo". 195 Más indicios de estas prácticas aparecen en los cancioneros Coplas... sobre devoçiones y misterios de nuestra sancta fe catholica (1485?) y su edición ampliada Cancionero de diversas obras de nuevo trobadas (1508), publicados en Toledo por Ambrosio Montesino. En estas colecciones de poesía, el autor indica el título de la melodía con la cual debía ser cantado cada poema y la persona a la que iba dirigido; las melodías tuvieron que formar parte de una tradición oral de manera que fuesen lo suficientemente conocidas como para que los lectores las identificasen únicamente por el título. Emilio RosFábregas muestra la íntima conexión de los poemas de Montesino con las mujeres, ya que 17 de los 23 dedicatarios de las canciones eran mujeres, entre ellas Isabel la Católica y su hija Isabel de Portugal, así como mujeres de la nobleza y abadesas de conventos toledanos. ${ }^{196}$ La mayoría de los poemas de Montesino fueron patrocinados por mujeres, posiblemente para manifestar su religiosidad, lo que supondría una correspondencia con el caso de Catalina de Zúñiga y el Arte de canto llano de Francisco de Montanos.

Un ejemplo posterior de poesía devota para ser cantada y su vinculación con una mujer es la colección de villancicos Minerva sacra (Madrid, 1616) publicada por Miguel Toledano y dedicada a Alfonsa de Salazar (†1639/1641), una religiosa del Convento de Constantinopla de Madrid de quien se decía que cantaba los versos de Toledano. ${ }^{197}$ Minerva sacra contiene incluso una ilustración que representa a Alfonsa de Salazar tocando el arpa y cantando, un soneto de Miguel de Cervantes alabando las ha-

\footnotetext{
${ }^{194}$ Emilio Ros-Fábregas, "Melodies for Private Devotion at the Court of Queen Isabel", en Queen Isabel I of Castile: Power, Patronage, Persona, ed. por Barbara F. Weissberger (Woodbridge: Tamesis, 2008), pp. 83-107, p. 90; véase también la versión previa en español "Canciones sin música en la corte de Isabel la Católica: Se canta al tono de...", Revista de Musicología, XVI/3 (1993), pp. 1505-1514.

${ }^{195}$ Beceiro Pita, "La relación de las mujeres castellanas con la cultura escrita", p. 41. Para un estudio de las Cantigas de Santa María como testimonio de las actividades de las mujeres medievales, véase Connie L. Scarborough, Women in Thirteenth-Century Spain as Portrayed in Alfonso X's Cantigas de Santa Maria (Lewiston: Edwin Mellen Press, 1993).

${ }^{196}$ Ros-Fábregas, "Melodies for Private Devotion at the Court of Queen Isabel”, pp. 95-96.

${ }^{197}$ Baade, "Music and Misgiving", p. 94. Sobre las conexiones entre Alfonsa González de Salazar y Minerva sacra, véanse también Baade, "La 'música sutil' del Monasterio de la Madre de Dios de Constantinopla", p. 226; y “'Hired' Nun Musicians in Early Modern Castile", p. 300; y Aguirre Rincón, "Sonido en el silencio", p. 287.
} 
bilidades musicales de la religiosa, y dos poemas escritos por la propia Alfonsa de Salazar como muestra de gratitud a Toledano. Las vidas de monjas ofrecen también evidencia del canto de religiosas acompañándose con el arpa. Así, en su relato de la vida de Isabel de Velasco (c. 1602-1669), María Pinel explica cómo en su lecho de muerte la religiosa pidió que le cantaran un Acto de Contrición: “llevaron el arpa, y la religiosa se le canta, más llorando que cantando, asistiendo toda la comunidad, hechas arroyos de lágrimas". ${ }^{198}$ Otra fuente que documenta estas prácticas son los pliegos de cordel poéticos, puesto que algunos indican que sus versos se cantaban con acompañamiento de vihuela, siendo ejemplo de ello Aqui se contienen doze Romances de amores muy sentidos $[\ldots]$ para cantar y tañer con vihuela (Granada, 1570). ${ }^{199}$

Antonio Baciero comenta la tradición oral del canto como recreación musical de los conventos y de la producción de libros de cantos en honor a Santa Teresa de Jesús, como Vida, muerte, milagros, y fundaciones de la B. Madre Teresa de Iesvs (Barcelona, 1615) de Pablo Verdugo de la Cueva, un libro "muy apto para el uso en esta actividad musical y lírica de los Conventos". ${ }^{200}$ Baciero también incluye la fotografía de un cancionero manuscrito de pequeño formato procedente de Palencia que contiene canciones de los siglos XVII y XVIII. ${ }^{201}$ Como en el caso del cancionero de Montesino, en este ejemplo encontramos referencias a la melodía con la que se debían cantar los versos: "a las folias italianas", "se cantan al tono del Gran Minue Hermosa Dama Ysabel bella", "al mismo tono", "se an de cantar a tono con las luzes que en el mar" o "tonadilla de las que se suelen cantar al pandero". Además, Baciero ha recogido canciones tal y como se cantaban en los conventos de Carmelitas Descalzas en el siglo XX. Es sumamente interesante que se siguiesen cantando en Valladolid canciones atribuidas, por ejemplo, a la ya mencionada Cecilia del Nacimiento, hija de Cecilia Morillas (véase Ejemplo musical VI.3).

\footnotetext{
${ }^{198}$ Pinel, Retablo de Carmelitas, p. 192.

199 John Griffiths, "Hidalgo, Merchant, Poet, Priest: The Vihuela in the Urban Soundscape", Early Music, XXXVII/3 (2009), pp. 355-365, pp. 362-363.

${ }^{200}$ Baciero, El Órgano de cámara del Convento de la Encarnación de Ávila, p. 102.

${ }^{201}$ Baciero, El Órgano de cámara del Convento de la Encarnación de Ávila, p. 105.
} 


\title{
Ejemplo musical VI.3: Transcripción de la melodía recogida en Antonio Baciero, El Órgano de
} cámara del Convento de la Encarnación de Ávila (Madrid: Poniente, 1982), p. 109.

\section{En brazos de una doncella}

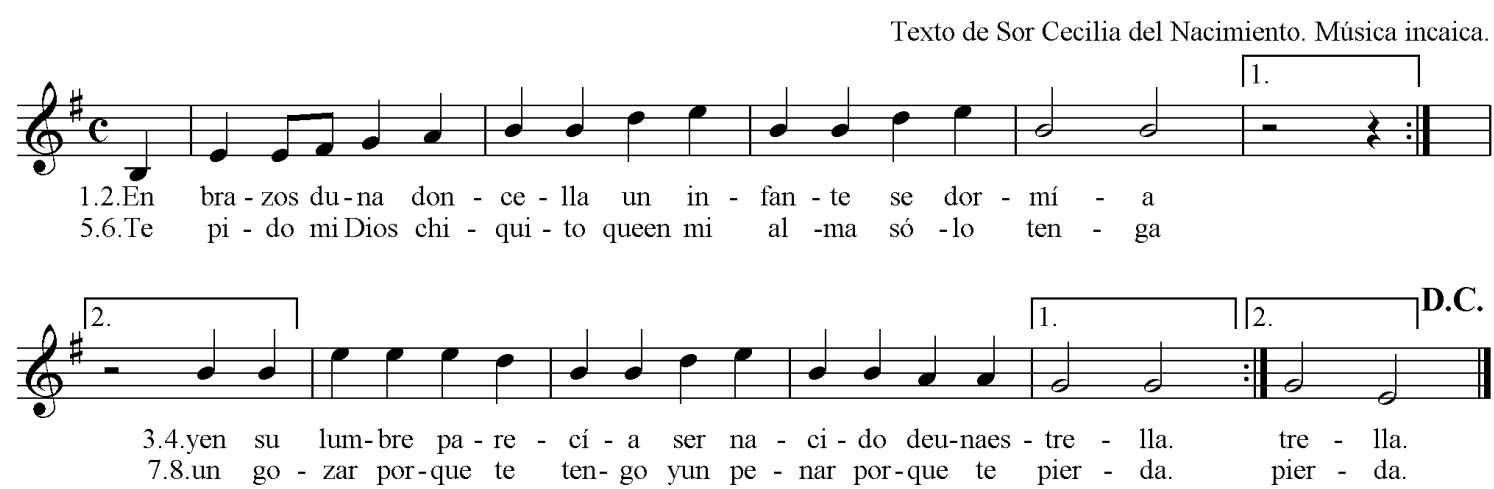

En la "vida" de la monja música Clara Eugenia narrada por María Pinel encontramos más evidencia de la creación de coplas por parte de las propias monjas:

\begin{abstract}
Y en el de 1650 la dispuso nuestro Señor para el camino, y la víspera de la Natividad de nuestra Señora, noche que ella celebraba siempre con muchos júbilos haciendo coplas a la Niña y a Santa Ana, y a nuestro Padre San Joaquín, de quien era sumamente devota, más amorosas que bien concertadas, cantábaselas con grande afecto. ${ }^{202}$
\end{abstract}

El último caso de canto de poesía como entretenimiento conventual que mencionaré es el libro de Romanzes i coplas desta casa de la Conçeçion del Carmen, una compilación manuscrita de 132 poemas del Convento de la Concepción de Nuestra Señora del Carmen de Valladolid, copiados principalmente por Isabel del Sacramento, “desde el recuerdo propio o al dictado de hermanas" y pocas veces a partir de textos. ${ }^{203}$ El estudio llevado a cabo por Víctor García de la Concha y Ana María Álvarez Pellitero a propósito de la edición de este cancionero muestra las numerosas referencias que se hallan en la correspondencia de Santa Teresa de Jesús al canto de coplas y a la circulación de

\footnotetext{
${ }^{202}$ Pinel, Retablo de Carmelitas, p. 204.

203 Víctor García de la Concha y Ana María Álvarez Pellitero, eds., Libro de Romances y Coplas del Carmelo de Valladolid c. 1590-1609 (Salamanca: Consejo General Castilla y León, 1982), 2 vols. El segundo volumen es una edición facsímile del cancionero.
} 
copias de éstas entre conventos con finalidad devota. Encontramos un ejemplo en una carta escrita en 1577 por Santa Teresa a su hermano Lorenzo:

[...] gran fiesta tuvimos ayer con el Nombre de Jesús; Dios se lo pague a vuestra merced. No sé qué le envié por tantas como me hace, si no es esos villancicos que hice yo, que como me mandó el confesor las regocijase, y he estado estas noches con ellas y no supe cómo si no así. Tienen graciosa tonada, si la atinase Francisquito, para cantar. ${ }^{204}$

Es curioso cómo esta poesía cantada en la que los límites entre lo profano y lo devoto se difuminan era utilizada para adoctrinar a la infancia y a la clase trabajadora, pero a la vez se empleaba como entretenimiento honesto por parte de religiosas y mujeres de clase alta. Como las artes de canto, estos cancioneros muestran que las mujeres participaron en la cultura musical más plenamente de lo que los relatos históricos reflejan; y, como las artes de canto, estos cancioneros son artefactos materiales que preservan el entrecruzamiento de cultura escrita y tradiciones musicales orales en el mundo ibérico de la temprana Edad Moderna. Tales lugares de superposición entre tradiciones orales y escritas abren una ventana a prácticas musicales (no sólo por parte de las mujeres) ocultas de otro modo a los musicólogos. El que de las religiosas conocidas en su época por sus destrezas musicales se haya conservado producción poética y no musical, podría indicar que posiblemente sus poesías fuesen destinadas a ser cantadas, tal vez con música de tradición oral o con música creada por ellas que no se ha conservado. Aunque se ha dicho que la ausencia de mujeres en relatos históricos es el resultado de su confinamiento en el ámbito doméstico, este Capítulo muestra que las fronteras entre lo privado y lo público no están lo suficientemente claras, y que es precisamente en las áreas en que ambas esferas se superponen donde, a través de la concentración en el Otro, podemos visibilizar no sólo la participación activa de las mujeres en diversas facetas de la cultura musical, sino también vestigios del lugar de la música en la vida cotidiana.

${ }^{204}$ García de la Concha y Álvarez Pellitero, eds. Libro de Romances y Coplas del Carmelo de Valladolid, vol. 1, p. x. Para una edición de las cartas de Santa Teresa, véase Santa Teresa: Cartas, ed. por Tomás Álvarez y Simeón de la Sagrada Familia (Burgos: Monte Carmelo, 1981). 


\section{RESUMEN DEL CAPÍTULO VI}

En el Capítulo VI se analiza el papel de las mujeres como autoras, impresoras y propietarias de libros de música, y se propone que las áreas en que se produce una superposición entre lo privado y lo público o entre lo oral y lo escrito permiten visibilizar prácticas musicales femeninas y vestigios de la cultura musical de la época invisibles desde perspectivas tradicionales. El Capítulo se estructura en dos secciones. En la primera, se muestra que cuando los límites entre lo privado y lo público se difuminan aparecen indicios de mujeres trabajando en los campos tradicionalmente masculinos de la composición y la imprenta musical. En la segunda sección se presentan artes de canto y cancioneros como artefactos materiales en que tradición oral y cultura escrita se superponen, permitiendo vislumbrar vestigios de la participación de la mujer en la vida musical y del grado de imbricación de la música en la vida cotidiana de la época. Este Capítulo aporta nombres de mujeres músicas del siglo XVI que habían pasado inadvertidas hasta ahora en los estudios musicológicos; véanse la Tabla VI.1 y el Apéndice 20.

La única pieza compuesta por una mujer del mundo ibérico del siglo XVI que se ha conservado es el himno Conditor alme de la monja Gracia Baptista, incluido en el Libro de cifra nиeua (1557) de Luis Venegas de Henestrosa, una antología que ha sido infravalorada por haberse cuestionado el método editorial de su autor/recopilador, responsable de las adaptaciones para tablatura. La vinculación que se ha hecho tradicionalmente de Gracia Baptista con Santa Teresa de Jesús y la Orden Carmelita podría deberse a una confusión, puesto que no he encontrado fuentes que lo confirmen. En este Capítulo presento los resultados de un análisis musical detallado del himno de Gracia Baptista, en comparación con las versiones también para tecla de Bermudo y Baena que utilizan el mismo cantus firmus. Aunque se había señalado que el himno de Gracia Baptista "no despliega especiales vuelos", esta pieza se asemeja a las texturas a tres partes que se hicieron más frecuentes a finales del siglo XVII.

La aportación de Gracia Baptista se hace visible a los ojos del historiador (y en su momento captó la atención de Venegas de Henestrosa) porque su actividad musical en el ámbito privado se transfirió a la esfera pública, quizás debido a que los conventos eran lugares en que los límites entre lo público y lo privado se difuminaban. El Monasterio de la Piedad de Guadalajara era un ejemplo de la permeabilidad de los conventos de monjas de clausura y de la amalgama de lo privado y lo público. La descripción que hace Francisco Torres en el siglo XVII de la capilla musical de monjas de este monasterio evidencia el uso de la música por parte de las monjas como una forma de comunicación con el exterior. Los Avisos de Jerónimo de Barrionuevo indican que entre las "distracciones del duque de Lorena en Toledo" en 1654 estaban sus visitas a los "conventos de monjas, donde le divierten y cantan". Los cuentos populares de la época y las vidas de monjas también indican la exhibición pública de las interpretaciones musicales de las monjas. La donación de Catalina de Zúñiga de un libro en italiano de música y danza al monasterio de las Descalzas de Monforte de Lemos (el único libro de música legado al monasterio) muestra la existencia de repertorio profano italiano en el ámbito conventual femenino de Galicia. Aunque se ha dicho que el contexto conventual era el único en que las mujeres podían ejercer la docencia de forma socialmente aceptada, en este Capítulo presento casos de maestras de música en los ámbitos cortesano y doméstico, como por ejemplo Ángela Sigea y Paula Vicente en la corte de María de Portugal, y Cecilia Morillas en el ámbito doméstico. 
Para las mujeres la música era una faceta más de sus habilidades, lo que muestra la fuerte integración de la música en el entramado cultural de la época. Muchas mujeres del período han pasado a los anales de la historia como poetas porque su producción poética es lo que se ha conservado, aunque escribir poesía era sólo una de sus actividades. Por ejemplo, la descripción que hace Francisco Torres de la capilla de música de la Piedad de Guadalajara permite identificar a once de sus integrantes. De dos de ellas (Isabel de Aguiar y María de Arellano) se conserva producción poética. En este Capítulo se da noticia de la poetisa catalana Tecla de Borja (1435-1459), que "tocava la lira $\mathrm{i}$ poetitzava", pero de la que sólo se ha conservado poesía, y de Laurencia Méndez de Zurita $(\dagger 1599 / 1600)$, procedente de Madrid, que cantaba acompañándose del arpa versos de Homero, Ovidio y Virgilio, los salmos de David e himnos eclesiásticos. Los ejemplos de Tecla de Borja y Laurencia Méndez de Zurita recuerdan, en el contexto italiano, a la música de la poesía cantada del siglo XV en la que destacó Pietrobono del Chitarino y a la música de la seconda prattica de finales del siglo XVI, respectivamente.

La superposición de lo privado y lo público (de hogar y taller) que tenía lugar en los talleres de imprenta hace visibles a algunas mujeres impresoras de libros de música. Las impresoras se hacían visibles en la historia cuando enviudaban, aunque seguramente también trabajaban en los talleres en vida de sus maridos, al no existir una división clara entre las ocupaciones domésticas y las del negocio. La edición de 1562, hasta ahora desconocida, del Arte de canto llano de Martínez fue impresa en Zaragoza por María de Solórzano, viuda de Bartolomé de Nájera. María Ramírez, viuda de Juan Gracián, solicitó licencia en 1598 para imprimir el mismo libro en Alcalá de Henares. Susana Muñoz, viuda de Artus Taberniel, imprimió en 1616 el Arte de canto llano de Montanos, mientras que la siguiente edición del libro, que vio la luz en esta imprenta en 1625 , lleva el nombre del impresor Antonio Vázquez, con quien Susana Muñoz se había casado en segundas nupcias.

El vaciado de inventarios de bienes de mujeres muestra la significativa presencia de artes de canto y libros de canto entre los libros de música; véase el Apéndice 17. Las mujeres estaban vinculadas con las artes de canto y los cancioneros poéticos, dos categorías librescas que comparten las características de los llamados "libritos de mujeres" y que constituyen artefactos materiales que preservan la superposición de tradiciones musicales orales y cultura impresa. Los cancioneros poéticos se concebían para adoctrinar a niños y a la clase trabajadora, o bien iban dirigidos a religiosas y mujeres de clase alta como entretenimiento musical devoto. Un romance que relata la vida de María Clemente, religiosa del Convento de San Nicolás de La Orotava (Tenerife), muestra la tradición del canto infantil de tradición oral para alabar a Dios. En este Capítulo se da noticia de una miscelánea manuscrita del siglo XIX conservada en la Biblioteca de Reserva de la Universitat de Barcelona con una mano guidoniana y su explicación a continuación de cuatro folios que contienen poesías. 


\title{
CAPÍTULO VII
}

\section{TRATADOS DE CONDUCTA FEMENINA VERSUS REALIDAD MUSICAL}

\begin{abstract}
Claro que hay momentos en nuestro trabajo - usted también los habrá tenido, Müller- en que uno está tentado de pensar que sólo lo que escapa a nuestro registro es importante, que sólo lo que pasa sin dejar trazas existe verdaderamente, mientras que todo lo que nuestros ficheros conservan es la parte muerta, las rebabas, la escoria. ${ }^{1}$
\end{abstract}

Mientras que los Capítulos V y VI exploran diferentes nexos entre libros de música y mujeres (como dedicatarias, autoras, impresoras y propietarias), este Capítulo utiliza como fuentes libros de disciplinas diferentes a la música y documentación no musical, como tratados de conducta, obras literarias y documentos de la Inquisición, con el propósito de examinar desde otra perspectiva los conocimientos musicales que se esperaban de las mujeres y los rasgos de la panorámica musical en la vida cotidiana. Aunque, en el ámbito italiano, Baldassarre Castiglione incluía el conocimiento moderado de la música entre las cualidades de una perfecta dama, ${ }^{2}$ se ha afirmado que la mayoría de los libros de conducta femenina publicados en el mundo ibérico durante el siglo XVI rechazaban el aprendizaje de la música, "saluo el organo" en el caso de "las Monjas, o a las que lo han de ser". ${ }^{3}$ En este Capítulo se analiza el lugar de la música en tratados de conducta dirigidos a mujeres a través de los términos en que estos manuales

\footnotetext{
${ }^{1}$ Italo Calvino, "La memoria del mundo" [1968], en La gran bonanza de las Antillas, trad. por Aurora Bernárdez (Barcelona: Tusquets, 1993), p. 70.

${ }^{2}$ Castiglione, Il libro del Cortegiano, Libro III, Capítulo 2. La moderación no era una prescripción dirigida exclusivamente a las nobles, también de los hombres se esperaba que practicaran la música y otros ejercicios con moderación. Véase, por ejemplo, Sánchez de Arévalo, Verjel de los príncipes, p. 55. Sobre la educación de la mujer en el contexto italiano, véase Gian Ludovico Masetti Zannini, Motivi storici della educaziones femminile (1500-1650), I: Morale, religione, lettere, arte, musica (Bari: Editorialebari, 1980).

${ }^{3}$ Cerda, Libro intitvlado vida politica de todos los estados de mugeres, f. $18 \mathrm{v}$.
} 
tratan la cuestión de la pertinencia o inconveniencia de que las mujeres lean libros. Mi hipótesis es que, aunque los tratados de conducta femenina advertían a las mujeres en contra de practicar la música, ésta era rechazada por sus connotaciones de ocio secular y no como una práctica devota. Existe una divergencia entre los ideales descritos en los tratados de conducta y el escenario al que apuntan otras fuentes. ${ }^{4}$ El caso de Gracia Baptista tratado en el Capítulo VI sugiere que algunas monjas del siglo XVI aprendieron más de lo prescrito por Juan Luis Vives ("algo de órgano"); ${ }^{5}$ fuentes literarias y registros inquisitoriales también demuestran la existencia de mujeres músicas muy estimadas en su época.

\section{TRATADOS DE CONDUCTA FEMENINA, LECTURA Y MÚSICA}

Las mujeres comenzaron a ser consideradas "personas" en el siglo XV, en el marco del debate sobre la naturaleza de las mujeres o "querelle des femmes". En el siglo XVI, la función social de "la mujer" y los modelos de comportamiento femenino empezaron a discutirse ${ }^{6}$ Como resultado, los tratados de conducta de la época (la mayoría dirigidos a mujeres de la clase media-alta urbana y, en consecuencia, a un sector muy restringido de la población femenina) adjudicaban a las mujeres las tareas de educación de los hijos, establecían el medio doméstico como la esfera de actuación femenina, y definían y clasificaban a las mujeres conforme a su condición sexual y su papel con respecto al hombre. Encontramos tratados dedicados a doncellas, esposas, viudas o

\footnotetext{
${ }^{4}$ Pilar Ramos, "Music and Women in Early Modern Spain: Some Discrepancies Between Educational Theory and Musical Practice", en Musical Voices of Early Modern Women. Many-Headed Melodies, ed. por Thomasin K. LaMay (Aldershot: Ashgate, 2005), pp. 97-118, p. 97. En lo que respecta a los siglos XVII y XVIII, véase Fernández-Cortés, Mujeres y música en la Casa ducal de Osuna, p. 27: "La necesaria 'polifonía de voces' que proporciona el análisis documental demuestra que, al menos en el caso de la familia Osuna, y muy probablemente en otras de la nobleza española aún por estudiar, la restringida visión que proporcionan los textos teóricos, no coincide con la imagen que proyecta la lectura de los documentos administrativos en los que la música aparece frecuentemente entre las actividades de formación habituales en las mujeres de la alta nobleza y de su entorno doméstico, especialmente entre los siglos XVII y XVIII". Sobre la discrepancia entre teoría y práctica en la educación general de las mujeres, véase Howe, Education and Women in the Early Modern Hispanic World, p. 126.
}

\footnotetext{
${ }^{5}$ Vives, Instruccion de la muger christiana, pp. 152-153: "Con todo seria de mi voto que la virgen christiana, si quisiese aprender algo de organo para Monja, que la enseñasen mucho de enhorabuena".

${ }^{6}$ Véanse Vigil, La vida de las mujeres en los siglos XVI y XVII, p. 44; y María Isabel Romero Tabares, La mujer casada y la amazona: un modelo femenino renacentista en la obra de Pedro de Luján (Sevilla: Universidad de Sevilla, 1998), p. 151.
} 
monjas, y manuales estructurados en secciones independientes destinadas específicamente a estas categorías femeninas. El tratado de Juan Luis Vives, Instruccion de la muger christiana (Valencia, 1528), se estructura en tres libros sobre doncellas, casadas y viudas, ${ }^{7}$ La perfecta casada (Zaragoza, 1584) de Fray Luis de León es un tratado dedicado únicamente a las esposas; ${ }^{8}$ y el Libro intitvlado vida politica de todos los estados de mugeres (Alcalá de Henares, 1599) de Juan de la Cerda se divide en cuatro secciones sobre doncellas, monjas, casadas y viudas.

En el contexto de la alta sociedad inglesa del siglo XVIII, Richard Leppert reivindica que la educación funcionaba como un mecanismo mediante el cual el grupo social dominante perpetuaba sus ideologías y jerarquías inculcándolas en la generación siguiente. ${ }^{9}$ Cabe preguntarse si la misma idea es aplicable al caso de los tratados españoles de conducta femenina, ya que éstos a menudo representaban a la mujer como un “Otro", probablemente con el propósito de controlar su comportamiento y delimitar su ámbito de actuación. Este proceso es similar al que se producía en la tragedia griega: según Edith Hall, "las tragedias representan el estallido y resolución de una crisis [...] causada por los 'otros' del varón ateniense, especialmente mujeres y agentes no atenienses"; como los tratados de conducta femenina, la tragedia griega proporcionaba "voz" a las mujeres y la controlaba simultáneamente. ${ }^{10}$ Uno de los ejemplos más claros de control de la alteridad a través de su representación en tratados de educación femenina es el Jardin de nobles doncellas, escrito en 1468 ó 1469 por Fray Martín de Córdoba. Concebido para la educación de la futura reina Isabel I, este libro refleja la preocupación hacia "el reto sin precedentes" que una poderosa mujer soberana planteaba "al status

\footnotetext{
${ }^{7}$ Según Ramos, "Musical Practice and Idleness", p. 267, la no inclusión de una sección dedicada a las monjas en el libro de Vives se relaciona con la tendencia erasmista del autor: "In my opinion the absence of a book on nuns by Vives must be related to his Erasmian trend".

${ }^{8}$ Tratados de educación no dirigidos expresamente a las mujeres, pero útiles como fuente de información son Juan Costa, Gobierno del ciudadano (Pamplona: Tomás Porralis de Saboya, 1575); Juan Bonifaz, Christiani pueri institutio (Salamanca: Matías Gast, 1575); Luján, Coloquios matrimoniales; y López de Montoya, Libro de la buena educacion y enseñanza de los nobles.

${ }^{9}$ Richard Leppert, Music and Image (Cambridge: Cambridge University Press, 1988), p. 2.

${ }^{10}$ Edith Hall, "The Sociology of Athenian Tragedy", en The Cambridge Companion to Greek Tragedy, ed. por Patricia E. Easterling (Cambridge: Cambridge University Press, 1997), pp. 93-126, pp. 94-95: "tragedies enact the outbreak and resolution of a crisis [...] caused by the Athenian male's 'others', especially women and non-Athenian agents".
} 
quo patriarcal". ${ }^{11}$ La visión tradicional de este tratado como "profeminista" y como "una defensa de la soberanía femenina" ha sido cuestionada por Barbara F. Weissberger, quien reivindica que la obra "trata de contener el poder de Isabel" principalmente por dos vías: 1) "exponiendo la visión teológica tradicional de una feminidad esencialmente carnal e irracional" que necesita ser controlada por los hombres; y 2) modelando a la "joven princesa Isabel como reina consorte más que como reina reinante". ${ }^{12} \mathrm{El}$ estudio de Weissberger enlaza con el análisis de Mark Breitenberg de la "anxious masculinity" que se refleja en la literatura que emergió más tarde en torno a Elizabeth I de Inglaterra, ${ }^{13}$ y su argumento coincide con la hipótesis de Joan Kelly-Gadol según la cual el humanismo no significó equidad entre hombres y mujeres porque, si bien las nobles eran educadas junto a sus hermanos varones, era un tutor masculino quien daba forma a la perspectiva de las mujeres. ${ }^{14}$ Una excepción a la norma de un conocimiento femenino determinado por hombres podría ser el caso de la edición en portugués de 1518 del Livre des trois vertus (1405-1406) de Christine de Pisan patrocinada por Leonor de Viseu, viuda del rey João II de Portugal. ${ }^{15}$ La base de esta edición fue una traducción manuscrita del libro probablemente enviada por Isabel de Portugal (1397-1471), esposa de Felipe el Bueno de Borgoña, como regalo a su sobrina Isabel, esposa del rey Afonso V de Portugal. ${ }^{16}$ Es interesante que dos versiones portuguesas renacentistas de un libro

\footnotetext{
${ }^{11}$ Barbara F. Weissberger, Isabel Rules: Constructing Queenship, Wielding Power (Minneapolis: University of Minnesota Press, 2004), p. xiv: "For each of the male writers I discuss, many of whom had close personal and professional ties with the Queen, I have asked the following question: how does his work respond to the unprecedented challenge that a powerful female sovereign poses to the patriarchal status quo?".
}

${ }^{12}$ Weissberger, Isabel Rules, pp. 30, xxiii y xv. Véase también Marta Haro Cortés, "Mujer, corona y poder en un espejo de princesas: El jardín de nobles doncellas de Fray Martín de Córdoba", en Vivir al margen. Mujer, poder e institución literaria, ed. por María Pilar Celma Valero y Mercedes Rodríguez Pequeño (Burgos: Instituto Castellano y Leonés de la Lengua, 2009), pp. 43-57.

${ }^{13}$ Mark Breitenberg, Anxious Masculinity in Early Modern England (Cambridge: Cambridge University Press, 1996).

${ }^{14}$ Kelly-Gadol, “Did Women Have a Renaissance?”, p. 152.

${ }^{15}$ Pisan, Aqui comença o liuro chamado espelho de Cristina.

${ }^{16}$ Christine de Pisan, Livro das tres vertudes, MS (siglo XV), Madrid, Biblioteca Nacional de España, MSS/11515. Véase Tobias Brandenberger, "Una traducción bajomedieval y su público: notas acerca del Espelho de Cristina (Lisboa, 1518)", en Essays on Medieval Translation in the Iberian Peninsula, ed. por Tomàs Martínez i Romero y Roxana Recio (Castelló de la Plana: Publicacions de la Universitat Jaume I, Servei de Comunicació i Publicacions, 2001), pp. 75-94, p. 77. Existen tres copias manuscritas del original en francés, Livre des trois vertus. Se conservan en Boston, Public Library MS 101; Londres, British Library, Additional MS 31841; y París, Bibliothèque nationale de France, n.a.fr. 25636. 
medieval sobre la educación de las mujeres que trataba de responder a las "salvas literarias misóginas" y escrito por una mujer fuesen iniciativas femeninas. ${ }^{17}$

Los tratados de conducta han sido utilizados como fuente para acercarse a la música en la sociedad inglesa de la temprana Edad Moderna por Pamela Starr, quien considera que proporcionan una visión "más equilibrada" que los tratados de música. ¿Qué lugar ocupaba la música en los libros de conducta femenina del ámbito ibérico? Juan Luis Vives se oponía a que las doncellas aprendiesen o escuchasen música, mientras que Juan de la Cerda consideraba que el ejercicio "de todo genero de musica" debía estar a "cien leguas de la honesta donzella". ${ }^{19}$ Pilar Ramos advierte la paradoja que se da en los tratados de conducta: los dirigidos a los hombres recomiendan la inclusión de la música en la formación; los dirigidos a las mujeres rechazan la música. Según Ramos, esta situación se debe a que el tipo de música al que se hace referencia en ambos casos es diferente: para los hombres se trata de la música como ciencia; en el caso de las mujeres (para cuya formación la ciencia no se concebía de ninguna manera) se trata de la práctica de la música popular. ${ }^{20}$ Lo que argumentaré en esta sección es que, aunque rechazasen la práctica “de todo género de música”, la música que deploraban los moralistas era únicamente la asociada al ocio secular y la danza, y no aquélla conectada con prácticas religiosas y concebida como un instrumento de devoción.

\footnotetext{
${ }^{17}$ Susan Groag Bell, "Christine de Pizan (1364-1430): Humanism and the Problem of a Studious Woman", Feminist Studies, III/3-4 (1976), pp. 173-184, p. 177.

${ }^{18}$ Véase Pamela F. Starr, "Music Education and the Conduct of Life in Early Modern England: A Review of the Sources", en Music Education in the Middle Ages and the Renaissance: Reading and Writing the Pedagogy of the Past, ed. por Susan Forscher Weiss, Russell E. Murray y Cynthia J. Cyrus (Bloomington: Indiana University Press, 2010), pp. 193-206.

${ }^{19}$ Vives, Instruccion de la muger christiana, p. 152; Cerda, Libro intitvlado vida politica de todos los estados de mugeres, f. $18 \mathrm{v}$.

${ }^{20}$ Ramos, "The Spanish Prohibition on Women Listening to Music": "The treatises addressed to princes, gentlemen and noblemen recommended the inclusion of music in their male formative programme. In contrast, the treatises addressed to women (written sometimes by the same authors) rejected music. This paradox is not only due to the known double moral code (women were submitted to a much stricter one), but also to the fact that different kinds of music are discussed. The prince is advised to become acquainted with music as a mathematical science and also as a healthy entertainment. For women, the learning of a science is not even mentioned, because it was outside the limits regarded as suitable for the female mind. What is questioned instead is the access of women to the daily practice of music, to the popular airs performed at court as well as in the streets".
} 


\title{
1.1. Música y convites
}

En los tratados de conducta femenina, la cuestión musical se discute en secciones dedicadas a los perjuicios que las fiestas y convites causan en la juventud (hombres y mujeres). Tanto Juan Luis Vives como Juan de la Cerda trataban la cuestión de la música en las secciones de sus tratados dedicadas a las doncellas y, por tanto, en relación con la educación de las niñas y las jóvenes. Vives hacía referencia a la música en su capítulo XV, titulado "De las fiestas y convites", en clara vinculación con el ocio secular:

\begin{abstract}
Otrosí, ¿qué dirémos de las músicas y cantares que son brevajos emponzoñados para matar el mundo todo? ¿Despues de esto los suspiros fingidos y los visages sobrepuestos y contrahechos, ansí de los que cantan, como de los que oyen, y los otros embaymientos y trampantojos, con que se ciegan las simples doncellas, como las inocentes avecitas se toman en la rama, adonde ménos se temen presas. Y por eso yo no permito ni es de mi voto que las doncellas aprendan música, ni ménos que se huelguen de oirla en ninguna parte, ni en casa, ni afuera, ni á puerta ni á ventana, ni de dia ni de noche, y esto no lo digo sin causa. Pues que no sin causa San Atanasio disputó con hartas razones probables y argumentos, que ni aun en la Iglesia, no habia de haber música ni sones muy delicados, sino quanto era necesario para alabar a Dios $[\ldots] .{ }^{21}$
\end{abstract}

Por tanto, Vives se oponía a que las doncellas aprendieran u oyeran música, pero lo hacía en un contexto muy determinado: el de las fiestas y convites en que las músicas son "trampantojos" que "ciegan" a las jóvenes. Como ha advertido Pilar Ramos, este capítulo "De las fiestas y convites" no aparece en las ediciones latinas ni en las inglesas del tratado de Vives, sino que fue una adición a las ediciones españolas introducida por el traductor Juan Justiniano en $1528 .^{22}$ La hipótesis de Ramos es que "el rechazo de la música práctica femenina en los círculos moralistas de la España de la temprana Edad Moderna puede explicarse en parte por el contexto de la herencia cultural musulmana y judía". 23

Juan de la Cerda advertía en contra de la música en un ámbito conceptual muy similar: el de la danza, el baile y sus consecuentes "desasosiegos" para las doncellas. Consideraba que las jóvenes debían evitar "todo genero de música”, porque la música y

\footnotetext{
${ }^{21}$ Vives, Instruccion de la muger christiana, p. 152.

${ }^{22}$ Ramos, "The Spanish Prohibition on Women Listening to Music".

${ }^{23}$ Ramos, "The Spanish Prohibition on Women Listening to Music": "I will argue in this brief essay that the rejection of female practical music in moralist circles in Early Modern Spain can be partly explained by the context of Muslim and Jewish cultural heritage".
} 
la danza son "diabolicos exercicios" que "despiertan malos pensamientos" y causan "mucha deshonestidad":

La razon porque estos exercicios de dançar y baylar, y de todo genero de musica (saluo el organo a las Monjas, o a las que lo han de ser) han de estar cien leguas de la honesta donzella, es porque a ratos (sin mirar en ello) falta vna centella de aficion del que bien dança, en el tierno coraçon de la que bayla con el, o que le vee baylar, que abrasa su coraçon poco a poco y le destruyste. [...] Pues que mejor auiso se puede dar a la honesta donzella, sino que huya estos diabolicos exercicios, de donde suelen proceder estos desassossiegos y tormentos, que son danças, bayles, musicas? $?^{24}$

En los razonamientos de Vives y de la Cerda difícilmente se puede estar haciendo referencia al canto religioso o a la música como ejercicio devoto, sino a una música relacionada con el ocio secular. En otras fuentes se especifica que es la música deshonesta la que debe evitarse; por ejemplo, en los Estatutos fundacionales de la Casa de Nuestra Señora de Misericordia de Zaragoza para prostitutas arrepentidas (1594) se establecía que no estaba permitido "baylar ni cantar cosa que no sea muy honesta y de Dios". ${ }^{25}$ Las reglas de los colegios femeninos apoyan la misma hipótesis. El currículo del Colegio de Doncellas Pobres de San Juan de la Penitencia fundado en Toledo en 1514 incluía labores domésticas, rezo y lectura pero, según Elizabeth Teresa Howe, "la regla específicamente prohibía la música", puesto que "las niñas no podían aprender polifonía en los locutorios, ni tocar el arpa ni ningún otro instrumento, ni cantar en alto en la reja". ${ }^{26} \mathrm{Al}$ examinar la prohibición a la luz de las prácticas conventuales tratadas en el Capítulo VI, notamos que la prohibición de interpretar música en los locutorios y "cantar en alto en la reja" atañe a una música relacionada con la exhibición pública, si bien, como se mostró en el Capítulo VI, la realidad era completamente distinta.

El ocio debía ser evitado puesto que podía conducir a los "tornadizos" pensamientos femeninos. Fray Luis de León titulaba uno de los capítulos de su tratado dedi-

\footnotetext{
${ }^{24}$ Cerda, Libro intitvlado vida politica de todos los estados de mugeres, f. $18 \mathrm{v}$.

${ }^{25}$ Estatutos fundacionales de la Casa de Nuestra Señora de Misericordia de Zaragoza para prostitutas arrepentidas, MS (1594), Zaragoza, Archivo Histórico Provincial de Zaragoza, Diego Casales, año 1594, ff. 1361 y ss.; citado en María Tausiet, Abracadabra omnipotens: magia urbana en Zaragoza en la Edad Moderna (Madrid: Siglo XXI de España Editores, 2007), pp. 181-182.

${ }^{26}$ Howe, Education and Women in the Early Modern Hispanic World, p. 106: "the rule specifically forbade music [...] neither in the parlors may they be taught or learn polyphony, or to play the harp or any other instrument, nor to sing loudly at the grille".
} 
cado a las casadas "Cuanto debe evitar la mujer buena el ocio, y de los vicios y malas resultas que de el nacen", mientras que Juan Luis Vives aconsejaba a las mujeres que hicieran labores manuales como tejer después de sus obligaciones domésticas con el propósito de evitar pensar. ${ }^{27}$ Hernando de Talavera incluía la "honesta musica" entre los “pasatiempos honestos” que debía practicar Isabel Pacheco para “evitar la ociosidad”. En el capítulo XII de su libro, titulado "De como se expendera el tiempo desde el medio dia hasta la cena", Hernando de Talavera señalaba que:

Leuantada ya la mesa: y hecha oracion tan bien al comienço como al cabo, podeys entonces pasar tiempo: quanto media hora en alguna recreacion: o de honesta e prouechosa fabla con algunas buenas personas: o de alguna honesta musica: o de alguna buena leccion y esto seria lo mejor avnque non para la digestion. ${ }^{28}$

Por tanto, el análisis del lugar que ocupa la música en los tratados de conducta femenina y el complemento de esta información con la que proporcionan otras fuentes, como las reglas de los colegios femeninos de la época, sugieren que en los tratados de conducta femenina se rechazaba la música en relación al ocio, al pecado y al concepto negativo de emociones como "accidentes del alma". ${ }^{29}$

\subsection{Una aproximación indirecta: mujeres y lectura}

La hipótesis de que el rechazo de los moralistas a la práctica de la música por parte de las mujeres aludía a la música como entretenimiento secular y no atañía a la música como honesto ejercicio se refuerza mediante el análisis de la manera en que estos tratados de conducta se aproximan a la cuestión de la conveniencia de que las muje-

\footnotetext{
${ }^{27}$ Vives, Obras completas, pp. 992-993: "Pero a mí no me agrada que la mujer ignore aquellas artes en que se ocupan las manos [la lana y el lino], aun cuando fuera princesa o reina. ¿Qué otra cosa preferente o mejor hará cuando hubiere dado recaudo a los quehaceres de su casa? ¿Estarse hablando con varones o con otras mujeres? ¿De qué cosas hablará? ¿Hablará siempre? ¿No se callará nunca? O tal vez pensará; pero ¿qué cosas pensará? Veloz es el pensamiento de la mujer y tornadizo por lo común, y vagaroso y andariego, y no sé bien adónde le trae su propia lubricada ligereza". Según Ramos, "Musical Practice and Idleness", p. 271, la postura de Vives sobre la ociosidad, "crucial para entender su postura sobre la música", es quizás consecuencia del origen judeoconverso del autor.

${ }^{28}$ Talavera, De como ordenar y ocupar el tiempo, s.f. [cap. xii].

${ }^{29}$ María Tausiet y James S. Amelang, eds., Accidentes del alma: las emociones en la Edad Moderna (Madrid: Abada, 2009), p. 8: "La actual sobrevaloración -o más bien abuso- de las emociones en nuestra sociedad de mercado contrasta, en principio, con la consideración, predominantemente negativa, acerca de éstas en la época estudiada en este libro".
} 
res lean libros. Juan Luis Vives y Juan de la Cerda advertían contra la lectura de libros "profanos y de mentiras", como las novelas de caballería o los libros "de armas y de amores", y aconsejaban a las jóvenes que se ocupasen en la lectura de "deuotos libros" y la práctica de ejercicios honestos y virtuosos. Por ejemplo, el quinto capítulo del libro de la Instruccion de la muger christiana de Juan Luis Vives dedicado a las doncellas se titula “Quáles libros se deben leer, y quáles no", y en él incluso se expone un listado de "libros vanos". ${ }^{30}$ Este capítulo tenía su paralelo en el manual de Juan de la Cerda, en que el capítulo quinto del tratado sobre el estado de las doncellas se titula "de el daño que haze en las donzellas la leccion de los libros profanos y de mentiras: y de el prouecho que de los buenos y sanctos libros se saca". 31

Cabe preguntarse por qué motivo estos tratados se afanan en distinguir entre libros no recomendables y lecturas honestas, mientras que cuando se refieren a la música lo hacen en un sentido genérico que identifica "música" con las músicas seculares de los convites y fiestas. Por ejemplo, en La perfecta casada Fray Luis de León incluía "libros de caballeria" y "canciones" en una enumeración de las actividades a evitar por parte de las mujeres, términos que sugieren que con "canciones" se aludía a la música secular. ${ }^{32}$ El que Vives no tratase la música religiosa ni la litúrgica en su tratado de conducta femenina es un hecho que se relaciona, según Pilar Ramos, con la tendencia erasmista del autor y una opinión contraria al monacato que evitó expresar dado su origen judeoconverso. ${ }^{33}$ La ausencia de una distinción entre música religiosa y música secular en estos

${ }^{30}$ Vives, Instruccion de la muger christiana, pp. 28-39.

${ }^{31}$ Cerda, Libro intitvlado vida politica de todos los estados de mugeres, f. 12v: "En lo que toca en si es bien occupar a la donzella en el exercicio de leer, y escreuir: ha auido diuersos pareceres. Y examinados los fundamentos de estas opiniones, parece que aunque es bien que aprenda a leer para que reze y lea buenos y deuotos libros mas el escreuir ni es necessario, ni lo querria ver en las mugeres: no porque ello de suyo sea malo, sino porque tienen la ocasion en las manos, de escreuir villetes, y responder a los que hombres liuianos les embian".

${ }^{32}$ León, La perfecta casada, p. 80: “[...] y de sus maridos los duques y reyes que las precien por ello y que las estimen; y aun acabare con ellos, que en pago deste cuidado las absuelvan de otros mil importunios y memorables trabajos con que atormentan sus cuerpos y rostros, y que las excusen y libren del leer en los libros de caballerias, y del traer el soneto y la cancion en el seno, y del billete, y del donaire de los recaudos, y del terreno, y del sarao, y de otras cien cosas de este jaez, aunque nunca las hagan".

${ }^{33}$ Ramos, "Musical Practice and Idleness", p. 267: "En mi opinión, la ausencia de un libro de Vives sobre Monjas debe relacionarse con su tendencia erasmista. Y lo mismo puede decirse con respecto a su silencio sobre la música litúrgica. Vives, uno de los pocos humanistas laicos españoles, estaba en contra del monacato aunque, cuidadosamente, no explicó este punto. Esto no es sorprendente, conocía demasiado amargamente las consecuencias de ser considerado como sospechoso por la Inquisición. Su padre y otros miembros de su familia fueron quemados por la Inquisición tras largos juicios después de ser acusados de "judaizantes" ["In my opinion the absence of a book on nuns by Vives must be related to his Erasmian 
tratados puede proporcionarnos una dosis de "shock cultural", puesto que tampoco Juan de la Cerda ni Fray Luis de León se ocupaban de la música como honesto ejercicio. El que estos tratados de conducta utilizaran el concepto de música reduciendo su extensión significativa a la música secular sugiere que la categorización de la música por géneros en secular, religiosa y litúrgica supone un distanciamiento que quizás no encaje con las perspectivas de la época. Esto podría deberse a que el arte musical estaba tan intrínsecamente integrado en los procesos religiosos que en este caso la música (religiosa) no era concebida desde una perspectiva "gnóstica" como una abstracción desligada de la materialidad del hecho sonoro, de su funcionalidad religiosa y de los procesos en que se integraba. $^{34}$

\subsection{Discrepancias entre el plano teórico y la realidad}

Las discordancias entre las prescripciones de los tratados de los teólogos dirigidos a las mujeres y la vida cotidiana de la época son claras y no sólo ocurren en el ámbito musical, sino que se relacionan con cuestiones generales relativas al comportamiento de las mujeres y a su educación; es decir, la discrepancia entre literatura teórica y prácticas reales va más allá de la música. ${ }^{35}$ La tesis defendida por Grace E. Coolidge en su estudio de la nobleza española en la temprana Edad Moderna es que, paradójicamente, los hombres promovían un estereotipo de mujer silenciosa y recluida, pero al mismo

trend. And the same can be said in respect of his silence about liturgical music. Vives, one of the few Spanish lay humanists, was against monasticism although he carefully does not expound on this point. This is not surprising, he knew all too bitterly the consequences of being considered suspect by the Inquisition. His father and others members of his family were burnt by the Inquisition following long trials after being accused of being 'Judaizers"'].

${ }^{34}$ Esta terminología es tomada de la distinción entre las perspectivas "drastique" y "gnostique" hacia la música que lleva a cabo Vladimir Jankélévitch en La musique et l'ineffable (París: Éditions Armand Colin, 1961), y del controvertido artículo de Carolyn Abbate, "Music -Drastic or Gnostic?", Critical Inquiry, XXX/3 (2004), pp. 505-536. La perspectiva "drástica" se centra en la experiencia de la interpretación musical, lo cual, según Jankélévitch y Abbate es la "música real”. En contraste, la posición "gnóstica" supone el desplazamiento de la experiencia de la música por una abstracción, "la obra musical". Según Abbate, tanto el formalismo como la llamada "musicología crítica" encajan en el segundo tipo de aproximación a la música, puesto que estudian obras musicales y no la "música real".

${ }^{35}$ Véase, por ejemplo, Vigil, La vida de las mujeres en los siglos XVI y XVII, p. 24: "los moralistas estaban empeñados en la defensa de unas normas que en el siglo XVI no constituían formas de comportamiento habituales. Entonces, la sociedad esperaba de una joven que fuera manejable, desde luego, pero también que tuviera una cierta desenvoltura y una mínima gracia. En contextos sociales urbanos, y entre las clases alta y media -cuyo sistema de valores representaba un modelo a imitar por el resto de la sociedad-, no era normal educar a las niñas como decían los moralistas. Los padres que lo hicieran así se exponían a tener luego graves dificultades para casarlas". 
tiempo dependían de mujeres activas para mantener su autoridad. ${ }^{36}$ A pesar de que los tratados de conducta prescribían una educación limitada para las mujeres, estos manuales por sí mismos presuponen que sus destinatarias (mujeres urbanas de clase media y alta) eran capaces de leer y/o comprender referencias a fuentes clásicas. El caso de Catalina de Zúñiga analizado en el Capítulo V muestra que las mujeres de clase alta podían llegar a adquirir una amplia formación. Es sumamente interesante que, aunque sobre Catalina de Zúñiga habían escrito poemas figuras tan conocidas como Lope de Vega, fue precisamente una mujer escritora, María de Zayas (1590-1661), quien subrayó la formación de la Condesa de Lemos ensalzando su amplia cultura y su dominio del latín. ${ }^{37}$ Stephen Haliczer ha señalado que el miedo a que cualquier educación más allá de lo más rudimentario llevara a las mujeres a desafiar el control que tenían los hombres en los contextos político y religioso se manifiesta en los escritos de dramaturgos como Lope de Vega. ${ }^{38}$ El caso de Catalina de Zúñiga funciona como un ejemplo claro de este fenómeno.

El rechazo de la música en los tratados de conducta femenina no encaja con la formación musical de algunas de las mujeres de clase alta a quienes tales manuales iban dirigidos. Un ejemplo es la discrepancia entre los preceptos contenidos en el tratado de Juan Luis Vives y los conocimientos musicales de la noble Mencía de Mendoza (15081554), II Marquesa del Cenete, de la que el propio Vives fue tutor en los Países Bajos, donde Mencía de Mendoza vivió tras casarse con Enrique III de Nassau-Dillemburg en 1524. ${ }^{39}$ Mencía de Mendoza y sus hermanas María y Catalina recibieron una formación

\footnotetext{
${ }^{36}$ Coolidge, Guardianship, Gender and the Nobility in Early Modern Spain.

${ }^{37}$ María de Zayas, Desengaños amorosos: parte segunda del sarao y entretenimiento honesto, ed. por Agustín G. de Amezúa y Mayo (Madrid: Aldus, 1950), p. 177. Véanse Marina Brownlee, The Cultural Labyrinth of María de Zayas (Filadelfia: University of Pennsylvania Press, 2000); y Lisa Vollendorf, Reclaiming the Body: María de Zayas's Early Modern Feminism (Chapel Hill: University of North Carolina Press, 2001).

${ }^{38}$ Haliczer, Between Exaltation and Infamy, pp. 50-51.

${ }^{39}$ Sobre la relación entre Mencía de Mendoza y Juan Luis Vives, véase Simon A. Vosters, La dama y el humanista: doña Mencía de Mendoza y Juan Luis Vives entre Flandes y Valencia (Murcia: Nausícaä, 2007). Para un estudio biográfico de Mencía de Mendoza, véanse Miguel Lasso de la Vega y López de Tejada, Marqués del Saltillo, Doña Mencía de Mendoza, Marquesa del Cenete (1508-1554) (Madrid: Viudad de Estanislado Maestre, 1942); y Noelia García Pérez, Mencía de Mendoza (1508-1554) (Madrid: Ediciones del Orto, 2004). En el campo musicológico, véanse Ferran Muñoz, Mencía de Mendoza y la Viuda de Mateo Flecha (Valencia: Institució Alfons el Magnànim, 2001), donde se defiende que la viuda de la ensalada de Mateo Flecha es Mencía de Mendoza y no sólo "la música"; y Francesc Villanueva Serrano, "Mateo Flecha, el Viejo, en la Catedral de Valencia: sus dos períodos de magisterio de capilla (1526-1531? y 1539-1541) y su entorno musical", Anuario musical, LXIV (2009), pp. 57-108.
} 
musical en el ámbito doméstico de su castillo de Ayora (Valencia), no sólo por parte de su padre Rodrigo Díaz de Vivar y Mendoza (†1523), gran aficionado a la música, ${ }^{40}$ sino que también dos músicos profesionales de Valencia, Miguel Ortiz y Miguel Celma, fueron contratados para enseñar música y danza a las niñas. ${ }^{41}$ Mencía de Mendoza aprendió a tocar diferentes instrumentos, entre ellos la vihuela y el clave. ${ }^{42}$ En el inventario postmortem del Marqués de Cenete encontramos los siguientes libros de música: “un libre apellat de quintze mises de cant de orgue", "regule musicales", "musice Franchium Gaforis", "pratica musice Gaforis", "hun libre de aristetica musice et alia", "musice” y "opera boetis". ${ }^{43}$ Generalmente se había creído que Mencía de Mendoza heredó de su padre una biblioteca de 632 volúmenes que ella posteriormente amplió, de manera que su inventario post-mortem incluía 949 libros. ${ }^{44}$ Sin embargo, Mercedes Gómez-Ferrer ha presentado recientemente dos documentos desconocidos hasta ahora que ponen de manifiesto que años después de la muerte del Marqués del Cenete buena parte de los libros de éste fueron vendidos en almonedas públicas en Valencia por representantes de sus hijas, de manera que no pudieron ser heredados por Mencía, lo que lleva a replantear la relación de ésta con los libros:

Podemos interrogarnos sobre el interés de Mencía por los libros y si es que éste se despierta más
tardíamente, sobre el papel de sus sucesivos maridos, el círculo de humanistas e intelectuales que
rodeaba al conde de Nassau en Breda o la posible competencia con la biblioteca de su segundo
marido, el duque de Calabria que poseía una de las colecciones de libros más significativos del
renacimiento español [...]. A falta de un análisis más exhaustivo del proceso de adquisición de
libros por parte de Mencía de Mendoza, cabría apuntar dos posibles hipótesis, o el despertar de
un interés por los libros relativamente tardío, ya que no tuvo inconveniente en deshacerse de más
de 400 libros de la biblioteca de su padre o el hecho de preferir la adquisición de los suyos pro-

${ }^{40}$ García Pérez, Mencía de Mendoza (1508-1554), p. 33: "El Marqués del Zenete había sido educado en la corte del infante don Juan, hijo de los Reyes Católicos. Fue allí, donde aprendió las primeras letras e inició su afición por la música".

${ }^{41}$ Barcelona, Archivo de la Corona de Aragón, Casa de Cenete, legajo 142, recibos de 22 de mayo y 26 de junio de 1523; citado en Lasso de la Vega, Doña Mencía de Mendoza, pp. 35-36.

${ }^{42}$ Noelia García Pérez, "La huella petrarquista en la biblioteca y colección de obras de arte de Mencía de Mendoza”, Tonos. Revista electrónica de Estudios Filológicos, 8 (2004)

$<$ http://www.um.es/tonosdigital/znum8/estudios/7-petrarca.htm>.

${ }^{43}$ Francisco Javier Sánchez Cantón, Biblioteca del marqués del Cenete iniciada por el cardenal Mendoza (1470-1523) (Madrid: S. Aguirre, 1942).

${ }^{44}$ Véanse García Pérez, "La huella petrarquista en la biblioteca y colección de obras de arte de Mencía de Mendoza"; y Arte poder y género en el Renacimiento español: el patronazgo artístico de Mencía de Mendoza (Murcia: Nausícaä, 2006). 
pios de forma independiente y terminar con los problemas de una herencia recurrida, en continuos pleitos con su tío y a su vez, compartida con su hermana. ${ }^{45}$

En 1529 se vendieron 202 libros, mientras que en 1535 se subastaron 213 libros y otros objetos, entre ellos una viola, del Marqués del Cenete. Cabe preguntarse si Mencía de Mendoza mantuvo los libros de música de su padre o los vendió en estas almonedas. En los documentos únicamente se detallan los títulos vendidos en la primera almoneda y entre ellos sólo encontramos uno de los libros de temática musical: "Item hun libre intitulat Mussice a Andres librer", que se corresponde con "musice" del inventario post-mortem del Marqués. No sabemos si los otros libros de música se vendieron en la almoneda de 1535, en cuya documentación no se desglosaron los títulos vendidos, o si pasaron a Mencía de Mendoza. La investigación de la biblioteca de la noble, que está llevando a cabo Josep Solervicens Bo, quizás permita determinar si la Marquesa preservó el resto de libros de música de su padre y también si ella adquirió algún libro de música para ampliar la biblioteca que había heredado, lo que arrojaría luz sobre la relación de esta noble con los libros de música. ${ }^{46}$ La adquisición de libros de música por parte de Mencía de Mendoza no sería sorprendente dada su formación musical, su posesión de instrumentos musicales y su mantenimiento de una capilla de música tras la muerte de su segundo marido Fernando de Aragón, Duque de Calabria, con quien se casó en $1540 . .^{47}$

\footnotetext{
${ }^{45}$ Mercedes Gómez-Ferrer, "Las almonedas de los libros del Marqués de Zenete en 1529 y 1535 en Valencia", Lemir, 14 (2010), pp. 231-246, p. 237. El descubrimiento de estos documentos también lleva a cuestionar qué parte de los libros del Marqués de Cenete pasaron a su hermano, Diego Hurtado de Mendoza, I Conde Mélito; véase Dadson, Libros, lectores y lecturas, pp. 95-118.

${ }^{46}$ La biblioteca de Mencía de Mendoza ha sido reconstruida a partir de cuatro fuentes documentales diferentes que se complementan; véase Josep Solervicens Bo, "La literatura humanística a la selecta biblioteca de Mencía de Mendoza, marquesa del Cenete, duquessa de Calàbria i deixebla de Joan Lluís Vives", en La Universitat de València i l'Humanisme: Studia Humanitatis i renovació cultural a Europa i al nou Món, ed. por Ferran Grau Codina, Xavier Gómez Font, Jordi Pérez Durà y José María Estellés González (Valencia: Departament de Filologia Clàssica, Universitat de València, 2003), pp. 313-324.

${ }^{47}$ La importancia de la capilla del Duque queda reflejada en los cuentos populares de la época; véase Juan Timoneda, El sobremesa y alivio de caminantes (Valencia: Juan Navarro, 1569), Parte II, f. D8v, cuento xxix: "El duque de Calabria fue tan dado á la musica, que no habia en España quien tantos y tan buenos musicos tuviese, á causa de los grandes salarios que les daba. Viniendo un gran musico forastero al real para oir la musica el dia de los reyes, que tanto le habian alabado, oido é informado de la renta del duque, dijo: "para tan chica capa, gran capilla es esta". La capilla de los duques ha sido analizada en detalle en Lasso de la Vega, Doña Mencía de Mendoza, p. 47, donde se describe como "un verdadero cabildo, presidido por un Obispo, e integrada por clérigos, teólogos, cantores, músicos y sacristanes". Véase también Josep Romeu Figueras, "Mateo Flecha el Viejo, la corte literario musical del duque de Calabria y el Cancionero llamado de Upsala", Anuario musical, XIII (1958), pp. 25-101.
} 
En conclusión, existe una discrepancia entre los preceptos de los tratados de conducta y la realidad de sus prospectivas lectoras (mujeres de clase media-alta). Parece que, más allá de los tratados, tuvo lugar "una cultura de educación informal para las mujeres", y que este proceso debe de haber sido "tan natural" que "se quedaba sin mencionar y por tanto invisible". ${ }^{48}$ Como consecuencia de la existencia de tal discrepancia entre teoría y práctica en la educación femenina, para llevar a cabo un escrutinio más minucioso de la relación entre mujeres y música deben emplearse fuentes diferentes a los manuales de conducta.

\section{VESTIGIOS DE LA MÚSICA (DE MUJERES) EN LA VIDA COTIDIANA: JUEGOS CORTESANOS, TEATRO, LITERATURA Y MUSICOTERAPIAS}

A pesar de la restrictiva imagen que proporcionan los libros de conducta, existe evidencia de que las mujeres eran participantes activas en entretenimientos cortesanos con un componente musical. Surgido en la corte valenciana de Germana de Foix y Fernando de Calabria, El libro de motes (Valencia, 1535), escrito por el vihuelista Luis de Milán y dirigido "a las damas", funciona como testimonio de las actividades de ocio que practicaban las mujeres y los hombres de esta corte, incluyendo referencias a cantar y tocar la vihuela. ${ }^{49}$ Paradójicamente, Germana de Foix $(† 1536)$ es la dedicataria de la

\footnotetext{
${ }^{48}$ Nader, ed. Power and Gender in Renaissance Spain, p. 6: "In one aspect of life, education, these essays reveal a previously unknown or unexamined culture of informal education for women. The authors found no descriptions of the means by which women received education in childhood, yet every action and written record of their adult years reveals a level of education that far exceeds the stereotype of girls simply learning to sew and embroider. [...] From birth, females trained to be wives, mothers, and widows. Educating girls seemed indispensable and natural, so natural that the process of women's education remained unmentioned and therefore almost invisible". María Sanhuesa Fonseca, "Maestros, amigos, alcahuetes: los modos de educación musical doméstica en el XVII español", en Miscel-lània Oriol Martorell, ed. por Xosé Aviñoa (Barcelona: Universidat de Barcelona, 1998), pp. 393-404, estudia la educación musical doméstica en la España del siglo XVII tal y como aparece documentada en novelas cortesanas y picarescas. Sanhuesa identifica una serie de figuras involucradas en un proceso de educación musical informal, tales como instructores que enseñaban lo que estaba de moda a las mujeres, y estudiantes que impartían lecciones con el propósito de conseguir algo de dinero.

${ }^{49}$ Sobre la vida musical y cultural de esta corte, véase Bernadette Nelson, "The Court of Don Fernando de Aragón, Duke of Calabria in Valencia, c. 1526-c. 1550: Music, Letters and the Meeting of Cultures", Early Music, XXXII/2 (2004), pp. 195-222. Véanse también William M. McMurry, "Ferdinand, Duke of Calabria, and the Estensi: A Relationship Honored in Music", The Sixteenth Century Journal, VIII/3 (1977), pp. 17-30; y Francesc Villanueva Serrano, "Poemas inéditos del vihuelista y escritor Luis Milán y nuevas consideraciones sobre su identidad: el ms. 2050 de la Biblioteca de Catalunya", Anuario musical, LXVI (2011), pp. 61-118.
} 
edición española del tratado de conducta de Juan Luis Vives que contenía la prohibición de la música. Un ejemplo de la presencia de la música en estos entretenimientos es el siguiente juego: “A la noche yo querría / que cantéis en la vihuela: / nadie de mi mal se duela, / pues que todo es alegría. // A la noche cantaré: / nadie de mi mal se duela, / pues él mismo me consuela". 50

Pilar Ramos ha argumentado que la vida musical femenina en España, si bien "no tan sombría como la deseada por moralistas y teóricos de la música”, en los ámbitos cortesanos y conventual estaba "lejos de ser comparable a la floreciente actividad musical de las mujeres italianas de la misma época”, aunque la música teatral constituía una excepción. ${ }^{51}$ Los límites entre el medio teatral y los ámbitos tanto conventual como cortesano no estaban lo suficientemente definidos en el período. Las referencias musicales son constantes en trabajos sobre el teatro conventual y en estudios de la vida conventual en general llevados a cabo en disciplinas distintas a la musicología. Por ejemplo, según Elissa B. Weaver, en el siglo XVI había en España e Italia (“y probablemente en toda la Europa católica y sus colonias") una tradición de teatro con un componente musical no sólo en la corte, sino también en los conventos como un tipo de "diversión espiritual y aprendizaje para las mujeres". ${ }^{52} \mathrm{El}$ estudio de Weaver se concentra en las escritoras de los conventos toscanos y las obras que éstas escribieron como fuente para determinar su grado de alfabetismo y el de su público. Weaver declara que "la música quizás era siempre parte del evento teatral conventual". ${ }^{53}$ Según Silvia Evangelisti, las obras de

\footnotetext{
${ }^{50}$ Vega Vázquez, ed., El libro de motes de damas y caballeros de Luis de Milán, p. 52.

${ }^{51}$ Ramos, "Music and Women in Early Modern Spain", p. 117: "Although the reality for female musical activity in Spain is not as somber as the one desired by moralists and musical theorists, this panorama is far from being comparable to the flourishing musical activity of the Italian women of the same time. Spain was not the scene for Il Cortegiano. It is true that female prominence was enormous in the field of Spanish theatrical music. But the musical activity of women was more restricted in the Church, in the courts and in the houses of the Castilian and Aragonese urban centers".

52 Elissa B. Weaver, Convent Theatre in Early Modern Italy: Spiritual Fun and Learning for Women (Cambridge: Cambridge University Press, 2002). El drama musical sacro Ordo Virtutum (c.1151) de Hildegard von Bingen, que supone una síntesis de teatro, música, poesía y teología y fue creado por la abadesa para las religiosas de su convento de Rupertsberg (Alemania) con un propósito pedagógico, constituye un lejano precedente.
}

${ }^{53}$ Weaver, Convent Theatre in Early Modern Italy, pp. 2, 47: "music was perhaps always a part of the convent theatrical event". 
teatro tenían lugar en el refectorio, el patio o el locutorio, con asistencia de visitantes en este último caso. ${ }^{54}$

Electa Arenal y Stacey Schlau reproducen un manuscrito de música compuesta por María de San Alberto, la hija de Cecilia Morillas, en el Monasterio de las Carmelitas Descalzas de Valladolid. ${ }^{55}$ Se trata de música para su obra de teatro sobre la Natividad "Fiestecilla del nacimiento". Arenal y Schlau señalan que precisamente las instrucciones escénicas de María de San Alberto se han usado como evidencia de "la inseparabilidad de poesía y música en ese período”, ya que, por ejemplo, se indica al comienzo de una escena que dos monjas entren "cantando y tañendo" y se escribe la música. La tonada de María de San Alberto debía ser tocada a la vihuela y sonar como "música de fondo" a lo largo de la obra. Éste es el único manuscrito de los examinados por Arenal y Schlau en que se encuentra notación musical. ${ }^{56}$ Por tanto, aunque se conoce a una sola compositora procedente del mundo ibérico del siglo XVI (Gracia Baptista) por el hecho de que una pieza suya fue impresa, las monjas componían música para sus obras de teatro, y estos casos qujizás sean sólo el trazo visible de una rica actividad musical (femenina y masculina) en la vida cotidiana. ${ }^{57}$

También en el ámbito cortesano encontramos referencias a eventos teatrales con un componente musical, como evidencia la representación de La fábula de Dafne en las dependencias privadas de la emperatriz viuda María de Austria (1528-1603), probablemente en el convento de las Descalzas Reales de Madrid, un domingo de Carnaval entre 1585 y 1593, siendo los intérpretes las meninas y meninos de la infanta Isabel Clara Eugenia. ${ }^{58}$ Tres de las músicas que participaron en esta representación son elogiadas por

\footnotetext{
${ }^{54}$ Evangelisti, Nuns, pp. 102-103.

${ }^{55}$ Arenal y Schlau, Untold Sisters, p. 130.

${ }^{56}$ Arenal y Schlau, Untold Sisters, p. 149; véase también Evangelisti, Nuns, pp. 99-124.

${ }^{57}$ Arenal y Schlau, Untold Sisters, p. 148: “Como las Vidas de monjas a veces hacen explícito, aunque más a menudo ocultan, teatro y música, la dramatización de los servicios, ejercicios devotos y coloquios espirituales acompañados por instrumentos y canto formaban parte integral del año religioso en el convento" ["As women's Vidas sometimes make explicit, but more often hint, theatre and music, the dramatization of services, devotional exercises, and coloquios espirituales accompanied by instruments and the singing voice formed and integral part of the religious year in the convent (...)]".

${ }^{58}$ MS Espagnol 501, París, Bibliothèque nationale de France, R.52.915. Véanse Norman David Shergold, A History of the Spanish Stage from Medieval Times Until the End of the Seventeenth Century (Oxford: Clarendon Press, 1967), pp. 250-252; Pilar Ramos, "Dafne, una fábula en la corte de Felipe II", Anuario musical, L (1995), pp. 23-46, pp. 23 y 30; y “Mujeres, música y teatro en el Siglo de Oro", en Música y mujeres. Género y poder, ed. por Marisa Manchado Sánchez (Madrid: Horas y Horas, 1998), pp. 39-61,
} 
Vicente Espinel en el "Canto Segundo de la casa de la memoria" (1591), un poema en que los principales músicos de esa época son celebrados: ${ }^{59}$ Francisca de Guzmán, cantante; Isabel Sánchez Coello (1564-1612), pintora y música, hija del también pintor Alonso Sánchez Coello; ${ }^{60}$ y Ana de Zuazo (1580-antes de 1618), poetisa, música, monja y camarera de la reina Margarita de Austria. ${ }^{61}$ Espinel elogia también a Agustina de Torres que, a pesar de ser mencionada en el poema únicamente como la madre de Ana de Zuazo, era también cantante. ${ }^{62}$ En la nota marginal de una carta fechada en Madrid a 18 de abril de 1613 Catalina de Zúñiga que, como Ana de Zuazo, trabajaba al servicio de Margarita de Austria, hacía referencia a "Ana de Çuaço": "No deges de ver esa copia de vn villete de D. Ana de Çuaço, que es particular cosa auerse confirmado con el pronostico de su muerte de aquel santo fraile". ${ }^{63}$ En La fábula de Dafne Ana de Zuazo actuó en el papel de Diana e interpretó el Soneto XIII de Garcilaso “A Dafne ya los braços le crecían" cantando y tocando la guitarra, mientras que Isabel Coello interpretó el romance de Apolo "Venteçico murmurador" cantando y tocando el arpa. La conexión entre el surgimiento de actrices profesionales y músicas profesionales en las dos últimas

p. 58; Louise K. Stein, "The Musicians of the Spanish Royal Chapel and Court Entertainments, 15901648", en The Royal Chapel in the Time of the Habsburgs: Music and Ceremony in the Early Modern European Court, ed. por Juan José Carreras y Bernardo García García, trans. por Yolanda Acker, versión inglesa ed. por Tess Knighton (Woodbridge, Suffolk: The Boydell Press, 2005), pp. 173-194, p. 178; y María Asunción Flórez, Música teatral en el Madrid de los Austrias durante el Siglo de Oro (Madrid: ICCMU, 2006), pp. 410-418.

${ }^{59}$ Vicente Espinel, "Canto segundo de la casa de la memoria", en Diversas rimas, ed. por Alberto Navarro González y Pilar González Velasco (Salamanca: Universidad de Salamanca, 1980 [1591]), pp. 112124.

${ }^{60}$ Para un resumen de las referencias a Isabel Coello en la bibliografía, véase Ramos, "Dafne, una fábula en la corte de Felipe II", p. 8. Véanse también Stein, "The Musicians of the Spanish Royal Chapel", p. 179; y Flórez, Música teatral en el Madrid de los Austrias durante el Siglo de Oro, pp. 412-413.

${ }^{61}$ Además de la de Espinel, se encuentran referencias poéticas a Ana de Zuazo en Vega, Laurel de Apolo, f. 73v; y El peregrino en su patria, ed. por Juan Bautista Avalle-Arce (Madrid: Castalia, 1973 [1604]), p. 380; Alonso de Salas Barbadillo, Rimas castellanas (Madrid: Viuda de Alonso Martín, 1618), f. A3v, "Á la muerte de Doña Ana de Zuaço" (soneto); y Antonio de Maluenda, Algunas rimas castellanas: Descubriólas entre los manuscritos de la Biblioteca Nacional de Madrid D. Juan Perez de Guzmán y Gallo y las publica por vez primera, bajo los auspicios del Excelentisimo Señor D. Manuel Perez de Guzmán y Roza, Marqués de Xerez de los Caballeros (Sevilla: Imp. de E. Rasco, 1892), p. 31, Soneto XXV.

${ }^{62}$ Flórez, Música teatral en el Madrid de los Austrias, p. 412; Luis Astrana Marín, Vida ejemplar y heroica de Miguel de Cervantes Saavedra: con mil documentos hasta ahora inéditos (Madrid: Instituto Editorial Reus, 1948-1958), p. 238; Real Academia Española, Memorias de la Real Academia Española (Madrid: Real Academia Española, 1886-1926), vol. 10, pp. 236, 237 y 306; y Juan López Maldonado, Cancionero (Madrid: Guillermo Droy, 1586), ff. 101r-103v.

${ }^{63}$ La carta se transcribe en Barbeito Carneiro, Escritoras madrileñas del siglo XVII, vol. 2, p. 893. 
décadas del siglo XVI que apunta Anthony Newcomb en el caso italiano parecería plausible también en el contexto ibérico, puesto que las referencias a estas mujeres en la literatura de la época sugieren que eran consideradas principalmente músicas y no "tipos especializados de cortesanas". ${ }^{64}$ El lugar en que se llevó a cabo la representación de La fábula de Dafne indica una ruta más de mecenazgo musical femenino consistente en ambiciosas interpretaciones en espacios femeninos.

De nuevo, como en el caso de las monjas poetisas y músicas, Isabel Sánchez Coello no ha pasado a los anales de la historia como música, sino como pintora. Sin embargo, como señala Pilar Ramos, "es significativo que en La Casa de la Memoria de Vicente Espinel se la destaque como instrumentista y cantante". ${ }^{65}$ Como en el caso de la poesía, la pintura se plasmaba materialmente; la música de estas actrices, por el contrario, se transmitía oralmente y no se creía necesario escribirla porque no era "tan complicada de vozes". ${ }^{66}$ Louis K. Stein señala que la música de las obras teatrales cortesanas integraba piezas complejas interpretadas por músicos de la capilla real y "géneros musicales más populares" que circulaban más allá de la corte, como el romance "Venteçico murmurador", "adecuados para amateurs (y para solistas femeninas)". ${ }^{67}$ Según Pilar Ramos, en general las mujeres se relacionaban con el teatro y por tanto con la música popular, mientras que los hombres se vinculaban a la música de las capillas y las iglesias, situación que se relaciona con "la ideología de género en España y cómo ésta afectaba a la música". ${ }^{68}$ En contraste con la imagen que presentan los tratados de conducta,

\footnotetext{
${ }^{64}$ Anthony Newcomb, "Courtesans, Muses, or Musicians? Professional Women Musicians in SixteenthCentury Italy", en Women Making Music: The Western Art Tradition, 1150-1950, ed. por Jane Bowers y Judith Tick (Urbana y Chicago: University of Illinois Press, 1986), pp. 90-115, pp. 101-103.

${ }^{65}$ Ramos, “Dafne, una fábula en la corte de Felipe II”, p. 30.

${ }^{66}$ Ramos, "Dafne, una fábula en la corte de Felipe II", p. 33, hace referencia al libro de Francisco de Salinas, De musica libri Septem, f. 501: "Además, la composición musical que suele ejecutarse en las asambleas profanas y en los banquetes de los príncipes no es tan complicada de vocez que no pueda cantarse sin partitura".

${ }^{67}$ Stein, "The Musicians of the Spanish Royal Chapel and Court Entertainments", pp. 194 y 179. Según María Asunción Flórez, "Los vientos se paran oyendo su voz: de 'partes de música' a 'damas de lo cantado'. Sobre la evolución de la técnica vocal en el teatro español de los siglos XVII y XVIII", Revista de Musicología, XXIX/2 (2006), pp. 521-536, pp. 523-524, "un denominador común que parece haber dominado la música teatral hispana desde fechas muy tempranas" es el "carácter popular o 'popularizante' de ritmos y melodías y la importancia concedida a la legibilidad del texto cantado".

${ }^{68}$ Ramos, "Mujeres, música y teatro en el Siglo de Oro", p. 39.
} 
las obras literarias actúan como indicio de la existencia de mujeres músicas altamente estimadas en el mundo ibérico. ${ }^{69}$

El teatro con un componente musical no sólo tenía lugar en conventos y en la corte, sino que a finales del siglo XVI funcionaban teatros comerciales en las principales ciudades ibéricas, como el Corral de la Cruz (1579) y el Corral del Príncipe (1582), ambos en Madrid. ${ }^{70}$ Contamos con los trabajos de Álvaro Torrente, acerca de la música en el teatro medieval y renacentista ${ }^{71}$ Louis K. Stein y Pilar Ramos sobre la música en el teatro del siglo XVII; y María Asunción Flórez quien, centrándose en los siglos XVII y XVIII, señala que las mujeres eran las protagonistas del teatro musical, desempeñando papeles femeninos y masculinos, hasta la aparición del cantante profesional a mediados del siglo XVIII. Además, Flórez hace referencia a la organización de recitales por parte de mujeres en el siglo XVII:

De hecho, en fecha tan temprana como 1623 ya era costumbre entre la sociedad madrileña organizar 'recitales a cargo de señoras' como los que tuvieron lugar en los apartamentos de la condesa de Olivares y en casa de las princesas de Esquilache y Mélito durante la estancia del Cardenal Barberini en Madrid. ${ }^{72}$

Se ha señalado que la música en el teatro del XVI se producía en los entreactos y al final, que los músicos no se colocaban en la escena y que la música se reducía a voz con acompañamiento de guitarra, mientras que en la comedia nueva del siglo XVII la música estaba más integrada en la obra teatral; por ejemplo, Emilio Cotarelo y Mori, tratando los orígenes de la zarzuela, llama la atención sobre la poca importancia atribuida a la música:

\footnotetext{
${ }^{69}$ Para un breve estudio de mujeres y música en novelas españolas del siglo XVII, véase María Sanhuesa Fonseca, "Mujeres y música en la novelística del XVII español: personajes, actitudes y peculiaridades", en Scripta: estudios en homenaje a Elida García García (Oviedo: Universidad de Oviedo, 1998), vol. 2, pp. 939-955.

${ }^{70}$ Louis K. Stein, Songs of Mortals, Dialogues of the Gods (Oxford: Clarendon Press, 1993), p. 11; Shergold, A History of the Spanish Stage, pp. 177-208.

71 Álvaro Torrente, "La música en el teatro medieval y renacentista", en Historia del Teatro Español, ed. por Javier Huerta Calvo (Madrid: Gredos, 2003), vol. 1, pp. 269-302.

72 Flórez, "Los vientos se paran oyendo su voz", p. 589. Debe de tratarse de Inés de Zúñiga y Velasco (1584-1647), esposa del III Conde de Olivares; Ana de Borja y Pignatelli, V Princesa de Esquilache (c. 1580-1644); y Leonor de Guzmán, Princesa de Mélito (†1657).
} 
[...] la música de estas piezas incidentales, o era ya conocida y el poeta le adaptaba la nueva letra, o bien la componía para cada caso el músico de la compañía, que además tocaba la vihuela, la guitarra o el arpa y aun cantaba detrás de bastidores cuando era necesario. En la organización de las compañías se veía ya cuán poca importancia se daba a la música y al canto; pues entre las damas, sólo la cuarta era la destinada especialmente a cantar cuando había necesidad de ello y entre los galanes no había ninguno con el oficio de cantor, que lo era el llamado "músico", que casi nunca salía a escena. Cuando, más adelante, fue necesario, para las fiestas de Palacio y Buen Retiro, mayor número de cantantes, se tomaban los de varias compañías sólo para aquel acto. ${ }^{73}$

Sin embargo, Norman David Shergold sugiere que dramaturgos como Cervantes, Agustín de Rojas y Juan Rufo, que escribieron sobre el papel de la música en el teatro del siglo XVI, posiblemente exageren en sus referencias a la pobreza musical de éste, puesto que intentaban dignificar la comedia nueva comparándola con lo anterior. ${ }^{74}$ Esto sugiere que la investigación del papel que desempeñaban las actrices cantantes en el teatro del siglo XVI sería de gran interés, así como el estudio de las compañías teatrales de finales de siglo como centros de formación musical para estas mujeres.

En su novela Relaciones de la vida del Escudero Marcos de Obregon (Madrid, 1618), Vicente Espinel celebraba las reuniones musicales y poéticas que tenían lugar en la casa de Agustina de Torres en Salamanca en torno a $1572 .{ }^{75}$ Como señalé en el Capítulo IV, la música solía tener una presencia en las academias literarias, y existen testimonios de la participación de las mujeres en éstas. Por ejemplo, aunque no tenemos pruebas de la inclusión de actividades musicales, las actas de una academia llamada "Pítima contra la Ociosidad" que se celebró en Zaragoza durante el verano 1608 demuestran que las condesas de Eril y Guimerá se encontraban entre sus participantes activos. ${ }^{76}$ Además, según Vicente Espinel, Bernardina Clavijo, arpista y organista, hija del maestro Bernardo Clavijo del Castillo, tomó parte en reuniones de músicos que se celebraban en su casa de Madrid en torno a su padre. ${ }^{77}$ De nuevo, el uso de fuentes diferen-

\footnotetext{
${ }^{73}$ Emilio Cotarelo y Mori, Historia de la zarzuela o sea el drama lírico en España, desde su origen a fines del siglo XIX (Madrid: Tipografía de Archivos, 1934), p. 33.

${ }^{74}$ Shergold, A History of the Spanish Stage, pp. 162-167.

${ }^{75}$ Sánchez, Academias literarias del Siglo de Oro (Madrid: Gredos, 1961), p. 295; y Sanhuesa Fonseca, "Armería del ingenio y recreación de los sentidos".

${ }^{76}$ Adolphe Coster, Una Academia literaria aragonesa. La "Pítima contra la ociosidad” 1608 (Huesca: L. Pérez, 1912); Willard F. King, "The Academies and Seventeenth-Century Spanish Literature", PMLA, LXXV/4 (1960), pp. 367-376, p. 369; Sánchez, Academias literarias del Siglo de Oro español, pp. 252259; y Academia de los Nocturnos, Actas de la Academia de los Nocturnos, vol. 1, p. 33. Véase el Apéndice 15.
} 
tes a los propios libros de música permite descubrir valiosa información sobre los conocimientos musicales de algunas mujeres de la época y su estatus cultural. Este tipo de fuentes proporciona pistas de una educación musical informal (femenina), así como trazos de la participación de las mujeres en la vida musical de la época.

Otra muestra del importante papel de la música en la vida cotidiana del período es que era considerada un remedio para determinadas enfermedades, lo cual queda demostrado por las referencias en cuentos populares al uso de la música por parte de los médicos y por las alusiones que a la música se hacían en los manuales de medicina publicados en la época. En el ya citado Cuento muy gracioso que sucedió a un arriero con su mujer (1603) de Francisco de Medina, se dice que Juan Prados curaba a las mujeres con cantos fingiendo ser médico:

\section{[...] hago recetas a muchas fingiendo ser boticario, sin ser médico las curo con palabras, yerbas, cantos $[\ldots]^{78}$}

La música era ensalzada como el principal remedio contra el mal de amores, que en aquella época se consideraba una enfermedad. María Tausiet señala entre los tratamientos del mal de amores "baños, buena comida y bebida, un sueño reparador, juegos, viajes, conversaciones con buenos amigos y, sobre todo, el cultivo de la música como armonizadora por excelencia de la mente y el cuerpo". ${ }^{79}$ Curiosamente, estos remedios eran medicinales y, por tanto, contrastaban con la "magia" que llevaban a cabo las mujeres hechiceras: "quienes se entregaban al cultivo de la magia erótica no tenían otro objetivo que transmitir o contagiar su desazón al hombre objeto de sus deseos como único alivio para sus pesares". ${ }^{80}$ Respecto a qué tipo de música se utilizaba para curar el mal de amores, Linda Phyllis Austern ha señalado que ni los médicos ni los teóricos de la época pusieron por escrito la música que remediaba esta enfermedad ni indican un determinado repertorio, sino que "simplemente explican que la música eficaz en este

\footnotetext{
${ }^{77}$ Espinel, Relaciones de la vida del escudero Marcos de Obregón, p. 174.

${ }^{78}$ Chevalier, Cuentos españoles de los siglos XVI y XVII, pp. 200-213.

${ }^{79}$ Tausiet, Abracadabra omnipotens, p. 96.

${ }^{80}$ Tausiet, Abracadabra omnipotens, p. 97.
} 
caso debería agradar o distraer, debería simpatizar y armonizar con la constitución del enfermo y el objetivo de restablecimiento somático"; esto significa que, "o había un entendimiento cultural tácito de qué tipo de música lograba estos efectos, o el enfermo hacía selecciones basadas en su gusto estético individual". ${ }^{81}$ Tomando como fuente a Johannes Tinctoris, Austern indica que también se creía que la música tenía la propiedad de suscitar el amor. ${ }^{82}$

El estudio de Austern se fundamenta en manuales de medicina publicados principalmente en el contexto británico, por lo que cabe preguntarse si en los libros de medicina publicados en el mundo ibérico renacentista encontramos referencias a la música. La investigación de este aspecto me ha conducido a una respuesta afirmativa y a una asociación de las creencias en las propiedades curativas de la música con el pensamiento árabe. En su Medicina española contenida en proverbios vulgares de nuestra lengua (Granada, 1616), un libro dirigido explícitamente a filósofos, médicos, teólogos y juristas "para el buen regimiento de la salud”, Juan Sorapán de Rieros fundamentaba científicamente el refrán popoular "quien canta sus males espanta” a lo largo de diez páginas; véase la Ilustración VII.1. Tras citar a numerosos autores clásicos y a Avicena, Sorapán de Rieros explicaba que para que haya dolor concurren dos cosas: 1) "la alteracion de la parte que duele"; y 2) el "conocimiento de la tal alteracion". Esto significa que "estando la mente, ó imaginacion distraida en otra cosa, no advirtiendo a la causa del dolor, falta la dignoscion, y no puede auer dolor"; por consiguiente, la música es un medicamento "porque atrae assi con su melodia, la fuerça del alma, para que no advierta, y conozca la causa del dolor $[\ldots] " .{ }^{83}$

\footnotetext{
${ }^{81}$ Linda Phyllis Austern, "Musical Treatments for Lovesickness: The Early Modern Heritage", en Music as Medicine. The History of Music Therapy Since Antiquity, ed. por Peregrine Horden (Aldershot: Ashgate, 2000), pp. 213-245, p. 226-227: "They simply explain that efficacious music in this case should please or distract, should sympathize and harmonize with the sufferer's constitution and goal of somatic restoration. Either there was tacit cultural understanding of what sort of music accomplished these effects, or the sufferer made selections based on individual aesthetic taste". Véanse también Penelope Gouk, ed., Musical Healing in Cultural Contexts (Aldershot: Ashgate, 2000), volumen colectivo sobre el poder sanador atribuido a la música por diferentes grupos socioculturales; y Penelope Gouk y Helen Hills, eds., Representing Emotions: New Connections in the Histories of Art, Music and Medicine (Aldershot: Ashgate, 2005).

${ }^{82}$ Austern, "Musical Treatments for Lovesickness", p. 227.

${ }^{83}$ Juan Sorapán de Rieros, Medicina española contenida en proverbios vulgares de nuestra lengua muy provechosa para todo genero de estados, para Philosophos, y Medicos, para Theologos, y Iuristas, para el buen regimiento de la salud, y mas larga vida (Granada: Martín Fernández Zambrano, 1616), pp. [502]-511.
} 
Ilustración VII.1: Juan Sorapán de Rieros, Medicina española contenida en proverbios vulgares de nuestra lengua muy provechosa para todo genero de estados, para Philosophos, y Medicos, para Theologos, y Iuristas, para el buen regimiento de la salud, y mas larga vida (Granada: Martín Fernández Zambrano, 1616), portada y p. [502]. Munich, Bayerische Staatsbibliothek, 4 Path. 352.
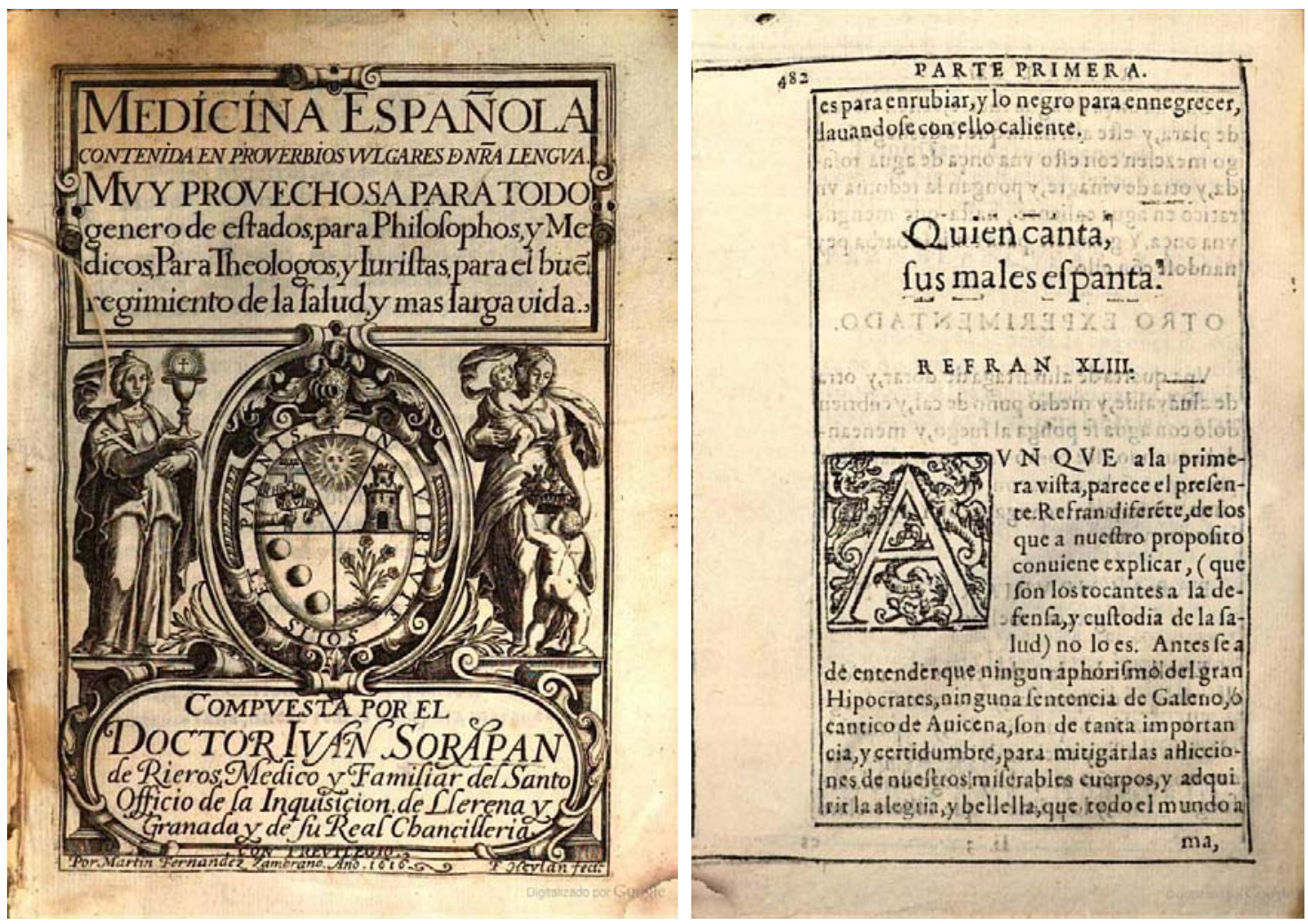

Transcripción:

Quien canta, sus males espanta.

REFRAN XLIII

Aunque a primera vista, parece el presente Refran diferente, de los que a nuestro proposito conuiene explicar, (que son los tocantes a la defensa, y custodia de la salud) no lo es. Antes se a de entender que ningun aphorismo del gran Hipocrates, ninguna sentencia de Galeno, ó cantico de Auicena, son de tanta importancia, y certidumbre, para mitigar las aflicciones de nuestros miserables cuerpos, y adquirir la alegria, y bellella, que todo el mundo ama, como es el canto, y musica, medicina admirable, para ahuyentar, y espantar cualquier genero de males, como nuestro Refran dize $[. .$.$] .$

Otro ejemplo de las propiedades medicinales atribuidas a la música se encuentra en Nueva filosofia de la naturaleza del hombre no conocida ni alcanzada de los grandes filosofos antiguos: la cual mejora la vida y salud humana (Madrid, 1587), obra publicada bajo el nombre de Oliva Sabuco (1562-1620), hija del farmacéutico de Alcaraz (Albacete) Miguel Sabuco; véase la Ilustración VII.2. En esta obra también se aboga por la relación entre la mente y el cuerpo y por la eficacia de la musicoterapia: 
ANTONIO. [...] La musica tambien es eficacisimo remedio, que quita el daño que el enojo esta haciendo, como los mordidos de las tarantulas sanan bailando a buena musica, y no con otra cosa, y si falta la musica muere luego.

RODONIO. Ahora digo que tenia gran razon Ismenias, medico Tebano, que curaba todas las enfermedades con la musica. ${ }^{84}$

Ilustración VII.2: Oliva Sabuco, Nueva filosofia de la naturaleza del hombre no conocida ni alcanzada de los grandes filosofos antiguos: la cual mejora la vida y salud humana (Madrid: P. Madrigal,

1587), portada. Madrid, Biblioteca Nacional de España, R/4599.
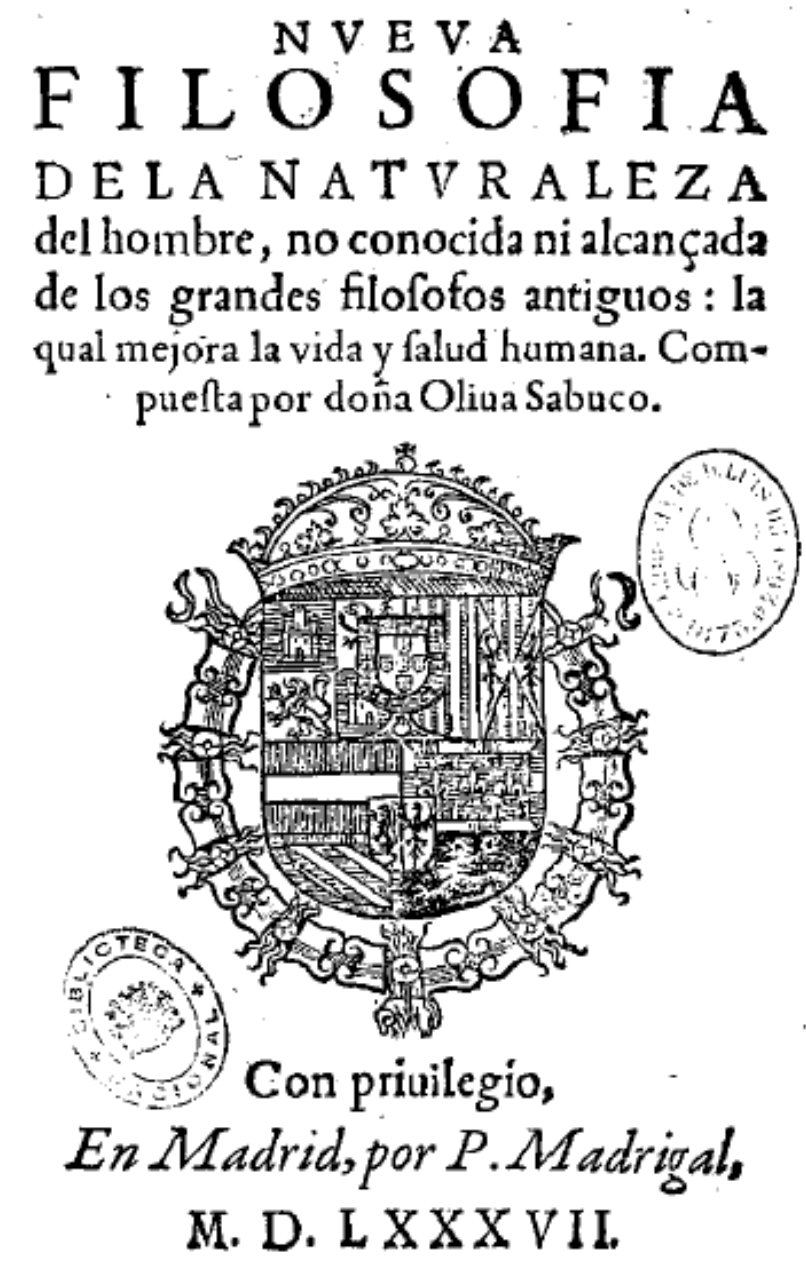

\footnotetext{
${ }^{84}$ Olivia Sabuco, Nueva filosofia de la naturaleza del hombre no conocida ni alcanzada de los grandes filosofos antiguos: la cual mejora la vida y salud humana (Madrid: P. Madrigal, 1587), f. C3v, Título VI. Para una traducción inglesa, véase Oliva Sabuco, New Philosophy of Human Nature: Neither Known to nor Attained by the Great Ancient Philosophers, Which Will Improve Human Life and Health, trad. por Mary Ellen Waithe, Mary Colomer Vintro y C. Ángel Zorita (Urbana: University of Illinois Press, 2007). Para una edición crítica del libro bajo el nombre de Miguel Sabuco, el padre de Oliva, véase Miguel Sabuco Álvarez, Nueva Filosofía, ed. crítica por Samuel García Rubio y Domingo Henares (Albacete: Instituto de Estudios Albacetenses "Don Juan Manuel”, Diputación de Albacete, 2009).
} 
El libro tuvo un enorme impacto, reimprimiéndose en 1588 y 1589 en el mismo taller. Es significativo que, en la dedicatoria del libro, Oliva Sabuco pidiese al dedicatario, Felipe II, que favoreciese "a las mujeres en sus aventuras". Tras el descubrimiento del testamento (1588) de Antonio Sabuco, en que declaraba ser el autor de la Nueva filosofia y haber atribuido el libro a Oliva "solo por darle el nombre e la onrra" y no el "fruto y probecho que resultare de los dichos libros", 85 ha tenido lugar una controversia historiográfica sobre si el libro fue escrito por Oliva Sabuco o por su padre. ${ }^{86}$ Se ha dicho que Miguel Sabuco publicó el libro con el nombre de su hija para evitar los juicios de la Inquisición, pero también se ha argumentado que se atribuyó el libro a sí mismo en su testamento para proteger a su hija de la Inquisición. Fuera quien fuese el autor de la Nueva filosofía, la historia de este libro pone de manifiesto los problemas de autoría que afrontaban las mujeres en el siglo XVI, y sugiere la especial represión que ejerció la Inquisición sobre éstas.

\section{MUJERES MÚSICAS Y DOCUMENTOS DE LA INQUISICIÓN}

Mediante la reducción de la escala de observación, lo que para otro estudioso podría haber sido una simple nota a pie de página en una hipotética monografía sobre la Reforma Protestante en Friuli se transformó en un libro. ${ }^{87}$

En el Capítulo VI he afrontado el problema de la invisibilidad femenina en documentos históricos a través del estudio de algunas conexiones entre libros de música y mujeres (como autoras, impresoras y propietarias) partiendo de la hipótesis de que las

\footnotetext{
${ }^{85}$ José Marco é Hidalgo, "Doña Oliva de Sabuco no fue escritora”, Revista de Archivos, Bibliotecas y Museos, VII/9 (1903), pp. 1-13, p. 8.

${ }^{86}$ Mònica Balltondre, "La nueva filosofía de la naturaleza del hombre de Oliva Sabuco", Athenea Digital, 10 (2006), pp. 259-262 <http://antalya.uab.es/athenea/num10/sabuco.pdf>. Para referencias bibliográficas, véanse Rosalía Romero Pérez, Oliva Sabuco (1562-1620): filósofa del Renacimiento español (Toledo: Almud, Centro de Estudios de Castilla-La Mancha, 2008); y "La Nueva Filosofía de Oliva Sabuco (s. XVI) y el problema de su autoría", en Mujeres y Ausencias: Duelo y Escritura, ed. por Miriam Palma Ceballos y Eva Parra Membrives (Bern, Munich: Peter Lang, 2009), pp. 243-260.

${ }^{87}$ Carlo Ginzburg, "Microhistory: Two or Three Things That I Know About It", Critical Inquiry, XX/1 (1993), pp. 10-35, p. 22: "In reducing the scale of observation, that which for another scholar could have been a simple footnote in a hypothetical monograph on the Protestant Reformation in Friuli was transformed into a book".
} 
áreas en que se produce una superposición entre lo privado y lo público o entre lo oral y lo escrito permiten vislumbrar prácticas musicales femeninas y vestigios de la cultura musical de la época. Dada la necesidad de analizar artefactos materiales en que lo oral y lo escrito se superponen, las metodologías usadas por la musicología tradicional ofrecen una panorámica fragmentaria de la cultura musical de la época, de manera que se requieren otras estrategias como complemento. Aunque se consideran ya superadas en las ciencias históricas, las “aproximaciones indirectas" y las prácticas microhistóricas permanecen casi inexploradas en los estudios musicológicos. En esta sección mostraré los resultados de una aplicación al campo de la música de las metodologías utilizadas para documentar la cultura popular. Emplearé una metodología similar a la utilizada por Carlo Ginzburg en El queso y los gusanos (1976) para estudiar los documentos inquisitoriales del proceso contra Isabel Ortiz entre 1564 y 1565 por alumbrada, con el objetivo de visualizar indicios de actividad musical femenina quizás invisibles de otro modo a los ojos del historiador. ${ }^{88}$

\subsection{Introducción y base metodológica}

Los documentos inquisitoriales han sido utilizados por Lisa Vollendorf como fuente para definir género y feminidad en España; ${ }^{89}$ también Stephen Haliczer emplea quince procesos inquisitoriales como fuente en su estudio de las místicas de la España del Siglo de Oro. ${ }^{90}$ La Inquisición ejerció una especial represión sobre las mujeres, pero también sobre los libros en lengua vernácula que eran accesibles a un amplio público; es decir, sobre los dos objetos de la presente investigación. En los trabajos de José Pardo Tomás sobre censura inquisitorial y libros científicos se afirma que la mayoría de los libros censurados se corresponden con la categoría del "librillo ordinario que anda en manos de oficiales y mozuelos y mujercillas". 91 También los procesos inquisitoriales

\footnotetext{
${ }^{88}$ Carlo Ginzburg, Il formaggio e I vermin: il cosmo di un mugnaio del '500 (Florencia: Einaudi, 1976).

${ }^{89}$ Vollendorf, The Lives of Women. En particular, se estudian los casos de Eleno/a de Céspedes y Bernarda Manuel.

${ }^{90}$ Haliczer, Between Exaltation and Infamy. Los documentos inquisitoriales se complementan con treinta biografías y autobiografías de místicas, obras de devoción, tratados teológicos y vidas de santos.

${ }^{91}$ José Pardo Tomás, "Censura inquisitorial y lectura de libros científicos. Una propuesta de replanteamiento", Tiempos modernos, IX/4 (2003), pp. 1-18, p. 16. Este trabajo constituye una reelaboración de algunas de las conclusiones del libro Ciencia y censura. La Inquisición Española y los libros científicos en los siglos XVI y XVII (Madrid: CSIC, 1991). Ambos trabajos suponen una crítica de la historiografía
} 
por brujería se vinculaban a las mujeres, puesto que el concepto de brujería (el ser malvado "por naturaleza") sólo se aplicaba a éstas, mientras que los hombres se llamaban "hechiceros" o "nigromantes" ("poseedores de ciertos conocimientos y técnicas adquiridos"). ${ }^{92}$ Curiosamente, el aquelarre se relacionaba con las mujeres y con la música. Según un testigo del juicio contra Dominga Ferrer "La Coja", procesada por brujería en Pozán de Vero (Huesca) en 1534, el hijo de ésta había dicho sobre el aquelarre "que el habia hido una noche con su madre, que lo habia lebado a una fiesta que habia mucha gente y muchachas y muy gran fiesta de muchas musicas". ${ }^{93}$ Por tanto, los documentos de la Inquisición pueden funcionar como fuente de la concepción de la música en la mentalidad de la época y del lugar que la música ocupaba en la vida cotidiana, en particular entre las mujeres.

El queso y los gusanos se ha considerado un paradigma de microhistoria. Aunque se trata de una práctica historiográfica teóricamente indeterminada, Giovanni Levi ha señalado algunos elementos compartidos por la mayoría de los enfoques microhistóricos: 1) "la reducción de escala"; 2) "el debate sobre la racionalidad”; 3) "el pequeño indicio como paradigma científico"; 4) "el rol de lo particular (aunque no como oposición a lo social)"; 5) "la atención a la recepción y la narrativa"; 6) el uso de "una definición específica de contexto"; y 7) "el rechazo del relativismo". ${ }^{94}$ No obstante, las perspectivas microhistóricas han sido subsecuentemente rebatidas por estudiosos como Josep Fontana, John H. Elliott y Franco Venturi. Carlo Ginzburg, en particular, ha recibido críticas de Ruggiero Romano, Jean Bouvier y Philippe Boutry, entre otros. James S. Amelang ha resumido en cuatro puntos las críticas a la microhistoria: 1) la reducción

tradicional y la aportación de un nuevo paradigma interpretativo del "debate sobre la influencia de la censura inquisitorial en el desarrollo del pensamiento científico". La hipótesis que se presenta en Pardo Tomás, "Censura inquisitorial y lectura de libros científicos", pp. 16-17, es que "la Inquisición fijó su punto de mira en el control y la represión de capas semi-instruidas (mujeres, jóvenes, no universitarios o tonsurados,...) de la sociedad, dejando de lado e incluso buscando -y encontrando- la complicidad de las élites intelectuales", y que "la censura inquisitorial se dirigió más a los lectores que a los autores".

${ }^{92}$ María Tausiet, Ponzoña en los ojos. Brujería y superstición en Aragón en el siglo XVI (Madrid: Turner, 2004 [2000]), p. 30.

93 "Proceso contra Dominga, 'La Coja'. Pozán de Vero. 1534”, Zaragoza, Archivo Histórico de Protocolos de Zaragoza, C. 31-2, f. 58; citado en Tausiet, Ponzoña en los ojos, p. 297. Sobre las relaciones entre música y magia en el Renacimiento, véase Tomlinson, Music in Renaissance Magic, especialmente pp. 14.

${ }^{94}$ Levi, “On Microhistory”, p. 110. Ginzburg, "Microhistory”, p. 10, decía haber oído hablar de la microhistoria por primera vez a Giovanni Levi en 1977 ó 1978, lo que prueba la indeterminación del concepto. 
de escala conduce a una historia local; 2) la narrativa lleva a formas historiográficas tradicionales como la biografía; 3) la focalización en objetos de estudio marginales presenta el problema de representatividad; y 4) la microhistoria es un producto del posmodernismo y por tanto una moda pasajera. ${ }^{95}$

La propuesta metodológica de El queso y los gusanos consiste en la utilización de un enfoque indirecto para examinar los documentos emanados del caso de Domenico Scandella (1532-1601), conocido como Menocchio, un molinero que vivió en la región italiana del Friuli en el siglo XVI y fue procesado en dos ocasiones por la Inquisición romana a causa de sus creencias heréticas. Ginzburg ilumina el universo del molinero y, por tanto, su comportamiento, ${ }^{96}$ intentado vislumbrar de qué manera comprendía los libros que decía haber leído y de los que surgieron sus ideas heréticas, es decir, su relación con el texto impreso, que debió ser totalmente diferente a la de cualquier lector de nuestros días. ${ }^{97}$ Para evitar un enfoque anacrónico, Ginzburg complementa la información extraída de los documentos inquisitoriales con su investigación previa de las tradiciones orales de los benandanti (un culto de fertilidad agrícola del Friuli en los siglos XVI y XVII), que debieron configurar el pensamiento del molinero y funcionar como un filtro en sus lecturas: "no era el libro como tal, sino el encuentro entre la página im-

\footnotetext{
95 James S. Amelang, "Microhistory and Its Discontents: The View from Spain", en Historia a Debate. Tomo II: Retorno del sujeto. Actas del Congreso Internacional "A historia a debate" celebrado el 7-11 de julio de 1993 en Santiago de Compostela, ed. por Carlos Barros (Santiago de Compostela: Historia a Debate, 1995), pp. 307-312, p. 308, muestra que en España el debate sobre la microhistoria estaba empezando en los noventa y su tesis principal es que "los historiadores españoles tienen razones particulares para ser receptivos al mensaje microhistórico" y que, de hecho, Miguel de Unamuno anticipó con su concepto de "intrahistoria" muchas de las cuestiones microhistóricas.

${ }^{96}$ Geertz, “Thick Description”, p. 17: “Al comportamiento se le debe prestar atención y con algo de exactitud, porque es a través del flujo del comportamiento - 0 , más precisamente, de la acción social- que las formas culturales encuentran articulación" ["Behavior must be attended to, and with some exactness, because it is through the flow of behavior - or, more precisely, social action- that cultural forms find articulation"].

${ }^{97}$ Carlo Ginzburg, The Cheese and the Worms. The Cosmos of a Sixteenth-Century Miller (Londres: Routledge, 1980 [1976]), p. xxii: “¿Hasta qué punto la cultura prevalentemente oral de aquellos lectores se interpuso en el uso del texto, modificándolo, rehaciéndolo, quizás hasta el punto de cambiar su esencia? Los relatos de Menocchio sobre sus lecturas nos proporcionan un sorprendente ejemplo de una relación con el texto que es totalmente diferente de la del lector educado de hoy en día" ["To what extent did the prevalently oral culture of those readers interject itself in the use of the text, modifying it, reworking it, perhaps to the point of changing its very essence? Menocchio's accounts of his readings provide us with a striking example of a relationship to the text that is totally different from that of today's educated reader'].
} 
presa y la cultura oral lo que formaba una mezcla explosiva en la cabeza de Menocchio". 98

Ginzburg aspira a superar los dos principales obstáculos que percibe en los estudios de la cultura popular: 1) las distorsiones causadas por la existencia de intermediarios; y 2) el problema de la representatividad. Según la quinta característica de la microhistoria identificada por Giovanni Levi (la atención a la recepción y la narrativa), Ginzburg advierte que "El queso y los gusanos no se limita a la reconstrucción de un caso individual; lo narra". ${ }^{99}$ El discurso de Ginzburg no parece concebido como una exposición de resultados, sino como una narración que incluye el punto de vista del escritor, así como el explícito reconocimiento de las limitaciones que presentan sus fuentes. ¿Cómo supera Ginzburg los obstáculos de distorsión y representatividad? En primer lugar, no se limita al estudio de los documentos de la Inquisición, sino que propone un acercamiento al comportamiento de Menocchio relacionando estas fuentes con una investigación previa de la tradición oral de los benandanti. En segundo lugar, Ginzburg narra la historia de un molinero sin intentar presentarla como representativa de una cultural popular particular; sin embargo, su investigación conduce a hallazgos que conducen a la hipótesis de una influencia recíproca entre cultura hegemónica y cultura subalterna en la época de Menocchio. ${ }^{100}$ Parece por tanto que, en palabras de Clifford Geertz, "pequeños hechos hablan de grandes cuestiones". 101

La historia que concibe Ginzburg sería por tanto "una disciplina que funcionaría por fragmentos: una averiguación, una pesquisa que pone en relación conjetural vestigios, huellas, indicios”. ${ }^{102}$ ¿Podría aplicarse una perspectiva similar al estudio de la cultura musical del mundo ibérico renacentista? O, tomando prestada la terminología de

\footnotetext{
${ }^{98}$ Ginzburg, The Cheese and the Worms, p. 51: "it was not the book as such, but the encounter between the printed page and oral culture that formed an explosive mixture in Menocchio's head". Véase Carlo Ginzburg, I benandanti: stregoneria e culti agrari tra cinquecento e seicento (Turín: Einaudi, 1966).

${ }^{99}$ Ginzburg, "Microhistory", p. 23

${ }^{100}$ Ginzburg, The Cheese and the Worms, p. 126.

${ }^{101}$ Geertz, "Thick Description", p. 23: "small facts speak to large issues".

${ }^{102}$ Justo Serna y Anaclet Pons, Cómo se escribe la microhistoria. Ensayo sobre Carlo Ginzburg (Madrid: Frónesis, Cátedra, Universitat de València, 2000), p. 15.
} 
Robert Scribner, ¿es posible una microhistoria de la cultura musical de ese período? ${ }^{103}$ Utilizando como modelo la táctica de Ginzburg, analizaré a continuación los documentos inquisitoriales relacionados con el proceso contra Isabel Ortiz, con el propósito de entrever vestigios de la cultura musical del mundo ibérico del siglo XVI. La aproximación a estos documentos desde un tipo de perspectiva microhistórica permitirá hacer visible a una mujer música formada en el ámbito doméstico que estuvo a las puertas de tener una carrera internacional, vestigios del mecenazgo musical de las nobles de la época e indicios de actividad musical en el seno de una comunidad de mujeres en torno a Isabel de Aragón, IV Duquesa del Infantado.

\subsection{Mujeres músicas en el mundo ibérico renacentista: Isabel de Plazaola}

El propósito de este apartado es aportar información sobre la cantante y tañedora del siglo XVI Isabel de Plazaola utilizando como fuente los documentos relacionados con el proceso llevado a cabo en el Tribunal de la Inquisición de Toledo entre 1564 y 1565 contra su madre, Isabel Ortiz (c. 1524-1526-después de 1575), vecina de Guadalajara. Los documentos relacionados con el proceso contra Isabel Ortiz han recibido gran atención por parte de los historiadores de la literatura, en parte debido al potencial de este material para ser estudiado desde perspectivas de género. ${ }^{104}$ Hija del platero de la emperatriz Isabel de Portugal, Isabel Ortiz pasó su infancia sirviendo en la Corte en Madrid. ${ }^{105}$ A los 10 años de edad marchó a Guadalajara como doncella al servicio de

${ }^{103}$ Bob Scribner, “Is a History of Popular Culture Possible?", History of European Ideas, X/2 (1989), pp. $175-191$.

104 "Proceso de fe de Isabel Ortiz", Madrid, Archivo Histórico Nacional, Sección Inquisición, legajo 104, expediente 5. El documento consta de 181 folios, algunos sin numerar. En esta Tesis Doctoral se numeran los folios por orden de presentación en el legajo del 1 al 181. Aunque encontramos algunos datos biográficos de Isabel Ortiz en Manuel Serrano y Sanz, Apuntes para una biblioteca de escritoras españolas, vol. 2, p. 90 (donde se la llama María en lugar de Isabel), e información sobre este proceso inquisitorial en Fray Lucio María Núñez, "Dos cartas de Sor Isabel de Baena a la Duquesa del Infantado", Archivo IberoAmericano, I/4 (1914), pp. 322-325, el primer estudio publicado sobre Isabel Ortiz es Milagros Ortega Costa, "Spanish Women in the Reformation", en Women in Reformation and Counter-Reformation Europe: Public and Private Worlds, ed. por Sherrin Marshall (Bloomington e Indianapolis: Indiana University Press, 1989), pp. 89-119. Para referencias bibliográficas, véase Castillo Gómez, Entre la pluma y la pared, p. 157, nota 1. El libro de Antonio Castillo Gómez incluye entre las páginas 157 y 183 el material de su ponencia "Autoría y lectura femeninas en el siglo XVI. El 'librico de doctrina christiana' de Isabel Ortiz", presentada en el Coloquio Internacional "Lecturas femeninas en el ámbito ibérico (Siglos XVIXVIII)" (Salamanca, 1999).

\footnotetext{
105 "Proceso de fe de Isabel Ortiz", f. 45r. Véanse Muñoz Fernández, Acciones e intenciones de mujeres,
} p. 200; y Castillo Gómez, Escrituras y escribientes, p. 348. 
Isabel de Aragón (1491-1564), esposa de Íñigo López de Mendoza (1493-1566), IV Duque del Infantado. Tres años más tarde, la Duquesa del Infantado dispuso su matrimonio con Gonzalo Hernández de Plazaola (también platero), con quien tuvo dos hijas. ${ }^{106}$ Cuando su marido se marchó a las Indias, Ortiz fue capaz de integrarse en la comunidad de la Duquesa, educaba a dos niñas en Alcalá de Henares (donde tenía varios familiares), ${ }^{107}$ y se convirtió en una ávida lectora de literatura espiritual. En 1564 fue arrestada por haber aconsejado a Leonor de Toledo, Marquesa de Távara, que abandonase la oración vocal y practicase la contemplación y la oración mental.

En el transcurso de la investigación inquisitorial, que pretendía determinar si Isabel Ortiz estaba vinculada con los alumbrados de Guadalajara, ${ }^{108}$ se descubrió que Ortiz trataba con Isabel de Baena, una monja del Convento de Santa Clara de Alcalá de Henares que tenía reputación de santa, y que hacía de mensajera entre esta religiosa y la Duquesa del Infantado. También se puso de manifiesto que había compilado un libro de devoción que, como ha señalado Antonio Castillo Gómez, cumplía todos los requisitos para disfrutar de una gran circulación: pequeño formato (en octavo), poca extensión (unas 20 hojas) y lengua vernácula (castellano). ${ }^{109}$ Este manuscrito disfrutó de una enorme difusión; ${ }^{110}$ al parecer, "era tan bueno que todos los de la compañia de Alcala le auian visto y le alabauan mucho". 111 Sin embargo, su mayor éxito tuvo lugar entre las mujeres, en particular aquéllas pertenecientes a la comunidad en torno a la Duquesa del

\footnotetext{
106 "Proceso de fe de Isabel Ortiz", f. 29v.

107 "Proceso de fe de Isabel Ortiz", f. 69v.

${ }^{108}$ Véanse Márquez, Los alumbrados; Bataillon, Erasmo y España; y Eugenio Asensio, "El erasmismo y las corrientes espirituales afines. Conversos, franciscanos, italianizantes", Revista de Filología Española, XXXVI (1952), pp. 31-99. Acerca del papel de las mujeres en el iluminismo, véase Haliczer, Between Exaltation and Infamy, p. 127 y 141-142.

${ }^{109}$ Castillo Gómez, Entre la pluma y la pared, p. 173.

${ }^{110}$ Castillo Gómez, Entre la pluma y la pared, p. 177: "La circulación y apropiación del 'librico de doctrina christiana' evidencia la notable difusión que los manuscritos alcanzaron en pleno apogeo de la tipografía".

111 "Proceso de fe de Isabel Ortiz", f. 31r. Véase María del Val González de la Peña, "Libros impresos de los siglos XV a XVII del convento de Santa Clara de Alcalá de Henares", en Anexos Signo 4 paisajes de cultura escrita, ed. por Carlos Sáez (Alcalá de Henares: Universidad de Alcalá de Henares, 2001), pp. 155-184, p. 180.
} 
Infantado; el libro de Ortiz era incluso el libro de oración que María de Ávila leía a su señora la Duquesa del Infantado cada noche. ${ }^{112}$

Cuando Isabel Ortiz intentó imprimir su libro en Alcalá de Henares, consiguió la correspondiente licencia de impresión en 1558 con la condición de que el libro "no se yntitule de muger", cláusula impuesta por el doctor Miguel Majuelo, comisario de la Inquisición, quien alegaba "lo de san Pablo mulierem in ecclesia docere non permito y asi no se ymprimio que yo sepa". ${ }^{113}$ Por tanto, este caso muestra las dificultades afrontadas por las mujeres que hacían propuestas de oración que implicaban evitar la mediación de sacerdotes (como la oración interior) y que pretendían publicar obras sobre doctrina religiosa ("un campo de producción simbólica estrictamente reservado a los varones de la Iglesia"). ${ }^{114}$ Según Stephen Haliczer, la incomodidad de las autoridades eclesiásticas ante la vinculación de las mujeres con la enseñanza religiosa a los laicos es la causa por la que "en España nunca se desarrollaron grupos de mujeres implicadas en la enseñanza y catequesis de los pobres, como las Hermanas de la Caridad en Francia". ${ }^{115}$ Pero, a la vez, este caso pone de manifiesto la amplia y rápida difusión de libros manuscritos (y por tanto no validados por los altos cargos eclesiásticos) "sobre todo entre los círculos de mujeres". 116

Quizás en relación con el "falso orgullo" del que eran acusadas las falsas místicas, ${ }^{117}$ Ginesa de Villalobos, criada de la Duquesa del Infantado, testificó que Isabel

\footnotetext{
112 "Proceso de fe de Isabel Ortiz", f. 47r.

${ }^{113}$ La licencia de impresión tiene fecha de 5 de abril de 1558 y está firmada por el licenciado Francisco de Mendiola, vicario de Alcalá de Henares; véase "Proceso de fe de Isabel Ortiz", f. 62r. En su declaración durante el proceso, Miguel Majuelo explicaba su decisión; véase "Proceso de fe de Isabel Ortiz", f. 22r.

${ }^{114}$ Castillo Gómez, Entre la pluma y la pared, p. 158.

${ }^{115}$ Haliczer, Between Exaltation and Infamy, pp. 51-52: "church authorities were very nervous about any open involvement by women in living religious instruction to the laity. This unease is probably why Spain never really developed groups of laywomen who became involved in teaching and catechizing the poor, like the Daughters of Charity in France".

${ }^{116}$ González de la Peña, "Libros impresos de los siglos XV a XVII del convento de Santa Clara de Alcalá de Henares", p. 180.

${ }^{117}$ Véase Haliczer, Between Exaltation and Infamy, p. 136: "Tales delirios de grandeza, que ocurrían en no menos del $76.9 \%$ de los casos de 'falsas' místicas, se manifestaban en excesivas demandas de deferencia a seguidores y adeptos y dejaban a las mujeres expuestas a cargos de falso orgullo que una verdadera santa nunca exhibiría" ["Such delusions of grandeur, which occurred in no less than 76.9 percent of the cases of 'false' mystics, manifested themselves in excessive demands for deference from followers and supporters and left the women open to charges of false pride that a true saint would never display"].
} 
Ortiz era muy "alabançiosa", mientras que Juana de Gamarra, criada de la Condesa de Coruña dijo que Isabel Ortiz hablaba sólo de "vanidades y de su hija", ${ }^{118}$ la música Isabel de Plazaola. Los documentos inquisitoriales indican que Isabel de Plazaola era una cantante y tañedora que solía ser invitada a las casas nobles para interpretar música, y que había sido contratada por la esposa del Duque de Alburquerque cuando éste fue nombrado gobernador de Milán. Sin embargo, el gobernador había cancelado el contrato antes de que Plazaola embarcara con destino a Italia. La única referencia a Isabel de Plazaola en trabajos musicológicos es la mención que hace Karin Pendle tomando como referencia una fuente secundaria: una nota en el trabajo sobre Isabel Ortiz de Milagros Ortega Costa. ${ }^{119}$

A continuación, analizaré los documentos originales del caso de Isabel Ortiz desde una perspectiva musical. Este análisis proporcionará datos sobre la formación y las vicisitudes profesionales de la música Isabel de Plazaola, la contratación de mujeres músicas por parte de mujeres de la nobleza, y la presencia y el estatus moral de la música en la vida cotidiana del mundo ibérico del siglo XVI. El análisis de los documentos inquisitoriales servirá como punto de partida para: 1) localizar la ejecutoria de un pleito litigado posteriormente por Isabel Ortiz a causa de la anulación del contrato de su hija música con la Duquesa de Alburquerque; y 2) llevar a cabo un estudio de la vinculación de Isabel de Aragón, IV Duquesa del Infantado, con la música.

\footnotetext{
118 "Proceso de fe de Isabel Ortiz", ff. 29r, 30v.

${ }^{119}$ Karin Pendle, "Musical Women in Early Modern Europe", en Women \& Music. A History, ed. by Karin Pendle (Bloomington e Indianapolis: Indiana University Press, 1991), pp. 57-96, p. 79; Ortega Costa, "Spanish Women in the Reformation", p. 102, nota 88: "Isabel de Plazaola, la hija de Isabel, tenía unos 22 años. Era una buena cantante y tañedora de instrumentos de cuerda pulsada que solía ser invitada a cantar y tocar en muchas de las casas nobles. Poco antes de que su madre fuese arrestada, Plazaola había sido contratada como música interna para la esposa del Duque de Alburquerque, que acababa de ser nombrado gobernador de Milán. Cuando Plazaola llegó a Barcelona para embarcar con destino a Italia, el gobernador canceló su puesto diciendo que el Rey no aprobaba tener una joven sólo para cantar y tocar en una expedición militar, y Plazaola fue enviada de vuelta a Alcalá" ["Isabel de Plazaola, Isabel's daughter, was about twenty-two years old. She was a good singer and player of plucked instruments who used to be invited to sing and play at many of the noble houses. Shortly before her mother was arrested, Plazaola had been hired as a house musician to the wife of the duke de Alburquerque, newly appointed governor of Milan. When Plazaola reached Barcelona to embark for Italy, the governor cancelled her position saying that the king did not approve of having a young woman just to sing and play on a military expedition, and Plazaola was sent back to Alcalá’']. Muñoz Fernández, Acciones e intenciones de mujeres, pp. 200-201, también da noticia de la hija música de Isabel Ortiz.
} 


\subsubsection{LA MÚSICA ISABEL DE PLAZAOLA EN LOS DOCUMENTOS INQUISITORIALES DE SU MADRE ISABEL ORTIZ (1564-1565)}

[...] y quanto peor hazen los padres, que dan a sus hijas Maestros de danzar, tañer, cantar, o baylar; si han de faltar vn punto de su presencia, y aun es menos daño que no lo sepan: que si han de ser casadas, bastales dar gusto a sus maridos, y criar sus hijos, y gouernar su casa: y si han de ser Monjas, aprendanlo en el Monasterio [...]. ${ }^{120}$

Aunque los documentos que surgieron del proceso inquisitorial contra Isabel Ortiz por alumbrismo han sido estudiados desde la perspectiva de género en cuanto a las restricciones que disuadieron a Ortiz de imprimir su libro de doctrina religiosa ("que no se yntitule de muger"), es sorprendente descubrir que este proceso pudo tener su origen en las vicisitudes profesionales de su hija música. Mediante el vaciado de los documentos inquisitoriales, he encontrado referencias a Isabel de Plazaola a lo largo de todo el proceso (véase el Apéndice 18), siendo mencionada ya en el primer folio como razón del vínculo entre Isabel Ortiz y la denunciante, Leonor de Toledo: “y venia a traer una hija suya que cantaua" (Apéndice 18, Fragmento 1). Isabel Ortiz es identificada en la documentación como "la madre de la cantora" (Apéndice 18, Fragmento 18). En este apartado llevaré a cabo una aproximación a este proceso tan estudiado en otras disciplinas, colocando en el centro de atención, en lugar de a Isabel Ortiz, a su hija, la música Isabel de Plazaola.

Isabel de Plazaola nació en torno a 1542 ó 1543, puesto que en 1564 Isabel Ortiz señalaba que su hija tenía 21 ó 22 años (Apéndice 18, Fragmento 19). En los documentos se la define como "musica" (Apéndice 18, Fragmentos 2, 3 y 8) o como "cantora" (Apéndice 18, Fragmentos 4, 18 y 22), y Ortiz explicaba que su hija "tañe bien todo genero de instrumento y canta muy bien" (Apéndice 18, Fragmento 21). Probablemente, las destrezas musicales de Isabel de Plazaola jugaron un papel determinante en la configuración del círculo social de su madre, tanto en el establecimiento de relaciones con algunas mujeres de la nobleza que pedían a Ortiz que les llevase a su hija, como en el origen del controvertido vínculo de Ortiz con la monja Isabel de Baena. En cuanto a la relación de Ortiz con un círculo de mujeres nobles, es interesante que el primer detalle

\footnotetext{
${ }^{120}$ Espinel, Relaciones de la vida del escudero Marcos de Obregon, f. 8r.
} 
que daba la criada de la Marquesa de Távara cuando le preguntaron acerca de Isabel Ortiz era que tenía una hija música (Apéndice 18, Fragmento 3). Ortiz aclaraba que inició su vínculo con la Marquesa de Távara porque ésta le pidió que le llevase a su hija: "como esta declarante tiene aquella hija cantora avia algunas bezes ydo a ver a la marquesa con la dicha su hija porque la dicha marquesa se lo avia enviado a rogar" (Apéndice 18, Fragmento 22). Respecto a la relación entre Isabel Ortiz y la monja Isabel de Baena, Juan Losillo, platero al servicio de un tío de Ortiz, señalaba en su declaración que el motivo por el que ésta iba al Convento de Santa Clara de Alcalá de Henares era llevar a su hija para que cantase allí (Apéndice 18, Fragmento 4). La propia Isabel Ortiz declaraba que había visto a Isabel de Baena sólo tres o cuatro veces, una o varias de las cuales debido a la solicitud que había recibido de que llevase a su hija al convento para que "tañese y cantase" (Apéndice 18, Fragmento 24). Este punto es muy interesante porque demuestra que músicas externas visitaban el convento. Cabe preguntarse si Plazaola enseñaba música a las monjas o únicamente cantaba y tocaba para ellas y, en este último caso, qué repertorio interpretaba.

En el proceso se hace alusión a la intención de Isabel Ortiz de que su hija ingresase como monja en el Convento de Santa Clara hacía seis o siete años, es decir, cuando Isabel de Plazaola tenía unos 14 años. El Doctor Miguel Majuelo señalaba que "en santa clara desta villa trataua de meter una hija monja y alla la querian y lo trataua con el abadesa [sic] y con una monja que se llama ysabel de vaena" (Apéndice 18, Fragmento 5). La misma declaración de Miguel Majuelo ofrece confirmación de que el propósito de ingresar a Isabel de Plazaola como monja de Santa Clara fue uno de los motivos de los primeros contactos entre Ortiz y Baena: “y por esto la fue a hablar la dicha ysabel ortiz a la dicha ysabel de vaena y a lo que cree este testigo a tratar de la hija tambien porque le paresçio a este testigo que tenia entonces deseo de metella monja" (Apéndice 18, Fragmento 6). Desconocemos si Isabel Ortiz pretendía que su hija ingresase como monja música, si bien dos datos extraídos de la documentación inquisitorial apoyan esta hipótesis: la situación económica de Isabel Ortiz (Apéndice 18, Fragmentos 14, 16 y 20) y la coincidencia temporal entre la formación musical de Plazaola (Apéndice 18, Fragmentos 31 y 32) y las negociaciones de su madre con las monjas de Santa Clara para que ingresase en el convento. En cualquier caso, todo apunta a que, por algún motivo, Plazaola no ingresó en el convento y trabajaba como música para mujeres de la nobleza. 
En las referencias al libro que había compilado Isabel Ortiz, encontramos alusiones a la formación general de su hija. Ginesa de Villalobos señalaba que Isabel de Plazaola leía el texto de su madre y “era tan deuota que le sabia de coro” (Apéndice 18, Fragmento 11), mientras que Catalina de la Cerda, Condesa de Coruña, declaraba que Isabel Ortiz le había dicho que "otra persona o ella que desto no se acuerda hazia un libro de doctrina y lescreuia plaçaola su hija a lo que le pareçe” (Apéndice 18, Fragmento 15). Esto indica que Isabel de Plazaola sabía leer y escribir y que tuvo una relación directa con el libro de devoción de su madre. La documentación del proceso también proporciona información acerca del modo en que Plazaola adquirió estas destrezas: Ginesa de Villalobos indicaba que fue el maestro Alvar Gómez, sobrino de Luis Gómez (médico del Duque del Infantado) que vivía en la misma casa que Ortiz, quien enseñó a escribir a Plazaola (Apéndice 18, Fragmento 12). El cuestionamiento de la fe de Isabel Ortiz en el proceso inquisitorial tiene como consecuencia que se haga alusión en ocasiones a la formación religiosa de su hija. Por ejemplo, Alvar Gómez explicaba que Isabel Ortiz le había pedido que "enseñase a rezar por un breviario" a Isabel de Plazaola (Apéndice 18, Fragmento 10). Del expediente inquisitorial pueden extraerse datos referentes a la formación musical de Isabel de Plazaola. La música recibía clases particulares que tenían lugar en su ámbito doméstico, como muestra la declaración de Ginesa de Villalobos: "entra mucha gente en su casa y esta llena de tañedores que enseñan a su hija" (Apéndice 18, Fragmento 9). Los profesores de Plazaola mencionados en la documentación inquisitorial se relacionan en la Tabla VII.1. 
Tabla VII.1: Profesores de música de Isabel de Plazaola mencionados en el proceso inquisitorial de su madre Isabel Ortiz (1564-1565)

\begin{tabular}{lll}
\hline Músico & Datos aportados & Relación con Isabel de Plazaola \\
\hline Miguel Sánchez & $\begin{array}{l}\text { 20 años de edad; cantor de } \\
\text { Toledo. }\end{array}$ & $\begin{array}{l}\text { En su declaración indicaba haber dado lecciones } \\
\text { de canto a Plazaola en Guadalajara (Apéndice 18, } \\
\text { Fragmento 31). }{ }^{121}\end{array}$ \\
Garci González & $\begin{array}{l}53 \text { años de edad; músico de la } \\
\text { Santa Iglesia de Toledo. }\end{array}$ & $\begin{array}{l}\text { Según su declaración, "yva a ver cantar y tañer" a } \\
\text { Plazaola (Apéndice 18, Fragmento 32). }\end{array}$ \\
Antonio Martínez & $\begin{array}{l}\text { Músico de la IV Condesa de } \\
\text { Coruña. }\end{array}$ & $\begin{array}{l}\text { La documentación sugiere que podría haber sido } \\
\text { profesor de Plazaola y de otras mujeres del } \\
\text { entorno de ésta (Apéndice 18, Fragmentos 37, 39 } \\
\text { y 42). }\end{array}$ \\
\hline
\end{tabular}

En la documentación encontramos referencias a las visitas de Antonio Martínez, músico de la IV Condesa de Coruña, a la casa de Isabel Ortiz (Apéndice 18, Fragmento 37) o se le menciona entre los presentes en el hogar en un determinado momento (Apéndice 18, Fragmento 39), aunque no se explicita que enseñase música a Plazaola. Sin embargo, sí es evidente que Antonio Martínez tenía alumnas cercanas a Isabel Ortiz, puesto que ésta declaraba haber suplicado a la Condesa de Coruña que no se llevase al músico a Torija (Guadalajara) "porque sus discipulas querian yr todas llorando a le pedir misericordia" (Apéndice 18, Fragmento 42).

Además de información acerca de la formación general y musical de Isabel de Plazaola, es de sumo interés la información que proporcionan estos documentos inquisitoriales con respecto al estatus moral de la música en las casas de las mujeres que no pertenecían a la nobleza. Se cuestionaba que Isabel Ortiz fuese tan "santa" como decía a la vista de "lo de la musica de su casa" (Apéndice 18, Fragmento 17). Como señalaba anteriormente, Ginesa de Villalobos explicaba que hacía tiempo que no trataba con Isabel de Ortiz "por oyr decir que entra mucha gente en su casa y esta llena de tañedores que enseñan a su hija”. Por tanto, la actividad musical en el hogar de Isabel Ortiz se

${ }^{121}$ Cabe preguntarse si se trata de Miguel Sánchez, compositor del siglo XVI de quien se conserva un Christus factus est para tenor, alto y dos tiples en dos manuscritos copiados en El Escorial a comienzos del siglo XVII y preservados en la Real Biblioteca del Monasterio de San Lorenzo de El Escorial y en la Hispanic Society of America de Nueva York; véase Michael Noone, "Sánchez, Miguel”, en Diccionario de la música española e hispanoamericana, ed. por Emilio Casares Rodicio (Madrid: Sociedad General de Autores y Editores, 1999-2002), vol. 9, p. 669. 
consideraba contraria a las buenas costumbres, y la presencia de tañedores en su casa debía de haber tenido connotaciones de inmoralidad, puesto que los maestros de música eran a menudo sospechosos de seducir a sus alumnas.

Otros documentos de la Inquisición actúan como evidencia de la asociación de los músicos con la seducción. Luis Lázaro "un joven labrador de Cosuenda (Zaragoza), de veintidós años de edad, testigo en el proceso inquisicional contra Isabel Garay" declaró que hacía entonces cuatro años él y un primo suyo "fueron a la puerta de dicha Isabel Garay a hacer con otros amigos suyos musica a una sobrina suya". ${ }^{22}$ En 1570 se procesó a Antonio de Torres, músico de unos 20 años, "que tiene escuela de danza en la calle de Barrio Nuevo de Madrid y vecino del Burgo de Osma, por deshonestidad". ${ }^{23}$ El proceso de Antonio de Torres, como el de Isabel Ortiz, ofrece vestigios de la vida de un músico profesional de la época. Al parecer, en una conversación que tuvo con los sastres Pedro de Robles y Yuste de Orduña en una posada, Torres había dicho que "no hera pecado mortal sino venial tener conversacion carnal con una muger soltera". ${ }^{124} \mathrm{~A}$ Torres, que fue finalmente condenado, se le identifica como "músico" o como "tañedor" en la documentación. ${ }^{125}$ También los cuentos populares de la época funcionan como fuente de la reputación de seductores que tenían los músicos; por ejemplo, el Cuento muy gracioso que sucedió a un arriero con su mujer (1603) de Francisco de Medina explica cómo "la mujer de Juan Prados se enamoró de un estudiante músico en una boda":

Entre tres músicos que hubo,

Sus sentidos la robaron

Las gracias de un estudiante

Diestro, que cantaba el bajo [...]. ${ }^{126}$

122 "Proceso contra Isabel Garay. Cosuenda. 1591", Zaragoza, Archivo Diocesano, C. 33-23, ff. 110v111; citado en Tausiet, Ponzoña en los ojos, pp. 360-361.

123 "Proceso de fe de Antonio de Torres, músico que tiene escuela de danza en la calle de Barrio Nuevo de Madrid y vecino del Burgo de Osma, por deshonestidad", Madrid, Archivo Histórico Nacional, Inquisición, legajo 75, expediente 16 .

124 "Proceso de fe de Antonio de Torres", f. 4r.

125 "Proceso de fe de Antonio de Torres", f. 2v: "le dixeron al dicho torres [tachado: 'tañedor'] que se viniese acusar de aquello".

${ }^{126}$ Se trata de un pliego suelto conservado en Londres, British Library, C.63.g.19.(4.), y reproducido por Alan C. Soons, Haz y Envés del cuento risible en el Siglo de Oro (Londres: Tamesis Books, 1976), $\mathrm{n}^{\circ}$ XV; transcrito en Chevalier, Cuentos españoles de los siglos XVI y XVII, pp. 200-213. 
No sólo los maestros de música y los músicos, sino también los maestros en general eran sospechosos de seducir a sus alumnas. Por ejemplo, Álvar Gómez, sacerdote y profesor de griego en el Colegio Universitario de Santa Catalina de Toledo, quien visitaba la casa de María de Mendoza y de la Cerda como su tutor, se enamoró de su alumna y le hacía llegar poemas en latín a los que posiblemente María de Mendoza daba respuesta. ${ }^{127}$ Otro caso es el de Juan Latino, poeta y músico que enseñaba a las aristócratas granadinas y se casó con una de sus alumnas. ${ }^{128}$ Por tanto, las fuentes indican que, en la mentalidad de la época, los maestros, y en particular los músicos, eran sospechosos de seducir a las damas.

Es esclarecedora la contestación de Isabel Ortiz a las acusaciones que relacionaban la actividad musical que tenía lugar en su casa con la inmoralidad. Ortiz alegaba que la música era algo "virtuoso" por lo que tendrían que hablar bien de su persona, pero que, en contraste, los testigos utilizaban la música para hablar mal de ella, y prometía probar "con la honestidad y recato que se trato en mi casa la musica" (Apéndice 18, Fragmento 40). La declaración de Isabel Ortiz muestra, por tanto, la doble connotación honesta y deshonesta de la música y lo difusa que era la línea divisoria entre ambas. Desde la perspectiva del estatus moral de la música, y también de la conexión entre ésta y las mujeres, es de gran interés otro extracto de la declaración de Isabel Ortiz en que ésta señalaba que había hecho dos obras virtuosas: 1) el libro de doctrina cristiana que recopiló; y 2) el "aver mostrado a su hija las mayores abilidades que juntas puede aver en una muger" (Apéndice 18, Fragmento 34). Ortiz añadía que "las obras que a hecho por el mundo que son estas que tiene declaradas en esta audiencia del librico y las abilidades de su hija las hizo por el mundo y dios se las a buelto en desonra". Isabel Ortiz entendía que la educación de su hija música como una obra de devoción.

\footnotetext{
${ }^{127}$ Vaquero Serrano, "Books in the Sewing Basket", p. 96: "Posiblemente María respondió a los poemas de su tutor con versos latinos compuestos por ella misma. Si ése era el caso, es una posible explicación de la desaparición de la mitad de la correspondencia poética de María; habría sido indecoroso para un clérigo conservar escritos que le había dirigido una joven" ["Possibly María answered her tutor's poems with Latin verse of her own. If that was the case, it is a possible explanation for the disappearance of Maria's half of the poetic correspondence; it would have been indecorous for a man of the cloth to preserve writings directed to him by a young woman"].

${ }^{128}$ Lope de Vega, La dama boba (Barcelona: Linkgua, 2007), p. 99. Véase José Antonio Sánchez Marín y María Nieves Muñoz Martín, "El Maestro Juan Latino en la Granada renacentista. Su ciudad, su vida, sus protectores", Florentia iliberritana: Revista de estudios de antigüedad clásica, XX (2009), pp. 227-260.
} 
Más allá de la formación general y musical de Isabel de Plazaola y de la doble connotación moral de la música en la época, este caso muestra vestigios de una activa vida musical en el ámbito privado femenino y permite indagar en la contratación de mujeres músicas por parte de mujeres de la nobleza en el mundo ibérico del siglo XVI; las nobles contrataban a mujeres músicas para que cantaran y tocaran en sus casas y las acompañasen en sus viajes. Según la documentación inquisitorial, Isabel de Plazaola trabajó como música para las nobles que aparecen en la Tabla VII.2.

Tabla VII.2: Relación de las nobles para las que trabajó la música Isabel de Plazaola según los documentos del proceso inquisitorial de su madre Isabel Ortiz (1564-1565)

\begin{tabular}{lll}
\hline Noble & Lugar & $\begin{array}{c}\text { Referencias en los documentos } \\
\text { inquisitoriales }\end{array}$ \\
\hline $\begin{array}{c}\text { Leonor Enríquez de Toledo, II } \\
\text { Marquesa de Távara } 29\end{array}$ & Alcalá de Henares & Apéndice 18, Fragmentos 1, 3 y 22 \\
$\begin{array}{c}\text { Catalina de la Cerda, IV } \\
\text { Condesa de Coruña }\end{array}$ & Guadalajara & Apéndice 18, Fragmentos 10, 42 y 43 \\
$\begin{array}{c}\text { Juana de la Lama, V Duquesa de } \\
\text { Alburquerque, }\end{array}$ & [Milán] & Apéndice 18, Fragmentos 13, 21, 23, 25, 26, \\
¿Juana de Austria? & ¿Valladolid? & Apéndice 18, Fragmentos 26, 13 y 25 \\
\hline
\end{tabular}

\footnotetext{
${ }^{129}$ Leonor Enríquez de Toledo, II Marquesa de Távara, nació en Zamora hacia 1533 (en su declaración de 17 de mayo de 1564 decía tener 31 años). Era hija de Enrique Enríquez de Guzmán, IV Conde de Alba de Liste, y de María de Toledo. Se casó con Pedro Pimentel y Osorio, II Marqués de Távara. Véase "Leonor Enríquez funda en su testamento una capellanía en la parroquia de los Santos Justo y Pastor, de Toledo", Toledo, Sección Nobleza del Archivo Histórico Nacional, Frías, C.849, D.32.

${ }^{130}$ Catalina de la Cerda era hija de Juan de la Cerda, II Duque de Medinaceli, y de María de Silva y Toledo. Se casó con Lorenzo Suárez de Mendoza (1518-1583), Virrey de Nueva España entre 1580 y 1583. Lorenzo Suárez de Mendoza fue nombrado Virrey de Nueva España por Felipe II el 26 de marzo de 1580 y tomó posesión el 4 de octubre en Nueva España. Su esposa murió cuando él ya había sido nombrado Virrey, como muestra la noticia que se dio en la sesión del Cabildo de Nueva España el 16 de junio de 1581. Véanse J. Ignacio Rubio Mañé, Introducción al estudio de los virreyes de Nueva España, 15351746, I: Orígenes y Jurisdicciones, y Dinámica Social de los Virreyes (Ciudad de México: Universidad Nacional Autónoma, 1955); y "Noticias de la muerte de doña Catalina de la Cerda y Silva, Condesa de la Coruña, virreina de la Nueva España, 1581”, Boletín del Archivo General de la Nación de México, $2^{\mathrm{a}}$ serie, VIII (1967), p. 23-26. Aurelio García López, "Notas sobre la emigración alcarreña a Indias en los siglos XVI y XVII. Apuntes para una investigación a través de las fuentes notariales", Estudios de historia social y económica de América, XII (1995), pp. 245-266, p. 255, incluye la transcripción de un documento datado en Madrid a 20 de marzo de 1580 titulado "Traslado de una carta de poder otorgada por el conde de Coruña, virrey de Nueva España, nombrando administradores de sus bienes en caso de fallecimiento de su mujer, la condesa de Coruña, administradora actual", conservado en Guadalajara, Archivo Histórico de Protocolos, Protocolos Notariales, a.p. Gervasio Pérez, legajo 119.
} 
Catalina de la Cerda y Silva (c. 1513-1580), IV Condesa de Coruña, una de las nobles para las que trabajó Isabel de Plazaola, fundó en 1571 el hospital del Corpus Christi de Toledo y es dedicataria de un libro sobre la vida del Cardenal Cisneros. ${ }^{131}$ Por la documentación inquisitorial de Isabel Ortiz sabemos que la Condesa de Coruña tenía a su servicio al músico Antonio Martínez. Además, su interés en la música queda reflejado en la cantidad de misas cantadas que en su testamento mandaba se celebrasen tras su fallecimiento. ${ }^{132}$ Catalina de la Cerda debió pertenecer al círculo de mujeres nobles relacionadas con la Duquesa del Infantado. Su hija Juana Magdalena se casó con Álvaro de Mendoza, hijo de la Duquesa del Infantado; ${ }^{133}$ además, el Palacio del Conde de Coruña se encuentra en la plaza del Jardinillo de Guadalajara, a unos 200 metros del Palacio del Infantado.

En sus declaraciones, Isabel Ortiz hablaba de un asiento para su hija "con la reina que abia tratado la marquesa de montesclaros" (Apéndice 18, Fragmentos 26, 13 y 25). Podría tratarse de Isabel Manrique de Padilla, II Marquesa de Montesclaros y dama de la princesa Juana de Austria (1535-1573), hermana de Felipe II. ${ }^{134}$ Juana de Austria

${ }^{131}$ Suma de la vida del R. S. cardenal D. Fray Francisco Ximenez de Cisneros, sacada de los Memoriales de Vallejo, paje de cámara, è de algunas personas que en su tiempo le vieron; para la ilustrisima señora $D^{a}$ Catalina de la Zerda, condesa de Coruña, á quien Dios guarde, y dé su gracia, por un criado de su casa, MS, Madrid, Biblioteca Nacional de España, MSS/20242/35.

132 "Testamento otorgado por doña Catalina de la Cerda, condesa de Coruña" (Guadalajara, 23 de agosto de 1580), Madrid, Biblioteca de la Real Academia de la Historia, Colección de don Luis de Salazar y Castro, M-41, ff. 164-169; véanse, en particular, f. 1v: "yten mando que el cavildo de los clerigos desta ciudad me agan un ofiçio de una vigilia solenemente cantada de tres liçiones con sus responsos y una misa cantada con su responsso y esto sea en la yglesia quellos quisieren señalar para esto pagandoles por ello lo acostumbrado y los frayles que ay en esta ciudad que son tres monesterios en cada uno dellos quiero que me digan otra vigilia con su misa cantada y responsos [...]"; f. 2r: "[...] que en la yglesia de la [...] villa de [...] me hagan otra vigilia con su novenario"; f. $2 \mathrm{v}$ : "[...] yten mando por la devoçion que tengo a los tres reyes magos que se digan en el año de mi fallecimiento el [...] dia despues [...] unas visperas solenes con un responso al fin dellas y una mysa cantada solenemente el dia siguiente con responso [...]".

133 “Obligaciones, poderes, cartas de pago y otros documentos relativos a las capitulaciones matrimoniales de: Álvaro de Mendoza y Aragón con Juana Magdalena de Mendoza y de la Cerda" (1565), Toledo, Sección Nobleza del Archivo Histórico Nacional, Osuna, C.1776, D.19; "Escritura otorgada por Álvaro de Mendoza y Aragón y por su parte Íñigo López de Mendoza, IV duque del Infantado, ofreciendo seguridad de la dote de doña Juana Magdalena de Mendoza y de la Cerda, mujer del primero e hija de Lorenzo Suárez de Mendoza, IV conde de Coruña, y de doña Catalina de la Cerda, su mujer” (1565), Madrid, Biblioteca de la Real Academia de la Historia, Colección de don Luis de Salazar y Castro, M-19, ff. 170171 .

${ }^{134}$ En la colección Salazar y Castro hay cartas de Isabel Manrique de Padilla de 1593 y una escritura de 1558 procedente del Archivo de Medinaceli: "Escritura otorgada por doña Isabel Manrique de Padilla, después marquesa de Castil de Vayuela, dama de la princesa de Portugal doña Juana, infanta de Castilla; doña Inés Manrique de Padilla, monja de las Huelgas, de Burgos, y doña Antonia Manrique, monja en la Concepción de Santa Gadea, de una parte, y en su representación Iñigo de Ayala, vecino de Toledo, y doña Angela Manrique, señora de Aramayona, por la que se conciertan sobre el pago de cierta cantidad" 
estuvo en Valladolid entre 1554 y 1559 llamada por Felipe II para gobernar Castilla, lo que coincide con las fechas que se dan en el proceso de Ortiz. El interés de Juana de Austria en Isabel de Plazaola no sería sorprendente dadas las habilidades musicales de la Princesa, la presencia de músicas a su servicio (Alfonso de Vicente da noticia de Cecilia de la Cruz, monja música de las Descalzas Reales, antigua dama de Juana de Austria), ${ }^{135}$ su posesión de libros de música e instrumentos musicales, y su labor de mecenazgo musical. ${ }^{136}$ Ortiz hacía otras alusiones a la realeza: "quando salimos de casa del principe"; y "porque como el principe enbio a llamar mi hija" (Apéndice 18, Fragmento 37). Es de gran interés la relación de Plazaola con la realeza y la posibilidad de que se hubiera negociado el que ésta trabajase para la casa real.

Los documentos del proceso inquisitorial contra Isabel Ortiz indican que Isabel de Plazaola iba a trabajar como música para Isabel Juana de la Lama (†1584), III Marquesa de Ladrada y esposa de Gabriel III de la Cueva y Girón (Cuéllar, Segovia, 1515Milán, 1571), V Duque de Alburquerque, cuando éste fue nombrado gobernador de Milán por cédula de Felipe II de 18 de enero de 1564. Sin embargo, el contrato de Isabel de Plazaola fue cancelado antes de que ésta embarcara en Barcelona con destino a Milán porque el Duque alegó que el Rey no aprobaría que llevaran a Plazaola a la guerra para cantar y tañer. $^{137}$

(Plasencia, 1558), Madrid, Biblioteca de la Real Academia de la Historia, Colección de don Luis de Salazar y Castro, M-36, f. 271.

${ }^{135}$ Vicente Delgado, "El entorno femenino de la dinastía", p. 201.

${ }^{136}$ Fray Juan Carrillo, Relacion historica de la Real fundacion del Monasterio de las Descalças de S. Clara de la Villa de Madrid, con ... las vidas de la Princesa de Portugal doña Iuana de Austria su fundadora y de la M.C. de la Emperatriz Maria su hermana, que vivio y acabo santamente alli su vida... (Madrid: Luis Sánchez, 1616); Cristóbal Pérez Pastor, "Inventarios de la infanta doña Juana, hija de Carlos V", en Noticias y documentos relativos a la historia y literaturas españolas (Madrid: Real Academia Española, 1910-1926), 4 vols., vol. 2, pp. 315-380; José María March, Niñez y juventud de Felipe II: documentos inéditos sobre su educación civil, literaria y religiosa y su iniciación al gobierno: 1527-1547 (Madrid: Ministerio de Asuntos Exteriores, 1941-1942), vol. 2, p. 447; Jaime Moll, "La princesa Juana de Austria y la música", Anuario musical, XIX (1964), pp. 119-122; y "Libros de música e instrumentos musicales de la princesa Juana de Austria", Anuario musical, XX (1965), pp. 11-24; Rafael Mota Murillo, "La princesa Juana de Austria y su capilla de las Descalzas", en III Semana de Música Española. El Renacimiento (Madrid: Comunidad de Madrid, 1988), pp. 263-288; Ros-Fábregas, "Libros de música en bibliotecas españolas del siglo XVI" (III), pp. 25-29; y Vicente Delgado, "El entorno femenino de la dinastía", sobre el mecenazgo musical de Juana de Austria a través de la fundación del Convento de Clarisas de las Descalzas Reales. Para un listado de los libros de música de Juana de Austria, véase el Apéndice 17.

${ }^{137}$ No queda claro en la documentación si Felipe II había expresado su desacuerdo con el servicio de Plazaola o si era algo que presumía o preveía Gabriel de la Cueva. La búsqueda de información a este respecto en cartas de Felipe II a Gabriel de la Cueva pertenecientes a la Colección de don Luis de Salazar 
No sólo las nobles contrataban músicos. En mi investigación he encontrado el registro del pleito litigado en 1560 por el músico Ginés Bezón con el regidor de Toro (Zamora), Antonio de Fonseca, por una deuda, documento que atestigua que Ginés Bezón servía a Antonio de Fonseca y a su esposa Doña Blanca “cantando y tañendo". ${ }^{38}$ Otra fuente de la contratación de músicos en familias no pertenecientes a la nobleza es la literatura de viaje. En Itinerarium sive peregrinatio per Hispaniam, Franciam et Alemaniam, donde Jeronimo Münzer narra su viaje por España entre el 17 de septiembre de 1494 y el 9 de febrero de 1495, se hace alusión a la presencia de músicos en las casas de un grupo de mercaderes alemanes residentes en Barcelona:

Entre otros mercaderes alemanes que allí vivían a la sazón, estaban Gregorio Rasp, de Augsburgo; Erardo Wigant, llamado Frank, de Mergentheim, ciudad de Franconia y Wolfang Ferber, de Ulma; asimismo hallábase en la ciudad fray Juan, de la Orden de San Francisco, a quien conoce mucho el doctor Stahel, su amigo Nicolás y Leonardo, que tiene un hermano en la casa de los teutones de Nuremberga, todos los cuales nos regalaron con extremada liberalidad. Convidados en sus casas, nos sirvieron en vajillas de oro y plata; comimos y bebimos al uso catalán; durante el banquete, músicos con diversos instrumentos tocaron continuamente para solazarnos, cantaron coros y bailaron al estilo morisco [...]. ${ }^{139}$

No es extraño que Juana de la Lama contratase a Isabel de Plazaola para que la acompañase en su viaje a Milán. Los relatos de viaje muestran que la música formaba parte de la vida cotidiana de la realeza y la nobleza y no sólo era un medio para dar so-

y Castro en la Real Academia de la Historia de Madrid ha sido infructuosa. En este fondo he localizado asientos descriptivos correspondientes a 11 documentos del V Duque de Alburquerque datados en 1564, año del proceso de Ortiz. Se trata de la "Noticia de la cédula del rey Felipe II por la que nombra gobernador del estado de Milán a Gabriel de la Cueva, después V duque de Alburquerque" (18-01-1564); la "Noticia de la cédula del rey Felipe II por la que nombra capitán general del ejército de Lombardía a Gabriel de la Cueva" (19-01-1564); la "Carta del rey Felipe II a Gabriel de la Cueva, gobernador del estado de Milán, después $\mathrm{V}$ duque de Alburquerque, en la que le avisa haber nombrado capitán general de la mar a García de Toledo, virrey de Cataluña, y le ordena apreste la mayor cantidad de gente de armas que pueda, para embarcarla en la escuadra" (16-04-1564); y 7 cartas del duque a Lope de Acuña y Avellaneda. En el Archivo General de Simancas también se conserva documentación del virreinato de Milán; véanse Ricardo Magdaleno, Papeles de Estado: Milán y Saboya (siglos XVI y XVII) (Valladalid: Gráf. Andrés Martín, 1961); y Adela González Vega, Títulos y privilegios de Milán: siglos XVI-XVII (Simancas: Archivo General de Simancas, 1991).

138 "Ejecutoria del pleito litigado por Ginés Bezón, músico, con Antonio de Fonseca, vecino y regidor de Toro (Zamora), sobre deuda", Valladolid, Real Audiencia Chancillería de Valladolid, Registro de Ejecutorías, Caja 968-39. Diego Pacheco, "Beyond Church and Court", p. 369, da noticia de una banda formada por amateurs que "había contratado dos atabales de una viuda, María de Fonseca" ["This band had hired two atabales (drums) from a widow María de Fonseca, and the contract for the suspension of their activities confirms that they were all amateurs"]. El documento se encuentra en Valladolid, Archivo Histórico de Protocolos, 518-28.

${ }^{139}$ García Mercadal, Viajes de extranjeros por España y Portugal, p. 332. 
lemnidad a actos oficiales; por ejemplo, Lamberto Wyts narraba cómo siguió a la reina Ana de Austria en un viaje a Amberes en 1570 y señalaba que, en torno a la Reina:

[...] había muchos españoles cantando por el camino, todos castrados, los cuales estaban muy adelantados por sus voces y la música, y fueron los que más servicio hicieron tanto en la mesa como en el camino; entre otros, había un gordo capón que cantó solo muchas canciones con gusto, el cual gorjeaba como un ruiseñor, habiéndose repetidas veces acercado. ${ }^{140}$

El puesto ocupado por el Duque de Albuquerque antes de su destino en Milán fue el de Virrey de Navarra, entre 1560 y $1564 .{ }^{141}$ De su esposa Juana de la Lama sabemos que el papa Pío V le concedió la Rosa de Oro por una Breve fechada en Roma el 21 de marzo de 1569, que al enviudar se retiró al monasterio jerónimo de la Concepción de la Madre de Dios de Madrid, y que en 1580 se casó en segundas nupcias con Juan Luis de la Cerda (1544-1594), V Duque de Medinaceli. ${ }^{142}$ ¿Cuáles fueron las conexiones que llevaron a la Duquesa de Albuquerque a conocer y contratar a Isabel de Plazaola? Según la declaración de Ortiz, los términos del contrato fueron negociados con Fray Pedro Portocarrero, tío de la Duquesa y lector del Colegio de los Dominicos de Alcalá de Henares. Según el contrato, Plazaola estaría seis años al servicio de la Duquesa, su madre recibiría 400 ducados (200 durante el mes siguiente a la firma del contrato y 200 antes del día de San Juan) y, además, se le pagarían 12.000 maravedíes cada uno de los seis años; acabado el servicio, Plazaola recibiría 2.000 ducados (Apéndice 18, Fragmento 26). Tras negociar las condiciones del contrato, Fray Pedro acompañó a Ortiz y a Plazaola hasta Escalona, donde estaba la Duquesa, y en Marchamalo (Guadalajara) ésta confirmó que cumpliría el asiento que había hecho su tío, siendo avalada por su abuela Juana Portocarrero, y por su tío Diego de la Cueva (Apéndice 18, Fragmentos 21, 25 y

\footnotetext{
${ }^{140}$ El relato de Lamberto Wyts se inserta en un manuscrito de 218 hojas escrito en 1573 que se conserva en Viena, Biblioteca Imperial, no 3325 Pr. Eug. 107; citado en García Mercadal, Viajes de extranjeros por España y Portugal, p. 1173.

${ }^{141}$ María Teresa Sola Lanada, "El Virreinato de Navarra en la etapa de los Austrias. Gobierno político y administración. Siglos XVI-XVII", Tesis Doctoral (Ph.D.), Universidad Pública de Navarra, 1996. Fuentes primarias sobre los Duques de Alburquerque se encuentran en el Archivo Ducal de la Casa Alburquerque, que se localiza en el Archivo Municipal de Cuéllar (Segovia). Véase Maximiliano Barrio Gozalo, "El archivo de la Casa Ducal de Alburquerque. Panorama general de sus fondos documentales", Investigaciones históricas: época moderna y contemporánea, VIII (1988), pp. 307-322.

${ }^{142}$ Fernández de Béthencourt, Historia genealógica y heráldica de la monarquía española, vol. 10, pp. 252-253; vol. 5, pp. 247-250.
} 
26). La Tabla VII.3 presenta un esquema de los lazos familiares de Juana de la Lama, Duquesa de Alburquerque.

Tabla VII.3: Relaciones familiares de Juana de la Lama, V Duquesa de Alburquerque

*Los personajes mencionados en el proceso de Isabel Ortiz aparecen en negrita.

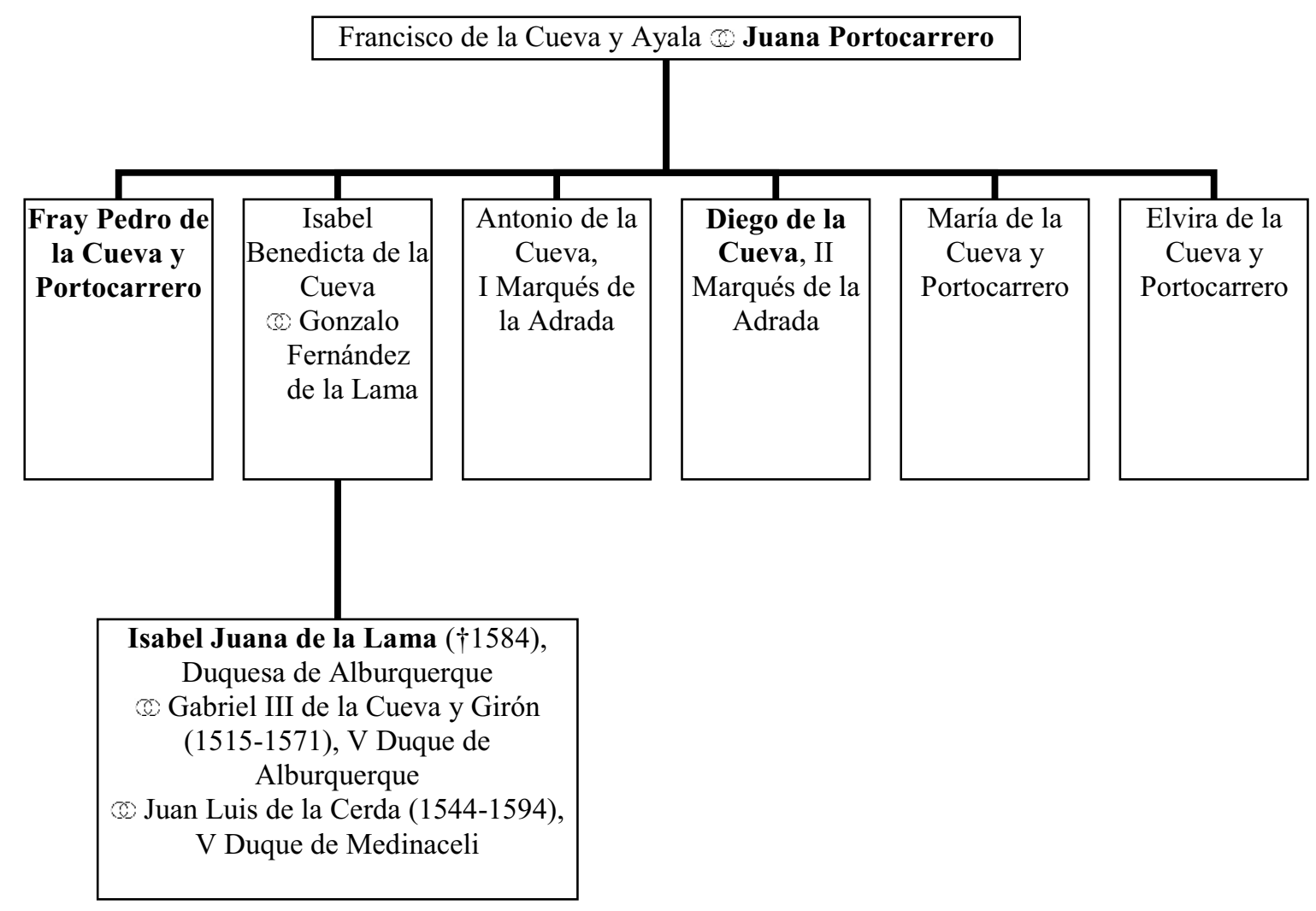

La importante presencia de referencias al contrato de Isabel de Plazaola en el proceso de su madre no sólo se debe a que ésta fuese acusada de comer carne en tiempo de Cuaresma durante el viaje de Guadalajara a Barcelona acompañando a su hija, que debía embarcar allí hacia Milán (Apéndice 18, Fragmento 7), sino también a las sospechas de Isabel Ortiz de que Fray Pedro Portocarrero, que contaba con el favor del inquisidor Francisco de Soto Salazar, era la persona que había tramado su procesamiento por la Inquisición: "al nono testigo dixo queste es fray pedro puertocarrero y quel es el que la hizo traer aqui" (Apéndice 18, Fragmento 29). El motivo es que, cuando se canceló sin motivo el contrato de Plazaola, Fray Pedro había pedido a Ortiz el documento fir- 
mado por la familia Portocarrero con el fin de que su madre, Juana Portocarrero, que había avalado a la Duquesa, no pudiera resultar perjudicada, pero Ortiz había querido conservar el documento para que quedara constancia "del daño y burla que a ella y a su hija se les avia hecho" (Apéndice 18, Fragmento 26), y para poder pedir una compensación económica a los Portocarrero (Apéndice 18, Fragmento 37). Por tanto, la prolijidad en detalles relativos al contrato de Plazaola se debe a que Ortiz argumentaba que su enemistad con Fray Pedro era la causa de que la hubiesen detenido, lo que sitúa el contrato de la música en el centro de este proceso: “oy ha sospechado que el [Fray Pedro] es el que ha dicho que esta comia carne en cuaresma y que el y el rector de santo domingo se juntarian y harian que la marquesa [Leonor Enríquez de Toledo, II Marquesa de Távara] denunçiase desta o ellos denunçiarian por ella" (Apéndice 18, Fragmento 26; véanse también los Fragmentos 36, 37 y 41).

\subsubsection{El Litigio De IsABEL DE PlaZAOLA EN 1575}

El proceso de fe de Isabel Ortiz ha constituido un punto de partida para localizar otra documentación relativa a Isabel de Plazaola. En el transcurso de mi investigación he hallado la ejecutoria de un pleito litigado en la Audiencia de Valladolid en 1575 entre Isabel Ortiz y Juana de la Lama, Duquesa de Alburquerque, "sobre pago de $400 \mathrm{du}$ cados por despedir a su hija antes de cumplir los seis años al servicio de la duquesa como constaba en cierta escritura de obligación". ${ }^{143}$ Este documento, del que se presenta una muestra en la Ilustración VII.3 y que se trascribe en el Apéndice 19, es sumamente interesante porque completa la información que proporciona la documentación inquisitorial sobre las vicisitudes que afectaron a una música profesional en el mundo ibérico del siglo XVI. Los protagonistas del litigio aparecen en la Tabla VII.4.

\footnotetext{
143 "Ejecutoria del pleito litigado por Isabel Ortiz, viuda de Gonzalo Hernández de Plazaola, Blas Carrillo, como curador de Isabel de Plazaola, hija de los primeros, todos vecinos de Guadalajara, con Diego de la Cueva, marqués de La Adrada, Juana de la Lama, duquesa de Alburquerque, Juana Portocarrero, viuda de Antonio de la Cueva, y consortes sobre pago de 400 ducados por despedir a su hija antes de cumplir los seis años al servicio de la duquesa como constaba en cierta escritura de obligación" (1575), Valladolid, Real Audiencia y Chancillería de Valladolid, Registro de ejecutorias, caja 1314, 80.
} 
Ilustración VII.3: "Ejecutoria del pleito litigado por Isabel Ortiz, viuda de Gonzalo Hernández de Plazaola, Blas Carrillo, como curador de Isabel de Plazaola, hija de los primeros, todos vecinos de Guadalajara, con Diego de la Cueva, marqués de La Adrada, Juana de la Lama, duquesa de Alburquerque, Juana Portocarrero, viuda de Antonio de la Cueva, y consortes sobre pago de 400 ducados por despedir a su hija antes de cumplir los seis años al servicio de la duquesa como constaba en cierta escritura de obligación" (1575) [MINISTERIO DE CULTURA, Archivo de la Real Chancillería de Valladolid, ES.47186.ARCHV/1.1.1/REGISTRO DE EJECUTORIAS,CAJA 1314,80, f. 1 r].

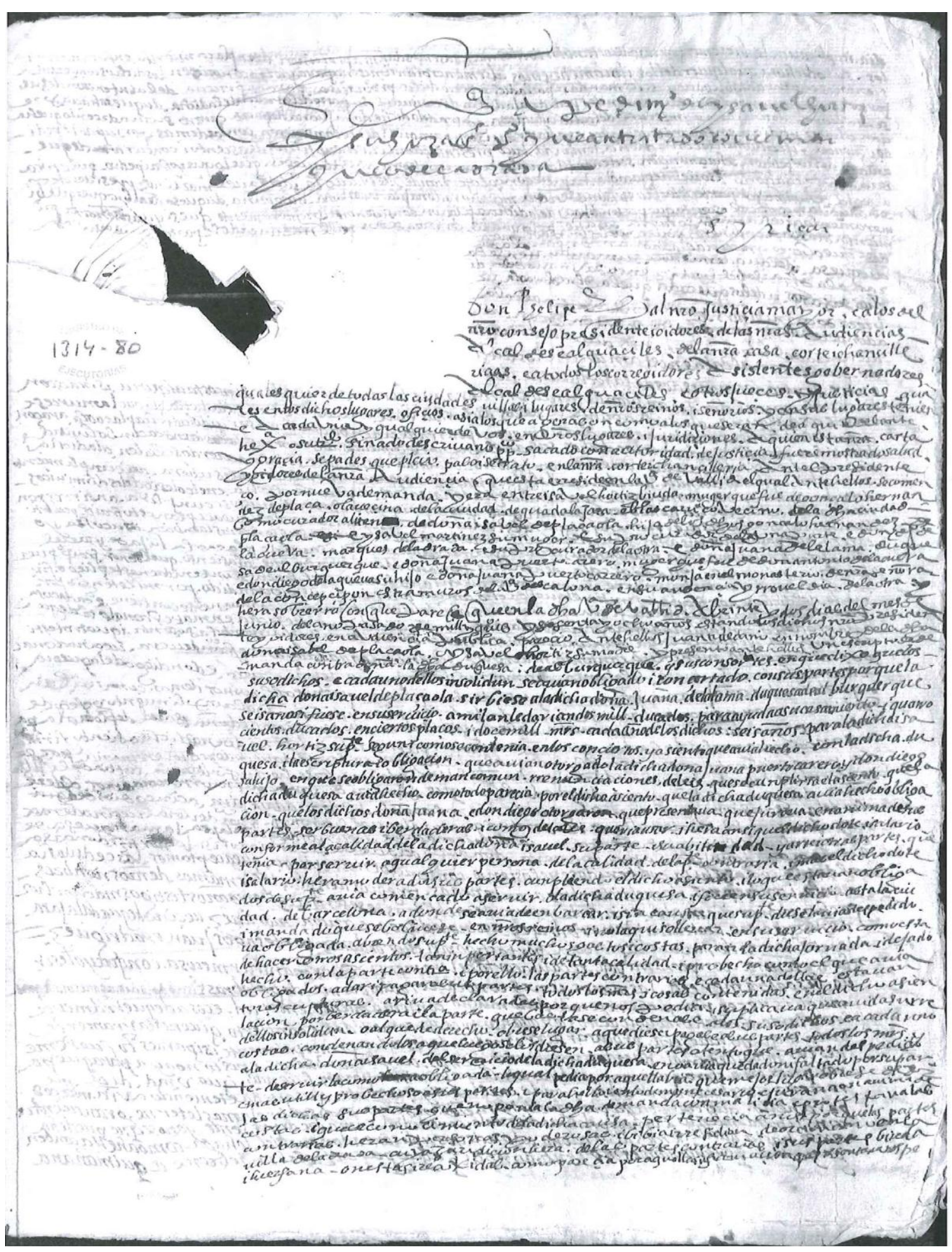


Tabla VII.4: Protagonistas de las dos partes del pleito litigado por Isabel Ortiz en 1575

\begin{tabular}{|c|c|}
\hline Parte demandante & Parte demandada \\
\hline $\begin{array}{l}\text { Isabel Ortiz, viuda de Gonzalo Hernández de } \\
\text { Plazaola }\end{array}$ & $\begin{array}{l}\text { Juana Portocarrero, abuela de la Duquesa de Al- } \\
\text { burquerque }\end{array}$ \\
\hline $\begin{array}{l}\text { Blas Carrizo/Carrillo, curador ad litem de Isabel } \\
\text { de Plazaola (huérfana) }\end{array}$ & $\begin{array}{l}\text { Diego de la Cueva, hijo de Juana Portocarrero y tío } \\
\text { de la Duquesa de Alburquerque }\end{array}$ \\
\hline \multirow[t]{3}{*}{ Juan Toledano, procurador } & Juana de la Lama, Duquesa de Alburquerque \\
\hline & $\begin{array}{l}\text { Juana Portocarrero, monja en el Monasterio de } \\
\text { Nuestra Señora de la Concepción de Escalona } \\
\text { (Toledo). }\end{array}$ \\
\hline & Pedro Moriz, procurador de Diego de la Cueva \\
\hline
\end{tabular}

Cronológicamente, el litigio tuvo lugar del siguiente modo: el 20 de junio de 1568 Juan de Cano presentó un escrito de demanda en nombre de Isabel de Plazaola e Isabel Ortiz contra la Duquesa de Alburquerque; el 10 de mayo de 1575 se dictó sentencia a favor de Isabel Ortiz y su hija, condenando a Diego de la Cueva (como heredero de Juana Portocarrero) a pagar 400 ducados y se absolvió a Juana de la Lama, a su abuela y a la monja Juana Portocarrero. La sentencia fue reclamada, ${ }^{144}$ pero finalmente confirmada a 8 de julio; el caso se cerró el 11 de julio de 1575. La ejecutoria contiene una copia del contrato de Plazaola de 1564 al que se hacía referencia en los documentos inquisitoriales de Ortiz. El asiento fue llevado a cabo por Pedro Portocarrero en nombre de su sobrina el 18 de febrero en el Colegio de los Dominicos de Alcalá de Henares. La Duquesa de Alburquerque firmó su conformidad con el acuerdo al que había llegado su tío el 5 de marzo de 1564 en Marchamalo, mencionándose entre los testigos a Antonio Martínez, el músico de la Condesa de Coruña, lo que apoya la hipótesis de que éste fuese profesor de Plazaola. Es muy interesante el motivo por el cual la abuela y el tío de la Duquesa de Alburquerque firmaron el asiento avalando que ésta cumpliría los términos del contrato: "ser como es casada la dicha doña juana nuestra hija e sobrina i aberse hecho sin licencia [...] del ilustrissimo señor don grauiel de la queua duque de albur-

\footnotetext{
${ }^{144}$ Juan Toledano, en nombre de Isabel Ortiz, alegaba que los 400 ducados eran insuficientes; en la parte contraria, Diego de la Cueva reivindicaba que el contrato que había hecho la Duquesa de Alburquerque a Isabel e Plazaola no tenía validez por haberlo hecho una mujer casada sin la licencia de su marido. Véase el Apéndice 19.
} 
querque su marido". ${ }^{145}$ Esto sugiere que fue la propia Duquesa de Alburquerque quien tomó la iniciativa de contratar a su servicio a Isabel de Plazaola.

Como muestra el Apéndice 19, los términos del contrato coinciden con lo declarado por Ortiz en el expediente inquisitorial, pero encontramos más detalles: si Isabel de Plazaola muriese antes de cumplir los seis años de servicio a la Duquesa de Alburquerque, se le pagaría a su madre la parte proporcional al tiempo que hubiese servido; si los duques la casaran, deberían hacerlo con el consentimiento de Isabel Ortiz; si Isabel de Plazaola se casara o ingresara como monja contra la voluntad de su madre, se pagarían los 2.000 ducados a ésta y no a la música; si Plazaola quisiera volver con su madre cuando se cumplieran los seis años, sería enviada a su costa. Además, se enfatiza que la dote y el salario de Isabel de Plazaola eran conformes a su "calidad" y "su abilidad y arte $\mathrm{i}$ otras partes que tenia por seruir a qualquier persona de la calidad de la parte contraria". 146

Lo que Isabel Ortiz reclamaba era que se pagase igualmente a su hija lo estipulado en el asiento de 1564, puesto que Plazaola había comenzado a servir a la Duquesa de Alburquerque dirigiéndose a Barcelona, donde había sido despedida antes de que los duques embarcaran hacia Milán, "i mandado que se boluiese" ("que auian despedido a la dicha doña isauel del seruicio de la dicha duquesa e no auia quedado ni faltado por su parte de seruirla"). Ortiz había afrontado "muchos gastos i costas" con motivo del viaje de su hija y, lo que es más interesante, Plazaola había "dejado de hacer otros asientos tan importantes i de tanta calidad y probecho como el que hauia hecho con la parte contraria". ${ }^{147}$ Esto indica que los servicios de Isabel de Plazaola habían sido requeridos quizás por otras nobles o, como sugería antes, por la princesa Juana de Austria, pero finalmente se había optado por la oferta de la Duquesa de Albuquerque. En la sentencia se dice "que mereçia el dicho salario e que auia perdido otros muy mejores [...] en su onor y reputacion ansi [...] se le auia seguido daño". ${ }^{148}$

Isabel Ortiz aportó "las escripturas de asiento y concierto" de 1564, así como una carta de la Duquesa en que expresaba la alegría que le causaba llevar a Isabel de

\footnotetext{
145 "Ejecutoria del pleito litigado por Isabel Ortiz", f. 1v.

146 “Ejecutoria del pleito litigado por Isabel Ortiz”, f. 1r.

147 "Ejecutoria del pleito litigado por Isabel Ortiz", f. 1r.

148 “Ejecutoria del pleito litigado por Isabel Ortiz", f. 3r.
} 
Plazaola a su servicio y hablaba de la necesidad de que ésta llegara pronto a Barcelona para embarcar sin demora, y otra carta posterior de Juana Portocarrero, abuela de la Duquesa, en la que ésta se lamentaba de que Isabel de Plazaola no hubiese podido acompañar a su nieta a Milán. La carta de la Duquesa, fechada el 14 de febrero y por tanto anterior al asiento de Pedro Portocarrero, supone una contestación a otra misiva de Isabel Ortiz. ${ }^{149}$ La Duquesa expresaba su voluntad de que todo resultase conveniente para las dos partes, así como cuál era su prioridad con respecto al futuro de Isabel de Plazaola: "lo que yo hare sera procurar de casarla principalmente i si para esto fuere menester mas de dos mill ducados no procuraremos cumplir con menos en esto no aya para que parar". La Duquesa también explicaba que le producía "mucho contentamiento salir de aqui con esta doncella”. La carta de Juana Portocarrero, dirigida a Isabel Ortiz, está fechada a 13 de abril de 1564 y es posterior al despido de Isabel de Plazaola. Juana Portocarrero se lamentaba de que Isabel de Plazaola no pudiera ir a Milán al servicio de la Duquesa de Alburquerque: "me a pesado mucho por que doña isabel fuera con mi hija [¿nieta?] porque le diera mucho contento". ${ }^{150}$ Juana Portocarrero mencionaba a Isabel de Plazaola junto a Doña Francisca: "la pena que a mi me a dado ver boluer a doña ysauel e a doña francisca". La información que proporciona la carta no permite establecer cuál era el papel de Doña Francisca; sólo se indica que era prima de Isabel de Plazaola. ${ }^{151}$ Una hipótesis es que Doña Francisca acompañara a Isabel de Plazaola en calidad de sirviente. ${ }^{152}$

Lo que más llama la atención en este litigio es que en ningún momento, ni en el pleito ni en el contrato, se hiciera alusión a Isabel de Plazaola como música, sino como "criada", aunque mencionando reiteradamente su "calidad", "habilidad" y "arte". Por eso, sin la información extraída del proceso inquisitorial contra su madre, Isabel Ortiz,

\footnotetext{
149 "Ejecutoria del pleito litigado por Isabel Ortiz", f. 2v.

150 “Ejecutoria del pleito litigado por Isabel Ortiz", f. 2r.

${ }^{151}$ En el proceso inquisitorial de Ortiz se la menciona como "otra muchacha que con ella yba". Véase Apéndice 18, Fragmento 26.

${ }^{152}$ No era extraño que los músicos viajasen acompañados por sirvientes. Por ejemplo, en la licencia que solicitó Rodrigo Muñoz para que el cantor Juan de Villarrubia, "capado y clerigo presbitero de muy buena boz y otras abilidades", pasase a México para servir en la Iglesia Metropolitana, se pedía que también se "le procure liçençia para que lleue a su madre y un criado y una criada como todo corista". Véase "Expediente de concesión de licencia para pasar a México a favor de Juan de Villarrubia, clérigo, músico para la Catedral de México” (1591), Sevilla, Archivo General de Indias, Indiferente, 2065, N. 88, f. 1.
} 
habría sido imposible determinar que este litigio tenía como protagonista a una mujer música. Por consiguiente, este caso muestra la invisibilidad de las músicas del mundo ibérico del siglo XVI en los registros históricos, y sugiere que Plazaola podría ser sólo el vestigio visible de una activa vida musical en las esferas de mujeres.

\subsubsection{ACTIVIDAD MUSICAL EN TORNO A ISABEL DE ARAGÓN,}

\section{DUQUESA DEL INFANTADO}

La consulta de inventarios de bienes, testamentos y otra documentación de archivo relacionada con las nobles para las que trabajó Isabel de Plazaola (véase la Tabla VII.2) y el establecimiento de relaciones entre ellas sugiere que el centro de esta red de mujeres interesadas en la música estaba en el Palacio del Infantado en Guadalajara. En el proceso inquisitorial contra Isabel Ortiz, se menciona en numerosas ocasiones a Isabel de Aragón y Portugal, IV Duquesa del Infantado. Esta Duquesa era hija de Guiomar de Portugal y Enrique de Aragón, I Duque de Segorbe, y sobrina de Fernando el Católico quien, junto a Germana de Foix, apadrinó su boda con el Duque del Infantado. ${ }^{153}$ La Duquesa del Infantado tuvo a su servicio a Isabel Ortiz cuando era una niña, la casó y, cuando fue abandonada por su marido, la ayudó económicamente, la trató como confidente y la apreció como guía espiritual. ${ }^{154}$ Aunque en el proceso contra Isabel Ortiz no se explicita que su hija música, Isabel de Plazaola, estuviera al servicio de la Duquesa, el vínculo entre las tres mujeres hace pensar que una investigación de las mujeres de la casa del Infantado podría conducir al descubrimiento de más indicios de actividad musical y mecenazgo musical femenino en el seno de esta familia. ${ }^{155}$ Además, los IV Du-

\footnotetext{
153 “Capitulaciones matrimoniales, arras, dotes, cartas de pago etc., sobre el matrimonio de Iñigo López de Mendoza, conde de Saldaña e Isabel de Aragón, hija del infante Enrique de Aragón”, Toledo, Sección Nobleza del Archivo Histórico Nacional, Osuna, C.1773, D.27-36. Acerca de la impresionante dote de Isabel de Aragón, véanse Faustino Gil Ayuso, El equipo de boda de doña Isabel de Aragón (Madrid: Archivo Histórico Nacional, 1934); y Arteaga y Falguera, La casa del Infantado cabeza de los Mendoza, vol. 1, p. 325. Sobre la boda, véase Antonio Serrano Cueto, "La boda de Íñigo López de Mendoza (IV duque del Infantado) e Isabel de Aragón cantada en verso latino por Martín Ivarra", Silva: estudios de humanismo y tradición clásica, V (2006), pp. 361-385.

${ }^{154}$ Sobre la ayuda económica que proporcionaba la Duquesa del Infantado a Isabel Ortiz, véase el Apéndice 18, Fragmentos 14, 16 y 20.

${ }^{155}$ Además de la documentación sobre los duques del Infantado en la Sección Nobleza del Archivo Histórico Nacional, existen documentos en la Biblioteca de la Real Academia de la Historia y unos pocos en la Biblioteca Nacional de España en Madrid: "Nóminas y cuentas de la Casa del Infantado, v. 3: años 15961739" (MSS/11148); "Correspondencia familiar de la Casa del Infantado" (MSS/11157); y "Carta del Infante D. Enrique de Aragón a su hija Isabel. Segorbe, 15 diciembre 1514” (MSS/12978/15). En la bi-
} 
ques del Infantado estuvieron estrechamente relacionados con el Monasterio de la Piedad de Guadalajara que, como mostré en el Capítulo VI, destacaba por su vida musical; los IV Duques eran sobrinos de la fundadora del monasterio, Brianda de Mendoza, y ésta en su testamento les nombró "patrones, protectores y defensores" del monasterio. ${ }^{156}$

\section{a) La música en la casa del Infantado: estudio preliminar}

El grado de importancia de los IV Duques del Infantado en la vida social de la época queda demostrado por la celebración en su palacio de Guadalajara de la boda de Felipe II con Isabel de Valois en 1560. Mientras que el mecenazgo musical de algunas familias de la nobleza española ha sido objeto de estudio, ${ }^{157}$ el papel de los Mendoza y, en particular, de los Duques del Infantado en la vida musical permanece sin investigar en detalle. El propósito de esta sección es llevar a cabo una primera aproximación a esta cuestión. A pesar de sus limitaciones, los relatos de viajeros proporcionan información acerca de la presencia de músicos y sus funciones en el palacio de los Mendoza en La Alhambra de Granada. Jeronimo Münzer que, como mencioné antes, viajó por España entre 1494 y 1495, narraba su visita a Íñigo López, Conde de Tendilla, a su palacio de La Alhambra: "Por orden del conde vinieron a darnos música a nuestra posada tañedo-

bliografía de su trabajo La casa del Infantado cabeza de los Mendoza, Cristina Arteaga y Falguera aporta un listado de los "historiadores de la casa", con referencias a numerosos volúmenes tanto impresos como manuscritos.

${ }^{156}$ Layna Serrano, Los conventos antiguos de Guadalajara, p. 189. Además, existen dos documentos que
daban permiso al Duque y a la Duquesa, respectivamente, para entrar al Convento de Santa Clara y visitar
a sus hijas monjas: "Letras de Msr. Ranucio Farnesio, Cardenal del Santo Ángel, Arzobispo de Nápoles,
autorizando a Iñigo López de Mendoza, duque del Infantado (IV), a entrar en el convento de Santa Clara
de Guadalajara, para visitar a sus hijas profesas. 17 de agosto 1546"; y "Letras del Msr. Antonio Pucci,
Cardenal de los Cuatro Santos Coronados, concediendo igual autorización a Isabel de Aragón, duquesa
del Infantado (IV), añadiendo una llave del Monasterio. 5 de febrero de 1537", Toledo, Sección Nobleza
del Archivo Histórico Nacional, Osuna, C.1971, D.9-10.

${ }^{157}$ Un estudio pionero sobre el mecenazgo musical de la nobleza es José Subirá, La música en la Casa de Alba: estudios históricos y biográficos (Madrid: Establ. Tip. Sucesores de Rivadeneyra, 1927). Para una época posterior, donde se cita una amplia bibliografía sobre el tema, contamos con los trabajos de Juan Pablo Fernández Cortés, La música en las casas de Osuna y Benavente (1733-1882). Un estudio sobre el mecenazgo musical de la alta nobleza española (Madrid: SEdeM, 2007); y su libro ya mencionado Mujeres y música en la Casa Ducal de Osuna. Sobre el mecenazgo musical de los Duques de Medina Sidonia, véanse Lucía Gómez Fernández, "Mecenazgo musical de la Casa Medina Sidonia (1410-1664)", Tesis Doctoral (Ph.D.), Universidad de Cádiz [en curso]; y "El mecenazgo musical de la casa de Medina Sidonia y el Nuevo Mundo en el siglo XVI", en La Música y el Atlántico, coord. y ed. por María Gembero Ustárroz y Emilio Ros-Fábregas (Granada: Universidad de Granada, 2007), pp. 59-68; y Juan Ruiz Jiménez, "Power and Musical Exchange: The Dukes of Medina Sidonia in Renaissance Seville", Early Music, XXXVII/3 (2009), pp. 401-415. Sobre el mecenazgo musical de los Cardona y los Fernández de Córdoba, véase Ros-Fábregas, "The Cardona and Fernández de Córdoba Coats of Arms in the Chigi Codex". 
res de flautas, vihuelas y trompetas". ${ }^{158}$ Este relato muestra que el Conde de Tendilla empleaba a sus músicos para agasajar a los visitantes. En el relato de su viaje por España, el Embajador de Venecia alabó la capilla musical del Duque del Infantado en Guadalajara. ${ }^{159}$ Además de los relatos de viaje, los inventarios de bienes, los registros de la Inquisición y los libros de música son fuentes que permiten acercarse a la vida musical en el palacio de los Duques del Infantado en particular.

Los inventarios de bienes proporcionan evidencia de la importancia que los Duques del Infantado dieron a la música. Se puede extraer información musicológica de los trabajos de Roberto González Ramos sobre los patrones de "conducta cultural” y las maneras de "poseer" mediante el cotejo de los bienes libres que eran propiedad de las tres primeras generaciones del ducado del Infantado del siglo XVI. ${ }^{160}$ Como muestra la Tabla VII.5, los libros de música y los instrumentos musicales tienen una significativa presencia en los inventarios de bienes de los Duques del Infantado y, en especial, en el del IV Duque, el marido de Isabel de Aragón.

${ }^{158}$ García Mercadal, Viajes de extranjeros por España y Portugal, p. 366.

${ }^{159}$ Andrea Navagero, Viaje por España (1524-1526), traducido y anotado por Antonio María Fabie (Madrid: Turner, 1983), p. 23; citado en Emilio Ros-Fábregas, "De L’homme armé a la Missa Pro Victoria: la música como representación de poder desde la corte borgoñona hasta Tomás Luis de Victoria”, en Tomás Luis de Victoria y la cultura musical en la España de Felipe III, dir. por Alfonso de Vicente y Pilar Tomás (Madrid: Centro de Estudios Europa Hispánica, 2012), pp. 33-62, p. 60, nota 43.

${ }^{160}$ Roberto González Ramos, "Imágenes, libros y armas. Tipología y significado de los bienes de Diego Hurtado de Mendoza, conde de Saldaña y marqués del Cenete (1520-1560)", Anuario del Departamento de Historia y Teoría del Arte, XXI (2009), pp. 31-46; y "Evolución cultural y contraste generacional. Tres generaciones de la casa del Infantado y cuatro categorías de sus bienes (1531-1566)", Tiempos modernos, XX/1 (2010), <http://www.tiemposmodernos.org/tm3/index.php/tm/article/viewFile/176/279>. Sobre la biblioteca de los duques del Infantado, véase Marcelino González Pascual, "La biblioteca de los Mendoza en Guadalajara (siglos XV-XVI)", Tesis Doctoral (Ph.D.), Universidad de Deusto, 1998. Los inventarios post-mortem recogen los bienes libres que pertenecían a cada duque y no los adheridos a la biblioteca ducal herencia del Marqués de Santillana. Sobre ésta, véanse José María Rocamora, Catálogo abreviado de los manuscritos de la biblioteca del Excelentísimo Señor Duque de Osuna (Madrid: Imprenta de Fortanet, 1882); Mario Schiff, La bibliothèque du marquis de Santillane. Etude historique et bibliographique de la collection de livres manuscrits de don Iñigo López de Mendoza (París: Emile Bouillon, 1905); Mario Penna, Exposición de la Biblioteca de los Mendoza del Infantado (Madrid: Biblioteca Nacional, 1958); Jean-Michel Laspéras, "Chronique du livre espagnol: inventaires de bibliothèques et documents de libraires dans le monde hispanique aux XVe, XVIe et XVIIe siècles”, Revue Française d'Histoire du Livre, XXVIII (1980), pp. 535-557; Isabel Beceiro Pita y Ricardo Córdoba de la Llave, Parentesco, poder y mentalidad. La nobleza castellana, siglos XII-XV (Madrid: CSIC, 1990), pp. 105-106; y Adolfo Carrasco Martínez, "Guadalajara, corte de los Mendoza en la segunda mitad del siglo XVI", en Felipe II y las artes (Actas del congreso) (Madrid: Universidad Complutense, 2000), pp. 57-69, p. 59. 
Tabla VII.5: Libros de música e instrumentos musicales en los inventarios de bienes de Diego Hurtado de Mendoza y Luna, III Duque del Infantado; Íñigo López de Mendoza y Pimentel, IV Duque del Infantado; y Diego Hurtado de Mendoza, primogénito del IV Duque

\begin{tabular}{|c|c|c|}
\hline Noble & $\begin{array}{l}\text { Libros de música no } \\
\text { adscritos al mayorazgo }\end{array}$ & Instrumentos musicales \\
\hline $\begin{array}{l}\text { Diego Hurtado de Men- } \\
\text { doza y Luna (1461- } \\
\text { 1531), III Duque del } \\
\text { Infantado }\end{array}$ & $\begin{array}{l}17 \text { libros de música ("de } \\
\text { canto, de órgano, de misas, } \\
\text { de canto italiano") en una } \\
\text { biblioteca de } 55 \text { libros. La } \\
\text { música es la materia más } \\
\text { representada después de } \\
\text { los libros religiosos y li- } \\
\text { túrgicos. }{ }^{161}\end{array}$ & $\begin{array}{l}\text { Tenía "diversos instrumentos musicales, como } \\
\text { vihuelas y órganos". }{ }^{62}\end{array}$ \\
\hline $\begin{array}{l}\text { Íñigo López de Mendoza } \\
\text { y Pimentel (1493-1566), } \\
\text { IV Duque del Infantado }\end{array}$ & $\begin{array}{l}23 \text { libros de música. La } \\
\text { música es la materia más } \\
\text { representada en su biblio- } \\
\text { teca. }\end{array}$ & $\begin{array}{l}\text { Destaca "por la posesión de arpas - una de } \\
\text { ébano". Además, tenía "arpas vihuelas, un } \\
\text { claviórgano, cuatro clavicémbalos, laúdes, una } \\
\text { vihuela, dos vihuelas de arco y una 'tumbada', } \\
\text { una guitarra, una caja de flautas y otra de dul- } \\
\text { zainas, una caja de orlos, un pífano y diversas } \\
\text { flautas más". } 163\end{array}$ \\
\hline $\begin{array}{l}\text { Diego Hurtado de Men- } \\
\text { doza (1520-1560), Con- } \\
\text { de de Saldaña y Marqués } \\
\text { del Cenete }\end{array}$ & $\begin{array}{l}\text { "8 libros de música para } \\
\text { canto de órgano y otros } 4 \\
\text { de órgano 'de cançiones } \\
\text { françeca (sic) de molde"" } \\
\text { en una biblioteca de } 120 \\
\text { libros. } 164\end{array}$ & $\begin{array}{l}\text { "Encontramos gran número de instrumentos, } \\
\text { destacando especialmente los de cuerda, con } 4 \\
\text { arpas, una dorada y el resto adornadas de tara- } \\
\text { cea, } 2 \text { vihuelas y un laúd. Son, sin duda, ins- } \\
\text { trumentos perfectamente orientados a la ejecu- } \\
\text { ción personal, como en el caso del padre de } \\
\text { nuestro personaje. Había también } 2 \text { clavicor- } \\
\text { dios. Todos estos instrumentos alcanzaban } \\
\text { valores de tasación realmente importantes, } \\
\text { quizás debido sobre todo a su riqueza decora- } \\
\text { tiva ( } 12 \text { ducados que son } 4.488 \text { maravedíes, y } \\
6.000 \text { maravedíes los más valorados)". } 165\end{array}$ \\
\hline
\end{tabular}

${ }^{161}$ González Ramos, "Evolución cultural y contraste generacional”, p. 22.

162 González Ramos, “Evolución cultural y contraste generacional”, p. 33.

${ }^{163}$ González Ramos, "Evolución cultural y contraste generacional”, p. 33.

${ }^{164}$ González Ramos, “Imágenes, libros y armas”, p. 35.

${ }^{165}$ González Ramos, "Imágenes, libros y armas”, p. 40. González Sánchez emplea como fuente el inventario post-mortem, la tasación y la almoneda pública de los bienes del Marqués del Cenete, que se conservan en Toledo, Sección Nobleza del Archivo Histórico Nacional, Osuna, leg. 1835, doc. 1, 2 y 3-6, respectivamente. 
Como muestra la Tabla VII.5, el análisis desde la perspectiva musical de los estudios de González Ramos sobre los inventarios post-mortem de los duques del Infantado del siglo XVI muestra que estos nobles se caracterizaron por la posesión de libros que indican una concepción de la música como entretenimiento ligado a la devoción y a la liturgia y por la propiedad de instrumentos musicales que probablemente eran tañidos personalmente por los propios duques. González Sánchez señala que "lo que más parece haber llevado al III Duque a la adquisición de libros es la declarada pasión por la liturgia y su escenificación musical"; ${ }^{166}$ como en el caso del III Duque, la mayor parte de los libros del IV Duque eran "libros devocionales o dedicados a la capilla musical del palacio del Infantado" ${ }^{167}$ Esto apunta a una concepción de la música como entretenimiento devoto. Respecto a los instrumentos musicales, González Ramos señala que la importante colección de instrumentos del IV Duque se relaciona con su afición a "la ejecución musical personal" a la que se hace alusión en relatos de la época: "fue mañoso en obras exteriores de manos, pulido, gran musico, tocaua todos los instrumentos con suficiencia, en especial en puntear vn laud; era consumado", señalaba Alonso Núñez de Castro en el siglo XVII. ${ }^{168}$ En un manuscrito del siglo XVIII, Fray Hernando Pecha se refería al Duque en términos similares:

\begin{abstract}
Era el duque don Iñigo mañoso en obras exteriores de manos, pulido, aseado, aliñado, fue gran musico, tocaba todos los instrumentos, en especial en puntear un laud era consumado / Con estos exercicios ya de letras ya de Armas, ya de Caza (que son todos propios de un gran señor) nunca estaba oçioso, con que evitó mayores daños, que trae consigo la ociosidad, y cobró fama de cavallero virtuosso, discreto, sabio, cuerdo, valiente, letrado, diestro en las armas, abentajado en música, y gran cazador $\left[\ldots . .{ }^{169}\right.$
\end{abstract}

En el inventario del primogénito del IV Duque del Infantado se encuentra también una importante presencia de instrumentos musicales, hecho que González Ramos relaciona con los gustos que le habían sido inculcados en el seno familiar. González

\footnotetext{
${ }^{166}$ González Ramos, "Evolución cultural y contraste generacional”, p. 22.

${ }^{167}$ González Ramos, “Evolución cultural y contraste generacional”, p. 24.

${ }^{168}$ Núñez de Castro, Historia eclesiastica y seglar de la muy noble y muy leal ciudad de Guadalaxara, p. 181; Arteaga y Falguera, La casa del Infantado cabeza de los Mendoza, p. 323.

${ }^{169}$ Hernando Pecha, Historia de Guadalaxara y como la Religión de Sn. Geronymo en España fue fundada y restaurada por sus ciudadanos (Guadalajara: Diputación Provincial de Guadalajara, 1977 [MS (1756), Madrid, Biblioteca Nacional de España, MSS/1756]), p. 293.
} 
Ramos compara las posesiones de Diego Hurtado de Mendoza con las halladas en el inventario post-mortem de Pérez de Guzmán, VI Duque de Medina Sidonia llevado a cabo en $1558,{ }^{170}$ llegando a una importante conclusión en cuanto a la posesión de instrumentos musicales: mientras que el Duque de Medina Sidonia poseía "gran cantidad de instrumentos de viento al servicio de su capilla de música, además del órgano del oratorio y otro pequeño, con ejecutantes contratados a su servicio", el hijo del IV Duque del Infantado "tenía instrumentos de cuerda y, aparentemente, eran piezas de lujo para su disfrute y uso personal". ${ }^{171}$ También el IV Duque del Infantado presentaba esta particularidad:

Más que para la celebración de conciertos por parte de músicos profesionales, que también, interesa destacar que muchos de los instrumentos parecen más indicados para la ejecución personal de diferentes composiciones, incluso, como he señalado, por parte del propio duque. Este detalle señala un claro acercamiento a modos cortesanos plenamente renacentistas. ${ }^{172}$

Además de los inventarios de bienes, los documentos inquisitoriales son otra fuente que permite vislumbrar la actividad musical en el ámbito del Infantado. El proce-

\footnotetext{
${ }^{170}$ Publicado en Antonio Urquízar Herrera, Coleccionismo y nobleza. Signos de distinción social en la Andalucía del Renacimiento (Madrid: Marcial Pons Historia, 2007), pp. 175-207.

${ }^{171}$ González Ramos, "Imágenes, libros y armas", p. 42. Llevando a cabo un vaciado del inventario que presenta Urquízar Herrera, Coleccionismo y nobleza, pp. 197 y 201-202, encontramos que el VI Duque de Medina Sidonia tenía los siguientes instrumentos: "una corneta de marfil de las Indias"; "un órgano con su peana e fuelles que tiene muchas mixturas de música, que sirve en la capilla"; "otro órgano pequeño que llaman ricalejo, con sus fuelles"; "un claviórgano que tiene los cañones de madera e cuerdas de alambre"; "una caja con su cerradura de golpe en que están seis vihuelas de arco, las cinco nuevas con sus cuerdas e arcos e otra vieja"; "otras cuatro vihuelas de arco grandes viejas"; "una cintola [sic] sin cuerdas"; "otra caja en que están metidos los instrumentos siguientes"; "una caja de hornos [sic] que tiene ocho piezas grandes e pequeñas"; "otra caja de hornos [sic] que tiene otras ocho"; "otra caja que tiene cinco dulzainas"; "una caja que tiene cuatro cornetas sordas"; "otra caja que tiene cinco pífanos"; "otra caja con cuatro dulzainas, que tiene los bocales e guarnición de plata, todas ellas guarnecidas de arriba debajo de plata, e la una le falta un bocal de arriba"; "otra caja de cornetas que tiene seis cornetas con su llave"; "cinco chirimías contra altos"; "un bajón"; "cinco flautas"; "cuatro flautas pequeñas"; "otra caja de cornetas que tiene cuatro cornetas"; "un sacabuche"; "otro medio sacabuche"; "otra dulzaina vieja"; "un tiple de chirimía que tiene Rodrigo"; "un contraalto que tiene Cristóbal"; "un tenor que tiene Antonio"; "dos sacabuches que tiene Francisco, el uno tiene guarnición de plata"; "otras dos cajas para guardar instrumentos". Los libros del Duque son los siguientes: "dos libros de música de los menestrales"; "cuatro libros de canto de órgano, el uno de ellos enforrado en terciopelo carmesí y el otro en terciopelo azul, y los dos en cueros, y el uno de ellos con tablas de madera con unos tachones en cada tabla"; "otro libro en tablas de madera e cuero blanco de pergamino, de canto llano"; "trece cuadernos de pliegos de pergamino en que están apuntadas magníficas"; "un libro pequeño de música para poner instrumentos"; y "otro libro grande de música donde hay ciertas misas e algunas maguinfilas [sic] de Pedro Guerrero"; véase Urquízar Herrera, Coleccionismo y nobleza, pp. 187-188 y 207.
}

${ }^{172}$ González Ramos, "Evolución cultural y contraste generacional”, p. 34. 
so de Isabel Ortiz no es el único que vincula a los IV Duques del Infantado con los alumbrados. Antonio Márquez sostiene que el centro geográfico de los alumbrados estaba en Guadalajara y, en concreto, en el palacio del Infantado; tanto los alumbrados que son objeto de su estudio como quienes los denunciaron eran criados de los Duques del Infantado. ${ }^{173}$ Uno de estos procesados, Rodrigo de Bivar, clérigo presbítero beneficiado de la iglesia de Santiago del Arrabal de Toledo, que sería condenado por iluminado en 1539, y al que hice referencia en el Capítulo IV en relación con las academias, era “cantor temple" del III Duque del Infantado. ${ }^{174}$ El nombre de Rodrigo de Bivar ya aparecía mencionado en el conocido proceso iniciado en 1524 contra Pedro Ruiz de Alcaraz, en el que también encontramos referencias a otro músico del Duque del Infantado, "Espinosa, chirimia", entre el círculo de amigos de Alcaraz:

Los que en Guadalajara me comunicaban con Campuzano el moço y contino del sr duque de Infantado, y Espinosa, chirimia, y Vega, despensero del sr Conde de Saldaña, y Bivar, capellan del sr duque y doña Leonor de Quiros; e otras personas que alli ay buenas comunicaba asy como a estos. $^{175}$

Los documentos inquisitoriales del caso contra el músico Rodrigo de Bivar ofrecen vestigios de la actividad musical en torno a los Duques del Infantado. Gracias al proceso de Rodrigo de Bivar, podemos determinar los nombres de algunos músicos que trabajaban para el III Duque; véase la Tabla VII.6. Fray Hernando Pecha describía del siguiente modo la capilla del III Duque del Infantado:

Desde su tierna edad se mostro nuestro don Diego deuoto y christianissimo y tuuo tan grande afficion a los offiçios y ceremonias de la iglesia, que hizo su casa vna iglesia Cathedral o capilla Real, donde tenia sus capellanes, Cantores Menestriles, Organo y otros instrumentos musicos conçernientes al offiçio diuino [...] y todos los dias de fiesta se dezia vna missa cantada a canto de organo como si fuera Capilla Real, y a esta siempre se hallaua presente el Duque Don Diego. ${ }^{176}$

\footnotetext{
${ }^{173}$ Márquez, Los alumbrados, pp. 61-62.

174 "Proceso de fe de Rodrigo de Bivar", Madrid, Archivo Histórico Nacional, Inquisición, 213, exp. 7; Hamilton, El proceso de Rodrigo de Bivar.

175 "Proceso de fe de Pedro Ruiz de Alcaraz, natural y vecino de Guadalajara, e incidentalmente de Isabel de la Cruz y de Gaspar de Bedoya, sobre proposiciones heréticas y alumbrismo", Madrid, Archivo Histórico Nacional, Inquisición, legajo 106, expediente 5, f. 19r.

${ }^{176}$ Hernando Pecha, Historia de las vidas de los Excelentisimos señores Duques del Ynfantado y sus progenitores, desde el Infante Don Zuria primer Señor de Vizcaya hasta la Exelentisima Señora Duquesa
} 
Tabla VII.6: Músicos del III Duque del Infantado mencionados en el "Proceso de fe de Rodrigo de Bivar" (1539)

\begin{tabular}{ll}
\hline Nombre & Puesto \\
\hline Rodrigo de Bivar & "cantor temple" \\
Diego de Espinosa (nacido c. 1498) & chirimía $^{177}$ \\
Gascón & trompeta $^{178}$ \\
Viana & "contrabaxa"179 \\
Torres & "tañedor"" \\
Jerónimo de Sotomayor & sacabuche \\
¿Juan de Morales? & sacabuche \\
\hline
\end{tabular}

Además de los inventarios de bienes y los registros de la Inquisición, los libros de música constituyen fuentes que permiten aproximarse a la vida musical en el palacio de los Duques del Infantado. El material preliminar de los Tres libros de musica en cifra para vihuela (Sevilla, 1546) de Alonso Mudarra (c. 1510-1580) evidencia la importante presencia de músicos en el palacio del Infantado, donde el propio Mudarra "pasó su

Doña Ana y su Hija Doña Luysa Condesa de Saldaña, MS (1635), Guadalajara, Biblioteca Pública Provincial, Ms. 57, f. $139 \mathrm{v}$.

${ }^{177}$ Véase Hamilton, El proceso de Rodrigo de Bivar, p. 17, nota 51: Diego de Espinosa "era uno de los discípulos de Isabel de la Cruz mencionado más frecuentemente en los procesos contra los alumbrados".

178 "Proceso de fe de Rodrigo de Bivar", f. 2r: "la mujer de Gascon trompeta" [Declaración de Diego de Espinosa a 1 de mayo de 1524].

179 "Proceso de fe de Rodrigo de Bivar", f. 4v: "crehe que estavan presentes Vyana, contrabaxa del duque [...]" [Declaración de Diego de Guadalajara a 7 de marzo de 1525].

180 "Proceso de fe de Rodrigo de Bivar", f. 11r: "Torres, tañedor del duque" [Examen de Bivar a 3 de marzo de 1525].

181 "Proceso de fe de Rodrigo de Bivar", f. 41r: "Sotomayor e su muger, sacabuche de la yglesia"; y f. $44 \mathrm{v}$ : "Hieronimo de Sotomayor, sacabuche".

182 "Proceso de fe de Rodrigo de Bivar", f. 41r: "Juan de Morales, sacabuche de la dicha yglesia". Juan de Morales fue uno de los testigos presentados en Toledo, pero no he encontrado su declaración para determinar si trabajó para el III Duque del Infantado junto a Bivar. 
juventud presumiblemente como paje" del III y el IV Duques, ${ }^{183}$ y se formó en su capi$11 \mathrm{a}:{ }^{184}$

[...] me e criado en casa de los Illustrissimos señores Duques del Infantado mis señores don Diego hurtado de mendoça que Dios tiene en su gloria y don Iñigo Lopez que oy viue y dios nuestro señor guarde a donde de toda Musica auia excelentes hombres pensara que en estos mis Libros ay algunas migajas de tanto bueno como e visto en aquella casa y en otras partes de España y en Italia, Las quales deseosas me han hecho tener atreuimento de querer sacar a luz esta mi obra $[\ldots]$. $^{185}$

Mudarra señalaba, por tanto, que lo que le llevó a publicar su obra fue el dar a conocer parte de lo que había aprendido en el palacio del Infantado, pero también en Italia, a donde probablemente viajó con el IV Duque del Infantado acompañando a Carlos V en 1529. ${ }^{186}$ En los versos 31 a 33 de la ensalada La Viuda de Mateo Flecha se menciona al Duque del Infantado como uno de los cuatro protectores de la música, siendo los otros tres el papa León X, Fernando el Católico y el Arzobispo Alonso IV de Fonseca y Acevedo: “¡Oh duque del Infantazgo / 'que fuiste la mejor lança / qu’en Francia comía pan"”. Encontramos otra referencia a la familia del Infantado en las artes de canto: los libros de Juan de Espinosa Tractado de principios de musica practica e theorica (1520) y Tratado breue de principios de canto llano (c. 1521) están dedicados a Martín de Mendoza, arcediano de Talavera y Guadalajara, hijo del III Duque del Infantado y hermano del IV Duque. En consecuencia, los relatos de viaje, los inventarios de bienes, los documentos de la Inquisición y los propios libros de música hacen vislumbrar el interés de una investigación exhaustiva de la casa del Infantado desde la perspectiva musicológica. Pero no sólo los duques del Infantado se relacionan con la música, sino también sus esposas.

\footnotetext{
${ }^{183}$ Griffiths, "Hidalgo, Merchant, Poet, Priest”, p. 356: "Entre aquéllos con fuertes tradiciones musicales están los Duques del Infantado en Guadalajara, donde el vihuelista Alonso Mudarra pasó su juventud, presumiblemente como paje" ["Among those with strong musical traditions are the dukes of the Infantado in Guadalajara where vihuelist Alonso Mudarra spent his youth, presumably as a page”].

${ }^{184}$ Muñoz, Mencía de Mendoza y la Viuda de Mateo Flecha, p. 43.

${ }^{185}$ Alonso de Mudarra, Tres libros de musica en cifra para vihuela (Sevilla: Juan de León, 1546), f. A1v, "Epistola al mvy magnifico señor Don Luys çapata".

${ }^{186}$ John Griffiths. "Mudarra, Alonso", Grove Music Online. Oxford Music Online, 13 junio 2011

$<$ http://www.oxfordmusiconline.com/subscriber/article/grove/music/19285>.
} 


\section{b) El mecenazgo de las Mendoza}

En Italia, las mujeres a menudo eran mecenas de libros de música publicados por mujeres; Isabella de Medici patrocinó la primera publicación de obras musicales de una mujer, Maddalena Casulana (Il primo libro de madrigali, publicado en Venecia en 1568). Tales intervenciones culturales no serían sorprendentes en el mundo ibérico, puesto que las nobles de la familia Mendoza, las de más talento y educación de España según Helen Nader, "estaban involucradas en un tipo de mecenazgo con una larga tradición en España: proporcionaban apoyo financiero a mujeres poetas y reformadoras religiosas"; por ejemplo, Juana de Mendoza fue mecenas de Teresa de Cartagena y dedicataria de su obra, mientras que Ana de Mendoza, María de Mendoza y Luisa de la Cerda fueron mecenas de Santa Teresa de Jesús. ${ }^{187}$ La propia Isabel de Aragón satisfacía las peticiones de Isabel de Baena, la religiosa del convento de Santa Clara de Alcalá de Henares que levantaba sospechas ante la Inquisición por su fama de santidad, a cambio de su consuelo espiritual, como demuestran las dos cartas de Isabel de Baena a la Duquesa del Infantado conservadas entre los documentos inquisitoriales del proceso contra Isabel Ortiz. ${ }^{188}$

El trabajo colectivo Power and Gender in Renaissance Spain editado por Helen Nader recoge ensayos sobre ocho mujeres de la familia Mendoza entre 1450 y 1650 con un foco biográfico, en los que encontramos varias referencias a la actividad musical de las mujeres Mendoza. ${ }^{189}$ Por ejemplo, se señala que la Princesa de Éboli era la encargada de organizar en Pastrana "festividades con música, baile y torneos" cuando su marido Ruy Gómez estaba ausente, y que ambos crearon colegios religiosos y conventos cuyas fundaciones eran celebradas “con procesiones, danzas y música en las que los

\footnotetext{
${ }^{187}$ Nader, ed., Power and Gender in Renaissance Spain, p. 1: "In the company of Mendoza women, the young queen would enjoy the companionship of Spain's most gifted and well-educated females"; p. 12: "The Mendoza women engaged in a type of patronage with a long tradition in Spain: they provided financial support to women poets and religious reformers".

188 "Proceso de fe de Isabel Ortiz”, ff. 52 y 63. Para una transcripción de las cartas, véanse Núñez, "Dos cartas de Sor Isabel de Baena a la Duquesa del Infantado"; y Castillo Gómez, Escrituras y escribientes, pp. 329-330. Véanse también Muñoz Fernández, Acciones e intenciones de mujeres, pp. 193-207; y González de la Peña, "Libros impresos de los siglos XV a XVII del convento de Santa Clara de Alcalá de Henares", p. 180.

${ }^{189}$ Las mujeres estudiadas son Juana Pimentel (†1484); Juana de Mendoza $(\dagger 1493)$; María de Pacheco; María de Mendoza y de la Cerda (1522-1567); Luisa de la Cerda (†1596), que no pertenecía a la familia Mendoza pero mostró las mismas capacidades; Magdalena de Bobadilla (1545-1580); Ana de Mendoza (1540-1592), princesa de Éboli; y Luisa de Carvajal y Mendoza (1566-1614).
} 
patrones participaban activamente", ${ }^{190}$ lo que muestra además la imbricación de la música en el mecenazgo de obras arquitectónicas. El libro de Helen Nader se centra en una de las dos ramas de la familia Mendoza, la rama Tendilla, por lo que las mujeres de la rama del Infantado, en particular las esposas de los Duques, no reciben atención en este libro. ${ }^{191}$ Una investigación desde la perspectiva musicológica de María Pimentel (III Duquesa del Infantado) e Isabel de Aragón (IV duquesa), así como de sus hijas y nueras (como María de Mendoza) puede conducir a importantes hallazgos; véase la Tabla VII.7.

${ }^{190}$ Helen H. Reed, "Mother Love in the Renaissance: The Princess of Éboli's Letters to Her Favorite Son", en Power and Gender in Renaissance Spain: Eight Women of the Mendoza Family, 1450-1650, ed. por Helen Nader (Urbana: University of Illinois Press; Bristol: University Presses Marketing, 2003), pp. 152-176, pp. 157-158.

191 Encontramos una situación similar en trabajos más recientes sobre el mecenazgo de las Mendoza. Juana Hidalgo Ogáyar, "La familia Mendoza, ejemplo de patronazgo femenino en la Edad Moderna", Nuevo Mundo-Mundos Nuevos, 2008 [Coloquio "Familia y organización social en Europa y América siglos XV-XX"; Murcia-Albacete 12-14 diciembre 2007]

$<$ http://nuevomundo.revues.org/index30593.html>, analiza las pautas del mecenazgo ejercido por ocho mujeres de la familia Mendoza relacionadas con Alcalá de Henares en el siglo XVI e inicios del XVII: María de Mendoza (c. 1522-1567), María de Mendoza "la Blanca" (1526-1580), Catalina de Mendoza (1542-1602), Beatriz de Cardona (†1631), Catalina Suárez de Mendoza y Cisneros (†c. 1597), Juana de Gamboa y Mendoza $(† 1625 / 1626)$, Juana de Mendoza y Zúñiga (†1587) y Beatriz de Mendoza y Zúñiga $(\dagger 1647)$. Hidalgo Ogáyar se ocupa, además, de las hermanas María y Mencía de Mendoza. 
Tabla VII.7: Esposas e hijas (en negrita) de los cuatro primeros Duques del Infantado

\begin{tabular}{|l|}
\hline I DUQUE: \\
Diego Hurta- \\
do de Mendo- \\
za $(1417-$ \\
$1479) \bigcirc$ \\
Brianda de \\
Mendoza y \\
Luna \\
\hline
\end{tabular}

II DUQUE:

Íñigo López de

Mendoza (1438-

1500) María

$\rightarrow$

de Luna

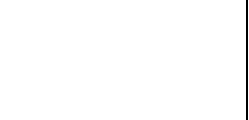

\section{HIJAS DEL I DUQUE}

\section{Catalina de}

Alfonso Ramírez

de Arellano

I DUQUE:

Diego Hurta-

do de Mendo-

za

Isabel

Henriques de

Noronha

\section{HIJAS DEL II} DUQUE

Mencía de

Mendoza y

Luna $(\dagger 1476) \propto$

Beltrán I (Fer-

nández) de la

Cueva

Mayor de Men-

doza $\propto$ Pedro

de Navarra

Ana de Mendo-

za $\propto$ Juan Pérez

de Cabrera y

Bobadilla

$\rightarrow$
Mendoza $\infty$

\begin{tabular}{|c|c|}
\hline $\begin{array}{l}\text { Catalina de } \\
\text { Mendoza } \propto \\
\text { Alfonso Ramírez } \\
\text { de Arellano }\end{array}$ & $\begin{array}{l}\text { Brianda de } \\
\text { Mendoza }\end{array}$ \\
\hline $\begin{array}{l}\text { María Hurtado } \\
\text { de Mendoza y } \\
\text { Luna }(\dagger 1506) \propto \\
\text { Diego Fernández } \\
\text { de Córdoba }\end{array}$ & $\begin{array}{l}\text { Francisca de } \\
\text { Mendoza } \\
(\dagger 1539) \propto \text { Luis } \\
\text { de la Cerda }\end{array}$ \\
\hline
\end{tabular}
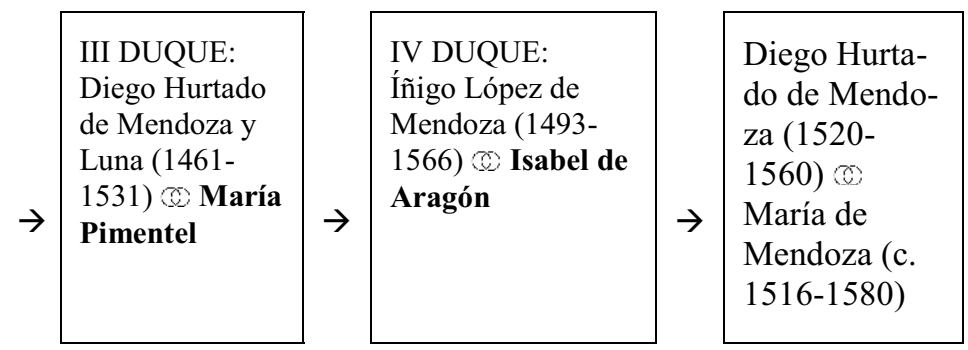

Beatriz de

Mendoza

Diego de Castilla

\begin{tabular}{|c|}
\hline $\begin{array}{l}\text { HIJAS DEL III } \\
\text { DUQUE }\end{array}$ \\
\hline $\begin{array}{l}\text { Ana de Mendoza } \\
\propto \text { Luis de la Cerda }\end{array}$ \\
\hline $\begin{array}{l}\text { María de } \\
\text { Mendoza }\end{array}$ \\
\hline $\begin{array}{l}\text { Elvira de } \\
\text { Mendoza }\end{array}$ \\
\hline $\begin{array}{l}\text { Brianda de } \\
\text { Mendoza } \\
\text { Alvar Gómez de } \\
\text { Ciudad Real }\end{array}$ \\
\hline $\begin{array}{l}\text { Francisca de } \\
\text { Mendoza } \\
\text { Sancho Paz }\end{array}$ \\
\hline $\begin{array}{l}\text { Mariana de } \\
\text { Mendoza } \propto \text { Diego } \\
\text { Arias Dávila; } \\
\text { Juan Arias } \\
\text { Dávila }\end{array}$ \\
\hline $\begin{array}{l}\text { Brianda de Men- } \\
\text { doza }\end{array}$ \\
\hline
\end{tabular}
DUQUE

Guiomar de

Mendoza y

Aragón $\propto$

Francisco de

Zúñiga

Sotomaior

Ana de

Mendoza y

Aragón

Luis Fer-

nández

Manrique

Brianda de

Mendoza y

Aragon
HIJAS DEL IV 
Dominique de Courcelles ha señalado que, en el caso de Cataluña, los círculos literarios promovidos por mujeres eran en el siglo XVI predominantemente espirituales y humanistas, mientras que en el siglo XV prevalecía la temática cortesana. ${ }^{192} \mathrm{El}$ proceso de fe de Isabel Ortiz proporciona información sobre las mujeres que rodeaban a Isabel de Aragón, IV Duquesa del Infantado, y muestra que ésta lideraba una red de mujeres (nobles, criadas, monjas) inmersas en la lectura devota y vinculadas a las reformas espirituales de la Guadalajara del siglo XVI. La lectura de libros devotos sugiere un posible enlace con otros entretenimientos espirituales como el canto de poesía devota. María Pimentel, esposa del III Duque del Infantado, y suegra de Isabel de Aragón, había sido la dedicataria de la edición de 1508 del Cancionero de diversas obras de nuevo trobadas, la colección de poesía publicada en Toledo por Ambrosio Montesino mencionada en el Capítulo VI. La Duquesa de Alburquerque y la Condesa de Coruña, probablemente las predecesoras en el título de las nobles para las que trabajó la música Isabel de Plazaola, también figuran entre las dedicatarias de los poemas de Montesino. Tal y como procede Ginzburg en El queso y los gusanos, la complementación de la información extraída de documentos inquisitoriales de Isabel Ortiz con el estudio de las prácticas musicales orales de la época permite entrever vestigios de una potencial actividad musical en torno a la Duquesa del Infantado.

El caso de Isabel de Aragón, IV Duquesa del Infantado, es complejo, pues quemó sus cartas y, además, nunca enviudó, lo que conduce a su invisibilidad en documentos históricos. En mi investigación en la Sección Nobleza del Archivo Histórico Nacional en Toledo he llevado a cabo un análisis de dos documentos con el propósito de profundizar en el tema: 1) el "Testamento original y copias autorizadas de Isabel de Aragón" (1563); y 2) el "Inventario de los bienes que dejaron los Duques del Infantado, Iñigo López de Mendoza e Isabel de Aragón” (1564 y 1566). ${ }^{193}$ La Duquesa del Infan-

\footnotetext{
${ }^{192}$ Véase Dominique de Courcelles, "Recherches sur les livres et les femmes en Catalogne aux XVe et XVIe siècles: figures de lectrices", en Des femmes et des livres: France et Espagnes, XIVe-XVIIe siècle: Actes de la Journée d'Étude organisée par l'École Nationale des Chartes et l'École Normale Supérieure de Fontenay Saint-Cloud (Paris, 30 avril 1998), ed. por Dominique de Courcelles y Carmen Val Julián (Génova: Librairie Doz, 1999), pp. 95-114, p. 114: "Mientras que en el siglo XV los círculos literarios animados por las mujeres en Cataluña son todavía predominantemente cortesanos, en el siglo XVI son predominantemente humanistas y espirituales" ["Tandis qu'au $\mathrm{XV}^{\mathrm{e}}$ siècle les cercles littéraires animés par les femmes en Catalogne sont encore à dominante courtoise, au XVIe siècle ils sont à dominante humaniste et spirituelle"].

${ }^{193}$ Toledo, Sección Nobleza del Archivo Histórico Nacional, Osuna, C.1763, D.14; y C.1834, D.1-2, respectivamente.
} 
tado hizo testamento en Guadalajara a 18 de febrero de $1563{ }^{194}$ la única referencia musical que encontramos en este documento es su provisión de que en la iglesia donde fuese sepultada le dijeran durante un año una misa cantada cada día. ${ }^{195}$ La Duquesa del Infantado murió el 22 de mayo de 1564, cinco días después de que la Marquesa de Távara acusase ante la Inquisición a Isabel Ortiz y comenzase su proceso. El 31 de mayo Íñigo López de Mendoza pidió que se hiciera inventario de los bienes de su esposa y éste se llevó a cabo entre los meses de junio y agosto. En el inventario encontramos algunos libros de música y, sobre todo, numerosos instrumentos musicales.

Como muestran la Ilustración VII.4 y la Tabla VII.8, los libros de música que tenía Isabel de Aragón ascienden a doce, agrupados por tamaños (cuatro libros grandes, cinco medianos y tres pequeños). Por su formato, los libros de música de Isabel de Aragón eran libros de repertorio musical, probablemente de música vocal polifónica, como el libro de Josquin, el único descrito más allá de sus características físicas ("libro grande guarneçido de dos tablas con un cuero colorado de las misas de jusquin"), que podría ser identificado como el Liber quindecim missarum (Roma: Antico, 1516), con misas de Josquin, Brumel, Févin, La Rue, Mouton, Pipelare y Rosselli, o como el Liber quindecim missarum (Nüremberg: Petreius, 1539), con misas de Breitengrasser, Brumel, Isaac, Josquin, La Rue, Layolle, Lupi, Moulu y Ockeghem. ${ }^{196}$ Es llamativo que en el inventario de la Duquesa del Infantado no haya secciones dedicadas a libros de otras materias.

\footnotetext{
194 “Testamento original y copias autorizadas de Isabel de Aragón”, f. 1v.

195 “Testamento original y copias autorizadas de Isabel de Aragón”, f. 2v.

196 Ros-Fábregas, "Libros de música en bibliotecas españolas del siglo XVI" (II), p. 37, señala que el Liber quindecim missarum es una de las publicaciones "que se encuentra con más frecuencia en las bibliotecas españolas del siglo XVI".
} 
Ilustración VII.4: Libros de música en el inventario post-mortem de Isabel de Aragón, IV Duquesa del Infantado (1491-1564) [MINISTERIO DE CULTURA, Sección Nobleza del Archivo Histórico Nacional, ES.41168.SNAHN/121.4.12//OSUNA,C.1834,D.2, f. xii].

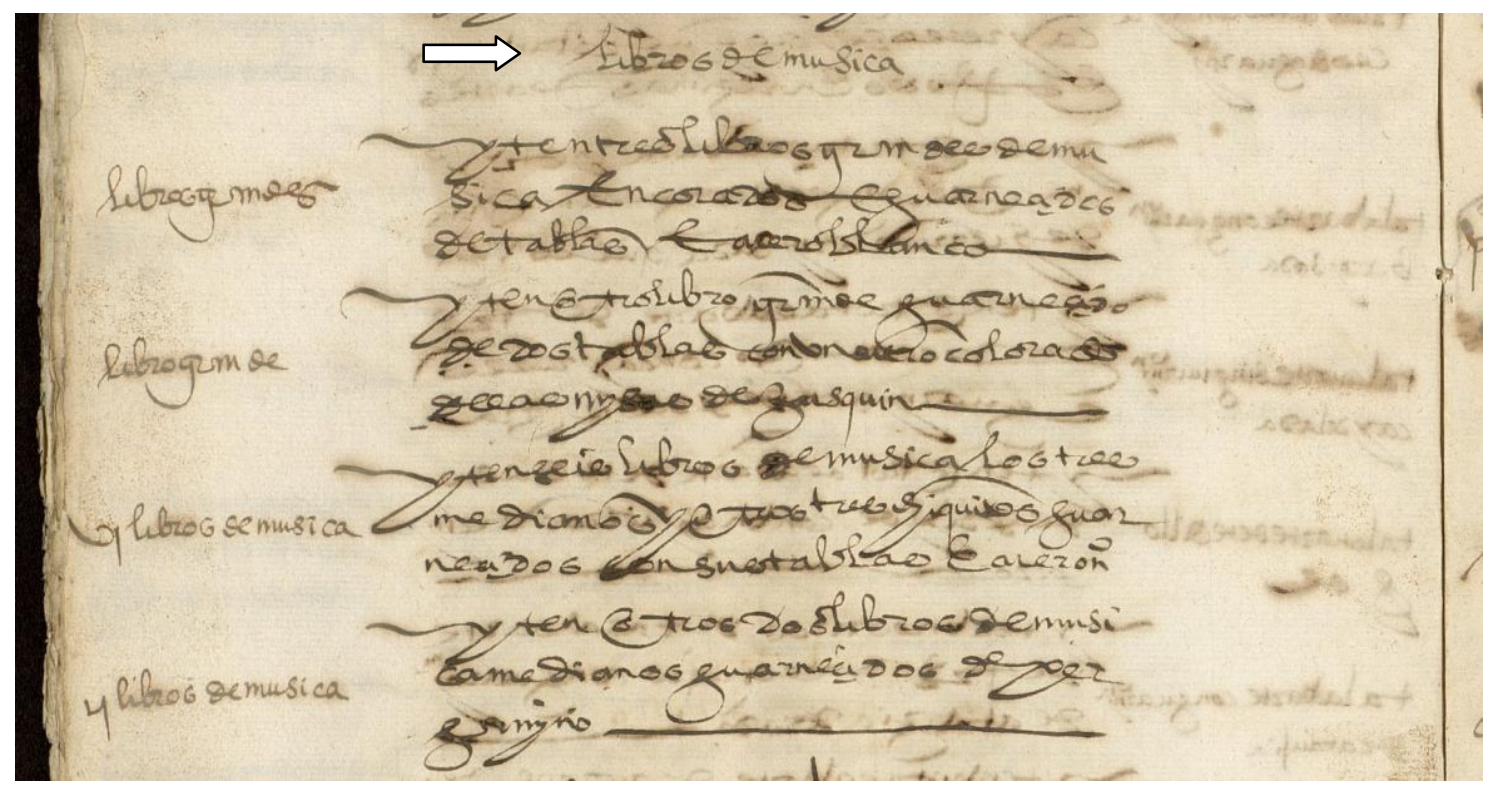

Tabla VII.8: Libros de música en el inventario post-mortem de Isabel de Aragón, IV Duquesa del Infantado (1491-1564). "Inventario de los bienes que dejaron los Duques del Infantado, Iñigo López de Mendoza e Isabel de Aragón”. Toledo, Sección Nobleza del Archivo Histórico Nacional, Osuna, C.1834, D.2, f. xii

Ítems

[1] yten tres libros grandes de musica encorados e guarneçidos de tablas e cuero blanco

[2] yten obro libro grande guarneçido de dos tablas con un cuero colorado de las misas de jusquin

[3] yten seis libros de musica los tres medianos otros tres chiquitos guarneçidos con sus tablas e cuero negro

[4] yten otros dos libros de musica medianos guarneçidos de pergamino

En 1566 Enrique de Aragón y de Mendoza y Alvar de Mendoza y de Aragón, como herederos universales del Duque y la Duquesa del Infantado, pidieron que se tasaran los bienes de sus padres. En el documento resultante aparece la tasación de los libros de música de la Duquesa, llevada a cabo el 19 de junio de 1567 por el músico An- 
tonio Martínez. ${ }^{197}$ Seguramente se trata del mismo Antonio Martínez mencionado en los documentos inquisitoriales del proceso de Isabel Ortiz, que era músico de la IV Duquesa de Coruña en Guadalajara y que impartía clases de música a algunas mujeres del entorno de Isabel Ortiz, entre ellas, probablemente, Isabel de Plazaola. ${ }^{198}$ Los tres libros grandes sin identificar se vendieron a 8 ducados, mientras que 20 ducados fue el precio de venta del libro de misas de Josquin. El lote de tres libros medianos y tres pequeños fueron tasados en 6 ducados. El último lote, que según el inventario de 1564 constaba de dos libros medianos, se describe en la tasación como integrado por tres libros medianos tasados en 4, 3 y 1 ducados, respectivamente.

La colección de instrumentos de música de la Duquesa del Infantado es sorprendente y seguramente es una de las mejores de su época. ${ }^{199}$ Bajo el encabezado "arpas viguelas y clavecinbanos", en su inventario post-mortem encontramos una larga lista de instrumentos musicales: dos claviórganos, cuatro clavicémbalos, siete arpas, tres laúdes, una vihuela, dos vihuelas de arco, una vihuela tumbada, una guitarra, siete flautas de Flandes, tres dulzainas, un pífano, una flauta doble y ocho orlos; véanse la Ilustración VII.5 y la Tabla VII.9. El inventario de Isabel de Aragón proporciona en algunos casos información de la procedencia de los instrumentos musicales, el medio por el que fueron adquiridos o el constructor de los mismos. Por ejemplo, uno de los claviórganos fue comprado en Toledo (Tabla VII.9, $n^{\circ} 4$ ) y un clavicémbalo pequeño se le había comprado a un fraile (Tabla VII.9, $\mathrm{n}^{\mathrm{o}}$ 6). Además de instrumentos comprados, encontramos otros regalados; el doctor Laguna le había dado a Isabel de Aragón un clavicémbalo (Tabla VII.9, $\mathrm{n}^{\circ}$ 5).

\footnotetext{
197 “Inventario de los bienes que dejaron los Duques del Infantado...”, D.1, f. 54.

${ }^{198}$ Véase el Apéndice 18, Fragmento 42.

199 Trabajos recientes basados en inventarios muestran que las mujeres poseían instrumentos musicales. En Valladolid, Isabel de Santisteban (ya mencionada como propietaria de un ejemplar del libro de Martínez de Bizcargui) poseía un clavicordio, un arpa, un órgano y una vihuela de mano; Juana Manrique tenía una guitarra; e Isabel Rodríguez, un pandero; véase Diego Pacheco, "Beyond Church and Court", pp. 372-373. En Sevilla, Catalina de Bobadilla tenía una vihuela; aunque Griffiths, "Hidalgo, Merchant, Poet, Priest", p. 363, afirmaba que Catalina de Bobadilla es una de las pocas mujeres poseedoras de instrumentos de las que se encuentra evidencia en documentos de archivo, en esta Tesis Doctoral se docuemnta la posesión de instrumentos por parte de varias mujeres.
} 
Ilustración VII.5: Instrumentos musicales en el inventario post-mortem de Isabel de Aragón, IV Duquesa del Infantado (1491-1564). [MINISTERIO DE CULTURA, Sección Nobleza del Archivo Histórico Nacional, ES.41168.SNAHN/121.4.12//OSUNA,C.1834,D.2, f. 13].

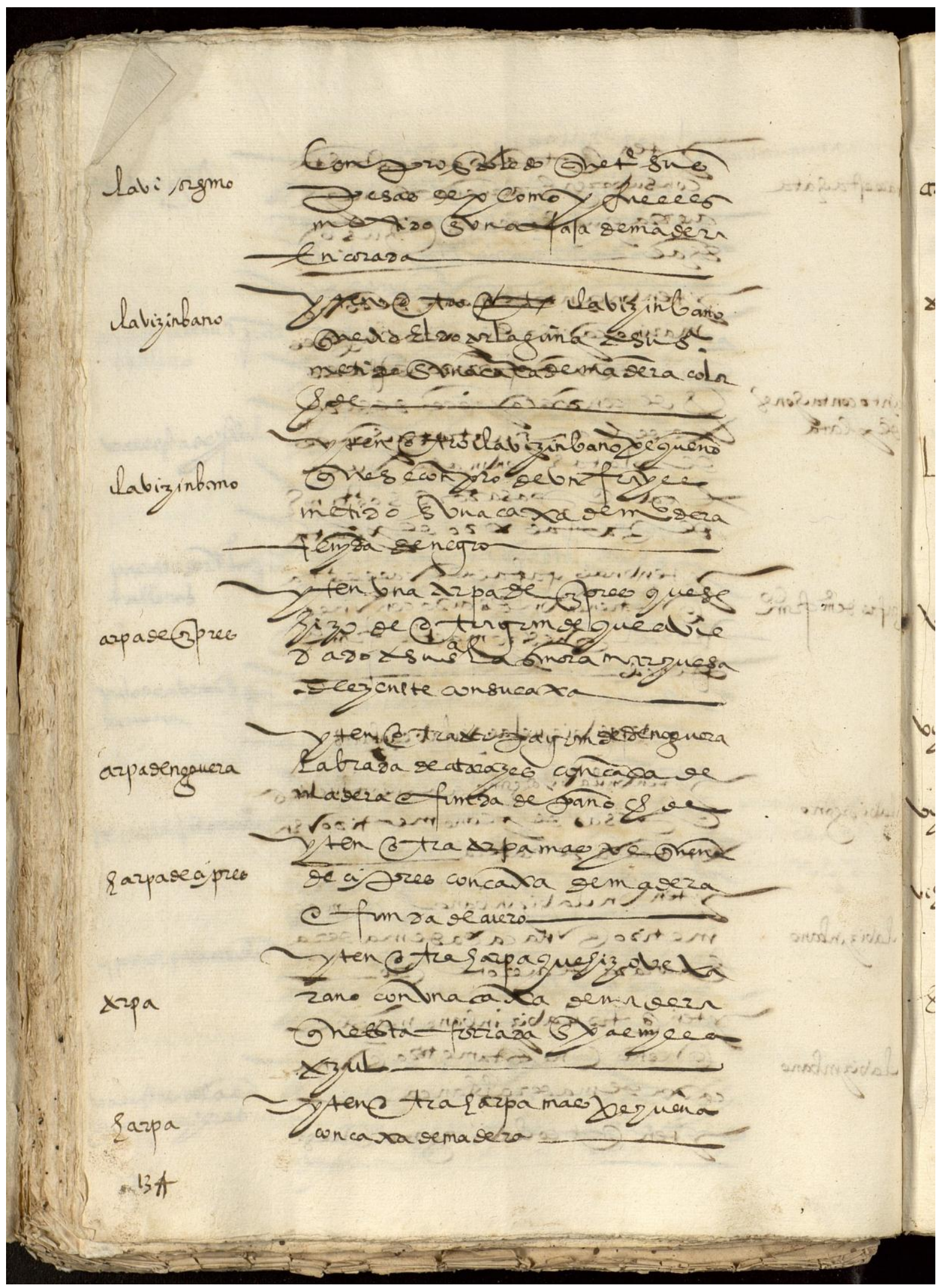


Tabla VII.9: "Arpas viguelas y clavecinbanos" en el inventario post-mortem de Isabel de Aragón, IV Duquesa del Infantado (1491-1564). "Inventario de los bienes que dejaron los Duques del Infantado, Iñigo López de Mendoza e Isabel de Aragón”, Toledo, Sección Nobleza del Archivo Histórico Nacional, Osuna, C.1834, D.2 (año 1564), ff. 13-14

\section{Ítems}

[1] yten un clavi organo con sus fuelles y pesas de plomo metido en una caxa de madera

[2] yten un clavizinbano grande metido en una caxa de madera encorada de cuero negro

[3] yten otro clavizinbano mas pequeño que esta metido en una caxa de madera blanca

[4] yten otro clavi organo que se compro en toledo que tiene sus pesas de plomo y fuelles metido en una caja de madera encorada

[5] yten otro clavizinbano que dio el dotor laguna a su señora metido en una caxa de madera color verde

[6] yten otro clavizinbano pequeño que se compro de un frayle metido en una caxa de madera teñida de negro

[7] yten una arpa de cipres que se hizo de otra grande que auia dado a su señora la señora marquesa del zenete con su caxa

[8] yten otra arpa grande de noguera labrada de atarazes con caxa de madera e funda de paño verde

[9] yten otra arpa mas pequeña de cipres con caxa de madera e funda de cuero

[10] yten otra harpa que hizo vexarano con una caxa de madera que esta forrada en palmilla azul

[11] yten otra harpa mas pequeña con caxa de madera

[12] yten otra arpa de hevano de muy rica labor de atarazes con medallas de marfyl con su caxa de madera blanca

[13] yten otra arpa que la hizo vexarano con caxa de madera

[14] yten un laud grande con caxa aforrada en paño colorado

[15] yten otros dos laudes con caxas de madera aforradas en cuero negro

[16] yten vihuela grande con cortezas de brayl e algunas pinturas de atarazes con caxa de madera que esta aforrada con un pañuelo de paño colorado porde dentro

[17] yten una viguela de arco grande

[18] yten otra viguela de arco pequeña

[19] yten otra viguela de hechura de tunba [¿vihuela con fondo tumbado?] que hizo vejarano con su caxa de madera teñida de negro

[20] yten una guitarra comun con una funda de faseta parda vieja

[21] yten otra caxa de flautas de flandes con syete piezas que es de madera aforrada en cuero negro y la una flauta dellas es pequeña que se dize zabeua [axabeba (flauta travesera morisca)]

[22] yten otra caxa de duzaynas de madera guarneçida de cuero negro vieja e quebrada que tiene tres piezas que la mayor esta des [...]

[23] yten otra caxa de madera vieja quebrada que tiene ocho piezas de orlos de palo amarillo a trozos chicos e grandes [...] que el uno grande [..] esta quebrado

[24] yten un pifano con dos cabos de hueso [...]

[25] yten dos flautas pegadas una a otra 
Es sumamente interesante el caso del "arpa de cipres que se hizo de otra grande que auia dado a su señora la señora marquesa del zenete con su caxa", puesto que sugiere que probablemente la Duquesa mandase modificar un arpa que le había regalado la Marquesa del Cenete (Tabla VII.9, $\mathrm{n}^{\mathrm{o}}$ 7). Probablemente se trate de María de Mendoza (c. 1516-1580), nuera de la IV Duquesa del Infantado al casarse con Diego Hurtado de Mendoza. ${ }^{200}$ Puesto que Mencía de Mendoza había muerto en 1554, la Marquesa del Cenete a la que se refiere Ginesa de Villalobos en el proceso inquisitorial contra Isabel Ortiz debe de ser María: "que no se acuerda quando le dixo a esta la dicha ysabel ortiz que las criadas de la marquesa de zenete la querian infinito y hazian lo que ella les pedia" ${ }^{201}$ Como indiqué anteriormente, María de Mendoza había recibido una formación musical desde la infancia en el ámbito doméstico de su castillo de Ayora (Valencia) junto a sus hermanas Mencía y Catalina. Mencía de Mendoza, tras casarse en 1524 con Enrique de Nassau, se convirtió en la tutora de su hermana, llevándola con ella a los Países Bajos, ${ }^{202}$ y concertó su boda con el hijo de la IV Duquesa del Infantado en 1534. ${ }^{203}$ María de Mendoza iba a ser Duquesa del Infantado, pero su marido murió antes

\footnotetext{
${ }^{200}$ Respecto a la fecha de fallecimiento de María de Mendoza, el inventario de sus pertenencias que se inició el 26 de septiembre de 1580 en su casa de Madrid (Toledo, Sección Nobleza del Archivo Histórico Nacional, Osuna, C.1835, D.1-13) comienza diciendo que "hará ocho días que ha muerto esta señora"; citado en Juana Hidalgo Ogáyar, "Doña María de Mendoza: ejemplo de pervivencia del coleccionismo medieval en el siglo XVI", en Congreso Internacional Imagen Apariencia. Noviembre 19, 2008 - noviembre 21, 2008. Murcia: Universidad de Murcia, Servicio de Publicaciones, 2009

$<$ http://congresos.um.es/imagenyapariencia/imagenyapariencia2008/paper/view/1351/1331>.

Encontramos el "Inventario y particiones de los bienes dejados al fallecimiento del conde de Saldaña, Diego Hurtado de Mendoza y de la marquesa del Cenete, María de Mendoza y otros papeles relacionados con la testamentaria" (1560-1587) en Toledo, Sección Nobleza del Archivo Histórico Nacional, Osuna, C.1835, D.1-16. En esta investigación he consultado el documento Osuna, C.424, D.16 que, según la catalogación del Archivo, corresponde al "Testamento de María de Mendoza, [futura III marquesa del Cenete], hija de Rodrigo de Mendoza Vivar, [I] marqués del Cenete y María de Fonseca, [(I)] marquesa de Cenete" (Burgos, 1535). Sin embargo, parece haber una confusión, puesto que no se trata del testamento de María de Mendoza, sino del de su hermana Mencía. El "Testamento original y copias autorizadas de María de Mendoza y Fonseca" data de 1565 y su signatura es Osuna, C.1763, D.16. En la Colección Salazar y Castro hay numerosos documentos sobre María de Mendoza, incluyendo cartas de Felipe II y una copia de su testamento; véase "Testamento de doña María de Mendoza, III marquesa del Cenete, condesa de Saldaña" (Alcalá de Henares, 1565), Madrid, Biblioteca de la Real Academia de la Historia, Colección de don Luis de Salazar y Castro, M-19, ff. 64-68. El Archivo Nacional de Cataluña en Sant Cugat del Vallès (Barcelona) ingresó en 2011 el Archivo del Palau-Requesens que incluye documentación de la casa Calabria-Cenete, como libros de cuentas del marquesado de Cenete y correspondencia de Mencía de Mendoza.

${ }^{201}$ Véase el Apéndice 18, Fragmento 12.

${ }^{202}$ Hidalgo Ogáyar, "Doña María de Mendoza".

203 "Capitulaciones matrimoniales de Diego Hurtado de Mendoza con María de Mendoza" (1534), Toledo, Sección Nobleza del Archivo Histórico Nacional, Osuna, C.1774, D.1(1).
} 
que su padre. Como la Condesa de Coruña y la Duquesa del Infantado, María de Mendoza tenía residencia en Guadalajara puesto que el IV Duque del Infantado dio a su hijo la casa que el Cardenal Mendoza había construido en Guadalajara:

[...] una vez que hubo regresado a España en 1534 para casarse con el Conde de Saldaña, no se movió del entorno de Guadalajara, ocupándose especialmente de aquellas cosas que eran las más usuales en la vida de una mujer noble, como era contar con una renta adecuada a su categoría social y, además, ser una buena cristiana, una buena esposa y una buena madre, preocupándose, sobre todo, por la educación y el bienestar de sus hijos. ${ }^{204}$

El inventario de Isabel de Aragón también indica que Bejarano es el constructor de dos de las arpas y de la vihuela tumbada de la duquesa (Tabla VII.9, $\mathrm{n}^{\mathrm{os}} 10,13$ y 19). Los Vázquez de Miranda Bejarano fueron una familia de violeros y tañedores activa en Madrid en los siglos XVI y XVII. Luis Robledo Estaire señala que la primera referencia a esta familia "la encontramos en la nómina de los criados del duque del Infantado correspondiente a 1564" en la que se detalla "a hernando bejarano y a su hijo, mis musicos de viguela de arco, 24000 mrvs". ${ }^{205}$ Puesto que los violeros de los que se tenía noticia trabajaron en una época posterior, el inventario de la Duquesa sugiere que quizás los Bejarano del siglo XVI también construyeran instrumentos. ${ }^{206}$ Encontramos más ítems de interés musical en otros lugares del inventario de la Duquesa. En un apartado titulado "cosas diferentes", dentro de las "cosas que estan en la recamara", hay, entre otras pertenencias, algunos libros de devoción (sobre todo libros de Horas), "una guitarra” y cuerdas para arpa, vihuela y clavicordio. ${ }^{207}$

\footnotetext{
${ }^{204}$ Hidalgo Ogáyar, "Doña María de Mendoza".

${ }^{205}$ Luis Robledo Estaire, "La música en la casa de la Reina, Príncipe e Infantas", en Aspectos de la cultura musical en la Corte de Felipe II, ed. por Luis Robledo Estaire, Tess Knighton, Cristina Bordas Ibáñez y Juan José Carreras (Madrid, Fundación Caja Madrid, Editorial Alpuerto, 2000), pp. 195-212, pp. 207208.

${ }^{206}$ Véanse Cristina Bordas y Matilde Olarte, "Vázquez de Miranda Bejarano”, en Diccionario de la música española e hispanoamericana, ed. por Emilio Casares Rodicio (Madrid: Sociedad General de Autores y Editores, 1999-2002), vol. 10, p. 766; Xosé Crisanto García, "El violón ibérico", Revista de Musicologia, XXII/2 (1999), pp. 123-163, p. 134; y Robledo Estaire, "La música en la casa de la Reina, Príncipe e Infantas", p. 207.

207 "Inventario de los bienes que dejaron los Duques del Infantado", D.2, s.f.: "yten media gruesa de cuerdas de arpa y biguela de quintas y sestas y dos dozenas de segundas de [...] e dos dozenas de quartas de a dos y los de cuenca e quatro vordones gruesos"; "yten cuarenta y seis cuerdas de azero para el clavicordio".
} 
Llama la atención que los instrumentos del inventario de Isabel de Aragón sean los mismos que González Ramos había identificado como propiedad de Íñigo López de Mendoza, IV Duque del Infantado. ${ }^{208}$ Parece, por tanto, que los instrumentos que eran propiedad de Isabel de Aragón pasaron a su viudo; no fueron tasados en 1567 para su venta junto a los libros de música de la Duquesa. ${ }^{209}$ Pero sobre todo es llamativo que la colección de instrumentos del Duque se haya considerado evidencia de una "declarada afición por la ejecución musical personal”, cuando en realidad los había heredado de su esposa. ${ }^{210}$ La espléndida colección de instrumentos musicales de Isabel de Aragón, IV Duquesa del Infantado, es una clara evidencia de su mecenazgo musical, pero también es un ejemplo paradigmático de cómo la actividad musical de las mujeres de la época ha permanecido invisible en los documentos históricos.

Partiendo de una aproximación musical a los documentos de la Inquisición relacionados con el proceso contra Isabel Ortiz es posible vislumbrar huellas de potenciales actividades invisibles a simple vista que sugieren que las mujeres estaban más profundamente involucradas en la vida musical de lo que sugieren los restrictivos tratados de conducta femenina de la época. Sabemos de la música Isabel de Plazaola sólo por casualidad, es decir, porque su madre fue procesada por la Inquisición. Incluso el pleito litigado por Isabel de Plazaola al ser despedida por la Duquesa de Alburquerque no mencionaba su calidad de música, por lo que no es aventurado pensar que contratos todavía no estudiados aporten datos de actividad musical por parte de otras mujeres al servicio de la nobleza. Analizando el caso aisladamente, como un tipo de estudio microhistórico, es difícil determinar en qué medida Isabel de Plazaola es representativa de la formación musical de las mujeres músicas de su época. Sin embargo, la documenta-

\footnotetext{
${ }^{208}$ González Ramos, "Evolución cultural y contraste generacional”, p. 33.

${ }^{209}$ Sí se tasaron y vendieron ocho cornetas el 15 de febrero por Francisco Osorio; véase "Inventario de los bienes que dejaron los Duques del Infantado...", D.1, f. 30r.

${ }^{210}$ González Ramos, “Evolución cultural y contraste generacional”, p. 33.
} 
ción inquisitorial del proceso de Isabel Ortiz demuestra que, como en El queso y los gusanos, "pequeños hechos hablan de grandes cuestiones". 211

La documentación inquisitorial ha permitido conocer que Isabel de Plazaola recibió formación musical dentro de su ámbito doméstico, que esta música era conocida y empleada por importantes mujeres de la nobleza (y tal vez de la realeza), y que estuvo a las puertas de tener una carrera internacional, lo que conduce a preguntarse si era usual que la esfera privada de la música doméstica condujese a tal proyección. Además, este expediente inquisitorial presenta vestigios de la doble consideración moral que se tenía de la música y funciona como un hilo conductor que abre nuevas vías de investigación, como sugiere el interés musical del rico inventario de la Duquesa del Infantado.

En esta investigación se ha hecho evidente el grado de imbricación de la música en la cultura del mundo ibérico renacentista, como parte integrante del culto religioso, de las costumbres sociales y de las celebraciones en cualquier estrato socioeconómico; como vehículo de la poesía; como parte de las obras teatrales; y como remedio contra las enfermedades del alma y del cuerpo. Frente a la restrictiva imagen que los tratados de conducta femenina presentan, y a pesar de su restringida actuación en el ámbito público (como el mecenazgo de libros de música), fuentes como los documentos inquisitoriales muestran que las mujeres participaban en la vida musical desde diferentes niveles de competencia. La aproximación a la cultura musical de la época a través de las artes de canto y de la historia de las mujeres proporciona evidencia de la importancia intrínseca de la música en el todo cultural y permite vislumbrar trazas de la cultura popular de la época, cuya reconstrucción depende sin duda de la imaginación del historiador. ${ }^{212}$ Carlo Ginzburg señalaba con respecto a su libro El queso y los gusanos que "reduciendo la escala de observación, lo que para otro estudioso podría haber sido una simple nota al pie en una hipotética monografía sobre la Reforma Protestante en Friuli se transformó

\footnotetext{
${ }^{211}$ Geertz, “Thick Description”, p. 23.

212 Treitler, Music and the Historical Imagination, p. 1; Amelang, "Microhistory and Its Discontents", p. 310: "El procedimiento microhistórico se basa fuertemente, aunque no exclusivamente, en lo que Ginzburg ha llamado el paradigma circunstancial o evidencial (paradigma indiziaro), es decir, el alegre reconocimiento del papel crucial que la imaginación y la buena disposición a la conjetura del historiador juegan en la construcción del conocimiento histórico" ["Microhistorical procedure relies heavily, although not exclusively, on what Ginzburg has called the circumstantial or evidential paradigm (paradigma indiziaro), that is, cheerful recognition of the crucial role the historian's imagination and willingness to conjecture play in the construction of historical knowledge"].
} 
en un libro". ${ }^{213}$ De modo similar, casos como el de la IV Duquesa del Infantado o el de Isabel de Plazaola, que habían pasado desapercibidos, y de hecho Plazaola es sólo una nota al pie de página en el trabajo de Milagros Ortega Costa sobre el proceso de Isabel Ortiz, hablan de grandes cuestiones sobre la vida musical en el mundo ibérico del siglo XVI.

\section{RESUMEN DEL CAPÍTULO VII}

En este Capítulo se investigan fuentes diferentes a los libros de música, como tratados de conducta femenina, documentos inquisitoriales, cuentos populares, tratados de medicina e inventarios, entre otras. Mediante el empleo de metodologías tomadas de los historiadores de la cultura popular, se pone de manifiesto que, en contraste con la restrictiva panorámica que ofrecen los manuales de conducta femenina, las mujeres participaban activamente en la vida musical como mecenas, creadoras e intérpretes, tanto aficionadas como profesionales, y que eran reconocidas por ello.

Como la tragedia griega, los tratados de conducta femenina proporcionaban voz a la mujer (el Otro) y la controlaban simultáneamente. Al comparar los tratados de conducta femenina (con especial énfasis en los de Juan Luis Vives, Fray Luis de León y Juan de la Cerda) con la información que proporcionan las reglas de los colegios femeninos y estudiar sus consejos sobre la conveniencia de que las mujeres leyeran libros, se observa que los tratados de conducta femenina distinguen entre libros no recomendables y lecturas honestas, pero se refieren a la música en sentido genérico. La "música" a la que aluden los libros de conducta se relaciona con el ocio (fiestas y convites) y con el concepto negativo de emociones como "accidentes del alma", por lo que el rechazo de la música en los tratados de conducta femenina publicados en España no alude a la música como instrumento de devoción. La ausencia de distinción entre música honesta y deshonesta puede deberse a que la música religiosa no se concebía como una abstracción desligada de su funcionalidad religiosa y de los procesos en que se integraba. Las prescripciones de los tratados de conducta contrastan con la realidad musical que indican otras fuentes. Algunas de las mujeres de clase media-alta (destinatarias de los tratados de conducta) tenían una rica formación musical; un ejemplo es Mencía de Mendoza, alumna de Juan Luis Vives. La literatura y documentos inquisitoriales presentan casos de mujeres músicas muy estimadas en su época y demuestran que, más allá de los tratados, existía una educación musical en el ámbito privado raramente reflejada en documentos escritos.

Los juegos cortesanos, el papel de la música en el teatro, los documentos literarios y el lugar ocupado por la música en los tratados de medicina muestran la imbricación de la música en la cultura de la época. Los documentos literarios estudiados en este Capítulo proporcionan indicios de ósmosis entre el medio teatral y los ámbitos conven-

${ }^{213}$ Ginzburg, "Microhistory", p. 22: "In reducing the scale of observation, that which for another scholar could have been a simple footnote in a hypothetical monograph on the Protestant Reformation in Friuli was transformed into a book". 
tual y cortesano, y sugieren que la conexión entre el surgimiento de actrices profesionales y músicas profesionales en las dos últimas décadas del siglo XVI es similar en el contexto ibérico a la realidad que documenta Anthony Newcomb en Italia. En los manuales de medicina de la época encontramos referencias a la música como remedio contra las enfermedades del cuerpo y del alma.

Este Capítulo presenta el primer estudio desde la perspectiva musicológica de los documentos inquisitoriales relacionados con el conocido proceso de fe (1564-1565) de Isabel Ortiz. Esta documentación aporta información sobre la hija de la procesada, Isabel de Plazaola, una música profesional del siglo XVI ajena a los ámbitos cortesano y conventual (véase el Apéndice 18). Esta mujer música debió nacer en 1542 ó 1543, se formó en el ámbito doméstico y sabía leer, escribir y rezar (le enseñó Alvar Gómez, sobrino de Luis Gómez, médico del Duque del Infantado). Plazaola recibió clases particulares de música en su casa de los profesores Miguel Sánchez, cantor de Toledo de 20 años; Garci González, músico de la Catedral de Toledo de 53 años; y Antonio Martínez, músico de la Condesa de Coruña. La relación de Ortiz con un grupo de mujeres nobles con las que supuestamente trataba cuestiones de devoción debió de estar motivada también por las habilidades musicales de Plazaola, puesto que estas nobles pedían a Ortiz que les llevase a su hija para que cantase y tocase en sus casas. Seguramente Plazaola fue también el origen de la relación de Ortiz con la monja Isabel de Baena, que tenía reputación de santa; Ortiz quiso que su hija (cuando tenía unos 14 años) ingresase en el Convento de Santa Clara de Alcalá de Henares (seguramente como música) y, posteriormente, las dos visitaron el convento con frecuencia. Durante esas visitas Plazaola cantaba y tocaba, por lo que no se puede descartar que también enseñara música a las monjas. Del proceso inquisitorial de Ortiz se extrae información sobre la presencia y el estatus moral de la música en la vida cotidiana de la época. Los testigos reprobaban que la casa de Ortiz fuese visitada por tañedores, pero Ortiz afirmaba en su declaración que la música era algo "virtuoso", que se había utilizado sin embargo para hablar mal de ella, y que había educado a su hija en la música como una obra de devoción.

El registro de un litigio de 1575 de Isabel Ortiz contra la Duquesa de Alburquerque por haber cancelado sin motivo el acuerdo por el cual su hija la serviría como música en Milán supone una aportación nueva a los estudios sobre Isabel Ortiz llevados a cabo en otras disciplinas; en 1575 aún vivía y se define como viuda (véase el Apéndice 19). En este documento nunca se hace referencia a su hija Isabel de Plazaola como música, sino como criada, aunque se habla de su "calidad", "habilidad" y "arte". En este Capítulo hago referencia a otros tres documentos que ofrecen información sobre músicos de la época: un documento inquisitorial de 1570 que tiene como protagonista al músico Antonio de Torres, de 20 años, que tenía una escuela de danza en Madrid; el pleito de 1560 por una deuda litigado por el músico Ginés Bezón contra Antonio de Fonseca, regidor de Toro (Zamora), a quien servía; y la licencia solicitada para que el cantor Juan de Villarrubia pasase a México para servir en la Iglesia Metropolitana.

Isabel de Plazaola abre una vía para la investigación desde la perspectiva musicológica de un círculo de mujeres interesadas en la música a la cabeza de las cuales se encontraba la IV Duquesa del Infantado en Guadalajara. Entre ellas estaban Leonor Enríquez de Toledo, II Marquesa de Távara, para quien trabajó Plazaola en Alcalá de Henares; Catalina de la Cerda, IV Condesa de Coruña, para quien Plazaola trabajó en Guadalajara; Juana de la Lama, IV Duquesa de Alburquerque, que fue avalada por dos familiares para contratar a Plazaola, por hacerlo sin licencia de su marido; María de Mendoza, Marquesa del Cenete, establecida en Guadalajara y nuera de la Duquesa del Infantado, que tuvo conexión con Isabel Ortiz; y Juana de Austria, que pudo estar interesada en 
contratar a Isabel de Plazaola. El proceso inquisitorial contra Rodrigo de Bivar, cantor del Duque del Infantado, aporta el nombre de otros músicos: Diego de Espinosa (nacido c. 1498), chirimía; Gascón, trompeta; Viana, "contrabaxa"; Torres, "tañedor"; Jerónimo de Sotomayor, sacabuche"; y Juan de Morales, sacabuche. La IV Duquesa del Infantado no sólo lideraba un grupo de mujeres inmersas en la lectura de devoción, sino que, al igual que su predecesora la III Duquesa, es posible que también promoviera el canto de poesía de temática devocional, como indican las dedicatorias de los poemas de Ambrosio Montesino. El inventario de la Duquesa del Infantado en la Sección Nobleza del Archivo Histórico Nacional permite documentar su importante colección de libros e instrumentos musicales y la práctica de regalar instrumentos entre mujeres: la Marquesa de Cenete (seguramente María de Mendoza) había dado a la Duquesa un arpa que después fue modificada. El inventario de la Duquesa del Infantado también muestra que los Vázquez de Miranda Bejarano del siglo XVI eran, además de músicos, constructores de instrumentos. Sin embargo, resulta de especial relevancia el que esta espléndida colección de instrumentos musicales se hubiera considerado anteriormente como propiedad del IV Duque del Infantado y no de su esposa, lo que muestra una vez más la invisibilidad de las mujeres en las narrativas históricas tradicionales. 



\section{CONCLUSIONES}

En estas Conclusiones presento los principales resultados de la investigación, mientras que otras aportaciones más concretas se resumen en detalle al final de cada capítulo. El análisis de las artes de canto impresas en el mundo ibérico entre 1492 y 1626 confirma el interés de una historia de la música contada por libros en formato octavo, muy diferente de la que cuentan los libros en formato folio, normalmente en latín, y a los que muy pocos podían acceder. Este estudio ha permitido presentar, desde una nueva perspectiva, la vida musical de la época a través de las artes de canto, generalmente consideradas carentes de interés, y de su relación con las mujeres, insuficientemente representadas en la historiografía musical.

Las artes de canto impresas en el mundo ibérico renacentista eran, como he mostrado en esta Tesis Doctoral, libros para aprender los fundamentos de la música y no sólo canto gregoriano. El estudio de las artes de canto siguiendo la metodología de los historiadores del libro evidencia que el énfasis en la polifonía renacentista no había permitido advertir la importancia de los manuales de canto llano como difusores del alfabetismo musical. Las artes de canto se imprimieron en tiradas de miles de ejemplares y eran vendidas a bajo precio, tuvieron una enorme circulación en la Península Ibérica y el Nuevo Mundo, y contribuyeron al incremento y la difusión de la educación musical en contextos educativos diferenciados (la iglesia, la universidad y el ámbito privado) y entre grupos sociales hasta entonces excluidos del aprendizaje de los fundamentos de la música. Estos libros, en los que se hace patente el contraste entre un contenido medieval (el canto gregoriano) y características modernas (pequeño formato, énfasis en la práctica, brevedad), ocuparon un lugar primordial en la cultura musical de los siglos XVI al XVIII. Las características por las que las artes de canto han sido infravaloradas hasta ahora por la historiografía musical (extrema brevedad, contenido eminentemente práctico) son precisamente las mismas que demuestran que estos libros son 
fruto de su época y que respondían a una necesidad pedagógica y a la demanda de manuales asequibles, breves y prácticos por parte de un amplio mercado.

El estudio de la producción, distribución y mercado de las artes de canto permite concluir que fueron los libros de música hispánicos con mayores tiradas de los publicados en el siglo XVI y que se reeditaron frecuentemente entre los siglos XVI y XVIII. Las artes de canto tuvieron una circulación más amplia que los libros de polifonía y música instrumental, ya que entraron de lleno en los circuitos comerciales de los empresarios del libro, e iban dirigidas a un mercado diversificado. Este mercado estaba constituido no sólo por religiosos que necesitaban aprender canto gregoriano, sino también por aficionados que también consumían artes de tañer, y no sólo por principiantes, sino también por maestros. La lectura no era la única forma de consumo de estas obras didácticas, ya que incluso un público iletrado podía convertirse en consumidor de artes de canto mediante la audición de las clases gratuitas y abiertas al público que tenían lugar en las capillas eclesiásticas. En otras palabras, el alfabetismo musical debió de estar aún más extendido de lo que sugiere la ya de por sí amplia difusión de las artes de canto.

El Arte de canto llano (Sevilla, 1530) de Juan Martínez emerge como el tratado de música del mundo hispánico más difundido geográfica y cronológicamente en el siglo XVI e inicios del XVII, pero del que casi nada se sabía. La reconstrucción del contenido de este libro (Apéndice 13) a partir de ediciones hasta ahora desconocidas ha permitido analizar sus características; destaca la calidad didáctica de la obra, en la que posiblemente residió la razón de su éxito. El libro de Martínez supone la continuación de una larga tradición de enseñanza de la música en la Catedral de Sevilla que enlaza con dos artes de canto conservadas en la Biblioteca Nacional de España, R/14670(1) y (2), que datan de la segunda década del siglo XVI, cuyo contenido coincide con el Arte de canto llano de Martínez, y que a su vez enlazan con los contenidos del tratado manuscrito de Fernand Estevan (Sevilla, 1410). Las grandes tiradas que seguramente se hicieron de los manuales de la Biblioteca Nacional y del Arte de canto llano de 1530 de Juan Martínez (a juzgar por los lotes de miles de ejemplares que aparecen en los inventarios de los impresores Cromberger) indican que estas obras servían para enseñar música no sólo en la Catedral de Sevilla, sino también en otras instituciones educativas de la Península Ibérica y el Nuevo Mundo. La historia del Arte de canto llano de Juan Martínez ejemplifica las características de las artes de canto investigadas en esta Tesis Doctoral. Su estudio supone una importante contribución a la historia de la enseñanza de la 
música en el mundo ibérico renacentista, puesto que indica que las artes de canto no eran libros dirigidos exclusivamente a "sacristanes de aldea", como había afirmado Cerone en El Melopeo y Maestro (Nápoles, 1613), sino manuales para iniciarse en la música. Esta constatación me condujo a investigar los usos de las artes de canto en contextos diferenciados, hasta ahora inexplorados.

La enorme diseminación de las artes de canto podría deberse en parte a su utilización como vehículos de difusión de la religiosidad. Su contribución al ceremonial de la iglesia y su vinculación con la denominada "vulgarización de la Escritura" fuera de los contextos eclesiásticos hizo que las artes de canto difundieran no sólo la religiosidad, sino también la competencia musical en un amplio espectro social. El análisis de la evidencia externa de uso de las artes de canto conservadas muestra que eran utilizadas por religiosos y laicos, algo también sugerido a través del vaciado de inventarios de bienes. El Tractat de música, un manuscrito datado en el siglo XVI conservado en la Universitat de Barcelona, evidencia que las artes de canto formaban parte de lo que Cristle Collins Judd ha denominado la cultura del "cuaderno del humanista", o la transcripción manuscrita de pasajes tomados de textos impresos bajo encabezados establecidos por un maestro, lo que permite confirmar la utilización de algunos ejemplares de artes de canto como libros de texto.

Frente a la hipótesis tradicional de que las artes de canto eran utilizadas exclusivamente en las lecciones de música que tenían lugar en las capillas eclesiásticas para aprender a cantar la Misa y el Oficio Divino, esta investigación muestra que, como indica la historia del Arte de canto llano de Juan Martínez, la vinculación de las artes con las clases de música trascendía el ámbito eclesiástico. Las múltiples reediciones de que fueron objeto algunas artes de canto en los siglos XVI y XVII en ciudades con universidad como Salamanca, Alcalá de Henares y Coimbra sugieren la utilización de estos libros en el contexto universitario. En Salamanca se imprimieron el Comento sobre Lux bella (1498) de Domingo Marcos Durán, la Introduction muy breue de canto llano (c. 1498) de Cristóbal Escobar, el Tratado de Canto llano (1503) perdido de Juan Rodríguez, la Sumula de canto de organo (c. 1504) de Marcos Durán, el tratado de canto llano perdido de 1504 de Alonso del Castillo, Portus musice (1504) de Diego del Puerto, la reedición de 1509 de Lux bella de Marcos Durán, la reedición de 1599 del libro de Juan Martínez y las reediciones de 1610, 1616 y 1625 del Arte de canto llano de Francisco de Montanos. En Alcalá de Henares se imprimió en 1532 y 1598 el Arte de canto 
llano de Juan Martínez, y en 1544, 1554, 1559 y 1566 se llevaron a cabo ediciones del Arte ingeniosa de musica de Melchor de Torres. En Coimbra salió a la luz la traducción portuguesa del Arte de canto llano de Juan Martínez en 1550, 1597, 1603, 1612, 1614 y 1625, y el Arte de canto chão de Pedro Thalesio en 1618 y 1628. Además, Mateo de Aranda y Pedro Thalesio, catedráticos de música de la Universidad de Coimbra, publicaron artes de canto, y el también catedrático Afonso Perea Bernal tradujo al portugués (1550) y amplió (1597) el Arte de canto llano de Juan Martínez. Las artes de canto también eran utilizadas en clases particulares impartidas en el ámbito doméstico, como muestra la anotación de la portada de un ejemplar del Arte de canto llano de Montanos, según la cual este libro pertenecía a "Rossa Maria de $\operatorname{Sam}^{\circ}$ y Serna", que lo utilizaba en las clases particulares de canto que recibía en su casa de un profesor externo.

Dadas las conexiones entre artes de canto y mujeres (como dedicatarias, impresoras y usuarias) que han emergido a través del estudio de estos libros, en la Parte II de esta Tesis Doctoral he analizado estas vinculaciones entre lo que considero dos manifestaciones de alteridad: las artes de canto, consideradas como un Otro que ha sido menospreciado, y las mujeres, que tradicionalmente han sido relegadas en la bibliografía musicológica. Los dos únicos libros de música impresos en la España del siglo XVI dedicados a mujeres -El arte Tripharia (Osuna, 1550) de Juan Bermudo y el Arte de canto llano (Valladolid, 1594) de Francisco de Montanos- son artes de canto. Estos dos libros, contrariamente a lo afirmado por algunos historiadores, fueron utilizados indistintamente por hombres y por mujeres. Es decir, que las artes de canto estaban dirigidas a usuarios de ambos de géneros y no pueden emplearse como evidencia de desigualdades entre la enseñanza musical femenina y masculina. El hallazgo en esta investigación de la dedicatoria del Arte de canto llano de Montanos a Catalina de Zúñiga, Condesa de Lemos, ha abierto una línea de investigación que me ha llevado a documentar una capilla de música de los Condes de Lemos y el mecenazgo musical ejercido por estos nobles en Monforte de Lemos (Lugo), y ha aportado nuevos detalles de la biografía de Francisco de Montanos. La Condesa de Lemos muestra de forma paradigmática el prisma de doble moralidad desde el que se juzgaba la música. La Condesa ejerció como mecenas en el ámbito religioso, promoviendo la publicación de un libro para mejorar la formación musical del clero gallego, manifestando así su religiosidad en la esfera pública; sin embargo, la Condesa poseía instrumentos musicales y un libro en italiano de danza y música profana, lo que sugiere que practicaba música profana en la esfera privada. 
El hecho de que sólo se hayan podido documentar dos mujeres dedicatarias de libros de música impresos en el mundo ibérico del siglo XVI demuestra que las mujeres tenían y/o asumían limitaciones para expresarse musicalmente como mecenas en la esfera pública. En esta Tesis Doctoral, sin embargo, estudio dos áreas de superposición (privado-público, escrito-oral) que permiten visibilizar actividad musical femenina. La atención a las áreas en que se superponen los ámbitos privado y público me ha permitido analizar el papel de las mujeres como compositoras en el contexto conventual, así como el trabajo de las mujeres en la producción impresa de artes de canto. La investigación de los límites entre lo oral y lo escrito me ha conducido a estudiar las artes de canto y los cancioneros poéticos en relación a los denominados "libritos de mujeres". En una época en que los libros estaban a medio camino entre ser considerados un bien de mercado y un "producto del arte divino", los libritos de mujeres no eran sólo una categoría comercial, sino también artefactos materiales portadores de una carga cultural que eran incorporados a los ajuares y legados de madres a hijas.

Los tratados de conducta femenina publicados en el siglo XVI distinguían entre libros no recomendables y lecturas honestas, pero en cambio no distinguían entre música honesta y deshonesta, sino que se referían a la música en sentido genérico, quizás porque la música religiosa no se concebía desligada de su funcionalidad religiosa; la "música" a la que aludían los tratados morales se relaciona con el ocio (fiestas y convites) y con el concepto negativo de las emociones como "accidentes del alma", por lo que la música es rechazada y no se alude a ella como instrumento de devoción. La literatura y los documentos inquisitoriales muestran la discrepancia entre las prescripciones de los tratados de conducta y la realidad musical; los casos de mujeres músicas muy estimadas en su época que he podido documentar demuestran que, más allá de los tratados, existía una educación musical informal en el ámbito privado raramente reflejada en documentos escritos.

Los documentos inquisitoriales del proceso a Isabel Ortiz acusándola de ser alumbrada evidencian que había mujeres músicas y mujeres que empleaban a músicas para que cantaran y tocasen para ellas, y ofrecen evidencias de cómo se formaban las músicas en el ámbito doméstico con profesores externos. Esta investigación ha aportado el nombre de una música muy reconocida en su época y detalles de su formación y vicisitudes profesiones: Isabel de Plazaola, hija de Isabel Ortiz. El círculo social de Isabel de Plazaola incluía una red de mujeres afincadas en torno al palacio de los Duques del 
Infantado en Guadalajara y en Alcalá de Henares interesadas en cuestiones de devoción, y que empleaban a mujeres músicas a su servicio (incluso sin el permiso de sus maridos). También he podido documentar que la espléndida colección de instrumentos musicales que hasta ahora se pensaba pertenecía al IV Duque del Infantado era en realidad de su esposa, Isabel de Aragón, IV Duquesa del Infantado. Dado que esta colección se había utilizado como evidencia de las habilidades musicales del Duque, con esta investigación aflora un claro ejemplo de cómo la actividad musical de las mujeres quedaba a menudo oculta detrás de sus maridos, padres o hermanos.

Como en el caso de Catalina de Zúñiga, mencionado anteriormente, el de Isabel de Plazaola muestra la doble valoración moral de la música en la época. La formación que recibió como música podía entenderse como una obra de devoción o como una inmoralidad, dependiendo en gran medida del estatus socioeconómico de la mujer. La presencia de música y de maestros de música en el hogar de Isabel de Plazaola, que no pertenecía a la nobleza, se consideró por la Inquisición contrario a la espiritualidad, pero su madre se defendió afirmando que la educación musical era una obra de devoción dirigida a Dios y al mundo. Los documentos inquisitoriales relacionados con músicos como Juan Sherwin, Antonio de Torres e Isabel de Plazaola que presento en esta Tesis muestran el lugar que ocupaban los músicos en la sociedad y las vicisitudes de algunos hombres y mujeres que se dedicaban a la música profesionalmente.

El arte Tripharia de Juan Bermudo ha sido utilizado por la historiografía musicológica para afirmar que los conocimientos musicales a los que podían aspirar las mujeres en el siglo XVI eran muy limitados, pero mi investigación constata que había monjas muy bien formadas musicalmente, como la compositora Gracia Baptista, y otras mujeres que sabían "tañer todo género de instrumentos", como Isabel de Plazaola. Había criterios más importantes que el género, como la edad o el estatus social, para categorizar a los potenciales usuarios de los libros de música. La actividad musical de la mujer no puede reducirse a entretener a los hombres o a expresar celo religioso, como tradicionalmente se ha afirmado. Esta investigación muestra la implicación de las mujeres del contexto ibérico renacentista en una amplia variedad de géneros vocales e instrumentales a diferentes niveles de destreza técnica como creadoras y/o intérpretes, y también como mecenas.

Las mujeres tenían grandes dificultades para poder imprimir sus obras literarias, como muestra el ejemplo de Isabel Ortiz, que decidió no imprimir un libro de devoción 
que había compilado, puesto que uno de los requisitos que le habían impuesto para llevarlo a la imprenta era que "no se yntitule de muger". Sin embargo, ese "librico de doctrina cristiana" de Isabel Ortiz (que levantó las sospechas de la Inquisición) disfrutó de una enorme difusión manuscrita, sobre todo entre mujeres. La documentación presentada en esta Tesis Doctoral permite vislumbrar un paralelismo en el ámbito musical; es decir, que existía una activa vida musical (femenina y masculina) más allá de la basada en una cultura impresa.

Partiendo de unos documentos inquisitoriales que aparentemente no tenían interés musicológico, he podido descubrir una activa vida musical en las casas de la nobleza castellana. La música Isabel de Plazaola fue requerida para actuar en las casas de Leonor Enríquez de Toledo, II Marquesa de Távara; Catalina de la Cerda, IV Condesa de Coruña; Juana de la Lama, V Duquesa de Alburquerque; y quizás también Juana de Austria. De particular interés resulta la actividad musical y la lectura de contenido devocional de estas mujeres nobles en torno a la Duquesa del Infantado, y la labor de mecenazgo musical de los Duques del Infantado durante el siglo XVI. Los casos presentados en esta investigación evidencian que los documentos inquisitoriales constituyen una fuente musicológica apenas explorada para captar vestigios del lugar que ocupaba la música en la vida cotidiana, más allá de la música escrita que ha sobrevivido. Aunque generalmente se ha argumentado que la ausencia de las mujeres en documentos históricos es un resultado de su confinamiento en el medio doméstico, esta investigación muestra que los límites entre lo privado y lo público no son precisos y que es particularmente en las fronteras entre lo privado y lo público (como la música de monjas para oyentes externos o la combinación de hogar y empresa en los talleres de imprenta) donde emergen visibles vinculaciones entre las mujeres y la música. Las mujeres no son completamente invisibles en las fuentes que documentan la vida cotidiana de la época.

Tras la crítica a las artes de canto por parte de los teóricos renacentistas se esconde la controversia medieval en torno al verdadero músico (el teórico) frente al "siervo de la música" (el cantor o instrumentista); la música, como cualquier otra ciencia, no se podía aprender "brevemente", de ahí que las artes de canto, según sus críticos, no sirvieran para convertirse en músico. Sin embargo, la música sobre la que se teorizaba a menudo poco tenía que ver con la música real que mujeres y hombres creaban y consumían en la vida cotidiana. La música que no siempre se plasmaba por escrito servía para 
alabar a Dios, para enseñar a leer o para entretenerse, y estaba profundamente integrada en las prácticas culturales de la época. 